\title{
Bildung auf einen Blick
}

OECD-Indikatoren 2004

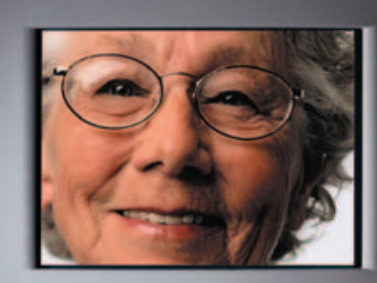

OECD 


\section{Bildung auf einen Blick OECD-Indikatoren 2004}




\section{Organisation für wirtschaftliche Zusammenarbeit und Entwicklung}

Gemäß Artikel I des am I4. Dezember I960 in Paris unterzeichneten und am 30. September 196I in Kraft getretenen Übereinkommens fördert die Organisation für wirtschaftliche Zusammenarbeit und Entwicklung (OECD) eine Politik, die darauf gerichtet ist:

in den Mitgliedstaaten unter Wahrung der finanziellen Stabilität eine optimale Wirtschaftsentwicklung und Beschäftigung sowie einen steigenden Lebensstandard zu erreichen und dadurch zur Entwicklung der Weltwirtschaft beizutragen;

in den Mitglied- und Nichtmitgliedstaaten, die in wirtschaftlicher Entwicklung begriffen sind, zu einem gesunden wirtschaftlichen Wachstum beizutragen; und

im Einklang mit internationalen Verpflichtungen auf multilateraler und nichtdiskriminierender Grundlage zur Ausweitung des Welthandels beizutragen.

Die Gründungsmitglieder der OECD sind: Belgien, Dänemark, Deutschland, Frankreich, Griechenland, Irland, Island, Italien, Kanada, Luxemburg, Niederlande, Norwegen, Österreich, Portugal, Schweden, Schweiz, Spanien, Türkei, Vereinigtes Königreich und Vereinigte Staaten. Folgende Staaten wurden zu den nachstehend genannten Daten Mitglieder der OECD: Japan (28. April I964), Finnland (28. Januar I969), Australien (7. Juni I97I), Neuseeland (29. Mai 1973), Mexiko (I8. Mai 1994), die Tschechische Republik (2I. Dezember I995), Ungarn (7. Mai 1996), Polen (22. November 1996), Korea (12. Dezember 1996) und die Slowakische Republik (I4. Dezember 2000). Die Kommission der Europäischen Gemeinschaften nimmt an den Tätigkeiten der OECD teil (Artikel I3 des Übereinkommens über die OECD).

Das Zentrum für Forschung und Innovation im Bildungswesen (CERI) wurde im Juni 1968 vom Rat der Organisation für wirtschaftliche Zusammenarbeit und Entwicklung ins Leben gerufen. Alle OECD-Mitgliedsländer nehmen daran teil.

Die Hauptziele dieses Zentrums sind:

Förderung und Unterstützung der Entwicklung von Forschungsaktivitäten im Bildungsbereich und gegebenenfalls die Durchführung solcher Forschungsaktivitäten;

Förderung und Unterstützung von Pilotversuchen im Hinblick auf die Einführung und Erprobung von Innovationen im Bildungssystem;

Förderung der Entwicklung einer Zusammenarbeit zwischen den Mitgliedstaaten auf dem Gebiet der pädagogischen Forschung und Innovation.

Das Zentrum arbeitet innerhalb der Organisation für wirtschaftliche Zusammenarbeit und Entwicklung gemäß den Entscheidungen des Rats der Organisation und im Auftrag des Generalsekretärs sowie unter der direkten Kontrolle eines Lenkungsausschusses, in den jeder am Arbeitsprogramm des CERI beteiligte Mitgliedstaat einen nationalen Experten für den Aufgabenbereich des Zentrums entsendet.

PISA(tm), OECD/PISA(tm) und das PISA-Logo sind geschützte Marken der Organisation für wirtschaftliche Zusammenarbeit und Entwicklung (OECD). Jegliche Nutzung von OECD-Marken ist ohne schriftliche Genehmigung der OECD verboten.

Die englische und französische Originalfassung wurde von der OECD publiziert unter dem Titel:

Education at a Glance - OECD-Indicators 2004

Regards sur L'Éducation - Les indicateurs de l'OCDE 2004

() 2004, Organisation für Wirtschaftliche Zusammenarbeit und Entwicklung, OECD, Paris.

Alle Rechte vorbehalten

Deutsche Übersetzung durch das Bundesministerium für Bildung und Forschung, Deutschland.

(C) 2004, Bundesministerium für Bildung und Forschung, Deutschland für die deutsche Übersetzung.

Veröffentlicht in Absprache mit der OECD, Paris

Für die Qualität der deutschen Version und die Übereinstimmung mit dem Originaltext übernimmt das Bundesministerium für Bildung und Forschung die Verantwortung

Genehmigungen zum Nachdruck von Teilen dieses Werks für nichtkommerzielle Zwecke oder zur Verwendung im Unterricht sind einzuholen beim Centre français d'exploitation du droit de copie (CFC), 20, rue des Grands-Augustins, 76006 Paris, Frankreich, tel: (33-1) 440747 70, fax: (33-1) 463467 19. Dies gilt für alle Länder mit Ausnahme der Vereinigten Staaten, wo das Copyright Clearance Center Inc. (CCC), Customer Service, tel: (508) 750-8400, 222 Rosewood Drive, Danvers, MA 01923, USA oder CCC online: www.copyright.com die entsprechenden Genehmigungen erteilt. Alle sonstigen Anträge auf Überlassung von Nachdruckoder Übersetzungsrechten für das gesamte Dokument oder Teile davon sind zu richten an: OECD Publications, 2, rue André-Pascal, 75775 Paris Cedex 16, Frankreich. 


\section{Vorwort}

Bei der Suche nach einer Bildungspolitik, die die sozialen und wirtschaftlichen Aussichten des Einzelnen verbessert, Anreize für eine größere Effizienz bei der Bildungsvermittlung bietet und dazu beiträgt, Ressourcen zur Bewältigung der steigenden Bildungsnachfrage zu mobilisieren, lenken die Regierungen ihre Aufmerksamkeit in verstärktem Maße auf internationale Vergleiche. Als Teil der Bemühungen, die Arbeit der OECD in diesem Bereich weiter zu verbessern und den Bedürfnissen der Bürger und der Regierungen besser gerecht werden zu können, sieht die Direktion für Bildungswesen eine ihrer Hauptaufgaben in der Entwicklung und Analyse international vergleichbarer, quantitativer Indikatoren, die dann jährlich in Bildung auf einen Blick veröffentlicht werden. Diese Veröffentlichung bietet den Regierungen die Möglichkeit, das eigenes Bildungssystem im Licht der Leistungsfähigkeit anderer Länder zu betrachten. Zusammen mit den länderspezifischen Untersuchungen der OECD sind die Indikatoren darauf ausgelegt, die Regierungen in ihren Bemühungen um Reformen in der Bildungspolitik zu unterstützen.

Die Veröffentlichung Bildung auf einen Blick ist für die Bedürfnisse einer breit gestreuten Leserschaft angelegt- von den Regierungen, die von den bildungspolitischen Erfahrungen anderer Länder lernen wollen, über Wissenschaftler, die Daten für weitergehende Analysen benötigen, bis zur allgemeinen Öffentlichkeit, die einen Überblick darüber gewinnen möchte, welche Fortschritte das Bildungssystem des eigenen Landes dabei macht, Schüler und Studierende von Weltklasseformat auszubilden. Der Schwerpunkt der Ausgabe des Jahres 2004 von Bildung auf einen Blick liegt auf der Qualität der Lernergebnisse, den politischen Ansatzpunkten und Bedingungen, die die Bildungserfolge beeinflussen, und den - im weitesten Sinne individuellen und gesellschaftlichen Erträgen aus Investitionen in Bildung.

Diese Veröffentlichung ist das Ergebnis langjähriger gemeinsamer Bemühungen der Regierungen der OECD-Länder, der Experten und Institutionen, die im Rahmen des OECD Education Indicators Programme (INES) zusammenarbeiten, sowie dem Sekretariat der OECD. Sie wurde erstellt von der
Abteilung für Indikatoren und Analysen unter der Leitung von Andreas Schleicher in Zusammenarbeit mit Etienne Albiser, Eric Charbonnier, Michael Davidson, Catherine Duchêne, Stéphane Guillot, Jean-Luc Heller, Alistair Nolan and Karine Tremblay. Manuela de Sousa und Annette Panzera waren unterstützend in den Bereichen Statistik und Recherche tätig und Cécile Slape war für die Sekretariatsarbeiten zuständig. Die Entwicklung der Veröffentlichung wurde von den Nationalen INES-Koordinatoren in den Mitgliedsländern gesteuert und durch die drei Länder, die für die Koordination der INES-Netzwerke verantwortlich zeichnen - die Niederlande, Schweden und die Vereinigten Staaten finanziell und sachlich unterstützt. Außerdem wurde die Arbeit an dieser Veröffentlichung durch das National Center for Education Statistics (NCES) in den Vereinigten Staaten finanziell gefördert. Der Anhang enthält eine Liste der Mitglieder der verschiedenen Organisationen sowie der einzelnen Fachleute, die an diesem Bericht und den OECDIndikatoren generell mitgewirkt haben.

In den letzten Jahren ist viel erreicht worden, aber es sind noch umfangreiche Bemühungen notwendig, um für eine ganze Reihe von bildungspolitischen Fragen die besten verfügbaren Daten zusammenstellen zu können. Im Rahmen dieses Arbeitsprogramms sind verschiedene Herausforderungen zu bestehen: Erstens müssen die Indikatoren die Fragen ansprechen, die in den einzelnen Ländern von großer bildungspolitischer Bedeutung sind, und bei denen eine international vergleichende Perspektive gegenüber nationalen Analysen und Bewertungen tatsächlich einen Informationsgewinn liefert. Zweitens müssen die Indikatoren zwar so vergleichbar wie möglich sein, gleichzeitig aber auch länderspezifisch genug, um historische, systembedingte und kulturelle Unterschiede zwischen den einzelnen Ländern berücksichtigen zu können. Drittens muss die Darstellung in den Indikatoren so klar wie möglich sein, gleichzeitig aber auch der facettenreichen Realität von Bildungssystemen in der heutigen Welt gerecht werden. Viertens besteht der allgemeine Wunsch, die Zahl der Indikatoren so niedrig wie möglich zu halten, während gleichzeitig ihre Anzahl aber groß genug sein muss, um den politischen Entscheidungsträgern in den einzelnen 
Vorwort

Ländern, die sich teilweise ganz unterschiedlichen bildungspolitischen Herausforderungen gegenüber sehen, wirklich von Nutzen zu sein.

Die OECD wird diese Herausforderungen auch weiterhin entschieden angehen und die Entwicklung von Indikatoren nicht nur in den Bereichen vorantreiben, in denen dies möglich und vielversprechend ist, sondern auch in jene Bereiche vordringen, in denen noch sehr viel grundlegende konzeptionelle Arbeit vonnöten ist.

Für diesen Bericht zeichnet der Generalsekretär der OECD verantwortlich.

Barry McGaw

Leiter der Direktion Bildungswesen OECD

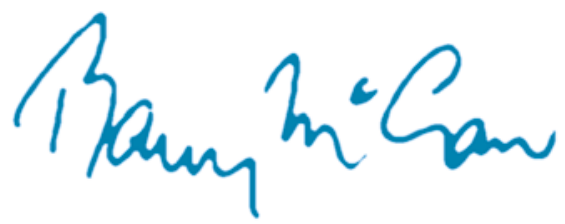

4

BILDUNG AUF EINEN BLICK ㄷ OECD 2004 


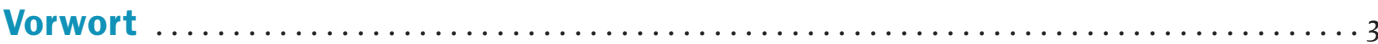

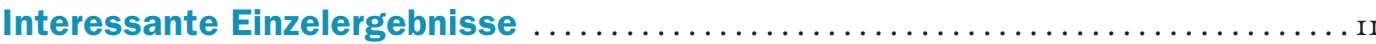

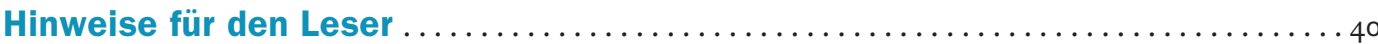

Kapitel A: Bildungsergebnisse und die Auswirkungen von Lernen $\ldots \ldots \ldots \ldots \ldots 43$

Indikator A1: Bildungsstand der Erwachsenenbevölkerung . . . . . . . . . . . . . . . . . 45

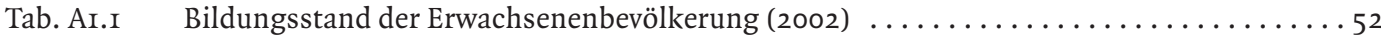

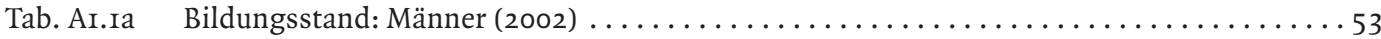

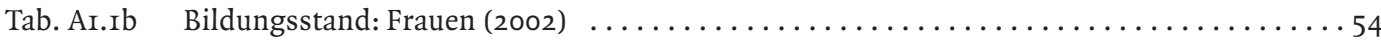

Tab. Ar.2 Bevölkerung im Alter für den Elementar-, Primar- und Sekundarbereich I,

den Sekundarbereich II und den Tertiärbereich $(1992,2002,2012) \ldots \ldots \ldots \ldots \ldots \ldots 55$

Indikator A2: Aktuelle Abschlussquoten im Sekundarbereich II und Bildungsstand der

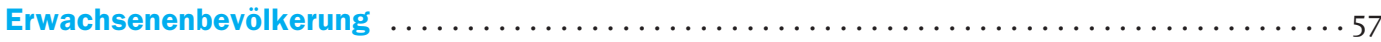

Tab. A2.I Abschlussquoten im Sekundarbereich II (2002) .......................... 64

Tab. A2.2 Anteil der Bevölkerung mit mindesten einem Abschluss

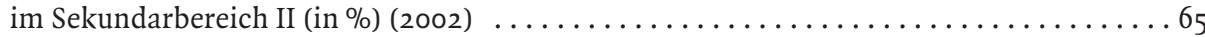

Tab. A2.3 Abschlussquoten im post-sekundaren, nicht-tertiären Bildungsbereich (2002) . . . . . . 66 Indikator A3: Aktuelle Abschluss- und Erfolgsquoten im Tertiärbereich

und Bildungsstand der Erwachsenenbevölkerung . .............................. 67

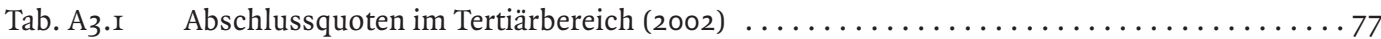

Tab. A3.2 Erfolgsquoten im Tertiärbereich (2000) ........................... 78

Tab. A3.3 Bevölkerung mit einem Abschluss im Tertiärbereich (2002) $\ldots \ldots \ldots \ldots \ldots \ldots \ldots \ldots \ldots 79$

Tab. A3.4a Entwicklung des Bildungsstand der 25- bis 64-Jährigen (I99I-2002) $\ldots \ldots \ldots \ldots \ldots$. 80

Tab. A3.4b Entwicklung des Bildungsstand der 25-bis 34-Jährigen (I99I-2002) . . . . . . . . . 8 I

Tab. A3.4C Entwicklung des Bildungsstand der 25- bis 34-Jährigen (1998-2002) $\ldots \ldots \ldots \ldots \ldots . \ldots 2$

Indikator A4: Absolventen des Tertiärbereichs nach Studienbereichen . . . . . . . . . . . 83

Tab. A4.I Absolventen des Tertiärbereichs, nach Studienbereichen (2002) . . . . . . . . . . . 89

Tab. A4.2 Anteil der von Frauen erworbenen Abschlüsse im Tertiärbereich (in \%),

nach Bildungsbereich und Studienbereich (2002) ...................... 90

Indikator A5: Entwicklung der Lesefähigkeiten und des Leseverständnisses

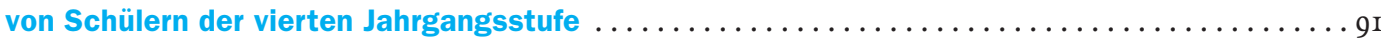

Tab. A5.I Entwicklung der Leseleistungen (I99I-200I) $\ldots \ldots \ldots \ldots \ldots \ldots \ldots \ldots \ldots \ldots \ldots \ldots \ldots \ldots \ldots \ldots \ldots$

Tab. A5.2 Entwicklung der geschlechtsspezifischen Unterschiede bei den Leseleistungen (I99I-200I) 99

Tab. A5.3 Fortschritte bei den Leseleistungen, nach Unterskalen (I99I-200I) $\ldots \ldots \ldots \ldots \ldots \ldots$ I00

Indikator A6: Lesefähigkeiten und Leseverständnis 15-jähriger Schüler . . . . . . . . . . . IOI

Tab. A6.I Lesefähigkeiten und - verständnis I5-Jähriger (2000) $\ldots \ldots \ldots \ldots \ldots \ldots \ldots \ldots \ldots \ldots \ldots \ldots \ldots \ldots$

Tab. A6.2 Unterschiede in den Lesefähigkeiten und dem Leseverständnis I5-jähriger Schüler (2000) II4

Tab. A6.3 Mittlere Leseleistungen von Schülern der 4. Jahrgangsstufe

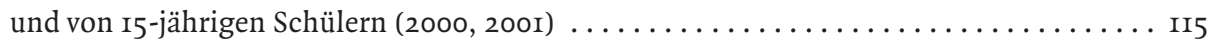

Indikator A7: Mathematische und naturwissenschaftliche Grundbildung 15-Jähriger ........ II7

Tab. A7.I Unterschiede in der Leistung I5-jähriger Schüler auf der PISA-Skala für mathematische

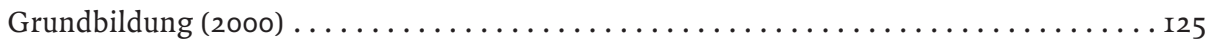

Tab. A7.2 Unterschiede in der Leistung I5-jähriger Schüler auf der PISA-Skala für

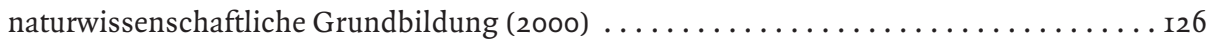


Indikator A8: Das Engagement 15-Jähriger in der Schule - Zugehörigkeitsgefühl und

Unterrichtsteilnahme . . . . . . . . . . . . . . . . . . . 27

Tab. A8.I Mittelwerte der zwei Indizes des Engagements von Schülern in der Schule (2000) . . . . I38

Tab. A8.2 Anteil der Schüler mit einem schwachen Zugehörigkeitsgefühl und geringer

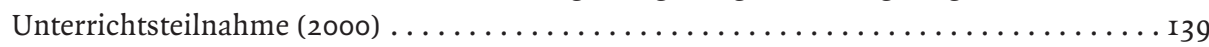

Indikator A9: Geschlechtsspezifische Unterschiede bei Schülerleistungen . . . . . . . . . . I4I

Tab. A9.I Erwartungen I5-Jähriger hinsichtlich des Berufs, dem sie mit 30 Jahren nachgehen

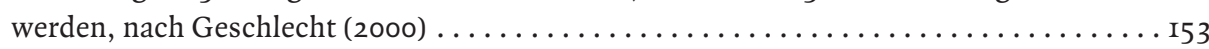

Tab. A9.2 Geschlechtsspezifische Leistungen von Schülerinnen und Schülern der

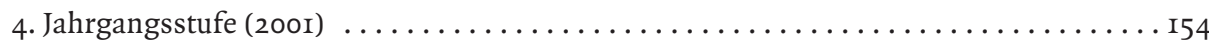

Tab. A9.3 Geschlechtsspezifische Leistungen I5-jähriger Schülerinnen und Schüler (2000) . . . . I55

Tab. A9.4 Politische Bildung I4-jähriger Schüler und geschlechtsspezifische Unterschiede (I999) . . I56

Tab. A9.5 Geschlechtsspezifische Unterschiede I5-jähriger Schülerinnen und Schülern beim

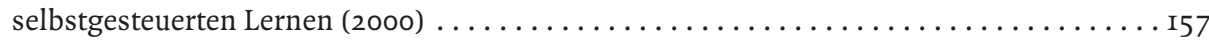

Indikator A10: Erwerbsbeteiligung nach Bildungsstand . . . . . . . . . . . . . . . I59

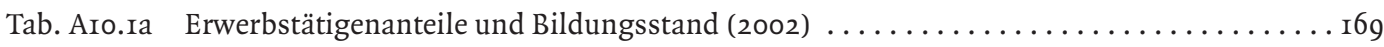

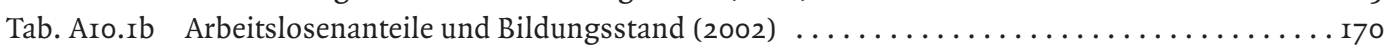

Tab. Aro.Ic Anteil der Bevölkerung, die sich nicht im Arbeitsmarkt befindet und Bildungsstand (2002) . . I7I

Tab. Aro.2a Entwicklungen der Erwerbstätigenanteile nach Bildungsstand (I99I-2002) . . . . . I72

Tab. Aro.2b Entwicklungen der Arbeitslosenanteile nach Bildungsstand (I99I-2002) . . . . . . . . I73

Tab. Aro.2c Entwicklungen des Anteil der Bevölkerung, die sich nicht im Arbeitsmarkt

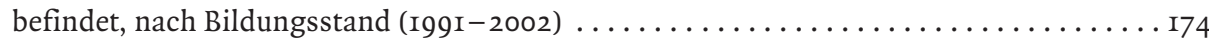

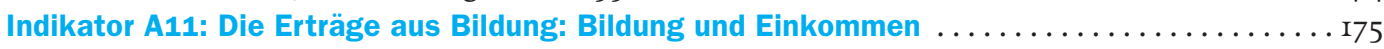

Tab. Aır.ıa Relative Einkommen der Bevölkerung mit Erwerbseinkommen (2002) . . . . . . . . I87

Tab. Aır.rb Einkommensunterschiede zwischen Frauen und Männern (2002) . . . . . . . . . . I88

Tab. AIr.2 Entwicklung der relativen Einkommen: Erwachsenenbevölkerung (I997-2002) ...... I89

Tab. Aır.2a Entwicklung der relativen Einkommen: männliche Bevölkerung (I997-2002) . . . . . . I90

Tab. Arr.2b Entwicklung der relativen Einkommen: weibliche Bevölkerung (I997-2002) . . . . . . . I9I

Tab. AIr.3 Entwicklung der Einkommensunterschiede zwischen Frauen und Männern (I997-2002) I92

Tab. AIr.4 Individuelle Ertragsraten für Personen, die einen Abschluss im Sekundarbereich II

oder dem post-sekundaren, nicht-tertiären Bereich (ISCED 3/4) nach einem Abschluss

unterhalb Sekundarbereich II (ISCED o/I/2) erwerben (200I) $\ldots \ldots \ldots \ldots \ldots \ldots \ldots$ I93

Tab. AIr.5 Individuelle Ertragsraten für Personen, die einen Abschluss im Tertiärbereich oder einem weiterführenden Forschungsprogramm (ISCED 5(A/B)/6) nach einem Abschluss im Sekundarbereich II oder dem post-sekundaren, nicht-tertiären

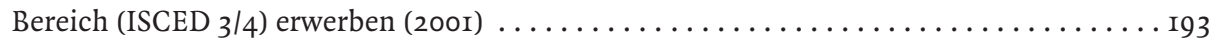

Tab. Arr.6 Gesellschaftliche Ertragsraten für Personen, die einen Abschluss im Sekundarbereich II oder dem post-sekundaren, nicht-tertiären Bereich (ISCED 3/4) nach einem Abschluss

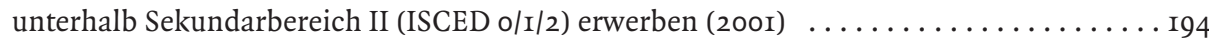

Tab. AIr.7 Gesellschaftliche Ertragsraten für Personen, die einen Abschluss im Tertiärbereich oder einem weiterführenden Forschungsprogramm (ISCED 5(A/B)/6) nach einem Abschluss im Sekundarbereich II oder dem post-sekundaren, nicht-tertiären Bereich

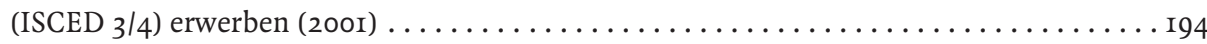
Indkator A12: Die Erträge aus Bildung - Zusammenhänge zwischen Humankapital und

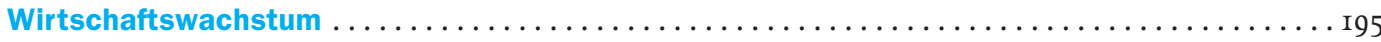


Kapitel B: Die in Bildung investierten Finanz- und Humanressourcen . . . . . . . 207

Indikator B1: Bildungsausgaben pro Schüler/Studierenden ...................... 209

Tab. Bı.I Jährliche Ausgaben für Bildungseinrichtungen pro Schüler/Studierenden (200I) $\ldots \ldots .228$

Tab. BI.2 Jährliche Ausgaben für Bildungseinrichtungen pro Schüler/Studierenden im

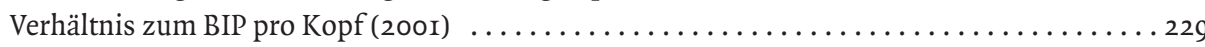

Tab. BI.3 Kumulierte Ausgaben für Bildungseinrichtungen pro Studierenden über die durchschnittliche Verweildauer im Tertiärbereich (200I) $\ldots \ldots \ldots \ldots \ldots \ldots \ldots \ldots \ldots \ldots \ldots$

Tab. BI.4 Verteilung der Ausgaben für Bildungseinrichtungen im Vergleich zur Zahl der Schüler/Studierenden pro Bildungsbereich (200I) $\ldots \ldots \ldots \ldots \ldots \ldots \ldots \ldots \ldots \ldots \ldots \ldots \ldots \ldots$

Tab. BI.5 Veränderungen der jährlichen Ausgaben für Bildungseinrichtungen pro Schüler/ Studierenden aufgrund verschiedener Faktoren, nach Bildungsbereich (1995, 200I) . . . 232

Tab. Bı.6 Veränderung der Ausgaben für Bildungseinrichtungen pro Schüler/Studierenden und

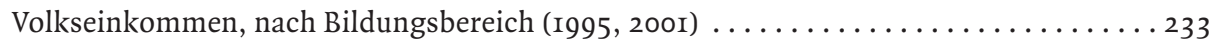

Indikator B2: Ausgaben für Billdungseinrichtungen im Verhältnis zum Bruttoinandsprodukt . . 235

Tab. B2.ra Ausgaben für Bildungseinrichtungen als Prozentsatz des BIP, für alle Bildungsbereiche

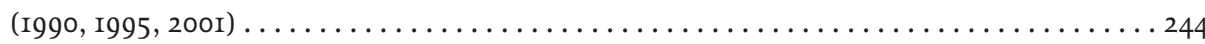

Tab. B2.Ib Ausgaben für Bildungseinrichtungen als Prozentsatz des BIP, nach Bildungsbereich

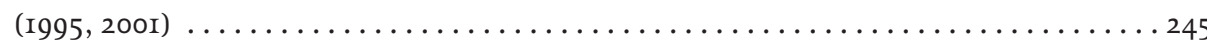

Tab. B2.Ic Ausgaben für Bildungseinrichtungen als Prozentsatz des BIP, nach Bildungsbereich (200I) . 246

Tab. B2.2 Veränderungen der Ausgaben für Bildungseinrichtungen $(1995,2001) \ldots \ldots \ldots \ldots \ldots 247$ Indikator B3: Relative Anteile öffentlicher und privater Ausgaben für Bildungseinrichtungen 249 Tab. B3.I Relative Anteile öffentlicher und privater Ausgaben für Bildungseinrichtungen aller

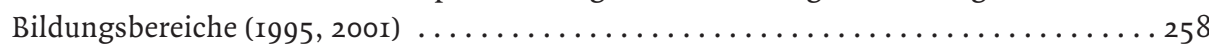

Tab. B3.2a Relative Anteile öffentlicher und privater Ausgaben für Bildungseinrichtungen,

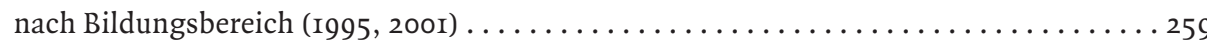

Tab. B3.2b Relative Anteile öffentlicher und privater Ausgaben für Bildungseinrichtungen,

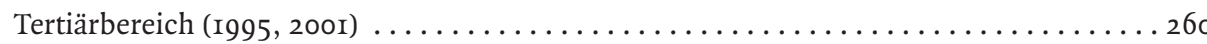

Tab. B3.3 Verteilung der öffentlichen Gesamtausgaben für Bildung (200I) $\ldots \ldots \ldots \ldots \ldots \ldots$. 6 I

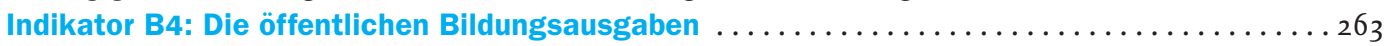

Tab. B4.I Öffentliche Gesamtausgaben für Bildung (1995, 200I) $\ldots \ldots \ldots \ldots \ldots \ldots \ldots \ldots \ldots$ Indikator B5: Unterstützung für Schüler/Studierende und private Haushalte durch

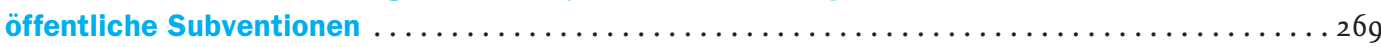

Tab. B5.I Öffentliche Subventionen an private Haushalte und andere private Einrichtungen als Prozentsatz der öffentlichen Gesamtausgaben für Bildung und des BIP, für den Primar-, Sekundar- und post-sekundaren, nicht-tertiären Bereich (200I) . . . . . . . 277

Tab. B5.2 Öffentliche Subventionen an private Haushalte und andere private Einrichtungen als Prozentsatz der öffentlichen Gesamtausgaben für Bildung und des BIP, für den

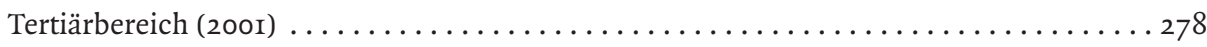

Indikator B6: Ausgaben für Bildungseinrichtungen nach Art der erbrachten Leistung und

Ausgabenkategorien ............................................. 279

Tab. B6.I Ausgaben für Bildungseinrichtungen nach Ausgabenkategorien

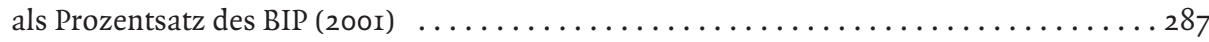

Tab. B6.2 Jährliche Ausgaben pro Schüler/Studierenden für Unterricht, zusätzliche Dienstleistungen sowie Forschung und Entwicklung (200I) $\ldots \ldots \ldots \ldots \ldots \ldots \ldots \ldots \ldots$

Tab. B6.3 Ausgaben für Bildungseinrichtungen nach Ausgabenkategorien

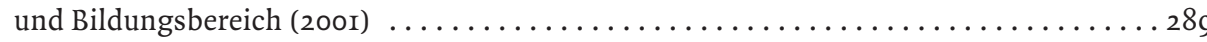




\section{Kapitel C: Bildungszugang, Bildungsbeteiligung und}

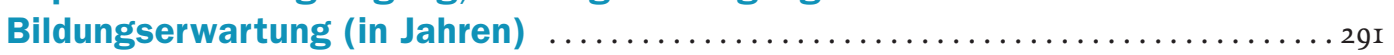

Indikator C1: Bildungserwartung (in Jahren) und Bildungsbeteiligung . . . . . . . . . . . . 293

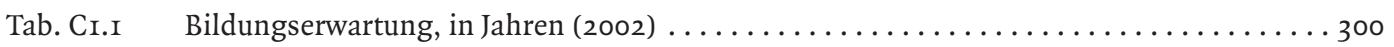

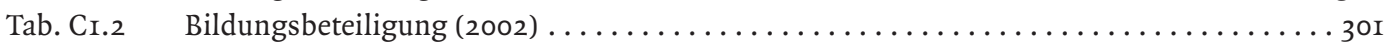

Tab. CI.3 Übergangscharakteristika bei I5-, I6-, I7-, I8-, I9- und 20-Jährigen (2002) . . . . . 302 Indikator C2: Zugang zum Tertiärbereich, zu erwartende Jahre im Tertiärbereich und

Bildungsbeteiligung im Sekundarbereich . . . . . . . . . . . . . . . . . . 303

Tab. C2.I Studienanfängerquoten im Tertiärbereich und Altersverteilung der Studienanfänger

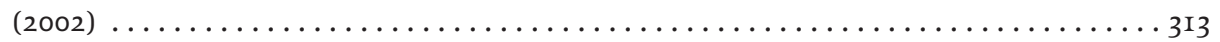

Tab. C2.2 Zu erwartende Ausbildungsjahre im Tertiärbereich und Veränderung der Gesamtzahl

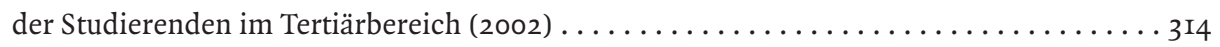

Tab. C2.3 Studierende an öffentlichen und privaten Bildungseinrichtungen und in Vollzeit- und

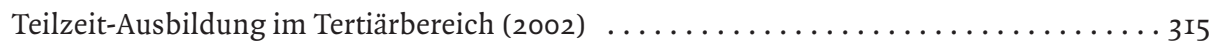

Tab. C2.4 Schüler an öffentlichen und privaten Bildungseinrichtungen und Schüler in Vollzeit-

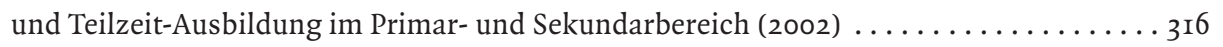

Tab. C2.5 Struktur der Bildungsteilnahme im Sekundarbereich II (2002) $\ldots \ldots \ldots \ldots \ldots \ldots \ldots$ II

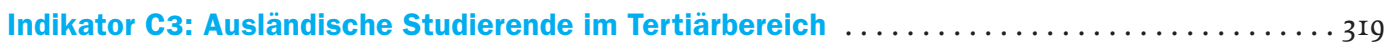

Tab. C3.I Austausch von Studierenden im Tertiärbereich (2002) . . . . . . . . . . . . 335

Tab. $\mathrm{C}_{3.2}$ Ausländische Studierende im Tertiärbereich nach dem Heimatland (2002) . . . . . 336

Tab. $\mathrm{C}_{3} \cdot 3$ Ausländische Studierende im Tertiärbereich nach dem Zielland (2002) . . . . . . . 338

Tab. $\mathrm{C}_{3.4}$ Verteilung ausländischer Studierender nach Bildungsbereich (2002) .......... 340

Tab. $\mathrm{C}_{3.5}$ Verteilung ausländischer Studierender nach Studienbereichen (2002) $\ldots \ldots \ldots \ldots$. . .

Tab. C3.6 Entwicklungstendenzen bei der Zahl ausländischer Studierender, die außerhalb ihres

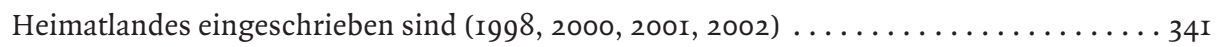

Indikator C4: Bildungs- und Beschäftigungsstatus junger Menschen . . . . . . . . . . . . 343

Tab. C4.ra Zu erwartende Jahre in Ausbildung und nicht in Ausbildung für 15- bis 29-Jährige

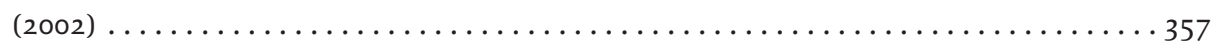

Tab. C4.rb Veränderung der zu erwartenden Jahre in Ausbildung und nicht in Ausbildung für

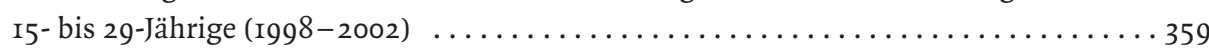

Tab. $\mathrm{C}_{4.2}$ Prozentsatz junger Menschen, die sich in Ausbildung bzw. nicht in Ausbildung befinden (2002) ..........................................

Tab. C4.2a Prozentsatz junger Männer, die sich in Ausbildung bzw. nicht in Ausbildung befinden

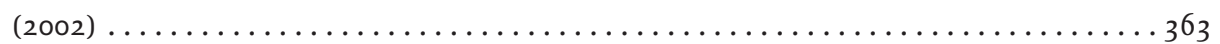

Tab. 44.2 Prozentsatz junger Frauen, die sich in Ausbildung bzw. nicht in Ausbildung befinden

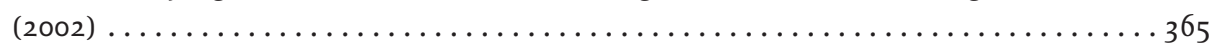

Tab. C4.3 Prozentsatz Arbeitsloser, die sich nicht in Ausbildung befinden, an der Gesamt-

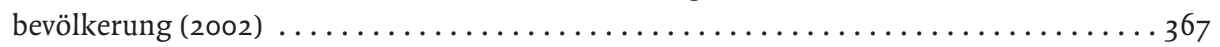

Tab. C4.4 Änderung des Prozentsatzes junger Menschen, die sich in Ausbildung bzw. nicht in

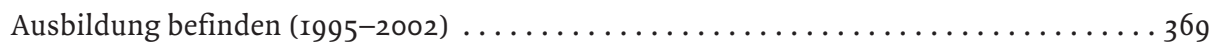

Tab. C4.4a Änderung des Prozentsatzes junger Männer, die sich in Ausbildung bzw. nicht

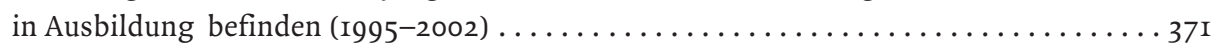

Tab. C4.4b Änderung des Prozentsatzes junger Frauen, die sich in Ausbildung bzw. nicht in

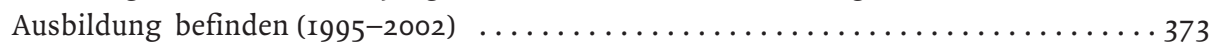

Indikator C5: Die Situation junger Menschen mit niedrigem Bildungsniveau $\ldots \ldots \ldots \ldots . \ldots 375$ Tab. C5.I Prozentsatz 20- bis 24-Jähriger, die sich nicht in Ausbildung befinden, nach

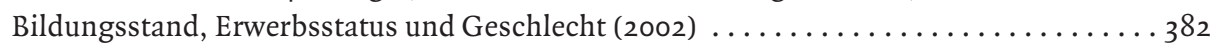

Tab. $\mathrm{C}_{5.2}$ Prozentsatz 20- bis 24-Jähriger, nach Geburtsort (2002) $\ldots \ldots \ldots \ldots \ldots \ldots \ldots \ldots$

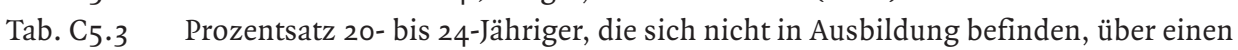
niedrigen Bildungsstand verfügen, sich nicht im Arbeitsmarkt befinden und nie

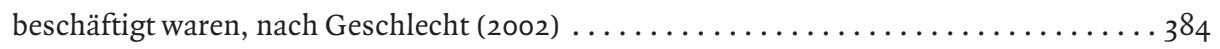


Kapitel D: Das Lernumfeld und die Organisation von Schulen $\ldots \ldots \ldots \ldots \ldots . \ldots 385$

Indikator D1: Insgesamt vorgesehene Unterrichtszeit im Primar- und Sekundarbereich ......387

Tab. DI.I Vorgesehene Unterrichtszeit für den Pflicht- und Nicht-Pflichtteil des Lehrplans in

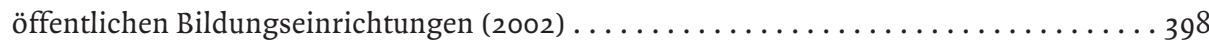

Tab. Dr.2a Unterrichtszeit pro Fach in Prozent der insgesamt vorgesehenen Unterrichtszeit für den Pflichtteil des Lehrplans für 9- bis II-Jährige (2002) ….............. 399

Tab. Di.2b Unterrichtszeit pro Fach in Prozent der insgesamt vorgesehenen Unterrichtszeit für den Pflichtteil des Lehrplans für I2- bis I4-Jährige (2002) $\ldots \ldots \ldots \ldots \ldots \ldots \ldots, \ldots$

Indikator D2: Klassengrößen und zahlenmäßiges Schüler/Lehrkräfte-Verhältnis $\ldots \ldots \ldots \ldots$. Tab. D2.I Durchschnittliche Klassengröße, nach Art der Bildungseinrichtung

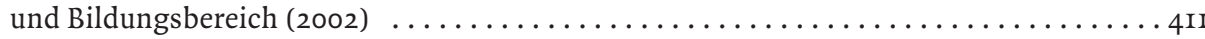

Tab. D2.2 Zahlenmäßiges Schüler/Lehrkräfte-Verhältnis in Bildungseinrichtungen (2002) … . 4 12 Tab. D2.3 Unterrichtende und nicht-unterrichtende Beschäftige in Bildungseinrichtungen (2002) . $4 \mathrm{II}$

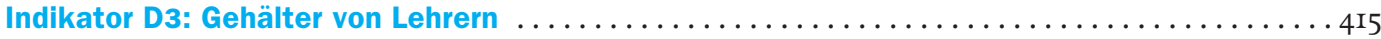

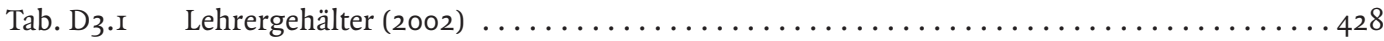

Tab. D3.2a Zulagen zum Grundgehalt für Lehrer an öffentlichen Bildungseinrichtungen (2002) $\ldots 430$

Tab. D3.2b Zulagen zum Grundgehalt für Lehrer an öffentlichen Bildungseinrichtungen, über die vom Schulleiter entschieden wird (2002) . . . . . . . . . . . . . . 432

Tab. D3.2c Zulagen zum Grundgehalt für Lehrer an öffentlichen Bildungseinrichtungen, über die von der lokalen oder regionalen Behörde entschieden wird (2002) $\ldots \ldots \ldots \ldots 433$

Tab. D3.2d Zulagen zum Grundgehalt für Lehrer an öffentlichen Bildungseinrichtungen, über die von der nationalen Behörde entschieden wird (2002) ................... 434

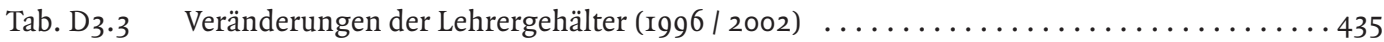
Indikator D4: Unterrichtszeit und Arbeitszeit der Lehrer ....................... 437

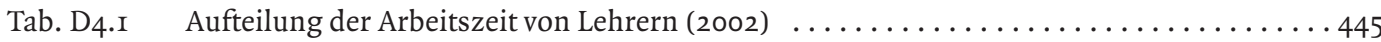

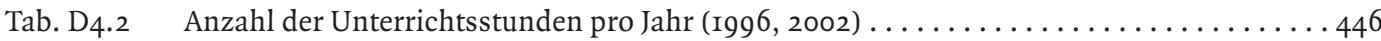
Indikator D5: Kriterien zur Aufnahme, Klassenzuweisung und -zusammensetzung in Schulen

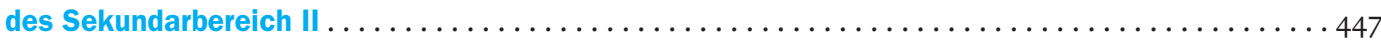

Tab. D5.I Kriterien zur Aufnahme von Schülern und Klassenzuweisung im Sekundarbereich II

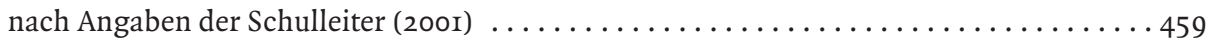

Tab. D5.2 Index der Praxis zur Aufnahme von Schülern und Klassenzuweisung im

Zusammenhang mit den Leistungen der Schüler (200I) $\ldots \ldots \ldots \ldots \ldots \ldots \ldots \ldots \ldots \ldots$

Tab. D5.3 Häufigkeit, mit der laut Angaben der Schulleiter bestimmte Kriterien bei der Klassenzusammensetzung im Sekundarbereich II berücksichtig werden (200I) $\ldots \ldots \ldots \ldots .46$ I

Tab. D5.4 Index der selektiven Praxis der Klassenzusammensetzung in Schulen, nach Angaben

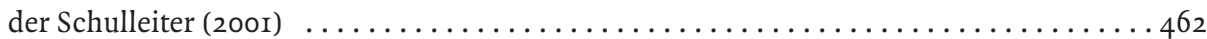

Indikator D6: Entscheidungskompetenzen im Bildungsbereich . . . . . . . . . . . . . . 463

Tab. D6.I Prozentsatz an Entscheidungen in Bezug auf öffentliche Bildungseinrichtungen im Sekundarbereich I, die auf der jeweiligen Entscheidungsebene getroffen werden (2003) . . . 474

Tab. D6.2 Prozentsatz an Entscheidungen in Bezug auf öffentliche Bildungseinrichtungen im Sekundarbereich I, die auf der jeweiligen Entscheidungsebene getroffen werden, nach

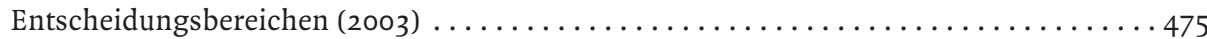

Tab. D6.3 Prozentsatz an Entscheidungen in Bezug auf öffentliche Bildungseinrichtungen im Sekundarbereich I, die auf Schulebene getroffen werden, nach Entscheidungsart (2003) . . 476

Tab. D6.4 Prozentsatz an Entscheidungen in Bezug auf öffentliche Bildungseinrichtungen im Sekundarbereich I, die auf Schulebene getroffen werden, nach Entscheidungsbereich

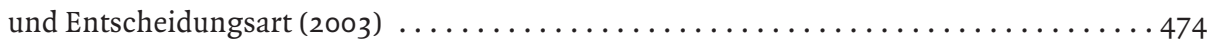

Tab. D6.5 Entscheidungsebene, auf der verschiedene Entscheidungen über den Lehrplan an öffentlichen Bildungseinrichtungen im Sekundarbereich I getroffen werden (2003) . . . 478

Tab. D6.6 Prozensatz an Entscheidungen in Bezug auf öffentliche Bildungseinrichtungen im Sekundarbereich I, die auf der jeweiligen Entscheidungsebene

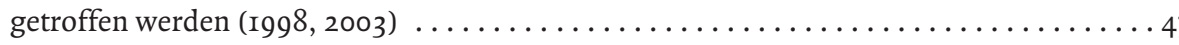


Anhang 1: Merkmale der Bildungssysteme $\ldots \ldots \ldots \ldots \ldots \ldots \ldots \ldots \ldots \ldots \ldots, \ldots \ldots \ldots$

Tab. XI.ra Typisches Abschlussalter im Sekundarbereich II $\ldots \ldots \ldots \ldots \ldots \ldots \ldots \ldots \ldots \ldots 483$

Tab. Xı.rb Typisches Abschlussalter im post-sekundaren, nicht-tertiären Bereich . . . . . . 484

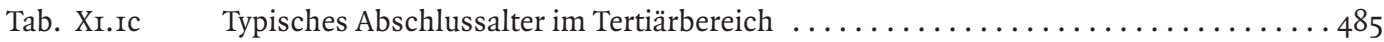

Tab. XI.2a Für die Berechnung der Indikatoren verwendete Haushalts- und Schuljahre . . . . . . 488

Tab. XI.2b Für die Berechnung der Indikatoren verwendete Haushalts- und Schuljahre . . . . . . 487

Tab. XI.3 Abschlussanforderungen für Bildungsgänge im Sekundarbereich II (ISCED 3) $\ldots \ldots 488$

Anhang 2: Statistische Bezugsdaten ............................... 489

Tab. X2.I

Überblick über das wirtschaftliche Umfeld anhand von grundlegenden Kennzahlen

(Referenzzeitraum: Kalenderjahr 200I, zu konstanten Preisen von 200I) . . . . . 49 I

Tab. X2.2 Grundlegende statistische Bezugsdaten (Referenzzeitraum: Kalenderjahr 200I,

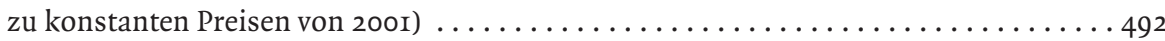

Tab. X2.3 Grundlegende statistische Bezugsdaten (Referenzzeitraum: Kalenderjahr I995,

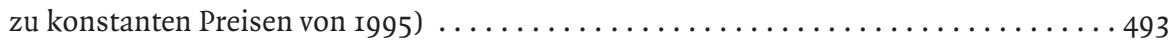

Tab. X2.4a Statistische Bezugsdaten zur Berechnung der Lehrergehälter,

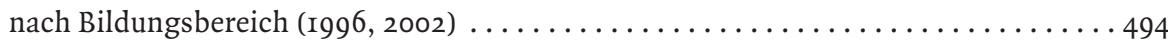

Tab. X2.4b Statistische Bezugsdaten zur Berechnung der Lehrergehälter $($ I996, 2002) $\ldots \ldots 496$

Anhang 3: Quellen, Methoden und technische Hinweise $\ldots . \ldots \ldots \ldots \ldots \ldots \ldots . \ldots 49$

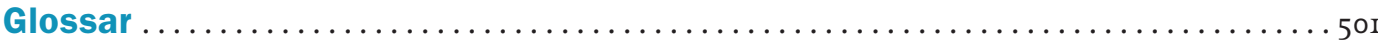

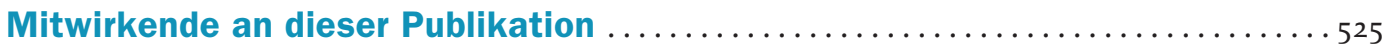

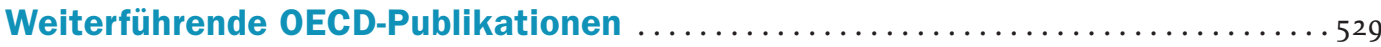




\section{Interessante Einzelergebnisse}

Die Veränderungen der wirtschaftlichen und gesellschaftlichen Rahmenbedingungen lassen der Bildung eine immer größere Bedeutung für den Erfolg der einzelnen Menschen und der Länder zukommen. Schon lange wird dem Humankapital eine Schlüsselrolle beim Kampf gegen Arbeitslosigkeit und niedriges Lohnnivieau beigemessen, nun aber liegen solide Beweise dafür vor, dass es mit einer Reihe von nichtökonomischen Vorteilen wie besserer Gesundheit und größerem Wohlbefinden einhergeht.

Die Vorteile von Bildung sind in den letzten Jahren die treibende Kraft hinter der zunehmenden Beteiligung von Menschen aller Altersstufen - von der frühen Kindheit bis zum späten Erwachsenenleben - an einem immer größer werdenden Spektrum von Lernangeboten gewesen. In Zeiten einer zunehmenden und immer vielfältigeren Nachfrage nach lebenslangem Lernen besteht die große Aufgabe für die Regierungen darin, sicherzustellen, dass die verschiedenen Arten und Formen des Lernens dem sich ständig ändernden Bedarf auf möglichst kosteneffektive Art und Weise entsprechen.

Bildung aufeinen Blick - OECD-Indikatoren 2004 bietet ein umfangreiches aktuelles Spektrum an vergleichbaren Indikatoren zu den Leistungen von Bildungssystemen, die auf dem Konsens der Fachwelt beruhen, wie der gegenwärtige Stand der Bildung im internationalen Vergleich zu bewerten ist. Sie enthalten Informationen zu den in Bildung investierten personellen und finanziellen Ressourcen, zur Funktionsweise und Weiterentwicklung von Bildungssystemen, und zu den Erträgen aus Bildungsinvestitionen. Zu den zentralen Ergebnissen dieser Veröffentlichung gehören:

\section{Bildungs- und Lernergebnisse}

- Der durchschnittliche Bildungsstand der Erwachsenenbevölkerung in den OECD-Ländern auf Grundlage der Dauer aktueller formaler Bildungsgänge entspricht einer Ausbildungsdauer von II,8 Jahren. Für die I8 Länder, die über dem OECD-Durchschnitt liegen, beträgt die durchschnittliche Ausbildungsdauer zwischen II,8 und I3,8 Jahren. Für die verbleibenden I2 Länder ist die Spanne sehr viel größer und umfasst mehr als 4 Jahre von der kürzesten Ausbildungsdauer von 7,4 Jahren bis hin zur längsten von II, 8 Jahren (Tab. Ar.I).

- In 17 der 20 OECD-Länder, für die vergleichbare Zahlen zur Verfügung stehen, liegt das Verhältnis von Absolventen des Sekundarbereich II zur Bevölkerung im typischen Abschlussalter bei über 70 Prozent. In Dänemark, Deutschland, Japan, Norwegen, Polen und der Schweiz liegen die Abschlussquoten bei go Prozent oder darüber. Jetzt muss verhindert werden, dass der übrige Teil den Anschluss verliert und sich dem möglichen Risiko sozialer Ausgrenzung gegenübersieht (Tab. A2.I).
Dauer der (Aus-)Bildung in den OECD-Ländern

Mindestvoraussetzungen für einen erfolgreichen Eintritt in den Arbeitsmarkt 
Abschlüsse im Tertiärbereich

Die Qualität der Lern-

ergebnisse im Primarbereich
Bei einem Vergleich des Bildungsstands der 25- bis 34-Jährigen mit dem der 45- bis 54-Jährigen zeigt sich, dass der Anteil der Personen, die über einen Abschluss im Sekundarbereich II verfügen, in fast allen OECD-Ländern gestiegen ist, in einigen Ländern sogar recht deutlich: in zwei Dritteln der Länder reicht bei der jüngsten Altersgruppe der Anteil von 70 bis 95 Prozent. Viele Länder mit einem in der Vergangenheit geringen Bildungsstand holen nun auf (Tab. A2.2).

Im Durchschnitt von 17 OECD-Ländern mit vergleichbaren Daten erzielen gegenwärtig 32 Prozent der Personen im typischen Abschlussalter einen Abschluss im Tertiärbereich A, zu dem Universitäten und andere Bildungseinrichtungen gehören, die ähnliche Qualifikationen anbieten. Die Zahl reicht jedoch von weniger als 20 Prozent in Deutschland, Österreich, der Schweiz und der Tschechischen Republik bis zu mehr als 40 Prozent in Australien, Finnland, Island und Polen (Tab. A3.I).

Gemessen am Bildungsstand hat der Anteil der Erwachsenenbevölkerung in den OECD-Ländern mit einer Ausbildung im Tertiärbereich entsprechenden Kenntnissen und Fähigkeiten zugenommen. Der größte Teil dieser Zunahme ist jedoch auf einen signifikanten Anstieg der tertiären Abschlussquoten in einer vergleichsweise geringen Zahl von Ländern zurückzuführen (Tab. A3.4).

Im Durchschnitt gilt für ein Drittel der Studierenden in den OECD-Ländern, dass sie die Ausbildung im Tertiärbereich vor einem ersten Abschluss abbrechen (Tab. A3.2).

Im Durchschnitt aller OECD-Länder erwirbt fast jeder dritte Absolvent des Tertiärbereichs mit einem Universitätsabschluss bzw. einem gleichwertigen Abschluss diesen in den Sozial-, Rechts- oder Wirtschaftswissenschaften. Darauf folgen auf der Beliebheitsskala die naturwissenschaftlich ausgerichteten Studienbereiche (Ingenieurwesen, Fertigung und Bauwesen, Biowissenschaften, Physik und Agrarwissenschaft, Mathematik und Informatik, jedoch ohne Gesundheit und Soziales), in denen im Durchschnitt jeder Vierte einen Abschluss erwirbt (Tab. A4.I).

In den Bereichen Geisteswissenschaften, Kunst, Erziehungswissenschaften, Gesundheit und Soziales sind im Durchschnitt der OECD-Länder mehr als zwei Drittel der Absolventen mit einem Universitätsabschluss bzw. einem gleichwertigen Abschluss Frauen. Ihr Anteil in Mathematik und Informatik beträgt jedoch weniger als ein Drittel und weniger als ein Fünftel in den Bereichen Ingenieurwesen, Fertigung und Bauwesen (Tab. A4.2).

In den meisten OECD-Ländern entsprechen oder übersteigen die Abschlussquoten der Frauen an Universitäten bzw. gleichwertigen Bildungseinrichtungen diejenigen der Männer, aber es erwerben immer noch eher Männer als Frauen einen Abschluss in einem weiterführenden Forschungsprogramm, z.B. eine Promotion (Tab. A4.2).

Bei einem Vergleich von neun Ländern wiesen vier (Griechenland, Island, Slowenien und Ungarn) zwischen I99I und 200I einen statistisch signifikanten Anstieg der durchschnittlichen Lesekompetenz bei Schülern der 4. Jahrgangsstufe auf. Dieser Anstieg reicht von I6 Punkten in Ungarn bis zu 4I Punkten in Griechenland. In Schweden ist dagegen die Leistung im gleichen Zeitraum zurückgegangen - von 513 Punkten im Jahr I99I auf 498 Punkte im Jahr 200I (Tab. A5.I). 
In Ungarn haben Leistungsverbesserungen im oberen Leistungsviertel der Schüler zu einem Anstieg des Leistungsdurchschnitts geführt. Im Gegensatz dazu hat in Schweden der Rückgang beim oberen Leistungsviertel zu einem Rückgang der durchschnittlichen Leistungen der Schüler geführt (Tab. A5.I).

I99I schnitten in allen neun Ländern Mädchen besser ab als Jungen. 200I bestanden zwar die Unterschiede zugunsten der Mädchen noch in den meisten Ländern, in Italien und Island jedoch waren keine messbaren Unterschiede mehr zu beobachten (Tab. A5.2).

- Im Durchschnitt der OECD-Länder zeigten Io Prozent der 15-jährigen Schüler Leistungen gemäß den Anforderungen der Stufe 5 im Bereich Lesekompetenz, bei der es um die Bewertung von Informationen und die Entwicklung von Hypothesen geht, die Nutzung von Fachwissen und die Verarbeitung von gedanklichen Konzepten, die unter Umständen den eigenen Erwartungen widersprechen. Dieser Prozentsatz variiert jedoch von ig Prozent in Finnland und Neuseeland bis zu weniger als I Prozent in Mexiko. Im Durchschnitt erfüllen I2 Prozent der I5-jährigen Schüler nur die Anforderungen der grundlegendsten Kompetenzstufe 1 und weitere 6 Prozent liegen sogar noch darunter (Tab. A6.I).

15-Jährige in Japan erzielen die höchste mittlere Punktzahl bei der mathematischen Grundbildung, obwohl sich ihre Punktwerte nicht statistisch von denen der Schüler in zwei anderen Ländern an der Spitze - Korea und Neuseeland - unterscheiden. Bei der naturwissenschaftlichen Grundbildung erzielen die Schüler in Korea und Japan die höchsten Durchschnittsleistungen (Tab. A7.I und A7.2).

Während es große Unterschiede bei den mittleren Leistungen zwischen den einzelnen Ländern gibt, ist die Varianz der Leistungen 15-Jähriger innerhalb der einzelnen Länder um ein Vielfaches größer. Große Disparitäten bei den Leistungen sind jedoch nicht notwendigerweise eine Voraussetzung dafür, dass ein Land ein insgesamt hohes Leistungsniveau erzielt. Ganz im Gegenteil - die Leistungen von fünf der Länder mit den kleinsten Leistungsunterschieden auf der Skala für mathematische Grundbildung, nämlich Island, Finnland, Japan, Kanada und Korea liegen signifikant über dem OECD-Durchschnitt, und vier von ihnen (Finnland, Japan, Kanada und Korea) sind bei der mathematischen Grundbildung unter den sechs besten Ländern (Tab. A7.I).

- In der 4. Jahrgangsstufe übertrifft die durchschnittliche Lesekompetenz der Mädchen häufig die der Jungen und im Alter von I5 Jahren ist der Abstand zwischen den Geschlechtern dann meist recht groß (Tab. A9.2 und A9.3).

- In Mathematik haben in den meisten Ländern die I5-jährigen Jungen tendenziell einen leichten Vorsprung; in den Naturwissenschaften sind die geschlechtsspezifischen Unterschiede weniger deutlich ausgeprägt und weniger einheitlich (Tab. A9.2).

- In der politischen Bildung zeigen sich bei den I4-Jährigen nur wenige geschlechtsspezifische Unterschiede (Tab. A9.4).

Mädchen scheinen höhere Erwartungen an ihre künftigen Berufe zu haben als die Jungen, es gibt jedoch bei beiden Geschlechtern große Unterschiede zwischen den einzelnen Ländern (Tab. A9.I).

- In ungefähr der Hälfte der Länder bevorzugten mehr Mädchen als Jungen kooperative Formen des Lernens, während in den meisten Ländern die Jungen eher zu wettbewerbsorientierten Lernformen neigten (Tab. A9.5b).
Die Qualität der Lernergebnisse gegen Ende des Sekundarbereichs

Geschlechtsspezifische Unterschiede bei den Leistungen und Einstellungen der Schüler 
Unterrichtsteilnahme und Zugehörigkeitsgefühl der Schüler

Beschäftigungsvorteile von Bildung

Einkommensvorteile für den Einzelnen
Im Durchschnitt hat fast ein Viertel der 15-Jährigen negative Ansichten über ihre Zugehörigkeit zur Schule und im Durchschnitt gibt jeder Fünfte an, kürzlich die Schule nicht besucht zu haben, zu spät gekommen zu sein oder geschwänzt zu haben (Abb. A8.I).

Die Schüler in Schweden, Österreich und der Schweiz geben ein besonders starkes Zugehörigkeitsgefühl an, während das Zugehörigkeitsgefühl der Schüler in Belgien, Japan, Korea, Polen und der Tschechischen Republik unter dem Durchschnitt liegt (Tab. A8.I).

- In den meisten Ländern variiert der Anteil der Schüler mit einem geringen Zugehörigkeitsgefühl signifikant zwischen den Schulen und diese Varianz zwischen den Schulen ist bei der Unterrichtsteilnahme noch größer (Indikator A8).

Bei den einzelnen Schülern ist der Zusammenhang zwischen Unterrichtsteilnahme und Zugehörigkeitsgefühl nur schwach, was vermuten lässt, dass viele Schüler, die sich nicht zugehörig fühlen, dennoch regelmäßig die Schule besuchen und umgekehrt (Abb. A8.3).

- Im Gegensatz dazu sind Zugehörigkeitsgefühl und Unterrichtsteilnahme auf Schulebene eher miteinander verknüpft und stehen in engem Zusammenhang zur Leistung der Schule, was vermuten lässt, dass Schulen mit einem hohen Grad an Engagement auch ein hohes Niveau an schulischer Leistung erzielen (Abb. A8.3).

Die Analyse zeigt insbesondere, dass ein großer Teil der Schüler mit vergleichsweise guten schulischen Leistungen dennoch ein geringes Zugehörigkeitsgefühl angibt (Abb. A8.4).

Die Erwerbstätigenanteile steigen in den meisten OECD-Ländern mit zunehmendem Bildungsstand. Von sehr wenigen Ausnahmen abgesehen, ist der Erwerbstätigenanteil unter Absolventen des Tertiärbereichs wesentlich höher als unter Absolventen des Sekundarbereich II. Bei Männern ist der Abstand zwischen Absolventen des Sekundarbereich II und denen ohne einen solchen Abschluss besonders groß (Tab. Aro.ra).

- Der Erwerbstätigenanteil unter Frauen ohne einen Abschluss im Sekundarbereich II ist besonders niedrig. Die Anteile unter Frauen mit einem Abschluss im Tertiärbereich A liegen, mit Ausnahme von vier Ländern, überall bei 75 Prozent oder darüber. Sie sind jedoch in allen Ländern niedriger als die der Männer (Tab. Aro.ra).

Mit zunehmendem Bildungsstand nimmt der geschlechtsspezifische Unterschied in den Erwerbstätigenanteilen ab. Er beläuft sich auf 23 Prozentpunkte bei Personen ohne einen Abschluss im Sekundarbereich II und II Prozentpunkte bei denen mit dem höchsten Bildungsstand (Tab. Aro.I.a).

Zwischen Bildungsstand und Einkommen besteht eine positive Korrelation. Der Abschluss des Sekundarbereich II stellt in vielen Ländern einen Wendepunkt dar, ab dem jede zusätzliche Ausbildung einen besonders hohen Einkommenszuschlag mit sich bringt. In allen Ländern verdienen Absolventen des Tertiärbereichs deutlich mehr als Absolventen des Sekundarbereich II. Die Einkommensunterschiede zwischen Absolventen des Tertiärbereichs und denen des Sekundarbereich II sind im Allgemeinen deutlich größer als zwischen Absolventen des Sekundarbereich II und denen des Sekundarbereich I und darunter (Tab. AII.ra).

Einkommen von Personen mit einem Abschluss unterhalb des Sekundarbereich II belaufen sich in der Regel auf 6o bis go Prozent der Einkommen von Absolventen des Sekundarbereich II (Tab Arr.ra). 
Frauen verdienen nach wie vor weniger im Vergleich zu Männern mit einem ähnlichen Bildungsstand (Tab. Arr.rb).

- Neuere Untersuchungen des Humankapitals in den Volkswirtschaften von I4 OECD-Ländern, basierend auf Bewertungen der Lesekompetenz, deuten darauf hin, dass dieses sich deutlich positiv auf das Wirtschaftswachstum auswirkt (Indikator AI2).

- Eine Zunahme des Bestands an Humankapital erhöht die Arbeitsproduktivität und dient auch als Motor für den technologischen Fortschritt (Indikator AI2).

- In den meisten OECD-Ländern ist mindestens die Hälfte des Anstiegs des BIP pro Kopf zwischen I9go und 2000 auf den Anstieg der Arbeitsproduktivität zurückzuführen (Abb. AI2.I).

Es wird davon ausgegangen, dass in den OECD-Ländern allgemein ein Anstieg im durchschnittlichen Bildungsniveau um ein Jahr die Pro-Kopf-Produktion zwischen 3 und 6 Prozent steigert (Indikator Ar2).

\section{In Bildung investierte öffentliche Mittel}

- Insgesamt geben die OECD-Länder jährlich 4.819 US-Dollar pro Schüler im Primarbereich, 6.688 US-Dollar pro Schüler im Sekundarbereich und I2.3Ig USDollar pro Studierenden im Tertiärbereich aus. Hinter diesen Durchschnittswerten stehen jedoch große Unterschiede bei den Ausgaben zwischen den einzelnen Ländern. Im Durchschnitt der OECD-Länder, dargestellt als arithmetisches Mittel aller OECD-Länder, sind die Ausgaben pro Studierenden im Tertiärbereich 2,2-mal so hoch wie im Primarbereich (Tab. BI.I).

- Ohne F\&E-Aktivitäten liegen die Ausgaben für Bildungseinrichtungen im Tertiärbereich im Durchschnitt bei 7.203 US-Dollar pro Studierenden und reichen von 4.00o US-Dollar pro Studierenden oder weniger in Griechenland, Mexiko, Polen und der Türkei bis zu mehr als 8.000 US-Dollar in Australien, Belgien, Dänemark, Irland, den Niederlanden, Schweden, dem Vereinigten Königreich und den Vereinigten Staaten (Tab. BI.I).

- In einigen OECD-Ländern führen geringe jährliche Ausgaben pro Studierenden im Tertiärbereich jedoch trotzdem aufgrund der langen Studienzeiten zu hohen Gesamtkosten pro Studierenden (Tab. BI.3).

Niedrigere Ausgaben sind nicht automatisch mit einer geringeren Qualität der Bildungsdienstleistungen gleichzusetzen. So gehören beispielsweise Australien, Finnland, Irland, Korea und das Vereinigte Königreich, Länder mit moderaten Bildungsausgaben pro Schüler im Primar- und Sekundarbereich I, zu den OECD-Ländern mit den besten Leistungen I5-Jähriger in zentralen Fächern (Indikatoren A6 und BI).

Es gibt erhebliche Unterschiede zwischen dem Anteil der Mittel, die im Tertiärbereich investiert werden und dem Anteil der Lernenden im Tertiärbereich. Im Durchschnitt der 24 OECD-Länder, für die Daten vorliegen, fließen 24 Prozent aller für Bildungseinrichtungen vorgesehenen Mittel in den Tertiärbereich, obwohl nur I4 Prozent aller Schüler/Studierenden diesen Bildungsbereich besuchen (Tab. Br.4).

Die Bildungsausgaben pro Schüler im Primar-, Sekundar- und post-sekundaren, nicht-tertiären Bereich stiegen zwischen 1995 und 2001 in Australien, Griechenland, Irland, Polen, Portugal, Spanien und der Türkei um 29 Prozent
Bildung, Arbeitsproduktivität und Wirtschaftswachstum

Ausgaben pro Schüler/ Studierenden 
Der in Bildung investierte Anteil des Volkseinkommens

Mittel aus öffentlichen und privaten Quellen

Der Teil der öffentlichen Haushalte, der in Bildung fließt oder mehr. Im Tertiärbereich haben die Bildungsausgaben nicht immer mit dem raschen Anwachsen der Zahl der Studierenden Schritt gehalten (Tab. BI.5).

In 7 von 22 OECD-Staaten mit verfügbaren Daten gingen die Ausgaben für Bildungseinrichtungen pro Studierenden (in US-Dollar, kaufkraftbereinigt) zwischen 1995 und 2001 zurück, während das Bruttoinlandsprodukt pro Kopf während des gleichen Zeitraums zunahm (Tab. Br.6).

Die OECD-Länder geben 6,2 Prozent der Gesamtsumme ihrer Bruttoinlandsprodukte für Bildungseinrichtungen aus (Tab. B2.ra).

In I7 von I8 OECD-Ländern mit verfügbaren Daten erhöhten sich zwischen 1995 und 2001 die realen privaten und öffentlichen Ausgaben für Bildungseinrichtungen um mehr als 5 Prozent. Im Gegensatz zu den Entwicklungen Anfang der neunziger Jahre blieb jedoch der Anstieg der Ausgaben für Bildungseinrichtungen tendenziell hinter dem Wachstum des Volkseinkommens zurück (Tab. B2.ra und B2.2).

- Kanada, Korea und die Vereinigten Staaten verwenden jeweils mehr als 2 Prozent ihres BIP für den Tertiärbereich (Tab. B2.Ib).

Bildungseinrichtungen werden immer noch überwiegend aus öffentlichen Mitteln finanziert: 88 Prozent aller Mittel für Bildungseinrichtungen stammen direkt aus öffentlichen Quellen. Die Finanzierung aus privaten Quellen spielt jedoch in Korea (wo sie über 43 Prozent der Gesamtausgaben ausmacht), den Vereinigten Staaten (beinahe ein Drittel der Gesamtausgaben) sowie in Australien und Japan (beinahe ein Viertel der Gesamtausgaben) eine bedeutende Rolle (Tab. B3.I).

In einer Reihe von OECD-Ländern übernimmt der Staat den größten Teil der Kosten für den Primar- und Sekundarbereich, überlässt jedoch die Leitung der Bildungseinrichtungen dem privaten Sektor. So wird eine größere Bandbreite an Lernmöglichkeiten zur Verfügung gestellt, ohne Schülern aus einkommensschwachen Familien den Zugang zu Bildung zu erschweren (Tab. B3.2a und $\mathrm{B}_{3} .3$ ).

Tendenziell beziehen tertiäre Bildungseinrichtungen einen weitaus größeren Teil ihrer Finanzierung aus privaten Quellen als Bildungseinrichtungen des Primar- und Sekundarbereichs. Allerdings reicht der Anteil der privaten Finanzierung einschließlich staatlich-subventionierter privater Zahlungen von weniger als 4 Prozent in Dänemark, Finnland, Griechenland und Norwegen bis zu mehr als drei Viertel in Korea (Tab. B3.2b).

In einem Drittel der Länder (Australien, Belgien, Kanada, Korea, den Niederlanden, Schweden, Ungarn, dem Vereinigten Königreich und den Vereinigten Staaten) beträgt der Anteil der Ausgaben für tertiäre Bildungseinrichtungen, der von anderen privaten Einheiten als den privaten Haushalten getragen wird, Io Prozent und mehr (Tab. B3.2b).

Die Entwicklung der jeweiligen Anteile privater und öffentlicher Bildungsausgaben ist über alle Bildungsbereiche hinweg ganz unterschiedlich - es gibt einige Länder mit einer Verschiebung hin zu öffentlichen Ausgaben, während es in anderen eine Verschiebung hin zu privaten Ausgaben gibt. In den meisten Fällen, in denen es eine Verschiebung zu den privaten Ausgaben hin gab, führte dies jedoch nicht zu einer Verringerung der realen öffentlichen Ausgaben (Tab. B2.2, B3.2a und b).

Im Durchschnitt wenden die OECD-Länder 12,7 Prozent ihrer gesamten öffentlichen Ausgaben für Bildung auf. Die Werte für die einzelnen Länder reichen 
jedoch von weniger als io Prozent in Deutschland, Luxemburg, der Slowakischen sowie der Tschechischen Republik bis zu 24 Prozent in Mexiko (Tab. B4.I).

Die öffentliche Finanzierung der Bildung ist eine vorrangige gesellschaftspolitische Aufgabe - selbst in denjenigen OECD-Ländern, in denen die Staatsquote insgesamt gering ist (Tab. B4.I).

Die öffentlichen Ausgaben für Bildung stiegen eher schneller als die öffentlichen Gesamtausgaben, jedoch langsamer als das BIP. Die öffentlichen Bildungsausgaben als Prozentsatz der öffentlichen Gesamtausgaben wuchsen zwischen I995 und 200I in Dänemark, Mexiko und Schweden am stärksten (Tab. B4.I).

Öffentliche Subventionen für Schüler/Studierende und private Haushalte finden sich hauptsächlich im Tertiärbereich (Tab. B5.I und B5.2).

- Durchschnittlich I7 Prozent der öffentlichen Ausgaben für den Tertiärbereich betreffen finanzielle Unterstützungsleistungen an Studierende, private Haushalte und andere private Einheiten. In Australien, Dänemark, Neuseeland, Norwegen, Schweden und den Vereinigten Staaten machen die öffentlichen Subventionen ungefähr 30 Prozent und mehr der öffentlichen Bildungsetats für den Tertiärbereich aus (Tab. B5.2).

- Subventionen sind generell häufiger in Systemen anzutreffen, bei denen von den Schülern/Studierenden erwartet wird, dass sie wenigstens einen Teil ihrer Bildungskosten selbst tragen (Indikator B5).

- Subventionierte Darlehenssysteme für Schüler/Studierende existieren in der Regel in Ländern mit einer hohen Bildungsbeteiligung im Tertiärbereich. In den meisten OECD-Ländern genießen die Empfänger von Subventionen einen erheblichen Ermessensspielraum hinsichtlich der Verwendung der erhaltenen Subventionen. In allen OECD-Ländern, für die Zahlen vorliegen, werden Subventionen in erster Linie außerhalb der Bildungseinrichtungen ausgegeben - in jedem dritten sogar ausschließlich (Tab. B5.2).

- Im Durchschnitt entfallen ein Viertel der Ausgaben für den Tertiärbereich auf Forschung und Entwicklung an tertiären Bildungseinrichtungen. Die erheblichen Unterschiede zwischen den einzelnen OECD-Ländern beim Umfang von Forschung und Entwicklung an tertiären Einrichtungen können zum Teil die großen Unterschiede bei den Ausgaben pro Studierenden in diesem Bildungsbereich erklären (Tab. B6.I).

In den Bildungsbereichen unterhalb des Tertiärbereichs belaufen sich die laufenden Ausgaben im Durchschnitt der OECD-Länder auf 92 Prozent der gesamten Ausgaben. Mit Ausnahme von vier Ländern entfallen in allen OECD-Ländern mindestens 70 Prozent der laufenden Ausgaben in diesen Bildungsbereichen auf die Vergütung der Beschäftigten (Tab. B6.3).

\section{Bildungszugang, Bildungsbeteiligung und Bildungserwartung (in Jahren)}

In 24 von 27 OECD-Ländern nimmt der Einzelne im Durchschnitt zwischen 16 und 20 Jahren an einer formalen Ausbildung teil. Der größte Teil der Unterschiede bei dieser Kennzahl zwischen den einzelnen Ländern beruht auf Unterschieden bei den Schülerzahlen im Sekundarbereich II (Tab. CI.I).
Art und Umfang der öffentlichen Subventionen an private Haushalte

Die Aufteilung der Mittel auf die unterschiedlichen Ausgabenkategorien

Zu erwartende Jahre in Ausbildung 
Zugang zum Tertiärbereich

Die Internationalisierung des Tertiärbereichs
Zwischen 1995 und 2002 stieg die Bildungserwartung (in Jahren) in allen OECD-Ländern, für die vergleichbare Zeitreihendaten verfügbar sind (Tab. CI.I).

In der Hälfte der OECD-Länder werden mehr als 70 Prozent der 3- bis 4-Jährigen im Elementar-oder Primarbereich unterrichtet. Am anderen Ende des Spektrums kann ein heute I7-Jähriger davon ausgehen, dass er voraussichtlich im Durchschnitt 2,7 Jahre im tertiären Bildungsbereich verbringen wird (Tab. Cr.2).

- In der Mehrheit der OECD-Länder können Frauen eine im Durchschnitt um 0,7 Jahre längere Bildungsdauer erwarten als Männer (Tab. CI.I).

- Im Laufe seines Lebens wird jeder zweite Jugendliche in den OECD-Ländern an einem universitären bzw. gleichwertigen Studiengang teilnehmen (Tab. C2.I).

Im Durchschnitt der OECD-Länder wird ein heute 17-Jähriger 2,7 Jahre im Tertiärbereich verbringen, davon 2 Jahre in Vollzeit. In Finnland, Korea und den Vereinigten Staaten nimmt ein junger Mensch im Laufe seines Lebens voraussichtlich mindestens 4 Jahre an Vollzeit- und Teilzeitstudiengängen im Tertiärbereich teil (Tab. C2.2).

Mit Ausnahme von Österreich` und Frankreich hat die Bildungsbeteiligung im Tertiärbereich zwischen 1995 und 2002 in allen OECD-Ländern zugenommen (Tab. C2.2).

Während die Mehrzahl der Studierenden an öffentlichen Bildungseinrichtungen eingeschrieben ist, besuchen in Belgien, Japan, Korea, den Niederlanden und dem Vereinigten Königreich die meisten Studierenden privat geleitete Bildungseinrichtungen (Tab. C2.3).

2002 waren 1,9 Millionen Studierende außerhalb ihres Heimatlandes in einem OECD-Land oder in einem in dieser Veröffentlichung erfassten OECD-Partnerland eingeschrieben. Dies stellt eine Zunahme der Gesamtmobilität Studierender von I5 Prozent gegenüber dem Vorjahr dar (Tab. C3.6).

Fast 73 Prozent aller ausländischen Studierenden im OECD-Raum konzentrieren sich auf 5 Gastländer: Australien, Frankreich, Deutschland, das Vereinigte Königreich und die Vereinigten Staaten (Abb. C3.2).

Absolut gesehen entsenden Deutschland, Frankreich, Griechenland, Japan, Korea und die Türkei die meisten der in OECD-Ländern und-Partnerländern Studierenden aus OECD-Ländern. Die meisten Studierenden aus OECD-Partnerländern kommen aus China, Indien und Südostasien in die OECD-Länder und -Partnerländer (Tab. C3.2).

In Relation zur Gesamtzahl der in einem Land im Tertiärbereich eingeschriebenen Studierenden variiert der Anteil der ausländischen Studierenden in den OECD-Ländern von weniger als I Prozent bis zu fast I8 Prozent in Australien und der Schweiz. Im Verhältnis zu ihrer Größe, d.h. als Prozentsatz der Studierenden in den jeweiligen Ländern, weisen Australien, Belgien, Deutschland, Frankreich, Österreich, die Schweiz und das Vereinigte Königreich den größten Zugang ausländischer Studierender auf (Tab. C3.I).

* In Österreich war zwischen 1995 und 2001 ein Rückgang der Studierendenzahl im Tertiärbereich zu verzeichnen, was im Zusammenhang mit der Einführung von Studienbeiträgen im Jahr 2001 stand. Andere Indikatoren der Bildungsbeteiligung im Tertiärbereich (Hochschulzugang, Abschlussquoten, Erfolgsquoten) zeigen keinen Rückgang der Beteiligung an tertiärer Bildung in Österreich. 
In Finnland, Spanien und der Schweiz ist mindestens jeder sechste ausländische Studierende in einem der sehr theoretisch orientierten weiterführenden Forschungsprogramme eingeschrieben (Tab. C3.4).

- In Australien, Deutschland, Finnland, Schweden, der Schweiz und dem Vereinigten Königreich sind mindestens 30 Prozent der ausländischen Studierenden in naturwissenschaftlich ausgerichteten Fächern oder im Bereich Ingenieurwesen eingeschrieben (Tab. $\mathrm{C}_{3} \cdot 5$ ).

- Im Durchschnitt kann ein Fünfzehnjähriger erwarten, für knapp 6,5 Jahre im formalen Bildungssystem zu verbleiben. In 17 der 28 untersuchten Länder liegt dieser Zeitraum zwischen fast 6 und 7,5 Jahren (Tab. C4.Ia).

Zusätzlich zu den in Ausbildung zu erwartenden Jahren kann ein Fünfzehnjähriger damit rechnen, während der nächsten 15 Jahre für 6,4 Jahre beschäftigt, für insgesamt o,8 Jahre arbeitslos und für I,3 Jahre nicht auf dem Arbeitsmarkt zu sein. Am stärksten unterscheiden sich die Länder in der durchschnittlichen Länge der Phasen der Arbeitslosigkeit (Tab. C4.Ia)

- In 23 von 27 OECD-Ländern haben 20 - bis 24-jährige Frauen eine höhere Bíldungsbeteiligung als gleichaltrige Männer. Die 20- bis 24-jährigen Männer sind eher berufstätig. In den meisten OECD-Ländern liegt der Prozentsatz 20bis 24-Jähriger, die sich nicht in Ausbildung befinden, zwischen 50 und 70 Prozent (Tab. C4.2a).

In einigen Ländern erfolgen Bildung und Arbeit überwiegend nacheinander, während sie in anderen parallel stattfinden. Duale Ausbildungsgänge, in europäischen Ländern relativ weit verbreitet, bieten eine strukturierte berufliche Ausbildung, die zu anerkannten Berufsabschlüssen führt. In anderen Ländern werden Erstausbildung und bezahlte Arbeit selten kombiniert (Abb. 4.4).

Der Anteil 20-bis 24-Jähriger, die sich nicht in Ausbildung befinden und über keinen Abschluss im Sekundarbereich II verfügen, liegt nur in 8 von 27 OECD-Ländern unter ıo Prozent. In II Ländern gehören dieser potentiellen 'Risikogruppe' zwischen Io und I8 Prozent der Altersgruppe an und in den verbleibenden 8 OECD-Ländern sind mehr als 20 Prozent der Altersgruppe dieser Kategorie zuzurechnen (Tab. $\mathrm{C}_{5}$.I)

- In I9 von 27 Ländern fällt ein höherer Prozentsatz männlicher als weiblicher 20- bis 24-Jähriger in diese Risikogruppe, insbesondere in Griechenland, Island, Irland, Italien, Portugal und Spanien. Die gegenteilige Entwicklung ist in Dänemark, Luxemburg und der Türkei am offensichtlichsten (Tab. C5.I).

\section{Das Lernumfeld und die Organisation von Schulen}

Schüler im Alter von 7 bis I4 Jahren erhalten im Durchschnitt 6.868 Stunden Unterricht. Hiervon entfallen I.576 Stunden auf das 7. und 8. Lebensjahr, 2.510 Stunden auf das 9. bis II. Lebensjahr und 2.782 auf die Zeit vom I2. zum I4. Lebensjahr (Tab. Di.I).

- Im Durchschnitt der OECD-Länder haben 7- bis 8-jährige Schüler im Jahr 752 Stunden Unterricht im Pflichtteil des Lehrplans und 788 Stunden vorgesehene Unterrichtszeit im Klassenzimmer. Von der vorgesehenen Unterrichtszeit her erhalten 9- bis II-jährige Schüler pro Jahr fast 50 Stunden Unterricht mehr als die 7- bis 8-Jährigen, und die I2- bis I4-Jährigen wiederum fast Ioo
Der Übergang von der Ausbildung in die Berufstätigkeit
Die Unterrichtsstunden der Schüler 
Aufnahmepolitik für Schüler im Sekundarbereich II

Klassengröße und zahlenmäßiges Schüler/LehrkräfteVerhältnis

Gehälter von Lehrern
Stunden mehr als die 9- bis II-Jährigen. Es gibt hierbei jedoch erhebliche Unterschiede zwischen den einzelnen Ländern (Tab. DI.I).

Bei den 9- bis II-jährigen Schülern entfällt fast die Hälfte der Pflicht-Unterrichtszeit auf Lesen und Schreiben, Mathematik und Naturwissenschaften, bei den I2- bis I4-Jährigen sind es 4I Prozent. Der prozentuale Anteil des Lehrplans der 9- bis II-Jährigen, der für Lesen und Schreiben in der Unterrichtssprache verpflichtend vorgesehen ist, unterscheidet sich jedoch erheblich zwischen den einzelnen Ländern, er reicht von I2 Prozent des Lehrplans in Portugal bis zu 3I Prozent in der Slowakischen Republik (Tab. Di.2).

Basierend auf den Angaben von Schulleitern in einer Erhebung von 2002 lässt sich sagen, dass die schulischen Leistungen das am häufigsten genutzte Kriterium zur Aufnahme von Schülern an Schulen des Sekundarbereich II sind, obwohl es zwischen den Ländern große Unterschiede gibt. In Finnland, Norwegen und Ungarn besuchen mehr als 80 Prozent der Schüler eine Schule, in der die schulischen Leistungen der Schüler immer als Aufnahmekriterium dienen, dagegen sind es in Spanien weniger als ıo Prozent (Tab. D5.I).

Die anderen am häufigsten verwendeten Aufnahmekriterien sind die Bedürfnisse der Schüler und ihr Interesse an einem Bildungsgang sowie ihr Wohnort (Tab. D5.I).

Die Klassenzusammensetzung wird am häufigsten durch die Auswahl eines bestimmten Faches oder Bildungsganges durch die Schüler bestimmt; im Durchschnitt besuchen 73 Prozent der Schüler eine Schule, die dieses Kriterium immer verwendet. Dagegen besucht in Mexiko fast die Hälfte der Schüler eine Schule, an der dies nie so gehandhabt wird. Die nächst häufige Vorgehensweise besteht darin, Klassen so zusammenzusetzen, dass sie eine Mischung von Fähigkeiten enthalten, danach folgt die Zusammenstellung nach dem Alter der Schüler (Tab. 5·3).

Die Schulen in Belgien (fläm.), Irland, Italien und Ungarn sind im Durchschnitt sowohl bei der Aufnahme der Schüler als auch bei der Klassenzusammensetzung selektiver als der internationale Durchschnitt. In Schweden und Spanien dagegen scheinen die Schulen eine weniger selektive Aufnahmepolitik zu verfolgen als der internationale Durchschnitt und auch bei der Klassenzusammensetzung tendenziell seltener selektiv vorzugehen (Abb.D 5.3).

Die durchschnittliche Klassengröße liegt im Primarbereich bei 22 Schülern, sie reicht jedoch von 36 Schülern pro Klasse in Korea bis zu weniger als 18 in Griechenland, Island und Luxemburg (Tab. D2.I).

Die Zahl der Schüler pro Klasse nimmt vom Primar- zum Sekundarbereich I im Durchschnitt um 2 Schüler zu, aufgrund der höheren Unterrichtsstundenzahl pro Jahr nimmt das zahlenmäßige Schüler/Lehrkräfte-Verhältnis jedoch eher ab, je höher der Bildungsbereich ist (Tab. D2.I).

Die Zahl der unterrichtenden und nicht-unterrichtenden Beschäftigten im Primarund Sekundarbereich reicht von weniger als 8I Beschäftigten pro I.000 Schülern in Japan, Korea und Mexiko bis zu IIg Beschäftigten und mehr pro I.00o Schülern in Frankreich, Island, Italien, Ungarn und den Vereinigten Staaten (Tab. D2.3).

Die mittleren Gehälter von Lehrern des Sekundarbereich I reichen von weniger als I0.000 US-Dollar in der Slowakischen Republik bis zu 40.000 US-Dollar 
und mehr in Australien, Deutschland, Japan, Korea, Schottland, der Schweiz und den Vereinigten Staaten (Tab. D3.I).

- Im Durchschnitt liegt das Gehalt je Unterrichtsstunde für einen Lehrer im Sekundarbereich II um rund 40 Prozent über dem eines Lehrers im Primarbereich, wobei dieser Unterschied in Neuseeland, der Türkei und den Vereinigten Staaten weniger als 5 Prozent ausmacht, während er in Spanien ganze 82 Prozent beträgt. Dort ist die Differenz zwischen Primar- und Sekundarbereich II in der Anzahl der zu abzuleistenden Unterrichtsstunden am größten (Tab. D3.I)

- Sowohl im Primar-als auch im Sekundarbereich sind die Höchstgehälter im Durchschnitt um rund 70 Prozent höher als die Anfangsgehälter, wobei dies von Land zu Land variiert und im großen und ganzen im Verhältnis zur Anzahl der Jahre steht, die ein Lehrer benötigt, um alle Gehaltsstufen zu durchlaufen. Die Höchstgehälter in Korea sind beispielsweise fast dreimal so hoch wie die Anfangsgehälter, doch dauert es 37 Jahre, bis man die Spitze der Gehaltsskala erreicht (Tab. D3.I).

Zwischen 1996 und 2002 sind die Lehrergehälter in praktisch allen Ländern real angestiegen, wobei der größte Anstieg in Mexiko und Ungarn zu verzeichnen war. In Spanien kam es im gleichen Zeitraum zu einem realen Rückgang der Gehälter im Primar- und Sekundarbereich (Tab. D3.3).

- Die durchschnittliche jährliche Zahl der Unterrichtsstunden an öffentlichen Schulen des Primarbereichs beträgt 803 Stunden, reicht aber von 617 Stunden in Japan bis zu I.I39 Stunden in den Vereinigten Staaten (Tab. D4.2).

- Im Sekundarbereich I liegt die Zahl der Unterrichtsstunden bei durchschnittlich 717 Stunden im Jahr, die Spannweite reicht jedoch von 513 Stunden in Japan bis zu I.I67 Stunden in Mexiko (Tab. D4.2).

- Im Sekundarbereich II liegt die Zahl der Unterrichtsstunden bei durchschnittlich 674 Stunden im Jahr, sie reicht jedoch von 449 Stunden in Japan bis zu I.I2I Stunden in den Vereinigten Staaten (Tab. D4.2).

- Der prozentuale Anteil der auf das Unterrichten entfallenden Arbeitszeit ist im Primarbereich höher als im Sekundarbereich. In beiden Bereichen ist der Anteil der auf das Unterrichten entfallenden Arbeitszeit nur in wenigen Ländern größer als 50 Prozent (Tab. D4.I und Abb. D4.2).

Die Vorgaben für die Arbeitszeit der Lehrer unterscheiden sich in den einzelnen Ländern. In den meisten Ländern müssen die Lehrer gesetzlich oder vertraglich geregelt eine bestimmte Zahl von Stunden arbeiten; einige Länder dagegen legen nur die Zahl der wöchentlich abzuleistenden Unterrichtsstunden fest( Indikator $\mathrm{D}_{4}$ ).

Insgesamt gesehen sind basierend auf den Daten für 2003 in Australien, Griechenland, Luxemburg, Mexiko, Österreich, Portugal, Spanien und der Türkei die Entscheidungskompetenzen am stärksten zentralisiert (d.h. sie werden auf zentraler und/oder bundesstaatlicher Ebene getroffen), wobei die Zentralregierung in Griechenland (mit 88 Prozent der Entscheidungen auf zentraler Ebene) und Luxemburg (66 Prozent) besonders dominiert (Tab. D6.I).

In England, Neuseeland, der Slowakischen Republik, der Tschechischen Republik und Ungarn werden Entscheidungen häufiger auf Schulebene getroffen. In den Niederlanden ist dies bei allen Entscheidungen der Fall (Tab. D6.I).
Arbeitszeit der Lehrer

Die Verteilung der Entscheidungskompetenzen im Sekundarbereich I 
Entscheidungen zur Unterrichtsorganisation werden in allen OECD-Ländern überwiegend auf Schulebene getroffen, dagegen fallen strukturelle und Planungsentscheidungen überwiegend in den Kompetenzbereich eher zentraler Regierungsebenen. Bei den Entscheidungen über Ressourcen und Personalangelegenheiten ist das Bild heterogener (Tab. D6.2).

Knapp die Hälfte der auf Schulebene getroffenen Entscheidungen erfolgt in völliger Autonomie und etwa der gleiche Anteil an Entscheidungen wird innerhalb von Rahmenrichtlinien getroffen, die von höherer Ebene festgelegt werden. Relativ wenige Entscheidungen auf Schulebene werden nach Beratung mit anderen getroffen. Strukturelle und Planungsentscheidungen werden von den Schulen in der Regel seltener autonom gefällt als andere Entscheidungen (Tab D6.3).

Zwischen 1998 und 2003 wurden die Entscheidungskompetenzen in den meisten Ländern stärker dezentralisiert, das gilt besonders für Korea, die Tschechische Republik und die Türkei. In Belgien (frz.) und Griechenland ist jedoch ein gegenläufiger Trend zu beobachten (Abb. D6.3).

\section{Neue Indikatoren in dieser Ausgabe}

Zusätzlich zur Aktualisierung der ständigen Indikatoren enthält diese Ausgabe folgende neue Indikatoren:

A5: Entwicklungen der Lesefähigkeiten und des Leseverständnisses von Schülern bewertet die Entwicklung der Lesefähigkeiten und des Leseverständnisses von 9-jährigen Schülern, sowohl insgesamt als auch nach Geschlecht aufgegliedert.

A8: Das Engagement von Schülern - untersucht zwei Aspekte des schulischen Engagements von Schülern: das Zugehörigkeitsgefühl der Schüler und ihre Unterrichtsteilnahme. Es wird aufgezeigt, wie sich diese in den einzelnen Ländern unterscheiden.

D5: Kriterien zur Aufnahme, Klassenzuweisung und -zusammensetzung in Schulen des Sekundarbereich - untersucht, wie diese Kriterien im Sekundarbereich I zur Anwendung kommen, ab dem sich das Bildungsangebot vielfältiger gestaltet.

D6: Entscheidungskompetenzen im Bildungsbereich - untersucht die Verteilung der Entscheidungskompetenzen in den einzelnen Ländern und zeigt auf, welche Stellen in welchen Entscheidungsbereichen Entscheidungen fällen und wie viel Autonomie sie hierbei genießen.

Außerdem umfassen die ständigen Indikatoren einige neue Analysen:

Demographische Faktoren, die sich auf die zukünftig verfügbaren Qualifikationen auswirken werden (Indikator AI)

Entwicklungen bei der Beziehung zwischen Bildungsstand und Erwerbstätigkeit (A I0)

Ein Vergleich der relativen Einkommen im Zeitverlauf, sowohl insgesamt als auch nach Geschlecht aufgegliedert (AII)

Ein Vergleich der Verteilung der Ausgaben und der Schüler-/Studierendenzahlen nach Bildungsbereich (BI)

Eine Aufgliederung der privaten Bildungsausgaben nach den Ausgaben privater Haushalte und denen anderer privater Einheiten (B3) 
Die Bildungsbeteiligung junger Menschen nach Altersjahrgängen aufgegliedert (CI)

Entwicklungen der Mobilität Studierender und eine Analyse der von ausländischen Studierenden besuchten Studienbereiche $\left(\mathrm{C}_{3}\right)$

- Vergleiche im Zeitverlauf, wie der Übergang von der Ausbildung in das Erwerbsleben bewältigt wird $\left(\mathrm{C}_{4}\right)$

Analyse der Situation junger Menschen, die im Ausland geboren wurden und nur über geringe Qualifikationen verfügen $\left(\mathrm{C}_{5}\right)$

Ein Vergleich des zahlenmäßigen Schüler/Lehrkräfte-Verhältnisses an öffentlichen und privaten Bildungseinrichtungen (D2)

- Der Anteil der auf das Unterrichten entfallenden Arbeitszeit der Lehrer (D4)

\section{Hinweis der Herausgeber}

Wenn nichts anderes angegeben ist, beziehen sich die Zahlen im Allgemeinen auf das Schuljahr 2002 und das Haushaltsjahr 200I. Zahlen zu den Lesefähigkeiten und dem Leseverständnis, der mathematischen sowie naturwissenschaftlichen Grundbildung von I5-jährigen Schülern stammen aus der Internationalen Schulleistungs-Studie PISA im Jahr 2000.

Die in dieser Ausgabe enthaltenen Indikatoren basieren auf Zahlen, die der OECD bis zum 30. Juni 2004 vorlagen. Spätere Änderungen der Länder an ihren spezifischen Daten, die Auswirkungen auf die Werte der Indikatoren haben, finden sich auf der OECD-Website unter www.oecd.org/eduleag2004.

\section{Glossar der in diesem Kapitel (Interessante Einzel- ergebnisse) enthaltenen Begriffe:}

Ausgaben für Bildungseinrichtungen - umfassen sowohl Ausgaben für unterrichterteilende Bildungseinrichtungen als auch für solche, die keinen Unterricht erteilen, und z.B. in der Verwaltung des Bildungssystems aktiv sind.

Bildungserwartung (in Jahren) - ist die voraussichtliche durchschnittliche Dauer der formalen (Aus-)Bildung eines 5-jährigen Kindes während seines gesamten Lebens.

Bildungsstand - wird ausgedrückt durch den höchsten von einer Person abgeschlossenen Bildungsbereich, wobei die Bildungsbereiche gemäß ISCED definiert sind.

Erwerbstätigenanteil - ist die Anzahl der Beschäftigten dividiert durch die Gesamtzahl der betreffenden Bevölkerung

Humankapital - ist der produktive Bildungsstand in Form von Arbeitskraft, Fähigkeiten und Wissen.

ISCED - die Internationale Standardklassifikation des Bildungswesens, in der die Festlegung der einzelnen Bildungsbereiche erfolgte. 
OECD-Partnerländer - die Länder, die am UNESCO/OECD World Education Indicators (WEI) Programm teilnehmen: Ägypten, Argentinien, Brasilien, Chile, China, Indien, Indonesien, Jamaika, Jordanien, Malaysia, Paraguay, Peru, Philippinen, Russische Föderation, Sri Lanka, Thailand, Tunesien, Uruguay und Simbabwe. Außerdem ist Israel, das sich an den OECD-Aktivitäten im Bereich Bildung als Beobachter beteiligt, mit einbezogen.

Öffentliche Bildungsausgaben - umfasst die direkten öffentlichen Finanzmittel für Bildungseinrichtungen ebenso wie die öffentlichen Subventionen für private Haushalte (z.B. für Lebenshaltungskosten) sowie Zahlungen an andere private Einheiten.

Tertiärbereich - Studiengänge im Tertiärbereich A und B sowie weiterführende Forschungsprogramme.

Tertiärbereich A - entspricht Studiengängen auf Niveau von ISCED 5A. Diese sind weitgehend theoretisch orientiert und sollen hinreichende Qualifikationen für den Zugang zu weiterführenden Forschungsprogrammen und Berufen mit hohem Qualifikationsniveau, wie Medizin, Zahnmedizin oder Architektur, vermitteln. Üblicherweise gehören hierzu Bachelor- und Master- sowie gleichwertige Abschlüsse.

Tertiärbereich B - entspricht Studiengängen auf Niveau von ISCED 5 B. Diese sind typischerweise kürzer als im Tertiärbereich A und konzentrieren sich auf praktische/technische/berufsbezogene Fähigkeiten für den direkten Eintritt in den Arbeitsmarkt, obwohl in diesen Studiengängen auch einige theoretische Grundlagen vermittelt werden können.

Universitäts- oder gleichwertiges Niveau - nimmt Bezug auf Studiengänge im Tertiärbereich A und auf weiterführende Forschungsprogramme

Weiterführende Forschungsprogramme - bezieht sich auf tertiäre Studiengänge, die direkt zum Erwerb eines weiterführenden Forschungsabschlusses führen, z.B. einer Promotion. 


\section{Die Indikatoren und ihr konzeptioneller Rahmen}

\section{Das zugrundeliegende Referenzsystem}

Bildung aufeinen Blick - OECD-Indikatoren 2004 bietet ein umfangreiches aktuelles Spektrum an vergleichbaren Indikatoren, die auf dem Konsens der Fachwelt beruhen, wie der gegenwärtige Stand der Bildung im internationalen Vergleich zu bewerten ist. Die Veröffentlichung enthält Informationen zu den in Bildung investierten personellen und finanziellen Ressourcen, zur Funktionsweise und Weiterentwicklung von Bildungssystemen, und zu den Erträgen aus Bildungsinvestitionen. Die Indikatoren sind thematisch gegliedert und jeweils von entsprechendem Hintergrundmaterial begleitet. Die OECD-Indikatoren sind in einen konzeptionellen Rahmen eingestellt, der

zwischen den Akteuren im Bildungssystem unterscheidet: einzelne Schüler und Studierende, Arten des Unterrichts und der Lernumgebungen, Anbieter von Bildungsleistungen, sowie das Bildungssystem als Ganzes;

die Indikatoren in Gruppen zusammenfasst, je nachdem, womit sie sich beschäftigen: die Lernergebnisse von Einzelnen oder ganzen Ländern, die politischen Ansatzpunkte oder Zusammenhänge, die diese Ergebnisse beeinflussen, oder die Gegebenheiten und Bedingungen, die bei politischen Entscheidungen zu berücksichtigen sind und

die politischen Fragen identifiziert, auf die sich die Indikatoren beziehen, und die in drei Kategorien eingeteilt sind - die Qualität der Bildungserfolge und des Bildungsangebots, Fragen der Chancengleichheit beim Bildungsangebot und den Bildungsergebnissen sowie die Angemessenheit und Effektivität des Ressourcenmanagements.

Die folgende Referenz-Matrix veranschaulicht die ersten beiden Dimensionen. Die Querverweise zwischen den einzelnen Indikatoren und den Zellen dieser Referenzmatrix finden sich daran anschließend. 


\begin{tabular}{|c|c|c|c|}
\hline & $\begin{array}{l}\text { (1) } \\
\text { Bildungs- und } \\
\text { Lernergebnisse }\end{array}$ & $\begin{array}{l}\text { (2) } \\
\text { Politische Ansatzpunkte } \\
\text { und Zusammenhänge, } \\
\text { die die Bildungserfolge } \\
\text { beeinflussen }\end{array}$ & $\begin{array}{l}\text { (3) } \\
\text { Gegebenheiten und } \\
\text { Bedingungen, die von } \\
\text { der Politik zu berück- } \\
\text { sichtigen sind }\end{array}$ \\
\hline $\begin{array}{l}\text { (I) } \\
\text { Einzelne Bildungsteil- } \\
\text { nehmer und Lernende }\end{array}$ & $\begin{array}{l}\text { (1.I) } \\
\text { Die Qualität und Ver- } \\
\text { teilung der individuellen } \\
\text { Bildungsergebnisse }\end{array}$ & $\begin{array}{l}\text { (2.I) } \\
\text { Einstellungen Engage- } \\
\text { ment und Verhalten } \\
\text { des Einzelnen }\end{array}$ & $\begin{array}{l}\text { (3.I) } \\
\text { Persönlicher Hintergrund } \\
\text { des einzelnen Lernenden }\end{array}$ \\
\hline $\begin{array}{l}\text { (II) } \\
\text { Arten des Unterrichts }\end{array}$ & $\begin{array}{l}\text { (1.II) } \\
\text { Die Qualität des } \\
\text { Unterrichts }\end{array}$ & $\begin{array}{l}\text { (2.II) } \\
\text { Pädagogische Methoden } \\
\text { und Lern-Strategien sowie } \\
\text { das Unterrichtsklima }\end{array}$ & $\begin{array}{l}\text { (3.II) } \\
\text { Unterrichts- und Lernbe- } \\
\text { dingungen der Lernenden } \\
\text { und Arbeitsbedingungen } \\
\text { der Lehrenden }\end{array}$ \\
\hline $\begin{array}{l}\text { (III) } \\
\text { Anbieter von Bildungs- } \\
\text { dienstleistungen }\end{array}$ & $\begin{array}{l}\text { (1.III) } \\
\text { Die Abschlussquoten und } \\
\text { Leistungen der Bildungs- } \\
\text { einrichtungen }\end{array}$ & $\begin{array}{l}\text { (2.III) } \\
\text { Organisation der } \\
\text { Bildungseinrichtungen } \\
\text { und ihr Umfeld }\end{array}$ & $\begin{array}{l}\text { (3.III) } \\
\text { Merkmale der Anbieter } \\
\text { von Bildungsdienstleis- } \\
\text { tungen und ihres Umfelds }\end{array}$ \\
\hline $\begin{array}{l}\text { (IV) } \\
\text { Das Bildungssystem als } \\
\text { Ganzes }\end{array}$ & $\begin{array}{l}\text { (1.IV) } \\
\text { Die Gesamtleistung des } \\
\text { Bildungssystems }\end{array}$ & $\begin{array}{l}\text { (2.IV) } \\
\text { Systemweite institutio- } \\
\text { nelle Struktur, Zuweisung } \\
\text { von Mitteln und politische } \\
\text { Maßnahmen }\end{array}$ & $\begin{array}{l}\text { (3.IV) } \\
\text { Der jeweilige nationale, } \\
\text { bildungspolitische, soziale, } \\
\text { wirtschaftliche und } \\
\text { demographische Kontext }\end{array}$ \\
\hline
\end{tabular}




\section{Die Indikatoren}

\section{Kapitel A:}

Bildungsergebnisse und die Auswirkungen von Lernen

\section{(Indikatoren A1 bis A12)}

Kapitel A untersucht zunächst den Bildungsstand der Erwachsenenbevölkerung (Indikator A1), der als indirekte Kenngröße für den Bestand an ,Humankapital' in den einzelnen Ländern gilt, und gleichzeitig eine Kennzahl für den ,Output' der Bildungssysteme liefert (Zelle 1.IV der Referenzmatrix). Er liefert auch den wichtigen Gesamtzusammenhang, in dem Bildungssysteme aktiv sind (Zelle 3.IV der Referenzmatrix), indem die engen Zusammenhänge zwischen Schülerleistungen und dem Bildungsstand der Eltern aufzeigt werden (OECD, 200I) Neu: Dieser Indikator enthält auch neue Analysen der demographischen Faktoren, die das zukünftige Angebot an Qualifikationen beeinflussen.

Indikator A2 konzentriert sich auf die Abschlussquoten im Sekundarbereich II, ein Abschluss der oft als Mindestvoraussetzung für einen erfolgreichen Eintritt in den Arbeitsmarkt angesehen wird. Indem in diesem Indikator sowohl die jährlichen Abschlussquoten im Sekundarbereich II als auch der Bestand an Absolventen des Sekundarbereich II in der Bevölkerung dargestellt werden, deckt er sowohl die aktuellen Abschlussquoten in den Bildungseinrichtungen als auch die der Vergangenheit ab, wodurch ein Bild des Systems als Ganzem entsteht. (Zellen 1.III und 1.IV der Referenzmatrix). Eine geschlechtsbezogene Analyse ermöglicht einzuschätzen, ob die Abschlussquoten im Sekundarbereich II ausgewogen zwischen den Geschlechtern verteilt sind.

Die Indikatoren $\mathrm{A}_{3}$ und $\mathrm{A}_{4}$ beschäftigen sich dann mit dem Tertiärbereich, indem sie sowohl die aktuellen Abschlussquoten im Tertiärbereich als auch den Bestand an Absolventen des Tertiärbereichs im Zeitverlauf untersuchen. Abschlussquoten im Tertiärbereich sind ein Indikator dafür, in welchem Umfang die Bildungssysteme der einzelnen Länder zum gegenwärtigen Zeitpunkt höhere Kenntnisse und Fähigkeiten vermitteln, während Kennzahlen zum Bildungsstand nach Altersgruppen die Entwicklung von höheren Kenntnissen und Fähigkeiten aufzeigen (Zellen 1.III und 1.IV der Referenzmatrix) Der Bildungsstand unterschiedlicher Generationen liefert wichtige Hintergrundinformationen für die aktuelle Bildungspolitik (Zelle 3.IV der Referenzmatrix), und trägt somit zur Diskussion um politische Maßnahmen zur Förderung des lebenslangen Lernens bei.

Analysen der Absolventen des Tertiärbereich nach Studienbereichen (Indikator A4) ergeben sowohl Hinweise zur Zulassungspolitik tertiärer Bildungseinrichtungen (Zelle 2.III der Referenzmatrix) als auch zu den vorherrschenden Bedingungen auf dem Arbeitsmarkt (Zelle C 3.IV der Referenzmatrix) und beleuchten die Nachfrage nach Ausbildungsangeboten und Lehrkräften ebenso wie das Angebot an neuen Absolventen.

Schließlich werden in diesem Indikator auch die Fortschritte der einzelnen Länder bei der Überwindung des 'gender gap', der Geschlechterkluft, bei den tertiären Abschlussquoten und den Personen mit einem tertiären Abschluss untersucht, und zwar sowohl insgesamt als auch über die einzelnen Bildungs- und Studienbereiche hinweg. ... den Abschlussquoten in

Kapitel A untersucht die Bildungs- und Lernergebnisse, und zwar in Form ... ... des Bildungsstands der Erwachsenenbevölkerung, ... den Bildungseinrichtungen, ... 
... der Qualität der Lernergebnisse, ...
... der geschlechtsspezifischen Unterschiede bei diesen

Ergebnissen, ...
Indikator $\mathrm{A}_{3}$ untersucht auch die Abbruchquoten, die in gewissem Maß Aufschluss über die interne Effizienz von tertiären Bildungssystemen geben (Zelle 1.III der Referenz-Matrix). Es gibt viele Gründe, warum Studierende ihr Studium abbrechen: Die Studierenden stellen fest, dass sie das falsche Fachgebiet oder den falschen Studiengang gewählt haben, die von den Bildungseinrichtungen vorgegebenen Mindestleistungen werden nicht erreicht, oder es bietet sich bereits vor Abschluss des Studiums eine attraktive Beschäftigung an. Hohe Studienabbruchquoten weisen jedoch darauf hin, dass das Bildungssystem den Bedürfnissen seiner Nutzer nicht gerecht wird. Studierende sind vielleicht der Ansicht, dass die angebotenen Studiengänge ihren Erwartungen bzw. den Arbeitsmarktanforderungen nicht entsprechen. Und möglicherweise rechtfertigt aus Sicht der Studierenden das lange Studium nicht die entgangene Zeit im Arbeitsmarkt.

Das reine Zählen der Absolventen liefert jedoch keinerlei Informationen hinsichtlich der Qualität der Lernergebnisse. Um diese Frage zu untersuchen, werden in Kapitel A auch die Kenntnisse und Kompetenzen der Schüler über die einzelnen Länder hinweg verglichen (Zelle 1.I der Referenzmatrix). Neu: Indikator A5 ist neu und bewertet die Entwicklung der Lesefähigkeiten und des Leseverständnisses von 9-jährigen Schülern, sowohl insgesamt als auch nach Geschlecht aufgegliedert.

Während in Indikator A5 die Lesefähigkeiten gegen Beginn der Schulzeit untersucht werden, erlauben die Indikatoren A6 und A7 einen Vergleich der Kompetenzen in den Bereichen Lesen, Mathematik und Naturwissenschaften 15-jähriger Schüler, d.h. gegen Ende der Schulpflicht (aus PISA 2000). Diese Indikatoren sind von zentraler Bedeutung für eine Bewertung der Qualität der Bildungssysteme, denn sie ermöglichen eine Bewertung, inwieweit es den Ländern gelingt, den Heranwachsenden in einem Alter grundlegende Schlüsselqualifikationen zu vermitteln, in dem der Übergang ins Arbeitsleben für viele von ihnen zu einem zentralen Anliegen wird.

Die Indikatoren A5, A6 und A7 vergleichen nicht nur die Gesamtleistungen der Länder (Zelle 1.IV der Referenzmatrix), sondern untersuchen auch genau, wie Kenntnisse und Fähigkeiten in der Schülerpopulation verteilt sind, um zu bewerten, inwieweit es Ländern gelingt, eine hohes Gesamtergebnis mit einer ausgewogenen Verteilung der Bildungsergebnisse zu verbinden (Zelle 1.I der Referenzmatrix).

Angesichts der Auswirkungen von (Aus-)Bildung auf die Erwerbsbeteiligung, die berufliche Mobilität und die Lebensqualität unterstreichen politische Entscheidungsträger und Pädagogen die Bedeutung einer Verringerung der Bildungsunterschiede zwischen Männern und Frauen. Bei der Verringerung der geschlechtsspezifischen Unterschiede beim Bildungsstand (s. Indikatoren $\mathrm{A}_{1}$ und $\mathrm{A} 2$ ) wurden große Fortschritte erzielt, wenngleich in bestimmten Fächern, wie Mathematik und Informatik, immer noch ein Unterschied zugunsten der Männer besteht (s. Indikator $\mathrm{A}_{4}$ ).

Nachdem die Frauen ihren Rückstand in vielen Bildungsbereichen aufgeholt und dann die Männer sogar überholt haben, geben nun häufig die schwachen Leistungen der Jungen in bestimmten Bereichen, wie z.B. dem Lesen, Anlass 
zur Besorgnis. Indikator A5 zeigt sogar auf, dass die wenig befriedigenden Leseleistungen der Jungen schon sehr lange bestehen und sich im Laufe von Io Jahren nicht wesentlich verbessert haben. Daher müssen die Entscheidungsträger, wenn sie ausgewogenere Lernerfolge zwischen den Geschlechtern erreichen wollen, genau auf die geschlechtsspezifischen Unterschiede bei den Leistungen der Schüler achten.

Ferner können sich die Vorstellungen der Schüler über die für sie erreichbaren Berufe auf ihre Bildungsentscheidungen und schulischen Leistungen auswirken. Daher sollte es ein wichtiges politisches Ziel sein, das Bildungssystem dabei zu unterstützen, die geschlechtsspezifischen Unterschiede bei den beruflichen Erwartungen abzumildern und das Leistungsgefälle in bestimmten Fächern zu reduzieren. Zunächst werden in Indikator Ag die Daten aus der PISA-Studie der OECD zu geschlechtsspezifischen Unterschieden hinsichtlich der Berufe untersucht, in denen sich heute I5-Jährige im Alter von 30 Jahren sehen. Es folgt eine Analyse der geschlechtsspezifischen Unterschiede in Leistungen, Einstellungen und Lernstrategien in Schulen des Primar- und Sekundarbereichs (Zellen 1.I und 2.I der Referenzmatrix)

Ein wichtiges Element bei den Einstellungen der Schüler ist ihr Engagement in der Schule. Die Schule ist ein bestimmender Teil des täglichen Lebens junger Menschen und ihre Wahrnehmung der Schule spiegelt sich in ihrer Teilnahme an schulischen wie außerschulischen Aktivitäten. Neu: Indikator A8 untersucht zwei Aspekte des schulischen Engagements von Schülern: ihr Zugehörigkeitsgefühl und die Unterrichtsteilnahme, und wie diese sich in den einzelnen Ländern unterscheiden. Danach wird der Zusammenhang zwischen dem schulischen Engagement der Schüler und ihren Leseleistungen untersucht. Das Engagement der Schüler kann sowohl als Ergebnis des Bildungsprozesses gesehen werden (Zelle 1.I der Referenzmatrix) als auch als Kontext, der die Bildungsergebnisse beeinflusst (Zelle 2.I der Referenzmatrix).

Da das Niveau an Kenntnissen und Fähigkeiten in der Regel mit zunehmendem Bildungsstand wächst, steigen auch die Kosten für die Gesellschaft, wenn die besser Ausgebildeten nicht arbeiten; und da die Bevölkerung in den OECD-Ländern zunehmend älter wird, kann eine stärkere und längere Erwerbsbeteiligung zu einer Senkung der Abhängigenquoten und der Entlastung der staatlichen Rentenkassen beitragen. Indikator A1o untersucht die Beziehung zwischen Bildungsstand und Erwerbstätigkeit, wobei zuerst die Erwerbstätigenanteile und anschließend die Arbeitslosenanteile verglichen werden, auch aufgegliedert nach Geschlecht. Neu hinzugefügt ist diesem Indikator eine Analyse der Veränderungen der geschlechtsspezifischen Unterschiede in diesem Bereich im Zeitverlauf. Bei einer Untersuchung der Beziehungen zwischen Erwerbsquote und Bildungsstand ist zu berücksichtigen, dass diese beiden Kenngrößen vor allem ein Maßstab der langfristigen Ergebnisse von Bildungssystemen ist (Zelle 1.IV der Referenzmatrix). Für die politischen Entscheidungsträger ist es jedoch von großer Bedeutung, inwieweit die Kenntnisse und Fähigkeiten der Arbeitnehmer angemessen sind und der Arbeitsmarkt in der Lage ist, die passenden Arbeitsplätze für diese Kenntnisse und Fähigkeiten bereitzustellen (Zelle 3.IV der Referenzmatrix). Arbeitslosenanteile unter den Absolventen der einzelnen Bildungsbereiche können sich auch auf die Entscheidung der Schüler/Studierenden auswirken, ... sowie der individuellen
und gesellschaftlichen
Bildungserträge. 
Kapitel B untersucht die in Bildung investierten Finanzund Humanressourcen und zwar in Form ... weiter im Bildungssystem zu verbleiben, und daher unterschiedliche Beteiligungsquoten in den verschiedenen Ländern erklären.

Eine Möglichkeit, durch die die Märkte Anreize für Arbeitskräfte schaffen, angemessene Fähigkeiten und Kenntnisse zu entwickeln und zu erhalten, sind Einkommensunterschiede und hier insbesondere höhere Verdienstmöglichkeiten für diejenigen, die sich weiterbilden und zusätzliche Abschlüsse erzielen. Das Streben nach einem höheren Bildungsstand kann auch als Investition in das Humankapital gesehen werden. Das Humankapital stellt den Bestand an Fähigkeiten und Kenntnissen dar, die der Einzelne besitzt oder - normalerweise durch Bildung oder Ausbildung - (weiter-)entwickelt und sodann als Gegenleistung für ein Einkommen auf dem Arbeitsmarkt anbietet. Je höher die Einkommen sind, die sich aus einer Vermehrung des Humankapitals ergeben, umso höher ist der Ertrag dieser Investition und der Einkommenszuschlag für bessere Fähigkeiten und Kenntnisse und/oder eine höhere Produktivität. Die Indikatoren A11 und A 12 versuchen, die Erträge von Bildung zu messen, für den Einzelnen (Zelle 1.I der Refernzmatrix) in Form der höheren Einkommen, für den Steuerzahler in Form eines höheren Steueraufkommens aufgrund besser ausgebildeter Arbeitskräfte, und für die Gesellschaften ganz allgemein (Zelle 1.IV der Referenzmatrix) durch den Zusammenhang zwischen Bildung und Arbeitsproduktivität. So beschreiben diese beiden Indikatoren die langfristigen Auswirkungen von Bildung für den Einzelnen und die Gesellschaft. Indikator A II beleuchtet auch einen wichtigen nationalen Kontext (Zelle 3.IV der Referenzmatrix) für die politischen Entscheidungsträger, womit sowohl die öffentliche Finanzierungspolitik im Allgemeinen als auch die Finanzhilfen für Schüler und Studenten im Besonderen beeinflusst werden können. Er kann auch den Kontext für die Entscheidungen der Schüler/Studierenden liefern, in den verschiedenen Bildungsbereichen zu lernen und zu studieren (Zelle 3.I der Referenzmatix). Ein neuer Aspekt des Indikators AII ist der Vergleich der relativen Einkommensniveaus im Zeitverlauf, sowohl insgesamt als auch nach Geschlecht aufgegliedert.

\section{Kapitel B:}

Die in Bildung investierten Finanz- und Humanressourcen (Indikatoren B1 bis B6)

Die Finanzressourcen sind ein zentraler politischer Ansatzpunkt, wenn es darum geht, die Bildungsergebnisse zu verbessern. Bildung ist eine Investition in die Kenntnisse und Fähigkeiten von Menschen. Daher kann sie dazu beitragen, das Wirtschaftswachstum zu stärken, die Produktivität zu steigern, die persönliche und gesellschaftliche Entfaltung zu fördern und soziale Unterschiede zu verringern. Wie jede andere Investition muss jedoch auch Bildung finanziert werden. Nachdem in Kapitel A die Erträge von Bildung untersucht wurden, enthält Kapitel B eine vergleichende Untersuchung der Bildungsausgaben in den OECD-Ländern. Durch die stärkere Betonung von tendenziellen Entwicklungen bei den Bildungsausgaben wird in diesem Kapitel untersucht, wie verschiedene Angebots- und Nachfragefaktoren sich gegenseitig beeinflussen, und wie sich die Ausgaben für Bildung im Verhältnis zu den Ausgaben in anderen Bereichen von großer gesellschaftlicher Bedeutung verändert haben. 
Leistungsfähige Bildungseinrichtungen brauchen die richtige Mischung aus gut ausgebildetem und begabtem Personal, angemessenen baulichen Einrichtungen und moderner Ausstattung sowie motivierten und lernwilligen Schülern oder Studierenden. Allerdings muss die Forderung nach hochwertiger Bildung, die höhere Kosten pro Schüler/Studierenden mit sich bringen kann, gegen die zumutbare Belastung für den Steuerzahler abgewogen werden. Es gibt keine absolut gültigen Richtwerte für die pro Schüler/Studierenden erforderlichen Ressourcen, um optimale Erträge für den einzelnen Schüler/Studierenden bzw. die Gesellschaft insgesamt zu erreichen. Internationale Vergleiche können jedoch als Ausgangspunkt für die Diskussion dienen, indem sie die Unterschiede bei den in Bildung investierten Mitteln zwischen den OECD-Ländern untersuchen. Indikator B1 untersucht die direkten öffentlichen und privaten Ausgaben für Bildungseinrichtungen im Verhältnis zur Anzahl der vollzeitäquivalenten Schüler/Studierenden dieser Bildungseinrichtungen und setzt dies in Beziehung zu dem relativen Wohlstand der Länder, gemessen am BIP pro Kopf. Untersucht wird ferner, wie die einzelnen OECDLänder ihre Ausgaben pro Schüler/Studierenden zwischen den verschiedenen Bildungsbereichen aufteilen. Die diesen Zahlen zugrunde liegenden Veränderungen der Schüler/Studierendenzahlen und der Ausgaben werden aufgezeigt. Um die Vergleiche auf Ebene der Bildungsbereiche noch aussagekräftiger zu gestalten, enthält dieser Indikator als neuen Aspekt einen Vergleich der Verteilung der Ausgaben sowie der Schüler/Studierendenzahlen nach Bildungsbereich.

Die Ausgaben pro Schüler sind ein entscheidender bildungspolitischer Faktor, der sich direkt auf den einzelnen Lernenden auswirkt, denn er beeinflusst die Lernumgebung in den Schulen sowie die Lernbedingungen der Schüler im Klassenzimmer (Zellen 2.I, 3.III und 3.II der Referenzmatrix).

Wenn man jedoch Indikator BI zu den Indikatoren A6 und A7 in Beziehung setzt, zeigt sich auch, dass geringere Ausgaben pro Schüler/Studierenden nicht automatisch mit einer geringeren Qualität der Bildungsdienstleistungen gleichgesetzt werden können.

Indikator B2 untersucht den Anteil nationaler Ressourcen, der für Bildungseinrichtungen bereitgestellt wird und die Bildungsbereiche, in die er fließt. Die Entscheidung, welcher Anteil der insgesamt zur Verfügung stehenden Finanzmittel für das Bildungswesen bereitgestellt werden soll, ist in jedem OECD-Land von zentraler Bedeutung. An dieser Entscheidung sind Regierungen und Unternehmensleitungen ebenso wie der einzelne Schüler/Studierende und seine Familie beteiligt. Indikator B2 zeigt auch auf, wie sich im Verlauf der Jahre in den OECD-Ländern der Umfang der Bildungsausgaben in Relation zum Bruttoinlandsprodukt und in absoluten Zahlen verändert hat. Die von einem Land für Bildung bereitgestellten Ressourcen sind ein zentraler politischer Ansatzpunkt (Zelle 2.IV der Referenzmatrix), sie wirken sich aber auch ursächlich auf die Aktivitäten der Schulen, den Unterricht sowie den einzelnen Lernenden aus (Zellen 3.III, 3.II und 3.I der Referenzmatrix).

... und im Verhältnis zum Volkseinkommen, ... 
... der Finanzierung der Bildungssysteme sowie der Herkunft der investierten Mittel, ...
... im Verhältnis zum Umfang der öffentlichen Haushalte, ...
Die Lastenverteilung bei den Kosten zwischen den Teilnehmern der Bildungsangebote einerseits und der Gesellschaft als Ganzes andererseits ist in vielen OECD-Ländern ein Diskussionspunkt. Diese Frage stellt sich insbesondere zu Beginn und am Ende des Bildungsweges, also für den Elementar- und Tertiärbereich, für die eine staatliche Vollfinanzierung oder nahezu vollständige Finanzierung durch den Staat weniger üblich ist. Angesichts einer wachsenden Beteiligung neuer Gruppen von Bildungsinteressenten und eines immer breiteren Angebots an Bildungsmöglichkeiten, Bildungsgängen und Bildungsanbietern gehen die Regierungen neue Partnerschaften für die Mobilisierung der für die Bildungsfinanzierung erforderlichen Ressourcen ein. Die öffentlichen Bildungsausgaben werden heute immer mehr als nur ein - wenn auch sehr wichtiger - Teil der Investitionen in die Bildung gesehen. Die privaten Finanzierungsquellen gewinnen zunehmend an Bedeutung.

Neue Finanzierungsstrategien zielen nicht nur darauf ab, die Finanzierung durch öffentliche und private Mittel auf eine breitere Basis zu stellen, sondern auch darauf, das Bildungsangebot auszuweiten und die Effektivität der Schulausbildung zu verbessern. In den meisten OECD-Ländern wird die Bildung im öffentlich finanzierten Primar- und Sekundarbereich auch von öffentlichen Einrichtungen organisiert und bereitgestellt. Es gibt aber auch eine nennenswerte Anzahl von OECD-Ländern, in denen die öffentlichen Mittel an private Einrichtungen oder direkt an die privaten Haushalte gehen, damit diese die betreffenden Mittel für die Bildungseinrichtungen ihrer Wahl verwenden. Im erstgenannten Fall kann die letztendliche Finanzierung und Bereitstellung von Bildungsangeboten als eine Art Auftragsvergabe durch die öffentliche Hand an nicht-öffentliche Einrichtungen betrachtet werden, während im letztgenannten Fall den Schülern und ihren Familien die Entscheidung überlassen wird, welche Art von Einrichtung ihren Bedürfnissen am besten gerecht wird. Sofern die private Bildungsfinanzierung Barrieren für die Bildungsbeteiligung von Lernenden aus niedrigeren Einkommensgruppen schafft, kann sich dies in den Leistungsunterschieden zwischen verschiedenen Institutionen niederschlagen.

Um hier zu einem besseren Verständnis zu gelangen, untersucht Indikator B3 die relativen Anteile öffentlicher und privater Investitionen in Bildungseinrichtungen und deren Veränderung gegenüber 1995. Neu: Zum ersten Mal werden die privaten Bildungsausgaben nach den Ausgaben privater Haushalte und denen anderer privater Einheiten aufgegliedert, was eine detailliertere Analyse der öffentlichen und privaten Finanzierung erlaubt. Wie bei Indikator B2 sind die von einem Land für Bildung bereitgestellten Ressourcen nicht nur ein zentraler politischer Ansatzpunkt (Zelle 2.IV der Referenzmatrix), sondern sie wirken sich auch ursächlich auf die Aktivitäten der Schulen, den Unterricht sowie den einzelnen Lernenden aus (Zellen 3.III, 3.II und 3.I der Referenzmatrix).

Bildung ist ein Bereich, in dem alle Staaten intervenieren, indem sie das Leistungsangebot finanzieren oder lenken. Da keine Garantie dafür besteht, dass die Märkte allen den gleichen Zugang zu Bildungschancen bieten, wird durch die staatliche Finanzierung der Bildung sichergestellt, dass sie der gesamten Gesellschaft zugänglich ist. Die öffentlichen Ausgaben für Bil- 
dung als Prozentsatz der gesamten öffentlichen Ausgaben sind ein Indiz für den Stellenwert der Bildung im Vergleich zu anderen öffentlichen Aufgaben wie Gesundheitswesen, soziale Sicherung, Verteidigung und innere Sicherheit. Indikator B4 vervollständigt das Bild des Umfangs der in Bildung investierten Ressourcen, indem die Veränderungen bei den öffentlichen Ausgaben für Bildung, sowohl absolut als auch im Verhältnis zu dem sich ändernden Umfang der öffentlichen Gesamtausgaben, untersucht werden.

Seit der zweiten Hälfte der neunziger Jahre haben die meisten OECD-Länder große Anstrengungen zur Konsolidierung ihrer öffentlichen Haushalte unternommen. Bildung stand im Wettstreit mit einer Vielzahl anderer in den staatlichen Haushalten enthaltener Finanzierungsaufgaben. Um dies zu verdeutlichen, werden in diesem Indikator die Veränderungen bei den Bildungsausgaben sowohl in absoluten Zahlen als auch im Verhältnis zur Entwicklung der öffentlichen Haushalte untersucht.

Wie bei den Indikatoren B2 und B3 sind die von einem Land für Bildung bereitgestellten Ressourcen nicht nur ein zentraler politischer Ansatzpunkt (Zelle 2.IV der Referenzmatrix ) sondern sie wirken sich auch ursächlich auf die Aktivitäten der Schulen, den Unterricht sowie den einzelnen Lernenden aus (Zellen 3.III, 3.II und 3.I der Referenzmatrix) .

In den meisten OECD-Ländern besteht der Hauptfinanzierungsmechanismus für Bildung immer noch in direkten Ausgaben für Bildungseinrichtungen. Die Staaten bemühen sich jedoch verstärkt um eine größere Diversifizierung der Finanzierungsinstrumente. Ein Vergleich solcher Instrumente kann hilfreich dabei sein, politische Alternativen auszumachen. Subventionen an Schüler/Studierende und ihre Familien, der Schwerpunkt von Indikator B5, stellen eine solche Alternative zu den Direktausgaben für Bildungseinrichtungen dar. Sie fungieren als Anreiz für Einzelne oder Gruppen, an Bildungsmaßnahmen teilzunehmen bzw. eröffnen ihnen Chancen in unterschiedlichen Bildungseinrichtungen (Zelle 2.I und 2.III der Referenzmatrix).

Regierungen tragen mittels Subventionen zur Deckung der direkten und indirekten Bildungskosten bei, um den Bildungszugang zu erweitern und soziale Ungleichheiten abzubauen. Darüber hinaus spielen öffentliche Subventionen auch bei der indirekten Finanzierung von Bildungseinrichtungen eine nicht unerhebliche Rolle. Indem Finanzierungsmittel für Bildungseinrichtungen über Schüler/Studierende gelenkt werden, kann möglicherweise ein Beitrag zu mehr Wettbewerb zwischen den Bildungseinrichtungen und zu einer größeren Effizienz der Bildungsfinanzierung geleistet werden. Da Zuschüsse zu den Lebenshaltungskosten der Schüler/Studierenden eine Erwerbstätigkeit zur Finanzierung von Bildung ersetzen können, tragen öffentliche Subventionen vermutlich auch dazu bei, den Bildungsstand anzuheben, indem Schülern/Studierenden die Möglichkeit eines Vollzeitschulbesuchs bzw. Vollzeitstudiums bei verminderter oder überhaupt keiner Erwerbstätigkeit gegeben wird.

Öffentliche Subventionen können in vielfältiger Weise bereitgestellt werden: als einkommensabhängige Zuschüsse, in Form einer Art Kindergeldes
... der unterschiedlichen Finanzierungsinstrumente, ... 
... und der Aufteilung der Mittel auf die unterschiedlichen Ausgabenkategorien.

In Kapitel $\boldsymbol{C}$ werden der Bildungszugang, die Bildungsbeteiligung und die Bildungserwartung untersucht, und zwar in Form ... für alle Schüler/Studierenden, als Steuerfreibeträge für Schüler/Studierende oder ihre Eltern oder in Form sonstiger Transferleistungen an private Haushalte. Sollen Finanzhilfen an private Haushalte in Form von Zuschüssen oder Darlehen gewährt werden? Können Finanzhilfen in Form von Darlehen dazu beitragen, die Wirksamkeit der in Bildung investierten Ressourcen zu erhöhen und einen Teil der Bildungskosten auf die Nutznießer der Bildungsinvestitionen zu verlagern? Oder sind Studiendarlehen weniger wirksam als Zuschüsse, wenn es darum geht, einkommensschwache Schüler/Studierende zu mehr Bildung zu ermutigen? Indikator B5 kann diese Fragen zwar nicht beantworten, er kann jedoch die von den einzelnen OECD-Ländern in diesem Bereich verfolgte Subventionspolitik aufzeigen.

Kapitel B schließt mit einer Untersuchung der Aufteilung der Finanzressourcen auf die unterschiedlichen Ausgabenkategorien (Indikator B6). Die Zuweisung der Finanzmittel kann sich auf die Qualität des Unterrichts auswirken (z.B. durch die relativen Ausgaben für Lehrergehälter), auf den Zustand der Bildungseinrichtungen (z.B. durch die Instandhaltungsausgaben für Schulgebäude und -einrichtungen) sowie auf die Anpassungsfähigkeit des Bildungssystems an sich ändernde Entwicklungstendenzen der Bevölkerung und der Bildungsbeteiligung. OECD-Ländervergleiche über die Verteilung der Bildungsausgaben auf die verschiedenen Ausgabenkategorien können Einblick in das Ausmaß der Unterschiede im Bereich der Organisationsstrukturen und der Leitung von Bildungseinrichtungen gewähren. Die auf der jeweils zuständigen Ebene getroffenen Verteilungsentscheidungen - sowohl zu Fragen des gesamten Bildungsetats als auch seiner Aufteilung - finden letztendlich ihren Niederschlag im Klassenzimmer, und beeinflussen sowohl die Art des Unterrichts als auch die Bedingungen, unter denen er stattfindet. Der Indikator enthält eine umfassende Beschreibung der Entscheidungen darüber, wie der Bildungsetat verwendet wird - was letztendlich die Bildungsergebnisse auf jeder Ebene beeinflusst (Zelle 2.IV der Referenzmatrix).

\section{Kapitel C:}

Der Bildungszugang, die Bildungsbeteiligung und die Bildungserwartung (in Jahren)

\section{(Indikatoren C1 bis C5)}

Eine gut ausgebildete Bevölkerung ist sowohl für die gegenwärtige als auch die zukünftige wirtschaftliche und soziale Entwicklung eines Landes von entscheidender Bedeutung. Aus diesem Grunde haben die Gesellschaften ein großes Interesse daran, für Kinder und Erwachsene einen umfassenden Zugang zu einer breiten Palette an Bildungsmöglichkeiten zu gewährleisten. Programme im Elementarbereich bereiten die Kinder auf den Primarbereich vor. Sie können bei der Bekämpfung sprachlicher und sozialer Nachteile helfen und dazu beitragen, die Bildungserfahrungen aus dem Elternhaus auszubauen und zu ergänzen. Primar- und Sekundarbereich statten junge Menschen mit grundlegenden Kompetenzen aus und bereiten sie so auf lebenslanges Lernen und die Entwicklung hin $\mathrm{zu}$ produktiven Mitgliedern der Gesellschaft vor. Der Tertiärbereich bietet entweder direkt nach der Schulbildung oder später im Leben eine Vielzahl von Möglichkeiten, erweiterte und spezielle Kenntnisse und Fähigkeiten zu erwerben. Kapitel C zeichnet ein vergleichendes Bild des Bil- 
dungszugangs, der Bildungsbeteiligung und des Fortschreitens auf dem Bildungsweg in den OECD-Ländern.

Praktisch können alle jungen Menschen in den OECD-Ländern erwarten, II Jahre lang an formaler Bildung teilzunehmen. Wer jedoch wann, wie und für wie lange an welchen Bildungsmaßnahmen teilnimmt, das variiert während der gesamten Lebensspanne erheblich. Sowohl die Bildungsbeteiligung an sich als auch ihre zeitliche Ausdehnung während der Vorschuljahre und nach Beendigung der Schulpflicht weichen in den einzelnen Ländern erheblich voneinander ab. In einigen Ländern wurde die Bildungsbeteiligung zum Beispiel dadurch erhöht, dass eine nahezu vollständige Vorschulbildung ab dem Alter von drei Jahren eingeführt wurde, dass man die Mehrheit der Jugendlichen bis zum Alter von I8 oder I Jahren im Bildungssystem behält, oder dadurch, dass in den Altersgruppen bis Ende 20 eine Bildungsbeteiligung von Io bis 20 Prozent erzielt wurde.

Indikator $\mathrm{C}_{1}$ untersucht diese Punkte genauer, indem die Bildungsbeteiligung und die zu erwartende Ausbildungsdauer dargestellt werden. Dies vermittelt einen ersten Einblick in die Struktur der verschiedenen Bildungssysteme sowie den Zugang zum Bildungsangebot dieser Systeme. Ein neuer Aspekt dieses Indikators ist die Bildungsbeteiligung für die einzelnen Altersjahrgänge der jungen Menschen. Dies zeigt das Alter, in dem in den einzelnen Ländern der Übergang zwischen den einzelnen Bildungsbereichen stattfindet, und das Alter, ab dem immer weniger junge Menschen an formalen Bildungsmaßnahmen teilnehmen. Die Bildungsbeteiligung lässt sowohl Rückschlüsse auf die Gesamtergebnisse der Bildungspolitik zu (Zelle 1.IV der Referenzmatrix) als auch, in Form der Bildungserwartung in Jahren, auf die Bildungserfolge jedes Einzelnen (Zelle 1.I der Referenzmatrix).

Während ein erfolgreicher Abschluss des Sekundarbereich II in den meisten OECD-Ländern zunehmend zum Normalfall wird (s. Indikator A2), gestalten sich die Wege zu diesem Bildungsziel immer vielfältiger. Die Bildungsgänge im Sekundarbereich II können sich beispielsweise hinsichtlich der Lerninhalte unterscheiden, die oftmals davon abhängen, auf welche weiteren Bildungsgänge oder welchen Beruf die Schüler vorbereitet werden sollen. Die meisten Bildungsgänge im Sekundarbereich II in den OECD-Ländern zielen vornehmlich auf die Vorbereitung zum weiterführenden Studium im Tertiärbereich ab. Insgesamt kann jedoch die Ausrichtung der Bildungsgänge im Sekundarbereich II allgemeinbildend, berufsvorbereitend oder berufsbildend sein. Neben Bildungsgängen, die die Schüler hauptsächlich auf eine weiterführende Bildung vorbereiten, gibt es in den meisten OECD-Ländern auch Bildungsgänge im Sekundarbereich II, die zur Vorbereitung auf den direkten Eintritt in den Arbeitsmarkt ausgelegt sind. Indikator $\mathrm{C}_{2}$ untersucht die Schülerzahlen in den unterschiedlichen Bildungsgängen.

Indikator $C_{2}$ untersucht auch die Studienanfängerquoten für den Tertiärbereich, die ein wichtiges Anzeichen für das Ausmaß sind, in dem die Bevölkerung sich aufmacht, jene hochqualifizierten Fähigkeiten und Kenntnisse zu erlangen, die auf dem Arbeitsmarkt einer Wissensgesellschaft von Bedeutung sind. Der Indikator zeigt auch die geschlechtsspezifischen Unterschiede in der Bildungsbeteiligung.
... der Bildungserwartung in Jahren, sowohl insgesamt als auch in den einzelnen Bildungsbereichen, ...

... des Zugangs zu und der Bildungsbeteiligung an verschiedenen Bildungsgängen und Bildungseinrichtungen, ... 
... der grenzüberschreitenden Mobilität Studierender,
... und des Lernens über die Erstausbildung hinaus.
Wie Indikator C1 spiegelt Indikator C2 sowohl die Gesamtergebnisse der Bildungspolitik (Zelle 1.IV der Referenzmatrix) als auch die Bildungsergebnisse auf der Ebene des Einzelnen wider (Zelle 1.I der Referenzmatrix).

Der Zugang zum Tertiärbereich und die Teilnahme an Studiengängen im Tertiärbereich sind nicht mehr durch nationale Grenzen eingeschränkt. Eine Möglichkeit für Studierende, ihre Kenntnisse anderer Kulturen und Gesellschaften zu erweitern, besteht darin, tertiäre Bildungseinrichtungen anderer Länder zu besuchen. Diese internationale Mobilität von Studierenden impliziert für die Studierenden ebenso wie für die Bildungseinrichtungen Kosten und Nutzen, und zwar sowohl in den 'Sender'- als auch den 'Empfänger'-Ländern. Während sich die kurzfristigen monetären Kosten und der Nutzen dieser Mobilität relativ leicht erfassen lassen, sind die längerfristigen sozialen und wirtschaftlichen Vorteile für die Studierenden, die Bildungseinrichtungen und auch die beteiligten Länder selbst schwer zu quantifizieren. Zahlen über die im Ausland studierenden jungen Menschen ( Indikator $\mathrm{C}_{3}$ ) vermitteln einen ersten Eindruck von dem Ausmaß dieser grenzüberschreitenden Mobilität Studierender und zeigen, welche Länder per Saldo mehr ausländische Studierende aufnehmen als eigene Studierende ins Ausland zu schicken bzw. in welchen Ländern das Umgekehrte zutrifft. Neu: So wie dieser Indikator zum ersten Mal auch Informationen über die Mobilität Studierender im Zeitverlauf enthält, umfasst er auch zum ersten Mal eine Analyse der Studienbereiche, die von den ausländischen Studierenden bei ihrem Auslandsstudium gewählt werden. Eine solche Analyse hebt die Studiengänge mit einer besonderen Anziehungskraft hervor, die Studierende in großen Zahlen aus dem Ausland anziehen, und deren Anziehungskraft auf einer Reihe von Faktoren des Angebots und der Nachfrage von bestimmten Studiengängen beruht.

Dieser Indikator untersucht die Motivation der Studierenden, in anderen Ländern zu studieren und dadurch ihre Chancen auf dem Arbeitsmarkt zu verbessern (Zelle 2.I der Referenzmatrix), zeigt aber gleichzeitig auch, welche Politik die einzelnen Länder hinsichtlich der Mobilität der Studierenden verfolgen (Zelle 2.IV der Referenzmatrix). Die Politik selbst bietet natürlich den Rahmen, innerhalb dessen die Mobilität der Studierenden erfolgt (Zelle 3.I der Referenzmatrix), und das Ausmaß der Mobilität der Studierenden wirkt sich auf die Lernumgebung in den Hochschulen aus (Zellen 3.III und 3.II der Referenzmatrix).

Alle OECD-Länder erleben einen rapiden gesellschaftlichen und wirtschaftlichen Wandel, der die Unsicherheit des Übergangs ins Erwerbsleben erhöht. Der Eintritt in den Arbeitsmarkt stellt oftmals eine schwierige Zeit des Übergangs dar. Während sich einerseits die Dauer der Zeit, die im Bildungssystem verbracht wird, erhöht hat, bleibt andererseits ein beträchtlicher Teil der jungen Menschen außen vor, wenn sie sich weder in Ausbildung befinden noch arbeiten, d.h. wenn sie arbeitslos sind oder sich nicht in Beschäftigung befinden. Die Indikatoren $C_{4}$ und $C_{5}$ untersuchen den Bildungs- und Erwerbsstatus von jungen Männern und Frauen und liefern Informationen dazu, wie erfolgreich der Übergang von der Schule ins Berufsleben gelingt. Indikator $\mathrm{C}_{4}$ konzentriert sich auf die Kombination von Arbeit und Ausbildung und Indikator $\mathrm{C}_{5}$ auf den Erwerbsstatus junger Menschen, die sich nicht mehr in Ausbildung befinden. Neu: Eine wichtige Weiterentwicklung von Indikator $\mathrm{C}_{4}$ ist die Aufnahme von Vergleichen im Zeitver- 
lauf, die aufzeigen, wie sich die Erfahrungen junger Menschen beim Übergang von der Ausbildung in das Erwerbsleben in jüngster Zeit geändert haben. Neu: Zum ersten Mal beschäftigt sich Indikator $\mathrm{C}_{5}$ mit jungen Menschen mit niedrigen Qualifikationen hinsichtlich des Aspekts, ob sie im Erhebungsland geboren wurden oder nicht. Dies zeigt einen weiteren Aspekt der Herausforderungen auf, denen sich die Länder in ihren Bemühungen um ein steigendes Ausbildungsniveau gegenübersehen. In dem Indikator wird auch genauer untersucht, welchen Schwierigkeiten sich junge Menschen mit niedrigen Qualifikationen bei der Arbeitssuche gegenüber sehen, indem derjenige Anteil von ihnen aufgezeigt wird, der noch nie eine Beschäftigung hatte.

Beide Indikatoren zeigen Bildungsergebnisse nicht nur für den einzelnen Schüler/Studierenden auf (Zelle 1.I der Referenzmatrix) sondern auch für das Bildungssystem als Ganzes in seiner Wechselbeziehung mit dem Arbeitsmarkt (Zelle 1.IV der Referenzmatrix). Gleichzeitig bieten sie auch einen Rahmen für die momentanen Beteiligungsquoten und -profile sowohl in Bezug auf den Einzelnen als auch das System insgesamt (Zellen 3.I und 3.IV der Referenzmatrix)

\section{Kapitel D:}

Das Lernumfeld und die Organisation von Schulen (Indikatoren D1 bis D6)

Während in den vorangegangenen Kapiteln die in Bildung investierten finanziellen Mittel, die unterschiedliche Bildungsbeteiligung und die Ergebnisse von Bildung in Form von Schülerleistungen und der Auswirkungen von Qualifikationen für das spätere Erwerbsleben untersucht wurden, schließt Kapitel D die Veröffentlichung mit der Untersuchung der Unterrichts- und Lernbedingungen der Lernenden, den Arbeitsbedingungen der Lehrenden und den Entscheidungskompetenzen in den jeweiligen Bildungssystemen. All dies sind Faktoren des Kontextes, innerhalb dessen das Lernen der Schüler stattfindet und die im Prinzip von der Politik beeinflusst werden können.

Wie viel und wie gut ein Mensch von der frühen Kindheit bis zum Eintritt ins Berufsleben lernt, beeinflusst sein späteres Leben, sowohl unter wirtschaftlichen als auch unter sozialen Gesichtspunkten. Wie effektiv die zum Lernen vorhandene Zeit genutzt wird, hängt zum einen davon ab, wie angemessen die einzelnen Bildungsgänge sind und zum anderen, wie viel Unterricht der einzelne Schüler erhält. Ein großer Teil der öffentlichen Investitionen in das Lernen der Schüler erfolgt in Form der Bereitstellung von formalem Unterricht im Klassenzimmer. Die Unterrichtszeit ist daher ein wichtiger politischer Ansatzpunkt, der sich einerseits unmittelbar auf den einzelnen Lernenden auswirkt (Zelle 2.I der Referenzmatrix), andererseits aber ebenso die Unterrichts- und Lernpraxis im Klassenzimmer und an den Schulen beeinflusst (Zellen 3.II und 3.III der Referenzmatrix).

Indikator D1 untersucht die in verschiedenen Fachbereichen vorgesehene Unterrichtszeit für Schüler unterschiedlicher Altersstufen.

Abgesehen von der offiziell vorgegebenen Unterrichtszeit wird die Lernumgebung der Schüler auch von den Aufnahmekriterien und der Aufnahmepraxis in die verschiedenen Schulen und der jeweiligen Praxis der Klassenzusammensetzung beeinflusst. Kriterien zur Aufnahme, Klassenzuweisung und -zusammensetzung
In Kapitel D wird das Lernumfeld und die Organisation von Schulen untersucht, und zwar in Form ...

... der Unterrichts- und Lernbedingungen der Schüler, ... 
von Schülern sind der Rahmen für die Auswahl von Schülern für schulische Bildungsgänge und die Einteilung der Schüler nach ihren angestrebten Schullaufbahnen und ihren Bildungsbedürfnissen. Der neu eingeführte Indikator D5 untersucht diese Kriterien in Bezug auf den Sekundarbereich II, mit dem das Bildungsangebot vielfältiger wird, und wo die von den Schülern getroffene Wahl sorgsam gehandhabt werden muss, um ihnen einerseits zu ermöglichen, ihr Potential zu nutzen und wo andererseits gleiche Chancen für alle sicherzustellen sind.

Kriterien zur Aufnahme und Klassenzusammensetzung sind politische Ansatzpunkte, die sich auf den einzelnen Schüler auswirken (Zelle 2.I der Referenzmatrix). aber auch den Hintergrund für den Unterricht im Klassenzimmer und den Betrieb der Schulen bilden (Zellen 3.II und 3.III der Referenzmatrix).

Die Größe der Lerngruppe, in der sich der einzelne Schüler die Aufmerksamkeit des Lehrers mit anderen teilen muss, ist eine weitere Variable, die sich darauf auswirkt, wie die verfügbare Unterrichtszeit genutzt werden kann. Indikator D2 betrachtet die Bandbreite der durchschnittlichen Klassengrößen sowie des zahlenmäßigen Schüler/Lehrkräfte-Verhältnisses in den OECD-Ländern, um die Humanressourcen zu erfassen, die letztlich dem einzelnen Schüler zur Verfügung stehen. Beide Kenngrößen können im Allgemeinen von den Schulen selbst beeinflusst werden (Zelle 2.III der Referenzmatrix), in einigen Fällen können jedoch politische Vorgaben auf Systemebene den Spielraum einschränken. Beide Faktoren haben auch Einfluss auf das Lernverhalten der Schüler (Zelle 3.I der Referenzmatrix) und den Unterricht im Klassenzimmer (Zelle 3.II der Referenzmatrix). Ein neuer Aspekt des Indikators ist der Vergleich des zahlenmäßigen Schüler/Lehrkräfte-Verhältnisses zwischen öffentlichen und privaten Bildungseinrichtungen, der für die Debatte über die relativen Stärken und Schwächen der öffentlichen gegenüber den privaten Bildungseinrichtungen von Bedeutung ist.

... der Arbeitsbedingungen der Lehrer ...
Kapitel D fährt fort mit einer vergleichenden Übersicht der Arbeitsbedingungen der Lehrer, wobei zuerst die Lehrergehälter und dann die Arbeits- und Unterrichtszeit der Lehrer untersucht werden. Im Bildungssystem ist eine große Anzahl von qualifizierten Fachkräften unter zunehmend wettbewerbsorientierten Marktbedingungen beschäftigt. Allen OECD-Ländern ist es ein großes Anliegen, dafür Sorge zu tragen, dass es genug qualifizierte Lehrer gibt. Das Angebot an qualifizierten Lehrkräften wird hauptsächlich bestimmt durch die Gehälter und Arbeitsbedingungen von Lehrern, einschließlich dem Anfangsgehalt und dem System der Besoldungs- und Vergütungsgruppen, sowie die dem Einzelnen während der Ausbildung zum Lehrer entstehenden Kosten im Vergleich zu den Gehältern und Kosten für andere hochqualifizierte Berufe. All dies beeinflusst die beruflichen Entscheidungen potentieller Lehrer und derjenigen, die sich für den Lehrerberuf interessieren. Gleichzeitig sind die Lehrergehälter der größte Einzelposten, wenn es um die Kosten der Bildung geht. Die Gehälter der Lehrer sind daher für die politischen Entscheidungsträger, die die Qualität des Unterrichts und einen ausgeglichenen Bildungsetat aufrechterhalten wollen, ein entscheidender Faktor. Die Höhe der Bildungsetats spiegelt das Ausbalancieren einer ganzen Reihe untereinander verbundener Faktoren wider. Hierzu gehören die Lehrergehälter, das zahlenmäßige Schüler/Lehrkräfte-Verhältnis, der Umfang der geplanten Unterrichtszeit für Schüler und die vorgesehene An- 
zahl der Unterrichtsstunden der Lehrer. Um dies näher zu beleuchten, untersucht Indikator D3 die gesetzlichen bzw. vertraglich festgelegten Gehälter von Lehrern, genauer gesagt, das Anfangs-, das mittlere und das Höchstgehalt von Lehrern an öffentlichen Schulen des Primar- und Sekundarbereichs und die zusätzlich zu den Grundvergütungen und -besoldungen gewährten Zulagen und bestehenden Anreizsysteme.

Zusammen mit Faktoren wie der Klassengröße und dem zahlenmäßigen Schüler/Lehrkräfte- Verhältnis (Indikator D 2), der Unterrichtszeit für die Schüler (Indikator D1) und den Lehrergehältern (Indikator $\mathrm{D}_{3}$ ) beeinflusst die Zeit, die ein Lehrer tatsächlich unterrichtet, die für Bildung aufzuwendenden Finanzmittel der einzelnen Länder. Die Unterrichtszeit und die nicht-unterrichtsbezogenen Aktivitäten sind ein entscheidender Bestandteil der Arbeitsbedingungen der Lehrer, sie beeinflussen auch die Attraktivität des Lehrerberufs. Um diese Zusammenhänge näher zu beleuchten, untersucht Indikator $\mathrm{D}_{4}$ die gesetzliche, bzw. vertraglich festgelegte Arbeitszeit der Lehrer in den verschiedenen Bildungsbereichen sowie die vorgeschriebene Unterrichtszeit, d.h. die Zeit, die Vollzeitlehrer auf das Unterrichten der Schüler verwenden müssen. Obwohl die Arbeits- und Unterrichtszeit die tatsächliche Arbeitsbelastung der Lehrer nur zu einem Teil bestimmen, gewähren sie doch einen Einblick in die Unterschiede zwischen den Ländern hinsichtlich der Anforderungen an die Lehrer. Neu: Um einen genaueren Einblick in die Tätigkeiten der Lehrer während ihrer Arbeitszeit zu ermöglichen, erhält dieser Indikator dieses Jahr zum ersten Mal eine Analyse desjenigen Teils der Arbeitszeit, der für das Unterrichten verwandt wird.

Die Lehrergehälter und die Arbeitszeit wirken sich nicht nur auf die Einstellung von neuen Lehrern und ihre Bindung an die Einrichtung aus (Zelle 2.III der Referenzmatrix), sondern sie bilden als Teil der Arbeitsbedingungen der Lehrer auch den Rahmen für die Unterrichtsqualität im formalen Bildungssystem sowie für die Lernergebnisse der einzelnen Lernenden (Zellen 3.I und 3.II der Referenzmatrix).

Ein wichtiger Aspekt der Bildungspolitik ist die Verteilung der Zuständigkeiten zwischen nationalen, regionalen und lokalen Behörden und den Schulen. Eine Verlagerung der Kompetenzen auf untere Ebenen des Bildungssystems war in vielen Ländern ein zentrales Anliegen bei der seit Anfang der achtziger Jahre realisierten Umstrukturierung und Reform der Bildungssysteme. Gleichzeitig jedoch gab es immer wieder Beispiele für eine Stärkung des Einflusses der Zentralbehörden in einigen Bereichen. Beispielsweise kann die Dezentralisierung von Verfahrens- und Finanzvorgaben mit einer verstärkten zentralen Ergebniskontrolle und nationalen Richtlinien für den Lehrplan einhergehen. Neu: Kapitel D schließt mit dem neu eingeführten Indikator D6, der die Entscheidungskompetenzen im Bildungswesen untersucht: welche Behörde trifft welche Entscheidung in welchem Bereich und mit welchem Ausmaß an Autonomie?

Auch wenn die Entscheidungskompetenzen in einem Land mehr oder minder zentral organisiert sind, ist die spezifische Verteilung der Kompetenzen in einem bestimmten Land oft eher auf Systemebene festgelegt. So bietet die Verteilung der Entscheidungskompetenzen einen politischen Ansatzpunkt auf Systemebene (Zelle 2.IV der Referenzmatrix), der den Kontext für die Arbeit der Bildungseinrichtungen und die Organisation des Unterrichts liefert (Zellen 3.II und 3.III der Referenzmatrix). 


\section{Hinweise für den Leser}

\section{Statistische Erfassung}

Zwar ist die Aussagefähigkeit der Indikatoren in vielen Ländern nach wie vor durch unvollständige Daten eingeschränkt, prinzipiell wird jedoch jeweils das gesamte nationale Bildungssystem (innerhalb der nationalen Grenzen) erfasst, unabhängig davon, wer Eigentümer oder Geldgeber der betreffenden Bildungseinrichtungen ist und in welchen Strukturen das Bildungsangebot vermittelt wird. Abgesehen von einer Ausnahme, die nachstehend näher erläutert ist, werden sämtliche Schüler und Studierende sowie alle Altersgruppen berücksichtigt: Kinder (einschließlich derjenigen, die als Kinder mit einem besonderen pädagogischen Bedarf eingestuft sind), Erwachsene, Inländer, Ausländer sowie Schüler und Studierende, die an Fernkursen, in Sonderschulmaßnahmen oder an Ausbildungsgängen teilnehmen, die von anderen Ministerien als dem Bildungsministerium angeboten werden, sofern das Hauptziel der betreffenden Ausbildung die bildungsmäßige Förderung des Einzelnen ist. Die berufliche und technische Ausbildung am Arbeitsplatz bleibt jedoch - mit Ausnahme der dualen Ausbildung, d.h. einer kombinierten schulischen und betrieblichen Ausbildung, die ausdrücklich als Bestandteil des Bildungssystems gilt - bei den Angaben zu den Ausgaben für die Ausbildung und zur Bildungsbeteiligung unberücksichtigt.

Bildungsaktivitäten, die als ,Erwachsenenbildung' oder ,nicht-reguläre Bildung' eingestuft sind, werden berücksichtigt, sofern diese Aktivitäten Bildungsangebote und Studiengänge umfassen oder fachliche Inhalte vermitteln, die mit ,regulären' Bildungsgängen vergleichbar sind, oder sofern die zugrundeliegenden Bildungsgänge zu ähnlichen Abschlüssen führen wie die entsprechenden regulären Bildungsgänge. Kurse für Erwachsene, die in erster Linie aus allgemeinem Interesse, zur persönlichen Entwicklung, als Freizeitvergnügen oder zur Erholung belegt werden, sind hierbei ausgeschlossen.

\section{Berechnung von internationalen Mittelwerten}

Für viele Indikatoren ist ein Ländermittel und für manche ein OECD-Gesamtwert angegeben.

Das Ländermittel wird als der ungewichtete Mittelwert der Datenwerte aller OECD-Länder berechnet, für die entsprechende Daten vorliegen oder geschätzt werden können. Das Ländermittel bezieht sich somit auf einen Durchschnitt von Datenwerten auf Ebene des nationalen Bildungssystems und dient als Antwort auf die Frage, wie ein Indikatorwert für ein bestimmtes Land im Vergleich zum Wert eines typischen Landes bzw. eines Landes mit durchschnittlichen Werten abschneidet. Dabei bleibt die absolute Größe des jeweiligen Bildungssystems unberücksichtigt.

OECD insgesamt wird als der gewichtete Mittelwert der Datenwerte aller Länder berechnet, für die entsprechende Daten vorliegen oder geschätzt werden können. Er spiegelt den Wert eines bestimmten Indikators für die OECD-Länder in ihrer Gesamtheit wider. Die Ermittlung dieses Wertes dient zu Vergleichszwecken, wenn beispielsweise die Ausgabenzahlen für einzelne Länder mit denen aller OECD-Länder insgesamt verglichen werden sollen, für die jeweils relevante Daten vorliegen, wobei diese OECD-Länder als eine Einheit betrachtet werden.

Es sei darauf hingewiesen, dass sowohl das Ländermittel als auch OECD insgesamt durch fehlende Daten für einzelne Länder erheblich beeinflusst werden können. Aufgrund der relativ kleinen Zahl der untersuchten Länder wird dies nicht durch statistische Verfahren ausgeglichen. In den Fällen, in denen eine Kategorie für ein Land nicht zutrifft (gekennzeichnet durch ein ,a') oder der Datenwert für die entsprechende Berechnung vernachlässigbar gering ist (gekennzeichnet durch ein ,n') wird zur Berechnung der Ländermittelwerte der Wert Null angesetzt. In den Fällen, in denen ein Datenpunkt das Verhältnis von zwei Werten angibt, die beide 
auf ein bestimmtes Land nicht zutreffen (angezeigt durch ein ,a'), wird das betreffende Land bei der Mittelwertberechnung nicht berücksichtigt.

In den Tabellen zur Finanzstatistik, die das Jahr I995 berücksichtigen, wurden sowohl das Ländermittel als auch OECD insgesamt nur für die Länder berechnet, die Daten sowohl für 1995 als auch für 200I zur Verfügung stellten. Dies erlaubt einen Vergleich im Zeitablauf, der nicht durch fehlende Daten für eines der Jahre beeinträchtigt wird.

\section{Einstufung der Bildungsbereiche nach dem ISCED-System}

Die Einstufung der einzelnen Bildungsbereiche beruht auf der überarbeiteten Internationalen Standardklassifikation des Bildungswesens (International Standard Classification of Education - ISCED97). Der größte Unterschied zwischen der alten (ISCED-76) und der überarbeiteten Fassung der ISCED-Klassifikation ist die Einführung eines mehrdimensionalen Systems für die Klassifizierung, das die Bildungsinhalte von Bildungsprogrammen mittels multipler Kriterien abschätzt und einordnet. Die ISCED-Klassifikation ist ein Instrument zur Erstellung von internationalen Bildungsstatistiken und unterscheidet sechs Bildungsbereiche. Im Glossar am Ende dieser Publikation werden die ISCED-Stufen ausführlich erläutert, und in Anhang I ist das typische Abschlussalter für die wichtigsten Bildungsgänge nach ISCED-Stufen aufgeführt.

\section{Symbole für fehlende Daten}

In den Tabellen und Abbildungen werden zur Kennzeichnung fehlender Daten die folgenden Symbole verwendet:

a Daten nicht zutreffend, da die Kategorie nicht zutrifft.

c $\mathrm{Zu}$ wenige Beobachtungen, um verlässliche Schätzungen vorzunehmen, (d.h. eine Zelle ist mit weniger als fünf Schulen oder weniger als 30 Schülern besetzt.)

$m$ Keine Daten verfügbar.

$n$ Die Größenordnung ist entweder vernachlässigbar oder Null.

$x$ Die Daten sind in einer anderen Kategorie oder Spalte der Tabelle enthalten. (z.B. bedeutet x(2), dass die Daten in Spalte 2 der Tabelle enthalten sind).

\section{Weitere Quellen}

Auf der Website www.oecd.org/edu/eag2004 finden sich umfangreiche Informationen zu den bei den Indikatoren verwendeten Berechnungsmethoden, der Interpretation der Indikatoren im jeweiligen nationalen Kontext und den benutzten Datenquellen. Die Website bietet auch Zugang zu den Daten, die den Indikatoren zugrunde liegen sowie ein umfangreiches Glossar der Fachbegriffe, die in dieser Publikation verwendet werden (Die deutsche Fassung des Glossars ist in der vorliegenden Publikation zu finden).

Auf der Website www.pisa.oecd.org finden sich Informationen zu der Internationalen Schulleistungsstudie PISA der OECD, die für viele der Indikatoren von Bildung aufeinen Blick 2004 herangezogen wurde.

Die Veröffentlichung Bildungspolitische Analyse ist ein Begleitband zu Bildung auf einen Blick und greift ausgewählte Themen von besonderer Relevanz für die Politik wieder auf. Die Ausgabe des Jahres 2004 enthält 4 Kapitel, in denen zentrale Ergebnisse und politische Entwicklungen dargestellt werden: Bildung und alternde Gesellschaften, Erträge aus IKTInvestitionen in der Bildung, Lehrer und Schulen von morgen, Positive Effekte der Umstrukturierung des Tertiärbereichs: die Rolle von Instituten und Colleges im Tertiärbereich.

$\begin{array}{llll}\text { Ländercodes } & & \\ \text { Australien } & \text { AUS } & \text { Finnland } & \text { FIN } \\ \text { Japan } & \text { JPN } & \text { Schottland } & \text { SCO } \\ \text { Österreich } & \text { AUT } & \begin{array}{l}\text { Frankreich } \\ \text { Korea }\end{array} & \text { FRA } \\ \text { Belgien } & \text { BEL } & \text { Slowakische } & \\ \text { Luxemburg } & \text { LUX } & \text { Deutschland } & \text { SVK } \\ \text { Belgien (fläm.) } & \text { BFL } & \text { Spanien } & \text { ESP } \\ \text { Mexiko } & \text { MEX } & \text { Griechenland } & \text { GRC } \\ \text { Belgien (frz.) } & \text { BFR } & \text { Schweden } & \text { SWE } \\ \text { Niederlande } & \text { NLD } & \text { Ungarn } & \text { HUN } \\ \text { Kanada } & \text { CAN } & \text { Schweiz } & \text { CHE } \\ \text { Neuseeland } & \text { NZL } & \text { Island } & \text { ISL } \\ \text { Tschechische } & & \text { Türkei } & \text { TUR } \\ \quad \text { Republik } & \text { CZE } & \text { Irland } & \text { IRL } \\ \text { Norwegen } & \text { NOR } & \text { Vereinigtes } & \\ \text { Dänemark } & \text { DNK } & \text { Königreich } & \text { UKM } \\ \text { Polen } & \text { POL } & \text { Italien } & \text { ITA } \\ \text { England } & \text { ENG } & \text { Vereinigtes } & \\ \text { Portugal } & \text { PRT } & \text { Staaten } & \text { USA }\end{array}$


Länder, die am UNESCO/OECD World Education Indicators (WEI) Programm teilnehmen Ägypten, Argentinien, Brasilien, Chile, China, Indien, Indonesien, Jamaika, Jordanien, Malaysia, Paraguay, Peru, Philippinen, Russische Föderation, Sri Lanka, Thailand, Tunesien, Uruguay und Simbabwe nehmen am UNESCO/OECD World Education Indicators (WEI) Programm teil. Die Daten für diese Länder wurden auf Grundlage derselben Standards erhoben, die auch für die OECD-Länder gelten, und sie sind daher auch in dieser Veröffentlichung enthalten. Israel beteiligt sich an den OECD-Aktivitäten im Bereich Bildung als Beobachter. 


\section{Bildungsergebnisse}

\section{und die Auswirkungen von Lernen}

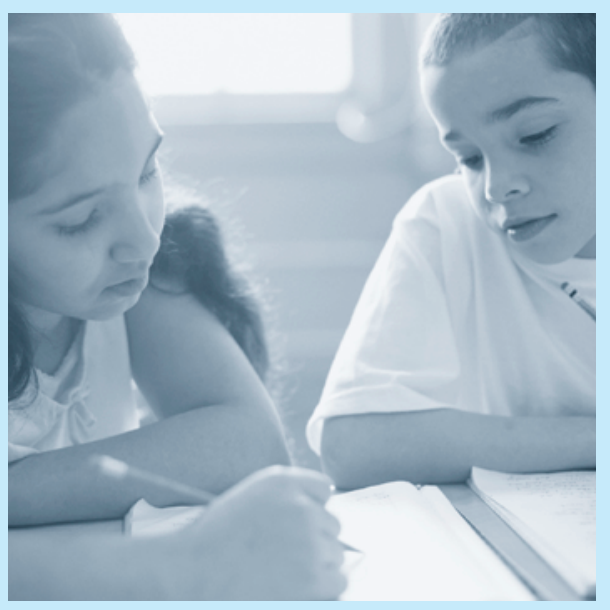





\section{Bildungsstand der Erwachsenenbevölkerung}

Der durchschnittliche Bildungsstand der Erwachsenenbevölkerung in den OECD-Ländern entspricht einer Ausbildungsdauer von 11,8 Jahren (basierend auf der Dauer aktueller formaler Bildungsgänge). Für die 18 Länder, die über dem OECD-Durchschnitt liegen, beträgt die durchschnittliche Ausbildungsdauer zwischen 11,8 und 13,8 Jahren. Für die verbleibenden 12 Länder ist die Spanne größer und reicht von 7,4 Jahren bis zu 11,8 Jahren.

Der starke Rückgang der Zahl junger Menschen in den 70er und 80er Jahren hat sich allgemein verlangsamt, jedoch deuten Bevölkerungsprognosen darauf hin, dass der Anteil der 5- bis 14-Jährigen in vielen OECD-Ländern weiterhin zurückgehen wird.

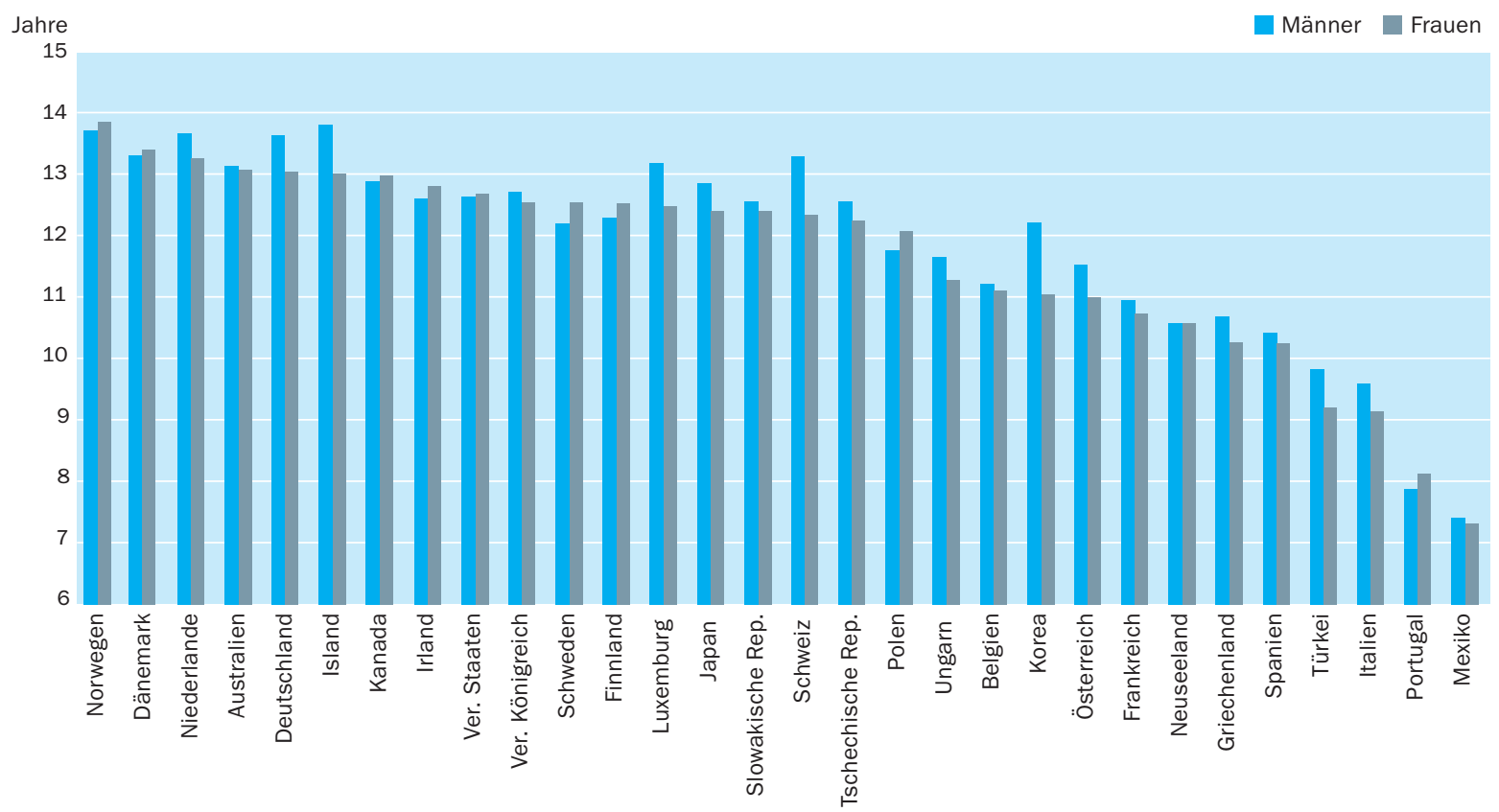




\section{Politischer Hintergrund}

1 Dieser Indikator zeigt den Bildungsstand als indirekte Kennzahl für die in Wirtschaft und Gesellschaft vorhandenen Kenntnisse und Fähigkeiten auf.

Der Bildungsstand der Erwachsenenbevölkerung lässt sich anhand der durchschnittlichen Ausbildungsdauer aufzeigen.
In 20 von 30 OECD-Ländern ist der Bildungsstand von Männern immer noch höher als der von Frauen.
Die Länder unterscheiden sich stark hinsichtlich der Verteilung des Bildungsstands innerhalb der Bevölkerung.
Eine gut ausgebildete und qualifizierte Erwerbsbevölkerung ist für das soziale und wirtschaftliche Wohl eines Landes und auch des einzelnen Bürgers von großer Bedeutung. Bildung ist ein entscheidender Faktor, damit der Einzelne über Wissen, Kenntnisse, Fähigkeiten und Kompetenzen verfügt, um vollständig am gesellschaftlichen und wirtschaftlichen Leben teilnehmen zu können. Bildung trägt auch zu einer Erweiterung des wissenschaftlichen und kulturellen Wissens bei. Dieser Indikator zeigt den unterschiedlichen Bildungsstand der Erwachsenenbevölkerung auf. Er untersucht außerdem die demographischen Faktoren, die sich auf die Gesamtheit der zukünftig verfügbaren Qualifikationen auswirken werden.

Der Bildungsstand der Bevölkerung wird weithin als indirekte Kennzahl für das „Humankapital“ verwendet, das heißt für die in der Bevölkerung und Erwerbsbevölkerung zur Verfügung stehenden Kenntnisse und Fähigkeiten. Wenn man ein einzelnes Ausbildungsjahr immer als äquivalent betrachtet, und zwar in jedem Bildungsbereich, lässt sich der Bildungsstand der Erwachsenenbevölkerung anhand der durchschnittlichen Ausbildungsdauer ausdrücken. Hierbei ist allerdings zu berücksichtigen, dass die Berechnung auf der Dauer aktueller Ausbildungsgänge beruht und daher einen Schätzwert für den „Wiederbeschaffungswert“ des gegenwärtigen Humankapitals darstellt und keinen Schätzwert der tatsächlichen durchschnittlichen Ausbildungsdauer einer Bevölkerung in der Vergangenheit.

\section{Ergebnisse und Erläuterungen}

Davon ausgehend, wie lange die Ausbildung in aktuellen Bildungsgängen betragen müsste, um einen bestimmten Bildungsstand zu erreichen - und wiederzuerlangen - entspricht der Bildungsstand der Erwachsenenbevölkerung in den OECD-Ländern einer durchschnittlichen Ausbildungsdauer von II, 8 Jahren. Für die I 8 über dem Durchschnitt liegenden Länder ist die Streuung begrenzt und liegt innerhalb einer Bandbreite von zwei Jahren zwischen II, 8 und I3,8 Jahren. Unterhalb des Durchschnittswerts ist die Spanne für die verbleibenden I2 Länder sehr viel größer und umfasst mehr als 4 Jahre von der kürzesten Ausbildungsdauer von 7,4 Jahren bis hin zur längsten von II, 8 Jahren.

In zehn OECD-Ländern ist der Bildungsstand von 25- bis 64-jährigen Frauen bemessen nach der durchschnittlichen Ausbildungsdauer - praktisch der gleiche wie bei den Männern, oder sogar ein wenig höher (in Dänemark, Finnland, Irland, Kanada, Neuseeland, Norwegen, Polen, Portugal, Schweden und den Vereinigten Staaten). In allen anderen OECD-Ländern verfügen Männer über einen höheren Bildungsstand, manchmal sogar in beträchtlichem Maße, wie in Island, Korea, Luxemburg und der Schweiz (Abb. AI.I).

In 24 von 30 OECD-Ländern verfügen mehr als 6o Prozent der Bevölkerung im Alter von 25 bis 64 Jahren mindestens über einen Abschluss im Sekundarbereich II (Abb. Ar.2). Dieser Anteil liegt in Norwegen, der Schweiz, der Tschechischen sowie der Slowakischen Republik und in den Vereinigten Staaten bei 


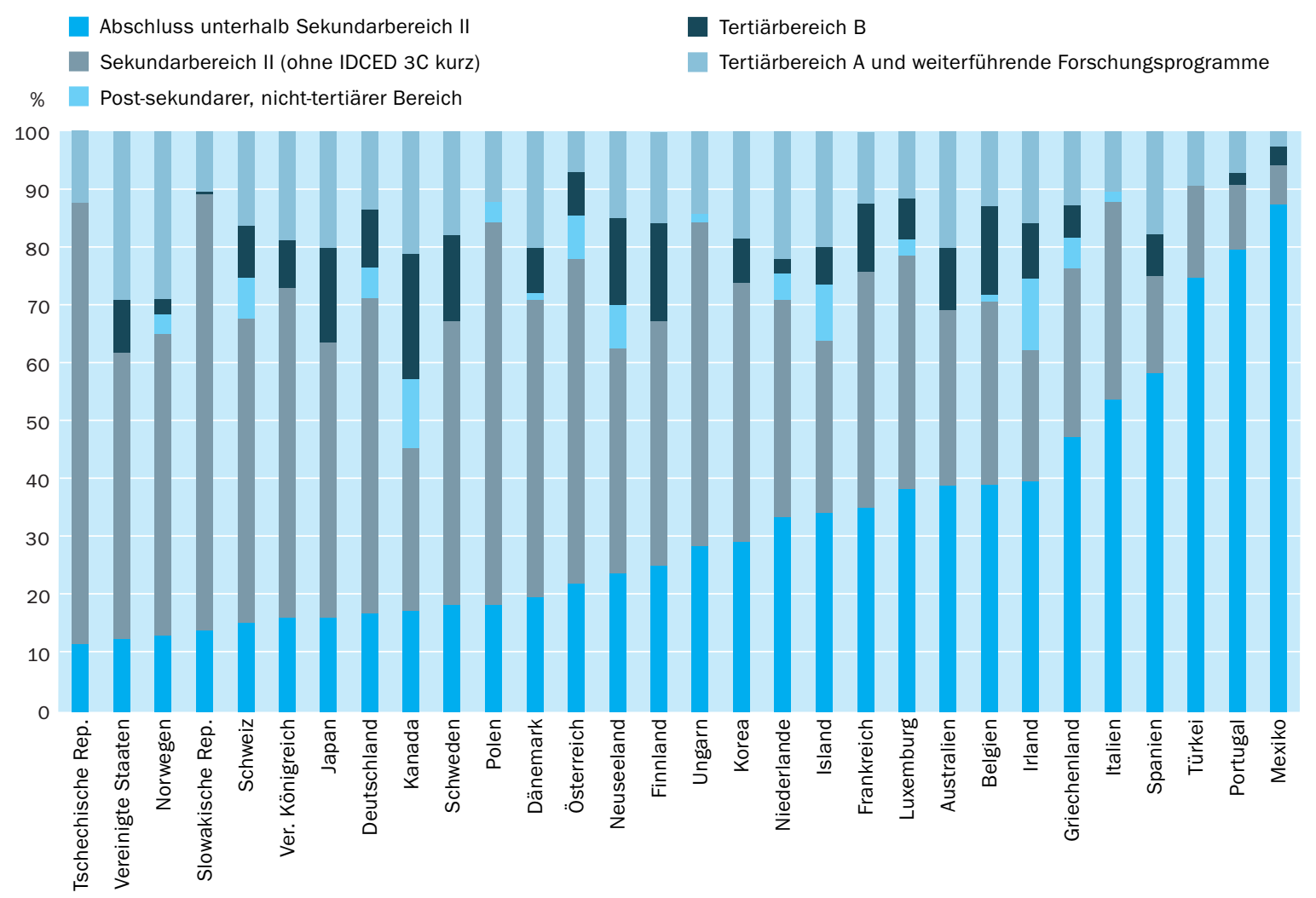

Anordnung der Länder in absteigender Reihenfolge der 25- bis 64-Jährigen mit zumindest einem Abschluss im Sekundarbereich II. Quelle: OECD, Tabelle A1.1. Hinweise s. Anhang 3 unter www.oecd.org/edu/eag2004.

85 Prozent oder mehr. In anderen Ländern, vor allem in Südeuropa, weist der Bildungsstand der Erwachsenenbevölkerung ein anderes Profil auf: In Italien, Mexiko, Portugal, Spanien, und der Türkei hat mehr als die Hälfte der Bevölkerung im Alter von 25 bis 64 Jahren keinen Abschluss im Sekundarbereich II.

Die komplexeren Anforderungen des Arbeitsmarktes, die Zunahme der Arbeitslosigkeit in den letzten Jahren und die höheren Erwartungen des Einzelnen und der Gesellschaft haben den Anteil junger Menschen, die mindestens einen Abschluss im Tertiärbereich erwerben, ansteigen lassen.

Infolgedessen variiert der Anteil der 25-bis 64-Jährigen in den OECD-Ländern mit einem Abschluss des Tertiärbereich A oder in einem weiterführenden Forschungsprogramm zwischen weniger als Io Prozent in Mexiko, Österreich, Portugal und der Türkei und 20 Prozent oder mehr in Australien, Dänemark, Island, Japan, Kanada, den Niederlanden, Norwegen und den Vereinigten Staaten. Allerdings gibt es in bestimmten Ländern seit langem auch berufsbildende Bildungsgänge im Tertiärbereich (Tertiärbereich B). Der Anteil der Absolventen des Tertiärbereich B liegt in Belgien, Finnland, Japan, Kanada, Neuseeland und Schweden bei I5 Prozent oder mehr (Tab. AI.I).
Der Anteil junger Menschen mit mindestens einem $A b$ schluss im Tertiärbereich hat zugenommen. 
Männer weisen hier im Durchschnitt einen höheren Bildungsstand auf als Frauen.

Die Unterschiede zwischen den Ländern in bezug auf die relative Größe der Bevölkerungsgruppe junger Menschen sind seit 1992 zurückgegangen, doch lassen sich nach wie vor klar erkennbare Unterschiede feststellen.

Der starke Rückgang der Zahl junger Menschen in den 70er und 80er Jahren hat sich allgemein verlangsamt, jedoch deuten Bevölkerungsprognosen darauf hin, dass der Anteil der 5- bis 14-Jährigen in vielen OECD-Ländern weiterhin zurückgehen wird.
In 23 von 30 Ländern verfügt in der Altersgruppe der 25- bis 64-Jährigen ein größerer Anteil von Männern als Frauen mindestens über einen Abschluss des Sekundarbereich II. Beim Tertiärbereich A und bei weiterführenden Forschungsprogrammen beträgt in Belgien, Deutschland, Japan, Korea, Luxemburg und der Schweiz der Abstand zwischen Männern und Frauen bei den 25bis 64-Jährigen 5 Prozentpunkte oder mehr zugunsten der Männer (Tab. AI.ra und AI.rb). Das Gegenteil gilt - in etwas geringerem Ausmaß - zugunsten der Frauen in Dänemark, Norwegen, Polen, Portugal, Schweden, Spanien und Ungarn. Bei Abschlüssen des Tertiärbereich B unterscheiden sich die Länder sehr stark voneinander - mehr als 6 Prozentpunkte zugunsten der Frauen in Belgien, Finnland, Japan, Kanada und Neuseeland und mehr als 3 Prozentpunkte zugunsten der Männer in Deutschland, Österreich und der Schweiz.

\section{Demographische Daten als Indikator für das Potential an zukünftig verfügbaren Qualifikationen}

Die Zahl junger Menschen in der Bevölkerung wirkt sich sowohl auf das Ausmaß aus, mit der eine Erwerbsbevölkerung ihre Qualifikationen erneuert, als auch auf die Ressourcen und den organisatorischen Aufwand, die ein Land in sein Bildungssystem investieren muss.

Während der Anteil der 5- bis I4-Jährigen als Prozentsatz der Gesamtbevölkerung in den meisten OECD-Ländern zwischen II und I5 Prozent liegt, ist der Anteil der 20- bis 29-Jährigen in der Regel ein wenig höher (Tab. Ar.2). Auch wenn die Unterschiede zwischen den Ländern in bezug auf die relative Größe der Bevölkerungsgruppe junger Menschen seit 1992 zurückgegangen sind, lassen sich nach wie vor klar erkennbare Unterschiede feststellen. In Irland, Island, Korea, Mexiko, Polen und der Slowakischen Republik sind mehr als 38 Prozent der Bevölkerung im Alter zwischen 5 und 29 Jahren. In Griechenland, Italien, Japan, Portugal und Spanien sind nur ro Prozent der Bevölkerung zwischen 5 und I4 Jahre alt. Dies steht im Gegensatz zu Mexiko, wo diese Zahl 22 Prozent beträgt.

Mit der Bevölkerungszahl des Jahres 2002 als Bezugswert (Index = I00) zeigt Tab. AI.2 die erwartete Entwicklung über die nächsten zehn Jahre für die Bevölkerungszahl in drei Altersgruppen (die in etwa dem typischen Alter von Schülern und Studierenden im Primar- und Sekundarbereich I, im Sekundarbereich II und im Tertiärbereich entsprechen).

Der starke Rückgang der Zahl junger Menschen in den 7oer und 8oer Jahren hat sich allgemein verlangsamt, jedoch deuten Bevölkerungsprognosen darauf hin, dass im Verlauf der nächsten zehn Jahre der Anteil der 5- bis I4-Jährigen in vielen OECD-Ländern weiterhin zurückgehen wird. Polen ist das einzige Land, in dem der Anteil der 5- bis I4-Jährigen in den nächsten zehn Jahren um mehr als 25 Prozent zurückgehen wird. Bemerkenswert ist, dass in Österreich, der Tschechischen Republik, der Slowakischen Republik, der Schweiz und zUngarn der Rückgang mehr als 20 Prozent betragen wird (Tab. AI.2). 


\section{Abbildung A1.3}

Erwartete Veränderungen in der Zahl junger Menschen innerhalb der nächsten 10 Jahre (2002-2012)
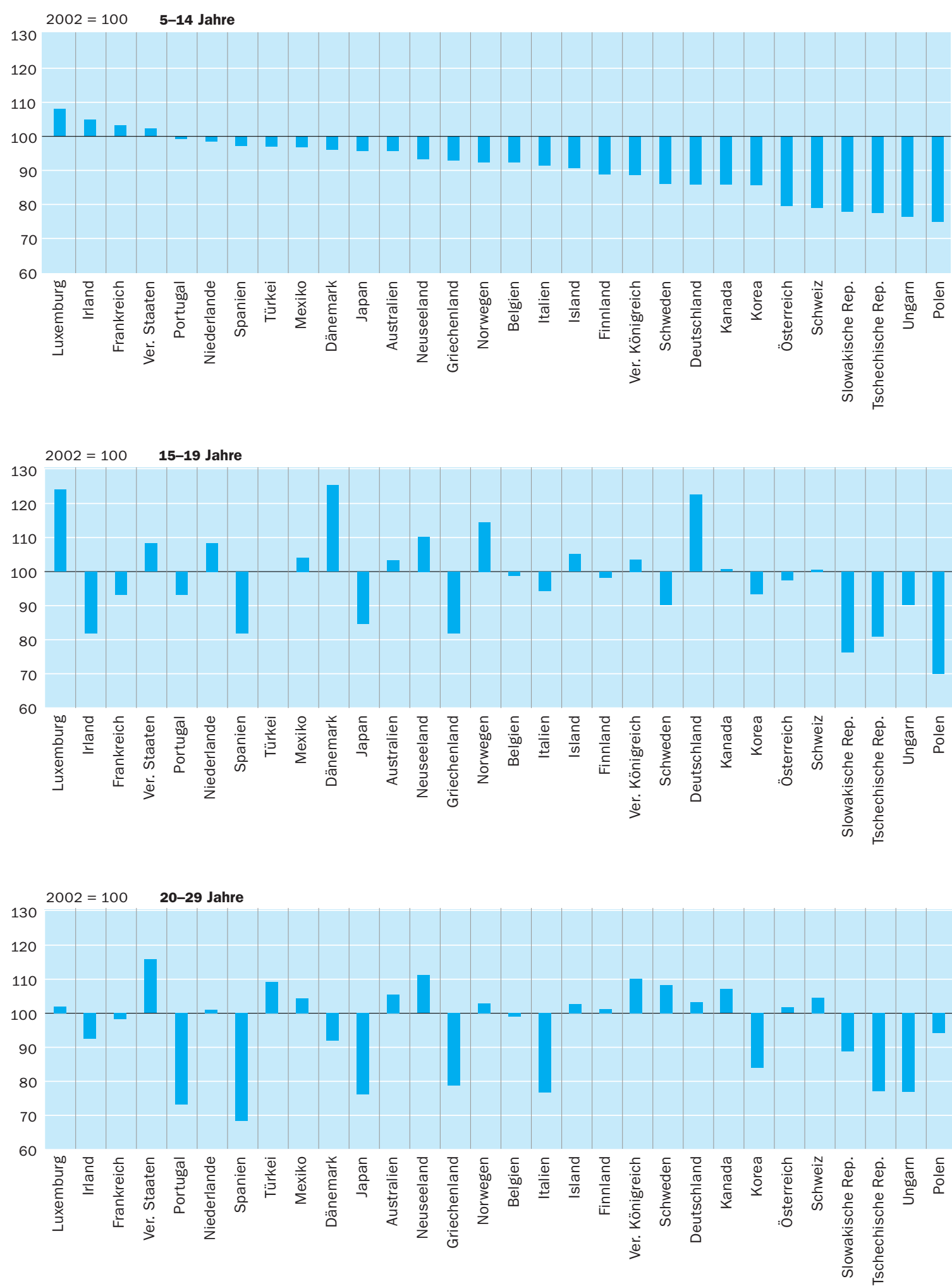
Eine abnehmende Zahl junger Menschen scheint die Regel zu sein. Allerdings wird im Zeitraum von 2002 bis 2012 in vier von 30 OECD-Ländern, nämlich in Frankreich, Irland, Luxemburg und den Vereinigten Staaten, die Zahl der 5- bis I4-Jährigen um zwischen 2 und 8 Prozent ansteigen.

Größere Schwankungen lassen sich bei den älteren Altersgruppen feststellen. In vierzehn Ländern wird die Zahl der I5- bis I9-Jährigen in der nahen Zukunft ansteigen. In Dänemark, Luxemburg, Neuseeland, den Niederlanden, Norwegen, Schweden und den Vereinigten Staaten rechnet man mit einem Anstieg der Zahl der 15- bis I9-Jährigen um 8 bis 25 Prozent, während gleichzeitig der Zugang zu Bildungsgängen im Sekundarbereich II zunehmen wird (Indikator $\mathrm{CI})$.

Bei den 20- bis 29-Jährigen, der typischen Altergruppe für Studiengänge im Tertiärbereich, wird in Griechenland, Italien, Japan, Portugal, Spanien, der Tschechischen Republik und Ungarn ein Rückgang von mehr als 20 Prozent den Ausgabendruck im Tertiärbereich verringern. Im Gegensatz dazu rechnet man während der nächsten ıo Jahre in Deutschland, Kanada, Neuseeland, der Türkei, dem Vereinigten Königreich und den Vereinigten Staaten mit einem Anstieg um 7 bis I6 Prozent bei der Zahl der 20- bis 29-Jährigen, was für die Bildungssysteme im Tertiärbereich in diesen Ländern eine Herausforderung darstellt (Tab. Ar.2).

\section{Definitionen und angewandte Methodik}

Die Daten zum Bildungsstand stammen aus nationalen Arbeitskräfteerhebungen und beruhen auf der Internationalen Standardklassifikation des Bildungswesens (ISCED-97).
Die Daten zu Bevölkerung und Bildungsstand stammen aus Datenbanken der OECD und EUROSTAT, die aus nationalen Arbeitskräfteerhebungen zusammengetragen sind. Länderspezifische Datenquellen s. Anhang unter www.oecd. orgleduleag 2004 .

Die Unterschiede im Bildungsstand basieren auf dem Prozentsatz der Bevölkerung im Alter von 25 bis 64 Jahren, die einen bestimmten Bildungsstand erreicht hat. Die Festlegung der einzelnen Bildungsbereiche erfolgt auf Grundlage der Internationalen Standardklassifikation des Bildungswesens (ISCED97). Zur Beschreibung der Bildungsbereiche laut ISCED-97 und der entsprechenden Zuordnung der landesspezifischen Bildungsgänge s. Anhang 3 unter www.oecd.org/eduleag2004.

Die Berechnung der durchschnittlichen formalen Ausbildungsdauer (in Jahren) beruht auf der gewichteten theoretischen Ausbildungsdauer für das Erlangen eines bestimmten Bildungsstandes entsprechend der gegenwärtigen Dauer von Bildungsgängen, wie sie in der UOE-Datenerhebung angegeben sind. Daher handelt es sich eher um eine Schätzung des „Wiederbeschaffungswerts" des gegenwärtigen Humankapitals als um einen Schätzwert für die durchschnittliche Dauer der Ausbildung, die die Bevölkerung in der Vergangenheit tatsächlich absolviert hat. 
Die Hochrechungsdaten basieren auf der UN-Datenbank und nicht der UOEDatenerhebung; daher ist es nicht möglich, die Zahlen aus der UOE-Datenerhebung zu reproduzieren. Daten zum Prozentsatz der 5- bis I4-, I5- bis I9und 20- bis 29-Jährigen an der Gesamtbevölkerung beziehen sich auf den Zeitraum I998/1999 und beruhen auf der UOE-Datenerhebung und dem World Education Indicators Projekt. Veränderungen in der Größe der jeweiligen Altersgruppe im Zeitraum von 1992 bis 2012 sind als Prozentsatz relativ zur Größe der entsprechenden Altersgruppe im Jahr 2002 angegeben (Index = I0o). Die Statistiken erfassen die Einwohner eines Landes, unabhängig von Staatsbürgerschaft und Bildungs- oder Arbeitsmarktstatus. Diese Hochrechnungen sind aus der UN Bevölkerungsdatenbank abgeleitet. 
Tabelle A1.1

Bildungsstand der Erwachsenenbevölkerung (2002)

Bildungsstand der 25- bis 64-Jährigen, nach dem höchsten erreichten Bildungsstand

\begin{tabular}{|c|c|c|c|c|c|c|c|c|c|c|}
\hline \multirow{3}{*}{ OECD-Länder } & \multirow{2}{*}{$\begin{array}{l}\text { Elementar- } \\
\text { und Primar- } \\
\text { bereich }\end{array}$} & \multirow{2}{*}{$\begin{array}{l}\text { Sekundar- } \\
\text { bereich I }\end{array}$} & \multicolumn{3}{|c|}{ Sekundarbereich II } & \multirow{2}{*}{$\mid \begin{array}{c}\text { Post- } \\
\text { sekundarer, } \\
\text { nicht-tertiärer } \\
\text { Bereich }\end{array}$} & \multicolumn{2}{|c|}{ Tertiärbereich } & \multirow{2}{*}{$\begin{array}{c}\text { Alle Bildungs- } \\
\text { bereiche } \\
\text { zusammen }\end{array}$} & \multirow{2}{*}{$\begin{array}{l}\text { Durchschn. } \\
\text { (Aus-)Bil- } \\
\text { dungsdauer } \\
\text { (in Jahren) }\end{array}$} \\
\hline & & & $\begin{array}{l}\text { ISCED 3C } \\
\text { kurz }\end{array}$ & $\begin{array}{l}\text { ISCED 3C } \\
\text { lang/3B }\end{array}$ & ISCED $3 \mathrm{~A}$ & & $\begin{array}{l}\text { Tertiär- } \\
\text { bereich B }\end{array}$ & $\begin{array}{l}\text { Tertiär- } \\
\text { bereich A } \\
\text { und weiter- } \\
\text { führende } \\
\text { Forschungs- } \\
\text { programme } \\
\text { (8) }\end{array}$ & & \\
\hline & & & & & & & & & & \\
\hline Australien & $x(2)$ & 39 & a & 11 & 19 & $x(5)$ & 11 & 20 & 100 & 13,1 \\
\hline Österreich & $x(2)$ & 22 & a & 49 & 7 & 7 & 7 & 7 & 100 & 11,3 \\
\hline Belgien & 19 & 21 & a & 8 & 24 & 1 & 15 & 13 & 100 & 11,2 \\
\hline Kanada & 6 & 12 & a & $x(5)$ & 28 & 12 & 22 & 21 & 100 & 12,9 \\
\hline Tschechische Rep. & $\mathrm{n}$ & 12 & $x(4)$ & 43 & 33 & $x(5)$ & $x(8)$ & 12 & 100 & 12,4 \\
\hline Dänemark & $\mathrm{n}$ & 20 & $x(2)$ & 46 & 5 & 1 & 8 & 20 & 100 & 13,3 \\
\hline Finnland & $x(2)$ & 25 & a & a & 42 & $\mathrm{n}$ & 17 & 16 & 100 & 12,4 \\
\hline Frankreich & 17 & 18 & 27 & 3 & 10 & $\mathrm{n}$ & 12 & 12 & 100 & 10,9 \\
\hline Deutschland & 2 & 15 & a & 52 & 3 & 5 & 10 & 13 & 100 & 13,4 \\
\hline Griechenland & 37 & 10 & 2 & 2 & 25 & 5 & 6 & 13 & 100 & 10,5 \\
\hline Ungarn & 3 & 26 & a & 29 & 27 & 2 & $\mathrm{n}$ & 14 & 100 & 11,5 \\
\hline Island & 2 & 32 & 7 & a & 23 & 10 & 6 & 20 & 100 & 13,4 \\
\hline Irland & 21 & 18 & a & a & 23 & 12 & 10 & 16 & 100 & 12,7 \\
\hline Italien & 20 & 33 & 2 & 6 & 26 & 2 & $x(8)$ & 10 & 100 & 9,4 \\
\hline Japan & $x(2)$ & 16 & a & $x(5)$ & 47 & $x(9)$ & 16 & 20 & 100 & 12,6 \\
\hline Korea & 15 & 15 & a & $x(5)$ & 45 & a & 8 & 18 & 100 & 11,7 \\
\hline Luxemburg & 23 & 15 & 5 & 21 & 14 & 3 & 7 & 12 & 100 & 12,9 \\
\hline Mexiko & 73 & 14 & a & 7 & a & a & 3 & 2 & 100 & 7,4 \\
\hline Niederlande & 12 & 22 & $x(4)$ & 24 & 13 & 5 & 3 & 22 & 100 & 13,5 \\
\hline Neuseeland & $x(2)$ & 24 & a & 21 & 18 & 8 & 15 & 15 & 100 & 10,6 \\
\hline Norwegen & $n$ & 13 & a & 40 & 12 & 3 & 3 & 28 & 100 & 13,8 \\
\hline Polen & $x(2)$ & 18 & 35 & a & 31 & 4 & $x(8)$ & 12 & 100 & 11,9 \\
\hline Portugal & 67 & 13 & $x(5)$ & $x(5)$ & 11 & $x(5)$ & 2 & 7 & 100 & 8,0 \\
\hline Slowakische Rep. & 1 & 13 & $x(4)$ & 40 & 35 & $x(5)$ & 1 & 10 & 100 & 12,5 \\
\hline Spanien & 32 & 26 & $n$ & 6 & 11 & $n$ & 7 & 17 & 100 & 10,3 \\
\hline Schweden & 8 & 10 & a & $x(5)$ & 49 & $x(7)$ & 15 & 18 & 100 & 12,4 \\
\hline Schweiz & 3 & 12 & 2 & 44 & 6 & 7 & 9 & 16 & 100 & 12,8 \\
\hline Türkei & 65 & 10 & a & 6 & 10 & a & $x(8)$ & 9 & 100 & 9,6 \\
\hline Ver. Königreich & $\mathrm{n}$ & 16 & 19 & 22 & 15 & $x(9)$ & 8 & 19 & 100 & 12,7 \\
\hline Vereinigte Staaten & 5 & 8 & $x(5)$ & $x(5)$ & 49 & $x(5)$ & 9 & 29 & 100 & 12,7 \\
\hline Ländermittel & 14 & 18 & 3 & 16 & 22 & 3 & 8 & 15 & 100 & 11,8 \\
\hline OECD-Partnerländer & & & & & & & & & & \\
\hline Israel & 2 & 17 & $x(5)$ & $x(5)$ & 38 & $x(7)$ & 16 & 26 & 100 & $\mathrm{~m}$ \\
\hline
\end{tabular}

Hinweis: $x$ bedeutet, dass die Daten in einer anderen Spalte enthalten sind, deren Referenz in runden Klammern nach dem ,x‘ angegeben ist. So bedeutet $z . B$. $x(2)$, dass die Daten in Spalte 2 enthalten sind.

Quelle: OECD. Zur Beschreibung der Bildungsbereiche laut ISCED-97 und der entsprechenden Zuordnung der landesspezifischen Bildungsgänge s. Anhang 3 unter www.oecd.org/edu/eag2004. 
Bildungsstand: Männer (2002)

Bildungsstand 25- bis 64-jähriger Männer, nach dem höchsten erreichten Bildungsstand

\begin{tabular}{|c|c|c|c|c|c|c|c|c|c|c|}
\hline & \multirow{2}{*}{$\begin{array}{l}\text { Elementar- } \\
\text { und Primar- } \\
\text { bereich }\end{array}$} & \multirow{2}{*}{$\begin{array}{l}\text { Sekundar- } \\
\text { bereich I }\end{array}$} & \multicolumn{3}{|c|}{ Sekundarbereich II } & \multirow{2}{*}{$\begin{array}{c}\text { Post- } \\
\text { sekundarer, } \\
\text { nicht-tertiärer } \\
\text { Bereich }\end{array}$} & \multicolumn{2}{|c|}{ Tertiärbereich } & \multirow{2}{*}{$\begin{array}{c}\text { Alle Bildungs- } \\
\text { bereiche } \\
\text { zusammen }\end{array}$} & \multirow{2}{*}{$\begin{array}{l}\text { Durchschn. } \\
\text { (Aus-)Bil- } \\
\text { dungsdauer } \\
\text { (in Jahren) }\end{array}$} \\
\hline & & & $\begin{array}{c}\text { ISCED 3C } \\
\text { kurz } \\
\text { (3) }\end{array}$ & $\begin{array}{c}\text { ISCED 3C } \\
\text { lang/3B }\end{array}$ & ISCED $3 \mathrm{~A}$ & & $\begin{array}{l}\text { Tertiär- } \\
\text { bereich B } \\
\text { (7) }\end{array}$ & $\begin{array}{c}\text { Tertiär- } \\
\text { bereich A } \\
\text { und weiter- } \\
\text { führende } \\
\text { Forschungs- } \\
\text { programme } \\
\text { (8) }\end{array}$ & & \\
\hline \multicolumn{11}{|l|}{ OECD-Länder } \\
\hline Australien & $x(2)$ & 33 & a & 19 & 19 & $x(5)$ & 9 & 20 & 100 & 13,2 \\
\hline Österreich & $x(2)$ & 16 & a & 53 & 7 & 7 & 9 & 8 & 100 & 11,5 \\
\hline Belgien & 17 & 22 & a & 7 & 25 & 1 & 12 & 15 & 100 & 11,2 \\
\hline Kanada & 6 & 12 & a & $x(5)$ & 27 & 15 & 18 & 22 & 100 & 12,9 \\
\hline Tschechische Rep. & $\mathrm{n}$ & 7 & $x(4)$ & 51 & 28 & $x(5)$ & $x(8)$ & 14 & 100 & 12,6 \\
\hline Dänemark & $\mathrm{n}$ & 18 & $x(2)$ & 49 & 5 & 2 & 9 & 16 & 100 & 13,3 \\
\hline Finnland & $x(2)$ & 27 & a & a & 44 & $\mathrm{n}$ & 14 & 16 & 100 & 12,3 \\
\hline Frankreich & 15 & 18 & 32 & 3 & 9 & $\mathrm{n}$ & 10 & 13 & 100 & 11,0 \\
\hline Deutschland & 2 & 11 & a & 51 & 3 & 5 & 12 & 16 & 100 & 13,6 \\
\hline Griechenland & 34 & 12 & 4 & 3 & 23 & 5 & 6 & 14 & 100 & 10,7 \\
\hline Ungarn & 2 & 22 & a & 39 & 22 & 2 & $\mathrm{n}$ & 14 & 100 & 11,7 \\
\hline Island & 1 & 26 & 6 & a & 25 & 17 & 5 & 20 & 100 & 13,8 \\
\hline Irland & 23 & 19 & a & a & 21 & 13 & 8 & 16 & 100 & 12,6 \\
\hline Italien & 17 & 36 & 2 & 6 & 27 & 2 & $x(8)$ & 10 & 100 & 9,6 \\
\hline Japan & $x(2)$ & 17 & a & $x(5)$ & 45 & $x(9)$ & 9 & 30 & 100 & 12,9 \\
\hline Korea & 10 & 13 & a & $x(5)$ & 46 & a & 8 & 24 & 100 & 12,2 \\
\hline Luxemburg & 21 & 13 & 5 & 22 & 14 & 4 & 7 & 14 & 100 & 13,2 \\
\hline Mexiko & 72 & 15 & a & 7 & a & a & 3 & 3 & 100 & 7,4 \\
\hline Niederlande & 11 & 19 & $x(4)$ & 25 & 14 & 5 & 3 & 24 & 100 & 13,7 \\
\hline Neuseeland & $x(2)$ & 23 & a & 27 & 15 & 8 & 11 & 16 & 100 & 10,6 \\
\hline Norwegen & $\mathrm{n}$ & 13 & a & 43 & 10 & 4 & 3 & 26 & 100 & 13,7 \\
\hline Polen & $x(2)$ & 17 & 43 & a & 28 & 2 & $x(8)$ & 11 & 100 & 11,8 \\
\hline Portugal & 67 & 14 & $x(5)$ & $x(5)$ & 12 & $x(5)$ & 2 & 6 & 100 & 7,9 \\
\hline Slowakische Rep. & 1 & 9 & $x(4)$ & 48 & 31 & $x(5)$ & 0 & 10 & 100 & 12,6 \\
\hline Spanien & 30 & 27 & $\mathrm{n}$ & 6 & 12 & $\mathrm{n}$ & 8 & 17 & 100 & 10,4 \\
\hline Schweden & 9 & 11 & a & $x(5)$ & 49 & $x(7)$ & 14 & 16 & 100 & 12,2 \\
\hline Schweiz & 3 & 10 & 1 & 42 & 4 & 7 & 13 & 21 & 100 & 13,3 \\
\hline Türkei & 59 & 12 & a & 8 & 11 & a & $x(8)$ & 11 & 100 & 9,8 \\
\hline Ver. Königreich & $\mathrm{n}$ & 14 & 16 & 25 & 17 & $x(9)$ & 8 & 20 & 100 & 12,7 \\
\hline Vereinigte Staaten & 5 & 8 & $x(5)$ & $x(5)$ & 49 & $x(5)$ & 8 & 30 & 100 & 12,6 \\
\hline Ländermittel & 13 & 17 & 4 & 18 & 21 & 3 & 7 & 16 & 100 & 11,9 \\
\hline OECD-Partnerländer & & & & & & & & & & \\
\hline Israel & 1 & 19 & $x(5)$ & $x(5)$ & 40 & $x(7)$ & 15 & 25 & 100 & $\mathrm{~m}$ \\
\hline
\end{tabular}

Hinweis: $x$ bedeutet, dass die Daten in einer anderen Spalte enthalten sind, deren Referenz in runden Klammern nach dem , x' angegeben ist. So bedeutet $z . B . x(2)$, dass die Daten in Spalte 2 enthalten sind.

Quelle: OECD. Zur Beschreibung der Bildungsbereiche laut ISCED-97 und der entsprechenden Zuordnung der landesspezifischen Bildungsgänge s. Anhang 3 unter www.oecd.org/edu/eag2004. 
Tabelle A1.1b

Bildungsstand: Frauen (2002)

Bildungsstand 25- bis 64-jähriger Frauen, nach dem höchsten erreichten Bildungsstand

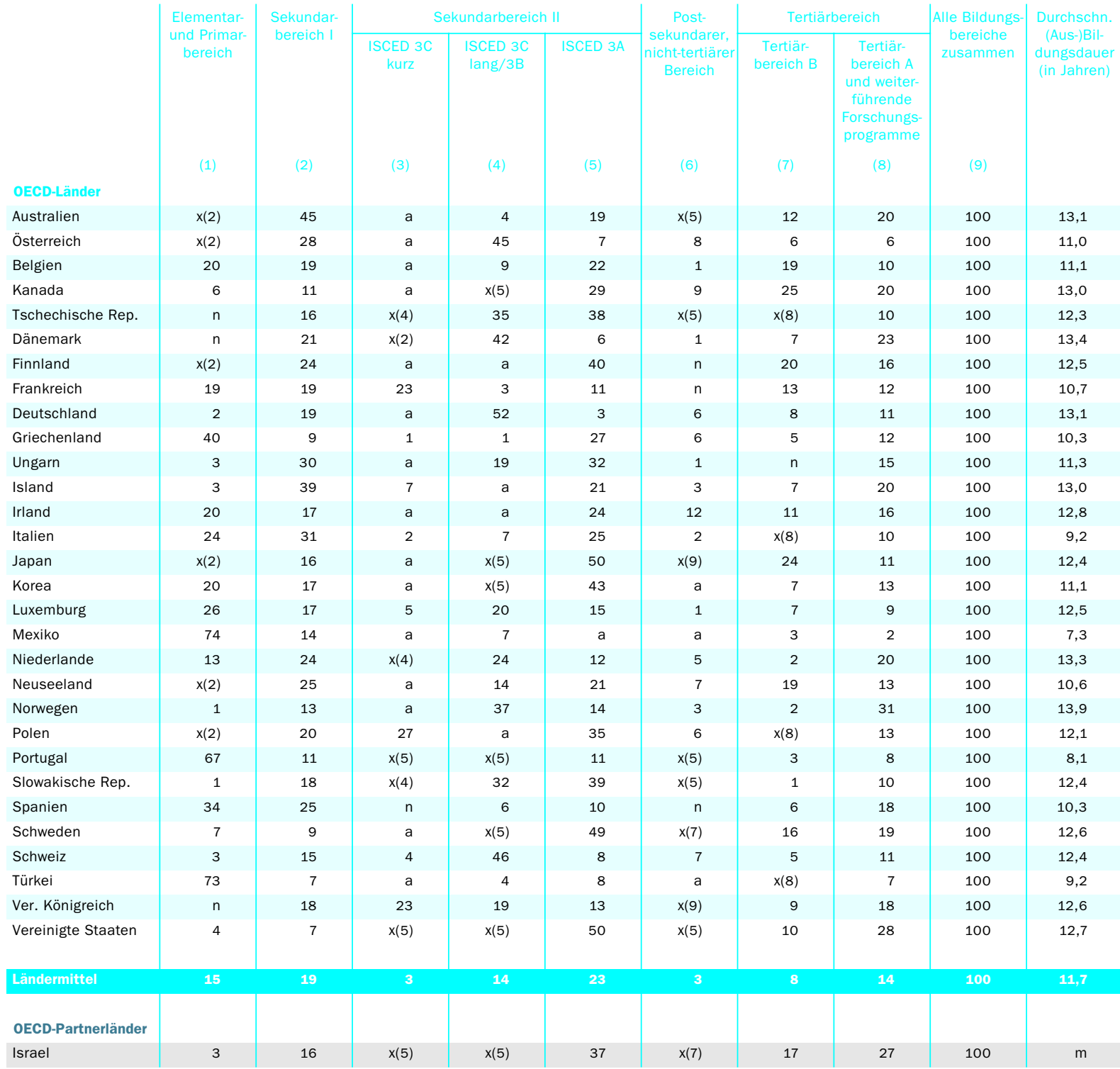

Hinweis: $x$ bedeutet, dass die Daten in einer anderen Spalte enthalten sind, deren Referenz in runden Klammern nach dem , $x$ ‘ angegeben ist. So bedeutet $z$. $B$. $x(2)$, dass die Daten in Spalte 2 enthalten sind.

Quelle: OECD. Zur Beschreibung der Bildungsbereiche laut ISCED-97 und der entsprechenden Zuordnung der landesspezifischen Bildungsgänge s. Anhang 3 unter www.oecd.org/edu/eag2004. 
Bevölkerung im Alter für den Elementar-, Primar- und Sekundarbereich I, den Sekundarbereich II und den Tertiärbereich $(1992,2002,2012)$

\begin{tabular}{|c|c|c|c|c|c|c|c|c|c|c|}
\hline & \multicolumn{3}{|c|}{ Anteil der Bevölkerung (in \%) } & \multicolumn{6}{|c|}{ Veränderung in der Größe der Population $(2002=100)$} & \multirow{4}{*}{$\begin{array}{l}\text { Zahl der Schüler } \\
\text { /Studierenden } \\
\text { als Prozentsatz } \\
\text { der } 25 \text { - bis } \\
\text { 64-jährigen } \\
\text { Beschäftigten }\end{array}$} \\
\hline & \multicolumn{3}{|c|}{ Altersgruppe } & \multicolumn{6}{|c|}{ Altersgruppe } & \\
\hline & \multirow[t]{2}{*}{$5-14 \mathrm{~J}$} & \multirow[t]{2}{*}{$15-19 \mathrm{~J}$} & $20-29 \mathrm{~J}$ & \multicolumn{2}{|c|}{$5-14 \mathrm{~J}}$. & \multicolumn{2}{|c|}{$15-19 \mathrm{~J}}$. & \multicolumn{2}{|c|}{$20-29 \mathrm{~J}}$. & \\
\hline & & & & 1992 & \multicolumn{5}{|c|}{ OECD-Länder } & \\
\hline Australien & 14 & 7 & 14 & 94 & 96 & 98 & 103 & 99 & 105 & 80 \\
\hline Österreich & 12 & 6 & 12 & 98 & 79 & 100 & 98 & 135 & 102 & 52 \\
\hline Belgien & 12 & 6 & 13 & 100 & 92 & 105 & 99 & 118 & 99 & 74 \\
\hline Kanada & $\mathrm{m}$ & $\mathrm{m}$ & $\mathrm{m}$ & 96 & 85 & 93 & 101 & 107 & 107 & $\mathrm{~m}$ \\
\hline Tschechische Rep. & 12 & 7 & 17 & 125 & 77 & 133 & 81 & 84 & 77 & 52 \\
\hline Dänemark & 12 & 5 & 13 & 85 & 96 & 126 & 125 & 120 & 92 & 56 \\
\hline Finnland & 12 & 6 & 12 & 102 & 89 & 95 & 98 & 109 & 101 & 63 \\
\hline Frankreich & 12 & 7 & 13 & 104 & 103 & 104 & 93 & 109 & 98 & 65 \\
\hline Deutschland & 11 & 6 & 12 & 99 & 86 & 90 & 90 & 139 & 108 & 53 \\
\hline Griechenland & 10 & 6 & 15 & 123 & 93 & 115 & 82 & 96 & 79 & 60 \\
\hline Ungarn & 12 & 6 & 16 & 119 & 76 & 134 & 90 & 85 & 77 & 66 \\
\hline Island & 16 & 7 & 15 & 94 & 91 & 98 & 105 & 99 & 103 & 73 \\
\hline Irland & 14 & 8 & 17 & 121 & 105 & 101 & 82 & 75 & 92 & 70 \\
\hline Italien & 10 & 5 & 13 & 107 & 91 & 138 & 94 & 123 & 77 & 54 \\
\hline Japan & 10 & 6 & 14 & 124 & 96 & 135 & 85 & 100 & 76 & 44 \\
\hline Korea & 14 & 7 & 17 & 111 & 84 & 121 & 101 & 108 & 81 & 61 \\
\hline Luxemburg & 13 & 6 & 13 & 80 & 108 & 93 & 124 & 108 & 102 & 50 \\
\hline Mexiko & 22 & 10 & 19 & 95 & 97 & 99 & 104 & 82 & 104 & 105 \\
\hline Niederlande & 12 & 6 & 13 & 91 & 99 & 107 & 108 & 129 & 101 & 54 \\
\hline Neuseeland & 15 & 7 & 13 & 87 & 93 & 100 & 110 & 112 & 111 & 77 \\
\hline Norwegen & 13 & 6 & 13 & 87 & 92 & 109 & 115 & 118 & 103 & 59 \\
\hline Polen & 13 & 9 & 16 & 132 & 74 & 93 & 70 & 81 & 94 & 81 \\
\hline Portugal & 10 & 6 & 16 & 120 & 99 & 137 & 93 & 96 & 73 & 53 \\
\hline Slowakische Rep. & 13 & 8 & 17 & 125 & 77 & 105 & 77 & 83 & 89 & 67 \\
\hline Spanien & 10 & 6 & 16 & 131 & 97 & 139 & 82 & 98 & 68 & 60 \\
\hline Schweden & 13 & 6 & 12 & 85 & 86 & 106 & 123 & 112 & 103 & 64 \\
\hline Schweiz & 12 & 6 & 12 & 94 & 78 & 100 & 101 & 140 & 104 & 44 \\
\hline Türkei & $\mathrm{m}$ & $\mathrm{m}$ & $\mathrm{m}$ & 97 & 97 & 91 & 100 & 83 & 109 & 101 \\
\hline Ver. Königreich & 13 & 6 & 13 & 93 & 88 & 94 & 104 & 116 & 110 & 74 \\
\hline Vereinigte Staaten & 15 & 7 & 13 & 88 & 102 & 86 & 108 & 102 & 116 & 64 \\
\hline Ländermittel & 12 & 6 & 14 & 104 & 91 & 108 & 97 & 106 & 96 & 64 \\
\hline
\end{tabular}

\begin{tabular}{|c|c|c|c|c|c|c|c|c|c|c|}
\hline Ländermittel & 12 & 6 & 14 & 104 & 91 & 108 & 97 & 106 & 96 & 64 \\
\hline \multicolumn{11}{|c|}{ OECD-Partnerländer } \\
\hline Argentinien & 19 & 9 & 16 & 97 & 104 & 92 & 105 & 77 & 103 & $\mathrm{~m}$ \\
\hline Brasilien & 20 & 11 & 17 & 106 & 99 & 87 & 91 & 86 & 106 & $\mathrm{~m}$ \\
\hline Chile & 19 & 9 & 15 & 89 & 97 & 91 & 108 & 103 & 115 & 89 \\
\hline China & $\mathrm{m}$ & $\mathrm{m}$ & $\mathrm{m}$ & 97 & 86 & 104 & 91 & 119 & 106 & $\mathrm{~m}$ \\
\hline Ägypten & 22 & 12 & 19 & 94 & 110 & 76 & 101 & 72 & 129 & $\mathrm{~m}$ \\
\hline Indien & 24 & 11 & 17 & 88 & 100 & 83 & 111 & 86 & 120 & $\mathrm{~m}$ \\
\hline Israel & 18 & 9 & 16 & 85 & 114 & 85 & 113 & 73 & 109 & $\mathrm{~m}$ \\
\hline Indonesien & 19 & 11 & 18 & 101 & 98 & 93 & 98 & 86 & 105 & $\mathrm{~m}$ \\
\hline Jamaika & 22 & 10 & 16 & 101 & 95 & 93 & 98 & 92 & 107 & $\mathrm{~m}$ \\
\hline Jordanien & 26 & 12 & 18 & 78 & 113 & 76 & 119 & 64 & 115 & $\mathrm{~m}$ \\
\hline Malaysia & 22 & 10 & 17 & 84 & 103 & 81 & 122 & 81 & 116 & $\mathrm{~m}$ \\
\hline Paraguay & 25 & 11 & 17 & 81 & 113 & 70 & 117 & 80 & 136 & $\mathrm{~m}$ \\
\hline Philippinen & 24 & 10 & 17 & 87 & 101 & 83 & 114 & 80 & 120 & $\mathrm{~m}$ \\
\hline Russische Föd. & 12 & 8 & 15 & 133 & 70 & 86 & 58 & 94 & 103 & $\mathrm{~m}$ \\
\hline Sri Lanka & 17 & 10 & 17 & 113 & 92 & 91 & 86 & 94 & 100 & $\mathrm{~m}$ \\
\hline Thailand & 15 & 8 & 17 & 109 & 98 & 106 & 93 & 96 & 94 & $\mathrm{~m}$ \\
\hline Tunesien & 21 & 11 & 19 & 105 & 83 & 86 & 87 & 82 & 110 & $\mathrm{~m}$ \\
\hline Uruguay & 16 & 8 & 16 & 96 & 101 & 105 & 108 & 87 & 98 & $\mathrm{~m}$ \\
\hline Simbabwe & 24 & 13 & 20 & 87 & 94 & 73 & 103 & 77 & 131 & $\mathrm{~m}$ \\
\hline
\end{tabular}

Quelle: OECD. Hinweise s. Anhang 3 unter www.oecd.org/edu/eag2004. 



\section{Aktuelle Abschlussquoten im Sekundarbereich II und Bildungsstand der Erwachsenenbevölkerung}

In 17 der 20 OECD-Länder, für die vergleichbare Zahlen zur Verfügung stehen, liegt das Verhältnis von Absolventen des Sekundarbereich II zur Bevölkerung im typischen Abschlussalter bei über 70 Prozent. In Dänemark, Deutschland, Japan, Norwegen. Polen und der Schweiz liegen die Abschlussquoten bei $\mathbf{9 0}$ Prozent oder darüber. Jetzt muss verhindert werden, dass der übrige Teil den Anschluss nicht verliert und sich dem möglichen Risiko sozialer Ausgrenzung gegenübersieht.

Bei einem Vergleich des Bildungsstands der 25- bis 34-Jährigen mit dem der 45- bis 54-Jährigen zeigt sich, dass der Anteil der Personen, die über einen Abschluss im Sekundarbereich II verfügen, in fast allen OECD-Ländern gestiegen ist, in einigen Ländern sogar recht deutlich: in zwei Dritteln der Länder reicht bei der jüngsten Altersgruppe der Anteil von 70 bis 95 Prozent. Viele Länder mit einem in der Vergangenheit geringen Bildungsstand holen nun auf.

Heute übersteigen in den meisten OECD-Ländern die Abschlussquoten von Frauen die der Männer. Bei den älteren Altersgruppen weisen Frauen einen niedrigeren Bildungsstand als Männer auf, doch bei den jüngeren Menschen hat sich dieses Verhältnis umgekehrt. 


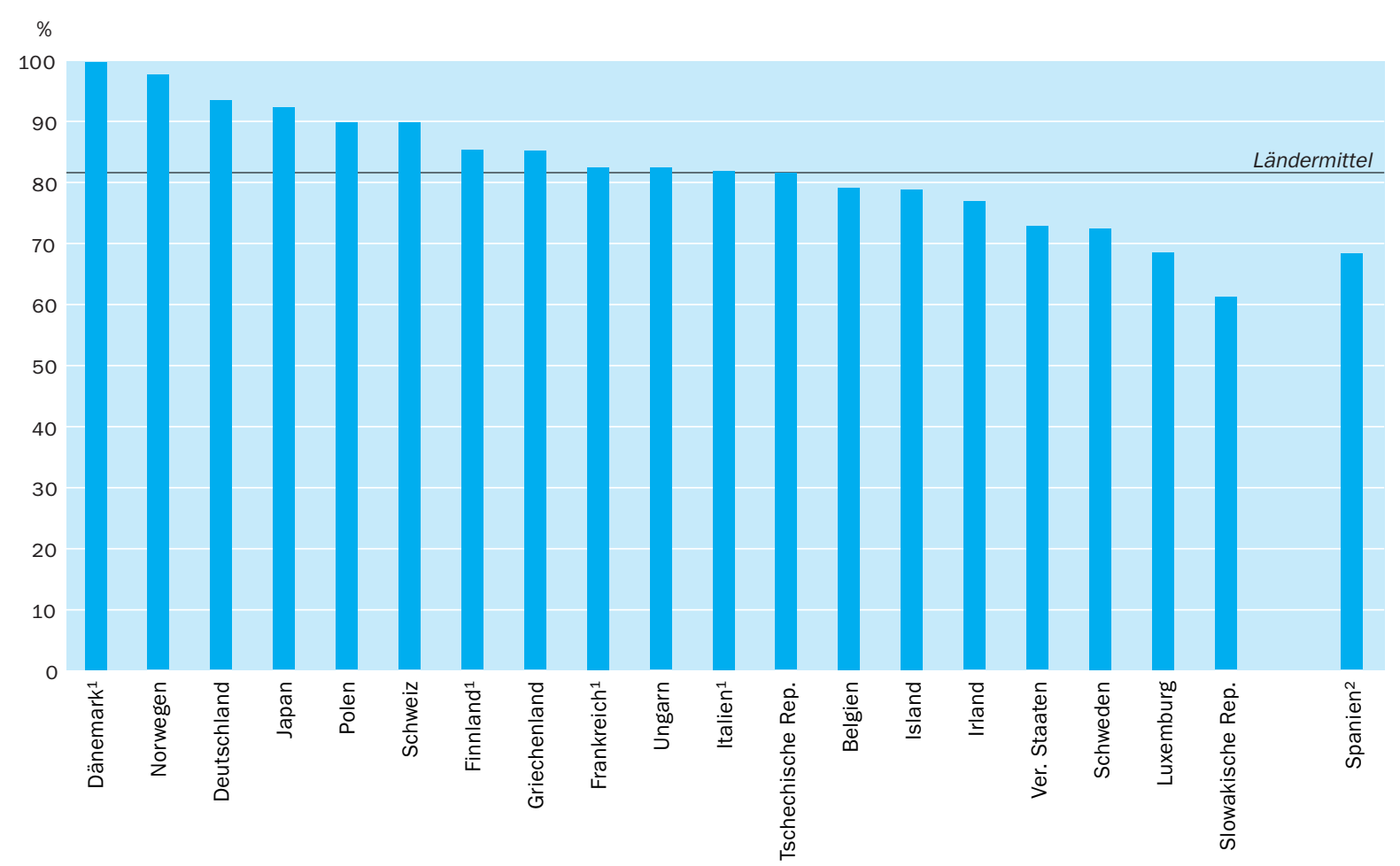

1. Referenzjahr 2001. 2. Signifikanter Anteil der Kohorte an Jugendlichen nicht enthalten. Anordnung der Länder in absteigender Reihenfolge der Gesamtabschlussquoten im Sekundarbereich II. Quelle: OECD, Tabelle A2.1. Hinweise s. Anhang 3 unter www.oecd.org/edu/eag2004.

Um den Anteil der Bevölkerung zu erfassen, der über die Mindestvoraussetzungen für einen erfolgreichen Eintritt in den Arbeitsmarkt verfügt, ...

... zeigt dieser Indikator sowohl die aktuellen Abschlussquoten der Bildungseinrichtungen im Sekundarbereich II auf ...

\section{Politischer Hintergrund}

Aufgrund der gestiegenen Anforderungen an Kenntnisse und Fähigkeiten in den OECD-Ländern ist ein Abschluss des Sekundarbereich II zur Mindestvoraussetzung für einen erfolgreichen Eintritt in den Arbeitsmarkt geworden. Er bildet die Grundlage für weiterführendes Lernen sowie Fort- und Weiterbildungsmöglichkeiten und dient auch der Vorbereitung auf den direkten Eintritt in den Arbeitsmarkt. Obwohl es die Bildungssysteme vieler Länder ermöglichen, dass Schüler die Schule nach dem Ende des Sekundarbereich I verlassen können, treffen in den OECD-Ländern Jugendliche, die ohne einen Abschluss des Sekundarbereich II abgehen, in der Regel auf große Schwierigkeiten bei ihrem Eintritt in den Arbeitsmarkt (s. Indikatoren Aro bis Ar2).

Die Abschlussquoten des Sekundarbereich II zeigen den gegenwärtigen ,Output' der Bildungssysteme, d.h. den Prozentsatz der Bevölkerung im typischen Alter für den Sekundarbereich II, der einen Bildungsgang des Sekundarbereich II besucht und erfolgreich abschließt. Obwohl hohe Abschlussquoten im Sekundarbereich II nicht garantieren, dass ein Bildungssystem seine Schulabgänger ausreichend mit dem notwendigen Wissen und den grundlegenden 
Fertigkeiten und Fähigkeiten ausgerüstet hat, die für den Eintritt in den Arbeitsmarkt erforderlich sind, weil hierbei nicht die Qualität der Ausbildung erfasst wird, sind diese Abschlussquoten für den Sekundarbereich II doch ein Indikator dafür, inwieweit es den Bildungssystemen gelingt, den Mindestanforderungen des Arbeitsmarktes zu entsprechen.

Durch den Vergleich des Bildungsstands zwischen verschiedenen Generationen lässt sich die Entwicklung des Bildungsstands in der Bevölkerung nachverfolgen, die sowohl bildungspolitische Veränderungen und Änderungen der Zugangsbedingungen widerspiegelt als auch die potentiell vorhandenen Kenntnisse und Kompetenzen.

\section{Ergebnisse und Erläuterungen}

Abschlussquoten im Sekundarbereich II werden geschätzt als die Zahl jener Personen, die, unabhängig von ihrem Alter, einen Erstabschluss im Sekundarbereich II erzielen, bezogen auf Ioo Personen in dem Alter, in dem Schüler in der Regel Bildungsgänge des Sekundarbereich II abschließen (s. Anhang I). Diese Abschlussquoten beinhalten also sowohl Schüler, die den Sekundarbereich II im typischen Alter abschließen, als auch ältere Absolventen (z. B. über den zweiten Bildungsweg). In 17 OECD-Ländern mit vergleichbaren Daten liegen die Abschlussquoten für den Sekundarbereich II bei über 70 Prozent (Abb. A2.I). Die in Abbildung A2.I dargestellten Abschlussquoten sollten in Bezug auf Spanien jedoch mit Vorsicht interpretiert werden, da dort vor kurzem die Dauer von Bildungsgängen im Sekundarbereich verlängert wurde, wodurch die Abschlussquoten zu niedrig angesetzt sind.

In sechs der 20 Länder, für die vergleichbare Absolventenzahlen verfügbar sind, genauer gesagt in Dänemark, Deutschland, Japan, Norwegen, Polen und der Schweiz, liegen die Abschlussquoten bei oder über 90 Prozent.

Ein Vergleich des Bildungsstands jüngerer mit dem älterer Jahrgangsgruppen deutet auf einen starken Anstieg des Prozentsatzes derjenigen Personen hin, die einen Abschluss im Sekundarbereich II erzielen (Abb. A2.2). Im Durchschnitt verfügen 75 Prozent der 25- bis 34-Jährigen über einen Abschluss im Sekundarbereich II, im Vergleich zu nur 6r Prozent der 45- bis 54-Jährigen. In 22 von 30 OECD-Ländern reicht dieser Anteil von 70 bis 95 Prozent für die jüngste Jahrgangsgruppe, was für die OECD-Länder einen neuen Maßstab von rund 80 Prozent bei den Abschlussquoten im Sekundarbereich II setzt.

In den Ländern, in denen die Erwachsenenbevölkerung in der Regel über einen hohen Bildungsstand verfügt, sind die Unterschiede bezüglich des Bildungsstands der verschiedenen Altersgruppen weniger ausgeprägt (Tab. A2.2). Abgesehen von der bemerkenswerten Ausnahme von Korea, wo der Unterschied zwischen den 25- bis 34-Jährigen und den 45 - bis 54-Jährigen 44 Prozentpunkte beträgt, beläuft sich in denjenigen Ländern, in denen die jüngere Generation (im Alter von 25 bis 34 Jahren) beim Bildungsstand die Marke von 80 Prozent überschreitet, der Zuwachs im Vergleich zur vorhergehenden Generation (im Alter von 45 bis 54 Jahren) im Durchschnitt auf nur 8 Prozentpunkte. Für die

In 17 von 20 OECD-Ländern mit vergleichbaren Daten liegen die Abschlussquoten im Sekundarbereich II bei über 70 Prozent.

In Dänemark, Deutschland, Japan, Norwegen, Polen und der Schweiz liegen die Abschlussquoten bei 90 Prozent oder darüber.

In fast allen Ländern sind die Abschlussquoten im Sekundarbereich II gestiegen, ...

... und viele Länder mit einem in der Vergangenheit geringen Bildungsstand holen nun auf. 


\section{Abbildung A2.2}

Bevölkerung mit mindestens einem Abschluss im Sekundarbereich II ${ }^{1}$ (2002)

In Prozenten, nach Altersgruppen

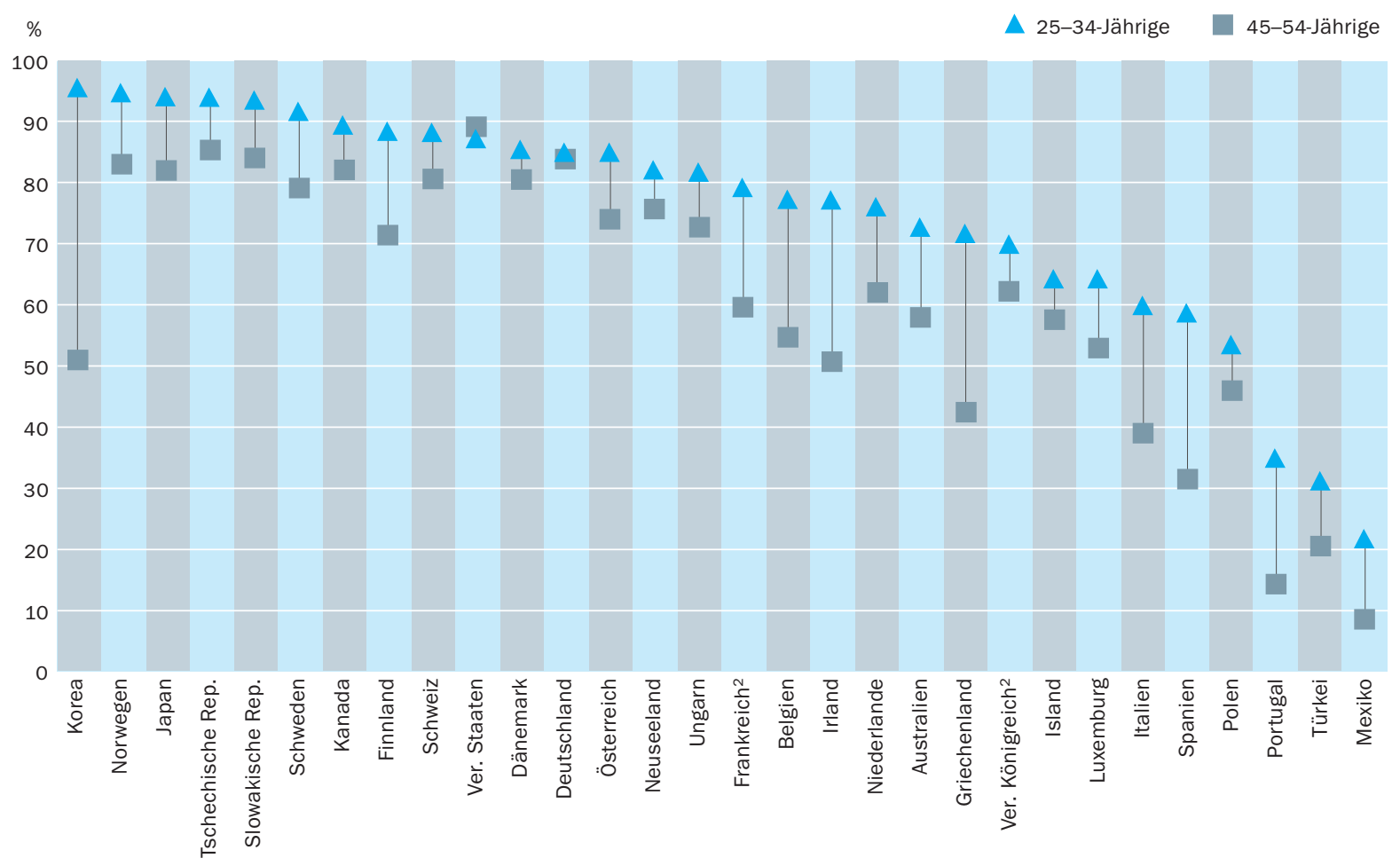

1. Ohne ISCED 3C kurze Bildungsgänge. 2. Nicht alle ISCED 3 Bildungsgänge erfüllen die Mindestanforderungen für ISCED $3 C$ lange Bildungsgänge. Anordnung der Länder in absteigender Reihenfolge des Prozentsatzes 25- bis 34-Jähriger mit mindestens einem Abschluss im Sekundarbereich II. Quelle: OECD, Tabelle A2.2. Hinweise s. Anhang 3 unter www.oecd.org/edu/eag2004.

anderen Länder, in denen es einen größeren Nachholbedarf gibt, beträgt der durchschnittliche Zuwachs I7 Prozentpunkte. Nur drei Länder, Island, Polen und das Vereinigte Königreich, weisen einen Zuwachs von weniger als ıo Prozentpunkten auf. In den anderen Ländern, wie beispielsweise Belgien, Frankreich, Griechenland, Irland, Italien, Portugal und Spanien, sind bemerkenswerte Anstrengungen zu verzeichnen. Auch in Mexiko und der Türkei werden verhältnismäßig herausragende Bemühungen unternommen.

Eine andere Perspektive bietet sich, wenn man ausschließlich die Abschlüsse im Sekundarbereich II betrachtet - d. h. als Maximal- und nicht als Minimalbildungsstand. Im OECD-Durchschnitt blieb hier der Wert für die Erwachsenenbevölkerung über die letzten fünf Jahre konstant bei ungefähr 44 Prozent (Tab. A3.4a). Dies ist das Ergebnis zweier gegenläufiger Tendenzen: Der Anteil der Erwachsenenbevölkerung mit einem Abschluss im Sekundarbereich I ist um 3 Prozentpunkte zurückgegangen, während gleichzeitig der Anteil derjenigen, die einen Abschluss im Tertiärbereich erzielten, um 3 Prozentpunkte zugenommen hat.

Trenddaten zeigen hierbei unterschiedliche Verhältnisse in den einzelnen Ländern. Aufgrund des erweiterten Zugangs zu Bildungsgängen im Tertiärbereich 
Entwicklung der Abschlussquoten von 25- bis 64 Jährigen im Sekundarbereich II und post-sekundaren, nicht-tertiären Bereich (1991-2002)

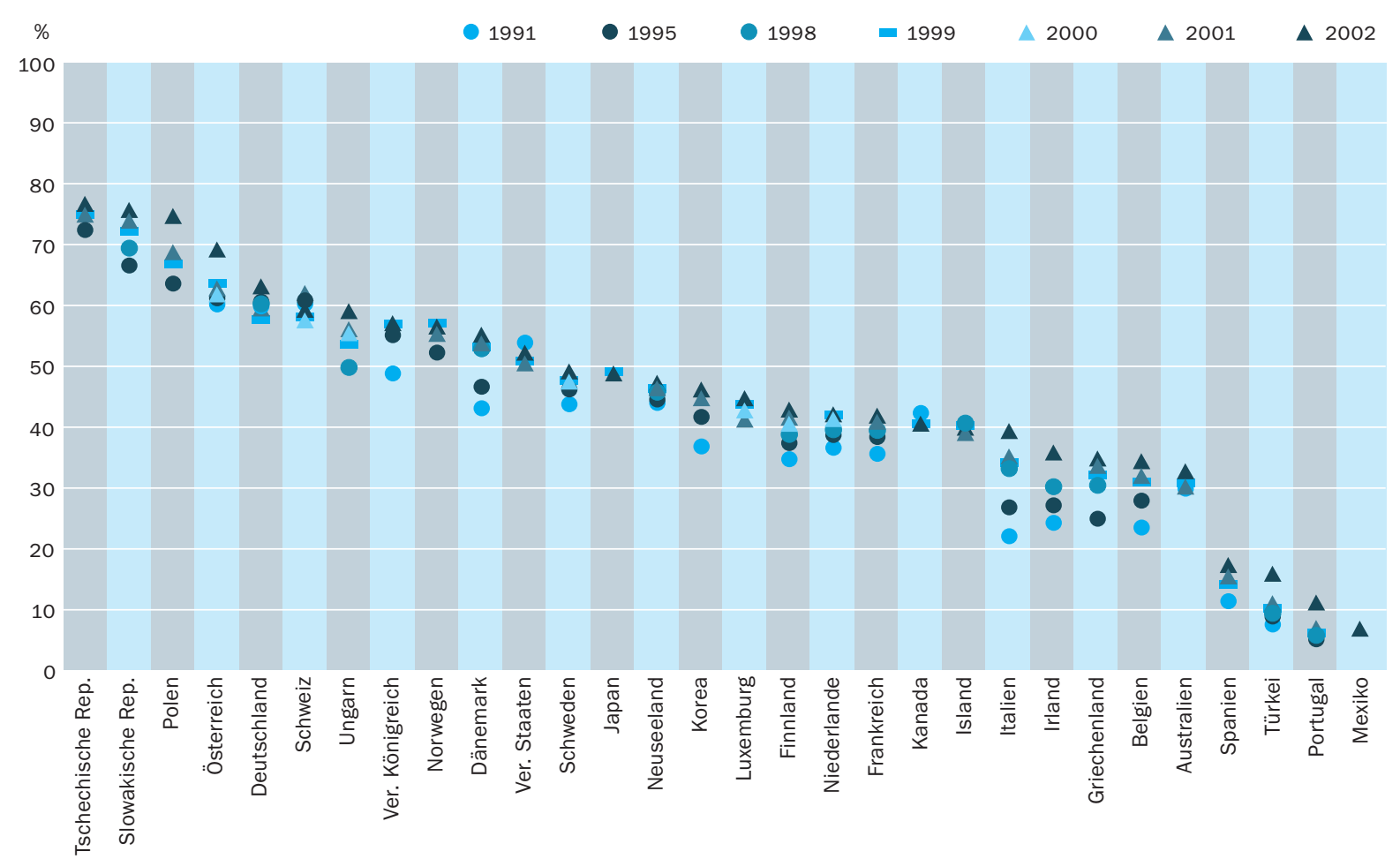

Anordnung der Länder in absteigender Reihenfolge des Bildungsstands im Jahr 2002.

Quelle: OECD, Tabelle A3.4a. Hinweise s. Anhang 3 unter www.oecd.org/edu/eag2004.

ging der Anteil derjenigen Personen, die lediglich über einen Abschluss des Sekundarbereich II verfügen, im Verlauf der letzten fünf Jahre zurück. Dies war in Japan, Kanada und den Vereinigten Staaten der Fall. Auf der anderen Seite zeigte sich in Belgien, Dänemark, Griechenland, Irland, Italien, der Slowakischen Republik, Spanien und Ungarn, dass sich bei höheren Abschlusszahlen für den Sekundarbereich II gleichzeitig die Zahl derjenigen mit höchstens einem Abschluss des Sekundarbereich I verringert (Tab. A3.4a und A3.4b).

\section{Geschlechtsspezifische Unterschiede bei den Abschlussquoten}

Das Verhältnis zwischen dem Bildungsstand von erwachsenen Männern und Frauen ist in den meisten OECD-Ländern unausgeglichen. In der Vergangenheit hatten Frauen nicht genügend Möglichkeiten und/oder Anreize, den gleichen Bildungsstand wie Männer zu erreichen. Frauen sind in der Regel überrepräsentiert in der Gruppe derjenigen, die gar nicht erst den Sekundarbereich II besuchten, und unterrepräsentiert bei den höheren Bildungsniveaus.

Allerdings sind diese Unterschiede hauptsächlich auf die großen geschlechtsspezifischen Unterschiede bei den älteren Altersgruppen zurückzuführen und haben sich in den jüngeren Altersgruppen beträchtlich reduziert oder sogar umgekehrt.
Bei den älteren Altersgruppen weisen Frauen einen niedrigeren Bildungsstand als Männer auf, ...

... doch bei den jüngeren Generationen kehrt sich dieses Verhältnis gegenwärtig um. 
Heute übersteigen in den meisten Ländern die Abschlussquoten von Frauen die der Männer.
Bei den Abschlussquoten von berufsvorbereitenden und berufsbildenden Bildungsgängen des Sekundarbereichs II lässt sich in den OECD-Ländern kein klarer Trend bei den geschlechtsspezifischen Unterschieden ausmachen.

In einigen Ländern erweitert ein beträchtlicher Anteil von Schülern nach einem ersten Abschluss im Sekundarbereich II sein Wissen durch einen Abschluss im postsekundaren, nicht-tertiären Bereich.

In Irland, der Schweiz und Ungarn schließen 20 Prozent und mehr der jeweils typischen Altersgruppe einen post-sekundaren, nicht tertiären Bildungsgang ab.
Heute zeigen sich in der Hälfte der Länder mit verfügbaren Daten keine signifikanten Unterschiede mehr bei den Abschlussquoten zwischen Frauen und Männern (Tab. A2.I). In I8 von I9 OECD-Ländern, für die nach Geschlecht aufgeschlüsselte Abschlussquoten des Sekundarbereich II verglichen werden können, übertreffen die Abschlussquoten für Frauen die der Männer. Eine Ausnahme ist hier die Schweiz, wo die Abschlussquoten für Frauen und Männer gleich sind. In Deutschland, Japan und der Tschechischen Republik findet sich ein relativ kleiner Abstand von fünf Prozentpunkten oder weniger, wohingegen er in Finnland, Griechenland, Irland, Island, Norwegen und Spanien II Prozentpunkte oder mehr beträgt.

In Io von 23 Ländern mit vergleichbaren Daten erwerben mehr Männer als Frauen einen Abschluss in berufsvorbereitenden und berufsbildenden Bildungsgängen des Sekundarbereich II. In acht Ländern erwerben mehr Frauen einen Abschluss in solchen Bildungsgängen, während in den fünf verbleibenden Ländern die Abschlussquoten von Männern und Frauen gleich sind.

\section{Abschlussquoten bei post-sekundaren, nicht-tertiären Bildungsgängen}

In 27 OECD-Ländern werden Bildungsgänge im post-sekundaren, nicht-tertiären Bereich angeboten; sie befinden sich aus vergleichender Sicht im Grenzbereich zwischen Sekundarbereich II und post-sekundarem Bereich, auch wenn sie im nationalen Zusammenhang eindeutig als zum Sekundarbereich II oder zum post-sekundaren Bereich gehörig angesehen werden können. Auch wenn der Inhalt dieser Bildungsgänge nicht wesentlich anspruchsvoller ist als der des Sekundarbereich II, können sie doch den Kenntnisstand derjenigen, die schon einen Abschluss im Sekundarbereich II erworben haben, erweitern. Die Teilnehmer der betreffenden Bildungsgänge sind in der Regel älter als im Sekundarbereich II.

Typische Beispiele für solche post-sekundaren, nicht tertiären Bildungsgänge sind die ,Trade and Vocational Certificates" in Kanada und den Vereinigten Staaten, die Kindergärtnerausbildung in Österreich und der Schweiz oder die Berufsausbildung von Absolventen des allgemeinbildenden Sekundarbereich II im dualen Berufsbildungssystem System in Deutschland. In den meisten Ländern sind diese post-sekundaren, nicht tertiären Bildungsgänge auf Berufsausbildung ausgerichtet.

In 5 von I6 OECD-Ländern, für die vergleichbare Daten vorliegen, erwerben II Prozent und mehr der Absolventen des Sekundarbereich II auch einen postsekundaren, nicht-tertiären Abschluss, entweder als Alternative oder zusätzlich zu einem Abschluss im Tertiärbereich (bei einem OECD-Durchschnitt von 9,0 Prozent). In Irland, der Schweiz und Ungarn schließen 20 Prozent und mehr der jeweils typischen Altersgruppe einen post-sekundaren, nicht tertiären Bildungsgang ab (Tab. A2.3).

In 12 der 20 OECD-Länder mit verfügbaren Daten sind die meisten, wenn nicht sogar alle, Abschlüsse im post-sekundaren, nicht-tertiären Bereich Abschlüsse in ISCED ${ }_{4} \mathrm{C}$-Bildungsgängen, die hauptsächlich der Vorbereitung auf den direkten Einstieg in den Arbeitsmarkt dienen sollen. Auch Lehrlingsausbil- 
dungen für Schüler, die bereits einen Abschluss im Sekundarbereich II erzielt haben, fallen in diese Kategorie. In den 8 übrigen Ländern mit vergleichbaren Daten kommt jedoch die Mehrheit der Abgänger im post-sekundaren, nichttertiären Bereich aus Bildungsgängen, die einen direkten Zugang zu Studiengängen im Tertiärbereich A oder B gewähren sollen.

\section{Definitionen und angewandte Methodik}

Als Absolventen des Sekundarbereich II gelten diejenigen Schulabgänger, die das letzte Jahr der Ausbildung im Sekundarbereich II erfolgreich abschließen und zwar unabhängig von ihrem Alter. In einigen Ländern gehört zum erfolgreichen Abschluss eine Abschlussprüfung, in anderen nicht.

Die Brutto-Abschlussquoten für die Bildungsgänge der ISCED-Kategorien $3 \mathrm{~A}$, ${ }_{3} \mathrm{~B}$ und ${ }_{3} \mathrm{C}$ können nicht einfach aufaddiert werden, da die Absolventen von mehr als einem dieser Bildungsgänge im Sekundarbereich II doppelt gezählt würden. Das gleiche gilt für Abschlussquoten nach Ausrichtung des Bildungsgangs, d. h. allgemeinbildend oder berufsbildend. Die Anzahl der Absolventen ohne Doppelzählungen wird ermittelt, indem man die Anzahl der Absolventen abzieht, die in einem vorherigen Jahr einen anderen Bildungsgang im Sekundarbereich II abgeschlossen haben.

Für einige Länder stehen keine Angaben zur Zahl der Absolventen post-sekundarer, nicht-tertiärer Bildungsgänge ohne Doppelzählung zur Verfügung und die Abschlussquoten könnten wegen der Absolventen, die mehrere Bildungsgänge im gleichen Bildungsbereich abschließen, etwas zu hoch angesetzt sein. In Tabelle A2.3 sind die betreffenden Länder gekennzeichnet.

Berufsvorbereitende und berufsbildende Bildungsgänge umfassen sowohl schulische als auch kombinierte schulische und betriebliche Ausbildungen, die als Bestandteil des Bildungssystems gelten. Ausschließlich in Betrieben durchgeführte Ausbildungen, die keiner formalen Aufsicht durch eine Bildungsbehörde unterstehen, bleiben unberücksichtigt.

Die Daten zu Bevölkerung und Bildungsstand stammen aus Datenbanken der OECD und EUROSTAT, die aus nationalen Arbeitskräfteerhebungen zusammengetragen sind. Angaben zu den länderspezifischen Datenquellen s. Anhang 3 unter www.oecd.org/eduleag 2004 .

Die Unterschiede im Bildungsstand basieren auf dem Prozentsatz der Bevölkerung im Alter von 25 bis 64 Jahren, der einen bestimmten Bildungsstand erreicht hat. Die Festlegung der einzelnen Bildungsbereiche erfolgt auf Grundlage der Internationalen Standardklassifikation des Bildungswesens (ISCED97). Zur Beschreibung der Bildungsbereiche laut ISCED-97 und der jeweiligen landesspezifischen Bildungsgänge s. Anhang 3 unter www.oecd.org/eduleag2 004.

Die Daten zum Bildungsstand stammen aus nationalen Arbeitskräfteerhebungen und beruhen auf der Internationalen Standardklassifikation

Die Daten beziehen sich auf das Schuljahr 2001-2002 und beruhen auf der alljährlich von der OECD aufgelegten UOEDatenerhebung zur Bildungsstatistik.

des Bildungswesens (ISCED-97). 
Tabelle A2.1

Abschlussquoten im Sekundarbereich II (2002)

Anteil der Absolventen des Sekundarbereich II an der Gesamtpopulation im typischen Abschlussalter an öffentlichen und privaten Bildungseinrichtungen (in \%), nach Ausrichtung und Ziel des Bildungsgangs und Geschlecht

\begin{tabular}{|c|c|c|c|c|c|c|c|c|c|c|c|c|c|c|c|}
\hline & \multicolumn{3}{|c|}{$\begin{array}{c}\text { Gesamt } \\
\text { (keine Doppelzählungen) }\end{array}$} & \multicolumn{2}{|c|}{$\begin{array}{c}\text { ISCED 3A } \\
\text { (Bildungsgänge } \\
\text { sollen direkten } \\
\text { Zugang zum } \\
\text { Tertiärbereich A } \\
\text { eröffnen) }\end{array}$} & \multicolumn{2}{|c|}{$\begin{array}{c}\text { ISCED 3B } \\
\text { (Bildungsgänge } \\
\text { sollen direkten } \\
\text { Zugang zum } \\
\text { Tertiärbereich B } \\
\text { eröffnen) }\end{array}$} & \multicolumn{2}{|c|}{$\begin{array}{c}\text { ISCED 3C (lang) } \\
\text { ähnlich lang } \\
\text { wie typische } \\
\text { 3A- oder 3B } \\
\text { Bildungsgänge }\end{array}$} & \multicolumn{2}{|c|}{$\begin{array}{l}\text { ISCED 3C (kurz) } \\
\text { ähnlich lang } \\
\text { wie typische } \\
\text { 3A- oder 3B } \\
\text { Bildungsgänge }\end{array}$} & \multicolumn{2}{|c|}{$\begin{array}{l}\text { Allgemein- } \\
\text { bildende } \\
\text { Ausbildungs- } \\
\text { gänge }\end{array}$} & \multicolumn{2}{|c|}{$\begin{array}{l}\text { Berufs- } \\
\text { vorbereitende/ } \\
\text { berufsbildende } \\
\text { Bildungsgänge }\end{array}$} \\
\hline & $\begin{array}{l}M+F \\
(1)\end{array}$ & $\begin{array}{c}\text { Männer } \\
\text { (2) }\end{array}$ & $\begin{array}{l}\text { Frauen } \\
\text { (3) }\end{array}$ & $\begin{array}{l}M+F \\
(4)\end{array}$ & $\begin{array}{c}\text { Frauen } \\
(5)\end{array}$ & $\begin{array}{l}M+F \\
(6)\end{array}$ & $\begin{array}{c}\text { Frauen } \\
\text { (7) }\end{array}$ & $\begin{array}{l}M+F \\
(8)\end{array}$ & $\begin{array}{c}\text { Frauen } \\
\text { (9) }\end{array}$ & $\begin{array}{l}M+F \\
(10)\end{array}$ & $\begin{array}{c}\text { Frauen } \\
\text { (11) }\end{array}$ & $\begin{array}{l}M+F \\
(12)\end{array}$ & $\begin{array}{c}\text { Frauen } \\
\text { (13) }\end{array}$ & $\begin{array}{l}M+F \\
(14)\end{array}$ & $\begin{array}{l}\text { Frauen } \\
(15)\end{array}$ \\
\hline \multicolumn{16}{|l|}{ OECD-Länder } \\
\hline Australien & $\mathrm{m}$ & $\mathrm{m}$ & $\mathrm{m}$ & 69 & 74 & $x(8)$ & $x(9)$ & 33 & 35 & $x(8)$ & $x(9)$ & 69 & 74 & 33 & 35 \\
\hline Österreich & $\mathrm{m}$ & $\mathrm{m}$ & $\mathrm{m}$ & $\mathrm{m}$ & $\mathrm{m}$ & $\mathrm{m}$ & $\mathrm{m}$ & $\mathrm{m}$ & $\mathrm{m}$ & $\mathrm{m}$ & $\mathrm{m}$ & $\mathrm{m}$ & $\mathrm{m}$ & $\mathrm{m}$ & $\mathrm{m}$ \\
\hline Belgien & 79 & 74 & 83 & 60 & 66 & $\mathrm{a}$ & $\mathrm{a}$ & 19 & 18 & 18 & 25 & 36 & 42 & 61 & 66 \\
\hline Kanada & $\mathrm{m}$ & $\mathrm{m}$ & $\mathrm{m}$ & $\mathrm{m}$ & $\mathrm{m}$ & $\mathrm{m}$ & $\mathrm{m}$ & $\mathrm{m}$ & $\mathrm{m}$ & $\mathrm{m}$ & $\mathrm{m}$ & $\mathrm{m}$ & $\mathrm{m}$ & $\mathrm{m}$ & $\mathrm{m}$ \\
\hline Tschechische Rep. & 81 & 80 & 83 & 50 & 58 & $\mathrm{n}$ & $n$ & 32 & 24 & $\mathrm{n}$ & $\mathrm{n}$ & 13 & 17 & 70 & 68 \\
\hline Dänemark ${ }^{1}$ & 100 & $\mathrm{~m}$ & $\mathrm{~m}$ & 56 & 67 & a & a & 66 & 73 & a & a & 56 & 67 & 66 & 73 \\
\hline Finnland $^{1}$ & 85 & 78 & 93 & 85 & 93 & a & a & a & $a$ & a & a & 51 & 62 & 69 & 78 \\
\hline Frankreich $^{1}$ & 82 & 79 & 86 & 51 & 59 & 10 & 9 & 3 & 2 & 36 & 31 & 32 & 38 & 67 & 63 \\
\hline Deutschland & 93 & 91 & 96 & 34 & 37 & 60 & 58 & a & a & a & a & 34 & 37 & 60 & 58 \\
\hline Griechenland & 85 & 74 & 97 & 53 & 61 & a & a & 32 & 36 & $x(8)$ & $x(9)$ & 53 & 61 & 34 & 38 \\
\hline Ungarn & 82 & 79 & 86 & 58 & 65 & $x(4)$ & $x(5)$ & 22 & 18 & $x(8)$ & $x(9)$ & 30 & 36 & 49 & 47 \\
\hline Island & 79 & 68 & 89 & 52 & 65 & $n$ & 1 & 32 & 24 & 20 & 22 & 54 & 67 & 49 & 44 \\
\hline Irland & 77 & 70 & 84 & 72 & 78 & a & a & 5 & 6 & a & a & 53 & 57 & 23 & 27 \\
\hline Italien ${ }^{1}$ & 82 & 79 & 85 & 72 & 76 & 4 & 5 & a & a & 19 & 17 & 30 & 40 & 64 & 58 \\
\hline Japan & 92 & 90 & 94 & 68 & 72 & 1 & $\mathrm{n}$. & 23 & 22 & $x(8)$ & $x(9)$ & 68 & 72 & 24 & 22 \\
\hline Korea & $\mathrm{m}$ & $\mathrm{m}$ & $\mathrm{m}$ & 64 & 64 & a & a & 34 & 35 & a & a & 64 & 64 & 34 & 35 \\
\hline Luxemburg & 68 & 64 & 73 & 39 & 48 & 8 & 8 & 20 & 17 & a & a & 27 & 32 & 42 & 42 \\
\hline Mexiko & $\mathrm{m}$ & $\mathrm{m}$ & $\mathrm{m}$ & 30 & 33 & a & a & 4 & 4 & $x(8)$ & $x(9)$ & 30 & 33 & 4 & 4 \\
\hline Niederlande & $\mathrm{m}$ & $\mathrm{m}$ & $\mathrm{m}$ & 63 & 69 & a & a & 19 & 21 & 20 & 17 & 32 & 36 & 61 & 62 \\
\hline Neuseeland & $\mathrm{m}$ & $\mathrm{m}$ & $\mathrm{m}$ & 60 & 65 & 25 & 29 & 43 & 55 & $x(8)$ & $x(9)$ & $\mathrm{m}$ & $\mathrm{m}$ & a & a \\
\hline Norwegen & 97 & 89 & 107 & 66 & 80 & a & a & 43 & 38 & $\mathrm{~m}$ & $\mathrm{~m}$ & 66 & 80 & 42 & 36 \\
\hline Polen & 90 & 86 & 93 & 76 & 84 & a & a & a & a & 23 & 16 & 38 & 48 & 63 & 52 \\
\hline Portugal & $\mathrm{m}$ & $\mathrm{m}$ & $\mathrm{m}$ & $\mathrm{m}$ & $\mathrm{m}$ & $\mathrm{m}$ & $\mathrm{m}$ & $\mathrm{m}$ & $\mathrm{m}$ & $\mathrm{m}$ & $\mathrm{m}$ & $\mathrm{m}$ & $\mathrm{m}$ & $\mathrm{m}$ & $\mathrm{m}$ \\
\hline Slowakische Rep. & 61 & 57 & 66 & 59 & 64 & a & a & 13 & 10 & 2 & 2 & 16 & 19 & 57 & 57 \\
\hline Spanien ${ }^{2}$ & 68 & 62 & 75 & 48 & 56 & $\mathrm{n}$ & $\mathrm{n}$ & 16 & 17 & 7 & 7 & 48 & 56 & 24 & 24 \\
\hline Schweden & 72 & 69 & 76 & 72 & 75 & $\mathrm{n}$ & $\mathrm{n}$ & $\mathrm{n}$ & $\mathrm{n}$ & a & a & 41 & 45 & 31 & 31 \\
\hline Schweiz & 90 & 90 & 90 & 28 & 30 & 50 & 43 & 14 & 20 & $\mathrm{~m}$ & $\mathrm{~m}$ & 32 & 36 & 61 & 57 \\
\hline Türkei & $\mathrm{m}$ & $\mathrm{m}$ & $\mathrm{m}$ & $\mathrm{m}$ & $\mathrm{m}$ & $\mathrm{m}$ & $\mathrm{m}$ & $\mathrm{m}$ & $\mathrm{m}$ & $\mathrm{m}$ & $\mathrm{m}$ & $\mathrm{m}$ & $\mathrm{m}$ & $\mathrm{m}$ & $\mathrm{m}$ \\
\hline Ver. Königreich & $\mathrm{m}$ & $\mathrm{m}$ & $\mathrm{m}$ & $\mathrm{m}$ & $\mathrm{m}$ & $\mathrm{m}$ & $\mathrm{m}$ & $\mathrm{m}$ & $\mathrm{m}$ & $\mathrm{m}$ & $\mathrm{m}$ & $\mathrm{m}$ & $\mathrm{m}$ & $\mathrm{m}$ & $\mathrm{m}$ \\
\hline Vereinigte Staaten & 73 & 69 & 76 & 73 & 76 & $\mathrm{~m}$ & $\mathrm{~m}$ & $\mathrm{~m}$ & $\mathrm{~m}$ & $\mathrm{~m}$ & $\mathrm{~m}$ & 73 & 76 & $\mathrm{~m}$ & $\mathrm{~m}$ \\
\hline Ländermittel & 81 & 75 & 87 & 61 & 68 & 5 & 6 & 19 & 19 & 8 & 7 & 43 & 49 & 44 & 44 \\
\hline \multicolumn{16}{|l|}{ OECD-Partnerländer } \\
\hline Argentinien ${ }^{1}$ & 41 & 38 & 44 & 41 & 44 & a & a & a & a & a & a & 22 & 25 & 19 & 19 \\
\hline Brasilien $^{1}$ & 62 & 54 & 69 & 51 & 56 & 10 & 12 & a & a & a & a & 51 & 56 & 10 & 12 \\
\hline Chile & 63 & 59 & 67 & 63 & 67 & a & a & a & a & a & a & 34 & 39 & 28 & 28 \\
\hline China & 31 & $\mathrm{~m}$ & 34 & $x(1)$ & $x(3)$ & a & a & $x(1)$ & $x(3)$ & a & a & 16 & 20 & $\mathrm{~m}$ & $\mathrm{~m}$ \\
\hline Indien & $\mathrm{m}$ & $\mathrm{m}$ & $\mathrm{m}$ & 19 & 17 & $\mathrm{~m}$ & $\mathrm{~m}$ & $\mathrm{~m}$ & $\mathrm{~m}$ & $\mathrm{~m}$ & $\mathrm{~m}$ & $\mathrm{~m}$ & $\mathrm{~m}$ & $\mathrm{~m}$ & $\mathrm{~m}$ \\
\hline Indonesien & 36 & 36 & 36 & 23 & 25 & 13 & 11 & a & a & a & a & $x(1)$ & $x(3)$ & $\mathrm{m}$ & $\mathrm{m}$ \\
\hline Israel & 90 & 87 & 92 & 87 & 91 & a & a & 3 & 1 & a & a & 60 & 66 & 30 & 26 \\
\hline Jamaika & 73 & 70 & 77 & $\mathrm{~m}$ & $\mathrm{~m}$ & $\mathrm{~m}$ & $\mathrm{~m}$ & $\mathrm{~m}$ & $\mathrm{~m}$ & $\mathrm{~m}$ & $\mathrm{~m}$ & $\mathrm{~m}$ & $\mathrm{~m}$ & $\mathrm{~m}$ & $\mathrm{~m}$ \\
\hline Jordanien & 65 & 58 & 73 & 62 & 72 & a & $\mathrm{a}$ & $\mathrm{a}$ & a & 3 & $\mathrm{n}$ & 50 & 61 & $a$ & a \\
\hline Paraguay ${ }^{1,3}$ & 40 & 36 & 43 & 40 & 43 & a & a & $\mathrm{m}$ & $\mathrm{m}$ & a & a & 31 & 35 & 8 & 8 \\
\hline Peru & 62 & $\mathrm{~m}$ & 64 & 63 & 64 & $x(4)$ & $x(5)$ & a & a & a & a & 63 & 64 & $\mathrm{~m}$ & $\mathrm{~m}$ \\
\hline Philippinen & 60 & 55 & 66 & 60 & 66 & a & a & a & a & a & a & 60 & 66 & $\mathrm{~m}$ & $\mathrm{~m}$ \\
\hline Russische Föd. & 73 & $\mathrm{~m}$ & $\mathrm{~m}$ & 54 & $\mathrm{~m}$ & 15 & $\mathrm{~m}$ & 4 & $\mathrm{~m}$ & a & a & 54 & $\mathrm{~m}$ & $\mathrm{~m}$ & $\mathrm{~m}$ \\
\hline Thailand & 53 & 51 & 56 & 34 & 40 & 19 & 16 & a & a & a & a & 34 & 39 & 19 & 16 \\
\hline Tunesien & 42 & 40 & 45 & 36 & 40 & 3 & 2 & 3 & 3 & a & a & 36 & 40 & $\mathrm{~m}$ & $\mathrm{~m}$ \\
\hline
\end{tabular}

Hinweise: $x$ bedeutet, dass die Daten in einer anderen Spalte enthalten sind, deren Referenz in runden Klammern nach dem , $x$ ' angegeben ist. So bedeutet $z$. B. $x(2)$, dass die Daten in Spalte 2 enthalten sind. Unterschiede im Erhebungsbereich der Bevölkerungsdaten und der Schüler-/Absolventendaten bedeuten, dass die Teilnahme-/Abschlussquoten von Ländern mit einem Nettoabgang von Schülern/Studierenden wohl zu niedrig angesetzt und von Ländern mit einem Nettozugang von Schülern/Studierenden wohl zu hoch angesetzt sind.

1. Referenzjahr 2001. 2. Signifikanter Anteil der Kohorte an Jugendlichen nicht enthalten. 3. Ohne ISCED 3C.

Quelle: OECD. Hinweise s. Anhang 3 unter www.oecd.org/edu/eag2004. 
Tabelle A2.2

Anteil der Bevölkerung mit mindestens einem Abschluss im Sekundarbereich $\|^{1}$ (in \%) (2002) Nach Altersgruppen

\begin{tabular}{|c|c|c|c|c|c|}
\hline \multirow[b]{2}{*}{ OECD-Länder } & \multicolumn{5}{|c|}{ Altersgruppe } \\
\hline & 25-64 Jahre & 25-34 Jahre & 35-44 Jahre & 45-54 Jahre & 55-64 Jahre \\
\hline Australien & 61 & 73 & 62 & 58 & 46 \\
\hline Österreich & 78 & 85 & 82 & 74 & 67 \\
\hline Belgien & 61 & 77 & 66 & 55 & 41 \\
\hline Kanada & 83 & 89 & 86 & 82 & 69 \\
\hline Tschechische Republik & 88 & 94 & 91 & 85 & 80 \\
\hline Dänemark & 80 & 85 & 81 & 80 & 72 \\
\hline Finnland & 75 & 88 & 85 & 71 & 52 \\
\hline Frankreich ${ }^{2}$ & 65 & 79 & 68 & 60 & 48 \\
\hline Deutschland & 83 & 85 & 86 & 84 & 77 \\
\hline Griechenland & 50 & 72 & 58 & 42 & 28 \\
\hline Ungarn & 71 & 82 & 79 & 73 & 48 \\
\hline Island & 59 & 64 & 62 & 58 & 48 \\
\hline Irland & 60 & 77 & 65 & 51 & 37 \\
\hline Italien & 44 & 60 & 50 & 39 & 24 \\
\hline Japan & 84 & 94 & 94 & 82 & 64 \\
\hline Korea & 71 & 95 & 79 & 51 & 31 \\
\hline Luxemburg & 57 & 64 & 59 & 53 & 46 \\
\hline Mexiko & 13 & 21 & 7 & 9 & 13 \\
\hline Niederlande & 66 & 76 & 71 & 62 & 53 \\
\hline Neuseeland & 76 & 82 & 80 & 76 & 62 \\
\hline Norwegen & 86 & 95 & 91 & 83 & 73 \\
\hline Polen & 47 & 53 & 48 & 46 & 37 \\
\hline Portugal & 20 & 35 & 20 & 14 & 8 \\
\hline Slowakische Republik & 86 & 93 & 91 & 84 & 68 \\
\hline Spanien & 41 & 58 & 46 & 31 & 18 \\
\hline Schweden & 82 & 91 & 87 & 79 & 67 \\
\hline Schweiz & 82 & 88 & 85 & 80 & 75 \\
\hline Türkei & 25 & 31 & 25 & 20 & 14 \\
\hline Vereinigtes Königreich ${ }^{2}$ & 64 & 70 & 65 & 62 & 56 \\
\hline Vereinigte Staaten & 87 & 87 & 88 & 89 & 84 \\
\hline Ländermittel & 65 & 75 & 69 & 61 & 50 \\
\hline OECD-Partnerländer & & & & & \\
\hline Argentinien $^{3}$ & 42 & 52 & 43 & 38 & 28 \\
\hline Brasilien $^{3}$ & 27 & 32 & 30 & 24 & 15 \\
\hline Chile & 47 & 61 & 49 & 42 & 28 \\
\hline Indonesien & 22 & 32 & 23 & 17 & 9 \\
\hline Israel & 80 & 87 & 80 & 78 & 71 \\
\hline Jordanien & 39 & $\mathrm{~m}$ & $\mathrm{~m}$ & $\mathrm{~m}$ & $\mathrm{~m}$ \\
\hline Malaysia $^{3}$ & 41 & 58 & 42 & 24 & 13 \\
\hline Paraguay ${ }^{3}$ & 22 & 30 & 23 & 16 & 11 \\
\hline Peru $^{3}$ & 44 & 55 & 46 & 35 & 22 \\
\hline Philippinen & 43 & 54 & 37 & $\mathrm{~m}$ & $\mathrm{~m}$ \\
\hline Thailand & 19 & 28 & 20 & 12 & 7 \\
\hline Uruguay $^{3}$ & 33 & 38 & 36 & 32 & 23 \\
\hline
\end{tabular}

1. Ohne ISCED 3C kurze Studiengänge. 2. Nicht alle ISCED 3 Studiengänge erfüllen die Mindestanforderungen für ISCED 3C lange Studiengänge. 3. Referenzjahr 2001. Quelle: OECD. Hinweise s. Anhang 3 unter www.oecd.org/edu/eag2004. 
Tabelle A2.3

Abschlussquoten im post-sekundaren, nicht-tertiären Bildungsbereich (2002)

2 Anteil der Absolventen des post-sekundaren, nicht-tertiären Bereichs an der Gesamtpopulation im typischen Abschlussalter an öffentlichen und privaten Bildungseinrichtungen (in \%), nach Ziel des Bildungsgangs und Geschlecht.

\begin{tabular}{|c|c|c|c|c|c|c|c|c|c|}
\hline \multirow[b]{2}{*}{ OECD-Länder } & \multicolumn{3}{|c|}{ Gesamt (ohne Doppelzählungen) } & \multicolumn{2}{|c|}{$\begin{array}{c}\text { ISCED } 4 \mathrm{~A} \\
\text { (Bildungsgänge sollen } \\
\text { direkten Zugang zum Tertiär- } \\
\text { bereich A eröffnen) }\end{array}$} & \multicolumn{2}{|c|}{$\begin{array}{c}\text { ISCED 4B } \\
\text { (Bildungsgänge sollen den } \\
\text { direkten Zugang zum Tertiär- } \\
\text { bereich B eröffnen) }\end{array}$} & \multicolumn{2}{|c|}{$\begin{array}{l}\text { ISCED } 4 \text { C } \\
\text { (Bildungsgänge sollen auf } \\
\text { den direkten Eintritt in den } \\
\text { Arbeitsmarkt vorbereiten) }\end{array}$} \\
\hline & $M+F$ & Männer & Frauen & $M+F$ & Frauen & $M+F$ & Frauen & $M+F$ & Frauen \\
\hline Australien & $\mathrm{m}$ & $\mathrm{m}$ & $\mathrm{m}$ & a & a & a & a & 17,8 & 19,7 \\
\hline Österreich & $\mathrm{m}$ & $\mathrm{m}$ & $\mathrm{m}$ & $\mathrm{m}$ & $\mathrm{m}$ & $\mathrm{m}$ & $\mathrm{m}$ & $\mathrm{m}$ & $\mathrm{m}$ \\
\hline Belgien $^{1}$ & 16,9 & 15,2 & 18,6 & 10,1 & 10,4 & a & a & 7,0 & 8,5 \\
\hline Canada & $\mathrm{m}$ & $\mathrm{m}$ & $\mathrm{m}$ & $\mathrm{m}$ & $\mathrm{m}$ & $\mathrm{m}$ & $\mathrm{m}$ & $\mathrm{m}$ & $\mathrm{m}$ \\
\hline Tschechische Rep. & $\mathrm{m}$ & $\mathrm{m}$ & $\mathrm{m}$ & 12,9 & 13,9 & a & a & 2,5 & 2,9 \\
\hline Dänemark 1,2 & 0,8 & 1,3 & 0,4 & 0,8 & 0,4 & a & a & a & a \\
\hline Finnland $^{2}$ & 2,2 & 2,0 & 2,3 & a & $a$ & a & a & 3,7 & 4,0 \\
\hline Frankreich 1,2 & 1,3 & 0,8 & 1,7 & 0,7 & 0,9 & $\mathrm{a}$ & a & 0,6 & 0,8 \\
\hline Deutschland & 14,1 & 15,3 & 12,9 & 8,6 & 8,0 & 5,5 & 4,9 & a & a \\
\hline Griechenland & $\mathrm{m}$ & $\mathrm{m}$ & $\mathrm{m}$ & $a$ & a & a & a & $\mathrm{m}$ & $\mathrm{m}$ \\
\hline Ungarn ${ }^{1}$ & 31,6 & 28,4 & 34,9 & 8,2 & 8,5 & a & a & 23,2 & 26,2 \\
\hline Island & 4,9 & 6,5 & 3,3 & $\mathrm{n}$ & $n$ & $\mathrm{n}$ & $\mathrm{n}$ & 5,1 & 3,3 \\
\hline Irland & 20,4 & 18,5 & 22,4 & a & a & a & a & 20,4 & 22,4 \\
\hline Italien ${ }^{2}$ & 4,4 & 3,4 & 5,4 & a & a & a & a & 4,4 & 5,4 \\
\hline Japan & $\mathrm{m}$ & $\mathrm{m}$ & $\mathrm{m}$ & $\mathrm{m}$ & $\mathrm{m}$ & $\mathrm{m}$ & $\mathrm{m}$ & $\mathrm{m}$ & $\mathrm{m}$ \\
\hline Korea & $a$ & a & a & $a$ & a & a & a & a & a \\
\hline Luxemburg & 4,1 & 5,5 & 2,6 & a & a & a & a & 4,1 & 2,6 \\
\hline Mexiko & a & a & a & $a$ & a & a & a & a & a \\
\hline Niederlande $^{1}$ & 1,3 & 2,0 & 0,7 & a & a & a & a & 1,3 & 0,7 \\
\hline Neuseeland & $\mathrm{m}$ & $\mathrm{m}$ & $\mathrm{m}$ & 1,9 & 2,3 & 7,7 & 9,6 & 18,8 & 22,9 \\
\hline Norwegen & 6,6 & 10,2 & 2,9 & 2,4 & 1,4 & a & a & 4,3 & 1,5 \\
\hline Polen $^{1}$ & 10,7 & 7,4 & 14,1 & a & a & a & a & 10,7 & 14,1 \\
\hline Portugal & $\mathrm{m}$ & $\mathrm{m}$ & $\mathrm{m}$ & $\mathrm{m}$ & $\mathrm{m}$ & $\mathrm{m}$ & $\mathrm{m}$ & $\mathrm{m}$ & $\mathrm{m}$ \\
\hline Slowakische Rep. & 4,6 & 5,2 & 4,1 & 4,6 & 4,1 & a & a & $\mathrm{n}$ & $\mathrm{n}$ \\
\hline Spanien & 3,8 & 3,6 & 4,0 & 3,8 & 4,0 & 0,1 & 0,1 & $\mathrm{n}$ & $\mathrm{n}$ \\
\hline Schweden & $\mathrm{m}$ & $\mathrm{m}$ & $\mathrm{m}$ & $\mathrm{m}$ & $\mathrm{m}$ & $\mathrm{m}$ & $\mathrm{m}$ & 0,4 & 0,3 \\
\hline Schweiz & 22,4 & 20,7 & 24,0 & 3,3 & 2,4 & 19,5 & 22,2 & $\mathrm{~m}$ & $\mathrm{~m}$ \\
\hline Türkei & a & a & a & a & a & a & a & a & a \\
\hline Ver. Königreich & $\mathrm{m}$ & $\mathrm{m}$ & $\mathrm{m}$ & $\mathrm{m}$ & $\mathrm{m}$ & $\mathrm{m}$ & $\mathrm{m}$ & $\mathrm{m}$ & $\mathrm{m}$ \\
\hline Vereinigte Staaten ${ }^{1}$ & $\mathrm{~m}$ & $\mathrm{~m}$ & $\mathrm{~m}$ & $\mathrm{~m}$ & $\mathrm{~m}$ & $\mathrm{~m}$ & $\mathrm{~m}$ & $\mathrm{~m}$ & $\mathrm{~m}$ \\
\hline Ländermittel & 9,0 & 9,1 & 8,9 & 5,2 & 5,1 & 8,2 & 9,2 & 7,6 & 8,3 \\
\hline
\end{tabular}

Hinweis: Unterschiede im Erhebungsbereich der Bevölkerungsdaten und der Schüler-/Absolventendaten bedeuten, dass die Teilnahme-/Abschlussquoten von Ländern mit einem Nettoabgang von Schülern/Studierenden wohl zu niedrig angesetzt und von Ländern mit einem Nettozugang von Schülern/Studierenden wohl zu hoch angesetzt sind.

1. Bruttoabschlussquote kann einige Doppelzählungen enthalten. 2. Referenzjahr 2001.

Quelle: OECD. Hinweise s. Anhang 3 unter www.oecd.org/edu/eag2004. 


\section{Aktuelle Abschluss- und Erfolgsquoten im Tertiärbereich und Bildungsstand der Erwachsenenbevölkerung}

Im Durchschnitt von 17 OECD-Ländern mit vergleichbaren Daten erzielen gegenwärtig 32 Prozent der Bevölkerung im typischen Abschlussalter einen Abschluss im Tertiärbereich A. Die Zahl reicht jedoch von weniger als 20 Prozent in Deutschland, Österreich, der Schweiz und der Tschechischen Republik bis zu mehr als 40 Prozent in Australien, Finnland, Island und Polen.

Gemessen am Bildungsstand hat der Anteil der Erwachsenenbevölkerung mit einer Ausbildung im Tertiärbereich entsprechenden Kenntnissen und Fähigkeiten zugenommen. Der größte Teil dieser Zunahme ist jedoch auf einen signifikanten Anstieg der tertiären Abschlussquoten in einer vergleichsweise geringen Zahl von Ländern zurückzuführen.

- Im Durchschnitt bricht ein Drittel der Studierenden in den OECD-Ländern das Studium vor einem ersten Abschluss ab, unabhängig davon, ob sie einen Studiengang im Tertiärbereich A oder B belegt haben.

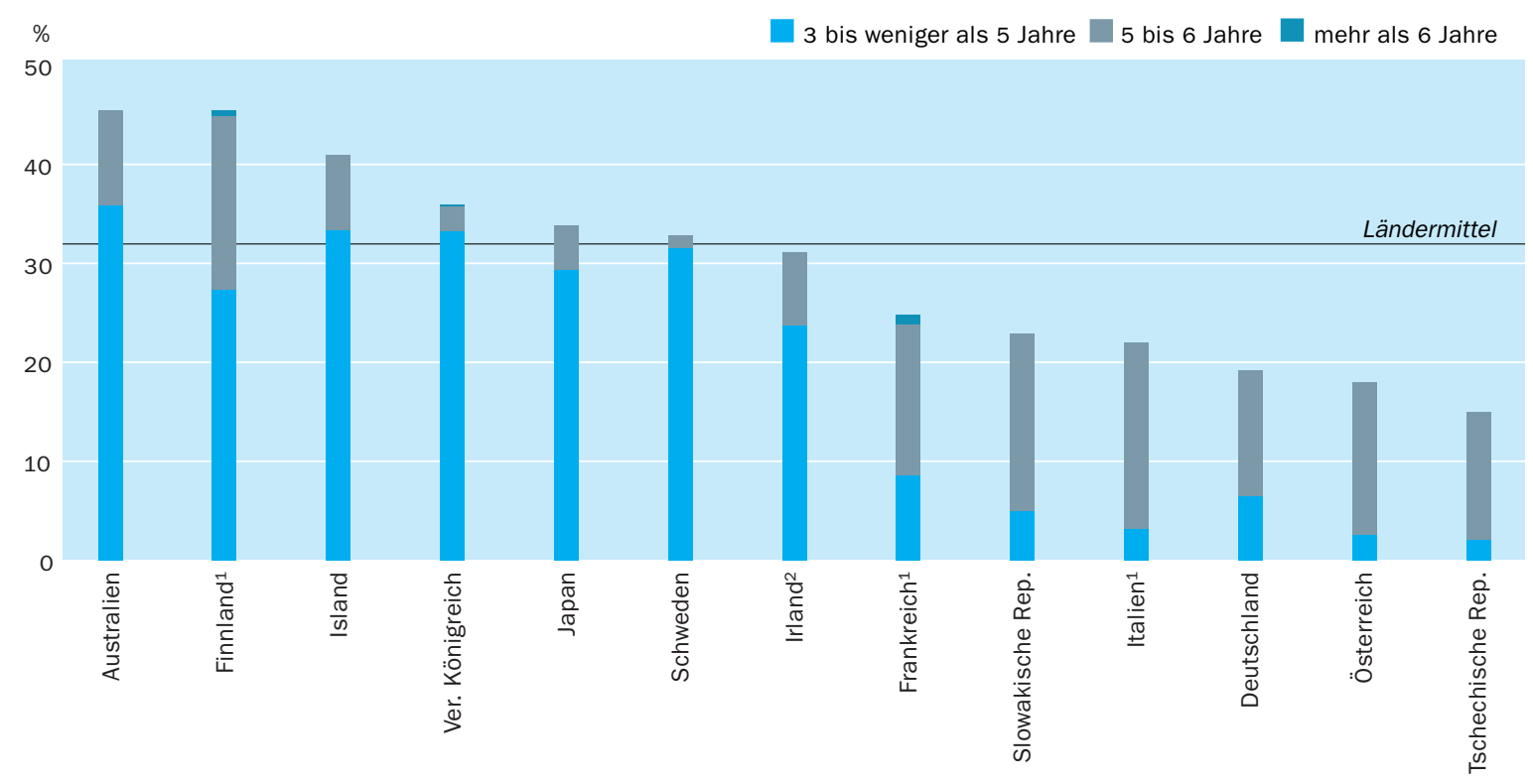

1. Referenzjahr 2001. 2. Studiengänge mit einer Dauer von 5 bis 6 Jahren beeinhalten auch länger als 6 Jahre dauernde Studiengänge. Anordnung der Länder in absteigender Reihenfolge der Gesamtabschlussquoten im Tertiärbereich A.

Quelle: OECD. Tabelle A3.1. Hinweise s. Anhang 3 unter www.oecd.org/edu/eag2004. 


\section{Politischer Hintergrund}

3 Dieser Indikator zeigt die gegenwärtigen Abschlussquoten im Tertiärbereich ebenso auf wie ihre historische Entwicklung ...

... und gibt Auskunft über die Effizienz von tertiären Bildungssystemen.
Aufbau und Umfang der Bildungsgänge im Tertiärbereich unterscheiden sich in den einzelnen Ländern erheblich.
Abschlussquoten im Tertiärbereich sind ein Indikator dafür, in welchem Umfang die Bildungssysteme der einzelnen Länder zum gegenwärtigen Zeitpunkt höhere Kenntnisse und Fähigkeiten vermitteln. Länder mit hohen Abschlussquoten im Tertiärbereich haben bzw. entwickeln derzeit aller Wahrscheinlichkeit nach eine hochqualifizierte Erwerbsbevölkerung. Kennzahlen zum Bildungsstand zeigen die Entwicklung des Wissensstandes in der Bevölkerung auf.

Sowohl Abschluss- als auch Abbruchquoten können hilfreiche Indikatoren für die Effizienz von tertiären Bildungssystemen sein. Es gibt jedoch viele Gründe, warum Studierende ihr Studium abbrechen: Sie stellen fest, dass sie das falsche Fachgebiet oder den falschen Studiengang gewählt haben, dass sie die von den Bildungseinrichtungen vorgegebenen Mindestleistungen nicht erreichen, was insbesondere bei tertiären Systemen mit einem breiten Zugang vorkommt, oder es bietet sich bereits vor Abschluss des Studiums eine attraktive Beschäftigung an. Ein Studienabbruch ist nicht unbedingt ein Anzeichen für ein persönliches Versagen des einzelnen Studierenden. Vielmehr können hohe Studienabbruchquoten darauf hinweisen, dass das Bildungssystem den Bedürfnissen seiner Nutzer nicht gerecht wird. Die Studierenden sind vielleicht der Meinung, dass die angebotenen Studiengänge ihren Erwartungen bzw. den Arbeitsmarktanforderungen nicht entsprechen. Und es kann sein, dass die Studiengänge aus Sicht der Studierenden länger dauern, als in ihren Augen Zeit außerhalb des Arbeitsmarktes zu rechtfertigen ist.

\section{Ergebnisse und Erläuterungen}

\section{Abschlussquoten im Tertiärbereich}

Die Abschlussquoten im Tertiärbereich werden sowohl von den Zugangsmöglichkeiten zu Studiengängen im Tertiärbereich als auch von der Nachfrage nach entsprechenden Kenntnissen und Fähigkeiten auf dem Arbeitsmarkt beeinflusst. Die Abschluss- und Qualifikationsstrukturen in den einzelnen Ländern wirken sich ebenfalls aus.

Der Indikator unterscheidet zwischen verschiedenen Kategorien von Abschlüssen: I. Abschlüsse im Tertiärbereich B (ISCED ${ }_{5} B$ ), 2. Abschlüsse im Tertiärbereich $\mathrm{A}$ (ISCED $5 \mathrm{~A}$ ) und 3 . Abschlüsse in weiterführenden Forschungsprogrammen auf dem Niveau der Promotion (ISCED 6).

Studiengänge im Tertiärbereich A sind weitgehend theoretisch orientiert und sollen hinreichende Qualifikationen für den Zugang zu weiterführenden Forschungsprogrammen und Berufen mit hohen Qualifikationsanforderungen vermitteln. Der Aufbau der Studiengänge im Tertiärbereich A ist von Land zu Land unterschiedlich. Der institutionelle Rahmen kann sowohl durch Universitäten als auch durch andere Bildungseinrichtungen gegeben sein. Die Dauer von Studiengängen im Tertiärbereich A, die zu einem Erstabschluss führen, variiert zwischen drei Jahren (z. B. der Bachelor-Abschluss in sehr vielen Studienbereichen an den meisten Colleges in Irland und dem Vereinigten Königreich 
sowie die Licence in Frankreich), bis zu fünf Jahren und länger (z. B. das Diplom in Deutschland und die Laurea in Italien).

Während in vielen Ländern klar zwischen erstem und zweitem akademischem Abschluss, d. h. zwischen Undergraduate- und Graduate-Studiengängen unterschieden wird, gibt es diese Unterscheidung in denjenigen Ländern nicht, in denen man einen akademischen Grad, der international mit dem Niveau eines Master-Abschlusses vergleichbar ist, am Ende eines einzigen, langen Studiengangs erwirbt. Um die internationale Vergleichbarkeit zu gewährleisten, müssen deshalb zu akademischen Abschlüssen führende Studiengänge mit ähnlicher Gesamtdauer sowie die Abschlussquoten der zum ersten akademischen Abschluss führenden Studiengänge verglichen werden.

Abschlüsse im Tertiärbereich Typ A werden gemäß der theoretischen Gesamtdauer tertiärer Studiengänge untergliedert, um einen von den unterschiedlichen nationalen Abschlussstrukturen unabhängigen Vergleich zu ermöglichen. Zu diesem Zweck wird in der OECD-Klassifizierung unterschieden zwischen Abschlüssen von Studiengängen mittlerer ( 3 bis weniger als 5 Jahre), langer ( 5 bis weniger als 6 Jahre) und sehr langer Studiendauer (6 Jahre und länger). Abschlüsse, die nach kurzen Studiengängen mit einer Dauer von weniger als 3 Jahren erworben werden, gelten hier als nicht gleichwertig mit einem Abschluss des Tertiärbereich A und werden somit bei diesem Indikator nicht berücksichtigt. Zu einem zweiten Abschluss führende Studiengänge werden nach der kumulierten Dauer der zum ersten und zum zweitem Abschluss führenden Studiengänge klassifiziert, wobei Absolventen, die bereits über einen Erstabschluss verfügen, hiervon abgezogen werden.

Im Durchschnitt der 17 OECD-Länder mit vergleichbaren Daten erzielen gegenwärtig 32 Prozent der Bevölkerung im typischen Abschlussalter einen Abschluss im Tertiärbereich A. Die Zahl reicht von weniger als 20 Prozent in Deutschland, Österreich, der Schweiz und der Tschechischen Republik bis zu mehr als 40 Prozent in Australien, Finnland, Island und Polen (Tab. A3.I). Allgemein absolvieren in den Ländern mit höheren Abschlussquoten die Studierenden überwiegend Bildungsgänge mittlerer Dauer ( 3 bis weniger als 5 Jahre) (Abb. A3.I). In Deutschland, Frankreich, Italien, Österreich, der Slowakischen sowie der Tschechischen Republik wird die Mehrheit der Abschlüsse in den längeren Studiengängen (mit einer Studiendauer von mindestens 5 Jahren) erzielt. Die Abschlussquoten liegen bei 23 Prozent und darunter.

Vom Niveau der erworbenen Kompetenzen her werden Studiengänge im Tertiärbereich B genauso wie Studiengänge im Tertiärbereich A eingeordnet, sie sind jedoch stärker berufsorientiert und führen zum direkten Eintritt in den Arbeitsmarkt. Üblicherweise sind diese Studiengänge kürzer als die des Tertiärbereich A (in der Regel 2 bis 3 Jahre), und im Allgemeinen gelten sie nicht als auf einen akademischen Abschluss hinführend. Die Abschlussquoten für Bildungsgänge im Tertiärbereich B betragen im Durchschnitt der OECDLänder ıo Prozent der jeweiligen Altersgruppe (Tab. A3.I). In Japan machen 27 Prozent der Personen im typischen Abschlussalter einen Abschluss in einem Studiengang des Tertiärbereich B. In Frankreich und der Schweiz sind es ig Prozent.

Studiengänge im Tertiärbereich A werden nach ihrer theoretischen Gesamtdauer unterteilt, um sie unabhängig von unterschiedlichen nationalen Abschlussstrukturen vergleichen zu können.

Im Durchschnitt der OECDLänder erwerben 32 Prozent der Personen im typischen Abschlussalter einen Abschluss in einem Studiengang des Tertiärbereich A, ...

... während die Abschlussquote im Tertiärbereich B bei 10 Prozent liegt ... 


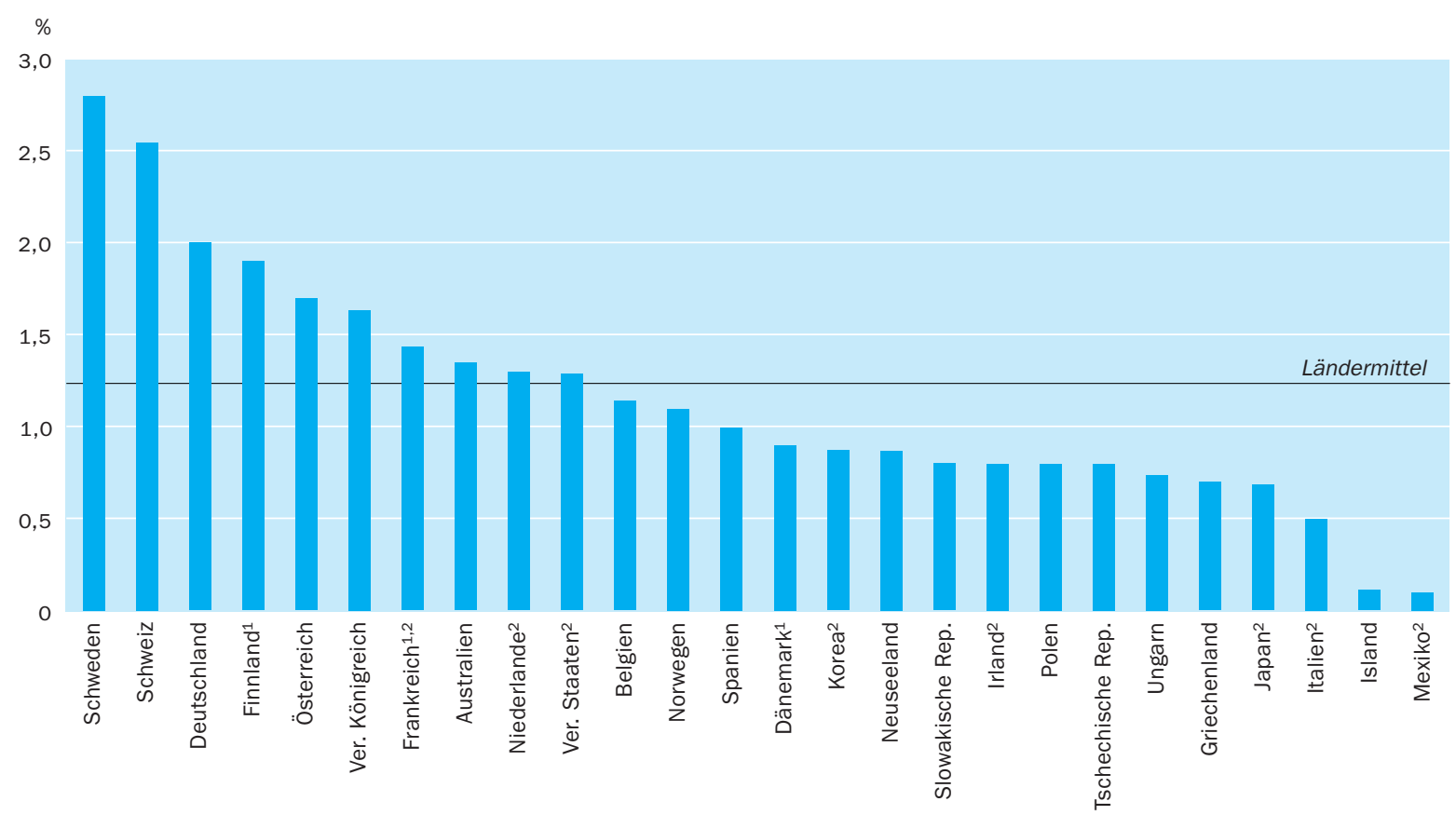

1. Referenzjahr 2001. 2. Für diese Länder wurden Bruttoabschlussquoten angesetzt, die sich als Anteil der Absolventen an der Bevölkerung im typischen Abschlussalter in Prozent berechnen.

Anordnung der Länder in absteigender Reihenfolge der Abschlussquoten für weiterführende Forschungsprogramme.

Quelle: OECD. Tabelle A3.1. Hinweise s. Anhang 3 unter www.oecd.org/edu/eag2004.

... und 1,2 Prozent der

Bevölkerung einen Abschluss

in einem weiterführenden

Forschungsprogramm

erwerben.

Ein Drittel der Studierenden in den OECD-Ländern bricht das Studium vor einem ersten Abschluss ab.
Im Durchschnitt erwerben in den OECD-Ländern I,2 Prozent der Bevölkerung einen Abschluss in einem weiterführenden Forschungsprogramm wie den Doktortitel. Die Zahl variiert zwischen o, I Prozent in Island und Mexiko und 2,0 Prozent in Deutschland, 2,6 Prozent in der Schweiz und 2,8 Prozent in Schweden (Abb. A3.2).

\section{Erfolgsquoten im Tertiärbereich}

Im Durchschnitt bricht ein Drittel der Studierenden in den OECD-Ländern das Studium vor einem ersten Abschluss ab, unabhängig davon, ob sie einen Studiengang im Tertiärbereich A oder B belegt haben. Die Abbruchquote ist bei den weiterführenden Forschungsprogrammen wesentlich höher, hier liegt die Erfolgsquote bei unter 6o Prozent.

Die Erfolgsquoten im Tertiärbereich A unterscheiden sich deutlich zwischen den einzelnen OECD-Ländern und liegen zwischen weniger als 6o Prozent in Frankreich, Italien, Österreich und Schweden und über 8o Prozent in Irland, Japan, der Türkei und dem Vereinigten Königreich (Tab. A3.2).

Die Erfolgsquoten im Tertiärbereich B liegen zwischen mehr als 8o Prozent in Belgien (fläm.), Dänemark, Japan, Mexiko, Polen und Schweden und ungefähr 50 Prozent in Irland und Italien (Tab. A3.2). Im Allgemeinen sind die Studiengänge im Tertiärbereich B von kürzerer Dauer als im Tertiärbereich A. In der 


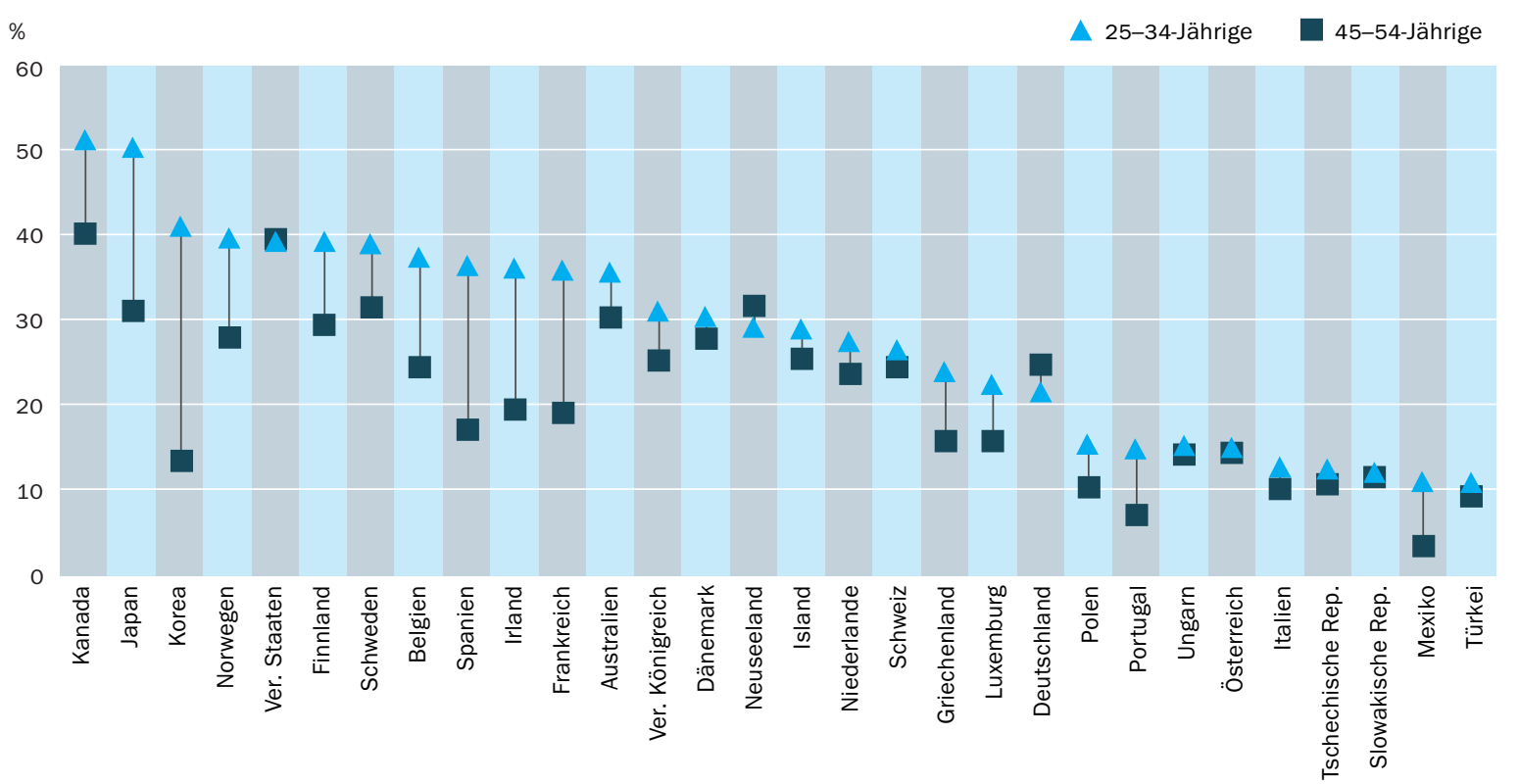

Anordnung der Länder in absteigender Reihenfolge des Prozentsatzes von 25- bis 34-Jährigen mit einem Abschluss im Tertiärbereich.

Quelle: OECD. Tabelle A3.з. Hinweise s. Anhang 3 unter www.oecd.org/edu/eag2004.

Mehrheit der Länder, für die Daten verfügbar sind, erwerben die meisten Studierenden einen Abschluss in einem kurzen Studiengang (2 bis 3 Jahre). Interessanterweise absolvieren jedoch sowohl in Dänemark als auch in Belgien (fläm.) die meisten der Studierenden im Tertiärbereich B Studiengänge mittlerer Dauer (im flämischen Teil Belgiens die einzige Möglichkeit eines Studiengangs im Tertiärbereich B).

In Italien, Japan und Korea liegen die Erfolgsquoten für Studierende in weiterführenden Forschungsprogrammen bei 85 Prozent und darüber. Umgekehrt ist die Abbruchwahrscheinlichkeit für diese Studiengänge in Frankreich und Island beträchtlich höher (mit einer Erfolgsquote von 36 bzw. 50 Prozent) (Tab. A3.2).

Die gestiegenen Anforderungen des Arbeitsmarktes, die Zunahme der Arbeitslosigkeit in den letzten Jahren und die höheren Erwartungen des Einzelnen und der Gesellschaft haben den Anteil junger Menschen, die mindestens einen Abschluss im Tertiärbereich erwerben, verändert. Gemessen an der Zahl tertiärer Abschlüsse hat die Zahl der Erwachsenen mit hochentwickelten Kenntnissen und Fähigkeiten im Allgemeinen zugenommen.

In 12 der 30 OECD-Länder beträgt der Anteil der 24- bis 36-Jährigen mit einem Abschluss im Tertiärbereich über 36 Prozent. Eine solche Verbesserung ist das Ergebnis erheblicher Bemühungen im Verlauf der letzten zwanzig Jahre, was sich annäherungsweise im Unterschied zwischen den einzelnen Generationen widerspiegelt. Für die führenden Länder beträgt der Abstand zwischen den
Bei den weiterführenden Forschungsprogrammen weisen Italien, Japan und Korea hohe Erfolgsquoten auf.

Der Anteil junger Menschen mit einem Abschluss, der einem Abschluss des Tertiärbereich A oder einem weiterführenden Forschungsprogramm gleichwertig ist, hat zugenommen. 
älteren und jüngeren Lernenden ungefähr I3 Prozentpunkte. Nur in drei Ländern gab es in den letzten Jahrzehnten kaum Veränderungen, und dies auf einem recht hohen Niveau - in Australien, Schweden und den Vereinigten Staaten. Die durchschnittlichen Abschlusszahlen für den Tertiärbereich insgesamt sind in den OECD-Ländern von 2r auf 28 Prozent gestiegen, wenn man die 50- mit den 30-Jährigen vergleicht.

Das Augenmerk gilt nach wie vor den am schlechtesten abschneidenden Ländern, in denen von einer Generation zur nächsten kein Fortschritt erzielt wurde (wobei sich hier ein vollständig anderes Muster als bei den Abschlüssen im Sekundarbereich zeigt, s. Indikator A2). Mit den bemerkenswerten Ausnahmen Griechenland, Mexiko und Portugal haben die anderen Länder so gut wie keine Fortschritte erzielt (Abb. A3.3).

\section{Entwicklung der Abschlüsse im Tertiärbereich}

Betrachtet man die Entwicklung der Abschlüsse im Tertiärbereich (Tab. A3.4a) im Verlauf der letzten zehn Jahre, bestätigt sich ein deutlicher Trend hin zu einem Anstieg im Anteil der Erwachsenenbevölkerung mit einen Abschluss im Tertiärbereich.

Eine zunehmende Bildungsbeteiligung im Tertiärbereich hat die Unterschiede zwischen den Ländern verringert ...
Diese zunehmende Bildungsbeteiligung im tertiären Bildungsbereich hat zu einer Verringerung der Unterschiede zwischen den Ländern geführt. Für das Jahr 2002 bilden bei der Altersgruppe der 25- bis 64-Jährigen I6 von

\section{Abbildung A3.4}

Entwicklung des Anteils der Bevölkerung mit einem Abschluss im Tertiärbereich (1991-2002)

Prozentsatz der 25- bis 64-Jährigen

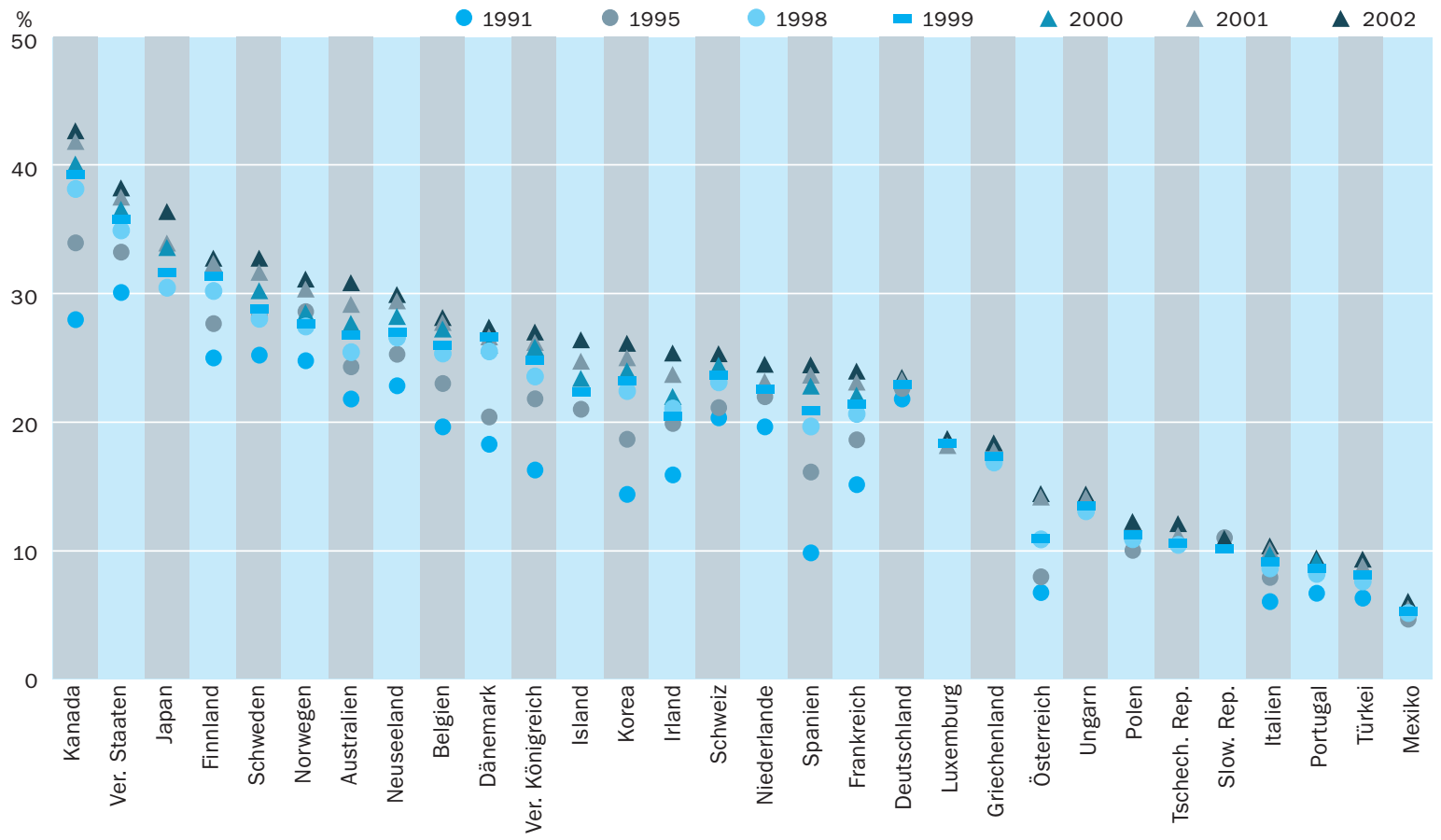

Anordnung der Länder in absteigender Reihenfolge des Anteils der Bevölkerung mit einem Abschluss im Tertiärbereich in 2002.

Quelle: OECD. Tabelle A3.4c. Hinweise s. Anhang 3 unter www.oecd.org/edu/eag2004. 
30 Ländern eine Gruppe mit recht geringen Unterschieden, zwischen 23 und 33 Prozent ihrer Bevölkerung verfügen über einen Abschluss im Tertiärbereich. Drei dieser Länder weisen beachtlich hohe Werte auf: Japan, Kanada und die Vereinigten Staaten. Im Gegensatz dazu liegen II Länder bei den Abschlussquoten im Tertiärbereich deutlich unter 20 Prozent, teilweise sogar wesentlich darunter.

Diese allgemeine Entwicklung ist das Ergebnis ständiger Verbesserungen in den meisten Ländern. Allerdings steigt in den drei am weitesten fortgeschrittenen Ländern der Anteil der Erwachsenenbevölkerung mit einem Abschluss im Tertiärbereich auch weiterhin an. Die anderen OECD-Länder, vor allem Korea und Spanien, verfügen inzwischen auch über einen größeren Anteil von hochqualifizierten Personen in ihrer Bevölkerung, so dass sich die Zahlen jetzt auf einem vergleichbaren Niveau mit dem der führenden Länder bewegen. Abgesehen von geringen Verbesserungen in Österreich und in Italien lässt sich eine solche Verbesserung im unteren Bereich der Verteilungsskala nicht wahrnehmen. Der Anteil von Absolventen des Tertiärbereich bleibt in Portugal und der Türkei weiterhin relativ niedrig, dort ist es im Laufe der letzten zehn Jahre anscheinend nur in begrenztem Ausmaß zu Verbesserungen gekommen.

... aber einige Länder haben nicht in gleichem Ausmaß an dieser Entwicklung teilgenommen.

\section{Abbildung A3.5}

Entwicklung des Anteils der Bevölkerung mit einem Abschluss im Tertiärbereich A und in einem weiterführenden Forschungsprogramm (1998-2002)

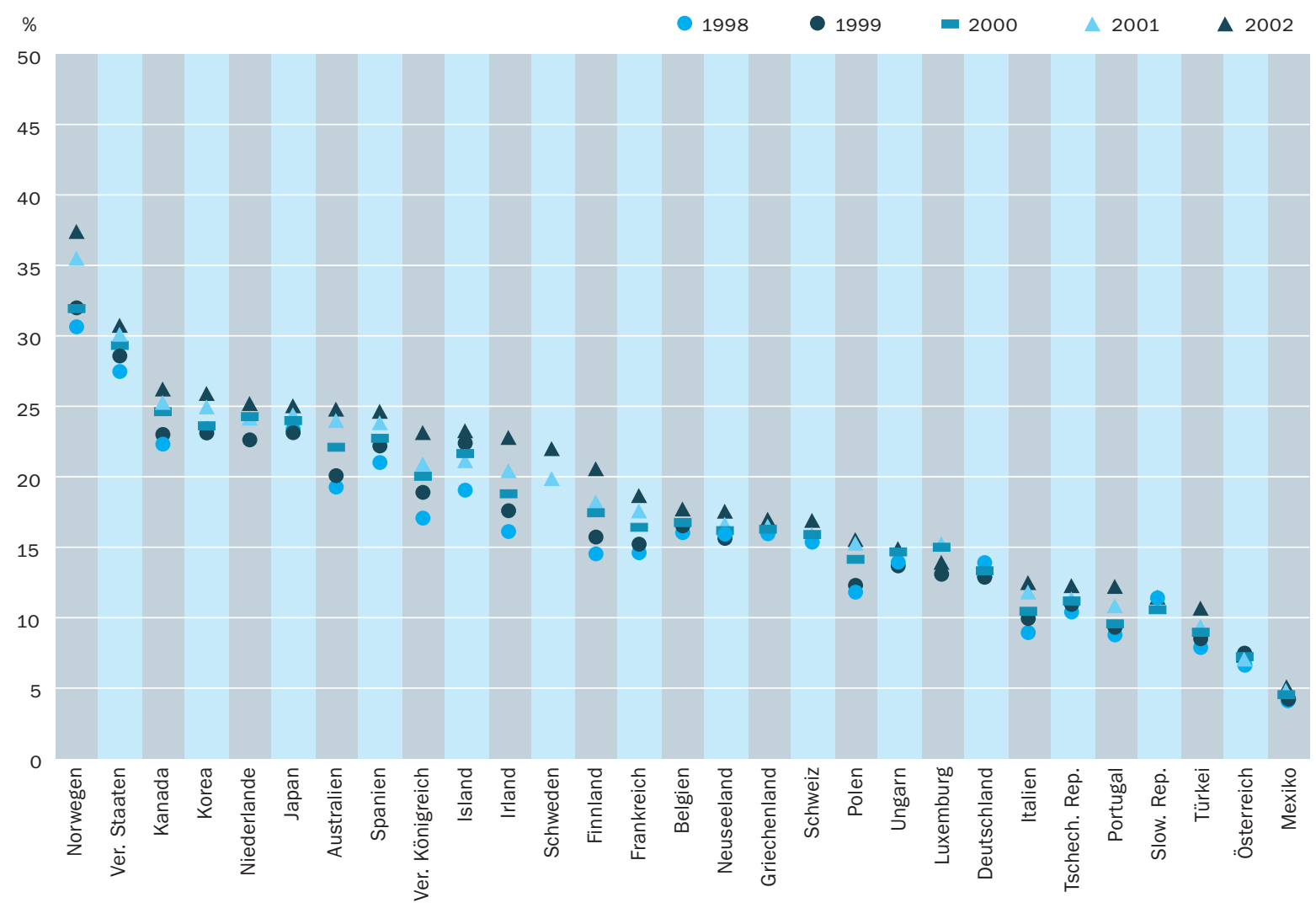

Anordnung der Länder in absteigender Reihenfolge des Anteils der Bevölkerung mit einem Abschluss im Tertiärbereich A und in einem weiterführenden Forschungsprogramm in 2002

Quelle: OECD. Tabelle A3.4c. Hinweise s. Anhang 3 unter www.oecd.org/edu/eag2004. 
Konzentriert man sich vor allem auf die jüngste Altersgruppe in diesem Vergleich, die der 25- bis 34-Jährigen (Tab. A3.4a und A3.4b), zeigt sich, dass der Zuwachs bei den Abschlüssen im Tertiärbereich zwischen I99I und 2002, der sich bei der Gesamtbevölkerung von I 8 auf 23 Prozent belief, bei der jüngsten Altersgruppe eine Steigerung von 20 auf 28 Prozent ausmachte. Eine solche Verbesserung spiegelt natürlich wider, dass die ältesten Generationen durch besser qualifizierte jüngere Generationen ,ersetzt' werden. Von diesen 28 Prozent der jungen Generation mit einem Abschluss im Tertiärbereich erwarben Ig Prozent einen Abschluss im Tertiärbereich A oder sogar in einem weiterfüh-

\section{Abbildung A3.6}

Veränderungen der geschlechtsspezifischen Unterschiede bei Abschlüssen im Tertiärbereich $A$ und in einem weiterführenden Forschungsprogramm (1998-2002)

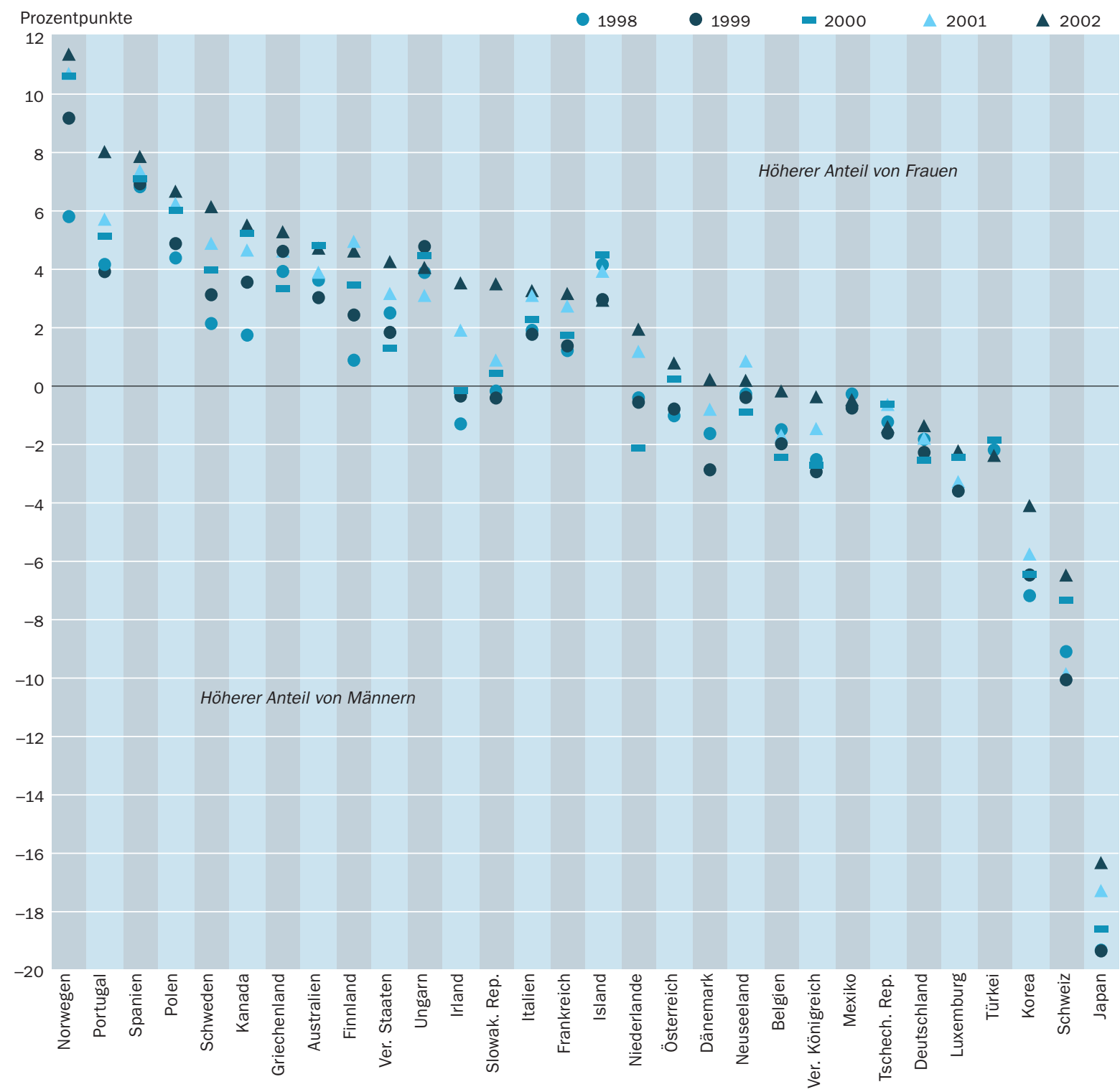

Anordnung der Länder in absteigender Reihenfolge des Unterschieds zwischen dem Anteil von Männern und Frauen mit einem Abschluss des Tertiärbereichs A und in einem weiterführenden Forschungsprogramm in 2002.

Quelle: OECD. Tabelle A3.4c. Hinweise s. Anhang 3 unter www.oecd.org/edu/eag2004. 
renden Forschungsprogramm. Oberhalb des Durchschnittwertes von ig Prozent unterscheiden sich die OECD-Länder nicht sehr. Außer Norwegen und den Vereinigten Staaten, die bei über 30 Prozent liegen, weisen alle Länder Werte zwischen 2I und 26 Prozent auf, eine Spanne von 5 Prozentpunkten. Auch hier sind die Werte oberhalb des Durchschnitts wesentlich weiter gestreut, was besonders darauf zurückzuführen ist, dass einige Länder Studiengänge im Tertiärbereich B bei der Berechnung mit einbeziehen.

Die Aufwärtsentwicklung ist zwischen 1998 und 2002 besonders in Finnland, Irland, Norwegen, Österreich und dem Vereinigten Königreich von Bedeutung, die allesamt bereits eine Position in der oberen Hälfte der Verteilungsskala innehaben. Auch Frankreich, Island und Kanada erlebten während der letzten vier Jahre einen Anstieg von durchschnittlich mehr als einem Prozentpunkt pro Jahr. Auf der anderen Seite der Durchschnittswerte gab es die Stagnation in Deutschland, Österreich, der Schweiz und den osteuropäischen Ländern. Mit Ausnahme von Polen und Italien kommt es in den Ländern, die sich nach wie vor auf einem niedrigen Niveau bewegen, nicht zu den notwendigen Verbesserungen.

Eine höhere Beteiligung und höhere Abschlussquoten für Frauen selbst bei tertiären Studiengängen auf dem Niveau von ISCED $5 \mathrm{~A} / 6$ spielen eine wichtige Rolle bei der Verbesserung des Qualifikationspotentials der Bevölkerung. 2002 war in zwei Dritteln der Länder der Anteil junger Frauen, die einen Abschluss im Tertiärbereich A erwarben, höher als der der Männer. Im Durchschnitt beträgt der Abstand zwischen jungen Männern und Frauen etwa 4 Prozentpunkte zugunsten der Frauen. Bei den übrigen Ländern ist dieser Unterschied weniger stark ausgeprägt, etwas über einen Prozentpunkt im Durchschnitt. Allerdings ist zu berücksichtigen, dass in Korea, Japan und der Schweiz der Abstand zwischen Frauen und Männern auch im Tertiärbereich B von Bedeutung ist.

Eine Betrachtung der Trenddaten ergibt, dass der Abstand selbst in den drei Ländern, in denen er sehr groß ist, geringer wird. Gleichzeitig geht der Trend in denjenigen Ländern, in denen es bereits deutliche Vorteile für die Frauen gab, weiter in Richtung eines noch größeren Abstands zugunsten der Frauen.

\section{Definitionen und angewandte Methodik}

Als Absolventen im Tertiärbereich gelten alle Personen, die in einem bestimmten Referenzjahr einen Abschluss im Tertiärbereich erworben haben. Der Indikator unterscheidet zwischen verschiedenen Kategorien von Abschlüssen: I. Abschluss im Tertiärbereich B (ISCED 5 B), 2. Abschluss im Tertiärbereich A (ISCED $5 \mathrm{~A}$ ) und 3 . Abschluss in einem weiterführenden Forschungsprogramm auf dem Niveau der Promotion (ISCED 6). Für einige Länder sind für die einzelnen Kategorien keine entsprechend gegliederten Daten verfügbar. In diesen Fällen wurden die Absolventen von der OECD der passendsten Kategorie zugeordnet. Im Anhang 3 unter www.oecd.orgleduleag 2004 findet sich eine Aufstellung der in den einzelnen Ländern berücksichtigten Studiengänge im Tertiärbereich $\mathrm{A}$ und $\mathrm{B}$.

Die Daten beziehen sich auf das Schuljahr 2001/2002 und beruhen auf der alljährlich von der OECD durchgeführten UOE-Datenerhebung zur Bildungsstatistik. 
Abschlüsse im Tertiärbereich A wurden außerdem gemäß der theoretischen Gesamtstudiendauer im Bereich ISCED 5 A untergliedert, um Vergleiche unabhängig von der jeweils landespezifischen Abschlussstruktur zu ermöglichen.

Die Abschlussquoten für Studiengänge, die zu einem Erstabschluss führen (Tertiärbereich A und B), werden als Brutto-Abschlussquoten berechnet. Zur Berechnung der Brutto-Abschlussquoten gab jedes Land das typische Abschlussalter an (s. Anhang I). Die Absolventen können jedoch jeden Alters sein. Die Zahl der Absolventen wurde dann durch die Bevölkerung im üblichen Abschlussalter geteilt. In vielen Ländern ist es jedoch schwierig, ein typisches Abschlussalter anzugeben, weil die Altersverteilung der Absolventen sehr weit gestreut ist.

Eine Nettoabschlussquote wird für Studiengänge, die zu einem Zweit- oder weiteren Abschluss führen, als Summe der altersspezifischen Abschlussquoten ermittelt (hier stellt die Doppelzählung von Abschlüssen kein Problem dar). Die Netto-Abschlussquoten können interpretiert werden als prozentualer Anteil einer fiktiven Altersgruppe, der einen Abschluss im Tertiärbereich erwirbt. Sie sind damit unbeeinflusst von Änderungen der Größe der entsprechenden Bevölkerungsgruppe oder des typischen Abschlussalters. Für diejenigen Länder, die keine genauer aufgegliederten Daten bereitstellen konnten, werden die Brutto-Abschlussquoten dargestellt.

Erfolgsquoten im Tertiärbereich werden definiert als Prozentsatz derjenigen Studienanfänger im jeweiligen Bildungsbereich, die diesen erfolgreich mit einem ersten Abschluss beenden. Studienabbrecher werden dementsprechend definiert als Studierende, die den jeweiligen Bildungsbereich ohne einen ersten Abschluss verlassen. Als erster Abschluss im Tertiärbereich gilt unabhängig von der Studiendauer jeder Abschluss, der am Ende eines Studiengangs erworben wird, der nicht einen vorherigen erfolgreichen Abschluss im gleichen Bildungsbereich voraussetzt. Die Erfolgsquote wird berechnet als das Verhältnis der Anzahl Studierender, die einen ersten Abschluss erwerben, zur Anzahl Studienanfänger im entsprechenden Bildungsbereich vor $\mathrm{n}$ Jahren, wobei $\mathrm{n}$ der Anzahl an Jahren entspricht, die zum Erwerb des Abschlusses in einem Vollzeitstudium erforderlich ist.

Die Daten zum Bildungsstand stammen aus nationalen Arbeitskräfteerhebungen und beruhen auf der Internationalen Standardklassifikation des Bildungswesens (ISCED-97).
Die Daten zu Bevölkerung und Bildungsstand stammen aus Datenbanken der OECD und EUROSTAT, die aus nationalen Arbeitskräfteerhebungen zusammengetragen sind. Angaben zu den länderspezifischen Datenquellen s. Anhang 3 unter www.oecd.org/edu/eag 2004.

Die Unterschiede im Bildungsstand basieren auf dem Prozentsatz der Bevölkerung im Alter von 25 bis 64 Jahren, der einen bestimmten Bildungsstand erreicht hat. Die Festlegung der einzelnen Bildungsbereiche erfolgt auf Grundlage der Internationalen Standardklassifikation des Bildungswesens (ISCED97). Zur Beschreibung der Bildungsbereiche laut ISCED-97 und der entsprechenden Zuordnung der landesspezifischen Bildungsgänge s. Anhang 3 unter www.oecd.org/eduleag2004. 
Tabelle A3.1

Abschlussquoten im Tertiärbereich (2002)

Anteil der Absolventen des Tertiärbereichs an der Bevölkerung im typischen Abschlussalter (in \%), nach Ausrichtung und Ziel des Studiengang

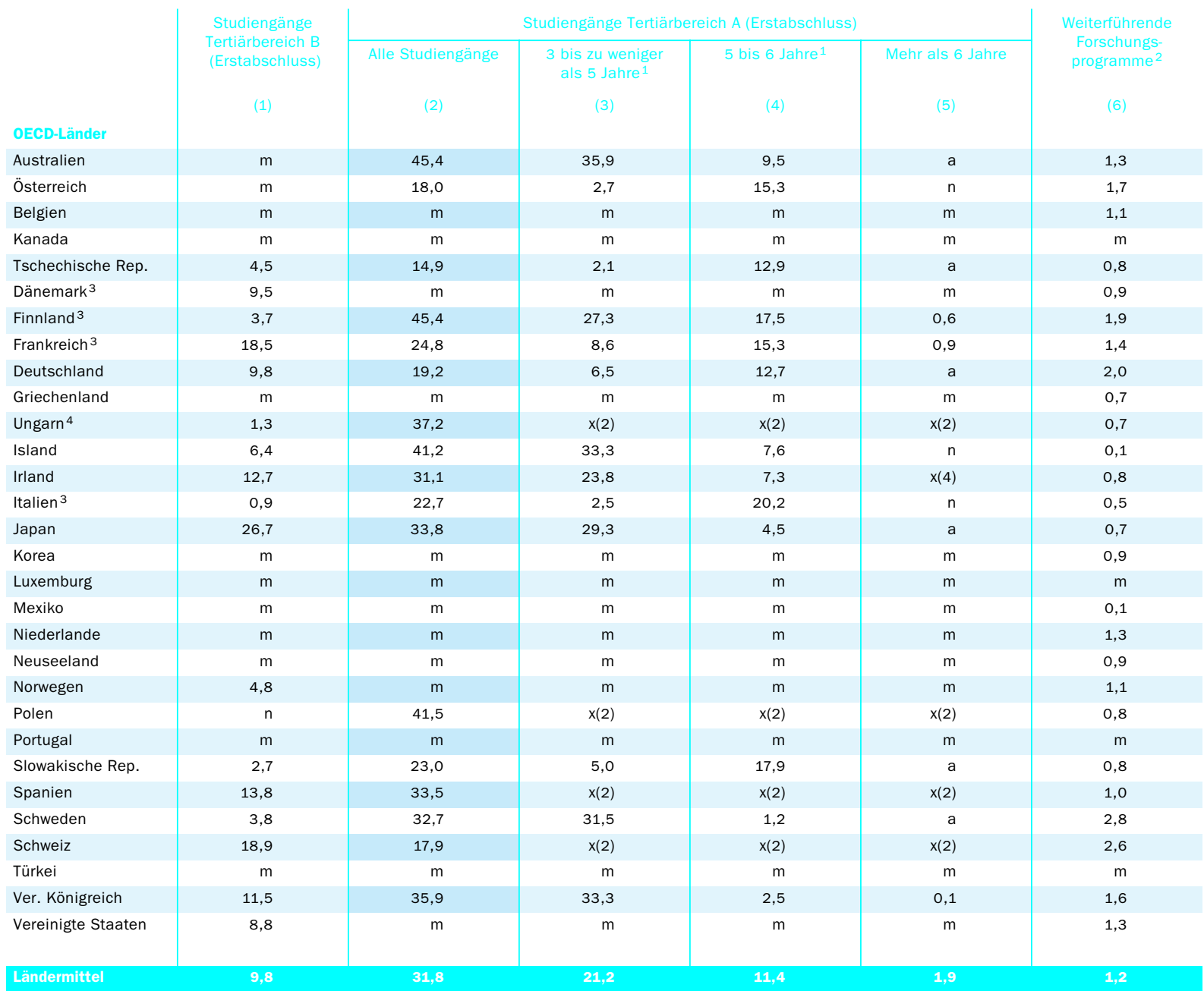

Hinweise: $x$ bedeutet, dass die Daten in einer anderen Spalte enthalten sind, deren Referenz in runden Klammern nach dem , $x$ ' angegeben ist. So bedeutet $z$. B. $x(2)$, dass die Daten in Spalte 2 enthalten sind. Unterschiede im Erhebungsbereich der Bevölkerungsdaten und der Schüler-/Absolventendaten bedeuten, dass die Teilnah me-/Abschlussquoten von Ländern mit einem Nettoabgang von Schülern/Studierenden wohl zu niedrig und von Ländern mit einem Nettozugang von Schülern/Studierenden wohl zu hoch angesetzt sind.

1. Ohne Studierende, die nachfolgend einen langen Studiengang abgeschlossen haben. 2. Netto-Abschlussquoten werden berechnet, indem man die Abschlussquoten für jeden einzelnen Altersjahrgang aufaddiert (mit Ausnahme von Frankreich, Italien, Japan, Korea, Mexiko, die Niederlande und die Vereinigten Staaten).

3. Referenzjahr 2001 4. Brutto-Abschlussquoten können einige Doppelzählungen enthalten.

Quelle: OECD. Hinweise s. Anhang 3 unter www.oecd.org/edu/eag20o4. 


\section{Tabelle A3.2}

3 Anzahl der Absolventen dividiert durch die Anzahl der Studienanfänger im typischen Studienanfangsjahr, nach Ziel des Studiengangs, und Verteilung der Absolventen nach Dauer des Studiengangs

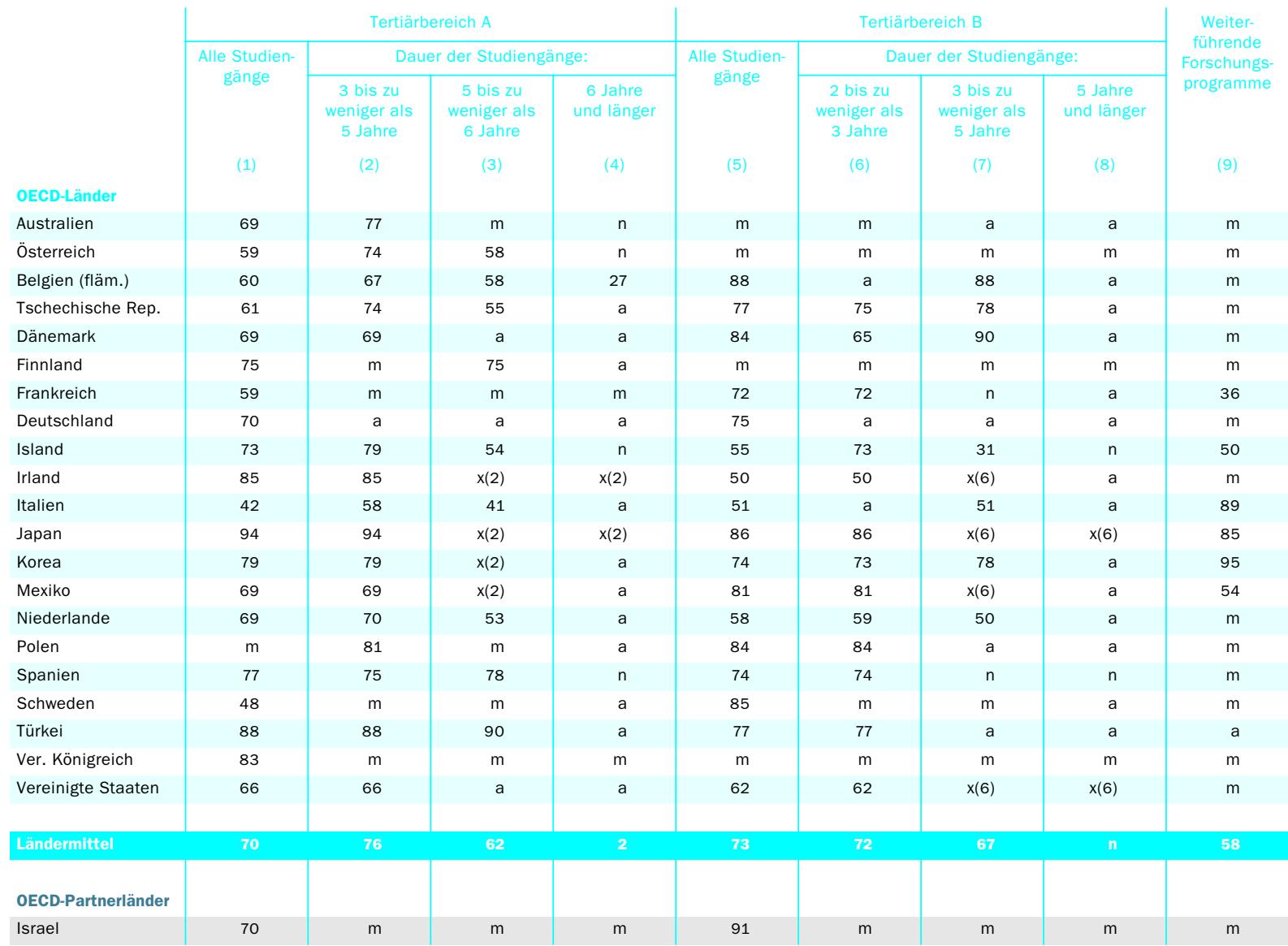

Hinweis: $x$ bedeutet, dass die Daten in einer anderen Spalte enthalten sind, deren Referenz in runden Klammern nach dem ,x‘ angegeben ist. So bedeutet $z$. B. $x(2)$, dass die Daten in Spalte 2 enthalten sind.

Quelle: OECD. Hinweise s. Anhang 3 unter www.oecd.org/edu/eag2004. 
Tabelle A3.3

Bevölkerung mit einem Abschluss im Tertiärbereich (2002)

Anteil der Bevölkerung mit einem Abschluss des Tertiärbereich B oder A und in einem weiterführenden Forschungsprogramm, nach Altersgruppen

\begin{tabular}{|c|c|c|c|c|c|c|c|c|c|c|}
\hline \multirow{2}{*}{ OECD-Länder } & \multicolumn{5}{|c|}{ Tertiärbereich B } & \multicolumn{5}{|c|}{ Tertiärbereich A und weiterführende Forschungsprogramme } \\
\hline & $\begin{array}{c}25-64 \text { Jahre } \\
\text { (1) }\end{array}$ & \begin{tabular}{|c|}
$25-34$ Jahre \\
(2)
\end{tabular} & $\begin{array}{c}35-44 \text { Jahre } \\
\text { (3) }\end{array}$ & $\begin{array}{c}45-54 \text { Jahre } \\
\text { (4) }\end{array}$ & $\begin{array}{c}55-64 \text { Jahre } \\
\text { (5) }\end{array}$ & $\begin{array}{c}25-64 \text { Jahre } \\
\text { (6) }\end{array}$ & \begin{tabular}{|c|}
$25-34$ Jahre \\
$(7)$
\end{tabular} & $\begin{array}{c}35-44 \text { Jahre } \\
\text { (8) }\end{array}$ & $\begin{array}{c}45-54 \text { Jahre } \\
\text { (9) }\end{array}$ & $\begin{array}{c}\text { 55-64 Jahre } \\
\text { (10) }\end{array}$ \\
\hline Australien & 11 & 11 & 11 & 11 & 10 & 20 & 25 & 21 & 19 & 13 \\
\hline Österreich & 7 & 7 & 8 & 8 & 6 & 7 & 7 & 8 & 7 & 5 \\
\hline Belgien & 15 & 20 & 16 & 13 & 10 & 13 & 18 & 13 & 11 & 8 \\
\hline Kanada & 22 & 25 & 23 & 21 & 16 & 21 & 26 & 20 & 20 & 16 \\
\hline Tschechische Rep. & $x(6)$ & $x(7)$ & $x(8)$ & $x(9)$ & $x(10)$ & 12 & 12 & 14 & 11 & 11 \\
\hline Dänemark & 5 & 6 & 6 & 5 & 4 & 23 & 23 & 24 & 25 & 18 \\
\hline Finnland & 17 & 19 & 21 & 16 & 12 & 16 & 21 & 17 & 14 & 11 \\
\hline Frankreich & 12 & 17 & 12 & 9 & 6 & 12 & 19 & 11 & 10 & 9 \\
\hline Deutschland & 10 & 8 & 11 & 11 & 10 & 13 & 13 & 15 & 14 & 11 \\
\hline Griechenland & 6 & 7 & 8 & 4 & 3 & 13 & 17 & 14 & 12 & 7 \\
\hline Island & 6 & 6 & 7 & 7 & 4 & 20 & 23 & 22 & 19 & 12 \\
\hline Irland & 10 & 14 & 10 & 7 & 5 & 16 & 23 & 15 & 12 & 9 \\
\hline Italien & $x(6)$ & $x(7)$ & $x(8)$ & $x(9)$ & $x(10)$ & 10 & 12 & 11 & 10 & 7 \\
\hline Japan & 16 & 25 & 20 & 12 & 7 & 20 & 25 & 25 & 19 & 11 \\
\hline Korea & 8 & 15 & 7 & 2 & 1 & 18 & 26 & 21 & 11 & 8 \\
\hline Luxemburg & 7 & 9 & 8 & 6 & 5 & 12 & 14 & 12 & 10 & 10 \\
\hline Mexiko & 3 & 6 & 2 & 2 & 3 & 2 & 5 & 1 & 1 & 2 \\
\hline Niederlande & 3 & 2 & 3 & 2 & 2 & 22 & 25 & 23 & 21 & 17 \\
\hline Neuseeland & 15 & 12 & 15 & 17 & 17 & 15 & 18 & 16 & 15 & 9 \\
\hline Norwegen & 3 & 2 & 3 & 2 & 2 & 28 & 37 & 29 & 26 & 20 \\
\hline Polen & $x(6)$ & $x(7)$ & $x(8)$ & $x(9)$ & $x(10)$ & 12 & 16 & 11 & 11 & 11 \\
\hline Portugal & 2 & 3 & 2 & 2 & 2 & 7 & 12 & 7 & 5 & 3 \\
\hline Slowakische Rep. & 1 & 1 & 1 & 1 & 1 & 10 & 11 & 10 & 11 & 8 \\
\hline Spanien & 7 & 12 & 7 & 4 & 2 & 17 & 25 & 18 & 13 & 8 \\
\hline Türkei & $x(6)$ & $\mathrm{x}(7)$ & $x(8)$ & $x(9)$ & $x(10)$ & 9 & 11 & 8 & 9 & 7 \\
\hline Ver. Königreich & 8 & 8 & 9 & 8 & 7 & 19 & 23 & 18 & 18 & 13 \\
\hline Vereinigte Staaten & 9 & 9 & 10 & 10 & 7 & 29 & 31 & 29 & 30 & 26 \\
\hline Ländermittel & 8 & 9 & 8 & 7 & 5 & 16 & 19 & 16 & 14 & 11 \\
\hline OECD-Partnerländer & & & & & & & & & & \\
\hline Argentinien ${ }^{1}$ & 5 & 6 & 5 & 4 & 2 & 9 & 9 & 10 & 10 & 6 \\
\hline Brasilien ${ }^{1}$ & $x(6)$ & $x(7)$ & $x(8)$ & $x(9)$ & $x(10)$ & 8 & 7 & 9 & 9 & 6 \\
\hline Chile & 1 & 2 & 2 & 1 & 1 & 11 & 15 & 10 & 11 & 7 \\
\hline Indonesien & 2 & 2 & 2 & 2 & 1 & 2 & 3 & 2 & 2 & 1 \\
\hline Israel & 16 & 15 & 16 & 17 & 17 & 26 & 25 & 26 & 27 & 25 \\
\hline Jordanien & 12 & $x(1)$ & $x(1)$ & $x(1)$ & $x(1)$ & 12 & $x(6)$ & $x(6)$ & $x(6)$ & $x(6)$ \\
\hline Malaysia & $x(6)$ & $x(7)$ & $x(8)$ & $x(9)$ & $x(10)$ & 10 & 14 & 10 & 6 & 4 \\
\hline Paraguay & 2 & 2 & 2 & 1 & 2 & 9 & 11 & 9 & 7 & 4 \\
\hline Peru & 7 & 10 & 8 & 6 & 3 & 8 & 8 & 9 & 8 & 6 \\
\hline Philippinen & 12 & 15 & 10 & $x(3)$ & $x(3)$ & 8 & 9 & 8 & $x(8)$ & $x(8)$ \\
\hline Thailand & 3 & 4 & 3 & 1 & 1 & 9 & 10 & 10 & 7 & 4 \\
\hline Uruguay ${ }^{1}$ & 9 & 8 & 11 & 10 & 8 & $x(1)$ & $x(2)$ & $x(3)$ & $x(4)$ & $x(5)$ \\
\hline
\end{tabular}

Hinweis: $x$ bedeutet, dass die Daten in einer anderen Spalte enthalten sind, deren Referenz in runden Klammern nach dem , $x$ ‘ angegeben ist. So bedeutet $z$. B. $x(2)$, dass die Daten in Spalte 2 enthalten sind.

1. Referenzjahr 2001.

Quelle: OECD. Hinweise s. Anhang 3 unter www.oecd.org/edu/eag2004. 
Tabelle A3.4a

Entwicklung des Bildungsstands der 25- bis 64-Jährigen (1991-2002)

\begin{tabular}{|c|c|c|c|c|}
\hline OECD-Länder & & 1991 & 1995 & 1998 \\
\hline Australien & Abschluss unterhalb des Sekundarbereich II & 48 & 45 & 44 \\
\hline & Sekundarbereich II und post-sekundarer, nicht-tertiärer Bereich & 30 & 31 & 31 \\
\hline & Tertiärbereich & 22 & 24 & 25 \\
\hline Österreich & Abschluss unterhalb des Sekundarbereich II & 33 & 31 & 26 \\
\hline & Sekundarbereich II und post-sekundarer, nicht-tertiärer Bereich & 61 & 62 & 63 \\
\hline & Tertiärbereich & 7 & 8 & 11 \\
\hline Belgien & Abschluss unterhalb des Sekundarbereich II & 57 & 49 & 43 \\
\hline & Sekundarbereich II und post-sekundarer, nicht-tertiärer Bereich & 24 & 28 & 31 \\
\hline & Tertiärbereich & 20 & 23 & 25 \\
\hline Kanada & Abschluss unterhalb des Sekundarbereich II & 30 & 25 & 21 \\
\hline & Sekundarbereich II und post-sekundarer, nicht-tertiärer Bereich & 42 & 41 & 40 \\
\hline & Tertiärbereich & 28 & 34 & 38 \\
\hline Tschechische & Abschluss unterhalb des Sekundarbereich II & $\mathrm{m}$ & 17 & 15 \\
\hline Republik & Sekundarbereich II und post-sekundarer, nicht-tertiärer Bereich & $\mathrm{m}$ & 73 & 75 \\
\hline & Tertiärbereich & $\mathrm{m}$ & 11 & 10 \\
\hline Dänemark & Abschluss unterhalb des Sekundarbereich II & 39 & 33 & 21 \\
\hline & Sekundarbereich II und post-sekundarer, nicht-tertiärer Bereich & 43 & 47 & 53 \\
\hline & Tertiärbereich & 18 & 20 & 25 \\
\hline Finnland & Abschluss unterhalb des Sekundarbereich II & 40 & 35 & 31 \\
\hline & Sekundarbereich II und post-sekundarer, nicht-tertiärer Bereich & 35 & 38 & 39 \\
\hline & Tertiärbereich & 25 & 28 & 30 \\
\hline Frankreich & Abschluss unterhalb des Sekundarbereich II & 49 & 43 & 39 \\
\hline & Sekundarbereich II und post-sekundarer, nicht-tertiärer Bereich & 36 & 38 & 40 \\
\hline & Tertiärbereich & 15 & 19 & 21 \\
\hline Deutschland & Abschluss unterhalb des Sekundarbereich II & 18 & 16 & 16 \\
\hline & Sekundarbereich II und post-sekundarer, nicht-tertiärer Bereich & 60 & 61 & 61 \\
\hline & Tertiärbereich & 22 & 23 & 23 \\
\hline Griechenland & Abschluss unterhalb des Sekundarbereich II & $\mathrm{m}$ & 57 & 53 \\
\hline & Sekundarbereich II und post-sekundarer, nicht-tertiärer Bereich & $\mathrm{m}$ & 25 & 31 \\
\hline & Tertiärbereich & $\mathrm{m}$ & 17 & 17 \\
\hline Ungarn & Abschluss unterhalb des Sekundarbereich II & $\mathrm{m}$ & $\mathrm{m}$ & 37 \\
\hline & Sekundarbereich II und post-sekundarer, nicht-tertiärer Bereich & $\mathrm{m}$ & $\mathrm{m}$ & 50 \\
\hline & Tertiärbereich & $\mathrm{m}$ & $\mathrm{m}$ & 13 \\
\hline Island & Abschluss unterhalb des Sekundarbereich II & $\mathrm{m}$ & $\mathrm{m}$ & 38 \\
\hline & Sekundarbereich II und post-sekundarer, nicht-tertiärer Bereich & $\mathrm{m}$ & $\mathrm{m}$ & 41 \\
\hline & Tertiärbereich & $\mathrm{m}$ & $\mathrm{m}$ & 21 \\
\hline Irland & Abschluss unterhalb des Sekundarbereich II & 60 & 53 & 49 \\
\hline & Sekundarbereich II und post-sekundarer, nicht-tertiärer Bereich & 24 & 27 & 30 \\
\hline & Tertiärbereich & 16 & 20 & 21 \\
\hline Italien & Abschluss unterhalb des Sekundarbereich II & 72 & 65 & 58 \\
\hline & Sekundarbereich II und post-sekundarer, nicht-tertiärer Bereich & 22 & 27 & 33 \\
\hline & Tertiärbereich & 6 & 8 & 9 \\
\hline Japan & Abschluss unterhalb des Sekundarbereich II & $\mathrm{m}$ & $\mathrm{m}$ & 20 \\
\hline & Sekundarbereich II und post-sekundarer, nicht-tertiärer Bereich & $\mathrm{m}$ & $\mathrm{m}$ & 50 \\
\hline & Tertiärbereich & $\mathrm{m}$ & $\mathrm{m}$ & 30 \\
\hline Korea & Abschluss unterhalb Sekundarbereich II & 49 & 39 & 34 \\
\hline & Sekundarbereich II und post-sekundarer, nicht-tertiärer Bereich & 37 & 42 & 44 \\
\hline & Tertiärbereich & 14 & 19 & 22 \\
\hline Luxemburg & Abschluss unterhalb Sekundarbereich II & $\mathrm{m}$ & $\mathrm{m}$ & $\mathrm{m}$ \\
\hline & Sekundarbereich II und post-sekundarer, nicht-tertiärer Bereich & $\mathrm{m}$ & $\mathrm{m}$ & $\mathrm{m}$ \\
\hline & Tertiärbereich & $\mathrm{m}$ & $\mathrm{m}$ & $\mathrm{m}$ \\
\hline Mexiko & Abschluss unterhalb Sekundarbereich II & $\mathrm{m}$ & 90 & 89 \\
\hline & Sekundarbereich II und post-sekundarer, nicht-tertiärer Bereich & $\mathrm{m}$ & 5 & 6 \\
\hline & Tertiärbereich & $\mathrm{m}$ & 5 & 5 \\
\hline Niederlande & Abschluss unterhalb Sekundarbereich II & 44 & 39 & 36 \\
\hline & Sekundarbereich II und post-sekundarer, nicht-tertiärer Bereich & 37 & 39 & 40 \\
\hline & Tertiärbereich & 20 & 22 & 24 \\
\hline Neuseeland & Abschluss unterhalb Sekundarbereich II & 33 & 30 & 27 \\
\hline & Sekundarbereich II und post-sekundarer, nicht-tertiärer Bereich & 44 & 45 & 46 \\
\hline & Tertiärbereich & 23 & 25 & 27 \\
\hline Norwegen & Abschluss unterhalb Sekundarbereich II & 21 & 19 & 15 \\
\hline & Sekundarbereich II und post-sekundarer, nicht-tertiärer Bereich & 54 & 53 & 57 \\
\hline & Tertiärbereich & 25 & 29 & 27 \\
\hline Polen & Abschluss unterhalb Sekundarbereich II & $\mathrm{m}$ & 26 & 22 \\
\hline & Sekundarbereich II und post-sekundarer, nicht-tertiärer Bereich & $\mathrm{m}$ & 64 & 67 \\
\hline & Tertiärbereich & $\mathrm{m}$ & 10 & 11 \\
\hline Portugal & Abschluss unterhalb Sekundarbereich II & 86 & 80 & 82 \\
\hline & Sekundarbereich II und post-sekundarer, nicht-tertiärer Bereich & 8 & 9 & 10 \\
\hline & Tertiärbereich & 7 & 11 & 8 \\
\hline Slowakische & Abschluss unterhalb Sekundarbereich II & $\mathrm{m}$ & 22 & 20 \\
\hline Republik & Sekundarbereich II und post-sekundarer, nicht-tertiärer Bereich & $\mathrm{m}$ & 67 & 70 \\
\hline & Tertiärbereich & $\mathrm{m}$ & 11 & 10 \\
\hline Spanien & Abschluss unterhalb Sekundarbereich II & 78 & 72 & 67 \\
\hline & Sekundarbereich II und post-sekundarer, nicht-tertiärer Bereich & 12 & 12 & 14 \\
\hline & Tertiärbereich & 10 & 16 & 20 \\
\hline Schweden & Abschluss unterhalb Sekundarbereich II & 31 & 25 & 24 \\
\hline & Sekundarbereich II und post-sekundarer, nicht-tertiärer Bereich & 44 & 46 & 48 \\
\hline & Tertiärbereich & 25 & 28 & 28 \\
\hline Schweiz & Abschluss unterhalb Sekundarbereich II & 19 & 18 & 18 \\
\hline & Sekundarbereich II und post-sekundarer, nicht-tertiärer Bereich & 60 & 61 & 59 \\
\hline & Tertiärbereich & 20 & 21 & 23 \\
\hline Türkei & Abschluss unterhalb Sekundarbereich II & 82 & 77 & 78 \\
\hline & Sekundarbereich II und post-sekundarer, nicht-tertiärer Bereich & 11 & 15 & 14 \\
\hline & Tertiärbereich & 6 & 8 & 8 \\
\hline Vereinigtes & Abschluss unterhalb Sekundarbereich II & 35 & 23 & 19 \\
\hline Königreich & Sekundarbereich II und post-sekundarer, nicht-tertiärer Bereich & 49 & 55 & 57 \\
\hline & Tertiärbereich & 16 & 22 & 24 \\
\hline Vereinigte & Abschluss unterhalb Sekundarbereich II & 16 & 14 & 14 \\
\hline Staaten & Sekundarbereich II und post-sekundarer, nicht-tertiärer Bereich & 54 & 53 & 52 \\
\hline & 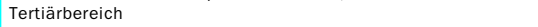 & 30 & 33 & 35 \\
\hline Laandermittel & Abschluss unterhalb Sekundarbereich II & 45 & 40 & 36 \\
\hline & Sekundarbereich II und post-sekundarer, nicht-tertiärer Bereich & 37 & 41 & 43 \\
\hline & Tertiarbereich & 18 & 19 & 20 \\
\hline
\end{tabular}

Quelle: OECD. Hinweise s. Anhang 3 unter www.oecd.org/edu/eag2004. 
Tabelle A3.4b

Entwicklung des Bildungsstands der 25- bis 34-Jährigen (1991-2002)

\begin{tabular}{|c|c|c|c|}
\hline & & 1991 & 1995 \\
\hline OECD-Lander & & & \\
\hline Australien & Abschluss unterhalb Sekundarbereich II & 43 & 40 \\
\hline & Sekundarbereich II und post-sekundarer, nicht-tertiärer Bereich & 34 & 35 \\
\hline & Tertiärbereich & 23 & 25 \\
\hline Österreich & Abschluss unterhalb Sekundarbereich II & 21 & 19 \\
\hline & Sekundarbereich II und post-sekundarer, nicht-tertiärer Bereich & 71 & 72 \\
\hline & Tertiärbereich & 8 & 9 \\
\hline Belgien & Abschluss unterhalb Sekundarbereich II & 42 & 33 \\
\hline & Sekundarbereich II und post-sekundarer, nicht-tertiärer Bereich & 31 & 37 \\
\hline & Tertiärbereich & 27 & 30 \\
\hline Kanada & Abschluss unterhalb Sekundarbereich II & 20 & 16 \\
\hline & Sekundarbereich II und post-sekundarer, nicht-tertiärer Bereich & 48 & 43 \\
\hline & Tertiärbereich & 32 & 40 \\
\hline Tschechische & Abschluss unterhalb Sekundarbereich II & $\mathrm{m}$ & 9 \\
\hline Republik & Sekundarbereich II und post-sekundarer, nicht-tertiärer Bereich & $\mathrm{m}$ & 79 \\
\hline & Tertiärbereich & $\mathrm{m}$ & 12 \\
\hline Dänemark & Abschluss unterhalb Sekundarbereich II & 25 & 25 \\
\hline & Sekundarbereich II und post-sekundarer, nicht-tertiärer Bereich & 56 & 55 \\
\hline & Tertiärbereich & 19 & 20 \\
\hline Finnland & Abschluss unterhalb Sekundarbereich II & 19 & 17 \\
\hline & Sekundarbereich II und post-sekundarer, nicht-tertiärer Bereich & 48 & 48 \\
\hline & Tertiärbereich & 33 & 35 \\
\hline Frankreich & Abschluss unterhalb Sekundarbereich II & 34 & 29 \\
\hline & Sekundarbereich II und post-sekundarer, nicht-tertiärer Bereich & 46 & 46 \\
\hline & Tertiärbereich & 20 & 25 \\
\hline Deutschland & Abschluss unterhalb Sekundarbereich II & 11 & 11 \\
\hline & Sekundarbereich II und post-sekundarer, nicht-tertiärer Bereich & 68 & 68 \\
\hline & Tertiärbereich & 21 & 21 \\
\hline Griechenland & Abschluss unterhalb Sekundarbereich II & $\mathrm{m}$ & 36 \\
\hline & Sekundarbereich II und post-sekundarer, nicht-tertiärer Bereich & $\mathrm{m}$ & 38 \\
\hline & Tertiärbereich & $\mathrm{m}$ & 26 \\
\hline Ungarn & Abschluss unterhalb Sekundarbereich II & $\mathrm{m}$ & $\mathrm{m}$ \\
\hline & Sekundarbereich II und post-sekundarer, nicht-tertiärer Bereich & $\mathrm{m}$ & $\mathrm{m}$ \\
\hline & Tertiärbereich & $\mathrm{m}$ & $\mathrm{m}$ \\
\hline Island & Abschluss unterhalb Sekundarbereich II & $\mathrm{m}$ & $\mathrm{m}$ \\
\hline & Sekundarbereich II und post-sekundarer, nicht-tertiärer Bereich & $\mathrm{m}$ & $\mathrm{m}$ \\
\hline & Tertiärbereich & $\mathrm{m}$ & $\mathrm{m}$ \\
\hline Irland & Abschluss unterhalb Sekundarbereich II & 46 & 36 \\
\hline & Sekundarbereich II und post-sekundarer, nicht-tertiärer Bereich & 35 & 37 \\
\hline & Tertiärbereich & 20 & 27 \\
\hline Italien & Abschluss unterhalb Sekundarbereich II & 57 & 51 \\
\hline & Sekundarbereich II und post-sekundarer, nicht-tertiärer Bereich & 36 & 41 \\
\hline & Tertiärbereich & 7 & 8 \\
\hline Japan & Abschluss unterhalb Sekundarbereich II & $\mathrm{m}$ & $\mathrm{m}$ \\
\hline & Sekundarbereich II und post-sekundarer, nicht-tertiärer Bereich & $\mathrm{m}$ & $\mathrm{m}$ \\
\hline & Tertiärbereich & $\mathrm{m}$ & $\mathrm{m}$ \\
\hline Korea & Abschluss unterhalb Sekundarbereich II & 27 & 14 \\
\hline & Sekundarbereich II und post-sekundarer, nicht-tertiärer Bereich & 52 & 57 \\
\hline & Tertiärbereich & 21 & 29 \\
\hline Luxemburg & Abschluss unterhalb Sekundarbereich II & $\mathrm{m}$ & $\mathrm{m}$ \\
\hline & Sekundarbereich II und post-sekundarer, nicht-tertiärer Bereich & $\mathrm{m}$ & $\mathrm{m}$ \\
\hline & Tertiärbereich & $\mathrm{m}$ & $\mathrm{m}$ \\
\hline Mexiko & Abschluss unterhalb Sekundarbereich II & $\mathrm{m}$ & 84 \\
\hline & Sekundarbereich II und post-sekundarer, nicht-tertiärer Bereich & $\mathrm{m}$ & 8 \\
\hline & Tertiärbereich & $\mathrm{m}$ & 8 \\
\hline Niederlande & Abschluss unterhalb Sekundarbereich II & 33 & 30 \\
\hline & Sekundarbereich II und post-sekundarer, nicht-tertiärer Bereich & 45 & 46 \\
\hline & Tertiärbereich & 22 & 25 \\
\hline Neuseeland & Abschluss unterhalb Sekundarbereich II & 26 & 23 \\
\hline & Sekundarbereich II und post-sekundarer, nicht-tertiärer Bereich & 51 & 53 \\
\hline & Tertiärbereich & 23 & 24 \\
\hline Norwegen & Abschluss unterhalb Sekundarbereich II & 12 & 12 \\
\hline & Sekundarbereich II und post-sekundarer, nicht-tertiärer Bereich & 61 & 56 \\
\hline & Tertiärbereich & 27 & 32 \\
\hline Polen & Abschluss unterhalb Sekundarbereich II & $\mathrm{m}$ & 12 \\
\hline & Sekundarbereich II und post-sekundarer, nicht-tertiärer Bereich & $\mathrm{m}$ & 78 \\
\hline & Tertiärbereich & $\mathrm{m}$ & 10 \\
\hline Portugal & Abschluss unterhalb Sekundarbereich II & 79 & 69 \\
\hline & Sekundarbereich II und post-sekundarer, nicht-tertiärer Bereich & 12 & 17 \\
\hline & Tertiärbereich & 9 & 14 \\
\hline Slowakische & Abschluss unterhalb Sekundarbereich II & $\mathrm{m}$ & 9 \\
\hline Republik & Sekundarbereich II und post-sekundarer, nicht-tertiärer Bereich & $\mathrm{m}$ & 79 \\
\hline & Tertiärbereich & $\mathrm{m}$ & 12 \\
\hline Spanien & Abschluss unterhalb Sekundarbereich II & 60 & 53 \\
\hline & Sekundarbereich II und post-sekundarer, nicht-tertiärer Bereich & 24 & 21 \\
\hline & Tertiärbereich & 16 & 27 \\
\hline Schweden & Abschluss unterhalb Sekundarbereich II & 16 & 12 \\
\hline & Sekundarbereich II und post-sekundarer, nicht-tertiärer Bereich & 57 & 59 \\
\hline & Tertiärbereich & 27 & 29 \\
\hline Schweiz & Abschluss unterhalb Sekundarbereich II & 12 & 12 \\
\hline & Sekundarbereich II und post-sekundarer, nicht-tertiärer Bereich & 66 & 67 \\
\hline & Tertiärbereich & 21 & 22 \\
\hline Türkei & Abschluss unterhalb Sekundarbereich II & 78 & 74 \\
\hline & Sekundarbereich II und post-sekundarer, nicht-tertiärer Bereich & 16 & 19 \\
\hline & Tertiärbereich & 6 & 8 \\
\hline Vereinigtes & Abschluss unterhalb Sekundarbereich II & 21 & 14 \\
\hline Königreich & Sekundarbereich II und post-sekundarer, nicht-tertiärer Bereich & 61 & 63 \\
\hline & 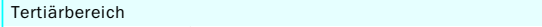 & 19 & 23 \\
\hline Vereinigte & Abschluss unterhalb Sekundarbereich II & 14 & 13 \\
\hline Staaten & Sekundarbereich II und post-sekundarer, nicht-tertiärer Bereich & 56 & 54 \\
\hline & Tertiärbereich & 30 & 34 \\
\hline Ländermittel & Abschluss unterhalb Sekundarbereich II & 33 & 29 \\
\hline & Sekundarbereich II und post-sekundarer, nicht-tertiärer Bereich & 46 & 49 \\
\hline & Tertiarbereich & 20 & 22 \\
\hline
\end{tabular}

Quelle: OECD. Hinweise s. Anhang 3 unter www.oecd.org/edu/eag2004. 
Tabelle A3.4c

Entwicklung des Bildungsstands der 25- bis 34-Jährigen (1998-2002)

Anteil (in \%) mit einem Abschluss im Tertiärbereich (ISCED 5A/B)

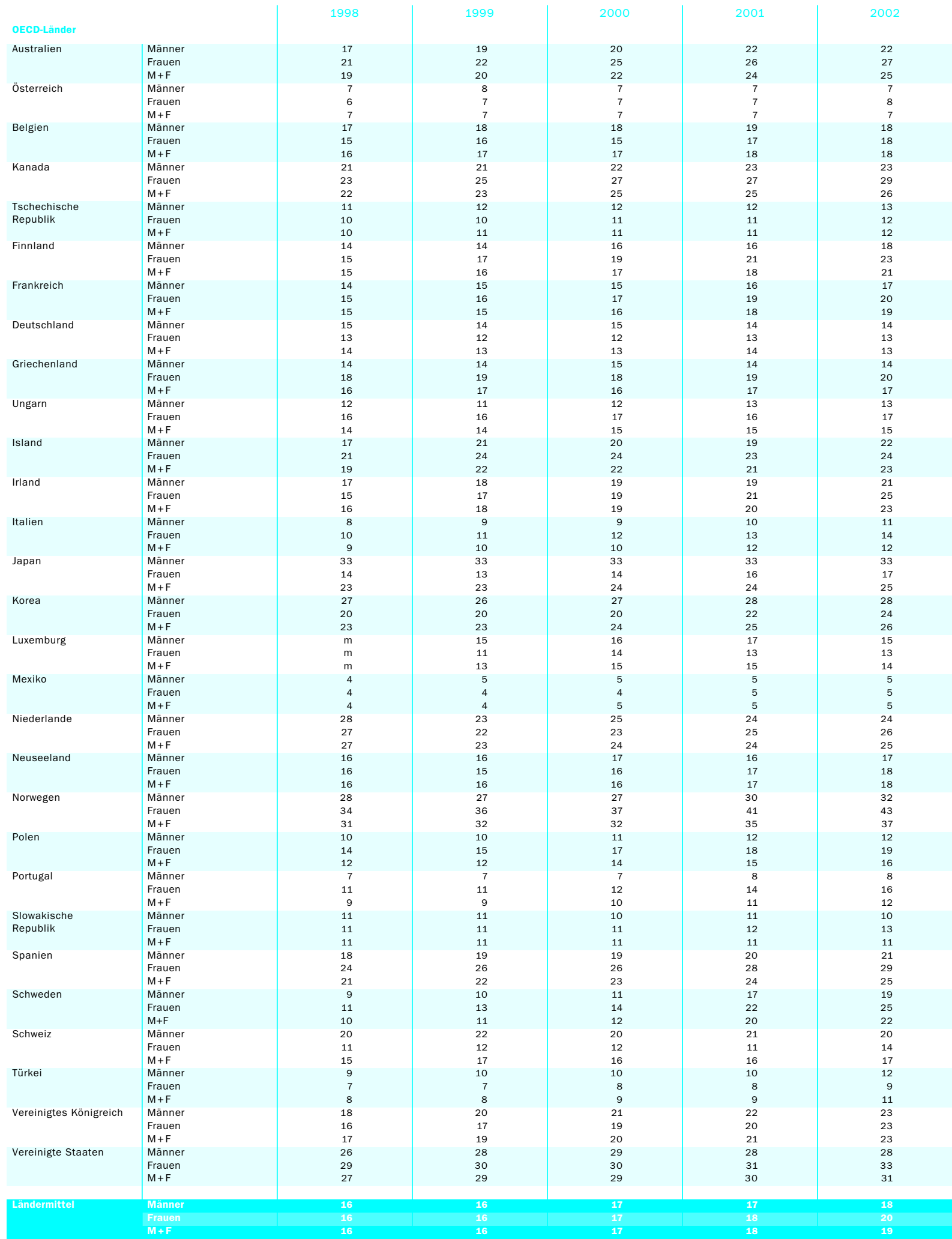

Quelle: OECD. Hinweise s. Anhang 3 unter www.oecd.org/edu/eag2004. 


\section{Absolventen des Tertiärbereichs nach Studienbereichen}

Im Durchschnitt aller OECD-Länder erzielt fast jeder dritte Absolvent des Tertiärbereich A einen Abschluss in den Sozial-, Rechts- oder Wirtschaftswissenschaften. Darauf folgen auf der Beliebtheitsskala die naturwissenschaftlich ausgerichteten Fächer (Ingenieurwesen, Fertigung und Bauwesen, Biowissenschaften, Physik und Agrarwissenschaft, Mathematik und Informatik, jedoch ohne Gesundheit und Soziales), in denen im Durchschnitt jeder Vierte einen Abschluss erwirbt.

Naturwissenschaftlich ausgerichtete Fächer, eng gefolgt von den Sozial-, Rechts-, Wirtschaftswissenschaften sind die beliebtesten Studienfächer im Tertiärbereich B, in dem die Studiengänge mehr berufsspezifisch ausgerichtet sind.

In den Bereichen Geisteswissenschaften, Kunst, Pädagogik, Gesundheit und Soziales sind im Durchschnitt der OECD-Länder mehr als zwei Drittel der Absolventen des Tertiärbereich A Frauen. Ihr Anteil in Mathematik und Informatik beträgt weniger als ein Drittel und weniger als ein Fünftel in den Bereichen Ingenieurwesen, Fertigung und Bauwesen.

In den meisten OECD-Ländern entsprechen oder übersteigen im Tertiärbereich A die Abschlussquoten der Frauen diejenigen der Männer, aber es erwerben immer noch eher Männer als Frauen einen Abschluss in einem weiterführenden Forschungsprogramm, z. B. eine Promotion. 
A

\section{Abbildung A4.1}

Absolventen im Tertiärbereich, nach Studienbereichen (2002)

Absolventen mit einem Abschluss im Tertiärbereich $A$ und in einem weiterführenden Forschungsprogramm

Biowissenschaften, Physik und Agrarwissenschaft

Mathematik und Informatik

Ingenieurwesen, Fertigung und Bauwesen

Gesundheit und Soziales

Dienstleistungen

\author{
Sozial-, Rechts- und Wirtschaftswissenschaften \\ Geisteswissenschaften und Kunst \\ Erziehungswissenschaften \\ $\square$ Nicht bekannt oder keine Angabe
}

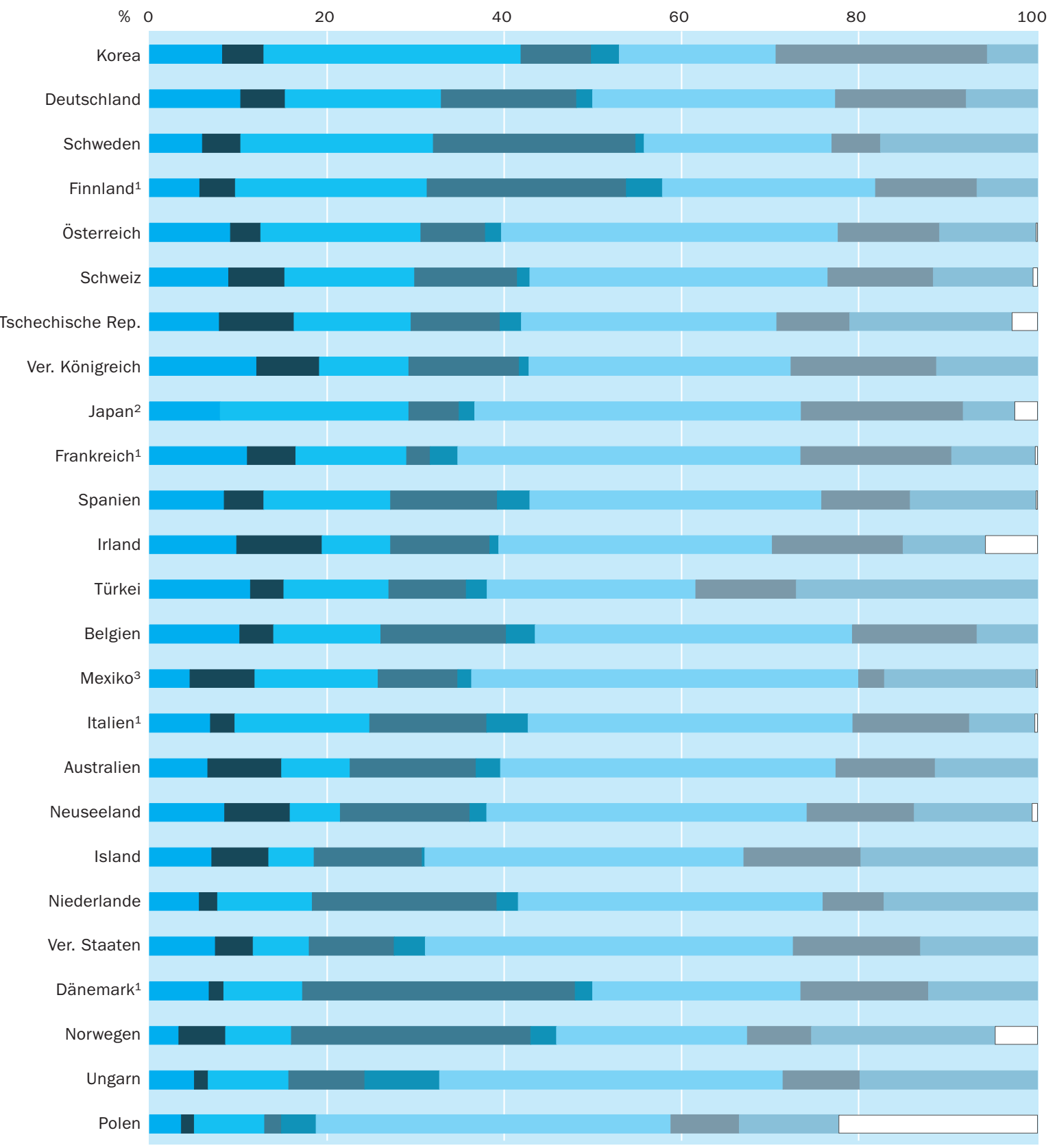

1. Referenzjahr 2001. 2. Mathematik und Informatik in 'Biowissenschaften, Physik und Agrarwissenschaft' enthalten. 3. Ohne Studiengänge im Tertiärbereich A, die zu einem Zweitabschluss führen.

Anordnung der Länder in absteigender Reihenfolge des Anteils der Abschlüsse in Biowissenschaften, Physik und Agrarwissenschaft, Mathematik und Informatik, sowie Ingenieurwesen, Fertigung und Bauwesen.

Quelle: OECD, Tabelle A4.1. Hinweise s. Anhang 3 unter www.oecd.org/edu/eag2004. 


\section{Politischer Hintergrund}

Die sich ändernden Möglichkeiten im Arbeitsmarkt, die relativen Einkommensaussichten in den verschiedenen Berufen und Wirtschaftszweigen sowie die Zulassungspolitik und -praxis der tertiären Bildungsreinrichtungen können sich auf die von den Studierenden gewählten Studienfächer auswirken. Die jeweilige Beliebtheit der verschiedenen Studienfächer bzw. Studienbereiche beeinflusst wiederum die Nachfrage nach Studiengängen und Lehrpersonal sowie das Angebot an neuen Studienabsolventen. Dieser Indikator gibt Auskunft über die Verteilung der Absolventen des Tertiärbereichs nach Studienbereichen sowie den relativen Anteil von weiblichen Absolventen in den verschiedenen Studienbereichen.

\section{Ergebnisse und Erläuterungen}

\section{Absolventen nach Studienbereichen}

In 2I der 26 Länder, die Daten zur Verfügung gestellt haben, werden die meisten Abschlüsse im Tertiärbereich A und weiterführenden Forschungsprogrammen in den Sozial-, Rechts- und Wirtschaftswissenschaften erworben (Tab. A4.I). Im Durchschnitt der OECD-Länder erzielt fast jeder dritte Absolvent des Tertiärbereich A einen Abschluss in den Sozial-, Rechts- oder Wirtschaftswissenschaften. Der Anteil der Sozial-, Rechts- und Wirtschaftswissenschaften an den Abschlüssen im Tertiärbereich A liegt zwischen weniger als 23 Prozent in Korea, Norwegen und Schweden und mehr als 40 Prozent in Mexiko und den Vereinigten Staaten. In der Türkei findet sich die größte Konzentration von Abschlüssen im Tertiärbereich A und in weiterführenden Forschungsprogrammen in den Erziehungswissenschaften, in Korea im Bereich Ingenieurwesen, Fertigung und Bauwesen und in Dänemark, Norwegen und Schweden im Bereich Gesundheit und Soziales.

Im Durchschnitt der OECD-Länder erwerben 26 Prozent der Studierenden im Tertiärbereich A und in weiterführenden Forschungsprogrammen einen Abschluss in den naturwissenschaftlich ausgerichteten Fächern (Ingenieurwesen, Fertigung und Bauwesen, Biowissenschaften, Physik und Agrarwissenschaft, Mathematik und Informatik, jedoch ohne Gesundheit und Soziales). Diese Zahl reicht von weniger als I7 Prozent in Norwegen, Polen und Ungarn über ungefähr ein Drittel in Deutschland und Schweden bis zu 4I Prozent in Korea. Etwas weniger beliebt sind im Durchschnitt der OECD-Länder die Bereiche Geisteswissenschaften, Kunst und Erziehungswissenschaften, in denen 24 Prozent der Studierenden im Tertiärbereich A und in weiterführenden Forschungsprogrammen einen Abschluss erwerben.

Die Verteilung der erworbenen Abschlüsse auf die Studienbereiche richtet sich nach deren relativer Beliebtheit bei den Studierenden, der relativen Anzahl der in den betreffenden Studienbereichen an den Hochschulen und entsprechenden Bildungseinrichtungen zugelassenen Studierenden und der Struktur der in diesen Studienfächern angebotenen Abschlüsse in dem jeweiligen Land.
Dieser Indikator zeigt die Absolventen des Tertiärbereichs, aufgegliedert nach Studienbereichen.

Im Durchschnitt der OECDLänder erzielt fast jeder dritte Absolvent des Tertiärbereich A einen Abschluss in den Sozial-, Rechts- oder Wirtschaftswissenschaften.

Die zweitgrößte Konzentration von Abschlüssen im Tertiärbereich $A$ und in weiterführenden Forschungsprogrammen findet sich in den Fächern mit naturwissenschaftlicher Ausrichtung.

Individuelle Präferenzen, die jeweilige Zulassungspolitik und die Struktur der

Abschlüsse beeinflussen die Beliebtheit der einzelnen Studienbereiche. 
Die Mehrheit der Absolventen in der OECD im Tertiärbereich $B$ erwirbt einen Abschluss in naturwissenschaftlich ausgerichteten Fächern.
In den meisten Ländern entsprechen oder übersteigen die Abschlussquoten der Frauen im Tertiärbereich A diejenigen der Männer, ...

... während er in Japan, der Schweiz und der Türkei bei 44 Prozent und darunter liegt.
Die unterschiedlichen Abschlussquoten der einzelnen Länder (Tab. A3.I) lassen sich teilweise auch durch die Unterschiede in der Anzahl der Abschlüsse in Studiengängen des Tertiärbereich A in den Fächern Erziehungs- und Geisteswissenschaften erklären. Länder mit hohen Abschlussquoten haben im Durchschnitt einen höheren Anteil von Absolventen der Erziehungs- und Geisteswissenschaften und einen geringeren Anteil von Absolventen in den naturwissenschaftlich ausgerichteten Fächern. Mit anderen Worten variiert die Anzahl der Absolventen der naturwissenschaftlich ausgerichteten Fächer zwischen den einzelnen Ländern nicht so stark wie die Abschlussquoten insgesamt.

Obwohl die gleichen drei Studienbereichsgruppen die Mehrzahl der Absolventen stellen, ergibt sich für den Tertiärbereich B, in dem die Studiengänge stärker berufsorientiert sind, ein etwas anderes Bild. Die meisten Absolventen konzentrieren sich dort in den naturwissenschaftlich ausgerichteten Fächern (26 Prozent), gefolgt von den Sozial-, Wirtschafts- und Rechtswissenschaften (25 Prozent) sowie den Geisteswissenschaften, Kunst und Erziehungswissenschaft (20 Prozent). Es finden sich in diesem Bereich jedoch mehr Absolventen von Studiengängen in Gesundheit und Soziales als von Studiengängen in Ingenieurwesen, Fertigung und Bauwesen (zusammen I8 bzw. i6 Prozent) (Tab. A4.I).

Die Auswahl eines bestimmten Studienfachs auf diesem Niveau hängt sehr stark davon ab, ob man auch im post-sekundaren, nicht-tertiären Bereich oder auf Ebene der Studiengänge im Tertiärbereich A ähnliche Fachgebiete studieren bzw. sich auf ähnliche Berufe vorbereiten kann. Wenn z. B. die Ausbildung in der Krankenpflege in einem bestimmten Land vor allem in Bildungsgängen des Tertiärbereich B erfolgt, wird der Anteil der Absolventen mit einem Abschluss in medizinischen Fächern im Tertiärbereich B höher sein, als wenn diese Berufsgruppe vor allem im Sekundarbereich II oder in Studiengängen des Tertiärbereich A ausgebildet wird.

\section{Geschlechtsspezifische Unterschiede bei den Abschlüssen im Tertiärbereich}

Alles zusammengenommen entsprechen die Abschlussquoten von Frauen in Studiengängen des Tertiärbereich A in 2I von 27 OECD-Ländern denjenigen der Männer, bzw. übersteigen diese noch. Im Durchschnitt aller OECD-Länder sind 55 Prozent aller Absolventen mit einem ersten Abschluss im Tertiärbereich A Frauen. Allerdings gibt es hier weiterhin beträchtliche Unterschiede zwischen den einzelnen Studienbereichen. In den Bereichen Geisteswissenschaften, Kunst, Erziehungswissenschaft sowie Gesundheit und Soziales sind im OECD-Durchschnitt mehr als zwei Drittel der Absolventen des Tertiärbereich A Frauen, wohingegen ihr Anteil in Mathematik und Informatik weniger als ein Drittel ausmacht und weniger als ein Fünftel in den Bereichen Ingenieurwesen, Fertigung und Bauwesen (Tab. A4.2).

In Dänemark, Finnland, Island, Neuseeland, Norwegen, Polen, Schweden und Ungarn macht der Anteil der Frauen mit einem ersten Abschluss im Tertiärbereich A über 6o Prozent aus, während er in Japan, der Schweiz und der Türkei bei 44 Prozent und darunter liegt (Tab. A4.2). 
Anteil der von Frauen erworbenen Abschlüsse im Tertiärbereich (in \%) (2002)

Anteil aller Abschlüsse (in \%) (alle Studienbereiche)

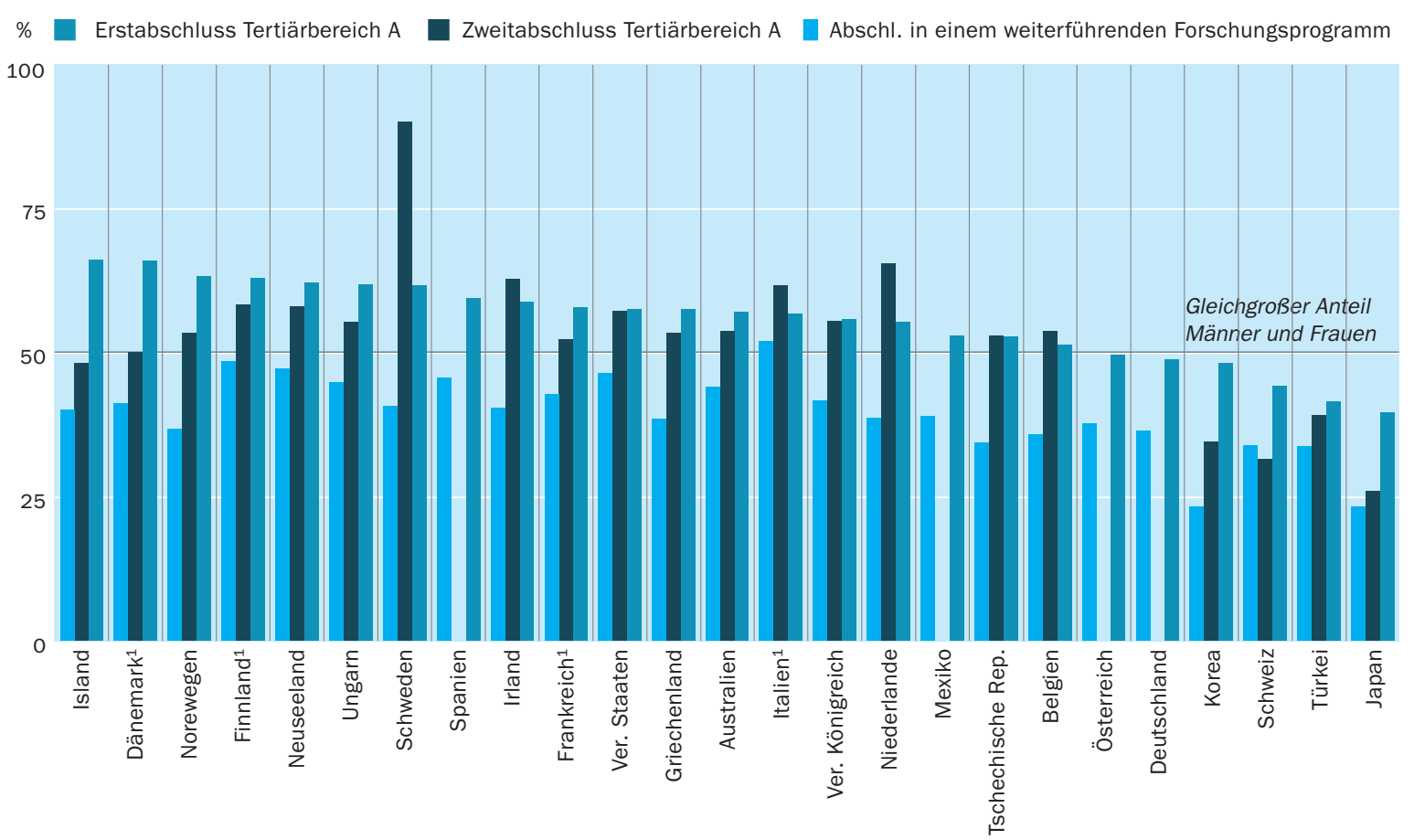

1. Referenzjahr 2001.

Anordnung der Länder in absteigender Reihenfolge des Anteils von Frauen mit einem Erstabschluss im Tertiärbereich A (in \%).

Quelle: OECD, Tabelle A4.2. Hinweise s. Anhang 3 unter www.oecd.org/edu/eag2004.

In den OECD-Ländern erwerben immer noch eher Männer als Frauen einen Abschluss in einem weiterführenden Forschungsprogramm (Tab. A4.2). Die Abschlussquoten in weiterführenden Forschungsprogrammen, z. B. Promotionsstudiengängen, sind in allen Ländern außer Italien für Frauen niedriger als für Männer. Im Durchschnitt aller OECD-Länder sind fast zwei Drittel aller Absolventen auf diesem Niveau männlich. In Japan und Korea werden etwas mehr als drei Viertel der Abschlüsse in weiterführenden Forschungsprogrammen von Männern erworben.

\section{Definitionen und angewandte Methodik}

Als Absolventen im Tertiärbereich gelten alle Personen, die in einem bestimmten Referenzjahr einen Abschluss im Tertiärbereich erworben haben. Der Indikator unterscheidet zwischen verschiedenen Kategorien von Abschlüssen: I. Abschluss im Tertiärbereich B (ISCED ${ }_{5} \mathrm{~B}$ ), 2. Abschluss im Tertiärbereich A (ISCED 5A) und 3. Abschluss in einem weiterführenden Forschungsprogramm (ISCED 6). Für einige Länder sind für die einzelnen Kategorien keine entsprechend gegliederten Daten verfügbar. In diesen Fällen wurden die Absolventen von dem jeweiligen Land der passendsten Kategorie zugeordnet.
In den OECD-Ländern erwerben immer noch eher Männer als Frauen einen Abschluss in einem weiterführenden Forschungsprogramm, z. B. eine Promotion.

Die Absolventendaten beziehen sich auf das akademische Jahr 2001/2002 und beruhen auf der alljährlich von der OECD aufgelegten UOE-Datenerhebung zur Bildungsstatistik. 
Die Zahlen in den Tabellen A4.I und A4.2 berücksichtigen Absolventen aller tertiären Abschlüsse aus Tabelle A3.I. Absolventen des Tertiärbereichs, die ihren Abschluss innerhalb des Referenzjahres erwerben, werden entsprechend ihrer Hauptfachausrichtung in die Kategorien aufgeteilt. 
Tabelle A4.1

Absolventen des Tertiärbereichs, nach Studienbereichen (2002)

\begin{tabular}{|c|c|c|c|c|c|c|c|c|c|c|c|c|c|}
\hline & & $\begin{array}{l}\text { Erziehungs- } \\
\text { wissen- } \\
\text { schaften }\end{array}$ & $\begin{array}{l}\text { Geistes- } \\
\text { wissen- } \\
\text { schaften } \\
\text { und Kunst } \\
\text { (2) }\end{array}$ & $\begin{array}{l}\text { Sozial-, } \\
\text { Rechts-, } \\
\text { Wirtschafts- } \\
\text { wissen-- } \\
\text { schaften } \\
\text { (3) }\end{array}$ & $\begin{array}{c}\text { Dienst- } \\
\text { leistungen }\end{array}$ & $\begin{array}{l}\text { Ingenieur- } \\
\text { wesen, } \\
\text { Fertigung } \\
\text { und } \\
\text { Bauwesen } \\
\text { (5) }\end{array}$ & $\begin{array}{c}\text { Agrar- } \\
\text { wissen- } \\
\text { schaften }\end{array}$ & \begin{tabular}{|} 
Gesundheit \\
und \\
Soziales
\end{tabular} & $\begin{array}{c}\text { Bio- } \\
\text { wissen- } \\
\text { schaften }\end{array}$ & Physik & $\left|\begin{array}{c}\text { Mathematik } \\
\text { und } \\
\text { Statistik }\end{array}\right|$ & Informatik & $\begin{array}{c}\text { Nicht } \\
\text { bekannt } \\
\text { oder keine } \\
\text { Angabe } \\
\text { (12) }\end{array}$ \\
\hline \multicolumn{14}{|l|}{ OECD-Länder } \\
\hline \multirow[t]{2}{*}{ Australien } & A & 11,5 & 11,2 & 37,8 & 2,7 & 7,7 & 1,0 & 14,2 & 3,3 & 2,3 & 0,5 & 7,9 & a \\
\hline & B & 1,5 & 11,3 & 36,0 & 12,2 & 11,3 & 3,8 & 13,1 & $\mathrm{~m}$ & $\mathrm{~m}$ & $\mathrm{~m}$ & $\mathrm{~m}$ & 0,1 \\
\hline \multirow[t]{2}{*}{ Österreich } & A & 10,8 & 11,4 & 38,0 & 1,8 & 18,0 & 2,5 & 7,2 & 3,6 & 3,0 & 0,7 & 2,7 & 0,2 \\
\hline & B & $\mathrm{m}$ & $\mathrm{m}$ & $\mathrm{m}$ & $\mathrm{m}$ & $\mathrm{m}$ & $\mathrm{m}$ & $\mathrm{m}$ & $\mathrm{m}$ & $\mathrm{m}$ & $\mathrm{m}$ & $\mathrm{m}$ & A \\
\hline \multirow[t]{2}{*}{ Belgien1 } & A & 6,8 & 14,1 & 35,7 & 3,3 & 12,1 & 2,9 & 14,1 & 4,2 & 3,0 & 1,0 & 2,9 & $\mathrm{n}$ \\
\hline & B & 23,7 & 6,1 & 26,6 & 1,3 & 9,1 & 0,5 & 27,1 & 0,7 & 0,2 & $\mathrm{n}$ & 4,8 & $\mathrm{n}$ \\
\hline \multirow[t]{2}{*}{ Kanada } & A & $\mathrm{m}$ & $\mathrm{m}$ & $\mathrm{m}$ & $\mathrm{m}$ & $\mathrm{m}$ & $\mathrm{m}$ & $\mathrm{m}$ & $\mathrm{m}$ & $\mathrm{m}$ & $\mathrm{m}$ & $\mathrm{m}$ & $\mathrm{m}$ \\
\hline & B & $\mathrm{m}$ & $\mathrm{m}$ & $\mathrm{m}$ & $\mathrm{m}$ & $\mathrm{m}$ & $\mathrm{m}$ & $\mathrm{m}$ & $\mathrm{m}$ & $\mathrm{m}$ & $\mathrm{m}$ & $\mathrm{m}$ & $\mathrm{m}$ \\
\hline \multirow[t]{2}{*}{ Tschechische Rep. } & A & 18,3 & 8,2 & 28,7 & 2,4 & 13,2 & 3,6 & 10,0 & 2,0 & 2,3 & 1,0 & 7,4 & 2,9 \\
\hline & B & a & 7,7 & 33,2 & 9,8 & 5,8 & 3,2 & 35,6 & a & a & a & 4,7 & a \\
\hline \multirow[t]{2}{*}{ Dänemark ${ }^{2}$} & A & 12,3 & 14,4 & 23,5 & 1,9 & 8,9 & 1,5 & 30,7 & 3,0 & 2,3 & 0,6 & 1,1 & a \\
\hline & B & a & 3,6 & 25,2 & 7,6 & 35,2 & 7,7 & a & a & a & a & 20,8 & a \\
\hline \multirow[t]{2}{*}{ Finnland ${ }^{2}$} & A & 6,8 & 11,4 & 24,0 & 4,1 & 21,6 & 2,2 & 22,4 & 1,4 & 2,0 & 0,6 & 3,4 & $\mathrm{n}$ \\
\hline & B & 4,6 & 10,2 & 10,0 & 23,3 & 30,3 & 4,0 & 12,4 & a & a & a & 5,3 & a \\
\hline \multirow[t]{2}{*}{ Frankreich ${ }^{2}$} & A & 9,4 & 17,0 & 38,6 & 3,1 & 12,5 & 0,3 & 2,7 & 5,8 & 4,9 & 2,5 & 3,0 & 0,3 \\
\hline & B & a & 1,6 & 40,5 & 6,2 & 26,9 & 0,3 & 18,7 & a & 0,1 & 0,4 & 5,2 & a \\
\hline Deutschland & A & 8,0 & 14,7 & 27,4 & 1,8 & 17,6 & 1,9 & 15,2 & 3,4 & 5,0 & 1,7 & 3,3 & a \\
\hline & B & 8,8 & 1,0 & 8,9 & 9,0 & 15,3 & 3,5 & 51,7 & $\mathrm{n}$ & a & a & 0,5 & 1,2 \\
\hline Griechenland & A & $\mathrm{m}$ & $\mathrm{m}$ & $\mathrm{m}$ & $\mathrm{m}$ & $\mathrm{m}$ & $\mathrm{m}$ & $\mathrm{m}$ & $\mathrm{m}$ & $\mathrm{m}$ & $\mathrm{m}$ & $\mathrm{m}$ & $\mathrm{m}$ \\
\hline & B & $\mathrm{m}$ & $\mathrm{m}$ & $\mathrm{m}$ & $\mathrm{m}$ & $\mathrm{m}$ & $\mathrm{m}$ & $\mathrm{m}$ & $\mathrm{m}$ & $\mathrm{m}$ & $\mathrm{m}$ & $\mathrm{m}$ & $\mathrm{m}$ \\
\hline Ungarn ${ }^{1}$ & A & 20,0 & 8,7 & 38,7 & 8,4 & 9,1 & 3,7 & 8,5 & 0,7 & 0,7 & 0,2 & 1,4 & a \\
\hline & B & $n$ & $\mathrm{n}$ & 47,4 & 23,4 & 17,8 & $\mathrm{n}$ & 3,4 & $\mathrm{n}$ & $n$ & 6,7 & 1,3 & a \\
\hline Island & A & 19,9 & 13,2 & 35,9 & 0,3 & 5,1 & 0,8 & 12,2 & 3,9 & 2,3 & 0,3 & 6,1 & a \\
\hline & B & 30,9 & 6,3 & 41,8 & $n$ & $n$ & $\mathrm{n}$ & $\mathrm{n}$ & $\mathrm{n}$ & $\mathrm{n}$ & $\mathrm{n}$ & 21,1 & a \\
\hline Irland & A & 9,3 & 14,7 & 30,8 & 1,0 & 7,7 & 1,2 & 11,2 & 5,8 & 2,8 & 0,9 & 8,7 & 5,8 \\
\hline & B & 2,6 & 6,7 & 34,1 & 10,5 & 16,6 & 0,7 & 9,7 & 1,3 & 2,2 & $\mathrm{n}$ & 15,3 & 0,3 \\
\hline Italien ${ }^{2}$ & A & 7,4 & 13,1 & 36,6 & 4,6 & 15,2 & 2,0 & 13,2 & 3,3 & 1,6 & 2,0 & 0,7 & 0,3 \\
\hline & B & 60,8 & 39,2 & a & a & a & a & a & a & a & a & a & a \\
\hline Japan $^{3}$ & A & 5,8 & 18,2 & 36,8 & 1,8 & 21,2 & 3,3 & 5,7 & 4,7 & $x(8)$ & $x(8)$ & $x(8)$ & 2,6 \\
\hline & B & 8,3 & 13,7 & 7,6 & 25,3 & 16,5 & 0,6 & 21,5 & $n$ & $x(8)$ & $x(8)$ & $x(8)$ & 6,4 \\
\hline Korea & a & 5,2 & 21,4 & 22,3 & 2,9 & 27,4 & 2,6 & 7,1 & 2,1 & 3,5 & 1,9 & 3,5 & a \\
\hline & B & 9,0 & 14,8 & 15,9 & 8,1 & 32,4 & 1,0 & 9,6 & $\mathrm{n}$ & 0,2 & $\mathrm{n}$ & 8,8 & a \\
\hline Luxemburg & A & $\mathrm{m}$ & $\mathrm{m}$ & $\mathrm{m}$ & $\mathrm{m}$ & $\mathrm{m}$ & $\mathrm{m}$ & $\mathrm{m}$ & $\mathrm{m}$ & $\mathrm{m}$ & $\mathrm{m}$ & $\mathrm{m}$ & $\mathrm{m}$ \\
\hline & B & $\mathrm{m}$ & $\mathrm{m}$ & $\mathrm{m}$ & $\mathrm{m}$ & $\mathrm{m}$ & $\mathrm{m}$ & $\mathrm{m}$ & $\mathrm{m}$ & $\mathrm{m}$ & $\mathrm{m}$ & $\mathrm{m}$ & $\mathrm{m}$ \\
\hline Mexiko 4 & A & 17,1 & 2,9 & 43,6 & 1,5 & 13,9 & 2,1 & 9,0 & 0,9 & 1,5 & 0,4 & 6,9 & 0,1 \\
\hline & B & 0,2 & 1,2 & 26,3 & 10,2 & 38,0 & 1,1 & 6,8 & 0,6 & 0,1 & $n$ & 15,5 & a \\
\hline Niederlande & A & 17,3 & 6,9 & 34,3 & 2,4 & 10,7 & 2,4 & 20,8 & 1,0 & 2,2 & 0,3 & 1,8 & $\mathrm{n}$ \\
\hline & B & 12,1 & a & 28,6 & 11,8 & 2,9 & a & 37,6 & a & a & a & 7,1 & a \\
\hline Neuseeland & $a$ & 13,3 & 12,1 & 36,1 & 1,9 & 5,7 & 1,7 & 14,6 & 2,6 & 4,2 & 1,0 & 6,4 & 0,6 \\
\hline & B & 18,9 & 19,6 & 23,3 & 9,5 & 3,9 & 2,4 & 9,4 & 0,5 & 1,3 & 0,6 & 9,9 & 0,7 \\
\hline Norwegen & a & 20,7 & 7,2 & 21,5 & 2,9 & 7,4 & 1,2 & 27,0 & 1,1 & 1,1 & 0,2 & 5,1 & 4,7 \\
\hline & B & a & 8,2 & 65,4 & 4,2 & 6,0 & a & 1,5 & 0,1 & a & a & 14,2 & 0,4 \\
\hline Polen & $a$ & 11,5 & 6,5 & 40,0 & 3,6 & 7,3 & 1,7 & 1,9 & 0,7 & 1,2 & 0,6 & 1,0 & 23,8 \\
\hline & B & 13,5 & 7,6 & 42,1 & 3,1 & 2,7 & 1,4 & 2,0 & 0,9 & 1,1 & 0,7 & 0,3 & 24,6 \\
\hline Portugal & $a$ & $\mathrm{~m}$ & $\mathrm{~m}$ & $\mathrm{~m}$ & $\mathrm{~m}$ & $\mathrm{~m}$ & $\mathrm{~m}$ & $\mathrm{~m}$ & $\mathrm{~m}$ & $\mathrm{~m}$ & $\mathrm{~m}$ & $\mathrm{~m}$ & $\mathrm{~m}$ \\
\hline & B & $\mathrm{m}$ & $\mathrm{m}$ & $\mathrm{m}$ & $\mathrm{m}$ & $\mathrm{m}$ & $\mathrm{m}$ & $\mathrm{m}$ & $\mathrm{m}$ & $\mathrm{m}$ & $\mathrm{m}$ & $\mathrm{m}$ & $\mathrm{m}$ \\
\hline Slowakische Rep. & A & 17,2 & 5,5 & 30,1 & 6,6 & 17,9 & 3,9 & 9,4 & 2,4 & 2,4 & 0,5 & 4,0 & a \\
\hline & B & 5,5 & 9,8 & 4,1 & 5,6 & 3,9 & 2,4 & 68,0 & $n$ & $n$ & $\mathrm{n}$ & 0,8 & a \\
\hline Spanien & A & 14,2 & 10,0 & 32,9 & 3,6 & 14,3 & 2,9 & 12,0 & 2,5 & 3,1 & 1,2 & 3,2 & 0,1 \\
\hline & B & 5,0 & 7,6 & 25,2 & 13,0 & 23,3 & 0,6 & 12,5 & $\mathrm{n}$ & $\mathrm{n}$ & $\mathrm{n}$ & 12,7 & $\mathrm{n}$ \\
\hline Schweden & A & 17,7 & 5,5 & 21,1 & 0,9 & 21,7 & 0,9 & 22,8 & 2,7 & 2,3 & 0,5 & 3,8 & a \\
\hline & B & 6,6 & 10,2 & 16,1 & 13,3 & 24,3 & 4,5 & 8,0 & 0,2 & 0,2 & 0,2 & 16,4 & a \\
\hline Schweiz & A & 11,2 & 11,9 & 33,6 & 1,4 & 14,6 & 1,4 & 11,6 & 3,6 & 4,0 & 1,1 & 5,2 & 0,5 \\
\hline & B & 13,9 & 4,1 & 39,3 & 9,5 & 11,1 & 1,7 & 12,5 & $\mathrm{n}$ & $\mathrm{n}$ & $n$ & 7,8 & $n$ \\
\hline Türkei & A & 27,2 & 11,3 & 23,5 & 2,3 & 11,8 & 4,5 & 8,8 & 2,0 & 4,9 & 2,8 & 1,0 & a \\
\hline & B & a & 2,6 & 38,6 & 6,4 & 33,7 & 6,4 & 5,4 & a & 0,1 & $n$ & 6,7 & a \\
\hline Ver. Königreich & A & 11,4 & 16,4 & 29,5 & 1,1 & 10,1 & 1,1 & 12,4 & 6,2 & 4,8 & 1,4 & 5,7 & a \\
\hline & B & 8,5 & 9,2 & 16,7 & 1,3 & 9,8 & 1,7 & 40,2 & 1,8 & 1,9 & 0,4 & 8,5 & a \\
\hline Vereinigte Staaten & A & 13,2 & 14,4 & 41,4 & 3,5 & 6,3 & 2,3 & 9,6 & 3,7 & 1,4 & 0,9 & 3,4 & $\mathrm{n}$ \\
\hline & B & 2,7 & 0,1 & 32,6 & 11,5 & 17,3 & 1,8 & 24,5 & $\mathrm{~m}$ & 0,3 & $\mathrm{~m}$ & 9,1 & 0,1 \\
\hline Ländermittel & A & 12,9 & 11,6 & 32,3 & 2,9 & 13,3 & 2,2 & 12,9 & 2,9 & 2,8 & 1,0 & 3,9 & 1,7 \\
\hline & B & 12,2 & 7,9 & 25,1 & 9,7 & 16,3 & 2,0 & 17,9 & $\mathrm{n}$ & $n$ & n & 8,0 & 1,0 \\
\hline OECD-Partnerländer & & & & & & & & & & & & & \\
\hline Israel & A & 16,3 & 13,1 & 41,8 & a & 10,7 & 0,9 & 5,3 & 3,4 & 1,7 & 6,6 & $x(10)$ & a \\
\hline & B & $\mathrm{m}$ & $\mathrm{m}$ & $\mathrm{m}$ & $\mathrm{m}$ & $\mathrm{m}$ & $\mathrm{m}$ & $\mathrm{m}$ & $\mathrm{m}$ & $\mathrm{m}$ & $\mathrm{m}$ & $\mathrm{m}$ & a \\
\hline
\end{tabular}

Hinweis: Spalte 1 gibt den Bildungsbereich an, wobei A Studiengängen im Tertiärbereich $A$ und weiterführenden Forschungsprogrammen entspricht und B Studiengängen im Tertiärbereich B. $x$ bedeutet, dass die Daten in einer anderen Spalte enthalten sind, deren Referenz in runden Klammern nach dem , $x$ ' angegeben ist. So bedeutet z. B. x(2), dass die Daten in Spalte 2 enthalten sind.

1. Ohne Studiengänge im Tertiärbereich B, die zu einem zweiten Abschluss führen. 2. Referenzjahr 2001. 3. Alle Naturwissenschaften in Biowissenschaften enthalten.

4. Ohne Studiengänge im Tertiärbereich A, die zu einem zweiten Abschluss führen.

Quelle: OECD. Hinweise s. Anhang 3 unter www.oecd.org/edu/eag2004. 
Tabelle A4.2

Anteil der von Frauen erworbenen Abschlüsse im Tertiärbereich (in \%), nach Tertiärbereich und Studienbereich (2002)

\begin{tabular}{|c|c|c|c|c|c|c|c|c|c|c|c|c|c|c|c|c|c|}
\hline & \multicolumn{5}{|c|}{ Alle Studienbereiche } & \multicolumn{2}{|c|}{$\begin{array}{l}\text { Gesundheit } \\
\text { und Soziales }\end{array}$} & \multicolumn{2}{|c|}{$\begin{array}{c}\text { Bio-, Natur- und } \\
\text { Agarwissen- } \\
\text { schaften }\end{array}$} & \multicolumn{2}{|c|}{$\begin{array}{c}\text { Mathematik } \\
\text { und Informatik }\end{array}$} & \multicolumn{2}{|c|}{$\begin{array}{l}\text { Geisteswissen- } \\
\text { schaften, Kunst } \\
\text { und Erziehungs- } \\
\text { wissenschaften }\end{array}$} & \multicolumn{2}{|c|}{$\begin{array}{c}\text { Sozial-, Wirt- } \\
\text { schafts- und } \\
\text { Rechtswissen- } \\
\text { schaften und } \\
\text { Dienst- } \\
\text { leistungen }\end{array}$} & \multicolumn{2}{|c|}{$\begin{array}{l}\text { Ingenieur- } \\
\text { wesen, } \\
\text { Fertigung und } \\
\text { Bauwesen }\end{array}$} \\
\hline & $\begin{array}{l}\text { Tertiär- } \\
\text { bereich } \\
\text { B } \\
\text { (Erstab- } \\
\text { schluss) } \\
\\
\\
\text { (1) }\end{array}$ & \begin{tabular}{|c} 
Tertiär- \\
bereich \\
B \\
(Zweitab- \\
schluss) \\
\\
\\
$(2)$
\end{tabular} & $\begin{array}{l}\text { Tertiär- } \\
\text { bereich } \\
\text { A } \\
\text { (Erstab- } \\
\text { schluss) }\end{array}$ & $\begin{array}{c}\text { Tertiär- } \\
\text { bereich } \\
\text { A } \\
\text { (Zweitab- } \\
\text { schluss) } \\
\\
\text { (4) }\end{array}$ & \begin{tabular}{|c|} 
Weiter- \\
führende \\
For- \\
schungs- \\
pro- \\
gramme \\
\\
$(5)$
\end{tabular} & \begin{tabular}{|c} 
Tertiär- \\
berich \\
B
\end{tabular} & \begin{tabular}{|c|} 
Tertiär- \\
bereich A \\
und wei- \\
terf. For- \\
schungs- \\
pro- \\
gramme \\
$(7)$
\end{tabular} & \begin{tabular}{|c} 
Tertiär- \\
bereich \\
B
\end{tabular} & $\begin{array}{c}\text { Tertiär- } \\
\text { bereich A } \\
\text { und wei- } \\
\text { terf. For- } \\
\text { schungs- } \\
\text { pro-- } \\
\text { gramme } \\
\text { (9) }\end{array}$ & $\begin{array}{c}\text { Tertiär- } \\
\text { bereich } \\
\text { B }\end{array}$ & $\begin{array}{c}\text { Tertiär- } \\
\text { bereich A } \\
\text { und wei- } \\
\text { terf. For- } \\
\text { schungs- } \\
\text { pro- } \\
\text { gramme } \\
\text { (11) }\end{array}$ & $\begin{array}{c}\text { Tertiär- } \\
\text { bereich } \\
\text { B }\end{array}$ & $\begin{array}{c}\text { Tertiär- } \\
\text { bereich A } \\
\text { und wei- } \\
\text { terf. For- } \\
\text { schungs- } \\
\text { pro- } \\
\text { gramme } \\
\text { (13) }\end{array}$ & $\begin{array}{l}\text { Tertiär- } \\
\text { bereich } \\
\text { B }\end{array}$ & \begin{tabular}{|c|} 
Tertiär- \\
bereich A \\
und wei- \\
terf. For- \\
schungs- \\
pro- \\
gramme \\
(15)
\end{tabular} & $\begin{array}{c}\text { Tertiär- } \\
\text { bereich } \\
\text { B }\end{array}$ & $\begin{array}{l}\text { Tertiär- } \\
\text { bereich A } \\
\text { und wei- } \\
\text { terf. For- } \\
\text { schungs- } \\
\text { pro- } \\
\text { gramme } \\
\text { (17) }\end{array}$ \\
\hline \multicolumn{18}{|l|}{ OECD-Länder } \\
\hline Australien & 52 & 42 & 57 & 54 & 44 & 82 & 77 & $\mathrm{~m}$ & 53 & $\mathrm{~m}$ & 28 & 62 & 71 & 56 & 53 & 14 & 23 \\
\hline Österreich & $\mathrm{m}$ & $\mathrm{m}$ & 49 & $\mathrm{n}$ & 38 & $\mathrm{~m}$ & 59 & $\mathrm{~m}$ & 49 & $\mathrm{~m}$ & 19 & $\mathrm{~m}$ & 68 & $\mathrm{~m}$ & 51 & $\mathrm{~m}$ & 17 \\
\hline Belgien & 62 & 62 & 51 & 54 & 36 & 81 & 60 & 48 & 45 & 12 & 21 & 71 & 66 & 58 & 54 & 17 & 21 \\
\hline Kanada & $\mathrm{m}$ & $\mathrm{m}$ & $\mathrm{m}$ & $\mathrm{m}$ & $\mathrm{m}$ & $\mathrm{m}$ & $\mathrm{m}$ & $\mathrm{m}$ & $\mathrm{m}$ & $\mathrm{m}$ & $\mathrm{m}$ & $\mathrm{m}$ & $\mathrm{m}$ & $\mathrm{m}$ & $\mathrm{m}$ & $\mathrm{m}$ & $\mathrm{m}$ \\
\hline Tschechische Rep. & 72 & a & 53 & 53 & 34 & 88 & 71 & 60 & 50 & 42 & 26 & 57 & 70 & 73 & 55 & 27 & 23 \\
\hline Dänemark ${ }^{1}$ & 34 & a & 66 & 50 & 41 & a & 82 & 27 & 45 & 17 & 28 & 67 & 70 & 46 & 45 & 30 & 23 \\
\hline Finnland $^{1}$ & 51 & $\mathrm{a}$ & 63 & 58 & 48 & 87 & 86 & 54 & 54 & 48 & 39 & 75 & 79 & 58 & 68 & 18 & 21 \\
\hline Frankreich $^{1}$ & 53 & a & 58 & 52 & 43 & 81 & 61 & 37 & 50 & 21 & 31 & 57 & 73 & 68 & 60 & 16 & 25 \\
\hline Deutschland & 63 & a & 49 & $a$ & 36 & 83 & 60 & 13 & 43 & 11 & 23 & 86 & 69 & 51 & 45 & 7 & 21 \\
\hline Griechenland & 53 & $\mathrm{a}$ & 57 & 53 & 38 & $\mathrm{~m}$ & $\mathrm{~m}$ & $\mathrm{~m}$ & $\mathrm{~m}$ & $\mathrm{~m}$ & $\mathrm{~m}$ & $\mathrm{~m}$ & $\mathrm{~m}$ & $\mathrm{~m}$ & $\mathrm{~m}$ & $\mathrm{~m}$ & $\mathrm{~m}$ \\
\hline Ungarn & 60 & $\mathrm{~m}$ & 62 & 55 & 45 & 100 & 75 & $\mathrm{n}$ & 48 & 56 & 20 & $\mathrm{n}$ & 75 & 68 & 58 & 19 & 26 \\
\hline Island & 46 & $\mathrm{n}$ & 66 & 48 & 40 & $a$ & 81 & a & 48 & 32 & 20 & 55 & 80 & 45 & 59 & $n$ & 27 \\
\hline Irland & 52 & 52 & 59 & 63 & 40 & 91 & 82 & 65 & 55 & 40 & 37 & 69 & 72 & 59 & 58 & 10 & 22 \\
\hline Italien ${ }^{1}$ & 56 & $\mathrm{a}$ & 57 & 61 & 52 & $a$ & 64 & $\mathrm{a}$ & 52 & $a$ & 52 & 56 & 82 & a & 55 & a & 28 \\
\hline Japan & 66 & $\mathrm{a}$ & 39 & 26 & 23 & 77 & 53 & 53 & 39 & $x(8)$ & $x(9)$ & 82 & 67 & 76 & 33 & 17 & 10 \\
\hline Korea & 55 & 39 & 48 & 34 & 23 & 81 & 58 & 32 & 43 & 40 & 43 & 72 & 71 & 55 & 42 & 34 & 25 \\
\hline Luxemburg & $\mathrm{m}$ & $\mathrm{m}$ & $\mathrm{m}$ & $\mathrm{m}$ & $\mathrm{m}$ & $\mathrm{m}$ & $\mathrm{m}$ & $\mathrm{m}$ & $\mathrm{m}$ & $\mathrm{m}$ & $\mathrm{m}$ & $\mathrm{m}$ & $\mathrm{m}$ & $\mathrm{m}$ & $\mathrm{m}$ & $\mathrm{m}$ & $\mathrm{m}$ \\
\hline Mexiko & 43 & $\mathrm{~m}$ & 53 & $\mathrm{~m}$ & 39 & 80 & 62 & 54 & 42 & 48 & 42 & 78 & 64 & 53 & 57 & 22 & 25 \\
\hline Niederlande & 59 & a & 55 & 65 & 38 & 81 & 74 & a & 40 & 11 & 16 & 82 & 73 & 44 & 50 & $\mathrm{n}$ & 13 \\
\hline Neuseeland & 60 & 66 & 62 & 58 & 47 & 83 & 78 & 46 & 52 & 27 & 31 & 71 & 74 & 62 & 57 & 25 & 32 \\
\hline Norwegen & 52 & a & 63 & 53 & 37 & 84 & 83 & a & 49 & 36 & 24 & 66 & 73 & 56 & 48 & 10 & 22 \\
\hline Polen & 83 & a & 63 & 68 & 44 & a & 69 & a & 64 & a & 41 & 83 & 76 & a & 67 & a & 24 \\
\hline Portugal & $\mathrm{m}$ & $\mathrm{m}$ & $\mathrm{m}$ & $\mathrm{m}$ & $\mathrm{m}$ & $\mathrm{m}$ & $\mathrm{m}$ & $\mathrm{m}$ & $\mathrm{m}$ & $\mathrm{m}$ & $\mathrm{m}$ & $\mathrm{m}$ & $\mathrm{m}$ & $\mathrm{m}$ & $\mathrm{m}$ & $\mathrm{m}$ & $\mathrm{m}$ \\
\hline Slowakische Rep. & 81 & a & 55 & 42 & 41 & 91 & 69 & 66 & 49 & a & 17 & 70 & 68 & 64 & 55 & 22 & 31 \\
\hline Spanien & 52 & $n$ & 59 & $\mathrm{~m}$ & 45 & 82 & 77 & 26 & 52 & 25 & 32 & 68 & 73 & 68 & 60 & 17 & 29 \\
\hline Schweden & 54 & a & 61 & 90 & 41 & 95 & 81 & 54 & 57 & 42 & 40 & 55 & 77 & 69 & 59 & 31 & 28 \\
\hline Schweiz & 47 & 43 & 44 & 31 & 34 & 77 & 59 & 10 & 36 & 18 & 9 & 71 & 62 & 43 & 37 & 7 & 14 \\
\hline Türkei & 45 & a & 41 & 39 & 34 & 61 & 56 & 50 & 44 & 33 & 40 & 80 & 46 & 54 & 39 & 25 & 23 \\
\hline Ver. Königreich & 61 & $x(1)$ & 56 & 55 & 42 & 85 & 74 & 44 & 54 & 27 & 28 & 61 & 67 & 54 & 55 & 14 & 20 \\
\hline Vereinigte Staaten & 59 & a & 57 & 57 & 46 & 87 & 76 & 40 & 53 & 36 & 32 & 79 & 69 & 64 & 54 & 14 & 22 \\
\hline Ländermittel & 57 & 44 & 55 & 51 & 40 & 84 & 70 & 41 & 49 & 31 & 30 & 67 & 70 & 59 & 53 & 18 & 23 \\
\hline \multicolumn{18}{|l|}{ OECD-Partnerländer } \\
\hline Israel & $\mathrm{m}$ & a & 61 & 60 & 47 & $\mathrm{~m}$ & 68 & $\mathrm{~m}$ & 57 & $\mathrm{~m}$ & 35 & $\mathrm{~m}$ & 79 & $\mathrm{~m}$ & 60 & $\mathrm{~m}$ & 24 \\
\hline
\end{tabular}

Hinweis: $x$ bedeutet, dass die Daten in einer anderen Spalte enthalten sind, deren Referenz in runden Klammern nach dem ,x' angegeben ist. So bedeutet z. B. x(2), dass die Daten in Spalte 2 enthalten sind.

1. Referenzjahr 2001.

Quelle: OECD. Hinweise s. Anhang 3 unter www.oecd.org/edu/eag2004. 


\section{Entwicklung der Lesefähigkeiten und des Lesever- ständnisses von Schülern der 4. Jahrgangsstufe}

Bei einem Vergleich von neun Ländern wiesen vier (Griechenland, Island, Slowenien und Ungarn) zwischen 1991 und 2001 einen statistisch signifikanten Anstieg der durchschnittlichen Lesekompetenz bei Schülern der 4. Jahrgangsstufe auf. Dieser Anstieg reicht von 16 Punkten in Ungarn bis zu 41 Punkten in Griechenland. In Schweden ist dagegen die Leistung im gleichen Zeitraum zurückgegangen - von 513 Punkten im Jahr 1991 auf 498 Punkte im Jahr 2001.

In Ungarn haben Leistungsverbesserungen im oberen Leistungsviertel der Schüler zu einem Anstieg des Leistungsdurchschnitts geführt. Im Gegensatz dazu hat in Schweden der Rückgang beim oberen Leistungsviertel zu einem Rückgang des Leistungsdurchschnitts der Schüler der 3. Jahrgangsstufe geführt.

1991 schnitten Mädchen in allen neun Ländern besser ab als Jungen. 2001 bestanden zwar die Unterschiede zugunsten der Mädchen noch in den meisten Ländern, in Italien und Island jedoch waren keine messbaren Unterschiede mehr zu beobachten.

Vorsprung der Mädchen bei den Leseleistungen (1991 und 2001)

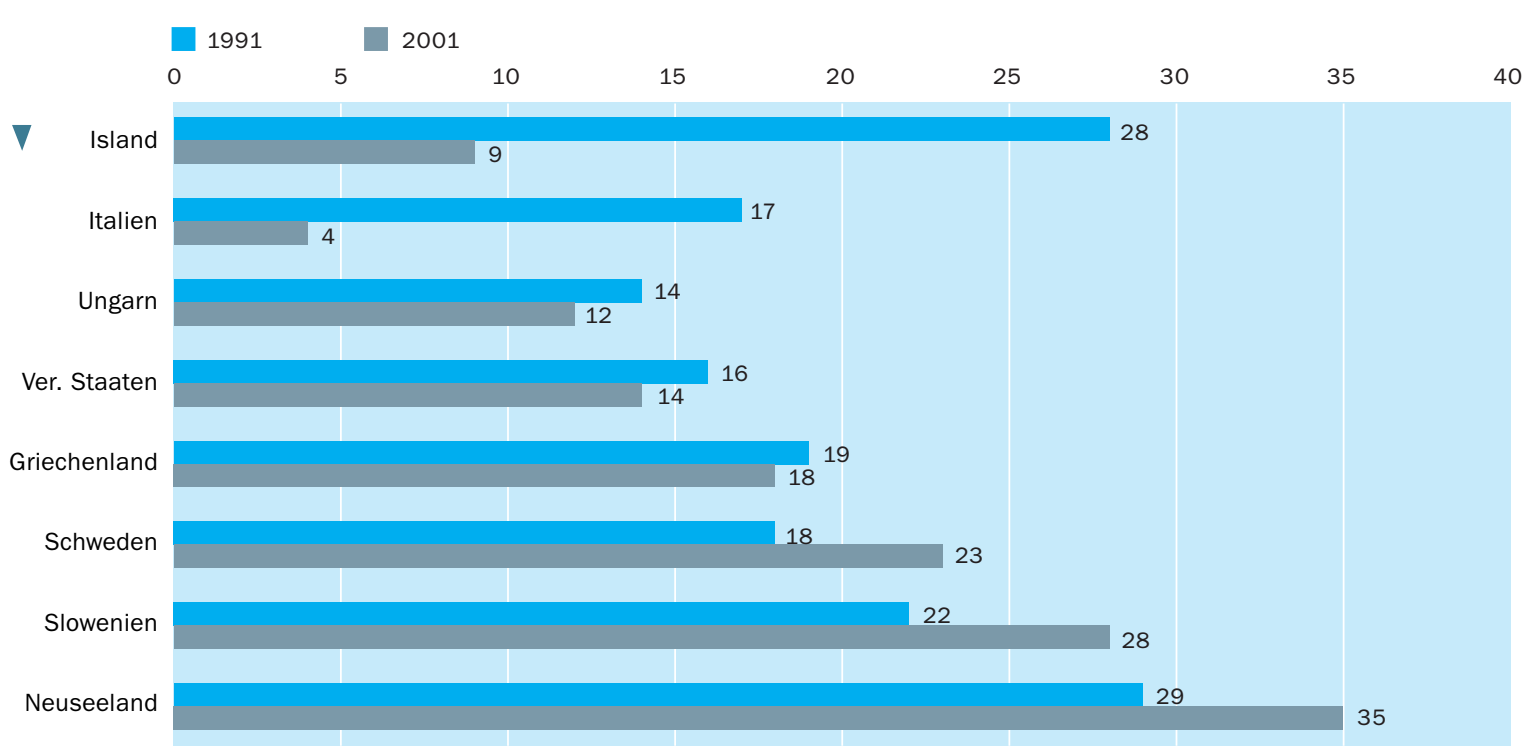

A Vorsprung der Mädchen in 2001 signifikant größer als in 1991.

V Vorsprung der Mädchen in 2001 signifikant kleiner als in 1991. 


\section{Politischer Hintergrund}

Dieser Indikator untersucht Veränderungen der Lesekompetenz von Schülern der 4. Jahrgangsstufe in neun Ländern sowohl insgesamt als auch nach Geschlecht.
Zwischen 1991 und 2001 stieg die durchschnittliche Lesekompetenz der Schüler der 4. Jahrgangsstufe in Griechenland, Island, Slowenien, und Ungarn an.
Die Fähigkeit, Informationen zu lesen, zu verstehen und zu verwenden, ist der Schlüssel zur intellektuellen und persönlichen Entwicklung. Lesefähigkeiten und Leseverständnis, kurz Lesekompetenz genannt, sind die Grundlage für das Lernen über einzelne Schulfächer hinaus und befähigen die Menschen, am Leben in ihrem Umfeld und in der Gesellschaft teilzunehmen. Es handelt sich um eine der wichtigsten Fähigkeiten, die Schüler im Verlauf ihrer Schulzeit erwerben und entwickeln. Gegen Ende der Primarstufe wandelt sich der Lehrplan weg vom Unterrichten von Grundkenntnissen und -fähigkeiten (z. B. Lesen) hin zum Lehren von Grundlagenwissen. Daher sind Kinder, die auf dieser Bildungsebene Schwierigkeiten mit dem Lesen haben, möglicherweise stärker gefährdet, in der Schule und auf ihrem weiteren Bildungsweg zu versagen. Seit I970 hat die International Association for the Evaluation of Educational Achievement (IEA) die Lesekompetenz von Schülern der 4. Jahrgangsstufe bereits zweimal untersucht (s. Kasten A5.I). Aufbauend auf Daten der jüngsten IEAStudie „Trends in Reading Literacy“ untersucht dieser Indikator, wie sich in neun Ländern die Lesekompetenz von Schülern am Ende der Primarstufe zwischen I99I und 200I verändert hat.

\section{Ergebnisse und Erläuterungen}

\section{Länderspezifische Mittelwerte und Leistungsverteilung bei der Lesekompetenz}

Die länderspezifischen Mittelwerte können einen ganz allgemeinen Hinweis darauf liefern, was die Bildungssysteme auf einer bestimmten Jahrgangsstufe und in einem bestimmten Fachbereich leisten. Die Untersuchung von Entwicklungen der Mittelwerte kann Einblick darin gewähren, wie die Bildungssysteme im Verlauf der Zeit abschneiden.

In der Regel wurden in den teilnehmenden Ländern die Schüler der Jahrgangsstufe 4 bewertet. Nachfolgend wird daher „Schüler der 4. Jahrgangsstufe“ verwendet, um die Zielpopulation zu beschreiben. In Neuseeland erfolgte die Erhebung jedoch in der 5. Jahrgangsstufe und in Schweden, Singapur, Slowenien und Ungarn in der 3. Jahrgangsstufe.

Tabelle A5.I zeigt sowohl die Mittelwerte der Lesekompetenz in den Jahren I99I und 200I als auch die Unterschiede zwischen den beiden erfassten Jahren für Schüler der 4. Jahrgangsstufe in jedem der neun an der Studie teilnehmenden Länder. Vier Länder (Griechenland, Island, Slowenien und Ungarn) wiesen zwischen I99I und 200I einen Anstieg der durchschnittlichen Schülerleistung bei der Lesekompetenz auf, der von I6 Punkten in Ungarn bis zu 4I Punkten in Griechenland reicht. Schweden zeigte als einziges Land in diesem Zeitraum einen statistisch signifikanten Rückgang der Leistung - von 5 I3 Punkten im Jahr I99I auf 498 Punkte im Jahr 200I. Vier Länder (Italien, Neuseeland, Singapur und die Vereinigten Staaten) wiesen keine signifikante Veränderung der Gesamtleistung zwischen I99I und 200I auf. Bei der Interpretation dieser Ergebnisse ist jedoch zu berücksichtigen, dass die Stichproben hinsichtlich des Alters der Schüler nicht vergleichbar waren (s. unten). 


\section{IGLU und Entwicklungen bei der Lesekompetenz}

200I hat die International Association for the Evaluation of Educational Achievement (IEA) die Internationale Grundschul-Lese-Untersuchung - IGLU (Progress in International Reading Literacy Study - PIRLS) durchgeführt, um eine internationale Bewertung der Lesekompetenz der Schüler der 4. Jahrgangsstufe zu erhalten. IGLU setzte auf den zwei vorhergehenden IEA Reading Literacy Studies von 1970/7I und I990/9I auf. Mit dieser Studie begann ein 5-Jahreszyklus zur Erhebung von Daten zu Entwicklungen der Lesekompetenz. 35 Länder nahmen am ersten Zyklus, IGLU 200I, teil.

Da IGLU 200I sich in einigen Aspekten von der IEA-Studie zur Lesekompetenz aus dem Jahr I990/9I unterschied, ist es nicht möglich, die Ergebnisse der beiden Studien direkt zu vergleichen. Da jedoch IGLU 200I geplant wurde, um zehn Jahre nach der Studie von I99I Daten über Schüler der 4. Jahrgangsstufe zu erheben, erhielten die IGLU-Länder, die I99I teilgenommen hatten, die Möglichkeit, Veränderungen der Lesekompetenz innerhalb dieses Zeitraums zu erfassen, indem sie als Teil von IGLU die Untersuchung der Lesekompetenz von I99I bei den Schülern des Primarbereichs erneut durchführten. Diese Studie ist bekannt als Trends in Reading Literacy Study im Rahmen von IGLU und bildet die Datenquelle für diesen Indikator.

Die Bewertung, auf der die Trendstudie beruht, basiert auf drei Textarten (narrativ, erklärend, dokumentarisch). Fragen (überwiegend MultipleChoice) verlangten von den Schülern eine Vielzahl von Fähigkeiten und kognitiven Prozessen, wie z.B. Informationen zu erschließen, zu verarbeiten oder Rückschlüsse daraus zu ziehen. Da sich die Studie jedoch in einigen Aspekten von IGLU 200I unterscheidet, können leichte Abweichungen bei den Ergebnissen der einzelnen Länder in den beiden Studien auftreten. Die Trendstudie bietet einen Indikator der Veränderungen über den untersuchten Zeitraum hinweg, die IGLU-Studie einen neuen Vergleichsmaßstab mit einer großen Gruppe von Ländern.

Durchschnittswerte sind zwar sinnvoll, um ein generelles Bild der Leistungen zu erhalten, gleichzeitig verbergen sie jedoch häufig signifikante Leistungsunterschiede zwischen den Schülern eines Landes, die normalerweise weit über die Unterschiede zwischen den einzelnen Ländern hinausgehen. Im Jahr $200 \mathrm{I}$ beispielsweise variierten die Ländermittelwerte um 38 Punkte, die Ergebnisse der mittleren 50 Prozent der Schüler variierten jedoch in allen Ländern nahezu um das Dreifache (und waren damit höher als eine Standardabweichung). Tabelle A5.I zeigt in graphischer Form auch die Verteilung der Ergebnisse für das 5., 25., 75. und 95. Perzentil der beiden untersuchten Jahre.

Betrachtet man genauer, wo die Veränderungen innerhalb der Verteilung der Schülerleistungen auftreten, lassen sich daraus Schlüsse ziehen, wie sich die Leistung innerhalb verschiedener Schülergruppen verändert hat und wie sich dies auf Veränderungen der Gesamtleistung auswirken kann. In Ungarn bei-

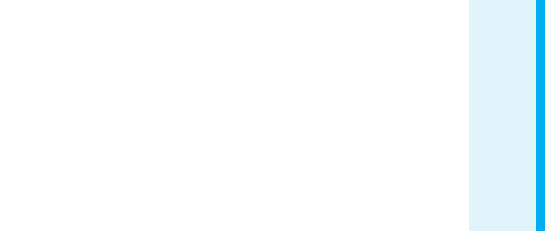

Insgesamt hatten die Veränderungen der Leseleistung in verschiedenen Ländern unterschiedliche Ursachen, ...

... Steigerungen beim oberen Leistungsviertel der Schüler trugen in Ungarn zu einem Anstieg des nationalen Mittelwerts bei, ... 
... während ein Rückgang der Leistung im oberen Viertel in Schweden zu einem Abfallen des nationalen Mittelwertes beigetragen hat. spielsweise scheint der Anstieg des Gesamtmittelwertes das Ergebnis des Leistungsanstiegs der Schüler des 75. und 95. Perzentils in den ro Jahren zu sein d. h. Verbesserungen des obersten Leistungsviertels der Schüler haben anscheinend zu einem Anstieg der Durchschnittsleistungen geführt.

In Schweden dagegen trug ein Rückgang der Leistung des obersten Leistungsviertels zu einem Rückgang der Durchschnittsleistung der Schüler der 3. Jahrgangsstufe bei.

$\mathrm{Zu}$ den anderen Ländern mit Leistungsveränderungen in den verschiedenen Schülergruppen zählen Island und Slowenien, wo die Ergebnisse der Schüler in allen vier Perzentilen anstiegen, und Griechenland, das einen Anstieg bei den mittleren 50 Prozent der Schüler verzeichnete.

Kasten A5.2 enthält einen kurzen Überblick über einige der Hintergrundfaktoren, die sich auf die Leseleistungen der Schüler auswirken können.

Kasten A5.2

\section{Trends bei Faktoren, die sich positiv auf die Leseleistung auswirken}

Die Leseleistung der Schüler kann von zahlreichen Variablen abhängig sein, beispielsweise davon, wie sehr das Lesen zu Hause gefördert wird, von ihren Lesegewohnheiten und von ihrer Einstellung zum Lesen. Aufbauend auf Informationen aus dem Hintergrundfragebogen liefert dieser Kasten eine Übersicht über Entwicklungstrends bei einigen der Faktoren, die sich gemäß der Studien von I99I und/oder 200I in den meisten Ländern positiv auf die Leseleistung auswirken.

In allen neun Ländern, die an der Trendstudie 200 I teilnahmen, erreichten die Schüler, die immer oder fast immer zu Hause die Testsprache sprechen, bessere Leseleistungen als diejenigen, die sie nur gelegentlich oder fast nie sprechen. Diese Ergebnisse unterschieden sich von denen der Studie in I99I, bei der dieser Zusammenhang zwischen der zu Hause gesprochenen Sprache und der Leseleistung in den Ländern stärker variierte. Die Ergebnisse von 200I belegen, dass in allen Ländern außer Italien und Singapur mindestens 88 Prozent der Schüler immer oder fast immer zu Hause die Testsprache sprechen. Dies stellt keine Veränderungen oder allenfalls einen mäßigen Rückgang gegenüber I99I dar.

Entsprechend den Ergebnissen von I99I wurde auch 200I beobachtet, dass Schüler, die viele Bücher zu Hause haben (mehr als 50), bessere Leseleistungen erzielen. 200I reichte der Prozentsatz der Schüler mit sehr vielen Büchern zu Hause (mehr als Ioo) von einem bis zu zwei Dritteln (3I bis 65 Prozent). In sechs der Länder - Island, Italien, Slowenien, Schweden, Ungarn und den Vereinigten Staaten - stellte dies im Vergleich zu I99I einen Rückgang dar. 
Ähnlich wie in früheren Studien schnitten auch 200I die Schüler, die beim Punkt Bücher zum Vergnügen lesen angaben, dies täglich zu tun, besser $\mathrm{ab}$, als diejenigen, die nur einmal pro Monat oder seltener Bücher zum Vergnügen lesen. Im Jahr 200 I gaben die Schüler an, genau so häufig oder seltener als zehn Jahre früher zum Vergnügen zu lesen, die einzige Ausnahme ist hier Island. Island war das einzige Land, das einen Anstieg verzeichnete, und das einzige Land, in dem die Mehrzahl der Schüler (5I Prozent) angab, täglich zum Vergnügen Bücher zu lesen.

Anders als bei der Studie von I99I war der Zusammenhang zwischen der Leseleistung und der Häufigkeit, die bei dem Punkt Bücher aus der Bibliothek ausleihen angegeben wurde, $200 \mathrm{I}$ weniger deutlich, was vielleicht großen Unterschieden bei der Nutzung von Bibliotheken bzw. dem allgemeinen Rückgang ihrer Nutzung zuzuschreiben ist. 200I reichte der Prozentsatz der Schüler, die angaben, wenigstens wöchentlich ein Buch auszuleihen, von mäßig hoch ( 57 bis 66 Prozent) in Neuseeland, Singapur, Slowenien und den Vereinigten Staaten, über durchschnittlich (42 Prozent) in Island bis zu relativ gering (20 bis 33 Prozent) in Griechenland, Italien, Schweden und Ungarn. Diese Zahlen stellen in Singapur, Slowenien, Schweden und Ungarn einen signifikanten Rückgang dar.

200I variierten die Angaben zum täglichen Lesen im Schulbuch während des Unterrichts beträchtlich: zwischen 7I Prozent bei griechischen und I4 Prozent bei schwedischen Schülern. Der allgemeine Trend über das Jahrzehnt hinweg ging hin zu weniger häufigem Lesen im Schulbuch. Dennoch blieb der positive Zusammenhang zwischen Lesen im Schulbuch und Leseleistung bestehen, und Schüler, die nur einmal pro Monat oder seltener im Schulbuch lesen, zeigten im Durchschnitt geringere Leseleistungen als die Schüler, die häufiger lesen. Die Entwicklungstrends der Leistung in verschiedenen Kategorien des Lesens im Schulbuch folgten generell den allgemeinen Entwicklungstrends - Griechenland, Island und Slowenien verzeichnen einen Anstieg und Schweden einen Rückgang.

In Island, Schweden und den Vereinigten Staaten gaben die Schüler an, mehr Hausaufgaben zu haben oder mehr Zeit dafür aufzuwenden. Schüler in Neuseeland gaben keine Veränderung bei der Menge der Hausaufgaben an und die Schüler der übrigen Länder gaben an, weniger Hausaufgaben zu haben. Es ist jedoch schwierig, den Zusammenhang zwischen Leseleistung und Hausaufgaben zu interpretieren, denn Hausaufgaben können für einige Schüle als Herausforderung und für andere zur Förderung genutzt werden, und auch die dafür erforderliche Zeit variiert von Schüler zu Schüler. Für 200r scheint das Ergebnis zu sein, dass die Schüler mit den wenigsten Hausaufgaben die besten Leistungen erzielen.

\section{Geschlechtsspezifische Unterschiede .}

Die linke Hälfte von Tabelle A5.2 zeigt, wie Jungen und Mädchen in den beiden untersuchten Jahren abschnitten. Im Allgemeinen ähneln die Leistungstrends der Mädchen und Jungen den Trends beim Lesen insgesamt. In Griechenland, 
1991 schnitten die Mädchen in allen neun Ländern besser $a b$ als die Jungen. 2001 dagegen waren die Unterschiede zugunsten der Mädchen in den meisten Ländern unverändert, während in Island und Italien keine messbaren Unterschiede mehr zu beobachten waren

In einigen Ländern entwickelte sich die Leistung der Schüler in den verschiedenen Bereichen der Leseleistung unterschiedlich.
Island, Slowenien und Ungarn nahm die Leseleistung der Mädchen und Jungen während des Zeitraums zu. Die Zunahme war in Griechenland, Slowenien und Ungarn in beiden Gruppen ähnlich, dagegen nahmen die Leistungen der Jungen in Island stärker zu als die der Mädchen. In Schweden nahm der Mittelwert sowohl für Mädchen als auch für Jungen zwischen I99I und 200I ab. In Italien, Neuseeland, Singapur und den Vereinigten Staaten wurden keine statistisch signifikanten Veränderungen bei den Ergebnissen von Mädchen und Jungen festgestellt.

Die rechte Seite der Tabelle A5.2 bietet einen anderen Blickwinkel, sie zeigt den Unterschied der Ergebnisse der Mädchen und Jungen für die beiden untersuchten Jahre und zeigt auch, ob dieser Unterschied größer oder kleiner wurde. I99I schnitten die Mädchen in allen neun Ländern besser ab als die Jungen. 200I waren die Unterschiede zugunsten der Mädchen in den meisten Ländern unverändert, in Island und Italien waren die Unterschiede jedoch nicht länger statistisch signifikant. Darüber hinaus wurde in Island ein signifikanter Rückgang der geschlechtspezifischen Unterschiede bei der Leseleistung zwischen Mädchen und Jungen beobachtet (von 28 Punkten Unterschied im Jahr I99I zu 9 Punkten im Jahr 200I), der auf den oben erwähnten Anstieg der Leistung der Jungen zurückzuführen ist (s. auch Abb. A5.I.).

\section{Unterschiedliche Texte}

Zusätzlich zur Gesamtskala bietet die Trends in Reading Literacy Study der IEA auch Informationen zur Leistung der Schüler auf drei Unterskalen, die auf unterschiedlichen Textarten basieren: narrative, erklärende und dokumentarische Texte. Narrative Texte sind fortlaufende Texte, bei denen der Verfasser eine wahre oder fiktive Geschichte erzählen möchte. Diese Textart hat normalerweise eine lineare Zeitenfolge und zielt darauf $a b$, den Leser zu unterhalten oder emotional einzubinden. Die narrativen Texte, die bei der Bewertung genutzt wurden, reichten von kurzen Fabeln bis zu längeren Geschichten mit bis zu Iooo Worten. Erklärende Texte sind ebenfalls fortlaufend und sollen dem Leser Fakten oder Meinungen beschreiben, erklären oder auf andere Weise vermitteln. Dokumentarische Texte sind nicht fortlaufende Texte und bestehen aus strukturierten Informationen, die in Form von Grafiken, Tabellen, Landkarten, Diagrammen, Listen oder Anleitungen dargeboten werden.

Griechenland, Island, Slowenien und Ungarn, die vier Länder, die zwischen I99I und 200I eine Verbesserung der durchschnittlichen Leseleistung aufwiesen, zeigten in allen drei Unterskalen einen Leistungsanstieg (Tab. A5.3). Diese vier Länder waren auch die einzigen, die einen statistisch signifikanten Anstieg bei den Unterskalen narrative Texte und erklärende Texte zeigten. In Schweden und den Vereinigten Staaten dagegen gingen die Leistungen auf der Skala narrative Texte zurück. In Schweden war ebenfalls ein Rückgang bei der Skala erklärende Texte zu verzeichnen.

Was die Skala dokumentarische Texte betrifft, so zeigten alle Länder bis auf zwei, Schweden und die Vereinigten Staaten, im Jahr 200I gegenüber I99I einen Leistungsanstieg. 


\section{Alter und Dauer des Schulbesuchs}

Bei der Interpretation der Ergebnisse ist zu berücksichtigen, dass die Stichproben auf einer bestimmten Jahrgangsstufe basierten, was zu beträchtlichen Unterschieden beim Durchschnittsalter der getesteten Schüler in den teilnehmenden OECD-Ländern führte. Eine Analyse der II OECD-Länder, die sowohl an IGLU als auch an PISA teilnahmen, ergab beispielsweise, dass das durchschnittliche Alter der Schüler 49 Prozent der Leistungsunterschiede zwischen den einzelnen Ländern bei der Gesamtleseleistung erklärt. Außerdem stammt die Stichprobe aus derjenigen Jahrgangsstufe, die den größten Anteil an 9-Jährigen aufweist, und da das Schuleintrittsalter in den einzelnen Ländern variiert, unterscheidet sich auch die Anzahl der Jahre des formalen Schulbesuchs.

Obwohl I99I und 200I die gleiche Jahrgangsstufe untersucht wurde, ergaben sich doch in einigen Ländern Unterschiede beim Durchschnittsalter der Schüler dieser Jahrgangsstufe. Insgesamt reichte das Durchschnittsalter der Schüler der 4. Jahrgangsstufe I99I von 9,3 bis ro Jahre und 200I von 9, I bis Io Jahre. In zwei der Länder, die einen signifikanten Anstieg der Mittelwerte verzeichneten, stieg jedoch das Durchschnittsalter der Schüler ebenfalls signifikant an. In Griechenland stieg das Durchschnittsalter der Schüler der 4. Jahrgangsstufe von 9,3 im Jahr I99I auf Io im Jahr 200I, in Ungarn von 9,3 auf 9,7.

\section{Definitionen und angewandte Methodik}

Die Bewertungen basieren auf der Reading Literacy Study der IEA, die I99I zum ersten Mal durchgeführt wurde (außer in Neuseeland und Singapur, dort wurde sie I990 durchgeführt) und dann $200 \mathrm{I}$ in Zusammenhang mit der Internationalen Grundschul-Lese-Untersuchung - IGLU (Progress in International Reading Literacy Study - PIRLS) wiederholt wurde.

Die Zielpopulation der Trendstudie waren Schüler der Jahrgangsstufe, die zum Zeitpunkt des Tests den größten Anteil an 9-jährigen Schülern aufwies. In der Regel wurden in den teilnehmenden Ländern die Schüler der Jahrgangsstufe 4 bewertet. In Neuseeland erfolgte die Erhebung jedoch in der 5 . Jahrgangsstufe und in Schweden, Singapur, Slowenien und Ungarn in der 3. Jahrgangsstufe.

Die Trends in Reading Literacy Study verwendete Methoden der Item Response Theory (IRT), um die Leistungsergebnisse der Jahre I99I und 200I auf einer gemeinsamen Skala mit einem Mittelwert von 500 und einer Standardabweichung von roo zusammenzufassen. Der mittlere Skalenwert von 500 entspricht den durchschnittlichen Skalenergebnissen der Daten aus dem Jahr 200I der neun Länder, die in diesem Indikator gezeigt werden. Daher weichen die für I99I angegebenen Mittelwerte vom ursprünglichen IGLU-Bericht ab, denn die Daten von I99I wurden neu skaliert, um mit den Daten von $200 \mathrm{I}$ in ein gemeinsames System eingesetzt zu werden.

Hinweise zu Standardfehlern, Signifikanztests und multiplen Vergleichen s. Anhang 3 unter www.oecd.org/eduleag 2004.

Die Leistungsergebnisse basieren auf den Bewertungen, die als Teil der Trends in Reading Literacy Study von der International Association for the Evaluation of Educational Achievement (IEA) durchgeführt wurden. 
Tabelle A5.1

Entwicklung der Leseleistungen (1991-2001)

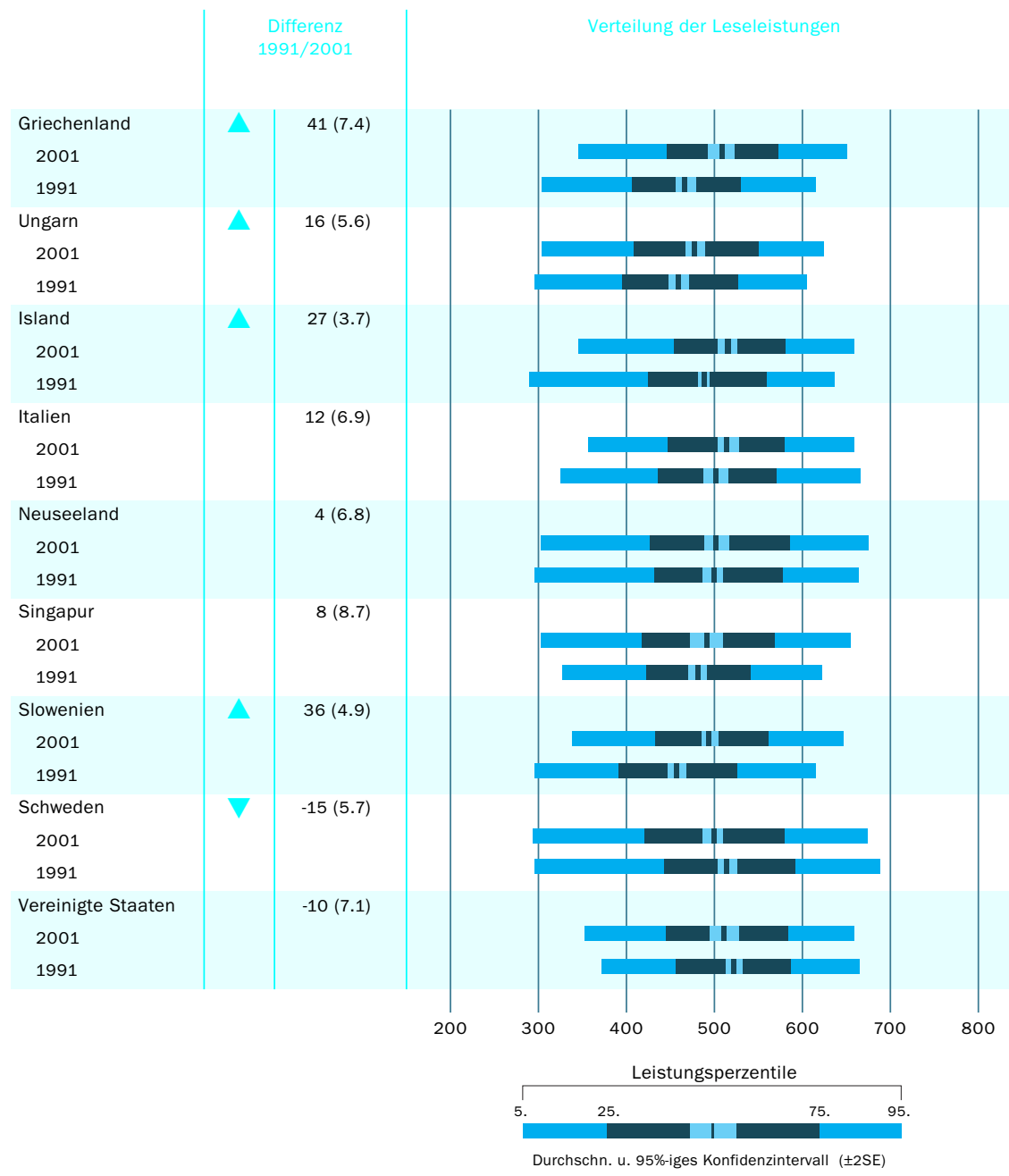

\begin{tabular}{|c|c|c|}
\hline $\begin{array}{l}\text { Durchschn. } \\
\text { Punktzahl }\end{array}$ & $\begin{array}{c}\text { Jahre formaler } \\
\text { (Aus-)Bildung }\end{array}$ & $\begin{array}{c}\text { Durchschn. } \\
\text { Alter }\end{array}$ \\
\hline 507 (5.9) & 4 & 10,0 \\
\hline $466(4.5)$ & 4 & 9,3 \\
\hline 475 (3.9) & 3 & 9,7 \\
\hline $459(4.0)$ & 3 & 9,3 \\
\hline $513(3.5)$ & 4 & 9,8 \\
\hline $486(1.5)$ & 4 & 9,8 \\
\hline $513(4.4)$ & 4 & 9,9 \\
\hline $500(5.4)$ & 4 & 9,8 \\
\hline $502(5.3)$ & 5 & 10,0 \\
\hline $498(4.1)$ & 5 & 10,0 \\
\hline $489(7.9)$ & 3 & 9,1 \\
\hline $481(3.6)$ & 3 & 9,3 \\
\hline 493 (3.7) & 3 & 9,8 \\
\hline $458(3.2)$ & 3 & 9,7 \\
\hline 498 (3.9) & 3 & 9,8 \\
\hline $513(4.2)$ & 3 & 9,8 \\
\hline $511(6.3)$ & 4 & 10,0 \\
\hline $521(3.2)$ & 4 & 10,0 \\
\hline
\end{tabular}

Durchschnitt 2001 signifikant höher als Durchschnitt 1991
Durchschnitt 2001 signifikant niedriger als Durchschnitt 1991

Hinweis: Standardfehler in runden Klammern.

Quelle: Trends in Reading Literacy Study, IEA 2001. 
Tabelle A5.2

Entwicklung der geschlechtsspezifischen Unterschiede bei den Leseleistungen (1991-2001)

\begin{tabular}{|c|c|c|c|c|c|c|c|c|c|}
\hline & \multicolumn{2}{|c|}{ Durchschn. Punktzahl } & \multirow{2}{*}{\multicolumn{2}{|c|}{ Differenz 1991/2001 }} & \multicolumn{4}{|c|}{ Unterschied zwischen Mädchen und Jungen } & \multirow{2}{*}{$\begin{array}{c}\text { Veränderung } \\
\text { der Differenz } \\
1991 / 2001\end{array}$} \\
\hline & 2001 & 1991 & & & & 01 & & 1991 & \\
\hline \multicolumn{10}{|l|}{ Griechenland } \\
\hline Mädchen & $516(7.3)$ & $476(5.7)$ & $\Delta$ & $40(9.2)$ & M & $18(6.3)$ & M & $19(4.8)$ & \\
\hline Jungen & $499(6.0)$ & $457(4.4)$ & $\Delta$ & $41(7.4)$ & & & & & \\
\hline \multicolumn{10}{|l|}{ Ungarn } \\
\hline Mädchen & $481(4.2)$ & $467(4.4)$ & $\Delta$ & $14(6.0)$ & M & $12(3.2)$ & MI & $14(4.4)$ & \\
\hline Jungen & $469(4.2)$ & $453(4.7)$ & $\Delta$ & $16(6.3)$ & & & & & \\
\hline \multicolumn{10}{|l|}{ Island } \\
\hline Mädchen & $517(3.2)$ & $501(2.1)$ & & $17(3.7)$ & & $9(4.8)$ & M & $28(3.6)$ & -- \\
\hline Jungen & $508(5.1)$ & $473(2.6)$ & & $35(5.7)$ & & & & & \\
\hline \multicolumn{10}{|l|}{ Italien } \\
\hline Mädchen & $514(5.2)$ & $512(5.6)$ & & $3(7.6)$ & & $4(5.5)$ & M & $17(5.7)$ & \\
\hline Jungen & $511(5.3)$ & $495(6.4)$ & & $16(8.2)$ & & & & & \\
\hline \multicolumn{10}{|l|}{ Neuseeland } \\
\hline Mädchen & $520(7.0)$ & $514(5.0)$ & & $6(8.7)$ & M & $35(8.7)$ & M & $29(6.3)$ & \\
\hline Jungen & $485(6.6)$ & $485(5.4)$ & & $0(8.6)$ & & & & & \\
\hline \multicolumn{10}{|l|}{ Singapur } \\
\hline Mädchen & $504(7.9)$ & 489 (3.9) & & $15(8.8)$ & M & $29(4.8)$ & M & $16(4.3)$ & ++ \\
\hline Jungen & $475(8.5)$ & $473(4.5)$ & & $2(9.6)$ & & & & & \\
\hline \multicolumn{10}{|l|}{ Slowenien } \\
\hline Mädchen & $508(5.2)$ & 469 (3.5) & & $39(6.3)$ & M & $28(5.7)$ & M & $22(3.7)$ & \\
\hline Jungen & $480(4.1)$ & $447(3.8)$ & $\Delta$ & $33(5.6)$ & & & & & \\
\hline \multicolumn{10}{|l|}{ Schweden } \\
\hline Mädchen & $509(4.3)$ & $523(4.9)$ & $\nabla$ & $-13(6.5)$ & M & $23(4.1)$ & M & $18(4.6)$ & \\
\hline Jungen & $486(4.4)$ & $505(4.8)$ & $\nabla$ & $-18(6.4)$ & & & & & \\
\hline \multicolumn{10}{|c|}{ Vereinigte Staaten } \\
\hline Mädchen & $517(6.7)$ & $529(3.3)$ & & $-12(7.5)$ & M & $14(5.4)$ & M & $16(3.4)$ & \\
\hline Jungen & $504(7.1)$ & $513(4.0)$ & & $-9(8.2)$ & & & & & \\
\hline
\end{tabular}

A Durchschnitt 2001 signifikant höher als Durchschnitt 1991.

V Durchschnitt 2001 signifikant niedriger als Durchschnitt 1991.

IM Mädchen erbringen wesentlich bessere Leistungen als Jungen

++ Geschlechtspezifische Unterschiede 2001 signifikant größer als 1991.

-- Geschlechtspezifische Unterschiede 2001 signifikant geringer als 1991.

Hinweis: Standardfehler in runden Klammern.

Quelle: Trends in Reading Literacy Study, IEA 2001. 


\section{Tabelle A5.3}

Fortschritte bei den Leseleistungen, nach Unterskalen (1991-2001)

\begin{tabular}{|c|c|c|c|c|}
\hline \multirow[b]{3}{*}{ Narrative Texte } & \multicolumn{2}{|c|}{ Durchnittl. Punktzahl } & \multicolumn{2}{|c|}{ Differenz 1991/2001 } \\
\hline & 2001 & 1991 & & \\
\hline & & & & \\
\hline Griechenland & $513(4.8)$ & 479 (3.7) & $\Delta$ & $34(6.0)$ \\
\hline Ungarn & $479(3.1)$ & $467(3.2)$ & $\Delta$ & $12(4.5)$ \\
\hline Island & $524(3.3)$ & $493(1.6)$ & $\Delta$ & $31(3.8)$ \\
\hline Italien & $517(4.1)$ & $507(4.7)$ & & $10(6.2)$ \\
\hline Neuseeland & $496(5.3)$ & $500(4.3)$ & & $-5(6.9)$ \\
\hline Singapur & $487(8.6)$ & $486(3.5)$ & & $1(9.3)$ \\
\hline Slowenien & $490(3.7)$ & $465(3.0)$ & $\Delta$ & $25(4.8)$ \\
\hline Schweden & $496(3.6)$ & $513(3.4)$ & $\nabla$ & $-17(4.8)$ \\
\hline Vereinigte Staaten & $498(6.8)$ & $518(3.3)$ & $\nabla$ & $-20(7.7)$ \\
\hline \multicolumn{5}{|l|}{ Erklärende Texte } \\
\hline Griechenland & $509(5.2)$ & $476(4.3)$ & $\Delta$ & $33(6.8)$ \\
\hline Ungarn & $464(4.4)$ & $443(4.8)$ & $\Delta$ & $21(6.4)$ \\
\hline Island & $502(3.3)$ & $483(1.9)$ & $\Delta$ & $18(3.9)$ \\
\hline Italien & $513(4.5)$ & $507(5.5)$ & & $6(7.1)$ \\
\hline Neuseeland & $510(5.3)$ & $502(3.9)$ & & $8(6.5)$ \\
\hline Singapur & $495(6.6)$ & $489(3.1)$ & & $6(7.3)$ \\
\hline Slowenien & 489 (3.3) & $455(3.6)$ & $\Delta$ & $34(4.9)$ \\
\hline Schweden & $496(4.1)$ & $519(4.4)$ & $\nabla$ & $-23(6.1)$ \\
\hline Vereinigte Staaten & $521(5.4)$ & $516(3.2)$ & & $5(6.2)$ \\
\hline \multicolumn{5}{|c|}{ Dokumentarische Texte } \\
\hline Griechenland & $490(5.2)$ & $443(4.9)$ & $\Delta$ & $48(7.1)$ \\
\hline Ungarn & $486(3.7)$ & $468(4.3)$ & $\Delta$ & $18(5.6)$ \\
\hline Island & $506(3.4)$ & $479(1.7)$ & $\Delta$ & $28(4.0)$ \\
\hline Italien & $499(4.5)$ & $482(5.4)$ & $\Delta$ & $17(6.9)$ \\
\hline Neuseeland & $506(5.2)$ & $491(4.0)$ & $\Delta$ & $16(6.3)$ \\
\hline Singapur & $484(6.8)$ & $465(3.1)$ & $\Delta$ & $18(7.5)$ \\
\hline Slowenien & $502(3.8)$ & $456(3.0)$ & $\Delta$ & $47(4.9)$ \\
\hline Schweden & $506(4.4)$ & $504(4.5)$ & & $2(6.4)$ \\
\hline Vereinigte Staaten & $520(6.1)$ & $527(3.2)$ & & $-7(6.6)$ \\
\hline
\end{tabular}

A Durchschnitt 2001 signifikant höher als Durchschnitt 1991.

V Durchschnitt 2001 signifikant niedriger als Durchschnitt 1991.

Hinweis: Standardfehler in runden Klammern.

Quelle: Trends in Reading Literacy Study, IEA 2001. 


\section{Lesefähigkeiten und Leseverständnis 15-jähriger Schüler}

Im Durchschnitt der OECD-Länder zeigten 10 Prozent der 15-jährigen Schüler Leistungen gemäß den Anforderungen der Stufe 5 im Bereich Lesekompetenz, bei der es um die Bewertung von Informationen und die Entwicklung von Hypothesen geht, die Nutzung von Fachwissen und die Verarbeitung von gedanklichen Konzepten, die unter Umständen den eigenen Erwartungen widersprechen. Dieser Prozentsatz variiert jedoch von 19 Prozent in Finnland und Neuseeland bis zu weniger als 1 Prozent in Mexiko.

Im Durchschnitt erfüllen 12 Prozent der 15-jährigen Schüler nur die Anforderungen der grundlegendsten Kompetenzstufe 1 und weitere 6 Prozent liegen sogar noch darunter.

Einige Länder, insbesondere Finnland, Japan und Korea, haben sowohl hohe Durchschnittsergebnisse erreicht als auch nur geringe Abweichungen zwischen den einzelnen Schülerleistungen.

Sechs Länder (Deutschland, Griechenland, Italien, die Tschechische Republik, Ungarn und die Vereinigten Staaten) schnitten relativ gesehen bei IGLU besser ab als bei PISA. In Deutschland, Italien, der Tschechischen Republik und Ungarn liegen die Ergebnisse bei IGLU über dem OECD-Durchschnitt und bei PISA darunter. Island, Neuseeland und Norwegen schnitten bei PISA relativ besser ab als bei IGLU. Frankreich und Schweden schnitten im Vergleich zu anderen Ländern bei beiden Studien ähnlich ab. 
Lesefähigkeiten und Leseverständnis 15-Jähriger (2000)

Prozentsatz 15-jähriger Schüler auf den einzelnen Kompetenzstufen der PISA-Skala der Lesefähigkeiten und des Leseverständnisses

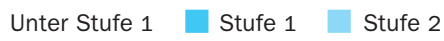
Stufe 3
Stufe 4
Stufe 5

$\% 100$

80

60

40

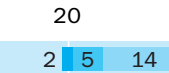

0

$\begin{array}{lllllll}0 & 20 & 40 & 60 & 80 & 100 & \%\end{array}$

$1 \sqrt{5} \quad 19$

$2 \quad 7 \quad 18$

$\begin{array}{lll}3 & 7 & 18\end{array}$

$\begin{array}{lll}3 & 8 & 18\end{array}$

$\begin{array}{lll}5 & 9 & 17\end{array}$

$\begin{array}{lll}3 & 9 & 19\end{array}$

$\begin{array}{lll}4 & 9 & 20\end{array}$

$\begin{array}{lll}3 & 9 & 20\end{array}$

\begin{tabular}{l|l|l}
8 & 11 & 17
\end{tabular}

$\begin{array}{lll}4 & 10 & 22\end{array}$

$\begin{array}{lll}4 & 11 \quad 22\end{array}$

6 $11 \quad 20$

\begin{tabular}{l|l}
4 & $11 \quad 22$
\end{tabular}

\begin{tabular}{l|l|l}
\hline 6 & 12 & 21
\end{tabular}

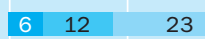

$\begin{array}{lll}7 & 13 & 21\end{array}$

$\begin{array}{lll}4 & 12 & 26\end{array}$

$\begin{array}{lll}6 & 11 & 25\end{array}$

$\begin{array}{lll}5 & 14 & 26\end{array}$

$\begin{array}{lll}10 & 13 & 22\end{array}$

$\begin{array}{lll}9 & 15 & 24\end{array}$

\begin{tabular}{l|l|l}
7 & 16 & 25
\end{tabular}

\begin{tabular}{l|l|l}
9 & 16 & 26
\end{tabular}

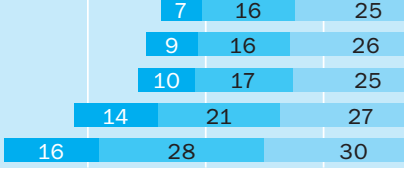

30

\begin{tabular}{|c|}
\hline Finnland \\
\hline Korea \\
\hline Kanada \\
\hline Japan \\
\hline Irland \\
\hline Neuseeland \\
\hline Australien \\
\hline Ver. Königreich \\
\hline Schweden \\
\hline Belgien \\
\hline Österreich \\
\hline Island \\
\hline Norwegen \\
\hline Frankreich \\
\hline Ver. Staaten \\
\hline Dänemark \\
\hline Schweiz \\
\hline Spanien \\
\hline Tschechische Rep. \\
\hline Italien \\
\hline Deutschland \\
\hline Polen \\
\hline Ungarn \\
\hline Griechenland \\
\hline Portugal \\
\hline Luxemburg \\
\hline Mexiko \\
\hline
\end{tabular}

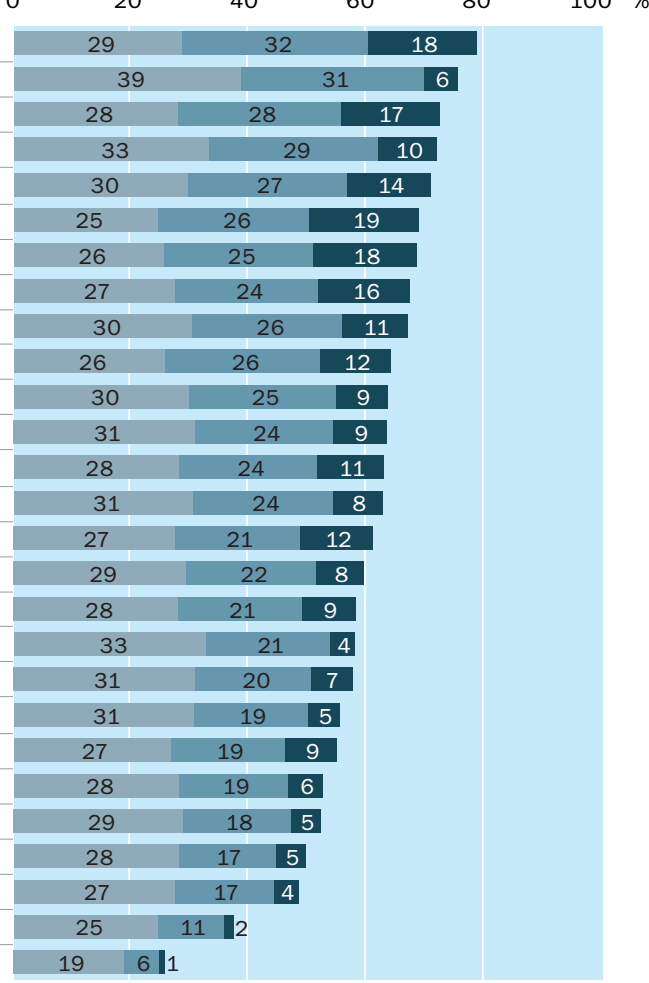

Anordnung der Länder in absteigender Reihenfolge der Schüler auf den Stufen 3, 4 und 5 der PISA-Skala der Lesefähigkeiten und des Leseverständnisses. Quelle: OECD PISA-Datenbank, 2001. Tabelle A6.1. Hinweise zu Methodik s. Anhang 3 (www.oecd.org/edu/eag2004) und www.pisa.oecd.org.

\section{Politischer Hintergrund}

Dieser Indikator zeigt die Leistungen 15-jähriger Schüler im Bereich Lesefähigkeiten und Leseverständnis, kurz der Lesekompetenz, auf.
Die Fähigkeit von Schülern, am Ende der Schulpflicht schriftliche Informationen zu erschließen, zu verarbeiten, zu integrieren, zu bewerten und darüber zu reflektieren, bildet die Grundlage für weiteres Lernen und dafür, aktiv und umfassend am Leben in der modernen Gesellschaft teilzunehmen.

Dieser Indikator zeigt die Leistungen I5-jähriger Schüler bei Aufgaben, die auf einem Konzept der Lesekompetenz beruhen, das über die Vorstellung hinausgeht, wonach Lesekompetenz in dem Entschlüsseln und wörtlichen Verständnis von Texten besteht. Zur Lesekompetenz im Rahmen von PISA gehört auch das Verstehen von Texten und das Nachdenken darüber. Lesekompetenz beinhaltet die Fähigkeit, schriftliche Informationen so zu nutzen, dass diese den jeweiligen Zielen dienen, sowie die entsprechende Fähigkeit komplexer moderner Gesellschaften, schriftliche Informationen effektiv zu nutzen.

Betrachtet man die Indikatoren A5 und A6 zusammen, so lassen sich die Unterschiede untersuchen, die sich in der Lesekompetenz vom Primarbereich bis 
zum Ende der Schulpflicht ergeben, auch wenn die PISA- und IGLU-Studien eine geringfügig unterschiedliche Ausrichtung haben und die Leistungsmessung von zwei Altersstufen zu einem Zeitpunkt nur annäherungsweise eine Aussage über langfristige Fortschritte ermöglicht.

\section{Ergebnisse und Erläuterungen}

\section{Prozentsatz 15-Jähriger auf den einzelnen Stufen der Lesekompetenz}

Bei diesem Indikator wird die Lesekompetenz auf verschiedene Art und Weise untersucht (s. Kasten A6.I zur Erläuterung der Lesekompetenz in der PISAStudie). Zuerst werden die Leistungen in Form der Bandbreite der von den I5-Jährigen in den einzelnen Ländern erzielten Punktzahlen beschrieben. Die Lesekompetenz wird auf fünf Leistungsstufen untersucht, wobei die Aufgaben von Stufe zu Stufe komplexer werden, Stufe 5 ist die höchste Stufe. Zweitens beschreibt dieser Indikator Leistungen in Form der von den I5-Jährigen erreichten mittleren Punktzahlen und wie sich die Punktwerte auf die einzelnen Schülerpopulationen aufteilen.

Kasten A6.1

\section{Was bedeutet Lesekompetenz im Rahmen von PISA?}

Lesefähigkeiten und Leseverständnis, auch als Lesekompetenz (reading literacy) bezeichnet, stehen für die Fähigkeit, geschriebene Texte zu verstehen, zu nutzen und über sie zu reflektieren, um eigene Ziele zu erreichen, das eigene Wissen und Potential weiterzuentwickeln und aktiv am Leben in der Gesellschaft teilzunehmen. Diese Definition geht über die Vorstellung hinaus, wonach Lesekompetenz in dem Entschlüsseln und wörtlichen Verständnis von Texten besteht. Zum Lesen gehört auch das Verstehen von Texten und das Nachdenken darüber, aus einer Reihe von Gründen und in den unterschiedlichsten Kontexten. Die Bewertung der Lesekompetenz im Rahmen von PISA berücksichtigt drei Dimensionen: die Leseaufgabe an sich, die Art des Lesestoffs und die Art des Gebrauchs, für den der Text geschrieben wurde.

\section{Was für Skalen werden benutzt?}

Die Bewertung der Lesekompetenz im Rahmen von PISA erfolgt mittels dreier Skalen. Die Skala „Informationen ermitteln“ gibt die Fähigkeit der Schüler wieder, Informationen in einem Text zu lokalisieren. Die Skala „Textbezogenes Interpretieren“ umfasst die Fähigkeit, der schriftlichen Information Bedeutung zu verleihen und Schlüsse daraus zu ziehen. Die Skala „Reflektieren und Bewerten“ bezieht sich auf die Fähigkeit der Schüler, Verbindungen zwischen einem Text und eigenen Kenntnissen, Vorstellungen und Erfahrungen herzustellen. Außerdem fasst eine Gesamtskala die Ergebnisse der drei Leseskalen zusammen. Indikator A6 konzentriert sich nur auf diese Gesamtskala, die als „PISA-Skala der Lesekompetenz“ bezeichnet wird".

PISA bietet ein aussagefähiges Rahmenwerk für die einzelnen Leistungsstufen der Lesekompetenz. 
10 Prozent der 15-Jährigen in den OECD Ländern verfügen über eine Lesekompetenz der Stufe $5, \ldots$

... dieser Prozentsatz variiert jedoch zwischen den einzelnen Ländern von 19 bis zu weniger als 1 Prozent.

\section{Was bedeuten die Punktzahlen auf diesen Skalen?}

Die Punktzahlen auf diesen Skalen stehen für ein unterschiedliches Ausmaß an Kompetenz bezüglich jeder der Dimensionen oder Aspekte der Lesekompetenz. So bedeutet beispielsweise eine niedrige Punktzahl auf einer Skala, dass ein Schüler in diesem Bereich nur über begrenzte Kompetenzen verfügt, während eine hohe Punktzahl bedeutet, dass ein Schüler in diesem Bereich über größere Kompetenzen verfügt.

\section{Was sind die einzelnen Kompetenzstufen?}

In dem Versuch, diese zunehmende Schwierigkeit der Aufgaben zu erfassen, ist jede der Lesekompetenzskalen in fünf Stufen unterteilt, basierend auf den Kenntnissen und Fähigkeiten, über die die Schüler auf einer bestimmten Stufe verfügen müssen. Schüler auf einer bestimmten Kompetenzstufe verfügen nicht nur über die Kenntnisse und Fähigkeiten, die dieser Stufe zugeordnet sind, sondern sie erbringen auch die auf den darunter liegenden Stufen geforderten Leistungen. So erbringen alle Schüler auf der Kompetenzstufe 3 auch die für die Kompetenzstufen I und 2 erforderlichen Leistungen.

Abbildung A6.I zeigt einen Überblick über die Leistungen auf der PISA-Skala der Lesekompetenz, wobei die Länge der einzelnen farbigen Abschnitte der Balken den prozentualen Anteil der I5-Jährigen angibt, die die Anforderungen der jeweiligen Kompetenzstufe erfüllen (s. Kasten A6.2). Wie aus der Abbildung ersichtlich ist, unterscheidet sich der Prozentsatz der Schüler auf den einzelnen Stufen der Lesekompetenz und die Verteilung über alle Kompetenzstufen hinweg von Land zu Land. Über alle Länder hinweg erreichen durchschnittlich ro Prozent der Schüler Kompetenzstufe 5, 32 Prozent zumindest Kompetenzstufe 4 (d.h. Kompetenzstufe 4 und 5), 6r Prozent erreichen zumindest Kompetenzstufe 3, 82 Prozent zumindest Kompetenzstufe 2, und 94 Prozent zumindest Stufe I.

Betrachtet man die in einem einzelnen Land erbrachten Leistungen Stufe für Stufe, so zeigen sich interessante Ergebnisse: In fünf Ländern (Australien, Finnland, Kanada, Neuseeland und dem Vereinigten Königreich) erreichen 15 Prozent der Schüler oder mehr die höchste Stufe bei der Lesekompetenz. Auch in Belgien, Irland, Norwegen, Schweden und den Vereinigten Staaten erreicht ein beträchtlicher Prozentsatz der Schüler Stufe 5 (zwischen II und I5 Prozent). Aber nur 5 Prozent der Schüler und weniger in Griechenland, Luxemburg, Mexiko, Portugal und Spanien erreichen diese höchste Kompetenzstufe. 
Was leisten Schüler auf den einzelnen Kompetenzstufen und welche Punktzahlen sind mit diesen Kompetenzstufen verbunden?

Schüler, deren Leistungen Stufe 5 (über 625 Punkte) entsprechen, sind in der Lage, anspruchsvolle Leseaufgaben zu lösen, d. h. mit Informationen umzugehen, die in ungewohnten Texten nur schwer zu finden sind, ein genaues Verständnis dieser Texte nachzuweisen und herauszufinden, welche der im Text enthaltenen Informationen für die betreffende Aufgabe von Belang sind, sowie einen Text kritisch zu bewerten und Hypothesen aufzustellen, dabei Fachwissen heranzuziehen und Konzepte zu begreifen, die u. U. im Widerspruch zu den eigenen Erwartungen stehen.

Schüler, deren Leistungen Stufe 4 (553 bis 625 Punkte) entsprechen, sind in der Lage, schwierige Leseaufgaben zu lösen, beispielsweise implizite Informationen zu finden, den Sinn sprachlicher Nuancen zu verstehen und einen Text kritisch zu bewerten.

Schüler, deren Leistungen Stufe 3 ( 481 bis 552 Punkte) entsprechen, sind in der Lage, Leseaufgaben mittlerer Komplexität zu lösen, z. B. mehrere Informationen aufzufinden, Verbindungen zwischen verschiedenen Abschnitten eines Textes herzustellen und den Text zu ihrem Alltagswissen in Beziehung zu setzen.

Schüler, deren Leistungen Stufe 2 (408 bis 480 Punkte) entsprechen, sind in der Lage, grundlegende Leseaufgaben zu lösen, z. B. eindeutige Informationen zu finden, wenig anspruchsvolle Schlussfolgerungen verschiedener Art zu ziehen, die Bedeutung eines genau definierten Textteils zu erkennen und gewisse externe Kenntnisse zu dessen Verständnis heranzuziehen.

Schüler, deren Leistungen Stufe 1 (335 bis 407 Punkte) entsprechen, können nur die einfachsten der für PISA ausgearbeiteten Leseaufgaben lösen, z. B. eine Einzelinformation finden, das Hauptthema eines Textes erkennen oder eine einfache Verbindung zu Alltagskenntnissen ziehen.

Schüler, deren Leistungen unterhalb Stufe 1 (weniger als 335 Punkte) liegen, sind nicht in der Lage, die elementarsten Lesekompetenzen nachzuweisen, die in PISA gemessen werden. Solchen Schülern kann es große Schwierigkeiten bereiten, Lesekompetenzen als ein wirksames Mittel zur Förderung und Erweiterung ihrer Kenntnisse und Fähigkeiten in anderen Bereichen einzusetzen.

Obwohl normalerweise die Länder mit einem hohen Anteil leistungsstarker I5-Jähriger weniger Schüler unterhalb der Stufe I haben (s. beispielsweise Finnland), ist dies nicht immer der Fall. So fallen beispielsweise Belgien und die Vereinigten Staaten aus diesem Muster, da sie einen überdurchschnittlich großen Anteil I5-Jähriger auf der höchsten Kompetenzstufe aufweisen, wäh-

Ein hoher Anteil leistungsstarker Schüler bedeutet normalerweise eine geringere Anzahl leistungsschwacher Schüler, aber in einigen 
Ländern gibt es große Disparitäten.

In einem Drittel der OECDLänder erreichen mehr als zwei Drittel der 15-Jährigen wenigstens Stufe 3.
Die einfachsten Aufgaben der PISA-Studie verlangen von den Schülern mehr als nur flüssig zu lesen. rend gleichzeitig auch der Anteil der Schüler unterhalb von Stufe I überdurchschnittlich groß ist (Tab. A6.I).

Die Hälfte aller I5-Jährigen in Finnland und mindestens 40 Prozent der Schüler in Australien, Irland, Kanada, Neuseeland und dem Vereinigten Königreich erreichen mindestens Stufe 4 auf der PISA-Skala der Lesekompetenz. Mit Ausnahme von Luxemburg und Mexiko erreicht in jedem OECD-Land wenigstens jeder fünfte 15 -Jährige die Kompetenzstufe 4 .

In einem Drittel der OECD-Länder erreichen zwischen 67 und 79 Prozent der I5-Jährigen wenigstens Stufe 3 auf der PISA-Skala der Lesefähigkeiten und des Leseverständnisses (Australien, Finnland, Irland, Japan, Kanada, Korea, Neuseeland, Schweden und das Vereinigte Königreich). Nimmt man diese neun Länder als Grundlage zur Beantwortung der Frage, ob sich die Leistungsprofile in den verschiedenen Ländern ähneln, lassen sich verschiedene Kategorien erkennen. In Finnland und Kanada beispielsweise erreichen relativ viele Schüler Stufe 5, und mindestens 9o Prozent der Schüler erreichen zumindest Stufe 2. Es sind also Länder, die insgesamt gute Ergebnisse auf der PISA-Skala der Lesekompetenz aufweisen. In Australien, Irland, Neuseeland und dem Vereinigten Königreich gibt es sehr viele Schüler auf der obersten Stufe, aber mehr als Io Prozent liegen dort auf Stufe I oder darunter. Diesen Ländern ist es zwar gelungen, die Schüler auf höhere Leistungsniveaus zu bringen, gleichzeitig ist es ihnen jedoch im Vergleich zu Finnland oder Kanada in nur geringerem Maße gelungen, den Anteil der leistungsschwachen Schüler zu verringern. Das Gegenteil ist bei Korea der Fall, wo weniger als 6 Prozent der Schüler auf Stufe I oder darunter liegen, während gleichzeitig nur ein unterdurchschnittlich niedriger Anteil (6 Prozent) Stufe 5 erreicht (Tab. A6.I).

In allen OECD-Ländern erbringt wenigstens die Hälfte aller Schüler Leistungen, die Stufe 2 oder einer höheren Stufe entsprechen. Interessanterweise erreichen in Spanien, wo nur 4 Prozent aller Schüler auf Stufe 5 liegen, überdurchschnittliche 84 Prozent zumindest Stufe 2. Allerdings erreichen auch über 40 Prozent der Schüler in Spanien überhaupt nur Stufe 2 (Tab. A6.I).

Beim PISA-Konzept der Lesekompetenz liegt der Schwerpunkt auf den Kenntnissen und Fähigkeiten, die für das „Lesen, um zu lernen“ notwendig sind und weniger auf den rein technischen Fertigkeiten des „Lesenlernens“. Da in den OECD-Ländern nur vergleichsweise wenige junge Erwachsene die rein „technischen" Lesefertigkeiten nicht erworben haben, soll mit PISA daher nicht gemessen werden, inwieweit I5-Jährige fließend lesen können, oder Wörter richtig buchstabieren oder erkennen können. In Einklang mit den meisten gegenwärtig anerkannten Definitionen der Lesekompetenz zielt PISA darauf ab festzustellen, inwieweit die Schüler in der Lage sind, die Bedeutung eines breiten Spektrums von Texten aus allgemeinen schulischen wie außerschulischen Kontexten zu erfassen, zu erweitern und darüber zu reflektieren. Die einfachsten Aufgaben, die diesem Konzept der Lesekompetenz gerecht werden, sind jene auf Stufe I. Schüler, deren Leistungen nur den Anforderungen dieser Stufe entsprechen, können nur die einfachsten der für PISA ausgearbeiteten Leseaufgaben lösen, z.B. eine Einzelinformation finden, das Hauptthema eines Textes erkennen oder eine einfache Verbindung zu Alltagskenntnissen ziehen. 
Schüler, die weniger als 335 Punkte erzielt haben, Stufe I also nicht erreichen, sind nicht in der Lage, die elementarsten Lesekompetenzen nachzuweisen, die in PISA gemessen werden. Dies soll nicht heißen, dass die fraglichen Schüler über keinerlei Grundqualifikationen in Bezug auf Lesen und Schreiben verfügen. Die meisten dieser Schüler dürften wohl im „technischen“ Sinne durchaus lesen können, und die Mehrzahl von ihnen (54 Prozent im OECD-Durchschnitt) sind in der Lage, mindestens Io Prozent der in PISA 2000 gestellten offenen Fragen, d. h. jenen, bei denen keine Multiple-Choice-Antworten vorgegeben sind, erfolgreich zu lösen (und 6 Prozent gelang es, ein Viertel dieser Aufgaben richtig zu lösen). Das Muster ihrer Antworten bei den Testaufgaben lässt jedoch darauf schließen, dass sie weniger als die Hälfte der Fragen eines Tests mit ausschließlich Stufe I entsprechenden Aufgaben beantworten könnten und den Anforderungen von Stufe I folglich nicht gerecht würden. Diesen Schülern bereitet es große Schwierigkeiten, Lesekompetenzen als ein wirksames Mittel zur Förderung und Erweiterung ihrer Kenntnisse und Fähigkeiten in anderen Bereichen einzusetzen. Bei Schülern, deren Grundqualifikationen unter Stufe I liegen, kann daher nicht nur die Gefahr bestehen, dass sie beim Übergang vom Schul- ins Arbeitsleben großen Problemen gegenüberstehen werden, sondern auch, dass sie in ihrem weiteren Leben Möglichkeiten zur Fort- und Weiterbildung nicht wirklich werden nutzen können.

Wenn in einem Bildungssystem die Leistung eines hohen Prozentsatzes der Schüler unter oder gerade noch bei Stufe I liegt, steht zu befürchten, dass ein großer Teil der Schüler unter Umständen nicht die erforderlichen Grundkenntnisse und -fähigkeiten erwirbt, um aus den gebotenen Bildungsmöglichkeiten wirklichen Nutzen zu ziehen. Diese Situation ist umso besorgniserregender, als zahlreiche Anzeichen dafür sprechen, dass es äußerst schwierig ist, in der Schulzeit entstandene Bildungslücken im späteren Leben zu schließen. Zwischen dem Grundqualifikationsniveau der Erwachsenen und deren Beteiligung an Fort- und Weiterbildung bestehen enge Zusammenhänge, selbst wenn man auch andere Merkmale kontrolliert, die Einfluss auf die Teilnahme an derartigen Maßnahmen haben.

In allen OECD-Ländern zusammen liegen die Leistungen von insgesamt I2 Prozent der Schüler bei Stufe I und von 6 Prozent unterhalb Stufe I, wobei jedoch große Unterschiede zwischen den einzelnen Ländern bestehen. In Finnland und Korea liegt die Leistung von nur ungefähr 5 Prozent der Schüler auf Stufe I, und weniger als 2 Prozent liegen darunter - diese beiden Länder sind jedoch Ausnahmen. In allen anderen OECD-Ländern liegen zwischen 9 und 44 Prozent der Schüler auf Stufe I oder darunter (Tab. A6.I).

Die Länder mit 20 Prozent der Schüler auf Stufe I oder darunter sind Deutschland, Griechenland, Luxemburg, Mexiko, Polen, Portugal, die Schweiz und Ungarn. In Deutschland, Luxemburg, Mexiko und Portugal erreichen zwischen Io und 23 Prozent der Schüler nicht Stufe I, d.h. sie sind nicht in der Lage, die elementarsten Kenntnisse und Fähigkeiten, die in PISA 2000 gemessen wurden, routinemäßig nachzuweisen. Dies ist besonders in Deutschland bemerkenswert, wo ein relativ hoher Prozentsatz von 9 Prozent der Schüler den Anforderungen von Stufe 5 entspricht (Tab. A6.I).
Schüler unterhalb der Stufe 1 mögen zwar über die technische Fähigkeit zu lesen verfügen, werden sich jedoch in ihrem weiteren Leben wahrscheinlich ernsten Schwierigkeiten gegenüber sehen ...

.... und zusammen mit den Schülern auf Stufe 1 nicht die notwendigen Lesekompetenzen erwerben, um Bildungsangebote wirklich nutzen zu können.

Der Prozentsatz von Schülern auf Stufe 1 oder darunter variiert stark zwischen den einzelnen Ländern, von weniger als 10 Prozent bis zu fast der Hälfte, ...

... und in einigen Ländern erreicht eine nicht zu vernachlässigende Minderheit nicht die Stufe 1. 
Durchschnittsergebnisse können nützlich sein, um ein Gesamtbild der Schülerleistungen eines Landes zu vermitteln, ...

... sie täuschen jedoch über die großen Leistungsunterschiede innerhalb der einzelnen Länder hinweg.

Finnland weist einzigartige Gesamtergebnisse auf, mit einem Mittelwert, der fast zwei Drittel einer Kompetenzstufe oberhalb des OECD-Durchschnitts liegt.

Hohe Durchschnittsergebnisse allein sind jedoch nicht ausreichend, die Länder sind auch bemüht, das Niveau der leistungsschwachen Schüler anzuheben.

\section{Länderspezifische Mittelwerte und Leistungsverteilung bei der Lesekompetenz}

Eine weitere Möglichkeit, die Schülerleistungen im Bereich Lesekompetenz zusammenfassend darzustellen und die jeweilige Position der Länder in PISA 2000 zueinander zu vergleichen, ist die Darstellung der Ländermittelwerte. Soweit eine hohe Durchschnittsleistung der I5-Jährigen eine für die Zukunft hoch qualifizierte Erwerbsbevölkerung andeutet, werden Länder mit hohen Durchschnittsergebnissen einen erheblichen wirtschaftlichen und sozialen Vorteil haben. Es muss jedoch berücksichtigt werden, dass sich hinter Durchschnittsergebnissen oft erhebliche Unterschiede innerhalb eines Landes verbergen, und sie die unterschiedlichen Leistungen der vielen verschiedenen Schülergruppen nicht widerspiegeln.

Wie bereits bei früheren internationalen Schulleistungsstudien, wie der Dritten Internationalen Mathematik- und Naturwissenschaftsstudie (TIMSS), entfällt auch bei PISA nur etwa ein Zehntel der erfassten Gesamtvarianz auf Leistungsunterschiede zwischen den einzelnen Ländern, so dass auch nur ein Zehntel davon in einem Vergleich der Durchschnittswerte der einzelnen Länder dargestellt werden kann. Die restliche Varianz tritt innerhalb der einzelnen Länder auf, d.h. zwischen unterschiedlichen Bildungsgängen, zwischen den einzelnen Schulen und zwischen den Schülern einer Schule. Daher bietet dieser Indikator auch Informationen zur Verteilung der erreichten Punktzahlen im Bereich Lesekompetenz, indem auch die Bandbreite der Leistungen zwischen dem obersten und dem untersten Quartil der Schüler innerhalb eines Landes untersucht wird.

Die Schüler Finnlands erzielen auf der Skala der Lesekompetenz höhere Durchschnittsergebnisse als die Schüler aller anderen Länder, die an der Studie teilgenommen haben (s. Abb. A6.2). Ihr Mittelwert liegt mit 546 Punkten fast zwei Drittel einer Kompetenzstufe über dem OECD-Mittelwert von 500 Punkten (bzw. statistisch ausgedrückt übertrifft er den OECD-Mittelwert um fast eine halbe internationale Standardabweichung). II andere OECD-Länder Australien, Belgien, Island, Irland, Japan, Korea, Kanada, Österreich, Neuseeland, Schweden und das Vereinigte Königreich - liegen signifikant über dem OECD-Durchschnitt. In fünf Ländern entspricht der Mittelwert in etwa dem OECD-Durchschnitt und die verbleibenden Länder liegen signifikant unter dem OECD-Durchschnitt.

Ein Blick auf die Verteilung der Schülerleistungen (Tab. A6.2) zeigt, dass die Unterschiede der Schülerleistungen auf der Skala für Lesekompetenz innerhalb der einzelnen Länder groß sind. Die Unterschiede innerhalb der einzelnen Länder sind deutlich größer als die Unterschiede zwischen den Ländern. Der Unterschied zwischen dem 3. und dem I. Quartil, der die mittlere Hälfte der Verteilung der nationalen Leistungen abdeckt, übersteigt in allen Ländern die Größenordnung einer ganzen Kompetenzstufe (72 Punkte), und ist in Australien, Belgien, Deutschland und Neuseeland ungefähr so groß wie zwei ganze Kompetenzstufen. (Der OECD-Durchschnitt bei dieser Kenngröße beläuft sich auf das I,8-fache einer Kompetenzstufe). 
Abbildung A6.2

Mehrfachvergleich der mittleren Schülerleistungen der Länder auf der PISA-Skala der Lesefähigkeiten und des Leseverständnisses (2000)

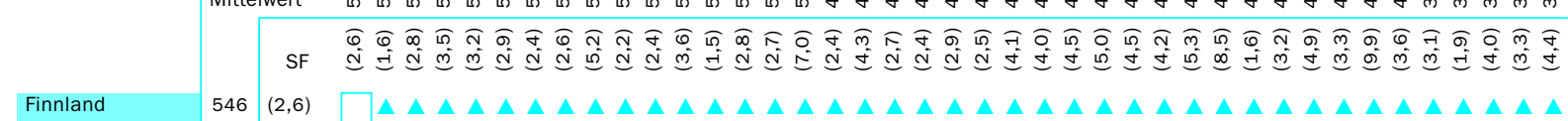

\section{Kanada}

Neuseeland

Australien

Irland

Hongk.- China

Korea

Ver. Königreich

Japan

Schweden

Österreich

Belgien

Island

Norwegen

Frankreich

Ver. Staaten

Dänemark

Schweiz

Spanien

Tschech. Rep.

Italien

Deutschland

Liechtenstein

Ungarn

Polen

Griechenland

Portugal

Russische Föd.

Lettland

Israel

Luxemburg

Thailand

Bulgarien

Mexiko

Argentinien

Chile

Brasilien

Rep. Mazedonien

Indonesien

Albanien

Peru
$534(1,6)$

$529 \quad(2,8)$

$528(3,5)$

$527(3,2)$

$525(2,9)$

$525 \quad(2,4)$

$523(2,6)$

$522(5,2)$

$516(2,2)$

$507 \quad(2,4)$

$507 \quad(3,6)$

$507 \quad(1,5)$

$505 \quad(2,8)$

$505 \quad(2,7)$

$504(7,0)$

$497 \quad(2,4)$

$494 \quad(4,3)$

$493 \quad(2,7)$

$492(2,4)$

$487 \quad(2,9)$

$484(2,5)$

$483(4,1)$

$480(4,0)$

$479(4,5)$

$474 \quad(5,0)$

$470(4,5)$

$462(4,2)$

$458(5,3)$

$452(8,5)$

$441(1,6)$

$431(3,2)$

$430(4,9)$

$422(3,3)$

$418(9,9)$

$410(3,6)$

$396(3,1)$

$373(1,9)$

$371(4,0)$

\begin{tabular}{l|l}
349 & $(3,3)$ \\
327 & $(4,4)$
\end{tabular}

$\nabla$ O O O O $\nabla 0$ O O O O O O $\nabla 00$ O O O O O O $A \Delta \Delta \Delta \Delta O \Delta \Delta \Delta \Delta \Delta \Delta \Delta \Delta \Delta \Delta \Delta \Delta \Delta \Delta \Delta \Delta \Delta \Delta \Delta \Delta \Delta \Delta \Delta \Delta \Delta$

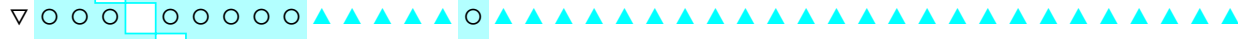

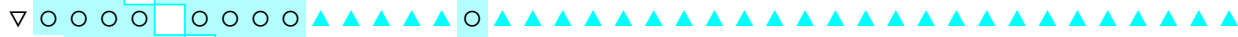
$\nabla \nabla 0$ O O O 0 O O $\nabla \nabla 00000$ O O O $\nabla 0000000$ O O O O O O O $\nabla \nabla \nabla$ O O O O O O 0 O 0 O O

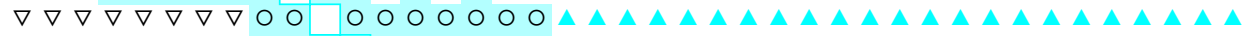

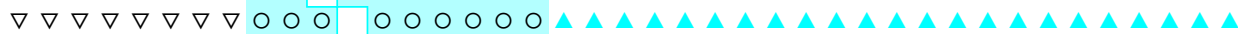
$\nabla \nabla \nabla \nabla \nabla \nabla \nabla \nabla 0 \nabla$ O O 0 O O O $\nabla \nabla \nabla \nabla \nabla \nabla \nabla \nabla 00000 \quad 0000 \Delta \Delta \Delta \Delta \Delta \Delta \Delta \Delta \Delta \Delta \Delta \Delta \Delta \Delta \Delta \Delta \Delta \Delta \Delta \Delta \Delta \Delta \Delta$ $\nabla \nabla \nabla \nabla \nabla \nabla \nabla \nabla 0 \nabla 000000000 \Delta \Delta \Delta \Delta \Delta \Delta \Delta \Delta \Delta \Delta \Delta \Delta \Delta \Delta \Delta \Delta \Delta \Delta \Delta \Delta$ $\nabla \nabla \nabla 0000000000000000000000 \Delta \Delta \Delta \Delta \Delta \Delta \Delta \Delta \Delta \Delta \Delta \Delta \Delta \Delta \Delta \Delta$ $\nabla \nabla \nabla \nabla \nabla \nabla \nabla \nabla \nabla \nabla 00 \nabla 00000000 \Delta 0 \Delta \Delta \Delta \Delta \Delta \Delta \Delta \Delta \Delta \Delta \Delta \Delta \Delta \Delta \Delta \Delta \Delta \Delta$

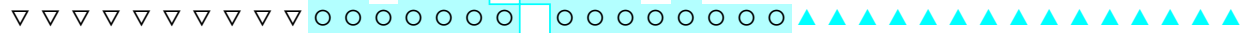
$\nabla \nabla \nabla \nabla \nabla \nabla \nabla \nabla \nabla \nabla \nabla \nabla \nabla \nabla 000$ ○ $\nabla \nabla 000000$

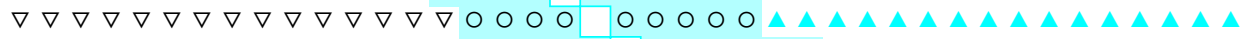
$\nabla \nabla \nabla \nabla \nabla \nabla \nabla \nabla \nabla \nabla \nabla \nabla \nabla \nabla \nabla 0000000000000$ $\nabla \nabla \nabla \nabla \nabla \nabla \nabla \nabla \nabla \nabla \nabla \nabla \nabla \nabla \nabla 0 \nabla 00000.00000 \Delta \Delta \Delta \Delta \Delta \Delta \Delta \Delta \Delta \Delta \Delta \Delta \Delta \Delta \Delta$ $\nabla \nabla \nabla \nabla \nabla \nabla \nabla \nabla \nabla \nabla \nabla \nabla \nabla \nabla \nabla 00000000.00000$ $\nabla \nabla \nabla \nabla \nabla \nabla \nabla \nabla \nabla \nabla \nabla \nabla \nabla \nabla \nabla 0 \nabla 00000000000$ $\nabla \nabla \nabla \nabla \nabla \nabla \nabla \nabla \nabla \nabla \nabla \nabla \nabla \nabla \nabla 0 \nabla 000000000.00000$ $\nabla \nabla \nabla \nabla \nabla \nabla \nabla \nabla \nabla \nabla \nabla \nabla \nabla \nabla \nabla \nabla \nabla 0 \nabla \nabla 00000000000$ $\nabla \nabla \nabla \nabla \nabla \nabla \nabla \nabla \nabla \nabla \nabla \nabla \nabla \nabla \nabla \nabla \nabla \nabla \nabla \nabla 00000000000$

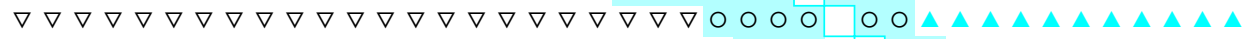

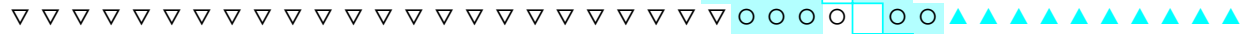
$\nabla \nabla \nabla \nabla \nabla \nabla \nabla \nabla \nabla \nabla \nabla \nabla \nabla \nabla \nabla \nabla \nabla \nabla \nabla \nabla \nabla \nabla \nabla 0000000000$ $\nabla \nabla \nabla \nabla \nabla \nabla \nabla \nabla \nabla \nabla \nabla \nabla \nabla \nabla \nabla \nabla \nabla \nabla \nabla \nabla \nabla \nabla \nabla \nabla \nabla \nabla \nabla \nabla 0$ O $\nabla \nabla \nabla \nabla \nabla \nabla \nabla \nabla \nabla \nabla \nabla \nabla \nabla \nabla \nabla \nabla \nabla \nabla \nabla \nabla \nabla \nabla \nabla \nabla \nabla \nabla \nabla \nabla \nabla 00 \quad 000 \Delta \Delta \Delta \Delta \Delta \Delta$ $\nabla \nabla \nabla \nabla \nabla \nabla \nabla \nabla \nabla \nabla \nabla \nabla \nabla \nabla \nabla \nabla \nabla \nabla \nabla \nabla \nabla \nabla \nabla \nabla \nabla \nabla \nabla \nabla \nabla 000 \quad 00 \Delta \Delta \Delta \Delta \Delta \Delta$

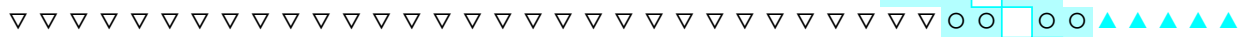
$\nabla \nabla \nabla \nabla \nabla \nabla \nabla \nabla \nabla \nabla \nabla \nabla \nabla \nabla \nabla \nabla \nabla \nabla \nabla \nabla \nabla \nabla \nabla \nabla \nabla \nabla \nabla \nabla \nabla 00$ O

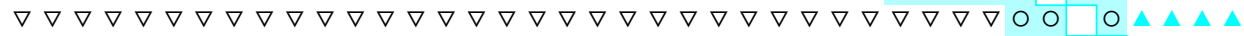

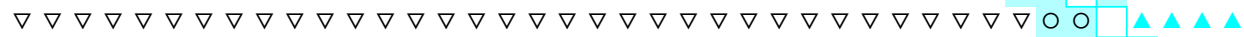
$\nabla \nabla \nabla \nabla \nabla \nabla \nabla \nabla \nabla \nabla \nabla \nabla \nabla \nabla \nabla \nabla \nabla \nabla \nabla \nabla \nabla \nabla \nabla \nabla \nabla \nabla \nabla \nabla \nabla \nabla \nabla \nabla \nabla \nabla \nabla \nabla \nabla \quad 0 \Delta \Delta$ $\nabla \nabla \nabla \nabla \nabla \nabla \nabla \nabla \nabla \nabla \nabla \nabla \nabla \nabla \nabla \nabla \nabla \nabla \nabla \nabla \nabla \nabla \nabla \nabla \nabla \nabla \nabla \nabla \nabla \nabla \nabla \nabla \nabla \nabla \nabla \nabla \nabla \mathbf{O} \nabla \mathbf{\Delta} \Delta$ $\nabla \nabla \nabla \nabla \nabla \nabla \nabla \nabla \nabla \nabla \nabla \nabla \nabla \nabla \nabla \nabla \nabla \nabla \nabla \nabla \nabla \nabla \nabla \nabla \nabla \nabla \nabla \nabla \nabla \nabla \nabla \nabla \nabla \nabla \nabla \nabla \nabla \nabla \nabla$ $\nabla \nabla \nabla \nabla \nabla \nabla \nabla \nabla \nabla \nabla \nabla \nabla \nabla \nabla \nabla \nabla \nabla \nabla \nabla \nabla \nabla \nabla \nabla \nabla \nabla \nabla \nabla \nabla \nabla \nabla \nabla \nabla \nabla \nabla \nabla \nabla \nabla \nabla \nabla \nabla$

Erläuterung: Zum Vergleich der Schülerleistungen eines Landes mit denen der Länder im Tabellenkopf ist die Zeile des betreffenden Landes zu lesen.

Statistische Signifilanz der Unterschiede bei mittleren Schülerleistungen

A Mittlere Schülerleistungen statistisch signifikant höher als im Vergleichsland

Kein statistisch signifikanter Unterschied gegenüber dem Vergleichsland

$\nabla$ Mittlere Schülerleistungen signifikant niedriger als im Vergleichsland
Statistische Signifikanz der Differenz zum Ländermittel Statistisch signifikant über dem Ländermittel. Kein statistisch signifikanter Unterschied zum Ländermittel. Statistisch signifikant unter dem Ländermittel.

Anordnung der Länder in absteigender Reihenfolge der mittleren Schülerleistungen auf der PISA-Skala der Lesefähigkeiten und des Leseverständnisses. Erläuterung: Aufgrund der geringen Beteiligungsquote sind die Niederlande nicht enthalten.

Quelle: OECD PISA-Datenbank, 2000. Hinweise zur Methodik s. Anhang 3 unter www.oecd.org/edu/eag2004 und www.pisa.oecd.org . 
Sind diese zu beobachtenden Disparitäten unvermeidlich?

Die Frage ist nicht leicht zu beantworten, aber einige Länder begrenzen sie auf eine wesentlich engere Bandbreite als andere...

... und einigen Ländern gelingt es, hohe Durchschnittsergebnisse mit geringen Disparitäten zu verbinden.
Zusammengenommen deuten diese Ergebnisse darauf hin, dass sich die Bildungssysteme in vielen Ländern schwierigen Herausforderungen dabei gegenüber sehen, dem Bildungsbedarf aller Schüler gerecht zu werden, sowohl derer, die den größten Bedarf haben als auch derer, die sehr leistungsstark sind.

Es zeigt sich außerdem, dass Länder mit ähnlichen Durchschnittsergebnissen beträchtliche Unterschiede bei der Varianz der Schülerleistungen aufweisen. So erzielten beispielsweise sowohl Korea als auch das Vereinigte Königreich mit ungefähr 525 Punkten überdurchschnittliche mittlere Leistungen auf der PISA-Skala der Lesekompetenz. Der Unterschied zwischen dem 3. und I. Quartil in Korea beträgt 92 Punkte, signifikant unter dem OECD-Durchschnitt, im Vereinigten Königreich jedoch beläuft er sich auf I 37 Punkte, mehr oder minder auf dem Niveau des OECD-Durchschnitts. Ähnliches lässt sich auch für Länder mit unterdurchschnittlichen Durchschnittsergebnissen beobachten. Sowohl in Deutschland als auch Italien beläuft sich der Mittelwert auf ungefähr 485 Punkte, signifikant unter dem OECD-Durchschnitt. In Italien beläuft sich der Unterschied zwischen dem 3. und I. Quartil auf I24 Punkte, in Deutschland jedoch auf I 46 Punkte. Das unterste Quartil der Schüler näher an den Mittelwert heranzubringen, ist für Länder mit großen internen Unterschieden eine der Möglichkeiten, die Gesamtleistungen zu steigern.

Schließlich zeigt ein Vergleich der Bandbreite der Leistungen innerhalb eines Landes mit seinem Mittelwert, dass es einigen Ländern gelingt, sowohl relativ geringe Unterschiede zwischen den leistungsstarken und den leistungsschwachen Schülern als auch relativ hohe Gesamtleistungen zu erreichen. Die Länder, die sehr gut abschneiden, weisen oft auch relativ geringe Disparitäten auf. So gehören beispielsweise die drei Länder mit dem geringsten Unterschied zwischen dem 3. und I. Quartil, Finnland, Japan und Korea, auch zu den Ländern mit den besten Leistungen im Bereich Lesekompetenz. Im Gegensatz dazu erzielt eins der drei Länder mit den größten Leistungsunterschieden, Deutschland, Punktwerte, die beträchtlich unter dem OECD-Durchschnitt liegen (Tab. A6.2).

Kasten A6.3

\section{Lesekompetenz in der PISA- und der IGLU-Studie}

Es gibt signifikante Ähnlichkeiten bei der Definition der Lesekompetenz bei der PISA- und der IGLU-Leistungsbewertung. Obwohl ein direkter Vergleich der Ergebnisse der beiden Studien nicht möglich ist - bei IGLU und PISA handelt es sich um unterschiedliche Leistungsbewertungen mit unterschiedlichen Ansätzen bei der Definition der Zielpopulation - ist es interessant, ganz allgemein die II Länder zu vergleichen, für die Daten aus beiden Erhebungen vorliegen.

\section{Position im Verhältnis zum OECD-Mittelwert}

Sechs Länder (Deutschland, Griechenland, Italien, die Tschechische Republik, Ungarn und die Vereinigten Staaten) erreichten bei der IGLU-Studie bessere Ergebnisse als bei PISA. In Deutschland, Italien, der Tschechischen 
Republik und Ungarn liegen die Ergebnisse bei IGLU über dem OECDDurchschnitt, bei PISA jedoch darunter. Drei Länder schnitten bei PISA besser ab als bei IGLU - Island, Neuseeland und Norwegen. Frankreich und Schweden schnitten im Vergleich zu anderen Ländern bei beiden Bewertungen ähnlich ab (Tab. A6.3).

\section{Unterschiede in den Leistungen}

In Schweden und der Tschechischen Republik ist die Varianz der Lesekompetenz sowohl bei den Schülern der 4. Jahrgangsstufe als auch bei den I5-jährigen gering. In Schweden liegt der Leistungsdurchschnitt in beiden Altersgruppen über dem OECD-Durchschnitt, während er in der Tschechischen Republik bei den Schülern der 4. Jahrgangsstufe über dem OECDWert, bei den I5-Jährigen jedoch darunter liegt (Tab. A6.2). In Deutschland schneiden die Schüler der 4. Jahrgangsstufe im Durchschnitt gut ab und es gibt nur geringe Unterschiede zwischen ihnen. Bei den 15 -Jährigen dagegen liegt die Leistung unter dem Durchschnitt und die Disparität der Schülerleistungen gehört zu den größten. Neuseeländische Schüler weisen in beiden Altersgruppen mit die größten Unterschiede auf.

Der Vergleich basiert auf Deutschland, Frankreich, Griechenland, Island, Italien, Neuseeland, Norwegen Schweden, der Tschechischen Republik, Ungarn und den Vereinigten Staaten. Kanada und das Vereinigte Königreich sind in diesem Vergleich nicht erfasst, da nur bestimmte Landesteile von ihnen an der IGLU-Studie teilnahmen. Die Niederlande sind nicht erfasst, da die dortigen durchschnittlichen Leseergebnisse der PISA-Studie aufgrund von geringen Rücklaufquoten nicht veröffentlicht wurden. Die Slowakische Republik und die Türkei, die zwar an der IGLU-Studie teilnahmen, haben an PISA 2000 nicht teilgenommen.

Bei der Interpretation dieser Ergebnisse muss berücksichtigt werden, dass anders als bei PISA die Stichproben für IGLU auf der Jahrgangsstufe basierten, was zu beträchtlichen Unterschieden beim Durchschnittsalter der Schüler in den teilnehmenden Ländern führte. Die Schüler in Schweden, dem Land, das am besten abschnitt, waren ein Jahr älter als die Schüler in Island und Italien und fast ein Jahr älter als die Schüler in Frankreich, Griechenland, Neuseeland und Norwegen. Bei den II Ländern, die sowohl an PISA als auch an IGLU teilnahmen, erklärt das durchschnittliche Alter der Schüler immerhin beträchtliche 49 Prozent der Leistungsunterschiede auf der IGLU-Skala. Diese Unterschiede müssen nicht nur bei der Interpretation der Durchschnittsleistungen im Rahmen von IGLU berücksichtigt werden, sondern auch, wenn man die Leistungsunterschiede zwischen PISA und IGLU innerhalb eines Landes vergleicht. Trotzdem ist bemerkenswert, dass die Leistungen der schwedischen Schüler der Jahrgangsstufe 3 auch nach einer Anpassung aufgrund des unterschiedlichen Alters immer noch zu den besten gehören. 


\section{Definitionen und angewandte Methodik}

6 Die erzielten Punktzahlen

basieren auf Leistungs-

messungen, die Teil der im

Jahr 2000 von der OECD

durchgeführten Internatio-

nalen Schulleistungsstudie

PISA waren.
Die für diesen Indikator untersuchte Zielpopulation waren I5-jährige Schüler. In der Praxis bezieht sich dies auf Schüler, die zu Beginn der Testperiode im Alter von I5 Jahren und 3 (abgeschlossenen) Monaten bis zu I6 Jahren und 2 (abgeschlossenen) Monaten waren und eine Bildungseinrichtung besuchten, ungeachtet der Klassenstufe und der Art der von ihnen besuchten Bildungseinrichtung und unabhängig davon, ob es sich um eine Ganztags- oder Halbtagsschule handelte.

Um die Interpretation der von den Schülern erzielten Punktwerte in der PISAStudie zu erleichtern, wurde die PISA-Skala der Lesefähigkeiten und des Leseverständnisses so konstruiert, dass der Mittelwert in den OECD-Ländern bei 500 Punkten liegt und die Standardabweichung bei roo, wobei die Daten gewichtet wurden, so dass jedes OECD-Land gleichermaßen hierzu beitrug. Diese Bezugspunkte bilden gewissermaßen den „Anker“ der im Rahmen von PISA durchgeführten Messung der Schülerleistungen.

Im Unterschied zur PISA-Studie wurde die IGLU-Skala so konstruiert, dass der Mittelwert für alle Länder, einschließlich der OECD-Partnerländer, bei 500 liegt, bei einer Standardabweichung von Ioo. Der internationale Mittelwert unterscheidet sich daher von der Trends in Reading Literacy Studie, über die in Indikator $\mathrm{A}_{5}$ berichtet wird.

Hinweise zu Standardfehlern, Signifikanztests und multiplen Vergleichen s. Anhang 3 unter www.oecd.org/edu/eag2004. 
Tabelle A6.1

Lesefähigkeiten und -verständnis 15-Jähriger (2000)

Prozentsatz 15-jähriger Schüler auf den einzelnen Kompetenzstufen der PISA-Skala der Lesefähigkeiten und des Leseverständnisses

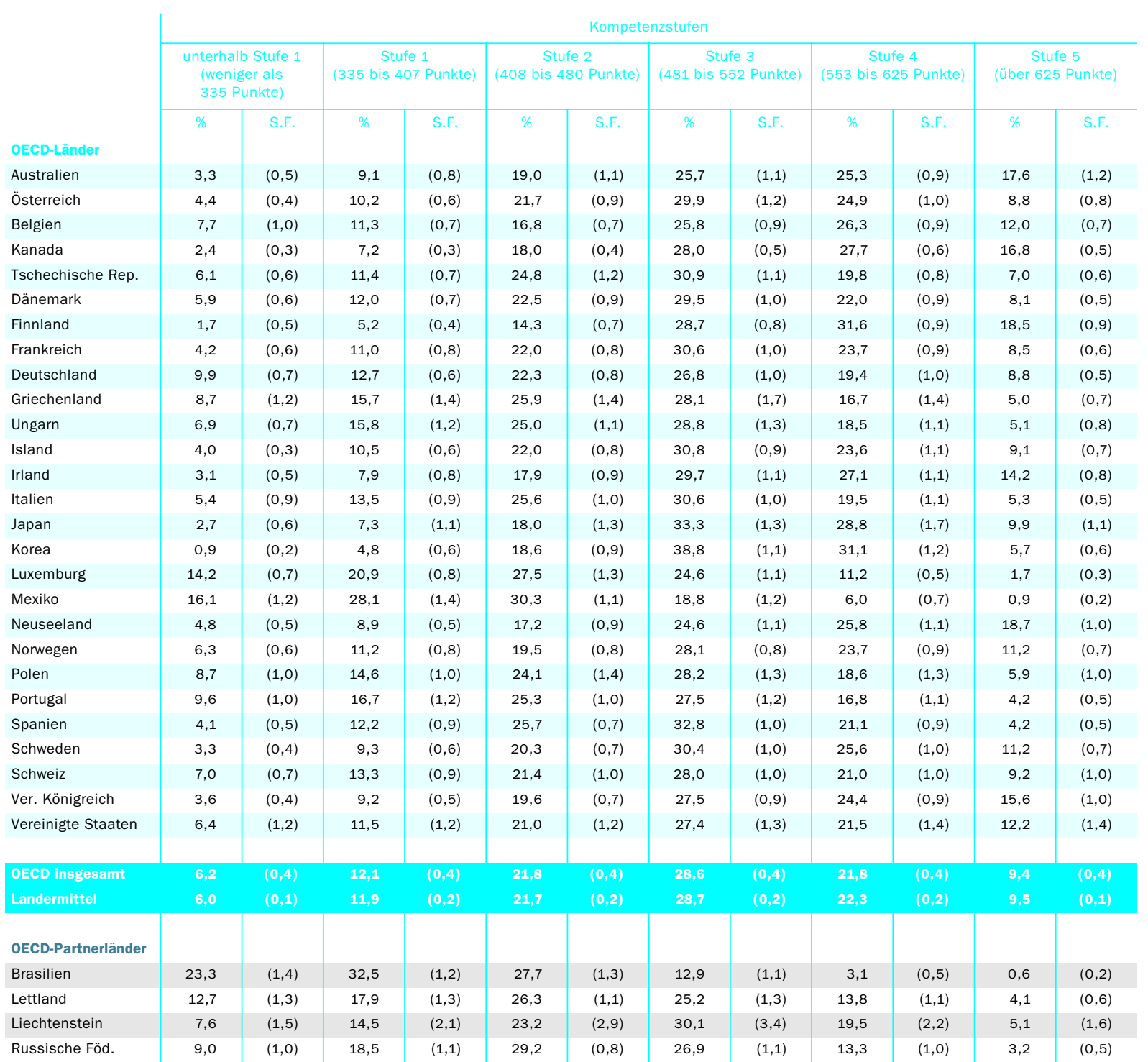


Tabelle A6.2

Unterschiede in den Lesefähigkeiten und dem Leseverständnis 15-jähriger Schüler (2000)

Leistungen 15-jähriger Schüler auf der PISA-Skala der Lesefähigkeiten und des Leseverständnisses, nach Perzentilen

\begin{tabular}{|c|c|c|c|c|c|c|c|c|c|c|c|c|c|c|c|c|}
\hline & \multirow{2}{*}{\multicolumn{2}{|c|}{ Mittelwert }} & \multirow{2}{*}{\multicolumn{2}{|c|}{$\begin{array}{l}\text { Standardabwei- } \\
\text { chung }\end{array}$}} & \multicolumn{12}{|c|}{ Perzentil } \\
\hline & & & & & \multicolumn{2}{|c|}{5.} & \multicolumn{2}{|c|}{10.} & \multicolumn{2}{|c|}{25.} & \multicolumn{2}{|c|}{75.} & \multicolumn{2}{|c|}{90.} & \multicolumn{2}{|c|}{95.} \\
\hline & $\begin{array}{c}\text { Mittel- } \\
\text { wert }\end{array}$ & S.F. & S.A. & S.F. & Punkte & S.F. & Punkte & S.F. & Punkte & S.F. & Punkte & S.F. & Punkte & S.F. & Punkte & S.F. \\
\hline \multicolumn{17}{|l|}{ OECD-Länder } \\
\hline Australien & 528 & $(3,5)$ & 102 & $(1,6)$ & 354 & $(4,8)$ & 394 & $(4,4)$ & 458 & $(4,4)$ & 602 & $(4,6)$ & 656 & $(4,2)$ & 685 & $(4,5)$ \\
\hline Österreich & 507 & $(2,4)$ & 93 & $(1,6)$ & 341 & $(5,4)$ & 383 & $(4,2)$ & 447 & $(2,8)$ & 573 & $(3,0)$ & 621 & $(3,2)$ & 648 & $(3,7)$ \\
\hline Kanada & 534 & $(1,6)$ & 95 & $(1,1)$ & 371 & $(3,8)$ & 410 & $(2,4)$ & 472 & $(2,0)$ & 600 & $(1,5)$ & 652 & $(1,9)$ & 681 & $(2,7)$ \\
\hline Tschechische Rep. & 492 & $(2,4)$ & 96 & $(1,9)$ & 320 & $(7,9)$ & 368 & $(4,9)$ & 433 & $(2,8)$ & 557 & $(2,9)$ & 610 & $(3,2)$ & 638 & $(3,6)$ \\
\hline Dänemark & 497 & $(2,4)$ & 98 & $(1,8)$ & 326 & $(6,2)$ & 367 & $(5,0)$ & 434 & $(3,3)$ & 566 & $(2,7)$ & 617 & $(2,9)$ & 645 & $(3,6)$ \\
\hline Finnland & 546 & $(2,6)$ & 89 & $(2,6)$ & 390 & $(5,8)$ & 429 & $(5,1)$ & 492 & $(2,9)$ & 608 & $(2,6)$ & 654 & $(2,8)$ & 681 & $(3,4)$ \\
\hline Frankreich & 505 & $(2,7)$ & 92 & $(1,7)$ & 344 & $(6,2)$ & 381 & $(5,2)$ & 444 & $(4,5)$ & 570 & $(2,4)$ & 619 & $(2,9)$ & 645 & $(3,7)$ \\
\hline Deutschland & 484 & $(2,5)$ & 111 & $(1,9)$ & 284 & $(9,4)$ & 335 & $(6,3)$ & 417 & $(4,6)$ & 563 & $(3,1)$ & 619 & $(2,8)$ & 650 & $(3,2)$ \\
\hline Griechenland & 474 & $(5,0)$ & 97 & $(2,7)$ & 305 & $(8,2)$ & 342 & $(8,4)$ & 409 & $(7,4)$ & 543 & $(4,5)$ & 595 & $(5,1)$ & 625 & $(6,0)$ \\
\hline Island & 507 & $(1,5)$ & 92 & $(1,4)$ & 345 & $(5,0)$ & 383 & $(3,6)$ & 447 & $(3,1)$ & 573 & $(2,2)$ & 621 & $(3,5)$ & 647 & $(3,7)$ \\
\hline Irland & 527 & $(3,2)$ & 94 & $(1,7)$ & 360 & $(6,3)$ & 401 & $(6,4)$ & 468 & $(4,3)$ & 593 & $(3,6)$ & 641 & $(4,0)$ & 669 & $(3,4)$ \\
\hline Italien & 487 & $(2,9)$ & 91 & $(2,7)$ & 331 & $(8,5)$ & 368 & $(5,8)$ & 429 & $(4,1)$ & 552 & $(3,2)$ & 601 & $(2,7)$ & 627 & $(3,1)$ \\
\hline Japan & 522 & $(5,2)$ & 86 & $(3,0)$ & 366 & $(11,4)$ & 407 & $(9,8)$ & 471 & $(7,0)$ & 582 & $(4,4)$ & 625 & $(4,6)$ & 650 & $(4,3)$ \\
\hline Korea & 525 & $(2,4)$ & 70 & $(1,6)$ & 402 & $(5,2)$ & 433 & $(4,4)$ & 481 & $(2,9)$ & 574 & $(2,6)$ & 608 & $(2,9)$ & 629 & $(3,2)$ \\
\hline Luxemburg & 441 & $(1,6)$ & 100 & $(1,5)$ & 267 & $(5,1)$ & 311 & $(4,4)$ & 378 & $(2,8)$ & 513 & $(2,0)$ & 564 & $(2,8)$ & 592 & $(3,5)$ \\
\hline Mexiko & 422 & $(3,3)$ & 86 & $(2,1)$ & 284 & $(4,4)$ & 311 & $(3,4)$ & 360 & $(3,6)$ & 482 & $(4,8)$ & 535 & $(5,5)$ & 565 & $(6,3)$ \\
\hline Neuseeland & 529 & $(2,8)$ & 108 & $(2,0)$ & 337 & $(7,4)$ & 382 & $(5,2)$ & 459 & $(4,1)$ & 606 & $(3,0)$ & 661 & $(4,4)$ & 693 & $(6,1)$ \\
\hline Norwegen & 505 & $(2,8)$ & 104 & $(1,7)$ & 320 & $(5,9)$ & 364 & $(5,5)$ & 440 & $(4,5)$ & 579 & $(2,7)$ & 631 & $(3,1)$ & 660 & $(4,6)$ \\
\hline Polen & 479 & $(4,5)$ & 100 & $(3,1)$ & 304 & $(8,7)$ & 343 & $(6,8)$ & 414 & $(5,8)$ & 551 & $(6,0)$ & 603 & $(6,6)$ & 631 & $(6,0)$ \\
\hline Portugal & 470 & $(4,5)$ & 97 & $(1,8)$ & 300 & $(6,2)$ & 337 & $(6,2)$ & 403 & $(6,4)$ & 541 & $(4,5)$ & 592 & $(4,2)$ & 620 & $(3,9)$ \\
\hline Spanien & 493 & $(2,7)$ & 85 & $(1,2)$ & 344 & $(5,8)$ & 379 & $(5,0)$ & 436 & $(4,6)$ & 553 & $(2,6)$ & 597 & $(2,6)$ & 620 & $(2,9)$ \\
\hline Schweden & 516 & $(2,2)$ & 92 & $(1,2)$ & 354 & $(4,5)$ & 392 & $(4,0)$ & 456 & $(3,1)$ & 581 & $(3,1)$ & 630 & $(2,9)$ & 658 & $(3,1)$ \\
\hline Schweiz & 494 & $(4,2)$ & 102 & $(2,0)$ & 316 & $(5,5)$ & 355 & $(5,8)$ & 426 & $(5,5)$ & 567 & $(4,7)$ & 621 & $(5,5)$ & 651 & $(5,3)$ \\
\hline OECD insgesamt & 499 & $(2,0)$ & 100 & $(0,8)$ & 322 & $(3,4)$ & 363 & $(3,3)$ & 433 & $(2,5)$ & 569 & $(1,6)$ & 622 & $(2,0)$ & 653 & $(2,1)$ \\
\hline Ländermittel & 500 & $(0,6)$ & 100 & $(0,4)$ & 324 & $(1,3)$ & 366 & $(1,1)$ & 435 & $(1,0)$ & 571 & $(0,7)$ & 623 & $(0,8)$ & 652 & $(0,8)$ \\
\hline \multicolumn{17}{|l|}{ OECD-Partnerländer } \\
\hline Brasilien & 396 & $(3,1)$ & 86 & $(1,9)$ & 255 & $(5,0)$ & 288 & $(4,5)$ & 339 & $(3,4)$ & 452 & $(3,4)$ & 507 & $(4,2)$ & 539 & $(5,5)$ \\
\hline Lettland & 458 & $(5,3)$ & 102 & $(2,3)$ & 283 & $(9,7)$ & 322 & $(8,2)$ & 390 & $(6,9)$ & 530 & $(5,3)$ & 586 & $(5,8)$ & 617 & $(6,6)$ \\
\hline Liechtenstein & 483 & $(4,1)$ & 96 & $(3,9)$ & 310 & $(15,9)$ & 350 & $(11,8)$ & 419 & $(9,4)$ & 551 & $(5,8)$ & 601 & $(7,1)$ & 626 & $(8,2)$ \\
\hline Russische Föd. & 462 & $(4,2)$ & 92 & $(1,8)$ & 306 & $(6,9)$ & 340 & $(5,4)$ & 400 & $(5,1)$ & 526 & $(4,5)$ & 579 & $(4,4)$ & 608 & $(5,3)$ \\
\hline
\end{tabular}

Hinweis: Standardfehler in Klammern.

Quelle: OECD PISA-Datenbank. Hinweise und Informationen zur Methodik s. Anhang 3 unter www.oecd.org/edu/eag2004 und www.pisa.oecd.org. 
Tabelle A6.3

Mittlere Leseleistungen von Schülern der 4. Jahrgangsstufe und von 15-jährigen Schülern $(2000,2001)$ Leistungen von Schülern der 4. Jahrgangsstufe auf der IGLU-Gesamtskala Lesen und von 15-jährigen Schülern auf der PISA-Skala der Lesefähigkeiten und des Leseverständnisses

\begin{tabular}{|c|c|c|c|c|c|c|}
\hline \multirow[b]{2}{*}{ Tschechische Republik } & \multicolumn{3}{|c|}{$\begin{array}{l}\text { Leistungen 15-jähriger Schüler auf der PISA-Skala } \\
\text { der Lesefähigkeiten und des Leseverständnisses }\end{array}$} & \multicolumn{3}{|c|}{$\begin{array}{l}\text { Leistungen von Schülern der 4. Jahrgangsstufe } \\
\text { auf der IGLU-Gesamtskala Lesen }\end{array}$} \\
\hline & $\nabla$ & 492 & $(2,4)$ & $\triangle$ & 537 & $(2,3)$ \\
\hline Frankreich & & 505 & $(2,7)$ & & 525 & $(2,4)$ \\
\hline Deutschland & $\nabla$ & 484 & $(2,5)$ & $\triangle$ & 539 & $(1,9)$ \\
\hline Griechenland & $\nabla$ & 474 & $(5,0)$ & & 524 & $(3,5)$ \\
\hline Ungarn & $\nabla$ & 480 & $(4,0)$ & $\triangle$ & 543 & $(2,2)$ \\
\hline Island & $\Delta$ & 507 & $(1,5)$ & $\nabla$ & 512 & $(1,2)$ \\
\hline Italien & $\nabla$ & 487 & $(2,9)$ & $\triangle$ & 541 & $(2,4)$ \\
\hline Neuseeland & $\Delta$ & 529 & $(2,8)$ & & 529 & $(3,6)$ \\
\hline Norwegen & & 505 & $(2,8)$ & $\nabla$ & 499 & $(2,9)$ \\
\hline Schweden & $\Delta$ & 516 & $(2,2)$ & $\triangle$ & 561 & $(2,2)$ \\
\hline Vereinigte Staaten & & 504 & $(7,1)$ & $\triangle$ & 542 & $(3,8)$ \\
\hline
\end{tabular}

\begin{abstract}
Mittlere Schülerleistungen statistisch signifikant über dem PISA OECD-Ländermittel (=500)
$\nabla$ Mittlere Schülerleistungen statistisch signifikant unter dem PISA OECD-Ländermittel (=500)

$\triangle$ Mittlere Schülerleistungen statistisch signifikant über dem IGLU OECD-Ländermittel (=529)

$\nabla \quad$ Mittlere Schülerleistungen statistisch signifikant unter dem IGLU OECD-Ländermittel (=529)
\end{abstract}

Hinweis: Standardfehler in Klammern.

Quelle: Internationale Grundschul-Lese-Untersuchung - IGLU (Progress in Reading Literacy Study - PIRLS) 2001 und OECD PISA-Datenbank. 



\section{Mathematische und naturwissenschaftliche Grundbildung 15-Jähriger}

15-Jährige in Japan erzielen die höchste mittlere Punktzahl bei der mathematischen Grundbildung, obwohl sich ihre Punktwerte statistisch nicht von denen der Schüler in zwei anderen Ländern an der Spitze - Korea und Neuseeland - unterscheiden lassen. Bei der naturwissenschaftlichen Grundbildung erzielen die Schüler in Korea und Japan die höchsten Durchschnittsleistungen.

Während es große Unterschiede bei den mittleren Leistungen zwischen den einzelnen Ländern gibt, ist die Varianz der Leistungen 15-Jähriger innerhalb der einzelnen Länder um ein Vielfaches größer. Große Disparitäten bei den Leistungen sind jedoch nicht notwendigerweise eine Voraussetzung dafür, dass ein Land ein insgesamt hohes Leistungsniveau erzielt. Ganz im Gegenteil - die Leistungen von fünf der Länder mit den kleinsten Leistungsunterschieden auf der Skala für mathematische Grundbildung, nämlich Island, Finnland, Japan, Kanada und Korea liegen signifikant über dem OECD-Durchschnitt, und vier von ihnen (Finnland, Japan, Kanada und Korea) sind bei der mathematischen Grundbildung unter den sechs besten Ländern. 


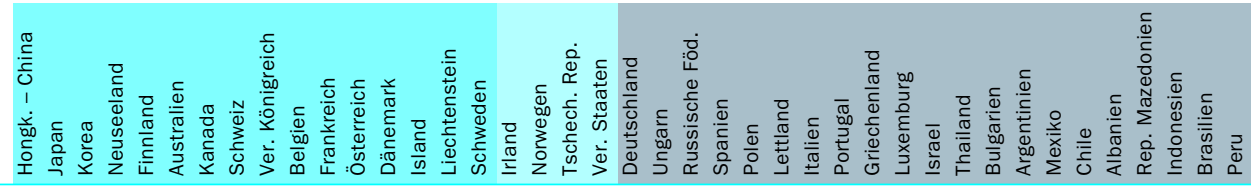

Mittelwert

SF

Hongk. - China

Japan

Korea

Neuseeland

Finnland

Australien

Kanada

Schweiz

Ver. Königreich

Belgien

Frankreich

Österreich

Dänemark

Island

Liechtenstein

Schweden

Irland

Norwegen

Tschech. Rep.

Ver. Staaten

Deutschland

Ungarn

Russische Föd.

Spanien

Polen

Lettland

Italien

Portugal

Griechenland

Luxemburg

Israel

Thailand

Bulgarien

Argentinien

Mexiko

Chile

Albanien

Rep. Mazedonien Indonesien

Brasilien

Peru $557 \quad(5,5)$

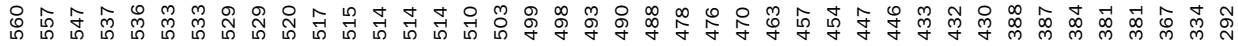

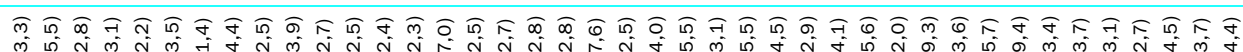

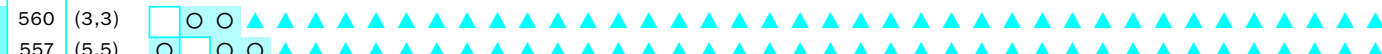
O 0 O O O 0 O O $A \Delta \Delta \Delta \Delta \Delta \Delta \Delta \Delta \Delta \Delta \Delta \Delta \Delta \Delta \Delta \Delta \Delta \Delta \Delta \Delta \Delta \Delta \Delta \Delta \Delta \Delta \Delta \Delta \Delta \Delta \Delta \Delta \Delta \Delta$ $\nabla$ O O O O O O O $A \Delta \Delta \Delta \Delta O \Delta \Delta \Delta \Delta \Delta \Delta \Delta \Delta \Delta \Delta \Delta \Delta \Delta \Delta \Delta \Delta \Delta \Delta \Delta \Delta \Delta \Delta \Delta \Delta \Delta \Delta$ $\nabla \nabla 0$ O O O O O $A \Delta \Delta \Delta \Delta O \Delta \Delta \Delta \Delta \Delta \Delta \Delta \Delta \Delta \Delta \Delta \Delta \Delta \Delta \Delta \Delta \Delta \Delta \Delta \Delta \Delta \Delta \Delta \Delta \Delta \Delta$ $\nabla \nabla 0$ O O O O O O

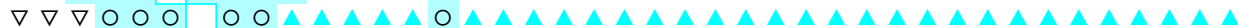
$\nabla \nabla \nabla 0000 \quad 0000000 \Delta \Delta \Delta \Delta \Delta \Delta \Delta \Delta \Delta \Delta \Delta \Delta \Delta \Delta \Delta \Delta \Delta \Delta \Delta \Delta \Delta \Delta \Delta \Delta \Delta \Delta$ $\nabla \nabla \nabla$ O O O O O O $\nabla \nabla \nabla \nabla \nabla 0 \nabla 00 \quad 000000 \Delta \Delta \Delta O \Delta \Delta \Delta \Delta \Delta \Delta \Delta \Delta \Delta \Delta \Delta \Delta \Delta \Delta \Delta \Delta \Delta \Delta \Delta \Delta \Delta$ $\nabla \nabla \nabla \nabla \nabla \nabla \nabla 0 \nabla 0 \mid 00000 \Delta \Delta \Delta O \Delta \Delta \Delta \Delta \Delta \Delta \Delta \Delta \Delta \Delta \Delta \Delta \Delta \Delta \Delta \Delta \Delta \Delta \Delta \Delta \Delta$ $\nabla \nabla \nabla \nabla \nabla \nabla \nabla 0 \nabla$ O O 0 O 0 O O O $\nabla \nabla \nabla \nabla \nabla \nabla \nabla 0 \nabla 000 \quad 0000 \Delta \Delta O \Delta \Delta \Delta \Delta \Delta \Delta \Delta \Delta \Delta \Delta \Delta \Delta \Delta \Delta \Delta \Delta \Delta \Delta \Delta \Delta \Delta \Delta$ $\nabla \nabla \nabla \nabla \nabla \nabla \nabla 0 \nabla 0000$ O O O $\nabla \nabla \nabla 00000000000 \mid 00000 \Delta \Delta \Delta \Delta \Delta \Delta \Delta \Delta \Delta \Delta \Delta \Delta \Delta \Delta \Delta \Delta \Delta \Delta \Delta \Delta \Delta$ $\nabla \nabla \nabla \nabla \nabla \nabla \nabla \nabla \nabla 000000 \mid 00 \Delta 0 \Delta \Delta \Delta \Delta \Delta \Delta \Delta \Delta \Delta \Delta \Delta \Delta \Delta \Delta \Delta \Delta \Delta \Delta \Delta \Delta \Delta$ $\nabla \nabla \nabla \nabla \nabla \nabla \nabla \nabla \nabla \nabla \nabla \nabla 0 \nabla 000000 \Delta 0 \Delta \Delta \Delta \Delta \Delta \Delta \Delta \Delta \Delta \Delta \Delta \Delta \Delta \Delta \Delta \Delta \Delta \Delta \Delta$

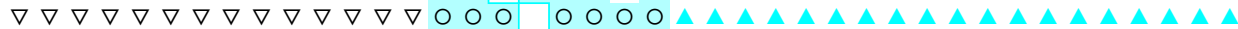
$\nabla \nabla \nabla \nabla \nabla \nabla \nabla \nabla \nabla \nabla \nabla \nabla \nabla \nabla 0 \nabla 0000000 \Delta \Delta \Delta \Delta \Delta \Delta \Delta \Delta \Delta \Delta \Delta \Delta \Delta \Delta \Delta \Delta \Delta \Delta \Delta$

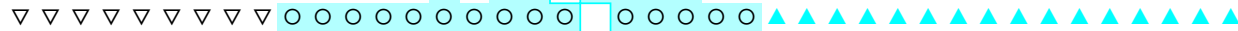
$\nabla \nabla \nabla \nabla \nabla \nabla \nabla \nabla \nabla \nabla \nabla \nabla \nabla \nabla \nabla \nabla \nabla 0$ O $\nabla$ O $\nabla \nabla \nabla \nabla \nabla \nabla \nabla \nabla \nabla \nabla \nabla \nabla \nabla \nabla \nabla \nabla 000000000$ O $\nabla \nabla \nabla \nabla \nabla \nabla \nabla \nabla \nabla \nabla \nabla \nabla \nabla \nabla \nabla \nabla \nabla \nabla 00000000 \Delta \Delta \Delta \Delta \Delta \Delta \Delta \Delta \Delta \Delta \Delta \Delta \Delta \Delta \Delta \Delta$ $\nabla \nabla \nabla \nabla \nabla \nabla \nabla \nabla \nabla \nabla \nabla \nabla \nabla \nabla \nabla \nabla \nabla \nabla \nabla 0 \nabla 00000$ O $\nabla \nabla \nabla \nabla \nabla \nabla \nabla \nabla \nabla \nabla \nabla \nabla \nabla \nabla \nabla \nabla \nabla \nabla \nabla 0 \nabla 00$ ○ $\nabla \nabla 0000$ $\nabla \nabla \nabla \nabla \nabla \nabla \nabla \nabla \nabla \nabla \nabla \nabla \nabla \nabla \nabla \nabla \nabla \nabla \nabla \nabla \nabla \nabla 00$ ～$\nabla \nabla 0000$ $\nabla \nabla \nabla \nabla \nabla \nabla \nabla \nabla \nabla \nabla \nabla \nabla \nabla \nabla \nabla \nabla \nabla \nabla \nabla \nabla \nabla \nabla \nabla \nabla 00000$ $\nabla \nabla \nabla \nabla \nabla \nabla \nabla \nabla \nabla \nabla \nabla \nabla \nabla \nabla \nabla \nabla \nabla \nabla \nabla \nabla \nabla \nabla \nabla \nabla 000000$

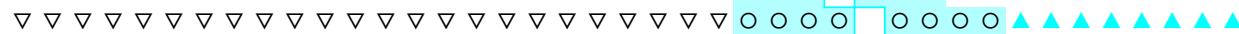

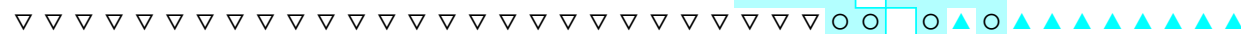
$\nabla \nabla \nabla \nabla \nabla \nabla \nabla \nabla \nabla \nabla \nabla \nabla \nabla \nabla \nabla \nabla \nabla \nabla \nabla \nabla \nabla \nabla \nabla \nabla \nabla 00$ ○ $\nabla \nabla$ ○

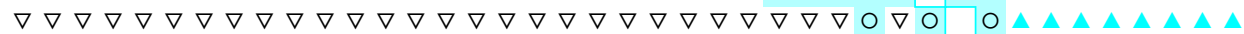
$\nabla \nabla \nabla \nabla \nabla \nabla \nabla \nabla \nabla \nabla \nabla \nabla \nabla \nabla \nabla \nabla \nabla \nabla \nabla \nabla \nabla \nabla \nabla \nabla \nabla \nabla \nabla \nabla$ O $\nabla \nabla$ O O O $\nabla \nabla \nabla \nabla \nabla \nabla \nabla \nabla \nabla \nabla \nabla \nabla \nabla \nabla \nabla \nabla \nabla \nabla \nabla \nabla \nabla \nabla \nabla \nabla \nabla \nabla \nabla \nabla \nabla \nabla \nabla \nabla \nabla \quad 00000$

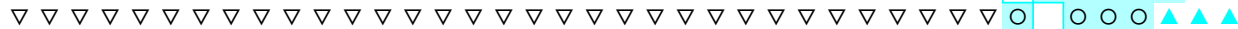

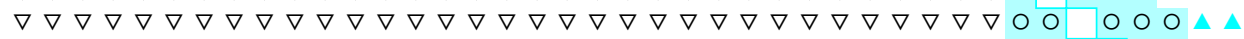
$\nabla \nabla \nabla \nabla \nabla \nabla \nabla \nabla \nabla \nabla \nabla \nabla \nabla \nabla \nabla \nabla \nabla \nabla \nabla \nabla \nabla \nabla \nabla \nabla \nabla \nabla \nabla \nabla \nabla \nabla \nabla \nabla \nabla 000 \quad 00$ $\nabla \nabla \nabla \nabla \nabla \nabla \nabla \nabla \nabla \nabla \nabla \nabla \nabla \nabla \nabla \nabla \nabla \nabla \nabla \nabla \nabla \nabla \nabla \nabla \nabla \nabla \nabla \nabla \nabla \nabla \nabla \nabla \nabla 00$ O O O $\nabla \nabla \nabla \nabla \nabla \nabla \nabla \nabla \nabla \nabla \nabla \nabla \nabla \nabla \nabla \nabla \nabla \nabla \nabla \nabla \nabla \nabla \nabla \nabla \nabla \nabla \nabla \nabla \nabla \nabla \nabla \nabla \nabla 0 \nabla 000$ $\nabla \nabla \nabla \nabla \nabla \nabla \nabla \nabla \nabla \nabla \nabla \nabla \nabla \nabla \nabla \nabla \nabla \nabla \nabla \nabla \nabla \nabla \nabla \nabla \nabla \nabla \nabla \nabla \nabla \nabla \nabla \nabla \nabla \nabla \nabla \nabla \nabla \nabla \nabla \nabla$ $\nabla \nabla \nabla \nabla \nabla \nabla \nabla \nabla \nabla \nabla \nabla \nabla \nabla \nabla \nabla \nabla \nabla \nabla \nabla \nabla \nabla \nabla \nabla \nabla \nabla \nabla \nabla \nabla \nabla \nabla \nabla \nabla \nabla \nabla \nabla \nabla \nabla \nabla \nabla \nabla$

Erläuterung: Zum Vergleich der Schülerleistungen eines Landes mit denen der Länder im Tabellenkopf ist die Zeile des betreffenden Landes zu lesen.

\section{Statistische Signifilanz der Unterschiede bei mittleren Schülerleistungen}

- Mittlere Schülerleistungen statistisch signifikant höher als im Vergleichsland

$\bigcirc$ Kein statistisch signifikanter Unterschied gegenüber dem Vergleichsland

$\nabla \quad$ Mittlere Schülerleistungen signifikant niedriger als im Vergleichsland

\section{Statistische Signifikanz der Differenz zum Ländermittel}

\section{Statistisch signifikant über dem Ländermittel.}

Kein statistisch signifikanter Unterschied zum Ländermittel.

Statistisch signifikant unter dem Ländermittel.

Anordnung der Länder in absteigender Reihenfolge der mittleren Schülerleistungen auf der PISA-Skala für mathematische Grundbildung. 


\section{Politischer Hintergrund}

Im vergangenen Jahrhundert standen die Curricula der Schulmathematik und der naturwissenschaftlichen Fächer meist im Zeichen der Notwendigkeit, eine solide Grundlage für die berufliche Ausbildung einer kleinen Zahl von Mathematikern, Wissenschaftlern und Ingenieuren zu liefern. Mit der zunehmenden Bedeutung von Naturwissenschaften, Mathematik und Technologie für das moderne Leben erfordern jedoch Ziele wie Selbstverwirklichung, Berufstätigkeit und aktive Teilnahme am gesellschaftlichen Leben, dass alle Erwachsenen über mathematische, naturwissenschaftliche und technische Grundkompetenzen verfügen.

Defizite in der mathematischen und naturwissenschaftlichen Grundbildung können nicht nur sehr negative Auswirkungen auf die Arbeitsmarkt- und Einkommensaussichten des Einzelnen, sondern auch auf die Wettbewerbsfähigkeit der einzelnen Länder haben. Umgekehrt können die Leistungen der besten Schüler eines Landes in Mathematik und naturwissenschaftlichen Fächern Auswirkungen auf die Rolle haben, die dieses Land bei den Spitzentechnologien von morgen einnehmen wird. Abgesehen von den Anforderungen im Berufsleben sind mathematische und naturwissenschaftliche Grundkompetenzen für das Verständnis ökologischer, medizinischer, ökonomischer und sonstiger Probleme von Bedeutung, denen sich die modernen Gesellschaften heute gegenübersehen, und deren Lösung sehr stark vom technologischen und naturwissenschaftlichen Fortschritt abhängt.

Infolgedessen messen politische Entscheidungsträger und Pädagogen gleichermaßen der mathematischen und naturwissenschaftlichen Bildung große Bedeutung bei. Um der wachsenden Nachfrage nach mathematischen und naturwissenschaftlichen Kompetenzen gerecht zu werden, bedarf es eines in jeder Hinsicht hervorragenden Bildungssystems, und es ist wichtig zu verfolgen, wie gut die Länder junge Erwachsene mit den Grundkompetenzen in diesen Bereichen ausstatten. Die internationale Schulleistungsstudie PISA liefert Informationen darüber, wie gut 15 -Jährige in diesen Bereichen abschneiden, wobei der Schwerpunkt auf der Bewertung derjenigen Kenntnisse und Fähigkeiten liegt, die die Schüler auf das Leben und lebenslanges Lernen vorbereiten (Kasten A7.I).

\section{Ergebnisse und Erläuterungen}

In den Abbildungen A7.I und A7.2 sind die Länder gemäß der mittleren Leistungen ihrer Schüler auf den PISA-Skalen für mathematische und naturwissenschaftliche Grundbildung angeordnet. Aus den Abbildungen ist auch ersichtlich, welche Länder Schülerleistungen oberhalb, unterhalb oder auf der Höhe des OECD-Durchschnitts aufweisen, und wie die Leistungen ihrer Schüler im Vergleich zu den Schülern in jedem anderen Land sind.
Kenntnisse und Fähigkeiten in Mathematik und den Naturwissenschaften werden heute von vielen und nicht nur einigen wenigen benötigt, ...

... wenn die Menschen die sie umgebende moderne Welt verstehen und an ihr aktiv teilnehmen sollen.

Dieser Indikator zeigt die Leistungen von 15-Jährigen auf den PISA-Skalen für mathematische und naturwissenschaftliche Grundbildung auf. 


\section{Was bedeuten mathematische und naturwissenschaftliche Grundbildung im Rahmen von PISA?}

\section{Was bedeutet mathematische Grundbildung?}

Mathematische Grundbildung im Rahmen von PISA bezieht sich auf die Fähigkeit der Schüler, mathematische Probleme zu erkennen und zu interpretieren, denen sie in ihrem Umfeld begegnen, diese Probleme in mathematische Strukturen umzusetzen, mathematische Kenntnisse und Verfahren zur Lösung von Problemen innerhalb dieses mathematischen Kontexts anzuwenden, die Lösung im Hinblick auf das Ausgangsproblem zu interpretieren, über die angewandte Methode zu reflektieren und die Ergebnisse $\mathrm{zu}$ formulieren und $\mathrm{zu}$ kommunizieren.

\section{Was bedeuten die unterschiedlichen Punktwerte auf der PISA-Skala für mathematische Grundbildung?}

Die Punktwerte spiegeln die Unterschiede in den nachzuweisenden Kenntnissen und Fähigkeiten im Bereich mathematische Grundbildung wider:

Am oberen Ende der Skala, bei rund 750 Punkten, nehmen die Schüler bei der Lösung mathematischer Probleme eine kreative und aktive Rolle ein.

Bei rund 570 Punkten auf der Skala sind die Schüler generell in der Lage, verschiedene Darstellungen eines mathematischen Problems oder Informationen aus verschiedenen Quellen zu interpretieren, zu verknüpfen und zu integrieren und/oder ein bestimmtes Modell anzuwenden oder zu handhaben, das in vielen Fällen algebraische Formeln oder sonstige symbolische Darstellungen enthält, und/oder gegebene Lösungsvorschläge bzw. Modelle zu überprüfen oder zu testen.

Am unteren Ende der Skala, bei rund 380 Punkten, sind die Schüler in der Regel nur in der Lage, einen einzigen Rechenschritt auszuführen, der darin besteht, grundlegende mathematische Fakten oder Prozesse wiederzugeben bzw. einfache Rechenfertigkeiten anzuwenden.

\section{Was bedeutet naturwissenschaftliche Grundbildung?}

Naturwissenschaftliche Grundbildung steht für die Fähigkeit der Schüler, naturwissenschaftliches Wissen anzuwenden, naturwissenschaftliche Fragen zu erkennen bzw. zu identifizieren, worum es bei naturwissenschaftlichen Untersuchungen geht, Behauptungen und Schlussfolgerungen mit naturwissenschaftlichen Daten zu verbinden und diese Aspekte der Naturwissenschaften zu kommunizieren.

\section{Was bedeuten die unterschiedlichen Punktwerte entlang der PISA-Skala für naturwissenschaftliche Grundbildung?}

Die Skala lässt sich anhand der zunehmenden Schwierigkeit der von den Schülern zu lösenden Aufgaben, bzw. der zu ihrer Lösung notwendigen Kenntnisse und Fähigkeiten, beschreiben: 
Am oberen Ende der Skala für naturwissenschaftliche Grundbildung, bei rund 690 Punkten, sind die Schüler generell in der Lage, konzeptuelle Modelle zu entwickeln und zu nutzen, um Vorhersagen $\mathrm{zu}$ machen und Erklärungen zu geben, naturwissenschaftliche Untersuchungen z. B. hinsichtlich der verwendeten Versuchsanordnung oder der in der Untersuchung geprüften Idee zu analysieren, auf der Basis des Vergleichs von Daten alternative Standpunkte oder unterschiedliche Perspektiven zu evaluieren, und wissenschaftliche Argumente und/oder Darlegungen detailliert und präzise zu kommunizieren.

Bei rund 550 Punkten sind die Schüler generell in der Lage, naturwissenschaftliche Konzepte zu benutzen, um Vorhersagen zu machen oder Erklärungen zu geben, Fragen zu erkennen, die durch naturwissenschaftliche Untersuchungen beantwortet werden können, und/oder Details über den Gegenstand einer naturwissenschaftlichen Untersuchung zu identifizieren, ferner können sie beim Ziehen von Schlussfolgerungen, bzw. bei der kritischen Bewertung derselben relevante Informationen aus konkurrierenden Daten oder Argumentationsketten auswählen.

Am unteren Ende der Skala, bei rund 400 Punkten, sind die Schüler in der Lage, einfaches naturwissenschaftliches Faktenwissen abzurufen (d.h. Namen, Fakten, Begriffe, einfache Regeln und Gesetze) und naturwissenschaftliches Allgemeinwissen beim Ziehen oder Bewerten von Schlussfolgerungen zu verwenden.

Die Schüler in Japan erreichen bei der mathematischen Grundbildung die höchste mittlere Punktzahl, allerdings besteht zwischen dem Durchschnittsergebnis von Japan und den Durchschnittsergebnissen von Korea und Neuseeland kein statistisch signifikanter Unterschied. Zu den anderen OECD-Ländern, deren Punktzahlen ebenfalls signifikant über dem OECD-Durchschnitt liegen, gehören Australien, Belgien, Dänemark, Finnland, Frankreich, Island, Kanada, Österreich, Schweden, die Schweiz und das Vereinigte Königreich (Abb. A7.I).

Japan und Korea weisen auf der PISA-Skala für naturwissenschaftliche Grundbildung im Vergleich zu den anderen OECD-Ländern die höchsten Ergebnisse auf. Zu den anderen Ländern, deren Ergebnisse ebenfalls statistisch signifikant über dem OECD-Durchschnitt liegen, gehören Australien, Finnland, Irland, Kanada, Neuseeland, Österreich, Schweden, die Tschechische Republik und das Vereinigte Königreich (Abb. A7.2).

Bei einem Blick auf die in den vorherigen Absätzen angeführten Auflistungen der Länder mit überdurchschnittlichen Ergebnissen zeigt sich, dass, ganz allgemein gesprochen, Länder mit guten Ergebnissen in einem Grundbildungsbereich auch im anderen Bereich gut abschneiden, d. h. es besteht eine enge Korrelation zwischen den Mittelwerten auf der PISA-Skala für mathematische Grundbildung und der PISA-Skala für naturwissenschaftliche Grundbildung. Es gibt jedoch einige Ausnahmen. So liegen beispielsweise die

Japan hat den höchsten Mittelwert bei der mathematischen Grundbildung, ...

... und zusammen mit Korea bei der naturwissenschaftlichen Grundbildung: 


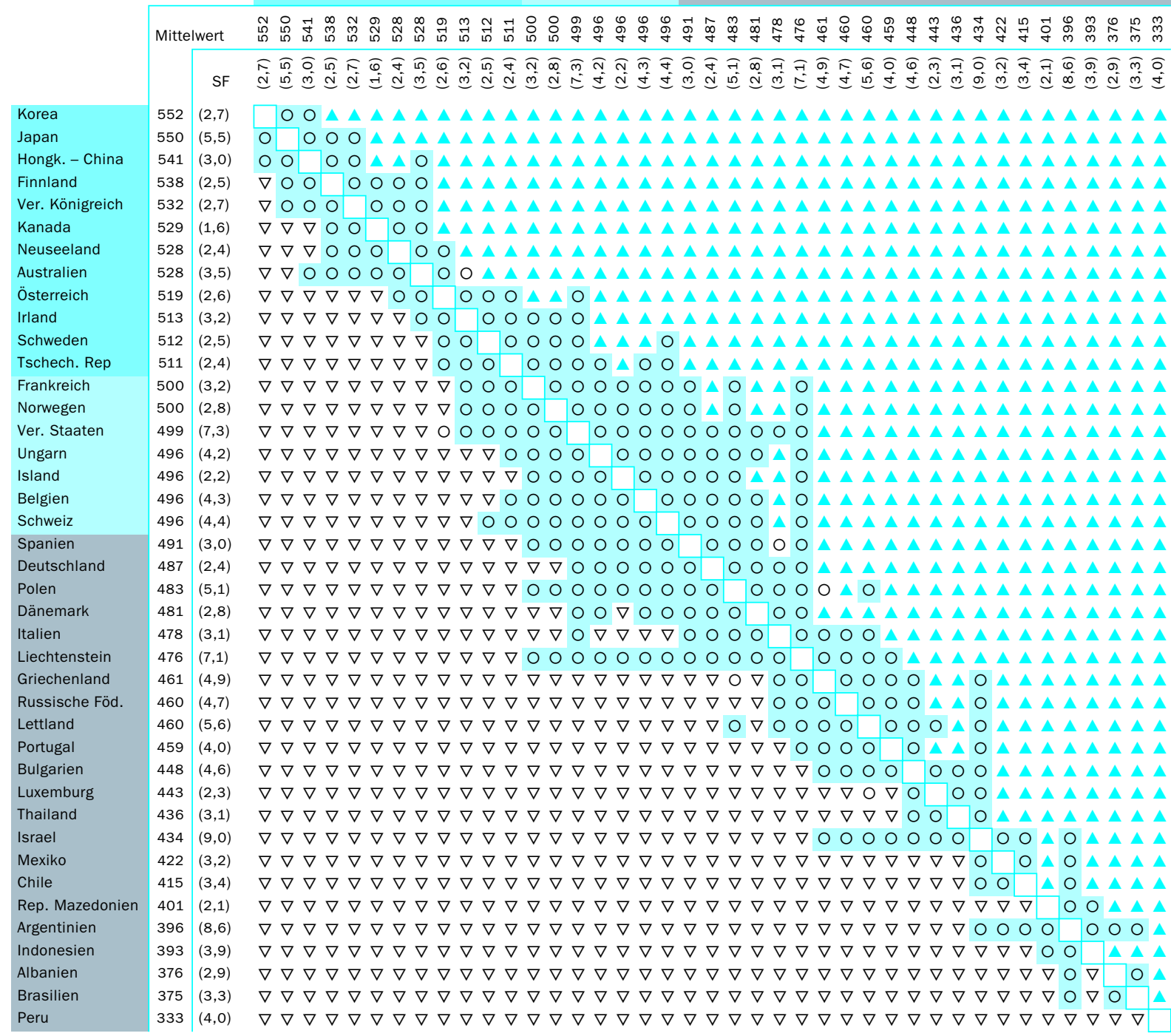

Erläuterung: Zum Vergleich der Schülerleistungen eines Landes mit denen der Länder im Tabellenkopf ist die Zeile des betreffenden Landes zu lesen.

\section{Statistische Signifilanz der Unterschiede bei mittleren Schülerleistungen}

Mittlere Schülerleistungen statistisch signifikant höher als im Vergleichsland

Kein statistisch signifikanter Unterschied gegenüber dem Vergleichsland

$\nabla$ Mittlere Schülerleistungen signifikant niedriger als im Vergleichsland
Statistische Signifikanz der Differenz zum Ländermittel

\section{Statistisch signifikant über dem Ländermittel.}

Kein statistisch signifikanter Unterschied zum Ländermittel. Statistisch signifikant unter dem Ländermittel.

Anordnung der Länder in absteigender Reihenfolge der mittleren Schülerleistungen auf der PISA-Skala für naturwissenschaftliche Grundbildung. Erläuterung: Aufgrund der geringen Beteiligungsquote sind die Niederlande nicht enthalten.

Quelle: OECD PISA-Datenbank, 2000. Hinweise zur Methodik s. Anhang 3 unter www.oecd.org/edu/eag2004 und www. pisa.oecd.org 
Ergebnisse bei der mathematischen Grundbildung in Irland und der Tschechischen Republik mehr oder minder auf dem OECD-Durchschnitt, bei der naturwissenschaftlichen Grundbildung liegen die Schüler dieser Länder jedoch signifikant über dem OECD-Durchschnitt. Umgekehrt erbringen Schüler in Belgien, Frankreich, Island und der Schweiz bei der mathematischen Grundbildung Leistungen, die signifikant über dem OECD-Durchschnitt liegen, während sich ihre Leistungen bei der naturwissenschaftlichen Grundbildung nicht signifikant vom OECD-Durchschnitt unterscheiden. Schüler in Dänemark liegen zwar bei der mathematischen Grundbildung über dem OECD-Durchschnitt, bei der naturwissenschaftlichen Grundbildung jedoch unter dem OECD-Mittelwert.

Es gibt große Unterschiede zwischen den Ländermittelwerten, wobei die Unterschiede der Schülerleistungen innerhalb der einzelnen Länder jedoch wesentlich größer sind. In den Tabellen A7.I und A7.2 sind die Schülerleistungen beim 5., 25., 75. und 95. Perzentil für jedes einzelne Land angegeben. Die Verteilungen der Schülerleistungen auf der PISA-Skala für mathematische Grundbildung in Belgien, Deutschland, Griechenland, Neuseeland, Polen, der Schweiz, Ungarn und den Vereinigten Staaten, zeigen eine relativ große Spannweite zwischen dem 75. und dem 25. Perzentil (also dem 3. und I. Quartil) - zwischen 135 und 149 Punkten. Finnland, Irland, Island, Japan und Korea weisen mit maximal II3 Punkten zwischen dem 75. und 25. Perzentil vergleichsweise kleinere Unterschiede auf.

Bei der naturwissenschaftlichen Grundbildung in Belgien, Dänemark, Deutschland, Frankreich, Neuseeland, der Schweiz, Ungarn und den Vereinigten Staaten bestehen relativ große Unterschiede zwischen den Schülerleistungen beim 75. und 25. Perzentil, jeweils zwischen I40 und I54 Punkten, während in Finnland, Japan, Korea und Mexiko die Unterschiede zwischen diesen beiden Schülergruppen mit weniger als II 8 Punkten relativ gering sind.

Es ist sehr hilfreich, die Bandbreite der Leistungen mit den Durchschnittsergebnissen in Relation zu setzen. Ein solcher Vergleich zeigt, dass große Disparitäten der Schülerleistungen nicht notwendigerweise Grundvoraussetzung für ein insgesamt höheres Leistungsniveau sind. Augenfällig ist ganz im Gegenteil, dass die Durchschnittsergebnisse in sechs der Länder mit den geringsten Unterschieden zwischen dem 3. und I. Quartil auf der PISA-Skala für mathematische Grundbildung, nämlich Finnland, Island, Irland, Japan, Kanada und Korea, alle signifikant über dem OECD-Durchschnitt liegen (Tab. A7.I). Außerdem gehören vier dieser Länder, nämlich Finnland, Japan, Kanada und Korea, zu den sechs leistungsstärksten OECD-Ländern in mathematischer Grundbildung. Ähnlich sieht es bei der naturwissenschaftlichen Grundbildung aus. Auch hier gehören Finnland, Japan, Kanada und Korea sowohl zu den sechs Ländern mit dem geringsten Unterschied zwischen dem 3. und I. Quartil als auch zu den sechs leistungsstärksten Ländern.

Umgekehrt liegen die Ergebnisse der Länder mit den größten Unterschieden innerhalb des Landes in der Regel unterhalb des OECD-Mittelwertes. So liegen beispielsweise bei der mathematischen Grundbildung von den sechs Ländern mit dem größten Unterschied zwischen dem I. und 3. Quartil (Belgien,
Es gibt große Unterschiede zwischen den Ländermittelwerten, wobei die Unterschiede der Schülerleistungen innerhalb der einzelnen Länder jedoch wesentlich größer sind.

Disparitäten bei den Leistungen sind nicht notwendigerweise Grundvoraussetzung für ein insgesamt höheres Leistungsniveau. 
Deutschland Griechenland, Polen, Ungarn und die Vereinigte Staaten) nur zwei (Belgien und die Vereinigten Staaten) nicht signifikant unter dem OECDDurchschnitt.

\section{Definitionen und angewandte Methodik}

Die erzielten Punktzahlen basieren auf Leistungsmessungen, die Teil der im Jahr 2000 von der OECD durchgeführten Internationalen Schulleistungsstudie PISA waren.
Die für diesen Indikator untersuchte Zielpopulation waren I5-jährige Schüler. In der Praxis bezieht sich dies auf Schüler, die zu Beginn der Testperiode im Alter von I5 Jahren und 3 (abgeschlossenen) Monaten bis zu I6 Jahren und 2 (abgeschlossenen) Monaten waren und eine Bildungseinrichtung besuchten, ungeachtet der Klassenstufe und der Art der von ihnen besuchten Bildungseinrichtung und unabhängig davon, ob es sich um eine Ganztags- oder Halbtagsschule handelte.

Um die Interpretation der von den Schülern erzielten Punktwerte in der PISA-Studie zu erleichtern, wurden die Skalen für mathematische und naturwissenschaftliche Grundbildung so konstruiert, dass der Mittelwert der OECD-Länder bei 500 Punkten liegt und die Standardabweichung bei 1oo, wobei die Daten gewichtet wurden, so dass jedes OECD-Land gleichermaßen hierzu beitrug.

Hinweise zu Standardfehlern, Signifikanztests und multiplen Vergleichen s. Anhang 3 unter www.oecd.orgleduleag2004. 
Tabelle A7.1

Unterschiede in der Leistung 15-jähriger Schüler auf der PISA-Skala für mathematische Grundbildung (2000) Leistungen 15-jähriger Schüler auf der PISA-Skala für mathematische Grundbildung, nach Perzentilen

\begin{tabular}{|c|c|c|c|c|c|c|c|c|c|c|c|c|c|c|}
\hline \multirow{3}{*}{ OECD-Länder } & \multirow{2}{*}{\multicolumn{2}{|c|}{ Mittelwert }} & \multicolumn{12}{|c|}{ Perzentil } \\
\hline & & & \multicolumn{2}{|c|}{5.} & \multicolumn{2}{|c|}{10.} & \multicolumn{2}{|c|}{25.} & \multicolumn{2}{|c|}{75.} & \multicolumn{2}{|c|}{90.} & \multicolumn{2}{|c|}{95.} \\
\hline & $\begin{array}{c}\text { Mittlere } \\
\text { Punktzahl }\end{array}$ & S.F. & Punkte & S.F. & Punkte & S.F. & Punkte & S.F. & Punkte & S.F. & Punkte & S.F. & Punkte & S.F. \\
\hline Australien & 533 & $(3,5)$ & 380 & $(6,4)$ & 418 & $(6,4)$ & 474 & $(4,4)$ & 594 & $(4,5)$ & 647 & $(5,7)$ & 679 & $(5,8)$ \\
\hline Österreich & 515 & $(2,5)$ & 355 & $(5,3)$ & 392 & $(4,6)$ & 455 & $(3,5)$ & 581 & $(3,8)$ & 631 & $(3,6)$ & 661 & $(5,2)$ \\
\hline Kanada & 533 & $(1,4)$ & 390 & $(3,2)$ & 423 & $(2,5)$ & 477 & $(2,0)$ & 592 & $(1,7)$ & 640 & $(1,9)$ & 668 & $(2,6)$ \\
\hline Tschechische Rep. & 498 & $(2,8)$ & 335 & $(5,4)$ & 372 & $(4,2)$ & 433 & $(4,1)$ & 564 & $(3,9)$ & 623 & $(4,8)$ & 655 & $(5,6)$ \\
\hline Dänemark & 514 & $(2,4)$ & 366 & $(6,1)$ & 401 & $(5,1)$ & 458 & $(3,1)$ & 575 & $(3,1)$ & 621 & $(3,7)$ & 649 & $(4,6)$ \\
\hline Finnland & 536 & $(2,2)$ & 400 & $(6,5)$ & 433 & $(3,6)$ & 484 & $(4,1)$ & 592 & $(2,5)$ & 637 & $(3,2)$ & 664 & $(3,5)$ \\
\hline Frankreich & 517 & $(2,7)$ & 364 & $(6,4)$ & 399 & $(5,4)$ & 457 & $(4,7)$ & 581 & $(3,1)$ & 629 & $(3,2)$ & 656 & $(4,6)$ \\
\hline Deutschland & 490 & $(2,5)$ & 311 & $(7,9)$ & 349 & $(6,9)$ & 423 & $(3,9)$ & 563 & $(2,7)$ & 619 & $(3,6)$ & 649 & $(3,9)$ \\
\hline Griechenland & 447 & $(5,6)$ & 260 & $(9,0)$ & 303 & $(8,1)$ & 375 & $(8,1)$ & 524 & $(6,7)$ & 586 & $(7,8)$ & 617 & $(8,6)$ \\
\hline Island & 514 & $(2,3)$ & 372 & $(5,7)$ & 407 & $(4,7)$ & 459 & $(3,5)$ & 572 & $(3,0)$ & 622 & $(3,1)$ & 649 & $(5,5)$ \\
\hline Irland & 503 & $(2,7)$ & 357 & $(6,4)$ & 394 & $(4,7)$ & 449 & $(4,1)$ & 561 & $(3,6)$ & 606 & $(4,3)$ & 630 & $(5,0)$ \\
\hline Italien & 457 & $(2,9)$ & 301 & $(8,4)$ & 338 & $(5,5)$ & 398 & $(3,5)$ & 520 & $(3,5)$ & 570 & $(4,4)$ & 600 & $(6,1)$ \\
\hline Japan & 557 & $(5,5)$ & 402 & $(11,2)$ & 440 & $(9,1)$ & 504 & $(7,4)$ & 617 & $(5,2)$ & 662 & $(4,9)$ & 688 & $(6,1)$ \\
\hline Korea & 547 & $(2,8)$ & 400 & $(6,1)$ & 438 & $(5,0)$ & 493 & $(4,2)$ & 606 & $(3,4)$ & 650 & $(4,3)$ & 676 & $(5,3)$ \\
\hline Luxemburg & 446 & $(2,0)$ & 281 & $(7,4)$ & 328 & $(4,2)$ & 390 & $(3,8)$ & 509 & $(3,4)$ & 559 & $(3,2)$ & 588 & $(3,9)$ \\
\hline Mexiko & 387 & $(3,4)$ & 254 & $(5,5)$ & 281 & $(3,6)$ & 329 & $(4,1)$ & 445 & $(5,2)$ & 496 & $(5,6)$ & 527 & $(6,6)$ \\
\hline Neuseeland & 537 & $(3,1)$ & 364 & $(6,1)$ & 405 & $(5,4)$ & 472 & $(3,9)$ & 607 & $(4,0)$ & 659 & $(4,2)$ & 689 & $(5,2)$ \\
\hline Norwegen & 499 & $(2,8)$ & 340 & $(7,0)$ & 379 & $(5,2)$ & 439 & $(4,0)$ & 565 & $(3,9)$ & 613 & $(4,5)$ & 643 & $(4,5)$ \\
\hline Polen & 470 & $(5,5)$ & 296 & $(12,2)$ & 335 & $(9,2)$ & 402 & $(7,0)$ & 542 & $(6,8)$ & 599 & $(7,7)$ & 632 & $(8,5)$ \\
\hline Portugal & 454 & $(4,1)$ & 297 & $(7,3)$ & 332 & $(6,1)$ & 392 & $(5,7)$ & 520 & $(4,3)$ & 570 & $(4,3)$ & 596 & $(5,0)$ \\
\hline Spanien & 476 & $(3,1)$ & 323 & $(5,8)$ & 358 & $(4,3)$ & 416 & $(5,3)$ & 540 & $(4,0)$ & 592 & $(3,9)$ & 621 & $(3,1)$ \\
\hline Schweden & 510 & $(2,5)$ & 347 & $(5,8)$ & 386 & $(4,0)$ & 450 & $(3,3)$ & 574 & $(2,6)$ & 626 & $(3,3)$ & 656 & $(5,5)$ \\
\hline Schweiz & 529 & $(4,4)$ & 353 & $(9,1)$ & 398 & $(6,0)$ & 466 & $(4,8)$ & 601 & $(5,2)$ & 653 & $(5,8)$ & 682 & $(4,8)$ \\
\hline OECD insgesamt & 498 & $(2,1)$ & 318 & $(3,1)$ & 358 & $(3,4)$ & 429 & $(3,0)$ & 572 & $(2,1)$ & 628 & $(1,9)$ & 658 & $(2,1)$ \\
\hline Ländermittel & 500 & $(0,7)$ & 326 & $(1,5)$ & 367 & $(1,4)$ & 435 & $(1,1)$ & 571 & $(0,8)$ & 625 & $(0,9)$ & 655 & $(1,1)$ \\
\hline \multicolumn{15}{|l|}{ OECD-Partnerländer } \\
\hline Brasilien & 334 & $(3,7)$ & 179 & $(5,5)$ & 212 & $(5,2)$ & 266 & $(4,2)$ & 399 & $(5,5)$ & 464 & $(7,5)$ & 499 & $(8,9)$ \\
\hline Lettland & 463 & $(4,5)$ & 288 & $(9,0)$ & 328 & $(8,9)$ & 393 & $(5,7)$ & 536 & $(6,2)$ & 593 & $(5,6)$ & 625 & $(6,6)$ \\
\hline Liechtenstein & 514 & $(7,0)$ & 343 & $(19,7)$ & 380 & $(18,9)$ & 454 & $(15,5)$ & 579 & $(7,5)$ & 635 & $(16,9)$ & 665 & $(15,0)$ \\
\hline Russische Föd. & 478 & $(5,5)$ & 305 & $(9,0)$ & 343 & $(7,4)$ & 407 & $(6,6)$ & 552 & $(6,6)$ & 613 & $(6,8)$ & 648 & $(7,8)$ \\
\hline
\end{tabular}

Hinweis: Standardfehler in Klammern.

Quelle: OECD PISA-Datenbank. Hinweise und Informationen zur Methodik s. Anhang 3 unter www.oecd.org/edu/eag2004 und www.pisa.oecd.org. 
Tabelle A7.2

Unterschiede in der Leistung 15-jähriger Schüler auf der PISA-Skala für naturwissenschaftliche Grundbildung (2000) Leistungen 15-jähriger Schüler auf der PISA-Skala für naturwissenschaftliche Grundbildung, nach Perzentilen

\begin{tabular}{|c|c|c|c|c|c|c|c|c|c|c|c|c|c|c|}
\hline & \multirow{2}{*}{\multicolumn{2}{|c|}{ Mittelwert }} & \multicolumn{12}{|c|}{ Perzentil } \\
\hline & & & \multicolumn{2}{|c|}{5.} & \multicolumn{2}{|c|}{10.} & \multicolumn{2}{|c|}{25.} & \multicolumn{2}{|c|}{75.} & \multicolumn{2}{|c|}{90.} & \multicolumn{2}{|c|}{95.} \\
\hline & $\begin{array}{c}\text { Mittlere } \\
\text { Punktzahl }\end{array}$ & S.F. & Punkte & S.F. & Punkte & S.F. & Punkte & S.F. & Punkte & S.F. & Punkte & S.F. & Punkte & S.F. \\
\hline \multicolumn{15}{|l|}{ OECD-Länder } \\
\hline Australien & 528 & $(3,5)$ & 368 & $(5,1)$ & 402 & $(4,7)$ & 463 & $(4,6)$ & 596 & $(4,8)$ & 646 & $(5,1)$ & 675 & $(4,8)$ \\
\hline Österreich & 519 & $(2,6)$ & 363 & $(5,7)$ & 398 & $(4,0)$ & 456 & $(3,8)$ & 584 & $(3,5)$ & 633 & $(4,1)$ & 659 & $(4,3)$ \\
\hline Kanada & 529 & $(1,6)$ & 380 & $(3,7)$ & 412 & $(3,4)$ & 469 & $(2,2)$ & 592 & $(1,8)$ & 641 & $(2,2)$ & 670 & $(3,0)$ \\
\hline Tschechische Rep. & 511 & $(2,4)$ & 355 & $(5,6)$ & 389 & $(4,0)$ & 449 & $(3,6)$ & 577 & $(3,8)$ & 632 & $(4,1)$ & 663 & $(4,9)$ \\
\hline Dänemark & 481 & $(2,8)$ & 310 & $(6,0)$ & 347 & $(5,3)$ & 410 & $(4,8)$ & 554 & $(3,5)$ & 613 & $(4,4)$ & 645 & $(4,7)$ \\
\hline Finnland & 538 & $(2,5)$ & 391 & $(5,2)$ & 425 & $(4,2)$ & 481 & $(3,5)$ & 598 & $(3,0)$ & 645 & $(4,3)$ & 674 & $(4,3)$ \\
\hline Frankreich & 500 & $(3,2)$ & 329 & $(6,1)$ & 363 & $(5,4)$ & 429 & $(5,3)$ & 575 & $(4,0)$ & 631 & $(4,2)$ & 663 & $(4,9)$ \\
\hline Deutschland & 487 & $(2,4)$ & 314 & $(9,5)$ & 350 & $(6,0)$ & 417 & $(4,9)$ & 560 & $(3,3)$ & 618 & $(3,5)$ & 649 & $(4,7)$ \\
\hline Griechenland & 461 & $(4,9)$ & 300 & $(9,3)$ & 334 & $(8,3)$ & 393 & $(7,0)$ & 530 & $(5,3)$ & 585 & $(5,3)$ & 616 & $(5,8)$ \\
\hline Island & 496 & $(2,2)$ & 351 & $(7,0)$ & 381 & $(4,3)$ & 436 & $(3,7)$ & 558 & $(3,1)$ & 607 & $(4,1)$ & 635 & $(4,8)$ \\
\hline Irland & 513 & $(3,2)$ & 361 & $(6,5)$ & 394 & $(5,7)$ & 450 & $(4,4)$ & 578 & $(3,4)$ & 630 & $(4,6)$ & 661 & $(5,4)$ \\
\hline Italien & 478 & $(3,1)$ & 315 & $(7,1)$ & 349 & $(6,2)$ & 411 & $(4,4)$ & 547 & $(3,5)$ & 602 & $(4,0)$ & 633 & $(4,4)$ \\
\hline Japan & 550 & $(5,5)$ & 391 & $(11,3)$ & 430 & $(9,9)$ & 495 & $(7,2)$ & 612 & $(5,0)$ & 659 & $(4,7)$ & 688 & $(5,7)$ \\
\hline Korea & 552 & $(2,7)$ & 411 & $(5,3)$ & 442 & $(5,3)$ & 499 & $(4,0)$ & 610 & $(3,4)$ & 652 & $(3,9)$ & 674 & $(5,7)$ \\
\hline Luxemburg & 443 & $(2,3)$ & 278 & $(7,2)$ & 320 & $(6,8)$ & 382 & $(3,4)$ & 510 & $(2,8)$ & 563 & $(4,4)$ & 593 & $(4,0)$ \\
\hline Mexiko & 422 & $(3,2)$ & 303 & $(4,8)$ & 325 & $(4,6)$ & 368 & $(3,1)$ & 472 & $(4,7)$ & 525 & $(5,5)$ & 554 & $(7,0)$ \\
\hline Neuseeland & 528 & $(2,4)$ & 357 & $(5,6)$ & 392 & $(5,2)$ & 459 & $(3,8)$ & 600 & $(3,4)$ & 653 & $(5,0)$ & 683 & $(5,1)$ \\
\hline Norwegen & 500 & $(2,8)$ & 338 & $(7,3)$ & 377 & $(6,6)$ & 437 & $(4,0)$ & 569 & $(3,5)$ & 619 & $(3,9)$ & 649 & $(6,2)$ \\
\hline Polen & 483 & $(5,1)$ & 326 & $(9,2)$ & 359 & $(5,8)$ & 415 & $(5,5)$ & 553 & $(7,3)$ & 610 & $(7,6)$ & 639 & $(7,5)$ \\
\hline Portugal & 459 & $(4,0)$ & 317 & $(5,0)$ & 343 & $(5,1)$ & 397 & $(5,2)$ & 521 & $(4,7)$ & 575 & $(5,0)$ & 604 & $(5,3)$ \\
\hline Spanien & 491 & $(3,0)$ & 333 & $(5,1)$ & 367 & $(4,3)$ & 425 & $(4,4)$ & 558 & $(3,5)$ & 613 & $(3,9)$ & 643 & $(5,5)$ \\
\hline Schweden & 512 & $(2,5)$ & 357 & $(5,7)$ & 390 & $(4,6)$ & 446 & $(4,1)$ & 578 & $(3,0)$ & 630 & $(3,4)$ & 660 & $(4,5)$ \\
\hline Schweiz & 496 & $(4,4)$ & 332 & $(5,8)$ & 366 & $(5,4)$ & 427 & $(5,1)$ & 567 & $(6,4)$ & 626 & $(6,4)$ & 656 & $(9,0)$ \\
\hline OECD insgesamt & 502 & $(2,0)$ & 332 & $(3,3)$ & 368 & $(3,1)$ & 431 & $(2,8)$ & 576 & $(2,1)$ & 631 & $(1,9)$ & 662 & $(2,3)$ \\
\hline Ländermittel & 500 & $(0,7)$ & 332 & $(1,5)$ & 368 & $(1,0)$ & 431 & $(1,0)$ & 572 & $(0,8)$ & 627 & $(0,8)$ & 657 & $(1,2)$ \\
\hline \multicolumn{15}{|l|}{ OECD-Partnerländer } \\
\hline Brasilien & 375 & $(3,3)$ & 230 & $(5,5)$ & 262 & $(5,9)$ & 315 & $(3,7)$ & 432 & $(4,9)$ & 492 & $(7,8)$ & 531 & $(8,2)$ \\
\hline Lettland & 460 & $(5,6)$ & 299 & $(10,1)$ & 334 & $(8,8)$ & 393 & $(7,7)$ & 528 & $(5,7)$ & 585 & $(7,2)$ & 620 & $(8,0)$ \\
\hline Liechtenstein & 476 & $(7,1)$ & 314 & $(23,5)$ & 357 & $(20,0)$ & 409 & $(12,3)$ & 543 & $(12,7)$ & 595 & $(12,4)$ & 629 & $(24,0)$ \\
\hline Russische Föd. & 460 & $(4,7)$ & 298 & $(6,5)$ & 333 & $(5,4)$ & 392 & $(6,2)$ & 529 & $(5,8)$ & 591 & $(5,9)$ & 625 & $(5,7)$ \\
\hline
\end{tabular}

Hinweis: Standardfehler in Klammern.

Quelle: OECD PISA-Datenbank. Hinweise s. Anhang 3 unter www.oecd.org/edu/eag2004 und www.pisa.oecd.org. 


\section{Das Engagement 15-Jähriger in der Schule - Zugehörigkeitsgefühl und Unterrichtsteilnahme}

- Im Durchschnitt hat fast ein Viertel der 15-Jährigen negative Ansichten über ihre Zugehörigkeit zur Schule und jeder Fünfte gibt an, kürzlich die Schule nicht besucht zu haben, zu spät gekommen zu sein oder geschwänzt zu haben.

Die Schüler in Schweden, Österreich und der Schweiz gaben ein besonders starkes Zugehörigkeitsgefühl an, während das der Schüler in Belgien, Japan, Korea, Polen und der Tschechischen Republik unter dem Durchschnitt lag.

- In den meisten Ländern variiert der Anteil der Schüler mit einem schwachen Zugehörigkeitsgefühl signifikant zwischen den Schulen und diese Varianz ist bei der Unterrichtsteilnahme noch größer.

Bei den einzelnen Schülern ist der Zusammenhang zwischen Unterrichtsteilnahme und Zugehörigkeitsgefühl nur schwach, was vermuten lässt, dass viele Schüler, die sich nicht zugehörig fühlen, dennoch regelmäßig die Schule besuchen und umgekehrt.

- Im Gegensatz dazu sind Zugehörigkeitsgefühl und Unterrichtsteilnahme auf Schulebene eher miteinander verknüpft und stehen in engem Zusammenhang zur Leistung der Schule, was vermuten lässt, dass Schulen mit einem hohen Grad an Engagement auch ein hohes Niveau an schulischer Leistung erzielen.

Die Analyse zeigt insbesondere, dass ein großer Teil der Schüler mit vergleichsweise guten schulischen Leistungen dennoch ein geringes Zugehörigkeitsgefühl angibt. 
A 8

Abbildung A8.1

Anteil der Schüler mit einem schwachen Zugehörigkeitsgefühl und geringer Unterrichtsteilnahme (2000)

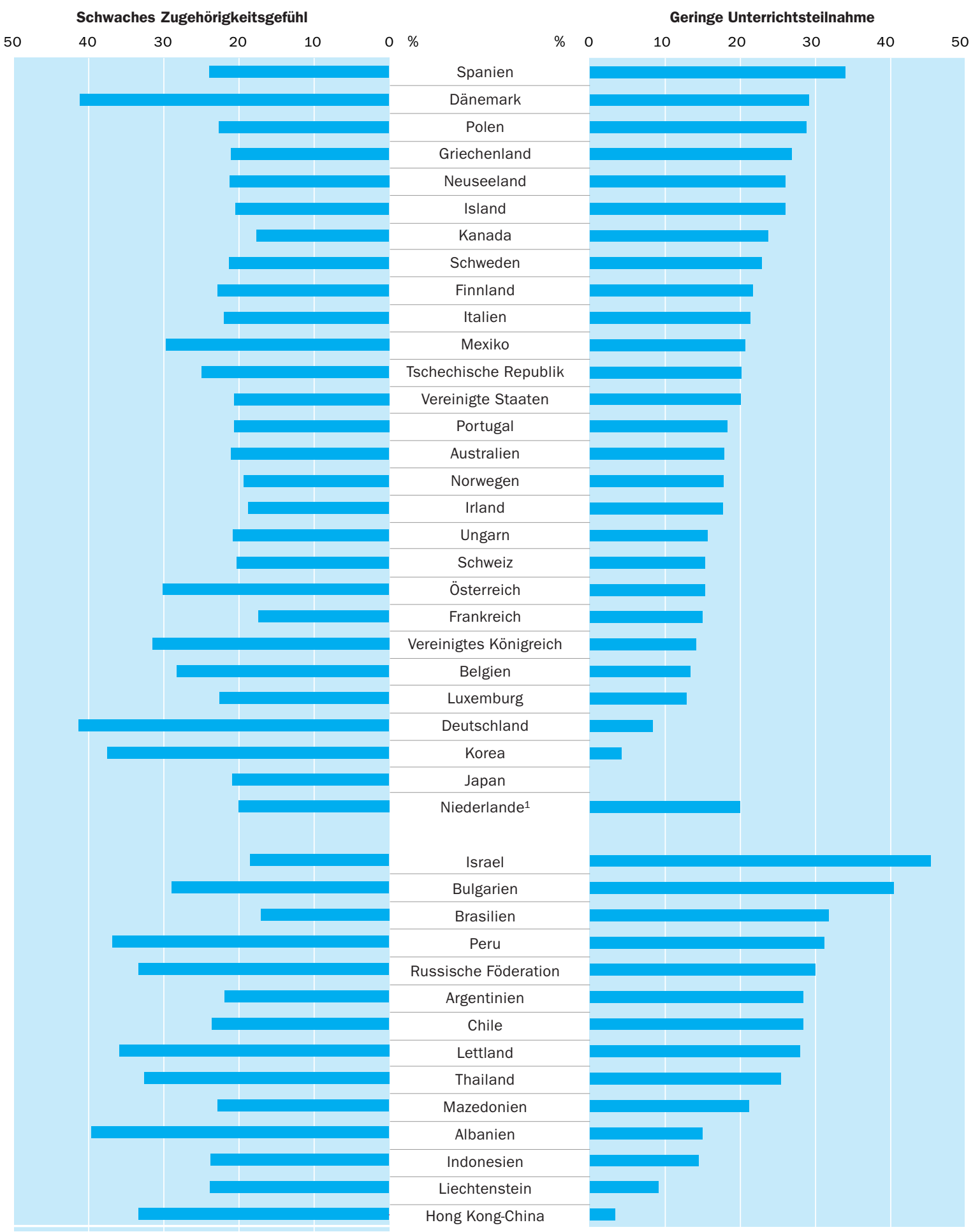

Hinweis: 1. Beteiligungsquote zu niedrig, um die Vergleichbarkeit zu gewährleisten.

Anordnung der Länder zuerst nach Mitgliedschaft in der OECD und dann in absteigender Reihenfolge des Anteils Schüler mit einer geringen Unterrichtsteilnahme. Quelle: OECD PISA 2000-Datenbank. Tabelle A8.2. 


\section{Politischer Hintergrund}

Die Schule ist ein bestimmender Teil des täglichen Lebens junger Menschen und ihre Wahrnehmung der Schule spiegelt sich in ihrer Teilnahme an schulischen wie außerschulischen Aktivitäten. Die meisten Schüler nehmen sowohl an schulischen als auch außerschulischen Aktivitäten teil und entwickeln ein Gefühl der Zugehörigkeit - ihre Freunde sind in der Schule, sie haben ein gutes Verhältnis zu ihren Lehrern und Mitschülern, sie identifizieren sich mit ihrem schulischen Erfolg und schätzen diesen auch. Andere Schüler teilen jedoch dieses Gefühl der Zugehörigkeit nicht und glauben nicht, dass sich schulischer Erfolg stark auf ihre Zukunft auswirken wird, was potenziell zu einem Rückzug vom schulischen Leben führen kann. Den Bedürfnissen dieser Schülergruppen gerecht zu werden, ist eine der größten Herausforderungen für Lehrer und Schulleitungen.

In der Literatur zu Forschungsarbeiten in diesem Gebiet hat Engagement sowohl eine psychologische Komponente, die sich auf das Zugehörigkeitsgefühl der Schüler und die Akzeptanz der schulischen Werte bezieht, als auch eine verhaltensbezogene Komponente, die sich in der Teilnahme an schulischen Aktivitäten zeigt. Im Jahr 2000 hat das Programme for International Student Assessment (PISA) das Engagement der Schüler im Hinblick auf beide Komponenten gemessen. Zunächst untersucht dieser Indikator, in welchem Maße die durchschnittlichen Ergebnisse bei zwei Messgrößen des Engagements in der Schule und der Anteil Schüler mit sehr niedrigen Punktzahlen bei diesen beiden Messgrößen zwischen den Ländern variieren. Außerdem bewertet er den Anteil unzufriedener Schüler an den Schulen innerhalb der einzelnen Länder, was wichtige Auswirkungen für die gezielte Auswahl von Maßnahmen zur Verminderung der Unzufriedenheit dieser Schüler hat.

Ein verbreiteter Ansatz bei der Untersuchung des Engagements der Schüler ist die Annahme, dass Engagement den schulischen Erfolgen vorangeht, und dass die schulischen Leistungen leiden, wenn sich Schüler von der Schule distanzieren. Dies mag für einige Schüler gelten. Ein anderes plausibles Modell lautet jedoch, dass mangelnder Erfolg in der Schule zu Unzufriedenheit der Schüler und zum Rückzug von schulischen Aktivitäten führt. Möglicherweise beeinflussen andere Faktoren - persönliche, familiäre und schulische - gemeinsam sowohl das Engagement als auch den schulischen Erfolg. Außerdem können kausale Zusammenhänge je nach Temperament des Schülers, den schulischen Fähigkeiten, sowie familiärem und schulischem Kontext variieren. PISA kann zwar den kausalen Zusammenhang zwischen Engagement und Leistungserfolgen nicht bestimmen, kann aber einen Hinweis darauf geben, wie stark diese Zusammenhänge sowohl hinsichtlich der Einstellungen als auch der schulischen Erfolge von I5-jährigen Schüler sind. Um dies zu beleuchten, untersucht der zweite Teil dieses Indikators den Zusammenhang zwischen dem schulischen Engagement der Schüler und ihrer Leistung. Zunächst untersucht er, wie stark die Beziehung zwischen den Messgrößen des Engagements und den Messgrößen der Lesekompetenz sowie der mathematischen und naturwissenschaftlichen Grundbildung ist, und beschreibt dann Schülerprofile im Hinblick auf Engagement und Leistung.
Dieser Indikator untersucht, in welchem Ausmaß die durchschnittlichen Ergebnisse bei zwei Messgrößen des Engagements in der Schule und der Anteil Schüler mit sehr niedrigen Punktzahlen beí diesen beiden Messgrößen zwischen den Ländern variieren, ...

... bewertet die Unterschiede beim Schülerengagement zwischen den Schulen, ...

... und untersucht den Zusammenhang zwischen dem Engagement der Schüler und der Leseleistung. 


\section{Ergebnisse und Erläuterungen}

8 Dieser Indikator untersucht zwei Aspekte des schulischen Engagements von Schülern:

... das Zugehörigkeitsgefühl der Schüler ...
Der Begriff Schülerengagement in diesem Indikator verweist auf die Einstellungen der Schüler zur Schule und ihre Teilnahme an schulischen Aktivitäten. Diese Kennzahl des Engagements unterscheidet sich von der „Freude am Lesen" der PISA-Studie, die sich speziell auf die Motivation der Schüler, zu lesen und ihr Interesse daran sowie auf die Zeit bezieht, die sie aus Vergnügen lesen, und welche Art von Lesematerial sie lesen. Das aus PISA 2000 abgeleitete Konzept des Schülerengagements in der Schule hat zwei Dimensionen: das Gefühl der Zugehörigkeit und die Unterrichtsteilnahme.

Das Zugehörigkeitsgefühl basiert auf den Antworten der Schüler auf Fragen, in denen sie ihre persönlichen Gefühle im Hinblick darauf beschreiben, ob sie sich von ihren Mitschülern akzeptiert fühlen, ob sie sich einsam fühlen, „wie ein Außenseiter" oder „fehl am Platz“. Wie die Leseleistungen oder jedes andere schulische Ergebnis wird das Zugehörigkeitsgefühl von den Erfahrungen der Schüler sowohl zu Hause und ihrer Gemeinschaft als auch in der Schule beeinflusst.

\section{Abbildung A8.2}

Mittlere Punktzahl bei zwei Indizes des Engagements von Schülern in der Schule (2000)

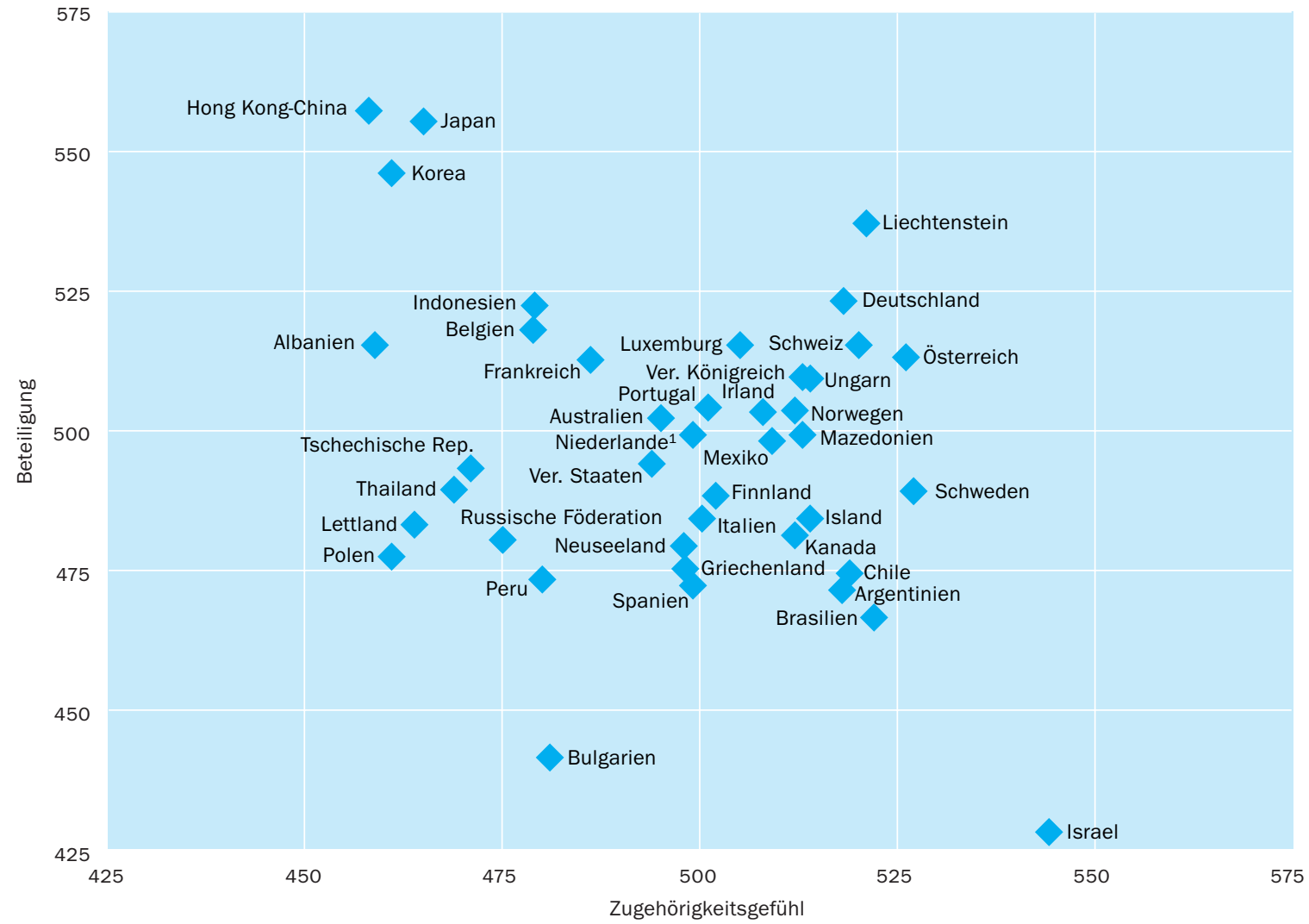


Die zweite Komponente, Unterrichtsteilnahme, wurde anhand der Häufigkeit des Fehlens, Schwänzens und Zuspätkommens während der beiden Wochen vor der PISA 2000 Befragung gemessen. (Nähere Einzelheiten dazu, wie die beiden Kategorien - vor allem Unterrichtsteilnahme - gemessen wurden s. Student Engagement at School - A Sense of Belonging and Participation, OECD 2003).

\section{Unterschiede beim Engagement der Schüler zwischen den Ländern}

Der OECD-Mittelwert für beide Formen des Engagements der Schüler wurde auf 500 festgelegt, entsprechend haben Länder, deren Punktzahl deutlich über 500 liegt, ein günstigeres Ergebnis beim Engagement als der OECD-Durchschnitt, während Länder mit Ergebnissen unter 500 weniger günstige Resultate erzielen. Tabelle A8.I zeigt, dass das Gefühl der Zugehörigkeit in den OECD-Ländern variiert - es reicht von 46r Punkten in Korea und Polen bis zu 520 Punkten oder mehr in Österreich, Schweden und der Schweiz.

Die Länder, die signifikant unter dem OECD-Mittelwert lagen, sind Belgien, Japan, Korea, Polen und die Tschechische Republik. Unter den OECD-Partnerländern hatten zwei, Brasilien und Israel, Ergebnisse, die signifikant über dem OECD-Mittelwert lagen, während acht der übrigen OECD-Partnerländer relativ geringe Punktzahlen erzielten und mindestens ig Punkte unter dem OECDMittelwert lagen.

Bei der Unterrichtsteilnahme war die Varianz größer und reichte von 472 Punkten in Spanien bis zu 555 in Japan. Drei OECD-Ländern erreichten Punktzahlen, die signifikant über dem OECD-Mittelwert lagen: Japan, Korea und Deutschland. Fünf Länder lagen unter dem OECD-Mittelwert: Griechenland, Kanada, Neuseeland, Polen und Spanien. Bei den OECD-Partnerländern lagen vier über dem OECD-Mittelwert und acht signifikant darunter.

Betrachtet man beide Kenngrößen gemeinsam (Abb. A8.2), ist interessant zu beobachten, dass bei den OECD-Ländern Schweden relativ hohe Punktzahlen bei dem Zugehörigkeitsgefühl erreicht, aber relativ geringe Punktzahlen bei der Unterrichtsteilnahme. Im Gegensatz dazu haben Japan und Korea relativ hohe Punktzahlen bei der Unterrichtsteilnahme, jedoch relativ geringe beim Zugehörigkeitsgefühl. Bei diesen Messgrößen waren auch andere geographische Muster zu beobachten, wie zum Beispiel in Deutschland, Österreich und der Schweiz, wo sowohl die Unterrichtsteilnahme als auch das Zugehörigkeitsgefühl relativ stark sind. Eine weitere Gruppe bilden Argentinien, Chile und Brasilien, OECD-Partnerländer in Südamerika, hier ist das Zugehörigkeitsgefühl der Schüler tendenziell relativ höher als ihre Unterrichtsteilnahme.

\section{Unterschiede zwischen den Ländern mit schwachem Zugehörig- keitsgefühl und geringer Unterrichtsteilnahme}

Dieses Thema lässt sich auch untersuchen, indem man die Schüler betrachtet, die sich von der Schule distanzieren, sich nicht zugehörig fühlen und sich signifikant von den schulischen Aktivitäten zurückgezogen haben. Diese Schüler können als „unzufrieden“ betrachtet werden. Die Analyse der Daten von PISA 2000 lässt die Schüler erkennen, die im Vergleich zu ihren Mitschülern ein schwaches Zugehörigkeitsgefühl haben und sich gering beteiligen. Ein schwaches Zugehörigkeitsgefühl und geringe Unterrichtsteilnahme wurde
... und ihre Teilnahme am Unterricht.

Im Durchschnitt geben die Schüler in Österreich, Schweden und der Schweiz ein besonders starkes Gefühl der Zugehörigkeit an, ...

... während das Zugehörigkeitsgefühl der Schüler in Belgien, Japan, Korea, Polen und der Tschechischen Republik unter dem Durchschnitt liegt.

In einigen Ländern ist das Zugehörigkeitsgefühl der schüler gering, aber ihre Unterrichtsteilnahme hoch, in anderen Ländern ist das Gegenteil der Fall. 
Im Durchschnitt macht fast ein Viertel der 15-Jährigen negative Aussagen darüber, wie gut sie sich in der Schule einfügen ...

... und im Durchschnitt gibt jeder Fünfte an, kürzlich die Schule nicht besucht zu haben, zu spät gekommen zu sein oder geschwänzt zu haben. denjenigen Schülern attestiert, deren Punktzahlen unterhalb bestimmter Grenzwerte lagen, die aufgrund von realen und empirischen Betrachtungen festgelegt wurden. Die Festlegung der Grenzwerte beeinflusst zwar den internationalen Vergleich nicht wesentlich, sehr wohl aber die Bewertung der Prävalenz. Bei der inhaltlichen Interpretation von „schwachem Zugehörigkeitsgefühl“ und „geringer Unterrichtsteilnahme“ sind daher die detaillierten Definitionen weiter unten zu berücksichtigen.

In den meisten Ländern lag der Anteil der Jugendlichen mit einem schwachem Zugehörigkeitsgefühl bei 25 Prozent (Abb. A8.I). In fünf Ländern, Belgien, Frankreich, Japan, Korea und Polen, lag der Durchschnitt jedoch bei über 30 Prozent. Der Anteil von Schülern mit einem schwachen Gefühl der Zugehörigkeit lag in Irland, Schweden, Ungarn und dem Vereinigten Königreich unter 20 Prozent.

Wie bei den Mittelwerten dieser Messgrößen variiert auch der Anteil der Schüler mit geringer Unterrichtsteilnahme stärker zwischen den einzelnen Ländern als der Anteil der Schüler mit einem schwachen Zugehörigkeitsgefühl. Obwohl der durchschnittliche Prozentsatz der Schüler mit einer geringen Unterrichtsteilnahme bei 20 Prozent lag (und damit unter dem Ergebnis für ein schwaches Zugehörigkeitsgefühl), gab es viele Länder mit einem relativ hohen Anteil und viele Länder mit einem relativ niedrigen Anteil Schüler mit geringer Unterrichtsteilnahme.

Die sechs Länder, in denen der Anteil der geringen Unterrichtsteilnahme über 25 Prozent lag, sind Griechenland, Island, Kanada, Neuseeland, Polen und Spanien. Die fünf Länder, in denen der Anteil unter I5 Prozent lag, sind Belgien, Deutschland, Japan, Korea und Luxemburg, wobei der Anteil der geringen Unterrichtsteilnahme in Japan mit 4 Prozent besonders niedrig ist.

\section{Unterschiede zwischen den Schulen beim schwachen Zugehörig- keitsgefühl und geringer Unterrichtsteilnahme}

Der Anteil von Schülern mit einem schwachen Zugehörigkeitsgefühl unterscheidet sich auch stark zwischen den Schulen innerhalb eines Landes. Das Ausmaß dieser Varianz zu bestimmen, ist aus mindestens zwei Gründen wichtig. Falls es erstens beträchtliche Unterschiede zwischen den Schulen gibt, könnte es effizienter sein, gezielt an bestimmten Schulen einzugreifen. Wenn hingegen der Anteil bei allen Schulen eines Landes relativ gleichartig ist, wäre ein allgemeineres Vorgehen empfehlenswert. Falls es zweitens beim Anteil unzufriedener Schüler beträchtliche Unterschiede zwischen den Schulen gibt, ließe sich möglicherweise erkennen, ob bestimmte Schulfaktoren mit dem Zugehörigkeitsgefühl oder der Unterrichtsteilnahme zusammenhängen. Das ließe Rückschlüsse darauf $\mathrm{zu}$, welche Vorgehensweisen am wirksamsten sein könnten.

Für jedes Land wurde der Anteil Schüler mit einem schwachen Zugehörigkeitsgefühl und geringer Unterrichtsteilnahme für jede Schule mit Mehrebenenanalysetechniken berechnet. Die Unterschiede bei der Schätzung des Anteils der unzufriedenen Schüler zwischen den Schulen eines Landes lässt sich als Verteilung darstellen, die den mittleren Anteil in allen Schulen eines Landes 
zeigt, sowie das 5., 25., 75. und 95. Perzentil der Verteilung des geschätzten Anteils für alle Schulen eines Landes.

Die Ergebnisse zeigen, dass in jedem Land, mit Ausnahme von Island, Neuseeland und Schweden, der Anteil der Schüler mit einem schwachen Zugehörigkeitsgefühl zwischen den Schulen stark variiert. Der durchschnittliche Quartilsabstand lag bei 5 Prozent und der durchschnittliche Abstand vom 5. zum 95. Perzentil bei I3 Prozent. In drei Ländern, Korea, Luxemburg und Polen, war der Abstand größer als 20 Prozent, was auf relativ große Unterschiede zwischen den Schulen hinweist.

In jedem OECD-Land variiert der Anteil der Schüler mit geringer Unterrichtsteilnahme signifikant zwischen den einzelnen Schulen. Der durchschnittliche Quartilsabstand lag bei 7 Prozent und der durchschnittliche Abstand zwischen dem 5. und dem 95. Perzentil bei 20 Prozent. Diese Zahlen lassen erkennen, dass es zwischen den Schulen deutlich größere Unterschiede beim Anteil der Schüler mit einer geringen Unterrichtsteilnahme gibt als beim Zugehörigkeitsgefühl. In Belgien, Italien, Polen, Spanien, der Schweiz, Ungarn und den Vereinigten Staaten lag der Abstand beim Anteil der Schüler mit einer geringen Unterrichtsteilnahme bei über 25 Prozent.

\section{Engagement und Leistung der Schüler}

PISA kann zwar den kausalen Zusammenhang zwischen Engagement und Leistungserfolgen nicht bestimmen, kann aber einen Hinweis darauf geben, wie stark diese Zusammenhänge sowohl hinsichtlich der Einstellungen als auch der schulischen Erfolge sind. Diese Analyse gibt Hinweise darauf, ob Schüler, die sich stärker in der Schule engagieren, eine höhere Grundbildung haben und ob das gleiche umgekehrt auch gilt. Die Korrelationen zwischen den beiden Ergebnisvariablen lassen sich in eine innerschulische Komponente und eine Komponente zwischen Schulen aufteilen. Die innerschulische Komponente zeigt, wie stark zwei Variablen bei den Schülern einer Schule zusammenhängen. Die zweite Komponente zeigt, ob Schulen mit höheren Durchschnittsergebnissen bei einer der beiden Messgrößen auch bei der anderen Messgröße höhere Durchschnittswerte erreichen und umgekehrt.

Abbildung A8.3 zeigt den durchschnittlichen Zusammenhang dieser Variablen für alle teilnehmenden OECD-Länder. Die Korrelation auf Schülerebene ist unterhalb der Diagonale abgebildet, die Korrelation auf Schulebene oberhalb. Auf Schülerebene ist der durchschnittliche Zusammenhang zwischen Zugehörigkeitsgefühl und Unterrichtsteilnahme mit o,o7 nur sehr schwach und lässt vermuten, dass es sich bei den beiden Variablen um sehr unterschiedliche Maßstäbe des Lernerfolges handelt.

Es mag viele Schüler geben, die sich nicht zugehörig fühlen und trotzdem regelmäßig die Schule besuchen. Umgekehrt kann es viele Schüler mit einem starken Zugehörigkeitsgefühl geben, die trotzdem oft den Unterricht versäumen, Stunden schwänzen und zu spät zur Schule kommen. Der Zusammenhang zwischen Zugehörigkeitsgefühl und den drei Messgrößen der Grundbildung ist ebenfalls nur schwach und reicht von 0,04 bis 0,06. Der Zusammenhang zwischen Unterrichtsteilnahme und schulischer Leistung ist

Bei den einzelnen Schülern ist der Zusammenhang zwischen Unterrichtsteilnahme und Zugehörigkeitsgefühl nur schwach, ...

... was vermuten lässt, dass viele Schüler, die sich nicht zugehörig fühlen, dennoch regelmäßig die Schule besuchen und umgekehrt. 


\section{Abbildung A8.3}

Korrelation zwischen den Messgrößen des Engagements der Schüler in der Schule und der Lesekompetenz sowie der mathematischen und naturwissenschaftlichen Grundbildung ${ }^{1}(2000)$

Korrelation auf Schülerebene Korrelation auf Schulebene

\begin{tabular}{|c|c|c|c|c|c|}
\hline & Zugehörigkeitsgefühl & Unterrichtsteilnahme & Lesekompetenz & $\begin{array}{l}\text { Mathematische } \\
\text { Grundbildung }\end{array}$ & $\begin{array}{l}\text { Naturwissenschaftl. } \\
\text { Grundbildung }\end{array}$ \\
\hline Zugehörigkeitsgefühl & & 0.37 & 0.51 & 0.48 & 0.50 \\
\hline Unterrichtsteilnahme & 0.07 & & 0.48 & 0.50 & 0.49 \\
\hline Lesekompetenz & 0.06 & 0.14 & & 0.97 & 0.99 \\
\hline $\begin{array}{l}\text { Mathematische } \\
\text { Grundbildung }\end{array}$ & 0.04 & 0.13 & 0.71 & & 0.99 \\
\hline $\begin{array}{l}\text { Naturwissenschaftliche } \\
\text { Grundbildung }\end{array}$ & 0.04 & 0.14 & 0.79 & 0.68 & \\
\hline $\begin{array}{l}\text { Nur OECD-Länder. } \\
\text { Ille: OECD PISA 200o-Daten }\end{array}$ & & & & & \\
\hline
\end{tabular}

Im Gegensatz dazu sind auf Schulebene das Zugehörigkeitsgefühl und die Unterrichtsteilnahme tendenziell miteinander verknüpft ...

... und stehen in engem

Zusammenhang zur Leistung der Schule, ...
... was vermuten lässt, dass Schulen mit einem hohen Grad an Engagement auch tendenziell ein hohes Leistungsniveau ihrer Schüler erzielen. mit $0, I_{3}$ bis o,I4 etwas stärker. Im Gegensatz dazu ist die Korrelation unter den drei Messgrößen der Grundbildung relativ hoch und reicht auf Schülerebene von 0,68 bis 0,79 .

Die Korrelation zwischen Zugehörigkeitsgefühl und Unterrichtsteilnahme auf Schulebene liegt dagegen bei o,37 und verweist damit auf einen engeren Zusammenhang. Schulen mit einem stärkeren Zugehörigkeitsgefühl weisen daher tendenziell auch eine höhere Unterrichtsteilnahme auf.

Auf Schulebene sind die Korrelationen zwischen den beiden Formen des Engagements und den drei Messungen der Grundkompetenz mit o,48 bis o,5I ebenfalls mäßig stark. Im Gegensatz dazu ist die Korrelation zwischen den drei Messgrößen der Grundkompetenz auf Schulebene relativ hoch und reicht von o,68 bis 0,79. Diese Ergebnisse haben zahlreiche Implikationen für Politik und Praxis. Die schwachen Korrelationen auf Schülerebene lassen vermuten, dass Lehrer und Schulberater oft auf Schüler treffen, die ein schwaches Zugehörigkeitsgefühl haben, obwohl sie an den schulischen Aktivitäten teilnehmen und ihre Grundkompetenzen relativ hoch sind. Schüler mit geringer Unterrichtsteilnahme haben oft eine etwas geringere Grundkompetenz als diejenigen, die an fast allen Stunden teilnahmen. Dennoch haben viele Schüler, die die Schule versäumen, Stunden schwänzen und zu spät zur Schule kommen, relativ starke Grundkompetenzen.

Die mäßig starken Korrelationen auf Schulebene zwischen dem Engagement der Schüler und ihren Grundkompetenzen lassen vermuten, dass Schulen mit einem hohen Grad an Engagement auch tendenziell ein hohes Niveau schulischer Leistungen erzielen. Dennoch lässt sich hieraus keineswegs schließen, 
Abbildung A8.4

Prozentsatz der Schüler und Mittelwert bei vier Kenngrößen des Lernerfolges, nach Kategorien des Schülerengagements für alle OECD-Länder ${ }^{1}(2000)$

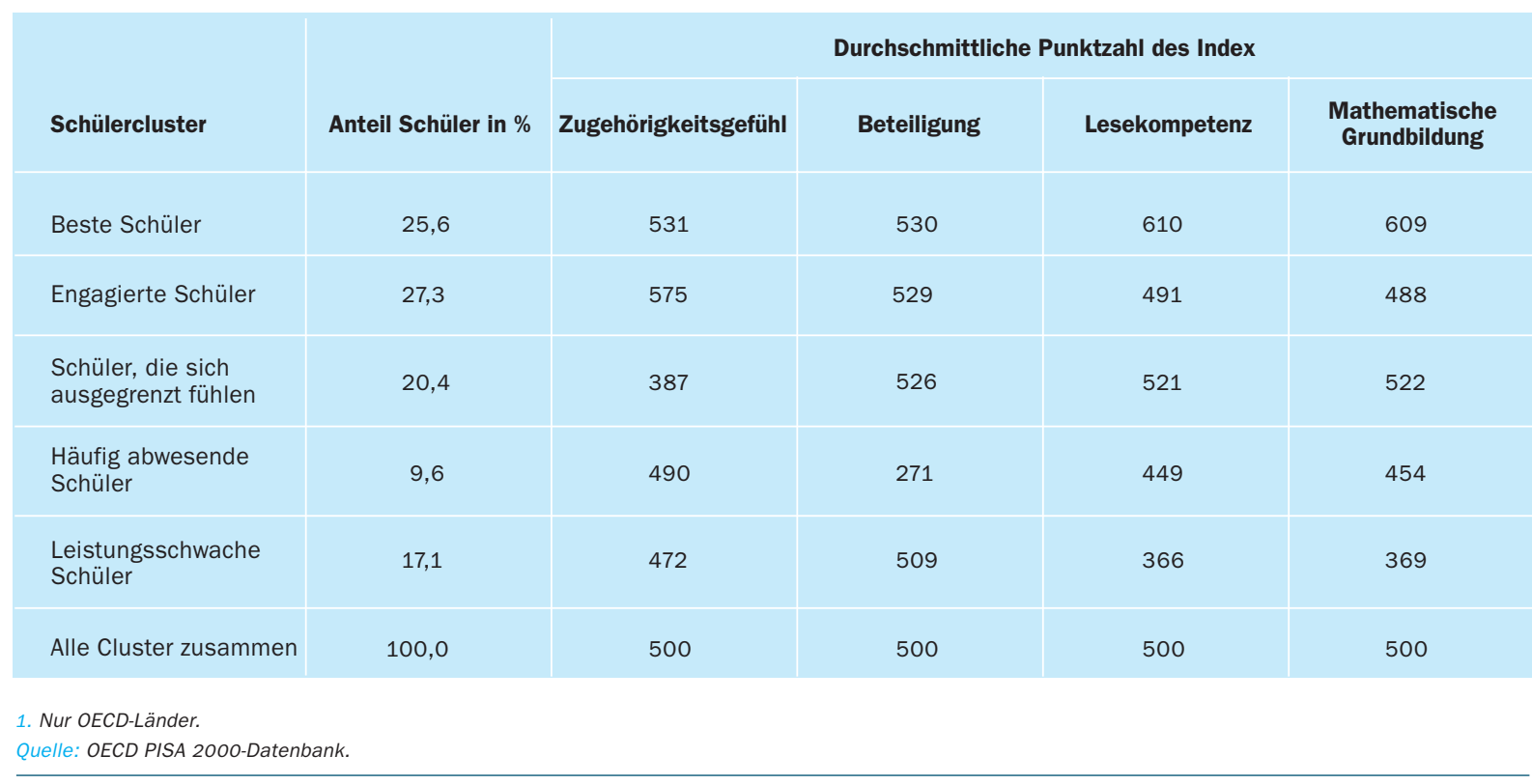

dass Bemühungen, das Engagement der Schüler auf Schulebene zu stärken, zu besseren schulischen Leistungen führen könnten.

Eine Möglichkeit, diese Zusammenhänge näher zu untersuchen besteht darin, Gruppen, oder statistisch ausgedrückt, Cluster von Schülern zu bilden, je nachdem wie ähnlich sie bei den Ergebnissen hinsichtlich Engagement und Leistung abschneiden. Abbildung A8.4 zeigt das Resultat der Clusteranalyse der Ergebnisse der OECD-Länder. Die Abbildung zeigt den Prozentsatz der Schüler in jedem der fünf Cluster, sowie die durchschnittliche Punktzahl bei jeder der vier Ergebnisvariablen (Zugehörigkeit, Unterrichtsteilnahme, Lesekompetenz, mathematische Grundkompetenz) für jedes Schülercluster.

Das erste Cluster umfasst etwa ein Viertel aller Schüler und wird als beste Schüler bezeichnet. Diese Schüler sind engagiert und erzielen relativ hohe Ergebnisse bei der Lesekompetenz und der mathematischen Grundkompetenz. Im Durchschnitt erreichen Schüler dieses Clusters 6ro Punkte auf der Skala Lesekompetenz, 609 Punkte auf der Skala mathematische Grundkenntnisse, 503 Punkte auf der Unterrichtsteilnahmeskala und 53I Punkte auf der Skala Zugehörigkeitsgefühl.

Die zweite Gruppe, engagierte Schüler, erreicht bei den beiden Formen des Engagements überdurchschnittliche Ergebnisse, aber ihre Leistungen bei der Lesekompetenz und der mathematischen Grundkompetenz liegen um etwa io Punkte unter dem OECD-Mittelwert von 500. Diese Schüler gehören zwar nicht zu denjenigen mit hohen Grundkompetenzen, fühlen sich aber zur Schule zugehörig und bleiben der Schule nicht regelmäßig fern. Auch diese Gruppe ... Schüler mit guten schulischen Leistungen sowie überdurchschnittlichem Zugehörigkeitsgefühl und überdurchschnittlicher Unterrichtsteilnahme, ... umfasst etwa ein Viertel aller Schüler.

...schüler mit einem starken Zugehörigkeitsgefühl, überdurchschnittlicher Unterrichtsteilnahme und durchschnittlichen schulischen Leistungen, ... 
... Schüler mit einem schwachen Zugehörigkeitsgefühl, aber mindestens durchschnittlicher Unterrichtsteilnahme und durchschnittlichen Leistungen, ...

... Schüler, die häufig fehlen ...

... und leistungsschwache Schüler.

Die Analyse zeigt vor allem, dass ein beträchtlicher Anteil der Schüler mit vergleichsweise hohen schulischen Leistungen dennoch ein schwaches Zugehörigkeitsgefühl angeben.
Engagement- und Leistungsmessgrößen basieren auf Bewertungen, die als Teil der PISA-Studie im Jahr 2000 von der OECD durchgeführt wurden.
Die dritte Schülergruppe, Schüler, die sich ausgegrenzt fühlen, umfasst etwa ein Fünftel aller Schüler. Diese Schüler erreichen im Durchschnitt geringe Ergebnisse beim Zugehörigkeitsgefühl aber überdurchschnittliche Werte bei der Unterrichtsteilnahme. Ihre Leistungsergebnisse sind tendenziell recht gut und liegen im Durchschnitt etwa 20 Punkte über dem OECD-Mittelwert.

Die vierte Schülergruppe, häufig abwesende Schüler, hat sehr geringe Werte bei der Unterrichtsteilnahme. Auch ihre Grundkompetenz liegt in der Regel unter dem Durchschnitt - im Schnitt um etwa 50 Punkte - aber ihr Zugehörigkeitsgefühl liegt fast beim OECD-Mittelwert. Diese Schüler machen etwa Io Prozent der Stichprobe aus.

Die letzte Gruppe, leistungsschwache Schüler, umfasst Schüler mit geringen Grundkompetenzen, im Durchschnitt etwa I30 bis I35 Punkte unterhalb des OECD-Mittelwerts. Diese Schüler erzielen im Durchschnitt geringe Werte bei der Zugehörigkeit, bleiben aber der Schule nicht regelmäßig fern. Sie machen etwa I7 Prozent der I5-jährigen Schüler der OECD-Länder aus.

Ein wichtiges Ergebnis dieser Analyse belegt, dass Schüler mit geringem Zugehörigkeitsgefühl in zwei unterschiedlichen Gruppen zu finden sind. Es gibt zum einen Schüler, die sich einsam und von ihren Klassenkameraden ausgegrenzt fühlen, obwohl sie relativ gute schulische Leistungen erzielen. Und es gibt Schüler, die sich ausgegrenzt fühlen und gleichzeitig schlechte schulische Leistungen erbringen. Dies erklärt in gewissem Maße die relativ geringe Korrelation zwischen Zugehörigkeitsgefühl und schulischen Leistungen (s. Abb. A8.3). Eine weitere wichtige Frage bei diesen Ergebnissen lautet, ob Schüler im Cluster mit hohen Grundkompetenzen aber schwachem Zugehörigkeitsgefühl über die Zeit der Schulpflicht hinaus Bildungsangebote wahrnehmen werden.

Die Clusteranalyse zeigt auch, dass Schüler mit sehr geringen Grundkompetenzen nicht grundsätzlich bei beiden Formen des Engagements besonders niedrige Werte erzielen. Die Analyse ergab kein Cluster von Schülern, die bei allen vier Messgrößen niedrige Punktzahlen erreichten.

\section{Definitionen und angewandte Methodik}

Die Indexwerte und Prozentsätze basieren auf Hintergrundfragebögen, die als Teil der Internationalen Schulleistungsstudie PISA-Studie im Jahr 2000 erhoben wurden. Die Zielpopulation dieses Indikators waren I5-jährige Schüler. In der Praxis bezog sich dies auf Schüler, die zu Beginn der Testperiode zwischen I5 Jahren und 3 (abgeschlossenen) Monaten und 6 Jahren und 2 (abgeschlossenen) Monaten alt waren und eine Bildungseinrichtung besuchten, ungeachtet der Klassenstufe und der Art der von ihnen besuchten Bildungseinrichtung und unabhängig davon, ob es sich um eine Ganztags- oder Halbtagsschule handelte.

Schülern, die auf der Skala Zugehörigkeitsgefühl (vor der Standardisierung) weniger als 3,0 erreichten, wurde ein schwaches Zugehörigkeitsgefühl attestiert. Diese Schüler antworteten im Durchschnitt bei den sechs Fragen häufiger 
mit „stimme nicht zu“ und „stimme überhaupt nicht zu“ als mit „stimme zu“ und „stimme ganz zu“. Schüler, die sich „zugehörig“ fühlen, antworten erwartungsgemäß im Schnitt wenigstens mit „stimme zu“ bei den positiven Aussagen und mit „stimme nicht zu“ bei den negativen Aussagen. Diejenigen mit einem geringeren Durchschnittswert wurden als „,besitzen ein geringes Zugehörigkeitsgefühl“ klassifiziert. Das bedeutet nicht, dass sie insgesamt negative Ansichten geäußert hätten, aber zumindest bei einer Frage war dies der Fall. Die Analyse der Verteilung der skalierten Ergebnisse legt nahe, dass 3, o ein angemessener Grenzwert ist. Die Skala Zugehörigkeitsgefühl hat eine linkschiefe Verteilung ( $-0,70$ für die teilnehmenden OECD-Länder), was darauf hinweist, dass es eine große Anzahl von Schülern mit sehr niedrigen Punktzahlen gab. Ein Viertel aller Schüler erreicht weniger als 3,o auf der nicht standardisierten Skala, was einem Ergebnis von 426 oder weniger auf der standardisierten Skala entspricht. An diesem Punkt ist ein deutlicher Bruch der Verteilung zu beobachten. Schüler mit 3,o oder höheren Werten erreichten 460 oder mehr Punkte. Daher gibt es für das Kriterium, das zur Klassifizierung der Schüler mit „geringem Zugehörigkeitsgefühl“ genutzt wurde, eine einfache inhaltliche Auslegung und es basiert auf einem signifikanten Bruch in der beobachteten Verteilung der Ergebnisse.

Schüler wurden als gering beteiligt betrachtet, wenn sie auf der nicht standardisierten Unterrichtsteilnahmeskala Io Punkte oder weniger erreichten. Es ist zu berücksichtigen, dass die Skala nicht zwischen entschuldigtem und unentschuldigtem Fehlen unterscheidet. Auch dies führt zu einer interessanten inhaltlichen Interpretation. Beispielsweise wurden alle Schüler als gering beteiligt klassifiziert, die bei allen drei Fragen „ein- bis zweimal“ antworteten oder „drei- bis viermal“ bei „Unterricht versäumen“ oder „drei- bis viermal“ auf „Stunden schwänzen“ und „zu spät zur Schule kommen“. Die Variable Unterrichtsteilnahme hatte ebenfalls eine starke linkschiefe Verteilung (-I, 82 für die OECD-Länder). Wie bei den Ergebnissen beim Zugehörigkeitsgefühl weist dies darauf hin, dass es eine Reihe von Schülern mit sehr niedrigen Werten gibt. Diese Kriterien wurden auf der Unterrichtsteilnahmeskala mit ro oder weniger festgelegt, entsprechend wurden 20 Prozent der Schüler der teilnehmenden OECD-Länder als gering beteiligt klassifiziert.

Hinweise zu Standardfehlern, Signifikanztests und multiplen Vergleichen s. Anhang 3 unter www.oecd.orgleduleag 2004. 
Tabelle A8.1

Mittelwerte der zweil Indizes des Engagements von Schülern in der Schule (2000)

\begin{tabular}{|c|c|c|c|c|c|c|}
\hline & \multicolumn{3}{|c|}{ Gefühl der Zugehörigkeit } & \multicolumn{3}{|c|}{ Unterrichtsteilnahme } \\
\hline & Mittelwert Index & S.F. & $\begin{array}{l}\text { Standard- } \\
\text { abweichung }\end{array}$ & Mittelwert Index & S.F. & $\begin{array}{l}\text { Standard- } \\
\text { abweichung }\end{array}$ \\
\hline \multicolumn{7}{|l|}{ OECD-Länder } \\
\hline Australien & 495 & $(2,0)$ & 97 & 502 & $(2,1)$ & 89 \\
\hline Österreich & 526 & $(2,3)$ & 109 & 513 & $(2,2)$ & 85 \\
\hline Belgien & 479 & $(1,3)$ & 90 & 518 & $(1,7)$ & 94 \\
\hline Tschechische Republik & 471 & $(1,6)$ & 78 & 493 & $(2,2)$ & 99 \\
\hline Dänemark & 513 & $(2,2)$ & 104 & $\mathrm{~m}$ & $\mathrm{~m}$ & $\mathrm{~m}$ \\
\hline Finnland & 502 & $(1,4)$ & 96 & 488 & $(2,1)$ & 103 \\
\hline Frankreich & 486 & $(1,6)$ & 94 & 512 & $(2,1)$ & 93 \\
\hline Deutschland & 518 & $(1,8)$ & 107 & 523 & $(1,9)$ & 85 \\
\hline Griechenland & 498 & $(2,0)$ & 95 & 475 & $(2,7)$ & 112 \\
\hline Ungarn & 514 & $(1,6)$ & 97 & 509 & $(1,9)$ & 96 \\
\hline Irland & 508 & $(1,7)$ & 101 & 503 & $(2,1)$ & 89 \\
\hline Italien & 500 & $(1,6)$ & 92 & 484 & $(2,6)$ & 98 \\
\hline Japan & 465 & $(1,9)$ & 89 & 555 & $(1,9)$ & 57 \\
\hline Korea & 461 & $(1,6)$ & 81 & 546 & $(1,5)$ & 71 \\
\hline Luxemburg & 505 & $(1,8)$ & 110 & 515 & $(1,4)$ & 96 \\
\hline Mexiko & 509 & $(2,2)$ & 98 & 498 & $(2,1)$ & 89 \\
\hline Neuseeland & 498 & $(1,9)$ & 98 & 479 & $(2,1)$ & 110 \\
\hline Norwegen & 512 & $(2,2)$ & 104 & 503 & $(2,0)$ & 102 \\
\hline Polen & 461 & $(1,9)$ & 85 & 477 & $(3,7)$ & 119 \\
\hline Portugal & 501 & $(1,9)$ & 88 & 504 & $(1,8)$ & 91 \\
\hline Spanien & 499 & $(1,6)$ & 91 & 472 & $(2,5)$ & 118 \\
\hline Schweden & 527 & $(1,8)$ & 103 & 489 & $(1,5)$ & 99 \\
\hline Schweiz & 520 & $(2,0)$ & 105 & 515 & $(1,9)$ & 90 \\
\hline Vereinigtes Königreich & 513 & $(1,4)$ & 101 & 509 & $(1,5)$ & 86 \\
\hline Ländermittel & 500 & $(0,4)$ & 100 & 500 & $(0,4)$ & 100 \\
\hline \multicolumn{7}{|l|}{ OECD-Partnerländer } \\
\hline Albanien & 459 & $(1,6)$ & 80 & 515 & $(2,1)$ & 89 \\
\hline Argentinien & 518 & $(3,7)$ & 107 & 471 & $(6,2)$ & 124 \\
\hline Brasilien & 522 & $(2,4)$ & 102 & 466 & $(2,9)$ & 109 \\
\hline Bulgarien & 481 & $(1,9)$ & 85 & 441 & $(3,4)$ & 133 \\
\hline Chile & 519 & $(2,3)$ & 110 & 474 & $(2,9)$ & 111 \\
\hline Hongkong - China & 458 & $(1,3)$ & 73 & 557 & $(1,2)$ & 51 \\
\hline Indonesien & 479 & $(1,7)$ & 72 & 522 & $(1,7)$ & 79 \\
\hline Israel & 544 & $(2,9)$ & 115 & 428 & $(5,3)$ & 129 \\
\hline Lettland & 464 & $(2,1)$ & 79 & 483 & $(2,7)$ & 103 \\
\hline Liechtenstein & 521 & $(5,5)$ & 113 & 537 & $(4,1)$ & 79 \\
\hline Republik Mazedonien & 513 & $(1,7)$ & 98 & 499 & $(1,6)$ & 109 \\
\hline Peru & 480 & $(2,5)$ & 99 & 473 & $(2,5)$ & 113 \\
\hline Russische Föderation & 475 & $(1,6)$ & 85 & 480 & $(2,5)$ & 114 \\
\hline Thailand & 469 & $(1,5)$ & 77 & 489 & $(2,1)$ & 97 \\
\hline Niederlande ${ }^{1}$ & 499 & $(2,8)$ & 84 & 499 & $(2,8)$ & 92 \\
\hline
\end{tabular}

Hinweis: Standardfehler in Klammern.

1. Beteiligungsquote zu niedrig, um die Vergleichbarkeit zu gewährleisten.

Quelle: OECD PISA 2000-Datenbank. 
Tabelle A8.2

Anteil der Schüler mit einem schwachen Zugehörigkeitsgefühl und geringer Unterrichtsteilnahme (2000)

\begin{tabular}{|c|c|c|c|c|}
\hline \multirow[b]{2}{*}{ OECD-Länder } & \multicolumn{2}{|c|}{ Geringes Zugehörigkeitsgefühl } & \multicolumn{2}{|c|}{ Geringe Unterrichtsteilnahme } \\
\hline & Prozent & S.F. & Prozent & S.F. \\
\hline Österreich & 20,3 & $(0,7)$ & 15,3 & $(0,8)$ \\
\hline Belgien & 31,6 & $(0,6)$ & 14,1 & $(0,6)$ \\
\hline Kanada & 20,5 & $(0,4)$ & 26,0 & $(0,5)$ \\
\hline Dänemark & 20,9 & $(0,7)$ & $\mathrm{m}$ & $\mathrm{m}$ \\
\hline Finnland & 21,3 & $(0,7)$ & 22,9 & $(0,9)$ \\
\hline Frankreich & 30,2 & $(0,7)$ & 15,3 & $(0,7)$ \\
\hline Deutschland & 22,6 & $(0,6)$ & 12,9 & $(0,7)$ \\
\hline Griechenland & 22,7 & $(0,9)$ & 28,8 & $(1,0)$ \\
\hline Ungarn & 18,8 & $(0,6)$ & 17,7 & $(0,7)$ \\
\hline Island & 22,4 & $(0,7)$ & 26,0 & $(0,8)$ \\
\hline Italien & 22,9 & $(0,8)$ & 21,7 & $(0,9)$ \\
\hline Japan & 37,6 & $(1,0)$ & 4,2 & $(0,6)$ \\
\hline Korea & 41,4 & $(1,1)$ & 8,4 & $(0,6)$ \\
\hline Luxemburg & 28,3 & $(0,8)$ & 13,4 & $(0,5)$ \\
\hline Mexiko & 22,0 & $(0,9)$ & 21,4 & $(0,8)$ \\
\hline Neuseeland & 21,1 & $(0,8)$ & 26,9 & $(0,9)$ \\
\hline Norwegen & 21,1 & $(0,8)$ & 17,9 & $(0,8)$ \\
\hline Polen & 41,2 & $(1,2)$ & 29,2 & $(1,3)$ \\
\hline Portugal & 20,7 & $(0,9)$ & 20,1 & $(0,7)$ \\
\hline Spanien & 24,0 & $(0,7)$ & 34,0 & $(1,0)$ \\
\hline Schweden & 17,7 & $(0,5)$ & 23,8 & $(0,6)$ \\
\hline Schweiz & 20,8 & $(0,7)$ & 15,7 & $(0,7)$ \\
\hline Vereinigtes Königreich & 17,4 & $(0,6)$ & 15,0 & $(0,6)$ \\
\hline Vereinigte Staaten & 25,0 & $(1,0)$ & 20,2 & $(1,1)$ \\
\hline OECD-Partnerländer & & & & \\
\hline Albanien & 39,7 & $(0,9)$ & 15,0 & $(0,8)$ \\
\hline Argentinien & 21,9 & $(1,7)$ & 28,4 & $(2,6)$ \\
\hline Brasilien & 17,1 & $(0,7)$ & 31,8 & $(1,2)$ \\
\hline Bulgarien & 29,0 & $(1,2)$ & 40,5 & $(1,1)$ \\
\hline Chile & 23,6 & $(0,9)$ & 28,4 & $(1,2)$ \\
\hline Hongkong - China & 33,4 & $(0,8)$ & 3,3 & $(0,3)$ \\
\hline Indonesien & 23,8 & $(1,1)$ & 14,5 & $(0,6)$ \\
\hline Israel & 18,5 & $(0,9)$ & 45,4 & $(1,9)$ \\
\hline Lettland & 36,0 & $(1,1)$ & 28,0 & $(1,3)$ \\
\hline Liechtenstein & 23,9 & $(2,1)$ & 9,1 & $(1,7)$ \\
\hline Republik Mazedonien & 22,9 & $(0,7)$ & 21,2 & $(0,6)$ \\
\hline Peru & 36,9 & $(1,2)$ & 31,2 & $(1,0)$ \\
\hline Russische Föderation & 33,4 & $(1,0)$ & 30,0 & $(0,9)$ \\
\hline Thailand & 32,7 & $(0,9)$ & 25,4 & $(0,9)$ \\
\hline Niederlande ${ }^{1}$ & 20,1 & $(1,2)$ & 20,0 & $(1,2)$ \\
\hline
\end{tabular}

Hinweis: Standardfehler in Klammern.

1. Beteiligungsquote zu niedrig, um die Vergleichbarkeit zu gewährleisten.

Quelle: OECD PISA 2000-Datenbank. 



\section{Geschlechtsspezifische Unterschiede bei Schülerleistungen}

In der vierten Klasse übertrifft die Lesekompetenz der Mädchen im Durchschnitt die der Jungen signifikant und im Alter von 15 Jahren ist der Abstand zwischen den Geschlechtern dann meist recht groß.

In Mathematik haben in den meisten Ländern die 15-jährigen Jungen tendenziell einen leichten Vorsprung vor den gleichaltrigen Mädchen, in den Naturwissenschaften sind die geschlechtsspezifischen Unterschiede weniger deutlich und einheitlich.

In der politischen Bildung zeigen sich bei den 14-Jährigen nur wenige geschlechtsspezifische Unterschiede.

Trotz dieser allgemeinen Muster variieren in den einzelnen Ländern die geschlechtsspezifischen Unterschiede bei den einzelnen Fächern stark.

Mädchen scheinen höhere Erwartungen an ihre künftigen Berufe zu haben als die Jungen, es gibt jedoch bei beiden Geschlechtern große Unterschiede zwischen den einzelnen Ländern.

In ungefähr der Hälfte der Länder bevorzugten mehr Mädchen als Jungen kooperative Formen des Lernens, während in den meisten Ländern die Jungen eher zu wettbewerbsorientierten Lernformen neigten. 
Abbildung A9.1

Erwartungen 15-jähriger Schüler, ob sie mit 30 Jahren einer Büro-/Dienstleistungstätigkeit oder einer betrieblichen/ handwerklichen Tätigkeit nachgehen werden, nach Geschlecht (2000)

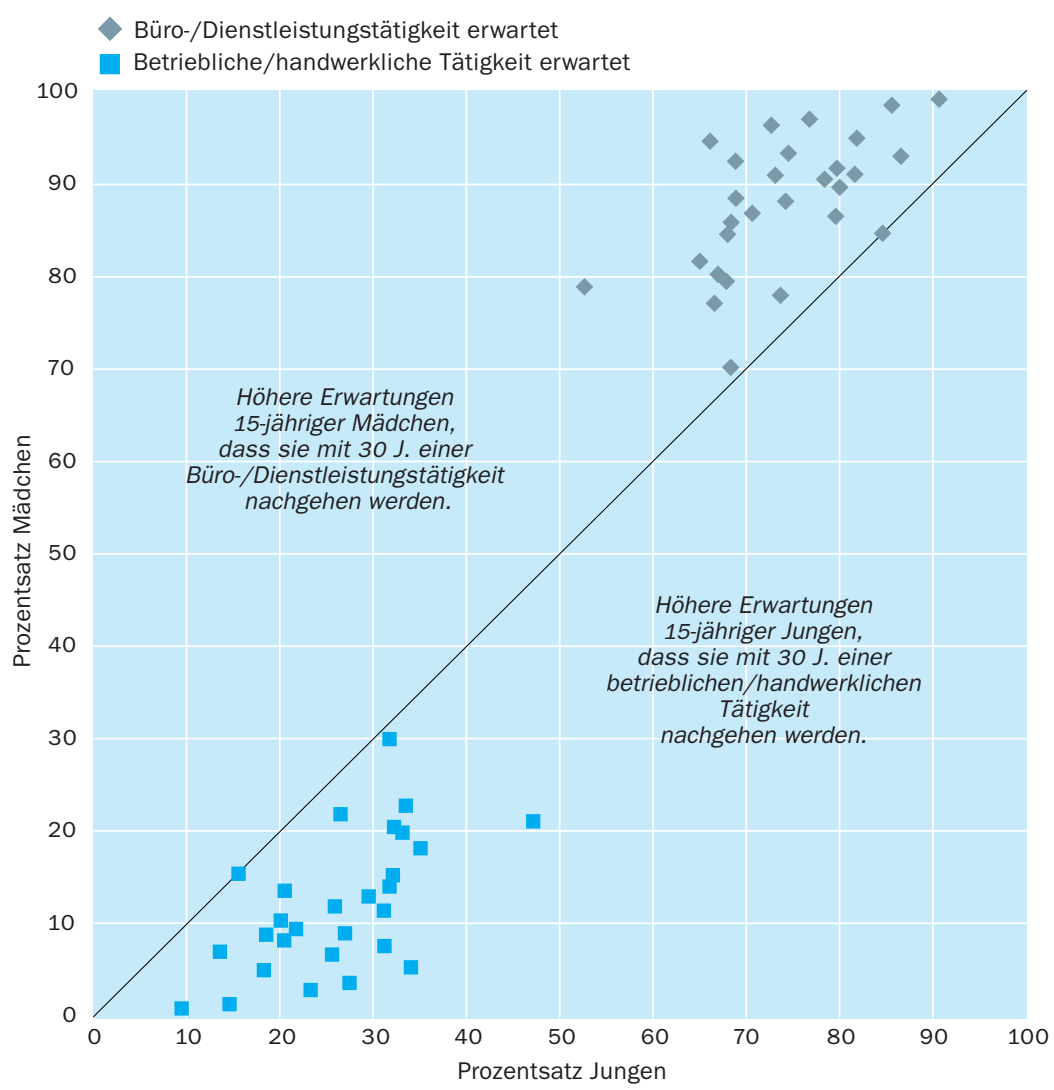

Dieser Indikator untersucht die geschlechtsspezifischen Unterschiede in verschiedenen Fächern und in Bezug auf verschiedene Einstellungen zum Lernen.

\section{Politischer Hintergrund}

Angesichts der Auswirkungen von Bildung auf die Erwerbsbeteiligung, die berufliche Mobilität und die Lebensqualität unterstreichen politische Entscheidungsträger und Pädagogen die Bedeutung einer Verringerung der Bildungsunterschiede zwischen Männern und Frauen. Beim Bildungsstand (s. Indikatoren AI und A2) wurden in dieser Hinsicht große Fortschritte erzielt, wenngleich in bestimmten Fächern, wie z. B. Mathematik und Informatik, immer noch ein Unterschied zugunsten der Männer besteht (s. Indikator A4).

Nachdem die Frauen ihren Rückstand in vielen Bildungsbereichen aufgeholt und dann die Männer in den OECD-Ländern sogar überholt haben, geben nun die schwachen Leistungen der Jungen in bestimmten Bereichen wie dem Lesen Anlass zur Besorgnis. Daher müssen die Entscheidungsträger, wenn sie ausgewogenere Lernerfolge zwischen den Geschlechtern erreichen wollen, genau auf die geschlechtsspezifischen Unterschiede bei den Leistungen, den Einstellungen zum Lernen und den Lernstrategien der Schüler achten. Ferner können sich die Vorstellungen der Schüler über die für sie erreichbaren Berufe auf ihre 
Bildungsentscheidungen und schulischen Leistungen auswirken. Daher sollte es ein wichtiges politisches Ziel sein, das Bildungswesen dabei zu unterstützen, die geschlechtsspezifischen Leistungsunterschiede in bestimmten Fächern zu reduzieren. Zunächst werden in diesem Indikator die Daten aus der PISA-Studie der OECD zu geschlechtsspezifischen Unterschieden hinsichtlich der Berufe untersucht, in denen sich heute I5-Jährige im Alter von 30 Jahren sehen. Es folgt eine Analyse der geschlechtsspezifischen Unterschiede in Leistungen, Einstellungen und Lernstrategien, basierend auf den Ergebnissen der PISA-Studie, der Internationalen Grundschul-Lese-Untersuchung (IGLU) der International Association for the Evaluation of Educational Achievement (IEA) sowie der IEA-Studie zur politischen Bildung.

\section{Ergebnisse und Erläuterungen}

Die PISA-Studie untersuchte, in welchen Berufen sich die Schüler im Alter von 30 Jahren sehen, um ihre Bestrebungen und Erwartungen für die Zukunft kennenzulernen. Diese Erwartungen werden sich wahrscheinlich auf ihre schulischen Leistungen sowie auf die Studiengänge und Bildungswege auswirken, die sie auswählen. Schüler, die weitergehende intellektuelle Ambitionen haben, werden auch eher an schulischen Aktivitäten im engeren und weiteren Sinne interessiert sein (s. www.pisa.oecd.org).

Es überrascht wohl nicht allzu sehr, dass die Ergebnisse der PISA-Studie den Schluss nahe legen, dass die Berufe, die Schüler für sich erwarten, mit denen ihrer Eltern im Zusammenhang stehen, obwohl diese Korrelation lediglich schwach bis mäßig ausgebildet ist. Im Durchschnitt aller Länder beträgt die Korrelation des von einem Schüler erwarteten Berufs mit dem seines Vaters o, I9 und mit dem seiner Mutter 0,15.

Noch wichtiger ist, dass die von den Schülern im Alter von 30 Jahren für sich erwarteten Berufe anscheinend schon ihre späteren Entscheidungen zur Berufswahl andeuten. So geben Schülerinnen in den untersuchten Ländern wesentlich häufiger als Schüler an, dass sie für sich Berufe im Zusammenhang mit den Biowissenschaften und dem Gesundheitswesen erwarten, u.a. Biologie, Pharmazie, Medizin und medizinische Hilfsberufe, Zahnheilkunde, Ernährungswesen und Pflege sowie auch mit einer Lehrtätigkeit zusammenhängende Berufe: 20 Prozent der Mädchen sehen sich in Berufen im Bereich Biowissenschaften oder Gesundheitswesen, verglichen mit nur 7 Prozent der Jungen; Unter den Mädchen erwarten 9 Prozent, in einem Lehrberuf zu sein, unter den Jungen 3 Prozent. Dagegen nennen Schüler häufiger Berufe im Zusammenhang mit Physik, Mathematik oder Ingenieurwesen (I8 Prozent der Schüler verglichen mit 5 Prozent der Schülerinnen) oder mit Metall, Maschinenbau und zugehörigen Gewerben (6 Prozent der Schüler, jedoch weniger als I Prozent der Schülerinnen).

In der PISA-Studie werden die von den Schülerinnen und Schülern im Alter von 30 Jahren für sich erwarteten Berufe in vier sozio-ökonomische Kategorien unterteilt und zwar: anspruchsvolle Büro-/Dienstleistungstätigkeit, einfache Büro-/Dienstleistungstätigkeit, anspruchsvolle betriebliche/handwerkliche

Die Hoffnungen und Erwartungen von Schülern hinsichtlich ihrer Zukunft können sich auf ihre schulischen Leistungen und Auswahlentscheidungen auswirken.

Die Tätigkeiten, die sie im Alter von 30 Jahren für sich erwarten, scheinen schon ihre zukünftigen beruflichen Entscheidungen anzudeuten.

Die Mädchen scheinen höhere Erwartungen an ihren künftigen Beruf zu haben als die Jungen, ... 
... bei beiden Geschlechtern gibt es jedoch zwischen den einzelnen Ländern erhebliche Unterschiede in den Erwartungen.
In der vierten Klasse

übertrifft die Lesekompetenz der Mädchen häufig die der Jungen ...
Tätigkeit, einfache betriebliche/handwerkliche Tätigkeit. Ein Vergleich anhand einer Taxonomie, bei der Berufe nach ihrer voraussichtlichen Auswirkung auf zukünftige Einkommen geordnet waren, zeigte, dass in 39 von 42 Ländern die Mädchen höhere Erwartungen an ihre künftigen Berufe zu haben scheinen als die Jungen. Abb. Ag.I illustriert diese Zusammenhänge. Jedes Symbol steht für ein Land, die Rhomben zeigen den Prozentsatz der Schüler, die im Alter von 30 Jahren damit rechnen, einer Büro-/Dienstleistungstätigkeit nachzugehen und die Quadrate den Prozentsatz derjenigen, die sich in einer betrieblichen/handwerklichen Tätigkeit sehen. In Belgien, Dänemark und der Tschechischen Republik rechnen 25 Prozent mehr Mädchen als Jungen im Alter von 30 Jahren mit einer Büro-/Dienstleistungstätigkeit. In Mexiko und Korea scheint ein hoher Prozentsatz von Mädchen und Jungen stark mit einer Büro-/Dienstleistungstätigkeit zu rechnen (über 8o Prozent), wobei es nur geringe Unterschiede in den Erwartungen von Mädchen und Jungen gibt (unter Io Prozent) (s. Tab. A9.I).

Aus Abbildung A9.2 lassen sich hierzu nähere Angaben entnehmen, es wird der Anteil der Schüler bzw. Schülerinnen gezeigt, die später mit einer Büro/Dienstleistungstätigkeit rechnen, sowohl mit einer anspruchsvollen als auch einer einfachen. Die linke Seite der Abbildung zeigt den Anteil der Jungen und die rechte den der Mädchen. Der Anteil der Mädchen, die im Alter von 30 Jahren mit einer Büro-/Dienstleistungstätigkeit rechnen, variiert zwischen ca. 95 Prozent in Belgien, Polen und den Vereinigten Staaten und 66 Prozent in Japan. Ähnliche Muster sind bei den Jungen zu erkennen - mit einer Varianz von über 8o Prozent in Korea, Mexiko und den Vereinigten Staaten bis 5I Prozent in Japan (s. Tab. Ag.I).

Diese Ergebnisse sind wichtig für die Formulierung entsprechender politischer Maßnahmen. Zusammengenommen legen die Daten der PISA-Studie über die Berufe, die I5-jährige Schülerinnen und Schüler im Alter von 30 Jahren für sich erwarten, und die Daten über die gegenwärtigen geschlechtsspezifischen Entscheidungsmuster hinsichtlich Bildungswegen und Berufen nahe, dass die geschlechtsspezifischen Unterschiede bei den beruflichen Erwartungen I5-Jähriger wahrscheinlich fortdauern und die Zukunft der Schülerinnen und Schüler nachhaltig beeinflussen werden. Daher sollte es ein wichtiges politisches Ziel sein, das Bildungswesen dabei zu unterstützen, die geschlechtsspezifischen Unterschiede bei den beruflichen Erwartungen zu verringern, und soweit dies mit geschlechtsspezifischen Verhaltensweisen bei den Leistungen und Neigungen der Schüler zusammenhängt, das Leistungsgefälle in bestimmten Fächern zu reduzieren.

Durchschnittlich ist es in allen Ländern in der vierten Klasse so, dass die Mädchen die Jungen auf der PISA-Skala der Lesekompetenz übertreffen (Abb. A9.3). Der Unterschied zwischen den Punktzahlen der Mädchen und der Jungen reicht von 8 Punkten in Italien bis zu mehr als 20 Punkten in England, Griechenland, Neuseeland, Norwegen und Schweden (ein Fünftel einer internationalen Standardabweichung). In allen Ländern sind die Unterschiede statistisch signifikant. 


\section{Abbildung A9.2}

Erwartungen 15-jähriger Schüler, ob sie mit 30 Jahren einer anspruchsvollen oder einfachen Büro-/ Dienstleistungstätigkeit nachgehen werden, nach Geschlecht (2000)

Anspruchsvolle Büro-/Dienstleistungstätigkeit $\square$

Einfache Büro-/Dienstleistungstätigkeit

$\% \quad 100$

Mexiko

Korea

Ver. Staaten

Portuga

Italien

Griechenland

Kanada

Neuseeland

Polen

Spanien

Australien

Schweden

Luxemburg

Island

Belgien

Ver. Königreich

Österreich

Irland

Finnland

Norwegen

Dänemark

Ungarn

Deutschland

Schweiz

Tschechische Rep.

Frankreich

Japan

Niederlande
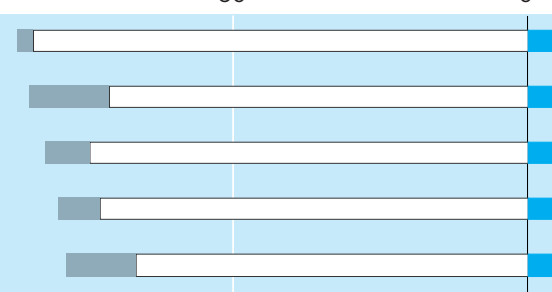

\section{Männer}

50

\section{Frauen}

- Anspruchsvolle Büro-/Dienstleistungstätigkeit

Einfache Büro-/Dienstleistungstätigkeit

50

$100 \%$
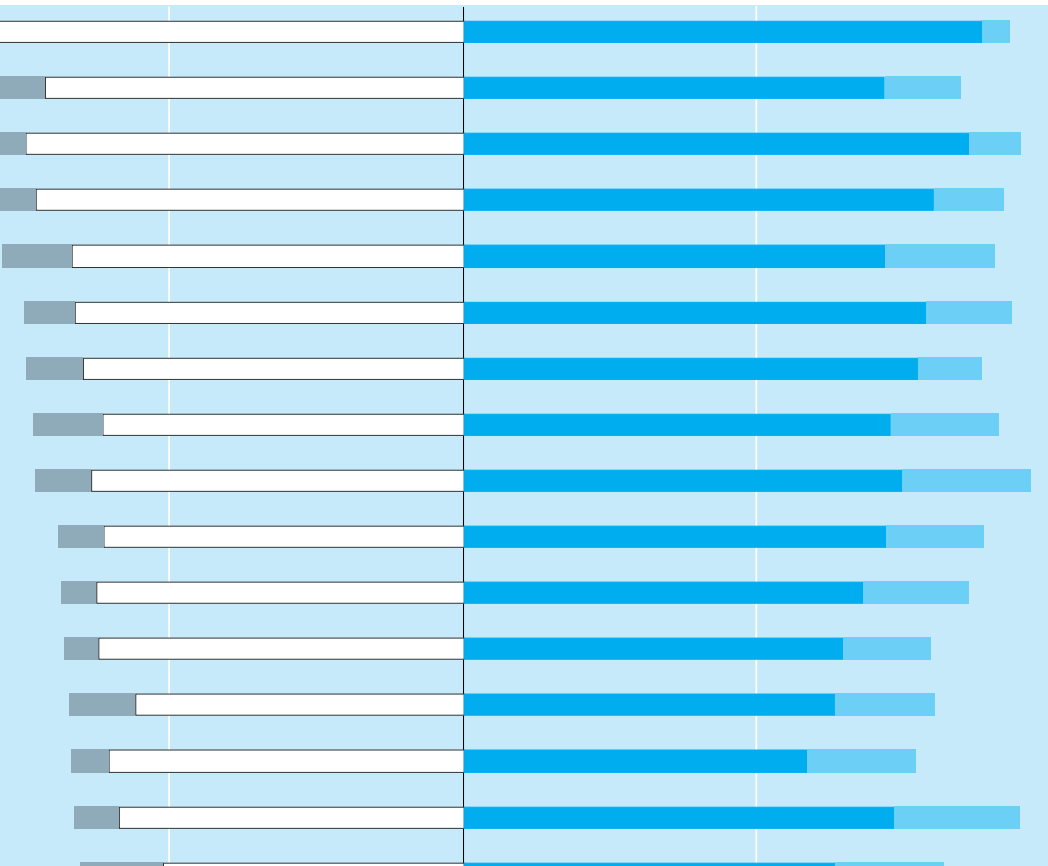

1. Beteiligungsquote zu niedrig, um die Vergleichbarkeit zu gewährleisten.

Anordnung der Länder in absteigender Reihenfolge der Erwartung einer Büro-/Dienstleistungstätigkeit.

Quelle: OECD PISA 2000-Datenbank. Tabelle A9.1. Hinweise s. Anhang 3 unter www.oecd.org/edu/eag2004. 
... und bei den 15-Jährigen ist der Unterschied in den Leseleistungen in der Regel groß.

In Mathematik scheinen die 15-jährigen Jungen einen leichten Vorsprung zu haben, ...

...in den Naturwissenschaften sind die geschlechtsspezifischen Unterschiede jedoch weniger deutlich und einheitlich ...

...und die IEA-Studie zur politischen Bildung stellt nur geringe geschlechtsspezifische Unterschiede in der politischen Bildung fest.

Die Länder unterscheiden sich jedoch stark im Ausmaß der geschlechtsspezifischen Unterschiede in den einzelnen Fächern.
Für die I5-Jährigen zeigt die PISA-Studie noch größere Unterschiede in der Lesekompetenz zwischen den Geschlechtern. In allen Ländern zeigen im Durchschnitt die Mädchen bessere Leistungen bei der Lesekompetenz als die Jungen. Dieser Unterschied ist nicht nur überall festzustellen, sondern auch erheblich: durchschnittlich beträgt er 32 Punkte (oder ein Drittel einer internationalen Standardabweichung) (Tab. A9.3 und Abb. A9.4).

Obwohl die geschlechtsspezifischen Unterschiede bei den I5-Jährigen deutlicher zu sein scheinen, korrelieren die Kenngrößen der PISA-Studie und der IGLU-Studie für die einzelnen Länder sehr stark $(r=0,8 \mathrm{I})$.

In der mathematischen Grundbildung zeigen sich in ungefähr der Hälfte der Länder statistisch signifikante Unterschiede, bei denen jeweils die Jungen besser abschneiden. Die durchschnittliche Differenz zwischen Mädchen und Jungen in der mathematischen Grundbildung beträgt II Punkte (ein Zehntel einer internationalen Standardabweichung) (Tab. A9.3 und Abb. A9.4).

Die Kenngrößen der PISA-Studie 2000 für die naturwissenschaftliche Grundbildung weisen weniger Unterschiede zwischen Jungen und Mädchen auf als die für die Lesekompetenz und die mathematische Grundbildung. Außerdem sind die Unterschiede in den einzelnen Ländern nicht so stringent. In 25 OECD-Ländern ist kein statistisch signifikanter geschlechtsspezifischer Unterschied bei den Leistungen in den Naturwissenschaften zu erkennen (Tab. A9.3 und Abb. A9.4).

Die geschlechtsspezifischen Unterschiede in der politischen Bildung, wie sie sich aus der IEA-Studie zur politischen Bildung ergeben, sind relativ gering (Tab. A9.4). Der Test zur politischen Bildung, der 1999 mit I4-Jährigen in 28 Ländern durchgeführt wurde, sollte die Kenntnisse der Schüler über grundlegende demokratische Prinzipien und ihre Fähigkeiten zur Interpretation von Material mit staatsbürgerlichen oder politischen Inhalten prüfen. Die Studie stellte fest, dass es - ohne eine Kontrolle für andere Variablen - bei den I4-Jährigen in den meisten Ländern keine geschlechtsspezifischen Unterschiede beim inhaltlichen Wissen oder der Interpretationsfähigkeit von Material zur politischen Bildung gibt. Hält man andere mit der politischen Bildung im Zusammenhang stehende Faktoren (wie das von den Schülern erwartete Bildungsniveau und den Zugang zu Lesematerial zu Hause) konstant, ergibt sich ein leichter Unterschied zugunsten der Jungen, jedoch nur in ungefähr einem Drittel der 28 untersuchten Länder.

Die Tatsache, dass die geschlechtsspezifischen Unterschiede in der Lesekompetenz und der mathematischen Grundbildung in allen Ländern recht einheitlich in eine Richtung verlaufen, lässt vermuten, dass die Bildungssysteme oder die Gesellschaften und Kulturen grundlegende Merkmale aufweisen, die derartige geschlechtsspezifische Unterschiede fördern. Die große Variationsbreite bei den einzelnen Ländern im Ausmaß dieser geschlechtsspezifischen Unterschiede weist darauf hin, dass die aktuellen Unterschiede auf unterschiedliche Lernerfahrungen der Schüler zurückzuführen sind und somit durch eine geänderte Politik beeinflusst werden können. 
Abbildung A9.3

Geschlechtsspezifische Unterschiede bei den Leseleistungen von Schülern der 4. Jahrgangsstufe auf der IGLU-Skala der Lesefähigkeiten und des Leseverständnisses (2001)

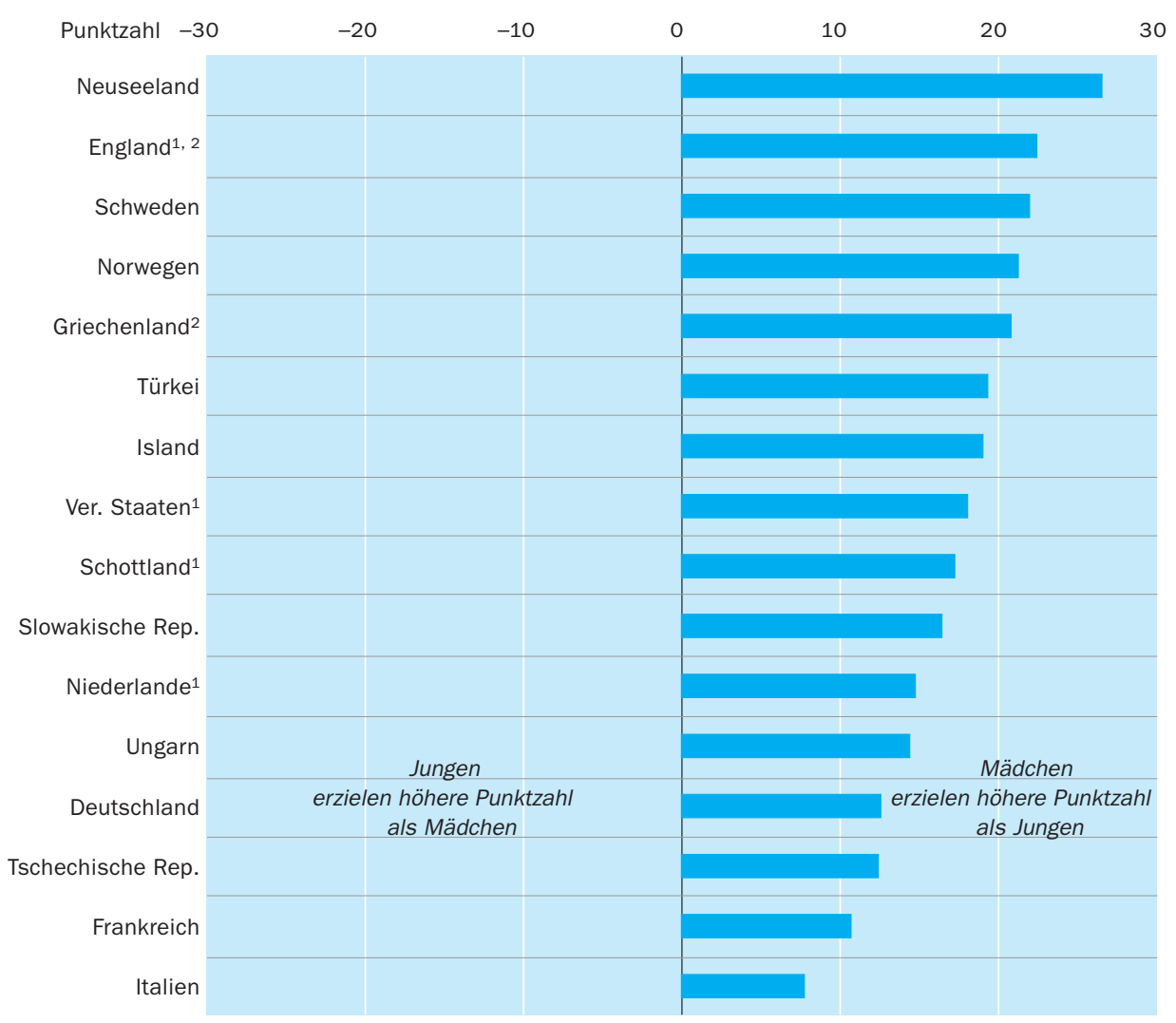

\footnotetext{
1. Richtlinien zur Ausschöpfungsquote der Stichprobe konnten nur unter Berücksichtigung der im Nachrückverfahren einbezogenen Schulen eingehalten werden. 2. Die ,national definierte Grundgesamtheit' erfasst weniger als $95 \%$ der , angestrebten nationalen Grundgesamtheit'.

Anordnung der Länder in absteigender Größenordnung der Differenz der mittleren Punktzahl von Jungen und Mädchen auf der IGLU-Skala der Lesefähigkeiten und des Leseverständnisses.

Quelle: Internationale Grundschul-Lese-Untersuchung - IGLU (Progress in Reading Literacy Study - PIRLS) 2001 Tabelle A9.2. Hinweise s. Anhang 3 unter www.oecd.org/edu/eag2004.
}

Der Abstand zwischen den von 15 -jährigen Jungen und Mädchen in der PISAStudie bei der Lesekompetenz erreichten Punktzahlen variierte zwischen 25 Punkten und weniger in Dänemark, Korea, Mexiko, Portugal und Spanien und fast doppelt so viel in Finnland. Bei der mathematischen Grundbildung reichte die Varianz von statistisch insignifikanten Unterschieden in I4 OECD-Ländern bis zu 27 Punkten in Österreich und Korea. Es scheint also so, als ob es einigen Ländern gelingt, entweder als direktes Ergebnis schulischer Bemühungen oder aufgrund günstigerer gesellschaftlicher Bedingungen, ein Lernumfeld zur Verfügung zu stellen, von dem beide Geschlechter gleichermaßen profitieren. Korea und in geringerem Ausmaß Japan und das Vereinigte Königreich erreichen bei der Lesekompetenz sowohl eine hohe mittlere Punktzahl als auch unterdurchschnittliche geschlechtsspezifische Unterschiede. Vergleichbar damit weisen auch Belgien, Finnland, Japan, Neuseeland und das Vereinigte Königreich bei der mathematischen Grundbildung sowohl eine hohe mittlere Punktzahl als auch relativ geringe geschlechtsspezifische Unterschiede auf (Tab. A9.3 sowie Indikatoren A6 und A7). 
Abbildung A9.4

Geschlechtsspezifische Leistungsunterschiede von 15-jährigen Schülerinnen und Schülern auf der PISA-Skala der 9 Lesefähigkeiten und des Leseverständnisses sowie auf den PISA-Skalen mathematische bzw. naturwissenschaftliche Grundbildung (2000)

Unterschied zwischen Jungen und Mädchen statistisch signifikant

Unterschied zwischen Jungen und Mädchen nicht statistisch signifikant

PISA-Skala der Lesefähigkeit und des Leseverständnisses
PISA-Skala für mathematische Grundbildung
PISA-Skala für naturwissenschaftliche Grundbildung

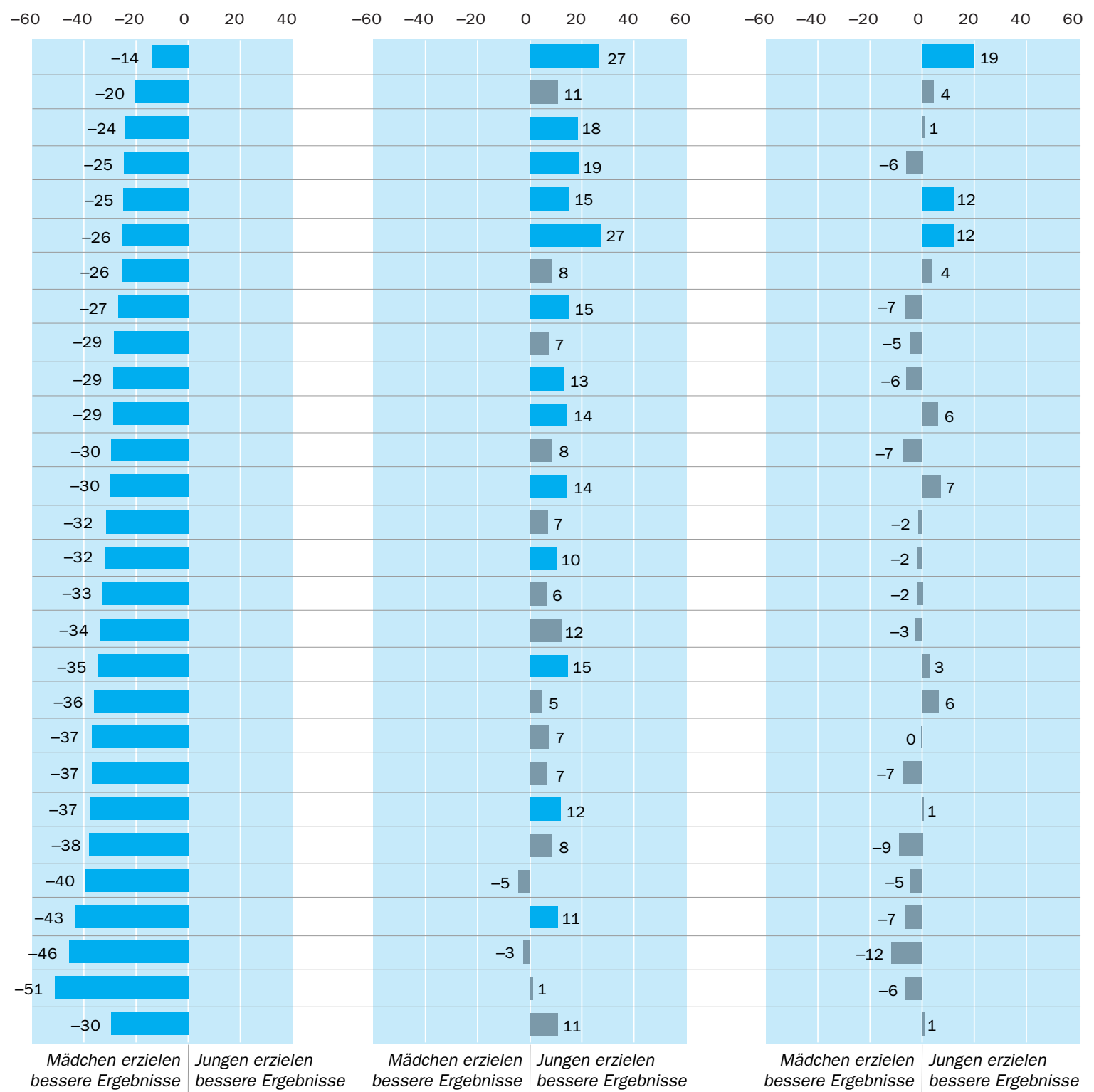

1. Beteiligungsquote zu niedrig, um die Vergleichbarkeit zu gewährleisten.

Anordnung der Länder in aufsteigender Größenordnung der Differenz der mittleren Punktzahl von Jungen und Mädchen auf der PISA-Skala der Lesefähigkeiten und des Leseverständnisses.

Quelle: OECD PISA 2000-Datenbank Tabelle A9.3. Hinweise s. Anhang 3 unter www.oecd.org/edu/eag2004. 


\section{Geschlechtsspezifische Unterschiede bei leistungsschwachen Schülern}

Wenn man die Leistungen steigern und die Gleichstellung der Geschlechter in der Bildung fördern will, muss man sich insbesondere auf die leistungsschwächsten Schüler konzentrieren. In allen OECD-Ländern sind I5-jährige Jungen bei der Lesekompetenz eher unter den leistungsschwächsten Schülern anzutreffen (d.h. auf oder unterhalb Stufe I der PISA-Skala der Lesekompetenz). Das Verhältnis von Jungen zu Mädchen auf dieser Kompetenzstufe beträgt in den OECD-Ländern durchschnittlich I,7 und reicht von I,3 in Mexiko bis zu 3,5 in Finnland.

Da I5-jährige Jungen auf der Skala für mathematische Grundbildung meist besser abschneiden als Mädchen, wäre zu erwarten, dass sich unter den Leistungsschwächsten in der mathematischen Grundbildung mehr Mädchen befinden. Ein Großteil des geschlechtsspezifischen Unterschieds in der mathematischen Grundbildung ist jedoch auf die größeren Vorsprünge der Jungen unter den Leistungsstärkeren zurückzuführen und nicht auf eine relativ geringere Anzahl von Jungen in der Gruppe der Leistungsschwachen. In I5 der an der PISA-Studie beteiligten OECD-Ländern sind I5-jährige Jungen eher unter den Spitzenschülern anzutreffen, I5-jährige Mädchen jedoch in keinem Land. Unter den Schülern, die mindestens soo Punkt unter dem OECD-Mittel für die mathematische Grundbildung liegen, sind Mädchen und Jungen fast gleich stark vertreten. Diese Ergebnisse legen nahe, dass die schwachen Leistungen der Jungen in den verschiedenen Fächern für die Bildungspolitik eine beachtliche Herausforderung darstellen, derer man sich dringend annehmen muss, wenn man den Anteil der Schüler am unteren Ende des Leistungsspektrums verringern will.

Weitere Informationen und Daten über leistungsschwache Schüler s. Lemen für das Leben - Erste Ergebnisse von PISA 2000 (OECD, 200I).

\section{Skalen für selbstgesteuertes Lernen}

Nicht nur bei den Leistungskenngrößen in bestimmten Fächern ergeben sich geschlechtsspezifische Unterschiede, sondern auch bei den Einstellungen und anderen Kenngrößen im Zusammenhang mit den Lerngewohnheiten. In der PISA-Studie 2000 wurden Daten über eine Reihe von Fähigkeiten und Einstellungen erhoben, die als Voraussetzung dafür angesehen werden, dass die Schüler in der Lage sind, den Lernprozess zu bewältigen - ihr selbstgesteuertes Lernverhalten. Die I3 Skalen für selbstgesteuertes Lernen erfassen, wie die Schüler Lernstrategien einsetzen, ihre Motivation, Selbstwahrnehmung und bevorzugten Lernmethoden (s. Learners for Life: Student Approaches to Learning, OECD, 2003). Dieser Indikator arbeitet die Unterschiede zwischen den Geschlechtern auf den Skalen für selbstgesteuertes Lernen (Tab. A9.5) heraus und weist so auf deren relative Stärken und Schwächen hin. Ein gezieltes Eingreifen zur Reduzierung der Unterschiede bei den Lernstrategien bzw. im 
In den meisten Ländern bevorzugen 15-jährige Mädchen wiederholungsbezogene Strategien, ...

... Jungen hingegen legen mehr Wert auf differenzierte Übungsstrategien.
In allen Ländern zeigen Mädchen ein stärkeres Interesse am Lesen als Jungen, ...

... während die Jungen mehr Interesse an Mathematik bekunden ...

...und diese Präferenzen spiegeln sich in den Leistungsprofilen.
Auch hinsichtlich des Selbstvertrauens der Schüler in ihre Fähigkeiten und ihrer Überzeugung vom Nutzen des Lernens sind geschlechtsspezifische Unterschiede erkennbar...
Lernverhalten der Schüler könnte sich stark auf die Pädagogik auswirken. Einige dieser Kenngrößen sind jedoch nur schwer über die Ländergrenzen hinweg vergleichbar.

\section{Lernstrategien}

Die Unterschiede beim Einsatz von Lernstrategien zwischen Mädchen und Jungen könnten mögliche Strategien zur Minderung der geschlechtsspezifischen Leistungsunterschiede aufzeigen. In den meisten Ländern geben I5-jährige Mädchen häufiger als Jungen an, wiederholungsbezogene Strategien zu bevorzugen (z.B. mehrmaliges lautes Vorlesen des Lernstoffes und Auswendiglernen der zentralen Punkte (Tab. A9.5).

Im Gegensatz dazu nennen Jungen häufiger als Mädchen differenzierte Übungsstrategien (z. B. Ergründen, in welchem Zusammenhang der Lernstoff mit anderem Wissen steht, das anderweitig erlernt wurde). In fast allen Ländern, in denen es statistisch signifikante geschlechtsspezifische Unterschiede gibt, erklären jedoch Mädchen häufiger als Jungen, dass sie kontrollbezogene Strategien einsetzen (d.h. Methoden, mit denen sie ihren Lernerfolg überprüfen können). Eine Ausnahme sind hier Norwegen und Schweden. Das legt nahe, dass Mädchen eher dazu tendieren, beim Lernen eine Selbstbeurteilung vorzunehmen. Andererseits könnte für Jungen eventuell eine generelle Hilfestellung bei der Planung, Organisation und Strukturierung ihres Lernens angebracht sein (Tab. A9.5).

\section{Motivation}

In allen Ländern zeigen Mädchen ein stärkeres Interesse am Lesen. Sie lesen meist auch häufiger Bücher, insbesondere Belletristik, und haben mehr Freude am Lesen als Jungen.

Im Gegensatz dazu bekunden die Jungen in fast allen an der Studie beteiligten Ländern mehr Interesse an Mathematik als Mädchen, auch wenn hier die Unterschiede wesentlich geringer sind als beim Lesen. Tatsächlich sind Portugal und Mexiko die einzigen Länder, in denen Mädchen und Jungen ein vergleichbar großes Interesse an Mathematik zeigen.

In den geschlechtsspezifischen Unterschieden bei den Leistungen im Lesen und in der mathematischen Grundbildung spiegelt sich das Interesse der Schüler an dem jeweiligen Fach deutlich wider. Diese Unterschiede in den Einstellungen könnten anzeigen, dass es Schule und Gesellschaft nicht gelingt, die Motivation und das Interesse an den verschiedenen Fächergruppen bei beiden Geschlechtern gleichermaßen zu fördern.

\section{Selbstwahrnehmung}

Weitere Faktoren, die eng mit der Leistung zusammenhängen, und die sich nach Geschlecht unterscheiden, sind das Selbstvertrauen der Schüler in die eigenen Fähigkeiten und ob sie an den Nutzen des Lernens glauben. In allen Ländern, mit Ausnahme Koreas, haben die Mädchen mehr Vertrauen in ihre Leseleistungen als die Jungen. Dieser Unterschied ist in Deutschland, Finnland, Italien, Norwegen, der Tschechischen Republik und den Vereinigten Staaten besonders ausgeprägt. In der mathematischen Grundbildung haben 
Jungen eher eine höhere Selbsteinschätzung als Mädchen, insbesondere in Deutschland, Norwegen, und der Schweiz. Insgesamt und in den meisten Ländern erzielen die Jungen wesentlich höhere Werte bei der allgemeinen Erfolgswirksamkeit, bzw. der Überzeugung, dass die selbst gesetzten Ziele erreicht werden können, als Mädchen. In Dänemark, Finnland, Norwegen und Schweden ist der Unterschied zwischen Jungen und Mädchen besonders groß (Tab. A9.5).

\section{Lernstile}

In ungefähr der Hälfte der Länder bevorzugten mehr Mädchen als Jungen kooperative Formen des Lernens, während die Jungen in den meisten Ländern eher zu wettbewerbsorientierten Lernformen neigten. Auf der Skala für kooperatives Lernen sind diese geschlechtsspezifischen Unterschiede in Irland, Italien und den Vereinigten Staaten am stärksten ausgeprägt. Auf der Skala für wettbewerbsorientiertes Lernen zeigen sie sich am deutlichsten in Irland, Portugal und Schottland (Tab. A9.5).

\section{Definitionen und angewandte Methodik}

Die IGLU-Zielpopulation waren die Schüler in der höheren der zwei aufeinanderfolgenden Jahrgangsstufen, die zum Zeitpunkt des Tests den größten Anteil 9-jähriger Schüler aufwiesen. Abgesehen von dem in der Definition enthaltenen Alterskriterium sollte die Zielpopulation den Zeitpunkt im Lehrplan repräsentieren, an dem die Schüler den Erwerb der Grundkenntnisse im Bereich Lesen abgeschlossen haben und sich in den nachfolgenden Jahrgangsstufen mehr auf das „Lesen, um zu Lernen“ konzentrieren. Deshalb wurde davon ausgegangen, dass die IGLU-Zielstufe die 4. Jahrgangsstufe sei (Tab. A9.2).

Die Punktzahlen für den Test in politischer Bildung ergeben sich aus den Leistungsmessungen der Schüler während der zweiten Phase der IEA-Studie zur politischen Bildung. Man wollte in allen Ländern eine Population aus Schülern in Vollzeitausbildung in einer Klassenstufe erreichen, in der sich bei der Durchführung der Tests die meisten Schüler im Alter zwischen I4 Jahren und I4 Jahren und II Monaten befanden. In den meisten Ländern wurden die Tests in der ersten Woche des achten Monats des Schuljahres durchgeführt (Tab. A9.4).

Die für diesen Indikator untersuchte Zielpopulation von PISA waren I5-jährige Schüler. In der Praxis bezog sich dies auf Schüler, die zu Beginn der Testperiode zwischen I5 Jahren und (abgeschlossenen) 3 Monate und I6 Jahren und (abgeschlossenen) 2 Monate alt waren und eine Bildungseinrichtung besuchten, ungeachtet der Klassenstufe und der Art der von ihnen besuchten Bildungseinrichtung und unabhängig davon, ob es sich um eine Ganztagsoder Halbtagsschule handelte.

22 der 28 an der PISA-Studie 2000 beteiligten Länder führten auch den Teil der Studie zum selbstgesteuerten Lernen durch, auf dem dieser Indikator basiert: Australien, Belgien (fläm.), Dänemark, Deutschland, Finnland, Irland, Island,

\author{
... ebenso wie in den \\ Einstellungen der Schüler zum \\ kooperativen und \\ wettbewerbsorientierten \\ Lernen. \\ Die Daten zur Lesekompetenz \\ von Schülern der 4. Jahr- \\ gangsstufe basieren auf der \\ Internationalen Grundschul- \\ Lese-Untersuchung (IGLU) \\ (Progress in Realding Literacy \\ Study - PIRLS, 2001).
}

Die Daten zur politischen Bildung basieren auf der 1999 von der International Association for the Evaluation of Educational Achievement (IEA) durchgeführten Studie zur politischen Bildung.

Die Punktzahlen für Lesekompetenz, mathematische und naturwissenschaftliche Grundbildung 15-Jähriger ergeben sich aus Leistungsmessungen im Rahmen der von der OECD 2000 durchgeführten Internationalen Schulleistungsstudie (PISA). 
Italien, Korea, Luxemburg, Mexiko, Neuseeland, die Niederlande, Norwegen, Österreich, Portugal, Schottland, Schweden, die Schweiz, die Tschechische Republik, Ungarn und die Vereinigten Staaten. Anzumerken ist, dass Belgien und das Vereinigte Königreich, die an der PISA-Hauptstudie teilgenommen hatten, hinsichtlich des selbstgesteuerten Lernens lediglich durch beteiligte Verwaltungsgebiete vertreten waren: den flämisch sprechendenden Teil Belgiens und Schottland im Vereinigten Königreich. Frankreich, Griechenland, Japan, Kanada und Spanien sowie der französisch sprechende Teil Belgiens und England haben sich an dieser Option nicht beteiligt.

Hinweise zu Standardfehlern, Signifikanztests und multiplen Vergleichen s. Anhang 3 unter www.oecd.org/eduleag2004. 
Tabelle A9.1

Erwartungen 15-Jähriger hinsichtlich des Berufs, dem sie mit 30 Jahren nachgehen werden, nach Geschlecht (2000) Erwartungen 15-jähriger Schüler, ob sie später einer Büro-/Dienstleistungstätigkeit oder einer betrieblichen/handwerklichen Tätigkeit nachgehen werden (in \%), nach Geschlecht

\begin{tabular}{|c|c|c|c|c|c|c|c|c|c|c|c|c|}
\hline & \multicolumn{4}{|c|}{ Alle Schüler } & \multicolumn{4}{|c|}{ Jungen } & \multicolumn{4}{|c|}{ Mädchen } \\
\hline & \begin{tabular}{|c|} 
Anspruchs- \\
volle \\
Büro-/ \\
Dienst- \\
leistungs- \\
tätigkeit
\end{tabular} & $\begin{array}{c}\text { Einfache } \\
\text { Büro-/ } \\
\text { Dienst- } \\
\text { leistungs- } \\
\text { tätigkeit }\end{array}$ & $\begin{array}{c}\text { Anspruchs- } \\
\text { volle be- } \\
\text { triebliche/ } \\
\text { hand- } \\
\text { werkliche } \\
\text { Tätigkeit }\end{array}$ & $\begin{array}{c}\text { Einfache } \\
\text { betrieb- } \\
\text { liche/ } \\
\text { hand- } \\
\text { werkliche } \\
\text { Tätigkeit }\end{array}$ & $\begin{array}{c}\text { Anspruchs- } \\
\text { volle } \\
\text { Büro-/ } \\
\text { Dienst- } \\
\text { leistungs- } \\
\text { tätigkeit }\end{array}$ & \begin{tabular}{|c|} 
Einfache \\
Büro-/ \\
Dienst- \\
leistungs- \\
tätigkeit
\end{tabular} & $\begin{array}{c}\text { Anspruchs- } \\
\text { volle be- } \\
\text { triebliche/ } \\
\text { hand- } \\
\text { werkliche } \\
\text { Tätigkeit }\end{array}$ & $\begin{array}{c}\text { Einfache } \\
\text { betrieb- } \\
\text { liche/ } \\
\text { hand- } \\
\text { werkliche } \\
\text { Tätigkeit }\end{array}$ & $\begin{array}{c}\text { Anspruchs- } \\
\text { volle } \\
\text { Büro-/ } \\
\text { Dienst- } \\
\text { leistungs- } \\
\text { tätigkeit }\end{array}$ & $\begin{array}{c}\text { Einfache } \\
\text { Büro-/ } \\
\text { Dienst- } \\
\text { leistungs- } \\
\text { tätigkeit }\end{array}$ & \begin{tabular}{|c|} 
Anspruchs- \\
volle be- \\
triebliche/ \\
hand- \\
werkliche \\
Tätigkeit
\end{tabular} & $\begin{array}{c}\text { Einfache } \\
\text { betrieb- } \\
\text { liche/ } \\
\text { hand- } \\
\text { werkliche } \\
\text { Tätigkeit }\end{array}$ \\
\hline \multicolumn{13}{|l|}{ OECD-Länder } \\
\hline Australien & 65,0 & 11,7 & 10,4 & 12,9 & 62,4 & 6,0 & 19,0 & 12,7 & 67,8 & 17,9 & 1,2 & 13,1 \\
\hline Österreich & 55,3 & 17,2 & 11,7 & 15,8 & 56,3 & 8,6 & 21,9 & 13,3 & 54,8 & 25,1 & 2,2 & 17,9 \\
\hline Belgien & 65,6 & 14,2 & 15,4 & 4,9 & 58,5 & 7,6 & 27,9 & 6,0 & 73,1 & 21,3 & 1,8 & 3,7 \\
\hline Kanada & 70,9 & 10,2 & 7,1 & 11,8 & 64,6 & 9,7 & 13,0 & 12,8 & 77,1 & 10,8 & 1,2 & 10,8 \\
\hline Tschechische Rep. & 44,5 & 22,0 & 16,2 & 17,3 & 41,1 & 11,9 & 28,3 & 18,7 & 47,6 & 31,1 & 5,3 & 16,0 \\
\hline Dänemark & 58,5 & 17,5 & 19,6 & 4,3 & 50,5 & 10,9 & 34,1 & 4,5 & 67,7 & 25,1 & 2,9 & 4,2 \\
\hline Finnland & 60,4 & 15,8 & 12,2 & 11,5 & 55,5 & 9,1 & 21,4 & 14,0 & 65,0 & 22,0 & 3,7 & 9,2 \\
\hline Frankreich & 48,9 & 14,7 & 9,9 & 26,5 & 44,1 & 8,5 & 18,7 & 28,7 & 53,4 & 20,5 & 1,7 & 24,4 \\
\hline Griechenland & 72,3 & 11,7 & 9,4 & 6,6 & 66,0 & 8,6 & 17,9 & 7,6 & 78,5 & 14,6 & 1,3 & 5,6 \\
\hline Ungarn & 52,7 & 19,0 & 16,6 & 11,7 & 50,3 & 9,5 & 28,0 & 12,2 & 55,3 & 28,5 & 5,1 & 11,1 \\
\hline Island & 59,2 & 12,6 & 7,9 & 20,3 & 60,3 & 6,4 & 13,5 & 19,8 & 58,4 & 18,5 & 2,4 & 20,7 \\
\hline Irland & 64,1 & 12,2 & 11,7 & 12,1 & 57,5 & 7,2 & 22,6 & 12,7 & 70,3 & 16,9 & 1,3 & 11,5 \\
\hline Italien & 69,1 & 15,2 & 5,8 & 9,9 & 66,6 & 11,9 & 10,6 & 10,9 & 71,6 & 18,7 & 0,9 & 8,8 \\
\hline Japan & 45,8 & 12,9 & 4,0 & 37,4 & 43,3 & 7,7 & 7,3 & 41,7 & 48,2 & 17,9 & 0,7 & 33,2 \\
\hline Korea & 71,2 & 13,2 & 1,6 & 13,9 & 71,1 & 13,4 & 2,4 & 13,0 & 71,4 & 13,0 & 0,6 & 15,0 \\
\hline Luxemburg & 59,6 & 14,3 & 8,7 & 17,4 & 55,7 & 11,3 & 15,4 & 17,6 & 63,0 & 16,9 & 2,8 & 17,2 \\
\hline Mexiko & 86,0 & 3,6 & 2,1 & 8,2 & 84,0 & 2,5 & 3,4 & 10,1 & 88,0 & 4,7 & 0,8 & 6,4 \\
\hline Neuseeland & 67,0 & 15,1 & 8,5 & 9,4 & 61,3 & 11,8 & 16,5 & 10,4 & 72,4 & 18,3 & 0,8 & 8,4 \\
\hline Norwegen & 57,4 & 12,7 & 12,9 & 17,1 & 55,0 & 6,4 & 23,2 & 15,4 & 60,1 & 18,9 & 2,3 & 18,7 \\
\hline Polen & 68,8 & 15,4 & 14,2 & 1,7 & 63,3 & 9,4 & 24,4 & 2,9 & 74,5 & 21,7 & 3,5 & 0,4 \\
\hline Portugal & 76,5 & 9,5 & 5,1 & 9,0 & 72,7 & 7,0 & 9,8 & 10,5 & 79,8 & 11,7 & 0,8 & 7,7 \\
\hline Spanien & 66,6 & 12,2 & 8,2 & 13,1 & 61,2 & 7,7 & 16,1 & 15,0 & 71,7 & 16,6 & 0,7 & 11,0 \\
\hline Ver. Königreich & 57,1 & 16,3 & 7,6 & 19,0 & 51,0 & 14,0 & 14,5 & 20,5 & 63,0 & 18,6 & 0,8 & 17,6 \\
\hline Vereinigte Staaten & 80,5 & 8,2 & 5,1 & 6,2 & 74,4 & 7,5 & 9,8 & 8,4 & 85,8 & 8,8 & 1,0 & 4,3 \\
\hline Ländermittel & 62,2 & 13,9 & 10,1 & 13,8 & 58,4 & 9,1 & 18,2 & 14,4 & 66,1 & 18,6 & 2,1 & 13,2 \\
\hline \multicolumn{13}{|l|}{ OECD-Partnerländer } \\
\hline Argentinien & 79,7 & 7,2 & 1,9 & 11,2 & 74,3 & 7,3 & 4,4 & 14,1 & 83,6 & 7,1 & 0,1 & 9,1 \\
\hline Brasilien & 87,4 & 7,8 & 2,4 & 2,3 & 86,0 & 4,7 & 4,5 & 4,8 & 88,6 & 10,4 & 0,7 & 0,2 \\
\hline Chile & 68,9 & 10,2 & 7,6 & 13,3 & 64,8 & 5,7 & 14,5 & 15,0 & 72,6 & 14,2 & 1,5 & 11,8 \\
\hline Hongkong - China & 58,6 & 17,2 & 0,6 & 23,7 & 54,1 & 19,5 & 0,6 & 25,8 & 63,1 & 14,9 & 0,5 & 21,5 \\
\hline Indonesien & 76,2 & 6,8 & 3,8 & 13,2 & 78,2 & 1,3 & 6,0 & 14,5 & 74,2 & 12,1 & 1,7 & 12,0 \\
\hline Israel & 63,7 & 5,6 & 1,1 & 29,7 & 64,8 & 3,5 & 2,2 & 29,5 & 62,9 & 7,0 & 0,3 & 29,8 \\
\hline Lettland & 63,1 & 18,0 & 13,4 & 5,5 & 55,0 & 13,8 & 22,7 & 8,5 & 70,5 & 21,8 & 5,0 & 2,7 \\
\hline Liechtenstein & 36,3 & 17,1 & 14,2 & 32,4 & 40,6 & 13,9 & 24,4 & 21,1 & 32,2 & 20,4 & 3,1 & 44,2 \\
\hline Peru & 84,1 & 7,9 & 6,2 & 1,8 & 82,9 & 2,6 & 11,0 & 3,4 & 85,2 & 13,1 & 1,4 & 0,2 \\
\hline Russische Föd. & 58,6 & 6,9 & 11,0 & 23,5 & 47,6 & 4,8 & 15,9 & 31,7 & 69,1 & 9,0 & 6,2 & 15,7 \\
\hline Thailand & 43,3 & 17,4 & 10,9 & 28,4 & 33,5 & 12,5 & 22,0 & 32,0 & 49,8 & 20,8 & 3,4 & 26,0 \\
\hline Niederlande ${ }^{1}$ & 57,6 & 18,6 & 8,4 & 15,5 & 58,6 & 9,4 & 15,7 & 16,3 & 56,4 & 28,1 & 0,8 & 14,7 \\
\hline
\end{tabular}

1. Beteiligungsquote zu niedrig, um die Vergleichbarkeit zu gewährleisten.

Quelle: OECD PISA 2000-Datenbank. 


\section{Tabelle A9.2}

Geschlechtsspezifische Leistungen von Schülerinnen und Schülern der 4. Jahrgangsstufe (2001)

9 Mittlere Leistungen von Schülern der 4. Jahrgangsstufe auf der IGLU-Gesamtskala Lesen, nach Geschlecht

\begin{tabular}{|c|c|c|c|c|c|c|}
\hline \multirow[b]{2}{*}{ OECD-Länder } & \multicolumn{2}{|c|}{ Mädchen } & \multicolumn{2}{|c|}{ Jungen } & \multicolumn{2}{|c|}{ Differenz ${ }^{1}$} \\
\hline & Mittelwert & S.F. & Mittelwert & S.F. & Punktedifferenz & S.F. \\
\hline Tschechische Republik & 543 & $(2,8)$ & 531 & $(2,6)$ & 12 & $(2,8)$ \\
\hline England 2,3 & 564 & $(3,9)$ & 541 & $(3,7)$ & 22 & $(3,3)$ \\
\hline Frankreich & 531 & $(2,7)$ & 520 & $(3,0)$ & 11 & $(3,3)$ \\
\hline Deutschland & 545 & $(2,2)$ & 533 & $(2,5)$ & 13 & $(2,7)$ \\
\hline Ungarn & 550 & $(2,4)$ & 536 & $(2,5)$ & 14 & $(3,8)$ \\
\hline Island & 522 & $(1,9)$ & 503 & $(1,5)$ & 19 & $(2,4)$ \\
\hline Italien & 545 & $(2,6)$ & 537 & $(2,7)$ & 8 & $(2,5)$ \\
\hline Niederlande ${ }^{2}$ & 562 & $(2,7)$ & 547 & $(2,8)$ & 15 & $(2,2)$ \\
\hline Neuseeland & 542 & $(4,7)$ & 516 & $4,2)$ & 27 & $(5,4)$ \\
\hline Norwegen & 510 & $(3,5)$ & 489 & $(3,4)$ & 21 & $(3,9)$ \\
\hline Schottland ${ }^{2}$ & 537 & $(3,9)$ & 519 & $(4,2)$ & 17 & $(4,0)$ \\
\hline Schweden & 572 & $(2,6)$ & 550 & $(2,5)$ & 22 & $(2,6)$ \\
\hline Türkei & 459 & $(4,0)$ & 440 & $(3,7)$ & 19 & $(3,1)$ \\
\hline Vereinigte Staaten ${ }^{2}$ & 551 & $(3,8)$ & 533 & $(4,9)$ & 18 & $(4,1)$ \\
\hline Ländermittel & 538 & $(0,8)$ & 521 & $(0,8)$ & 17 & $(0,8)$ \\
\hline
\end{tabular}

Hinweis: Standardfehler in Klammern.

1. Positive Differenzen bedeuten, dass die Mädchen besser als die Jungen abschneiden, während bei negativen Differenzen die Jungen besser als die Mädchen abschneiden. Statistisch signifikante Differenzen durch Fettdruck gekennzeichnet. 2. Richtlinien zur Ausschöpfungsquote der Stichprobe konnten nur unter Berücksichtigung der im Nachrückverfahren einbezogenen Schulen eingehalten werden. 3. Die , national definierte Grundgesamtheit' erfasst weniger als $95 \%$ der , angestrebten nationalen Grundgesamtheit:

Quelle: Internationale Grundschul-Lese-Untersuchung - IGLU (Progress in Reading Literacy Study - PIRLS) 2001. 
Tabelle A9.3

Geschlechtsspezifische Leistungen 15-jähriger Schülerinnen und Schüler (2000)

Mittlere Leistungen von 15-jährigen Schülerinnen und Schülern auf der PISA-Skala der Lesefähigkeiten und des Leseverständnisses sowie auf den PISA-Skalen mathematische bzw. naturwissenschaftliche Grundbildung

\begin{tabular}{|c|c|c|c|c|c|c|c|c|c|c|c|c|c|c|c|c|c|c|}
\hline \multirow{4}{*}{ OECD-Länder } & \multicolumn{6}{|c|}{ Lesekompetenz } & \multicolumn{6}{|c|}{ Mathematische Grundbildung } & \multicolumn{6}{|c|}{ Naturwissenschaftliche Grundbildung } \\
\hline & \multicolumn{2}{|c|}{ Jungen } & \multicolumn{2}{|c|}{ Mädchen } & \multicolumn{2}{|c|}{ Differenz $^{1}$} & \multicolumn{2}{|c|}{ Jungen } & \multicolumn{2}{|c|}{ Mädchen } & \multicolumn{2}{|c|}{ Differenz $^{1}$} & \multicolumn{2}{|c|}{ Jungen } & \multicolumn{2}{|c|}{ Mädchen } & \multicolumn{2}{|c|}{ Differenz $^{1}$} \\
\hline & $\begin{array}{l}\text { Mittel- } \\
\text { wert }\end{array}$ & S.F. & \begin{tabular}{|c|} 
Mittel- \\
wert
\end{tabular} & S.F. & \begin{tabular}{|c|} 
Punkte- \\
diffe- \\
renz
\end{tabular} & S.F. & $\begin{array}{c}\text { Mittel- } \\
\text { wert }\end{array}$ & S.F. & $\begin{array}{l}\text { Mittel- } \\
\text { wert }\end{array}$ & S.F. & \begin{tabular}{|c|} 
Punkte- \\
diffe- \\
renz
\end{tabular} & S.F. & $\begin{array}{l}\text { Mittel- } \\
\text { wert }\end{array}$ & S.F. & $\begin{array}{c}\text { Mittel- } \\
\text { wert }\end{array}$ & S.F. & \begin{tabular}{|c|} 
Punkte- \\
diffe- \\
renz
\end{tabular} & S.F. \\
\hline & & & & & & & & & & & & & & & & & & \\
\hline Australien & 513 & $(4,0)$ & 546 & $(4,7)$ & -34 & $(5,4)$ & 539 & $(4,1)$ & 527 & $(5,1)$ & 12 & $(6,2)$ & 526 & $(3,9)$ & 529 & $(4,8)$ & -3 & $(5,3)$ \\
\hline Österreich & 495 & $(3,2)$ & 520 & $(3,6)$ & -26 & $(5,2)$ & 530 & $(4,0)$ & 503 & $(3,7)$ & 27 & $(5,9)$ & 526 & $(3,8)$ & 514 & $(4,3)$ & 12 & $(6,3)$ \\
\hline Belgien & 492 & $(4,2)$ & 525 & $(4,9)$ & -33 & $(6,0)$ & 524 & $(4,6)$ & 518 & $(5,2)$ & 6 & $(6,1)$ & 496 & $(5,2)$ & 498 & $(5,6)$ & -2 & $(6,7)$ \\
\hline Kanada & 519 & $(1,8)$ & 551 & $(1,7)$ & -32 & $(1,6)$ & 539 & $(1,8)$ & 529 & $(1,6)$ & 10 & $(1,9)$ & 529 & $(1,9)$ & 531 & $(1,7)$ & -2 & $(1,9)$ \\
\hline Tschechische Rep. & 473 & $(4,1)$ & 510 & $(2,5)$ & -37 & $(4,7)$ & 504 & $(4,4)$ & 492 & $(3,0)$ & 12 & $(5,2)$ & 512 & $(3,8)$ & 511 & $(3,2)$ & 1 & $(5,1)$ \\
\hline Dänemark & 485 & $(3,0)$ & 510 & $(2,9)$ & -25 & $(3,3)$ & 522 & $(3,1)$ & 507 & $(3,0)$ & 15 & $(3,7)$ & 488 & $(3,9)$ & 476 & $(3,5)$ & 12 & $(4,8)$ \\
\hline Finnland & 520 & $(3,0)$ & 571 & $(2,8)$ & -51 & $(2,6)$ & 537 & $(2,8)$ & 536 & $(2,6)$ & 1 & $(3,3)$ & 534 & $(3,5)$ & 541 & $(2,7)$ & -6 & $(3,8)$ \\
\hline Frankreich & 490 & $(3,5)$ & 519 & $(2,7)$ & -29 & $(3,4)$ & 525 & $(4,1)$ & 511 & $(2,8)$ & 14 & $(4,2)$ & 504 & $(4,2)$ & 498 & $(3,8)$ & 6 & $(4,8)$ \\
\hline Deutschland & 468 & $(3,2)$ & 502 & $(3,9)$ & -35 & $(5,2)$ & 498 & $(3,1)$ & 483 & $(4,0)$ & 15 & $(5,1)$ & 489 & $(3,4)$ & 487 & $(3,4)$ & 3 & $(4,7)$ \\
\hline Ungarn & 465 & $(5,3)$ & 496 & $(4,3)$ & -32 & $(5,7)$ & 492 & $(5,2)$ & 485 & $(4,9)$ & 7 & $(6,2)$ & 496 & $(5,8)$ & 497 & $(5,0)$ & -2 & $(6,9)$ \\
\hline Island & 488 & $(2,1)$ & 528 & $(2,1)$ & -40 & $(3,1)$ & 513 & $(3,1)$ & 518 & $(2,9)$ & -5 & $(4,0)$ & 495 & $(3,4)$ & 499 & $(3,0)$ & -5 & $(4,7)$ \\
\hline Irland & 513 & $(4,2)$ & 542 & $(3,6)$ & -29 & $(4,6)$ & 510 & $(4,0)$ & 497 & $(3,4)$ & 13 & $(5,1)$ & 511 & $(4,2)$ & 517 & $(4,2)$ & -6 & $(5,5)$ \\
\hline Italien & 469 & $(5,1)$ & 507 & $(3,6)$ & -38 & $(7,0)$ & 462 & $(5,3)$ & 454 & $(3,8)$ & 8 & $(7,3)$ & 474 & $(5,6)$ & 483 & $(3,9)$ & -9 & $(7,7)$ \\
\hline Japan & 507 & $(6,7)$ & 537 & $(5,4)$ & -30 & $(6,4)$ & 561 & $(7,3)$ & 553 & $(5,9)$ & 8 & $(7,4)$ & 547 & $(7,2)$ & 554 & $(5,9)$ & -7 & $(7,2)$ \\
\hline Korea & 519 & $(3,8)$ & 533 & $(3,7)$ & -14 & $(6,0)$ & 559 & $(4,6)$ & 532 & $(5,1)$ & 27 & $(7,8)$ & 561 & $(4,3)$ & 541 & $(5,1)$ & 19 & $(7,6)$ \\
\hline Luxemburg & 429 & $(2,6)$ & 456 & $(2,3)$ & -27 & $(3,8)$ & 454 & $(3,0)$ & 439 & $(3,2)$ & 15 & $(4,7)$ & 441 & $(3,6)$ & 448 & $(3,2)$ & -7 & $(5,0)$ \\
\hline Mexiko & 411 & $(4,2)$ & 432 & $(3,8)$ & -20 & $(4,3)$ & 393 & $(4,5)$ & 382 & $(3,8)$ & 11 & $(4,9)$ & 423 & $(4,2)$ & 419 & $(3,9)$ & 4 & $(4,8)$ \\
\hline Neuseeland & 507 & $(4,2)$ & 553 & $(3,8)$ & -46 & $(6,3)$ & 536 & $(5,0)$ & 539 & $(4,1)$ & -3 & $(6,7)$ & 523 & $(4,6)$ & 535 & $(3,8)$ & -12 & $(7,0)$ \\
\hline Norwegen & 486 & $(3,8)$ & 529 & $(2,9)$ & -43 & $(4,0)$ & 506 & $(3,8)$ & 495 & $(2,9)$ & 11 & $(4,0)$ & 499 & $(4,1)$ & 505 & $(3,3)$ & -7 & $(5,0)$ \\
\hline Polen & 461 & $(6,0)$ & 498 & $(5,5)$ & -36 & $(7,0)$ & 472 & $(7,5)$ & 468 & $(6,3)$ & 5 & $(8,5)$ & 486 & $(6,1)$ & 480 & $(6,5)$ & 6 & $(7,4)$ \\
\hline Portugal & 458 & $(5,0)$ & 482 & $(4,6)$ & -25 & $(3,8)$ & 464 & $(4,7)$ & 446 & $(4,7)$ & 19 & $(4,9)$ & 456 & $(4,8)$ & 462 & $(4,2)$ & -6 & $(4,3)$ \\
\hline Spanien & 481 & $(3,4)$ & 505 & $(2,8)$ & -24 & $(3,2)$ & 487 & $(4,3)$ & 469 & $(3,3)$ & 18 & $(4,5)$ & 492 & $(3,5)$ & 491 & $(3,6)$ & 1 & $(4,0)$ \\
\hline Schweden & 499 & $(2,6)$ & 536 & $(2,5)$ & -37 & $(2,7)$ & 514 & $(3,2)$ & 507 & $(3,0)$ & 7 & $(4,0)$ & 512 & $(3,5)$ & 513 & $(2,9)$ & 0 & $(3,9)$ \\
\hline Vereinigte Staaten & 490 & $(8,4)$ & 518 & $(6,2)$ & -29 & $(4,1)$ & 497 & $(8,9)$ & 490 & $(7,3)$ & 7 & $(5,4)$ & 497 & $(8,9)$ & 502 & $(6,5)$ & -5 & $(5,3)$ \\
\hline Ländermittel & 485 & $(0,8)$ & 517 & $(0,7)$ & -32 & $(0,9)$ & 506 & $(1,0)$ & 495 & $(0,9)$ & 11 & $(1,2)$ & 501 & $(0,9)$ & 501 & $(0,8)$ & 0 & $(1,0)$ \\
\hline OECD-Partnerländer & & & & & & & & & & & & & & & & & & \\
\hline Brasilien & 388 & $(3,9)$ & 404 & $(3,4)$ & -17 & $(4,0)$ & 349 & $(4,7)$ & 322 & $(4,7)$ & 27 & $(5,6)$ & 376 & $(4,8)$ & 376 & $(3,8)$ & 0 & $(5,6)$ \\
\hline Lettland & 432 & $(5,5)$ & 485 & $(5,4)$ & -53 & $(4,2)$ & 467 & $(5,3)$ & 460 & $(5,6)$ & 6 & $(5,8)$ & 449 & $(6,4)$ & 472 & $(5,8)$ & -23 & $(5,4)$ \\
\hline Liechtenstein & 468 & $(7,3)$ & 500 & $(6,8)$ & -31 & $(11,5)$ & 521 & $(11,5)$ & 510 & $(11,1)$ & 12 & $(17,7)$ & 484 & $(10,9)$ & 468 & $(9,3)$ & 16 & $(14,7)$ \\
\hline Russische Föd. & 443 & $(4,5)$ & 481 & $(4,1)$ & -38 & $(2,9)$ & 478 & $(5,7)$ & 479 & $(6,2)$ & -2 & $(4,8)$ & 453 & $(5,4)$ & 467 & $(5,2)$ & -14 & $(4,5)$ \\
\hline Niederlande ${ }^{2}$ & 517 & $(4,8)$ & 547 & $(3,8)$ & -30 & $(5,7)$ & 569 & $(4,9)$ & 558 & $(4,6)$ & 11 & $(6,2)$ & 529 & $(6,3)$ & 529 & $(5,1)$ & 1 & $(8,1)$ \\
\hline
\end{tabular}

Hinweis: Standardfehler in Klammern.

1. Positive Differenzen bedeuten, dass die Jungen besser als die Mädchen abschneiden, während bei negativen Differenzen die Mädchen besser als die Jungen abschneiden. Statistisch signifikante Differenzen sind in Fettdruck. 2. Beteiligungsquote zu niedrig, um die Vergleichbarkeit zu gewährleisten.

Quelle: OECD PISA2000-Datenbank. 


\section{Tabelle A9.4}

Politische Bildung 14-jähriger Schüler und geschlechtsspezifische Unterschiede (1999)

$9 \quad$ Mittlere Leistungen 14-jähriger Schüler auf Skala der politischen Bildung

\begin{tabular}{|c|c|c|c|c|c|c|}
\hline \multirow[b]{2}{*}{ OECD-Länder } & \multicolumn{2}{|c|}{ Jungen } & \multicolumn{2}{|c|}{ Mädchen } & \multicolumn{2}{|c|}{ Differenz ${ }^{1}$} \\
\hline & Mittlere Punktzahl & S.F. & Mittlere Punktzahl & S.F. & Punktedifferenz & S.F. \\
\hline Australien & 101 & $(1,1)$ & 103 & $(0,9)$ & -2 & $(1,4)$ \\
\hline Belgien (frz.) ${ }^{2}$ & 93 & $(1,3)$ & 97 & $(1,1)$ & -5 & $(1,7)$ \\
\hline Tschechische Republik & 104 & $(1,0)$ & 102 & $(0,8)$ & 2 & $(1,3)$ \\
\hline Dänemark² & 102 & $(0,7)$ & 99 & $(0,7)$ & 3 & $(1,0)$ \\
\hline England $^{3}$ & 100 & $(1,0)$ & 99 & $(0,8)$ & 0 & $(1,3)$ \\
\hline Finnland & 108 & $(0,8)$ & 110 & $(0,9)$ & -2 & $(1,2)$ \\
\hline Deutschland ${ }^{4}$ & 101 & $(0,7)$ & 99 & $(0,6)$ & 1 & $(0,9)$ \\
\hline Griechenland & 107 & $(0,9)$ & 109 & $(0,8)$ & -2 & $(1,2)$ \\
\hline Ungarn & 101 & $(0,8)$ & 102 & $(0,7)$ & -1 & $(1,0)$ \\
\hline Italien & 104 & $(1,1)$ & 106 & $(0,9)$ & -2 & $(1,4)$ \\
\hline Norwegen ${ }^{2}$ & 103 & $(0,7)$ & 103 & $(0,6)$ & 1 & $(0,9)$ \\
\hline Polen & 109 & $(1,5)$ & 112 & $(2,2)$ & -3 & $(2,6)$ \\
\hline Portugal $^{5}$ & 97 & $(0,9)$ & 96 & $(0,8)$ & 1 & $(1,2)$ \\
\hline Slowakische Republik & 105 & $(0,9)$ & 105 & $(0,8)$ & 0 & $(1,1)$ \\
\hline Schweden ${ }^{3}$ & 99 & $(1,1)$ & 100 & $(0,8)$ & -1 & $(1,3)$ \\
\hline Schweiz & 100 & $(0,9)$ & 97 & $(0,8)$ & 2 & $(1,2)$ \\
\hline Vereinigte Staaten ${ }^{3}$ & 106 & $(1,3)$ & 107 & $(1,2)$ & -2 & $(1,8)$ \\
\hline
\end{tabular}

Hinweis: Standardfehler in Klammern.

1. Positive Differenzen bedeuten, dass die Jungen besser als die Mädchen abschneiden, während bei negativen Differenzen die Mädchen besser als die Jungen abschneiden. Statistisch signifikante Differenzen sind in Fettdruck. 2. Beteiligungsrate unter Berücksichtigung der im Nachrückverfahren einbezogenen Schulen unter 85 Prozent. 3. Länder mit Erhebungsdatum am Beginn des Schuljahrs. 4. Deckt nicht die Gesamtheit der nationalen Bevölkerung ab. 5. Anstelle Klassenstufe 9 aufgrund des durchschnittlichen Alters Klassenstufe 8 ausgewählt.

Quelle: IEA-Studie zur politischen Bildung (2001). 
Tabelle A9.5

Geschlechtsspezifische Unterschiede 15-jähriger Schülerinnen und Schülern beim sellostgesteuerten Lernen (2000) Unterschiede zwischen 15-jährigen Schülerinnen und Schülern auf den PISA-Indizes für selbstgesteuertes Lernen

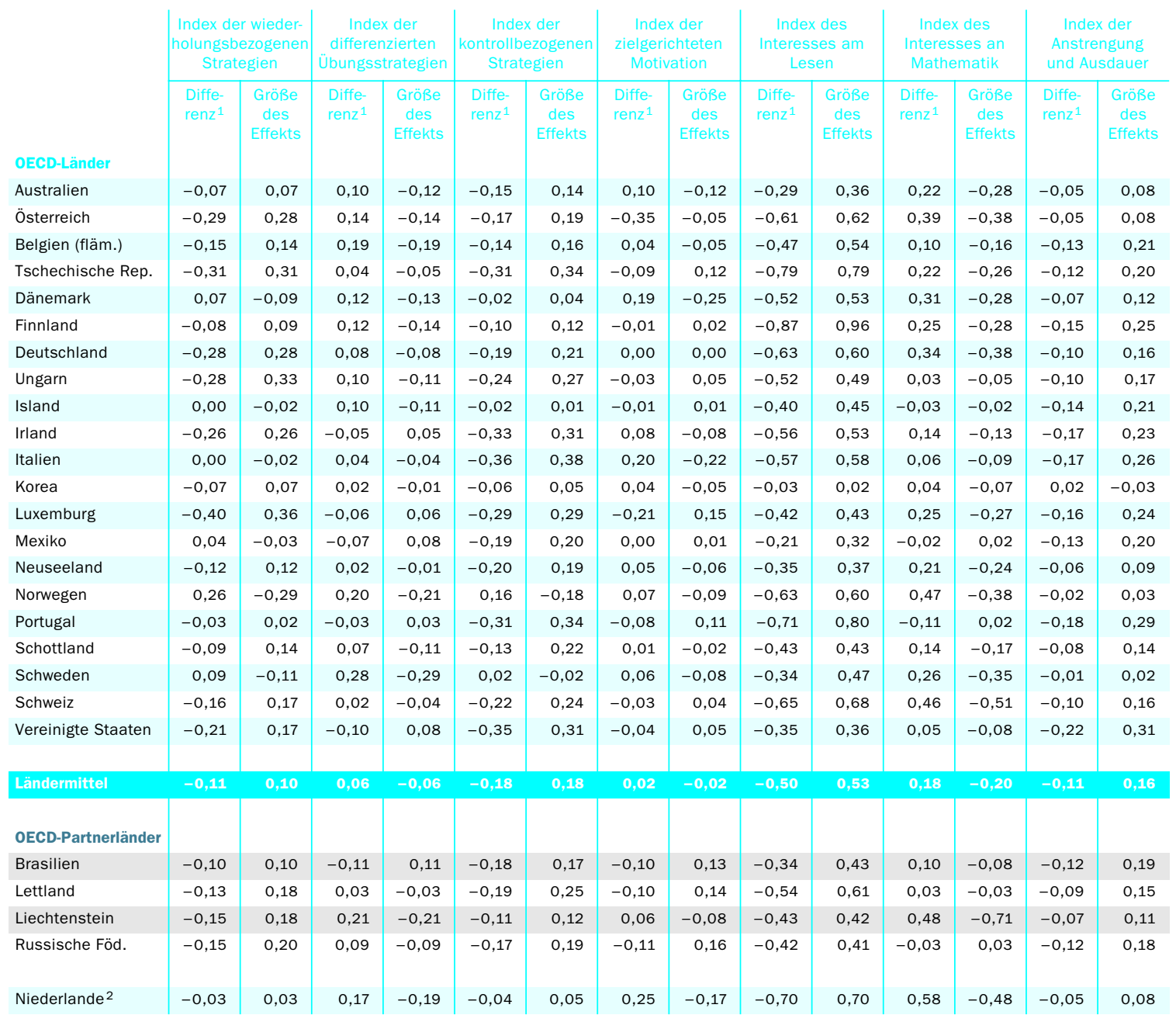

1. Positive Differenzen bedeuten, dass die Jungen besser als die Mädchen abschneiden, während bei negativen Differenzen die Mädchen besser als die Jungen abschneiden. 2. Beteiligungsquote zu niedrig, um die Vergleichbarkeit zu gewährleisten.

Quelle: OECD PISA 2000-Datenbank. 
Tabelle A9.5 (Forts.)

Geschlechtsspezifische Unterschiede 15-jähriger Schülerinnen und Schülern beim sellbstgesteuerten Lernen (2000) Unterschiede zwischen 15-jährigen Schülerinnen und Schülern auf den PISA-Indizes für selbstgesteuertes Lernen

\begin{tabular}{|c|c|c|c|c|c|c|c|c|c|c|c|c|}
\hline & \multicolumn{2}{|c|}{$\begin{array}{c}\text { Index des kooperativen } \\
\text { Lernens }\end{array}$} & \multicolumn{2}{|c|}{$\begin{array}{c}\text { PISA-Index des wettbe- } \\
\text { werbsorientierten Ler- } \\
\text { nens }\end{array}$} & \multicolumn{2}{|c|}{$\begin{array}{c}\text { Index der Erfolgswirk- } \\
\text { samkeit }\end{array}$} & \multicolumn{2}{|c|}{$\begin{array}{l}\text { Index des eigenen Kon- } \\
\text { zepts zur Lesefertigkeit }\end{array}$} & \multicolumn{2}{|c|}{$\begin{array}{c}\text { Index des eigenen Kon- } \\
\text { zepts zur Mathematik- } \\
\text { fertigkeit }\end{array}$} & \multicolumn{2}{|c|}{$\begin{array}{c}\text { Index zum theorieorien- } \\
\text { tierten Lernen }\end{array}$} \\
\hline OECD-Länder & Differenz $^{1}$ & $\begin{array}{l}\text { Größe des } \\
\text { Effekts }\end{array}$ & Differenz ${ }^{1}$ & $\begin{array}{c}\text { Größe des } \\
\text { Effekts }\end{array}$ & Differenz $^{1}$ & $\begin{array}{l}\text { Größe des } \\
\text { Effekts }\end{array}$ & Differenz $^{1}$ & $\begin{array}{c}\text { Größe des } \\
\text { Effekts }\end{array}$ & Differenz $^{1}$ & $\begin{array}{c}\text { Größe des } \\
\text { Effekts }\end{array}$ & Differenz $z^{1}$ & $\begin{array}{l}\text { Größe des } \\
\text { Effekts }\end{array}$ \\
\hline Australien & $-0,14$ & 0,03 & 0,20 & $-0,32$ & 0,13 & $-0,22$ & $-0,17$ & 0,21 & 0,23 & $-0,29$ & 0,03 & $-0,05$ \\
\hline Österreich & $-0,30$ & 0,17 & 0,12 & $-0,15$ & 0,20 & $-0,32$ & $-0,35$ & 0,34 & 0,29 & $-0,30$ & $-0,06$ & 0,10 \\
\hline Belgien (fläm.) & $-0,22$ & 0,14 & 0,19 & $-0,23$ & 0,14 & $-0,24$ & $-0,13$ & 0,18 & 0,18 & $-0,27$ & 0,04 & $-0,08$ \\
\hline Tschechische Rep. & $-0,33$ & 0,15 & 0,00 & $-0,01$ & 0,17 & $-0,30$ & $-0,36$ & 0,37 & 0,26 & $-0,31$ & $-0,04$ & 0,05 \\
\hline Dänemark & $-0,11$ & $-0,02$ & 0,29 & $-0,25$ & 0,28 & $-0,45$ & $-0,32$ & 0,31 & 0,39 & $-0,40$ & 0,10 & $-0,16$ \\
\hline Finnland & $-0,29$ & 0,11 & 0,22 & $-0,30$ & 0,21 & $-0,34$ & $-0,42$ & 0,45 & 0,35 & $-0,36$ & $-0,03$ & 0,04 \\
\hline Deutschland & $-0,24$ & 0,10 & 0,13 & $-0,16$ & 0,13 & $-0,21$ & $-0,45$ & 0,43 & 0,42 & $-0,42$ & 0,00 & 0,00 \\
\hline Ungarn & $-0,23$ & 0,01 & $-0,06$ & 0,02 & 0,11 & $-0,19$ & $-0,32$ & 0,33 & 0,12 & $-0,13$ & $-0,06$ & 0,08 \\
\hline Island & $-0,18$ & 0,08 & 0,22 & $-0,28$ & 0,18 & $-0,26$ & $-0,20$ & 0,20 & 0,20 & $-0,19$ & $-0,04$ & 0,05 \\
\hline Irland & $-0,42$ & $-0,23$ & 0,41 & $-0,39$ & 0,12 & $-0,17$ & $-0,15$ & 0,13 & 0,09 & $-0,13$ & $-0,02$ & 0,03 \\
\hline Italien & $-0,49$ & $-0,27$ & 0,13 & $-0,14$ & 0,12 & $-0,19$ & $-0,44$ & 0,40 & 0,18 & $-0,11$ & $-0,15$ & 0,21 \\
\hline Korea & 0,09 & $-0,14$ & 0,09 & $-0,12$ & 0,10 & $-0,15$ & 0,02 & $-0,03$ & 0,15 & $-0,16$ & 0,09 & $-0,12$ \\
\hline Luxemburg & $-0,36$ & 0,19 & 0,04 & $-0,13$ & 0,12 & $-0,18$ & $-0,21$ & 0,18 & 0,28 & $-0,28$ & $-0,04$ & 0,06 \\
\hline Mexiko & $-0,20$ & 0,11 & 0,10 & $-0,13$ & 0,00 & $-0,01$ & $-0,21$ & 0,25 & 0,05 & $-0,09$ & $-0,04$ & 0,06 \\
\hline Neuseeland & $-0,23$ & 0,08 & 0,23 & $-0,28$ & 0,12 & $-0,19$ & $-0,29$ & 0,27 & 0,26 & $-0,26$ & 0,04 & $-0,05$ \\
\hline Norwegen & $-0,34$ & 0,15 & 0,31 & $-0,34$ & 0,22 & $-0,33$ & $-0,38$ & 0,37 & 0,50 & $-0,44$ & 0,04 & $-0,05$ \\
\hline Portugal & $-0,35$ & 0,14 & 0,35 & $-0,38$ & 0,08 & $-0,14$ & $-0,31$ & 0,32 & 0,14 & $-0,16$ & 0,01 & $-0,02$ \\
\hline Schottland & $-0,03$ & 0,05 & 0,35 & $-0,42$ & 0,19 & $-0,32$ & $-0,10$ & 0,14 & 0,22 & $-0,24$ & 0,02 & $-0,03$ \\
\hline Schweden & $-0,05$ & $-0,05$ & 0,21 & $-0,27$ & 0,24 & $-0,37$ & $-0,30$ & 0,37 & 0,36 & $-0,41$ & 0,05 & $-0,08$ \\
\hline Schweiz & $-0,28$ & 0,14 & 0,24 & $-0,30$ & 0,13 & $-0,22$ & $-0,31$ & 0,35 & 0,50 & $-0,55$ & 0,03 & $-0,05$ \\
\hline Vereinigte Staaten & $-0,42$ & 0,21 & 0,05 & $-0,13$ & 0,04 & $-0,06$ & $-0,39$ & 0,36 & 0,09 & $-0,13$ & $-0,08$ & 0,11 \\
\hline Ländermittel & $-0,27$ & 0,10 & 0,18 & $-0,21$ & 0,14 & $-0,22$ & $-0,29$ & 0,29 & 0,25 & $-0,25$ & $-0,02$ & 0,02 \\
\hline OECD-Partnerländer & & & & & & & & & & & & \\
\hline Brasilien & $-0,24$ & 0,12 & 0,21 & $-0,21$ & 0,06 & $-0,09$ & 0,28 & 0,30 & 0,25 & $-0,21$ & 0,03 & $-0,05$ \\
\hline Lettland & $-0,31$ & 0,15 & $-0,11$ & 0,11 & 0,03 & $-0,05$ & 0,51 & 0,51 & 0,18 & $-0,18$ & $-0,07$ & 0,11 \\
\hline Liechtenstein & $-0,17$ & 0,09 & 0,27 & $-0,36$ & 0,07 & $-0,12$ & 0,37 & 0,37 & 0,39 & $-0,58$ & 0,00 & $-0,01$ \\
\hline Russische Föd. & $-0,20$ & 0,05 & $-0,15$ & 0,10 & 0,07 & $-0,11$ & 0,52 & 0,48 & 0,02 & 0,00 & $-0,08$ & 0,11 \\
\hline Niederlande2 & $-0,33$ & 0,20 & 0,36 & $-0,34$ & 0,24 & $-0,44$ & 0,25 & 0,26 & 0,65 & $-0,57$ & 0,12 & $-0,20$ \\
\hline
\end{tabular}

1. Positive Differenzen bedeuten, dass die Jungen besser als die Mädchen abschneiden, während bei negativen Differenzen die Mädchen besser als die Jungen abschneiden. 2. Beteiligungsquote zu niedrig, um die Vergleichbarkeit zu gewährleisten.

Quelle: OECD PISA 2000-Datenbank. 


\section{Erwerbsbeteiligung nach Bildungsstand}

In den meisten OECD-Ländern steigt der jeweilige Erwerbstätigenanteil mit zunehmendem Bildungsstand. Von sehr wenigen Ausnahmen abgesehen, ist der Erwerbstätigenanteil unter Absolventen des Tertiärbereichs wesentlich höher als der unter Absolventen des Sekundarbereich II. Bei Männern ist der Abstand zwischen den Erwerbstätigenanteilen unter Absolventen des Sekundarbereich II und unter denen ohne einen solchen Abschluss besonders groß.

Der Erwerbstätigenanteil unter Frauen ohne einen Abschluss im Sekundarbereich II ist besonders niedrig. Der Anteil unter Frauen mit einem Abschluss im Tertiärbereich A liegt, mit Ausnahme von vier Ländern, überall bei 75 Prozent oder darüber. Er ist jedoch in allen Ländern niedriger als der unter Männern.

Mit zunehmendem Bildungsstand nimmt der geschlechtsspezifische Unterschied in den Erwerbstätigenanteilen ab. Er beläuft sich auf 23 Prozentpunkte bei Personen ohne einen Abschluss im Sekundarbereich II und 11 Prozentpunkte bei denen mit dem höchsten Bildungsstand. 
Abbildung A10.1

10 Anteil der 25-bis 64-Jährigen, die sich in Beschäftigung befinden, in Prozent

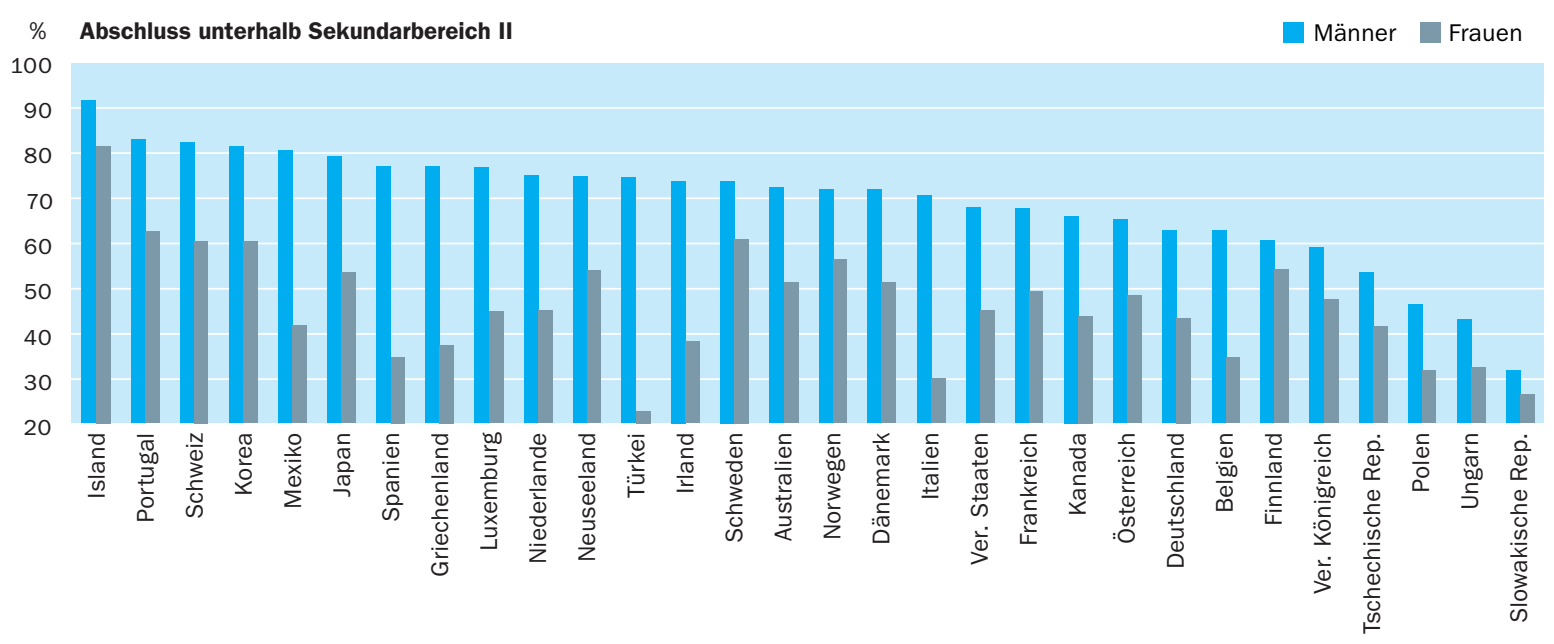

Sekundarbereich II u. post-sekundarer, nicht-tertiärer Bereich

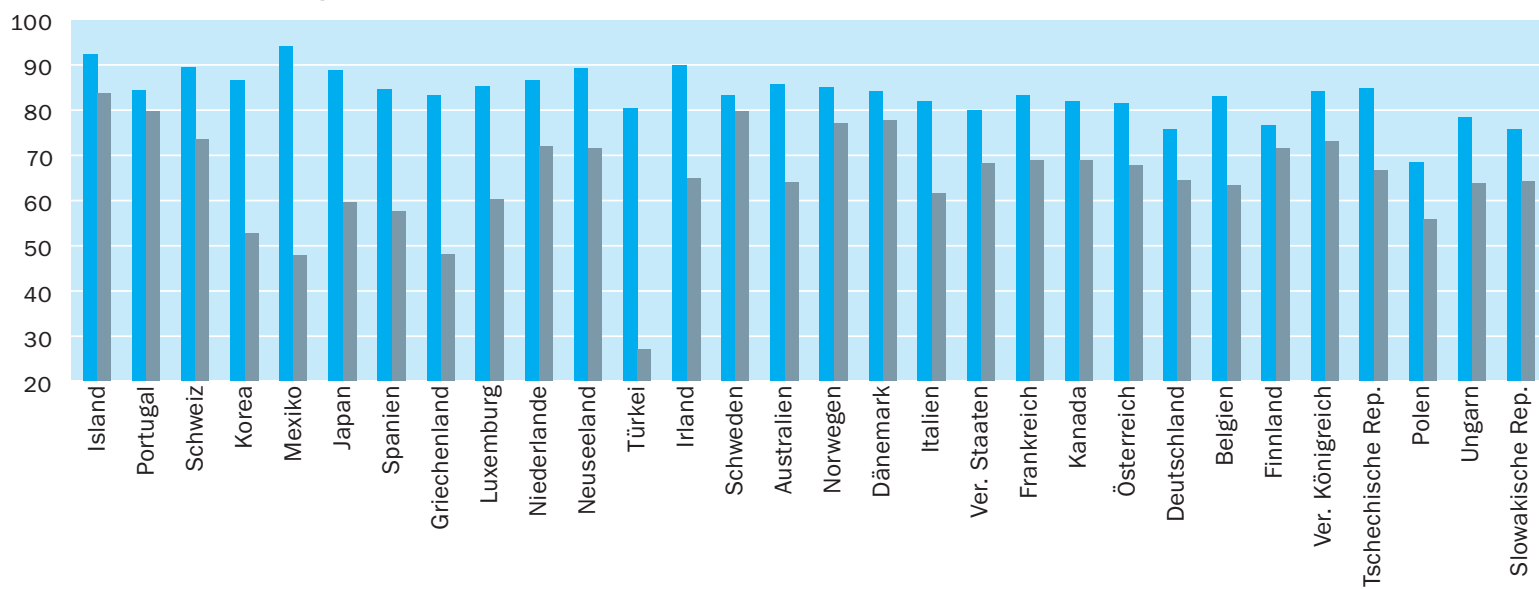

$\% \quad$ Tertiärbereich

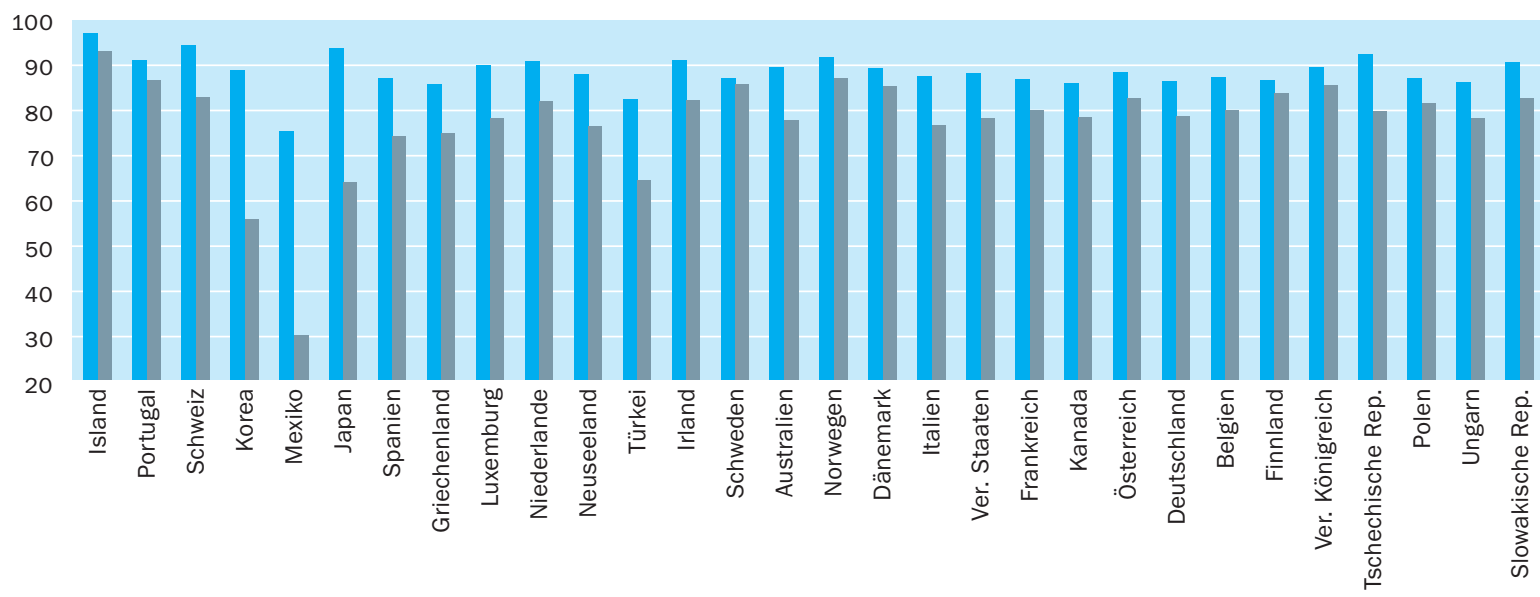

Anordnung der Länder in absteigender Reihenfolge der Erwerbstätigenanteile unter Männern mit einem Abschluss unterhalb des Sekundarbereich II.

Quelle: OECD, Tabelle A10.1a. Hinweise s. Anhang 3 unter www.oecd.org/edu/eag2004. 


\section{Politischer Hintergrund}

Um ihre wirtschaftliche Entwicklung voranzutreiben und ihre Wettbewerbsfähigkeit aufrecht zu erhalten, hängen die Volkswirtschaften und Arbeitsmärkte der OECD-Länder in zunehmendem Maße von einem stabilen Angebot gut ausgebildeter Arbeitskräfte ab. Da das Niveau an Kenntnissen und Fähigkeiten in der Regel mit zunehmendem Bildungsstand wächst, steigen auch die Kosten, wenn die besser Ausgebildeten nicht arbeiten; und da die Bevölkerung in den OECD-Ländern zunehmend älter wird, kann eine intensivere und längere Beschäftigungsbeteiligung zu einer Senkung der Abhängigkeitsquoten und der Entlastung der staatlichen Rentenkassen beitragen.

Dieser Indikator untersucht die Beziehung zwischen Bildungsstand und Erwerbsverhalten, wobei zuerst die Erwerbstätigenanteile (Zahl der beschäftigten Personen als Prozentsatz der betreffenden Bevölkerung, s. Definitionen und angewandte Methodik) und anschließend die Arbeitslosenanteile (Zahl der Arbeitslosen als Prozentsatz der betreffenden Bevölkerung, s. Definitionen und angewandte Methodik) verglichen werden, aufgegliedert nach Geschlecht und im zeitlichen Verlauf. Für die politischen Entscheidungsträger ist es von großer Bedeutung, inwieweit die Kenntnisse und Fähigkeiten der Arbeitskräfte angemessen sind und der Arbeitsmarkt in der Lage ist, die passenden Arbeitsplätze für diese Kenntnisse und Fähigkeiten bereitzustellen.

\section{Ergebnisse und Erläuterungen}

\section{Beschäftigungsbeteiligung}

Die Unterschiede zwischen den OECD-Ländern bei der Gesamtbeschäftigungsbeteiligung sind hauptsächlich auf die unterschiedliche Beschäftigungsbeteiligung der Frauen zurückzuführen. Die Gesamterwerbstätigenanteile unter 25- bis 64-jährigen Männern liegen zwischen 76 Prozent und darunter in Finnland, Polen, der Slowakischen Republik und Ungarn und 86 Prozent und darüber in Island, Japan, Korea, Neuseeland und der Schweiz (Tab. Aıo.ra). Im Gegensatz dazu zeigen sich die sehr unterschiedlichen kulturellen und sozialen Gegebenheiten in der großen Bandbreite der Beschäftigungsbeteiligung der Frauen. Sie reicht von 48 Prozent und weniger in Griechenland, Italien, Mexiko, Spanien und der Türkei bis zu mehr als 78 Prozent in Island, Norwegen und Schweden. Längere Zeiten der Ausbildung und der Arbeitslosigkeit sind zwei der Faktoren, die zu diesen Unterschieden beitragen.

Im Allgemeinen sind die Erwerbstätigenanteile unter Männern mit höheren Bildungsabschlüssen höher. Mit Ausnahme von Mexiko und Neuseeland, wo ein anderes Muster zu beobachten ist, sind die Erwerbstätigenanteile unter Absolventen des Tertiärbereichs wesentlich höher (im Durchschnitt der OECDLänder ungefähr 5 Prozentpunkte) als die unter Absolventen des Sekundarbereich II. Dieser Unterschied reicht von wenigen Prozentpunkten bis zu Io Prozentpunkten und mehr in Deutschland, Finnland, Polen und der Slowakischen Republik. Er könnte hauptsächlich auf die Tatsache zurückzuführen sein, dass weniger gut ausgebildete Arbeitskräfte den Arbeitsmarkt früher verlassen. Diejenigen mit einem höheren Bildungsstand verbleiben in der Regel länger in Beschäftigung (Abb. Aro.I).
Dieser Indikator untersucht die Beziehung zwischen Bildungsstand und der Stellung im Arbeitsmarkt.

Die länderspezifischen Unterschiede der Erwerbstätigenanteile unter Männern sind geringer als unter Frauen.

In den meisten OECD-Ländern steigen die Erwerbstätigenanteile unter den Männern mit zunehmendem Bildungsstand. 
Besonders groß ist der Abstand zwischen den Erwerbstätigenanteilen unter Männern mit einem Abschluss des Sekundarbereich II und ohne einen solchen.

Bei den Frauen weisen die Erwerbstätigenanteile nach dem Bildungsstand sogar noch größere Unterschiede auf.

Die Erwerbstätigenanteile unter Frauen mit einem Abschluss unterhalb des Sekundarbereich II sind besonders niedrig, ...

... der geschlechtsspezifische Unterschied in den Erwerbstätigenanteilen nimmt jedoch mit zunehmendem Bildungsstand ab.
Besonders groß ist der Abstand zwischen den Erwerbstätigenanteilen unter 25- bis 64-jährigen Männern mit einem Abschluss des Sekundarbereich II und ohne einen solchen. In 22 von 30 OECD-Ländern beträgt der Unterschied in den Erwerbstätigenanteilen unter denjenigen mit einem Abschluss des Sekundarbereich II und denjenigen ohne einen solchen Abschluss Io Prozentpunkte oder mehr. Die extremsten Beispiele sind hier die Slowakische sowie die Tschechische Republik und Ungarn, wo zwischen einem Drittel und ungefähr der Hälfte der männlichen Bevölkerung ohne einen Abschluss im Sekundarbereich II, aber mehr als 80 Prozent mit einem solchen Abschluss beschäftigt sind. Der Unterschied in den Erwerbstätigenanteilen unter Männern mit einem Abschluss im Sekundarbereich II und denjenigen ohne einen solchen beträgt in Island, Korea, Portugal und der Türkei weniger als sechs Prozentpunkte (Abb. Aro.I und Tab. Aro.ra).

Die Erwerbstätigenanteile unter Frauen im Alter zwischen 25 und 64 Jahren weisen noch deutlichere Unterschiede auf, und zwar nicht nur zwischen denen ohne einen Abschluss des Sekundarbereich II und denen, die einen solchen Abschluss besitzen (I5 Prozentpunkte oder mehr in 22 der 30 OECD-Länder), sondern auch zwischen denen mit einem Abschluss im Sekundarbereich II und denen mit einem Abschluss im Tertiärbereich A oder in einem weiterführenden Forschungsprogramm (9 Prozentpunkte oder mehr in 23 Ländern). Ausnahmen bilden hier Japan, Korea, Neuseeland, Portugal und Schweden, wo die Erwerbstätigenanteile unter Frauen mit einem Abschluss des Sekundarbereich II denen unter Frauen mit einem Abschluss des Tertiärbereichs vergleichbar sind (Unterschiede von ca. 3 bis 7 Prozentpunkten) (Abb. Aro.I und Tab. Aro.ra).

Die Erwerbstätigenanteile unter Frauen mit einem Abschluss im Sekundarbereich I sind besonders niedrig, im Durchschnitt aller OECD-Länder ungefähr 49 Prozent und ca. 35 Prozent oder weniger in Polen, der Slowakischen Republik, der Türkei und Ungarn. Die Anteile unter Frauen mit einem Abschluss im Tertiärbereich A liegen, mit Ausnahme von Japan, Korea, Mexiko und der Türkei in allen Ländern bei über 75 Prozent. Sie sind jedoch in allen Ländern geringer als die der Männer (Tab. Aıo.ıa).

Obwohl auch bei den höchsten Bildungsabschlüssen noch ein Unterschied zwischen den Erwerbstätigenanteilen unter Männern und Frauen besteht, ist er hier weit geringer als bei niedrigeren Bildungsabschlüssen. So verringert sich im Durchschnitt aller OECD-Länder der geschlechtsspezifische Unterschied im Erwerbstätigenanteil mit jeder nächsthöheren Bildungsstufe deutlich: von ca. 23 Prozentpunkten im Bereich unterhalb des Sekundarbereich II auf Ig Prozentpunkte im Sekundarbereich II und II Prozentpunkte im Tertiärbereich (Abb. AIo.I).

Der Unterschied ist für alle Bildungsniveaus in den einzelnen Ländern recht unterschiedlich. Für Abschlüsse unterhalb des Sekundarbereich II beträgt der Abstand in der Slowakischen Republik und Finnland weniger als ro Prozentpunkte, in Griechenland, Italien, Spanien und der Türkei jedoch mehr als 40 Prozentpunkte. Auch für Abschlüsse im Sekundarbereich II ist der Unterschied in den nordischen Ländern und Portugal kleiner als ıo Prozentpunkte, 
liegt aber in Korea, Griechenland, Mexiko und der Türkei bei über 34 Punkten. Im Tertiärbereich nähern sich die Werte dann meist stark an, mit Ausnahme von Japan, Korea und Mexiko.

Ein Großteil der Unterschiede zwischen den Erwerbstätigenanteilen unter Männern mit unterschiedlichem Bildungsstand ist auf die großen Unterschiede bei der älteren Bevölkerung zurückzuführen. Die sich ergebenden Profile spiegeln eine Reihe von Ursachen wieder. Da das Einkommen normalerweise mit höherem Bildungsstand wächst, besteht für Personen mit einem höheren Bildungsabschluss ein größerer finanzieller Anreiz für eine Erwerbstätigkeit. Daneben haben diese Personen meist interessantere und reizvollere Aufgaben und tragen mehr Verantwortung, wodurch ihre Motivation, erwerbstätig zu bleiben, steigt. Im Gegensatz dazu kann schwere körperliche Arbeit, die in der Regel mit einem eher niedrigen Bildungsstand in Verbindung steht, zum Bedürfnis nach einem vorzeitigen Ruhestand führen. Darüber hinaus hat die Umstrukturierung der Industrie in vielen Ländern zu einer Reduzierung der Arbeitsplätze für ungelernte Arbeitskräfte und für solche mit Fertigkeiten in technisch mittlerweile überholten Berufen geführt. In Ländern mit gut ausgebauten Rentensystemen mit langer Tradition wurden Personen mit niedrigerem Bildungsstand früher auf dem Arbeitsmarkt aktiv als diejenigen mit höherem Bildungsstand und sind daher, auch unabhängig von anderen Regelungen, häufig schon einige Jahre früher rentenberechtigt. Viele von ihnen sind aufgrund von Vorruhestandsregelungen oder nur begrenzten Beschäftigungsmöglichkeiten aus dem Arbeitsmarkt ausgeschieden. Der Bildungsstand von Frauen und ihre Erwerbsbeteiligung haben seit jeher unterhalb der von Männern gelegen, und trotz beträchtlicher Fortschritte im Laufe der letzten Jahrzehnte belegen die derzeitigen Erwerbstätigenanteile auch weiterhin den Einfluss dieser historischen Faktoren.

\section{Arbeitslosenanteile nach Bildungsstand}

Anhand der Arbeitslosenanteile lässt sich die Fähigkeit einer Volkswirtschaft bemessen, jeden Arbeitswilligen mit einem Arbeitsplatz zu versorgen. Soweit man den Bildungsstand als Indikator für vorhandene Kenntnisse und Fähigkeiten ansieht, kann er dem Arbeitgeber als Anhaltspunkt dafür dienen, welche Kenntnisse, Fähigkeiten und Leistungen am Arbeitsplatz von einem Stellenbewerber zu erwarten sind. Bei unterschiedlichem Bildungsstand werden die Beschäftigungsaussichten des Einzelnen sowohl von den Erfordernissen des Arbeitsmarktes abhängen als auch von dem Angebot an Arbeitskräften mit unterschiedlichen Kenntnissen und Fähigkeiten. Besonders diejenigen mit einem niedrigen Bildungsstand laufen Gefahr, wirtschaftlich ausgegrenzt zu werden, da sie sich einerseits eher nicht im Arbeitsmarkt befinden und andererseits auch eher ohne Arbeit bleiben, wenn sie sich aktiv um eine Arbeitsstelle bemühen.

Im Durchschnitt der OECD-Länder ist die Wahrscheinlichkeit, arbeitslos zu sein, für Männer im Alter von 25 bis 64 Jahren mit einem Abschluss unterhalb des Sekundarbereich II ungefähr I, 5 Mal so hoch wie für diejenigen mit einem Abschluss des Sekundarbereich II. Ähnlich sieht es im Durchschnitt der OECD-Länder bei den Arbeitslosenanteilen unter den männlichen Absolventen des Sekundarbereich II aus - sie sind ungefähr I, 5 Mal so hoch wie die unter

Mit höherem Bildungsstand gehen die Arbeitslosenanteile zurück. 
Die Unterschiede in den Arbeitslosenanteilen unter denjenigen mit einem niedrigen Bildungsstand verändern sich entsprechend den Gegebenheiten des Arbeitsplatzangebots.
Absolventen des Tertiärbereich A. Der Zusammenhang zwischen Arbeitslosenanteilen und Bildungsstand ist bei den Frauen ähnlich, obwohl in vielen Ländern der Abstand zwischen denjenigen mit einem Abschluss des Sekundarbereich II und denjenigen mit einem Abschluss des Tertiärbereichs noch größer ist.

Höhere Arbeitslosenanteile unter Frauen jeden Bildungsstands sind im Allgemeinen in Griechenland, Italien und Spanien die Regel. Dem gegenüber sind die Arbeitslosenanteile unter Männern jeden Bildungsstands in Irland, Japan, Kanada, Korea, Mexiko, Neuseeland, Norwegen, Schweden, dem Vereinigten Königreich und den Vereinigten Staaten im Allgemeinen höher als die der Frauen. Die Unterschiede bei den Arbeitslosenanteilen unter Männern und Frauen nach Bildungsstand sind in Finnland, Island und den Niederlanden nicht so deutlich ausgeprägt. In Deutschland, Polen, der Türkei und Ungarn weisen Männer mit einem niedrigen Bildungsstand tendenziell höhere Arbeitslosenanteile auf als Frauen, bei den höher Qualifizierten ist das Gegenteil der Fall. Bei den übrigen Ländern ergibt sich über die Bildungsniveaus hinweg ein gemischteres Bild (Tabelle Aro.rb).

\section{Die Veränderungen beim Mehrwert von Bildung in Bezug auf Arbeitslosigkeit}

Der Unterschied zwischen dem Arbeitslosenanteil unter den 25- bis 64-Jährigen ohne einen Abschluss im Sekundarbereich II und dem Arbeitslosenanteil derjenigen mit diesem Abschluss gilt als Maßstab für den Vorteil, den ein längerer Schulbesuch bis zum Abschluss des Sekundarbereich II mit sich bringt. Dies gilt als der Bildungsstand, der mindestens erreicht sein muss, um eine zufriedenstellende Position auf dem Arbeitsmarkt zu erreichen. Andererseits könnten die Unterschiede bei den Anteilen auch andeuten, dass diejenigen, die nicht den Mindestbildungsstand erreichen, beim Zugang zur Beschäftigung ausgegrenzt oder diskriminiert werden. Je nach der Angebotsstruktur der Arbeitsplätze variiert dieser Unterschied zwischen den einzelnen Ländern sehr stark und wirkt sich meist zu Ungunsten der weniger Qualifizierten aus.

In Griechenland und Korea, sowie in geringerem Maße in Italien, Norwegen, Portugal, Spanien und der Türkei, bringt ein Abschluss des Sekundarbereich II keinen Vorteil bei der Minimierung des Risikos der Arbeitslosigkeit. Hier hat sich die Situation im Verlauf der letzten ıo Jahre geändert (Tab. Io.2b). Das Beschäftigungsangebot, wahrscheinlich in der Landwirtschaft, dem primären Sektor, das keinen Sekundarabschluss erfordert, ist bezogen auf die Struktur des Bildungsstandes der Erwachsenenbevölkerung weiterhin ausreichend. Dies hat sich in den letzten Io Jahren in diesen Ländern immer wieder bestätigt, ist aber ein relativ neues Phänomen in Norwegen. Es ist auch erwähnenswert, dass I99I in der Schweiz der Arbeitslosenanteil unter denjenigen mit einem Abschluss unterhalb des Sekundarbereich II geringer war als der unter den Absolventen des Sekundarbereich II.

In allen anderen Ländern besteht der Vorteil eines Abschlusses des Sekundarbereich II in einem niedrigeren Arbeitslosenanteil - im Durchschnitt um I, I Prozentpunkte. Es gibt hierbei jedoch erhebliche Unterschiede bei den Entwicklungen in den einzelnen Ländern. 
In einigen Ländern wie Deutschland, Japan, Kanada, Schweden, der Schweiz, dem Vereinigten Königreich und den Vereinigten Staaten ist der relative Vorteil in Bezug auf die Beschäftigungsaussichten durch einen Abschluss im Sekundarbereich II in den letzten Jahren relativ stabil geblieben. In einigen anderen Ländern jedoch, Australien, Finnland, Österreich, der Türkei und Ungarn, gab es seit I99I Zeichen gesteigerter Beschäftigungsaussichten für diejenigen mit einem Abschluss im Sekundarbereich II verglichen mit denjenigen ohne einen solchen. In letzter Zeit war dies auch in der Slowakischen Republik zu beobachten. Das Gegenteil zeigte sich in Belgien, Irland und Norwegen. Ingesamt lässt sich jedoch sagen, dass ein Abschluss im Sekundarbereich II im Arbeitsmarkt nicht so einen großen Unterschied wie ein Abschluss im Tertiärbereich ausmacht (Tab. Aro.2b).

Kasten A10.1

\section{Deutschland: Arbeitsmarktrisiko für Absolventen des dualen Systems in vielen Berufen}

In Deutschland, wie in anderen Ländern, gehen verschiedene Bildungsniveaus mit unterschiedlichen Anteilen der Beschäftigung, der Arbeitslosigkeit und der Nichterwerbstätigkeit einher (Datenquelle: Europäische Arbeitskräfteerhebung und der nationale Mikrozensus).

Anteil Arbeitsloser an der betreffenden Bevölkerung, nach Bildungsstand und Altersgruppen (2002)

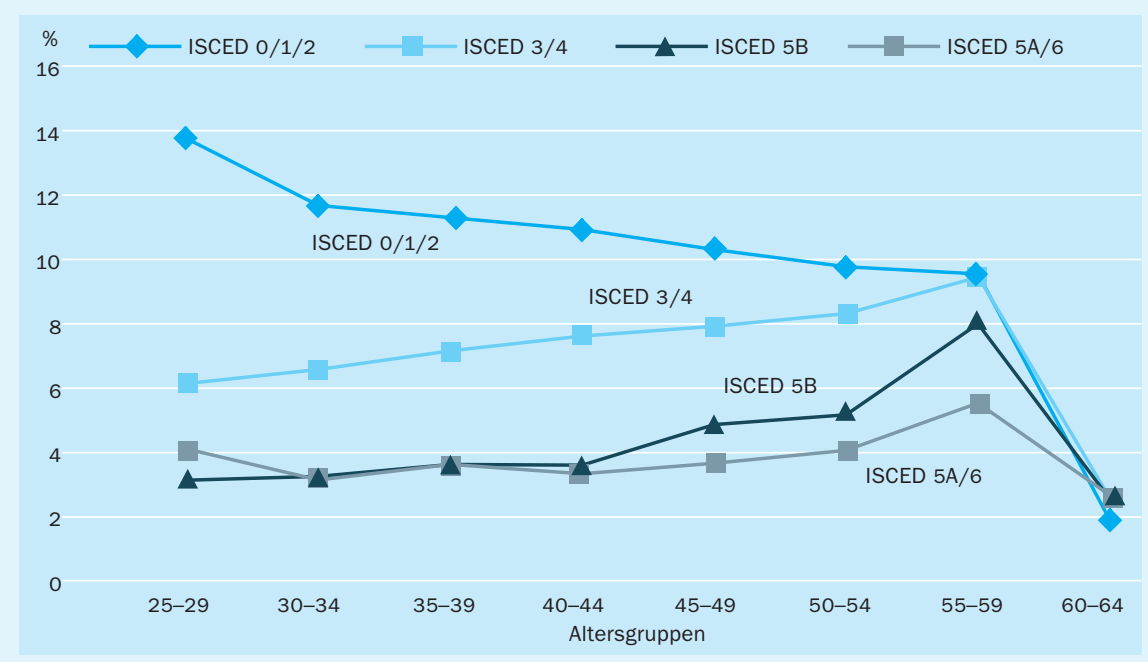

Angesichts der hohen Zahl von Personen mit einem Abschluss im Sekundarbereich II ist eine genauere Betrachtung der beruflichen Bildung insbesondere in Ländern wie Deutschland, Österreich und der Schweiz von Interesse, in denen der Berufsausbildung im dualen System (Lernorte Berufsschule und Betrieb) besondere Bedeutung zukommt. Eine Berufsausbildung im dualen System sorgt meist für eine gute Kombination von praktischer und theoretischer Ausbildung, die es den Absolventen leichter macht, im Arbeitsmarkt Fuß zu fassen. 
In Deutschland absolvierte 2002 die überwältigende Mehrheit (2I,5 Mio.) der 22,8 Mio. 25- bis 64-Jährigen mit einem berufsbildenden Abschluss im Sekundarbereich II als höchstem Bildungsabschluss eine Lehre im dualen System. In der Vergangenheit kam den Abschlüssen der Berufsfachschulen nur untergeordnete Bedeutung zu (I,2 Mio. Absolventen). In den letzten zehn Jahren haben die Berufsfachschulen jedoch zunehmend an Attraktivität gewonnen. Während 1993 ungefähr jeder neunte Teilnehmer an einem berufsbildenden Ausbildungsgang des Sekundarbereich II eine Berufsfachschule besuchte, war es im Schuljahr 2003/2004 schon jeder fünfte.

Die Analyse des Arbeitsmarktstatus von Absolventen des dualen Systems im Vergleich zu den Absolventen der Berufsfachschulen zeigt, dass der Erwerbstätigenanteil unter den 25- bis 64-Jährigen mit einer Lehre (70 Prozent) geringer ist als der unter den Berufsfachschulabsolventen (73 Prozent). Auch hinsichtlich der Personen, die sich nicht im Arbeitsmarkt befinden, zeigen sich Unterschiede. Bei den Absolventen einer Lehre liegt der Prozentsatz derjenigen, die sich nicht am Erwerbsleben beteiligen, bei 23 Prozent, bei den Berufsfachschulabsolventen bei 2r Prozent. Auch für die Jahre vor 2002 gelten ähnliche Ergebnisse.

Der Prozentsatz der Arbeitslosen, aufgegliedert nach Altergruppen, differiert auch stark. In allen Altersgruppen ist dieser Anteil unter den Absolventen einer Lehre höher als unter den Berufsfachschulabsolventen. Der Unterschied ist in der Altersgruppe der 20- bis 24-Jährigen besonders deutlich. In dieser Altersgruppe beträgt der Anteil der Arbeitslosen unter den Absolventen einer Lehre Io Prozent gegenüber 7 Prozent unter den Berufsfachschulabsolventen. Ähnliche Ergebnisse zeigen sich für die Altersgruppe der 25- bis 29-Jährigen mit Anteilen von 8 bzw. 5 Prozent. Dies mag darin begründet sein, dass die Absolventen des dualen Systems und die der Berufsfachschulen in unterschiedlichen Berufsfeldern tätig sind.

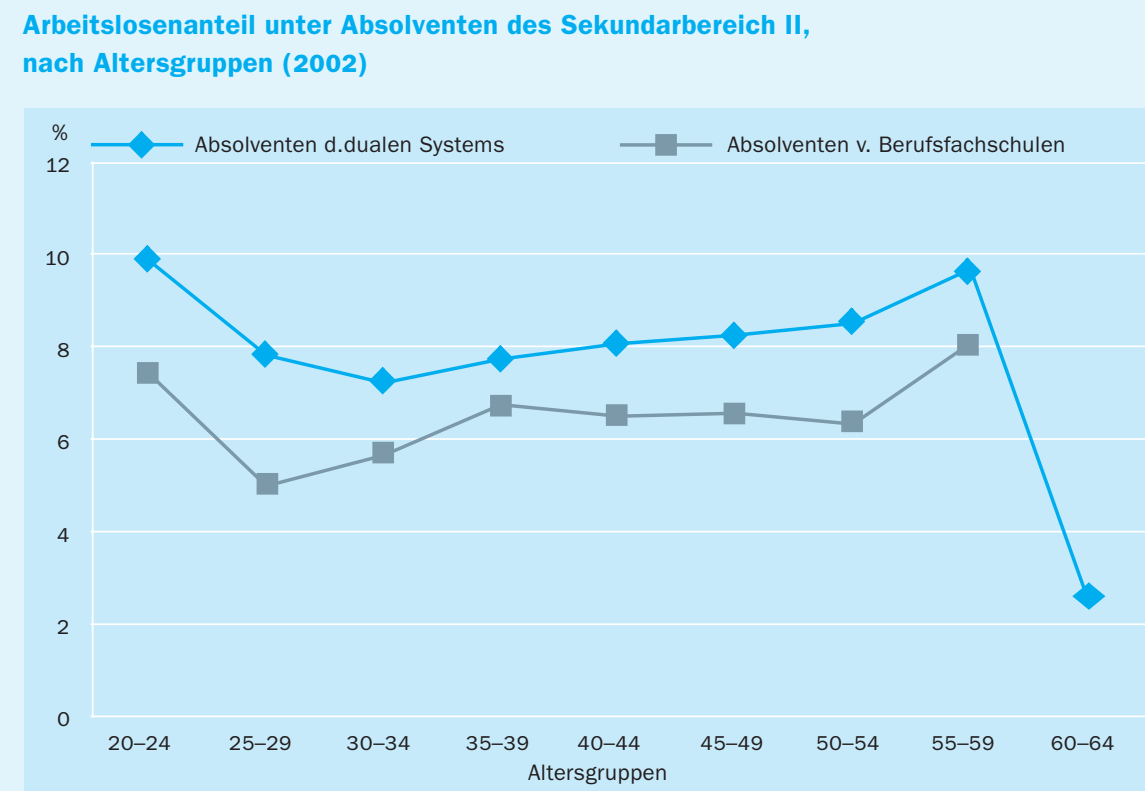


Mehr als die Hälfte der 20- bis 24-jährigen Absolventen einer Lehre (54 Prozent) sind in den zehn am häufigsten gewählten Berufsfeldern tätig (gemäß der nationalen Berufsklassifikation: Büroberufe/Kaufmännische Angestellte, Übrige Gesundheitsdienstberufe, Sicherheitsberufe, Verkaufspersonal, Groß- und Einzelhandelskaufleute/Ein- und Verkaufsfachleute, Elektroberufe, Fahr-, Flugzeugbau- und wartungsberufe, Soziale Berufe, Ausbauberufe, Maschinenbau- und -wartungsberufe). Eine Analyse der Arbeitslosenanteile zeigt beträchtliche Unterschiede zwischen den Berufen auf. Für Sicherheitsberufe und Büroberufe/kaufmännische Angestellte (jeweils 6 Prozent) bestehen anscheinend recht gute Beschäftigungsmöglichkeiten. In den Ausbauberufen ist dagegen eine recht hohe Anzahl von Jugendlichen (I8 Prozent) arbeitslos. Darüber hinaus ist der Anteil der Arbeitslosen in der Altersgruppe der 20- bis 24-Jährigen in den meisten dieser zehn Berufsfelder höher als der Anteil in der Altersgruppe der 25- bis 64-Jährigen in den gleichen Berufsfeldern. Eine eingehendere Untersuchung ist erforderlich, um festzustellen, ob den jungen Arbeitslosen der Übergang in das Arbeitsleben in Berufen gelingt, die ihrer Ausbildung entsprechen oder ob sie sich anderen Berufen zuwenden. Die hohe Zahl von Absolventen einer Lehre, die als Kraftfahrzeugführer oder Bote beschäftigt sind, könnte Letzteres nahe legen.

Eine entsprechende Analyse von Berufsfachschulabsolventen nach Berufen ist nicht möglich, da deren erheblich geringere Gesamtzahl zu unzureichend zuverlässigen Stichprobengrößen führen würde.

Eine Betrachtung der Vorteile eines Abschlusses im Tertiärbereich im Vergleich zu einem Abschluss im Sekundarbereich II bestätigt im Allgemeinen den erwarteten Trend, in einigen Ländern gibt es jedoch bedeutende Abweichungen. In sieben OECD-Ländern (Dänemark, Korea, Luxemburg, Neuseeland, den Niederlanden, der Schweiz und der Türkei) übertraf 2002 die Arbeitslosenanteil unter den Erwachsenen mit einem Abschluss im Tertiärbereich den unter den Absolventen des Sekundarbereich II. Dies ist ein Phänomen der jüngsten Zeit.

Betrachtet man alle OECD-Länder seit 1995 so hat sich im Durchschnitt der Vorteil einer Ausbildung im Tertiärbereich in Form niedrigerer Arbeitslosenanteile leicht verringert. 2002 waren die Arbeitslosenanteile unter Absolventen des Tertiärbereichs im Durchschnitt I,4 Prozentpunkte niedriger als die unter denjenigen mit einem Abschluss im Sekundarbereich II, I995 betrug die Differenz I,9 Prozentpunkte. Am offensichtlichsten war diese Entwicklung in Dänemark, Portugal, der Schweiz und der Türkei. Andererseits gibt es aber auch Beispiele für die gegenläufige Entwicklung, mit größeren Arbeitsmarktchancen für Absolventen des Tertiärbereichs, z. B. in Österreich und Deutschland (Tab. Aro.2b).

Ein höherer Bildungsstand garantiert nicht immer einen niedrigeren Arbeitslosenanteil. 


\section{Definitionen und angewandte Methodik}

10 Die Daten stammen aus nationalen Arbeitskräfteerhebungen.
Der Arbeitslosenanteil ist die Zahl der Arbeitslosen als Prozentsatz der betreffenden Bevölkerung.

Der Erwerbstätigenanteil ist die Zahl beschäftigter Personen als Prozentsatz der betreffenden Bevölkerung.

Die Quote derjenigen, die sich nicht im Arbeitsmarkt befinden, ist die Zahl derjenigen, die sich nicht im Arbeitsmarkt befinden, als Prozentsatz der betreffenden Bevölkerung.

Arbeitslose werden definiert als Personen, die keinen Arbeitsplatz haben, aktiv einen Arbeitsplatz suchen und dem Arbeitsmarkt zur Verfügung stehen. Erwerbstätige werden definiert als diejenigen, die während der untersuchten Bezugswoche: I. mindestens eine Stunde für ein Gehalt (Arbeitnehmer) oder für einen Gewinn (Selbständige und unentgeltlich mithelfende Familienangehörige) arbeiten oder 2. einen Arbeitsplatz haben, aber vorübergehend nicht zur Arbeit gehen (aufgrund von Verletzung, Krankheit, Urlaub, Streik oder Aussperrung, Bildungs- oder Schulungsurlaub, Mutterschafts- oder Erziehungsurlaub, usw.) und eine formelle Bindung an ihren Arbeitsplatz haben. Diejenigen, die nicht im Arbeitsmarkt sind, sind weder beschäftigt, noch arbeitslos.

Für die Tabellen Aıo.I(a, b, c) und Aro.2(a, b, c) wurde die Bevölkerung nach Bildungsstand den folgenden drei Gruppen zugeordnet: beschäftigt, arbeitslos, nicht im Arbeitsmarkt.

Die Angabe des Bildungsstandes richtet sich nach den Definitionen laut ISCED-97. 
Erwerbstätigenanteile und Bildungsstand (2002)

25- bis 64-Jährige in Beschäftigung als Prozentsatz der Bevölkerung im Alter von 25 bis 64 Jahren, nach Bildungsstand und Geschlecht

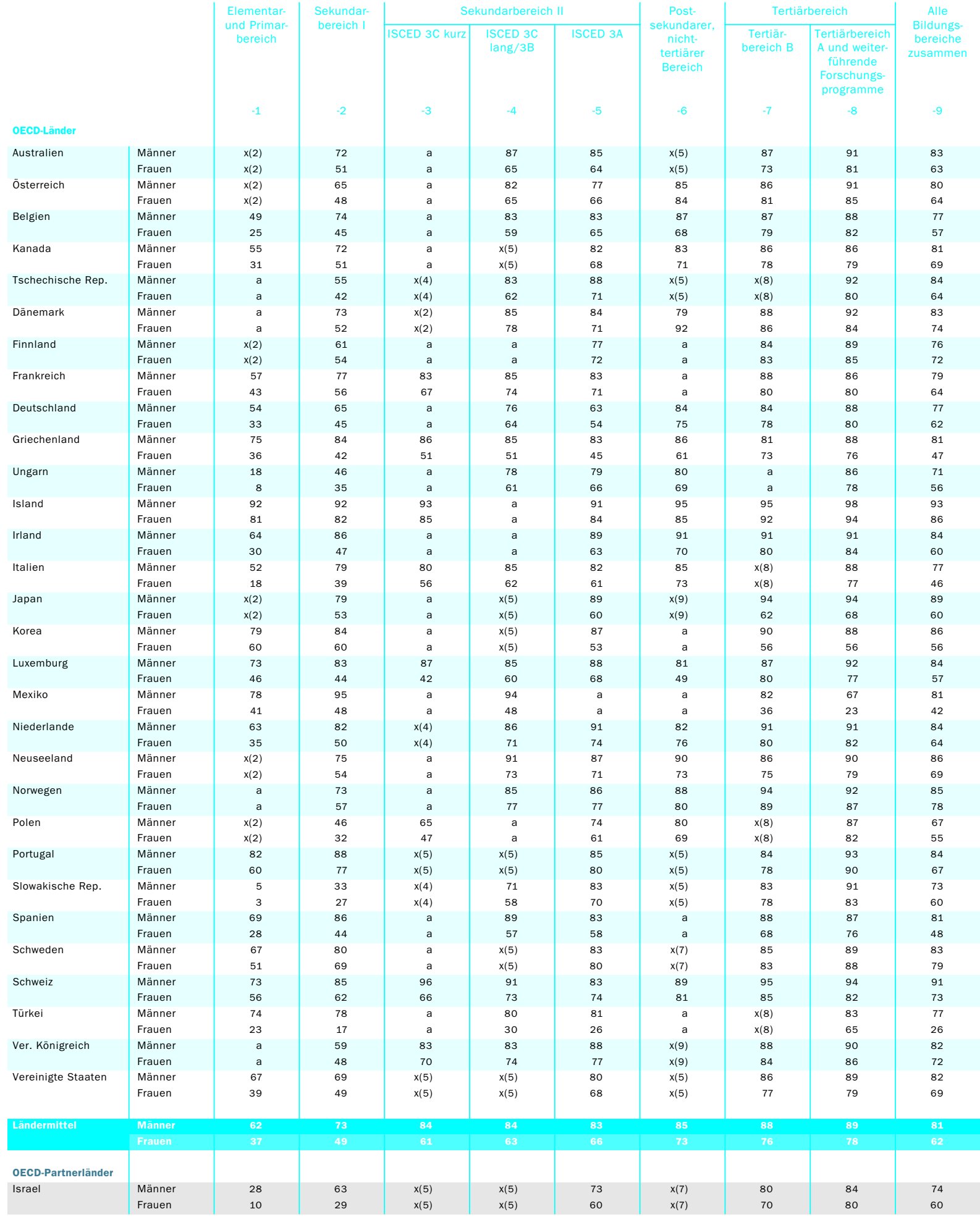

Hinweis: $x$ bedeutet, dass die Daten in einer anderen Spalte enthalten sind, deren Referenz in runden Klammern nach dem , $x^{\star}$ angegeben ist. So bedeutet $z$. B. $x(2)$, dass die Daten in Spalte 2 enthalten sind.

Quelle: OECD. Zur Beschreibung der Bildungsbereiche laut ISCED-97, der entsprechenden Zuordnung der landesspezifischen Bildungsgänge sowie der landesspezifischen Datenquellen s. Anhang 3 unter www.oecd.org/edu/eag2004. 
Arbeitslosenanteile und Bildungsstand (2002)

25- bis 64-jährige Arbeitslose als Prozentsatz der Bevölkerung im Alter von 25 bis 64 Jahren, nach Bildungsstand und Geschlecht

\begin{tabular}{|c|c|c|c|c|c|c|c|c|c|c|}
\hline & & Elementar- & Sekundar- & & rundarbereic & & & Tertiä & pereich & Alle Bildungs- \\
\hline & & $\begin{array}{l}\text { und Primar- } \\
\text { bereich }\end{array}$ & bereich I & $\begin{array}{c}\text { ISCED 3C } \\
\text { kurz }\end{array}$ & $\begin{array}{l}\text { ISCED 3C } \\
\text { lang/3B }\end{array}$ & ISCED $3 \mathrm{~A}$ & $\begin{array}{c}\text { sekundarer, } \\
\text { nicht-tertiärer } \\
\text { Bereich }\end{array}$ & $\begin{array}{l}\text { Tertiär- } \\
\text { bereich B }\end{array}$ & $\begin{array}{l}\text { Tertiärbereich } \\
\text { A und weiter- } \\
\text { führende } \\
\text { Forschungs- } \\
\text { programme }\end{array}$ & $\begin{array}{c}\text { bereiche } \\
\text { zusammen }\end{array}$ \\
\hline & & -1 & -2 & -3 & -4 & -5 & -6 & -7 & -8 & -9 \\
\hline OECD-Länder & & & & & & & & & & \\
\hline Australien & Männer & $x(2)$ & 6,8 & a & 2,9 & 4,3 & $x(5)$ & 4,1 & 2,6 & 4,5 \\
\hline & Frauen & $x(2)$ & 3,4 & a & 3,6 & 3,2 & $x(5)$ & 3,7 & 2,0 & 3,1 \\
\hline Österreich & Männer & $x(2)$ & 5,9 & a & 3,2 & 1,5 & 2,6 & 1,0 & 2,2 & 3,2 \\
\hline & Frauen & $x(2)$ & 2,9 & a & 2,5 & 2,7 & 1,5 & 1,0 & 2,4 & 2,5 \\
\hline Belgien & Männer & 6,7 & 5,3 & a & 6,5 & 3,6 & 5,9 & 2,6 & 3,1 & 4,5 \\
\hline & Frauen & 4,5 & 6,0 & a & 6,4 & 4,8 & 4,6 & 2,8 & 3,9 & 4,6 \\
\hline Kanada & Männer & 7,8 & 8,6 & a & $x(5)$ & 5,8 & 5,9 & 5,4 & 4,5 & 5,9 \\
\hline & Frauen & 4,5 & 5,7 & a & $x(5)$ & 5,0 & 5,1 & 3,9 & 3,9 & 4,6 \\
\hline Tschechische Rep. & Männer & a & 14,8 & $x(4)$ & 4,4 & 2,2 & $x(5)$ & $x(8)$ & 1,6 & 4,2 \\
\hline & Frauen & a & 8,6 & $x(4)$ & 7,2 & 3,9 & $x(5)$ & $x(8)$ & 1,6 & 5,6 \\
\hline Dänemark & Männer & a & 3,5 & $x(2)$ & 2,9 & 1,4 & 7,2 & 3,5 & 3,2 & 3,1 \\
\hline & Frauen & a & 4,6 & $x(2)$ & 2,7 & 2,9 & 4,7 & 2,5 & 4,8 & 3,2 \\
\hline Finnland & Männer & $x(2)$ & 8,0 & a & a & 7,4 & a & 4,8 & 3,1 & 6,5 \\
\hline & Frauen & $x(2)$ & 8,1 & a & a & 7,0 & a & 4,8 & 3,1 & 6,2 \\
\hline Frankreich & Männer & 6,0 & 9,8 & 4,4 & 3,8 & 6,0 & a & 5,0 & 4,8 & 5,8 \\
\hline & Frauen & 5,4 & 9,4 & 7,0 & 6,7 & 6,0 & a & 3,9 & 4,8 & 6,4 \\
\hline Deutschland & Männer & 17,7 & 12,8 & a & 8,1 & 5,4 & 5,2 & 3,9 & 3,6 & 7,4 \\
\hline & Frauen & 7,7 & 6,4 & a & 6,5 & 3,7 & 3,9 & 4,7 & 3,8 & 5,9 \\
\hline Griechenland & Männer & 3,4 & 5,6 & 5,4 & 7,2 & 4,4 & 5,9 & 4,6 & 3,6 & 4,3 \\
\hline & Frauen & 3,9 & 8,8 & 9,7 & 16,1 & 7,8 & 12,6 & 8,4 & 7,0 & 6,6 \\
\hline Ungarn & Männer & 7,1 & 6,2 & a & 4,4 & 2,7 & 1,9 & a & 1,0 & 4,0 \\
\hline & Frauen & 2,5 & 3,1 & a & 3,7 & 2,3 & 4,7 & a & 1,5 & 2,7 \\
\hline Island & Männer & a & 3,0 & 1,8 & a & 2,7 & 1,8 & 2,8 & 1,2 & 2,3 \\
\hline & Frauen & a & 2,7 & 3,3 & a & 2,5 & 1,5 & 1,0 & 1,7 & 2,3 \\
\hline Irland & Männer & 5,6 & 4,0 & a & a & 2,8 & 1,7 & 2,3 & 1,9 & 3,3 \\
\hline & Frauen & 1,7 & 2,5 & a & a & 2,0 & 2,3 & 1,4 & 1,1 & 1,9 \\
\hline Italien & Männer & 4,8 & 5,2 & 3,6 & 3,0 & 4,1 & 6,6 & $x(8)$ & 3,3 & 4,5 \\
\hline & Frauen & 3,2 & 6,1 & 9,3 & 5,5 & 5,6 & 10,5 & $x(8)$ & 5,9 & 5,4 \\
\hline Japan & Männer & $x(2)$ & 6,8 & a & $x(5)$ & 5,1 & $x(9)$ & 4,3 & 3,1 & 4,8 \\
\hline & Frauen & $x(2)$ & 2,6 & a & $x(5)$ & 3,2 & $x(9)$ & 3,1 & 2,7 & 3,0 \\
\hline Korea & Männer & 2,2 & 2,7 & a & $x(5)$ & 2,8 & a & 4,2 & 2,6 & 2,8 \\
\hline & Frauen & 0,7 & 1,0 & a & $x(5)$ & 1,1 & a & 1,9 & 1,1 & 1,1 \\
\hline Luxemburg & Männer & 2,5 & 1,1 & $n$ & 0,7 & 1,0 & 1,6 & 3,6 & 0,8 & 1,4 \\
\hline & Frauen & 2,3 & 3,4 & 1,1 & 1,5 & 0,4 & $n$ & $n$ & 2,3 & 1,8 \\
\hline Mexiko & Männer & 2,5 & 1,5 & a & 1,7 & a & a & 2,1 & 1,1 & 2,2 \\
\hline & Frauen & 1,5 & 0,5 & a & 0,5 & a & a & 0,2 & 0,1 & 1,2 \\
\hline Niederlande & Männer & 2,8 & 2,4 & $x(4)$ & 1,4 & 1,6 & 1,7 & 1,1 & 1,9 & 1,9 \\
\hline & Frauen & 2,1 & 2,2 & $x(4)$ & 1,9 & 2,1 & 2,7 & 1,7 & 2,0 & 2,1 \\
\hline Neuseeland & Männer & $\mathrm{x}(2)$ & 4,7 & a & 2,1 & 3,2 & 3,0 & 3,3 & 3,0 & 3,2 \\
\hline & Frauen & $x(2)$ & 3,0 & a & 3,9 & 2,1 & 3,9 & 2,7 & 2,4 & 2,9 \\
\hline Norwegen & Männer & a & 2,4 & a & 2,8 & 3,0 & 1,4 & 1,5 & 2,2 & 2,5 \\
\hline & Frauen & a & 2,1 & a & 2,2 & 2,0 & 2,9 & 2,1 & 1,7 & 2,0 \\
\hline Polen & Männer & $x(2)$ & 17,1 & 16,4 & a & 10,2 & 9,6 & $x(8)$ & 5,1 & 13,5 \\
\hline & Frauen & $x(2)$ & 11,2 & 16,9 & a & 12,0 & 9,8 & $x(8)$ & 6,1 & 12,3 \\
\hline Portugal & Männer & 3,0 & 3,6 & $x(5)$ & $x(5)$ & 3,5 & $x(5)$ & 4,5 & 1,8 & 3,1 \\
\hline & Frauen & 3,4 & 5,0 & $x(5)$ & $x(5)$ & 4,0 & $x(5)$ & 2,8 & 4,8 & 3,8 \\
\hline Slowakische Rep. & Männer & 35,8 & 28,8 & $x(4)$ & 14,8 & 8,2 & $x(5)$ & 6,3 & 3,1 & 12,9 \\
\hline & Frauen & 19,8 & 16,0 & $x(4)$ & 14,4 & 8,5 & $x(5)$ & 5,3 & 3,1 & 11,2 \\
\hline Spanien & Männer & 6,5 & 6,5 & a & 5,2 & 5,0 & a & 4,7 & 4,7 & 5,8 \\
\hline & Frauen & 5,8 & 10,1 & a & 12,1 & 8,6 & a & 10,4 & 8,4 & 8,3 \\
\hline Schweden & Männer & 3,8 & 4,5 & a & $x(5)$ & 4,5 & $x(7)$ & 3,3 & 3,2 & 4,0 \\
\hline & Frauen & 4,4 & 3,9 & a & $x(5)$ & 3,3 & $x(7)$ & 2,4 & 2,1 & 3,1 \\
\hline Schweiz & Männer & 2,0 & 4,6 & c & 1,7 & 1,5 & 1,7 & 1,0 & 2,3 & 2,0 \\
\hline & Frauen & 4,8 & 2,7 & 1,3 & 2,1 & 2,1 & 2,1 & 0,9 & 2,9 & 2,3 \\
\hline Türkei & Männer & 7,9 & 7,4 & a & 6,3 & 6,1 & a & $x(8)$ & 5,7 & 7,3 \\
\hline & Frauen & 1,3 & 3,1 & a & 5,2 & 5,2 & a & $x(8)$ & 6,5 & 2,3 \\
\hline Ver. Königreich & Männer & a & 6,8 & 4,5 & 3,5 & 3,1 & $x(9)$ & 2,6 & 2,5 & 3,8 \\
\hline & Frauen & a & 3,2 & 3,4 & 2,9 & 2,4 & $x(9)$ & 1,5 & 1,8 & 2,7 \\
\hline Vereinigte Staaten & Männer & 6,9 & 7,9 & $x(5)$ & $x(5)$ & 5,3 & $x(5)$ & 3,8 & 2,8 & 4,7 \\
\hline & Frauen & 5,1 & 5,5 & $x(5)$ & $x(5)$ & 3,7 & $x(5)$ & 2,5 & 2,1 & 3,3 \\
\hline Laandermittel & Männer & 7,1 & 6,9 & 6,0 & 4,3 & 4,1 & 4,0 & 3,5 & 2,9 & 4,6 \\
\hline & Frauen & 4,5 & 5,1 & 6,5 & 5,4 & 4,1 & 4,9 & 3,2 & 3,3 & 4,1 \\
\hline OECD-Partnerländer & & & & & & & & & & \\
\hline Israel & Männer & 6,1 & 10,2 & $x(5)$ & $x(5)$ & 6,9 & $x(7)$ & 6,4 & 5,2 & 7,0 \\
\hline & Frauen & 2,0 & 4,7 & $x(5)$ & $x(5)$ & 7,7 & $x(7)$ & 5,4 & 5,1 & 5,9 \\
\hline
\end{tabular}

Hinweis: $x$ bedeutet, dass die Daten in einer anderen Spalte enthalten sind, deren Referenz in runden Klammern nach dem , $x$ ' angegeben ist. So bedeutet $z$. B. $x(2)$, dass die Daten in Spalte 2 enthalten sind. c deutet darauf hin, dass zu wenige Daten zur Verfügung stehen, um verlässliche Schätzungen vorzunehmen.

Quelle: OECD. Zur Beschreibung der Bildungsbereiche laut ISCED-97, der entsprechenden Zuordnung der landesspezifischen Bildungsgänge sowie der landesspezifischen Datenquellen s. Anhang 3 unter www.oecd.org/edu/eag2004. 
Anteil der Bevölkerung, die sich nicht im Arbeitsmarkt befindet und Bildungsstand (2002)

25- bis 64-Jährige, die sich nicht im Arbeitsmarkt befinden, als Prozentsatz der Bevölkerung im Alter von 24 bis 64 Jahren, nach Bildungsstand und Geschlecht

\begin{tabular}{|c|c|c|c|c|c|c|c|c|c|c|}
\hline & & Elementar- & Sekundar- & & undarbereic & & & Tertiärb & pereich & \\
\hline & & $\begin{array}{l}\text { und Primar- } \\
\text { bereich }\end{array}$ & bereich I & ISCED 3C kurz & $\begin{array}{l}\text { ISCED 3C } \\
\text { lang/3B }\end{array}$ & ISCED 3A & \begin{tabular}{|c|} 
sekundarer, \\
nicht-tertiärer \\
Bereich
\end{tabular} & $\begin{array}{c}\text { Tertiärbereich } \\
\mathrm{B}\end{array}$ & $\begin{array}{l}\text { Tertiärbereich } \\
\text { A und weiter- } \\
\text { führende } \\
\text { Forschungs- } \\
\text { programme }\end{array}$ & $\begin{array}{l}\text { Bildungs- } \\
\text { bereiche } \\
\text { zusammen }\end{array}$ \\
\hline OECD-Länder & & -1 & -2 & -3 & -4 & -5 & -6 & -7 & -8 & -9 \\
\hline Australien & Männer & $x(2)$ & 21 & a & 10 & 11 & $x(5)$ & 8 & 7 & 13 \\
\hline & Frauen & $\mathrm{x}(2)$ & 45 & a & 32 & 33 & $x(5)$ & 23 & 17 & 34 \\
\hline Österreich & Männer & $x(2)$ & 29 & a & 15 & 21 & 13 & 13 & 7 & 17 \\
\hline & Frauen & $\mathrm{x}(2)$ & 49 & a & 32 & 31 & 15 & 18 & 13 & 33 \\
\hline Belgien & Männer & 44 & 21 & a & 11 & 13 & 7 & 11 & 9 & 19 \\
\hline & Frauen & 71 & 49 & a & 34 & 30 & 27 & 18 & 15 & 38 \\
\hline Kanada & Männer & 38 & 20 & a & $x(5)$ & 12 & 11 & 8 & 10 & 13 \\
\hline & Frauen & 64 & 44 & a & $x(5)$ & 27 & 24 & 18 & 17 & 26 \\
\hline Tschechische Rep. & Männer & a & 30 & $x(4)$ & 12 & 10 & $x(5)$ & $x(8)$ & 6 & 12 \\
\hline & Frauen & a & 49 & $\mathrm{x}(4)$ & 31 & 25 & $x(5)$ & $x(8)$ & 19 & 30 \\
\hline Dänemark & Männer & a & 24 & $\mathrm{x}(2)$ & 12 & 15 & 14 & 9 & 5 & 14 \\
\hline & Frauen & a & 44 & $\mathrm{x}(2)$ & 19 & 26 & 3 & 12 & 12 & 22 \\
\hline Finnland & Männer & $\mathrm{x}(2)$ & 31 & a & a & 16 & a & 11 & 8 & 18 \\
\hline & Frauen & $\mathrm{x}(2)$ & 38 & a & a & 22 & a & 13 & 12 & 22 \\
\hline Frankreich & Männer & 37 & 13 & 12 & 11 & 11 & a & 7 & 9 & 15 \\
\hline & Frauen & 52 & 35 & 26 & 19 & 23 & a & 16 & 16 & 29 \\
\hline Deutschland & Männer & 29 & 23 & a & 16 & 32 & 11 & 12 & 8 & 16 \\
\hline & Frauen & 59 & 49 & a & 29 & 42 & 21 & 18 & 17 & 32 \\
\hline Griechenland & Männer & 22 & 10 & 9 & 8 & 13 & 9 & 14 & 8 & 15 \\
\hline & Frauen & 60 & 49 & 40 & 33 & 47 & 26 & 19 & 17 & 46 \\
\hline Ungarn & Männer & 75 & 48 & a & 17 & 18 & 18 & a & 13 & 25 \\
\hline & Frauen & 89 & 62 & a & 35 & 32 & 27 & a & 20 & 42 \\
\hline Island & Männer & 8 & 5 & 5 & a & 6 & 3 & 2 & 1 & 4 \\
\hline & Frauen & 19 & 16 & 12 & a & 14 & 13 & 7 & 4 & 12 \\
\hline Irland & Männer & 30 & 10 & a & a & 8 & 7 & 7 & 7 & 13 \\
\hline & Frauen & 68 & 50 & a & a & 35 & 27 & 19 & 15 & 39 \\
\hline Italien & Männer & 43 & 16 & 16 & 12 & 14 & 9 & $x(8)$ & 9 & 19 \\
\hline & Frauen & 79 & 55 & 35 & 32 & 33 & 16 & $x(8)$ & 17 & 49 \\
\hline Japan & Männer & $\mathrm{x}(2)$ & 14 & $a$ & $\times(5)$ & 6 & $x(9)$ & 2 & 3 & 6 \\
\hline & Frauen & $\mathrm{x}(2)$ & 44 & a & $\times(5)$ & 37 & $\times(9)$ & 35 & 30 & 37 \\
\hline Korea & Männer & 19 & 14 & a & $\times(5)$ & 10 & a & 5 & 9 & 11 \\
\hline & Frauen & 39 & 39 & a & $x(5)$ & 46 & a & 42 & 43 & 43 \\
\hline Luxemburg & Männer & 25 & 15 & 13 & 15 & 11 & 17 & 9 & 8 & 15 \\
\hline & Frauen & 52 & 53 & 57 & 38 & 31 & 51 & 20 & 21 & 42 \\
\hline Mexiko & Männer & 20 & 4 & a & 4 & a & a & 16 & 32 & 16 \\
\hline & Frauen & 58 & 52 & a & 52 & a & a & 64 & 77 & 57 \\
\hline Niederlande & Männer & 34 & 16 & $x(4)$ & 13 & 8 & 16 & 8 & 7 & 14 \\
\hline & Frauen & 63 & 47 & $\mathrm{x}(4)$ & 27 & 24 & 22 & 19 & 16 & 34 \\
\hline Neuseeland & Männer & $\mathrm{x}(2)$ & 20 & a & 7 & 10 & 7 & 11 & 7 & 11 \\
\hline & Frauen & $\mathrm{x}(2)$ & 43 & a & 23 & 27 & 23 & 23 & 18 & 28 \\
\hline Norwegen & Männer & a & 25 & a & 12 & 11 & 11 & 5 & 6 & 12 \\
\hline & Frauen & a & 41 & a & 21 & 21 & 17 & 9 & 11 & 20 \\
\hline Polen & Männer & $\mathrm{x}(2)$ & 37 & 19 & a & 15 & 10 & $\mathrm{x}(8)$ & 8 & 20 \\
\hline & Frauen & $\mathrm{x}(2)$ & 57 & 36 & a & 27 & 21 & $x(8)$ & 12 & 33 \\
\hline Portugal & Männer & 15 & 9 & $x(5)$ & $x(5)$ & 12 & $\times(5)$ & 11 & 5 & 13 \\
\hline & Frauen & 36 & 18 & $x(5)$ & $\times(5)$ & 16 & $x(5)$ & 19 & 5 & 29 \\
\hline Slowakische Rep. & Männer & 59 & 38 & $x(4)$ & 14 & 9 & $x(5)$ & 11 & 6 & 14 \\
\hline & Frauen & 77 & 57 & $x(4)$ & 28 & 22 & $x(5)$ & 17 & 14 & 29 \\
\hline Spanien & Männer & 24 & 8 & a & 6 & 12 & a & 7 & 9 & 13 \\
\hline & Frauen & 66 & 46 & a & 30 & 34 & a & 21 & 15 & 44 \\
\hline Schweden & Männer & 29 & 16 & a & $x(5)$ & 12 & $x(7)$ & 11 & 8 & 13 \\
\hline & Frauen & 45 & 27 & a & $\times(5)$ & 17 & $x(7)$ & 15 & 10 & 18 \\
\hline Schweiz & Männer & 25 & 10 & 4 & 8 & 16 & 9 & 4 & 4 & 7 \\
\hline & Frauen & 39 & 36 & 33 & 25 & 24 & 17 & 14 & 15 & 25 \\
\hline Türkei & Männer & 18 & 15 & a & 13 & 13 & a & $x(8)$ & 12 & 16 \\
\hline & Frauen & 75 & 80 & a & 65 & 69 & a & $x(8)$ & 29 & 71 \\
\hline Ver. Königreich & Männer & a & 34 & 12 & 13 & 9 & $x(9)$ & 9 & 7 & 14 \\
\hline & Frauen & a & 49 & 26 & 23 & 20 & $x(9)$ & 14 & 12 & 25 \\
\hline Vereinigte Staaten & Männer & 27 & 23 & $x(5)$ & $x(5)$ & 15 & $x(5)$ & 10 & 8 & 14 \\
\hline & Frauen & 56 & 46 & $x(5)$ & $x(5)$ & 28 & $x(5)$ & 21 & 19 & 27 \\
\hline Ländermittel & Männer & 31 & 20 & 11 & 11 & 13 & 11 & 9 & 8 & 14 \\
\hline & Frauen & 58 & 46 & 33 & 31 & 30 & 22 & 21 & 19 & 34 \\
\hline OECD-Partnerländer & & & & & & & & & & \\
\hline Israel & Männer & 66 & 27 & $x(5)$ & $x(5)$ & 20 & $x(7)$ & 13 & 11 & 19 \\
\hline & Frauen & 88 & 66 & $x(5)$ & $x(5)$ & 33 & $x(7)$ & 24 & 15 & 34 \\
\hline
\end{tabular}

Hinweis: $x$ bedeutet, dass die Daten in einer anderen Spalte enthalten sind, deren Referenz in runden Klammern nach dem , $x^{\prime}$ angegeben ist. So bedeutet $z$. B. $x(2)$, dass die Daten in Spalte 2 enthalten sind.

Quelle: OECD. Zur Beschreibung der Bildungsbereiche laut ISCED-97, der entsprechenden Zuordnung der landesspezifischen Bildungsgänge sowie der landesspezifischen Datenquellen s. Anhang 3 unter www.oecd.org/edu/eag2004. 
Tabelle A10.2a

Entwicklungen der Erwerbstätigenanteile nach Bildungsstand (1991-2002)

25- bis 64-Jährige, die sich in Beschäftigung befinden, als Prozentsatz der Bevölkerung im Alter von 25 bis 64 Jahren, nach Bildungsstand

\begin{tabular}{|c|c|c|c|c|}
\hline OECD-Länder & & 1991 & 1995 & 1998 \\
\hline Australien & Abschluss unterhalb Sekundarbereich II & 54 & 60 & 59 \\
\hline & Sekundarbereich II und post-sekundarer, nicht-tertiärer Bereich & 71 & 75 & 76 \\
\hline & Tertiärbereich & 81 & 83 & 84 \\
\hline Österreich & Abschluss unterhalb Sekundarbereich II & 52 & 56 & 53 \\
\hline & Sekundarbereich II und post-sekundarer, nicht-tertiärer Bereich & 73 & 77 & 75 \\
\hline & Tertiärbereich & 88 & 88 & 86 \\
\hline Belgien & Abschluss unterhalb Sekundarbereich II & 49 & 47 & 47 \\
\hline & Sekundarbereich II und post-sekundarer, nicht-tertiärer Bereich & 75 & 72 & 72 \\
\hline & Tertiärbereich & 85 & 84 & 84 \\
\hline Kanada & Abschluss unterhalb Sekundarbereich II & 55 & 53 & 54 \\
\hline & Sekundarbereich II und post-sekundarer, nicht-tertiärer Bereich & 75 & 74 & 74 \\
\hline & Tertiärbereich & 82 & 81 & 82 \\
\hline Tschechische & Abschluss unterhalb Sekundarbereich II & $\mathrm{m}$ & 56 & 50 \\
\hline Republik & Sekundarbereich II und post-sekundarer, nicht-tertiärer Bereich & $\mathrm{m}$ & 82 & 78 \\
\hline & Tertiärbereich & $\mathrm{m}$ & 92 & 89 \\
\hline Dänemark & Abschluss unterhalb Sekundarbereich II & 62 & 61 & 61 \\
\hline & Sekundarbereich II und post-sekundarer, nicht-tertiärer Bereich & 81 & 76 & 79 \\
\hline & Tertiärbereich & 89 & 89 & 87 \\
\hline Finnland & Abschluss unterhalb Sekundarbereich II & 64 & 54 & 56 \\
\hline & Sekundarbereich II und post-sekundarer, nicht-tertiärer Bereich & 78 & 70 & 73 \\
\hline & Tertiärbereich & 88 & 81 & 83 \\
\hline Frankreich & Abschluss unterhalb Sekundarbereich II & 58 & 57 & 56 \\
\hline & Sekundarbereich II und post-sekundarer, nicht-tertiärer Bereich & 78 & 76 & 75 \\
\hline & Tertiärbereich & 85 & 82 & 82 \\
\hline Deutschland & Abschluss unterhalb Sekundarbereich II & 51 & 49 & 48 \\
\hline & Sekundarbereich II und post-sekundarer, nicht-tertiärer Bereich & 74 & 71 & 69 \\
\hline & Tertiärbereich & 86 & 84 & 83 \\
\hline Griechenland & Abschluss unterhalb Sekundarbereich II & $\mathrm{m}$ & 56 & 56 \\
\hline 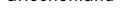 & Sekundarbereich II und post-sekundarer, nicht-tertiärer Bereich & $\mathrm{m}$ & 62 & 65 \\
\hline & Tertiärbereich & $\mathrm{m}$ & 79 & 80 \\
\hline Ungarn & Abschluss unterhalb Sekundarbereich II & $\mathrm{m}$ & $\mathrm{m}$ & 36 \\
\hline & Sekundarbereich II und post-sekundarer, nicht-tertiärer Bereich & $\mathrm{m}$ & $\mathrm{m}$ & 71 \\
\hline & Tertiärbereich & $\mathrm{m}$ & $\mathrm{m}$ & 81 \\
\hline Island & Abschluss unterhalb Sekundarbereich II & $\mathrm{m}$ & $\mathrm{m}$ & 85 \\
\hline & Sekundarbereich II und post-sekundarer, nicht-tertiärer Bereich & $\mathrm{m}$ & $\mathrm{m}$ & 89 \\
\hline & Tertiärbereich & $\mathrm{m}$ & $\mathrm{m}$ & 95 \\
\hline Irland & Abschluss unterhalb Sekundarbereich II & 46 & 49 & 53 \\
\hline & Sekundarbereich II und post-sekundarer, nicht-tertiärer Bereich & 63 & 67 & 72 \\
\hline & Tertiärbereich & 81 & 83 & 85 \\
\hline Italien & Abschluss unterhalb Sekundarbereich II & 54 & 49 & 47 \\
\hline & Sekundarbereich II und post-sekundarer, nicht-tertiärer Bereich & 74 & 70 & 70 \\
\hline & Tertiärbereich & 87 & 81 & 81 \\
\hline Japan & Abschluss unterhalb Sekundarbereich II & $\mathrm{m}$ & $\mathrm{m}$ & 69 \\
\hline & Sekundarbereich II und post-sekundarer, nicht-tertiärer Bereich & $\mathrm{m}$ & $\mathrm{m}$ & 76 \\
\hline & Tertiärbereich & $\mathrm{m}$ & $\mathrm{m}$ & 80 \\
\hline Korea & Abschluss unterhalb Sekundarbereich II & 70 & 71 & 66 \\
\hline & Sekundarbereich II und post-sekundarer, nicht-tertiärer Bereich & 70 & 71 & 66 \\
\hline & Tertiärbereich & 80 & 80 & 76 \\
\hline Luxemburg & Abschluss unterhalb Sekundarbereich II & $\mathrm{m}$ & $\mathrm{m}$ & $\mathrm{m}$ \\
\hline & Sekundarbereich II und post-sekundarer, nicht-tertiärer Bereich & $\mathrm{m}$ & $\mathrm{m}$ & $\mathrm{m}$ \\
\hline & Tertiärbereich & $\mathrm{m}$ & $\mathrm{m}$ & $\mathrm{m}$ \\
\hline Mexiko & Abschluss unterhalb Sekundarbereich II & $\mathrm{m}$ & 59 & 62 \\
\hline & Sekundarbereich II und post-sekundarer, nicht-tertiärer Bereich & $\mathrm{m}$ & 68 & 72 \\
\hline & Tertiärbereich & $\mathrm{m}$ & 49 & 53 \\
\hline Niederlande & Abschluss unterhalb Sekundarbereich II & 50 & 52 & 55 \\
\hline & Sekundarbereich II und post-sekundarer, nicht-tertiärer Bereich & 73 & 74 & 77 \\
\hline & Tertiärbereich & 85 & 83 & 85 \\
\hline Neuseeland & Abschluss unterhalb Sekundarbereich II & 57 & 58 & 59 \\
\hline & Sekundarbereich II und post-sekundarer, nicht-tertiärer Bereich & 73 & 80 & 79 \\
\hline & Tertiärbereich & 80 & 82 & 80 \\
\hline Norwegen & Abschluss unterhalb Sekundarbereich II & 62 & 61 & 68 \\
\hline & Sekundarbereich II und post-sekundarer, nicht-tertiärer Bereich & 80 & 80 & 84 \\
\hline & Tertiärbereich & 90 & 89 & 90 \\
\hline Polen & Abschluss unterhalb Sekundarbereich II & $\mathrm{m}$ & 50 & 49 \\
\hline & Sekundarbereich II und post-sekundarer, nicht-tertiärer Bereich & $\mathrm{m}$ & 70 & 71 \\
\hline & Tertiärbereich & $\mathrm{m}$ & 85 & 87 \\
\hline Portugal & Abschluss unterhalb Sekundarbereich II & 62 & 67 & 72 \\
\hline & Sekundarbereich II und post-sekundarer, nicht-tertiärer Bereich & 84 & 77 & 80 \\
\hline & Tertiärbereich & 92 & 89 & 89 \\
\hline Slowakische & Abschluss unterhalb Sekundarbereich II & $\mathrm{m}$ & 39 & 37 \\
\hline Republik & Sekundarbereich II und post-sekundarer, nicht-tertiärer Bereich & $\mathrm{m}$ & 75 & 75 \\
\hline & Tertiärbereich & $\mathrm{m}$ & 88 & 89 \\
\hline Spanien & Abschluss unterhalb Sekundarbereich II & 49 & 46 & 49 \\
\hline & Sekundarbereich II und post-sekundarer, nicht-tertiärer Bereich & 72 & 65 & 67 \\
\hline & Tertiärbereich & 79 & 75 & 76 \\
\hline Schweden & Abschluss unterhalb Sekundarbereich II & 83 & 78 & 66 \\
\hline & Sekundarbereich II und post-sekundarer, nicht-tertiärer Bereich & 91 & 84 & 79 \\
\hline & Tertiärbereich & 94 & 89 & 85 \\
\hline Schweiz & Abschluss unterhalb Sekundarbereich II & 78 & 67 & 69 \\
\hline & Sekundarbereich II und post-sekundarer, nicht-tertiärer Bereich & 80 & 80 & 81 \\
\hline & Tertiärbereich & 92 & 90 & 90 \\
\hline Türkei & Abschluss unterhalb Sekundarbereich II & 60 & 64 & 57 \\
\hline & Sekundarbereich II und post-sekundarer, nicht-tertiärer Bereich & 67 & 63 & 66 \\
\hline & Tertiärbereich & 87 & 74 & 81 \\
\hline Vereinigtes & Abschluss unterhalb Sekundarbereich II & 61 & 55 & 53 \\
\hline Königreich & Sekundarbereich II und post-sekundarer, nicht-tertiärer Bereich & 78 & 77 & 79 \\
\hline & Tertiärbereich & 86 & 86 & 87 \\
\hline Vereinigte & Abschluss unterhalb Sekundarbereich II & 52 & 54 & 58 \\
\hline Staaten & Sekundarbereich II und post-sekundarer, nicht-tertiärer Bereich & 74 & 75 & 76 \\
\hline & Tertiärbereich & 85 & 86 & 85 \\
\hline Ländermittel & Abschluss unterhalb Sekundarbereich II & 59 & 56 & 57 \\
\hline & Sekundarbereich II und post-sekundarer, nicht-tertiärer Bereich & 76 & 74 & 75 \\
\hline & Tertiärbereich & 86 & 83 & 83 \\
\hline
\end{tabular}

Quelle: OECD. Hinweise s. Anhang 3 unter www.oecd.org/edu/eag2004. 
Tabelle A10.2b

Entwicklungen der Arbeitslosenanteile nach Bildungsstand (1991-2002)

25- bis 64-jährige Arbeitslose als Prozentsatz der Bevölkerung im Alter von 25 bis 64 Jahren, nach Bildungsstand

\begin{tabular}{|c|c|}
\hline \multicolumn{2}{|l|}{ OECD-Länder } \\
\hline Australien & $\begin{array}{l}\text { Abschluss unterhalb Sekundarbereich II } \\
\text { Sekundarbereich II und post-sekundarer, nicht-tertiärer Bereich } \\
\text { Tertiärbereich }\end{array}$ \\
\hline Österreich & $\begin{array}{l}\text { Abschluss unterhalb Sekundarbereich II } \\
\text { Sekundarbereich II und post-sekundarer, nicht-tertiärer Bereich } \\
\text { Tertiärbereich }\end{array}$ \\
\hline Belgien & $\begin{array}{l}\text { Abschluss unterhalb Sekundarbereich II } \\
\text { Sekundarbereich II und post-sekundarer, nicht-tertiärer Bereich } \\
\text { Tertiärbereich }\end{array}$ \\
\hline Kanada & $\begin{array}{l}\text { Abschluss unterhalb Sekundarbereich II } \\
\text { Sekundarbereich II und post-sekundarer, nicht-tertiärer Bereich } \\
\text { Tertiärbereich }\end{array}$ \\
\hline Tschechische & Abschluss unterhalb Sekundarbereich II \\
\hline Republik & $\begin{array}{l}\text { Sekundarbereich II und post-sekundarer, nicht-tertiärer Bereich } \\
\text { Tertiärbereich }\end{array}$ \\
\hline Dänemark & $\begin{array}{l}\text { Abschluss unterhalb Sekundarbereich II } \\
\text { Sekundarbereich II und post-sekundarer, nicht-tertiärer Bereich } \\
\text { Tertiärbereich }\end{array}$ \\
\hline Finnland & $\begin{array}{l}\text { Abschluss unterhalb Sekundarbereich II } \\
\text { Sekundarbereich II und post-sekundarer, nicht-tertiärer Bereich } \\
\text { Tertiärbereich }\end{array}$ \\
\hline Frankreich & $\begin{array}{l}\text { Abschluss unterhalb Sekundarbereich II } \\
\text { Sekundarbereich II und post-sekundarer, nicht-tertiärer Bereich } \\
\text { Tertiärbereich }\end{array}$ \\
\hline Deutschland & $\begin{array}{l}\text { Abschluss unterhalb Sekundarbereich II } \\
\text { Sekundarbereich II und post-sekundarer, nicht-tertiärer Bereich } \\
\text { Tertiärbereich }\end{array}$ \\
\hline Griechenland & $\begin{array}{l}\text { Abschluss unterhalb Sekundarbereich II } \\
\text { Sekundarbereich II und post-sekundarer, nicht-tertiärer Bereich } \\
\text { Tertiärbereich }\end{array}$ \\
\hline Ungarn & $\begin{array}{l}\text { Abschluss unterhalb Sekundarbereich II } \\
\text { Sekundarbereich II und post-sekundarer, nicht-tertiärer Bereich } \\
\text { Tertiärbereich }\end{array}$ \\
\hline Island & $\begin{array}{l}\text { Abschluss unterhalb Sekundarbereich II } \\
\text { Sekundarbereich II und post-sekundarer, nicht-tertiärer Bereich } \\
\text { Tertiärbereich }\end{array}$ \\
\hline Irland & $\begin{array}{l}\text { Abschluss unterhalb Sekundarbereich II } \\
\text { Sekundarbereich II und post-sekundarer, nicht-tertiärer Bereich } \\
\text { Tertiärbereich }\end{array}$ \\
\hline Italien & $\begin{array}{l}\text { Abschluss unterhalb Sekundarbereich II } \\
\text { Sekundarbereich II und post-sekundarer, nicht-tertiärer Bereich } \\
\text { Tertiärbereich }\end{array}$ \\
\hline Japan & $\begin{array}{l}\text { Abschluss unterhalb Sekundarbereich II } \\
\text { Sekundarbereich II und post-sekundarer, nicht-tertiärer Bereich } \\
\text { Tertiärbereich }\end{array}$ \\
\hline Korea & $\begin{array}{l}\text { Abschluss unterhalb Sekundarbereich II } \\
\text { Sekundarbereich II und post-sekundarer, nicht-tertiärer Bereich } \\
\text { Tertiärbereich }\end{array}$ \\
\hline Luxemburg & $\begin{array}{l}\text { Abschluss unterhalb Sekundarbereich II } \\
\text { Sekundarbereich II und post-sekundarer, nicht-tertiärer Bereich } \\
\text { Tertiärbereich }\end{array}$ \\
\hline Mexiko & $\begin{array}{l}\text { Abschluss unterhalb Sekundarbereich II } \\
\text { Sekundarbereich II und post-sekundarer, nicht-tertiärer Bereich } \\
\text { Tertiärbereich }\end{array}$ \\
\hline Niederlande & $\begin{array}{l}\text { Abschluss unterhalb Sekundarbereich II } \\
\text { Sekundarbereich II und post-sekundarer, nicht-tertiärer Bereich } \\
\text { Tertiärbereich }\end{array}$ \\
\hline Neuseeland & $\begin{array}{l}\text { Abschluss unterhalb Sekundarbereich II } \\
\text { Sekundarbereich II und post-sekundarer, nicht-tertiärer Bereich } \\
\text { Tertiärbereich }\end{array}$ \\
\hline Norwegen & $\begin{array}{l}\text { Abschluss unterhalb Sekundarbereich II } \\
\text { Sekundarbereich II und post-sekundarer, nicht-tertiärer Bereich } \\
\text { Tertiärbereich }\end{array}$ \\
\hline Polen & $\begin{array}{l}\text { Abschluss unterhalb Sekundarbereich II } \\
\text { Sekundarbereich II und post-sekundarer, nicht-tertiärer Bereich } \\
\text { Tertiärbereich }\end{array}$ \\
\hline Portugal & $\begin{array}{l}\text { Abschluss unterhalb Sekundarbereich II } \\
\text { Sekundarbereich II und post-sekundarer, nicht-tertiärer Bereich } \\
\text { Tertiärbereich }\end{array}$ \\
\hline $\begin{array}{l}\text { Slowakische } \\
\text { Republik }\end{array}$ & $\begin{array}{l}\text { Abschluss unterhalb Sekundarbereich II } \\
\text { Sekundarbereich II und post-sekundarer, nicht-tertiärer Bereich } \\
\text { Tertiärbereich }\end{array}$ \\
\hline Spanien & $\begin{array}{l}\text { Abschluss unterhalb Sekundarbereich II } \\
\text { Sekundarbereich II und post-sekundarer, nicht-tertiärer Bereich } \\
\text { Tertiärbereich }\end{array}$ \\
\hline Schweden & $\begin{array}{l}\text { Abschluss unterhalb Sekundarbereich II } \\
\text { Sekundarbereich II und post-sekundarer, nicht-tertiärer Bereich } \\
\text { Tertiärbereich }\end{array}$ \\
\hline Schweiz & $\begin{array}{l}\text { Abschluss unterhalb Sekundarbereich II } \\
\text { Sekundarbereich II und post-sekundarer, nicht-tertiärer Bereich } \\
\text { Tertiärbereich }\end{array}$ \\
\hline Türkei & $\begin{array}{l}\text { Abschluss unterhalb Sekundarbereich II } \\
\text { Sekundarbereich II und post-sekundarer, nicht-tertiärer Bereich } \\
\text { Tertiärbereich }\end{array}$ \\
\hline $\begin{array}{l}\text { Vereinigtes } \\
\text { Königreich }\end{array}$ & $\begin{array}{l}\text { Abschluss unterhalb Sekundarbereich II } \\
\text { Sekundarbereich II und post-sekundarer, nicht-tertiärer Bereich } \\
\text { Tertiärbereich }\end{array}$ \\
\hline $\begin{array}{l}\text { Vereinigte } \\
\text { Staaten }\end{array}$ & $\begin{array}{l}\text { Abschluss unterhalb Sekundarbereich II } \\
\text { Sekundarbereich II und post-sekundarer, nicht-tertiärer Bereich } \\
\text { Tertiärbereich }\end{array}$ \\
\hline
\end{tabular}

\begin{tabular}{|c|c|c|c|c|}
\hline 1991 & 1995 & 1998 & 1999 & 2000 \\
\hline 5,5 & 5,7 & 5,9 & 5,4 & 4,9 \\
\hline 5,2 & 5,0 & 4,7 & 4,1 & 3,6 \\
\hline 3,3 & 3,5 & 2,9 & 2,9 & 3,1 \\
\hline 2,6 & 3,4 & 3,9 & 3,5 & 3,6 \\
\hline 2,4 & 2,3 & 2,8 & 2,5 & 2,3 \\
\hline 1,3 & 1,8 & 1,8 & 1,7 & 1,4 \\
\hline 6,5 & 7,3 & 7,2 & 6,7 & 5,5 \\
\hline 3,3 & 5,8 & 5,8 & 5,3 & 4,2 \\
\hline 1,7 & 3,1 & 2,8 & 2,7 & 2,4 \\
\hline 8,8 & 8,0 & 7,2 & 6,6 & 6,2 \\
\hline 7,2 & 6,7 & 6,0 & 5,4 & 4,7 \\
\hline 5,5 & 5,3 & 4,1 & 3,9 & 3,5 \\
\hline $\mathrm{m}$ & 4,7 & 8,4 & 10,9 & 11,2 \\
\hline $\mathrm{m}$ & 1,8 & 3,7 & 5,3 & 5,4 \\
\hline $\mathrm{m}$ & 0,7 & 1,7 & 2,4 & 2,2 \\
\hline 10,2 & 10,5 & 4,6 & 4,6 & 4,2 \\
\hline 8,1 & 8,4 & 3,8 & 3,4 & 3,3 \\
\hline 4,6 & 4,2 & 3,0 & 2,8 & 2,4 \\
\hline 6,1 & 14,9 & 9,0 & 8,8 & 7,9 \\
\hline 6,1 & 14,0 & 8,7 & 7,8 & 7,3 \\
\hline 3,1 & 8,1 & 5,1 & 4,2 & 4,2 \\
\hline 6,8 & 9,0 & 9,8 & 10,2 & 9,2 \\
\hline 5,5 & 7,5 & 7,9 & 7,6 & 6,5 \\
\hline 3,3 & 5,7 & 5,7 & 5,4 & 4,4 \\
\hline 4,1 & 7,6 & 9,2 & 9,2 & 8,1 \\
\hline 3,6 & 6,1 & 7,9 & 6,8 & 6,2 \\
\hline 2,9 & 4,3 & 4,8 & 4,4 & 3,6 \\
\hline $\mathrm{m}$ & 3,8 & 4,5 & 5,1 & 4,8 \\
\hline $\mathrm{m}$ & 6,2 & 7,6 & 7,9 & 7,9 \\
\hline $\mathrm{m}$ & 7,0 & 5,3 & 6,6 & 6,3 \\
\hline $\mathrm{m}$ & $\mathrm{m}$ & 4,6 & 4,5 & 4,0 \\
\hline $\mathrm{m}$ & $\mathrm{m}$ & 4,7 & 4,5 & 4,1 \\
\hline $\mathrm{m}$ & $\mathrm{m}$ & 1,4 & 1,1 & 1,1 \\
\hline $\mathrm{m}$ & $\mathrm{m}$ & 3,0 & 2,0 & 2,2 \\
\hline $\mathrm{m}$ & $\mathrm{m}$ & 1,2 & 0,9 & 1,4 \\
\hline $\mathrm{m}$ & $\mathrm{m}$ & 0,8 & 0,6 & 0,8 \\
\hline 11,7 & 9,5 & 7,0 & 5,5 & 4,2 \\
\hline 5,0 & 5,5 & 3,4 & 2,8 & 1,9 \\
\hline 3,5 & 3,6 & 2,6 & 1,5 & 1,4 \\
\hline 3,3 & 4,9 & 5,7 & 5,6 & 5,3 \\
\hline 5,7 & 6,1 & 6,3 & 6,1 & 5,6 \\
\hline 4,6 & 6,4 & 6,0 & 6,0 & 5,1 \\
\hline $\mathrm{m}$ & $\mathrm{m}$ & 3,1 & 4,0 & 4,3 \\
\hline $\mathrm{m}$ & $\mathrm{m}$ & 2,6 & 3,4 & 3,6 \\
\hline $\mathrm{m}$ & $\mathrm{m}$ & 2,2 & 2,7 & 2,9 \\
\hline 0,7 & 0,7 & 4,2 & 3,8 & 2,4 \\
\hline 1,4 & 1,2 & 4,8 & 4,5 & 2,7 \\
\hline 2,2 & 1,6 & 3,9 & 3,7 & 2,7 \\
\hline $\mathrm{m}$ & $\mathrm{m}$ & $\mathrm{m}$ & 2,1 & 1,9 \\
\hline $\mathrm{m}$ & $\mathrm{m}$ & $\mathrm{m}$ & 0,8 & 1,2 \\
\hline $\mathrm{m}$ & $\mathrm{m}$ & $\mathrm{m}$ & 0,9 & 0,8 \\
\hline $\mathrm{m}$ & 4,2 & 2,3 & 1,6 & 1,7 \\
\hline $\mathrm{m}$ & 2,7 & 1,1 & 0,9 & 1,0 \\
\hline $\mathrm{m}$ & 1,8 & 0,5 & 0,6 & 0,8 \\
\hline 4,7 & 4,4 & 0,5 & 2,9 & 2,3 \\
\hline 3,5 & 3,7 & 1,3 & 1,9 & 1,8 \\
\hline 1,3 & 3,5 & $\mathrm{n}$ & 1,5 & 1,7 \\
\hline 8,1 & 5,3 & 6,9 & 5,8 & 5,1 \\
\hline 5,7 & 2,7 & 3,9 & 3,8 & 2,9 \\
\hline 4,0 & 2,7 & 3,7 & 3,4 & 3,0 \\
\hline 4,5 & 4,2 & 2,0 & 1,7 & 1,5 \\
\hline 3,7 & 3,4 & 2,0 & 2,2 & 2,2 \\
\hline 1,8 & 2,2 & 1,4 & 1,2 & 1,7 \\
\hline $\mathrm{m}$ & 8,1 & 7,9 & 9,2 & 11,1 \\
\hline $\mathrm{m}$ & 8,8 & 7,1 & 8,3 & 10,7 \\
\hline $\mathrm{m}$ & 2,5 & 2,2 & 2,8 & 3,8 \\
\hline 3,5 & 4,5 & 3,3 & 3,0 & 2,7 \\
\hline 4,0 & 5,3 & 4,3 & 3,8 & 3,0 \\
\hline 1,7 & 3,0 & 2,6 & 2,8 & 2,5 \\
\hline $\mathrm{m}$ & 12,2 & 12,0 & 14,4 & 17,6 \\
\hline $\mathrm{m}$ & 8,0 & 7,3 & 9,7 & 11,8 \\
\hline $\mathrm{m}$ & 2,4 & 3,0 & 3,6 & 4,1 \\
\hline 7,9 & 12,0 & 10,2 & 8,8 & 8,5 \\
\hline 10,1 & 14,8 & 12,1 & 10,3 & 8,9 \\
\hline 8,1 & 12,7 & 11,5 & 9,6 & 8,3 \\
\hline 2,2 & 8,7 & 7,7 & 6,6 & 5,9 \\
\hline 2,1 & 7,9 & 6,7 & 5,5 & 4,6 \\
\hline 1,1 & 4,2 & 3,9 & 3,4 & 2,7 \\
\hline 0,9 & 4,1 & 4,1 & 3,6 & 3,5 \\
\hline 1,2 & 2,3 & 2,4 & 1,9 & 1,7 \\
\hline 1,2 & 1,8 & 2,6 & 1,6 & 1,2 \\
\hline 3,6 & 3,2 & 2,7 & 3,2 & 2,6 \\
\hline 5,2 & 4,7 & 4,6 & 5,6 & 3,6 \\
\hline 2,8 & 2,5 & 4,0 & 4,1 & 3,0 \\
\hline 7,1 & 8,1 & 6,2 & 5,8 & 5,2 \\
\hline 5,5 & 6,2 & 4,1 & 4,1 & 3,8 \\
\hline 3,0 & 3,4 & 2,3 & 2,4 & 1,9 \\
\hline 7,3 & 6,0 & 5,4 & 4,8 & 4,9 \\
\hline 5,2 & 4,0 & 3,5 & 3,0 & 2,9 \\
\hline 2,6 & 2,4 & 1,8 & 1,8 & 1,5 \\
\hline 5,5 & 6,7 & 5,8 & 5,7 & 5,4 \\
\hline 4,7 & 5,8 & 4,9 & 4,7 & 4,4 \\
\hline 3,0 & 3,9 & 3,3 & 3,1 & 2,8 \\
\hline
\end{tabular}

Quelle: OECD. Hinweise s. Anhang 3 unter www.oecd.org/edu/eag20o4. 
Tabelle A10.2c

Entwicklungen des Anteils der Bevölkerung, die sich nicht im Arbeitsmarkt befindet, nach Bildungsstand (1991-2002) 25- bis 64-Jährige, die sich nicht im Arbeitsmarkt befinden, als Prozentsatz der Bevölkerung im Alter von 24 bis 64 Jahren, nach Bildungsstand

\begin{tabular}{|c|c|}
\hline \multicolumn{2}{|l|}{ OECD-Länder } \\
\hline Australien & $\begin{array}{l}\text { Abschluss unterhalb Sekundarbereich II } \\
\text { Sekundarbereich II und post-sekundarer, nicht-tertiärer Bereich } \\
\text { Tertiärbereich }\end{array}$ \\
\hline Österreich & $\begin{array}{l}\text { Abschluss unterhalb Sekundarbereich II } \\
\text { Sekundarbereich II und post-sekundarer, nicht-tertiärer Bereich } \\
\text { Tertiärbereich }\end{array}$ \\
\hline Belgien & $\begin{array}{l}\text { Abschluss unterhalb Sekundarbereich II } \\
\text { Sekundarbereich II und post-sekundarer, nicht-tertiärer Bereich } \\
\text { Tertiärbereich }\end{array}$ \\
\hline Kanada & $\begin{array}{l}\text { Abschluss unterhalb Sekundarbereich II } \\
\text { Sekundarbereich II und post-sekundarer, nicht-tertiärer Bereich } \\
\text { Tertiärbereich }\end{array}$ \\
\hline Tschechische & Abschluss unterhalb Sekundarbereich II \\
\hline Republik & $\begin{array}{l}\text { Sekundarbereich II und post-sekundarer, nicht-tertiärer Bereich } \\
\text { Tertiärbereich }\end{array}$ \\
\hline Dänemark & $\begin{array}{l}\text { Abschluss unterhalb Sekundarbereich II } \\
\text { Sekundarbereich II und post-sekundarer, nicht-tertiärer Bereich } \\
\text { Tertiärbereich }\end{array}$ \\
\hline Finnland & $\begin{array}{l}\text { Abschluss unterhalb Sekundarbereich II } \\
\text { Sekundarbereich II und post-sekundarer, nicht-tertiärer Bereich } \\
\text { Tertiärbereich }\end{array}$ \\
\hline Frankreich & $\begin{array}{l}\text { Abschluss unterhalb Sekundarbereich II } \\
\text { Sekundarbereich II und post-sekundarer, nicht-tertiärer Bereich } \\
\text { Tertiärbereich }\end{array}$ \\
\hline Deutschland & $\begin{array}{l}\text { Abschluss unterhalb Sekundarbereich II } \\
\text { Sekundarbereich II und post-sekundarer, nicht-tertiärer Bereich } \\
\text { Tertiärbereich }\end{array}$ \\
\hline Griechenland & $\begin{array}{l}\text { Abschluss unterhalb Sekundarbereich II } \\
\text { Sekundarbereich II und post-sekundarer, nicht-tertiärer Bereich } \\
\text { Tertiärbereich }\end{array}$ \\
\hline Ungarn & $\begin{array}{l}\text { Abschluss unterhalb Sekundarbereich II } \\
\text { Sekundarbereich II und post-sekundarer, nicht-tertiärer Bereich } \\
\text { Tertiärbereich }\end{array}$ \\
\hline Island & $\begin{array}{l}\text { Abschluss unterhalb Sekundarbereich II } \\
\text { Sekundarbereich II und post-sekundarer, nicht-tertiärer Bereich } \\
\text { Tertiärbereich }\end{array}$ \\
\hline Irland & $\begin{array}{l}\text { Abschluss unterhalb Sekundarbereich II } \\
\text { Sekundarbereich II und post-sekundarer, nicht-tertiärer Bereich } \\
\text { Tertiärbereich }\end{array}$ \\
\hline Italien & $\begin{array}{l}\text { Abschluss unterhalb Sekundarbereich II } \\
\text { Sekundarbereich II und post-sekundarer, nicht-tertiärer Bereich } \\
\text { Tertiärbereich }\end{array}$ \\
\hline Japan & $\begin{array}{l}\text { Abschluss unterhalb Sekundarbereich II } \\
\text { Sekundarbereich II und post-sekundarer, nicht-tertiärer Bereich } \\
\text { Tertiärbereich }\end{array}$ \\
\hline Korea & $\begin{array}{l}\text { Abschluss unterhalb Sekundarbereich II } \\
\text { Sekundarbereich II und post-sekundarer, nicht-tertiärer Bereich } \\
\text { Tertiärbereich }\end{array}$ \\
\hline Luxemburg & $\begin{array}{l}\text { Abschluss unterhalb Sekundarbereich II } \\
\text { Sekundarbereich II und post-sekundarer, nicht-tertiärer Bereich } \\
\text { Tertiärbereich }\end{array}$ \\
\hline Mexiko & $\begin{array}{l}\text { Abschluss unterhalb Sekundarbereich II } \\
\text { Sekundarbereich II und post-sekundarer, nicht-tertiärer Bereich } \\
\text { Tertiärbereich }\end{array}$ \\
\hline Niederlande & $\begin{array}{l}\text { Abschluss unterhalb Sekundarbereich II } \\
\text { Sekundarbereich II und post-sekundarer, nicht-tertiärer Bereich } \\
\text { Tertiärbereich }\end{array}$ \\
\hline Neuseeland & $\begin{array}{l}\text { Abschluss unterhalb Sekundarbereich II } \\
\text { Sekundarbereich II und post-sekundarer, nicht-tertiärer Bereich } \\
\text { Tertiärbereich }\end{array}$ \\
\hline Norwegen & $\begin{array}{l}\text { Abschluss unterhalb Sekundarbereich II } \\
\text { Sekundarbereich II und post-sekundarer, nicht-tertiärer Bereich } \\
\text { Tertiärbereich }\end{array}$ \\
\hline Polen & $\begin{array}{l}\text { Abschluss unterhalb Sekundarbereich II } \\
\text { Sekundarbereich II und post-sekundarer, nicht-tertiärer Bereich } \\
\text { Tertiärbereich }\end{array}$ \\
\hline Portugal & $\begin{array}{l}\text { Abschluss unterhalb Sekundarbereich II } \\
\text { Sekundarbereich II und post-sekundarer, nicht-tertiärer Bereich } \\
\text { Tertiärbereich }\end{array}$ \\
\hline $\begin{array}{l}\text { Slowakische } \\
\text { Republik }\end{array}$ & $\begin{array}{l}\text { Abschluss unterhalb Sekundarbereich II } \\
\text { Sekundarbereich II und post-sekundarer, nicht-tertiärer Bereich } \\
\text { Tertiärbereich }\end{array}$ \\
\hline Spanien & $\begin{array}{l}\text { Abschluss unterhalb Sekundarbereich II } \\
\text { Sekundarbereich II und post-sekundarer, nicht-tertiärer Bereich } \\
\text { Tertiärbereich }\end{array}$ \\
\hline Schweden & $\begin{array}{l}\text { Abschluss unterhalb Sekundarbereich II } \\
\text { Sekundarbereich II und post-sekundarer, nicht-tertiärer Bereich } \\
\text { Tertiärbereich }\end{array}$ \\
\hline Schweiz & $\begin{array}{l}\text { Abschluss unterhalb Sekundarbereich II } \\
\text { Sekundarbereich II und post-sekundarer, nicht-tertiärer Bereich } \\
\text { Tertiärbereich }\end{array}$ \\
\hline Türkei & $\begin{array}{l}\text { Abschluss unterhalb Sekundarbereich II } \\
\text { Sekundarbereich II und post-sekundarer, nicht-tertiärer Bereich } \\
\text { Tertiärbereich }\end{array}$ \\
\hline $\begin{array}{l}\text { Vereinigtes } \\
\text { Königreich }\end{array}$ & $\begin{array}{l}\text { Abschluss unterhalb Sekundarbereich II } \\
\text { Sekundarbereich II und post-sekundarer, nicht-tertiärer Bereich } \\
\text { Tertiärbereich }\end{array}$ \\
\hline $\begin{array}{l}\text { Vereinigte } \\
\text { Staaten }\end{array}$ & $\begin{array}{l}\text { Abschluss unterhalb Sekundarbereich II } \\
\text { Sekundarbereich II und post-sekundarer, nicht-tertiärer Bereich } \\
\text { Tertiärbereich }\end{array}$ \\
\hline
\end{tabular}

\begin{tabular}{|c|c|c|c|c|}
\hline 1991 & 1995 & 1998 & 1999 & 2000 \\
\hline 40 & 34 & 35 & 36 & 34 \\
\hline 24 & 20 & 19 & 20 & 20 \\
\hline 16 & 13 & 13 & 15 & 14 \\
\hline 46 & 41 & 43 & 43 & 43 \\
\hline 24 & 21 & 22 & 22 & 23 \\
\hline 10 & 10 & 12 & 11 & 12 \\
\hline 45 & 45 & 45 & 44 & 44 \\
\hline 21 & 22 & 22 & 20 & 21 \\
\hline 13 & 13 & 13 & 12 & 12 \\
\hline 36 & 39 & 39 & 39 & 39 \\
\hline 18 & 19 & 19 & 19 & 19 \\
\hline 12 & 13 & 14 & 14 & 14 \\
\hline $\mathrm{m}$ & 40 & 42 & 42 & 42 \\
\hline $\mathrm{m}$ & 16 & 18 & 18 & 19 \\
\hline $\mathrm{m}$ & 7 & 10 & 10 & 11 \\
\hline 28 & 28 & 35 & 34 & 33 \\
\hline 11 & 15 & 17 & 16 & 16 \\
\hline 6 & 7 & 10 & 9 & 9 \\
\hline 30 & 31 & 35 & 33 & 35 \\
\hline 16 & 16 & 18 & 18 & 18 \\
\hline 9 & 11 & 12 & 11 & 11 \\
\hline 36 & 34 & 34 & 33 & 34 \\
\hline 16 & 17 & 17 & 17 & 18 \\
\hline 12 & 12 & 13 & 13 & 12 \\
\hline 45 & 43 & 43 & 42 & 41 \\
\hline 23 & 23 & 23 & 23 & 23 \\
\hline 11 & 12 & 12 & 13 & 13 \\
\hline $\mathrm{m}$ & 40 & 40 & 40 & 40 \\
\hline $\mathrm{m}$ & 32 & 27 & 27 & 27 \\
\hline $\mathrm{m}$ & 14 & 14 & 13 & 13 \\
\hline $\mathrm{m}$ & $\mathrm{m}$ & 59 & 60 & 60 \\
\hline $\mathrm{m}$ & $\mathrm{m}$ & 24 & 23 & 24 \\
\hline $\mathrm{m}$ & $\mathrm{m}$ & 18 & 17 & 17 \\
\hline $\mathrm{m}$ & $\mathrm{m}$ & 12 & 12 & 11 \\
\hline $\mathrm{m}$ & $\mathrm{m}$ & 10 & 8 & 9 \\
\hline $\mathrm{m}$ & $\mathrm{m}$ & 4 & 4 & 4 \\
\hline 42 & 42 & 40 & 40 & 40 \\
\hline 32 & 28 & 25 & 22 & 21 \\
\hline 16 & 13 & 12 & 11 & 11 \\
\hline 43 & 46 & 47 & 47 & 47 \\
\hline 21 & 24 & 24 & 24 & 23 \\
\hline 9 & 13 & 13 & 13 & 13 \\
\hline $\mathrm{m}$ & $\mathrm{m}$ & 28 & 28 & 29 \\
\hline $\mathrm{m}$ & $\mathrm{m}$ & 22 & 22 & 23 \\
\hline $\mathrm{m}$ & $\mathrm{m}$ & 18 & 18 & 18 \\
\hline 29 & 28 & 30 & 29 & 30 \\
\hline 28 & 28 & 29 & 29 & 29 \\
\hline 18 & 19 & 20 & 22 & 22 \\
\hline $\mathrm{m}$ & $\mathrm{m}$ & $\mathrm{m}$ & 43 & 40 \\
\hline $\mathrm{m}$ & $\mathrm{m}$ & $\mathrm{m}$ & 26 & 26 \\
\hline $\mathrm{m}$ & $\mathrm{m}$ & $\mathrm{m}$ & 14 & 15 \\
\hline $\mathrm{m}$ & 37 & 36 & 37 & 37 \\
\hline $\mathrm{m}$ & 29 & 27 & 29 & 29 \\
\hline $\mathrm{m}$ & 49 & 47 & 45 & 46 \\
\hline 45 & 43 & 44 & 40 & 40 \\
\hline 23 & 22 & 22 & 20 & 19 \\
\hline 14 & 14 & 15 & 11 & 12 \\
\hline 35 & 36 & 35 & 35 & 34 \\
\hline 22 & 17 & 17 & 16 & 17 \\
\hline 16 & 16 & 16 & 16 & 16 \\
\hline 33 & 35 & 30 & 31 & 33 \\
\hline 17 & 16 & 14 & 15 & 15 \\
\hline 8 & 9 & 8 & 9 & 8 \\
\hline $\mathrm{m}$ & 42 & 43 & 44 & 46 \\
\hline $\mathrm{m}$ & 21 & 22 & 22 & 23 \\
\hline $\mathrm{m}$ & 13 & 11 & 11 & 12 \\
\hline 35 & 28 & 25 & 25 & 25 \\
\hline 12 & 18 & 16 & 14 & 14 \\
\hline 6 & 8 & 8 & 7 & 7 \\
\hline $\mathrm{m}$ & 49 & 51 & 52 & 52 \\
\hline $\mathrm{m}$ & 17 & 18 & 18 & 18 \\
\hline $\mathrm{m}$ & 9 & 8 & 9 & 10 \\
\hline 43 & 42 & 40 & 40 & 38 \\
\hline 17 & 20 & 21 & 20 & 19 \\
\hline 13 & 13 & 12 & 13 & 12 \\
\hline 15 & 14 & 26 & 27 & 26 \\
\hline 7 & 9 & 14 & 15 & 14 \\
\hline 5 & 7 & 11 & 11 & 11 \\
\hline 21 & 29 & 27 & 27 & 31 \\
\hline 19 & 18 & 16 & 17 & 16 \\
\hline 7 & 8 & 7 & 7 & 8 \\
\hline 36 & 33 & 40 & 40 & 45 \\
\hline 28 & 32 & 29 & 31 & 35 \\
\hline 10 & 23 & 15 & 17 & 18 \\
\hline 32 & 37 & 41 & 42 & 41 \\
\hline 16 & 17 & 17 & 17 & 17 \\
\hline 11 & 10 & 10 & 10 & 10 \\
\hline 41 & 40 & 37 & 37 & 37 \\
\hline 21 & 21 & 21 & 21 & 20 \\
\hline 12 & 12 & 13 & 14 & 13 \\
\hline 36 & 37 & 37 & 37 & 38 \\
\hline 20 & 21 & 20 & 20 & 20 \\
\hline 11 & 13 & 13 & 13 & 13 \\
\hline
\end{tabular}




\section{Die Erträge aus Bildung: Bildung und Einkommen}

Zwischen Bildungsstand und Einkommen besteht eine positive Korrelation. Der Abschluss des Sekundarbereich II und eines post-sekundaren, nichttertiären Bildungsgangs stellt in vielen Ländern einen Wendepunkt dar, ab dem jede zusätzliche Ausbildung einen besonders hohen Einkommenszuschlag mit sich bringt. In allen Ländern verdienen Absolventen des Tertiärbereichs deutlich mehr als Absolventen des Sekundarbereich II und postsekundarer, nicht-tertiärer Bildungsgänge. Die Einkommensunterschiede zwischen Absolventen des Tertiärbereiches und denen des Sekundarbereich II sind im Allgemeinen deutlich größer als zwischen Absolventen des Sekundarbereich II und denen des Sekundarbereich I und darunter.

Die Einkommen von Personen mit einem Abschluss unterhalb des Sekundarbereich II belaufen sich in der Regel auf 60 bis 90 Prozent der Einkommen von Absolventen des Sekundarbereich II und post-sekundarer, nichttertiärer Bildungsgänge.

Frauen verdienen im Vergleich zu Männern mit einem ähnlichen Bildungsstand nach wie vor weniger. 

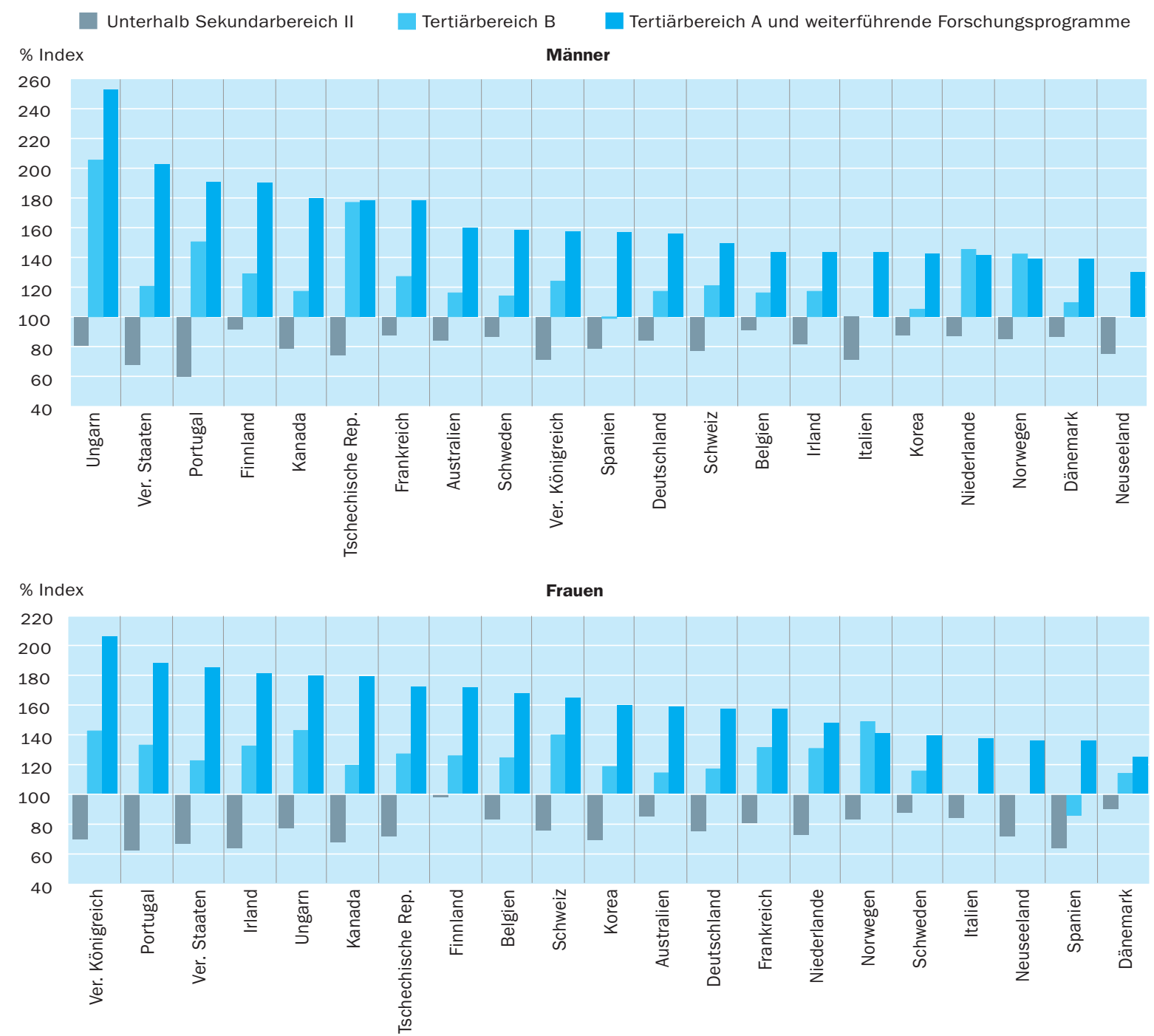

Anordnung der Länder in absteigender Reihenfolge der relativen Einkommen von Personen mit einem Abschluss im Tertiärbereich A und weiterführenden Forschungsprogrammen.

Quelle: OECD, Tabelle A11.1a. Hinweise s. Anhang 3 unter www.oecd.org/edu/eag2004.

Dieser Indikator zeigt die Einkommen von Arbeitskräften mit unterschiedlichen Bildungsabschlüssen ...

\section{Politischer Hintergrund}

Ein Möglichkeit, durch die die Märkte Anreize für Arbeitskräfte schaffen, angemessene Fähigkeiten und Kenntnisse zu entwickeln und zu erhalten, sind Einkommensunterschiede und hier insbesondere höhere Verdienstmöglichkeiten für diejenigen, die sich weiterbilden und zusätzliche Abschlüsse erzielen. Das Streben nach einem höheren Bildungsstand kann auch als Investition in das Humankapital gesehen werden. Das Humankapital stellt den Bestand an Fähigkeiten und Kenntnissen dar, die der Einzelne besitzt oder - normaler- 
weise durch Bildung oder Ausbildung - (weiter-) entwickelt und sodann als Gegenleistung für ein Einkommen auf dem Arbeitsmarkt anbietet. Je höher die Einkommen sind, die sich aus einer Vermehrung des Humankapitals ergeben, umso höher ist der Ertrag dieser Investition und der Einkommenszuschlag für bessere Fähigkeiten und Kenntnisse und/oder für eine höhere Produktivität.

Gleichzeitig verursacht es Kosten, an (Aus-)Bildungsangeboten teilzunehmen, die man bei einer Betrachtung der Erträge aus der Bildung gleichermaßen berücksichtigen muss. Dieser Indikator untersucht die Erträge aus Bildungsinvestitionen sowie die Kosten und den Nutzen, die dabei zu berücksichtigen sind.

\section{Ergebnisse und Erläuterungen}

\section{Bildung und Einkommen}

Einkommensunterschiede je nach Bildungsstand gelten als Maßstab für die in einem bestimmten Land momentan für den Einzelnen bestehenden finanziellen Anreize, in Weiterbildung zu investieren. Einkommensunterschiede können aber auch Unterschiede im Angebot von Bildungsgängen in verschiedenen Bildungsbereichen bzw. Beschränkungen des Zugangs zu diesen Bildungsgängen widerspiegeln. Der wirtschaftliche Vorteil eines tertiären Bildungsabschlusses kann anhand eines Vergleichs des Verhältnisses der mittleren Jahreseinkommen von Absolventen tertiärer Studiengänge zu den mittleren Jahreseinkommen von Absolventen des Sekundarbereich II oder eines post-sekundaren, nicht-tertiären Bildungsgangs verdeutlicht werden. Der Einkommensnachteil derjenigen ohne einen Abschluss des Sekundarbereich II oder eines post-sekundaren, nicht-tertiären Bildungsgangs wird in einem ähnlichen Vergleich offensichtlich. Die länderspezifischen Schwankungen der relativen Einkommen (vor dem Abzug von Steuern) spiegeln mehrere Einflussfaktoren wider, darunter Anforderungen an die Fähigkeiten und Kenntnisse der Arbeitskräfte, die Gesetzgebung zu den Mindestlöhnen, die Stärke der Gewerkschaften, den Abdeckungsgrad durch Tarifverträge, das Arbeitskräfteangebot für die einzelnen Bildungsebenen, die Berufserfahrung der gering und der hoch qualifizierten Arbeitnehmer, die Verteilung der Beschäftigung auf die verschiedenen Berufe und die relative Verbreitung von Teilzeit- bzw. Vollzeitarbeit bei Arbeitnehmern mit unterschiedlichem Bildungsstand.

Abbildung AIr.I zeigt einen starken positiven Zusammenhang zwischen Bildungsstand und Einkommen. In allen Ländern verdienen Absolventen des Tertiärbereichs deutlich mehr als Absolventen des Sekundarbereich II und post-sekundarer, nicht-tertiärer Bildungsgänge. Diese Einkommensunterschiede sind im Allgemeinen deutlich größer als zwischen Letzteren und Absolventen mit einem Abschluss unterhalb des Sekundarbereich II, was darauf schließen lässt, dass der Abschluss des Sekundarbereich II (und mit wenigen Ausnahmen eines post-sekundaren, nicht tertiären Bildungsgangs) in vielen Ländern einen Wendepunkt darstellt, ab dem eine weitere Ausbildung einen besonders hohen Einkommenszuschlag mit sich bringt. Tab Arr.ra zeigt, dass in den Ländern, die Daten über Bruttoeinkommen vorgelegt haben, der Ein-

Einkommensunterschiede gelten als Maßstab für die in einem bestimmten Land momentan für den Einzelnen bestehenden finanziellen Anreize, in Weiterbildung zu investieren.

Zwischen Bildungsstand und Einkommen besteht ein positiver Zusammenhang unabhängig vom sozioökonomischen System oder vom Entwicklungsstand der jeweiligen Volkswirtschaft. 
kommenszuschlag für 25-bis 64-jährige Männer für einen Abschluss des Tertiärbereichs gegenüber einem Abschluss im Sekundarbereich II zwischen 30 Prozent in Neuseeland und 152 Prozent in Ungarn liegt.

Die im vorliegenden Indikator aufgezeigten Einkommensdaten für die einzelnen Länder unterscheiden sich in mehrfacher Hinsicht. Die Ergebnisse sind daher mit Vorsicht zu interpretieren. Insbesondere bei Ländern, die Daten über Jahreseinkommen vorgelegt haben, beeinflussen Unterschiede in der Häufigkeit von Beschäftigungsverhältnissen, die nicht das gesamte Jahr andauern, bei Personen mit unterschiedlichem Bildungsstand das relative Einkommen, was sich in den Daten der Länder, die wöchentliche oder monatliche Gehaltsangaben vorgelegt haben, nicht niederschlägt (s. u. Definitionen und angewandte Methodik).

\section{Bildungs- und geschlechtspezifische Unterschiede bei den Einkommen}

In Belgien, Irland, Korea, Neuseeland, den Niederlanden, Norwegen, der Schweiz und dem Vereinigten Königreich verbessert ein Abschluss im Tertiärbereich im Vergleich zu einem Abschluss im Sekundarbereich II das Einkommen für Frauen stärker als für Männer. Für die anderen Länder gilt genau das Gegenteil, mit Ausnahme von Deutschland, wo ein Abschluss im Tertiärbereich die Einkommen von Frauen und Männern gegenüber einem Abschluss im Sekundarbereich II in gleichem Maße steigert (Tab. AII.I).

\section{Abbildung A11.2}

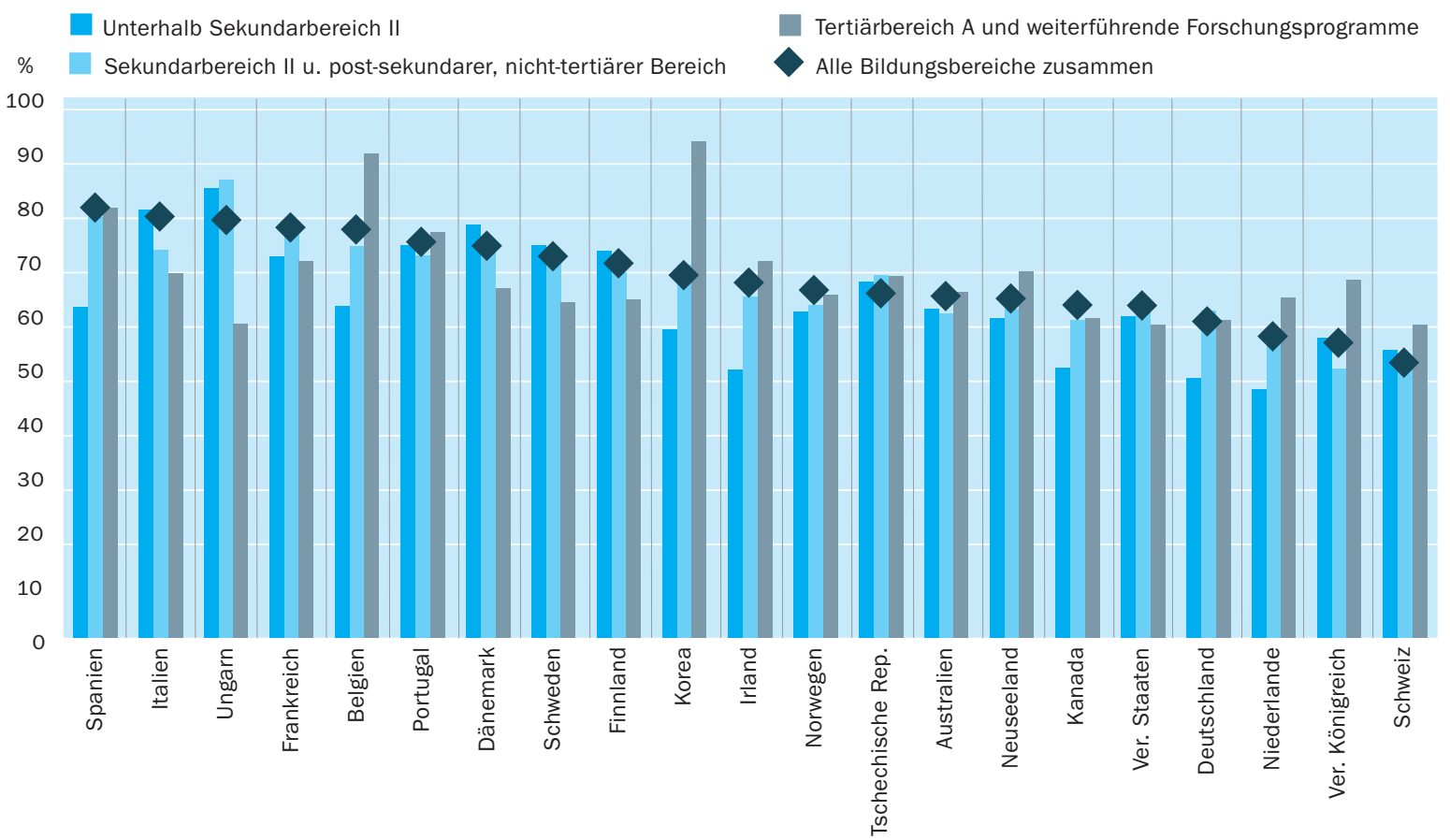


Zwar haben sowohl Männer als auch Frauen mit einem Abschluss des Sekundarbereich II oder höher erhebliche Einkommensvorteile gegenüber denjenigen des gleichen Geschlechts ohne einen Abschluss im Sekundarbereich II, doch sind die Einkommensunterschiede zwischen Männern und Frauen mit gleichem Bildungsstand nach wie vor erheblich (Abb. Arr.2 und Tab. Arr.rb).

Nimmt man alle Bildungsbereiche zusammen, so belaufen sich die Einkommen 30- bis 44-jähriger Frauen im Verhältnis zu denjenigen gleichaltriger Männer auf zwischen 50 Prozent in der Schweiz und 79 Prozent in Spanien (Abb. Air.2 und Tab. Air.Ib).

Die geschlechtsspezifischen Gehaltsunterschiede lassen sich zum Teil mit den Unterschieden bei der Laufbahn- und Berufswahl, den im Arbeitsmarkt verbrachten Jahren und der relativ großen Häufigkeit von Teilzeitarbeit bei Frauen erklären (Tab. AII.rb enthält für Polen, die Vereinigten Staaten und Ungarn keine Teilzeitarbeit).

\section{Individuelle Ertragsraten aus Bildungsinvestitionen}

Die Anreize für Investitionen in Humankapital spiegeln die damit verbundenen Arbeitsmarktvorteile und Bedingungen der Bildungsfinanzierung wider und lassen sich in Schätzungen der individuellen Ertragsrate zusammenfassen. Die Ertragsrate ist eine Kennzahl für die im Laufe der Zeit erzielten Vorteile in Relation zu den Kosten für die Investition in die Ausbildung. Sie wird als Prozentsatz dargestellt und ist analog zu prozentualen Renditen für Einlagen auf einem Sparkonto anzusehen (Die Verfahrensweise wird in Anhang 3 unter www.oecd.org/edu/eag2004 ausführlich erläutert).

Traditionell wurden die Ertragsraten von Bildungsinvestitionen für die gesamte Lebensdauer der Personen geschätzt, die als Jugendliche oder junge Erwachsene einen gewissen Bildungsstand erreicht hatten. Dieser Indikator bezieht sich jedoch auf die Investitionen in die Bildung, die Erwachsene im erwerbsfähigen Alter tätigen. So beziehen sich die Schätzungen der individuellen Ertragsraten in den Tabellen AIr.4 und AII.5 auf hypothetische 40-Jährige, die sich erneut dem formalen Bildungswesen zuwenden, um die nächst höhere Qualifikation zu erwerben. Daher sind diese Berechnungen für die aktuellen politischen Entscheidungen zur Förderung des lebenslangen Lernens in vielen OECD-Ländern relevant.

Untersucht wird der Übergang aus zwei unterschiedlichen Bildungsbereichen. Zunächst sind in Tabelle Arr.4 die individuellen Ertragsraten einer Person mit einem Abschluss unterhalb Sekundarbereich II (ISCED o/I/2) dargestellt, die investierte, um einen Abschluss im Sekundarbereich II oder dem post-sekundaren, nicht-tertiären Bereich (ISCED 3/4) zu erreichen. Die zweite Art von Übergang zeigt Tabelle AII.5 - hier handelt es sich um Personen mit einem Abschluss im Sekundarbereich II (ISCED 3/4), die in einen Abschluss im Tertiärbereich oder einem weiterführenden Forschungsprogramm (ISCED $5(\mathrm{~A} / \mathrm{B}) / 6)$ investierten. Die Schätzungen wurden für die folgenden Szenarien berechnet:
Der Einkommensunterschied zwischen Frauen und Männern mit gleichem Bildungsstand bleibt weiterhin erheblich, ...

... wobei sich die geschlechtsspezifischen Gehaltsunterschiede zum Teil mit der Laufbahn- und Berufswahl, unterschiedlich langen Zugehörigkeiten zum Arbeitsmarkt und der größeren Häufigkeit von Teilzeitarbeit bei Frauen erklären lassen.

Die Gesamtheit aller Anreize für Investitionen in Humankapital lässt sich in der individuellen Ertragsrate zusammenfassen.

Dieser Indikator bewertet die Anreize für Bildungsinvestitionen, die für Erwachsene im Erwerbsalter in einer Reihe von Bildungssituationen bestehen. 
Vollzeitteilnahme an der Bildungsmaßnahme.

Keine Erwerbstätigkeit und somit kein Einkommen während der Ausbildungsdauer. Die Ertragsraten wurden für zwei unterschiedliche Situationen berechnet. Im ersten Fall kommt der Bildungsteilnehmer selbst für die direkten Kosten für die Studiengebühren (entsprechend der Meldungen der nationalen Bildungsbehörden) und das entgangene Nettoeinkommen auf (nur die Steuern der Zentralbehörden werden berücksichtigt), ferner erfolgte eine Bereinigung um die Beschäftigungswahrscheinlichkeit. Im zweiten Fall trägt der Bildungsteilnehmer keine direkten Kosten für Studiengebühren, jedoch die Kosten in Form von entgangenem Einkommen.

Der Arbeitnehmer erlangte den nächst höheren Bildungsabschluss als Jugendlicher unmittelbar, noch bevor er in den Arbeitsmarkt eintrat.

Die Ergebnisse für Männer und Frauen werden getrennt aufgeführt. In jedem dieser Szenarien besteht der Nutzen der Bildungsinvestition aus dem erhöhten Nettoeinkommen (ausgehend von durchschnittlichen Unterschieden beim Nettoeinkommen zwischen den Personen, die den Bildungsabschluss direkt und solchen, die ihn später erworben haben) und der höheren Beschäftigungswahrscheinlichkeit. Über das Einkommen eines hypothetischen 40-Jährigen, der mit dem nächst höheren Bildungsabschluss auf den Arbeitsmarkt zurückkehrt, wurden folgende Annahmen gemacht: Es wird davon ausgegangen, dass diese Arbeitskraft sofort ein um ro Prozent höheres Lohnniveau gegenüber dem für den ursprünglichen Bildungsabschluss üblichen Lohnniveau erreicht. Ihr Lohnniveau gleicht sich dann linear an das durchschnittliche Lohnniveau derjenigen an, die diese höhere Qualifikation schon haben. Die Angleichung findet über drei Jahre hinweg statt, danach sind die Löhne gleich (die Abschnitte Definitionen und angewandte Methodik sowie Was die Ertragsraten aussagen enthalten eine Diskussion dieser Annahmen und der Auswirkungen alternativer Angleichungszeiträume auf die Ergebnisse).

Die berechneten Ertragsraten werden wahrscheinlich nach oben verzerrt sein, da staatliche Transferzahlungen, wie Arbeitslosengeld, nicht berücksichtigt werden. Dadurch, dass keine andere Einkommensquellen als Erwerbseinkommen berücksichtigt wurden (z. B. Einkommen aus Privatrenten, Immobilienoder anderem Vermögen usw.), werden die berechneten Ertragsraten jedoch wiederum nach unten verzerrt, insbesondere für die besser Gebildeten. Die im vorliegenden Indikator genannten Berechnungen zu den Ertragsraten lassen potentielle nicht-materielle Nutzeffekte der Bildung unberücksichtigt (z.B. den Spaß am Lernen, einen höheren sozialen Status und einen besseren Gesundheitszustand).

Personen, die ihre Bildungsabschlüsse zu einem frühen Zeitpunkt erwerben und dann deren Vorteile während des gesamten Lebens genießen, haben hohe Ertragsraten.
Vor allem die Tabellen AIr.4 und AIr.5 zeigen die hohen Ertragsraten, die sowohl Männer als auch Frauen erzielen können, wenn sie vor dem Eintritt in den Arbeitsmarkt direkt den nächst höheren Bildungsabschluss erwerben. Die mit der Erreichung eines Abschlusses im Sekundarbereich II verbundenen Ertragsraten (Tabelle AII.4) sind überraschend hoch und erreichen in den Vereinigte Staaten für Frauen 98 Prozent. Diese hohen Erträge resultieren aus dem deutlich höheren Lohn- und Gehaltsniveau, das nach dem Abschluss des 
Sekundarbereich II erreicht wird. Dies unterstreicht die unzulänglichen Einkommensaussichten für diejenigen, die den Sekundarbereich II nicht abschließen. In allen Ländern (außer in Spanien im Falle der Männer) liegen die individuellen Ertragsraten für diejenigen, die direkt vom Sekundarbereich II in den Tertiärbereich übergehen, höher als für diejenigen, die später als 40-Jährige an einer Vollzeitbildungsmaßnahme teilnehmen (Tab. AII.5). Die höheren individuellen Ertragsraten bei einem frühen Erwerb des nächsthöheren Bildungsabschlusses, unabhängig vom Qualifikationsniveau, erklären sich dadurch, dass die aufgrund der besseren Bildung erzielten höheren Einkommen über einen längeren Zeitraum hinweg erworben werden und dass das entgangene Einkommen bei Jugendlichen oder jungen Erwachsenen meist niedriger ist.

Wie zu erwarten ist, steigen die Ertragsraten sowohl in Tabelle AIr.4 als auch in AII.5, wenn keine Studiengebühren anfallen. Insgesamt gesehen sind die zusätzlichen Anreize, die sich aus fehlenden Studiengebühren ergeben, jedoch nicht bemerkenswert, sie betragen durchschnittlich o,6 Prozentpunkte für den Erwerb eines Abschlusses im Sekundarbereich II und durchschnittlich I, 8 Prozentpunkte für den Erwerb eines Abschlusses im Tertiärbereich (und lediglich I, 3 Prozentpunkte, wenn man die sehr hohen Zahlen für die Vereinigten Staaten herausrechnet). Insgesamt gesehen, verbessert sich die Ertragsrate dadurch, dass keine Studiengebühren zu zahlen sind, wesentlich stärker, wenn es um den Erwerb eines Abschlusses im Tertiärbereich geht, was auf die höheren Studiengebühren für Studierende im Tertiärbereich zurückzuführen ist. Allerdings sind die Auswirkungen des Fehlens von Studiengebühren auf die individuelle Ertragsraten in Ländern wie Dänemark und Finnland relativ gering, da Studierende dort sehr geringe Studiengebühren zu zahlen haben (in Dänemark fallen für den ersten Abschluss im Tertiärbereich sogar gar keine Studiengebühren an, für die, nicht-reguläre' Erwachsenenbildung jedoch schon). Im Gegensatz dazu verbessern sich die individuellen Ertragsraten in Ländern wie Australien, Spanien, Ungarn, dem Vereinigten Königreich und den Vereinigten Staaten meist deutlich, wenn keine Studiengebühren anfallen.

In Tabelle ArI.4 lassen sich im Zusammenhang mit der Erreichung eines Abschlusses im Sekundarbereich II je nach geschätzter Ertragsrate vier Ländergruppen unterscheiden:

Zunächst bilden Spanien, Ungarn und die Vereinigten Staaten eine separate Gruppe, hier bringt ein Abschluss im Sekundarbereich II besonders große Vorteile - zwischen 9,9 und 17,5 Prozent.

Als zweites folgen die Schweiz und das Vereinigte Königreich mit hohen Ertragsraten, die jedoch etwas hinter denen der ersten Gruppe zurückbleiben.

Als Drittes bildet Dänemark eine eigenständige Gruppe mit sehr niedrigen positiven Ertragsraten.

Viertens folgen Australien und Schweden mit negativen Ertragsraten, die auch für Finnland gelten. In Australien und Finnland sind die negativen Ertragsraten hauptsächlich auf die steuerlichen Auswirkungen zurückzuführen, da die Nettoeinkommen derjenigen mit einem Abschluss im Sekun-

Der Erlass von Studiengebühren wirkt meist nur als geringer Anreiz, die Wirkung ist im Tertiärbereich jedoch deutlicher. 
darbereich II unter den Nettoeinkommen derjenigen mit Abschlüssen im Sekundarbereich I liegen (dies gilt jedoch nicht für alle Altersgruppen). In Schweden hat die steuerliche Situation ähnliche Auswirkungen.

Tabelle AIr.5 zeigt hinsichtlich der Erreichung von Abschlüssen im Tertiärbereich einige spezielle Eigenheiten auf:

Ungarn bildet eine eigenständige Gruppe mit extrem hohen Ertragsraten.

Finnland und Spanien fallen durch Ertragsraten zwischen 8, I und I2, I Prozent auf.

Auch das Vereinigte Königreich und die Vereinigten Staaten weisen hohe Ertragsraten auf, wenngleich diese etwas unterhalb derjenigen in der vorherigen Gruppe liegen.

Die übrigen Länder haben moderate Ertragsraten, die jedoch meist positiv sind.

Der geschlechtsspezifische Unterschied in den Ertragsraten bei der Erreichung des Sekundarbereich II ist den meisten Ländern begrenzt. Die Ertragsraten sind in Spanien, der Schweiz und Ungarn für Frauen jedoch erheblich höher als für Männer - durchschnittlich 3,8 Prozentpunkte und zwar für beide Kostenszenarien. Dieser Unterschied ergibt sich hauptsächlich daraus, dass den Frauen in diesen Ländern ein geringeres Maß an Einkommen entgeht. Es ist erwähnenswert, dass mit Erreichung eines Abschlusses im Tertiärbereich die individuelle Ertragsrate für Frauen in allen Ländern, außer der Schweiz und dem Vereinigten Königreich, hinter der für Männer zurückbleibt.

\section{Gesellschaftliche Ertragsraten aus Billdungsinvestitionen}

Der Nutzen, den die Gesellschaft aus einer zusätzlicher Bildungsteilnahme zieht, lässt sich anhand der gesellschaftlichen Ertragsrate beurteilen, ...
Der Nutzen, den die Gesellschaft aus einer zusätzlicher Bildungsteilnahme zieht, lässt sich anhand der gesellschaftlichen Ertragsrate beurteilen. Die gesellschaftliche Ertragsrate spiegelt Kosten und Nutzen der Gesellschaft aus Bildungsinvestitionen wider, welche sich beträchtlich von denen für den Einzelnen unterscheiden können. Die gesellschaftlichen Kosten umfassen den Produktionsausfall während der Dauer der Bildungsmaßnahme, sowie die Kosten für das Bildungsangebot in voller Höhe, also nicht nur die vom Einzelnen getragenen Kosten. Ein Teil des gesellschaftlichen Nutzens ist die höhere Produktivität, die mit Bildungsinvestitionen einhergeht, sowie ferner eine ganze Palette potentieller, indirekter Nutzeffekte, die auch durchaus wirtschaftliche Auswirkungen haben, wie eine niedrigere Kriminalitätsrate, eine bessere Gesundheit, ein stärkerer sozialer Zusammenhalt, informiertere und mündigere Bürger.

Während Angaben zu den von der Gesellschaft zu tragenden Kosten für die meisten OECD-Länder vorliegen, ist es wesentlich schwieriger, Informationen über die Gesamtheit des gesellschaftlichen Nutzens zu beschaffen. Soweit Produktivitätssteigerungen im Lohnkostendifferenzial zum Ausdruck kommen, kann man dieses als Maß für den wirtschaftlichen Nutzen heranziehen, den die Gesellschaft aus Bildungsanstrengungen zieht. Mögliche mit der Bildung 
einhergehende externe Effekte lassen jedoch vermuten, dass die beobachteten Einkommensunterschiede die gesamtwirtschaftlichen Effizienzsteigerungen nicht vollständig erfassen. Andererseits zeigen Untersuchungen, dass ein (geringer) Teil der Entgeltzuschläge für die besser Qualifizierten auf der Vermutung bestimmter Qualitäten durch die Arbeitgeber im Zusammenhang mit einem Bildungstand zurückzuführen ist, und nicht auf Produktivitätsdifferenziale, die sich aus Steigerungen im Humankapital ergeben. Außerdem sind diese indirekten Vorteile der Bildung zwar beträchtlich, lassen sich jedoch zum Zwecke einer Ertragsberechnung meist nur schwer monetär ausdrücken.

Tabellen Arr.6 und Arr.7 zeigen die Schätzwerte der gesellschaftlichen Ertragsraten für drei Szenarien:

Der Arbeitnehmer erlangt den nächsthöheren Bildungsabschluss unmittelbar, noch bevor er in den Arbeitsmarkt eintritt.

Ein 40-Jähriger nimmt eine Vollzeitausbildung auf, um die nächsthöhere Qualifikation zu erwerben.

Der Bildungsteilnehmer nimmt berufsbegleitend und in Teilzeit an der Bildungsmaßnahme teil, d.h. er ist weiterhin erwerbstätig. Hierbei wird unterstellt, dass die Ausbildungsdauer doppelt so lang ist wie bei einem Bildungsteilnehmer in Vollzeitausbildung.

Angesichts der Probleme bei der Herleitung einer umfassenden gesellschaftlichen Ertragsrate enthalten diese Berechnungen die Schätzungen einer, eng gefassten' Definition, die sämtliche externen Effekte unberücksichtigt lässt. Daher werden diese Schätzungen nach unten verzerrt sein, soweit mit den Investitionen in Humankapital seitens des durchschnittlichen Studierenden beträchtliche positive externe Effekte verbunden sind. Arithmetisch gesehen stellen gesellschaftliche Kosten und Nutzen lediglich die Summe von individuellen und öffentlichen Kosten und Nutzen dar. Somit hat es keine Auswirkungen auf die gesellschaftliche Ertragsrate, ob der Bildungsteilnehmer die Studiengebühren selbst trägt oder nicht. Denn die Kosten, die für die Privatperson nicht anfallen, werden zu staatlichen Kosten. Daher sind in den Tabellen Arr.6 und Arr.7 keine getrennten gesellschaftlichen Ertragsraten für den Fall der Kostenübernahme bzw. Kostenfreiheit für den Bildungsteilnehmer aufgeführt, denn die gesellschaftlichen Ertragsraten (jedoch nicht die öffentliche Ertragsrate) bleiben ja in jedem Fall gleich.

Die in Tabelle Arr.6 aufgeführten Schätzungen legen nahe, dass die gesellschaftliche Ertragsrate im Sekundarbereich II in Spanien, Ungarn und den Vereinigten Staaten besonders hoch ist, während sie in Finnland am niedrigsten ausfällt und sogar beachtlich negativ ist. Im Tertiärbereich (Tab. AII.7) ist die gesellschaftliche Ertragsrate in Finnland, Spanien, Ungarn, dem Vereinigten Königreich und den Vereinigten Staaten besonders hoch und in Dänemark am niedrigsten.

Sowohl im Sekundarbereich II als auch im Tertiärbereich liegen die ,engen gesellschaftlichen Ertragsraten in den meisten Ländern unter den individuellen Ertragsraten. Dieses Ergebnis verdeutlicht die Tatsache, dass die gesell-

... die momentan jedoch nur im engeren Sinne, ohne Berücksichtigung der nicht direkt ökonomischen Vorteile, geschätzt werden kann.

Die gesellschaftlichen Ertragsraten liegen angesichts der erheblichen 
gesellschaftlichen Kosten der Bildung im Allgemeinen unter den individuellen Ertragsraten.
Mit wenigen Ausnahmen wirken sich politische Maßnahmen zur Senkung der direkten Bildungskosten nur geringfügig auf die Entscheidungen des Einzelnen aus, im Laufe seiner beruflichen Laufbahn in Bildung zu investieren.
In vielen Ländern liegen die individuellen und schaftlichen Kosten der Bildung normalerweise wesentlich höher sind als die individuellen Kosten. Die wesentlichsten Ausnahmen sind Schweden für den Sekundarbereich II sowie Australien und das Vereinigte Königreich für den Tertiärbereich. Die Unterschiede (private Ertragsrate über der gesellschaftlichen) sind im Tertiärbereich besonders signifikant in Dänemark, Finnland, der Schweiz und Ungarn und bewegen sich zwischen 2 und 5,4 Prozentpunkten. Im Sekundarbereich II ist der Unterschied zwischen der individuellen und der gesellschaftlichen Ertragsrate (private Ertragsrate über der gesellschaftlichen) in Dänemark und der Schweiz besonders groß.

Untersucht man das Szenario einer berufsbegleitenden Teilzeitausbildung, fällt beim Erreichen des Abschlusses im Sekundarbereich II auf, dass hierfür die Ertragsraten systematisch höher sind als für 40-Jährige in Vollzeitausbildung. Wird jedoch ein Bildungsabschluss im Tertiärbereich angestrebt, wird das Bild uneinheitlicher. Bei Teilzeitausbildung liegen die Ertragsraten sowohl für Männer als auch für Frauen in Schweden und dem Vereinigten Königreich höher. In einigen Ländern gibt es jedoch nur für Männer höhere Ertragsraten, so z. B. in Australien, Dänemark, Finnland, Spanien und der Schweiz.

\section{Was die Ertragsraten aussagen}

Gegenwärtig unterbrechen nur wenige Erwachsene ihre berufliche Laufbahn, um sich einer Vollzeit-(Aus)Bildung zu widmen. Das in den Tabellen Arr.6 und AII.7 behandelte Szenario, in dem ein Erwachsener im erwerbsfähigen Alter sich berufsbegleitend weiterbildet, um den nächst höheren Bildungsabschluss zu erreichen, ist weitaus häufiger anzutreffen. Die vorgestellten Ergebnisse reagieren recht sensibel auf Annahmen über das Einkommen von Personen im erwerbsfähigen Alter, die nach Erwerb des nächst höheren Bildungsabschlusses wieder in den Arbeitsmarkt zurückkehren. Verdoppelt man die Dauer für die Angleichung der Einkommen von 3 auf 6 Jahre, sinkt die individuelle Ertragsrate durchschnittlich um einen Prozentpunkt. Wie oben schon gesagt, sind die empirischen Grundlagen für die Einkommensannahmen recht schwach. Ferner stellen diese Daten ausschließlich die rechnerischen Ertragsraten dar. Diese Ergebnisse unterscheiden sich zweifellos von ökonometrischen Schätzungen, die als Kontrollvariablen eigene Fähigkeiten und andere Merkmale derjenigen einbeziehen würden, die sich für eine Bildungsinvestition entscheiden.

Sowohl für diejenigen, die einen Abschluss im Sekundarbereich II erwerben, als auch für diejenigen, die einen Abschluss im Tertiärbereich anstreben, liegen die individuellen Ertragsraten in einer Reihe von Ländern über den realen Zinssätzen, häufig sogar wesentlich darüber. In diesen Ländern scheint eine Investition in das Humankapital eine attraktive Art der Vermögensbildung für den Durchschnittsbürger zu sein. In anderen Ländern sind die Anreize für eine Investition in Bildung eher gering. Außerdem wirken sich, von wenigen Ausnahmen abgesehen, politische Maßnahmen zur Abschaffung (oder Senkung) der direkten Bildungskosten nur geringfügig auf die Entscheidungen des Einzelnen aus, im Laufe seiner beruflichen Laufbahn in Bildung zu investieren.

In den meisten Fällen übersteigen die berichteten individuellen und gesellschaftlichen Ertragsraten den risikofreien Realzins - in einer Reihe von Län- 
dern sogar recht deutlich. Die Erträge aus der Bildung von Humankapital sind jedoch nicht risikolos wie die große Einkommensspanne unter den besser Gebildeten zeigt. Daher werden diejenigen, die eine Bildungsinvestition erwägen, einen Risikoaufschlag zum Ausgleich fordern. In einer Reihe von Ländern ist der Abstand der Ertragsrate zum Realzins jedoch größer, als sich alleine durch den Risikoaufschlag erklären lässt. Politisch relevant ist hier die Erkenntnis, dass für den Einzelnen offensichtlich bestimmte Hindernisse bei diesen Investitionen bestehen müssen, wenn doch diese Investitionsalternative im Vergleich zu anderen Investitionen mit ähnlichem Risiko eine höhere Ertragsrate hat. Auf den ersten Blick liefern die um das hohe Risiko angepassten individuellen Ertragsraten Gründe für ein politisches Eingreifen zur Abmilderung der bestehenden Hindernisse.

Hohe Ertragsraten lassen sich z. B. als ein Hinweis auf einen Mangel an besser ausgebildeten Arbeitskräften interpretieren, was die Einkommen für besser ausgebildete Arbeitskräfte nach oben triebe. Dies könnte ein nur vorübergehender Zustand sein, da die hohe Ertragsrate der Bildung letztendlich eine ausreichende Reaktion auf der Angebotsseite ausgelöst haben wird, um diese Ertragsrate auf das Niveau für andere Produktionsmittel zu drücken. Diese Anpassungsperiode könnte sich jedoch recht lange hinziehen und das Tempo der Anpassung hinge dann stark von der Fähigkeit des Bildungssystems ab, die gesteigerte Nachfrage zu befriedigen sowie von der Fähigkeit des Arbeitsmarktes, das relativ geänderte Arbeitskräfteangebot zu verkraften. Der Anpassungsmechanismus könnte auch durch mehr Aufklärung der Studierenden über die Erträge aus den einzelnen Bildungs- und Studiengängen beschleunigt werden, so dass sie ihre Entscheidungen bewusster treffen könnten.

Diese hohen Erträge können teilweise durchaus mit dem Marktgleichgewicht in Einklang stehen. Dies wäre dann der Fall, wenn die Grenzertragsraten wesentlich unter den Durchschnittsertragsraten lägen. Die Grenzertragsrate läge tatsächlich unter der Durchschnittsertragsrate, wenn die Studierenden im Grenzbereich weniger begabt oder motiviert wären als der Durchschnitt und somit den durchschnittlichen Gehaltszuschlag wahrscheinlich gar nicht erhalten würden. Bei dieser Auslegung würden die hohen Ertragsraten teilweise den Preis für eine knappe Ressource, nämlich Talent und Motivation, zur Geltung bringen. Falls die Bildungserträge im Grenzbereich niedriger sind, ist staatliches Eingreifen zur Förderung der Bildung von Humankapital nicht mehr so dringlich, falls die Qualität der Studierenden im Grenzbereich ohnehin nicht mehr steigerungsfähig ist. In dem Maße jedoch, in dem Bildungssysteme die kognitiven und nicht-kognitiven Fähigkeiten junger Menschen verbessern können, würde die Bildungspolitik andererseits langfristig in der Lage sein, einen wesentlichen Beitrag zu mehr Effizienz und gleichen Bildungschancen zu leisten.

\section{Definitionen und angewandte Methodik}

Bei den Einkommensdaten in Tabelle AIr.I handelt es sich für Finnland, Italien, Kanada, die Niederlande, Norwegen, Schweden, Spanien, die Tschechische Republik und die Vereinigten Staaten um Jahresangaben. In Australien, 
Irland, Neuseeland und dem Vereinigten Königreich wurde das Wocheneinkommen angegeben und in den übrigen Ländern das Monatseinkommen (für Dänemark liegen dem OECD-Sekretariat allerdings keine Angaben über den Bezugszeitraum vor). Die Einkommensangaben für Portugal, Ungarn und die Vereinigten Staaten beziehen sich nur auf Vollzeitbeschäftigte. In Korea, Portugal und Ungarn sind auch keine Teilzeit- oder saisonal Beschäftigten einbezogen. Die französischen Daten beinhalten keine Angaben über Selbständige und die Einkommen von Firmenbesitzern bleiben in Frankreich, Irland, Korea, den Niederlanden, Portugal, Spanien und Ungarn unberücksichtigt. Die beobachteten länderspezifischen Unterschiede der relativen Einkommen spiegeln daher nicht nur Unterschiede in den Löhnen und Gehältern, sondern auch Unterschiede in der Erfassung, in der Zahl der Arbeitswochen pro Jahr und der Zahl der Arbeitsstunden pro Woche wider. Da ein niedrigerer Bildungsstand mit einer geringeren Arbeitsstundenzahl (insbesondere durch Teilzeitarbeit) und mit unsichereren Beschäftigungsverhältnissen (einer größeren Wahrscheinlichkeit von nur befristeten Anstellungen oder einer größeren Anfälligkeit für Arbeitslosigkeit im Laufe eines Jahres) einhergehen, werden die relativen Einkommen für höhere Bildungsniveaus in den Tabellen und Abbildungen höher sein als die, die sich aus einer Untersuchung der relativen Löhne und Gehälter ergeben würden. Auch die beobachteten geschlechtsspezifischen Unterschiede der relativen Einkommen innerhalb eines Landes können durch einige dieser Faktoren beeinflusst sein.

Zur Berechnung der Ertragsraten für Arbeitnehmer, die ihre berufliche Laufbahn unterbrochen haben und nach dem Erwerb des nächsthöheren Bildungsabschlusses die Berufstätigkeit wieder aufnehmen, wurden bestimmte Annahmen über das Einkommen gemacht. Die Annahmen betrafen den unmittelbaren Einkommensanstieg (Io Prozent) und die Länge des Zeitraums, der erforderlich ist, bis sich das Einkommen an das Durchschnittseinkommen der Personen angeglichen hat, die diesen nächsthöheren Bildungsabschluss schon besitzen ( 3 Jahre). Diese Annahmen sind einigermaßen willkürlich. Es gibt nur wenige empirische Erkenntnisse über das Einkommen Erwachsener, die nach Teilzeit- oder Vollzeitbildungsmaßnahmen wieder ins Erwerbsleben zurückkehren, insbesondere für solche, die einen Abschluss im Sekundarbereich II erwerben. Ergebnisse aus Kanada weisen jedoch darauf hin, dass der Anpassungszeitraum bei 30- bis 49-Jährigen, die einen Universitätsabschluss erwerben, knapp zwei Jahre dauert, für diejenigen, die ein College Certificate erwerben, ist er noch kürzer (OECD [2003], Bildungspolitische Analyse, Paris). Dennoch ist zu beachten, dass die kanadischen Daten bei einer relativ kleinen Stichprobe erhoben wurden, bei der es keine Kontrolle für die Tatsache gab, dass diejenigen, die in Bildung investierten, sich möglicherweise stark von denjenigen unterschieden, die das nicht taten, beispielsweise in so wichtigen Aspekten wie Motivation und individuelle Fähigkeiten.

Zur Berechnungsmethode für die Ertragsraten in Tabellen AII.4 bis AII.7 s. Anhang 3 unter www.oecd.org/eduleag2004. 
Relative Einkommen der Bevölkerung mit Erwerbseinkommen (2002)

Nach Bildungsstand und Geschlecht für 25- bis 64-Jährige und 30- bis 44-Jährige (Abschluss im Sekundarbereich II = 100)

\begin{tabular}{|c|c|c|c|c|c|c|c|c|c|c|c|c|}
\hline & & & \multicolumn{2}{|c|}{$\begin{array}{c}\text { Unterhalb } \\
\text { Sekundarbereich II }\end{array}$} & \multicolumn{2}{|c|}{$\begin{array}{l}\text { Post-sekundarer, } \\
\text { nicht-tertiärer Bereich }\end{array}$} & \multicolumn{2}{|c|}{ Tertiärbereich B } & \multicolumn{2}{|c|}{$\begin{array}{l}\text { Tertiärbereich A und } \\
\text { weiterführende } \\
\text { Forschungsprogramme }\end{array}$} & \multicolumn{2}{|c|}{$\begin{array}{l}\text { Tertiärbereich } \\
\text { insgesamt }\end{array}$} \\
\hline \multicolumn{13}{|l|}{ OECD-Länder } \\
\hline \multirow[t]{3}{*}{ Australien } & 2001 & Männer & 85 & 83 & $\mathrm{~m}$ & $\mathrm{~m}$ & 116 & 108 & 160 & 157 & 145 & 141 \\
\hline & & Frauen & 85 & 84 & $\mathrm{~m}$ & $\mathrm{~m}$ & 114 & 119 & 159 & 168 & 142 & 151 \\
\hline & & $\mathrm{M}+\mathrm{F}$ & 77 & 75 & $\mathrm{~m}$ & $\mathrm{~m}$ & 106 & 102 & 148 & 148 & 133 & 132 \\
\hline \multirow[t]{3}{*}{ Belgien } & 2002 & Männer & 91 & 97 & $\mathrm{~m}$ & $\mathrm{~m}$ & 116 & 120 & 144 & 149 & 132 & 136 \\
\hline & & Frauen & 84 & 83 & $\mathrm{~m}$ & $\mathrm{~m}$ & 124 & 124 & 168 & 185 & 140 & 146 \\
\hline & & $\mathrm{M}+\mathrm{F}$ & 91 & 95 & $\mathrm{~m}$ & $\mathrm{~m}$ & 114 & 115 & 152 & 162 & 132 & 136 \\
\hline \multirow[t]{3}{*}{ Kanada } & 2001 & Männer & 79 & 78 & 104 & 106 & 117 & 115 & 179 & 183 & 147 & 147 \\
\hline & & Frauen & 68 & 65 & 101 & 96 & 119 & 120 & 179 & 179 & 145 & 145 \\
\hline & & $\mathrm{M}+\mathrm{F}$ & 79 & 78 & 105 & 105 & 115 & 113 & 177 & 178 & 143 & 142 \\
\hline \multirow{3}{*}{$\begin{array}{l}\text { Tschechische } \\
\text { Republik }\end{array}$} & 1999 & Männer & 75 & 77 & a & a & 177 & 182 & 178 & 176 & 178 & 177 \\
\hline & & Frauen & 72 & 75 & a & a & 127 & 124 & 172 & 176 & 170 & 174 \\
\hline & & $\mathrm{M}+\mathrm{F}$ & 68 & 70 & a & a & 151 & 151 & 180 & 182 & 179 & 181 \\
\hline Dänemark & 2001 & Männer & 87 & 83 & 106 & 108 & 110 & 109 & 139 & 135 & 132 & 128 \\
\hline & & Frauen & 90 & 89 & 124 & 128 & 114 & 112 & 125 & 122 & 124 & 121 \\
\hline & & $\mathrm{M}+\mathrm{F}$ & 87 & 85 & 118 & 120 & 114 & 113 & 127 & 123 & 125 & 121 \\
\hline Finnland & 2001 & Männer & 92 & 89 & $\mathrm{~m}$ & $\mathrm{~m}$ & 129 & 125 & 190 & 180 & 163 & 155 \\
\hline & & Frauen & 98 & 94 & $\mathrm{~m}$ & $\mathrm{~m}$ & 126 & 124 & 172 & 167 & 146 & 141 \\
\hline & & $\mathrm{M}+\mathrm{F}$ & 95 & 92 & $\mathrm{~m}$ & $\mathrm{~m}$ & 121 & 115 & 181 & 171 & 150 & 141 \\
\hline Frankreich & 2002 & Männer & 88 & 86 & $\mathrm{~m}$ & $\mathrm{~m}$ & 127 & 132 & 178 & 173 & 159 & 157 \\
\hline & & Frauen & 81 & 80 & $\mathrm{~m}$ & $\mathrm{~m}$ & 131 & 135 & 157 & 159 & 146 & 148 \\
\hline & & $\mathrm{M}+\mathrm{F}$ & 84 & 84 & $\mathrm{~m}$ & $\mathrm{~m}$ & 125 & 129 & 167 & 165 & 150 & 150 \\
\hline Deutschland & 2002 & Männer & 85 & 87 & 110 & 110 & 117 & 113 & 156 & 152 & 142 & 137 \\
\hline & & Frauen & 75 & 72 & 132 & 136 & 117 & 112 & 157 & 153 & 142 & 138 \\
\hline & & $\mathrm{M}+\mathrm{F}$ & 78 & 80 & 116 & 116 & 120 & 115 & 161 & 154 & 146 & 139 \\
\hline Ungarn & 2001 & Männer & 81 & 81 & 140 & 137 & 205 & 182 & 252 & 253 & 252 & 253 \\
\hline & & Frauen & 77 & 80 & 128 & 124 & 143 & 128 & 180 & 174 & 179 & 174 \\
\hline & & $M+F$ & 77 & 78 & 131 & 126 & 164 & 144 & 210 & 203 & 210 & 202 \\
\hline Irland & 2000 & Männer & 82 & 77 & 79 & 60 & 117 & 123 & 143 & 140 & 135 & 133 \\
\hline & & Frauen & 64 & 61 & 94 & 78 & 132 & 126 & 181 & 155 & 161 & 144 \\
\hline & & $\mathrm{M}+\mathrm{F}$ & 87 & 83 & 82 & 67 & 124 & 130 & 163 & 152 & 149 & 143 \\
\hline Italien & 2000 & Männer & 71 & 72 & $\mathrm{~m}$ & $\mathrm{~m}$ & $\mathrm{~m}$ & $\mathrm{~m}$ & 143 & 140 & 143 & 140 \\
\hline & & Frauen & 84 & 80 & $\mathrm{~m}$ & $\mathrm{~m}$ & $\mathrm{~m}$ & $\mathrm{~m}$ & 137 & 132 & 137 & 132 \\
\hline & & $\mathrm{M}+\mathrm{F}$ & 78 & 77 & $\mathrm{~m}$ & $\mathrm{~m}$ & $\mathrm{~m}$ & $\mathrm{~m}$ & 138 & 133 & 138 & 133 \\
\hline Korea & 1998 & Männer & 88 & 90 & $\mathrm{~m}$ & $\mathrm{~m}$ & 105 & 109 & 143 & 136 & 132 & 129 \\
\hline & & Frauen & 69 & 75 & $\mathrm{~m}$ & $\mathrm{~m}$ & 118 & 138 & 160 & 181 & 141 & 164 \\
\hline & & $\mathrm{M}+\mathrm{F}$ & 78 & 80 & $\mathrm{~m}$ & $\mathrm{~m}$ & 106 & 113 & 147 & 142 & 135 & 134 \\
\hline Niederlande & 1997 & Männer & 88 & 86 & 126 & 121 & 145 & 130 & 141 & 133 & 142 & 132 \\
\hline & & Frauen & 73 & 73 & 120 & 124 & 131 & 136 & 148 & 154 & 146 & 152 \\
\hline & & $\mathrm{M}+\mathrm{F}$ & 85 & 84 & 121 & 119 & 139 & 131 & 144 & 139 & 144 & 138 \\
\hline Neuseeland & 2001 & Männer & 76 & 74 & $\mathrm{~m}$ & $\mathrm{~m}$ & $\mathrm{~m}$ & $\mathrm{~m}$ & 130 & 122 & 130 & 122 \\
\hline & & Frauen & 72 & 72 & $\mathrm{~m}$ & $\mathrm{~m}$ & $\mathrm{~m}$ & $\mathrm{~m}$ & 136 & 135 & 136 & 135 \\
\hline & & $\mathrm{M}+\mathrm{F}$ & 74 & 75 & $\mathrm{~m}$ & $\mathrm{~m}$ & $\mathrm{~m}$ & $\mathrm{~m}$ & 133 & 128 & 133 & 128 \\
\hline Norwegen & 2002 & Männer & 86 & 90 & 118 & 114 & 142 & 145 & 139 & 139 & 139 & 139 \\
\hline & & Frauen & 83 & 88 & 121 & 116 & 149 & 152 & 141 & 142 & 141 & 143 \\
\hline & & $M+F$ & 85 & 91 & 125 & 121 & 155 & 152 & 135 & 135 & 137 & 136 \\
\hline Portugal & 1999 & Männer & 60 & 57 & $\mathrm{~m}$ & $\mathrm{~m}$ & 150 & 155 & 190 & 194 & 180 & 185 \\
\hline & & Frauen & 63 & 58 & $\mathrm{~m}$ & $\mathrm{~m}$ & 133 & 139 & 188 & 206 & 170 & 185 \\
\hline & & $\mathrm{M}+\mathrm{F}$ & 62 & 58 & $\mathrm{~m}$ & $\mathrm{~m}$ & 141 & 146 & 192 & 202 & 178 & 187 \\
\hline Spanien & 2001 & Männer & 79 & 82 & $\mathrm{~m}$ & $\mathrm{~m}$ & 99 & 97 & 157 & 135 & 138 & 122 \\
\hline & & Frauen & 64 & 65 & $\mathrm{~m}$ & $\mathrm{~m}$ & 86 & 88 & 136 & 138 & 125 & 126 \\
\hline & & $\mathrm{M}+\mathrm{F}$ & 78 & 80 & $\mathrm{~m}$ & $\mathrm{~m}$ & 95 & 95 & 141 & 133 & 129 & 122 \\
\hline Schweden & 2001 & Männer & 87 & 86 & 128 & 134 & 114 & 114 & 158 & 162 & 146 & 149 \\
\hline & & Frauen & 88 & 85 & 108 & 111 & 116 & 109 & 139 & 137 & 130 & 126 \\
\hline & & $\mathrm{M}+\mathrm{F}$ & 89 & 87 & 127 & 132 & 110 & 105 & 148 & 148 & 135 & 133 \\
\hline Schweiz & 2003 & Männer & 77 & 79 & 110 & 106 & 121 & 122 & 149 & 149 & 138 & 138 \\
\hline & & Frauen & 76 & 85 & 118 & 120 & 140 & 150 & 164 & 174 & 156 & 166 \\
\hline & & $\mathrm{M}+\mathrm{F}$ & 76 & 81 & 112 & 111 & 141 & 146 & 168 & 170 & 158 & 161 \\
\hline Vereinigtes & 2001 & Männer & 72 & 67 & $\mathrm{~m}$ & $\mathrm{~m}$ & 124 & 126 & 157 & 162 & 147 & 151 \\
\hline Königreich & & Frauen & 70 & 74 & $\mathrm{~m}$ & $\mathrm{~m}$ & 142 & 133 & 206 & 216 & 183 & 183 \\
\hline & & $\mathrm{M}+\mathrm{F}$ & 67 & 68 & $\mathrm{~m}$ & $\mathrm{~m}$ & 128 & 124 & 174 & 181 & 159 & 161 \\
\hline Vereinigte & 2002 & Männer & 68 & 70 & 122 & 125 & 120 & 122 & 202 & 205 & 193 & 195 \\
\hline Staaten & & Frauen & 67 & 67 & 118 & 117 & 122 & 122 & 185 & 191 & 176 & 182 \\
\hline & & $\mathrm{M}+\mathrm{F}$ & 71 & 71 & 120 & 121 & 118 & 118 & 195 & 196 & 186 & 187 \\
\hline
\end{tabular}


Tabelle A11.1b

Einkommensunterschiede zwischen Frauen und Männern (2002)

Durchschnittliche Jahreseinkommen von Frauen als Prozentsatz derjenigen von Männern, nach Bildungsstand, für 30- bis 44-Jährige und 55- bis 64-Jährige

\begin{tabular}{l|l} 
OECD-Länder & 2001 \\
Australien & 2002 \\
Belgien & 2001 \\
Kanada & 1999 \\
Tschechische Rep. & 2001 \\
Dänemark & 2001 \\
Finnland & 2002 \\
Frankreich & 2002 \\
Deutschland & 2001 \\
Ungarn & 2000 \\
Irland & 2000 \\
Italien & 1998 \\
Korea & 1997 \\
Niederlande & 2001 \\
Neuseeland & 2002 \\
Norwegen & 1999 \\
Portugal & 2001 \\
Spanien & 2001 \\
Schweden & 2003 \\
Schweiz & 2001 \\
Ver. Königreich & 2001 \\
Vereinigte Staaten &
\end{tabular}

\begin{tabular}{|c|c|c|c|c|c|c|c|c|c|}
\hline \multicolumn{2}{|c|}{$\begin{array}{c}\text { Unterhalb } \\
\text { Sekundarbereich II }\end{array}$} & \multicolumn{2}{|c|}{$\begin{array}{l}\text { Sekundarbereich II } \\
\text { und post-sekundarer, } \\
\text { nicht-tertiärer Bereich }\end{array}$} & \multicolumn{2}{|c|}{ Tertiärbereich B } & \multicolumn{2}{|c|}{$\begin{array}{l}\text { Tertiärbereich A und } \\
\text { weiterführende } \\
\text { Forschungsprogramme }\end{array}$} & \multicolumn{2}{|c|}{$\begin{array}{c}\text { Alle Bildungsbereiche } \\
\text { zusammen }\end{array}$} \\
\hline $30-44 \mathrm{~J}$. & $55-64 \mathrm{~J}$. & $30-44 \mathrm{~J}$. & $55-64 \mathrm{~J}$. & $30-44 \mathrm{~J}$. & $55-64$ J. & $30-44 \mathrm{~J}$ & $55-64 J$. & $30-44 \mathrm{~J}$. & $55-64 J$. \\
\hline 61 & 59 & 60 & 70 & 65 & 58 & 64 & 58 & 63 & 60 \\
\hline 61 & 65 & 72 & 66 & 74 & 81 & 89 & 82 & 75 & 67 \\
\hline 50 & 60 & 59 & 70 & 63 & 57 & 59 & 55 & 61 & 62 \\
\hline 66 & 58 & 67 & 64 & 45 & 62 & 67 & 63 & 63 & 61 \\
\hline 76 & 68 & 71 & 70 & 73 & 74 & 64 & 64 & 72 & 67 \\
\hline 71 & 77 & 67 & 76 & 67 & 73 & 62 & 68 & 69 & 71 \\
\hline 70 & 65 & 76 & 72 & 78 & 68 & 69 & 66 & 76 & 62 \\
\hline 48 & 66 & 60 & 55 & 57 & 56 & 59 & 65 & 58 & 54 \\
\hline 83 & 81 & 84 & 94 & 59 & 48 & 58 & 69 & 77 & 78 \\
\hline 50 & 48 & 63 & 39 & 64 & 47 & 69 & 80 & 65 & 56 \\
\hline 79 & 78 & 72 & 53 & $\mathrm{~m}$ & $\mathrm{~m}$ & 67 & 83 & 77 & 69 \\
\hline 57 & 62 & 69 & 70 & 87 & 96 & 92 & 99 & 67 & 50 \\
\hline 46 & 43 & 55 & 50 & 57 & 39 & 63 & 50 & 55 & 45 \\
\hline 59 & 57 & 61 & 70 & $\mathrm{~m}$ & $\mathrm{~m}$ & 68 & 54 & 62 & 61 \\
\hline 60 & 62 & 61 & 63 & 65 & 66 & 63 & 62 & 64 & 61 \\
\hline 72 & 70 & 70 & 67 & 63 & 57 & 75 & 68 & 73 & 66 \\
\hline 61 & 48 & 78 & 74 & 70 & 57 & 79 & 42 & 79 & 47 \\
\hline 72 & 73 & 71 & 69 & 70 & 73 & 62 & 66 & 70 & 71 \\
\hline 53 & 47 & 50 & 51 & 61 & 51 & 58 & 59 & 50 & 46 \\
\hline 55 & 43 & 50 & 53 & 53 & 81 & 66 & 66 & 54 & 54 \\
\hline 59 & 65 & 61 & 61 & 62 & 69 & 58 & 59 & 61 & 58 \\
\hline
\end{tabular}

Quelle: OECD. Hinweise s. Anhang 3 unter www.oecd.org/edu/eag2004. 
Tabelle A11.2

Entwicklung der relativen Einkommen: Erwachsenenbevölkerung (1997-2002)

Nach Bildungsstand, für 25- bis 64-Jährige (Sekundarbereich II und post-sekundarer, nicht-tertiärer Bereich = 100

OECD-Länder

Australien

Belgien

Kanada

Tschechische

Republik

Dänemark

Finnland

Frankreich

Deutschland

Ungarn

Irland

Italien

Korea

Niederlande

Neuseeland

Norwegen

Portugal

Spanien

Schweden

Schweiz

Vereinigtes

Königreich

Vereinigte Staaten
Abschluss unterhalb Sekundarbereich II Tertiärbereich

Abschluss unterhalb Sekundarbereich II Tertiärbereich

Abschluss unterhalb Sekundarbereich II Tertiärbereich

Abschluss unterhalb Sekundarbereich II Tertiärbereich

Abschluss unterhalb Sekundarbereich II Tertiärbereich

Abschluss unterhalb Sekundarbereich II Tertiärbereich

Abschluss unterhalb Sekundarbereich II Tertiärbereich

Abschluss unterhalb Sekundarbereich II Tertiärbereich

Abschluss unterhalb Sekundarbereich II Tertiärbereich

Abschluss unterhalb Sekundarbereich II Tertiärbereich

Abschluss unterhalb Sekundarbereich II Tertiärbereich

Abschluss unterhalb Sekundarbereich II Tertiärbereich

Abschluss unterhalb Sekundarbereich II Tertiärbereich

Abschluss unterhalb Sekundarbereich II Tertiärbereich

Abschluss unterhalb Sekundarbereich II Tertiärbereich

Abschluss unterhalb Sekundarbereich II Tertiärbereich

Abschluss unterhalb Sekundarbereich II Tertiärbereich

Abschluss unterhalb Sekundarbereich II Tertiärbereich

Abschluss unterhalb Sekundarbereich II Tertiärbereich

Abschluss unterhalb Sekundarbereich II Tertiärbereich

Abschluss unterhalb Sekundarbereich II Tertiärbereich

\begin{tabular}{|c|c|c|}
\hline 1997 & 1998 & 1999 \\
\hline 79 & $\mathrm{~m}$ & 80 \\
\hline 124 & $\mathrm{~m}$ & 134 \\
\hline $\mathrm{m}$ & $\mathrm{m}$ & $\mathrm{m}$ \\
\hline $\mathrm{m}$ & $\mathrm{m}$ & $\mathrm{m}$ \\
\hline 84 & 78 & 80 \\
\hline 127 & 138 & 136 \\
\hline 68 & 68 & 68 \\
\hline 179 & 179 & 179 \\
\hline 85 & 86 & 86 \\
\hline 123 & 124 & 124 \\
\hline 97 & 96 & 96 \\
\hline 148 & 148 & 153 \\
\hline 84 & 84 & 84 \\
\hline 149 & 150 & 150 \\
\hline 81 & 78 & 79 \\
\hline 134 & 130 & 135 \\
\hline 68 & 68 & 70 \\
\hline 179 & 184 & 200 \\
\hline 75 & 79 & $\mathrm{~m}$ \\
\hline 146 & 142 & $\mathrm{~m}$ \\
\hline $\mathrm{m}$ & 58 & $\mathrm{~m}$ \\
\hline $\mathrm{m}$ & 127 & $\mathrm{~m}$ \\
\hline $\mathrm{m}$ & 78 & $\mathrm{~m}$ \\
\hline $\mathrm{m}$ & 135 & $\mathrm{~m}$ \\
\hline 83 & $\mathrm{~m}$ & $\mathrm{~m}$ \\
\hline 141 & $\mathrm{~m}$ & $\mathrm{~m}$ \\
\hline 77 & 76 & 76 \\
\hline 148 & 136 & 139 \\
\hline 85 & 84 & 84 \\
\hline 138 & 132 & 133 \\
\hline 62 & 62 & 62 \\
\hline 176 & 177 & 178 \\
\hline 76 & 80 & $\mathrm{~m}$ \\
\hline 149 & 144 & $\mathrm{~m}$ \\
\hline 90 & 89 & 89 \\
\hline 129 & 130 & 131 \\
\hline 74 & 75 & 76 \\
\hline 152 & 153 & 151 \\
\hline 64 & 65 & 65 \\
\hline 153 & 157 & 159 \\
\hline 70 & 67 & 65 \\
\hline 168 & 173 & 166 \\
\hline 78 & 76 & 77 \\
\hline 148 & 148 & 151 \\
\hline
\end{tabular}

$2000-\mid=2001$

m

92

128

80

140

m

m

$\mathrm{m}$

$\mathrm{m}$

m

m

m

$\mathrm{m}$

75

143

71

194

89

153

78

138
2002

\section{m}

m

91

132

m

m

m

m

m

$\mathrm{m}$

m

m

84

150

77

143

m

m

m

m

$\mathrm{m}$

m

m

m

m

m

m

$\mathrm{m}$

84

135

m

m

m

$\mathrm{m}$

m

m

77

156

m

m

66

172

Quelle: OECD. Hinweise s. Anhang 3 unter www.oecd.org/edu/eag2004. 
Tabelle A11.2a

Entwickiung der relativen Einkommen: manniliche Bevolkerung (1997-2002)

11 Nach Bildungsstand, für 25- bis 64-jährige Männer (Sekundarbereich II und post-sekundarer, nicht-tertiärer Bereich = 100)

\begin{tabular}{|c|c|c|c|c|c|c|c|}
\hline \multicolumn{8}{|l|}{ OECD-Länder } \\
\hline Australien & $\begin{array}{l}\text { Abschluss unterhalb Sekundarbereich II } \\
\text { Tertiärbereich }\end{array}$ & $\begin{array}{r}87 \\
136\end{array}$ & $\begin{array}{l}\mathrm{m} \\
\mathrm{m}\end{array}$ & $\begin{array}{r}86 \\
139\end{array}$ & $\mathrm{~m}$ & $\begin{array}{r}85 \\
145\end{array}$ & $\begin{array}{l}\mathrm{m} \\
\mathrm{m}\end{array}$ \\
\hline Belgien & $\begin{array}{l}\text { Abschluss unterhalb Sekundarbereich II } \\
\text { Tertiärbereich }\end{array}$ & $\begin{array}{l}\mathrm{m} \\
\mathrm{m}\end{array}$ & $\mathrm{m}$ & $\begin{array}{l}\mathrm{m} \\
\mathrm{m}\end{array}$ & $\begin{array}{r}93 \\
128\end{array}$ & $\begin{array}{l}\mathrm{m} \\
\mathrm{m}\end{array}$ & $\begin{array}{r}92 \\
132\end{array}$ \\
\hline Kanada & $\begin{array}{l}\text { Abschluss unterhalb Sekundarbereich II } \\
\text { Tertiärbereich }\end{array}$ & $\begin{array}{r}85 \\
127\end{array}$ & $\begin{array}{r}78 \\
140\end{array}$ & $\begin{array}{r}80 \\
138\end{array}$ & $\begin{array}{r}81 \\
144\end{array}$ & $\begin{array}{r}78 \\
145\end{array}$ & $\begin{array}{l}\mathrm{m} \\
\mathrm{m}\end{array}$ \\
\hline $\begin{array}{l}\text { Tschechische } \\
\text { Republik }\end{array}$ & $\begin{array}{l}\text { Abschluss unterhalb Sekundarbereich II } \\
\text { Tertiärbereich }\end{array}$ & $\begin{array}{r}75 \\
178\end{array}$ & $\begin{array}{r}75 \\
178\end{array}$ & $\begin{array}{r}75 \\
178\end{array}$ & $\mathrm{~m}$ & $\begin{array}{l}\mathrm{m} \\
\mathrm{m}\end{array}$ & $\begin{array}{l}\mathrm{m} \\
\mathrm{m}\end{array}$ \\
\hline Dänemark & $\begin{array}{l}\text { Abschluss unterhalb Sekundarbereich II } \\
\text { Tertiärbereich }\end{array}$ & $\begin{array}{r}86 \\
130\end{array}$ & $\begin{array}{r}87 \\
132\end{array}$ & $\begin{array}{r}87 \\
133\end{array}$ & $\begin{array}{l}m \\
m\end{array}$ & $\begin{array}{r}87 \\
132\end{array}$ & $\begin{array}{l}\mathrm{m} \\
\mathrm{m}\end{array}$ \\
\hline Finnland & $\begin{array}{l}\text { Abschluss unterhalb Sekundarbereich II } \\
\text { Tertiärbereich }\end{array}$ & $\begin{array}{r}94 \\
159\end{array}$ & $\begin{array}{r}93 \\
159\end{array}$ & $\begin{array}{r}93 \\
167\end{array}$ & $\begin{array}{l}\mathrm{m} \\
\mathrm{m}\end{array}$ & $\begin{array}{r}92 \\
163\end{array}$ & $\begin{array}{l}\mathrm{m} \\
\mathrm{m}\end{array}$ \\
\hline Frankreich & $\begin{array}{l}\text { Abschluss unterhalb Sekundarbereich II } \\
\text { Tertiärbereich }\end{array}$ & $\begin{array}{r}88 \\
158\end{array}$ & $\begin{array}{r}88 \\
159\end{array}$ & $\begin{array}{r}88 \\
159\end{array}$ & $\begin{array}{l}\mathrm{m} \\
\mathrm{m}\end{array}$ & $\mathrm{m}$ & $\begin{array}{r}88 \\
159\end{array}$ \\
\hline Deutschland & $\begin{array}{l}\text { Abschluss unterhalb Sekundarbereich II } \\
\text { Tertiärbereich }\end{array}$ & $\begin{array}{r}88 \\
130\end{array}$ & $\begin{array}{r}77 \\
126\end{array}$ & $\begin{array}{r}80 \\
138\end{array}$ & $\begin{array}{r}80 \\
141\end{array}$ & $\begin{array}{l}\mathrm{m} \\
\mathrm{m}\end{array}$ & $\begin{array}{r}84 \\
140\end{array}$ \\
\hline Ungarn & $\begin{array}{l}\text { Abschluss unterhalb Sekundarbereich II } \\
\text { Tertiärbereich }\end{array}$ & $\begin{array}{r}74 \\
213\end{array}$ & $\begin{array}{r}72 \\
218\end{array}$ & $\begin{array}{r}73 \\
238\end{array}$ & $\begin{array}{r}75 \\
232\end{array}$ & $\begin{array}{r}75 \\
232\end{array}$ & $\begin{array}{l}\mathrm{m} \\
\mathrm{m}\end{array}$ \\
\hline Irland & $\begin{array}{l}\text { Abschluss unterhalb Sekundarbereich II } \\
\text { Tertiärbereich }\end{array}$ & $\begin{array}{r}72 \\
131\end{array}$ & $\begin{array}{r}78 \\
131\end{array}$ & $\begin{array}{l}\mathrm{m} \\
\mathrm{m}\end{array}$ & $\begin{array}{r}84 \\
138\end{array}$ & $\begin{array}{l}\mathrm{m} \\
\mathrm{m}\end{array}$ & $\begin{array}{l}\mathrm{m} \\
\mathrm{m}\end{array}$ \\
\hline Italien & $\begin{array}{l}\text { Abschluss unterhalb Sekundarbereich II } \\
\text { Tertiärbereich }\end{array}$ & $\begin{array}{l}m \\
m\end{array}$ & $\begin{array}{r}54 \\
138\end{array}$ & $\begin{array}{l}\mathrm{m} \\
\mathrm{m}\end{array}$ & $\begin{array}{r}71 \\
143\end{array}$ & $\begin{array}{l}\mathrm{m} \\
\mathrm{m}\end{array}$ & $\begin{array}{l}\mathrm{m} \\
\mathrm{m}\end{array}$ \\
\hline Korea & $\begin{array}{l}\text { Abschluss unterhalb Sekundarbereich II } \\
\text { Tertiärbereich }\end{array}$ & $\begin{array}{l}\mathrm{m} \\
\mathrm{m}\end{array}$ & $\begin{array}{r}88 \\
132\end{array}$ & $\mathrm{~m}$ & $\begin{array}{l}\mathrm{m} \\
\mathrm{m}\end{array}$ & $\mathrm{m}$ & $\begin{array}{l}\mathrm{m} \\
\mathrm{m}\end{array}$ \\
\hline Niederlande & $\begin{array}{l}\text { Abschluss unterhalb Sekundarbereich II } \\
\text { Tertiärbereich }\end{array}$ & $\begin{array}{r}86 \\
139\end{array}$ & $\begin{array}{l}\mathrm{m} \\
\mathrm{m}\end{array}$ & $\begin{array}{l}\mathrm{m} \\
\mathrm{m}\end{array}$ & $\mathrm{m}$ & $\mathrm{m}$ & $\begin{array}{l}\mathrm{m} \\
\mathrm{m}\end{array}$ \\
\hline Neuseeland & $\begin{array}{l}\text { Abschluss unterhalb Sekundarbereich II } \\
\text { Tertiärbereich }\end{array}$ & $\begin{array}{r}82 \\
148\end{array}$ & $\begin{array}{r}76 \\
137\end{array}$ & $\begin{array}{r}76 \\
140\end{array}$ & $\begin{array}{r}76 \\
130\end{array}$ & $\begin{array}{r}76 \\
130\end{array}$ & $\begin{array}{l}\mathrm{m} \\
\mathrm{m}\end{array}$ \\
\hline Norwegen & $\begin{array}{l}\text { Abschluss unterhalb Sekundarbereich II } \\
\text { Tertiärbereich }\end{array}$ & $\begin{array}{r}85 \\
138\end{array}$ & $\begin{array}{r}85 \\
133\end{array}$ & $\begin{array}{r}85 \\
135\end{array}$ & $\begin{array}{l}\mathrm{m} \\
\mathrm{m}\end{array}$ & $\begin{array}{l}\mathrm{m} \\
\mathrm{m}\end{array}$ & $\begin{array}{r}84 \\
138\end{array}$ \\
\hline Portugal & $\begin{array}{l}\text { Abschluss unterhalb Sekundarbereich II } \\
\text { Tertiärbereich }\end{array}$ & $\begin{array}{r}60 \\
178\end{array}$ & $\begin{array}{r}61 \\
178\end{array}$ & $\begin{array}{r}60 \\
180\end{array}$ & $\begin{array}{l}\mathrm{m} \\
\mathrm{m}\end{array}$ & $\begin{array}{l}\mathrm{m} \\
\mathrm{m}\end{array}$ & $\begin{array}{l}\mathrm{m} \\
\mathrm{m}\end{array}$ \\
\hline Spanien & $\begin{array}{l}\text { Abschluss unterhalb Sekundarbereich II } \\
\text { Tertiärbereich }\end{array}$ & $\begin{array}{r}78 \\
154\end{array}$ & $\begin{array}{r}82 \\
152\end{array}$ & $\begin{array}{l}\mathrm{m} \\
\mathrm{m}\end{array}$ & $\begin{array}{l}\mathrm{m} \\
\mathrm{m}\end{array}$ & $\begin{array}{r}79 \\
138\end{array}$ & $\begin{array}{l}\mathrm{m} \\
\mathrm{m}\end{array}$ \\
\hline Schweden & $\begin{array}{l}\text { Abschluss unterhalb Sekundarbereich II } \\
\text { Tertiärbereich }\end{array}$ & $\begin{array}{r}88 \\
135\end{array}$ & $\begin{array}{r}87 \\
136\end{array}$ & $\begin{array}{r}87 \\
138\end{array}$ & $\begin{array}{l}\mathrm{m} \\
\mathrm{m}\end{array}$ & $\begin{array}{r}84 \\
141\end{array}$ & $\begin{array}{l}\mathrm{m} \\
\mathrm{m}\end{array}$ \\
\hline Schweiz & $\begin{array}{l}\text { Abschluss unterhalb Sekundarbereich II } \\
\text { Tertiärbereich }\end{array}$ & $\begin{array}{r}81 \\
134\end{array}$ & $\begin{array}{r}81 \\
135\end{array}$ & $\begin{array}{r}80 \\
134\end{array}$ & $\begin{array}{r}81 \\
139\end{array}$ & $\mathrm{~m}$ & $\begin{array}{r}78 \\
136\end{array}$ \\
\hline $\begin{array}{l}\text { Vereinigtes } \\
\text { Königreich }\end{array}$ & $\begin{array}{l}\text { Abschluss unterhalb Sekundarbereich II } \\
\text { Tertiärbereich }\end{array}$ & $\begin{array}{r}73 \\
147\end{array}$ & $\begin{array}{r}73 \\
149\end{array}$ & $\begin{array}{r}72 \\
150\end{array}$ & $\begin{array}{r}72 \\
147\end{array}$ & $\begin{array}{r}72 \\
147\end{array}$ & $\begin{array}{l}\mathrm{m} \\
\mathrm{m}\end{array}$ \\
\hline Vereinigte Staaten & $\begin{array}{l}\text { Abschluss unterhalb Sekundarbereich II } \\
\text { Tertiärbereich }\end{array}$ & $\begin{array}{r}69 \\
168\end{array}$ & $\begin{array}{r}65 \\
176\end{array}$ & $\begin{array}{r}63 \\
167\end{array}$ & $\begin{array}{r}64 \\
178\end{array}$ & $\begin{array}{l}\mathrm{m} \\
\mathrm{m}\end{array}$ & $\begin{array}{r}63 \\
178\end{array}$ \\
\hline Ländermittel & Abschluss unterhalb Sekundarbereich II & 81 & 78 & 79 & 78 & 81 & 82 \\
\hline & Tertiärbereich & 150 & 151 & 156 & 152 & 153 & 147 \\
\hline
\end{tabular}

Quelle: OECD. Hinweise s. Anhang 3 unter www.oecd.org/edu/eag2004. 
Tabelle A11.2b

Entwicklung der relativen Einkommen: weibliche Bevölkerung (1997-2002)

Nach Bildungsstand, für 25- bis 64-jährige Frauen (Sekundarbereich II und post-sekundarer, nicht-tertiärer Bereich = 100)

OECD-Länder

Australien

Belgien

Kanada

Tschechische

Republik

Dänemark

Finnland

Frankreich

Deutschland

Ungarn

Irland

Italien

Korea

Niederlande

Neuseeland

Norwegen

Portugal

Spanien

Schweden

Schweiz

Vereinigtes
Königreich

Vereinigte Staaten
Abschluss unterhalb Sekundarbereich II Tertiärbereich

Abschluss unterhalb Sekundarbereich II Tertiärbereich

Abschluss unterhalb Sekundarbereich II Tertiärbereich

Abschluss unterhalb Sekundarbereich II Tertiärbereich

Abschluss unterhalb Sekundarbereich II Tertiärbereich

Abschluss unterhalb Sekundarbereich II Tertiärbereich

Abschluss unterhalb Sekundarbereich II Tertiärbereich

Abschluss unterhalb Sekundarbereich II Tertiärbereich

Abschluss unterhalb Sekundarbereich II Tertiärbereich

Abschluss unterhalb Sekundarbereich II Tertiärbereich

Abschluss unterhalb Sekundarbereich II Tertiärbereich

Abschluss unterhalb Sekundarbereich II Tertiärbereich

Abschluss unterhalb Sekundarbereich II Tertiärbereich

Abschluss unterhalb Sekundarbereich II Tertiärbereich

Abschluss unterhalb Sekundarbereich II Tertiärbereich

Abschluss unterhalb Sekundarbereich II Tertiärbereich

Abschluss unterhalb Sekundarbereich II Tertiärbereich

Abschluss unterhalb Sekundarbereich II Tertiärbereich

Abschluss unterhalb Sekundarbereich II Tertiärbereich

Abschluss unterhalb Sekundarbereich II Tertiärbereich

Abschluss unterhalb Sekundarbereich II Tertiärbereich

\begin{tabular}{|c|c|c|}
\hline 1997 & 1998 & 1999 \\
\hline 85 & $\mathrm{~m}$ & 89 \\
\hline 137 & $\mathrm{~m}$ & 146 \\
\hline $\mathrm{m}$ & $\mathrm{m}$ & $\mathrm{m}$ \\
\hline $\mathrm{m}$ & $\mathrm{m}$ & $\mathrm{m}$ \\
\hline 75 & 68 & 70 \\
\hline 132 & 144 & 140 \\
\hline 72 & 72 & 72 \\
\hline 170 & 170 & 170 \\
\hline 88 & 89 & 90 \\
\hline 122 & 124 & 123 \\
\hline 100 & 99 & 99 \\
\hline 143 & 143 & 145 \\
\hline 80 & 79 & 79 \\
\hline 146 & 145 & 145 \\
\hline 88 & 86 & 83 \\
\hline 131 & 130 & 123 \\
\hline 66 & 67 & 68 \\
\hline 154 & 159 & 167 \\
\hline 57 & 59 & $\mathrm{~m}$ \\
\hline 156 & 145 & $\mathrm{~m}$ \\
\hline $\mathrm{m}$ & 61 & $\mathrm{~m}$ \\
\hline $\mathrm{m}$ & 115 & $\mathrm{~m}$ \\
\hline $\mathrm{m}$ & 69 & $\mathrm{~m}$ \\
\hline $\mathrm{m}$ & 141 & $\mathrm{~m}$ \\
\hline 71 & $\mathrm{~m}$ & $\mathrm{~m}$ \\
\hline 143 & $\mathrm{~m}$ & $\mathrm{~m}$ \\
\hline 69 & 74 & 75 \\
\hline 143 & 129 & 129 \\
\hline 84 & 84 & 83 \\
\hline 140 & 136 & 135 \\
\hline 62 & 62 & 63 \\
\hline 168 & 171 & 170 \\
\hline 64 & 66 & $\mathrm{~m}$ \\
\hline 145 & 137 & $\mathrm{~m}$ \\
\hline 89 & 89 & 88 \\
\hline 125 & 125 & 126 \\
\hline 74 & 73 & 72 \\
\hline 146 & 145 & 142 \\
\hline 64 & 68 & 69 \\
\hline 167 & 173 & 178 \\
\hline 62 & 63 & 61 \\
\hline 166 & 163 & 163 \\
\hline 75 & 74 & 77 \\
\hline 146 & 144 & 147 \\
\hline
\end{tabular}

$2000 \quad 2001$

m 85

m 142

82

132

70

140

m

$m$

$\mathrm{m}$

m

$\mathrm{m}$

$\mathrm{m}$

$\mathrm{m}$

$\mathrm{m}$

72

137

71

164

65

163

84

137

$m$

m

m

$\mathrm{m}$

72

136

m

$\mathrm{m}$

$\mathrm{m}$

m

m

m

m

73

150

70

183

62

164
2002

m

$\mathrm{m}$

83

140

m

$\mathrm{m}$

m

m

m

$\mathrm{m}$

m

m

81

146

73

137

$\mathrm{m}$

m

m

m

$\mathrm{m}$

$\mathrm{m}$

m

m

$\mathrm{m}$

m

m

m

83

140

m

m

$\mathrm{m}$

$\mathrm{m}$

m

m

74

151

m

63

165

Quelle: OECD. Hinweise s. Anhang 3 unter www.oecd.org/edu/eag2004. 
Tabelle A11.3

Entwicklung der Einkommensunterschiede zwischen Frauen und Männern (1997-2002)

Durchschnittliche Jahreseinkommen von Frauen als Prozentsatz derjenigen von Männer, nach Bildungsstand, für 25- bis 64-Jährige

\begin{tabular}{|c|c|}
\hline \multicolumn{2}{|l|}{ OECD-Länder } \\
\hline Australien & $\begin{array}{l}\text { Abschluss unterhalb Sekundarbereich II } \\
\text { Sekundarbereich II und post-sekundarer, nicht-tertiärer Bereich } \\
\text { Tertiärbereich }\end{array}$ \\
\hline Belgien & $\begin{array}{l}\text { Abschluss unterhalb Sekundarbereich II } \\
\text { Sekundarbereich II und post-sekundarer, nicht-tertiärer Bereich } \\
\text { Tertiärbereich }\end{array}$ \\
\hline Kanada & $\begin{array}{l}\text { Abschluss unterhalb Sekundarbereich II } \\
\text { Sekundarbereich II und post-sekundarer, nicht-tertiärer Bereich } \\
\text { Tertiärbereich }\end{array}$ \\
\hline $\begin{array}{l}\text { Tschechische } \\
\text { Republik }\end{array}$ & $\begin{array}{l}\text { Abschluss unterhalb Sekundarbereich II } \\
\text { Sekundarbereich II und post-sekundarer, nicht-tertiärer Bereich } \\
\text { Tertiärbereich }\end{array}$ \\
\hline Dänemark & $\begin{array}{l}\text { Abschluss unterhalb Sekundarbereich II } \\
\text { Sekundarbereich II und post-sekundarer, nicht-tertiärer Bereich } \\
\text { Tertiärbereich }\end{array}$ \\
\hline Finnland & $\begin{array}{l}\text { Abschluss unterhalb Sekundarbereich II } \\
\text { Sekundarbereich II und post-sekundarer, nicht-tertiärer Bereich } \\
\text { Tertiärbereich }\end{array}$ \\
\hline Frankreich & $\begin{array}{l}\text { Abschluss unterhalb Sekundarbereich II } \\
\text { Sekundarbereich II und post-sekundarer, nicht-tertiärer Bereich } \\
\text { Tertiärbereich }\end{array}$ \\
\hline Deutschland & $\begin{array}{l}\text { Abschluss unterhalb Sekundarbereich II } \\
\text { Sekundarbereich II und post-sekundarer, nicht-tertiärer Bereich } \\
\text { Tertiärbereich }\end{array}$ \\
\hline Ungarn & $\begin{array}{l}\text { Abschluss unterhalb Sekundarbereich II } \\
\text { Sekundarbereich II und post-sekundarer, nicht-tertiärer Bereich } \\
\text { Tertiärbereich }\end{array}$ \\
\hline Irland & $\begin{array}{l}\text { Abschluss unterhalb Sekundarbereich II } \\
\text { Sekundarbereich II und post-sekundarer, nicht-tertiärer Bereich } \\
\text { Tertiärbereich }\end{array}$ \\
\hline Italien & $\begin{array}{l}\text { Abschluss unterhalb Sekundarbereich II } \\
\text { Sekundarbereich II und post-sekundarer, nicht-tertiärer Bereich } \\
\text { Tertiärbereich }\end{array}$ \\
\hline Korea & $\begin{array}{l}\text { Abschluss unterhalb Sekundarbereich II } \\
\text { Sekundarbereich II und post-sekundarer, nicht-tertiärer Bereich } \\
\text { Tertiärbereich }\end{array}$ \\
\hline Niederlande & $\begin{array}{l}\text { Abschluss unterhalb Sekundarbereich II } \\
\text { Sekundarbereich II und post-sekundarer, nicht-tertiärer Bereich } \\
\text { Tertiärbereich }\end{array}$ \\
\hline Neuseeland & $\begin{array}{l}\text { Abschluss unterhalb Sekundarbereich II } \\
\text { Sekundarbereich II und post-sekundarer, nicht-tertiärer Bereich } \\
\text { Tertiärbereich }\end{array}$ \\
\hline Norwegen & $\begin{array}{l}\text { Abschluss unterhalb Sekundarbereich II } \\
\text { Sekundarbereich II und post-sekundarer, nicht-tertiärer Bereich } \\
\text { Tertiärbereich }\end{array}$ \\
\hline Portugal & $\begin{array}{l}\text { Abschluss unterhalb Sekundarbereich II } \\
\text { Sekundarbereich II und post-sekundarer, nicht-tertiärer Bereich } \\
\text { Tertiärbereich }\end{array}$ \\
\hline Spanien & $\begin{array}{l}\text { Abschluss unterhalb Sekundarbereich II } \\
\text { Sekundarbereich II und post-sekundarer, nicht-tertiärer Bereich } \\
\text { Tertiärbereich }\end{array}$ \\
\hline Schweden & $\begin{array}{l}\text { Abschluss unterhalb Sekundarbereich II } \\
\text { Sekundarbereich II und post-sekundarer, nicht-tertiärer Bereich } \\
\text { Tertiärbereich }\end{array}$ \\
\hline Schweiz & $\begin{array}{l}\text { Abschluss unterhalb Sekundarbereich II } \\
\text { Sekundarbereich II und post-sekundarer, nicht-tertiärer Bereich } \\
\text { Tertiärbereich }\end{array}$ \\
\hline $\begin{array}{l}\text { Vereinigtes } \\
\text { Königreich }\end{array}$ & $\begin{array}{l}\text { Abschluss unterhalb Sekundarbereich II } \\
\text { Sekundarbereich II und post-sekundarer, nicht-tertiärer Bereich } \\
\text { Tertiärbereich }\end{array}$ \\
\hline Vereinigte Staaten & $\begin{array}{l}\text { Abschluss unterhalb Sekundarbereich II } \\
\text { Sekundarbereich II und post-sekundarer, nicht-tertiärer Bereich } \\
\text { Tertiärbereich }\end{array}$ \\
\hline Ländermittel & Abschluss unterhalb Sekundarbereich II \\
\hline & Sekundarbereich II und post-sekundarer, nicht-tertiärer Bereich \\
\hline & Tertiärbereich \\
\hline
\end{tabular}

\begin{tabular}{|c|c|c|c|c|c|}
\hline 1997 & 1998 & 1999 & 2000 & 2001 & 2002 \\
\hline 60 & $\mathrm{~m}$ & 66 & $\mathrm{~m}$ & 62 & $\mathrm{~m}$ \\
\hline 62 & $\mathrm{~m}$ & 64 & $\mathrm{~m}$ & 62 & $\mathrm{~m}$ \\
\hline 62 & $\mathrm{~m}$ & 67 & $\mathrm{~m}$ & 61 & $\mathrm{~m}$ \\
\hline $\mathrm{m}$ & $\mathrm{m}$ & $\mathrm{m}$ & 64 & $\mathrm{~m}$ & 65 \\
\hline $\mathrm{m}$ & $\mathrm{m}$ & $\mathrm{m}$ & 72 & $\mathrm{~m}$ & 72 \\
\hline $\mathrm{m}$ & $\mathrm{m}$ & $\mathrm{m}$ & 74 & $\mathrm{~m}$ & 76 \\
\hline 54 & 53 & 53 & 53 & 53 & $\mathrm{~m}$ \\
\hline 61 & 61 & 61 & 62 & 61 & $\mathrm{~m}$ \\
\hline 64 & 62 & 62 & 60 & 61 & $\mathrm{~m}$ \\
\hline 66 & 66 & 66 & $\mathrm{~m}$ & $\mathrm{~m}$ & $\mathrm{~m}$ \\
\hline 69 & 69 & 69 & $\mathrm{~m}$ & $\mathrm{~m}$ & $\mathrm{~m}$ \\
\hline 66 & 65 & 65 & $\mathrm{~m}$ & $\mathrm{~m}$ & $\mathrm{~m}$ \\
\hline 73 & 73 & 73 & $\mathrm{~m}$ & 74 & $\mathrm{~m}$ \\
\hline 72 & 71 & 71 & $\mathrm{~m}$ & 71 & $\mathrm{~m}$ \\
\hline 68 & 66 & 66 & $\mathrm{~m}$ & 67 & $\mathrm{~m}$ \\
\hline 78 & 77 & 77 & $\mathrm{~m}$ & 76 & $\mathrm{~m}$ \\
\hline 74 & 72 & 72 & $\mathrm{~m}$ & 71 & $\mathrm{~m}$ \\
\hline 66 & 65 & 62 & $\mathrm{~m}$ & 63 & $\mathrm{~m}$ \\
\hline 68 & 68 & 68 & $\mathrm{~m}$ & $\mathrm{~m}$ & 70 \\
\hline 75 & 75 & 75 & $\mathrm{~m}$ & $\mathrm{~m}$ & 77 \\
\hline 69 & 69 & 69 & $\mathrm{~m}$ & $\mathrm{~m}$ & 70 \\
\hline 63 & 74 & 70 & 56 & $\mathrm{~m}$ & 53 \\
\hline 64 & 67 & 68 & 63 & $\mathrm{~m}$ & 61 \\
\hline 63 & 68 & 60 & 61 & $\mathrm{~m}$ & 60 \\
\hline 79 & 80 & 84 & 83 & 83 & $\mathrm{~m}$ \\
\hline 88 & 86 & 89 & 88 & 88 & $\mathrm{~m}$ \\
\hline 64 & 63 & 62 & 62 & 62 & $\mathrm{~m}$ \\
\hline 46 & 48 & $\mathrm{~m}$ & 46 & $\mathrm{~m}$ & $\mathrm{~m}$ \\
\hline 59 & 63 & $\mathrm{~m}$ & 60 & $\mathrm{~m}$ & $\mathrm{~m}$ \\
\hline 70 & 70 & $\mathrm{~m}$ & 71 & $\mathrm{~m}$ & $\mathrm{~m}$ \\
\hline $\mathrm{m}$ & 70 & $\mathrm{~m}$ & 76 & $\mathrm{~m}$ & $\mathrm{~m}$ \\
\hline $\mathrm{m}$ & 62 & $\mathrm{~m}$ & 65 & $\mathrm{~m}$ & $\mathrm{~m}$ \\
\hline $\mathrm{m}$ & 52 & $\mathrm{~m}$ & 62 & $\mathrm{~m}$ & $\mathrm{~m}$ \\
\hline $\mathrm{m}$ & 56 & $\mathrm{~m}$ & $\mathrm{~m}$ & $\mathrm{~m}$ & $\mathrm{~m}$ \\
\hline $\mathrm{m}$ & 70 & $\mathrm{~m}$ & $\mathrm{~m}$ & $\mathrm{~m}$ & $\mathrm{~m}$ \\
\hline $\mathrm{m}$ & 75 & $\mathrm{~m}$ & $\mathrm{~m}$ & $\mathrm{~m}$ & $\mathrm{~m}$ \\
\hline 46 & $\mathrm{~m}$ & $\mathrm{~m}$ & $\mathrm{~m}$ & $\mathrm{~m}$ & $\mathrm{~m}$ \\
\hline 56 & $\mathrm{~m}$ & $\mathrm{~m}$ & $\mathrm{~m}$ & $\mathrm{~m}$ & $\mathrm{~m}$ \\
\hline 57 & $\mathrm{~m}$ & $\mathrm{~m}$ & $\mathrm{~m}$ & $\mathrm{~m}$ & $\mathrm{~m}$ \\
\hline 52 & 61 & 65 & 61 & 61 & $\mathrm{~m}$ \\
\hline 62 & 63 & 67 & 64 & 64 & $\mathrm{~m}$ \\
\hline 60 & 59 & 61 & 67 & 67 & $\mathrm{~m}$ \\
\hline 60 & 60 & 61 & $\mathrm{~m}$ & $\mathrm{~m}$ & 61 \\
\hline 61 & 61 & 62 & $\mathrm{~m}$ & $\mathrm{~m}$ & 63 \\
\hline 63 & 62 & 62 & $\mathrm{~m}$ & $\mathrm{~m}$ & 64 \\
\hline 72 & 71 & 71 & $\mathrm{~m}$ & $\mathrm{~m}$ & $\mathrm{~m}$ \\
\hline 69 & 69 & 69 & $\mathrm{~m}$ & $\mathrm{~m}$ & $\mathrm{~m}$ \\
\hline 66 & 66 & 65 & $\mathrm{~m}$ & $\mathrm{~m}$ & $\mathrm{~m}$ \\
\hline 60 & 61 & $\mathrm{~m}$ & $\mathrm{~m}$ & 58 & $\mathrm{~m}$ \\
\hline 72 & 76 & $\mathrm{~m}$ & $\mathrm{~m}$ & 71 & $\mathrm{~m}$ \\
\hline 68 & 69 & $\mathrm{~m}$ & $\mathrm{~m}$ & 64 & $\mathrm{~m}$ \\
\hline 73 & 74 & 74 & $\mathrm{~m}$ & 74 & $\mathrm{~m}$ \\
\hline 72 & 72 & 73 & $\mathrm{~m}$ & 71 & $\mathrm{~m}$ \\
\hline 67 & 66 & 67 & $\mathrm{~m}$ & 65 & $\mathrm{~m}$ \\
\hline 51 & 51 & 53 & 51 & $\mathrm{~m}$ & 51 \\
\hline 55 & 57 & 58 & 57 & $\mathrm{~m}$ & 53 \\
\hline 60 & 61 & 62 & 62 & $\mathrm{~m}$ & 59 \\
\hline 47 & 50 & 51 & 50 & 50 & $\mathrm{~m}$ \\
\hline 53 & 53 & 53 & 52 & 52 & $\mathrm{~m}$ \\
\hline 60 & 62 & 63 & 64 & 64 & $\mathrm{~m}$ \\
\hline 53 & 60 & 59 & 59 & $\mathrm{~m}$ & 63 \\
\hline 59 & 62 & 61 & 60 & $\mathrm{~m}$ & 63 \\
\hline 59 & 58 & 59 & 56 & $\mathrm{~m}$ & 58 \\
\hline 61 & 64 & 66 & 60 & 66 & 60 \\
\hline 66 & 67 & 67 & 64 & 68 & 65 \\
\hline 64 & 64 & 64 & 64 & 64 & 65 \\
\hline
\end{tabular}

Quelle: OECD. Hinweise s. Anhang 3 unter www.oecd.org/edu/eag2004. 
Tabelle A11.4

Individuelle Ertragsraten für Personen, die einen Abschluss im Sekundarbereich II oder dem post-sekundaren, nicht-tertiären Bereich (ISCED 3/4) nach einem Abschluss unterhalb Sekundarbereich II (ISCED 0/1/2) erwerben (2001)

\begin{tabular}{|c|c|c|c|c|c|c|}
\hline & \multirow{2}{*}{\multicolumn{2}{|c|}{$\begin{array}{l}\text { Ertragsrate, wenn sofort der } \\
\text { nächsthöhere Abschluss erlangt wird }\end{array}$}} & \multicolumn{4}{|c|}{$\begin{array}{c}\text { Ertragsrate, wenn die Person mit } 40 \mathrm{~J} \text {. den nächsthöheren Bildungsbereich } \\
\text { vollzeit besucht und selbst aufkommt für: }\end{array}$} \\
\hline & & & \multicolumn{2}{|c|}{$\begin{array}{l}\text { Direkte Kosten und } \\
\text { entgangene Einkommen }\end{array}$} & \multicolumn{2}{|c|}{$\begin{array}{l}\text { Keine direkten Kosten, aber } \\
\text { entgangene Einkommen }\end{array}$} \\
\hline & Männer & Frauen & Männer & Frauen & Männer & Frauen \\
\hline Australien & 40 & 40 & (2) & $-17,7$ & $(2)$ & $-17,5$ \\
\hline Dänemark & (1) & (1) & 1,7 & 1,4 & 1,8 & 1,4 \\
\hline Finnland & (1) & (1) & $(2)$ & (2) & $(2)$ & (2) \\
\hline Ungarn & 97,2 & 74,9 & 9,9 & 12,9 & 10,3 & 13,3 \\
\hline Spanien & 11,5 & 20,6 & 11,6 & 16,8 & 11,9 & 17,5 \\
\hline Schweden & (1) & (1) & $-1,3$ & $-4,7$ & $-1,3$ & $-4,7$ \\
\hline Schweiz & 47,5 & 50,7 & 4,4 & 6,5 & 5,6 & 9,2 \\
\hline Vereinigtes Königreich & 60,5 & 73 & 6,7 & 6,4 & 7,5 & 7,5 \\
\hline Vereinigte Staaten & 92,7 & 98,1 & 14,3 & 13,7 & 14,8 & 14,6 \\
\hline
\end{tabular}

(1) Vernachlässigbar niedrige oder keine Kosten verursachen übertrieben hohe Schätzungen.

(2) Negative Vorteile aufgrund von steuerlichen Auswirkungen verursachen extrem geringe Schätzungen.

Quelle: OECD. Hinweise s. Anhang 3 unter www.oecd.org/edu/eag2004.

\section{Tabelle A11.5}

Individuelle Ertragsraten für Personen, die einen Abschluss im Tertiärbereich oder einem weiterführenden Forschungsprogramm (ISCED 5(A/B)/6) nach einem Abschluss im Sekundarbereich II oder dem post-sekundaren, nicht-tertiären Bereich (ISCED 3/4) erwerben (2001)

\begin{tabular}{|c|c|c|c|c|c|c|}
\hline & \multirow{2}{*}{\multicolumn{2}{|c|}{$\begin{array}{l}\text { Ertragsrate, wenn sofort der } \\
\text { nächsthöhere Abschluss erlangt wird }\end{array}$}} & \multicolumn{4}{|c|}{$\begin{array}{c}\text { Ertragsrate, wenn die Person mit } 40 \mathrm{~J} \text {. den nächsthöheren Bildungsbereich } \\
\text { vollzeit besucht und selbst aufkommt für: }\end{array}$} \\
\hline & & & \multicolumn{2}{|c|}{$\begin{array}{l}\text { Direkte Kosten und } \\
\text { entgangene Einkommen }\end{array}$} & \multicolumn{2}{|c|}{$\begin{array}{l}\text { Keine direkten Kosten, } \\
\text { aber entgangene Einkommen }\end{array}$} \\
\hline & Männer & Frauen & Männer & Frauen & Männer & Frauen \\
\hline Australien & 6,6 & 6,5 & 3,3 & $-0,8$ & 5,4 & 2,7 \\
\hline Dänemark & 6,7 & 6,1 & 4,9 & 3,0 & 5,0 & 3,1 \\
\hline Finnland & 14,2 & 15,2 & 10,6 & 8,1 & 10,8 & 8,4 \\
\hline Ungarn & 19,8 & 11,3 & 16,4 & 8,7 & 18,7 & 10,8 \\
\hline Spanien & 9,2 & 8,5 & 11,2 & 8,2 & 12,1 & 9,7 \\
\hline Schweden & 8,8 & 7,3 & 6,9 & 4,5 & 7,6 & 5,4 \\
\hline Schweiz & 9,8 & 7,8 & $\mathrm{a}$ & a & 6,3 & 9,1 \\
\hline Vereinigtes Königreich & 11,2 & 13,7 & 4,0 & 9,9 & 4,9 & 12,1 \\
\hline Vereinigte Staaten & 11,0 & 7,9 & 7,4 & 2,7 & 11,9 & 8,6 \\
\hline
\end{tabular}

Quelle: OECD. Hinweise s. Anhang 3 unter www.oecd.org/edu/eag2004. 
Tabelle A11.6

Gesellschaftliche Ertragsraten für Personen, die einen Abschluss im Sekundarbereich II oder dem post-sekundaren, nicht-tertiären Bereich (ISCED 3/4) nach einem Abschluss unterhalb Sekundarbereich II (ISCED 0/1/2) erwerben (2001)

\begin{tabular}{|c|c|c|c|c|c|c|}
\hline & \multicolumn{2}{|c|}{$\begin{array}{l}\text { Ertragsrate, wenn sofort der } \\
\text { nächsthöhere Abschluss erlangt wird }\end{array}$} & \multicolumn{2}{|c|}{$\begin{array}{c}\text { Ertragsrate, wenn die Person mit } 40 \mathrm{~J} \text {. } \\
\text { den nächsthöheren Bildungsbereich } \\
\text { vollzeit besucht }\end{array}$} & \multicolumn{2}{|c|}{$\begin{array}{c}\text { Ertragsrate, wenn die Person mit } 40 \mathrm{~J} . \\
\text { den nächsthöheren Bildungsbereich } \\
\text { teilzeit besucht } \\
\text { (Dauer verdoppelt sich) }\end{array}$} \\
\hline & Männer & Frauen & Männer & Frauen & Männer & Frauen \\
\hline Australien & 20,8 & 17,4 & $-0,5$ & $-1,1$ & 10,8 & 5,4 \\
\hline Dänemark & 18,8 & 14,6 & $-1,3$ & $-1,9$ & 2,2 & 0,0 \\
\hline Finnland & 22,9 & 16,1 & $-5,5$ & $-3,9$ & $-1,5$ & $-1,7$ \\
\hline Ungarn & 21,5 & 17,4 & 8,6 & 10,7 & 11,2 & 12,4 \\
\hline Spanien & 10,4 & 12,6 & 11,7 & 14,2 & 17,4 & 15,2 \\
\hline Schweden & 40,4 & 33,3 & 3,8 & 1,7 & 12,7 & 7,6 \\
\hline Schweiz & 20,3 & 21,1 & 3,6 & 4,0 & 6,1 & 2,9 \\
\hline Vereinigtes Königreich & 21,6 & 22,0 & 6,5 & 4,9 & 9,7 & 5,0 \\
\hline Vereinigte Staaten & 22,3 & 21,9 & 13,6 & 10,9 & 16,3 & 9,5 \\
\hline
\end{tabular}

Quelle: OECD. Hinweise s. Anhang 3 unter www.oecd.org/edu/eag20o4.

Tabelle A11.7

Gesellschaftliche Ertragsraten für Personen, die einen Abschluss im Tertiärbereich oder einem weiterführenden Forschungsprogramm (ISCED 5(A/B)/6) nach einem Abschluss im Sekundarbereich II oder dem post-sekundaren, nicht-tertiären Bereich (ISCED 3/4) erwerben (2001)

\begin{tabular}{|c|c|c|c|c|c|c|}
\hline & \multicolumn{2}{|c|}{$\begin{array}{l}\text { Ertragsrate, wenn sofort der } \\
\text { nächsthöhere Abschluss erlangt wird }\end{array}$} & \multicolumn{2}{|c|}{$\begin{array}{c}\text { Ertragsrate, wenn die Person mit } 40 \mathrm{~J} \text {. } \\
\text { den nächsthöheren Bildungsbereich } \\
\text { vollzeit besucht }\end{array}$} & \multicolumn{2}{|c|}{$\begin{array}{c}\text { Ertragsrate, wenn die Person mit } 40 \mathrm{~J} \text {. } \\
\text { den nächsthöheren Bildungsbereich } \\
\text { teilzeit besucht } \\
\text { (Dauer verdoppelt sich) }\end{array}$} \\
\hline & Männer & Frauen & Männer & Frauen & Männer & Frauen \\
\hline Australien & 8,3 & 7,6 & 5,5 & 1,7 & 6,9 & $-0,1$ \\
\hline Dänemark & 4,9 & 3,5 & 2,7 & 0,2 & 3,6 & $-0,5$ \\
\hline Finnland & 10,5 & 8,7 & 8,6 & 5,4 & 8,9 & 4,3 \\
\hline Ungarn & 16,1 & 9,1 & 13,4 & 6,6 & 11,6 & 5,1 \\
\hline Spanien & 8,1 & 6,7 & 10,2 & 6,2 & 12,3 & 4,9 \\
\hline Schweden & 8,2 & 6,5 & 6,5 & 3,9 & 12,7 & 7,6 \\
\hline Schweiz & 6,7 & 4,9 & - & - & 4,6 & 1,8 \\
\hline Vereinigtes Königreich & 12,6 & 13,7 & 6,2 & 10,3 & 11,8 & 10,9 \\
\hline Vereinigte Staaten & 11,1 & 7,9 & 8,0 & 3,2 & 7,3 & 0,8 \\
\hline
\end{tabular}

Quelle: OECD. Hinweise s. Anhang 3 unter www.oecd.org/edu/eag2004. 


\section{Die Erträge aus Bildung - Zusammenhänge zwischen Humankapital und Wirtschaftswachstum}

Neuere Untersuchungen des Humankapitals in den Volkswirtschaften von 14 OECD-Ländern, basierend auf Bewertungen der Lesekompetenz, deuten darauf hin, dass dieses sich deutlich positiv auf das Wirtschaftswachstum auswirkt.

Eine Analyse der dem Wirtschaftswachstum zugrunde liegenden Faktoren durch das OECD-Sekretariat ergibt, dass in den meisten OECD-Ländern mindestens die Hälfte des Anstiegs des BIP pro Kopf zwischen 1990 und 2000 auf den Anstieg der Arbeitsproduktivität zurückzuführen ist.

Eine Zunahme des Bestands an Humankapital erhöht die Arbeitsproduktivität und dient auch als Motor für den technologischen Fortschritt.

Der geschätzte langfristige Effekt eines zusätzlichen Bildungsjahres auf die wirtschaftliche Produktion beläuft sich im OECD-Gebiet im Allgemeinen auf 3 bis 6 Prozent.

\section{Politischer Hintergrund}

Seit Mitte der achtziger Jahre des letzten Jahrhunderts hat sich die makroökonomische Forschung vor allem auf das Wirtschaftswachstum konzentriert (s. Kasten AI2.I). Neue Theorien - insbesondere die neue Wachstumstheorie gaben der Forschung neue Impulse und brachten neue Ansätze für die empirischen Untersuchungen des Wachstums. Das ,Humankapital', das Wissen und die Fähigkeiten, die die Arbeitnehmer anzubieten haben, war für die neuen Denkansätze über das Wachstum ganz entscheidend. Auch die deutlichen Unterschiede zwischen den volkswirtschaftlichen Leistungen der OECD-Länder in der jüngsten Vergangenheit haben das Interesse an den Ursachen für Wachstum angefacht. Diese Unterschiede waren einer der Hauptbeweggründe für die Entwicklung des ,OECD Growth Project‘. Die Ausgabe 2003 von Bildung auf einen Blick berichtete über die wesentlichsten Ergebnisse des Projekts. Dieses Projekt unterstrich die Bedeutung stabiler und unterstützender makroökonomischer Bedingungen für das Wachstum sowie institutioneller Strukturen und politischer Voraussetzungen, die Wettbewerb und Flexibilität auf dem Kapitalund Arbeitsmarkt fördern. Auch die Entwicklung neuer Technologien und die Verbreitung von Innovationen und technischem Wandel erwiesen sich als ausschlaggebend für die Wachstumsaussichten. Ein zentrales Element in diesem Gefüge ist das ,Humankapital'. Dieser Indikator untersucht die Rolle des Humankapitals als bestimmenden Faktor von Ausmaß und Tempo des Anstiegs der Pro-Kopf-Produktion. Er ergänzt Indikator AII, in dem der Bezug zwischen dem Humankapital und der Ertragsrate für den Einzelnen untersucht wurde. Während Indikator AII untersucht, wie sich das Einkommen des Einzelnen mit zunehmendem Bildungsstand verändert, versucht Indikator AI2, die Auswir-
Dieser Indikator untersucht die Auswirkungen von Veränderungen unabhängiger Variablen, u. a. des Humankapitals, auf den Anstieg der Pro-Kopf-Produktion. 
Er sollte gemeinsam mit den in Indikator A11 untersuchten individuellen Bildungserträgen interpretiert werden. kungen von Veränderungen im Gesamtbestand des Humankapitals eines Landes auf die Arbeitsproduktivität (bei konstantem Gesamtbestand an Sachkapital) zu erfassen.

Vergleiche der auf Mikroebene bewerteten Bildungserträge (wie die in Indikator AII dargestellten) und den im vorliegenden Indikator behandelten makroökonomischen Auswirkungen könnten von erheblicher politischer Relevanz sein, da Diskrepanzen zwischen ihnen auf Unterschiede zwischen den individuellen und gesellschaftlichen Bildungserträgen hinweisen würden, die möglicherweise einer Korrektur durch politische Maßnahmen bedürfen. Wenn beispielsweise die Produktivität nach dem Erreichen eines höheren Bildungsstandes gesamtwirtschaftlich stärker steigt als die jedes Arbeitnehmers, stellt dies eine Externalität dar. Diese Externalität wird eine tendenzielle Entwicklung hin zu Unterinvestitionen in Bildung auslösen, da der Einzelne die indirekten gesellschaftlichen Vorteile, die sich aus seinen Bildungsentscheidungen ergeben, nicht berücksichtigen wird. In diesem Zusammenhang können mikroökonometrische Schätzungen von Lohngleichungen mit Querschnittsdaten für Einzelpersonen in einem Land nur die individuellen Effekte der Bildung erfassen, die makroökonometrischen Schätzungen mit länderübergreifenden Querschnittsdaten sollten jedoch auch die gesellschaftliche Externalität erfassen.

Kasten A12.1

\section{Bewertung der makroökonomischen Erträge aus Bildung}

Umfangreiche empirische Daten belegen den positiven Zusammenhang zwischen Bildung und Produktivität. Höher qualifizierte Mitarbeiter sind im Allgemeinen produktiver und können auch die Produktivität ihrer Kollegen steigern. Ein höherer Bestand an Humankapital erleichtert Investitionen in Sachkapital und fördert die Entwicklung und Verbreitung neuer Technologien. Auch eine Reihe indirekter Vorteile von Bildung hat meist positive Auswirkungen auf die Wirtschaft. So sieht man z. B. einen Zusammenhang zwischen höherem Bildungsstand und besserem Gesundheitszustand, geringerem Arbeitslosigkeitsrisiko, niedrigeren Kriminalitätsraten, stärkerem sozialem Zusammenhalt und größerem politischen Engagement. Für die politische Entscheidungsfindung ist das Wissen um die makroökonomischen Erträge aus Bildung sehr wichtig. Eine genaue Bewertung dieser makroökonomischen Erträge kann die mit der Bildung zusammenhängenden externen Effekte aufzeigen. Diese Externalitäten wiederum liefern wichtige Entscheidungsgrundlagen für das staatliche Handeln. Wenn man die makroökonomischen Bildungserträge kennt, kann man auch eher beurteilen, ob die Investition öffentlicher Mittel in das Humankapital eine bessere Anlageform ist als die Investition in andere Aktiva. Außerdem gewinnt die Verknüpfung von Bildung und Wachstum im heutigen Zeitalter des schnellen technologischen Wandels immer stärker an Bedeutung.

Die Untersuchungen über die makroökonomischen Erträge aus Bildung sind methodisch sehr unterschiedlich und basieren generell auf zwei theo- 
retischen Ansätzen. Der neo-klassische Ansatz modelliert die Beziehung zwischen dem Bildungsbestand und der langfristigen Entwicklung des BIPNiveaus. Die meisten Untersuchungen wenden diese Methode an. Der zweite Ansatz ist aus der ,neuen Wachstumstheorie' abgeleitet und bildet die Beziehung zwischen Bildungsbestand und der BIP-Wachstumsrate ab. Es ist noch unklar, ob sich der Bildungsbestand vorrangig auf das Produktionsniveau oder auf dessen Wachstumsrate auswirkt. Hinsichtlich der Größenordnung der Erträge besagen die vorliegenden Untersuchungen nach der neoklassischen Methode, dass ein Anstieg im durchschnittlichen Bildungsniveau um ein Jahr die Pro-Kopf-Produktion zwischen 3 und 6 Prozent steigert. Studien nach der ,neuen Wachstumstheorie‘ kommen zu dem Ergebnis, dass der gleiche Anstieg im durchschnittlichen Bildungsniveau die Wachstumsrate der Produktion um rund I Prozent steigert. Die beiden theoretischen Ansätze führen mittel- bis langfristig zu Ergebnissen ganz unterschiedlicher Größenordnung, da der absolute Effekt eines kumulativen I-prozentigen Anstiegs der Wachstumsrate auf die Produktion einen einmaligen Anstieg des Produktionsniveaus um 6 Prozent (der obere Wert) sehr schnell übertrifft. Die absolute Größenordnung der prognostizierten Effekte auf die Produktion bewegt sich jedoch über einen Zeitraum von nur wenigen Jahren hinweg bei beiden Theorien auf vergleichbarem Niveau.

Die Bewertung der Auswirkungen von Bildung auf das Wachstum unterliegt mehreren konzeptionellen und methodischen Schwierigkeiten. Ein zentraler Punkt ist die Wirkungsrichtung der Kausalität in der Wachstumsbeziehung: löst Bildung Wachstum aus oder veranlasst Wachstum die Menschen dazu, mehr Bildungsangebote wahrzunehmen? Tatsächlich wirkt die Kausalität wahrscheinlich in beide Richtungen. In ähnlicher Weise könnte die Effizienz bei der Erzielung von Bildungsergebnissen einfach nur mit der in anderen Wirtschaftsbereichen erzielten Effizienz zusammenhängen. Die Ergebnisse vieler Untersuchungen kranken auch an unzulänglichen Daten. So lassen sich beispielsweise nur geringe Korrelationen zwischen den Bildungskennzahlen einiger der Hauptquellen bildungsrelevanter Daten erkennen. Des weiteren wurde in Wachstumsuntersuchungen eine Reihe von Hilfsgrößen für das Humankapital verwendet, z. B. die durchschnittliche Bildungsdauer in Jahren, die Lesekompetenzen Erwachsener und die Bildungsbeteiligung. Außerdem wurden in einer Reihe von Untersuchungen verschiedene abhängige Variablen eingesetzt. Derartige Hilfsgrößen werfen eine Reihe von Schwierigkeiten auf. So beziehen sie sich beispielsweise ausschließlich auf die formale Bildung und vernachlässigen dabei die Kompetenzen und Fähigkeiten, die in der Ausbildung am Arbeitsplatz, durch Erfahrung und auf andere Weise erworben werden, sowie auch den Verlust an Fähigkeiten, wenn sie beispielsweise nicht mehr genutzt werden. Außerdem erfassen die Zahlen für die Lesekompetenz Erwachsener nur eine Dimension des Humankapitals und verkennen Kompetenzen wie mathematische Fähigkeiten und technisches Wissen. Ferner sind die Indikatoren für den Bildungsstand aufgrund der ungleichen Qualität der Bildungssysteme nicht unbedingt über die Länder hinweg voll vergleichbar. ${ }^{\star}$ So führen unterschiedliche Spezifikationen des Humankapitals tatsächlich zu erheblichen Abweichungen in den Schätzungen des Bestands an Humankapital in den einzelnen Ländern. Außerdem ist davon auszugehen, dass sich verschiede- 
ne Arten von Bildung unterschiedlich stark auf das Wachstum auswirken: Eine Kohorte von Absolventen der Ingenieurwissenschaften wird die Produktivität wahrscheinlich anders beeinflussen als eine gleich große Kohorte von Absolventen in künstlerischen Fächern und Kunstgeschichte. Die üblicherweise verwendeten kumulierten Hilfsgrößen für das Humankapital berücksichtigen diese unterschiedlichen Effekte jedoch nicht. In einigen Untersuchungen herrscht auch Unklarheit darüber, ob die Bildungsbeteiligung als Kennzahl für den Bestand oder für die $\mathrm{Zu}$ - und Abgänge an Investitionen in das Humankapital gelten sollen.

Ferner unterstellen länderübergreifende Wachstumsregressionen zumeist, dass sich die Bildung linear und in allen Ländern konstant auswirkt. Forschungsergebnisse deuten jedoch darauf hin, dass die Annahme konstanter Wachstumseffekte von Bildung über die einzelnen Länder hinweg nicht haltbar ist. Ferner gibt es Hinweise darauf, dass die Auswirkungen auf das Wachstum bei einer Bildungsdauer von durchschnittlich mehr als 7,5 Jahren schwächer werden (s. Definitionen und angewandte Methodik). Dies liegt deutlich unter dem Durchschnitt der Bildungsdauer in der OECD insgesamt, die I998 bei II,3 Jahren für die 20 OECD-Länder lag, für die Daten verfügbar waren.

In der Forschung über die Wechselbeziehungen von Bildung und Wachstum gibt es noch viele Unbekannte. Wie oben ausgeführt, ist es immer noch offen, ob sich Bildung und die Zunahme des Bestands an Humankapital auf die Höhe des BIP oder auf seine Wachstumsrate auswirken. Weitere Forschungsarbeiten könnten sich u. a. mit folgenden politisch relevanten Punkten beschäftigen:

Welche Auswirkungen auf das Wachstum haben Investitionen in den verschiedenen Bildungsbereichen (von der Vorschule bis zum Tertiärbereich und der berufsbezogenen Ausbildung)?

Nach wie vielen Jahren Bildungsdauer und in welchen Bildungsbereichen werden abnehmende Wachstumseffekte relevant?

Welche Auswirkungen auf das Wachstum haben Investitionen in verschiedene Bildungsarten und Fachrichtungen, z. B. in die Ingenieurwissenschaften oder Kunst?

Welche Auswirkungen hat die Bildungsqualität auf das Wachstum?

Werden die sich aus der Erweiterung eines Bildungsbereichs ergebenden Wachstumseffekte durch den zu einem früheren Zeitpunkt erreichten Bildungsstand beeinflusst, und falls ja, wie?

\footnotetext{
* Internationale Untersuchungen wie der Adult Literacy and Life Skills Survey und das Programme for the International Assessment of Adult Competencies der OECD, das momentan ausgearbeitet wird, enthalten international vergleichbare mehr-dimensionale Kompetenz-Indikatoren.

Quelle: Sianesi, B. and J. Van Reenan (2003), „The Returns to Education: Macroeconomics“, The Journal of Economic Surveys, Vol. 17, No. 2, S. 157-200, und De la Fuente, A. and Ciccone, A. (2003), Human Capital in a Global and Knowledge-based Economy, Europäische Kommission, GD für Beschäftigung und Soziales, Amt für Veröffentlichungen der Europäischen Gemeinschaften, Luxemburg.
} 


\section{Ergebnisse und Erläuterungen}

Der Bericht über die Ergebnisse des OECD Growth Projects in der Ausgabe 2003 von Bildung auf einen Blick stellte fest, dass 2000 das Bruttoinlandsprodukt pro Kopf in den meisten OECD-Ländern um 25 bis 35 Prozentpunkte unter dem der Vereinigten Staaten lag. Die Produktivitätsunterschiede wurden für jedes Land in die folgenden drei Elemente unterteilt: den demographischen Effekt, die Ausnutzung des Arbeitskräfteangebots und die Arbeitsproduktivität. Der demographische Effekt bezieht sich auf das Verhältnis der Bevölkerung im erwerbsfähigen Alter zur Gesamtbevölkerung, in den meisten Ländern war dieser Effekt nur zu einem geringen Teil für den Produktivitätsunterschied zu den Vereinigten Staaten verantwortlich. Eine Analyse der Ausnutzung des Arbeitskräfteangebots (Beschäftigungsquoten kombiniert mit Arbeitsstunden) zeigte eine Reihe von Ländern (z.B. die Vereinigten Staaten und Japan) mit sehr hohen Beschäftigungsquoten und überdurchschnittlich vielen Arbeitsstunden. Zwar hatten die meisten nordischen Länder höhere Beschäftigungsquoten, diese wurden jedoch durch die geringere Anzahl der geleisteten Arbeitsstunden relativiert. In einigen Ländern, in denen sowohl die Beschäftigungsquote als auch die Zahl der Arbeitsstunden relativ niedrig lagen (z. B. Belgien, Frankreich, Italien und die Niederlande) war praktisch der gesamte Abstand ihres jeweiligen BIP pro Kopf zu dem der Vereinigten Staaten auf die geringere Ausnutzung des Arbeitskräfteangebots zurückzuführen. Die Ausnutzung des Arbeitskräfteangebots ist daher ein wesentlicher Faktor bei den Unterschieden im BIP pro Kopf zwischen den einzelnen Ländern. Von den 25 Ländern, für die Daten zur Verfügung standen, übertrafen nur fünf (Belgien, Irland, Italien, die Niederlande und Norwegen) die Arbeitsproduktivität (BIP pro Arbeitsstunde) der Vereinigten Staaten. In einer Reihe von Ländern mit relativ hoher Ausnutzung des Arbeitskräfteangebots (wie Island, Japan, Korea, Mexiko, Neuseeland und der Tschechischen Republik) ergaben sich die Unterschiede zum BIP pro Kopf der Vereinigten Staaten hauptsächlich aus einer deutlich niedrigeren Arbeitsproduktivität.

Abbildung Ar2.I stellt die relative Bedeutung der wesentlichen Antriebskräfte für das Wachstum des BIP pro Kopf zwischen 1990 und 2000 dar und zeigt, dass sich die demographischen Veränderungen in den meisten OECD-Ländern nur relativ gering auswirkten. Die einzigen Länder, in denen die demographischen Veränderungen einen positiven und wesentlichen Beitrag zum Wachstum des BIP pro Kopf leisteten, waren Irland, Korea, Mexiko und die Türkei. In einigen OECD-Ländern (wie Belgien, Dänemark, Deutschland, Frankreich, Italien, Japan, Luxemburg, die Niederlande und die Schweiz) haben die demographischen Trends (in diesem rechnerischen Sinne) jedoch das Wachstum des BIP pro Kopf leicht abgebremst. Dieser Trend dürfte in Zukunft noch stärker werden, da die Gesamtbevölkerung schneller altert.

Abbildung Ar2.I zeigt, dass in den meisten OECD-Ländern mindestens die Hälfte des Anstiegs des BIP pro Kopf im letzten Jahrzehnt auf den Anstieg der Arbeitsproduktivität zurückzuführen war. In einigen Ländern war die höhere Arbeitsproduktivität sogar fast ausschließlich für den Anstieg des BIP pro Kopf verantwortlich. Hierzu gehören Dänemark, Deutschland, Finnland, Griechenland, Italien, Korea, Luxemburg, Österreich, Schweden und das Vereinig-
In den neunziger Jahren ist die Produktivität in einigen Ländern schneller, in anderen jedoch langsamer gestiegen.

Im letzten Jahrzehnt übten demographische Faktoren nur in wenigen Ländern einen wesentlichen Einfluss aus, ...

... während in den meisten OECD-Ländern mindestens die Hälfte des Wachstums des BIP pro Kopf auf eine erhöhte Arbeitsproduktivität zurückzuführen ist. 
te Königreich. Da in den meisten Ländern, insbesondere in Kontinentaleuropa, die geleisteten Arbeitsstunden in den neunziger Jahren abnahmen, übertraf die Steigerung der Arbeitsproduktivität pro Stunde die der Arbeitsproduktivität pro Person. Der Rückgang der Arbeitsstunden ist sowohl auf kürzere gesetzlich (bzw. tarifvertraglich) festgelegte Arbeitswochen zurückzuführen als auch auf eine deutliche Zunahme der Teilzeitarbeit, vor allem in einer Reihe von europäischen Ländern. Mit diesen tendenziellen Veränderungen der Produk-

\section{Abbildung A12.1}

Zugrundeliegende Faktoren des Wachstums des BIP pro Kopf (1990-2000)

Trendentwicklung, durchschnittliche jährliche Veränderung in Prozentpunkten

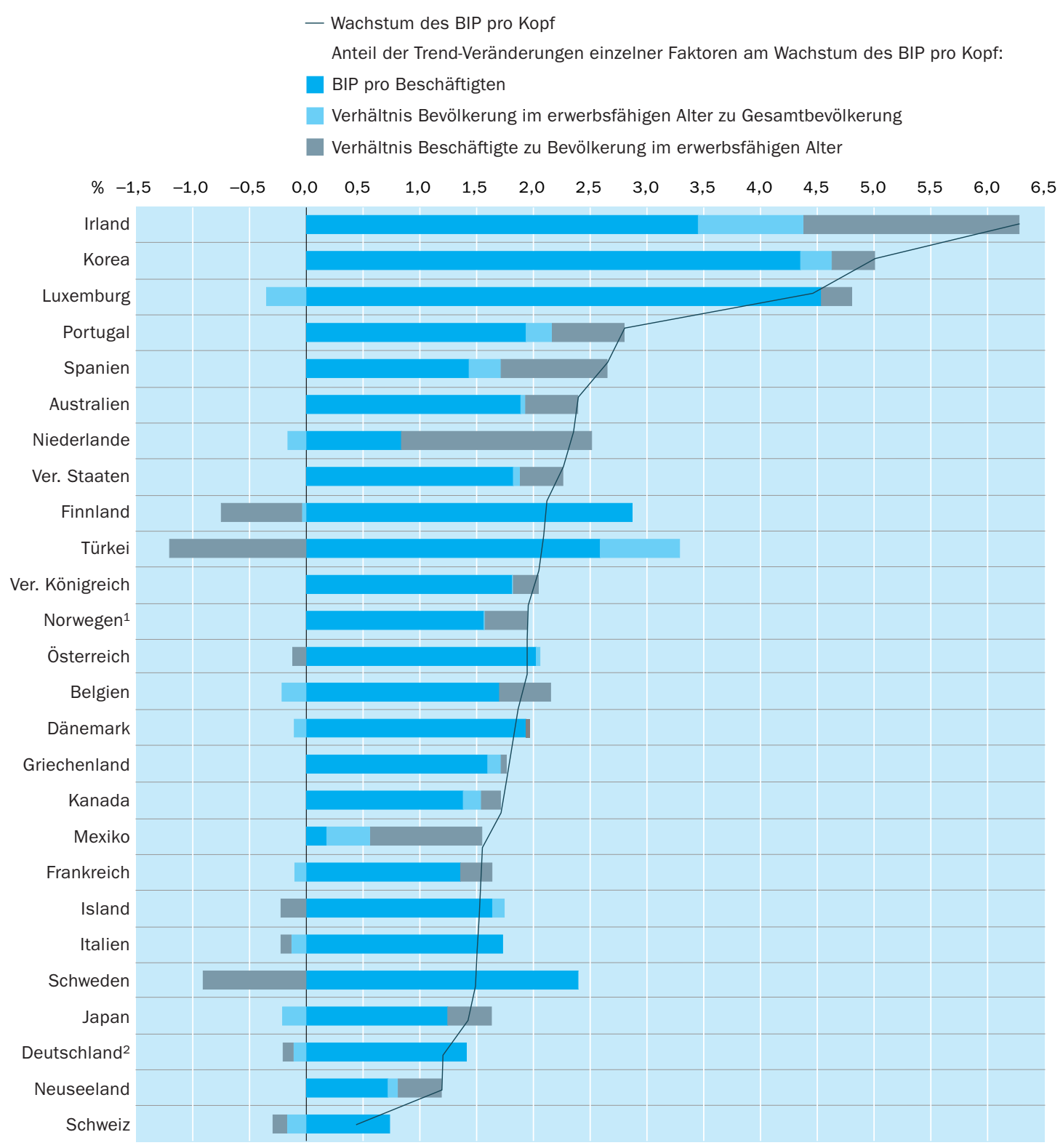


tivität gingen in den Ländern unterschiedliche Entwicklungen bei der Beschäftigung einher. So besteht beispielsweise in den Volkswirtschaften der G-7 Staaten ein scharfer Kontrast zwischen dem deutlichen Beschäftigungszuwachs in den Vereinigten Staaten (sowie in Kanada und Japan, jedoch ohne einen stärkeren Produktivitätszuwachs) und dem Beschäftigungsrückgang in Deutschland und Italien.

Die Arbeitsproduktivität lässt sich auf mehrere Arten steigern: durch die Verbesserung der Qualität der im Produktionsprozess eingesetzten Arbeitskräfte, durch die Erhöhung und qualitative Verbesserung des Kapitaleinsatzes pro Arbeitskraft oder durch eine gesteigerte Effizienz beim Zusammenwirken dieser Produktionsfaktoren insgesamt, was die Wirtschaftswissenschaftler mit multifaktorieller Produktivität bezeichnen. Die multifaktorielle Produktivität beinhaltet vielerlei Arten von Effizienzsteigerungen, u.a. verbesserte Managementpraktiken, organisatorische Veränderungen und Innovationen, die bei einer gegebenen Kombination von Kapital und Arbeit einen höherwertigen Produktionsoutput ermöglichen. Das Wissen, die Fähigkeiten und Kenntnisse der Arbeitskräfte - oder das ,Humankapital‘ - spielen beim Anstieg der ProKopf-Produktion eine zentrale Rolle. Die Erhöhung des Bildungsstandes der Arbeitskräfte während der neunziger Jahre ist nur ein Hinweis auf diese Rolle. Noch wichtiger könnte die Steigerung beim Ausmaß der nach der Ausbildung erworbenen Kompetenzen sein, wenngleich es dafür nur wenige eindeutige und verlässliche Messgrößen gibt. Somit ist das Humankapital eine bedeutende Determinante des Wirtschaftswachstums, wie verschiedene empirische Studien belegen (s. Kasten AI2.I und AI2.2). Das ,OECD Growth Project schätzte, dass der langfristige Effekt eines weiteren Ausbildungsjahres auf die Leistung bei der Erwachsenenbevölkerung im Allgemeinen in der Größenordnung von 3 bis 6 Prozent liegt.

Kasten A12.2

\section{Lesekompetenz und Wachstum in 14 OECD-Ländern}

Neuere Forschungsarbeiten versuchten, die Beziehung zwischen Humankapital und makroökonomischem Wachstum unter Verwendung einer direkten Kennzahl für das Humankapital zu bewerten, die auf international vergleichbaren Messwerten für die Lesekompetenz basiert. Dieser Ansatz hilft, das Problem der unzureichenden Vergleichbarkeit von Kennzahlen für den Bildungsstand in den einzelnen nationalen Bildungssystemen zu vermeiden. Die Kennzahlen für die Lesekompetenz wurden der Internationalen Untersuchung der Lesekompetenz von Erwachsenen (International Adult Literacy Survey - IALS) 1994 entnommen. Die IALS untersuchte die Fähigkeiten von I6- bis 64-Jährigen im Umgang mit Texten, schematischen Darstellungen und Zahlen. Die Daten beziehen sich auf I4 OECD-Länder. Anhand der Untersuchungsergebnisse wurde eine synthetische Zeitreihe für den Zeitraum I960-1995 erzeugt. Dann setzte man die Ergebnisse für die Lesekompetenz von 17 - bis 25-Jährigen während eines bestimmten Zeitraums als Hilfsgrößen für die Investitionen in Humankapital in der vorherigen

Die Arbeitsproduktivität lässt sich auf verschiedene Arten steigern, ... 
Periode ein (die Autoren weisen darauf hin, dass die Ableitung der Lesekompetenz in jungen Jahren von im Erwachsenenalter erhobenen Daten eigentlich eine Anpassung an die im Verlauf der Lebenszeit eintretenden Veränderungen am Humankapital verlangt. Diese Bereinigung ist nicht erfolgt und ist ein Nachteil dieses synthetischen Indikators gegenüber den Indikatoren der Bildungsteilnahme. Allerdings würde das Verfahren zur Eliminierung der Mittelwerte von den Querschnittsdaten die notwendige Anpassung bieten, wenn der Anpassungsprozess des Humankapitals im Lebensverlauf in allen Ländern homogen erfolgt). Zeitreihen und länderübergreifende Angaben wurden in einem Panel-Datensatz zusammengefasst. Die Autoren weisen darauf hin, dass es ein Schwachpunkt dieses Indikators ist, dass keine Angaben zu Immigrationsströmen berücksichtigt wurden.

Anhand dieser Forschungsergebnisse erweist sich die Lesekompetenz als eine besser geeignete direkte Kennzahl des Humankapitals für Wachstumsregressionen als die Indikatoren der Schulbildung. Ein Land, das bei der Lesekompetenz Ergebnisse erzielt, die ein Prozent über dem internationalen Durchschnitt liegen, übertrifft andere Länder bei der Arbeitsproduktivität um 2,5 Prozent und beim BIP um I, 5 Prozent. Die Autoren unterbreiten zwei mögliche Gründe für die Tatsache, dass die Daten zur Lesekompetenz über den relativen Wohlstand eines Landes mehr aussagen sollten als die Angaben zu den Jahren formaler Ausbildung. Zum einen könnte die Lesekompetenz eine übergeordnete Kennzahl für einige der Hauptantriebskräfte des Wachstums sein, wie beispielsweise die soziale Infrastruktur. Zum anderen könnten die Daten zur Lesekompetenz über die Länder hinweg vergleichbarer sein als die Daten zur Bildungsdauer. Zur Überprüfung dieser Interpretationen schlagen die Autoren weitere Untersuchungen vor, in denen die Wachstumseffekte in mehreren Regionen eines Landes mittels beider Indikatoren für das Humankapital verglichen werden. So ließen sich die Probleme der unzulänglichen internationalen Vergleichbarkeit überwinden. Das relative Abschneiden der beiden Indikatoren würde zeigen, welcher als Kennzahl für das Humankapital tauglicher ist und welcher am engsten mit dem wirtschaftlichen Wachstum zusammenhängt.

Es hat sich gezeigt, dass Kennzahlen, die auf den durchschnittlichen Ergebnissen für die Lesekompetenz aller Personen basieren, das kumulierte Humankapital wesentlich besser darstellen als solche, die sich auf den Anteil der Personen beziehen, die ein hohes Niveau der Lesekompetenz erlangt haben. Dies deckt sich mit der Vorstellung, dass die Steigerung der Produktivität der Erwerbsbevölkerung insgesamt die wesentlichere Auswirkung von Bildung auf das Wachstum ist und nicht die Steigerung der Zahl der Personen, die radikale Innovationen herbeiführen können. Ein überraschendes Resultat war beispielsweise, dass eine Verbesserung der Lesekompetenz der Frauen sich wesentlich stärker auf das Wachstum auswirkt als eine Verbesserung der Lesekompetenz der Männer. Hierfür wurden mehrere Erklärungen vorgeschlagen: die Investitionen in Bildung wurden möglicherweise besonders fähigen Frauen zuteil, denen früher aufgrund von gesellschaftlichen Hürden weitergehende Ausbildung vorenthalten wurde; die Ertragsraten für die Bildung waren eventuell für Frauen angesichts des niedrigen Ausgangs- 
niveaus ihrer Lesekompetenz besonders hoch; ein höheres Bildungsniveau könnte zu einer Umverteilung der Arbeit zwischen Männern und Frauen in den verschiedenen Berufen führen, so dass schließlich viel mehr Männer und Frauen in Berufen arbeiten, in denen sie einen relativen Vorteil haben; falls die männliche und die weibliche Arbeitsleistung nicht vollständig austauschbar ist, könnte ein höheres Bildungsniveau der Frauen eine Umbruchsphase im Bestand an Human- und Sachkapital mit schnellem Wachstum auslösen, nach der sich ein neuer ausgewogener Zustand einstellt; mögliche statistische Auswirkungen größerer Unterschiede bei den Leseleistungen von Frauen zwischen den Ländern und die Tatsache, dass die Lesekompetenz der Frauen mit nicht berücksichtigten Variablen zusammenhängt, die sich auf das Wachstum auswirken, wie z.B. dem sozialen Entwicklungsstand eines Landes.

Quelle: Coulombe, S., Tremblay, J-F. and Marchand, S. (2004), Literacy Scores, Human Capital and Growth Across Fourteen OECD Countries, Statistics Canada, und Human Resources and Skills Development, Canada, Ottawa

Abbildung Ar2.2 zeigt, dass die Produktionssteigerung pro Beschäftigten teilweise auf das höhere ,Humankapital' der Beschäftigten zurückzuführen ist. Die Abbildung verdeutlicht die Auswirkungen der Veränderungen im durchschnittlichen Humankapital der Arbeitnehmer auf das Wachstum des konjunkturbereinigten BIP pro geleisteter Arbeitsstunde. Im Grunde genommen werden in der Abbildung die durchschnittlichen prozentualen Veränderungen pro Jahr im BIP pro Kopf im Zeitraum 1990 bis 2000 in drei Bestandteile untergliedert: I. Veränderungen in der Anzahl der durchschnittlich geleisteten Arbeitsstunden, 2. Veränderungen in der durchschnittlichen Zahl der Jahre formaler Ausbildung (hier als Kennzahl für die qualitative Veränderung der Erwerbstätigen verwendet), und 3. Veränderungen des BIP pro Stunde tatsächlicher Arbeitseinheit, was - nach Berücksichtigung der Veränderungen bei den Arbeitsstunden und der durchschnittlichen Qualität der Erwerbspersonen der Veränderung im BIP pro Beschäftigten entspricht. Letzteres basiert auf einer Kennzahl für den Produktionsfaktor Arbeit, der die Anteile von Beschäftigten mit unterschiedlichem formalen Ausbildungsniveau zusammenfasst und jeweils nach ihrem relativen Lohnniveau gewichtet. Zwei Annahmen liegen dieser Maßzahl zugrunde: der Bildungsstand macht einen Großteil des Humankapitals aus, das die Beschäftigten verkörpern, und das jeweilige relative Lohnniveau stellt eine hinreichende quantitative Näherung für die relative Produktivität von Arbeitskräften mit unterschiedlichem Bildungsstand dar.

Im letzten Jahrzehnt (1990-2000) verbesserte sich das Kompetenzniveau insbesondere der europäischen Arbeitnehmer, obwohl damit nur eine zögerliche Beschäftigungszunahme einherging. Die Produktivitätsgewinne wurden teilweise durch Entlassungen bzw. die Nicht-Beschäftigung von niedrig qualifizierten Arbeitnehmern erreicht. Im Gegensatz dazu hat die Anhebung des Qualifikationsniveaus der Arbeitnehmerschaft in Australien, Dänemark, Kanada, den Niederlanden, Neuseeland, Norwegen, Schweden und den Vereinigten Staaten bestenfalls einen bescheidenen Beitrag zum BIP-Wachstum pro Beschäftigten geleistet.

... und das Humankapital ist von zentraler Bedeutung für die Steigerung der Produktionsleistung pro Arbeitnehmer... 
... außerdem ist es ein bestimmender Faktor für das
Ausmaß technologischen Fortschritts.
$\mathrm{Zu}$ den entscheidenden wirtschaftlich relevanten Aspekten der Bildung gehört deren Auswirkung auf den technologischen Fortschritt, welcher wiederum die Produktionsleistung pro Beschäftigten beeinflusst. Einer der zentralen Gründe für das erneute Interesse an der produktivitätssteigernden Rolle des Humankapitals ist die Tatsache, dass das Humankapital die neuen Technologien ergänzt. Kenntnisse und Kompetenzen sind entscheidend für die Entwicklung, die Verbreitung und den wirksamen Einsatz neuer Technologien. In den neunziger Jahren waren in den OECD-Ländern, für die Daten vorliegen, fast 30 Prozent der in diesem Zeitraum festgestellten Nettobeschäftigungszunahme auf die Zunahme der Zahl der Wissensarbeiter (Wissenschaftler, Ingenieure u.ä., wie IT-Spezialisten und -techniker, die Wissen schaffen) zurückzuführen. Die Löhne erfuhren eine ähnliche Entwicklung. So stiegen beispielsweise in den Vereinigten Staaten die Entgelte der Wissensarbeiter wesentlich schneller als die anderer Berufsgruppen. Zwischen 1985 und 1998 nahm das Realeinkommen der Wissensarbeiter kumulativ um fast 17 Prozent zu, das der durch-

Abbildung A12.2

Verbesserungen des Humankapitals und ihr Beitrag zur Steigerung der Arbeitsproduktivität (1990-2000)

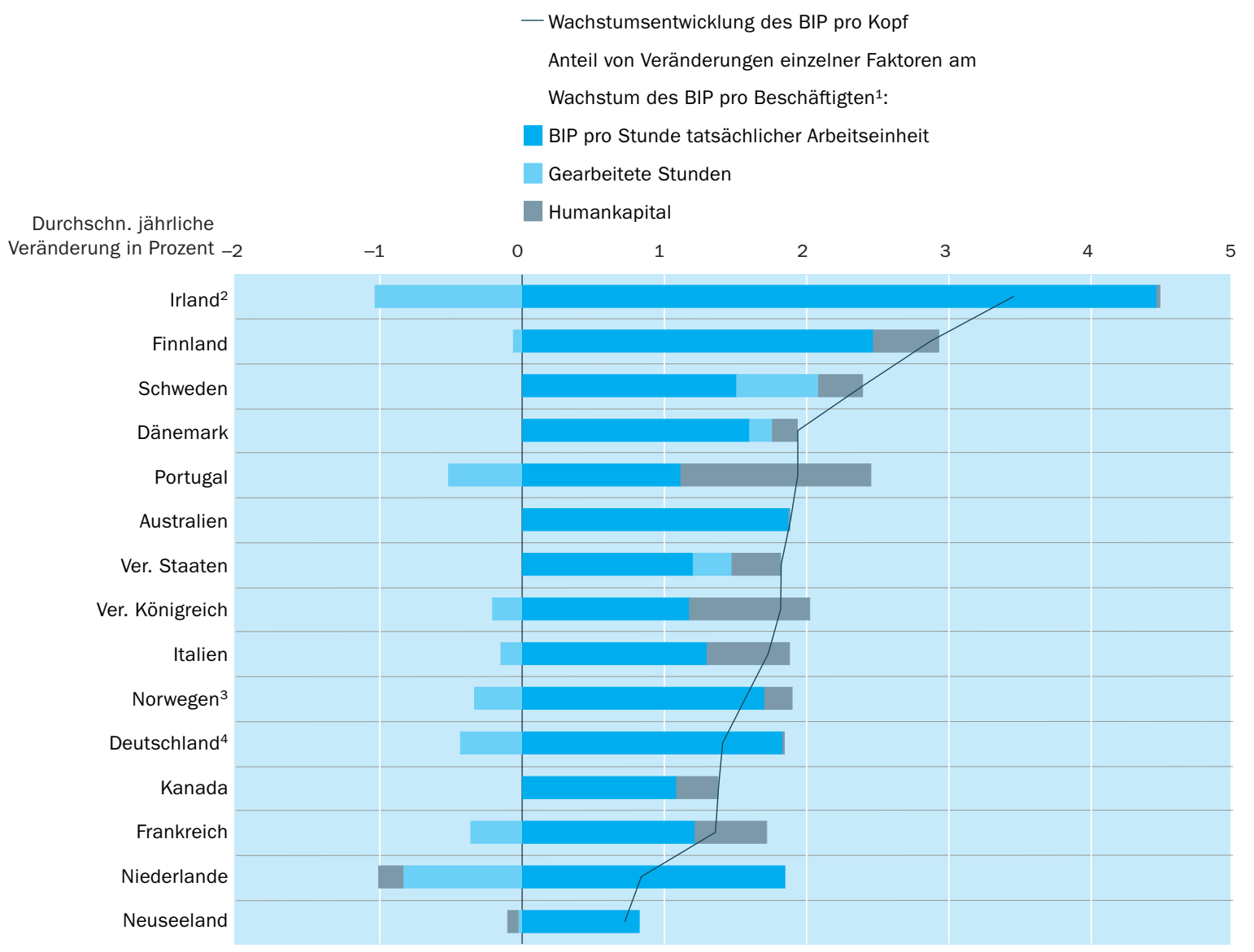

1. Basierend auf der folgenden Aufteilung: Wachstum des BIP pro Beschäftigten $=($ Veränderungen in dem BIP pro Stunde tatsächlicher Arbeitseinheit $)+($ Veränderungen in der Anzahl der durchschnittlich geleisteten Arbeitsstunden) + (Veränderungen des Humankapitals). 2. Referenzzeitraum für Irland 1990-1999. 3. Nur Festland. 4. Referenzzeitraum für Deutschland 1991-2000.

Anordnung der Länder in absteigender Reihenfolge des tendenziellen Wachstums des BIP pro Beschäftigten.

Quelle: OECD. 
schnittlichen US-amerikanischen Arbeitnehmer jedoch nur um 5,3 Prozent. Im gleichen Zeitraum erlebten die ,Güter produzierenden' Berufe einen realen Einkommensrückgang von fast 2,5 Prozent.

\section{Humankapital und konvergierende Einkommen in den Provinzen Kanadas}

In vielen OECD-Ländern gibt es auffallende geographische Konzentrationen des wirtschaftlichen Wohlstands, der Leistungsfähigkeit des Arbeitsmarktes und wichtiger sozialer Errungenschaften. Für viele Regierungen in den OECD-Ländern gehört der Abbau der regionalen wirtschaftlichen und sozialen Ungleichheiten zu den vorrangigen politischen Aufgaben. Seit Anfang der fünfziger Jahre des letzten Jahrhunderts haben sich die Einkommen und die Produktivität der verschiedenen kanadischen Provinzen einander ständig angenähert, wenn auch sehr langsam. Neuere Forschungen haben diesen Konvergenzprozess mittels eines Wachstumsmodells untersucht, das auch das Humankapital berücksichtigt. Es stellte sich heraus, dass sich ungefähr 50 Prozent der Unterschiede im Wachstum des Pro-Kopf-Einkommens und über 80 Prozent der Unterschiede der relativen Einkommensniveaus in allen kanadischen Provinzen über den Zeitraum von I95I bis 1996 durch die Konvergenz beim Bestand des Humankapitals erklären lassen. In diesem Modell einer offenen Volkswirtschaft mit vollständiger Freizügigkeit des Kapitals hält man Veränderungen im Bestand des Humankapitals für die Akkumulation des Sachkapitals in den Provinzen für ausschlaggebend. Als Kennzahl für das Humankapital wird ausgehend von den Zensusdaten ein Index des Bevölkerungsanteils verwendet, der bestimmte Benchmarks der Bildung erreicht hat (Auswirkungen aufWachstum und Einkommen stellten sich als besonders sensitiv im Hinblick auf einen Indikator für höhere Bildung heraus). Durch die Verwendung relativer Kennzahlen für den Bestand des Humankapitals im Zusammenhang mit mehr oder weniger homogenen Bildungssystemen, die sich nicht auf bestimmte Regionen eines Landes beschränken, werden einige der Probleme im Zusammenhang mit der Verwendung von Hilfsgrößen für das Humankapital vermieden.

Wie die Autoren anmerken, hätte die Untersuchung möglicherweise noch aussagekräftigere Erklärungen liefern können, wenn Daten zur Immigration und interregionalen Umverteilung mit einbezogen worden wären. Dennoch vermitteln diese Untersuchungen Erkenntnisse darüber, warum die wirtschaftliche Konvergenz selbst innerhalb einer Volkswirtschaft mit integrierten Finanzmärkten und ohne Einschränkungen des Kapitalverkehrs sich so langsam entwickeln kann. Da sich Sach- und Humankapital ergänzen, könnte es für Regionen mit wenig Sachkapital schwierig sein, weiteres Sachkapital anzuziehen, wenn ihre Basis beim Humankapital relativ unterentwickelt ist. Da für ältere Menschen weniger Anreize für Investitionen in Bildung bestehen als für junge, verlangsamt sich die regionale Konvergenz 
wegen der großen Anzahl weniger qualifizierter älterer Menschen, die in den ärmeren Provinzen bleiben. Die Autoren schätzen, dass die Konvergenz zwei bis drei Mal schneller vonstatten gegangen wäre, wenn alle Personen so stark in Bildung investiert hätten wie dies für die jungen Menschen gilt. Diese Arbeit schafft auch einen analytischen Rahmen zur Beurteilung der Auswirkungen der Umverteilung staatlicher Ressourcen - von reichen zu weniger reichen Provinzen - zur Finanzierung der Bildung.

Quelle: Coulombe, S. and Tremblay, J-F., (2001), „Human Capital and Regional Convergence in Canada“, Journal of Eco nomic Studies, Vol. 28 , No. 3, S. 154-180

\section{Definitionen und angewandte Methodik}

Das Humankapital wurde geschätzt auf Basis der erzielten Abschlüsse in den einzelnen Bildungsbereichen und der jeweiligen durchschnittlichen Dauer der (Aus-)Bildung der Bevölkerung im Erwerbsalter. Diese Kennzahl des Humankapitals wurde abgeleitet aus OECD-Daten in Kombination mit Daten von de la Fuente, A. und Doménech, R. (2000), Human Capital in Growth Regressions: How Much Difference does Data Quality Make?, Economics Department Working Papers, No. 262., OECD, Paris. Weitere Informationen über die Definitionen, Methodik und Quellen s. The Sources of Economic Growth in OECD Countries (OECD, 2003) und The New Economy: Beyond the Hype (OECD, 200I). Die genannten Zahlen entsprechen den in den jeweils angegebenen Berichten veröffentlichten, spätere Änderungen an den Angaben zum BIP einiger Länder wurden nicht berücksichtigt. Diese nachträglichen Änderungen haben jedoch keine Auswirkungen auf die allgemeinen Aussagen der Analyse.

$\mathrm{Zu}$ den im Zusammenhang mit Kasten Ai2.I relevanten Auswirkungen der unterschiedlichen Spezifikationen des Humankapitals auf internationale Vergleichsschätzungen für den Bestand an Humankapital s. Wösmann, L. (2003), „Specifying Human Capital“, Journal of Economic Surveys, Vol. 17, No. 3, S. 239-270. Belege dafür, dass die Auswirkungen von Bildung auf das Wachstum nicht alle Länder gleichermaßen betreffen, und sich im Verlaufe von durchschnittliche 7,5 Jahren (Aus-)Bildung verringern, finden sich in Krueger, A. B. and Lindhal, M. (200I), „Education and Growth: Why and for Whom?“, Journal of Economic Literature, Vol. XXXIX, S. IIOI-II36. 
Die in Bildung investierten

Finanz- und Humanressourcen

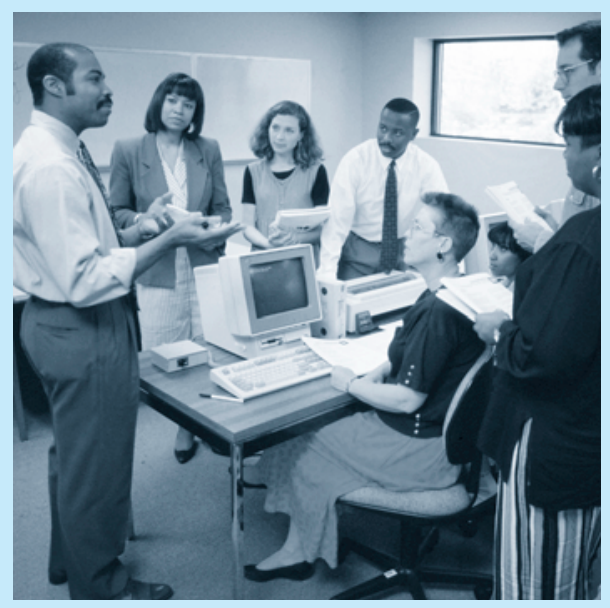




\section{Klassifizierung der Bildungsausgaben}

In diesem Kapitel werden die Bildungsausgaben anhand von drei Dimensionen klassifiziert:

Die erste Dimension ist im nachstehenden Diagramm durch die horizontale Achse dargestellt und bezieht sich auf den Ort, an dem Ausgaben anfallen. Die eine Komponente dieser Dimension bezieht sich auf die Ausgaben in den Schulen und Hochschulen sowie in den Bildungsministerien und anderen Einrichtungen, die direkt an der Bereitstellung und Unterstützung von Bildung beteiligt sind. Ausgaben für Bildung außerhalb von Bildungseinrichtungen sind eine weitere Komponente.

Die zweite Dimension ist im nachstehenden Diagramm durch die vertikale Achse dargestellt und kennzeichnet die für Bildungszwecke erworbenen Sach- und Dienstleistungen. Nicht alle Ausgaben für Bildungseinrichtungen sind als unmittelbare Ausgaben für Bildung oder Unterricht einzustufen. In vielen OECD-Ländern bestreiten die Bildungseinrichtungen nicht nur den Unterricht, sondern bieten auch noch verschiedene zusätzliche Dienstleistungen für Schüler/Studierende und ihre Familien an, wie z.B. Mahlzeiten, Transport, Unterbringung, etc. Ferner können im Tertiärbereich auch die Ausgaben für Forschung und Entwicklung einen nicht unerheblichen Anteil darstellen. Nicht alle Ausgaben für Sach- und Dienstleistungen im Bildungsbereich finden in Bildungseinrichtungen statt. So können beispielsweise Familien die erforderlichen Schulbücher und Unterrichtsmaterialien selbst kaufen oder ihren Kindern Privatunterricht erteilen lassen.

Die dritte Dimension - im nachstehenden Diagramm durch die farbliche Kennzeichnung dargestellt - nimmt eine Einteilung der Mittel nach ihrer Herkunft vor. $\mathrm{Zu}$ diesen Quellen zählen die öffentliche Hand und internationale Organisationen (hellgrau) sowie die privaten Haushalte und andere private Einheiten (hellblau). Wo private Bildungsausgaben durch öffentliche Mittel subventioniert werden, ist dies im Diagramm graublau gekennzeichnet. Dieses Diagramm wird jedem Indikator vorangestellt, um anzugeben, welcher Bereich in dem jeweiligen Indikator abgedeckt wird.

Ausgaben für eigentliche Bildungsdienstleistungen
Ausgaben für

Forschung und

Entwicklung

Ausgaben für nichtunterrichtsbezogene Dienstleistungen im Bildungsbereich

\section{Bildungsausgaben innerhalb von Bildungseinrichtungen (z. B. Schulen, Hochschulen, Einrichtungen der Bildungsverwaltung und soziale Dienste für Schüler/Studierende)}

z. B. öffentliche Ausgaben für Bildungsangebote in Bildungseinrichtungen

\section{z. B. subventionierte private Ausgaben für Unterrichtszwecke} in Bildungseinrichtungen

z. B. private Ausgaben für Unterrichts- bzw. Studiengebühren

z. B. öffentliche Ausgaben für Forschung an Hochschulen

z. B. Mittel der Privatwirtschaft für Forschung und Entwicklung an Bildungseinrichtungen

z. B. öffentliche Ausgaben für zusätzliche Dienstleistungen wie Mahlzeiten, Transport zur Schule, Unterbringung auf dem Campus

z. B. private Ausgaben für zusätzliche Dienstleistungen
Bildungsausgaben außerhalb von

Bildungseinrichtungen

z. B. der private Erwerb von Gütern und Dienstleistungen für Bildungszwecke, z. B. subventionierte private Ausgaben für Bücher

z. B. private Ausgaben für Bücher und anderes Unterrichtsmaterial oder Privatunterricht
Öffentliche Mittel z. B. subventionierte private Ausgaben für den
Lebensunterhalt der Schüler/Studierenden Lebensunterhalt der Schüler/St
bzw. reduzierte Tarife im OPNV z. B. subventionierte private Ausgaben für den Lebensunterhalt der Schüler/Studierenden bzw. reduzierte Tarife im OPNV
Private Mittel

öffentlichsubventionierte private Mittel 


\section{Bildungsausgaben pro Schüler/Studierenden}

Insgesamt geben die OECD-Länder jährlich 4.819 US-Dollar pro Schüler im Primarbereich, 6.688 US-Dollar pro Schüler im Sekundarbereich und 12.319 US-Dollar pro Studierenden im Tertiärbereich aus. Hinter diesen Durchschnittswerten stehen jedoch große Unterschiede bei den Ausgaben zwischen den einzelnen Ländern. Im Durchschnitt der OECD-Länder, dargestellt als arithmetisches Mittel aller OECD-Länder, sind die Ausgaben pro Studierenden im Tertiärbereich 2,2-mal so hoch wie im Primarbereich.

Ohne F\&E-Aktivitäten liegen die Ausgaben pro Studierenden im Tertiärbereich im Durchschnitt bei 7.203 US-Dollar und reichen von 4.000 US-Dollar oder weniger pro Studierenden in Griechenland, Mexiko, Polen und der Türkei bis zu mehr als 8.000 US-Dollar in Australien, Belgien, Dänemark, Irland, den Niederlanden, Schweden, dem Vereinigten Königreich und den Vereinigten Staaten.

In einigen OECD-Ländern führen geringe jährliche Ausgaben pro Studierenden im Tertiärbereich jedoch trotzdem aufgrund der langen Studienzeiten zu hohen Gesamtkosten pro Studierenden.

Niedrigere Ausgaben sind nicht automatisch mit einer geringeren Qualität der Bildungsdienstleistungen gleichzusetzen. So gehören beispielsweise Australien, Finnland, Irland, Korea und das Vereinigte Königreich, Länder mit moderaten Bildungsausgaben pro Schüler im Primar- und Sekundarbereich I, zu den OECD-Ländern mit den besten Leistungen 15-Jähriger in zentralen Fächern.

Es gibt erhebliche Unterschiede zwischen dem Anteil der Mittel, die im Tertiärbereich verwendet werden und dem Anteil der Lernenden im Tertiärbereich. Im Durchschnitt der 24 OECD-Länder, für die Daten vorliegen, fließen 24 Prozent aller für Bildungseinrichtungen vorgesehenen Mittel in den Tertiärbereich, obwohl nur 14 Prozent aller Schüler/Studierenden diesen Bildungsbereich besuchen.

Die Bildungsausgaben pro Schüler im Primar-, Sekundar- und post-sekundaren, nicht-tertiären Bereich stiegen zwischen 1995 und 2001 in Australien, Griechenland, Irland, Polen, Portugal, Spanien und der Türkei um 29 Prozent oder mehr. Im Tertiärbereich haben die Bildungsausgaben nicht immer mit dem raschen Anwachsen der Zahl der Studierenden Schritt gehalten.

In 7 von 22 OECD-Staaten mit verfügbaren Daten gingen die Ausgaben für Bildungseinrichtungen pro Studierenden (in US-Dollar, kaufkraftbereinigt) zwischen 1995 und 2001 zurück, während das Bruttoinlandsprodukt pro Kopf während des gleichen Zeitraums zunahm. 


\section{Abbildung B1.1}

Jährliche Ausgaben für Bildungseinrichtungen pro Schüler/Studierenden (2001)

In US-Dollar, kaufkraftbereinigt, vom Primar-bis zum Tertiärbereich (basierend auf Vollzeitäquivalenten)

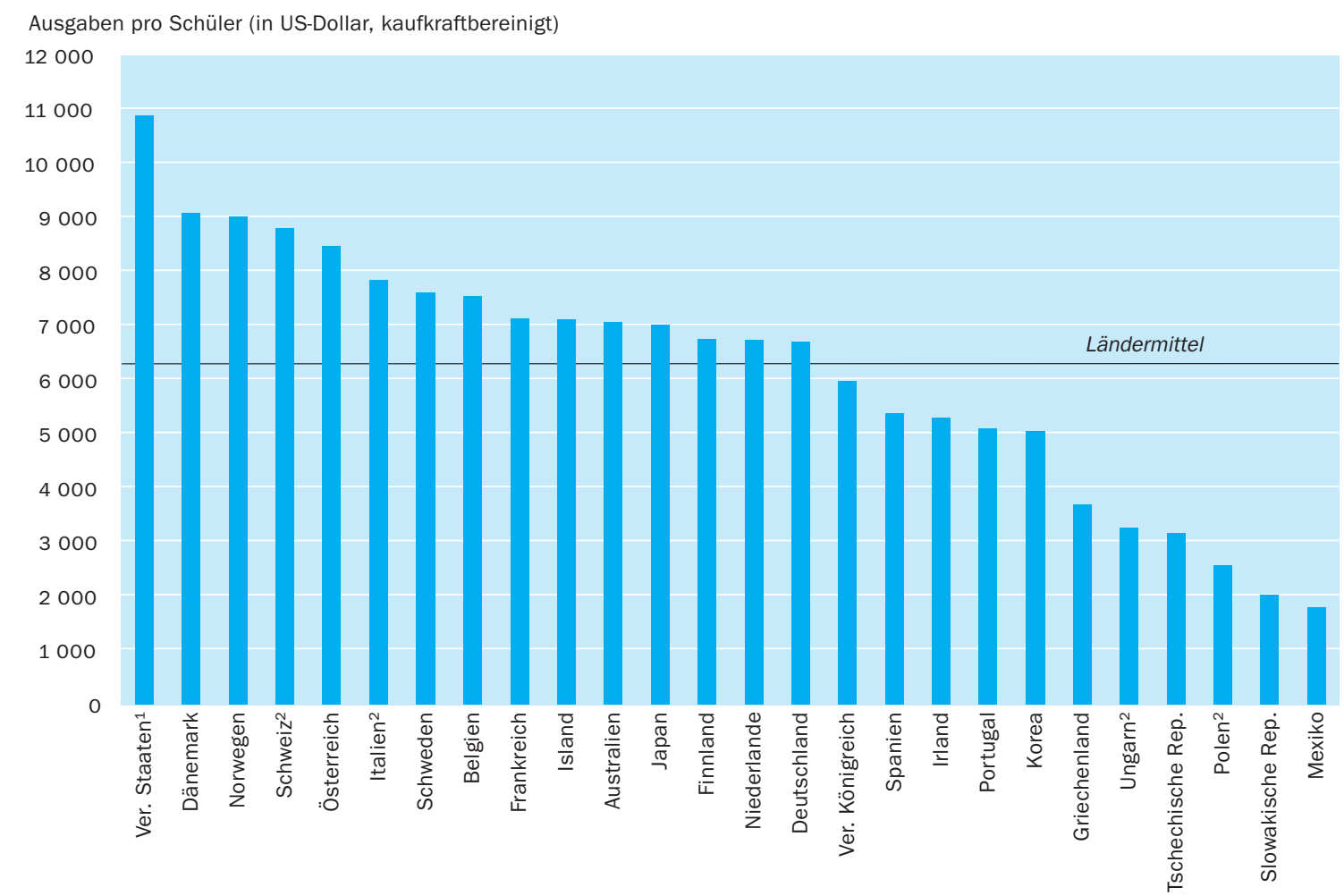

1. Nur öffentliche und unabhängie private Bildungseinrichtungen. 2. Nur öffentiche Bildungseinrichtungen.

Anordnung der Ländern in absteigender Reihenfolge der Ausgaben pro Schüler/Studierenden.

Quelle: OECD. Tabelle B1.1. Hinweise s. Anhang 3 unter www.oecd.org/edu/eag2004.

Dieser Indikator gibt die

jährlichen und kumulierten

Bildungsausgaben pro Schü-

ler/Studierenden in absoluten

Zahlen wider ...

... sowie im Verhältnis zum BIP pro Kopf.

\section{Politischer Hintergrund}

Leistungsfähige Schulen benötigen die richtige Mischung aus gut ausgebildetem und qualifiziertem Personal, angemessener Infrastruktur, moderner Ausstattung und motivierten, lernwilligen Schülern/Studierenden. Die Nachfrage nach hochwertiger Bildung, die mit höheren Kosten pro Schüler/Studierenden einhergehen kann, ist mit der Vermeidung unzumutbarer Belastungen für die Steuerzahler in Einklang zu bringen.

Aus diesem Grund ist die Frage, ob die für die Bildung eingesetzten Mittel auch einen entsprechenden Nutzen bringen, häufig Gegenstand öffentlicher Diskussionen. Zwar ist es schwierig, den optimalen Ressourcenumfang abzuschätzen, der notwendig ist, um jeden Schüler/Studierenden auf ein Leben und Arbeiten in einer modernen Gesellschaft vorzubereiten, doch können internationale Vergleiche der Bildungsausgaben pro Schüler/Studierenden als Anhaltspunkte für eine Bewertung der Effektivität der verschiedenen Bildungsangebote dienen. 
Die Politik muss auch abwägen zwischen der Notwendigkeit, die Qualität des Bildungsangebots zu verbessern, und dem Wunsch, den Zugang zur Bildung, insbesondere im Tertiärbereich, zu erweitern. Die vergleichende Übersicht der Entwicklung der Bildungsausgaben pro Schüler/Studierenden zeigt, dass in vielen OECD-Ländern mit dem Anstieg der Schüler-/Studierendenzahlen, insbesondere im Tertiärbereich, nicht immer auch eine entsprechende Veränderung der Bildungsausgaben einhergegangen ist.

Schließlich sind auch Entscheidungen über die Zuteilung der Mittel auf die verschiedenen Bildungsbereiche von Bedeutung. Während zum Beispiel einige OECD-Länder Wert auf einen breiten Zugang zur Hochschulausbildung legen, investieren andere stärker in die fast vollständige Bildungsbeteiligung kleiner Kinder im Alter von drei oder vier Jahren.

\section{Ergebnisse und Erläuterungen}

\section{Was dieser Indikator aufzeigt und was nicht}

Dieser Indikator gibt Auskunft über die direkten öffentlichen und privaten Ausgaben für Bildungseinrichtungen im Verhältnis zur Anzahl der vollzeitäquivalenten Schüler bzw. Studierenden an diesen Einrichtungen.

Im Interesse einer besseren internationalen Vergleichbarkeit sind öffentliche Zuwendungen zum Lebensunterhalt der Schüler/Studierenden in diesen Zahlen nicht enthalten. Für einige OECD-Länder sind keine Zahlen zu den Ausgaben für Schüler/Studierende an privaten Bildungseinrichtungen verfügbar. Einige andere Länder wiederum haben kein vollständiges Zahlenmaterial über unabhängige private Bildungseinrichtungen zur Verfügung gestellt. In diesen Fällen wurden nur die Ausgaben für öffentliche sowie staatlich-subventionierte private Einrichtungen berücksichtigt. Es ist zu beachten, dass Unterschiede bei den Bildungsausgaben pro Schüler/Studierenden nicht nur auf Unterschiede bei den materiellen Ressourcen, die für Schüler/Studierende zur Verfügung gestellt werden, zurückgeführt werden können (z. B. Unterschiede im zahlenmäßigen Verhältnis Schüler/Studierende zu Lehrpersonal), sondern auch auf Unterschiede in den relativen Gehaltsniveaus.

Im Primar- und Sekundarbereich überwiegen bei den Bildungsausgaben die Ausgaben für die Unterrichtsdienstleistungen, im Tertiärbereich können andere Leistungen, insbesondere im Zusammenhang mit Forschung und Entwicklung, oder zusätzliche Dienstleistungen, einen wesentlichen Teil der Bildungsausgaben ausmachen. Indikator B6 liefert weitergehende Informationen über die Verteilung der Ausgaben nach den verschiedenen (Dienst-)Leistungsangeboten.

\section{Bildungsausgaben pro Schüler/Studierenden in US-Dollar, kaufkraftbereinigt}

Ausgehend von den jährlichen Ausgaben für Bildungseinrichtungen pro Schüler/Studierenden vom Primar- bis zum Tertiärbereich kann ermittelt werden, wie viel Mittel für jeden Schüler/Studierenden ausgegeben werden. Insgesamt geben die OECD-Länder 6.82I US-Dollar pro Schüler/Studierenden vom Primar-
Der Indikator vergleicht auch die Entwicklung der Bildungsausgaben pro Schüler/Studierenden.

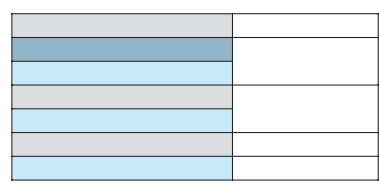

Erfasste Daten

(Erklärung S. S. 208)

In 8 von 26 Ländern bewegen sich die Bildungsausgaben vom Primar- bis zum Tertiärbereich zwischen 5.900 und 
7.100 US-Dollar pro

Schüler/Studierenden.

Insgesamt geben die OECD-

Länder 4.819 US-Dollar pro

Schüler im Primarbereich,

6.688 US-Dollar pro Schüler

im Sekundarbereich und

12.319 US-Dollar pro

Studierenden im Tertiär-

bereich aus, ...

... hinter diesen Durchschnittswerten stehen jedoch große Unterschiede bei den Ausgaben pro Schüler/Studierenden zwischen den einzelnen OECDLändern.

Die Ausgaben für Forschung und Entwicklung in Einrichtungen des Tertiärbereichs belaufen sich in Australien, Belgien, Dänemark, Deutschland, Finnland, Italien, den Niederlanden, Österreich und Schweden auf mehr als 3.000 US-Dollar pro Studierenden. bis zum Tertiärbereich aus. Die Bildungsausgaben in diesen Bereichen variieren zwischen 3.300 US-Dollar pro Schüler/Studierenden oder weniger in Mexiko, Polen, der Slowakischen sowie der Tschechischen Republik und Ungarn und mehr als 8.00o US-Dollar pro Schüler/Studierenden in Dänemark, Norwegen, Österreich, der Schweiz und den Vereinigten Staaten. In 8 von 26 Ländern bewegen sich die Bildungsausgaben zwischen 5.900 und 7.100 US-Dollar pro Schüler/Studierenden (Abb. BI.I).

Aber auch wenn die Gesamtausgaben pro Schüler/Studierenden in einigen OECD-Ländern ähnlich hoch sind, gibt es doch große Unterschiede bei der Verteilung der Mittel auf die einzelnen Bildungsbereiche. Insgesamt geben die OECD-Länder pro Schüler im Primarbereich 4.819 US-Dollar, im Sekundarbereich 6.688 US-Dollar und pro Studierenden im Tertiärbereich I2.3I9 US-Dollar aus. Im Tertiärbereich sind diese Durchschnittszahlen jedoch durch das hohe Ausgabenniveau in einigen wenigen großen OECD-Ländern, vor allem den Vereinigten Staaten, beeinflusst. Die Bildungsausgaben pro Schüler/Studierenden in einem ,typischen' OECD-Land, ausgedrückt durch das arithmetische Mittel aller OECD-Länder, beziffern sich auf 4.850 US-Dollar im Primarbereich, 6.5 Io US-Dollar im Sekundarbereich und I0.052 US-Dollar im Tertiärbereich (Tab. BI.I).

Diesen Durchschnittswerten liegt ein breites Spektrum von Bildungsausgaben pro Schüler/Studierenden in den verschiedenen OECD-Ländern zugrunde. Im Primarbereich reichen die Ausgaben für Bildungseinrichtungen von I.252 USDollar pro Schüler in der Slowakischen Republik bis zu 7.873 US-Dollar pro Schüler in Luxemburg. Im Sekundarbereich sind die Unterschiede zwischen den einzelnen OECD-Ländern sogar noch größer. Dort unterscheiden sich die Bildungsausgaben pro Schüler um bis zum 6-fachen und reichen von I.874 US-Dollar pro Schüler in der Slowakischen Republik bis zu I0.9I6 US-Dollar in der Schweiz. Die Bildungsausgaben pro Studierenden im Tertiärbereich reichen von 3.579 US-Dollar in Polen bis zu 22.234 US-Dollar in den Vereinigten Staaten (Tab. BI.I).

Diese Vergleiche beruhen auf kaufkraftbereinigten Zahlen und nicht auf mittels aktuellen Wechselkursen berechneten Zahlen, d.h. sie geben den Betrag einer Landeswährung an, mit dem in einem bestimmten Land der gleiche Waren- und Dienstleistungskorb erworben werden kann wie in den Vereinigten Staaten mit US-Dollar.

Im Durchschnitt belaufen sich im Tertiärbereich die Ausgaben für Forschung und Entwicklung (F\&E) auf 26 Prozent der Gesamtausgaben in diesem Bereich. In 5 von I9 OECD-Ländern, bei denen die Ausgaben im Tertiärbereich nach Leistungsarten getrennt aufgeführt werden, machen die F\&E-Ausgaben in tertiären Bildungseinrichtungen mehr als 35 Prozent der Gesamtausgaben im Tertiärbereich aus. Umgerechnet auf den einzelnen Studierenden kann dies erhebliche Beträge ausmachen, wie z.B. in Australien, Belgien, Dänemark, Deutschland, Finnland, Italien, den Niederlanden, Österreich und Schweden, wo sich die Ausgaben für F\&E in Einrichtungen des tertiären Bildungsbereichs auf mehr als 3.000 US-Dollar (kaufkraftbereinigt) pro Studierenden belaufen (Abb. Bi.2, Tab. Bi.I und B6.2). 
Abbildung B1.2

Jährliche Ausgaben für Bildungseinrichtungen pro Schüler/Studierenden, nach Bildungsbereich (2001)

In US-Dollar, kaufkraftbereinigt (basierend auf Vollzeitäquivalenten)

\section{Primärbereich}

Ausgaben pro Schüler (in US-Dollar, kaufkraftbereinigt)

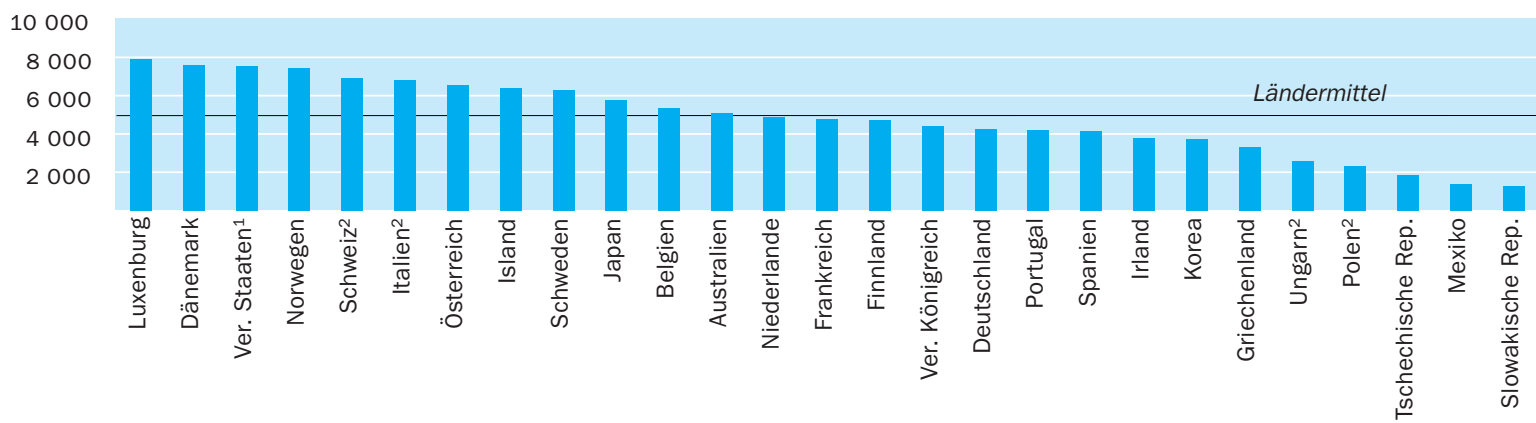

Sekundarbereich

Ausgaben pro Schüler (in US-Dollar, kaufkraftbereinigt) — Sekundarbereich Sekundarbereich I $>$ Sekundarbereich II

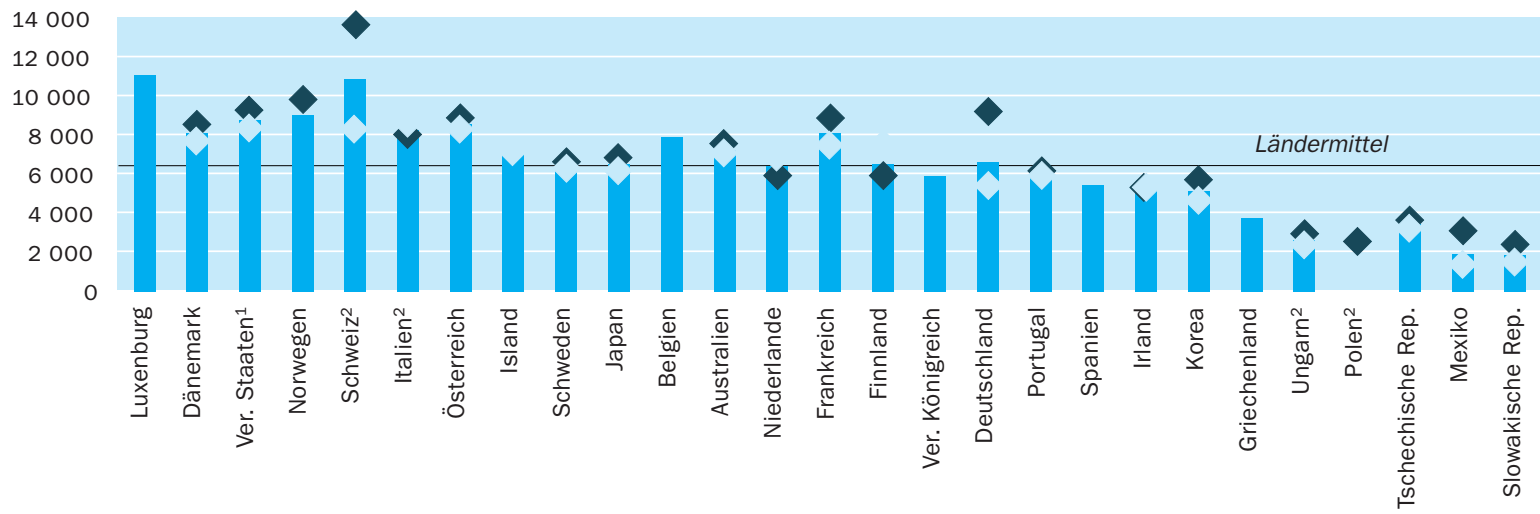

Tertiärbereich

Ausgaben pro Schüler (in US-Dollar, kaufkraftbereinigt) — Tertiärbereich (ohne F\&E-Aktivitäten) > Tertiärbereich (einschl. F\&E-Aktivitäten)

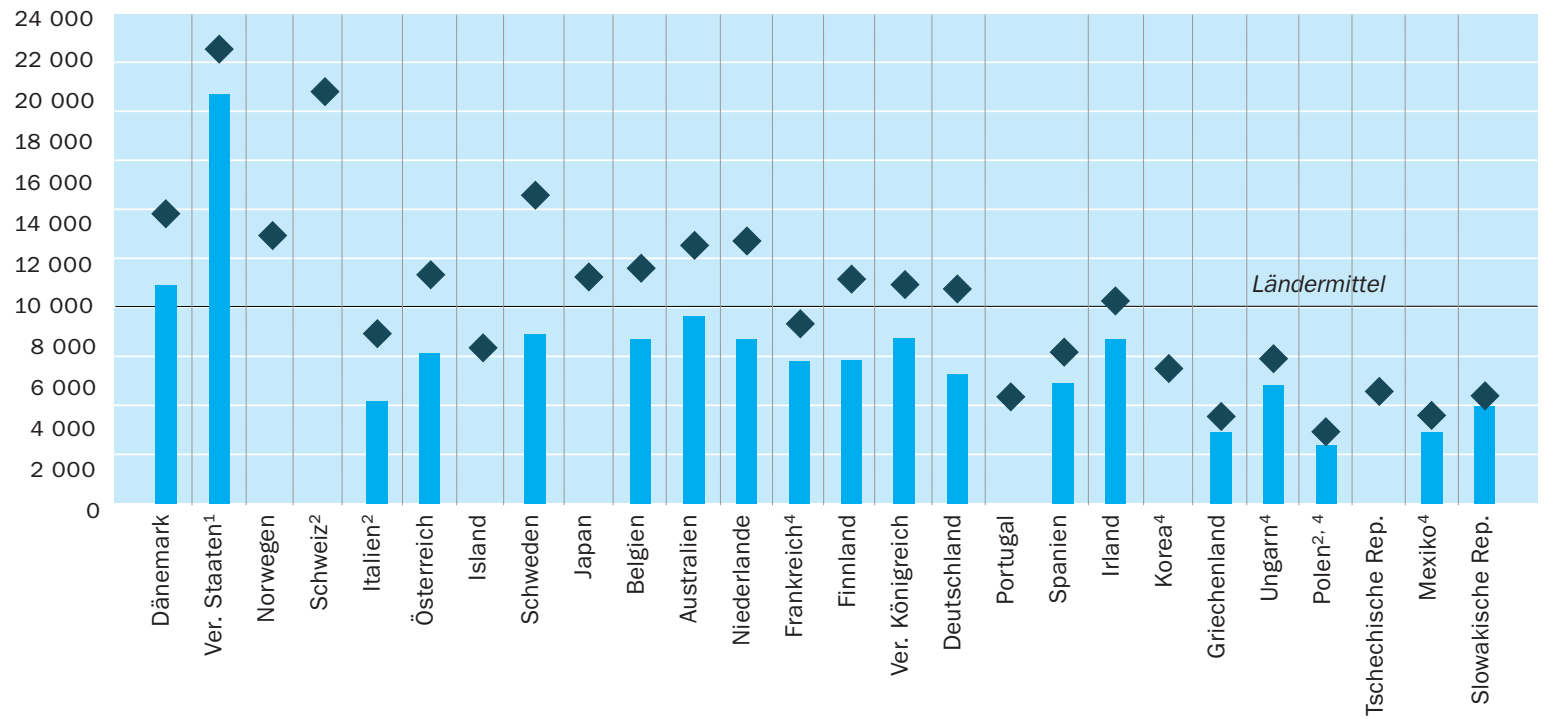

1. Nur öffentliche und unabhängige private Bildungseinrichtungen. 2. Nur öffentliche Bildungseinrichtungen. 3. Der Balken steht für die Gesamtausgaben im Tertiärbereich ohne Ausgaben für Forschung und Entwicklung. 4. Ausgaben für Forschung und Entwicklung im Tertiärbereich und somit die Gesamtausgaben einschl. F\&E-Aktivitaten sind zu niedrig angesetzt.

Anordnung der Ländern in absteigender Reihenfolge der Ausgaben pro Schüler im Primarbereich.

Quelle: OECD. Tabellen B1.1 und B6.2. Hinweise s. Anhang 3 unter www.oecd.org/edu/eag2004. 
Ohne F\&E-Aktivitäten liegen die Ausgaben für tertiäre Bildungseinrichtungen im Durchschnitt bei 7.203 USDollar pro Studierenden.

Die arbeitskräfteintensive Form der Bildungsvermittlung bedingt den überwiegenden Anteil, den die Gehälter für Lehrkräfte an den Gesamtkosten ausmachen.

Geringere Ausgaben pro Schüler/Studierenden können nicht automatisch mit geringeren Leistungen derselben gleichgesetzt werden.

Je höher der Bildungsbereich, desto höher die Bildungsausgaben pro Schüler/ Studierenden.
Die F\&E-Ausgaben in tertiären Bildungseinrichtungen sind nicht nur durch die F\&E-Gesamtaufwendungen eines Landes bedingt, sondern auch durch die nationale Infrastruktur für F\&E-Aktivitäten. Die OECD-Länder, in denen Forschung und Entwicklung hauptsächlich an tertiären Bildungseinrichtungen stattfinden, verzeichnen eher höhere Ausgaben pro Studierenden im Tertiärbereich als Länder, in denen ein Großteil der Forschungs- und Entwicklungsarbeiten in anderen öffentlichen Einrichtungen oder von der Wirtschaft durchgeführt werden. Ohne F\&E-Aktivitäten liegen die Ausgaben für tertiäre Bildungseinrichtungen im Durchschnitt bei 7.203 US-Dollar pro Studierenden und reichen von 4.000 US-Dollar oder weniger pro Studierenden in Griechenland, Mexiko, Polen und der Türkei bis zu mehr als 8.00o US-Dollar in Australien, Belgien, Dänemark, Irland, den Niederlanden, Schweden, dem Vereinigten Königreich und den Vereinigten Staaten (Tab. BI.I und Abb. BI.2).

Die Arbeitskräfteintensität des traditionellen Bildungsmodells mit Unterricht im Klassenzimmer/Hörsaal führt dazu, dass die Gehälter für die Lehrkräfte den Hauptteil der Gesamtkosten ausmachen. Unterschiede in der durchschnittlichen Klassengröße und im zahlenmäßigen Verhältnis zwischen Schülern/Studierenden und Lehrkräften (Indikator D2), in der Personalzusammensetzung, in den Lehrergehältern (Indikator $\mathrm{D}_{3}$ ) und in den Unterrichtsmaterialien und Ausstattungen führen $\mathrm{zu}$ Kostenunterschieden zwischen den einzelnen Bildungsbereichen, Bildungsgängen und Schultypen.

Es wäre irreführend, geringere Ausgaben pro Schüler/Studierenden ganz allgemein mit einer geringeren Qualität des Bildungsangebots gleichzusetzen. So gehören beispielsweise Australien, Finnland, Irland, Korea und das Vereinigte Königreich, Länder mit moderaten Bildungsausgaben pro Schüler im Primarund Sekundarbereich I, zu den OECD-Ländern mit den besten Leistungen I5Jähriger in zentralen Fächern (s. PISA).

\section{Unterschiede in den Bildungsausgaben pro Schüler/Studierenden in den verschiedenen Bildungsbereichen}

Den Bildungsausgaben pro Schüler/Studierenden aller OECD-Ländern ist eines gemeinsam: sie steigen vom Primar- zum Tertiärbereich stark an. Dies wird verständlich, wenn man die wichtigsten Faktoren betrachtet, die die Bildungsausgaben beeinflussen, insbesondere Ort und Art des Bildungsangebots. Bildung findet nach wie vor meistens an herkömmlichen Schulen und Hochschulen statt, die in Bezug auf Aufbau, Lehrplan, Art des Unterrichts und Management im Allgemeinen recht ähnlich sind. Diese Gemeinsamkeiten führen daher auch zu ähnlichen Strukturen der Ausgaben pro Schüler/Studierenden.

Vergleiche der Verteilung der Bildungsausgaben auf die einzelnen Bildungsbereiche sind ein Hinweis auf den relativen Stellenwert, den die einzelnen OECDLänder den verschiedenen Bildungsbereichen beimessen, sowie auf die relativen Kosten der Bildungsvermittlung in diesen Bereichen.

Obwohl in fast allen OECD-Ländern die Bildungsausgaben pro Schüler/Studierenden mit der Höhe des Bildungsbereichs steigen (vom Primar- zum Tertiärbereich), variieren die relativen Unterschiede doch erheblich zwischen den einzelnen Ländern (Abb. BI.3). Im Sekundarbereich betragen die Bildungs- 


\section{Abbildung B1.3}

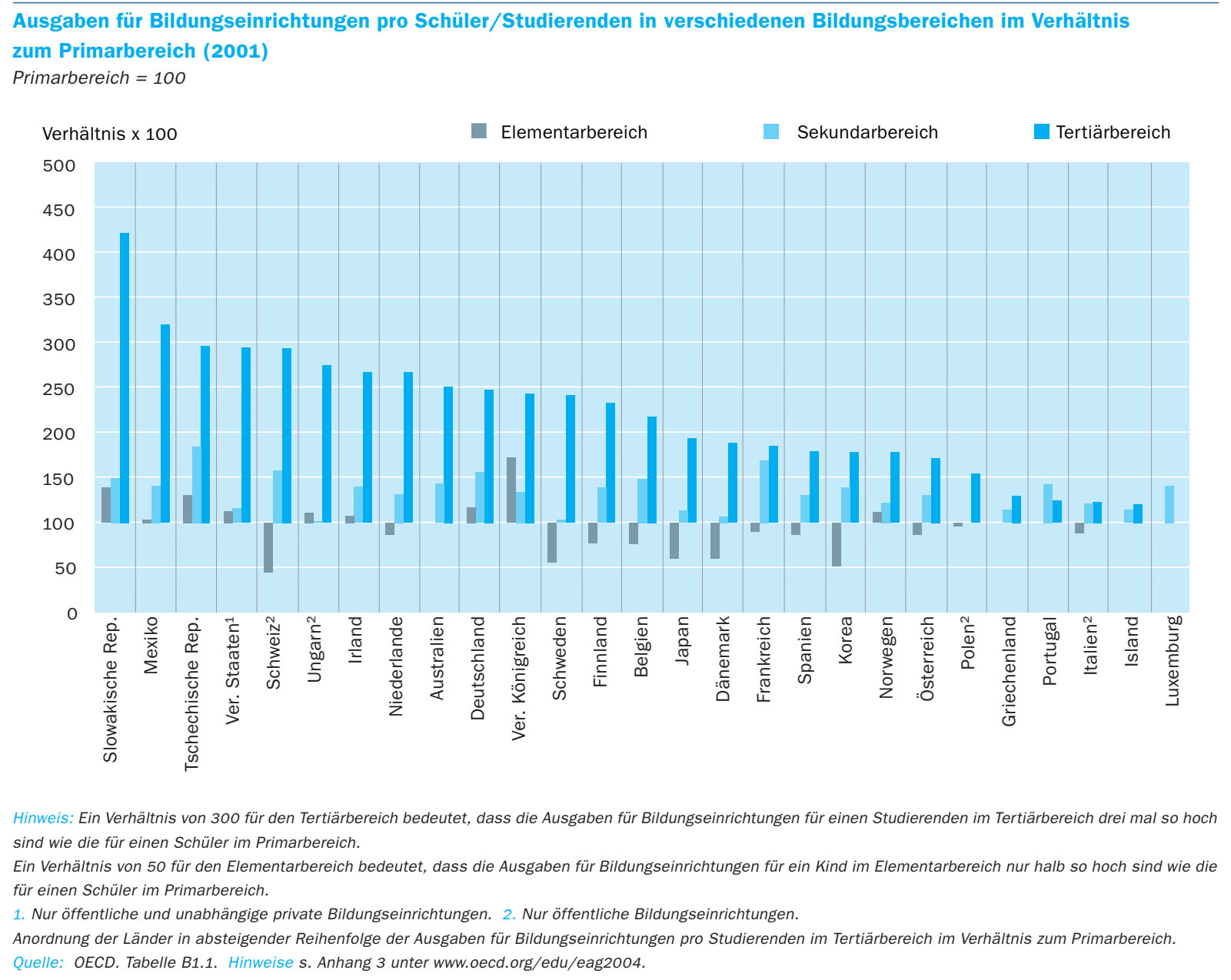

ausgaben pro Schüler im Durchschnitt das I,3-fache derjenigen im Primarbereich, obwohl die Spanne vom I-fachen der Höhe der Ausgaben pro Schüler im Primarbereich in Schweden und Ungarn bis zum I,6-fachen oder mehr in Deutschland, Frankreich und der Tschechischen Republik reicht.

Obwohl im Durchschnitt der OECD-Länder die Bildungsausgaben pro Studierenden im Tertiärbereich 2,2-mal so hoch wie die Bildungsausgaben pro Schüler im Primarbereich sind, gibt es große länderspezifische Unterschiede bei den Ausgabenstrukturen. Während beispielsweise Griechenland, Island, Italien und Portugal für einen Studierenden im Tertiärbereich zwischen I,2 und I, 3 mal soviel ausgeben wie für einen Schüler im Primarbereich, ist es in Mexiko und der Slowakischen Republik das 3,2- bzw. 4,2-fache (Abb. BI.3).

\section{Bildungsausgaben pro Studierenden über die durchschnittliche Verweildauer im Tertiärbereich}

Sowohl die typische Verweildauer als auch die Intensität der tertiären Bildung variieren stark zwischen den OECD-Ländern. Daher spiegeln die Unterschiede zwischen den einzelnen Ländern bei den jährlichen Bildungsausgaben pro Studierenden für Bildungsdienstleistungen, wie sie aus der Abbildung BI.2
Im Durchschnitt sind die Bildungsausgaben der OECDLänder pro Studierenden im Tertiärbereich 2,2-mal so hoch wie die pro Schüler im Primarbereich.
Die jährlichen Bildungsausgaben pro Studierenden spiegeln nicht immer die gesamten Kosten tertiärer Studiengänge wider. 


\section{Abbildung B1.4}

Kumulierte Ausgaben für Bildungseinrichtungen pro Studierenden über die durchschnittliche Verweildauer im Tertiärbereich (2001)

Jährliche Ausgaben für Bildungseinrichtungen pro Studierenden multipliziert mit der durchschnittlichen Verweildauer im Tertiärbereich, in US-Dollar, kaufkraftbereinigt

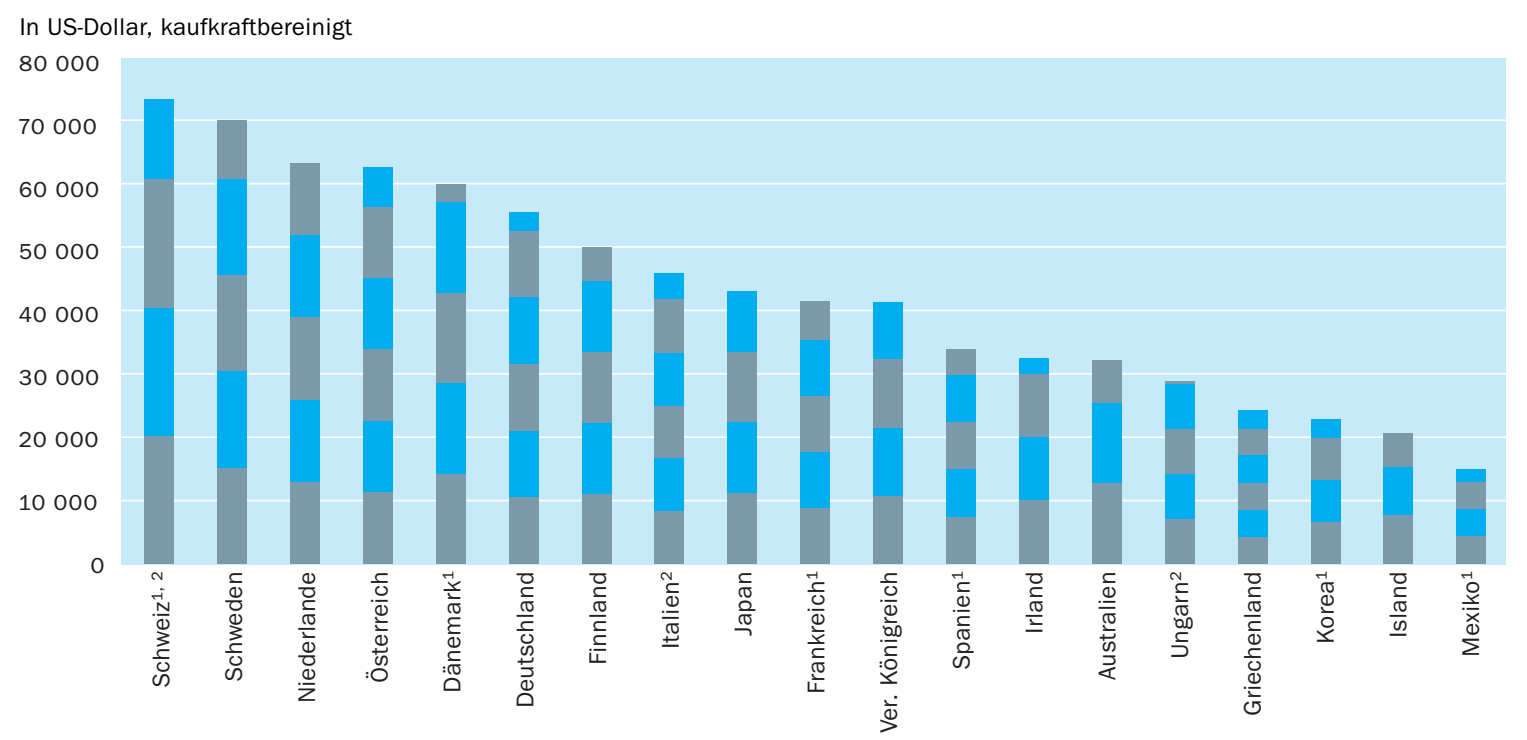

Hinweis: Jeder Abschnitt eines Balkens steht für die jährlichen Ausgaben für Bildungseinrichtungen pro Studierenden. Die Anzahl der Abschnitte steht für die Anzahl an Jahren, die ein Studierender im Durchschnitt im Tertiärbereich verbringt.

1. Die Angaben zur Verweildauer im Tertiärbereich stammen aus einer 1997 zum akademischen Jahr 1995 durchgeführten speziellen Erhebung. 2. Nur öffentliche Bildungseinrichtungen.

Anordnung der Länder in absteigender Reihenfolge der Gesamtausgaben für Bildungseinrichtungen pro Studierenden über die durchschnittliche Verweildauer im Tertiärbereich.

Quelle: OECD. Tabelle B1.3. Hinweise s. Anhang 3 unter www.oecd.org/edu/eag2004.

Die Studierenden können aus einer Vielfalt von Bildungseinrichtungen und Teilnahmemöglichkeiten wählen.

Niedrige jährliche Ausgaben können sich bei einer langen Verweildauer im Tertiärbereich zu hohen Gesamtkosten aufsummieren. hervorgehen, nicht unbedingt die Unterschiede in den Gesamtkosten für die tertiäre Bildung des typischen Studierenden wider.

Heutzutage können die Studierenden aus einer Vielfalt von Bildungseinrichtungen und Teilnahmemöglichkeiten wählen, um die für sie entsprechend ihren angestrebten Bildungsabschlüssen, Fähigkeiten und persönlichen Interessen beste Lösung zu finden. Viele Studierende nehmen an Teilzeitstudiengängen teil, während andere während des Studiums arbeiten oder an mehreren Einrichtungen studieren, bevor sie ihren Abschluss erwerben. Dieses unterschiedliche Teilnahmeverhalten kann die Interpretierbarkeit der Bildungsausgaben pro Studierenden beeinflussen.

Insbesondere vergleichsweise niedrige jährliche Bildungsausgaben pro Studierenden können zu vergleichsweise relativ hohen Gesamtkosten im Tertiärbereich führen, wenn die typische Verweildauer im Tertiärbereich lang ist. Abbildung Br.4 gibt einen Überblick über die durchschnittlichen Ausgaben pro Studierenden im Laufe des gesamten Studiums. Die Zahlen beziehen sich auf alle Studierenden, für die Ausgaben anfallen, also auch auf die Studienabbrecher. Zwar beruhen die Berechnungen auf einer Reihe vereinfachender Annahmen und sind daher mit Vorsicht zu interpretieren (s. Anhang 3 unter 
www.oecd.org/eduleag2004), dennoch lassen sich aus ihnen einige bedeutende Verschiebungen in der Rangfolge der OECD-Länder ablesen, je nachdem ob die jährlichen oder die kumulierten Ausgaben das entscheidende Kriterium sind.

So sind beispielsweise die jährlichen Bildungsausgaben pro Studierenden in Japan ungefähr genau so hoch wie in Österreich (II.I64 US-Dollar in Japan im Vergleich zu II.274 US-Dollar in Österreich) (Tab. BI.I). Aufgrund der Unterschiede in der Struktur der Abschlüsse im Tertiärbereich (Indikator A2) ist die durchschnittliche Verweildauer im Tertiärbereich in Österreich knapp zwei Jahre länger als in Japan (5,5 Jahre in Österreich gegenüber 3,8 Jahren in Japan). Daher sind die kumulierten Kosten für jeden Studierenden im Tertiärbereich in Österreich fast 20.000 US-Dollar höher als in Japan (62.459 US-Dollar verglichen mit 42.970 US-Dollar) (Abb. BI.4 und Tabelle BI.3).

Die Gesamtkosten eines Studiengangs im Tertiärbereich A sind in der Schweiz (II8.953 US-Dollar) mehr als doppelt so hoch als in den anderen Ländern, die Zahlen vorgelegt haben, mit Ausnahme Deutschlands und Österreichs (Tab. BI.3). Diese Unterschiede müssen natürlich im Zusammenhang mit den Unterschieden in den nationalen Abschlussstrukturen, aber auch mit möglichen Unterschieden im akademischen Qualifikationsniveau der Hochschulabsolventen in den einzelnen OECD-Ländern gesehen werden. Während man bei Studiengängen im Tertiärbereich B ähnliche Tendenzen feststellen kann, sind die Gesamtkosten bei diesen Studiengängen tendenziell wesentlich niedriger als bei Studiengängen im Tertiärbereich A, was vor allem mit der kürzeren Studiendauer zusammenhängt.

\section{Verteilung der Ausgaben für Bildungsreinrichtungen im Verhältnis zur Anzahl der Schüler/Studierenden an diesen Einrichtungen}

Die Mittel, die in das jeweilige Bildungssystem der OECD-Länder investiert werden, lassen sich vergleichen, wenn man den Anteil der Schüler/Studierenden im jeweiligen Bildungsbereich betrachtet. Ein Bildungsbereich mit einem hohen prozentualen Anteil an Schülern/Studierenden sollte auch einen hohen Anteil der investierten Mittel erhalten, damit günstige Unterrichtsbedingungen sichergestellt sind. Tabelle Br.4 zeigt den Zusammenhang zwischen dem Anteil der Ausgaben für Bildungseinrichtungen und der Anzahl der Schüler/Studierenden in den jeweiligen Einrichtungen, nach Bildungsbereichen. Im Durchschnitt der 23 OECD-Länder, die Daten gemeldet haben, fließen 4I Prozent aller Ausgaben für Bildungseinrichtungen in den Sekundarbereich, den 39 Prozent aller Schüler/Studierenden besuchen. Der Unterschied zwischen diesen beiden Zahlen ist in Belgien, Frankreich, der Slowakischen Republik, der Schweiz, Ungarn und den Vereinigten Staaten größer als 4 Prozent. Unter den Ländern, deren in den Sekundarbereich investierten Mittel im Vergleich zu den anderen Bildungsbereichen über dem OECD-Durchschnitt liegen, besuchen in Deutschland, Frankreich, Italien, Österreich, der Slowakischen Republik, der Tschechischen Republik und dem Vereinigten Königreich mehr als 45 Prozent der Schüler/Studierenden den Sekundarbereich. Im Gegensatz dazu liegt in Dänemark, Irland, Korea, Mexiko, Norwegen und den Vereinigten Staaten sowohl der Anteil der investierten Mittel als auch der Anteil der Schüler/Studierenden im Sekundarbereich bei 35 Prozent oder darunter (Tab. Br.4 und Abb. BI.5a).
Im Durchschnitt fließen 41 Prozent aller Ausgaben für Bildungseinrichtungen in den Sekundarbereich, den 39 Prozent aller Schüler/ Studierenden besuchen, ... 
... dagegen gibt es im Primarund Tertiärbereich große Unterschiede zwischen dem Anteil der investierten Mittel und dem prozentualen Anteil der Schüler/Studierenden.
Im Vergleich zum Sekundarbereich gibt es im Primar- und Tertiärbereich erhebliche Unterschiede zwischen dem Anteil der investierten Mittel und dem prozentualen Anteil der Schüler/Studierenden. Im Durchschnitt der 24 OECDLänder, für die Daten vorliegen, fließen 26 bzw. 24 Prozent aller Ausgaben für Bildungseinrichtungen in den Primar- bzw. den Tertiärbereich, obwohl 35 Prozent aller Schüler/Studierenden den Primarbereich besuchen und nur I4 Prozent den Tertiärbereich. Der Unterschied zwischen diesen beiden Größen liegt im Primarbereich in Australien, Irland und Mexiko bei über I2 Prozent und reicht im Tertiärbereich von unter 5 Prozent in Frankreich, Griechenland, Italien und Korea bis zu über 13 Prozent in Irland, den Niederlanden, Schweden, der Slowakischen Republik und den Vereinigten Staaten. In Io der 24 Länder liegt der Anteil der investierten Mittel und der Anteil der Schüler/Studierenden im Tertiärbereich unter dem OECD-Durchschnitt, während in Finnland, Griechenland, Irland, Korea und den Vereinigten Staaten mehr als 29 Prozent aller Bildungsausgaben in den Tertiärbereich fließen (Tab. BI.4 und Abb. Br.5b).

Abbildung B1.5a

Ausgaben für den Sekundarbereich und Anzahl der Schüler in diesem Bildungsbereich (2001) als Prozentsatz der Ausgaben und Anzahl der Schüler/Studierenden in allen Bildungsbereichen zusammen

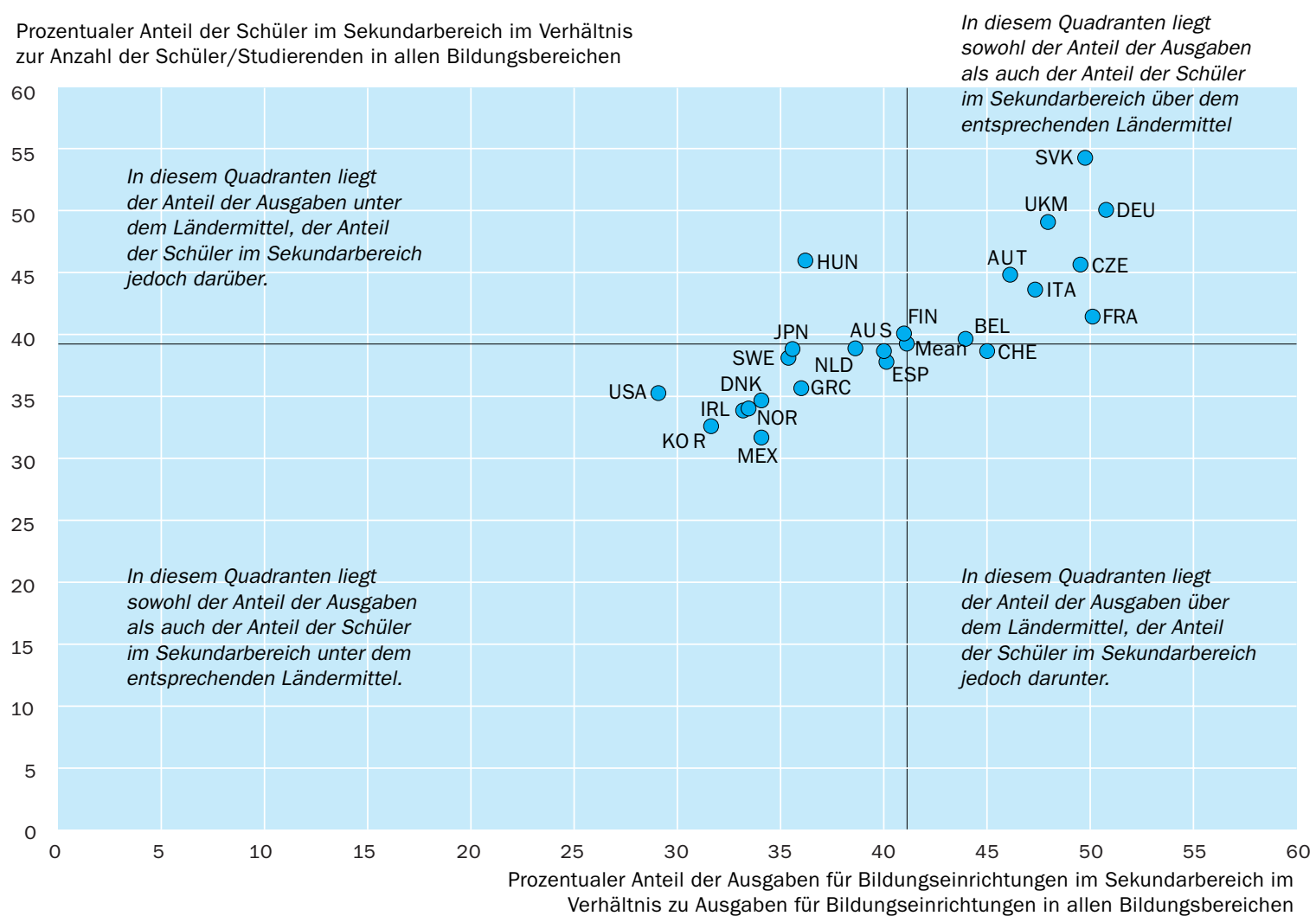

Hinweis: Im Durchschnitt fließen 41 Prozent aller Ausgaben für Bildungseinrichtungen in den Sekundarbereich, den 39 Prozent aller Schüler/Studierenden besuchen. Auflistung der verwendeten Ländercodes und der dazugehörenden Ländernamen s. Hinweise für den Leser.

Quelle: OECD. Tabelle B1.4. Hinweise s. Anhang 3 unter www.oecd.org/edu/eag2004. 


\section{Bildungsausgaben pro Schüler/Studierenden im Verhältnis zum}

\section{jeweiligen BIP pro Kopf}

Die Bildungsausgaben pro Schüler/Studierenden in Relation zum BIP pro Kopf sind ein Maßstab für die Bildungsausgaben, bei dem der relative Wohlstand der OECD-Länder berücksichtigt wird. Da in den unteren Bildungsbereichen die Bildungsteilnahme universell ist, können hier die Bildungsausgaben pro Schüler im Verhältnis zum BIP pro Kopf als Ausgaben für die nachwachsende Generation entsprechend der Finanzkraft eines Landes angesehen werden. Für die höheren Bildungsbereiche muss für eine Interpretation der Ausgaben eine Kombination aus Volkseinkommen, Ausgabenniveau und Bildungsbeteiligung berücksichtigt werden. Im Tertiärbereich können OECD-Länder beispielsweise einen relativ hohen Wert bei dieser Kennzahl erreichen, wenn ein relativ hoher Anteil ihres Volkseinkommens für eine relativ geringe Zahl von Studierenden aufgewendet wird. Für die OECD insgesamt beziffern sich die Bildungsausgaben pro Schüler/Studierenden im Primarbereich durchschnittlich auf 20 Prozent des BIP pro Kopf, pro Schüler im Sekundarbereich auf 26 Prozent und pro Studierenden im Tertiärbereich auf 42 Prozent (Tab. BI.2).

Die OECD-Länder geben durchschnittlich 20 Prozent des BIP pro Kopf pro Schüler im Primarbereich aus, 26 Prozent pro Schüler im Sekundarbereich und 42 Prozent pro Studierenden im Tertiärbereich.

\section{Abbildung B1.5b}

Ausgaben für den Tertiärbereich und Anzahl der Studierenden in diesem Bildungsbereich (2001) als Prozentsatz der Ausgaben und Anzahl der Schüler/Studierenden in allen Bildungsbereichen zusammen

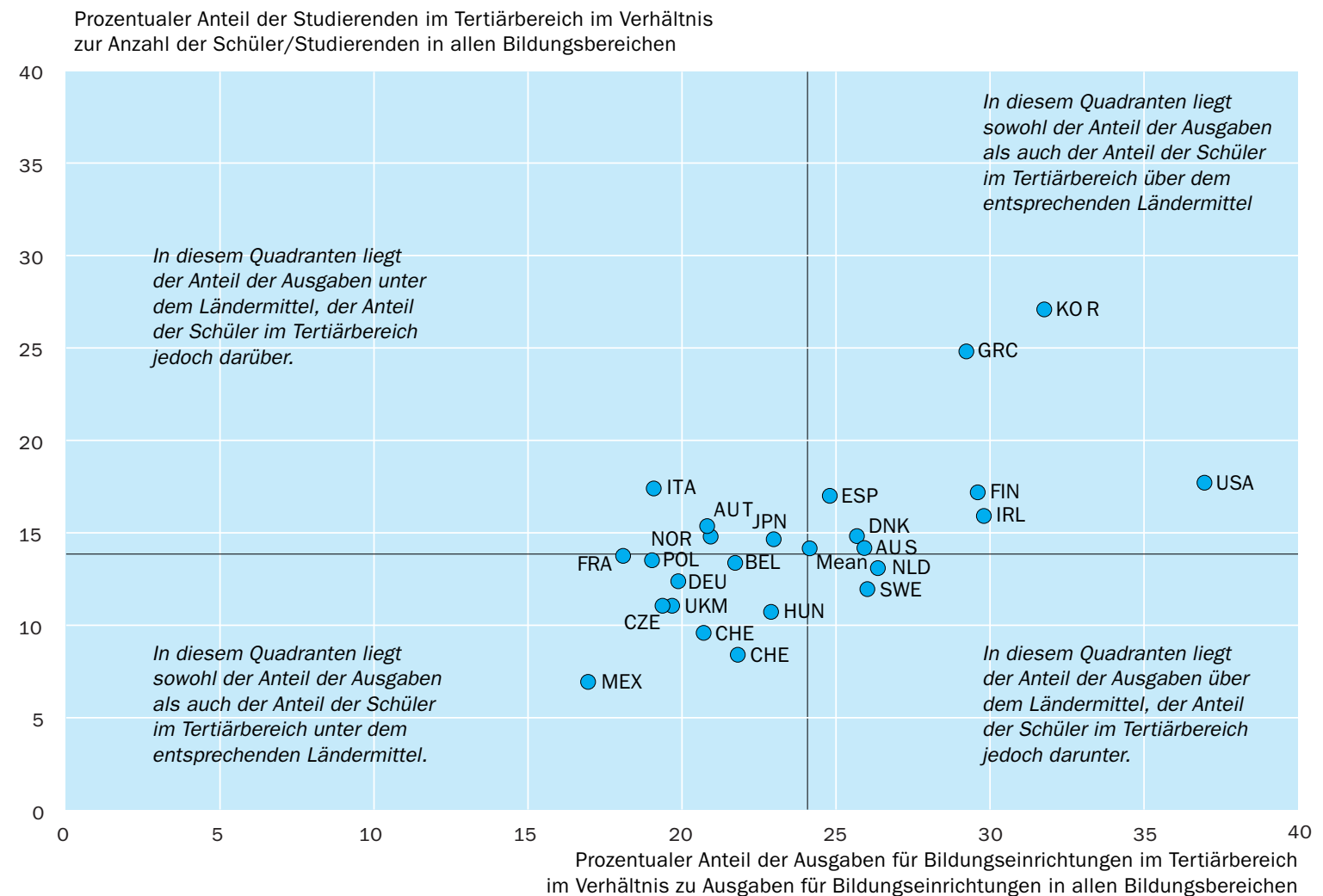

Hinweis: Im Durchschnitt fließen 24 Prozent aller Ausgaben für Bildungseinrichtungen in den Tertiärbereich, den 14 Prozent aller Schüler/Studierenden besuchen. Auflistung der verwendeten Ländercodes und der dazugehörenden Ländernamen s. Hinweise für den Leser.

Quelle: OECD. Tabelle B1.4. Hinweise s. Anhang 3 unter www.oecd.org/edu/eag2004. 
Unterhalb eines bestimmten BIP pro Kopf geben ärmere OECD-Länder in der Regel weniger pro Schüler/ Studierenden aus, ...

... doch dieser Trend lässt
Länder mit sehr unterschiedlichem BIP pro Kopf können dennoch eine ähnliche Verteilung der Bildungsausgaben auf die einzelnen Bildungsbereiche aufweisen.
Das Verhältnis zwischen BIP pro Kopf und Ausgaben pro Schüler/Studierenden ist vielschichtig. Abb. Br.6a zeigt die Koexistenz zweier verschiedener Beziehungen zwischen zwei sich klar unterscheidenden Ländergruppen (s. Ovale). Länder mit einem BIP pro Kopf von 22.50o US-Dollar oder weniger (kaufkraftbereinigt) weisen eine eindeutig positive Beziehung zwischen Bildungsausgaben pro Schüler/Studierenden und BIP pro Kopf auf. In der Gruppe dieser Länder, zu der Griechenland, Korea, Mexiko, Polen, Portugal, die Slowakische Republik, Spanien, die Tschechische Republik und Ungarn zählen, geben in der Regel ärmere OECD-Länder weniger pro Schüler/Studierenden aus als reichere OECD-Länder.

Andererseits gibt es in den Ländern mit einem BIP pro Kopf von über 22.500 US-Dollar erhebliche Unterschiede bei den Bildungsausgaben pro Schüler/ Studierenden (s. Ovale in Abb. BI.6a). Je höher das BIP pro Kopf, desto größer die Variationsbreite bei den Ausgaben für Schüler/Studierende. Australien, Frankreich und das Vereinigte Königreich sind beispielsweise Länder mit ähnlichem BIP pro Kopf, geben aber sowohl im Sekundar- als auch im Tertiärbereich sehr unterschiedliche Anteile ihres BIP pro Kopf aus. So liegt der Anteil des BIP pro Kopf, den Australien und Frankreich pro Schüler des Sekundarbereichs ausgeben ( 27 bzw. 30 Prozent), über dem OECD-Durchschnitt, im Vereinigten Königreich dagegen darunter (22 Prozent). Andererseits gibt das Vereinigte Königreich 40 Prozent des BIP pro Kopf pro Studierenden im Tertiärbereich aus, Australien und Frankreich dagegen mit 48 bzw. 33 Prozent sehr unterschiedliche Anteile (Tab. Br.2 und Abb. Br.6b).

Die Bildungsausgaben pro Schüler/Studierenden gemessen am BIP pro Kopf sind ein Maßstab für die Bildungsausgaben im Verhältnis zum Wohlstand eines Landes. Länder mit sehr unterschiedlichem BIP pro Kopf können eine ähnliche Verteilung der Bildungsausgaben auf die einzelnen Bildungsbereiche aufweisen. Korea und Portugal beispielsweise - zwei Länder deren Ausgaben pro Schüler/Studierenden und BIP pro Kopf unter dem OECD-Durchschnitt liegen - geben pro Schüler/Studierenden den gleichen Anteil aus wie Frankreich, Italien und Österreich und mehr als die Vereinigten Staaten, das Land mit einem der höchsten BIP pro Kopf. Mexiko und die Slowakische Republik geben etwa 47 Prozent des BIP pro Kopf pro Studierenden im Tertiärbereich aus - was in etwa dem Anteil in Australien, Dänemark und den Niederlanden entspricht (Abb. Br.6b).

\section{Veränderungen der Bildungsausgaben pro Schüler/Studierenden zwischen 1995 und 2001.}

Die Anzahl junger Menschen in der Bevölkerung beeinflusst sowohl die Bildungsteilnahme als auch den Umfang der Mittel und den organisatorischen Aufwand, den ein Land in sein Bildungssystem investieren muss. Daher ist die Größe der jugendlichen Population eines Landes maßgebend für die potenzielle Nachfrage nach schulischer und beruflicher Grundausbildung. Je mehr junge Menschen es gibt, desto größer ist die potentielle Nachfrage nach Bildungsdienstleistungen. Tabelle BI.5 und Abbildung Br.7 zeigen in absoluten Zahlen und zu konstanten Preisen des Jahres 200I die Auswirkungen von Veränderungen der Bildungsteilnahme und der Ausgaben zwischen 1995 und 200I auf die Bildungsausgaben pro Schüler/Studierenden. 


\section{Abbildung B1.6a}

Jährliche Ausgaben für Bildungseinrichtungen pro Schüler/Studierenden im Verhältnis zum BIP pro Kopf (2001) In US-Dollar, kaufkraftbereinigt, nach Bildungsbereichen

Primarbereich

Ausgaben pro Schüler (in US-Dollar, kaufkraftbereinigt)

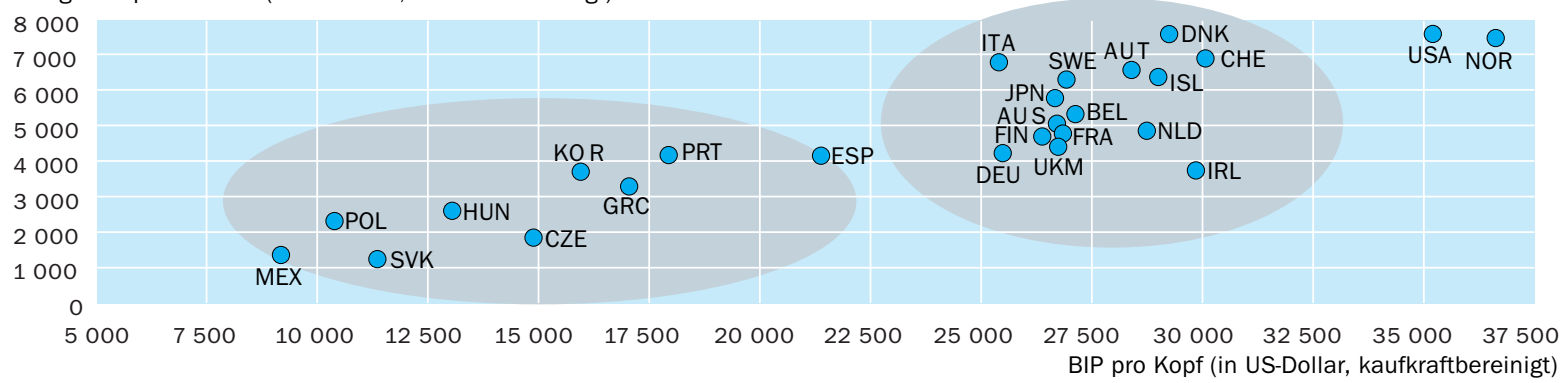

Sekundarbereich

Ausgaben pro Schüler (in US-Dollar, kaufkraftbereinigt)

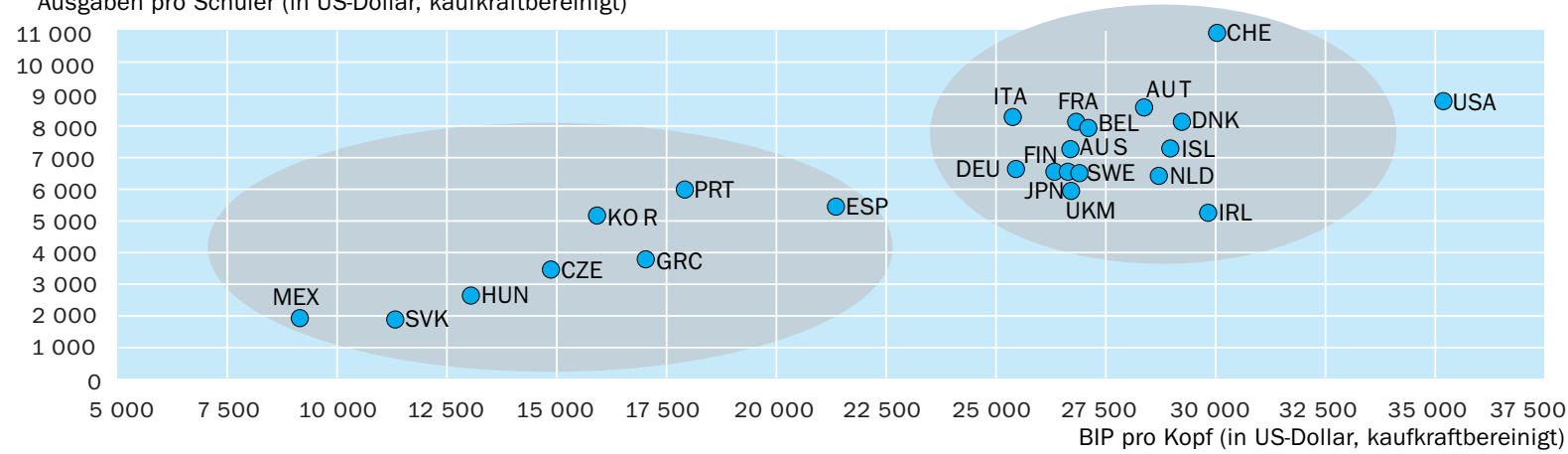

Teriärbereich

Ausgaben pro Schüler (in US-Dollar, kaufkraftbereinigt)

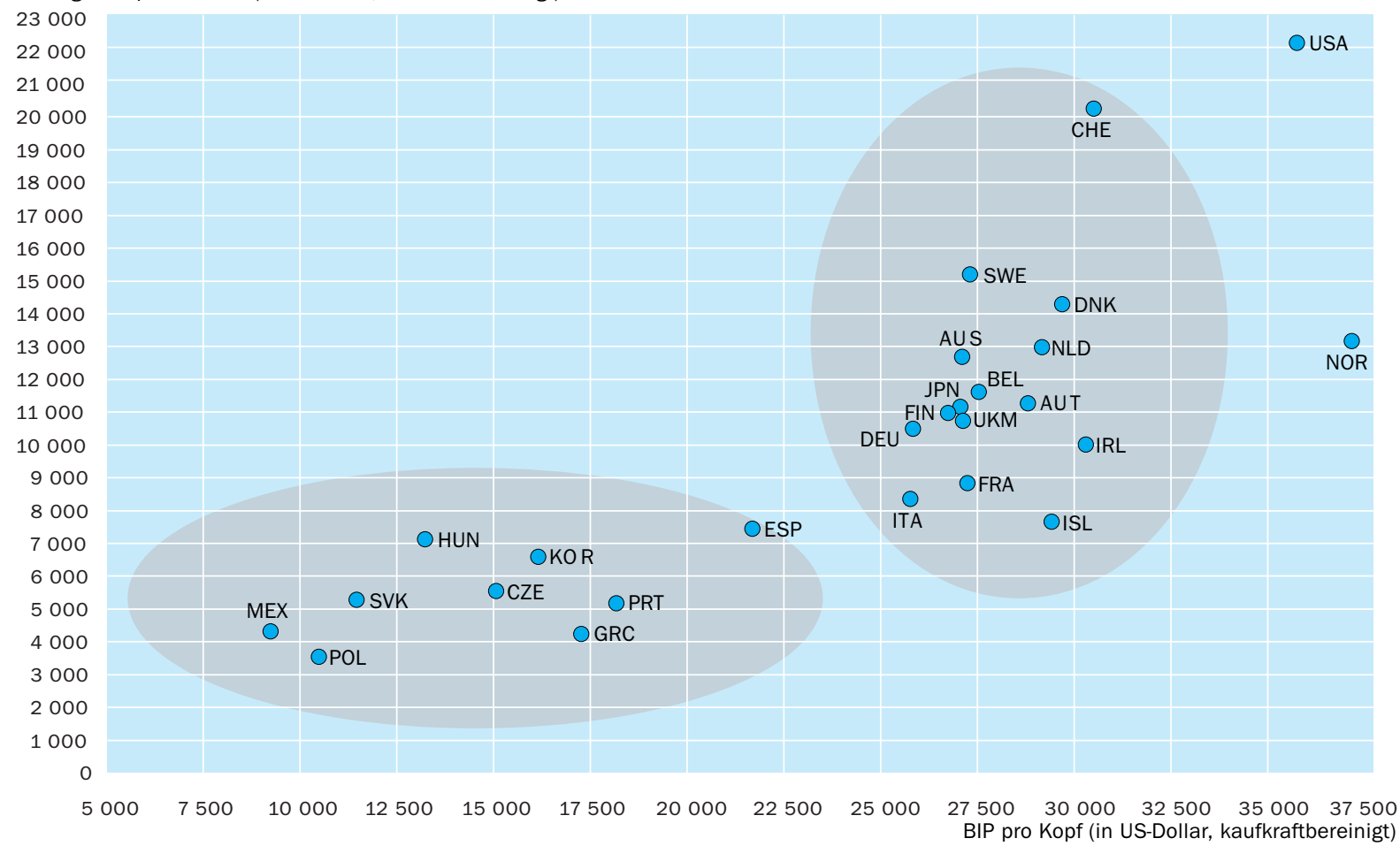

Hinweis: Auflistung der verwendeten Ländercodes und der dazugehörenden Ländernamen s. Hinweise für den Leser.

Quelle: OECD. Tabellen B1.1und B1.2 und Anhang 2. Hinweise s. Anhang 3 unter www.oecd.org/edu/eag2004. 


\section{Abbildung B1.6b}

Jährliche Ausgaben für Bildungseinrichtungen pro Schüler als Prozentsatz des BIP pro Kopf im Verhältnis zum BIP pro Kopf (2001)

Nach Bildungsbereich

Primarbereich

Ausgaben pro Schüler als Prozentsatz des BIP pro Kopf

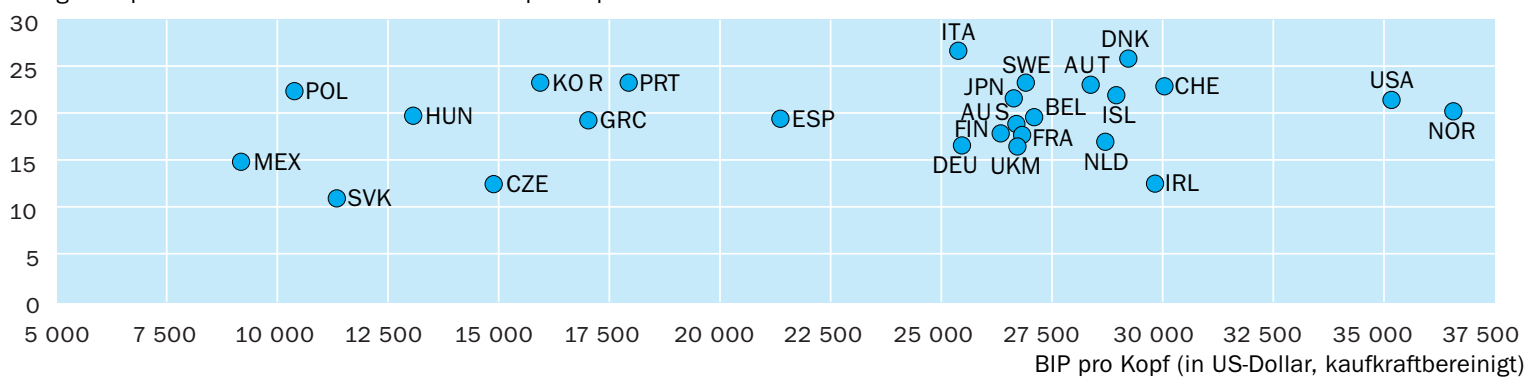

Sekundarbereich

Ausgaben pro Schüler als Prozentsatz des BIP pro Kopf

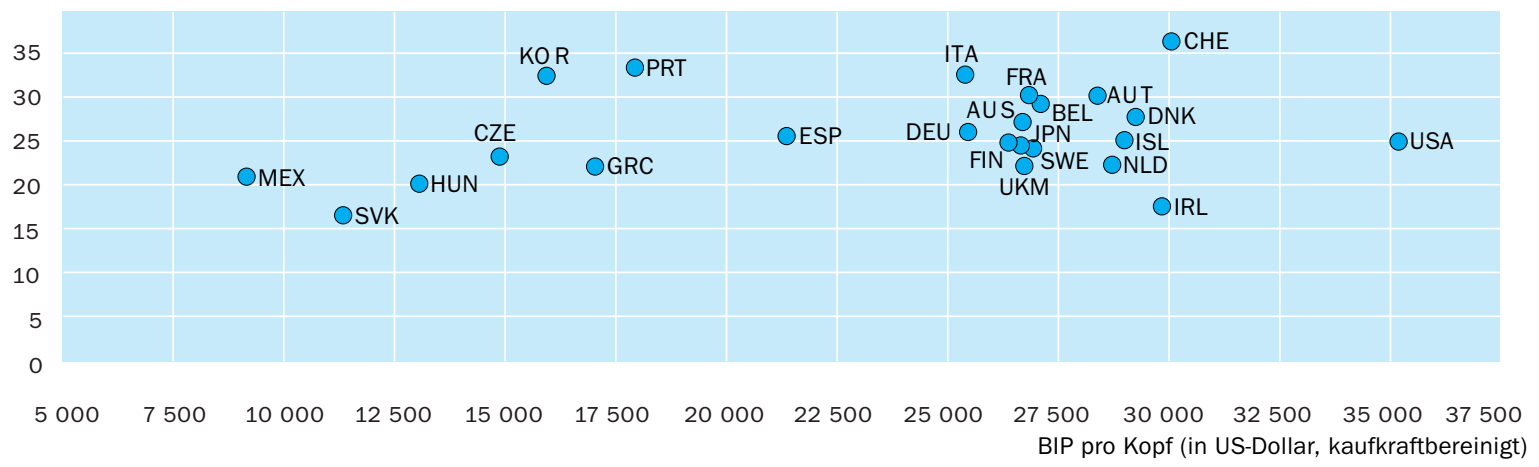

Teriärbereich

Ausgaben pro Schüler als Prozentsatz des BIP pro Kopf

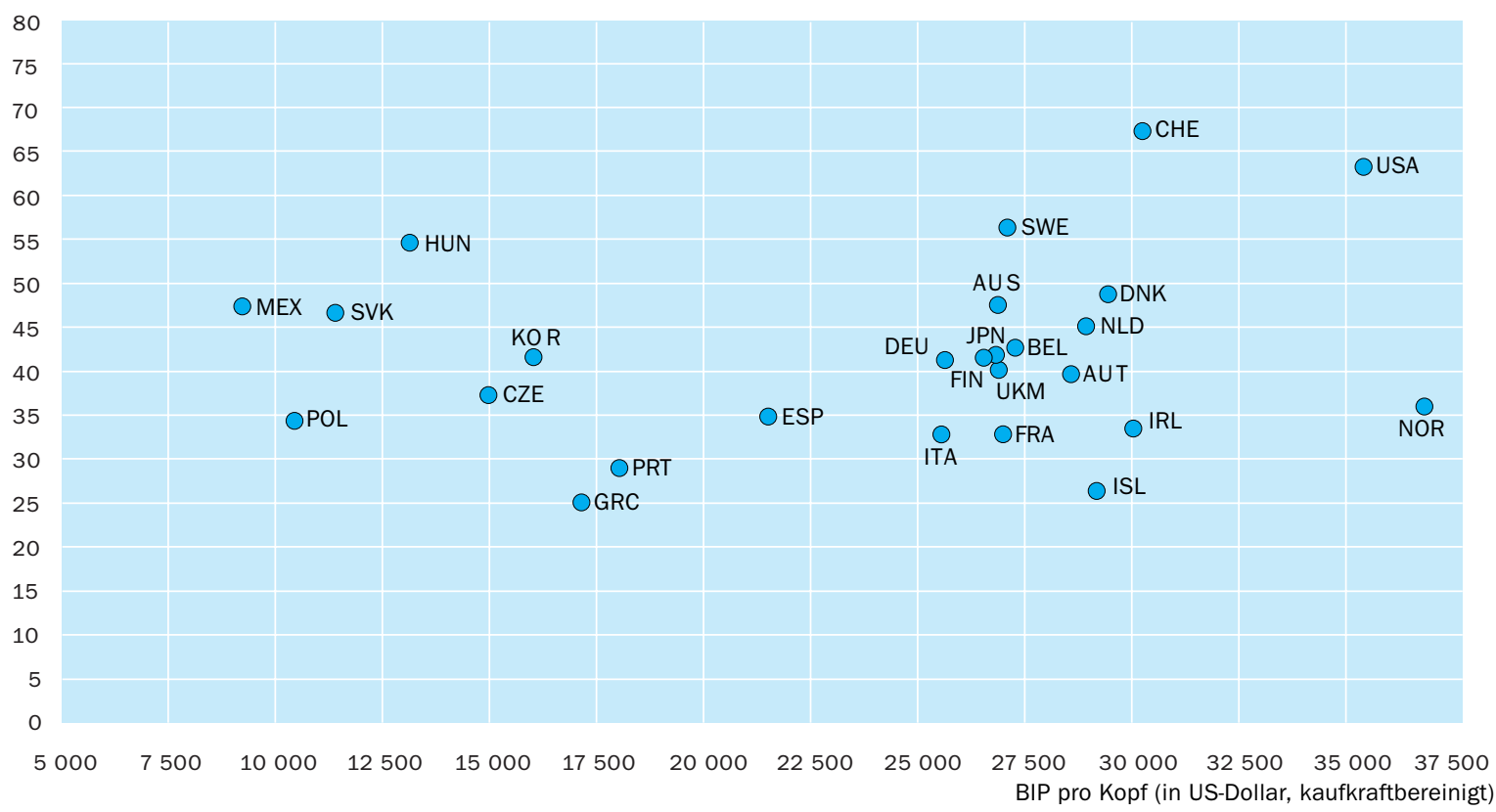

Hinweis: Auflistung der verwendeten Ländercodes und der dazugehörenden Ländernamen s. Hinweise für den Leser.

Quelle: OECD. Tabellen B1.1, B1.2 und Anhang 2. Hinweise s. Anhang 3 unter www.oecd.org/edu/eag2004. 
Abbildung B1.7

Veränderungen der Ausgaben für Bildungseinrichtungen pro Schüler/Studierenden unter Berücksichtigung verschiedener Faktoren, nach Bildungsbereich $(1995,2001)$

Index der Veränderungen zwischen 1995 und 2001 (1995=100, zu konstanten Preisen von 2001)

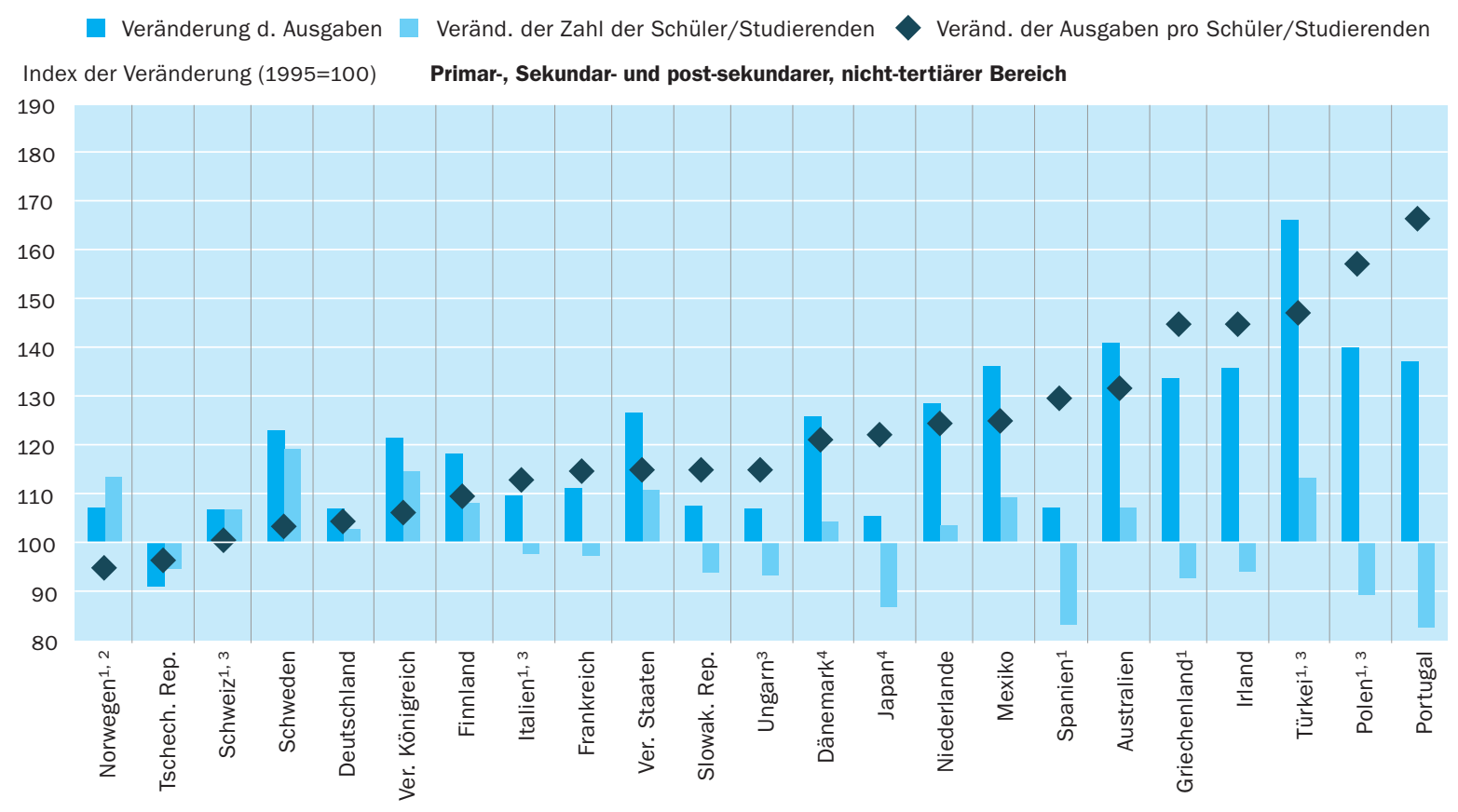

Index der Veränderung $(1995=100)$

Tertiärbereich

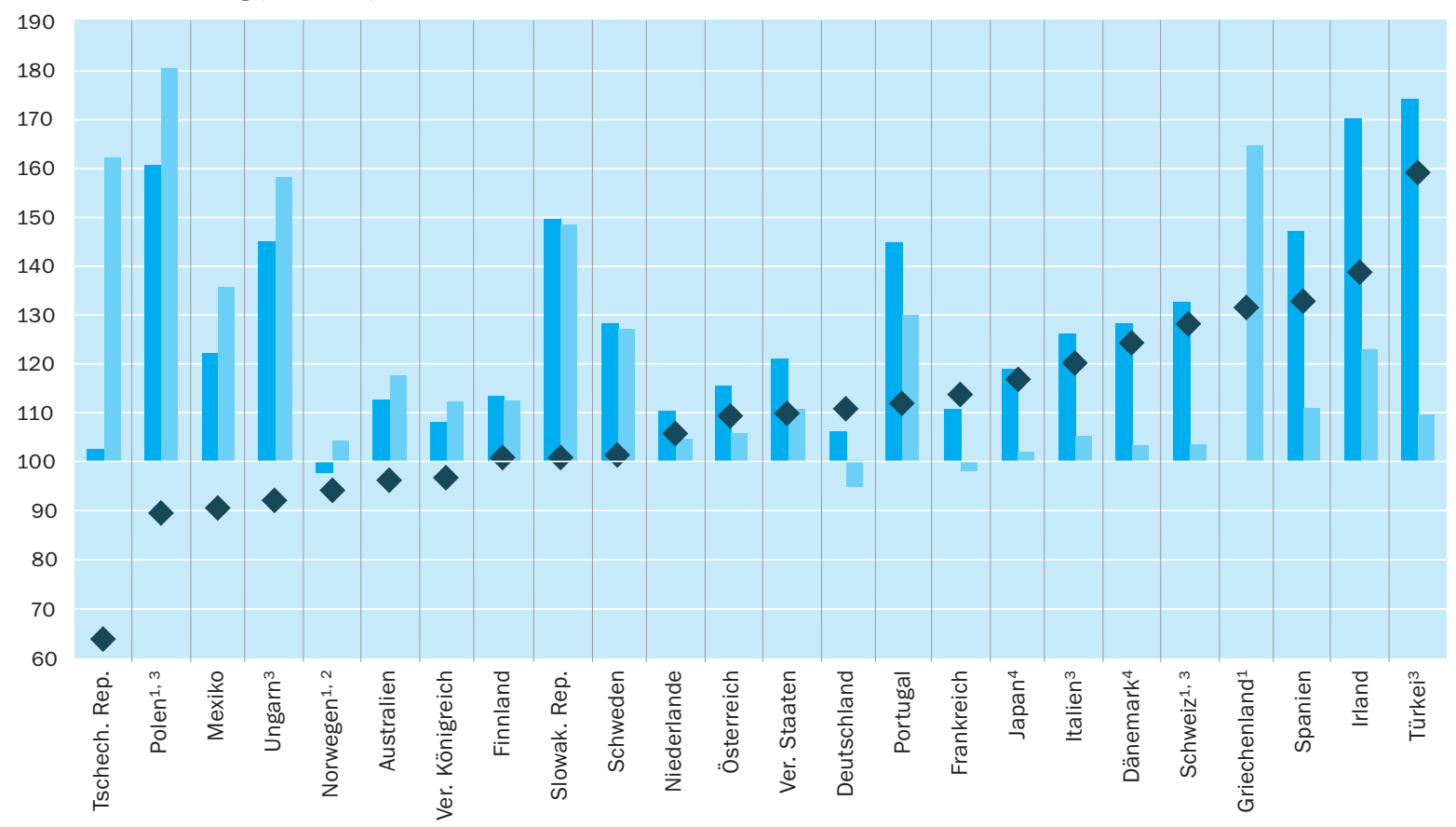

1. Nur öffentliche Ausgaben. 2. Der Rückgang der Ausgaben pro Schüler/Studierenden beruht auf einer wesentlichen Veränderung des BIP-Deflators, hauptsächlich aufgrund gestiegener Ölpreise. 3. Nur öffentliche Bildungseinrichtungen. 4. Post-sekundarer, nicht-tertiärer Bereich sowohl in Sekundarbereich II als auch in Tertiärbereich enthalten.

Anordnung der Ländern in aufsteigender Reihenfolge der Veränderungen der Ausgaben für Bildungseinrichtungen pro Schüler/Studierenden.

Quelle: OECD. Tabelle B1.5. Hinweise s. Anhang 3 unter www.oecd.org/edu/eag2004. 
Die Bildungsausgaben pro Schüler im Primar-, Sekundarund post-sekundaren, nichttertiären Bereich erhöhten sich in Australien, Griechenland, Irland, Polen, Portugal, Spanien und der Türkei um 29 Prozent oder mehr.

Im Primar- und Sekundarbereich waren nicht die sich ändernden Schülerzahlen der ausschlaggebende Faktor für die gestiegenen Ausgaben.

Die Bildungsausgaben im Tertiärbereich konnten nicht immer mit dem raschen Anwachsen der Zahl der Studierenden Schritt halten.
Die Ausgaben pro Schüler im Primar-, Sekundar- und post-sekundaren, nichttertiären Bereich erhöhten sich zwischen 1995 und 200I in Australien, Griechenland, Irland, Polen, Portugal, Spanien und der Türkei um 29 Prozent oder mehr. In II der 23 OECD-Länder, die Daten gemeldet haben, lagen die Veränderungen von 1995 bis 200 I bei über 20 Prozent. In Norwegen und der Tschechischen Republik gingen die Bildungsausgaben pro Schüler im Primar-, Sekundar- und post-sekundaren, nicht-tertiären Bereich um 6 bzw. 4 Prozent zurück. Dieser erfasste Rückgang der Ausgaben pro Schüler/Studierende in Norwegen ist auf einen wesentlichen Rückgang des Preisdeflators auf Ebene des Gesamt-BIP hauptsächlich wegen gestiegener Ölpreise zurückzuführen (Abb. BI.7).

Zwar passen sich Bildungseinrichtungen oft nur mit zeitlicher Verzögerung an veränderte demographische Gegebenheiten an, aber dennoch waren die sich ändernden Schülerzahlen offensichtlich nicht der ausschlaggebende Faktor für die Veränderungen bei den Ausgaben pro Schüler im Primar-, Sekundarund post-sekundaren, nicht-tertiären Bereich. Ausnahmen hiervon sind Japan, Polen, Portugal und Spanien, wo ein Rückgang der Schülerzahlen um mehr als Io Prozent in Verbindung mit einem leichten Anstieg der Bildungsausgaben in Japan und Spanien und einem drastischen Anstieg der Ausgaben in Polen und Portugal zu einer erheblichen Steigerung der Bildungsausgaben pro Schüler führte. Im Gegensatz dazu hat in Frankreich, Griechenland, Irland und Italien eine Aufstockung des Bildungsetats um ro bis 36 Prozent in Verbindung mit einem leichten Rückgang der Schülerzahlen den Anstieg der Ausgaben pro Schüler im Primar-, Sekundar- und post-sekundaren, nicht-tertiären Bereich noch verstärkt (Tab. BI.5 und Abb. BI.7).

Weitere Ausnahmen sind Norwegen, Schweden, die Türkei, das Vereinigte Königreich und die Vereinigten Staaten, die fünf Länder mit dem höchsten $\mathrm{Zu}$ wachs bei den kumulierten Schülerzahlen im Primar-, Sekundar- und post-sekundaren, nicht-tertiären Bereich zwischen 1995 und 200I. Allerdings sind in diesen Ländern bei den einzelnen Faktoren unterschiedliche Verhältnisse festzustellen. In Schweden, der Türkei, dem Vereinigten Königreich und den Vereinigten Staaten stiegen die Ausgaben stärker als die Schülerzahlen, so dass sich die Ausgaben pro Schüler erhöhten. Im Gegensatz dazu wurde in Norwegen die Erhöhung der Zahl der Schüler durch eine Erweiterung des Primarbereichs von sechs auf sieben Jahre im Schuljahr I997/98 nicht durch eine ähnliche Erhöhung der Bildungsausgaben ausgeglichen. Die Veränderungen des Preisdeflators für das Gesamt-BIP Norwegens zwischen 1995 und 200I (vorwiegend verursacht durch einen Anstieg der Ölpreise) führten allerdings zu einem Rückgang der Bildungsausgaben und somit auch der Ausgaben pro Schüler im Primar-, Sekundar- und post-sekundaren, nicht-tertiären Bereich (Tab. BI.5 und Abb. BI.7).

Anders sieht die Situation im tertiären Bildungsbereich aus. In 7 der 24 OECDLänder, für die Daten vorliegen (Australien, Mexiko, Norwegen, Polen, die Tschechische Republik, Ungarn und das Vereinigte Königreich), gingen zwischen 1995 und 200I die Bildungsausgaben pro Studierenden im Tertiärbereich zurück. Dies ist in allen Ländern mit Ausnahme Norwegens (s. o.) größtenteils auf den raschen Anstieg der Zahl der Studierenden im Tertiärbereich 
zurückzuführen, der sich während des genannten Zeitraums auf über ıo Prozent belief (Abb. BI.7). Im Unterschied dazu erhöhten sich in Griechenland, Irland und Portugal die Ausgaben pro Studierenden im Tertiärbereich signifikant trotz eines Anstiegs der Zahl der Studierenden um 65, 23 bzw. 30 Prozent. Deutschland und Frankreich waren die einzigen OECD-Länder, in denen die Zahl der Studierenden im Tertiärbereich zurückging. Allerdings war dieser Rückgang in Deutschland vor allem in den Anfangsjahren des entsprechenden Zeitraums zu verzeichnen, während danach wieder ein beachtlicher Zuwachs in den Studierendenzahlen zu beobachten war (Tab. BI.5 und Abb. BI.7).

\section{Veränderungen bei den Bildungsausgaben pro Schüler/Studieren- den gegenüber Veränderungen im BIP pro Kopf zwischen 1995 und 2001.}

Schlägt sich ein wachsendes Volkseinkommen zwangsläufig in höheren Bildungsausgaben pro Schüler/Studierenden nieder? Tabelle Br.6 zeigt für jedes OECD-Land die Veränderungen in den Bildungsausgaben pro Schüler/Studierenden im Verhältnis zu den Veränderungen des BIP pro Kopf zwischen 1995 und 200I, zu konstanten Preisen und Kaufkraftparitäten des Jahres $200 I$.

Im allgemeinen hängen Veränderungen der Bildungsausgaben pro Schüler/ Studierenden mit Veränderungen des BIP pro Kopf zusammen. In 7 der 22 OECD-Länder, für die Daten vorliegen, gingen jedoch die Ausgaben für Bildungseinrichtungen pro Studierenden im Tertiärbereich (in US-Dollar) zwischen I995 und 200I zurück, während das BIP pro Kopf im selben Zeitraum stieg (Tab. Br.6). In allen anderen Ländern nahmen die Ausgaben pro Studierenden zu. In sechs dieser Länder (Dänemark, Griechenland, Italien, Japan, der Schweiz und Spanien) stiegen die Bildungsausgaben pro Studierenden zwischen 1995 und 200I stärker als das BIP pro Kopf. In allen anderen OECDLändern stieg das BIP pro Kopf stärker als die Ausgaben pro Studierenden im Tertiärbereich (Tab. BI.6):

Bei Ländern mit einem vergleichbaren Niveau der Bildungsausgaben pro Studierenden im Tertiärbereich und des BIP pro Kopf im Jahr 200I lassen sich einige Unterschiede in der Entwicklung der in Bildung investierten Mittel zwischen 1995 und 200I erkennen. Im Jahr 200I hatten zum Beispiel Australien, Japan und das Vereinigte Königreich ungefähr das gleiche BIP pro Kopf und die gleichen Bildungsausgaben pro Studierenden im Tertiärbereich. Im Vergleich mit den Zahlen von 1995 wird jedoch deutlich, dass Japan die Bildungsausgaben pro Studierenden im Tertiärbereich stärker erhöhte als das BIP pro Kopf gewachsen ist. Im Gegensatz dazu stieg das BIP pro Kopf auch in Australien und dem Vereinigten Königreich zwischen 1995 und 200I deutlich an, während die Bildungsausgaben pro Studierenden im Tertiärbereich im selben Zeitraum leicht zurückgingen (Tab. Br.6).
In sieben der 22 OECD-Länder gingen die Ausgaben für Bildungseinrichtungen pro Studierenden im Tertiärbereich (in US-Dollar) zwischen 1995 und 2001 zurück, während das BIP pro Kopf im selben Zeitraum zunahm.

Länder mit einem vergleichbaren Ausgabenniveau und BIP pro Kopf im Jahr 2001 weisen zwischen 1995 und 2001 unterschiedliche Muster der in Bildung investierten Mittel auf. 


\section{Definitionen und angewandte Methodik}

Die Daten beziehen sich auf das Haushaltsjahr 2001 und beruhen auf einer von der OECD im Jahr 2003 durchgeführten UOE-Datenerhebung zur Bildungsstatistik (Einzelheiten s. Anhang 3).

Die Daten für das Haushaltsjahr 1995 beruhen auf einer speziellen Erhebung aus dem Jahr 2001, die 2003 aktualisiert wurde.
Die Bildungsausgaben pro Schüler/Studierenden für einen bestimmten Bildungsbereich werden mittels Division der Gesamtausgaben für Bildungseinrichtungen in diesem Bereich durch die entsprechende Schüler-/Studierendenzahl (Vollzeitäquivalente) ermittelt. Dabei wurden nur jene Bildungseinrichtungen und Bildungsgänge berücksichtigt, für die sowohl Daten über die Zahl der Schüler/Studierenden als auch Zahlen über die Ausgaben vorlagen. Die Ausgaben in nationaler Währung werden dann in US-Dollar umgerechnet, indem der betreffende Betrag in Landeswährung durch den Kaufkraftparität (KKP) Index dividiert wird. Der KKP-Umrechnungskurs gibt den Betrag einer Landeswährung an, mit dem man in einem bestimmten OECD-Land den gleichen Waren- und Dienstleistungskorb wie in den Vereinigten Staaten mit USDollar erwerben kann. Dieser Umrechnungskurs wird anstelle der aktuellen Wechselkurse verwendet, da diese von einer Vielzahl von Faktoren beeinflusst werden (Zinssätze, Handelspolitik, Konjunkturerwartungen etc.), die wenig mit der aktuellen, relativen inländischen Kaufkraft in den einzelnen OECDLändern zu tun haben (weitere Einzelheiten s. Anhang 2).

Die Tabellen Br.5 und Br.6 zeigen die Ausgaben für Bildungseinrichtungen pro Schüler/Studierenden im Haushaltsjahr 1995. Die Daten für die Ausgaben des Jahres 1995 wurden im Rahmen einer speziellen Erhebung im Jahre $200 \mathrm{I}$ ermittelt, und 2003 aktualisiert. Die OECD-Länder wurden aufgefordert, die Daten für 1995 entsprechend den Definitionen und dem Erhebungsbereich der UOE-Datenerhebung von 2003 zu erfassen. Alle Daten zu den Ausgaben ebenso wie die Angaben zum BIP von 1995 wurden mit Hilfe des BIP-Preisdeflators an das Preisniveau von 200I angepasst.

Die Bildungsausgaben pro Schüler/Studierenden im Verhältnis zum BIP pro Kopf werden berechnet, indem die Bildungsausgaben pro Schüler/Studierenden in Landeswährung als prozentualer Anteil des ebenfalls in Landeswährung ausgedrückten BIP pro Kopf angegeben werden. Wenn sich die Bildungsausgaben und die Daten zum BIP auf unterschiedliche Zeiträume beziehen, werden unter Verwendung der Inflationsraten des betreffenden OECD-Landes die Ausgabendaten auf den Bezugszeitraum der BIP-Daten umgerechnet (s. Anhang 2).

Die zu erwartenden Ausgaben während der durchschnittlichen Verweildauer im Tertiärbereich (Tabelle BI.3) werden durch Multiplikation der aktuellen jährlichen Ausgaben mit der typischen Dauer solcher Studiengänge berechnet. Die zur Ermittlung der typischen Durchschnittsdauer von tertiären Studiengängen angewandte Methodik ist in Anhang 3 unter www.oecd.org/edu/eag 2004 beschrieben. Die Schätzungen hinsichtlich der Verweildauer im Tertiärbereich stützen sich auf die Daten einer im Jahr 1997 in den OECD-Ländern durchgeführten speziellen Erhebung.

Die Erstellung einer Rangfolge der OECD-Länder nach ihren jährlichen Bildungsausgaben pro Schüler/Studierenden wird durch unterschiedliche Definitionen der einzelnen Ländern für die Begriffe Vollzeit-, Teilzeit- und vollzeitäquivalente Bildungsteilnahme erschwert. In einigen OECD-Ländern werden alle Studierenden des Tertiärbereichs als Vollzeitstudierende gezählt, während 
in anderen Ländern die Intensität der Beteiligung nach den innerhalb einer vorgegebenen Referenzzeit erworbenen Credits (Leistungspunkten) für die erfolgreiche Absolvierung bestimmter Kurseinheiten festgelegt wird. Bei OECDLändern, die genaue Angaben über Teilzeitstudierende machen können, werden sich höhere Ausgaben pro vollzeitäquivalenten Studierenden ergeben, als bei solchen OECD-Ländern, die nicht zwischen den verschiedenen Teilnahmemöglichkeiten differenzieren können.

Es ist zu beachten, dass die in früheren Ausgaben dieser Veröffentlichung aufgeführten Zahlen und Daten möglicherweise nicht immer mit denen der Ausgabe 2004 vergleichbar sind, da sich Änderungen in den Definitionen und Erhebungsbereichen ergeben haben. Diese wurden aufgrund der OECD Expenditure Comparability Study vorgenommen (Einzelheiten zu den Änderungen s. Anhang 3 unter www.oecd.org/eduleag2004). 
Tabelle B1.1

Jährliche Ausgaben für Bildungseinrichtungen pro Schüler/Studierenden (2001)

In US-Dollar, kaufkraftbereinigt, nach Bildungsbereich, (basierend auf Vollzeitäquivalenten)

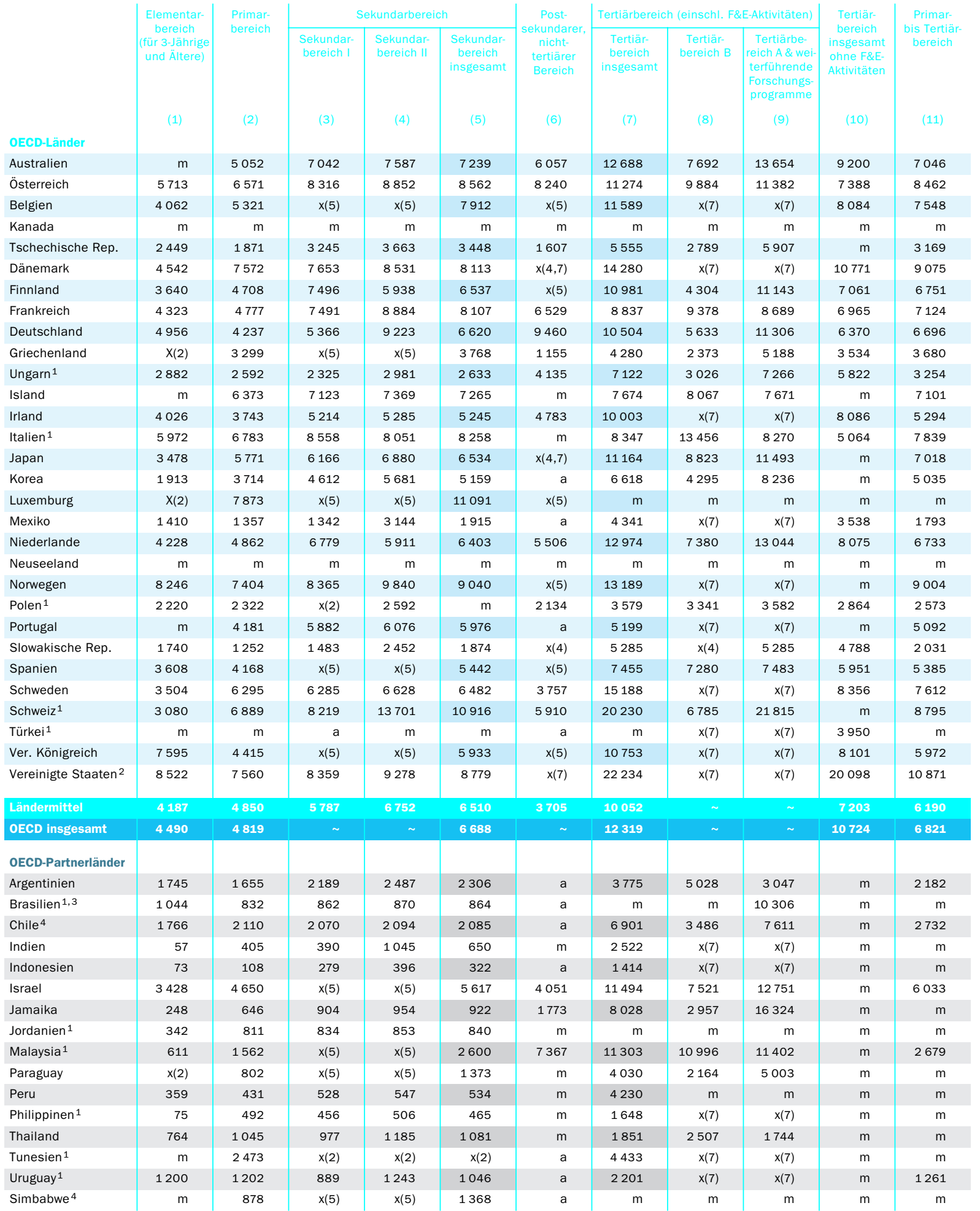

Hinweis: $x$ bedeutet, dass die Daten in einer anderen Spalte enthalten sind, deren Referenz in runden Klammern nach dem , $x$ ‘ angegeben ist. So bedeutet z. B. $x(2)$, dass die Daten in Spalte 2 enthalten sind.

1. Nur öffentliche Bildungseinrichtungen. $\quad$ 2. Nur öffentliche und unabhängige private Bildungseinrichtungen. 3. Referenzjahr 2000.4 . Referenzjahr 2002.

Quelle: OECD. Hinweise s. Anhang 3 unter www.oecd.org/edu/eag2004. 
Tabelle B1.2

Jährliche Ausgaben für Bildungseinrichtungen pro Schüler/Studierenden im Verhältnis zum BIP pro Kopf (2001) Nach Bildungsbereich (basierend auf Vollzeitäquivalenten)

\begin{tabular}{|c|c|c|c|c|c|c|c|c|c|c|c|}
\hline \multirow{3}{*}{ OECD-Länder } & \multirow[b]{2}{*}{\begin{tabular}{|c|} 
Elementar- \\
bereich \\
(für 3-Jährige \\
und Ältere) \\
\\
(1)
\end{tabular}} & \multirow[b]{2}{*}{$\begin{array}{l}\text { Primar- } \\
\text { bereich } \\
\text { (2) }\end{array}$} & \multicolumn{3}{|c|}{ Sekundarbereich } & \multirow{3}{*}{$\begin{array}{l}\text { Post- } \\
\text { sekundarer, } \\
\text { nicht- } \\
\text { tertiärer } \\
\text { Bereich } \\
\text { (6) }\end{array}$} & \multicolumn{3}{|c|}{ Tertiärbereich (einschl. F\&E-Aktivitäten) } & \multirow{3}{*}{$\mid \begin{array}{c}\text { Tertiärbereich } \\
\text { insgesamt } \\
\text { ohne F\&E- } \\
\text { Aktivitäten }\end{array}$} & \multirow{3}{*}{$\begin{array}{l}\text { Primar- } \\
\text { bis Tertiär- } \\
\text { bereich } \\
\text { (11) }\end{array}$} \\
\hline & & & $\begin{array}{l}\text { Sekundar- } \\
\text { bereich I }\end{array}$ & $\begin{array}{l}\text { Sekundar- } \\
\text { bereich II }\end{array}$ & $\begin{array}{l}\text { Sekundar- } \\
\text { bereich } \\
\text { insgesamt } \\
\text { (5) }\end{array}$ & & $\begin{array}{c}\text { Tertiärbereich } \\
\text { insgesamt }\end{array}$ & $\begin{array}{l}\text { Tertiär- } \\
\text { bereich B } \\
\text { (8) }\end{array}$ & \begin{tabular}{|c|} 
Tertiärbe- \\
reich A \& wei- \\
terführende \\
Forschungs- \\
programme \\
(9)
\end{tabular} & & \\
\hline & & & & & & & & & & & \\
\hline Australien & $\mathrm{m}$ & 19 & 26 & 28 & 27 & 23 & 48 & 29 & 51 & 34 & 26 \\
\hline Österreich & 20 & 23 & 29 & 31 & 30 & 29 & 40 & $x(7)$ & $x(7)$ & 26 & 30 \\
\hline Belgien & 15 & 20 & $x(5)$ & $x(5)$ & 29 & $x(5)$ & 43 & $x(7)$ & $x(7)$ & 30 & 28 \\
\hline Kanada & $\mathrm{m}$ & $\mathrm{m}$ & $\mathrm{m}$ & $\mathrm{m}$ & $\mathrm{m}$ & $\mathrm{m}$ & $\mathrm{m}$ & $\mathrm{m}$ & $\mathrm{m}$ & $\mathrm{m}$ & $\mathrm{m}$ \\
\hline Tschechische Rep. & 16 & 13 & 22 & 25 & 23 & 11 & 37 & 19 & 40 & $\mathrm{~m}$ & 21 \\
\hline Dänemark & 16 & 26 & 26 & 29 & 28 & $x(4,7)$ & 49 & $x(7)$ & $x(7)$ & 37 & 31 \\
\hline Finnland & 14 & 18 & 28 & 23 & 25 & $x(5)$ & 42 & 16 & 42 & 27 & 26 \\
\hline Frankreich & 16 & 18 & 28 & 33 & 30 & 24 & 33 & 35 & 32 & 26 & 27 \\
\hline Deutschland & 19 & 17 & 21 & 36 & 26 & 37 & 41 & 22 & 44 & 25 & 26 \\
\hline Griechenland & $x(2)$ & 19 & $x(5)$ & $x(5)$ & 22 & 7 & 25 & 14 & 30 & 21 & 22 \\
\hline Ungarn ${ }^{1}$ & 22 & 20 & 18 & 23 & 20 & 32 & 55 & 23 & 56 & 45 & 25 \\
\hline Island & $\mathrm{m}$ & 22 & 25 & 25 & 25 & $\mathrm{~m}$ & 26 & 28 & 26 & $\mathrm{~m}$ & 25 \\
\hline Irland & 13 & 13 & 17 & 18 & 18 & 16 & 34 & $x(7)$ & $x(7)$ & 27 & 18 \\
\hline Italien ${ }^{1}$ & 24 & 27 & 34 & 32 & 33 & $\mathrm{~m}$ & 33 & 53 & 33 & $\mathrm{~m}$ & 31 \\
\hline Japan & 13 & 22 & 23 & 26 & 25 & $x(4,7)$ & 42 & 33 & 43 & $\mathrm{~m}$ & 26 \\
\hline Korea & 12 & 23 & 29 & 36 & 32 & a & 42 & 27 & 52 & $\mathrm{~m}$ & 32 \\
\hline Luxemburg & $x(2)$ & 16 & $x(5)$ & $x(5)$ & 23 & $x(5)$ & $\mathrm{m}$ & $\mathrm{m}$ & $\mathrm{m}$ & $\mathrm{m}$ & $\mathrm{m}$ \\
\hline Mexiko & 15 & 15 & 15 & 34 & 21 & a & 47 & $x(7)$ & $x(7)$ & 39 & 20 \\
\hline Niederlande & 15 & 17 & 24 & 21 & 22 & 19 & 45 & 26 & 45 & 28 & 23 \\
\hline Neuseeland & $\mathrm{m}$ & $\mathrm{m}$ & $\mathrm{m}$ & $\mathrm{m}$ & $\mathrm{m}$ & $\mathrm{m}$ & $\mathrm{m}$ & $\mathrm{m}$ & $\mathrm{m}$ & $\mathrm{m}$ & $\mathrm{m}$ \\
\hline Norwegen & 23 & 20 & 23 & 27 & 25 & $x(5)$ & 36 & $x(7)$ & $x(7)$ & $\mathrm{m}$ & 25 \\
\hline Polen ${ }^{1}$ & 21 & 22 & $x(2)$ & 25 & $\mathrm{~m}$ & 21 & 35 & 32 & 35 & 28 & 25 \\
\hline Portugal & $\mathrm{m}$ & 23 & 33 & 34 & 33 & a & 29 & $x(7)$ & $x(7)$ & $\mathrm{m}$ & 28 \\
\hline Slowakische Rep. & 15 & 11 & 13 & 22 & 17 & $x(4)$ & 47 & $x(4)$ & 47 & 42 & 18 \\
\hline Spanien & 17 & 20 & $x(5)$ & $x(5)$ & 25 & $x(5)$ & 35 & 34 & 35 & 28 & 25 \\
\hline Schweden & 13 & 23 & 23 & 25 & 24 & 14 & 56 & $x(7)$ & $x(7)$ & 31 & 28 \\
\hline Schweiz ${ }^{1}$ & 10 & 23 & 27 & 46 & 36 & 20 & 67 & 23 & 73 & $\mathrm{~m}$ & 29 \\
\hline Türkei ${ }^{1}$ & $\mathrm{~m}$ & $\mathrm{~m}$ & a & $\mathrm{m}$ & $\mathrm{m}$ & a & $\mathrm{m}$ & $x(7)$ & $x(7)$ & 65 & $\mathrm{~m}$ \\
\hline Ver. Königreich & 28 & 17 & $x(5)$ & $x(5)$ & 22 & $x(5)$ & 40 & $x(7)$ & $x(7)$ & 30 & 22 \\
\hline Vereinigte Staaten ${ }^{2}$ & 24 & 21 & 24 & 26 & 25 & $x(7)$ & 63 & $x(7)$ & $x(7)$ & 57 & 31 \\
\hline Ländermittel & 17 & 20 & 23 & 28 & 26 & 16 & 42 & 28 & 43 & 34 & 26 \\
\hline OECD-Partnerländer & & & & & & & & & & & \\
\hline Argentinien & 15 & 14 & 19 & 21 & 20 & a & 32 & 43 & 26 & $\mathrm{~m}$ & 19 \\
\hline Brasilien 1,3 & 14 & 11 & 12 & 12 & 12 & a & $\mathrm{m}$ & $\mathrm{m}$ & 142 & $\mathrm{~m}$ & $\mathrm{~m}$ \\
\hline Chile $^{4}$ & 18 & 22 & 21 & 22 & 22 & a & 71 & 36 & 79 & $\mathrm{~m}$ & 28 \\
\hline Indien & 2 & 14 & 14 & 37 & 23 & $\mathrm{~m}$ & 89 & $x(7)$ & $x(7)$ & $\mathrm{m}$ & $\mathrm{m}$ \\
\hline Indonesien & 3 & 4 & 10 & 14 & 11 & a & 49 & $x(7)$ & $x(7)$ & $\mathrm{m}$ & $\mathrm{m}$ \\
\hline Israel & 16 & 22 & $x(5)$ & $x(5)$ & 26 & 19 & 54 & 35 & 60 & $\mathrm{~m}$ & 28 \\
\hline Jamaika & 7 & 17 & 24 & 26 & 25 & 48 & 217 & 80 & 442 & $\mathrm{~m}$ & $\mathrm{~m}$ \\
\hline Jordanien ${ }^{1}$ & 9 & 21 & 22 & 23 & 22 & $\mathrm{~m}$ & $\mathrm{~m}$ & $\mathrm{~m}$ & $\mathrm{~m}$ & $\mathrm{~m}$ & $\mathrm{~m}$ \\
\hline Malaysia $^{1}$ & 7 & 18 & $x(5)$ & $x(5)$ & 30 & 85 & 131 & 127 & 132 & $\mathrm{~m}$ & 31 \\
\hline Paraguay & $\mathrm{m}$ & 15 & $x(5)$ & $x(5)$ & 26 & $\mathrm{~m}$ & 77 & 41 & 96 & $\mathrm{~m}$ & $\mathrm{~m}$ \\
\hline Peru & 8 & 9 & 11 & 12 & 12 & $\mathrm{~m}$ & 81 & $\mathrm{~m}$ & $\mathrm{~m}$ & $\mathrm{~m}$ & $\mathrm{~m}$ \\
\hline Philippinen & 2 & 13 & 12 & 13 & 12 & $\mathrm{~m}$ & 43 & $x(7)$ & $x(7)$ & $\mathrm{m}$ & $\mathrm{m}$ \\
\hline Thailand & 13 & 17 & 16 & 20 & 18 & $\mathrm{~m}$ & 31 & 42 & 29 & $\mathrm{~m}$ & $\mathrm{~m}$ \\
\hline Tunesien $^{1}$ & $\mathrm{~m}$ & 38 & $x(2)$ & $x(2)$ & $x(2)$ & a & 68 & 93 & $x(7)$ & $\mathrm{m}$ & $\mathrm{m}$ \\
\hline Uruguay & 14 & 14 & 11 & 15 & 12 & a & 26 & $x(7)$ & $x(7)$ & $\mathrm{m}$ & 15 \\
\hline Simbabwe $^{4}$ & $\mathrm{~m}$ & 20 & $x(5)$ & $x(5)$ & 31 & a & $\mathrm{m}$ & $\mathrm{m}$ & $\mathrm{m}$ & $\mathrm{m}$ & $\mathrm{m}$ \\
\hline
\end{tabular}

Hinweis: $x$ bedeutet, dass die Daten in einer anderen Spalte enthalten sind, deren Referenz in runden Klammern nach dem , $x$ ‘ angegeben ist. So bedeutet $z . B$. $x(2)$, dass die Daten in Spalte 2 enthalten sind.

1. Nur öffentliche Bildungseinrichtungen. $\quad$ 2. Nur öffentliche und unabhängige private Bildungseinrichtungen. 3. Referenzjahr $2000 . \quad 4$. Referenzjahr 2002. Quelle: OECD. Hinweise s. Anhang 3 unter www.oecd.org/edu/eag2004. 


\section{Tabelle B1.3}

Kumulierte Ausgaben für Bildungseinrichtungen pro Studierenden über die durchschnittliche Verweildauer im Tertiärbereich (2001)

In US-Dollar, kaufkraftbereinigt, nach Art des Studiengangs

\begin{tabular}{|c|c|c|c|c|c|c|c|}
\hline \multirow[b]{3}{*}{ OECD-Länder } & \multirow[t]{2}{*}{ Methode ${ }^{1}$} & \multicolumn{3}{|c|}{$\begin{array}{l}\text { Durchschnittliche Verweildauer } \\
\text { im Tertiärbereich (in Jahren) }{ }^{2}\end{array}$} & \multicolumn{3}{|c|}{$\begin{array}{l}\text { Kumulierte Ausgaben pro Studierenden über die } \\
\text { durchschnittliche Verweildauer im Tertiärbereich }\end{array}$} \\
\hline & & $\begin{array}{c}\text { Tertiärbereich } \\
\text { insgesamt }\end{array}$ & Tertiärbereich B & $\begin{array}{l}\text { Tertiärbereich A } \\
\& \text { weiterführende } \\
\text { Forschungs- } \\
\text { programme } \\
\text { (3) }\end{array}$ & $\begin{array}{l}\text { Tertiärbereich } \\
\text { insgesamt }\end{array}$ & Tertiärbereich B & $\begin{array}{c}\text { Tertiärbereich A } \\
\text { \& weiterführende } \\
\text { Forschungs- } \\
\text { programme } \\
\text { (6) }\end{array}$ \\
\hline & & & & & & & \\
\hline Australien & VM & 2,5 & 1,6 & 2,6 & 32101 & 12076 & 34954 \\
\hline Österreich & $\mathrm{NF}$ & 5,5 & 2,8 & 6,3 & 62459 & 27873 & 72048 \\
\hline Kanada & VM & $\mathrm{m}$ & $\mathrm{m}$ & $\mathrm{m}$ & $\mathrm{m}$ & $\mathrm{m}$ & $\mathrm{m}$ \\
\hline Dänemark & $\mathrm{NF}$ & 4,2 & 2,1 & 4,4 & 59834 & $x(4)$ & $x(4)$ \\
\hline Finnland & VM & 4,5 & a & 4,5 & 49972 & a & 49972 \\
\hline Frankreich & $\mathrm{NF}$ & 4,7 & 2,8 & 5,3 & 41372 & 25957 & 46103 \\
\hline Deutschland & VM & 5,3 & 2,4 & 6,5 & 55426 & 13357 & 73488 \\
\hline Griechenland & $\mathrm{NF}$ & 5,7 & 3,5 & 8,1 & 24255 & 8270 & 42007 \\
\hline Ungarn ${ }^{3}$ & VM & 4,1 & 2,0 & 4,1 & 28844 & 6052 & 29426 \\
\hline Island & VM & 2,7 & 2,0 & 2,8 & 20566 & 15811 & 21786 \\
\hline Irland & VM & 3,2 & 2,2 & 4,0 & 32411 & $x(4)$ & $x(4)$ \\
\hline Italien ${ }^{3}$ & VM & 5,5 & 3,3 & 5,6 & 45824 & 44002 & 46064 \\
\hline Japan & VM & 3,8 & 2,1 & 4,6 & 42970 & 18148 & 52555 \\
\hline Korea & VM & 3,4 & 2,1 & 4,2 & 22701 & 8890 & 34756 \\
\hline Mexiko & $\mathrm{NF}$ & 3,4 & $x(3)$ & 3,4 & 14858 & $x(4)$ & $x(4)$ \\
\hline Niederlande & VM & 4,9 & $\mathrm{x}(1)$ & $x(1)$ & 63186 & $x(4)$ & $x(4)$ \\
\hline Norwegen & VM & $\mathrm{m}$ & $\mathrm{m}$ & $\mathrm{m}$ & $\mathrm{m}$ & $\mathrm{m}$ & $\mathrm{m}$ \\
\hline Polen ${ }^{3}$ & VM & $\mathrm{m}$ & $\mathrm{m}$ & 3,7 & $\mathrm{~m}$ & $\mathrm{~m}$ & 13184 \\
\hline Spanien & $\mathrm{NF}$ & 4,6 & 1,5 & 4,7 & 33920 & 10841 & 35221 \\
\hline Schweden & VM & 4,6 & 2,6 & 4,7 & 69981 & $x(4)$ & $x(4)$ \\
\hline Schweiz ${ }^{3}$ & VM & 3,6 & 2,2 & 5,5 & 73320 & 14839 & 118953 \\
\hline Ver. Königreich & VM & 3,8 & $x(1)$ & $x(1)$ & 41209 & $x(4)$ & $x(4)$ \\
\hline Ländermittel & & 4,2 & 2,2 & 4,7 & 42906 & & \\
\hline
\end{tabular}

Hinweis: $x$ bedeutet, dass die Daten in einer anderen Spalte enthalten sind, deren Referenz in runden Klammern nach dem ,x‘ angegeben ist. So bedeutet $z$. B. $x(2)$, dass die Daten in Spalte 2 enthalten sind.

1. Zur Schätzung der Verweildauer im Tertiärbereich wurde entweder die Verkettungsmethode (VM) oder eine Näherungsformel (NF) verwendet. 2. Die Angaben zur Verweildauer im Tertiärbereich stammen aus einer 1997 zum akademischen Jahr 1995 durchgeführten speziellen Erhebung. Die Daten für Deutschland, Finnland, Griechenland, Japan, Österreich, die Niederlande und das Vereinigte Königreich wurden aktualisiert und entsprechen dem Studienjahr $2002 . \quad 3$. Nur öffentliche Bildungseinrichtungen.

Quelle: OECD. Hinweise s. Anhang 3 unter www.oecd.org/edu/eag2004. 


\section{Tabelle B1.4}

Verteilung der Ausgaben für Bildungseinrichtungen im Vergleich zur Zahl der Schüler/Studierenden pro Bildungsbereich (2001) In Prozent

Die Tabelle zeigt die Verteilung der Bildungsausgaben und der Schüler/Studierenden pro Bildungsbereich. Die Zahl der Schüler/Studierenden ist an das Haushaltsjahr angepasst.

Beispiel: Bedeutung der Spalten (1) und (2): In der Tschechischen Republik sind 10 Prozent aller Ausgaben für Bildungseinrichtungen dem Elementarbereich zuzurechnen, während 13 Prozent der Schüler/Studierenden diesem Bildungsbereich zuzurechnen sind.

\begin{tabular}{|c|c|c|c|c|c|c|c|c|c|c|c|c|c|c|c|c|c|c|c|c|c|c|}
\hline & \multirow{2}{*}{\multicolumn{2}{|c|}{\begin{tabular}{|c|} 
Elementar- \\
bereich \\
(für 3 -Jährige \\
und Ältere)
\end{tabular}}} & \multirow{2}{*}{\multicolumn{2}{|c|}{$\begin{array}{l}\text { Primar- } \\
\text { bereich }\end{array}$}} & \multicolumn{6}{|c|}{ Sekundarbereich } & \multirow{2}{*}{\multicolumn{2}{|c|}{$\begin{array}{l}\text { Post- } \\
\text { sekundarer, } \\
\text { nicht- } \\
\text { tertiärer } \\
\text { Bereich }\end{array}$}} & \multicolumn{6}{|c|}{ Tertiärbereich (einschl. F\&E-Aktivitäten) } & \multirow{2}{*}{\multicolumn{2}{|c|}{\begin{tabular}{|c|} 
Nicht einem \\
einzelnen \\
Bereich \\
zugeordnet
\end{tabular}}} & \multirow{2}{*}{\multicolumn{2}{|c|}{$\begin{array}{l}\text { Alle } \\
\text { Bildungs- } \\
\text { bereiche } \\
\text { zusammen }\end{array}$}} \\
\hline & & & & & \multicolumn{2}{|c|}{$\begin{array}{l}\text { Sekundar- } \\
\text { bereich I }\end{array}$} & \multicolumn{2}{|c|}{$\begin{array}{l}\text { Sekundar- } \\
\text { bereich II }\end{array}$} & \multicolumn{2}{|c|}{$\begin{array}{l}\text { Sekundar- } \\
\text { bereich } \\
\text { insgesamt }\end{array}$} & & & \multicolumn{2}{|c|}{$\begin{array}{c}\text { Tertiär- } \\
\text { bereich } \\
\text { insgesamt }\end{array}$} & \multicolumn{2}{|c|}{$\begin{array}{l}\text { Tertiär- } \\
\text { bereich B }\end{array}$} & $\begin{array}{l}\text { Tert } \\
\text { reich } \\
\text { terfül } \\
\text { Forsc } \\
\text { progr }\end{array}$ & $\begin{array}{l}\text { arbe- } \\
\text { \& w wei- } \\
\text { rende } \\
\text { nungs- } \\
\text { amme }\end{array}$ & & & & \\
\hline OECD-Länder & 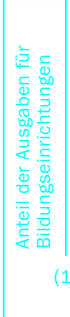 & 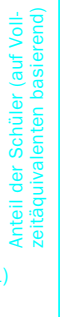 & 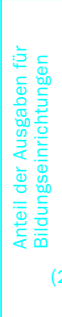 & 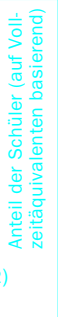 & 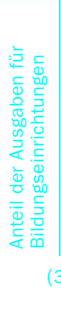 & 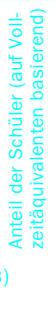 & 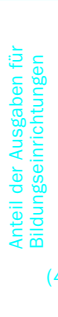 & 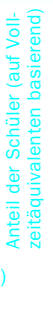 & 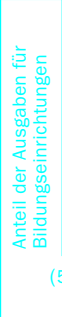 & 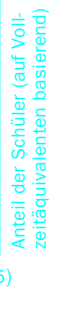 & 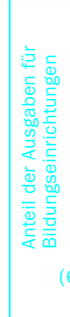 & 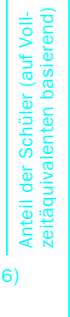 & 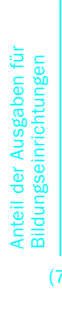 & 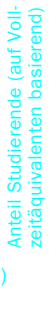 & 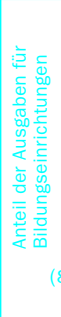 & 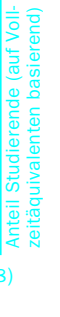 & 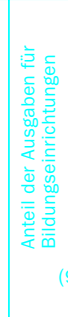 & 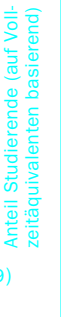 & 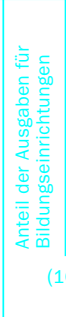 & 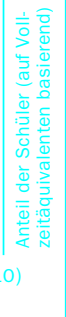 & 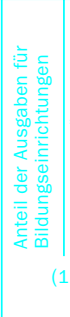 & 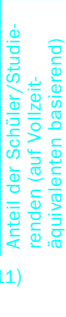 \\
\hline Australien & $\mathrm{m}$ & $\mathrm{m}$ & 32 & 45 & 25 & 25 & 15 & 14 & 40 & 39 & 2 & 2 & 26 & 15 & 3 & 2 & 24 & 12 & $\mathrm{n}$ & $\mathrm{n}$ & 100 & 100 \\
\hline Österreich & 9 & 14 & 20 & 25 & 24 & 24 & 22 & 21 & 46 & 45 & 1 & 1 & 21 & 15 & 1 & 1 & 19 & 14 & 3 & $\mathrm{n}$ & 100 & 100 \\
\hline Belgien & 9 & 16 & 23 & 31 & $x(5)$ & $x(5)$ & $x(5)$ & $x(5)$ & 44 & 40 & $x(5)$ & $x(5)$ & 22 & 13 & $x(7)$ & $x(7)$ & $x(7)$ & $x(7)$ & 2 & $\mathrm{n}$ & 100 & 100 \\
\hline Kanada & 4 & $\mathrm{~m}$ & $x(5)$ & $\mathrm{m}$ & $x(5)$ & $\mathrm{m}$ & $x(5)$ & $\mathrm{m}$ & 55 & $\mathrm{~m}$ & $x(8)$ & $\mathrm{m}$ & 41 & $\mathrm{~m}$ & 17 & $\mathrm{~m}$ & 24 & $\mathrm{~m}$ & a & $\mathrm{m}$ & 100 & $\mathrm{~m}$ \\
\hline Tschechische Rep. & 10 & 13 & 17 & 28 & 24 & 24 & 26 & 22 & 50 & 46 & 1 & 1 & 19 & 11 & 1 & 1 & 18 & 10 & 3 & a & 100 & 100 \\
\hline Dänemark & 11 & 21 & 27 & 29 & 15 & 17 & 19 & 18 & 34 & 35 & $\mathrm{x}(4,7)$ & $x(4,7)$ & 26 & 15 & $x(7)$ & $x(7)$ & $x(7)$ & $x(7)$ & 2 & a & 100 & 100 \\
\hline Finnland & 6 & 11 & 23 & 31 & 18 & 15 & 23 & 25 & 41 & 40 & $x(5)$ & $x(5)$ & 30 & 17 & $\mathrm{n}$ & $\mathrm{n}$ & 29 & 17 & $\mathrm{n}$ & $\mathrm{n}$ & 100 & 100 \\
\hline Frankreich & 11 & 17 & 19 & 27 & 26 & 23 & 24 & 18 & 50 & 42 & $n$ & $\mathrm{n}$ & 18 & 14 & 4 & 3 & 14 & 11 & 1 & a & 100 & 100 \\
\hline Deutschland & 11 & 14 & 13 & 21 & 28 & 34 & 23 & 16 & 51 & 50 & 4 & 3 & 20 & 12 & 2 & 2 & 18 & 11 & 1 & $\mathrm{n}$ & 100 & 100 \\
\hline Griechenland ${ }^{1}$ & $x(2)$ & 7 & 27 & 30 & $x(5)$ & 17 & $x(5)$ & 19 & 36 & 36 & 1 & 2 & 29 & 25 & 5 & 8 & 24 & 17 & 7 & a & 100 & 100 \\
\hline Ungarn ${ }^{1}$ & 15 & 17 & 18 & 23 & 17 & 24 & 19 & 22 & 36 & 46 & 3 & 3 & 23 & 11 & $\mathrm{n}$ & $n$ & 23 & 10 & 5 & a & 100 & 100 \\
\hline Island & $\mathrm{m}$ & $\mathrm{m}$ & $\mathrm{m}$ & $\mathrm{m}$ & $\mathrm{m}$ & $\mathrm{m}$ & $\mathrm{m}$ & $\mathrm{m}$ & $\mathrm{m}$ & $\mathrm{m}$ & $\mathrm{m}$ & $\mathrm{m}$ & $\mathrm{m}$ & $\mathrm{m}$ & $\mathrm{m}$ & $\mathrm{m}$ & $\mathrm{m}$ & $\mathrm{m}$ & $\mathrm{m}$ & $\mathrm{m}$ & $\mathrm{m}$ & $\mathrm{m}$ \\
\hline Irland & $\mathrm{n}$ & $\mathrm{n}$ & 32 & 46 & 18 & 19 & 15 & 15 & 33 & 34 & 3 & 4 & 30 & 16 & $x(7)$ & $x(7)$ & $x(7)$ & $x(7)$ & 1 & $\mathrm{n}$ & 100 & 100 \\
\hline Italien ${ }^{1}$ & 9 & 12 & 24 & 27 & 20 & 18 & 27 & 26 & 47 & 44 & 1 & $\mathrm{n}$ & 19 & 17 & $\mathrm{n}$ & n & 19 & 17 & $\mathrm{n}$ & a & 100 & 100 \\
\hline Japan & 4 & 8 & 27 & 34 & 16 & 19 & 19 & 20 & 36 & 39 & $x(4,7)$ & a & 23 & 15 & 2 & 2 & 21 & 13 & 10 & 4 & 100 & 100 \\
\hline Korea & 2 & 5 & 24 & 36 & 14 & 16 & 18 & 17 & 32 & 33 & a & a & 32 & 27 & 9 & 11 & 23 & 16 & 11 & a & 100 & 100 \\
\hline Luxemburg & $\mathrm{m}$ & $\mathrm{m}$ & $\mathrm{m}$ & $\mathrm{m}$ & $\mathrm{m}$ & $\mathrm{m}$ & $\mathrm{m}$ & $\mathrm{m}$ & $\mathrm{m}$ & $\mathrm{m}$ & $\mathrm{m}$ & $\mathrm{m}$ & $\mathrm{m}$ & $\mathrm{m}$ & $\mathrm{m}$ & $\mathrm{m}$ & $\mathrm{m}$ & $\mathrm{m}$ & $\mathrm{m}$ & $\mathrm{m}$ & $\mathrm{m}$ & $\mathrm{m}$ \\
\hline Mexiko & 9 & 12 & 38 & 50 & 16 & 22 & 18 & 10 & 34 & 32 & a & a & 17 & 7 & $x(7)$ & $\mathrm{n}$ & $x(7)$ & 7 & 2 & a & 100 & 100 \\
\hline Niederlande & 7 & 11 & 28 & 37 & 23 & 22 & 15 & 17 & 39 & 39 & $n$ & $\mathrm{n}$ & 26 & 13 & $\mathrm{n}$ & $\mathrm{n}$ & 26 & 13 & a & $\mathrm{m}$ & 100 & 100 \\
\hline Neuseeland & $\mathrm{m}$ & $\mathrm{m}$ & $\mathrm{m}$ & $\mathrm{m}$ & $\mathrm{m}$ & $\mathrm{m}$ & $\mathrm{m}$ & $\mathrm{m}$ & $\mathrm{m}$ & $\mathrm{m}$ & $\mathrm{m}$ & $\mathrm{m}$ & $\mathrm{m}$ & $\mathrm{m}$ & $\mathrm{m}$ & $\mathrm{m}$ & $\mathrm{m}$ & $\mathrm{m}$ & $\mathrm{m}$ & $\mathrm{m}$ & $\mathrm{m}$ & $\mathrm{m}$ \\
\hline Norwegen & 10 & 11 & 31 & 40 & 14 & 15 & 20 & 19 & 33 & 34 & $x(5)$ & 1 & 21 & 15 & $x(7)$ & 1 & $x(7)$ & 14 & 5 & a & 100 & 100 \\
\hline Polen ${ }^{1}$ & 8 & 9 & 50 & 55 & $x(2)$ & $x(2)$ & 22 & 22 & $\mathrm{~m}$ & $\mathrm{~m}$ & 1 & 1 & 19 & 14 & $\mathrm{n}$ & $\mathrm{n}$ & 19 & 13 & 1 & a & 100 & 100 \\
\hline Portugal & 6 & $\mathrm{~m}$ & 30 & $\mathrm{~m}$ & 21 & $\mathrm{~m}$ & 21 & $\mathrm{~m}$ & 42 & $\mathrm{~m}$ & a & a & 19 & $\mathrm{~m}$ & $x(7)$ & $\mathrm{m}$ & $x(7)$ & $\mathrm{m}$ & 3 & $\mathrm{~m}$ & 100 & $\mathrm{~m}$ \\
\hline Slowakische Rep. & 11 & 13 & 15 & 24 & 23 & 32 & 26 & 22 & 50 & 54 & $x(4)$ & $x(4)$ & 22 & 8 & $x(4)$ & $x(4)$ & 22 & 8 & 3 & a & 100 & 100 \\
\hline Spanien & 10 & 14 & 25 & 31 & $x(5)$ & 24 & $x(5)$ & 14 & 40 & 38 & $x(5)$ & $x(5)$ & 25 & 17 & 3 & 2 & 21 & 15 & a & a & 100 & 100 \\
\hline Schw & 7 & 15 & 31 & 34 & 15 & 16 & 21 & 22 & 35 & 38 & $\mathrm{n}$ & 1 & 26 & 12 & $x(7)$ & $\mathrm{n}$ & $x(7)$ & 12 & a & a & 100 & 100 \\
\hline Schweiz ${ }^{1}$ & 4 & 11 & 29 & 40 & 17 & 20 & 28 & 19 & 45 & 39 & 1 & 1 & 21 & 10 & 1 & 1 & 20 & 9 & 1 & $\mathrm{n}$ & 100 & 100 \\
\hline Türkei $^{1}$ & $\mathrm{~m}$ & 2 & $\mathrm{~m}$ & 74 & a & a & $\mathrm{m}$ & 17 & $\mathrm{~m}$ & 17 & a & a & $\mathrm{m}$ & 8 & $x(7)$ & 2 & $x(7)$ & 6 & a & a & $\mathrm{m}$ & 100 \\
\hline Ver. Königreich & 8 & 7 & 24 & 33 & $x(5)$ & 17 & $x(5)$ & 33 & 48 & 49 & $x(5)$ & $x(5)$ & 20 & 11 & $x(7)$ & 3 & $x(7)$ & 9 & a & a & 100 & 100 \\
\hline Vereinigte Staater & 7 & 8 & 27 & 39 & 15 & 19 & 14 & 16 & 29 & 35 & $x(7)$ & a & 37 & 18 & $x(7)$ & $x(7)$ & $x(7)$ & $x(7)$ & a & a & 100 & 100 \\
\hline Ländermittel & 8 & 11 & 26 & 35 & 18 & 20 & 21 & 20 & 41 & 39 & 1 & 1 & 24 & 14 & 3 & 2 & 21 & 12 & 2 & $\mathrm{n}$ & 100 & 100 \\
\hline OECD-Partnerlände & & & & & & & & & & & & & & & & & & & & & & \\
\hline Argentinien & 7 & 9 & 31 & 44 & 20 & 22 & 15 & 14 & 35 & 35 & a & $\mathrm{a}$ & 19 & 12 & 9 & 4 & 10 & 7 & 9 & $a$ & 100 & 100 \\
\hline Brasilien 1,2 & 9 & 9 & 32 & 41 & 26 & 32 & 13 & 16 & 39 & 48 & a & a & 20 & 2 & $x(7)$ & $x(7)$ & $x(7)$ & $x(7)$ & a & a & 100 & 100 \\
\hline Chile $^{3}$ & 7 & 10 & 33 & 41 & 11 & 14 & 18 & 23 & 29 & 37 & a & a & 31 & 12 & 3 & 2 & 28 & 10 & a & $a$ & 100 & 100 \\
\hline Indien & 1 & 9 & 39 & 53 & 14 & 20 & 26 & 14 & 40 & 34 & a & a & 19 & 4 & $x(7)$ & $x(7)$ & $x(7)$ & $x(7)$ & a & $a$ & 100 & 100 \\
\hline Indonesien & 1 & 3 & 25 & 59 & 21 & 19 & 18 & 11 & 39 & 31 & a & $\mathrm{a}$ & 35 & 6 & $x(7)$ & $x(7)$ & $x(7)$ & $x(7)$ & a & $a$ & 100 & 100 \\
\hline Israel & 10 & 17 & 30 & 39 & $x(5)$ & 13 & $x(5)$ & 17 & 27 & 30 & $\mathrm{n}$ & 1 & 23 & 13 & 4 & 3 & 20 & 10 & 10 & $a$ & 100 & 100 \\
\hline Jamaika & 5 & 18 & 28 & 43 & 18 & 20 & 10 & 11 & 28 & 30 & 9 & 5 & 30 & 4 & 7 & 2 & 23 & 1 & a & $a$ & 100 & 100 \\
\hline Jordanien 1 & $\mathrm{n}$ & $\mathrm{n}$ & 51 & 52 & 34 & 34 & 15 & 14 & 49 & 48 & $\mathrm{n}$ & $\mathrm{n}$ & $\mathrm{m}$ & $\mathrm{m}$ & $\mathrm{m}$ & $\mathrm{m}$ & a & $\mathrm{m}$ & a & $a$ & 100 & 100 \\
\hline Malaysia $^{1}$ & 1 & 5 & 30 & 52 & $x(5)$ & $x(5)$ & $x(5)$ & $x(5)$ & 36 & 37 & 1 & $\mathrm{n}$ & 29 & 7 & 5 & 1 & 23 & $\mathrm{n}$ & 3 & $\mathrm{n}$ & 100 & 100 \\
\hline Paraguay & 2 & $x(2)$ & 46 & 67 & $x(5)$ & $x(5)$ & $x(5)$ & $x(5)$ & 32 & 27 & $\mathrm{~m}$ & $\mathrm{~m}$ & 20 & 6 & 4 & 2 & 16 & 4 & a & a & 100 & 100 \\
\hline Peru & 8 & 13 & 37 & 50 & 18 & 20 & 9 & 9 & 27 & 29 & $\mathrm{~m}$ & 3 & 28 & 4 & 6 & 4 & 22 & 5 & a & $a$ & 100 & 100 \\
\hline Philippinen & $\mathrm{n}$ & 1 & 61 & 69 & 17 & 21 & 4 & 5 & 21 & 25 & $\mathrm{~m}$ & $\mathrm{~m}$ & 14 & 5 & a & a & 14 & 4 & 2 & a & 100 & 100 \\
\hline Thailand & 11 & $\mathrm{~m}$ & 34 & $\mathrm{~m}$ & 9 & $\mathrm{~m}$ & 11 & $\mathrm{~m}$ & 20 & $\mathrm{~m}$ & $\mathrm{~m}$ & $\mathrm{~m}$ & 19 & $\mathrm{~m}$ & 4 & $\mathrm{~m}$ & 16 & $\mathrm{~m}$ & 16 & $\mathrm{~m}$ & 100 & $\mathrm{~m}$ \\
\hline Tunesien $^{1}$ & $\mathrm{~m}$ & $\mathrm{~m}$ & 78 & 49 & $x(2)$ & 24 & $x(2)$ & 16 & $x(2)$ & 39 & a & a & 22 & 8 & $x(7)$ & 6 & $x(7)$ & $\mathrm{n}$ & a & 4 & 100 & 100 \\
\hline Uruguay $^{1}$ & 11 & 11 & 39 & 41 & 14 & 20 & 16 & 16 & 30 & 36 & a & a & 20 & 11 & $x(7)$ & 3 & $x(7)$ & 9 & a & $a$ & 100 & 100 \\
\hline Simbabwe ${ }^{3}$ & 2 & $\mathrm{~m}$ & 64 & 74 & $x(5)$ & 13 & $x(5)$ & 13 & 34 & 26 & $\mathrm{n}$ & $\mathrm{m}$ & $\mathrm{m}$ & $\mathrm{m}$ & $\mathrm{m}$ & $\mathrm{m}$ & $\mathrm{m}$ & $\mathrm{m}$ & a & a & 100 & 100 \\
\hline
\end{tabular}

Hinweis: $x$ bedeutet, dass die Daten in einer anderen Spalte enthalten sind, deren Referenz in runden Klammern nach dem , $x$ ' angegeben ist. So bedeutet $z$. B. $x(2)$, dass die Daten in Spalte 2 enthalten sind.

1. Nur öffentliche Bildungseinrichtungen. 2. Referenzjahr 2000. 3. Referenzjahr 2002.

Quelle: OECD. Hinweise s. Anhang 3 unter www.oecd.org/edu/eag2004. 


\section{Tabelle B1.5}

Veränderung der jährlichen Ausgaben für Bildungseinrichtungen pro Schüler/Studierenden aufgrund verschiedener Faktoren, nach Bildungsbereich (1995, 2001) Index der Veränderung zwischen 1995 und 2001 (1995=100, zu konstanten Preisen von 2001)

\begin{tabular}{|c|c|c|c|c|}
\hline \multirow[b]{3}{*}{ OECD-Länder } & \multicolumn{3}{|c|}{$\begin{array}{l}\text { Primar-, Sekundar- und post-sekundarer, } \\
\text { nicht-tertiärer Bereich }\end{array}$} & \multirow[b]{3}{*}{ OECD-Länder } \\
\hline & $\begin{array}{l}\text { Veränderung der } \\
\text { Ausgaben }\end{array}$ & $\begin{array}{l}\text { Veränderung in der } \\
\text { Zahl der Schüler }\end{array}$ & $\begin{array}{l}\text { Veränderung in } \\
\text { den Ausgaben } \\
\text { pro Schüler }\end{array}$ & \\
\hline & & & & \\
\hline Australien & 141 & 107 & 131 & Australien \\
\hline Österreich & 103 & $\mathrm{~m}$ & $\mathrm{~m}$ & Österreich \\
\hline Belgien & $\mathrm{m}$ & $\mathrm{m}$ & $\mathrm{m}$ & Belgien \\
\hline Kanada & 101 & $\mathrm{~m}$ & $\mathrm{~m}$ & Kanada $^{6}$ \\
\hline Tschechische Rep. & 91 & 95 & 96 & Tschechische Rep. \\
\hline Dänemark ${ }^{1}$ & 126 & 104 & 121 & Dänemark ${ }^{1}$ \\
\hline Finnland & 118 & 108 & 109 & Finnland \\
\hline Frankreich & 111 & 97 & 114 & Frankreich \\
\hline Deutschland & 107 & 104 & 103 & Deutschland \\
\hline Griechenland 2,4 & 134 & 93 & 144 & Griechenland $^{2}$ \\
\hline Ungarn ${ }^{3}$ & 107 & 93 & 115 & Ungarn ${ }^{3}$ \\
\hline Island & $\mathrm{m}$ & $\mathrm{m}$ & $\mathrm{m}$ & Island \\
\hline Irland & 136 & 94 & 145 & Irland \\
\hline Italien 2,3 & 110 & 98 & 112 & Italien ${ }^{3}$ \\
\hline Japan $^{1}$ & 105 & 87 & 122 & Japan $^{1}$ \\
\hline Korea & $\mathrm{m}$ & 92 & $\mathrm{~m}$ & Korea \\
\hline Luxemburg & $\mathrm{m}$ & $\mathrm{m}$ & $\mathrm{m}$ & Luxemburg \\
\hline Mexiko & 136 & 109 & 125 & Mexiko \\
\hline Niederlande & 129 & 103 & 124 & Niederlande \\
\hline Neuseeland $^{2}$ & 141 & $\mathrm{~m}$ & $\mathrm{~m}$ & Neuseeland ${ }^{2}$ \\
\hline Norwegen 2,4,5 & 107 & 113 & 94 & Norwegen ${ }^{2}$ \\
\hline Polen 2,3 & 140 & 89 & 157 & Polen ${ }^{2,3}$ \\
\hline Portugal & 137 & 83 & 166 & Portugal \\
\hline Slowakische Rep. & 108 & 94 & 115 & Slowakische Rep. \\
\hline Spanien ${ }^{2}$ & 107 & 83 & 129 & Spanien \\
\hline Schweden & 123 & 119 & 103 & Schweden \\
\hline Schweiz 2,3 & 107 & 107 & 100 & Schweiz 2,3 \\
\hline Türkei 2,3 & 166 & 113 & 147 & Türkei ${ }^{3}$ \\
\hline Ver. Königreich & 121 & 115 & 106 & Ver. Königreich \\
\hline Vereinigte Staaten & 127 & 111 & 114 & Vereinigte Staaten \\
\hline
\end{tabular}

\begin{tabular}{|c|c|c|}
\hline $\begin{array}{l}\text { Veränderung der } \\
\text { Ausgaben }\end{array}$ & $\begin{array}{l}\text { Veränderung in } \\
\text { der Zahl der } \\
\text { Studierenden }\end{array}$ & $\begin{array}{l}\text { Veränderung in } \\
\text { den Ausgaben pro } \\
\text { Studierenden }\end{array}$ \\
\hline 113 & 118 & 96 \\
\hline 115 & 106 & 109 \\
\hline $\mathrm{m}$ & $\mathrm{m}$ & $\mathrm{m}$ \\
\hline 122 & $\mathrm{~m}$ & $\mathrm{~m}$ \\
\hline 103 & 162 & 63 \\
\hline 128 & 103 & 124 \\
\hline 113 & 113 & 101 \\
\hline 111 & 98 & 113 \\
\hline 106 & 95 & 111 \\
\hline 216 & 165 & 131 \\
\hline 145 & 158 & 92 \\
\hline $\mathrm{m}$ & $\mathrm{m}$ & $\mathrm{m}$ \\
\hline 170 & 123 & 139 \\
\hline 126 & 105 & 120 \\
\hline 119 & 102 & 117 \\
\hline $\mathrm{m}$ & 154 & $\mathrm{~m}$ \\
\hline $\mathrm{m}$ & $\mathrm{m}$ & $\mathrm{m}$ \\
\hline 122 & 136 & 90 \\
\hline 110 & 105 & 105 \\
\hline 101 & $\mathrm{~m}$ & $\mathrm{~m}$ \\
\hline 98 & 104 & 94 \\
\hline 161 & 181 & 89 \\
\hline 145 & 130 & 111 \\
\hline 149 & 148 & 101 \\
\hline 147 & 111 & 133 \\
\hline 128 & 127 & 101 \\
\hline 133 & 104 & 128 \\
\hline 174 & 110 & 159 \\
\hline 108 & 112 & 96 \\
\hline 121 & 111 & 109 \\
\hline
\end{tabular}

1. Post-sekundarer, nicht-tertiärer Bereich sowohl in Sekundarbereich Il als auch Tertiärbereich enthalten. 2. Nur öffentliche Ausgaben. 3. Nur öffentliche Bildungseinrichtungen. 4. Elementarbereich in Primar-, Sekundar- und post-sekundarer, nicht-tertiärer Bereich enthalten. 5. Der Rückgang der Ausgaben pro Schüler/ Studierenden ist auf eine wesentliche Veränderung des BIP-Deflators zurückzuführen, der hauptsächlich durch den Anstieg der Ölpreise verursacht wurde. 6. Tertiärbereich A umfasst nur Tertiärbereich A und weiterführende Forschungsprogramme.

Quelle: OECD. Hinweise s. Anhang 3 unter www.oecd.org/edu/eag2004. 
Veränderung der Ausgaben für Bildungseinrichtungen pro Schüler/Studierenden und Volkseinkommen, nach Bildungsbereich $(1995,2001)$

In US-Dollar, kaufkraftbereinigt (zu konstanten Preise und konstanten KKP des Jahres 2001)

\begin{tabular}{|c|c|c|c|c|c|c|}
\hline & \multicolumn{3}{|c|}{1995} & \multicolumn{3}{|c|}{2001} \\
\hline & \multicolumn{2}{|c|}{ Ausgaben pro Schüler/Studierenden } & \multirow[t]{2}{*}{ BIP pro Kopf } & \multicolumn{2}{|c|}{ Ausgaben pro Schüler/Studierenden } & \multirow[t]{2}{*}{ BIP pro Kop } \\
\hline OECD-Länder & $\begin{array}{l}\text { Primar-, Sekundar- und } \\
\text { post-sekundarer, nicht- } \\
\text { tertiärer Bereich }\end{array}$ & Tertiärbereich & & $\begin{array}{l}\text { Primar-, Sekundar- und } \\
\text { post-sekundarer, nicht- } \\
\text { tertiärer Bereich }\end{array}$ & Tertiärbereich & \\
\hline Australien & 4846 & 13897 & 23135 & 6063 & 12688 & 26685 \\
\hline Österreich & $\mathrm{m}$ & 10341 & 24889 & 7852 & 11274 & 28372 \\
\hline Belgien & $\mathrm{m}$ & $\mathrm{m}$ & 23868 & 6781 & 11589 & 27096 \\
\hline Kanada & $\mathrm{m}$ & $\mathrm{m}$ & 24826 & $\mathrm{~m}$ & $\mathrm{~m}$ & 29290 \\
\hline Tschechische Rep. & 2927 & 8785 & 13426 & 2819 & 5555 & 14861 \\
\hline Dänemark & 6515 & 11499 & 25830 & 7865 & 14280 & 29223 \\
\hline Finnland & 5238 & 10900 & 20992 & 5733 & 10981 & 26344 \\
\hline Frankreich & 5938 & 7801 & 23580 & 6783 & 8837 & 26818 \\
\hline Deutschland & 5820 & 9698 & 23279 & 6055 & 10504 & 25456 \\
\hline Ungarn ${ }^{1}$ & 2335 & 7767 & 10171 & 2677 & 7122 & 13043 \\
\hline Island & $\mathrm{m}$ & $\mathrm{m}$ & 23564 & 7010 & 7674 & 29036 \\
\hline Irland & 3042 & 7223 & 18802 & 4397 & 10003 & 29821 \\
\hline Italien ${ }^{1}$ & 6577 & 5621 & 22889 & 7714 & 8347 & 25377 \\
\hline Japan & 5134 & 9691 & 25092 & 6179 & 11164 & 26636 \\
\hline Korea & $\mathrm{m}$ & $\mathrm{m}$ & 12780 & 4406 & 6618 & 15916 \\
\hline Luxemburg & $\mathrm{m}$ & $\mathrm{m}$ & 37220 & 11091 & $\mathrm{~m}$ & 49229 \\
\hline Mexiko & 1263 & 4821 & 7737 & 1575 & 4341 & 9148 \\
\hline Niederlande & 4548 & 12311 & 24503 & 5654 & 12974 & 28711 \\
\hline Neuseeland & $\mathrm{m}$ & $\mathrm{m}$ & 19053 & $\mathrm{~m}$ & $\mathrm{~m}$ & 21230 \\
\hline Norwegen ${ }^{2}$ & 8425 & 14087 & 31146 & 8109 & 13189 & 36587 \\
\hline Polen ${ }^{1}$ & 1528 & 4023 & 7682 & 2396 & 3579 & 10360 \\
\hline Portugal & 3052 & 4664 & 14939 & 5065 & 5199 & 17912 \\
\hline Slowakische Rep. & 1467 & 5250 & 8987 & 1681 & 5285 & 11323 \\
\hline Schweiz $^{1}$ & 8844 & 15802 & 27537 & 8844 & 20230 & 30036 \\
\hline Türkei ${ }^{1}$ & $\mathrm{~m}$ & $\mathrm{~m}$ & 5994 & $\mathrm{~m}$ & $\mathrm{~m}$ & 6046 \\
\hline Ver. Königreich & 4941 & 10981 & 23006 & 5324 & 10753 & 26715 \\
\hline Vereinigte Staaten & 7034 & 20207 & 30753 & 8144 & 22234 & 35179 \\
\hline
\end{tabular}

1. Nur öffentliche Bildungseinrichtungen. 2. Der Rückgang der Ausgaben pro Schüler/Studierenden zwischen 1995 und 2001 ist auf eine wesentliche Veränderung des BIP-Deflators zurückzuführen, der hauptsächlich durch den Anstieg der Ölpreise verursacht wurde.

Quelle: OECD. Hinweise s. Anhang 3 unter www.oecd.org/edu/eag2004. 



\section{Ausgaben für Bildungseinrichtungen im Verhältnis zum Bruttoinlandsprodukt}

Die OECD-Länder geben 6,2 Prozent der Gesamtsumme ihrer Bruttoinlandsprodukte für Bildungseinrichtungen aus.

In 17 von 18 OECD-Ländern mit verfügbaren Daten erhöhten sich zwischen 1995 und 2001 die privaten und öffentlichen Ausgaben für Bildungseinrichtungen um mehr als 5 Prozent. Im Gegensatz zu den Entwicklungen Anfang der neunziger Jahre blieb jedoch der Anstieg der Ausgaben für Bildungseinrichtungen tendenziell hinter dem Wachstum des Volkseinkommens zurück.

Zwei Drittel aller Ausgaben für Bildungseinrichtungen, oder 3,8 Prozent des BIP der OECD insgesamt, gehen in den Primar-, Sekundar- und post-sekundaren, nicht-tertiären Bildungsbereich. Kanada, Korea und die Vereinigten Staaten geben jeweils mehr als 2 Prozent ihres BIP für den Tertiärbereich aus. 


\section{Abbildung B2.1}

Ausgaben für Bildungseinrichtungen als Prozentsatz des BIP $(1995,2001)$

Aus öffentlichen und privaten Quellen, nach Bildungsbereich, Herkunft der Mittel und Jahr
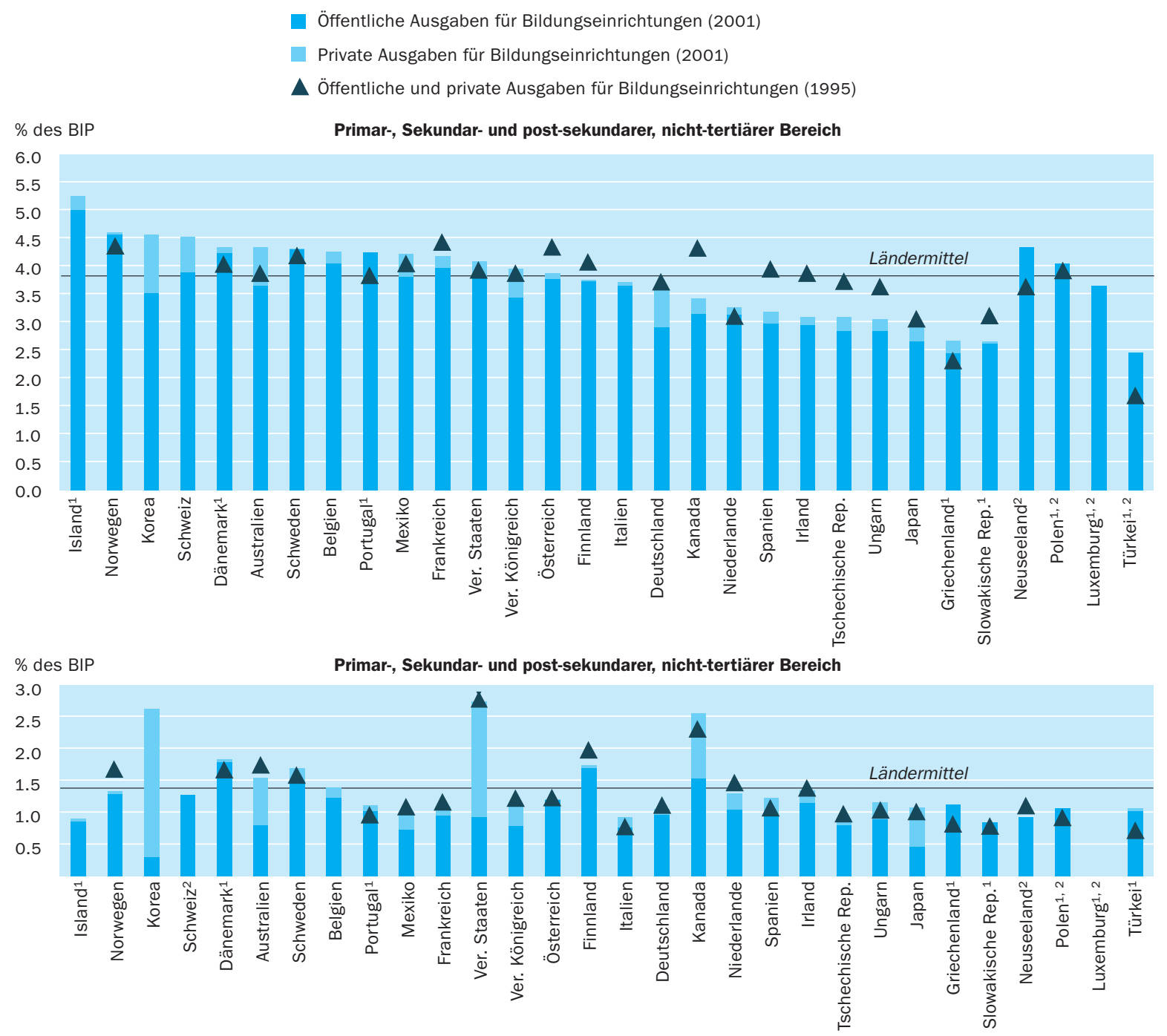

1. Öffentliche Subventionen in privaten Ausgaben enthalten. 2. Angaben zu den privaten Ausgaben für Bildungseinrichtungen fehlen.

Anordnung der Länder in absteigender Reihenfolge der Gesamtausgaben für Bildungseinrichtungen sowohl aus öffentlichen als auch privaten Quellen im Primar-, Sekundar- und post-sekundaren, nicht-tertiären Bereich im Jahr 2001. Länder, die nur öffentliche Ausgaben angeben, sind separat aufgeführt.

Quelle: OECD. Tabelle B2.1b. Hinweise s. Anhang 3 unter www.oecd.org/edu/eag2004.

Dieser Indikator liefert eine Kennzahl für den relativen Anteil des Volksvermögens, der in Bildungseinrichtungen fließt.

\section{Politischer Hintergrund}

Ausgaben für Bildung stellen eine Investition dar, die dazu beitragen kann, das Wirtschaftswachstum zu stärken, die Produktivität zu steigern, die persönliche und gesellschaftliche Entwicklung zu fördern sowie soziale Ungleichheiten zu verringern. Die Bildungsausgaben im Verhältnis zum BIP zeigen in Form des zugewiesenen Anteils der Gesamtressourcen die Priorität von Bildung innerhalb eines Landes. Die Entscheidung, welcher Anteil der insgesamt zur Verfügung stehenden Finanzmittel für das Bildungswesen bereitgestellt werden soll, ist in jedem OECD-Land von zentraler Bedeutung. An dieser Entschei- 
dung sind Regierungen und Unternehmensleitungen ebenso wie der einzelne Schüler/Studierende und seine Familie beteiligt. Falls die individuellen und gesellschaftlichen Erträge der Bildungsinvestition hoch genug sind, besteht ein Anreiz, die Bildungsbeteiligung zu erhöhen und die Gesamtinvestitionen im Bildungsbereich zu steigern.

Bei der Bewertung der Gesamtaufwendungen für Bildung müssen die Regierungen sich mit Forderungen nach Ausgabenerhöhungen z. B. im Bereich der Lehrergehälter oder der Bildungseinrichtungen auseinandersetzen. Dabei kann der vorliegende Indikator als Bezugspunkt dienen, denn er weist auf, wie sich der Umfang der Bildungsausgaben, sowohl gemessen am Volksvermögen, als auch in absoluten Zahlen im Zeitverlauf, in den einzelnen OECD-Ländern entwickelt hat.

\section{Ergebnisse und Erläuterungen}

Was dieser Indikator aufzeigt und was nicht.

Dieser Indikator erfasst Ausgaben für Schulen, Hochschulen und andere öffentliche wie private Einrichtungen, die selbst Bildungsangebote bereitstellen oder deren Bereitstellung unterstützen. Ausgaben für Bildungseinrichtungen beschränken sich nicht allein auf Ausgaben für Unterrichtszwecke, sondern beinhalten auch öffentliche und private Ausgaben für zusätzliche Leistungen zur Unterstützung von Schülern/Studierenden und deren Familien, soweit diese durch Bildungseinrichtungen erbracht werden. Im Tertiärbereich können auch die Ausgaben für Forschung und Entwicklung einen erheblichen Teil ausmachen. Sie sind in diesem Indikator enthalten, soweit die Forschungstätigkeit von Bildungseinrichtungen erbracht wird.

Nicht alle Ausgaben für Sach- und Dienstleistungen im Bildungsbereich finden in Bildungseinrichtungen statt. Beispielsweise erwerben Familien Schulbücher oder Unterrichtsmaterial im Handel oder lassen ihren Kindern Privatunterricht außerhalb von Bildungseinrichtungen zukommen. Im Tertiärbereich machen die Kosten für den Lebensunterhalt sowie für entgangene Einkommen einen beträchtlichen Teil der Bildungskosten aus. Solche außerhalb von Bildungseinrichtungen anfallenden Kosten bleiben bei diesem Indikator sämtlich außer Acht, auch wenn diese Ausgaben öffentlich subventioniert werden. Öffentliche Subventionen für Bildungsausgaben außerhalb von Bildungseinrichtungen werden in den Indikatoren $\mathrm{B}_{4}$ und $\mathrm{B}_{5}$ behandelt.

\section{Gesamtausgaben im Verhältnis zum Bruttoinlandsprodukt}

Alle OECD-Länder investieren einen bedeutenden Teil ihrer nationalen Ressourcen in Bildung. Unter Berücksichtigung sowohl der öffentlichen als auch der privaten Finanzquellen geben die OECD-Länder zusammen 6,2 Prozent der Gesamtsumme ihrer Bruttoinlandsprodukte für Bildungseinrichtungen im Elementar-, Primar-, Sekundar- und Tertiärbereich aus. Angesichts der derzeit herrschenden Finanzknappheit der öffentlichen Haushalte wird ein so großer Ausgabenposten auf der Suche nach Möglichkeiten zur Reduzierung oder Begrenzung des Ausgabenwachstums seitens der Regierungen einer kritischen Prüfung unterzogen.
Der Indikator liefert ferner eine vergleichende Übersicht der im Zeitverlauf eingetretenen Veränderungen bei den Bildungsausgaben.

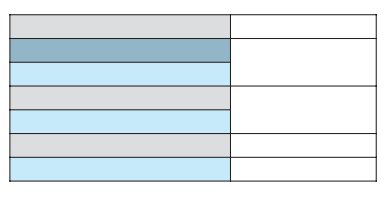

Erfasste Daten

(Erklärungen S. S. 208)

Insgesamt geben die OECDLänder 6,2 Prozent der Gesamtsumme ihrer Bruttoinlandsprodukte für Bildungseinrichtungen aus. 
Die von einem Land für die Bildung bereitgestellten Ressourcen hängen von mehreren, sich gegenseitig beeinflussenden Angebotsund Nachfragefaktoren ab.

In 17 von 18 OECD-Ländern erhöhten sich zwischen 1995 und 2001 die privaten und öffentlichen Ausgaben für Bildungseinrichtungen um mehr als 5 Prozent, ...

... tendenziell blieb jedoch im gleichen Zeitraum der Anstieg der Bildungsausgaben hinter dem Wachstum der Volkseinkommen zurück.
Die höchsten Ausgaben für Bildungseinrichtungen verzeichnen Dänemark, Korea und die Vereinigten Staaten, wo sich die öffentlichen und privaten Ausgaben für Bildungseinrichtungen auf 7,o Prozent des BIP belaufen. Es folgen Belgien, Island, Kanada, Norwegen und Schweden mit einem Anteil von mehr als 6,o Prozent. Neun von 28 OECD-Ländern mit verfügbaren Daten geben jedoch weniger als 5 Prozent ihres BIP für Bildungseinrichtungen aus. In Griechenland, Luxemburg, der Slowakischen Republik und der Türkei sind es sogar nur zwischen 3,5 und 4,I Prozent (Tab. B2.ra).

Die relative Stellung einzelner OECD-Länder bei diesem Indikator wird von einer Vielzahl von Faktoren beeinflusst. Möglicherweise haben OECD-Länder mit hohen Bildungsausgaben eine höhere Bildungsbeteiligung, während Länder mit niedrigen Bildungsausgaben den Zugang zu den höheren Bildungsbereichen beschränken oder die Bildungsinhalte auf besonders effiziente Weise vermitteln. Die Verteilung der Schüler und Studierenden auf die verschiedenen Bildungsbereiche und Fächer kann sich ebenso unterscheiden wie die Dauer der Bildungs- und Studiengänge sowie Umfang und Organisation der mit dem Bildungsbereich verbundenen Forschungsaktivitäten. Schließlich bedeuten große Unterschiede zwischen dem BIP der einzelnen OECD-Länder, dass selbst wenn der in Bildung investierte Anteil des BIP ähnlich hoch ist, die Unterschiede bei den auf jeden Schüler/Studierenden entfallenden absoluten Beträgen sehr groß sein können (s. Indikator BI).

\section{Veränderungen der Gesamtausgaben für Bildung zwischen 1995 und 2001}

In I7 der I8 OECD-Länder, für die vergleichbare Trendzahlen zur Verfügung stehen, sind die öffentlichen und privaten Investitionen in Bildung zwischen I995 und 200I real um 5 Prozent und mehr gestiegen. Australien, Dänemark, Mexiko, die Niederlande, Portugal, Schweden und die Vereinigten Staaten steigerten ihre Bildungsausgaben zwischen 20 und 40 Prozent, Irland um mehr als 40 Prozent. Ein ähnlicher Trend zeichnet sich ab, wenn nur die öffentlichen Ausgaben betrachtet werden: die direkten öffentlichen Ausgaben für Bildungseinrichtungen sowie die öffentlichen Subventionen an private Haushalte, die Bildungseinrichtungen zuzurechnen sind, stiegen zwischen 1995 und $200 \mathrm{I}$ in 24 von 26 OECD-Ländern um 5 Prozent und mehr. Griechenland, Neuseeland, Polen und die Türkei, für die keine Zahlen über die privaten Ausgaben vorliegen, verzeichneten einen erheblichen Anstieg der öffentlichen Ausgaben für Bildungseinrichtungen (Tab.B2.2).

In 6 der 9 OECD-Länder, die Daten für 1990, I995 und 200I zur Verfügung stellten, wuchsen die Ausgaben für Bildungseinrichtungen in der ersten Hälfte der neunziger Jahre schneller als das BIP, was zu einem Anstieg der durchschnittlichen Ausgaben für Bildungseinrichtungen von 5,5 Prozent des BIP im Jahre I990 auf 5,6 Prozent des BIP im Jahre I995 führte (Tab. B2.Ia). Diese Entwicklung begann sich in der zweiten Hälfte der neunziger Jahre umzukehren. Die Ausgaben für Bildungseinrichtungen stiegen zwischen I995 und $200 \mathrm{I}$ zwar in absoluten Zahlen, in der Regel jedoch nicht so stark wie das BIP im gleichen Zeitraum. In 13 der 22 OECD-Länder mit verfügbaren Daten ist der Anteil der Ausgaben für Bildungseinrichtungen am BIP im gleichen Zeitraum zurückgegangen. Besonders erwähnenswert sind Irland, Kanada, Norwegen 
und die Tschechische Republik, wo der Anteil der Bildungsausgaben am BIP um mehr als 0,7 Prozentpunkte zurückging (Tab. B2.ra).

Während das starke Wachstum des BIP in Irland erhebliche Ausgabensteigerungen für Bildungseinrichtungen verbirgt, wenn man die Bildungsausgaben als Anteil des BIP betrachtet, hat in der Tschechischen Republik der Bildungsbereich nicht besonders vom Wachstum des BIP profitiert. Beide Länder gehörten bereits $1995 \mathrm{zu}$ den OECD-Ländern mit geringeren Bildungsausgaben gemessen am BIP und sind seitdem weiter zurückgefallen (Tab. B2.Ia).

\section{Ausgaben für Bildungseinrichtungen aufgegliedert nach Bildungs- bereichen}

Insgesamt hohe Bildungsausgaben bedeuten nicht zwangsläufig, dass die Ausgaben in allen Bildungsbereichen hoch sind. Die Unterschiede in den Ausgaben für Bildungseinrichtungen zeigen sich am deutlichsten im Elementarbereich. Hier reicht die Spanne von weniger als o, 2 Prozent des BIP in Australien, Irland und Korea bis zu o,7 Prozent und mehr in Dänemark, Frankreich und Ungarn (Tab. B2.Ic). Unterschiede im Elementarbereich lassen sich zu einem großen Teil durch die unterschiedlichen Teilnahmequoten der jüngeren Kinder erklären (s. Indikator $\mathrm{CI}$ ).

In den Elementarbereich investierte Mittel sind von essentieller Bedeutung, um ein solides Fundament für lebenslanges Lernen aufzubauen und um Chancengleichheit im Hinblick auf den Zugang zum Lernangebot später in der Schule zu gewährleisten. Ein hochwertiges Angebot im Bereich Erziehung und Betreuung im Vorschulalter wird jedoch nicht nur an den in diesem Indikator behandelten Bildungseinrichtungen geboten. Schlussfolgerungen im Hinblick auf Zugang zu Erziehung und Betreuung im Vorschulalter und deren Qualität sollten daher nur mit Vorsicht gezogen werden.

Aufgrund der in den OECD-Ländern weitgehend universellen Bildungsbeteiligung im Primar- und Sekundarbereich I und der hohen Bildungsbeteiligung im Sekundarbereich II (s. Indikatoren CI und C2) entfällt der größte Teil der Ausgaben für Bildungseinrichtungen auf diese Bildungsbereiche, nämlich 3,8 Prozent der Gesamtsumme der Bruttoinlandsprodukte aller OECD-Länder (Abb. B2.I). Gleichzeitig sorgen die deutlich höheren Bildungsausgaben pro Schüler/Studierenden im Sekundarbereich II und im Tertiärbereich dafür, dass die Gesamtausgaben für diese Bildungsbereiche höher sind als die reinen Schüler-/Studierendenzahlen vermuten lassen. Ein Viertel der Ausgaben der OECD insgesamt für Bildungseinrichtungen entfallen auf Einrichtungen des Tertiärbereichs.

Kanada, Korea und die Vereinigten Staaten geben jeweils 2,5, 2,7 bzw. 2,7 Prozent ihres BIP für tertiäre Bildungseinrichtungen aus (Abb. B2.I). Dies entspricht mehr als einem Drittel ihrer Gesamtausgaben für Bildungseinrichtungen. Auch Australien, Dänemark, Finnland und Schweden haben hohe Bildungsausgaben - I, 5 Prozent des BIP und mehr werden für Einrichtungen des tertiären Bildungsbereichs aufgewendet. Andererseits liegt der Anteil des BIP, der in Frankreich, Island, Mexiko, Portugal und der Schweiz für tertiäre Bildungseinrichtungen ausgegeben wird, zwar leicht unter dem Durchschnitt,
Es gibt zwischen den einzelnen Ländern beträchtliche Unterschiede hinsichtlich der für Bildungseinrichtungen des Elementarbereichs aufgewandten Mittel.

Zwei Drittel aller Ausgaben für Bildungseinrichtungen gehen in den Primar-, Sekundar- und post-sekundaren, nicht-tertiären Bildungsbereich.

Kanada, Korea und die Vereinigten Staaten geben jeweils mehr als 2 Prozent ihres BIP für den Tertiärbereich aus. 
Während einige OECD-Länder die Ausgabensteigerungen gleichmäßig auf alle Bildungsbereiche verteilten, erhöhten andere die Ausgaben schwerpunktmäßig in bestimmten Bildungsbereichen.

Je mehr junge Menschen es gibt, desto größer ist die potenzielle Nachfrage nach Bildungsleistungen.
Je höher die Bildungsbeteiligung, desto mehr finanzielle Mittel sind erforderlich. gleichzeitig aber gehören diese Länder zu den OECD-Ländern, bei denen die für den Primar-, Sekundar- und post-sekundaren, nicht-tertiären Bereich aufgewendeten Mittel den höchsten Anteil am BIP ausmachen. Trotz eines relativ geringen BIP-Anteils der Ausgaben für tertiäre Einrichtungen gehört die Schweiz auf Grund der verhältnismäßig niedrigen Bildungsbeteiligung im tertiären Bereich bei einem gleichzeitig hohen BIP zu den Ländern mit den höchsten Ausgaben pro Studierenden (Tab. B2.Ib und Br.3).

Die einzelnen Länder unterscheiden sich hinsichtlich der Bildungsbereiche, in denen die Ausgaben gestiegen sind. Dänemark, Deutschland, Finnland, Frankreich, Portugal, Schweden, die Türkei und die Vereinigten Staaten, OECD-Länder mit einem vergleichsweise starken Anstieg der absoluten Ausgaben für Bildungseinrichtungen zwischen 1995 und 200I, haben die zusätzlichen Mittel zu ähnlichen Anteilen für den Primar-, Sekundar- und post-sekundaren, nicht-tertiären Bereich sowie den Tertiärbereich ausgegeben (Abb. B2.2 und Tab. B2.2). Australien, Mexiko, Neuseeland, die Niederlande und das Vereinigte Königreich haben einen Großteil ihrer zusätzlichen Mittel zwischen I995 und 200I für den Primar-, Sekundar- und post-sekundaren, nicht-tertiären Bereich verwendet. Dagegen erhöhten sich die Ausgaben für den Tertiärbereich in Griechenland, Irland, Kanada, Polen, der Schweiz, Spanien, der Slowakischen Republik und Ungarn zwischen 1995 und 200I um mehr als 20 Prozent, während die Ausgabensteigerungen für die vorgelagerten Bildungsbereiche wesentlich geringer ausfielen (Abb. B2.2).

\section{Wichtige Einflussgrößen der nationalen Bildungsausgaben}

Die von einem Land für Bildung bereitgestellten Finanzmittel hängen von mehreren, sich gegenseitig beeinflussenden Angebots- und Nachfragefaktoren ab, wie z. B. der demographischen Bevölkerungsstruktur, der Bildungsbeteiligung, dem Pro-Kopf-Einkommen, dem nationalen Niveau der Lehrergehälter sowie der Unterrichtsorganisation und der Art und Weise der Vermittlung von Lerninhalten.

Der Anteil junger Menschen im Schulalter in einem bestimmten Land (s. Indikator AI in Bildung aufeinen Blick 2001) ist maßgebend für die potenzielle Nachfrage nach schulischer und beruflicher Grundausbildung in diesem Land. Je mehr junge Menschen es gibt, desto größer ist die potenzielle Nachfrage nach Bildungsdienstleistungen. Bei OECD-Ländern mit einem vergleichbaren Volkseinkommen wird ein Land mit einem relativ großen Bevölkerungsanteil junger Menschen einen größeren Prozentsatz seines BIP für die Bildung ausgeben müssen, damit jeder junge Mensch in dem betreffenden Land die Chance hat, im gleichen Umfang an Bildung teilzunehmen wie junge Menschen in anderen OECD-Ländern. Ist dagegen der Bevölkerungsanteil junger Menschen verhältnismäßig klein, so wird das betreffende Land nur einen geringeren Anteil seines Volkseinkommen für Bildung einsetzen müssen, um ähnliche Bildungsergebnisse zu erzielen.

Obwohl die Länder im Allgemeinen nur wenig Einfluss darauf haben, wie hoch der Anteil junger Menschen an ihrer Bevölkerung ist, so ist doch der Anteil von Schülern/Studierenden, die in den verschiedenen Bildungsbereichen unterrichtet und ausgebildet werden, ein zentrales politisches Thema. Unter- 
Abbildung. B2.2

Veränderung der Gesamtausgaben für Bildungseinrichtungen aus öffentlichen und privaten Quellen und des BIP (1995, 2001)

Index der Veränderung zwischen 1995 und 2001 (1995 = 100, zu konstanten Preisen von 2001)

Veränderungen der Gesamtausgaben für Bildungseinrichtungen $\quad$ Veränderungen des BIP
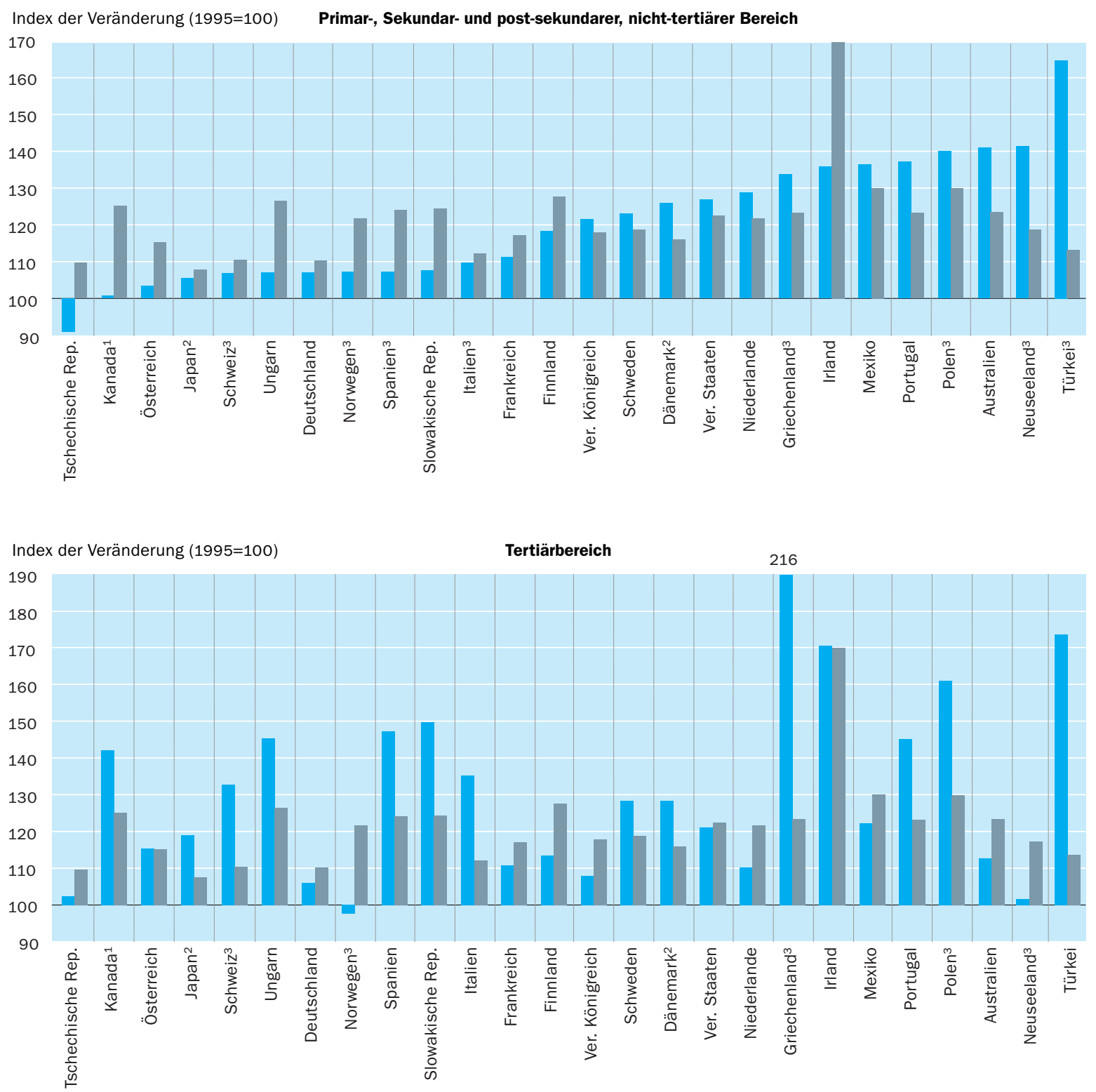

1. Tertiärbereich umfasst nur Tertiärbereich A und weiterführende Forschungsprogramme. 2. Post-sekundarer, nicht-tertiärer Bereich sowohl in Sekundarbereich II als auch in Tertiärbereich enthalten. 3. Nur öffentliche Ausgaben.

Anordnung der Ländern in aufsteigender Reihenfolge der Veränderungen der Ausgaben für Bildungseinrichtungen im Primar-, Sekundar- und post-sekundaren, nicht-tertiären Bereich zwischen 1995 und 2001.

Quelle: OECD. Tabelle B2.2 und Anhang 2. Hinweise s. Anhang 3 unter www.oecd.org/edu/eag2004. 
schiede in der Bildungsbeteiligung in den einzelnen OECD-Ländern sind Ausdruck unterschiedlicher Nachfrage nach Bildung - vom Elementar- bis zum Tertiärbereich - sowie unterschiedlicher Angebote an Bildungsgängen in allen Bildungsbereichen. Indikator CI zeigt, dass die zu erwartende Ausbildungsdauer eines 5-jährigen Kindes in den einzelnen OECD-Ländern zwischen $\mathrm{I}_{3}$ und 2I Jahren betragen kann. Noch größere Unterschiede ergeben sich für die zu erwartende Studiendauer im Tertiärbereich. Sie reicht von einem Jahr in Mexiko bis zu mehr als 4 Jahren in Finnland (Indikator C2).

\section{Definitionen und angewandte Methodik}

Die Daten beziehen sich auf das Haushaltsjahr 2001 und beruhen auf der von der OECD im Jahre 2003 durchgeführten UOE-Datenerhebung zur Bildungsstatistik (Einzelheiten s. Anhang 3).
Die Ausgaben für Bildungseinrichtungen, wie in diesem Indikator erfasst, umfassen sowohl Ausgaben für unterrichterteilende Bildungseinrichtungen als auch für solche, die keinen Unterricht erteilen. Unterrichterteilende Bildungseinrichtungen sind Bildungseinrichtungen, die einzelnen Personen in organisierter Form direkten Unterricht in der Gruppe oder per Fernunterricht erteilen. Nicht enthalten sind hierin Unternehmen oder sonstige Einrichtungen, die kurze Ausbildungs- oder Lehrkurse in Form von Einzelunterricht anbieten. Nichtunterrichterteilende Einrichtungen erbringen anderen Bildungseinrichtungen gegenüber administrative, beratende oder fachliche Dienstleistungen, nehmen jedoch selbst keine Schüler/Studierenden auf. Beispiele hierfür sind nationale, bundesstaatliche und regionale Bildungsministerien oder -abteilungen, sonstige auf den verschiedenen staatlichen Ebenen für Bildungsfragen zuständige Organe oder entsprechende private Einrichtungen, sowie Organisationen, die derartige bildungsbezogenen Dienstleistungen wie Berufs- oder psychologische Beratung, Vermittlung von Stellen und Praktika, Durchführung von Tests, Finanzhilfe für Schüler/Studierende, Lehrplanentwicklung, Bildungsforschung, Betrieb und Instandhaltung von Gebäuden, Transport von Schülern/Studierenden, sowie Unterkunft und Verpflegung für Schüler/Studierende anbieten.

Diese breit angelegte Definition der Einrichtungen gewährleistet, dass Ausgaben für Dienstleistungen, die in einigen OECD-Ländern von Schulen und Hochschulen, in anderen Ländern aber von nicht-schulischen Stellen erbracht werden, auf vergleichbarer Basis erfasst werden können.

Die Unterscheidung nach der Herkunft der Mittel bezieht sich auf die ursprüngliche Finanzierungsquelle. Anschließende Transferzahlungen vom öffentlichen an den privaten Sektor oder umgekehrt sind dabei nicht berücksichtigt. Aus diesem Grund fallen Unterstützungsleistungen an private Haushalte und andere Empfänger, wie z. B. Unterstützungszahlungen für Studiengebühren und andere Zahlungen an Bildungseinrichtungen, bei diesem Indikator unter die Kategorie öffentliche Ausgaben. Zahlungen der privaten Haushalte und anderer privater Stellen an Bildungseinrichtungen beinhalten Studien- und sonstige Gebühren, abzüglich der öffentlichen Subventionen. Eine detaillierte Darstellung der öffentlichen Subventionen findet sich in Indikator B5. 
Aus den Tabellen B2.Ia, B2.Ib und B2.2 sind die Ausgaben für Bildungseinrichtungen im Haushaltsjahr 1995 zu ersehen. Die Daten für die Ausgaben des Jahres 1995 wurden im Rahmen einer speziellen Erhebung im Jahre 200I ermittelt und 2003 aktualisiert; die Ausgaben für 1995 wurden entsprechend den Definitionen und den Methoden der 2003 durchgeführten UOE-Datenerhebung angepasst.

Abbildung B2.2 und Tabelle B2.2 enthalten einen Index der Veränderung der Ausgaben für Bildungseinrichtungen und des BIP zwischen den Jahren 1995 und 200I. Alle Ausgaben ebenso wie die Angaben für das BIP von I995 wurden mittels des BIP-Deflators an das Preisniveau von 200r angepasst.

Im Interesse der zeitlichen Vergleichbarkeit bezieht sich das Ländermittel nur auf diejenigen OECD-Länder, für die Zahlen für alle erfassten Referenzjahre vorlagen.

Es ist zu beachten, dass die in früheren Ausgaben dieser Veröffentlichung aufgeführten Zahlen und Daten möglicherweise nicht immer mit denen der Ausgabe 2004 vergleichbar sind, da sich Änderungen in den Definitionen und Erhebungsbereichen ergeben haben. Diese wurden aufgrund der OECD Expenditure Comparability Study vorgenommen (Einzelheiten zu den Änderungen s. Anhang 3 unter www.oecd.org/eduleag2004).
Die Daten für das Haushaltsjahr 1995 beruhen auf einer speziellen Erhebung in den OECD-Ländern aus dem Jahre 2001, die 2003 aktualisiert wurde.

Die Daten für 1995 sind in Preisen von 2001 dargestellt. 


\section{Tabelle B2.1a}

Ausgaben für Bildungseinrichtungen als Prozentsatz des BIP, für alle Bildungsbereiche $(1990,1995,2001)$ Aus öffentlichen und privaten Quellen, nach Herkunft der Mittel und Jahr

\begin{tabular}{|c|c|c|c|c|c|c|c|c|c|}
\hline \multirow[b]{2}{*}{ OECD-Länder } & \multicolumn{3}{|c|}{2001} & \multicolumn{3}{|c|}{1995} & \multicolumn{3}{|c|}{1990} \\
\hline & Öffentlich ${ }^{1}$ & Privat $^{2}$ & Gesamt & Öffentlich 1 & Privat $^{2}$ & Gesamt & Öffentlich ${ }^{1}$ & Privat $^{2}$ & Gesamt \\
\hline Australien & 4,5 & 1,4 & 6,0 & 4,5 & 1,2 & 5,7 & 4,2 & 0,8 & 5,0 \\
\hline Österreich & 5,6 & 0,2 & 5,8 & 5,9 & 0,3 & 6,2 & $\mathrm{~m}$ & $\mathrm{~m}$ & $\mathrm{~m}$ \\
\hline Belgien & 6,0 & 0,4 & 6,4 & $\mathrm{~m}$ & $\mathrm{~m}$ & $\mathrm{~m}$ & $\mathrm{~m}$ & $\mathrm{~m}$ & $\mathrm{~m}$ \\
\hline Kanada & 4,9 & 1,3 & 6,1 & 6,2 & 0,8 & 7,0 & $\mathrm{~m}$ & $\mathrm{~m}$ & $\mathrm{~m}$ \\
\hline Tschechische Republik & 4,2 & 0,4 & 4,6 & 4,7 & 0,7 & 5,4 & $\mathrm{~m}$ & $\mathrm{~m}$ & $\mathrm{~m}$ \\
\hline Dänemark ${ }^{3}$ & 6,8 & 0,3 & 7,1 & 6,1 & 0,2 & 6,3 & $\mathrm{~m}$ & $\mathrm{~m}$ & $\mathrm{~m}$ \\
\hline Finnland & 5,7 & 0,1 & 5,8 & 6,2 & $\mathrm{x}$ & 6,3 & $\mathrm{~m}$ & $\mathrm{~m}$ & $\mathrm{~m}$ \\
\hline Frankreich & 5,6 & 0,4 & 6,0 & 5,9 & 0,4 & 6,3 & 5,1 & 0,5 & 5,7 \\
\hline Deutschland & 4,3 & 1,0 & 5,3 & 4,5 & 1,0 & 5,5 & $\mathrm{~m}$ & $\mathrm{~m}$ & $\mathrm{~m}$ \\
\hline Griechenland $^{3}$ & 3,8 & 0,2 & 4,1 & 3,1 & $n$ & 3,2 & $\mathrm{~m}$ & $\mathrm{~m}$ & $\mathrm{~m}$ \\
\hline Ungarn & 4,6 & 0,6 & 5,2 & 4,9 & 0,6 & 5,5 & $\mathrm{~m}$ & $\mathrm{~m}$ & $\mathrm{~m}$ \\
\hline Island ${ }^{3}$ & 6,1 & 0,6 & 6,7 & $\mathrm{~m}$ & $\mathrm{~m}$ & $\mathrm{~m}$ & $\mathrm{~m}$ & $\mathrm{~m}$ & $\mathrm{~m}$ \\
\hline Irland & 4,1 & 0,3 & 4,5 & 4,7 & 0,5 & 5,3 & $\mathrm{~m}$ & $\mathrm{~m}$ & $\mathrm{~m}$ \\
\hline Italien & 4,9 & 0,4 & 5,3 & 4,7 & $\mathrm{~m}$ & $\mathrm{~m}$ & $\mathrm{~m}$ & $\mathrm{~m}$ & $\mathrm{~m}$ \\
\hline Japan & 3,5 & 1,2 & 4,6 & 3,5 & 1,1 & 4,6 & $\mathrm{~m}$ & $\mathrm{~m}$ & $\mathrm{~m}$ \\
\hline Korea & 4,8 & 3,4 & 8,2 & $\mathrm{~m}$ & $\mathrm{~m}$ & $\mathrm{~m}$ & $\mathrm{~m}$ & $\mathrm{~m}$ & $\mathrm{~m}$ \\
\hline Luxemburg $^{3}$ & 3,6 & $\mathrm{n}$ & 3,6 & $\mathrm{~m}$ & $\mathrm{~m}$ & $\mathrm{~m}$ & $\mathrm{~m}$ & $\mathrm{~m}$ & $\mathrm{~m}$ \\
\hline Mexiko & 5,1 & 0,8 & 5,9 & 4,6 & 1,0 & 5,6 & $\mathrm{~m}$ & $\mathrm{~m}$ & $\mathrm{~m}$ \\
\hline Niederlande & 4,5 & 0,4 & 4,9 & 4,5 & 0,4 & 4,9 & $\mathrm{~m}$ & $\mathrm{~m}$ & $\mathrm{~m}$ \\
\hline Neuseeland & 5,5 & $\mathrm{~m}$ & $\mathrm{~m}$ & 4,8 & $\mathrm{~m}$ & $\mathrm{~m}$ & $\mathrm{~m}$ & $\mathrm{~m}$ & $\mathrm{~m}$ \\
\hline Norwegen & 6,1 & 0,2 & 6,4 & 6,8 & 0,4 & 7,1 & 8,1 & $\mathrm{~m}$ & $\mathrm{~m}$ \\
\hline Polen ${ }^{3}$ & 5,6 & $\mathrm{~m}$ & $\mathrm{~m}$ & 5,7 & $\mathrm{~m}$ & $\mathrm{~m}$ & $\mathrm{~m}$ & $\mathrm{~m}$ & $\mathrm{~m}$ \\
\hline Portugal $^{3}$ & 5,8 & 0,1 & 5,9 & 5,3 & $\mathrm{n}$ & 5,3 & $\mathrm{~m}$ & $\mathrm{~m}$ & $\mathrm{~m}$ \\
\hline Slowakische Republik ${ }^{3,4}$ & 4,0 & 0,1 & 4,1 & 4,6 & 0,1 & 4,7 & 4,8 & 0,3 & 5,1 \\
\hline Spanien & 4,3 & 0,6 & 4,9 & 4,5 & 0,9 & 5,4 & 4,4 & 0,7 & 5,1 \\
\hline Schweden & 6,3 & 0,2 & 6,5 & 6,1 & 0,1 & 6,2 & 5,1 & $n$ & 5,1 \\
\hline Schweiz & 5,4 & $\mathrm{~m}$ & $\mathrm{~m}$ & 5,4 & $\mathrm{~m}$ & $\mathrm{~m}$ & $\mathrm{~m}$ & $\mathrm{~m}$ & $\mathrm{~m}$ \\
\hline Türkei ${ }^{3}$ & 3,5 & $n$ & 3,5 & 2,3 & $n$ & 2,3 & 2,8 & $\mathrm{~m}$ & 2,8 \\
\hline Vereinigtes Königreich & 4,7 & 0,8 & 5,5 & 4,8 & 0,7 & 5,5 & 4,2 & 0,1 & 4,3 \\
\hline Vereinigte Staaten & 5,1 & 2,3 & 7,3 & 5,0 & 2,2 & 7,2 & 4,9 & 2,2 & 7,1 \\
\hline Ländermittel & 5,0 & 0,7 & 5,6 & $\sim$ & $\sim$ & $\sim$ & $\sim$ & $\sim$ & $\sim$ \\
\hline OECD insgesamt & 4,8 & 1,4 & 6,2 & $\sim$ & $\sim$ & $\sim$ & $\sim$ & $\sim$ & $\sim$ \\
\hline $\begin{array}{l}\text { Ländermittel für Länder mit Daten für } \\
1990,1995 \text { und } 2001 \text { ( } 9 \text { Länder) }\end{array}$ & 4,9 & 0,7 & 5,6 & 4,9 & 0,7 & 5,6 & 4,9 & 0,7 & 5,5 \\
\hline
\end{tabular}

\begin{tabular}{|c|c|c|c|c|c|c|c|c|c|}
\hline \multicolumn{10}{|l|}{ OECD-Partnerländer } \\
\hline Argentinien ${ }^{3}$ & 4,8 & 1,4 & 6,2 & $\mathrm{~m}$ & $\mathrm{~m}$ & $\mathrm{~m}$ & $\mathrm{~m}$ & $\mathrm{~m}$ & $\mathrm{~m}$ \\
\hline Brasilien $^{3,5}$ & 4,1 & $\mathrm{~m}$ & $\mathrm{~m}$ & $\mathrm{~m}$ & $\mathrm{~m}$ & $\mathrm{~m}$ & $\mathrm{~m}$ & $\mathrm{~m}$ & $\mathrm{~m}$ \\
\hline Indien 5 & 4,0 & 0,2 & 4,2 & $\mathrm{~m}$ & $\mathrm{~m}$ & $\mathrm{~m}$ & $\mathrm{~m}$ & $\mathrm{~m}$ & $\mathrm{~m}$ \\
\hline Indonesien 3,4 & 1,3 & 0,7 & 2,0 & $\mathrm{~m}$ & $\mathrm{~m}$ & $\mathrm{~m}$ & $\mathrm{~m}$ & $\mathrm{~m}$ & $\mathrm{~m}$ \\
\hline Israel & 7,1 & 1,5 & 8,6 & 8,5 & 1,9 & 10,3 & $\mathrm{~m}$ & $\mathrm{~m}$ & $\mathrm{~m}$ \\
\hline Jordanien & 4,3 & $\mathrm{~m}$ & $\mathrm{~m}$ & $\mathrm{~m}$ & $\mathrm{~m}$ & $\mathrm{~m}$ & $\mathrm{~m}$ & $\mathrm{~m}$ & $\mathrm{~m}$ \\
\hline Malaysia $^{3}$ & 7,2 & $\mathrm{~m}$ & $\mathrm{~m}$ & $\mathrm{~m}$ & $\mathrm{~m}$ & $\mathrm{~m}$ & $\mathrm{~m}$ & $\mathrm{~m}$ & $\mathrm{~m}$ \\
\hline Paraguay & 4,5 & 2,1 & 6,6 & $\mathrm{~m}$ & $\mathrm{~m}$ & $\mathrm{~m}$ & $\mathrm{~m}$ & $\mathrm{~m}$ & $\mathrm{~m}$ \\
\hline Peru $^{3}$ & 2,9 & 1,3 & 4,2 & $\mathrm{~m}$ & $\mathrm{~m}$ & $\mathrm{~m}$ & $\mathrm{~m}$ & $\mathrm{~m}$ & $\mathrm{~m}$ \\
\hline Philippinen & 3,2 & 2,2 & 5,4 & $\mathrm{~m}$ & $\mathrm{~m}$ & $\mathrm{~m}$ & $\mathrm{~m}$ & $\mathrm{~m}$ & $\mathrm{~m}$ \\
\hline Russische Föderation & 3,0 & $\mathrm{~m}$ & $\mathrm{~m}$ & $\mathrm{~m}$ & $\mathrm{~m}$ & $\mathrm{~m}$ & $\mathrm{~m}$ & $\mathrm{~m}$ & $\mathrm{~m}$ \\
\hline Thailand $^{3}$ & 4,5 & 0,2 & 4,8 & $\mathrm{~m}$ & $\mathrm{~m}$ & $\mathrm{~m}$ & $\mathrm{~m}$ & $\mathrm{~m}$ & $\mathrm{~m}$ \\
\hline Uruguay 3,4 & 3,2 & 0,2 & 3,4 & $\mathrm{~m}$ & $\mathrm{~m}$ & $\mathrm{~m}$ & $\mathrm{~m}$ & $\mathrm{~m}$ & $\mathrm{~m}$ \\
\hline Simbabwe 3,6 & 5,6 & $\mathrm{~m}$ & $\mathrm{~m}$ & $\mathrm{~m}$ & $\mathrm{~m}$ & $\mathrm{~m}$ & $\mathrm{~m}$ & $\mathrm{~m}$ & $\mathrm{~m}$ \\
\hline
\end{tabular}

1. Einschließlich öffentlicher Subventionen an private Haushalte, die Bildungseinrichtungen zuzurechnen sind. Einschließlich direkter Ausgaben für Bildungseinrichtungen aus internationalen Quellen. 2. Abzüglich öffentlicher Subventionen, die Bildungseinrichtungen zuzurechnen sind. 3. Öffentliche Subventionen an private Haushalte nicht in öffentliche Ausgaben, sondern in private Ausgaben enthalten. 4. Direkte Ausgabe für Bildungseinrichtungen aus internationalen Quellen belaufen sich auf mehr als 1,5 Prozent der gesamten öffentlichen Ausgaben. 5. Referenzjahr 2000. 6. Referenzjahr 2002.

Quelle: OECD. Hinweise s. Anhang 3 unter www.oecd.org/edu/eag2004. 
Tabelle B2.1b

Ausgaben für Bildungseinrichtungen als Prozentsatz des BIP, nach Bildungsbereich $(1995,2001)$ Aus öffentlichen und privaten Quellen, nach Herkunft der Mittel und Jahr

\begin{tabular}{|c|c|c|c|c|c|c|c|c|}
\hline \multirow{3}{*}{ OECD-Länder } & \multicolumn{4}{|c|}{ Primar-, Sekundar- und post-sekundarer, nicht-tertiärer Bereich } & \multicolumn{4}{|c|}{ Tertiärbereich } \\
\hline & \multicolumn{3}{|c|}{2001} & \multirow{2}{*}{$\begin{array}{c}1995 \\
\text { Gesamt }\end{array}$} & \multicolumn{3}{|c|}{2001} & \multirow{2}{*}{$\begin{array}{c}1995 \\
\text { Gesamt }\end{array}$} \\
\hline & Öffentlich ${ }^{1}$ & Privat $^{2}$ & Gesamt & & Öffentlich ${ }^{1}$ & Privat $^{2}$ & Gesamt & \\
\hline Australien & 3,6 & 0,7 & 4,3 & 3,9 & 0,8 & 0,7 & 1,5 & 1,7 \\
\hline Österreich & 3,8 & 0,1 & 3,9 & 4,3 & 1,2 & $\mathrm{n}$ & 1,2 & 1,2 \\
\hline Belgien $^{3}$ & 4,0 & 0,2 & 4,2 & $\mathrm{~m}$ & 1,2 & 0,2 & 1,4 & $\mathrm{~m}$ \\
\hline Kanada $^{4}$ & 3,1 & 0,3 & 3,4 & 4,3 & 1,5 & 1,0 & 2,5 & 2,3 \\
\hline Tschechische Republik ${ }^{3}$ & 2,8 & 0,2 & 3,1 & 3,7 & 0,8 & 0,1 & 0,9 & 1,0 \\
\hline Dänemark ${ }^{5,6}$ & 4,2 & 0,1 & 4,3 & 4,0 & 1,8 & $\mathrm{n}$ & 1,8 & 1,6 \\
\hline Finnland & 3,7 & $\mathrm{n}$ & 3,7 & 4,0 & 1,7 & $\mathrm{n}$ & 1,7 & 1,9 \\
\hline Frankreich & 4,0 & 0,2 & 4,2 & 4,4 & 1,0 & 0,1 & 1,1 & 1,1 \\
\hline Deutschland & 2,9 & 0,7 & 3,6 & 3,7 & 1,0 & 0,1 & 1,0 & 1,1 \\
\hline Griechenland $^{5}$ & 2,4 & 0,2 & 2,7 & 2,3 & 1,1 & $\mathrm{n}$ & 1,1 & 0,8 \\
\hline Ungarn & 2,8 & 0,2 & 3,1 & 3,6 & 0,9 & 0,3 & 1,2 & 1,0 \\
\hline Island 5 & 5,0 & 0,2 & 5,2 & $\mathrm{~m}$ & 0,9 & $\mathrm{n}$ & 0,9 & $\mathrm{~m}$ \\
\hline Italien & 3,6 & 0,1 & 3,7 & $\mathrm{~m}$ & 0,8 & 0,2 & 0,9 & 0,8 \\
\hline $\operatorname{Japan}^{6}$ & 2,7 & 0,2 & 2,9 & 3,0 & 0,5 & 0,6 & 1,1 & 1,0 \\
\hline Korea & 3,5 & 1,0 & 4,6 & $\mathrm{~m}$ & 0,3 & 2,3 & 2,6 & $\mathrm{~m}$ \\
\hline Luxemburg ${ }^{5}$ & 3,6 & $\mathrm{n}$ & 3,6 & $\mathrm{~m}$ & $\mathrm{~m}$ & a & $\mathrm{m}$ & $\mathrm{m}$ \\
\hline Mexiko & 3,8 & 0,4 & 4,2 & 4,0 & 0,7 & 0,3 & 1,0 & 1,1 \\
\hline Niederlande & 3,1 & 0,1 & 3,3 & 3,1 & 1,0 & 0,3 & 1,3 & 1,4 \\
\hline Neuseeland & 4,3 & $\mathrm{~m}$ & $\mathrm{~m}$ & 3,6 & 0,9 & $\mathrm{~m}$ & $\mathrm{~m}$ & 1,1 \\
\hline Norwegen & 4,6 & $\mathrm{n}$ & 4,6 & 4,3 & 1,3 & $\mathrm{n}$ & 1,3 & 1,7 \\
\hline Polen 5 & 4,0 & $\mathrm{~m}$ & $\mathrm{~m}$ & 3,9 & 1,1 & $\mathrm{~m}$ & $\mathrm{~m}$ & 0,9 \\
\hline Portugal ${ }^{5}$ & 4,2 & $\mathrm{n}$ & 4,2 & 3,8 & 1,0 & 0,1 & 1,1 & 0,9 \\
\hline Slowakische Republik 3,5 & 2,6 & $\mathrm{n}$ & 2,7 & 3,1 & 0,8 & 0,1 & 0,9 & 0,8 \\
\hline Spanien & 3,0 & 0,2 & 3,2 & 3,9 & 1,0 & 0,3 & 1,2 & 1,0 \\
\hline Schweden ${ }^{3}$ & 4,3 & $\mathrm{n}$ & 4,3 & 4,2 & 1,5 & 0,2 & 1,7 & 1,6 \\
\hline Schweiz & 3,9 & 0,6 & 4,5 & $\mathrm{~m}$ & 1,3 & $\mathrm{~m}$ & $\mathrm{~m}$ & $\mathrm{~m}$ \\
\hline Türkei ${ }^{5}$ & 2,5 & $\mathrm{~m}$ & $\mathrm{~m}$ & 1,7 & 1,0 & $\mathrm{n}$ & 1,1 & 0,7 \\
\hline Ländermittel & 3,5 & 0,3 & 3,8 & $\sim$ & 1,0 & 0,3 & 1,4 & $\sim$ \\
\hline OECD insgesamt & 3,5 & 0,3 & 3,8 & $\sim$ & 0,9 & 0,9 & 1,8 & $\sim$ \\
\hline $\begin{array}{l}\text { Ländermittel für Länder mit } \\
\text { Daten für } 1995 \text { und } 2001\end{array}$ & $\sim$ & $\sim$ & 3,6 & 3,7 & $\sim$ & $\sim$ & 1,3 & 1,3 \\
\hline \multicolumn{9}{|l|}{ OECD-Partnerländer } \\
\hline Argentinien 5 & 3,6 & 0,5 & 4,0 & $\mathrm{~m}$ & 0,8 & 0,4 & 1,2 & $\mathrm{~m}$ \\
\hline Brasilien $^{5,7}$ & 2,9 & $\mathrm{~m}$ & $\mathrm{~m}$ & $\mathrm{~m}$ & 0,8 & $\mathrm{~m}$ & $\mathrm{~m}$ & $\mathrm{~m}$ \\
\hline Chile $^{8}$ & 3,4 & 1,4 & 4,8 & $\mathrm{~m}$ & 0,5 & 1,7 & 2,2 & $\mathrm{~m}$ \\
\hline Indien ${ }^{6}$ & 3,2 & 0,2 & 3,4 & $\mathrm{~m}$ & 0,8 & $\mathrm{n}$ & 0,8 & $\mathrm{~m}$ \\
\hline Indonesien 3,5 & 1,0 & 0,3 & 1,3 & $\mathrm{~m}$ & 0,3 & 0,4 & 0,7 & $\mathrm{~m}$ \\
\hline Israel & 4,7 & 0,2 & 4,9 & 5,0 & 1,2 & 0,7 & 2,0 & 2,3 \\
\hline Jamaika & 4,8 & 3,3 & 8,1 & $\mathrm{~m}$ & 1,1 & 1,3 & 2,4 & $\mathrm{~m}$ \\
\hline Jordanien $^{3}$ & 4,3 & $\mathrm{~m}$ & $\mathrm{~m}$ & $\mathrm{~m}$ & $n$ & $\mathrm{~m}$ & $\mathrm{~m}$ & $\mathrm{~m}$ \\
\hline Malaysia $^{5}$ & 4,9 & $\mathrm{~m}$ & $\mathrm{~m}$ & $\mathrm{~m}$ & 2,1 & $\mathrm{~m}$ & $\mathrm{~m}$ & $\mathrm{~m}$ \\
\hline Paraguay & 3,7 & 1,5 & 5,2 & $\mathrm{~m}$ & 0,8 & 0,5 & 1,3 & $\mathrm{~m}$ \\
\hline Philippinen & 2,7 & 1,3 & 4,0 & $\mathrm{~m}$ & 0,4 & 0,9 & 1,3 & $\mathrm{~m}$ \\
\hline Russische Föderation & 1,7 & $\mathrm{~m}$ & $\mathrm{~m}$ & $\mathrm{~m}$ & 0,5 & $\mathrm{~m}$ & $\mathrm{~m}$ & $\mathrm{~m}$ \\
\hline Thailand $^{5}$ & 2,5 & $\mathrm{~m}$ & $\mathrm{~m}$ & $\mathrm{~m}$ & 0,8 & 0,2 & 0,9 & $\mathrm{~m}$ \\
\hline Tunesien $^{5}$ & 5,3 & a & 5,3 & $\mathrm{~m}$ & 1,5 & a & 1,5 & $\mathrm{~m}$ \\
\hline Uruguay 3,5 & 2,2 & 0,2 & 2,4 & $\mathrm{~m}$ & 0,7 & $\mathrm{n}$ & 0,7 & $\mathrm{~m}$ \\
\hline Simbabwe 6,8 & 5,6 & $\mathrm{~m}$ & $\mathrm{~m}$ & $\mathrm{~m}$ & $\mathrm{~m}$ & $\mathrm{~m}$ & $\mathrm{~m}$ & $\mathrm{~m}$ \\
\hline
\end{tabular}

1. Einschließlich öffentlicher Subventionen an private Haushalte, die Bildungseinrichtungen zuzurechnen sind. Einschließlich direkter Ausgaben für Bildungseinrichtungen aus internationalen Quellen. 2. Abzüglich öffentlicher Subventionen, die Bildungseinrichtungen zuzurechnen sind. 3. Direkte Ausgaben für Bildungseinrichtungen im Tertiärbereich aus internationalen Quellen belaufen sich auf mehr als 1,5 Prozent der gesamten öffentlichen Ausgaben. Die Mittel aus internationalen Quellen im Primar- und Sekundarbereich in Uruguay belaufen sich auf mehr als 1,5 Prozent. 4. Post-sekundarer, nicht-tertiärer Bereich in Tertiärbereich enthalten.

5. Öffentliche Subventionen an private Haushalte nicht in öffentliche Ausgaben, sondern in private Ausgaben enthalten. 6. Post-sekundarer, nicht-tertiärer Bereich sowohl in Sekundarbereich II als auch Tertiärbereich enthalten. 7. Referenzjahr 2000. 8. Referenzjahr 2002.

Quelle: OECD. Hinweise s. Anhang 3 unter www.oecd.org/edu/eag2004. 
Tabelle B2.1c

Ausgaben für Bildungseinrichtungen als Prozentsatz des BIP, nach Bildungsbereich (2001) Aus öffentlichen und privaten Quellen ${ }^{1}$

\begin{tabular}{|c|c|c|c|c|c|c|c|c|c|}
\hline \multirow{3}{*}{ OECD-Länder } & \multirow{2}{*}{$\begin{array}{l}\text { Elementar- } \\
\text { bereich } \\
\text { (für 3-Jährige } \\
\text { und Ältere) }\end{array}$} & \multicolumn{4}{|c|}{ Primar-, Sekundar- und post-sekundarer, nicht-tertiärer Bereich } & \multicolumn{3}{|c|}{ Tertiärbereich } & \multirow[b]{2}{*}{\begin{tabular}{|c} 
Alle Bildungs- \\
bereiche zusam- \\
men (einschl. \\
weiterführenden \\
Forschungspro- \\
grammen und \\
nicht zugeord- \\
neter Ausgaben)
\end{tabular}} \\
\hline & & $\begin{array}{l}\text { Primar-, Sekun- } \\
\text { dar-und post- } \\
\text { sekundarer, } \\
\text { nicht-tertiarer } \\
\text { Bildungsbereich } \\
\text { insgesamt }\end{array}$ & $\begin{array}{l}\text { Primar- und } \\
\text { Sekundar- } \\
\text { bereich I }\end{array}$ & $\begin{array}{l}\text { Sekundar- } \\
\text { bereich II }\end{array}$ & $\begin{array}{c}\text { Post- } \\
\text { sekundarer, } \\
\text { nicht-tertiärer } \\
\text { Bereich }\end{array}$ & $\begin{array}{c}\text { Tertiärbereich } \\
\text { insgesamt }\end{array}$ & $\begin{array}{l}\text { Tertiär- } \\
\text { bereich B }\end{array}$ & $\begin{array}{l}\text { Tertiär- } \\
\text { bereich A }\end{array}$ & \\
\hline & (1) & (2) & (3) & (4) & (5) & (6) & (7) & (8) & (9) \\
\hline Australien & 0,1 & 4,3 & 3,3 & 0,9 & 0,1 & 1,5 & 0,2 & 1,4 & 6,0 \\
\hline Österreich & 0,5 & 3,9 & 2,6 & 1,3 & 0,1 & 1,2 & 0,1 & 1,1 & 5,8 \\
\hline Belgien $^{2}$ & 0,6 & 4,2 & 1,5 & 2,8 & $x(4)$ & 1,4 & $x(6)$ & $x(6)$ & 6,4 \\
\hline Kanada & 0,2 & 3,4 & $x(2)$ & $x(2)$ & $x(7)$ & 2,5 & 1,1 & 1,5 & 6,1 \\
\hline Tschechische Rep. & 0,5 & 3,1 & 1,9 & 1,2 & $\mathrm{n}$ & 0,9 & 0,1 & 0,8 & 4,6 \\
\hline Dänemark & 0,8 & 4,3 & 3,0 & 1,3 & $x(4,6)$ & 1,8 & $x(6)$ & $x(6)$ & 7,1 \\
\hline Finnland & 0,4 & 3,7 & 2,4 & 1,3 & $x(4)$ & 1,7 & $\mathrm{n}$ & 1,7 & 5,8 \\
\hline Frankreich & 0,7 & 4,2 & 2,7 & 1,5 & $\mathrm{n}$ & 1,1 & 0,2 & 0,8 & 6,0 \\
\hline Deutschland & 0,6 & 3,6 & 2,2 & 1,2 & 0,2 & 1,0 & 0,1 & 1,0 & 5,3 \\
\hline Griechenland ${ }^{2}$ & $x(2)$ & 2,7 & 1,1 & 1,5 & $\mathrm{n}$ & 1,1 & 0,2 & 0,9 & 4,1 \\
\hline Ungarn & 0,7 & 3,1 & 1,8 & 1,0 & 0,2 & 1,2 & $\mathrm{n}$ & 1,1 & 5,2 \\
\hline Island ${ }^{2}$ & $\mathrm{~m}$ & 5,2 & 3,5 & 1,5 & $\mathrm{~m}$ & 0,9 & $\mathrm{n}$ & 0,9 & 6,7 \\
\hline Irland & $\mathrm{n}$ & 3,1 & 2,3 & 0,7 & 0,1 & 1,3 & $x(6)$ & $x(6)$ & 4,5 \\
\hline Italien & 0,5 & 3,7 & 2,2 & 1,4 & $\mathrm{n}$ & 0,9 & $\mathrm{n}$ & 0,9 & 5,3 \\
\hline Japan & 0,2 & 2,9 & 2,0 & 0,9 & $x(4,6)$ & 1,1 & 0,1 & 1,0 & 4,6 \\
\hline Korea & 0,1 & 4,6 & 3,1 & 1,4 & a & 2,6 & 0,7 & 1,9 & 8,2 \\
\hline Luxemburg & $x(2)$ & 3,6 & 3,6 & $x(2)$ & $x(2)$ & $\mathrm{m}$ & $\mathrm{m}$ & $\mathrm{m}$ & 3,6 \\
\hline Mexiko & 0,5 & 4,2 & 3,2 & 1,0 & a & 1,0 & $x(6)$ & $x(6)$ & 5,9 \\
\hline Niederlande & 0,4 & 3,3 & 2,5 & 0,8 & $\mathrm{n}$ & 1,3 & $\mathrm{n}$ & 1,3 & 4,9 \\
\hline Neuseeland $^{3}$ & 0,2 & 4,3 & 3,0 & 1,2 & 0,1 & 0,9 & 0,2 & 0,7 & 5,5 \\
\hline Norwegen & $x(2)$ & 4,6 & 3,4 & 1,2 & $x(4)$ & 1,3 & $x(6)$ & $x(6)$ & 6,4 \\
\hline Polen $^{3}$ & 0,4 & 4,0 & 2,8 & 1,2 & $\mathrm{n}$ & 1,1 & $\mathrm{n}$ & 1,0 & 5,6 \\
\hline Portugal & 0,3 & 4,2 & 3,0 & 1,2 & $\mathrm{n}$ & 1,1 & $\mathrm{~m}$ & $\mathrm{~m}$ & 5,9 \\
\hline Slowakische Rep. & 0,5 & 2,7 & 1,6 & 1,1 & $x(4)$ & 0,9 & $x(4)$ & 0,9 & 4,1 \\
\hline Spanien $^{2}$ & 0,5 & 3,2 & 3,2 & $x(3)$ & $x(3)$ & 1,2 & 0,2 & 1,1 & 4,9 \\
\hline Schweden & 0,5 & 4,3 & 2,9 & 1,3 & $\mathrm{n}$ & 1,7 & $x(6)$ & $x(6)$ & 6,5 \\
\hline Schweiz & 0,2 & 4,5 & 2,7 & 1,8 & $\mathrm{n}$ & 1,2 & $\mathrm{n}$. & 1,2 & 5,3 \\
\hline Türkei & $\mathrm{m}$ & 2,5 & 1,8 & 0,7 & a & 1,1 & $x(6)$ & $x(6)$ & 3,5 \\
\hline Ver. Königreich² & 0,5 & 3,9 & 1,3 & 2,6 & $x(4)$ & 1,1 & $x(6)$ & $x(6)$ & 5,5 \\
\hline Vereinigte Staaten & 0,5 & 4,1 & 3,1 & 1,0 & $x(6)$ & 2,7 & $x(6)$ & $x(6)$ & 7,3 \\
\hline Ländermittel & 0,4 & 3,8 & 2,5 & 1,3 & 0,1 & 1,3 & 0,2 & 1,1 & 5,5 \\
\hline OECD insgesamt & 0,5 & 3,8 & 2,6 & 1,2 & 0,1 & 1,8 & $x(6)$ & $x(6)$ & 6,1 \\
\hline \multicolumn{10}{|l|}{ OECD-Partnerländer } \\
\hline Argentinien & 0,4 & 4,0 & 3,1 & 0,9 & a & 1,2 & 0,6 & 0,6 & 6,2 \\
\hline Brasilien 3,4 & 0,4 & 2,9 & 2,4 & $\mathrm{~m}$ & a & $\mathrm{m}$ & $\mathrm{m}$ & $\mathrm{m}$ & $\mathrm{m}$ \\
\hline Chile $^{5}$ & 0,5 & 4,8 & 3,4 & 1,4 & a & 2,2 & 0,2 & 2,0 & 7,5 \\
\hline Indien & $\mathrm{n}$ & 3,4 & 2,3 & 1,1 & $\mathrm{n}$ & 0,8 & $x(6)$ & $x(6)$ & 4,2 \\
\hline Indonesien & $\mathrm{n}$ & 1,3 & 0,9 & 0,4 & a & 0,7 & $x(6)$ & $x(6)$ & 2,0 \\
\hline Israel & 0,8 & 4,9 & 2,6 & 2,3 & $\mathrm{n}$ & 2,0 & $x(6)$ & $x(6)$ & 8,6 \\
\hline Jamaika & 0,7 & 8,1 & 6,0 & 1,3 & 0,8 & 2,4 & 0,6 & 1,8 & 11,3 \\
\hline Jordanien ${ }^{3}$ & $\mathrm{n}$ & 4,3 & 3,7 & 0,6 & $\mathrm{~m}$ & $\mathrm{~m}$ & $\mathrm{~m}$ & $\mathrm{~m}$ & $\mathrm{~m}$ \\
\hline Malaysia $^{2}$ & 0,1 & 4,9 & 2,2 & 2,6 & 0,1 & 2,1 & 0,4 & 1,7 & 7,2 \\
\hline Paraguay $^{2}$ & 0,1 & 5,2 & 3,1 & 2,1 & $\mathrm{~m}$ & 1,3 & 0,2 & 1,1 & $\mathrm{~m}$ \\
\hline Peru & 0,4 & 2,7 & 2,3 & 0,4 & $\mathrm{~m}$ & 1,1 & 0,2 & 0,9 & 4,2 \\
\hline Philippinen & $\mathrm{n}$ & 4,0 & 3,8 & 0,1 & 0,1 & 1,3 & $x(6)$ & $x(6)$ & 5,4 \\
\hline Russische Föd. & 0,5 & 1,7 & $\mathrm{~m}$ & $\mathrm{~m}$ & 0,2 & 0,5 & 0,1 & 0,4 & 3,0 \\
\hline Thailand & 0,5 & 2,6 & 2,0 & 0,5 & $\mathrm{~m}$ & 0,9 & 0,2 & 0,8 & $\mathrm{~m}$ \\
\hline Tunesien $^{3}$ & $\mathrm{~m}$ & 5,3 & $x(2)$ & $x(2)$ & a & $\mathrm{m}$ & 1,5 & $\mathrm{~m}$ & $\mathrm{~m}$ \\
\hline Uruguay & 0,4 & 2,4 & 1,8 & 0,5 & a & 0,7 & $x(6)$ & $x(6)$ & 3,4 \\
\hline Simbabwe 5 & $\mathrm{n}$ & 5,6 & $x(2)$ & $x(2)$ & a & $\mathrm{m}$ & $\mathrm{m}$ & $\mathrm{m}$ & $\mathrm{m}$ \\
\hline
\end{tabular}

Hinweis: $x$ bedeutet, dass die Daten in einer anderen Spalte enthalten sind, deren Referenz in runden Klammern nach dem ,x‘ angegeben ist. So bedeutet $z$. B. $x(2)$, dass die Daten in Spalte 2 enthalten sind.

1. Einschließlich Mitteln aus internationalen Quellen. 2. Spalte (3) bezieht sich nur auf den Primarbereich und Spalte (4) auf den gesamten Sekundarbereich.

3. Nur direkte öffentliche Ausgaben für Bildungseinrichtungen. 4. Referenzjahr 2000. 5. Referenzjahr 2002.

Quelle: OECD. Hinweise s. Anhang 3 unter www.oecd.org/edu/eag2004. 
Tabelle B2.2

Veränderungen der Ausgaben für Bildungseinrichtungen (1995, 2001)

Index der Veränderung der Ausgaben für Bildungseinrichtungen aus öffentlichen und privaten Mitteln zwischen 1995 und 2000 , nach Bildungsbereichen $(1995=100$, zu konstanten Preisen des Jahres 2001)

\begin{tabular}{|c|c|c|c|c|c|c|c|c|c|}
\hline & \multicolumn{3}{|c|}{ Alle Bildungsbereiche zusammen } & \multicolumn{3}{|c|}{$\begin{array}{l}\text { Primar-, Sekundar- und post-sekundarer, nicht- } \\
\text { tertiärer Bereich }\end{array}$} & \multicolumn{3}{|c|}{ Tertiärbereich } \\
\hline & $\begin{array}{l}\text { Öffentliche } \\
\text { Ausgaben für } \\
\text { Bildungs- } \\
\text { einrichtungen }\end{array}$ & $\begin{array}{l}\text { Private } \\
\text { Ausgaben für } \\
\text { Bildungs- } \\
\text { einrichtungen }\end{array}$ & \begin{tabular}{|} 
Gesamtaus- \\
gaben für Bil- \\
dungseinrich- \\
tungen aus öf- \\
fentlichen und \\
privaten Quellen
\end{tabular} & $\begin{array}{l}\text { Öffentliche } \\
\text { Ausgaben für } \\
\text { Bildungs- } \\
\text { einrichtungen }\end{array}$ & $\begin{array}{l}\text { Private } \\
\text { Ausgaben für } \\
\text { Bildungs- } \\
\text { einrichtungen }\end{array}$ & \begin{tabular}{|c|} 
Gesamtaus- \\
gaben für Bil- \\
dungseinrich- \\
tungen aus öf- \\
fentlichen und \\
privaten Quellen
\end{tabular} & $\begin{array}{l}\text { Öffentliche } \\
\text { Ausgaben für } \\
\text { Bildungs- } \\
\text { einrichtungen }\end{array}$ & $\begin{array}{l}\text { Private } \\
\text { Ausgaben für } \\
\text { Bildungs- } \\
\text { einrichtungen }\end{array}$ & $\begin{array}{l}\text { Gesamtaus- } \\
\text { gaben für Bil- } \\
\text { dungseinrich- } \\
\text { tungen aus öf- } \\
\text { fentlichen und } \\
\text { privaten Quellen }\end{array}$ \\
\hline OECD-Länder & (1) & (2) & (3) & (4) & (5) & (6) & (7) & (8) & (9) \\
\hline Australien & 127 & 153 & 132 & 139 & 152 & 141 & 89 & 156 & 113 \\
\hline Österreich & 108 & 90 & 107 & 103 & 99 & 103 & 114 & 160 & 115 \\
\hline Belgien & $\mathrm{m}$ & $\mathrm{m}$ & $\mathrm{m}$ & $\mathrm{m}$ & $\mathrm{m}$ & $\mathrm{m}$ & $\mathrm{m}$ & $\mathrm{m}$ & $\mathrm{m}$ \\
\hline Kanada $^{1}$ & 107 & 129 & 111 & 99 & 128 & 101 & 107 & 151 & 122 \\
\hline Tschechische Rep. & 97 & 62 & 93 & 92 & 79 & 91 & 127 & 34 & 103 \\
\hline Dänemark ${ }^{2}$ & 130 & 147 & 131 & 126 & 114 & 126 & 126 & 468 & 128 \\
\hline Finnland & 117 & $\mathrm{~m}$ & 118 & 118 & $\mathrm{~m}$ & 118 & 112 & $\mathrm{~m}$ & 113 \\
\hline Frankreich & 112 & 103 & 111 & 112 & 104 & 111 & 112 & 102 & 111 \\
\hline Deutschland & 106 & 106 & 106 & 108 & 104 & 107 & 104 & 129 & 106 \\
\hline Griechenland ${ }^{3}$ & 154 & $\mathrm{~m}$ & $\mathrm{~m}$ & 134 & $\mathrm{~m}$ & $\mathrm{~m}$ & 216 & $\mathrm{~m}$ & $\mathrm{~m}$ \\
\hline Ungarn & 119 & 119 & 119 & 109 & 88 & 107 & 140 & 165 & 145 \\
\hline Irland & 148 & 111 & 145 & 134 & 180 & 136 & 208 & 86 & 170 \\
\hline Italien & 113 & $\mathrm{~m}$ & $\mathrm{~m}$ & 110 & $\mathrm{~m}$ & $\mathrm{~m}$ & 126 & 175 & 135 \\
\hline $\operatorname{Japan}^{2}$ & 109 & 111 & 109 & 105 & 107 & 105 & 122 & 117 & 119 \\
\hline Mexiko & 140 & 121 & 137 & 142 & 107 & 136 & 111 & 160 & 122 \\
\hline Niederlande & 123 & 114 & 122 & 130 & 102 & 129 & 107 & 124 & 110 \\
\hline Neuseeland & 135 & $\mathrm{~m}$ & $\mathrm{~m}$ & 141 & $\mathrm{~m}$ & $\mathrm{~m}$ & 101 & $\mathrm{~m}$ & $\mathrm{~m}$ \\
\hline Norwegen 3,4 & 105 & $\mathrm{~m}$ & $\mathrm{~m}$ & 107 & $\mathrm{~m}$ & $\mathrm{~m}$ & 98 & $\mathrm{~m}$ & $\mathrm{~m}$ \\
\hline Polen & 132 & $\mathrm{~m}$ & $\mathrm{~m}$ & 140 & $\mathrm{~m}$ & $\mathrm{~m}$ & 161 & $\mathrm{~m}$ & $\mathrm{~m}$ \\
\hline Portugal & 135 & 314 & 136 & 137 & 178 & 137 & 139 & 320 & 145 \\
\hline Slowakische Rep. & 107 & 112 & 109 & 107 & 187 & 108 & 131 & 167 & 149 \\
\hline Spanien & 117 & $\mathrm{~m}$ & $\mathrm{~m}$ & 107 & $\mathrm{~m}$ & $\mathrm{~m}$ & 149 & 141 & 147 \\
\hline Schweden & 121 & 230 & 124 & 124 & 89 & 123 & $x(9)$ & $x(9)$ & 128 \\
\hline Schweiz & 112 & $\mathrm{~m}$ & $\mathrm{~m}$ & 107 & $\mathrm{~m}$ & $\mathrm{~m}$ & 133 & $\mathrm{~m}$ & $\mathrm{~m}$ \\
\hline Türkei & 167 & $\mathrm{~m}$ & $\mathrm{~m}$ & 166 & $\mathrm{~m}$ & $\mathrm{~m}$ & 170 & 237 & 174 \\
\hline Ver. Königreich & 115 & 143 & 119 & 120 & 136 & 121 & 96 & 156 & 108 \\
\hline Vereinigte Staaten & 125 & 125 & 125 & 126 & 134 & 127 & 121 & 121 & 121 \\
\hline
\end{tabular}

1. Tertiärbereich A umfasst nur Tertiärbereich A und weiterführende Forschungsprogramme. 2. Post-sekundarer, nicht-tertiärer Bereich sowohl in Sekundarbereich II als auch in Tertiärbereich enthalten. 3. Elementarbereich in Primar-, Sekundar- und post-sekundarer, nicht-tertiärer Bereich enthalten. 4. Der Rückgang der Ausgaben pro Schüler/Studierenden ist auf eine wesentliche Veränderung des BIP-Deflators zurückzuführen, der hauptsächlich durch den Anstieg der Ölpreise verursacht wurde. Quelle: OECD. Hinweise s. Anhang 3 unter www.oecd.org/edu/eag2004. 



\section{Relative Anteile öffentlicher und privater Ausgaben für Bildungseinrichtungen}

Bildungseinrichtungen werden immer noch überwiegend aus öffentlichen Mitteln finanziert: 88 Prozent aller Mittel für Bildungseinrichtungen stammen direkt aus öffentlichen Quellen. Die Finanzierung aus privaten Quellen spielt jedoch in Korea (wo sie über 43 Prozent der Gesamtausgaben ausmacht), den Vereinigten Staaten (beinahe ein Drittel der Gesamtausgaben) sowie in Australien und Japan (beinahe ein Viertel der Gesamtausgaben) eine bedeutende Rolle.

In einer Reihe von OECD-Ländern übernimmt der Staat den größten Teil der Kosten für den Primar-, Sekundar- und post-sekundaren, nicht-tertiären Bereich, überlässt jedoch die Leitung der Bildungseinrichtungen dem privaten Sektor, um so ein breiteres Lernangebot ohne Zugangsbeschränkungen für Schüler/Studierende aus einkommensschwachen Familien bereitzustellen.

Tendenziell beziehen tertiäre Einrichtungen einen weitaus größeren Teil ihrer Finanzierung aus privaten Quellen als Bildungseinrichtungen des Primar-, Sekundar- und post-sekundaren, nicht-tertiären Bereichs. Allerdings reicht der Anteil der privaten Finanzierung einschließlich staatlich-subventionierter privater Zahlungen von weniger als 4 Prozent in Dänemark, Finnland, Griechenland und Norwegen bis zu mehr als drei Vierteln in Korea.

In einem Drittel der Länder - Australien, Belgien, Kanada, Korea, den Niederlanden, Schweden, Ungarn, dem Vereinigten Königreich und den Vereinigten Staaten, beträgt der Anteil der Ausgaben für tertiäre Bildungseinrichtungen, der von anderen privaten Einheiten als den privaten Haushalten getragen wird, 10 Prozent und mehr.

Die Entwicklung der jeweiligen Anteile privater und öffentlicher Bildungsausgaben ist über alle Bildungsbereiche hinweg ganz unterschiedlich. Es gibt einige Länder mit einer Verschiebung hin zu öffentlichen Ausgaben, während es in anderen eine Verschiebung hin zu privaten Ausgaben gibt. In den meisten Fällen, in denen es eine Verschiebung zu den privaten Ausgaben hin gab, führte dies jedoch nicht zu einer Verringerung der realen öffentlichen Ausgaben. 


\section{Abbildung B3.1}

Verteilung der öffentlichen und privaten Ausgaben für Bildungseinrichtungen (2001) Nach Bildungsbereich

— Gesamte private Mittel einschließlich öffentliche Subventionen für die Lebenshaltungskosten von Schülern/Studierenden

Ausgaben anderer privater Einheiten

Ausgaben der privaten Haushalte

Öffentliche Ausgaben für Bildungseinrichtungen

$\% \quad$ Elementarbereich
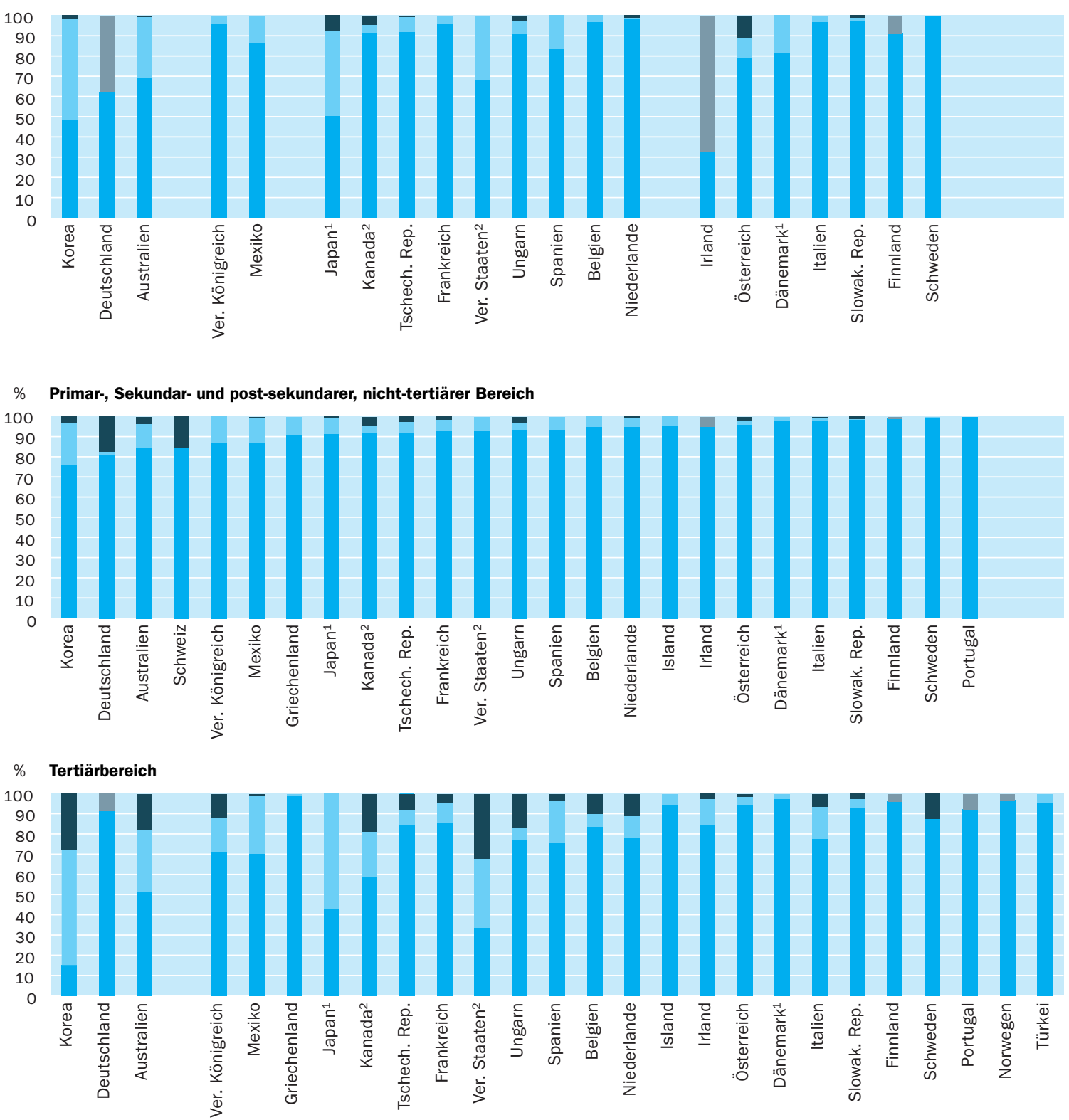

1. Post-sekundarer, nicht-tertiärer Bereich sowohl in Sekundarbereich II als auch Tertiärbereich enthalten. 2. Post-sekundarer, nicht-tertiärer Bereich in Tertiärbereich enthalten.

Anordnung der Ländern in aufsteigender Reihenfolge des Anteils der direkten öffentlichen Ausgaben für Bildungseinrichtungen im Primar-, Sekundar- und post-sekundaren, nichttertiären Bereich.

Quelle: OECD. Tabellen B3.2a und B3.2b. Hinweise s. Anhang 3 unter www.oecd.org/edu/eag2004. 


\section{Politischer Hintergrund}

In vielen OECD-Ländern ist die Beteiligung sowohl der Teilnehmer am Bildungssystem als auch der Gesellschaft als Ganzer an den Kosten des Bildungssystems Gegenstand intensiver Debatten. Die Frage nach der Aufteilung der Kosten stellt sich besonders zu Beginn und gegen Ende des Bildungsweges, d. h. im Elementar- und Tertiärbereich, wo eine vollständige oder fast vollständige Finanzierung durch öffentliche Mittel weniger üblich ist. Dieser Indikator zeigt jedoch nicht nur die jeweilige Politik der Kostenteilung in den einzelnen Ländern auf, sondern auch, welchen Einfluss die Finanzierung durch öffentliche Mittel als politischer Hebel auf den Output der Bildungssysteme insgesamt haben kann und auch hat.

Da neue Interessentengruppen zu einer zunehmenden Bildungsbeteiligung im Rahmen neuer Bildungsangebote führen und aufgrund einer steigenden Anzahl neuer Anbieter im Bildungsbereich gleichzeitig größere Wahlmöglichkeiten bestehen, gehen die Regierungen neue Partnerschaften zur Mobilisierung der notwendigen Ressourcen für die Finanzierung von Bildung ein. Neue bildungspolitische Ansätze sollen es den verschiedenen Akteuren und Beteiligten ermöglichen, die Bildungsangebote stärker in Anspruch zu nehmen und Kosten und Nutzen gerechter aufzuteilen.

Dementsprechend wird inzwischen die Finanzierung durch öffentliche Mittel in zunehmendem Maße als nur ein, wenn auch sehr wichtiger Teil, der Bildungsfinanzierung angesehen. Die Finanzierung von Bildung aus privaten Quellen hat an Bedeutung gewonnen. Einigen Beteiligten ist es ein Anliegen, dass sich das Gleichgewicht zwischen öffentlicher und privater Finanzierung nicht so stark verschiebt, dass potentielle Bildungsteilnehmer dadurch eher vom Lernen ferngehalten als ihm zugeführt werden. Somit können Veränderungen in den jeweiligen Anteilen der öffentlichen und privaten Finanzierung in einem Land wichtige Hintergrundinformationen für sich verändernde Beteiligungsmuster und einen sich verändernden Beteiligungsumfang innerhalb des jeweiligen Bildungssystems liefern.

\section{Ergebnisse und Erläuterungen}

Was dieser Indikator aufzeigt und was nicht.

Die öffentliche Hand kann ihre Mittel entweder direkt für Bildungseinrichtungen ausgeben oder sie zur Gewährung von Subventionen für Bildungszwecke an private Einheiten nutzen. Im Zusammenhang mit den öffentlichen und privaten Anteilen an den Bildungsausgaben ist daher zwischen der originären Herkunft der Mittel und den direkten Endverbrauchern von bildungsbezogenen Sach- und Dienstleistungen zu unterscheiden.

Zu den originär öffentlichen Ausgaben gehören sowohl die direkten öffentlichen Ausgaben für Bildungseinrichtungen als auch Transferzahlungen an den privaten Sektor. Um den Umfang der öffentlichen Ausgaben zu bestimmen, müssen daher die direkten öffentlichen Ausgaben für Bildungseinrichtungen und die öffentlichen Subventionen für Bildungszwecke addiert werden. Zu den
Dieser Indikator beschreibt die relativen Anteile öffentlicher und privater Ausgaben für Bildungseinrichtungen ...

... und deren Veränderung gegenüber 1995.

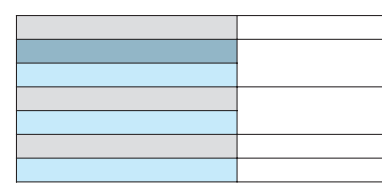

Erfasste Daten

(Erklärungen S. S. 208) 
Bildungseinrichtungen werden immer noch überwiegend aus öffentlichen Mitteln finanziert, ...
... jedoch gibt es hinsichtlich der Inanspruchnahme privater Mittel für Bildungszwecke erhebliche Unterschiede zwischen den einzelnen OECDLändern. originär privaten Mitteln gehören Schul-/Studiengebühren sowie sonstige Zahlungen der Schüler/Studierenden und der privaten Haushalte an Bildungseinrichtungen abzüglich des Anteils an diesen Zahlungen, der durch öffentliche Subventionen ausgeglichen wird.

Die Anteile der letztendlich öffentlichen und privaten Ausgaben sind die Prozentsätze der für Bildungszwecke verfügbaren Mittel, die einerseits direkt von öffentlichen und andererseits direkt von privaten Erwerbern von Bildungsdienstleistungen ausgegeben werden. Die letztendlich öffentlichen Ausgaben beinhalten die direkte öffentliche Beschaffung von Bildungsressourcen sowie Zahlungen an Bildungseinrichtungen und andere private Einheiten. Die letztendlich privaten Ausgaben beinhalten Schul-/Studiengebühren sowie andere private Zahlungen an Bildungseinrichtungen (unabhängig davon, ob sie durch öffentliche Subventionen ausgeglichen werden oder nicht).

Nicht alle Ausgaben für bildungsbezogene Sach- und Dienstleistungen fallen in Bildungseinrichtungen an. Beispielsweise erwerben Familien Schulbücher oder Unterrichtsmaterial im Handel oder lassen ihren Kindern Privatunterricht außerhalb von Bildungseinrichtungen zukommen. Im Tertiärbereich machen die Kosten für den Lebensunterhalt sowie für entgangene Einkommen einen beträchtlichen Teil der Bildungskosten aus. Diese außerhalb von Bildungseinrichtungen anfallenden Ausgaben bleiben bei diesem Indikator sämtlich außer Acht, auch wenn die entsprechenden Ausgaben öffentlich subventioniert werden. Öffentliche Subventionen für Bildungsausgaben außerhalb von Bildungseinrichtungen werden in den Indikatoren $\mathrm{B}_{4}$ und $\mathrm{B}_{5}$ behandelt.

\section{Der Anteil der öffentlichen und privaten Ausgaben für Bildungs- einrichtungen}

Schulen, Hochschulen und andere Bildungseinrichtungen werden immer noch überwiegend aus öffentlichen Mitteln finanziert, obwohl es einen erheblichen und zunehmenden Anteil privater Finanzierung gibt. Im Durchschnitt aller OECD-Länder stammen 88 Prozent aller Mittel für Bildungseinrichtungen direkt aus öffentlichen Quellen. Zusätzlich erreichen o,7 Prozent die Bildungseinrichtungen nicht direkt, sondern über die privaten Haushalte als öffentliche Unterstützungsleistungen (Tab. B3.I).

Bei den OECD-Ländern, für die Daten vorgelegt wurden, variiert der Anteil der privaten Mittel für Bildungseinrichtungen, einschließlich staatlich-subventionierter privater Mittel, sehr stark. In Dänemark, Finnland, Norwegen, Portugal, Schweden und der Slowakischen Republik beträgt er 5 Prozent oder weniger, in Australien und Japan fast 25 Prozent, in den Vereinigten Staaten fast ein Drittel und in Korea etwas mehr als 40 Prozent (Tab. B3.I).

Während in den meisten OECD-Ländern der Großteil der privaten Bildungsausgaben in Form von Studien- und sonstigen Gebühren von den privaten Haushalten an Einrichtungen im Tertiärbereich fließt, entfällt in Deutschland und der Schweiz fast der gesamte Anteil der privaten Ausgaben auf Beiträge der Wirtschaft zum dualen System der Berufsausbildung im Sekundarbereich II und dem post-sekundaren, nicht-tertiären Bereich. Ganz allgemein gesprochen ist die Erfassung privater Bildungsausgaben recht problematisch und es 
ist daher durchaus möglich, dass einige der angegebenen Zahlen unvollständig sind.

Investitionen in den Elementarbereich sind von essentieller Bedeutung, um ein solides Fundament für lebenslanges Lernen aufzubauen und um einen gerechten Zugang zum späteren Lernangebot in der Schule zu gewährleisten. Im Elementarbereich ist der private Anteil an den Gesamtausgaben für Bildungseinrichtungen in den einzelnen Ländern sehr unterschiedlich. Er reicht von 5 Prozent und weniger in Belgien, Frankreich, Italien, den Niederlanden, der Slowakischen Republik und dem Vereinigten Königreich über beträchtlich mehr als 30 Prozent in Australien und Deutschland, ungefähr 50 Prozent in Japan und Korea bis zu 67 Prozent in Irland (Tab. B).

In den OECD-Ländern dominiert im Primar-, Sekundar- und post-sekundaren, nicht tertiären Bildungsbereich eindeutig die öffentliche Finanzierung: im Durchschnitt liegt hier der Anteil der öffentlichen Mittel bei den OECD-Ländern bei 92 Prozent. Dennoch gibt es Länder, wo die private Finanzierung über I5 Prozent ausmacht, so in Australien, Deutschland, Korea und der Schweiz (Tab. B3.2a und Abb.B3.I).

Obwohl der überwiegende Teil der öffentlichen Mittel öffentlichen Einrichtungen zugute kommt, gibt es eine Reihe von OECD-Ländern, in denen die öffentlichen Mittel im Endeffekt an private Einrichtungen oder direkt an die privaten Haushalte gehen, damit diese die betreffenden Mittel an die Bildungseinrichtungen ihrer Wahl weiterleiten. Im erstgenannten Fall kann die Endfinanzierung und Bereitstellung von Bildungsangeboten als eine Art Auftragsvergabe durch die öffentliche Hand an nicht-öffentliche Einrichtungen betrachtet werden, während im letztgenannten Fall den Schülern und ihren Familien die Entscheidung überlassen wird, welche Art von Einrichtung ihren Bedürfnissen am besten gerecht wird.

Im Durchschnitt gehen in den OECD-Ländern ro Prozent der für Bildungseinrichtungen im Primar-, Sekundar- und post-sekundaren, nicht-tertiären Bereich vorgesehenen öffentlichen Mittel an private Bildungseinrichtungen (Tab. B3.3). In den Niederlanden, wo die Hauptquelle für Mittel letztendlich der staatliche Gesamthaushalt ist, werden 70 Prozent der öffentlichen Mittel für Einrichtungen des Primar-, Sekundar- und post-sekundaren, nicht-tertiären Bereichs den privaten Bildungseinrichtungen vom Staat in Form von Transferzahlungen zur Verfügung gestellt, in Belgien beläuft sich diese Zahl auf über 50 Prozent.

In Australien, Frankreich, Spanien und dem Vereinigten Königreich beträgt der Anteil der öffentlichen Transferzahlungen an private Einrichtungen im Primar-, Sekundar- und post-sekundaren, nicht-tertiären Bildungsbereich zwischen 13 und 20 Prozent.

Öffentliche Transferzahlungen an private Haushalte (und andere private Stellen) sind im Allgemeinen im Primar-, Sekundar- und post-sekundaren, nichttertiären Bereich zu vernachlässigen. Im Durchschnitt der OECD-Länder beträgt der Anteil der transferierten öffentlichen Mittel ungefähr 4 Prozent;
Im Elementarbereich beläuft sich der private Anteil an den Gesamtausgaben für Bildungseinrichtungen im Durchschnitt auf 19 Prozent; in Japan und Korea sind es 50 Prozent und in Irland 67 Prozent.

Im Primar-, Sekundar- und post-sekundaren, nichttertiären Bereich dominiert die öffentliche Finanzierung.

In einigen Ländern erhalten jedoch Einrichtungen im privaten Sektor umfangreiche öffentliche Mittel, ...

... um so eine größere Bandbreite an Lernmöglichkeiten zur Verfügung zu stellen, ohne Schülern aus einkommensschwachen Familien den Zugang zu Bildung zu erschweren. 
Tendenziell beziehen tertiäre Einrichtungen einen wesentlich höheren Anteil ihrer Finanzmittel aus privaten Quellen, ...

... allerdings variiert der Anteil der privaten Finanzierung einschließlich staatlich-subventionierter privater Zahlungen sehr stark, von weniger als 4 Prozent in Dänemark, Finnland, Griechenland und Norwegen bis zu 84 Prozent in Korea.

In einem Drittel der OECDLänder tragen andere private Einheiten als die privaten Haushalte mehr als 10 Prozent der Ausgaben für tertiäre Bildungseinrichtungen.

Im Tertiärbereich ist es weitaus üblicher als in den anderen Bildungsbereichen, dass private Haushalte bzw. Studierende öffentliche Mittel erhalten. nur in Dänemark, Schweden und Ungarn übersteigt er ro Prozent (Tab. B3.3). Diese neuen Finanzierungsstrategien stellen jedoch nicht nur die Finanzierung durch öffentliche und private Mittel auf eine breitere Basis, sondern sorgen auch für eine Mannigfaltigkeit des Bildungsangebots, die die Effektivität der Schulausbildung verbessern kann.

Mit Ausnahme von Dänemark, Deutschland, Griechenland und Island ist im Allgemeinen der Anteil der privaten Mittel an der Bildungsfinanzierung im tertiären Bereich weitaus höher als im Primar-, Sekundar- und post-sekundaren, nicht-tertiären Bereich. Während das Bildungsangebot im Primar-, Sekundarund post-sekundaren, nicht-tertiären Bereich normalerweise als öffentliches Gut angesehen wird, dessen Früchte auch hauptsächlich wieder der Öffentlichkeit zugute kommen, lässt der hohe private Nutzen im tertiären Bereich in Form besserer Beschäftigungsmöglichkeiten und höherer Einkommen (s. Indikator AII) den Schluss zu, dass eine stärkere Beteiligung des Einzelnen an den Kosten der tertiären Bildung gerechtfertigt sein könnte, vorausgesetzt natürlich, dass die öffentliche Hand gewährleisten kann, dass die Finanzierung für die Studierenden unabhängig von ihren wirtschaftlichen Verhältnissen möglich ist (s. auch Indikator B5).

Der Finanzierungsanteil für tertiäre Einrichtungen, der von Privatpersonen, Unternehmen und sonstigen privaten Einheiten getragen wird, einschließlich staatlich-subventionierter privater Zahlungen, reicht von weniger als 4 Prozent in Dänemark, Finnland, Griechenland und Norwegen, über ungefähr die Hälfte in Australien und Japan, zwei Drittel in den Vereinigten Staaten bis zu über drei Viertel in Korea (Abb. B3.I und Tab. B3.2b). Mehr als 8o Prozent der koreanischen Studierenden sind an privaten Hochschulen eingeschrieben, deren Etats zu über 95 Prozent aus Studiengebühren finanziert werden.

Diese Beiträge anderer privater Einheiten als der privaten Haushalte zur Finanzierung von Bildungseinrichtungen sind im Tertiärbereich höher als in den anderen Bildungsbereichen. Der Finanzierungsanteil für tertiäre Einrichtungen, der von anderen privaten Einheiten als den privaten Haushalten getragen wird, beträgt in einem Drittel der Länder (Australien, Belgien, Kanada, Korea, den Niederlanden, Schweden, Ungarn, dem Vereinigten Königreich und den Vereinigten Staaten) ungefähr Io Prozent und mehr. In Deutschland und der Schweiz wird ein beträchtlicher Anteil der Bildungsausgaben im Primar-, Sekundar- und post-sekundaren, nicht-tertiären Bereich von anderen privaten Einheiten als den privaten Haushalten getragen, in Österreich und Japan tragen diese anderen privaten Einheiten hauptsächlich zum Elementarbereich bei (Abb. B3.I).

Im Tertiärbereich ist es weitaus üblicher als in den anderen Bildungsbereichen, dass private Haushalte bzw. Studierende öffentliche Mittel erhalten. So gehen beispielsweise im Tertiärbereich im Durchschnitt etwa I8 Prozent der öffentlichen Mittel als Transferzahlungen an private Haushalte/Studierende. Dieser Anteil ist in Neuseeland (48 Prozent), den Vereinigten Staaten (37 Prozent), Dänemark (35 Prozent), Australien (33 Prozent), Norwegen (3I Prozent) und Schweden (30 Prozent) am höchsten (Tab. B3.3). 
Die Höhe der von den Studierenden und ihren Familien selbst aufgebrachten Mittel für Studiengebühren und sonstige bildungsbezogene Ausgaben ist je nach Steuer- und Ausgabenpolitik sowie der Bereitschaft des Staates, Studierende finanziell zu unterstützen, in den einzelnen OECD-Ländern recht unterschiedlich. Die Bereitschaft des Staates wiederum richtet sich nach der Art des Studiums (Voll- oder Teilzeitstudium), dem Alter der Studierenden und danach, ob diese zu Hause wohnen oder extern. Allerdings ist festzustellen, dass sich die Richtlinien für die Feststellung der Anspruchsberechtigung für solche Unterstützungsleistungen in gewisser Hinsicht lockern. Ältere Studierende, deren Zahl stetig zunimmt, haben eher schon einen eigenen Hausstand gegründet und geben einem Teilzeit- bzw. Fernstudium gegenüber einem Vollzeit-Präsenzstudium den Vorzug.

\section{Veränderungen bei den öffentlichen und privaten Bildungsausgaben}

Ein Vergleich des Anteils an den Bildungsausgaben, die zwischen 1995 und $200 \mathrm{I}$ aus privaten Mitteln bestritten wurden, zeigt, dass ebenso viele Länder eine Steigerung beim Anteil der privaten Mittel verzeichneten wie einen Rückgang (Abb. B3.2 und Tab. B3.I). In Australien, Kanada und dem Vereinigten Königreich erhöhte sich der Privatanteil der Finanzierung von 2I,I, I8,8 bzw. I2,7 Prozent im Jahr I995 auf 24,4, 21,8 bzw. 15,3 Prozent im Jahr 200I. Andererseits ergab sich in Irland, Mexiko, Spanien und der Tschechischen Republik ein Rückgang des Anteils der privaten Finanzierung von zwischen 2 und 4 Prozentpunkten.

Acht Länder, für die vergleichbare Daten zur Verfügung stehen, verzeichneten eine Verschiebung von der öffentlichen hin zur privaten Finanzierung des Primar-, Sekundar- und post-sekundaren, nicht-tertiären Bildungsbereichs. In der Hälfte dieser Länder - Australien, Irland, Kanada und dem Vereinigten Königreich belief sich der Anstieg der privaten Finanzierung auf mehr als I Prozentpunkt.

Verschiebungen bei der Finanzierung in die andere Richtung, hin zur öffentlichen Finanzierung, waren ebenfalls zu beobachten. Dies war insbesondere in Mexiko, den Niederlanden, Spanien, der Tschechischen Republik und Ungarn der Fall, wo sich der Anteil der öffentlichen Finanzierung zwischen I und 7 Prozentpunkte erhöhte (Abb. B3.2 und Tab. B3.2a).

In vielen OECD-Ländern ist die wachsende Teilnahme an tertiärer Bildung (Indikator C2) auf eine starke private und gesellschaftliche Nachfrage zurückzuführen. Aber nicht nur viele Strukturen und Studiengänge der tertiären Einrichtungen stammen aus einer anderen Zeit, sondern auch deren Finanzierungsmechanismen. Mit der zunehmenden Nachfrage nach tertiärer Bildung hat sich in vielen OECD-Ländern, z. B. Australien, Mexiko, Portugal, Österreich, Ungarn und dem Vereinigten Königreich, auch der Anteil der von privaten Einheiten getragenen finanziellen Belastung erhöht (Abb. B3.2).

Es bleibt festzuhalten, dass der Anstieg der privaten Bildungsausgaben nicht generell mit realen Kürzungen der öffentlichen Bildungsfinanzierung einhergegangen ist, weder im Primar-, Sekundar- und post-sekundaren, nicht-tertiären Bereich noch im Tertiärbereich. Das Gegenteil ist der Fall - die in Bildung investierten öffentlichen Mittel haben in fast allen OECD-Ländern, für die Vergleichsdaten für 1995 und 200I vorliegen, unabhängig von den Veränderungen bei der Privatfinanzierung zugenommen (Tab. B2.2). Tatsächlich hat-
Zwischen 1995 und 2001 gab es in einigen Ländern einen Anstieg des Anteils der privaten Bildungsfinanzierung, während andere Länder hier einen Rückgang verzeichneten.

Acht Länder verzeichneten eine leichte Verschiebung von der öffentlichen hin zu der privaten Finanzierung, ...

... während Verschiebungen in die andere Richtung in Mexiko, den Niederlanden, Spanien, der Tschechischen Republik und Ungarn am deutlichsten waren.

Im tertiären Bildungsbereich kam es zu einigen erstaunlichen Veränderungen, die zumindest teilweise eine Reaktion auf die stark gestiegenen Studierendenzahlen sind.

In den meisten OECD-Ländern, in denen es eine Verschiebung zu den privaten Ausgaben hin gab, führte dies jedoch nicht zu einer Verringerung der reaIen öffentlichen Ausgaben für den Tertiärbereich. 


\section{Abbildung B3.2}

Anteil der Privatausgaben für Bildungseinrichtungen (1995, 2001) In Prozent

$1995>2001$

$\% \quad$ Alle Bildungsbereiche

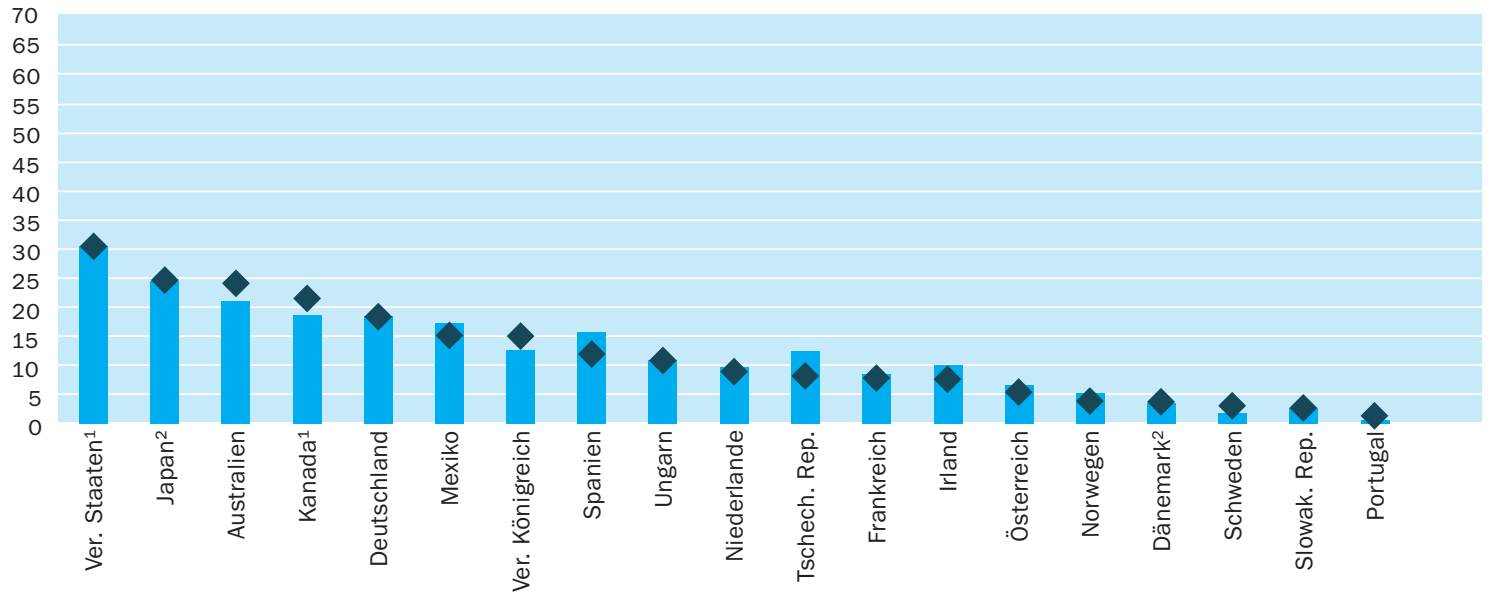

Primar-, Sekundar- und post-sekundarer, nicht-tertiärer Bereich
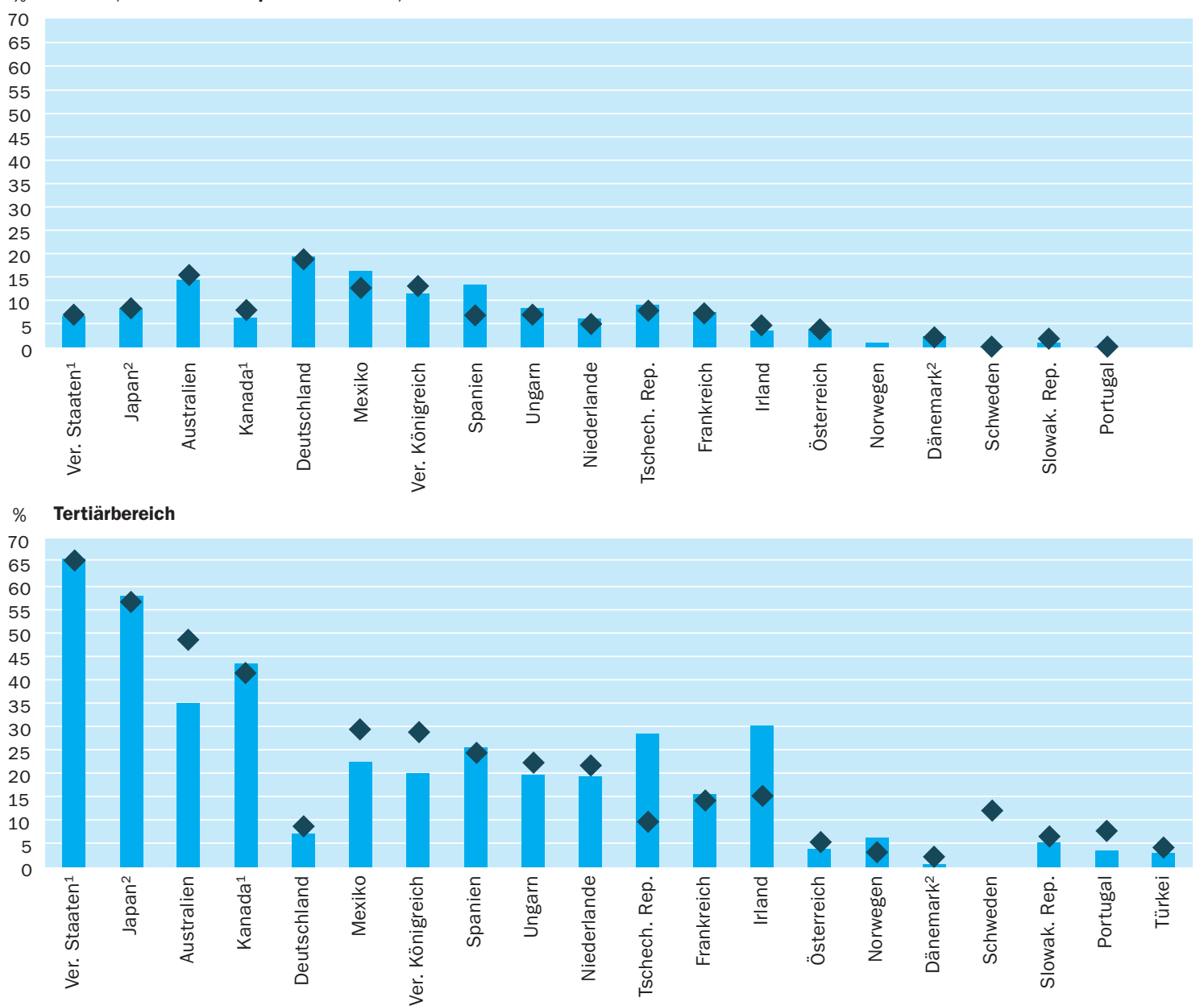

1. Post-sekundarer, nicht-tertiärer Bereich in Tertiärbereich enthalten. 2. Post-sekundarer, nicht-tertiärer Bereich sowohl in Sekundarbereich II als auch Tertiärbereich enthalten.

Anordnung der Länder in absteigender Reihenfolge des Anteils der privaten Ausgaben im Jahr 2001 für alle Bildungsbereiche.

Quelle: OECD. Tabellen B3.1, B3.2a und B3.2b. Hinweise s. Anhang 3 unter www.oecd.org/edu/eag2004. 
ten sogar viele OECD-Länder mit dem höchsten Anstieg der privaten Finanzierung auch den höchsten Anstieg der öffentlichen Bildungsfinanzierung zu verzeichnen. Dies deutet darauf hin, dass höhere private Ausgaben für die tertiäre Bildung die öffentlichen Investitionen eher ergänzen als ersetzen. Die wichtigste Ausnahme bildet hier Australien, wo mit der Verschiebung zur privaten Finanzierung im Tertiärbereich ein Rückgang der realen öffentlichen Ausgaben einherging.

\section{Definitionen und angewandte Methodik}

Die Anteile der öffentlichen und privaten Mittel an der Finanzierung von Bildungseinrichtungen sind angegeben in Prozent der gesamten Bildungsausgaben, die im öffentlichen bzw. privaten Sektor entstehen bzw. anfallen. $\mathrm{Zu}$ den privaten Mitteln zählen alle direkten Ausgaben für Bildungseinrichtungen, unabhängig davon, ob diese teilweise durch öffentliche Mittel subventioniert werden oder nicht. Die in den privaten Mitteln enthaltenen öffentlichen Subventionen an die privaten Haushalte werden getrennt ausgewiesen.

Die Etats der Bildungseinrichtungen betreffen teilweise auch zusätzliche Dienstleistungen für Studierende, u. a. soziale Dienste für Studierende wie Unterkunft und Verpflegung sowie Transport. Ein Teil der Kosten für diese Leistungen wird über Beiträge der Studierenden gedeckt, die in diesem Indikator mit erfasst sind.

,Andere private Einheiten' umfasst private Unternehmen und gemeinnützige Organisationen, einschließlich kirchlicher Organisationen, Wohltätigkeitsvereinen sowie Arbeitgeberverbände und Arbeitnehmervereinigungen. Hierzu gehören auch Ausgaben von privaten Unternehmen für den betrieblichen Teil der dualen Ausbildung von Lehrlingen und Schülern.

Die Veränderungen bei der privaten und öffentlichen Finanzierung von Bildungseinrichtungen sind durch einen Index der Veränderung dargestellt. Der Anteil der privaten Finanzierung im Jahre 1995 wird dem entsprechenden Anteil im Jahr 200 I gegenübergestellt. Die Daten für die Ausgaben des Jahres I995 wurden im Rahmen einer speziellen Erhebung im Jahre 200I ermittelt, in der die Ausgaben für 1995 entsprechend den Definitionen und den Methoden der aktuellen UOE-Datenerhebung angepasst wurden.

Das Glossar am Ende dieser Veröffentlichung enthält eine Definition der Begriffe „öffentliche Bildungseinrichtungen“, „staatlich-subventionierte private Bildungseinrichtungen“ und „unabhängige private Bildungseinrichtungen“.

Es ist zu beachten, dass die in früheren Ausgaben dieser Veröffentlichung aufgeführten Zahlen und Daten möglicherweise nicht immer mit denen der Ausgabe 2004 vergleichbar sind, da sich Änderungen in den Definitionen und Erhebungsbereichen ergeben haben. Diese wurden aufgrund der OECD Expenditure Comparability Study vorgenommen (Einzelheiten zu den Änderungen s. Anhang 3 unter www.oecd.org/edu/eag 2004).
Die Daten beziehen sich auf das Haushaltsjahr 2001 und beruhen auf der von der OECD im Jahre 2003 durchgeführten UOE-Datenerhebung zur Bildungsstatistik (Einzelheiten s. Anhang 3).

Die Daten für das Haushaltsjahr 1995 beruhen auf einer speziellen Erhebung aus dem Jahre 2001, die 2003 aktualisiert wurde. 


\section{Tabelle B3.1}

Relative Anteile öffentlicher und privater Ausgaben für Bildungseinrichtungen aller Bildungsbereiche (1995, 2001)

Verteilung der Mittel für Bildungseinrichtungen aus öffentlichen und privaten Quellen nach Transferzahlungen aus öffentlichen Quellen, nach Jahr

\begin{tabular}{|c|c|c|c|c|c|c|c|c|c|c|}
\hline \multirow{4}{*}{ OECD-Länder } & \multicolumn{5}{|c|}{2001} & \multicolumn{5}{|c|}{1995} \\
\hline & \multirow{2}{*}{$\begin{array}{c}\text { Aus } \\
\text { öffentlichen } \\
\text { Quellen }\end{array}$} & \multicolumn{3}{|c|}{ Aus privaten Quellen } & \multirow{2}{*}{$\begin{array}{l}\text { Aus privaten } \\
\text { Quellen: } \\
\text { hiervon } \\
\text { bezuschusst }\end{array}$} & \multirow{2}{*}{$\begin{array}{c}\text { Aus } \\
\text { öffentlichen } \\
\text { Quellen }\end{array}$} & \multicolumn{3}{|c|}{ Aus privaten Quellen } & \multirow{2}{*}{$\begin{array}{l}\text { Aus privaten } \\
\text { Quellen: } \\
\text { hiervon } \\
\text { bezuschusst }\end{array}$} \\
\hline & & $\begin{array}{l}\text { Ausgaben } \\
\text { privater } \\
\text { Haushalte }\end{array}$ & $\begin{array}{c}\text { Ausgaben an- } \\
\text { derer privater } \\
\text { Einheiten }\end{array}$ & $\begin{array}{l}\text { Alle privaten } \\
\text { Quellen }{ }^{1}\end{array}$ & & & $\begin{array}{l}\text { Ausgaben } \\
\text { privater } \\
\text { Haushalte }\end{array}$ & $\begin{array}{c}\text { Ausgaben an- } \\
\text { derer privater } \\
\text { Einheiten }\end{array}$ & $\begin{array}{l}\text { Alle privaten } \\
\text { Quellen }{ }^{1}\end{array}$ & \\
\hline & (1) & (2) & (3) & (4) & (5) & (6) & (7) & (8) & (9) & (10) \\
\hline Australien & 75,6 & 17,3 & 7,1 & 24,4 & 0,2 & 78,9 & 13,7 & 7,4 & 21,1 & 0,5 \\
\hline Österreich & 94,4 & 2,9 & 2,6 & 5,6 & 1,7 & 93,4 & 3,4 & 3,2 & 6,6 & 1,5 \\
\hline Belgien & 93,0 & 4,9 & 2,1 & 7,0 & 0,9 & $\mathrm{~m}$ & $\mathrm{~m}$ & $\mathrm{~m}$ & $\mathrm{~m}$ & $\mathrm{~m}$ \\
\hline Kanada $^{2}$ & 78,2 & 11,6 & 10,2 & 21,8 & $\mathrm{~m}$ & 81,2 & 7,7 & 11,1 & 18,8 & $\mathrm{~m}$ \\
\hline Tschechische Rep. & 91,6 & 5,0 & 3,4 & 8,4 & $\mathrm{~m}$ & 87,5 & $x(9)$ & $x(9)$ & 12,5 & 6,2 \\
\hline Dänemark ${ }^{3}$ & 96,1 & 3,9 & $\mathrm{n}$ & 3,9 & $\mathrm{~m}$ & 96,5 & 3,5 & $\mathrm{n}$ & 3,5 & $\mathrm{n}$ \\
\hline Finnland & 97,8 & $x(4)$ & $x(4)$ & 2,2 & $n$ & $\mathrm{~m}$ & $\mathrm{~m}$ & $\mathrm{~m}$ & $\mathrm{~m}$ & $\mathrm{~m}$ \\
\hline Frankreich & 92,0 & 6,2 & 1,8 & 8,0 & 1,7 & 91,4 & 6,9 & 1,6 & 8,6 & 1,9 \\
\hline Griechenland & 94,2 & 5,8 & $\mathrm{~m}$ & 5,8 & $\mathrm{~m}$ & $\mathrm{~m}$ & $\mathrm{~m}$ & $\mathrm{~m}$ & $\mathrm{~m}$ & $\mathrm{~m}$ \\
\hline Ungarn & 89,0 & 4,7 & 6,3 & 11,0 & $\mathrm{n}$ & 89,0 & 5,0 & 6,0 & 11,0 & $\mathrm{n}$ \\
\hline Island & 91,7 & 8,3 & $\mathrm{~m}$ & 8,3 & $\mathrm{n}$ & $\mathrm{m}$ & $x(9)$ & $x(9)$ & $\mathrm{m}$ & $\mathrm{m}$ \\
\hline Irland & 92,2 & 7,1 & 0,7 & 7,8 & $\mathrm{n}$ & 89,8 & 9,7 & 0,5 & 10,2 & $\mathrm{~m}$ \\
\hline Italien & 90,7 & 8,0 & 1,3 & 9,3 & 1,0 & $\mathrm{~m}$ & $\mathrm{~m}$ & $\mathrm{~m}$ & $\mathrm{~m}$ & $\mathrm{~m}$ \\
\hline Japan $^{3}$ & 75,0 & 22,5 & 2,5 & 25,0 & $\mathrm{~m}$ & 75,4 & 22,7 & 2,0 & 24,6 & $\mathrm{~m}$ \\
\hline Korea & 57,1 & 32,1 & 10,9 & 42,9 & 1,4 & $\mathrm{~m}$ & $\mathrm{~m}$ & $\mathrm{~m}$ & $\mathrm{~m}$ & $\mathrm{~m}$ \\
\hline Luxemburg & $\mathrm{m}$ & $\mathrm{m}$ & $\mathrm{m}$ & $\mathrm{m}$ & $\mathrm{m}$ & $\mathrm{m}$ & $\mathrm{m}$ & $\mathrm{m}$ & $\mathrm{m}$ & $\mathrm{m}$ \\
\hline Mexiko & 84,6 & 15,2 & 0,2 & 15,4 & 2,6 & 82,6 & 17,4 & $\mathrm{n}$ & 17,4 & $\mathrm{~m}$ \\
\hline Niederlande & 90,9 & 5,7 & 3,4 & 9,1 & 1,2 & 90,2 & 6,4 & 3,4 & 9,8 & 1,8 \\
\hline Neuseeland & $\mathrm{m}$ & $\mathrm{m}$ & $\mathrm{m}$ & $\mathrm{m}$ & $\mathrm{m}$ & $\mathrm{m}$ & $\mathrm{m}$ & $\mathrm{m}$ & $\mathrm{m}$ & $\mathrm{m}$ \\
\hline Norwegen & 95,9 & 4,1 & $\mathrm{~m}$ & 4,1 & $\mathrm{n}$ & 94,8 & $x(9)$ & $x(9)$ & 5,2 & $\mathrm{n}$ \\
\hline Polen & $\mathrm{m}$ & $\mathrm{m}$ & $\mathrm{m}$ & $\mathrm{m}$ & a & $\mathrm{m}$ & $\mathrm{m}$ & $\mathrm{m}$ & $\mathrm{m}$ & a \\
\hline Portugal & 98,5 & 1,5 & $\mathrm{~m}$ & 1,5 & $\mathrm{~m}$ & 99,4 & 0,6 & $\mathrm{~m}$ & 0,6 & $\mathrm{~m}$ \\
\hline Schweden & 96,8 & 0,1 & 3,1 & 3,2 & $\mathrm{~m}$ & 98,3 & 0,1 & 1,6 & 1,7 & $\mathrm{~m}$ \\
\hline Schweiz & $\mathrm{m}$ & $\mathrm{m}$ & $\mathrm{m}$ & $\mathrm{m}$ & $\mathrm{m}$ & $\mathrm{m}$ & $\mathrm{m}$ & $\mathrm{m}$ & $\mathrm{m}$ & $\mathrm{m}$ \\
\hline Türkei & $\mathrm{m}$ & $\mathrm{m}$ & $\mathrm{m}$ & $\mathrm{m}$ & $\mathrm{m}$ & $\mathrm{m}$ & $\mathrm{m}$ & $\mathrm{m}$ & $\mathrm{m}$ & $\mathrm{m}$ \\
\hline Ver. Königreich & 84,7 & 13,0 & 2,3 & 15,3 & 0,4 & 87,3 & $x(9)$ & $x(9)$ & 12,7 & 3,5 \\
\hline Vereinigte Staaten ${ }^{2}$ & 69,2 & 18,8 & 11,9 & 30,8 & $\mathrm{~m}$ & 69,3 & $x(9)$ & $x(9)$ & 30,7 & $\mathrm{~m}$ \\
\hline Ländermittel & 87,8 & 9,2 & 4,2 & 12,2 & 0,7 & $\sim$ & $\sim$ & $\sim$ & $\sim$ & $\sim$ \\
\hline OECD-Partnerländer & & & & & & & & & & \\
\hline Argentinien & 77,3 & 22,0 & 0,7 & 22,7 & $\mathrm{~m}$ & $\mathrm{~m}$ & $\mathrm{~m}$ & $\mathrm{~m}$ & $\mathrm{~m}$ & $\mathrm{~m}$ \\
\hline Chile $^{4}$ & 56,3 & 42,6 & 1,1 & 43,7 & 0,8 & $\mathrm{~m}$ & $\mathrm{~m}$ & $\mathrm{~m}$ & $\mathrm{~m}$ & $\mathrm{~m}$ \\
\hline Indien ${ }^{2}$ & 94,9 & 3,1 & 2,0 & 5,1 & $\mathrm{~m}$ & $\mathrm{~m}$ & $\mathrm{~m}$ & $\mathrm{~m}$ & $\mathrm{~m}$ & $\mathrm{~m}$ \\
\hline Indonesien & 64,2 & 32,6 & 3,3 & 35,8 & $\mathrm{~m}$ & $\mathrm{~m}$ & $\mathrm{~m}$ & $\mathrm{~m}$ & $\mathrm{~m}$ & $\mathrm{~m}$ \\
\hline Israel & 80,0 & 14,9 & 5,1 & 20,0 & 2,5 & 80,5 & 13,0 & 6,4 & 19,5 & 1,3 \\
\hline Jamaika & 53,9 & 43,9 & 2,1 & 46,1 & 1,3 & $\mathrm{~m}$ & $\mathrm{~m}$ & $\mathrm{~m}$ & $\mathrm{~m}$ & $\mathrm{~m}$ \\
\hline Malaysia & 99,9 & 0,1 & $\mathrm{n}$ & 0,1 & $\mathrm{n}$ & $\mathrm{m}$ & $\mathrm{m}$ & $\mathrm{m}$ & $\mathrm{m}$ & $\mathrm{m}$ \\
\hline Paraguay & 68,1 & 31,9 & $n$ & 31,9 & $\mathrm{~m}$ & $\mathrm{~m}$ & $\mathrm{~m}$ & $\mathrm{~m}$ & $\mathrm{~m}$ & $\mathrm{~m}$ \\
\hline Peru & 69,0 & 31,0 & $n$ & 31,0 & $\mathrm{~m}$ & $\mathrm{~m}$ & $\mathrm{~m}$ & $\mathrm{~m}$ & $\mathrm{~m}$ & $\mathrm{~m}$ \\
\hline Philippinen & 59,1 & 40,9 & $\mathrm{n}$ & 40,9 & a & $\mathrm{m}$ & $\mathrm{m}$ & $\mathrm{m}$ & $\mathrm{m}$ & $\mathrm{m}$ \\
\hline Thailand & 95,6 & 4,4 & $n$ & 4,4 & $\mathrm{~m}$ & $\mathrm{~m}$ & $\mathrm{~m}$ & $\mathrm{~m}$ & $\mathrm{~m}$ & $\mathrm{~m}$ \\
\hline Tunesien & 100,0 & $\mathrm{n}$ & $\mathrm{n}$ & $\mathrm{n}$ & $\mathrm{m}$ & $\mathrm{m}$ & $\mathrm{m}$ & $\mathrm{m}$ & $\mathrm{m}$ & $\mathrm{m}$ \\
\hline Uruguay & 93,4 & 6,5 & 0,1 & 6,6 & $\mathrm{~m}$ & $\mathrm{~m}$ & $\mathrm{~m}$ & $\mathrm{~m}$ & $\mathrm{~m}$ & $\mathrm{~m}$ \\
\hline Simbabwe $^{4}$ & 100,0 & $\mathrm{n}$ & $\mathrm{n}$ & $\mathrm{n}$ & $\mathrm{n}$ & $\mathrm{m}$ & $\mathrm{m}$ & $\mathrm{m}$ & $\mathrm{m}$ & $\mathrm{m}$ \\
\hline
\end{tabular}

Hinweis: $x$ bedeutet, dass die Daten in einer anderen Spalte enthalten sind, deren Referenz in runden Klammern nach dem ,x' angegeben ist. So bedeutet z. B. x(2), dass die Daten in Spalte 2 enthalten sind.

1. Einschließlich Subventionen, die Zahlungen an Bildungseinrichtungen zuzurechnen sind, die aus öffentlichen Quellen stammen. 2. Post-sekundarer, nicht-tertiärer Bereich in Tertiärbereich enthalten. 3. Post-sekundarer, nicht-tertiärer Bereich sowohl in Sekundarbereich II als auch Tertiärbereich enthalten. 4 . Referenzjahr 2002. Quelle: OECD. Hinweise s. Anhang 3 unter www.oecd.org/edu/eag2004. 
Tabelle B3.2a

Relative Anteile öffentlicher und privater Ausgaben für Bildungseinrichtungen, nach Bildungsbereich (1995, 2001)

Verteilung der Mittel für Bildungseinrichtungen aus öffentlichen und privaten Quellen nach Transferzahlungen aus öffentlichen Quellen, nach Jahr

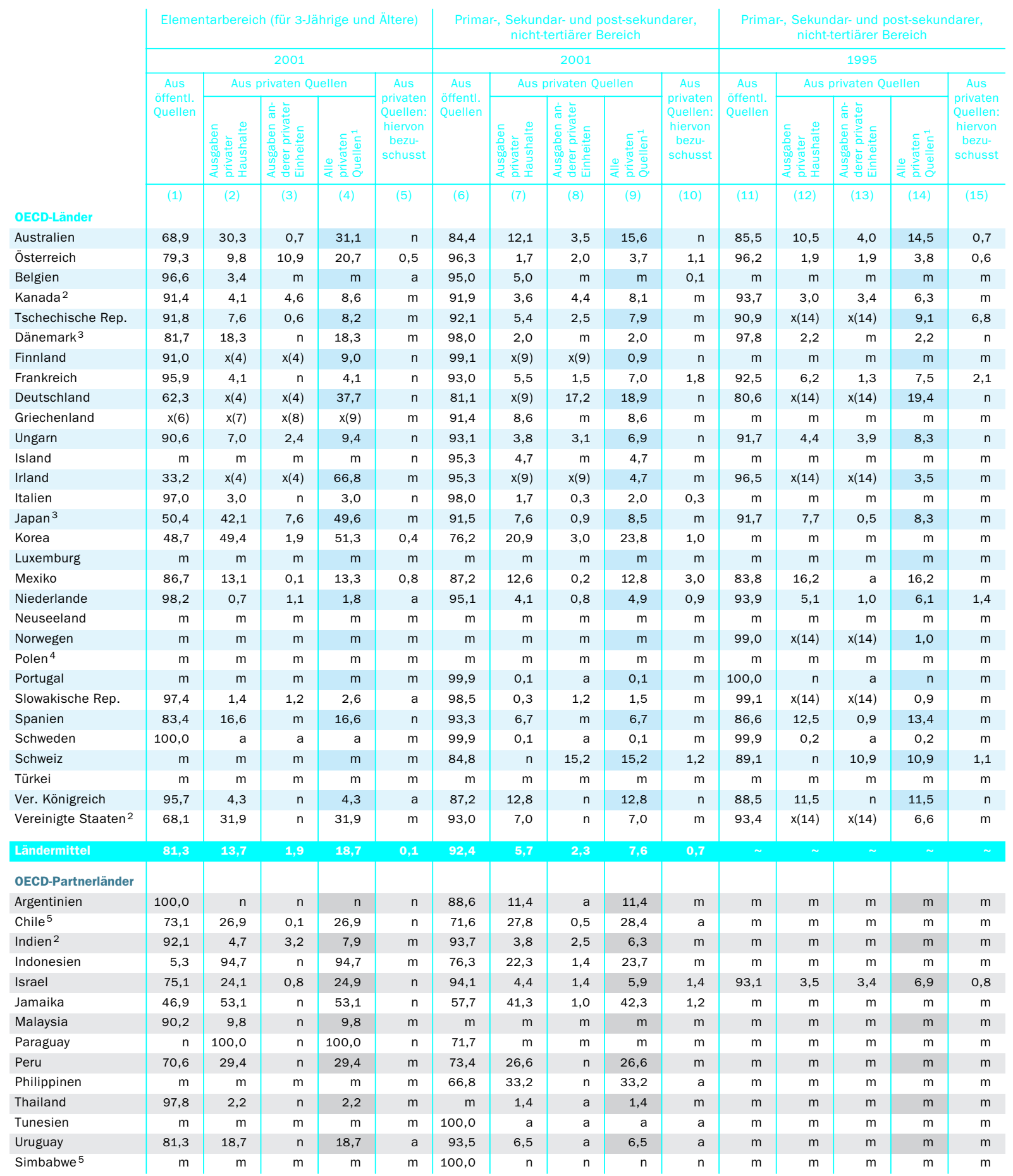

Hinweis: $x$ bedeutet, dass die Daten in einer anderen Spalte enthalten sind, deren Referenz in runden Klammern nach dem ,x‘ angegeben ist. So bedeutet $z . B$. $x(2)$, dass die Daten in Spalte 2 enthalten sind. Um private Mittel ohne Subventionen zu berechnen, sind von den privaten Mitteln (Spalten 4, 9, 14) die öffentlichen Subventionen abzuziehen (Spalten 5, 10, 15). Um die gesamten öffentlichen MIttel einschl. öffentliche Subventionen zu berechnen, sind den öffentlichen Subventionen (Spalten 5, 10, 15) die direkten öffentlichen Mittel (Spalten 1, 6, 11) hinzuzurechnen.

1. Einschließlich aus öffentlichen Quellen stammenden Subventionen, die Zahlungen an Bildungseinrichtungen zuzuordnen sind. 2. Post-sekundarer, nicht-tertiärer Bereich in Tertiärbereich enthalten. 3. Post-sekundarer, nicht-tertiärer Bereich sowohl in Sekundarbereich II als auch Tertiärbereich enthalten. 4 . Nur öffentliche Bildungseinrichtungen. 5. Referenzjahr 2002

Quelle: OECD. Hinweise s. Anhang 3 unter www.oecd.org/edu/eag2004. 
Relative Anteile öffentlicher und privater Ausgaben für Bildungseinrichtungen, Tertiärbereich $(1995,2001)$

Verteilung der Mittel für Bildungseinrichtungen aus öffentlichen und privaten Quellen nach Transferzahlungen aus öffentlichen Quellen, nach Jahr

\begin{tabular}{|c|c|c|c|c|c|c|c|c|c|c|}
\hline & & & 2001 & & & & & 1995 & & \\
\hline & Aus öffentl. & & s privaten Quel & & Aus privaten & Aus öffentl. & & s privaten Quel & & Aus privaten \\
\hline & & $\begin{array}{l}\text { Ausgaben } \\
\text { privater } \\
\text { Haushalte }\end{array}$ & $\begin{array}{c}\text { Ausgaben an- } \\
\text { derer privater } \\
\text { Einheiten }\end{array}$ & $\begin{array}{l}\text { Alle privaten } \\
\text { Quellen }{ }^{1}\end{array}$ & $\begin{array}{c}\text { hiervon } \\
\text { bezuschusst }\end{array}$ & & $\begin{array}{l}\text { Ausgaben } \\
\text { privater } \\
\text { Haushalte }\end{array}$ & $\begin{array}{c}\text { Ausgaben an- } \\
\text { derer privater } \\
\text { Einheiten }\end{array}$ & $\begin{array}{l}\text { Alle privaten } \\
\text { Quellen }{ }^{1}\end{array}$ & $\begin{array}{l}\text { hiervon } \\
\text { bezuschusst }\end{array}$ \\
\hline OECD-Länder & (1) & (2) & (3) & (4) & (5) & (6) & (7) & (8) & (9) & (10) \\
\hline Australien & 51,3 & 31,0 & 17,7 & 48,7 & 0,9 & 64,8 & 20,0 & 15,2 & 35,2 & $n$ \\
\hline Österreich & 94,6 & 4,1 & 1,3 & 5,4 & 4,6 & 96,1 & 1,9 & 2,0 & 3,9 & 4,6 \\
\hline Belgien & 84,1 & 6,0 & 9,9 & 15,9 & 4,1 & $\mathrm{~m}$ & $\mathrm{~m}$ & $\mathrm{~m}$ & $\mathrm{~m}$ & $\mathrm{~m}$ \\
\hline Kanada $^{2}$ & 58,6 & 22,9 & 18,5 & 41,4 & $\mathrm{~m}$ & 56,6 & 16,7 & 26,7 & 43,4 & $\mathrm{~m}$ \\
\hline Tschechische Rep. & 90,4 & 2,1 & 7,5 & 9,6 & $\mathrm{~m}$ & 71,5 & 3,3 & 25,2 & 28,5 & 8,7 \\
\hline Dänemark ${ }^{3}$ & 97,8 & 2,2 & $\mathrm{n}$ & 2,2 & $\mathrm{~m}$ & 99,4 & 0,6 & $\mathrm{n}$ & 0,6 & $\mathrm{n}$ \\
\hline Finnland & 96,5 & $x(4)$ & $x(4)$ & 3,5 & $\mathrm{n}$ & $\mathrm{m}$ & $\mathrm{m}$ & $\mathrm{m}$ & $\mathrm{m}$ & $\mathrm{m}$ \\
\hline Frankreich & 85,6 & 10,3 & 4,1 & 14,4 & 2,3 & 84,3 & 11,8 & 3,9 & 15,7 & 2,6 \\
\hline Griechenland & 99,6 & 0,4 & $\mathrm{~m}$ & 0,4 & $\mathrm{~m}$ & $\mathrm{~m}$ & $\mathrm{~m}$ & $\mathrm{~m}$ & $\mathrm{~m}$ & $\mathrm{~m}$ \\
\hline Ungarn & 77,6 & 6,1 & 16,3 & 22,4 & $\mathrm{n}$ & 80,3 & 4,8 & 14,9 & 19,7 & $\mathrm{n}$ \\
\hline Island & 95,0 & 5,0 & $\mathrm{~m}$ & 5,0 & $\mathrm{n}$ & $\mathrm{m}$ & $\mathrm{m}$ & $\mathrm{m}$ & $\mathrm{m}$ & $\mathrm{m}$ \\
\hline Irland & 84,7 & 12,8 & 2,4 & 15,3 & $\mathrm{~m}$ & 69,7 & 28,3 & 2,0 & 30,3 & $\mathrm{~m}$ \\
\hline Italien & 77,8 & 16,0 & 6,3 & 22,2 & 3,9 & 82,9 & 12,7 & 4,4 & 17,1 & 0,1 \\
\hline Japan $^{3}$ & 43,1 & 56,9 & $\mathrm{n}$ & 56,9 & $\mathrm{~m}$ & 42,0 & 58,0 & $n$ & 58,0 & $\mathrm{~m}$ \\
\hline Korea & 11,3 & 61,3 & 27,5 & 88,7 & 0,1 & $\mathrm{~m}$ & $\mathrm{~m}$ & $\mathrm{~m}$ & $\mathrm{~m}$ & $\mathrm{~m}$ \\
\hline Luxemburg & $\mathrm{m}$ & $\mathrm{m}$ & $\mathrm{m}$ & $\mathrm{m}$ & $\mathrm{m}$ & $\mathrm{m}$ & $\mathrm{m}$ & $\mathrm{m}$ & $\mathrm{m}$ & $\mathrm{m}$ \\
\hline Mexiko & 70,4 & 28,9 & 0,7 & 29,6 & 2,1 & 77,4 & 22,6 & $\mathrm{~m}$ & 22,6 & $\mathrm{~m}$ \\
\hline Niederlande & 78,2 & 11,1 & 10,7 & 21,8 & 2,0 & 80,6 & 10,1 & 9,3 & 19,4 & 2,5 \\
\hline Neuseeland & $\mathrm{m}$ & $\mathrm{m}$ & $\mathrm{m}$ & $\mathrm{m}$ & $\mathrm{m}$ & $\mathrm{m}$ & $\mathrm{m}$ & $\mathrm{m}$ & $\mathrm{m}$ & $\mathrm{m}$ \\
\hline Norwegen & 96,9 & $x(4)$ & $x(4)$ & 3,1 & a & 93,7 & $x(9)$ & $x(9)$ & 6,3 & $\mathrm{n}$ \\
\hline Polen ${ }^{4}$ & $\mathrm{~m}$ & $\mathrm{~m}$ & $\mathrm{~m}$ & $\mathrm{~m}$ & $\mathrm{~m}$ & $\mathrm{~m}$ & $\mathrm{~m}$ & $\mathrm{~m}$ & $\mathrm{~m}$ & $\mathrm{~m}$ \\
\hline Portugal & 92,3 & $x(4)$ & $x(4)$ & 7,7 & $\mathrm{~m}$ & 96,5 & 3,5 & $\mathrm{~m}$ & 3,5 & $\mathrm{~m}$ \\
\hline Schweden & 87,7 & $\mathrm{~m}$ & 12,3 & 12,3 & a & $\mathrm{m}$ & $\mathrm{m}$ & $\mathrm{m}$ & $\mathrm{m}$ & a \\
\hline Schweiz & $\mathrm{m}$ & $\mathrm{m}$ & $\mathrm{m}$ & $\mathrm{m}$ & $\mathrm{m}$ & $\mathrm{m}$ & $\mathrm{m}$ & $\mathrm{m}$ & $\mathrm{m}$ & $\mathrm{m}$ \\
\hline Türkei & 95,8 & 4,2 & $\mathrm{~m}$ & 4,2 & $\mathrm{n}$ & 97,0 & 3,0 & $\mathrm{~m}$ & 3,0 & 0,7 \\
\hline Ver. Königreich & 71,0 & 17,3 & 11,7 & 29,0 & 1,8 & 80,0 & $x(9)$ & $x(9)$ & 20,0 & $\mathrm{n}$ \\
\hline Vereinigte Staaten ${ }^{2}$ & 34,0 & 33,9 & 32,1 & 66,0 & $\mathrm{~m}$ & 34,0 & $x(9)$ & $x(9)$ & 66,0 & $\mathrm{~m}$ \\
\hline Ländermittel & 78,2 & 17,1 & 9,7 & 21,8 & 1,4 & $\sim$ & $\sim$ & $\sim$ & $\sim$ & $\sim$ \\
\hline OECD-Partnerländer & & & & & & & & & & \\
\hline Argentinien & 68,5 & 27,7 & 3,8 & 31,5 & $\mathrm{~m}$ & $\mathrm{~m}$ & $\mathrm{~m}$ & $\mathrm{~m}$ & $\mathrm{~m}$ & $\mathrm{~m}$ \\
\hline Chile $^{5}$ & 19,6 & 77,8 & 2,6 & 80,4 & 2,6 & $\mathrm{~m}$ & $\mathrm{~m}$ & $\mathrm{~m}$ & $\mathrm{~m}$ & $\mathrm{~m}$ \\
\hline Indien ${ }^{2}$ & 99,8 & 0,2 & $\mathrm{n}$ & 0,2 & $\mathrm{~m}$ & $\mathrm{~m}$ & $\mathrm{~m}$ & $\mathrm{~m}$ & $\mathrm{~m}$ & $\mathrm{~m}$ \\
\hline Indonesien & 43,8 & 49,4 & 6,8 & 56,2 & $\mathrm{~m}$ & $\mathrm{~m}$ & $\mathrm{~m}$ & $\mathrm{~m}$ & $\mathrm{~m}$ & $\mathrm{~m}$ \\
\hline Israel & 56,8 & 28,0 & 15,2 & 43,2 & 5,9 & 59,2 & 24,3 & 16,5 & 40,8 & 3,0 \\
\hline Jamaika & 43,5 & 50,0 & 6,4 & 56,5 & 2,1 & $\mathrm{~m}$ & $\mathrm{~m}$ & $\mathrm{~m}$ & $\mathrm{~m}$ & $\mathrm{~m}$ \\
\hline Paraguay & 59,1 & 40,9 & $\mathrm{n}$ & 40,9 & $\mathrm{~m}$ & $\mathrm{~m}$ & $\mathrm{~m}$ & $\mathrm{~m}$ & $\mathrm{~m}$ & $\mathrm{~m}$ \\
\hline Peru & 58,0 & 42,0 & $\mathrm{n}$ & 42,0 & $\mathrm{~m}$ & $\mathrm{~m}$ & $\mathrm{~m}$ & $\mathrm{~m}$ & $\mathrm{~m}$ & $\mathrm{~m}$ \\
\hline Philippinen & 33,1 & 66,9 & $\mathrm{n}$ & 66,9 & a & $\mathrm{m}$ & $\mathrm{m}$ & $\mathrm{m}$ & $\mathrm{m}$ & $\mathrm{m}$ \\
\hline Thailand & 82,5 & 17,5 & $\mathrm{n}$ & 17,5 & $\mathrm{~m}$ & $\mathrm{~m}$ & $\mathrm{~m}$ & $\mathrm{~m}$ & $\mathrm{~m}$ & $\mathrm{~m}$ \\
\hline Tunesien & 100,0 & a & a & a & a & $\mathrm{m}$ & $\mathrm{m}$ & $\mathrm{m}$ & $\mathrm{m}$ & $\mathrm{m}$ \\
\hline Uruguay & 99,5 & $\mathrm{n}$ & 0,5 & 0,5 & $\mathrm{~m}$ & $\mathrm{~m}$ & $\mathrm{~m}$ & $\mathrm{~m}$ & $\mathrm{~m}$ & $\mathrm{~m}$ \\
\hline
\end{tabular}

Hinweis: $x$ bedeutet, dass die Daten in einer anderen Spalte enthalten sind, deren Referenz in runden Klammern nach dem , $x$ ' angegeben ist. So bedeutet $z$. B. $x(2)$, dass die Daten in Spalte 2 enthalten sind. Um private MIttel ohne Subventionen zu berechnen, sind von den privaten Mitteln (Spalten 4, 9) die öffentlichen Subventionen abzuziehen (Spalten 5, 10). Um die gesamten öffentlichen Mlttel einschl. öffentliche Subventionen zu berechnen, sind den öffentlichen Subventionen (Spalten 5, 10) die direkten öffentlichen Mittel (Spalten 1, 6) hinzuzurechnen.

1. Einschließlich aus öffentlichen Quellen stammenden Subventionen, die Zahlungen an Bildungseinrichtungen zuzuordnen sind. 2. Post-sekundarer, nicht-tertiärer Bereich in Tertiärbereich enthalten. 3. Post-sekundarer, nicht-tertiärer Bereich sowohl in Sekundarbereich II als auch Tertiärbereich enthalten. 4 . Nur öffentliche Bildungseinrichtungen. 5. Referenzjahr 2002

Quelle: OECD. Hinweise s. Anhang 3 unter www.oecd.org/edu/eag2004. 
Tabelle B3.3

Verteilung der öffentlichen Gesamtausgaben für Bildung (2001)

Öffentliche Ausgaben für Bildung, die an Bildungseinrichtungen transferiert werden, und öffentliche Transferzahlungen an den privaten Sekor als Prozentsatz der öffentlichen Gesamtausgaben für Bildung, nach Bildungsbereichen

\begin{tabular}{|c|c|c|c|c|c|c|c|c|c|}
\hline & \multicolumn{3}{|c|}{$\begin{array}{c}\text { Primar-, Sekundar- und post-sekundarer, } \\
\text { nicht-tertiärer Bereich }\end{array}$} & \multicolumn{3}{|c|}{ Tertiärbereich } & \multicolumn{3}{|c|}{ Alle Bildungsbereiche zusammen } \\
\hline & $\begin{array}{c}\text { Direkte öffent- } \\
\text { liche Ausgaben } \\
\text { für öffentliche } \\
\text { Bildungsein- } \\
\text { richtungen }\end{array}$ & \begin{tabular}{|} 
Direkte öffent- \\
liche Ausgaben \\
für private \\
Bildungsein- \\
richtungen
\end{tabular} & \begin{tabular}{|c|} 
Indirekte öffent- \\
liche Transfer- \\
und sonstige \\
Zahlungen an \\
den privaten \\
Sektor
\end{tabular} & $\begin{array}{c}\text { Direkte öffent- } \\
\text { liche Ausgaben } \\
\text { für öffentliche } \\
\text { Bildungsein- } \\
\text { richtungen }\end{array}$ & $\begin{array}{l}\text { Direkte öffent- } \\
\text { liche Ausgaben } \\
\text { für private } \\
\text { Bildungsein- } \\
\text { richtungen }\end{array}$ & $\begin{array}{c}\text { Indirekte öffent- } \\
\text { liche Transfer- } \\
\text { und sonstige } \\
\text { Zahlungen an } \\
\text { den privaten } \\
\text { Sektor }\end{array}$ & \begin{tabular}{|} 
Direkte öffent- \\
liche Ausgaben \\
für öffentliche \\
Bildungsein- \\
richtungen
\end{tabular} & \begin{tabular}{|c} 
Direkte öffent- \\
liche Ausgaben \\
für private \\
Bildungsein- \\
richtungen
\end{tabular} & $\begin{array}{c}\text { Indirekte öffent- } \\
\text { liche Transfer- } \\
\text { und sonstige } \\
\text { Zahlungen an } \\
\text { den privaten } \\
\text { Sektor }\end{array}$ \\
\hline \multicolumn{10}{|l|}{ OECD-Länder } \\
\hline Österreich & 97,7 & 0,4 & 2,0 & 82,8 & 0,3 & 16,9 & 93,6 & 0,8 & 5,7 \\
\hline Belgien & 44,8 & 54,9 & 0,3 & 35,6 & 47,1 & 17,3 & 44,6 & 51,4 & 4,0 \\
\hline Kanada $^{1}$ & 98,2 & 1,8 & $x$ & 77,8 & 0,4 & 21,8 & 90,9 & 1,3 & 7,9 \\
\hline Tschechische Rep. & 90,7 & 3,5 & 5,9 & 91,0 & 1,1 & 7,9 & 91,7 & 2,7 & 5,6 \\
\hline Dänemark ${ }^{2}$ & 81,2 & 7,2 & 11,6 & 65,3 & $\mathrm{n}$ & 34,7 & 75,9 & 4,3 & 19,8 \\
\hline Finnland & 90,9 & 5,5 & 3,6 & 73,6 & 7,4 & 19,0 & 85,3 & 6,2 & 8,5 \\
\hline Frankreich & 83,1 & 13,5 & 3,4 & 88,3 & 3,3 & 8,4 & 85,1 & 11,0 & 3,9 \\
\hline Griechenland & 99,7 & a & 0,3 & 93,6 & a & 6,4 & 97,9 & a & 2,1 \\
\hline Ungarn & 82,4 & 7,5 & 10,1 & 77,0 & 3,5 & 19,5 & 83,6 & 5,8 & 10,5 \\
\hline Island & 97,3 & 1,5 & 1,2 & 67,9 & 8,4 & 23,7 & 92,4 & 2,6 & 5,0 \\
\hline Irland & 96,7 & $\mathrm{n}$ & 3,3 & 88,1 & $\mathrm{n}$ & 11,9 & 94,2 & $\mathrm{n}$ & 5,8 \\
\hline Italien & 96,5 & 2,2 & 1,3 & 85,9 & 1,7 & 12,4 & 94,4 & 2,3 & 3,3 \\
\hline$J_{a p a n}^{2}$ & 96,3 & 3,5 & 0,2 & 72,2 & 13,4 & 14,5 & 91,4 & 6,1 & 2,4 \\
\hline Korea & $\mathrm{m}$ & $\mathrm{m}$ & $\mathrm{m}$ & 56,9 & 33,4 & 9,6 & $\mathrm{~m}$ & $\mathrm{~m}$ & $\mathrm{~m}$ \\
\hline Luxemburg & 91,3 & 3,3 & 5,3 & $\mathrm{~m}$ & $\mathrm{~m}$ & $\mathrm{~m}$ & 91,3 & 3,3 & 5,3 \\
\hline Mexiko & 96,6 & $\mathrm{n}$ & 3,4 & 94,1 & $\mathrm{n}$ & 5,9 & 96,5 & $\mathrm{n}$ & 3,5 \\
\hline Niederlande & 23,4 & 69,7 & 6,9 & $\mathrm{n}$ & 76,4 & 23,6 & 18,0 & 71,2 & 10,8 \\
\hline Neuseeland & 88,4 & 4,0 & 7,6 & 50,3 & 2,1 & 47,7 & 77,5 & 4,5 & 18,0 \\
\hline Norwegen & 88,2 & 7,2 & 4,6 & 66,2 & 3,0 & 30,8 & 81,7 & 5,7 & 12,6 \\
\hline Polen & $\mathrm{m}$ & $\mathrm{m}$ & $\mathrm{m}$ & $\mathrm{m}$ & $\mathrm{m}$ & $\mathrm{m}$ & $\mathrm{m}$ & $\mathrm{m}$ & $\mathrm{m}$ \\
\hline Portugal & 92,1 & 6,6 & 1,3 & 93,8 & $\mathrm{n}$ & 6,2 & 91,8 & 6,1 & 2,1 \\
\hline Schweden & 86,0 & 3,9 & 10,1 & 65,2 & 4,6 & 30,1 & 80,4 & 4,5 & 15,1 \\
\hline Schweiz & 89,9 & 7,4 & 2,7 & 91,9 & 5,6 & 2,5 & 90,1 & 6,8 & 3,1 \\
\hline Türkei & 99,1 & $\mathrm{~m}$ & 0,9 & 85,6 & 0,3 & 14,0 & 94,8 & 0,1 & 5,1 \\
\hline Ver. Königreich & 79,8 & 20,0 & 0,2 & a & 94,7 & 5,3 & 68,0 & 31,0 & 1,0 \\
\hline Vereinigte Staaten $^{1}$ & 99,8 & 0,2 & $\mathrm{~m}$ & 61,3 & 1,3 & 37,4 & 89,2 & 1,0 & 9,8 \\
\hline Ländermittel & 86,5 & 10,4 & 3,8 & 69,8 & 11,6 & 18,2 & 83,0 & 10,0 & 7,1 \\
\hline \multicolumn{10}{|l|}{ OECD-Partnerländer } \\
\hline Argentinien & 86,3 & 13,0 & 0,7 & 97,1 & 2,5 & 0,3 & 88,2 & 11,2 & 0,6 \\
\hline Brasilien $^{3}$ & 97,2 & a & 2,8 & 83,4 & a & 16,6 & 94,2 & a & 5,8 \\
\hline Chile $^{4}$ & 63,6 & 36,0 & 0,4 & 37,2 & 33,3 & 29,5 & 60,1 & 35,5 & 4,5 \\
\hline Indien ${ }^{1}$ & 72,5 & 27,4 & 0,1 & 76,8 & 22,9 & 0,2 & 73,5 & 26,4 & 0,1 \\
\hline Indonesien & 90,0 & 6,6 & 3,4 & 100,0 & $\mathrm{n}$ & $\mathrm{m}$ & 92,4 & 5,0 & 2,6 \\
\hline Israel & 74,1 & 24,3 & 1,5 & 7,6 & 81,4 & 10,9 & 63,9 & 32,8 & 3,3 \\
\hline Jamaika & 97,7 & 0,2 & 2,1 & 87,6 & $\mathrm{n}$ & 12,4 & 92,3 & 3,7 & 4,0 \\
\hline Jordanien & 100,0 & a & $a$ & $\mathrm{~m}$ & $\mathrm{~m}$ & $\mathrm{~m}$ & $\mathrm{~m}$ & $\mathrm{~m}$ & $\mathrm{~m}$ \\
\hline Malaysia & 99,5 & a & 0,5 & 76,6 & a & 23,4 & 91,7 & a & 8,3 \\
\hline Paraguay & $\mathrm{m}$ & 6,3 & 0,3 & 98,7 & a & 1,3 & 94,3 & 5,2 & 0,5 \\
\hline Philippinen & 99,2 & a & 0,8 & 97,4 & a & 2,6 & 99,0 & a & 1,0 \\
\hline Thailand & 91,0 & 4,2 & 4,9 & 69,8 & $\mathrm{~m}$ & 30,2 & 87,8 & 2,2 & 10,0 \\
\hline Tunesien & 100,0 & a & $\mathrm{m}$ & 100,0 & a & $\mathrm{m}$ & 100,0 & a & $\mathrm{m}$ \\
\hline Uruguay & 99,9 & a & 0,1 & 100,0 & a & $\mathrm{n}$ & 100,0 & a & $\mathrm{n}$ \\
\hline
\end{tabular}

1. Post-sekundarer, nicht-tertiärer Bereich in Tertiärbereich enthalten. 2. Post-sekundarer, nicht-tertiärer Bereich sowohl in Sekundarbereich II als auch Tertiärbereich enthalten. 3. Referenzjahr 2000. 4. Referenzjahr 2002.

Quelle: OECD. Hinweise s. Anhang 3 unter www.oecd.org/edu/eag2004. 



\section{Die öffentlichen Bildungsausgaben}

Im Durchschnitt wenden die OECD-Länder 12,7 Prozent ihrer gesamten öffentlichen Ausgaben für Bildungseinrichtungen auf. Die Werte für die einzelnen Länder reichen jedoch von weniger als 10 Prozent in Deutschland, Luxemburg, der Slowakischen sowie der Tschechischen Republik bis zu 24 Prozent in Mexiko.

Die öffentliche Finanzierung der Bildung ist eine vorrangige gesellschaftspolitische Aufgabe - selbst in denjenigen OECD-Ländern, in denen die Staatsquote insgesamt gering ist.

Die öffentlichen Ausgaben für Bildung stiegen eher schneller als die öffentlichen Gesamtausgaben, jedoch langsamer als das BIP. Die öffentlichen Bildungsausgaben als Prozentsatz der öffentlichen Gesamtausgaben wuchsen zwischen 1995 und 2001 in Dänemark, Mexiko und Schweden am stärksten.

Abbildung B4.1

Gesamte öffentliche Ausgaben für Bildung als Prozentsatz der öffentlichen Gesamtausgaben (1995, 2001) Direkte öffentliche Ausgaben für Bildungseinrichtungen zuzüglich öffentlicher Subventionen für private Haushalte (einschl. Subventionen für den Lebensunterhalt und Subventionen für andere private Einheiten) als Prozentsatz der öffentlichen Gesamtausgaben, nach Bildungsbereich und Jahr

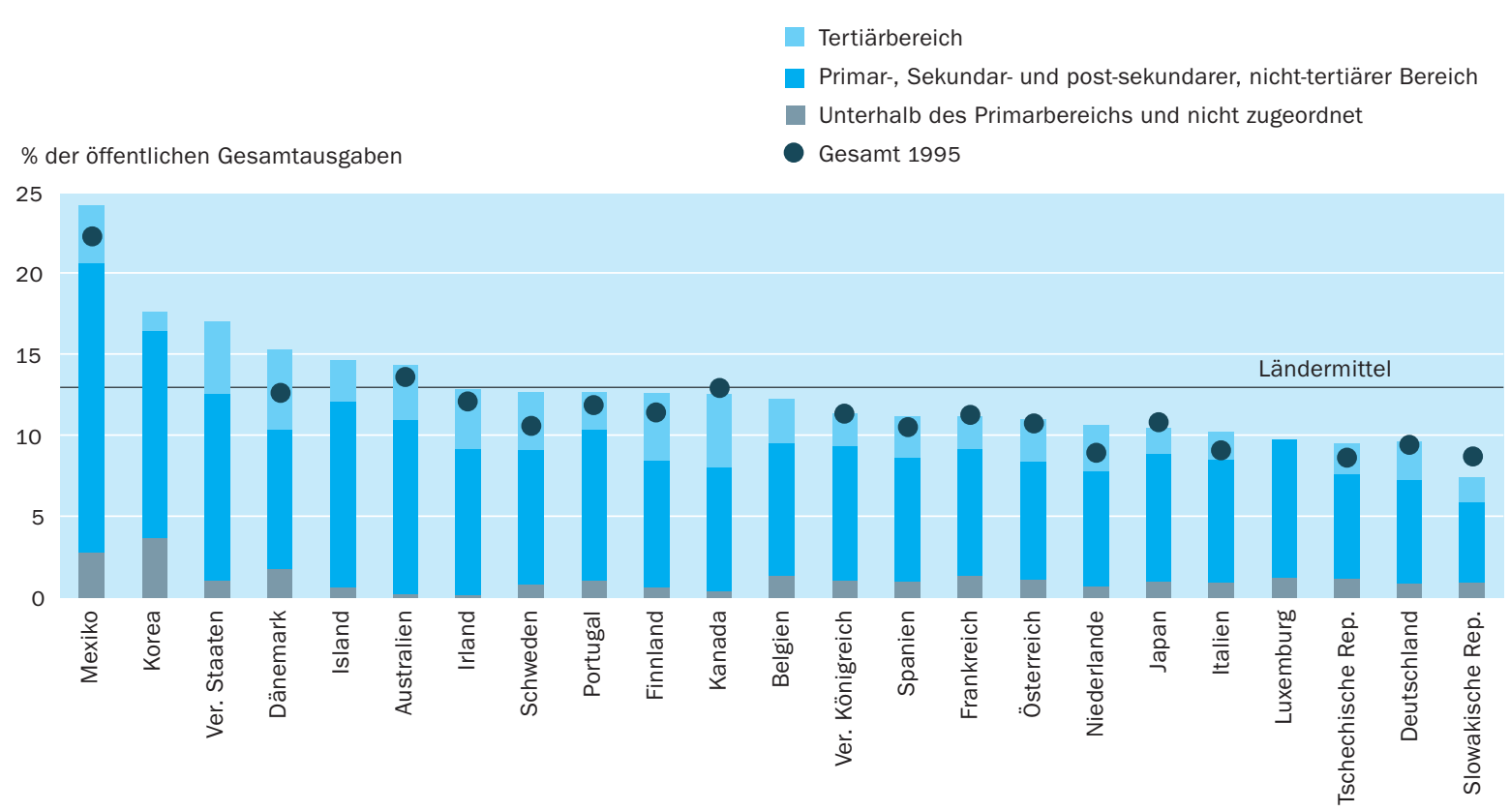

Anordnung der Länder in absteigender Reihenfolge der gesamten öffentlichen Ausgaben für Bildung als Prozentsatz der öffentlichen Gesamtausgaben im Jahr 2001. Quelle: OECD. Tabelle B4.1. Hinweise s. Anhang 3 unter www.oecd.org/edu/eag2004. 
Dieser Indikator konzentriert sich auf die öffentlichen Bildungsausgaben.

Ferner untersucht dieser Indikator die Veränderung der öfentlichen Bildungsausgaben über die Zeit, sowohl in absoluten Zahlen als auch im Vergleich zu den staatlichen Gesamtausgaben.

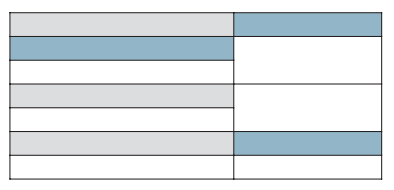

Erfasste Daten (Erklärungen s. S. 208)

\section{Politischer Hintergrund}

Der Staat beteiligt sich aus den unterschiedlichsten Gründen an der Bereitstellung von Dienstleistungen für die Bevölkerung. Wenn der öffentliche Nutzen einer bestimmten Dienstleistung größer als der private Nutzen ist, kann es sein, dass der Markt allein nicht in der Lage ist, derartige Dienstleistungen in angemessenem Umfang bereitzustellen. Bildung ist ein solcher Bereich, in dem der Staat in allen Ländern interveniert, um das Leistungsangebot zu finanzieren oder zu lenken. Da keine Garantie dafür besteht, dass die Märkte allen den gleichen Zugang zu Bildungschancen bieten, wird durch die staatliche Finanzierung der Bildung sichergestellt, dass nicht ein Teil der Gesellschaft von Bildungsmöglichkeiten ausgeschlossen wird. Die öffentlichen Ausgaben für Bildung als Prozentsatz der gesamten öffentlichen Ausgaben sind ein Indiz für den Stellenwert der Bildung im Vergleich zu anderen öffentlichen Aufgaben wie Gesundheitswesen, soziale Sicherung, Verteidigung und innere Sicherheit. Dieser Indikator liefert somit nicht nur den Hintergrund für die anderen Indikatoren, die sich mit den Ausgaben befassen (insbesondere Indikator B3 zu den Anteilen der öffentlichen und privaten Bildungsausgaben), sondern auch die Quantifizierung eines bildungspolitisch wichtigen Aspektes.

Seit der zweiten Hälfte der neunziger Jahre haben die meisten OECD-Länder große Anstrengungen zur Konsolidierung ihrer öffentlichen Haushalte unternommen. Bildung stand mit einer Vielzahl anderer in den staatlichen Haushalten enthaltener Finanzierungsaufgaben im Wettstreit um die öffentlichen Mittel. Um dies zu verdeutlichen, untersucht dieser Indikator die Veränderungen bei den Bildungsausgaben sowohl in absoluten Zahlen als auch im Verhältnis zur Entwicklung der öffentlichen Haushalte.

\section{Ergebnisse und Erläuterungen}

\section{Was dieser Indikator aufzeigt und was nicht.}

Dieser Indikator beschreibt die gesamten öffentlichen Ausgaben für Bildung. Darin sind die direkten öffentlichen Finanzmittel für Bildungseinrichtungen ebenso enthalten wie die öffentlichen Subventionen für private Haushalte (z. B. in Form von Stipendien und Studiendarlehen für Studiengebühren und Lebenshaltungskosten von Studierenden) sowie Zahlungen an andere private Einheiten für Bildungszwecke (z. B. Subventionen für Unternehmen oder Arbeitnehmerorganisationen, die Lehrlingsausbildungsprogramme durchführen). Im Unterschied zu den vorherigen Indikatoren beinhaltet dieser Indikator auch öffentliche Subventionen, die nicht Zahlungen privater Haushalte an Bildungseinrichtungen zuzurechnen sind, wie z. B. Unterstützungsleistungen für den Lebensunterhalt von Schülern/Studierenden.

Hinsichtlich der Verwendung öffentlicher Mittel für die Bildung gibt es Unterschiede zwischen den einzelnen OECD-Ländern. Öffentliche Mittel können direkt an Bildungseinrichtungen fließen oder über staatliche Programme oder die privaten Haushalte in die Bildungseinrichtungen gelenkt werden, sie können auf den Erwerb von Bildungsdienstleistungen beschränkt sein oder als Unterstützung zu den Lebenshaltungskosten von Schülern/Studierenden gewährt werden. 
$\mathrm{Zu}$ den öffentlichen Gesamtausgaben für Dienstleistungen, ohne Bildung, gehören auch die Ausgaben des Schuldendienstes (d.h. Zinszahlungen), die nicht in den öffentlichen Bildungsausgaben enthalten sind. Grund hierfür ist, dass einige Länder nicht zwischen den Zinszahlungen im Bereich Bildung und denen in anderen Bereichen differenzieren können. Das bedeutet, dass die öffentlichen Bildungsausgaben als Prozentsatz der öffentlichen Gesamtausgaben in denjenigen Ländern zu niedrig angesetzt sein können, in denen Zinszahlungen einen großen Teil der öffentlichen Gesamtausgaben für alle Dienstleistungsbereiche ausmachen.

Es ist wichtig, die öffentlichen Bildungsausgaben im Zusammenhang mit den in Indikator $\mathrm{B}_{3}$ behandelten privaten Bildungsausgaben zu betrachten.

\section{Gesamtvolumen der in die Bildung investierten öffentlichen Mittel} 200 I wendeten die OECD-Länder im Durchschnitt I2,7 Prozent ihrer gesamten öffentlichen Ausgaben für Bildung auf. Die Werte für die einzelnen Länder reichen jedoch von weniger als Io Prozent in Deutschland, Luxemburg, der Slowakischen sowie der Tschechischen Republik bis zu 24 Prozent in Mexiko (Abb. B4.I). Wie bei den Bildungsausgaben im Verhältnis zum BIP pro Kopf müssen auch die hier ausgewiesenen Werte im Zusammenhang mit den Schüler-/Studierendenzahlen sowie den jeweiligen Beteiligungsquoten betrachtet werden.

Der öffentliche Anteil an der Finanzierung der verschiedenen Bildungsbereiche ist in den einzelnen OECD-Ländern sehr unterschiedlich. Im Jahr $200 \mathrm{I}$ setzten die OECD-Länder zwischen 6,4 Prozent (Deutschland) und I8 Prozent (Mexiko) ihrer gesamten öffentlichen Ausgaben für den Primar-, Sekundarund post-sekundaren, nicht-tertiären Bereich ein und zwischen I,2 Prozent (Korea) und 4,9 Prozent (Dänemark) für den tertiären Bereich. Im Durchschnitt sind die öffentlichen Ausgaben in den OECD-Ländern im Primar-, Sekundar- und post-sekundaren, nicht-tertiären Bildungsbereich dreimal so hoch wie im Tertiärbereich, hauptsächlich aufgrund der Schüler/Studierendenzahlen. Dieses Verhältnis variiert je nach Land von weniger als zweimal so hoch in Dänemark, Finnland und Kanada bis zu beinahe II mal so hoch in Korea. Der letztere Wert ist ein Hinweis auf den relativ hohen Anteil privater Mittel, die in Korea in den Tertiärbereich fließen (Tab. B4.I).

Bei der Betrachtung der öffentlichen Bildungsausgaben als Anteil an den gesamten öffentlichen Ausgaben ist die relative Größe der öffentlichen Haushalte (gemessen im Verhältnis der öffentlichen Ausgaben zum BIP) zu berücksichtigen.

In allen OECD-Ländern wird bei einem Vergleich des öffentlichen Gesamthaushalts im Verhältnis zum BIP mit dem Anteil der öffentlichen Ausgaben für Bildungseinrichtungen offensichtlich, dass sogar in Ländern mit einem relativ geringen Anteil öffentlicher Ausgaben dem Bildungsbereich sehr hohe Priorität beigemessen wird. So gehören zum Beispiel die Anteile öffentlicher Ausgaben, die in Korea, Mexiko und den Vereinigten Staaten in die Bildung fließen, zu den höchsten unter den OECD-Ländern (Abb. B4.I), und dennoch machen die öffentlichen Gesamtausgaben in diesen Ländern nur einen relativ geringen Teil des BIP aus (Abb. B4.2).
2001 wendeten die OECDLänder im Durchschnitt 12,7 Prozent ihrer gesamten öffentlichen Ausgaben für Bildung auf:

Im Durchschnitt wenden die OECD-Länder dreimal so viel für den Primar-, Sekundarund post-sekundaren, nichttertiären Bildungsbereich auf wie für den Tertiärbereich.

Die öffentliche Finanzierung der Bildung ist eine vorrangige gesellschaftspolitische Aufgabe - selbst in denjenigen OECD-Ländern, in denen die Staatsquote insgesamt gering ist. 


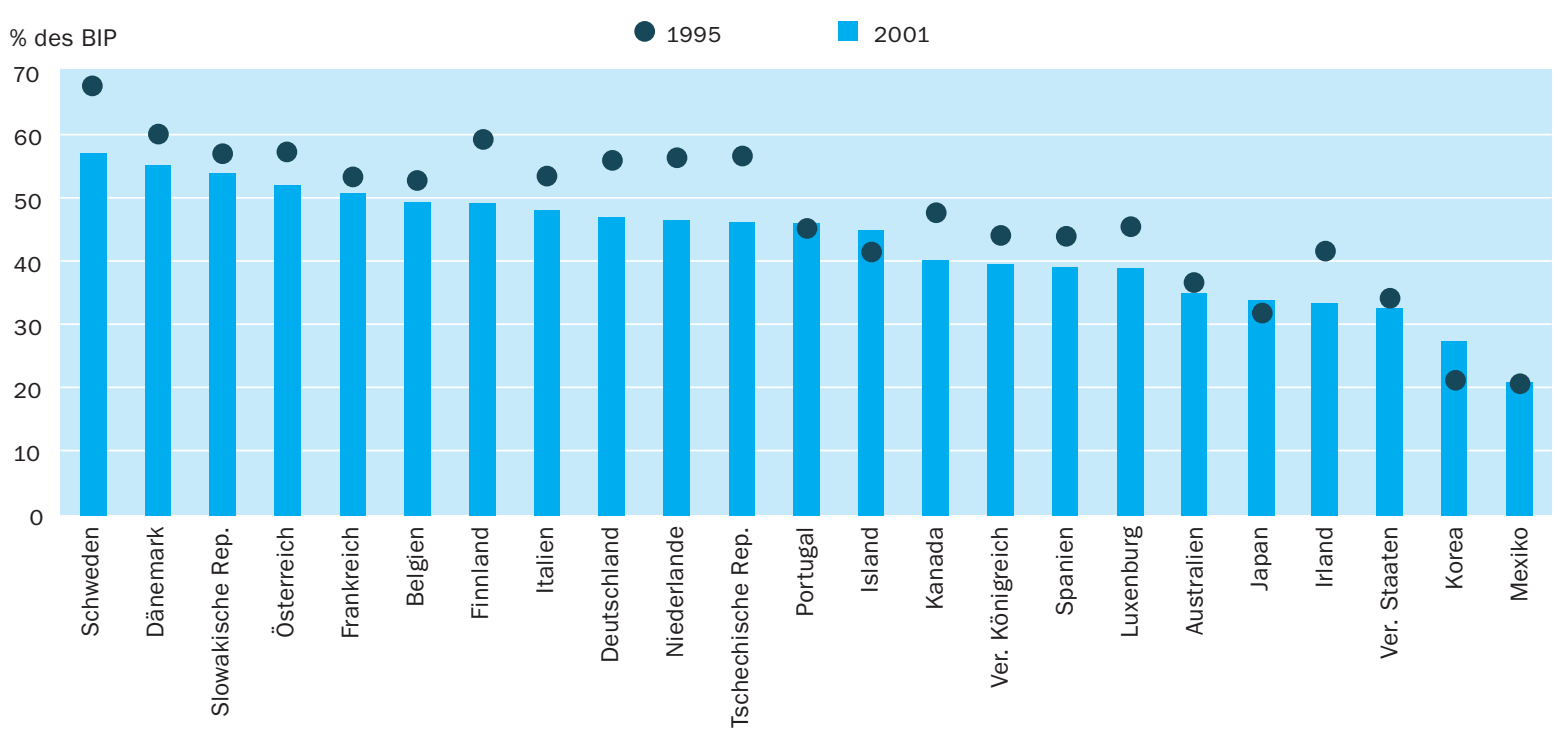

Anordnung der Länder in absteigender Reihenfolge der gesamten öffentlichen Ausgaben für Bildung als Prozentsatz der öffentichen Gesamtausgaben im Jahr 2001 Quelle: OECD. Tabelle B4.1. Hinweise s. Anhang 3 unter www.oecd.org/edu/eag2004.

In der Regel nahmen die öffentlichen Bildungsausgaben schneller zu als die öffentlichen Gesamtausgaben, aber nicht so schnell wie das Volkseinkommen zwischen 1994 und 2001.
Die Daten beziehen sich auf das Haushaltsjahr 2001 und beruhen auf der von der OECD im Jahre 2003 durchgeführten UOE-Datenerhebung
Obwohl das Bild nicht überall eindeutig ist, gibt es Hinweise darauf, dass Länder mit einem hohen Anteil öffentlicher Ausgaben proportional weniger davon für den Bildungsbereich ausgeben; nur vier der zehn bei den öffentlichen Gesamtausgaben für öffentliche Dienstleistungen führenden Länder (Dänemark, Finnland, Portugal und Schweden) sind auch bei den öffentlichen Bildungsausgaben unter den ,Top Ten' (Abb. B4.I und B4.2).

Wie jede andere öffentliche Dienstleistung wird auch die Bildung durch den Prozess der Haushaltskonsolidierung belastet. Dennoch stiegen - außer in Kanada, Japan und der Slowakischen Republik - die Bildungsausgaben mindestens genau so schnell wie die Ausgaben für andere öffentliche Bereiche zwischen 1995 und 200I. Der Anteil der Bildungsausgaben an den Gesamtetats erhöhte sich im Durchschnitt von II,8 Prozent im Jahre I995 auf I2,7 Prozent im Jahr 200I. Diese Zahlen zeigen, dass der stärkste Zuwachs im Anteil der öffentlichen Ausgaben für Bildung zwischen 1995 und 200I in Dänemark (Steigerung von I2,7 auf I5,4 Prozent), Mexiko (von 22,4 auf 24,3 Prozent) und Schweden (von Io, 6 auf I2, 8 Prozent) zu verzeichnen war.

\section{Definitionen und angewandte Methodik}

Bildungsausgaben werden ausgedrückt als Prozentsatz der öffentlichen Gesamtausgaben eines Landes und als Prozentsatz des BIP. Die öffentlichen Bildungsausgaben beinhalten die Ausgaben für Bildungseinrichtungen sowie Subventionen zum Lebensunterhalt von Schülern/Studierenden und für andere private Ausgaben außerhalb von Bildungseinrichtungen. In den öffentli- 
chen Bildungsausgaben sind die Ausgaben sämtlicher öffentlicher Einrichtungen einschließlich anderer Ministerien neben dem Bildungsministerium sowie die Ausgaben der Gebietskörperschaften und anderer öffentlicher Stellen enthalten.

Die öffentlichen Gesamtausgaben bzw. die staatlichen Gesamtausgaben sind nicht rückzahlbare laufende und investive Ausgaben aller Gebietskörperschaften: zentraler, regionaler und kommunaler. Die laufenden Ausgaben betreffen konsumtive Ausgaben, Pacht-, Miet- und Zinszahlungen, Subventionen sowie sonstige laufende Transferzahlungen (z. B. Sozialversicherungen, Sozialhilfe, Renten und sonstige Wohlfahrtsleistungen). Die Daten für die öffentlichen Gesamtausgaben stammen aus der OECD-Datenbank der volkswirtschaftlichen Gesamtrechnungen (s. Anhang 2) und beruhen auf dem ,System of National Accounts 1993،. In früheren Ausgaben von Bildung auf einen Blick bezogen sich die öffentlichen Gesamtausgaben auf das ,System of National Accounts I968،. Die Umstellung des Systems der volkswirtschaftlichen Gesamtrechnung könnte daher für Unterschiede bei diesem Indikator gegenüber früheren Ausgaben von „Bildung auf einen Blick“ verantwortlich sein.

Es ist zu beachten, dass die in früheren Ausgaben dieser Veröffentlichung aufgeführten Zahlen und Daten möglicherweise nicht immer mit denen der Ausgabe 2004 vergleichbar sind, da sich Änderungen in den Definitionen und Erhebungsbereichen ergeben haben. Diese wurden aufgrund der OECD Expenditure Comparability Study vorgenommen (Einzelheiten zu den Änderungen s. Anhang 3 unter www.oecd.org/edu/eag2004). 
Tabelle B4.1

Öffentliche Gesamtausgaben für Bildung (1995, 2001)

Direkte öffentliche Ausgaben für Bildungseinrichtungen zuzüglich öffentlicher Subventionen an private Haushalte (einschl. Subventionen für den Lebensunterhalt und Subventionen an andere private Einheiten) als Prozentsatz des BIP und als Prozentsatz der öffentlichen Gesamtausgaben, nach Bildungsbereich und Jahr

Die öffentlichen Bildungsausgaben ${ }^{1}$ als Prozentsatz der öffentlichen Gesamtausgaben

Die öffentlichen Bildungsausgaben ${ }^{1}$ als Prozentsatz des BIP

\begin{tabular}{|c|c|c|}
\hline \multicolumn{3}{|c|}{2001} \\
\hline $\begin{array}{l}\text { Primar-, Sekundar- } \\
\text { und post-sekun- } \\
\text { darer, nicht- } \\
\text { tertiärer Bereich }\end{array}$ & Tertiärbereich & $\begin{array}{l}\text { Alle Bildungs- } \\
\text { bereiche } \\
\text { zusammen }\end{array}$ \\
\hline 10,8 & 3,4 & 14,4 \\
\hline 7,3 & 2,6 & 11,1 \\
\hline 8,2 & 2,8 & 12,4 \\
\hline 7,6 & 4,6 & 12,7 \\
\hline 6,5 & 1,8 & 9,6 \\
\hline 8,7 & 4,9 & 15,4 \\
\hline 7,8 & 4,2 & 12,7 \\
\hline 7,9 & 2,0 & 11,2 \\
\hline 6,4 & 2,4 & 9,7 \\
\hline $\mathrm{m}$ & $\mathrm{m}$ & $\mathrm{m}$ \\
\hline $\mathrm{m}$ & $\mathrm{m}$ & $\mathrm{m}$ \\
\hline 11,5 & 2,5 & 14,7 \\
\hline 9,1 & 3,7 & 13,0 \\
\hline 7,6 & 1,7 & 10,3 \\
\hline 7,9 & 1,6 & 10,5 \\
\hline 12,8 & 1,2 & 17,7 \\
\hline 8,5 & $\mathrm{~m}$ & 9,8 \\
\hline 18,0 & 3,5 & 24,3 \\
\hline 7,1 & 2,8 & 10,7 \\
\hline $\mathrm{m}$ & $\mathrm{m}$ & $\mathrm{m}$ \\
\hline $\mathrm{m}$ & $\mathrm{m}$ & $\mathrm{m}$ \\
\hline $\mathrm{m}$ & $\mathrm{m}$ & $\mathrm{m}$ \\
\hline 9,3 & 2,3 & 12,7 \\
\hline 4,9 & 1,5 & 7,5 \\
\hline 7,6 & 2,6 & 11,3 \\
\hline 8,4 & 3,6 & 12,8 \\
\hline $\mathrm{m}$ & $\mathrm{m}$ & $\mathrm{m}$ \\
\hline $\mathrm{m}$ & $\mathrm{m}$ & $\mathrm{m}$ \\
\hline 8,4 & 2,0 & 11,4 \\
\hline 11,5 & 4,5 & 17,1 \\
\hline
\end{tabular}

\begin{tabular}{|c|c|c|c|c|}
\hline $\begin{array}{c}|c| \\
\text { Alle Bildungs- } \\
\text { bereiche } \\
\text { zusammen }\end{array}$ & $\begin{array}{c}\text { Primar-, Sekundar- } \\
\text { und post-sekun- } \\
\text { darer, nicht- } \\
\text { tertiärer Bereich }\end{array}$ & Tertiärbereich & $\begin{array}{c}\text { Alle Bildungs- } \\
\text { bereiche } \\
\text { zusammen }\end{array}$ & $\begin{array}{c}\text { Alle Bildungs- } \\
\text { bereiche } \\
\text { zusammen }\end{array}$ \\
\end{tabular}

OECD-Länder

Australien

Österreich

Belgien

Kanada ${ }^{2}$

Tschechische Rep.

Dänemark ${ }^{3}$

Finnland

Frankreich

Deutschland

Griechenland

Ungarn

Island

Irland

Italien

Japan $^{3}$

Korea

Luxemburg

Mexiko

Niederlande

Neuseeland

Norwegen

Polen

Portugal

Slowakische Rep.

Spanien

Schweden

Schweiz

Türkei

Ver. Königreich

Vereinigte Staaten ${ }^{2}$

\begin{tabular}{|c|c|c|c|c|c|c|c|c|}
\hline Ländermittel & 8,9 & 2,8 & 12,7 & 11,8 & 3,6 & 1,3 & 5,3 & 5,3 \\
\hline \multicolumn{9}{|c|}{ OECD-Partnerländer } \\
\hline Argentinien & 10,1 & 2,3 & 13,5 & $\mathrm{~m}$ & 3,6 & 0,8 & 4,8 & $\mathrm{~m}$ \\
\hline Brasilien 4 & 8,3 & 2,7 & 12,0 & $\mathrm{~m}$ & 3,0 & 1,0 & 4,4 & $\mathrm{~m}$ \\
\hline Chile $^{5}$ & 14,5 & 2,6 & 18,7 & $\mathrm{~m}$ & 3,4 & 0,6 & 4,4 & $\mathrm{~m}$ \\
\hline Indien ${ }^{2}$ & 9,9 & 2,6 & 12,7 & $\mathrm{~m}$ & 3,1 & 0,8 & 4,0 & $\mathrm{~m}$ \\
\hline Indonesien & 7,5 & 2,3 & 9,8 & $\mathrm{~m}$ & 1,0 & 0,3 & 1,3 & $\mathrm{~m}$ \\
\hline Israel & 9,1 & 2,4 & 13,7 & 13,3 & 4,7 & 1,3 & 7,1 & 8,5 \\
\hline Jamaika & 9,2 & 2,3 & 12,3 & $\mathrm{~m}$ & 4,8 & 1,2 & 6,3 & $\mathrm{~m}$ \\
\hline Jordanien & $\mathrm{m}$ & $\mathrm{m}$ & $\mathrm{m}$ & $\mathrm{m}$ & 4,3 & $\mathrm{~m}$ & $\mathrm{~m}$ & $\mathrm{~m}$ \\
\hline Malaysia & 12,4 & 6,8 & 20,0 & $\mathrm{~m}$ & 4,9 & 2,7 & 7,9 & $\mathrm{~m}$ \\
\hline Paraguay & 8,0 & 1,7 & 9,7 & $\mathrm{~m}$ & 3,7 & 0,8 & 4,5 & $\mathrm{~m}$ \\
\hline Peru & 16,1 & 5,3 & 23,5 & $\mathrm{~m}$ & 2,0 & 0,7 & 2,9 & $\mathrm{~m}$ \\
\hline Philippinen & 11,8 & 1,8 & 14,0 & $\mathrm{~m}$ & 2,7 & 0,4 & 3,2 & $\mathrm{~m}$ \\
\hline Russische Föd. & 6,7 & 2,0 & 11,5 & $\mathrm{~m}$ & 1,8 & 0,5 & 3,0 & $\mathrm{~m}$ \\
\hline Thailand & 14,9 & 6,1 & 28,3 & $\mathrm{~m}$ & 2,7 & 1,1 & 5,0 & $\mathrm{~m}$ \\
\hline Tunesien & 14,2 & 4,0 & 18,2 & $\mathrm{~m}$ & 5,3 & 1,5 & 6,8 & $\mathrm{~m}$ \\
\hline Uruguay & 8,9 & 2,7 & 12,8 & $\mathrm{~m}$ & 2,2 & 0,7 & 3,1 & $\mathrm{~m}$ \\
\hline Simbabwe 2,5 & $\mathrm{~m}$ & $\mathrm{~m}$ & $\mathrm{~m}$ & $\mathrm{~m}$ & 5,6 & a & 5,6 & $\mathrm{~m}$ \\
\hline
\end{tabular}

\begin{tabular}{|c|c|c|c|c|c|c|c|c|}
\hline Ländermittel & 8,9 & 2,8 & 12,7 & 11,8 & 3,6 & 1,3 & 5,3 & 5,3 \\
\hline \multicolumn{9}{|c|}{ OECD-Partnerländer } \\
\hline Argentinien & 10,1 & 2,3 & 13,5 & $\mathrm{~m}$ & 3,6 & 0,8 & 4,8 & $\mathrm{~m}$ \\
\hline Brasilien 4 & 8,3 & 2,7 & 12,0 & $\mathrm{~m}$ & 3,0 & 1,0 & 4,4 & $\mathrm{~m}$ \\
\hline Chile $^{5}$ & 14,5 & 2,6 & 18,7 & $\mathrm{~m}$ & 3,4 & 0,6 & 4,4 & $\mathrm{~m}$ \\
\hline Indien ${ }^{2}$ & 9,9 & 2,6 & 12,7 & $\mathrm{~m}$ & 3,1 & 0,8 & 4,0 & $\mathrm{~m}$ \\
\hline Indonesien & 7,5 & 2,3 & 9,8 & $\mathrm{~m}$ & 1,0 & 0,3 & 1,3 & $\mathrm{~m}$ \\
\hline Israel & 9,1 & 2,4 & 13,7 & 13,3 & 4,7 & 1,3 & 7,1 & 8,5 \\
\hline Jamaika & 9,2 & 2,3 & 12,3 & $\mathrm{~m}$ & 4,8 & 1,2 & 6,3 & $\mathrm{~m}$ \\
\hline Jordanien & $\mathrm{m}$ & $\mathrm{m}$ & $\mathrm{m}$ & $\mathrm{m}$ & 4,3 & $\mathrm{~m}$ & $\mathrm{~m}$ & $\mathrm{~m}$ \\
\hline Malaysia & 12,4 & 6,8 & 20,0 & $\mathrm{~m}$ & 4,9 & 2,7 & 7,9 & $\mathrm{~m}$ \\
\hline Paraguay & 8,0 & 1,7 & 9,7 & $\mathrm{~m}$ & 3,7 & 0,8 & 4,5 & $\mathrm{~m}$ \\
\hline Peru & 16,1 & 5,3 & 23,5 & $\mathrm{~m}$ & 2,0 & 0,7 & 2,9 & $\mathrm{~m}$ \\
\hline Philippinen & 11,8 & 1,8 & 14,0 & $\mathrm{~m}$ & 2,7 & 0,4 & 3,2 & $\mathrm{~m}$ \\
\hline Russische Föd. & 6,7 & 2,0 & 11,5 & $\mathrm{~m}$ & 1,8 & 0,5 & 3,0 & $\mathrm{~m}$ \\
\hline Thailand & 14,9 & 6,1 & 28,3 & $\mathrm{~m}$ & 2,7 & 1,1 & 5,0 & $\mathrm{~m}$ \\
\hline Tunesien & 14,2 & 4,0 & 18,2 & $\mathrm{~m}$ & 5,3 & 1,5 & 6,8 & $\mathrm{~m}$ \\
\hline Uruguay & 8,9 & 2,7 & 12,8 & $\mathrm{~m}$ & 2,2 & 0,7 & 3,1 & $\mathrm{~m}$ \\
\hline Simbabwe 2,5 & $\mathrm{~m}$ & $\mathrm{~m}$ & $\mathrm{~m}$ & $\mathrm{~m}$ & 5,6 & a & 5,6 & $\mathrm{~m}$ \\
\hline
\end{tabular}

\begin{tabular}{r|}
13,6 \\
10,7 \\
$m$ \\
13,1 \\
8,7
\end{tabular}

8,7

12,7

11,5

11,3

8,2
6,6

6,6
12,9

m

12,2
9,1

9,1
11,0

$\mathrm{m}$

22,4

9,0
14,4

15,3

11,9

11,9

8,8

10,6

10,6

14,2

m

\begin{tabular}{l|l}
2,5 \\
11,4 & 3,4
\end{tabular}

Simbabwe 2,5

1. In dieser Tabelle enthaltene öffentliche Ausgaben beinhalten öffentliche Subventionen an private Haushalte für den Lebensunterhalt, die nicht für Bildungseinrichtungen ausgegeben werden. Daher übersteigen die in dieser Tabelle angegebenen entsprechenden Zahlen die für die öffentlichen Ausgaben für Bildungseinrichtungen in Tabelle B2.1b. 2. Post-sekundarer, nicht-tertiärer Bereich in Tertiärbereich und nicht in Primar-, Sekundar- und post-sekundarer, nicht-tertiärer Bereich enthalten.

3. Post-sekundarer, nicht-tertiärer Bereich sowohl in Sekundarbereich II als auch Tertiärbereich enthalten. 4. Referenzjahr $2000 . \quad 5$. Referenzjahr 2002.

Quelle: OECD. Hinweise s. Anhang 3 unter www.oecd.org/edu/eag2004. 


\section{Unterstützung für Schüler/Studierende und private Haushalte durch öffentliche Subventionen}

Öffentliche Subventionen für Schüler/Studierende und private Haushalte finden sich hauptsächlich im Tertiärbereich.

Durchschnittlich 17 Prozent der öffentlichen Ausgaben für den Tertiärbereich betreffen finanzielle Unterstützungsleistungen an Studierende, private Haushalte und andere private Einheiten. In Australien, Dänemark, Neuseeland, Norwegen, Schweden und den Vereinigten Staaten machen die öffentlichen Subventionen ungefähr 30 Prozent und mehr der öffentlichen Bildungsetats für den Tertiärbereich aus.

Subventionen sind generell häufiger in Systemen anzutreffen, bei denen von den Schülern/Studierenden erwartet wird, dass sie wenigstens einen Teil ihrer Bildungskosten selbst tragen.

Subventionierte Darlehenssysteme für Schüler/Studierende existieren in der Regel in Ländern mit einer hohen Bildungsbeteiligung im Tertiärbereich.

In den meisten OECD-Ländern genießen die Empfänger von Subventionen einen erheblichen Ermessensspielraum hinsichtlich der Verwendung der erhaltenen Subventionen. In allen OECD-Ländern, für die Zahlen vorliegen, werden Subventionen in erster Linie außerhalb der Bildungseinrichtungen ausgegeben - in jedem dritten sogar ausschließlich. 
Öffentliche Subventionen für Bildung im Tertiärbereich (2001)

Öffentliche Subventionen für Bildung an private Haushalte und andere private Einheiten als Prozentsatz der öffentlichen Gesamtausgaben für Bildung, nach Art der Subvention

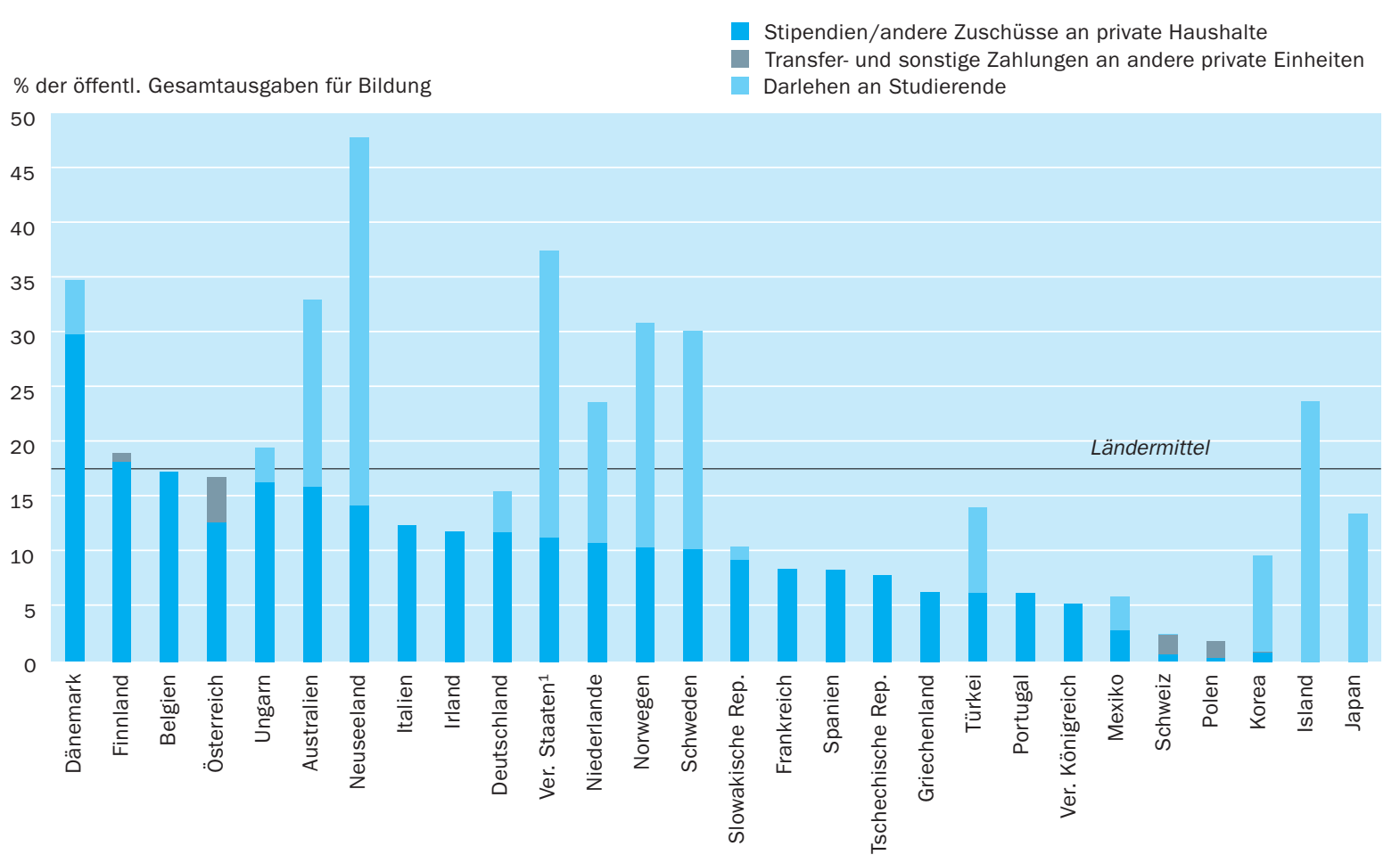

1.Einschließlich post-sekundarer, nicht-tertiärer Bereich.

Anordnung der Länder in absteigender Reihenfolge der Stipendien/anderen Zuschüsse an private Haushalte und Transfer- und sonstigen Zahlungen an andere private Einheiten im Tertiärbereich.

Quelle: OECD. Tabelle B5.2. Hinweise s. Anhang 3 unter www.oecd.org/edu/eag2004.

Dieser Indikator untersucht die direkten und indirekten öffentlichen Ausgaben für Bildungseinrichtungen sowie die an private Haushalte gezahlten öffentlichen Zuschüsse für den Lebensunterhalt von Schülern/Studierenden.

\section{Politischer Hintergrund}

Subventionen an Schüler/Studierende und ihre Familien sind politische Ansatzpunkte, durch die der Staat eine stärkere Bildungsbeteiligung, insbesondere von Schülern und Studierenden aus einkommensschwachen Familien, fördern kann, indem ein Teil der direkten und indirekten Bildungskosten bezuschusst wird. Sie sind somit eine Möglichkeit, Probleme des Zugangs und der Chancengleichheit anzugehen. Ihr erfolgreicher Einsatz muss daher, zumindest zum Teil, durch die Untersuchung von Indikatoren zu Bildungsbeteiligung, Erfolgs- und Abschlussquoten bewertet werden. Ferner spielen öffentliche Subventionen auch bei der indirekten Finanzierung von Bildungseinrichtungen eine wichtige Rolle.

Indem Finanzmittel für Bildungseinrichtungen über Schüler/Studierende gelenkt werden, kann auch ein Beitrag zu mehr Wettbewerb zwischen den Bildungseinrichtungen und zu einer größeren Effizienz der Bildungsfinanzierung geleistet werden. Da Zuschüsse zu den Lebenshaltungskosten der Schüler/Studierenden eine Erwerbstätigkeit zur Finanzierung von Bildung ersetzen können, tragen öffentliche Subventionen möglicherweise auch dazu bei, den 
Bildungsstand anzuheben, indem Schülern/Studierenden die Möglichkeit für einen Vollzeitschulbesuch bzw. ein Vollzeitstudium gegeben wird und sie entsprechend weniger oder überhaupt keiner bezahlten Tätigkeit zur Finanzierung ihres Studiums nachgehen müssen.

Öffentliche Subventionen können in vielfältiger Weise bereitgestellt werden: als einkommensabhängige Zuschüsse, als Familienbeihilfen für alle Schüler/ Studierenden, als Steuerfreibeträge für Schüler/Studierende bzw. ihre Eltern oder in Form sonstiger Transferleistungen an private Haushalte. Nicht an Bedingungen geknüpfte Subventionsleistungen wie Steuerermäßigungen oder Familienbeihilfen werden möglicherweise von einkommensschwachen Schülern/Studierenden weniger als Anreiz zu einer Bildungsteilnahme empfunden als dies bei einkommensabhängigen Zuschüssen der Fall ist. Sie können jedoch auf jeden Fall dazu beitragen, Ungleichheiten zwischen Haushalten mit und ohne Kindern in Ausbildung abzubauen.

Eine entscheidende Frage ist, ob Finanzhilfen an private Haushalte in Form von Zuschüssen oder Darlehen gewährt werden sollen. Können Finanzhilfen in Form von Darlehen dazu beitragen, die Wirksamkeit der in Bildung investierten Ressourcen zu erhöhen und einen Teil der Bildungskosten auf die Nutznießer der Bildungsinvestitionen zu verlagern? Oder sind Studiendarlehen weniger wirksam als Zuschüsse, wenn es darum geht, einkommensschwache Schüler/Studierende zu mehr Bildung zu ermutigen? Dieser Indikator kann diese Fragen zwar nicht beantworten, er zeigt jedoch die von den einzelnen OECD-Ländern verfolgte Subventionspolitik auf.

\section{Ergebnisse und Erläuterungen}

Was dieser Indikator aufzeigt und was nicht.

Dieser Indikator liefert Information über den Teil der öffentlichen Bildungsausgaben, der aus Transferzahlungen an Schüler/Studierende, ihre Familien und andere private Einheiten besteht. Ein Teil dieser Gelder geht indirekt an Bildungseinrichtungen, wenn z. B. Subventionen für die Zahlung von Schul-/ Studiengebühren genutzt werden. Andere Subventionsleistungen haben keinerlei Bezug zu Bildungseinrichtungen, z. B. finanzielle Zuschüsse zu den Lebenshaltungskosten von Schülern/Studierenden.

Bei diesem Indikator wird zwischen nicht-rückzahlbaren Subventionen in Form von Stipendien und Studienbeihilfen einerseits und rückzahlbaren Darlehen andererseits unterschieden. Nicht unterschieden wird jedoch zwischen den verschiedenen Arten von Beihilfen bzw. Darlehen, wie z. B. Stipendien einerseits und Familienbeihilfen und Subventionen in Form von Sachleistungen andererseits.

Der Staat kann die Schüler/Studierenden und ihre Familien auch durch die Gewährung von Steuerermäßigungen und Steueranrechnungen unterstützen. Diese Arten von Subventionen werden in diesem Indikator jedoch nicht berücksichtigt.

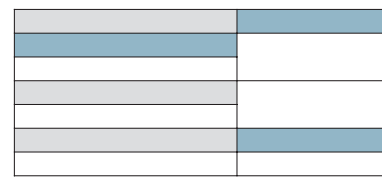

Erfasste Daten

(Erklärungen S. S. 208) 
Die OECD-Länder geben im Durchschnitt ungefähr 0,4 Prozent ihres BIP für öfentliche Subventionen an private Haushalte und andere private Einheiten aus.
Im Rahmen dieses Indikators wird das Gesamtvolumen der Darlehen angegeben, um Aufschluss über die Höhe der Unterstützungsleistungen für die derzeitigen Studierenden zu erhalten. Die Rückzahlungen der Darlehen werden nicht berücksichtigt, obwohl diese einen erheblichen Beitrag zur Senkung der realen Kreditkosten leisten können. Es wurde derart verfahren, weil der Bruttobetrag der Darlehen und Stipendien bzw. Zuschüsse die relevante Messgröße für die Ermittlung der Finanzhilfen an die gegenwärtigen Bildungsteilnehmer ist. Obwohl Zins- und Tilgungszahlungen durch den Darlehensnehmer bei der Ermittlung der öffentlichen und privaten Darlehensgebern durch Studiendarlehen entstehenden Nettokosten berücksichtigt werden müssten, werden diese Zahlungen in der Regel nicht von gegenwärtigen Schülern/Studierenden, sondern von ehemaligen Schülern/Studierenden geleistet. Außerdem fließen Darlehensrückzahlungen in den meisten Ländern nicht den Bildungsbehörden zu, so dass ihnen diese Gelder nicht zur Verfügung stehen, um damit andere Bildungsausgaben zu bestreiten.

Da es zur Zeit keine international vergleichbare Methode zur Berechnung der Nettokosten von Ausbildungsdarlehensprogrammen gibt, müssen die Darlehen entsprechend der wahrscheinlichen Verwendung der Mittel behandelt werden. Die OECD-Indikatoren berücksichtigen daher bei der Diskussion finanzieller Unterstützung für Schüler/Studierende die Gesamtsumme von Stipendien und Darlehen (brutto).

Häufig wird auch eine staatliche Bürgschaft für Studiendarlehen privater Kreditgeber gewährt. In einigen OECD-Ländern ist diese indirekte Form der Subventionierung ebenso bedeutend wie die direkte Finanzhilfe an Schüler/Studierende oder sogar noch bedeutender. Aus Gründen der besseren Vergleichbarkeit werden jedoch in diesem Indikator nur die öffentlichen Transferleistungen an private Einheiten berücksichtigt, das Gesamtvolumen der Darlehen wurde dagegen nicht berücksichtigt.

Für einige OECD-Länder gestaltet es sich außerdem recht schwierig, die den Schülern/Studierenden gewährte Gesamtsumme an Darlehen eindeutig zu ermitteln. Zahlen zu den Studiendarlehen sind daher mit Vorsicht zu interpretieren.

\section{Öffentliche Subventionen an private Haushalte und andere private Einheiten}

Die OECD-Länder geben im Durchschnitt für alle Bildungsbereiche zusammen 0,4 Prozent ihres BIP für öffentliche Subventionen an private Haushalte und andere private Einheiten aus. Die Subventionen im Verhältnis zum BIP sind in Dänemark ( $\mathrm{I}, 5$ Prozent des BIP) am höchsten, gefolgt von Neuseeland (I, 2 Prozent) und Schweden (I,I Prozent). Außerdem entfallen im Durchschnitt der OECD-Länder 7,I Prozent der öffentlichen Bildungsetats auf Transferleistungen an den privaten Sektor (Tabellen B4.I, B5.I und B5.2). Der größte Teil dieser Gelder geht in den Tertiärbereich, außer in Frankreich, Korea, Mexiko, Polen, der Schweiz, der Tschechischen Republik und Ungarn, wo über 50 Prozent der Transferzahlungen an den privaten Sektor auf den Primar-, Sekundar- und post-sekundaren, nicht-tertiären Bildungsbereich abzielen (Tab. B5.I und B5.2). 
Öffentiche Subventionen für Bildung im Primar-, Sekundar- und post-sekundaren, nicht-tertiären Bereich (2001) Öffentliche Subventionen für Bildung an private Haushalte und andere private Einheiten als Prozentsatz der öffentlichen Gesamtausgaben für Bildung, nach Art der Subvention

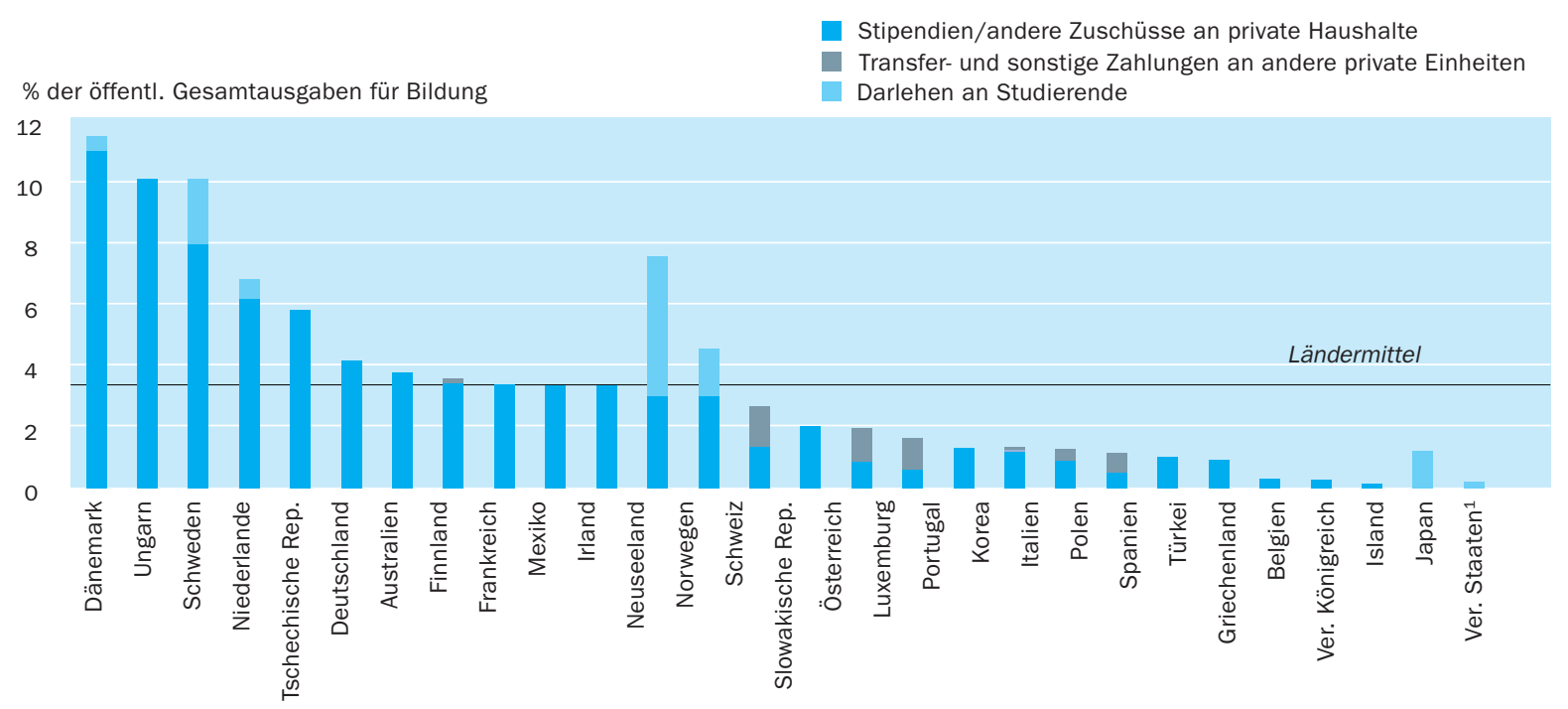

1. Ohne post-sekundaren, nicht-tertiären Bereich.

Anordnung der Länder in absteigender Reihenfolge der Stipendien/andere Zuschüsse an private Haushalte und Transfer- und sonstige Zahlungen an andere private Einheiten im Primar-, Sekundar- und post-sekundaren, nicht-tertiären Bereich.

Quelle: OECD. Tabelle B5.1. Hinweise s. Anhang 3 unter www.oecd.org/edu/eag2004.

Öffentliche Subventionen an private Haushalte werden in den meisten OECDLändern erst ab dem Sekundarbereich II gezahlt. Unterhalb dieser Ebene gibt es in der Regel kaum Subventionen, da in den meisten OECD-Ländern bis zu diesem Bereich allgemeine Schulpflicht besteht, der Schulbesuch kostenlos ist, Schulbildung überwiegend von der öffentlichen Hand bereitgestellt und weitgehend direkt am Wohnort der Schüler und ihrer Familien angeboten wird. In 7 von 29 OECD-Ländern mit verfügbaren Daten machen daher Subventionszahlungen an private Haushalte und andere private Einheiten nur I Prozent oder weniger der gesamten öffentlichen Bildungsausgaben für den Primar-, Sekundar- und post-sekundaren, nicht-tertiären Bildungsbereich aus. Dagegen betragen sie in Neuseeland, Schweden und Ungarn zwischen 7 und II Prozent der öffentlichen Gelder für diese Bildungsbereiche und in Dänemark II, 6 Prozent (Abb. B5.2) In den meisten OECD-Ländern, die einen hohen Anteil an Subventionszahlungen im Primar-, Sekundar- und post-sekundaren, nicht-tertiären Bereich aufweisen, gehen diese an Erwachsene, die wieder in den Sekundarbereich einsteigen.

Der in Form von Subventionen an private Haushalte und andere private Einheiten ausgezahlte Teil der Bildungsetats ist im Tertiärbereich wesentlich höher. Im Durchschnitt verwenden die OECD-Länder 17 Prozent ihres Bildungsetats für den Tertiärbereich in Form von Subventionen an private Haushalte und andere private Einheiten (Abb. B5.I). In Australien, Dänemark, Neuseeland, Norwegen, Schweden und den Vereinigten Staaten machen die öffentlichen Subventionen ungefähr 30 Prozent oder mehr der öffentlichen Ausgaben für den Tertiärbereich aus. Nur in Polen und der Schweiz machen diese Subventionen
Im Primar-, Sekundar- und post-sekundaren, nichttertiären Bereich stellen öffentliche Subventionen einen vergleichsweise geringen Anteil der öffentlichen Bildungsausgaben dar.

Australien, Dänemark, Neuseeland, Norwegen, Schweden und die Vereinigten Staaten verwenden mindestens 30 Prozent ihres Bildungsetats für den Tertiärbereich für Subventionen an den privaten Sektor. 
Zur Subventionierung der Bildungskosten von Schülern/ Studierenden praktizieren die OECD-Länder unterschiedliche Kombinationen aus Zuschüssen und Darlehen.

Die höchsten Subventionen in Form von Ausbildungsdarlehen sind in der Regel in den Ländern mit den höchsten Beteiligungsquoten im Tertiärbereich zu finden. weniger als 5 Prozent der öffentlichen Gesamtausgaben für den Tertiärbereich aus (Tab. B5.2).

In vielen OECD-Ländern stellt sich die zentrale Frage, ob die an private Haushalte geleisteten Finanzhilfen in erster Linie als Zuschüsse oder als Darlehen gewährt werden sollen. Die Staaten gewähren zur Subventionierung der Lebenshaltungs- bzw. Bildungskosten der Schüler/Studierenden verschiedene Kombinationen von Zuschüssen und Darlehen. Die Befürworter von Studiendarlehen argumentieren, dass mit den Geldern für Darlehen mehr erreicht werden kann: wenn die für Zuschüsse verwendeten Gelder dazu verwendet würden, Darlehen abzusichern bzw. zu subventionieren, könnte den Schülern/Studierenden insgesamt mehr an Finanzhilfe zur Verfügung gestellt werden und somit insgesamt der Zugang zum Bildungssystem erweitert werden. Außerdem wird durch Darlehen ein Teil der Bildungskosten auf diejenigen verlagert, die am meisten von den Bildungsinvestitionen profitieren. Die Gegner von Studiendarlehen führen dagegen an, dass Studiendarlehen in geringerem Maße als Zuschüsse dazu beitragen, einkommensschwache Schüler/Studierende dazu zu bewegen, eine weiterführende Bildung ins Auge zu fassen. Ferner führen sie an, dass Darlehen aufgrund der unterschiedlichen Subventionen für Darlehensnehmer und -geber und der Verwaltungs- und Tilgungskosten möglicherweise weniger effizient sein können als angenommen. Auch kulturelle Unterschiede zwischen und innerhalb der einzelnen Länder können sich auf die Bereitschaft von Schülern/Studierenden zur Aufnahme eines Ausbildungsdarlehens auswirken.

Abbildung B5.I gibt eine Übersicht über die Anteile von Darlehen, Zuschüssen und Stipendien sowie anderen Beihilfen für private Haushalte an den öffentlichen Bildungsausgaben im Tertiärbereich. Zu den Zuschüssen und Stipendien zählen auch Familienbeihilfen und sonstige spezifische Subventionen, nicht jedoch Steuerermäßigungen. In I3 von 29 OECD-Ländern, die Daten vorlegten, gibt es ausschließlich Stipendien oder Zuschüsse und Transferzahlungen an andere private Einheiten. Die übrigen OECD-Länder bieten sowohl Stipendien/Zuschüsse als auch Studiendarlehen an. Im Allgemeinen erhalten Studierende in denjenigen OECD-Ländern die höchsten Subventionen, die auch Studiendarlehen bieten. In den meisten Fällen investieren diese Länder einen überdurchschnittlich hohen Anteil ihrer Bildungsetats in Zuschüsse und Stipendien (Abb. B5.I und Tabelle B5.2).

Der Grund für die Einführung eines Ausbildungsdarlehenssystems liegt für die Regierungen möglicherweise häufig darin, die Kosten eines sich ausweitenden Tertiärbereichs besser im Griff zu haben. So ist zum Beispiel bemerkenswert, dass die vier Länder, die die höchsten Subventionen in Form von Studiendarlehen angegeben haben (Island, Neuseeland, Norwegen und Schweden), auch die höchsten Studienanfängerquoten innerhalb der OECD aufweisen (s. Indikator $\mathrm{C}_{2}$ ). Es gibt jedoch auch Ausnahmen hiervon. Finnland hat die vierthöchste Anfängerquote im Tertiärbereich A, verfügt aber über kein öffentlich finanziertes Studiendarlehenssystem. 
Die Rückzahlung staatlicher Darlehen kann für den Staat eine bedeutende Einnahmequelle darstellen und die Kosten der Darlehensprogramme beträchtlich senken. In den aktuellen Zahlen über die Bildungsausgaben der privaten Haushalte als Teil der privaten Ausgaben (Indikator B4) sind die Rückzahlungen durch frühere Darlehensempfänger nicht enthalten. Diese Rückzahlungen können für den Einzelnen eine erhebliche Belastung darstellen und seine Entscheidung hinsichtlich des Studiums an einer tertiären Bildungseinrichtung beeinflussen. Allerdings wird in vielen OECD-Ländern die Rückzahlung der Studiendarlehen vom späteren Einkommen der Absolventen abhängig gemacht.

Da die Rückzahlung an die Darlehensprogramme mehrere Jahre nach Inanspruchnahme der Darlehen durch die damaligen Studierenden erfolgt, ist eine Abschätzung der realen Kosten von Darlehensprogrammen schwierig. Deswegen werden die Darlehen nur als Bruttobeträge ausgewiesen. Internationale Vergleiche der gesamten Rückzahlungen innerhalb desselben Referenzzeitraums sind nicht möglich, da diese erheblich durch Änderungen bei den Vergabekriterien der Darlehen bzw. der Zahl der Darlehensempfänger beeinflusst werden.

\section{Wofür die Subventionen verwendet werden: Lebenshaltungskosten und Studiengebühren}

In den meisten OECD-Ländern sind die öffentlichen Zahlungen an private Haushalte für Bildung größtenteils nicht zweckgebunden, das heißt, über ihre Verwendung bestimmen die Empfänger, also die Studierenden und ihre Familien, selbst. In einigen OECD-Ländern jedoch sind die öffentlichen Subventionsmittel zweckgebunden für Zahlungen an Bildungseinrichtungen. So besteht beispielsweise in Australien, Neuseeland und im Vereinigten Königreich eine Zweckbindung derartiger öffentlicher Gelder für Studiengebühren. In Australien bestehen durch das HECS-System (Higher Education Contribution Scheme - Ausbildungsbeihilfeprogramm für Hochschulbildung) detaillierte Vorschriften für die Studiendarlehen und Studiengebühren. Im Rahmen dieses Programms können die Studierenden zwischen zwei Alternativen wählen: einer semesterweise geleisteten Vorauszahlung der Studiengebühren, für die sie einen 25-prozentigen Nachlass erhalten, oder die Zahlung der gesamten aufgelaufenen Gebühren im Nachhinein über die Einkommenssteuern, sobald ihr Jahreseinkommen eine bestimmte Mindestgrenze überschreitet. Im Rahmen der OECD-Bildungsindikatoren wird das HECS-System als Darlehenssystem eingestuft, auch wenn die Studierenden das Stunden der Zahlungen vielleicht nicht als Darlehen betrachten. In OECD-Ländern mit hohen Studiengebühren ist faktisch ein Teil der öffentlichen Subventionen an private Haushalte für Zahlungen an Bildungseinrichtungen zu verwenden, selbst wenn dies nicht ausdrücklich politisch intendiert ist.

Stipendien und andere Studienbeihilfen, die den Schülern/Studierenden zuzurechnen sind, werden weitgehend außerhalb der Bildungseinrichtungen ausgegeben. Sie leisten einen Beitrag zu den Bildungskosten, die keine Studiengebühren sind. In Dänemark, Finnland und Ungarn machen die Stipendien und anderen Studienbeihilfen, die nicht Studiengebührenzahlungen an Bildungseinrichtungen zuzurechnen sind, mehr als I5 Prozent der gesamten öffentlichen Ausgaben für den Tertiärbereich aus. Korea, Polen und die Schweiz sind
Die Rückzahlung der Darlehen verringert die realen Kosten der Darlehensprogramme für die öffentliche Hand, erhöht jedoch gleichzeitig die finanzielle Belastung der privaten Haushalte für Bildung.

In den meísten OECD-Ländern genießen die Empfänger von Subventionen einen erheblichen Ermessensspielraum hinsichtlich der Verwendung der erhaltenen Subventionen.

In allen OECD-Ländern, für die Zahlen vorliegen, werden Subventionen in erster Linie außerhalb der Bildungseinrichtungen ausgegeben - in jedem dritten OECD-Land sogar ausschließlich. 
Subventionen sind besonders dort von Bedeutung, wo von den Schülern/Studierenden erwartet wird, dass sie wenigstens einen Teil ihrer Bildungskosten selbst tragen.

Die Daten beziehen sich auf das Haushaltsjahr 2001 und beruhen auf der von der OECD im Jahre 2003 durchgeführten UOE-Datenerhebung zur Bildungsstatistik (Einzelheiten s. Anhang 3). die einzigen OECD-Länder, in denen Stipendien und andere Studienbeihilfen, die auf Ausgaben außerhalb der Bildungseinrichtungen abzielen, weniger als I Prozent der gesamten öffentlichen Bildungsausgaben ausmachen (Tab. B5.2).

In OECD-Ländern, in denen die Studierenden Studiengebühren zahlen müssen, sind öffentliche Subventionen von besonderer Bedeutung, um Studierenden unabhängig von ihren wirtschaftlichen Verhältnissen Zugang zu den Bildungsangeboten zu ermöglichen. Indikator B3 zeigt auf, welcher Anteil der Gelder für Bildungseinrichtungen aus privaten Quellen stammt.

In OECD-Ländern mit einem geringen Anteil privater Finanzierung von Bildungseinrichtungen ist tendenziell auch das Ausmaß der öffentlichen Subventionen geringer (Tabellen B5.2 und B3.2a und b). Eine Ausnahme bildet hier Korea, wo trotz der Tatsache, dass ungefähr 90 Prozent aller Mittel für den Tertiärbereich aus privaten Quellen stammen, die Höhe der Subventionen, die als Beihilfe zur Zahlung von Studiengebühren geleistet werden, mit I Prozent vergleichsweise gering ist (Tabellen $\mathrm{B}_{5} .2$ und $\mathrm{B}_{3} .2 \mathrm{a}$ und $\mathrm{b}$ ).

\section{Definitionen und angewandte Methodik}

$\mathrm{Zu}$ den öffentlichen Subventionen an private Haushalte zählen folgende Kategorien: I. Zuschüsse/Stipendien, 2. staatliche Studiendarlehen, 3. Kindergeld und andere Familienbeihilfen, die an den Status des Studierenden gebunden sind, 4. öffentliche Subventionen in Form von Geld- oder Sachleistungen, speziell für Unterbringung, Nutzung von Verkehrsmitteln, medizinische Versorgung, Bücher und Lernmittelbedarf, soziale, Freizeit- und sonstige Zwecke und 5. Zinssubventionen für private Darlehen.

Die Ausgaben für Studiendarlehen sind als Bruttobetrag ausgewiesen, d. h. ohne Abzug oder Verrechnung der Tilgungs- oder Zinszahlungen der Darlehensnehmer (Studierende oder private Haushalte). Diese Form wurde gewählt, weil der Bruttobetrag der Darlehen und Stipendien bzw. Zuschüsse die relevante Messgröße für die Ermittlung der Finanzhilfen an die gegenwärtigen Bildungsteilnehmer ist.

Öffentliche Kosten in Verbindung mit staatlich garantierten privaten Darlehen sind unter den Subventionen an andere private Einheiten enthalten. Im Unterschied zu den öffentlichen Darlehen sind hierbei nur die Nettokosten der Darlehen enthalten.

Nicht enthalten ist der Geldwert von Steuerermäßigungen und Steueranrechnungen, die privaten Haushalten und Studierenden gewährt werden.

Es ist zu beachten, dass die in früheren Ausgaben dieser Veröffentlichung aufgeführten Zahlen und Daten möglicherweise nicht immer mit denen der Ausgabe 2004 vergleichbar sind, da sich Änderungen in den Definitionen und Erhebungsbereichen ergeben haben. Diese wurden aufgrund der OECD Expenditure Comparability Study vorgenommen (Einzelheiten zu den Änderungen s. Anhang 3 unter www.oecd.org/eduleag2004). 
Tabelle B5.1

Öffentliche Subventionen an private Haushalte und andere private Einrichtungen als Prozentsatz der öffentlichen Gesamtausgaben für Bildung und des BIP, für den Primar-, Sekundar- und post-sekundaren, nicht-tertiären Bereich (2001) Direkte öffentliche Ausgaben für Bildungseinrichtungen sowie Subventionen für private Haushalte und andere private Einheiten

\begin{tabular}{|c|c|c|c|c|c|c|c|}
\hline & \multirow{3}{*}{$\begin{array}{l}\text { Direkte Ausgaben } \\
\text { für Bildungs- } \\
\text { einrichtungen }\end{array}$} & \multicolumn{5}{|c|}{ Subventionen für Bildung an private Einheiten } & \multirow{3}{*}{$\begin{array}{c}\text { Subventionen } \\
\text { für Bildung an } \\
\text { private Einheiter } \\
\text { als Prozentsatz } \\
\text { des BIP }\end{array}$} \\
\hline & & \multicolumn{3}{|c|}{ Finanzhilfen für Schüler } & \multirow{2}{*}{\begin{tabular}{|c|} 
Transfer- und sons- \\
tige Zahlungen \\
an andere private \\
Einheiten
\end{tabular}} & \multirow[t]{2}{*}{ Gesamt } & \\
\hline OECD-Länder & & $\begin{array}{l}\text { Stipendien/andere } \\
\text { Zuschüsse an } \\
\text { private Haushalte }\end{array}$ & $\begin{array}{l}\text { Darlehen } \\
\text { an Schüler }\end{array}$ & Gesamt & & & \\
\hline Australien & 96,2 & 3,8 & $\mathrm{n}$ & 3,8 & $\mathrm{n}$ & 3,8 & 0,14 \\
\hline Belgien & 99,7 & 0,3 & $\mathrm{n}$ & 0,3 & $\mathrm{n}$ & 0,3 & 0,01 \\
\hline Kanada $^{1}$ & $\mathrm{~m}$ & $\mathrm{~m}$ & $\mathrm{~m}$ & $\mathrm{~m}$ & $\mathrm{~m}$ & $\mathrm{~m}$ & $\mathrm{~m}$ \\
\hline Tschechische Rep. & 94,1 & 5,9 & a & 5,9 & $\mathrm{n}$ & 5,9 & 0,18 \\
\hline Dänemark & 88,4 & 11,1 & 0,5 & 11,6 & $\mathrm{n}$ & 11,6 & 0,55 \\
\hline Finnland & 96,4 & 3,4 & $\mathrm{n}$ & 3,4 & 0,2 & 3,6 & 0,14 \\
\hline Frankreich & 96,6 & 3,4 & a & 3,4 & a & 3,4 & 0,14 \\
\hline Deutschland & 95,8 & 4,2 & $\mathrm{n}$ & 4,2 & $\mathrm{n}$ & 4,2 & 0,13 \\
\hline Ungarn & 89,9 & 10,1 & a & 10,1 & $n$ & 10,1 & 0,32 \\
\hline Island & 98,8 & $\mathrm{~m}$ & 1,2 & 1,2 & $\mathrm{~m}$ & 1,2 & 0,06 \\
\hline Irland & 96,7 & 3,3 & $\mathrm{n}$ & 3,3 & $n$ & 3,3 & 0,10 \\
\hline Italien & 98,7 & 0,9 & a & 0,9 & 0,3 & 1,3 & 0,05 \\
\hline Japan & 99,8 & $\mathrm{~m}$ & 0,2 & 0,2 & $\mathrm{n}$ & 0,2 & 0,01 \\
\hline Korea & 98,7 & 1,2 & 0,1 & 1,3 & 0,1 & 1,3 & 0,05 \\
\hline Luxemburg & 98,3 & 0,6 & a & 0,6 & 1,0 & 1,7 & 0,06 \\
\hline Mexiko & 96,6 & 3,4 & a & 3,4 & a & 3,4 & 0,13 \\
\hline Niederlande & 93,1 & 6,2 & 0,6 & 6,9 & $\mathrm{n}$ & 6,9 & 0,23 \\
\hline Neuseeland & 92,4 & 3,0 & 4,6 & 7,6 & $\mathrm{n}$ & 7,6 & 0,36 \\
\hline Norwegen & 95,4 & 3,0 & 1,6 & 4,6 & $\mathrm{n}$ & 4,6 & 0,22 \\
\hline Polen & 98,9 & 0,5 & a & 0,5 & 0,6 & 1,1 & 0,05 \\
\hline Portugal & 98,7 & 1,3 & $\mathrm{~m}$ & 1,3 & $\mathrm{~m}$ & 1,3 & 0,06 \\
\hline Slowakische Rep. & 98,0 & 2,0 & a & 2,0 & $\mathrm{~m}$ & 2,0 & 0,06 \\
\hline Schweiz & 97,3 & 1,4 & $n$ & 1,4 & 1,3 & 2,7 & 0,11 \\
\hline Türkei & 99,1 & 0,9 & a & 0,9 & $\mathrm{~m}$ & 0,9 & 0,02 \\
\hline Ver. Königreich & 99,8 & 0,2 & a & 0,2 & $\mathrm{n}$ & 0,2 & 0,01 \\
\hline Vereinigte Staaten ${ }^{1}$ & 100,0 & $\mathrm{n}$ & $\mathrm{n}$ & $\mathrm{n}$ & $\mathrm{n}$ & $\mathrm{n}$ & $n$ \\
\hline Ländermittel & 96,7 & 3,0 & 0,4 & 3,1 & 0,2 & 3,3 & 0,13 \\
\hline \multicolumn{8}{|l|}{ OECD-Partnerländer } \\
\hline Argentinien & 99,3 & 0,4 & a & 0,4 & 0,3 & 0,7 & $\mathrm{n}$ \\
\hline Brasilien $^{2}$ & 97,2 & 0,4 & $\mathrm{~m}$ & 0,4 & 2,4 & 2,8 & 0,1 \\
\hline Chile $^{3}$ & 99,6 & 0,4 & a & 0,4 & a & 0,4 & $\mathrm{n}$ \\
\hline Indien ${ }^{1}$ & 99,9 & 0,1 & a & 0,1 & a & 0,1 & $\mathrm{n}$ \\
\hline Indonesien & 96,6 & 3,4 & $\mathrm{~m}$ & 3,4 & $\mathrm{~m}$ & 3,4 & $n$ \\
\hline Israel & 98,5 & 1,5 & $\mathrm{n}$ & 1,5 & $\mathrm{n}$ & 1,5 & 0,1 \\
\hline Jamaika & 97,9 & 2,1 & a & 2,1 & $a$ & 2,1 & 0,1 \\
\hline Jordanien & 100,0 & $a$ & a & a & $a$ & $a$ & a \\
\hline Malaysia & 99,5 & 0,5 & $a$ & 0,5 & $a$ & 0,5 & $\mathrm{n}$ \\
\hline Paraguay & 99,7 & 0,2 & a & 0,2 & 0,1 & 0,3 & $\mathrm{n}$ \\
\hline Peru $^{1}$ & 100,0 & a & $\mathrm{n}$ & a & $\mathrm{n}$ & a & $\mathrm{m}$ \\
\hline Philippinen & 99,2 & $a$ & $a$ & a & 0,8 & 0,8 & $\mathrm{n}$ \\
\hline Thailand & 95,1 & 0,7 & 4,2 & 4,9 & $\mathrm{~m}$ & 4,9 & $\mathrm{n}$ \\
\hline Uruguay & 99,9 & 0,1 & a & 0,1 & a & 0,1 & $\mathrm{n}$ \\
\hline Simbabwe $^{3}$ & 99,9 & 0,1 & a & 0,1 & $\mathrm{a}$ & 0,1 & $\mathrm{n}$ \\
\hline
\end{tabular}

1. Ohne post-sekundaren, nicht-tertiären Bereich. 2. Referenzjahr 2000. 3. Referenzjahr 2002.

Quelle: OECD. Hinweise s. Anhang 3 unter www.oecd.org/edu/eag2004. 


\section{Tabelle B5.2}

Öffentliche Subventionen an private Haushalte und andere private Einrichtungen als Prozentsatz der öffentlichen Gesamtausgaben für Bildung und des BIP, für den Tertiärbereich (2001)

Direkte öffentliche Ausgaben für Bildungseinrichtungen sowie Subventionen für private Haushalte und andere private Einheiten

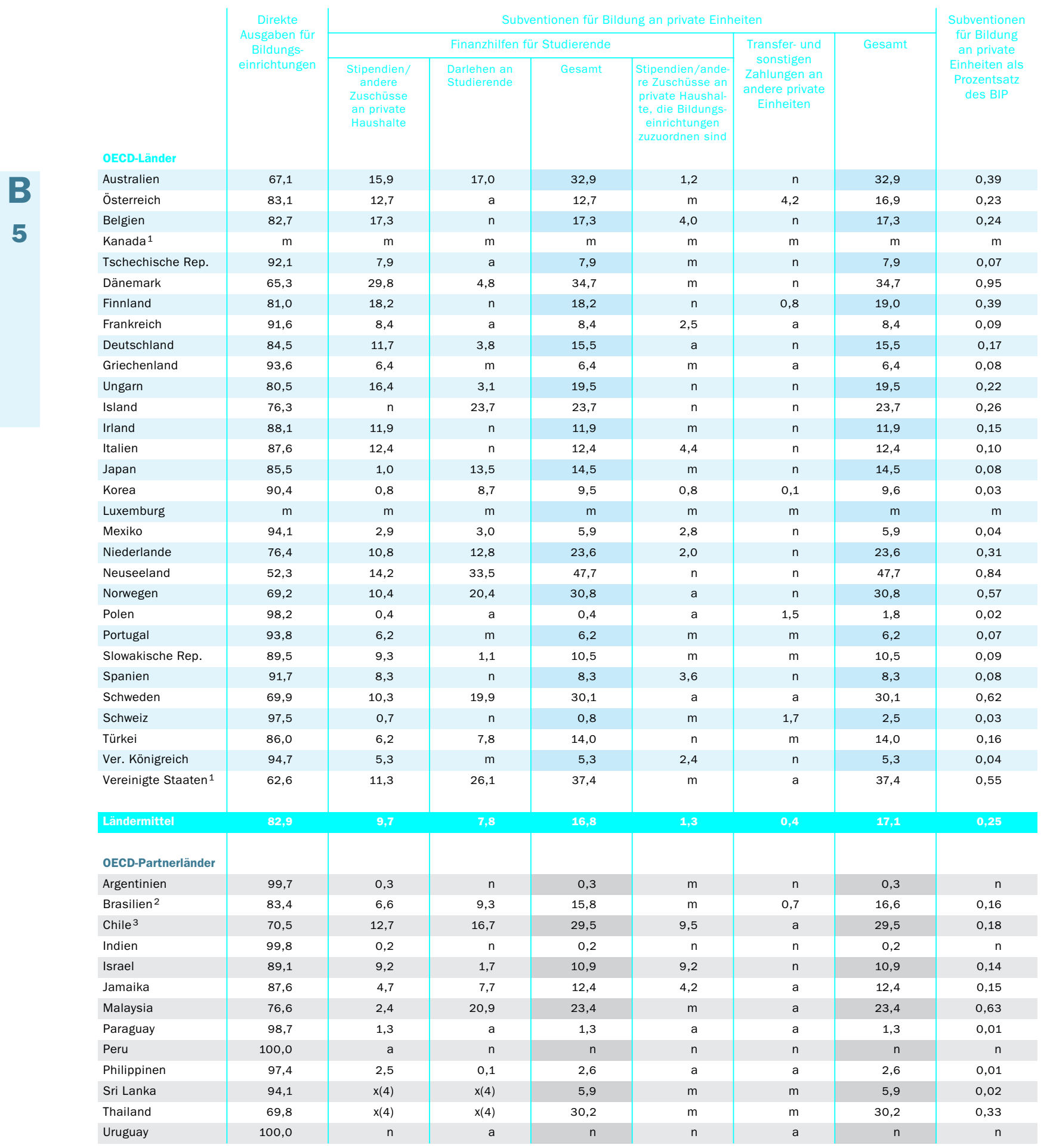

1. Einschließlich post-sekundarem, nicht-tertiärem Bereich. 2. Referenzjahr 2000. 3. Referenzjahr 2002.

Quelle: OECD. Hinweise s. Anhang 3 unter www.oecd.org/edu/eag2004. 


\section{Ausgaben für Bildungseinrichtungen nach Art der erbrachten Leistung und Ausgabenkategorien}

Im Durchschnitt entfallen ein Viertel der Ausgaben für den Tertiärbereich auf Forschung und Entwicklung an tertiären Bildungseinrichtungen. Die erheblichen Unterschiede zwischen den einzelnen OECD-Ländern beim Umfang von Forschung und Entwicklung an tertiären Einrichtungen können zum Teil die großen Unterschiede bei den Ausgaben pro Studierenden in diesem Bildungsbereich erklären.

— Im Primar-, Sekundar- und post-sekundaren, nicht-tertiären Bereich zusammengenommen belaufen sich die laufenden Ausgaben im Durchschnitt der OECD-Länder auf 92 Prozent der gesamten Ausgaben. Mit Ausnahme von vier OECD-Ländern machen die Personalkosten mindestens 70 Prozent der laufenden Ausgaben im Primar-, Sekundar- und post-sekundaren, nicht-tertiären Bereich aus. 
Abbildung B6.1

Ausgaben für Unterricht, Forschung und Entwicklung (F\&E) sowie zusätzliche Dienstleistungen an Bildungseinrichtungen des Tertiärbereichs als Prozentsatz des BIP (2001)

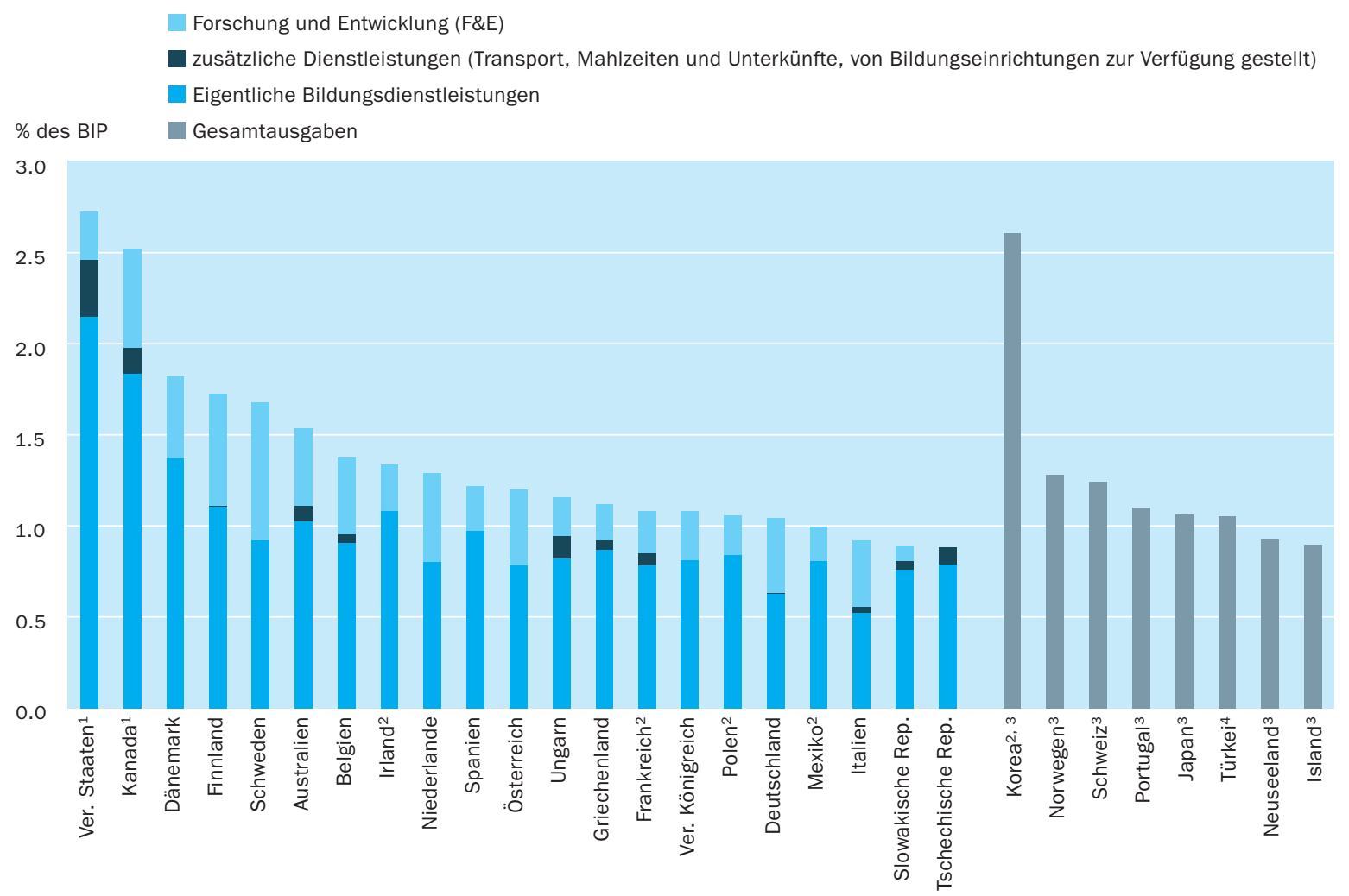

1. Einschließlich post-sekundarer, nicht-tertiärer Bereich. 2. Ausgaben für Forschung und Entwicklung (F\&E) im Tertiärbereich und damit Gesamtausgaben zu niedrig angesetzt. 3. Der Balken stellt die Gesamtausgaben im Tertiärbereich dar und umfasst auch Ausgaben für Forschung und Entwicklung (F\&E) 4. Der Balken stellt die Gesamtausgaben im Tertiärbereich dar. Angaben zu Ausgaben für Forschung und Entwicklung (F\&E) fehlen.

Anordnung der Länder in absteigender Reihenfolge der Ausgaben für Unterricht, Forschung und Entwicklung (F\&E) sowie zusätzliche Dienstleistungen an Bildungseinrichtungen des Tertiärbereichs.

Quelle: OECD. Tabelle B6.1. Hinweise s. Anhang 3 unter www.oecd.org/edu/eag2004.

Dieser Indikator vergleicht die Bildungsausgaben der einzelnen OECD-Länder hinsichtlich der Unterteilung in laufende und Investitionsausgaben sowie der Aufteilung der laufenden Ausgaben auf die verschiedenen Ausgabenkategorien.

\section{Politischer Hintergrund}

Die Aufteilung der verfügbaren Mittel auf die verschiedenen Ausgabenkategorien kann Einfluss haben auf die Qualität der zu erbringenden Leistungen (z. B. durch die Lehrergehälter), den Zustand der Bildungseinrichtungen (z. B. die Instandhaltung von Schulgebäuden) und die Fähigkeit der Bildungssysteme, sich den geänderten demographischen Gegebenheiten und der Entwicklung der Schüler-/Studierendenzahlen (z. B. durch den Neubau von Schulen) anzupassen.

Vergleiche, wie die einzelnen OECD-Länder ihre Bildungsausgaben auf die einzelnen Ausgabenkategorien verteilen, können Einblick geben in die unterschiedlichen Organisations- und Betriebsweisen von Bildungseinrichtungen. Auf Systemebene getroffene Budget- und Strukturentscheidungen über die $\mathrm{Zu}$ weisung von Mitteln machen sich letztendlich im Klassenzimmer bemerkbar 
und beeinflussen die Art des Unterrichts und die Bedingungen, unter denen er stattfindet.

Zusätzlich zu der Erteilung von Unterricht bieten die Bildungsrichtungen eine Vielzahl von bildungsbezogenen Dienstleistungen. Im Primar-, Sekundar- und post-sekundaren, nicht-tertiären Bereich können dies Schulverpflegung, kostenloser Transport von und zur Schule sowie Internatseinrichtungen sein. Im Tertiärbereich können Wohnmöglichkeiten angeboten werden und in vielen Fällen ist auch ein breites Spektrum an Forschungstätigkeiten integraler Bestandteil des tertiären Bildungsbereichs.

\section{Ergebnisse und Erläuterungen}

\section{Was dieser Indikator aufzeigt und was nicht.}

Dieser Indikator unterteilt die Bildungsausgaben nach laufenden und Investitionsausgaben sowie nach den Aufwendungen für die drei Hauptfunktionen, die Bildungseinrichtungen üblicherweise erfüllen. Dazu gehören erstens Kosten, die direkt mit dem Unterricht zusammenhängen, wie die Gehälter der Lehrkräfte und Kosten für Unterrichtsmaterialien, sowie Ausgaben, die indirekt mit der Unterrichtserteilung zusammenhängen, wie Verwaltungsausgaben, unterrichtsunterstützende Dienste, Aus- und Weiterbildung der Lehrkräfte, Beratung von Schülern/Studierenden sowie der Bau und/oder die Vorhaltung von Bildungseinrichtungen. Es gehören auch Ausgaben für zusätzliche Dienstleistungen dazu, wie z. B. die von den Bildungseinrichtungen erbrachten sozialen Dienste für Schüler/Studierende, schließlich Ausgaben für Forschung und Entwicklung (F\&E) an tertiären Bildungseinrichtungen, sei es in Form separat finanzierter F\&E-Aktivitäten oder in Form der Anteile von Gehältern und laufenden Ausgaben am allgemeinen Bildungsetat, die auf die Forschungstätigkeit des Personals entfallen.

Nicht enthalten sind in diesem Indikator die öffentlichen und privaten F\&EAusgaben außerhalb von Bildungseinrichtungen, wie z.B. die F\&E-Ausgaben der Wirtschaft. Eine vergleichende Übersicht der F\&E-Ausgaben außerhalb des Bildungsbereichs ist in den ,OECD-Indikatoren für Wissenschaft und Technologie‘ enthalten. Die Ausgaben der Bildungseinrichtungen für soziale Dienste für Schüler und Studierende beinhalten lediglich die öffentlichen Subventionen für diese Dienstleistungen. Die Ausgaben von Schülern/Studierenden und ihren Familien für Dienstleistungen, die von den Bildungseinrichtungen gegen ein kostendeckendes Entgelt angeboten werden, sind nicht enthalten.

\section{Ausgaben für Unterricht, Forschung und Entwicklung sowie zusätzliche Dienstleistungen}

Unterhalb des Tertiärbereichs überwiegen bei den Bildungsausgaben die in die eigentlichen Bildungsdienstleistungen investierten Mittel. Im Tertiärbereich können andere Leistungen, insbesondere im Zusammenhang mit Forschung und Entwicklung, einen wesentlichen Teil der Bildungsausgaben ausmachen. Die Unterschiede zwischen den einzelnen OECD-Ländern bei den Ausgaben für F\&E können daher auch einen wesentlichen Teil der Unterschiede zwischen den OECD-Ländern bei den Gesamtbildungsausgaben pro Studierenden im
Verglichen werden die $O E C D$ Länder auch nach der

Aufteilung der Mittel zwischen den verschiedenen Aufgaben der Bildungseinrichtungen.

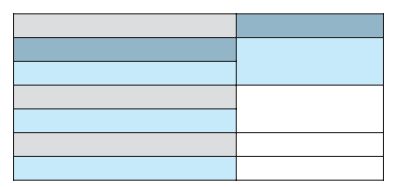

Erfasste Daten

(Erklärungen S. S. 208)

Die erheblichen Unterschiede zwischen den einzelnen OECD-Ländern beim Umfang von Forschung und Entwicklung an tertiären Einrichtungen können zum Teil die Varianz bei den 
Ausgaben pro Studierenden in diesem Bildungsbereich erklären.

Soziale Dienste für Schüler und Studierende gehören zu den integralen Aufgaben von Schulen und Hochschulen.

Im Primar-, Sekundar- und post-sekundaren, nicht-tertiären Bereich machen die Ausgaben für zusätzliche Dienstleistungen 5 Prozent der Gesamtausgaben für Bildungseinrichtungen aus.
Tertiärbereich erklären (Abb. B6.I). So lassen zum Beispiel hohe F\&E-Aufwendungen in Einrichtungen des Tertiärbereichs in Australien, Belgien, Dänemark, Deutschland, Finnland, Kanada, den Niederlanden, Österreich und Schweden (zwischen o,4 und o,8 Prozent des BIP) darauf schließen, dass die Bildungsausgaben pro Studierenden in diesen OECD-Ländern wesentlich geringer wären, wenn sie um den F\&E-Anteil bereinigt würden (Tab. B6.I).

In vielen OECD-Ländern gehören soziale Dienste für Schüler und Studierende sowie gelegentlich auch Dienstleistungen für die Allgemeinheit zu den integralen Aufgaben von Schulen und Hochschulen. Die Finanzierung dieser zusätzlichen Dienstleistungen erfolgt über unterschiedliche Kombinationen von öffentlichen Mitteln, öffentlichen Subventionen sowie Gebühren, die von Schülern/Studierenden und ihren Familien erhoben werden.

Im Durchschnitt geben die OECD-Länder 0,2 Prozent ihres BIP für die Subventionierung der im Primar-, Sekundar- und post-sekundaren, nicht-tertiären Bereich bereitgestellten zusätzlichen Dienstleistungen aus. Dies entspricht 5 Prozent der Gesamtausgaben für diese Bildungseinrichtungen. Am oberen Ende der Skala befinden sich Finnland, Frankreich, Schweden, die Tschechische Republik und Ungarn, die ungefähr ro Prozent und mehr der Gesamtausgaben für Bildungseinrichtungen für zusätzliche Dienstleistungen ausgeben. Dies entspricht real mehr als 250 US-Dollar (kaufkraftbereinigt) pro Schüler/Studierenden in Italien, der Tschechischen Republik, Ungarn und dem Vereinigten Königreich und sogar mehr als 500 US-Dollar (kaufkraftbereinigt) in Finnland, Frankreich und Schweden (Tabellen B6.I und B6.2).

In mehr als zwei Drittel der OECD-Länder sind die Aufwendungen für zusätzliche Dienstleistungen höher als die Aufwendungen für Subventionen an private Haushalte im Primar-, Sekundar- und post-sekundaren, nicht-tertiären Bereich. Ausnahmen stellen Deutschland, Irland, die Niederlande und Schweden dar, wo die Ausgaben für Subventionen an private Haushalte höher sind (Tabellen B5.I und B6.I).

Im Tertiärbereich betragen die Subventionen für zusätzliche Dienstleistungen im Durchschnitt lediglich o, I Prozent des BIP. Umgerechnet auf den einzelnen Studierenden kann dies jedoch erhebliche Beträge ausmachen, wie z.B. in Australien, Frankreich, der Tschechischen Republik, Ungarn und den Vereinigten Staaten, wo sich die Subventionen für zusätzliche Dienstleistungen auf mehr als 500 US-Dollar pro Studierenden (kaufkraftbereinigt) belaufen. Im Tertiärbereich müssen diese zusätzlichen Dienstleistungen häufiger von den Studierenden selbst bezahlt werden (Tabellen B6.I und B6.2).

\section{Laufende Ausgaben und Investitionsausgaben sowie Aufteilung der} laufenden Ausgaben nach Ausgabenkategorien

Bildungsausgaben können zunächst in laufende und Investitionsausgaben unterteilt werden. Investitionsausgaben sind Ausgaben für Sachmittel mit einer Nutzungsdauer von mehr als einem Jahr. Hierzu gehören Aufwendungen für Bau, Renovierung und größere Instandsetzungsarbeiten von Gebäuden. Laufende Ausgaben beinhalten finanzielle Aufwendungen für Ressourcen von Bildungseinrichtungen, die jedes Jahr für den laufenden Betrieb dieser Einrichtungen erforderlich sind. 
Abbildung B6.2

Aufteilung der Gesamtausgaben und der laufenden Ausgaben für Bildungseinrichtungen (2001) Nach Ausgabenkategorie und Bildungsbereich
- Laufende Ausgaben
Investitionsausgaben
Vergütung sonstige Beschäftigte
$\square$ Vergütung aller Beschäftigten
— Vergütung Lehrkräfte
- Sonstige laufende Ausgaben

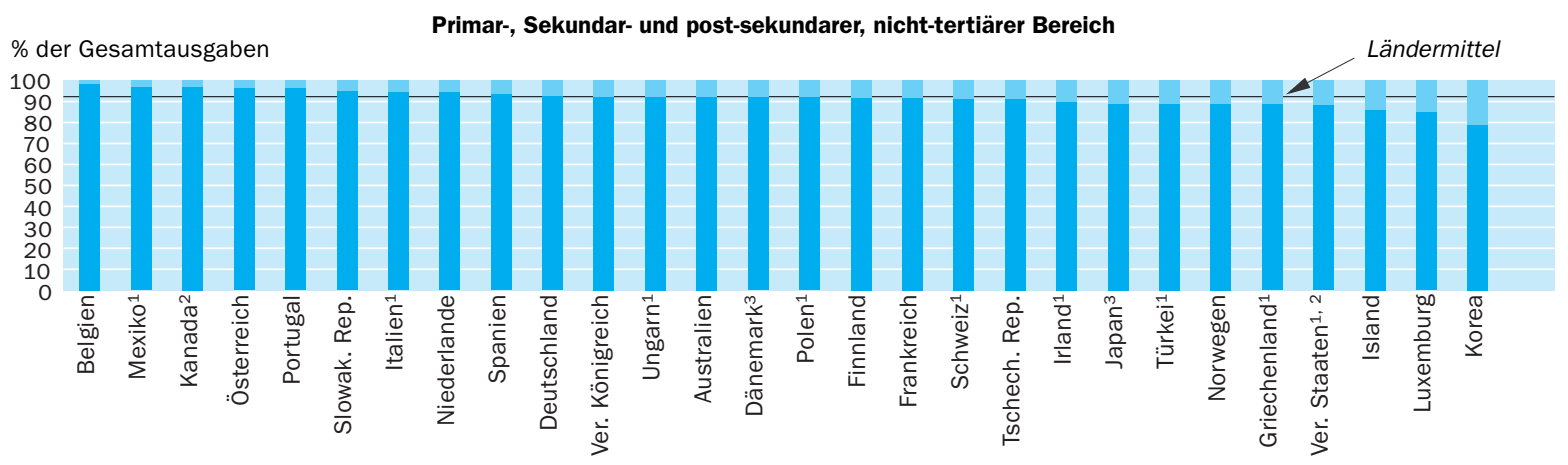

$\%$ der laufenden Ausgaben

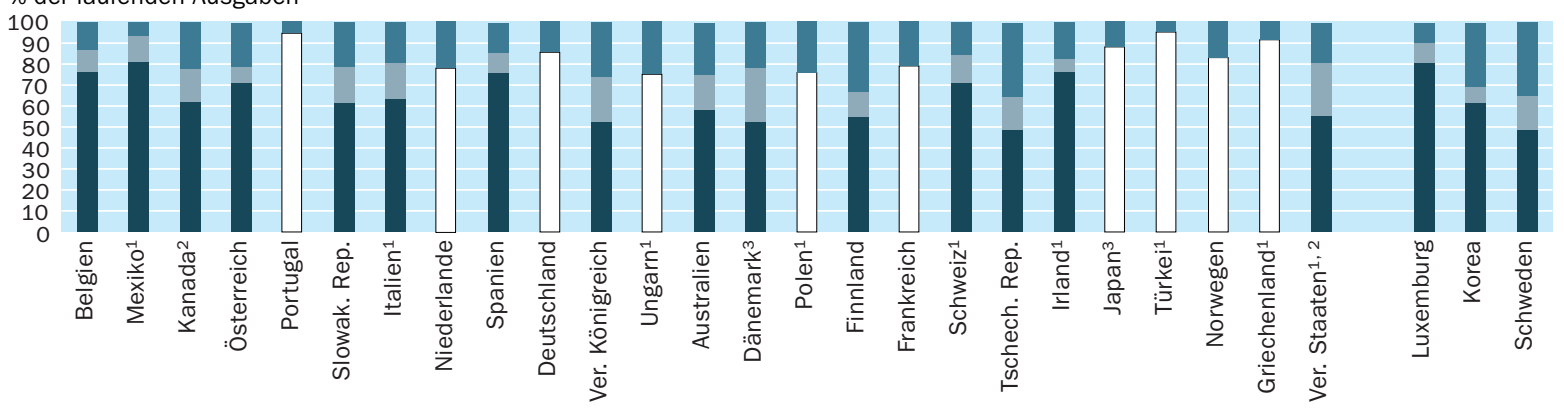

\% der Gesamtausgaben

Tertiärbereich
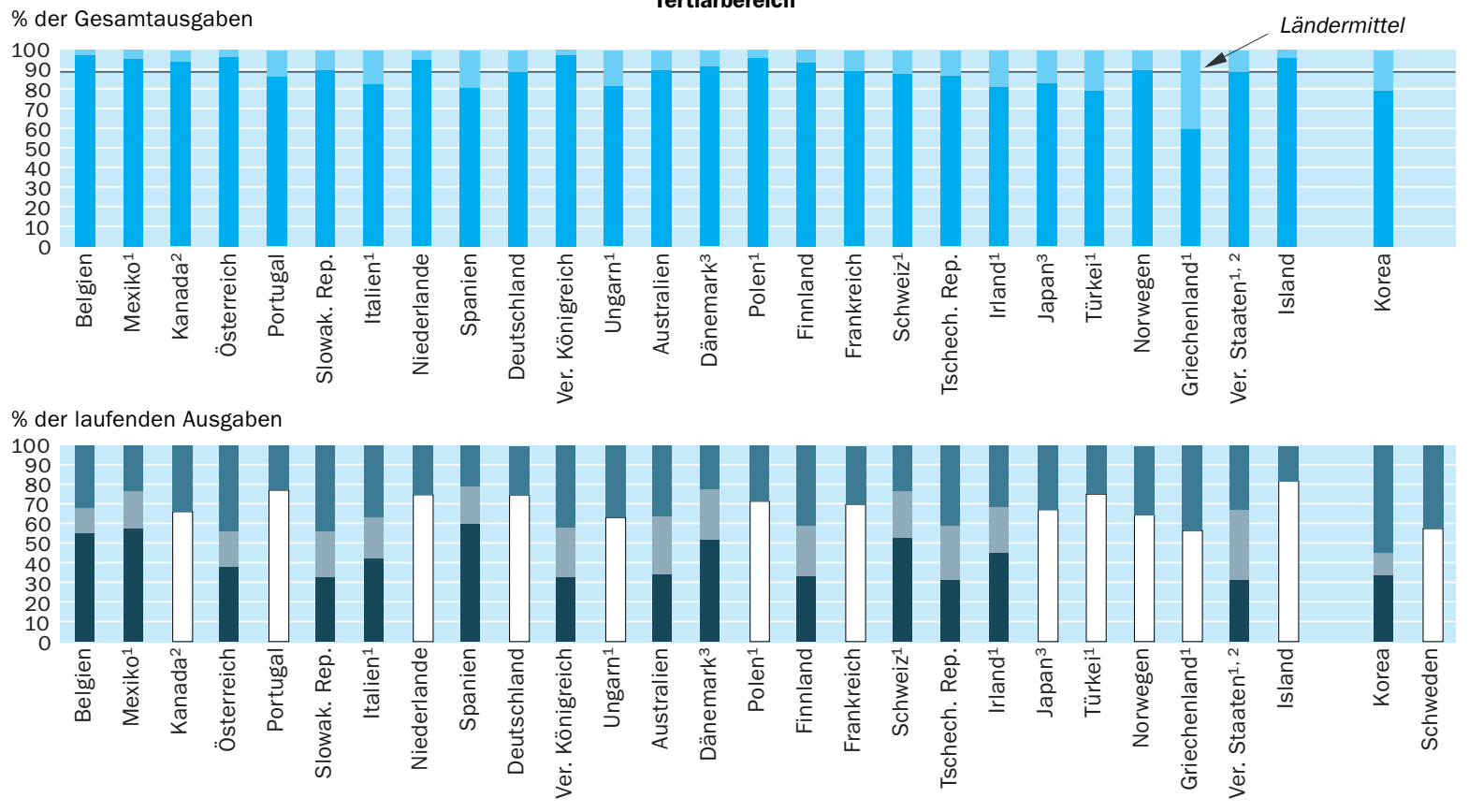

1. Nur öffentliche Bildungseinrichtungen. 2. Post-sekundarer, nicht-tertiärer Bereich in Tertiärbereich enthalten. 3. Post-sekundarer, nicht-tertiärer Bereich sowohl in Sekundarbereich II als auch Tertiärbereich enthalten.

Anordnung der Länder in in absteigender Reihenfolge der laufenden Ausgaben für den Primar-, Sekundar- und post-sekundaren, nicht-tertiären Bereich.

Quelle: OECD. Tabelle B6.3. Hinweise s. Anhang 3 unterwww.oecd.org/edu/eag2004). 
Mit Ausnahme von vier Ländern entfallen in allen OECD-Ländern mindestens 70 Prozent der laufenden Ausgaben im Primar-, Sekundar- und post-sekundaren, nicht-tertiären Bereich auf die Vergütung der Beschäftigten.

OECD-Länder mit kleineren Bildungsbudgets geben verhältnismäßig mehr für die Vergütung der Beschäftigten und weniger für andere Leistungen aus.

Es bestehen zwischen den einzelnen OECD-Ländern Unterschiede hinsichtlich des Anteils der laufenden Ausgaben, der für die Vergütung von Lehrern und anderen Beschäftigten vorgesehen ist.
Die laufenden Ausgaben lassen sich darüber hinaus in drei große funktional definierte Kategorien unterteilen: die Lehrerbesoldung, Vergütung der sonstigen Beschäftigten und sonstige laufende Ausgaben (z. B. für Unterrichts- und Hilfsmaterial, Instandhaltung von Schulgebäuden, Zubereitung von Mahlzeiten für Schüler/Studierende, Mietzahlungen für Lehreinrichtungen). Die Höhe der Mittelzuteilung für jede einzelne dieser Kategorien wird in gewissem Maße durch die gegenwärtige und erwartete Entwicklung der Schüler-/Studierendenzahlen, die Gehälter der im Bildungsbereich Beschäftigten und die Kosten für die Instandhaltung und den Bau von Bildungseinrichtungen beeinflusst.

Ausbildung und Unterricht finden überwiegend in Schulen und Hochschulen statt. Die arbeitskräfteintensiven Unterrichtsmethoden sind mitverantwortlich für den hohen Anteil der laufenden Ausgaben an den gesamten Bildungsausgaben. Im Primar-, Sekundar- und post-sekundaren, nicht-tertiären Bildungsbereich zusammengenommen machen die laufenden Ausgaben im Durchschnitt aller OECD-Länder fast 92 Prozent der Gesamtausgaben aus.

Im Hinblick auf den relativen Anteil der laufenden und der Investitionsausgaben bestehen zwischen den OECD-Ländern recht deutliche Unterschiede: im Primar-, Sekundar- und post-sekundaren, nicht-tertiären Bereich insgesamt liegt der Anteil der laufenden Ausgaben zwischen weniger als 87 Prozent in Island, Korea und Luxemburg und 96 Prozent und mehr in Belgien, Kanada, Mexiko, Österreich und Portugal (Abb. B6.2).

Die Gehälter der Lehrkräfte und der sonstigen Beschäftigten im Bildungsbereich machen in den OECD-Ländern den größten Teil der laufenden Ausgaben aus. Im Durchschnitt der OECD-Länder entfallen 8I Prozent der laufenden Ausgaben für den Primar-, Sekundar- und post-sekundaren, nicht-tertiären Bereich auf die Vergütung der im Bildungsbereich Beschäftigten. Während in Finnland, Korea, Schweden und der Tschechischen Republik der Anteil der Vergütung für die im Bildungsbereich Beschäftigten bei 70 Prozent und darunter liegt, beträgt der entsprechende Anteil in Griechenland, Luxemburg, Mexiko, Portugal und der Türkei go Prozent oder mehr (Abb. B6.2).

OECD-Länder mit relativ kleinen Bildungsetats (z.B. Mexiko, Portugal und die Türkei) geben tendenziell einen größeren Anteil ihrer laufenden Bildungsausgaben für die Vergütung der Beschäftigten und einen kleineren Anteil für andere per Auftrag vergebene oder zugekaufte Serviceleistungen (z. B. die Instandhaltung der Schulgebäude), zusätzliche Dienstleistungen (z.B. die Zubereitung von Schulmahlzeiten) und Mietzahlungen für Schulgebäude und andere Einrichtungen aus.

In Dänemark und den Vereinigten Staaten sind ungefähr ein Viertel der laufenden Ausgaben im Primar-, Sekundar- und post-sekundaren, nicht-tertiären Bereich insgesamt für die Vergütung von nicht-unterrichtenden Beschäftigten vorgesehen; in Irland, Korea, Luxemburg, Österreich und Spanien dagegen beträgt dieser Anteil ro Prozent und weniger. Diese Unterschiede spiegeln wahrscheinlich wider, inwieweit in einem bestimmten Land im Bildungsbereich Beschäftigte nicht unterrichtend tätig sind (z.B. Schulleiter, die selbst nicht unterrichten, Beratungslehrer, Busfahrer, Krankenschwestern im Schuldienst, Hausmeister und Handwerker) (Tab. B6.3). 
Im Tertiärbereich ist der Anteil der Investitionsausgaben an den Gesamtausgaben im Allgemeinen aufgrund der wesentlich differenzierteren und aufwendigeren Lehreinrichtungen höher als im Primar-, Sekundar- und post-sekundaren, nicht-tertiären Bereich. In I4 von 27 OECD-Ländern mit verfügbaren Daten liegt der Anteil der Investitionsausgaben im Tertiärbereich bei ro Prozent oder mehr, in Griechenland, Korea und der Türkei liegt er sogar bei über 20 Prozent (Abb. B6.2).

Die Unterschiede spiegeln wahrscheinlich die Organisation des Tertiärbereichs in den einzelnen OECD-Ländern sowie das Ausmaß wider, in dem wachsende Studierendenzahlen den Neubau von Gebäuden erfordern.

Die OECD-Länder wenden durchschnittlich 33 Prozent der laufenden Ausgaben im Tertiärbereich für andere Zwecke als die Vergütung der im Bildungsbereich Beschäftigten auf. Ein wesentlicher Grund hierfür sind die höheren Kosten für die Einrichtung und Ausrüstung der tertiären Bildungseinrichtungen (Abb. B6.2).

\section{Definitionen und angewandte Methodik}

Die Unterscheidung zwischen laufenden und Investitionsausgaben entspricht der in der volkswirtschaftlichen Gesamtrechnung üblichen Definition. Laufende Ausgaben beziehen sich auf Ausgaben für die im laufenden Haushaltsjahr verbrauchten Güter und Dienstleistungen, die immer wieder anfallen, um die Bereitstellung von Bildungsdienstleistungen aufrechtzuerhalten. Investitionsausgaben beziehen sich auf Ausgaben für Sachwerte mit einer Lebensdauer von mehr als einem Jahr. Hierzu zählen u. a. die Ausgaben für Bau, Renovierung und größere Instandsetzungsarbeiten von Gebäuden sowie für die Neubeschaffung oder den Ersatz von Ausrüstungsgegenständen. Die hier ausgewiesenen Investitionsausgaben beziehen sich auf den Wert der in dem betreffenden Jahr erworbenen oder geschaffenen bildungsbezogenen Vermögenswerte - ausgedrückt in der Höhe der Kapitalbildung -, unabhängig davon, ob die Investitionsausgaben durch laufende Einnahmen oder Kreditaufnahmen finanziert wurden. Weder in den Angaben für die laufenden Ausgaben noch für die Investitionsausgaben ist der Schuldendienst enthalten.

Die Berechnungen beziehen sich auf die Ausgaben der öffentlichen Bildungseinrichtungen oder, soweit verfügbar, auf die Ausgaben der öffentlichen und privaten Bildungseinrichtungen zusammen.

Die laufenden Ausgaben beinhalten, abgesehen von den Personalausgaben, auch Ausgaben für per Auftrag vergebene oder zugekaufte Serviceleistungen (z.B. die Instandhaltung von Schulgebäuden), zusätzliche Dienstleistungen (z.B. die Zubereitung von Schulmahlzeiten) und Mietzahlungen für Schulgebäude und andere Einrichtungen. Diese Dienstleistungen werden von externen Anbietern erbracht (im Unterschied zu Leistungen, die von den Bildungsbehörden oder den Bildungseinrichtungen selbst mit eigenem Personal erbracht werden).
Aufgrund der wesentlich differenzierteren und aufwendigeren Lehreinrichtungen ist der Anteil der Investitionsausgaben im Tertiärbereich im Allgemeinen höher.

Die Daten beziehen sich auf das Haushaltsjahr 2001 und beruhen auf der von der OECD im Jahre 2003 durchgeführten UOE-Datenerhebung zur Bildungsstatistik (Einzelheiten S. Anhang 3). 
Die F\&E-Ausgaben enthalten sämtliche Ausgaben für Forschung an Hochschulen und anderen tertiären Bildungseinrichtungen, unabhängig davon, $o b$ diese aus dem allgemeinen Etat der Einrichtungen, über separate Zuschüsse oder über Verträge mit öffentlichen oder privaten Geldgebern finanziert werden. Die Klassifizierung der Ausgaben als Forschungsausgaben basiert auf den Angaben der forschenden Institutionen und nicht auf einer Zuordnung durch die finanzierenden Stellen.

,Zusätzliche Dienstleistungen“ sind Dienstleistungen, die von den Bildungseinrichtungen neben dem eigentlichen Bildungsauftrag erbracht werden. Die beiden Hauptkomponenten hierbei sind soziale Dienste für Schüler/Studierende und Dienstleistungen für die Allgemeinheit. Im Primar-, Sekundar- und post-sekundaren, nicht-tertiären Bereich umfassen die sozialen Dienstleistungen die Bereitstellung von Mahlzeiten, die Gesundheitsdienste sowie Schultransporte. Im Tertiärbereich sind es Wohnheime, Mensen und Gesundheitsdienste. $\mathrm{Zu}$ den Dienstleistungen für die Allgemeinheit zählen Museen, Radiound Fernsehsendungen, Sport-, Freizeit- und Kulturprogramme. Nicht enthalten sind Ausgaben für zusätzliche Dienstleistungen, für die Gebühren von Schülern/Studierenden oder privaten Haushalten erhoben werden.

Die Ausgaben für eigentliche Bildungsdienstleistungen werden als der Restbetrag sämtlicher Ausgaben geschätzt, d.h. sie umfassen die Gesamtausgaben für Bildungseinrichtungen abzüglich der Aufwendungen für F\&E und zusätzliche Dienstleistungen.

Es ist zu beachten, dass die in früheren Ausgaben dieser Veröffentlichung aufgeführten Zahlen und Daten möglicherweise nicht immer mit denen der Ausgabe 2004 vergleichbar sind, da sich Änderungen in den Definitionen und Erhebungsbereichen ergeben haben. Diese wurden aufgrund der OECD Expenditure Comparability Study vorgenommen (Einzelheiten zu den Änderungen s. Anhang 3 unter www.oecd.org/eduleag2004). 
Tabelle B6.1

Ausgaben für Bildungseinrichtungen nach Ausgabenkategorien als Prozentsatz des BIP (2001) Ausgaben für Unterricht, Forschung und Entwicklung sowie zusätzliche Dienstleistungen in Bildungseinrichtungen als Prozentsatz des BIP sowie private Ausgaben für außerhalb von Bildungseinrichtungen erworbene Bildungsgüter

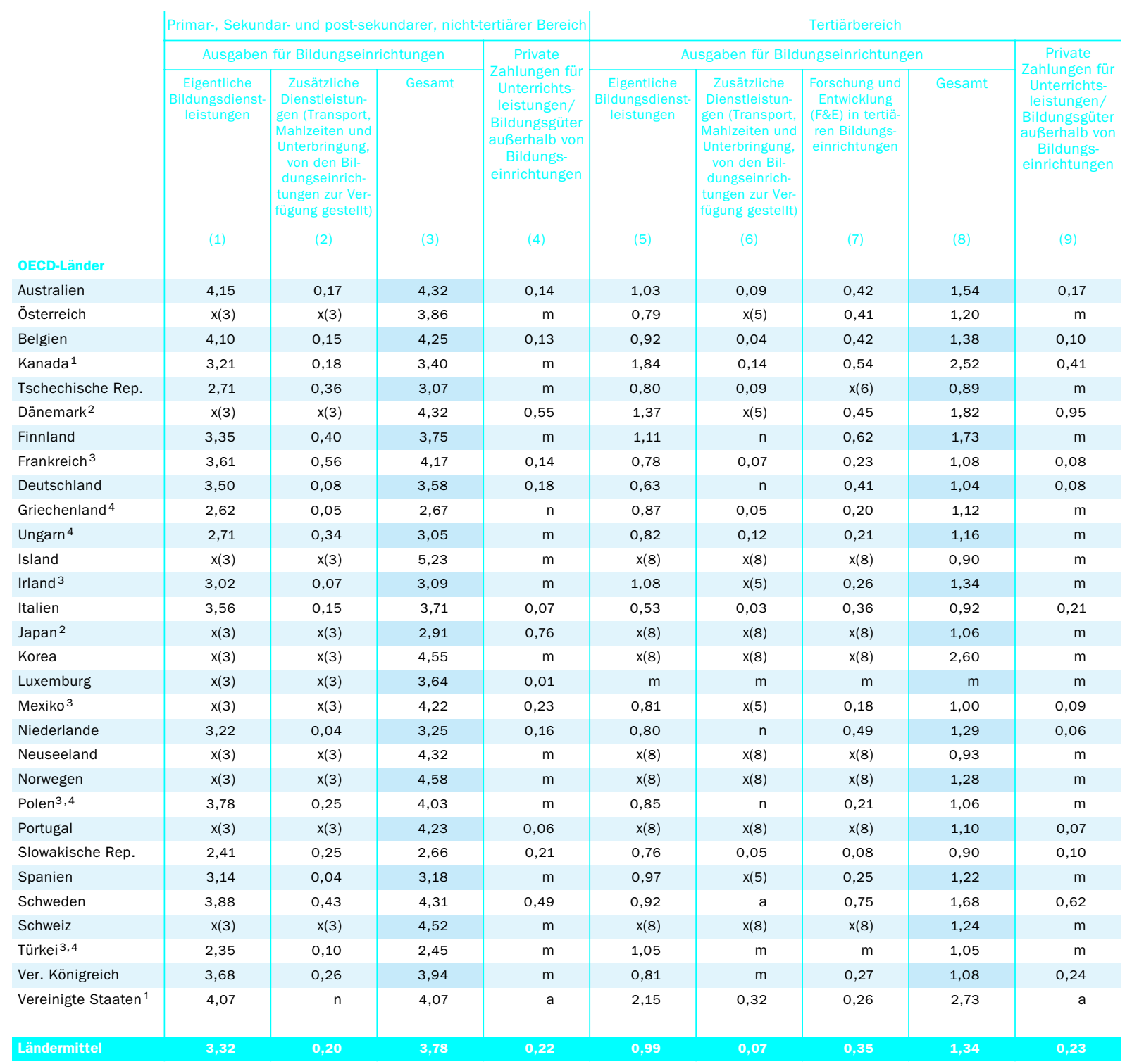

Hinweis: $x$ bedeutet, dass die Daten in einer anderen Spalte enthalten sind, deren Referenz in runden Klammern nach dem ,x‘ angegeben ist. So bedeutet $z$. B. $x(2)$, dass die Daten in Spalte 2 enthalten sind.

1. Post-sekundarer, nicht-tertiärer Bereich in Tertiärbereich und nicht in Primar-, Sekundar- und post-sekundarer, nicht-tertiärer Bereich enthalten. 2. Post-sekundarer, nicht-tertiärer Bereich sowohl in Sekundarbereich II als auch Tertiärbereich enthalten. 3. Ausgaben für Forschung und Entwicklung und daher auch Gesamtausgaben zu niedrig angesetzt. 4. Nur zusätzliche Dienstleistungen in öffentlichen Bildungseinrichtungen. Andere zusätzliche Dienstleistungen in Unterrichtsdienstleistungen enhalten.

Quelle: OECD. Hinweise s. Anhang 3 unter www.oecd.org/edu/eag2004. 
Tabelle B6.2

Jährliche Ausgaben pro Schüler/Studierenden für Unterricht, zusätzliche Dienstleistungen sowie Forschung und Entwicklung (2001)

Ausgaben für Bildungseinrichtungen aus öffentlichen und privaten Mitteln, in US-Dollar, kaufkraftbereinigt, nach Art der Dienstleistung und Bildungsbereich

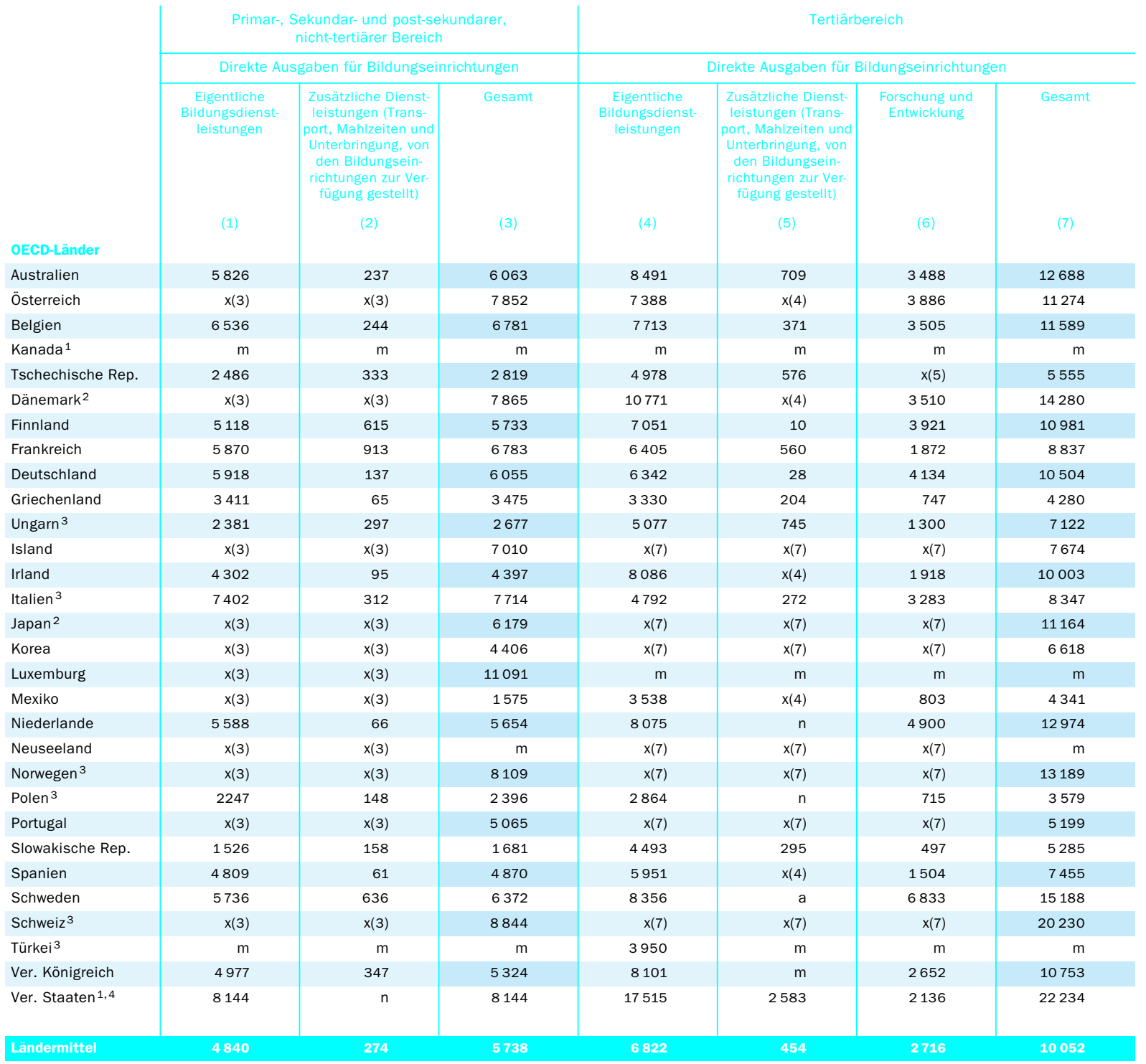

Hinweis: $x$ bedeutet, dass die Daten in einer anderen Spalte enthalten sind, deren Referenz in runden Klammern nach dem , $x$ ' angegeben ist. So bedeutet $z$. B. $x(2)$, dass die Daten in Spalte 2 enthalten sind.

1. Post-sekundarer, nicht-tertiärer Bereich in Tertiärbereich enthalten. 2. Post-sekundarer, nicht-tertiärer Bereich sowohl in Sekundarbereich II als auch Tertiärbereich enthalten. 3. Nur öffentliche Bildungseinrichtungen. 4. Nur öffentliche und unabhängige private Bildungseinrichtungen.

Quelle: OECD. Hinweise s. Anhang 3 unter www.oecd.org/edu/eag2004. 
Tabelle B6.3

Ausgaben für Bildungseinrichtungen nach Ausgabenkategorien und Bildungsbereich (2001)

Verteilung der Gesamtausgaben und der laufenden Ausgaben für Bildungseinrichtungen aus öffentlichen und privaten Quellen

\begin{tabular}{|c|c|c|c|c|c|c|c|c|c|c|c|c|}
\hline \multirow{3}{*}{ OECD-Länder } & \multicolumn{6}{|c|}{ Primar-, Sekundar- und post-sekundarer, nicht-tertiärer Bereich } & \multicolumn{6}{|c|}{ Tertiärbereich } \\
\hline & \multicolumn{2}{|c|}{$\begin{array}{l}\text { Prozentsatz der Ge- } \\
\text { samtausgaben }\end{array}$} & \multicolumn{4}{|c|}{ Prozentsatz der laufenden Ausgaben } & \multicolumn{2}{|c|}{$\begin{array}{l}\text { Prozentsatz der Ge- } \\
\text { samtausgaben }\end{array}$} & \multicolumn{4}{|c|}{ Prozentsatz der laufenden Ausgaben } \\
\hline & $\begin{array}{c}\text { Laufende } \\
\text { Ausgaben } \\
\text { (1) }\end{array}$ & $\begin{array}{c}\text { Investitions- } \\
\text { ausgaben } \\
\text { (2) }\end{array}$ & $\begin{array}{l}\text { Lehrer- } \\
\text { vergütung } \\
\text { (3) }\end{array}$ & \begin{tabular}{|} 
Vergütung \\
sonstige Be- \\
schäftigte \\
(4)
\end{tabular} & $\begin{array}{l}\text { Vergütung } \\
\text { aller Be- } \\
\text { schäftigten } \\
\text { (5) }\end{array}$ & $\begin{array}{c}\text { Sonstige } \\
\text { laufende } \\
\text { Ausgaben } \\
\text { (6) }\end{array}$ & $\begin{array}{c}\text { Laufende } \\
\text { Ausgaben } \\
\text { (7) }\end{array}$ & $\begin{array}{c}\text { Investitions- } \\
\text { ausgaben } \\
\text { (8) }\end{array}$ & $\begin{array}{l}\text { Lehrer- } \\
\text { vergütung } \\
\text { (9) }\end{array}$ & $\begin{array}{c}\text { Vergütung } \\
\text { sonstige Be- } \\
\text { schäftigte } \\
\text { (10) }\end{array}$ & $\begin{array}{c}\text { Vergütung } \\
\text { aller Be- } \\
\text { schäftigten } \\
\text { (11) }\end{array}$ & $\begin{array}{c}\text { Sonstige } \\
\text { laufende } \\
\text { Ausgaben } \\
\text { (12) }\end{array}$ \\
\hline Australien & 92,2 & 7,8 & 58,4 & 16,9 & 75,2 & 24,8 & 90,3 & 9,7 & 34,3 & 29,6 & 63,9 & 36,1 \\
\hline Österreich & 96,4 & 3,7 & 71,0 & 8,1 & 79,1 & 20,9 & 96,6 & 3,5 & 38,6 & 17,6 & 56,2 & 43,8 \\
\hline Belgien & 98,2 & 1,8 & 76,6 & 10,4 & 87,0 & 13,0 & 97,7 & 2,3 & 55,6 & 12,7 & 68,3 & 31,7 \\
\hline Kanada1 & 96,8 & 3,2 & 62,4 & 15,6 & 77,9 & 22,1 & 94,5 & 5,5 & $x(11)$ & $x(11)$ & 66,5 & 33,5 \\
\hline Tschechische Rep. & 91,2 & 8,8 & 48,7 & 16,1 & 64,8 & 35,2 & 87,5 & 12,5 & 31,2 & 27,7 & 58,9 & 41,1 \\
\hline Dänemark ${ }^{2}$ & 92,0 & 8,0 & 52,6 & 25,9 & 78,5 & 21,6 & 92,0 & 8,0 & 52,3 & 25,5 & 77,7 & 22,3 \\
\hline Finnland & 91,7 & 8,3 & 55,0 & 11,9 & 67,0 & 33,0 & 93,6 & 6,4 & 33,7 & 25,4 & 59,1 & 40,9 \\
\hline Frankreich & 91,7 & 8,3 & $x(5)$ & $x(5)$ & 78,9 & 21,1 & 89,7 & 10,3 & $x(11)$ & $x(11)$ & 70,1 & 29,9 \\
\hline Deutschland & 92,4 & 7,6 & $x(5)$ & $x(5)$ & 85,2 & 14,8 & 89,5 & 10,5 & $x(11)$ & $x(11)$ & 74,8 & 25,2 \\
\hline Griechenland $^{3}$ & 88,6 & 11,4 & $x(5)$ & $x(5)$ & 91,3 & 8,7 & 60,1 & 39,9 & $x(11)$ & $x(11)$ & 56,9 & 43,1 \\
\hline Ungarn $^{3}$ & 92,2 & 7,8 & $x(5)$ & $x(5)$ & 74,9 & 25,1 & 82,2 & 17,8 & $x(11)$ & $x(11)$ & 63,4 & 36,6 \\
\hline Island & 86,1 & 13,9 & $x(5)$ & $x(5)$ & $\mathrm{m}$ & $\mathrm{m}$ & 96,2 & 3,8 & $x(11)$ & $x(11)$ & 81,9 & 18,1 \\
\hline Irland $^{3}$ & 89,7 & 10,3 & 76,5 & 6,1 & 82,7 & 17,3 & 81,6 & 18,4 & 45,6 & 23,2 & 68,7 & 31,3 \\
\hline Italien ${ }^{3}$ & 94,7 & 5,3 & 63,8 & 17,0 & 80,8 & 19,2 & 83,0 & 17,0 & 42,3 & 21,1 & 63,4 & 36,6 \\
\hline Japan $^{2}$ & 88,9 & 11,1 & $x(5)$ & $x(5)$ & 87,7 & 12,3 & 83,7 & 16,3 & $x(11)$ & $x(11)$ & 67,5 & 32,5 \\
\hline Korea & 78,7 & 21,3 & 61,7 & 7,8 & 69,5 & 30,5 & 79,5 & 20,5 & 34,2 & 11,1 & 45,2 & 54,8 \\
\hline Luxemburg & 85,2 & 14,8 & 80,8 & 9,7 & 90,5 & 9,5 & $\mathrm{~m}$ & $\mathrm{~m}$ & $\mathrm{~m}$ & $\mathrm{~m}$ & $\mathrm{~m}$ & $\mathrm{~m}$ \\
\hline Mexiko $^{3}$ & 97,2 & 2,8 & 81,3 & 12,3 & 93,6 & 6,4 & 95,7 & 4,3 & 57,7 & 19,1 & 76,8 & 23,2 \\
\hline Niederlande & 94,6 & 5,4 & $x(5)$ & $x(5)$ & 77,8 & 22,2 & 95,4 & 4,6 & $x(11)$ & $x(11)$ & 75,2 & 24,8 \\
\hline Neuseeland & $\mathrm{m}$ & $\mathrm{m}$ & $\mathrm{m}$ & $\mathrm{m}$ & $\mathrm{m}$ & $\mathrm{m}$ & $\mathrm{m}$ & $\mathrm{m}$ & $\mathrm{m}$ & $\mathrm{m}$ & $\mathrm{m}$ & $\mathrm{m}$ \\
\hline Norwegen & 88,7 & 11,3 & $x(5)$ & $x(5)$ & 82,8 & 17,2 & 90,1 & 9,9 & $x(11)$ & $x(11)$ & 64,9 & 35,1 \\
\hline Polen $^{3}$ & 91,9 & 8,1 & $x(5)$ & $x(5)$ & 75,8 & 24,2 & 96,2 & 3,8 & $x(11)$ & $x(11)$ & 71,8 & 28,2 \\
\hline Portugal & 96,2 & 3,8 & $x(5)$ & $x(5)$ & 94,3 & 5,7 & 87,0 & 13,0 & $x(11)$ & $x(11)$ & 77,4 & 22,6 \\
\hline Slowakische Rep. & 94,9 & 5,1 & 62,0 & 16,8 & 78,8 & 21,2 & 90,3 & 9,7 & 33,0 & 23,3 & 56,3 & 43,8 \\
\hline Spanien & 93,5 & 6,5 & 76,0 & 9,9 & 85,9 & 14,1 & 80,9 & 19,1 & 59,9 & 19,4 & 79,3 & 20,7 \\
\hline Schweden & $\mathrm{m}$ & $\mathrm{m}$ & 48,7 & 16,1 & 65,1 & 34,9 & $\mathrm{~m}$ & $\mathrm{~m}$ & $x(11)$ & $x(11)$ & 57,9 & 42,1 \\
\hline Schweiz $^{3}$ & 91,2 & 8,8 & 71,5 & 13,1 & 84,6 & 15,4 & 88,5 & 11,5 & 52,8 & 24,1 & 76,9 & 23,1 \\
\hline Türkei ${ }^{3}$ & 88,8 & 11,2 & $x(5)$ & $x(5)$ & 94,8 & 5,2 & 79,8 & 20,2 & $x(11)$ & $x(11)$ & 75,3 & 24,7 \\
\hline Ver. Königreich & 92,2 & 7,8 & 53,0 & 20,9 & 73,9 & 26,1 & 97,7 & 2,3 & 32,8 & 25,3 & 58,1 & 41,9 \\
\hline Ver. Staaten ${ }^{1,3}$ & 88,1 & 11,9 & 55,7 & 25,3 & 81,0 & 19,0 & 89,4 & 10,6 & 31,6 & 35,9 & 67,4 & 32,6 \\
\hline Ländermittel & 91,6 & 8,4 & 64,2 & 14,4 & 80,7 & 19,3 & 88,5 & 11,5 & 42,4 & 22,7 & 67,1 & 32,9 \\
\hline OECD-Partnerländer & & & & & & & & & & & & \\
\hline Argentinien ${ }^{3}$ & 98,4 & 1,6 & 59,4 & 28,9 & 88,3 & 11,7 & 99,2 & 0,8 & 54,5 & 35,3 & 89,8 & 10,2 \\
\hline Brasilien ${ }^{3,4}$ & 93,3 & 6,7 & $x(5)$ & $x(5)$ & 79,2 & 20,8 & 96,9 & 3,1 & $x(11)$ & $x(11)$ & 82,2 & 17,8 \\
\hline Chile $^{3,5}$ & 83,5 & 16,5 & $x(5)$ & $x(5)$ & 61,0 & 39,0 & 90,2 & 9,8 & $x(11)$ & $x(11)$ & 66,4 & 33,6 \\
\hline Indien 1,3 & 95,3 & 4,7 & 86,7 & 5,4 & 92,2 & 7,8 & 98,8 & 1,2 & 99,7 & $\mathrm{x}: \mathrm{X} 1$ & 99,7 & 0,3 \\
\hline Indonesien ${ }^{3}$ & 93,9 & 6,1 & 78,0 & 7,8 & 85,8 & 14,2 & 82,0 & 18,0 & 87,2 & 11,8 & 99,0 & 1,0 \\
\hline Israel & 92,3 & 7,7 & $x(5)$ & $x(5)$ & 78,1 & 21,9 & 90,5 & 9,5 & $x(11)$ & $x(11)$ & 75,1 & 24,9 \\
\hline Jamaika $^{3}$ & 94,3 & 5,7 & 70,1 & 12,9 & 83,0 & 17,0 & 84,7 & 15,3 & 47,4 & 24,3 & 71,6 & 28,4 \\
\hline Jordanien $^{3}$ & 87,9 & 12,1 & 86,0 & 9,8 & 95,8 & 4,2 & a & $\mathrm{a}$ & $\mathrm{a}$ & a & a & a \\
\hline Malaysia $^{3}$ & 63,2 & 36,8 & 64,8 & 11,6 & 76,4 & 23,6 & 48,6 & 51,4 & 31,5 & 13,5 & 45,0 & 55,0 \\
\hline Paraguay ${ }^{3}$ & $\mathrm{~m}$ & $\mathrm{~m}$ & $\mathrm{~m}$ & $\mathrm{~m}$ & $\mathrm{~m}$ & $\mathrm{~m}$ & 87,0 & 13,0 & 65,3 & 16,5 & 81,8 & 18,2 \\
\hline Peru $^{3}$ & $\mathrm{~m}$ & 5,3 & $\mathrm{~m}$ & $\mathrm{~m}$ & $\mathrm{~m}$ & $\mathrm{~m}$ & 85,5 & 14,5 & 51,4 & 8,1 & 59,5 & 40,5 \\
\hline Philippinen ${ }^{3}$ & 91,6 & 8,4 & 85,6 & a & 85,6 & 14,4 & 95,4 & 4,6 & 75,2 & a & 75,2 & 24,8 \\
\hline Tunesien $^{3}$ & 89,6 & 10,5 & $x(1)$ & $x(1)$ & $x(1)$ & $x(1)$ & 75,2 & 24,8 & $\mathrm{~m}$ & $\mathrm{~m}$ & $\mathrm{~m}$ & $\mathrm{~m}$ \\
\hline Uruguay $^{3}$ & 96,6 & 3,4 & 35,3 & 12,0 & 47,4 & 52,6 & 92,0 & 8,0 & 59,3 & 24,2 & 83,5 & 16,5 \\
\hline Simbabwe 3,5 & 99,1 & 0,9 & 100,0 & $\mathrm{n}$ & 100,0 & a & a & a & a & a & a & a \\
\hline
\end{tabular}

Hinweis: $x$ bedeutet, dass die Daten in einer anderen Spalte enthalten sind, deren Referenz in runden Klammern nach dem ,x‘ angegeben ist. So bedeutet $z$. B. $x(2)$, dass die Daten in Spalte 2 enthalten sind.

1. Post-sekundarer, nicht-tertiärer Bereich in Tertiärbereich enthalten. 2. Post-sekundarer, nicht-tertiärer Bereich sowohl in Sekundarbereich II als auch Tertiärbereich enthalten. 3. Nur öffentliche Bildungseinrichtungen. 4. Referenzjahr 2000 5. Referenzjahr 2002.

Quelle: OECD. Hinweise s. Anhang 3 unter www.oecd.org/edu/eag2004. 



\section{Bildungszugang, Bildungsbeteiligung und Bildungserwartung (in Jahren)}

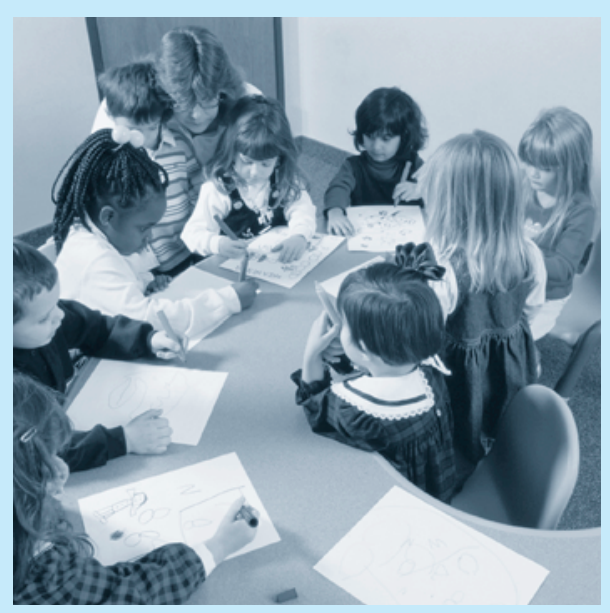





\section{Bildungserwartung (in Jahren) und Bildungsbeteiligung}

- In 24 von 27 OECD-Ländern nimmt der Einzelne im Durchschnitt zwischen 16 und 20 Jahren an einer formalen Ausbildung teil. Der größte Teil der Unterschiede bei dieser Kennzahl zwischen den einzelnen Ländern beruht auf Unterschieden bei den Schülerzahlen im Sekundarbereich II.

Zwischen 1995 und 2002 stieg die Bildungserwartung in allen OECDLändern, für die vergleichbare Zeitreihendaten verfügbar sind.

Der stärkste Rückgang der Bildungsbeteiligung ist nicht am Ende der Schulpflicht zu verzeichnen, sondern am Ende des Sekundarbereich II.

In der Hälfte der OECD-Länder werden mehr als 70 Prozent der 3- bis 4-Jährigen im Elementar- oder Primarbereich unterrichtet. Am anderen Ende des Spektrums kann ein heute 17-Jähriger davon ausgehen, dass er voraussichtlich im Durchschnitt 2,7 Jahre im tertiären Bildungsbereich verbringen wird.

In den OECD-Ländern können Frauen eine im Durchschnitt um 0,7 Jahre längere Bildungsdauer erwarten als Männer. 
Abbildung C1.1

Bildungserwartung in Jahren, nach Bildungsbereichen (2002)

Zu erwartende Jahre in Ausbildung unter gleichbleibenden Rahmenbedingungen (ohne Erziehung von Kindern, die jünger als 5 Jahre sind)

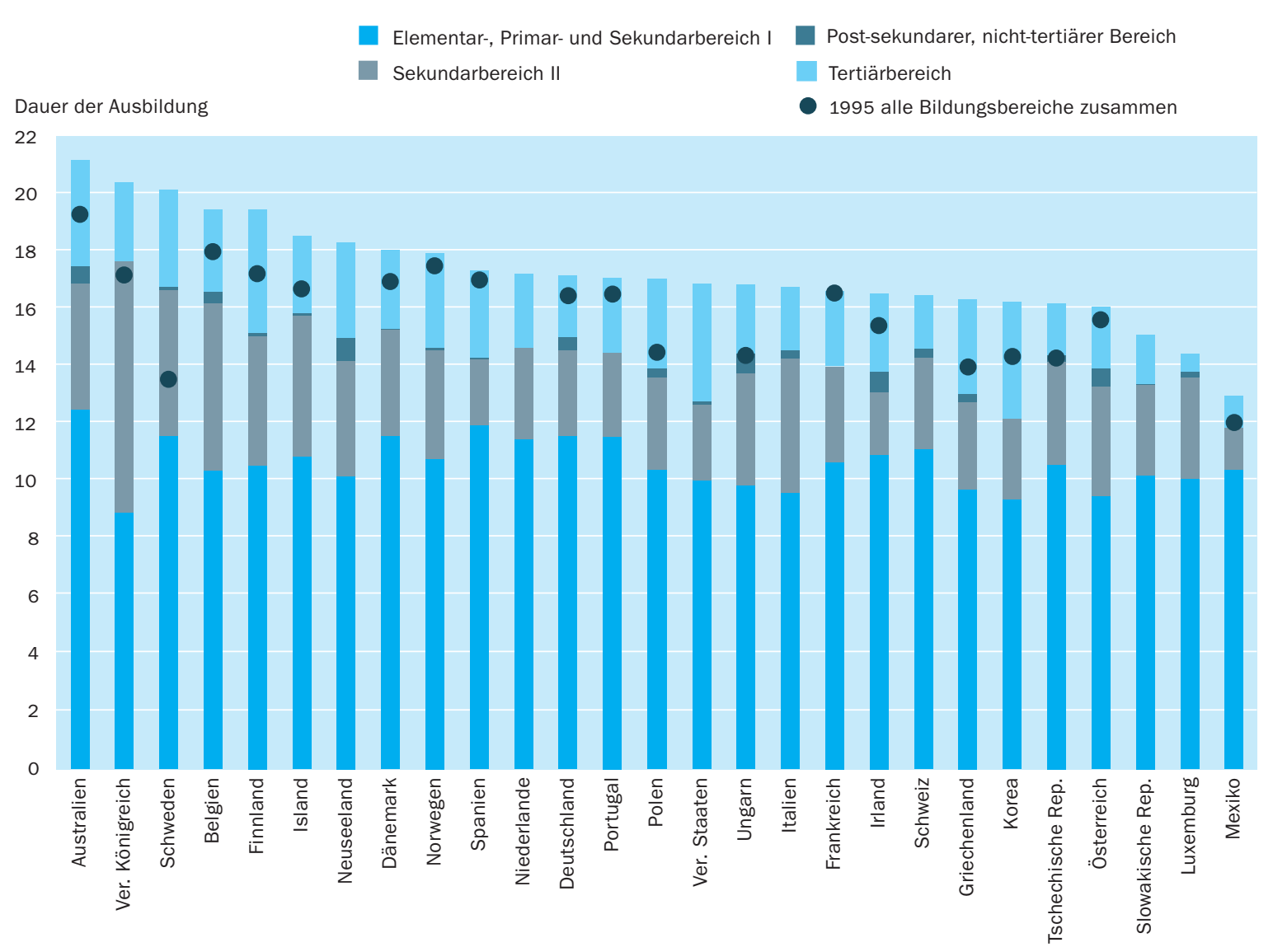

Anordnung der Länder in absteigender Reihenfolge der Gesamtbildungserwartung (in Jahren) für alle Bildungsbereiche in 2002. Quelle: OECD, Tab. C1.1. Hinweise s. Anhang 3 unter www.oecd.org/edu/eag2004.

\section{Politischer Hintergrund}

Dieser Indikator befasst sich mit der Bildungsbeteiligung in allen Bildungsbereichen.
Eine gut ausgebildete Bevölkerung ist sowohl für die gegenwärtige als auch die zukünftige wirtschaftliche und soziale Entwicklung eines Landes von entscheidender Bedeutung. Aus diesem Grunde haben die Gesellschaften ein großes Interesse daran, für Kinder und Erwachsene einen umfassenden Zugang zu einer breiten Palette an Bildungsmöglichkeiten zu gewährleisten. Programme im Elementarbereich bereiten die Kinder auf den Primarbereich vor. Sie können bei der Bekämpfung sprachlicher und sozialer Nachteile helfen und dazu beitragen, die Bildungserfahrungen aus dem Elternhaus auszubauen und zu ergänzen. Primar- und Sekundarbereich statten junge Menschen mit grundlegenden Kompetenzen aus und bereiten sie auf lebenslanges Lernen und die Entwicklung hin zu produktiven Mitgliedern der Gesellschaft vor. Der Tertiärbereich bietet entweder direkt nach der Schulbildung oder später im Leben eine Vielzahl von Möglichkeiten, erweiterte und spezielle Kenntnisse und Fähigkeiten zu erwerben. 
Dieser Indikator stellt verschiedene Kenngrößen für die Bildungsteilnahme vor, um die unterschiedlichen Ebenen des Bildungszugangs in den verschiedenen OECD-Ländern zu beschreiben. Die Entwicklungstendenzen der Bildungsbeteiligung in den verschiedenen Bildungsbereichen werden hier auch als Indikator dafür verwendet, wie sich der Zugang zu Bildung entwickelt hat.

\section{Ergebnisse und Erläuterungen}

\section{Bildungsteilnahme insgesamt}

Ein möglicher Blickwinkel bei der Betrachtung der Bildungsbeteiligung besteht darin, den Zeitraum abzuschätzen, den ein heute 5-jähriges Kind, unter Zugrundelegung der aktuellen Beteiligungsquoten, in seinem Leben voraussichtlich in Vollzeit- oder Teilzeitausbildung verbringen wird. Daher wird diese Bildungserwartung (in Jahren) geschätzt, indem die Bildungsbeteiligung für jede einzelne Altersstufe ab dem 5. Lebensjahr aufaddiert wird (Abb. C5.I). In den OECD-Ländern Luxemburg, Mexiko und der Slowakischen Republik kann ein Kind damit rechnen, maximal I5 Jahre in Ausbildung zu sein, während es in Australien, Belgien, Finnland, Schweden und dem Vereinigten Königreich mindestens ig Jahre sind.

Der größte Teil der Unterschiede der Bildungserwartung zwischen den einzelnen OECD-Ländern beruht auf der unterschiedlichen Bildungsbeteiligung im Sekundarbereich II. Die relativen Unterschiede sind zwar auch bei der Bildungsbeteiligung im Tertiärbereich groß, aber diese gelten nur für einen kleineren Anteil der entsprechenden Altersgruppe und wirken sich deshalb weniger auf die Bildungserwartung insgesamt aus.

Die Kenngrößen einer durchschnittlichen Ausbildungsdauer wie die Bildungserwartung (in Jahren) werden von der für die gesamte Lebensspanne geltenden Bildungsteilnahme beeinflusst und unterschätzen daher die tatsächliche Bildungsdauer des Einzelnen in Bildungssystemen mit expandierender Bildungsbeteiligung. Diese Kennzahlen unterscheiden auch nicht zwischen Vollzeitund Teilzeitausbildung. Daher weisen OECD-Länder mit einem relativ hohen Anteil von Teilzeitlernenden tendenziell relativ hohe Werte auf. In Australien, Belgien, Portugal, Schweden und dem Vereinigten Königreich etwa macht die Teilnahme an Teilzeitausbildung mindestens 3 Jahre der Bildungserwartung in Jahren aus (Tab. CI.I).

In den OECD-Ländern, in denen die Bildungserwartung in Jahren in einem bestimmten Bildungsbereich die Anzahl der Klassenstufen in diesem Bereich übersteigt, haben Klassenwiederholungen (oder wie im Fall von Australien, die Anzahl der Erwachsenen in solchen Bildungsgängen) größere Auswirkungen auf die Bildungserwartung als der Anteil derjenigen Schüler, die ihre Ausbildung vor dem entsprechenden Abschluss abbrechen.

Die Bildungsbeteiligung hängt von den Zugangsquoten eines bestimmten Bildungsbereichs und von der typischen Ausbildungsdauer ab. Eine Bildungserwartung von vielen Jahren bedeutet deshalb nicht unbedingt, dass alle jungen Menschen über einen langen Zeitraum im Bildungssystem verbleiben. So gibt
In 24 von 27 OECD-Ländern nimmt der Einzelne im Durchschnitt zwischen 16 und 20 Jahren an einer formalen Ausbildung teil.

Der größte Teil der Unterschiede beruht auf der unterschiedlichen Bildungsbeteiligung im Sekundarbereich II.

Eine Bildungserwartung von vielen Jahren bedeutet nicht unbedingt, dass alle jungen Menschen Zugang zu höherer Bildung haben, aber... 
... in den meisten OECDLändern nehmen praktisch alle jungen Menschen mindestens 12 Jahre lang an formaler Bildung teil.

In den OECD-Ländern können Frauen eine im Durchschnitt um 0,7 Jahre längere Bildungsdauer erwarten als Männer.

Zwischen 1995 und 2002 stieg die Bildungserwartung in allen OECD-Ländern, für die vergleichbare Zeitreihendaten verfügbar sind.

In der Hälfte der OECD-Länder werden mehr als 70 Prozent der 3- bis 4-Jährigen im Elementar- oder Primarbereich unterrichtet. es in Belgien, wo die Bildungserwartung für 5-Jährige bei über I9 Jahren liegt, eine fast vollständige Bildungsbeteiligung (mit über 90 Prozent) für einen Zeitraum von I5 Jahren. Im Gegensatz dazu gibt es bei einer gleich hohen Bildungserwartung in Australien, Finnland, Schweden und dem Vereinigten Königreich eine fast vollständige Beteiligung (über 90 Prozent) nur für eine Bildungsdauer von maximal I3 Jahren (Tab. CI.I und CI.2).

In den meisten OECD-Ländern haben praktisch alle Jugendlichen Zugang zu einer formalen Ausbildung von mindestens I2 Jahren. Die Altersspanne, in der mindestens 9o Prozent der Lernenden sich in einem Bildungsgang befinden, umfasst in Belgien, Frankreich, Island, Japan und Spanien I4 Jahre und mehr. Mexiko hingegen hat maximal für einen Zeitraum von 7 Jahren eine Bildungsbeteiligung von über 90 Prozent (Tab. Cr.2).

Die Schwankungen bei der zu erwartenden Bildungsdauer sind für Frauen meist stärker als für Männer. In den OECD-Ländern können Frauen eine im Durchschnitt um o,7 Jahre längere Bildungsdauer erwarten als Männer. In Belgien, Dänemark, Finnland, Island, Irland, Neuseeland, Norwegen, Schweden und dem Vereinigten Königreich übertrifft die zu erwartende Bildungsdauer für Frauen die für Männer um mehr als ein Jahr (in Schweden und dem Vereinigten Königreich beläuft sich der Unterschied auf 3 Jahre). Das Gegenteil trifft auf Korea und die Schweiz zu, wo die Männer mit einer zwischen I, 9 bzw. o,6 Jahren längeren Bildungsdauer als Frauen rechnen können (Tab. CI.I).

\section{Entwicklungen der Bildungsbeteiligung}

In allen OECD-Ländern, für die vergleichbare Zeitreihendaten verfügbar sind, stieg die Bildungserwartung zwischen 1995 und 2002 (Tab. CI.I). In Griechenland, Polen, Schweden, Ungarn und dem Vereinigten Königreich betrug der Anstieg über diesen relativ kurzen Zeitraum hinweg I5 Prozent oder mehr.

\section{Bildungsbeteiligung im Elementarbereich}

In der Mehrzahl der OECD-Länder beginnt eine universelle Bildungsbeteiligung - hier als eine Bildungsbeteiligung von mehr als go Prozent definiert - im Alter von 5 bis 6 Jahren. In Belgien, Dänemark, Frankreich, Deutschland, Island, Italien, Japan, Luxemburg, Neuseeland, Norwegen, Spanien, Schweden, der Slowakischen Republik, der Tschechischen Republik, Ungarn und dem Vereinigten Königreich werden jedoch bereits mehr als 70 Prozent der 3- bis 4Jährigen im Elementar- oder Primarbereich unterrichtet (Tab. CI.2). Ihre Bildungsbeteiligung reicht von weniger als 22 Prozent in Korea und der Schweiz bis zu über 90 Prozent in Belgien, Frankreich, Island, Italien und Spanien.

Angesichts der Tatsache, dass die Erziehung und Betreuung im Vorschulalter für den Aufbau einer soliden Grundlage für späteres lebenslanges Lernen und zur Sicherstellung von Chancengleichheit beim Zugang zu Bildungsmöglichkeiten später in der Schule eine wichtige Rolle spielt, ist der Elementarbereich von entscheidender Bedeutung. Allerdings ist die institutionalisierte Vorschulerziehung, die in diesem Indikator behandelt wird, nicht die einzige Form qualitativ hochwertiger Erziehung und Betreuung im Vorschulalter. Schlussfolgerungen bezüglich des Zugangs zu Erziehung und Betreuung im Vorschulalter und deren Qualität sollten deshalb mit großer Vorsicht gezogen werden. 


\section{Bildungsbeteiligung gegen Ende und nach der Pflichtschulzeit}

Eine Reihe von Faktoren, u. a. das erhöhte Risiko, arbeitslos zu werden, und andere Formen der Ausgrenzung junger Menschen mit unzureichender Ausbildung beeinflussen die Entscheidung, die Ausbildung über die Pflichtschulzeit hinaus zu verlängern. In vielen OECD-Ländern dauert der Übergang von der Ausbildung in die Berufstätigkeit länger als früher und ist komplexer geworden. Daraus ergibt sich für die Lernenden die Möglichkeit oder auch die Notwendigkeit, Lernen und Arbeiten miteinander zu verbinden, um Kenntnisse und Fähigkeiten zu erwerben, die für den Arbeitsmarkt relevant sind (s. Indikator $\mathrm{C}_{4}$ ).

Die Schulpflicht endet in den OECD-Ländern im Alter zwischen I4 Jahren (Korea, Portugal und Türkei) und I 8 Jahren (Belgien, Deutschland und die Niederlande), in den meisten Fällen mit 15 oder 16 Jahren (Tab. Cr.2). Das Alter, in dem die Schulpflicht endet, entspricht jedoch nicht immer der Altersstufe, in der die Bildungsbeteiligung fast vollständig ist.

Während in den meisten OECD-Ländern die Bildungsbeteiligung bis zum Ende der Schulpflicht hoch ist, fällt sie in Belgien, Deutschland, Mexiko, Neuseeland, den Niederlanden, dem Vereinigten Königreich und den Vereinigten Staaten vor dem Ende des schulpflichtigen Alters auf unter go Prozent. In Belgien, Deutschland, den Niederlanden und den Vereinigten Staaten mag dies zum Teil an dem relativ hohen Alter liegen, in dem die Schulpflicht endet (I8 Jahre bzw. I7 Jahre in den Vereinigten Staaten). Im Gegensatz hierzu gelingt es in 2I OECD-Ländern, nahezu alle Jugendlichen auch über das Ende der Schulpflicht hinaus in der Schule zu halten (Tab. Cr.2).

In Finnland, Japan, Norwegen, Schweden und der Tschechischen Republik beispielsweise nehmen noch mehr als 93 Prozent aller 17-Jährigen an einer formalen Ausbildung teil, obwohl die Schulpflicht schon vor dem 17. Geburtstag endet (Tabelle Cr.3). In Schweden besuchen sogar 93 Prozent der I8-Jährigen noch den Sekundarbereich.

In der Hälfte der OECD-Länder ist die Bildungsbeteiligung auch nach dem Ende der Schulpflicht noch fast vollständig, insbesondere in den Ländern, in denen die Schulpflicht schon in relativ jungen Jahren endet. Es gibt keinen engen Zusammenhang zwischen dem Ende der Schulpflicht und der Abnahme der Bildungsbeteiligung. Ab dem Alter von $\mathrm{I} 6$ Jahren geht die Bildungsbeteiligung in allen OECD-Ländern zurück. Im Durchschnitt der OECD-Länder beträgt die Bildungsbeteiligung bei den I7-Jährigen 84 Prozent, bei den I8-Jährigen 7I Prozent und bei den I9-Jährigen 57 Prozent (Tab. CI.3).

In 20 von 27 OECD-Ländern erfolgt der stärkste Rückgang der Bildungsbeteiligung am Ende des Sekundarbereich II. In Schweden nimmt die Bildungsbeteiligung ab dem Alter von I8 Jahren, wenn der Sekundarbereich normalerweise beendet wird, von 93 auf 42 Prozent ab (Tab. Cr.3).

In den meisten OECD-Ländern fängt in den letzten Jahren des Sekundarbereich II ein allmählicher Rückgang der Bildungsbeteiligung an. Es gibt jedoch mehrere bemerkenswerte Ausnahmen, in denen die Bildungsbeteiligung auch bei den 20- bis 29-Jährigen noch relativ hoch ist: in Australien, Dänemark,
Die Schulpflicht endet in den OECD-Ländern im Alter zwischen 14 und 18 Jahren, in den meisten Ländern mit 15 oder 16 Jahren.

Die Bildungsbeteiligung liegt bis zum Ende der Schulpflicht tendenziell hoch, es gibt jedoch 7 OECD-Länder, in denen mehr als 10 Prozent der Schüler das Ende der Pflichtschulausbildung nicht erreichen.

Der stärkste Rückgang der Bildungsbeteiligung ist nicht am Ende der Schulpflicht zu verzeichnen,...

... sondern am Ende des Sekundarbereich II.

In Australien, Dänemark, Finnland, Island und Schweden beträgt die Bildungsbeteillgung der 20-bis 29-Jährigen mehr als 30 Prozent. 
In 27 von 30 OECD-Ländern werden Bildungsgänge im post-sekundaren, nichttertiären Bereich angeboten.
In den OECD-Ländern nimmt ein 17-Jähriger im Durchschnitt voraussichtlich 2,7 Jahre an tertiärer Bildung teil.
Eine expansive Bildungspolitik hat in vielen OECD-Ländern auch den Druck in Richtung auf einen erweiterten Zugang zum Tertiärbereich verstärkt.
Finnland, Island und Schweden liegt die Bildungsbeteiligung der 20- bis 29Jährigen immer noch bei über 30 Prozent (Tab. Cr.2).

\section{Der Übergang zum post-sekundaren Bereich}

In vielen Bildungssystemen haben Absolventen des Sekundarbereich II auch die Möglichkeit, an relativ kurzen Ausbildungsgängen (mit einer Dauer von unter 2 Jahren) teilzunehmen, um sich für bestimmte Berufe oder Berufsfelder zu qualifizieren.

Während einige OECD-Länder diese post-sekundaren, nicht-tertiären Bildungsgänge als höhere oder zweite Stufe innerhalb des Sekundarbereich II anbieten (z.B. Deutschland, Österreich, Spanien und Ungarn), werden sie in anderen im post-sekundaren Bereich angeboten (z. B. in Kanada und den Vereinigten Staaten). Unter dem Aspekt des internationalen Vergleichs bewegen sich diese Bildungsgänge im Grenzbereich zwischen Sekundarbereich II und Tertiärbereich und werden daher als separater Bildungsbereich (post-sekundare, nicht-tertiäre Bildungsgänge) eingestuft. In 27 von 30 OECD-Ländern werden den Absolventen des Sekundarbereich II derartige Bildungsgänge angeboten (Tab. CI.I).

Abgänger des Sekundarbereich II, die nicht direkt den Übergang zum Arbeitsmarkt suchen und Berufstätige, die sich fortbilden wollen, können auch aus einem großen Angebot an tertiären Ausbildungsgängen wählen.

\section{Bildungsbeteiligung im Tertiärbereich}

Innerhalb der OECD unterscheiden sich die tertiären Studiengänge darin, dass sie entweder eher theoretisch ausgerichtet sind und darauf abzielen, Studierende für weiterführende Forschungsprogramme oder Berufe mit hohen Qualifikationsanforderungen vorzubereiten (Tertiärbereich A) oder sich eher auf die Vermittlung berufsspezifischer Fähigkeiten und Kenntnisse zum direkten Eintritt in den Arbeitsmarkt konzentrieren (Tertiärbereich B). Während man in der Vergangenheit anhand der Art der anbietenden Institution eines Bildungsgangs eine relativ gute Vorstellung von der Art des Bildungsgangs bekam (z. B. Bildungsangebote an Universitäten gegenüber denen an nicht-universitären Bildungseinrichtungen), haben sich diese Unterschiede inzwischen verwischt und werden daher bei den OECD-Indikatoren nicht herangezogen.

In den OECD-Ländern nimmt ein I7-Jähriger im Durchschnitt voraussichtlich 2,7 Jahre an tertiärer Bildung teil. Die Bildungserwartung im Tertiärbereich wird sowohl von den Studienanfängerquoten im Tertiärbereich als auch von der üblichen Studiendauer beeinflusst. In Australien, Finnland, Griechenland, Korea, Neuseeland, Norwegen, Polen, Spanien, Schweden und den Vereinigten Staaten beträgt sie 3 Jahre und mehr. In Luxemburg, Mexiko, der Schweiz, der Slowakischen Republik und der Tschechischen Republik beträgt die Bildungserwartung im Tertiärbereich hingegen maximal I,8 Jahre (Tab. CI.I und Indikator $\left.\mathrm{C}_{2}\right)$.

Eine expansive Bildungspolitik hat in vielen OECD-Ländern auch den Druck in Richtung auf einen erweiterten Zugang zum Tertiärbereich verstärkt. Bisher hat dieser Druck den Bevölkerungsrückgang der jüngeren Altersgruppen mehr als ausgeglichen, der bis vor kurzem zu Prognosen einer gleichbleibenden 
oder abnehmenden Nachfrage bei Schulabgängern in mehreren OECD-Ländern geführt hatte. Obwohl es in einigen OECD-Ländern jetzt Anzeichen für eine nicht weiter zunehmende Nachfrage nach Bildung im Tertiärbereich gibt, bleibt die Gesamttendenz jedoch steigend.

\section{Definitionen und angewandte Methodik}

Die Zahlen basieren auf Personenzahlen (außer wenn etwas anderes angegeben ist), d.h. es wird nicht zwischen Vollzeit- und Teilzeitlernenden unterschieden. Eine standardisierte Unterscheidung zwischen Vollzeit- und Teilzeitlernenden ist sehr schwierig, da in einigen Ländern das Konzept des Teilzeitbildungsgangs nicht anerkannt wird. In anderen OECD-Ländern wird die Teilzeitausbildung nicht vollständig von den zur Verfügung gestellten Daten erfasst.

Die Berechnung der voraussichtlichen durchschnittlichen Dauer der formalen Bildung eines 5-jährigen Kindes während seines gesamten Lebens, also der Bildungserwartung (in Jahren), erfolgt durch Addition der Netto-Bildungsbeteiligung für jede einzelne Altersstufe ab dem 5. Lebensjahr. Die durchschnittliche Dauer der (Aus-)Bildung für eine Kohorte wird Tendenzen zu einer längeren (kürzeren) Dauer der Ausbildung in den folgenden Jahren widerspiegeln. Beim Vergleich der Daten zur Bildungserwartung ist jedoch zu beachten, dass weder die Länge eines Schuljahres noch die Qualität der Bildung in allen Ländern notwendigerweise gleich sind.

Die Berechnung der in Tabelle Cr.2 verwendeten Netto-Bildungsbeteiligung (ausgedrückt in Prozent) erfolgte, indem die Zahl der Lernenden einer bestimmten Altersgruppe in allen Bildungsbereichen durch die Gesamtzahl der Personen in der entsprechenden Altersgruppe in der Bevölkerung dividiert wurde. Tabelle Cr.I zeigt den Index der Veränderung der Bildungserwartung zwischen 1995 und 2002. Die Daten über die Zahl der Lernenden für 1994/1995 stammen aus einer im Jahr 2000 durchgeführten Sonderuntersuchung und basieren auf der ISCED-97-Klassifikation.
Die Daten beziehen sich auf das Schuljahr 2001/2002 und beruhen auf der alljährlich von der OECD aufgelegten UOE-Datenerhebung zur Bildungsstatistik und dem World Education Indicators Programme 2003. 
Tabelle C1.1

Bildungserwartung, in Jahren (2002)

Zu erwartende Jahre in Ausbildung unter gleichbleibenden Rahmenbedingungen (ohne Erziehung von Kindern, die jünger als 5 Jahre sind)

\begin{tabular}{|c|c|c|c|c|c|c|c|c|c|c|}
\hline & \multicolumn{9}{|c|}{2002} & \multirow{3}{*}{$\begin{array}{l}\text { Index der Ver- } \\
\text { änderung der } \\
\text { Bildungserwar- } \\
\text { tung in Jahren } \\
\text { für alle Bil- } \\
\text { dungsbereiche } \\
\text { zusammen } \\
(1995=100)\end{array}$} \\
\hline & \multicolumn{7}{|c|}{ Voll- und Teilzeit } & \multirow{2}{*}{\begin{tabular}{|c|} 
Vollzeit \\
$\begin{array}{c}\text { Alle Bildungs- } \\
\text { bereiche } \\
\text { zusammen }\end{array}$ \\
\end{tabular}} & \multirow{2}{*}{\begin{tabular}{|c|} 
Teilzeit \\
$\begin{array}{c}\text { Alle Bildungs- } \\
\text { bereiche } \\
\text { zusammen }\end{array}$ \\
\end{tabular}} & \\
\hline & \multicolumn{3}{|c|}{ Alle Bildungsbereiche zusammen } & $\begin{array}{l}\text { Primar- und } \\
\text { Sekundar- } \\
\text { bereich I }\end{array}$ & $\begin{array}{l}\text { Sekundar- } \\
\text { bereich II }\end{array}$ & $\begin{array}{c}\text { Post- } \\
\text { sekundarer, } \\
\text { nicht-tertiärer } \\
\text { Bereich }\end{array}$ & $\begin{array}{l}\text { Tertiär- } \\
\text { bereich }\end{array}$ & & & \\
\hline & $M+F$ & Männer & Frauen & & & $+F$ & & $M$ & $+F$ & $M+F$ \\
\hline & (1) & (2) & (3) & (4) & (5) & (6) & (7) & (8) & (9) & (10) \\
\hline \multicolumn{11}{|l|}{ OECD-Länder } \\
\hline Australien & 21,1 & 20,9 & 21,4 & 11,8 & 4,4 & 0,6 & 3,6 & 14,7 & 6,4 & 110 \\
\hline Österreich & 16,0 & 16,0 & 16,1 & 8,2 & 3,8 & 0,6 & 2,1 & 16,0 & $n$ & 103 \\
\hline Belgien & 19,4 & 18,8 & 20,0 & 9,3 & 5,8 & 0,4 & 2,8 & 16,2 & 3,2 & 108 \\
\hline Kanada & $\mathrm{m}$ & $\mathrm{m}$ & $\mathrm{m}$ & $\mathrm{m}$ & $\mathrm{m}$ & $\mathrm{m}$ & $\mathrm{m}$ & $\mathrm{m}$ & $\mathrm{m}$ & $\mathrm{m}$ \\
\hline Tschechische Rep. & 16,2 & 16,1 & 16,3 & 9,0 & 3,6 & 0,2 & 1,8 & 16,0 & 0,2 & 114 \\
\hline Dänemark & 18,0 & 17,5 & 18,6 & 9,7 & 3,7 & $\mathrm{n}$ & 2,7 & 18,0 & $n$ & 107 \\
\hline Finnland & 19,4 & 18,7 & 20,2 & 9,0 & 4,5 & 0,1 & 4,3 & 17,7 & 1,7 & 113 \\
\hline Frankreich & 16,6 & 16,3 & 16,9 & 9,5 & 3,3 & $\mathrm{n}$ & 2,6 & 16,6 & $n$ & 100 \\
\hline Deutschland & 17,1 & 17,2 & 17,0 & 10,1 & 3,0 & 0,5 & 2,1 & 17,1 & 0,1 & 104 \\
\hline Griechenland & 16,3 & 15,9 & 16,7 & 8,9 & 3,0 & 0,3 & 3,3 & 16,1 & 0,2 & 117 \\
\hline Ungarn & 16,8 & 16,5 & 17,1 & 8,1 & 3,9 & 0,7 & 2,4 & 15,1 & 1,7 & 117 \\
\hline Island & 18,5 & 17,6 & 19,4 & 9,9 & 4,9 & 0,1 & 2,7 & 16,5 & 2,0 & 111 \\
\hline Irland & 16,5 & 16,0 & 17,1 & 10,9 & 2,2 & 0,7 & 2,7 & 15,5 & 1,0 & 107 \\
\hline Italien & 16,7 & 16,3 & 16,9 & 8,4 & 4,6 & 0,1 & 2,6 & 16,6 & 0,1 & $\mathrm{~m}$ \\
\hline Japan & $\mathrm{m}$ & $\mathrm{m}$ & $\mathrm{m}$ & 9,1 & 3,0 & $\mathrm{~m}$ & $\mathrm{~m}$ & $\mathrm{~m}$ & $\mathrm{~m}$ & $\mathrm{~m}$ \\
\hline Korea & 16,2 & 17,1 & 15,3 & 8,9 & 2,8 & a & 4,0 & 16,2 & $n$ & 113 \\
\hline Luxemburg & 14,4 & 13,8 & 13,9 & 9,1 & 3,5 & 0,2 & 0,6 & 14,2 & 0,2 & $\mathrm{~m}$ \\
\hline Mexiko & 12,9 & 12,8 & 13,1 & 9,6 & 1,5 & a & 1,1 & 12,9 & $\mathrm{n}$ & 107 \\
\hline Niederlande & 17,2 & 17,3 & 17,1 & 10,5 & 3,1 & $n$ & 2,6 & 16,5 & 0,6 & $\mathrm{~m}$ \\
\hline Neuseeland & 18,3 & 17,3 & 19,2 & 10,1 & 4,0 & 0,8 & 3,3 & 15,7 & 2,5 & $\mathrm{~m}$ \\
\hline Norwegen ${ }^{1}$ & 17,9 & 16,4 & 17,8 & 9,9 & 3,8 & 0,1 & 3,3 & 16,5 & 1,4 & 102 \\
\hline Polen & 17,0 & 16,5 & 17,5 & 9,0 & 3,2 & 0,3 & 3,1 & 14,9 & 2,1 & 118 \\
\hline Portugal & 17,0 & 16,6 & 17,5 & 10,6 & 2,9 & a & 2,6 & 13,8 & 3,3 & 103 \\
\hline Slowakische Rep. & 15,1 & 15,0 & 15,2 & 9,0 & 3,1 & 0,1 & 1,7 & 14,4 & 0,7 & $\mathrm{~m}$ \\
\hline Spanien & 17,3 & 16,9 & 17,8 & 10,9 & 2,3 & 0,1 & 3,0 & 16,7 & 0,6 & 102 \\
\hline Schweden & 20,1 & 18,7 & 21,6 & 9,8 & 5,1 & 0,1 & 3,4 & 16,8 & 3,3 & 146 \\
\hline Schweiz & 16,5 & 16,7 & 16,2 & 9,5 & 3,2 & 0,3 & 1,8 & 16,0 & 0,5 & $\mathrm{~m}$ \\
\hline Türkei & $\mathrm{m}$ & $\mathrm{m}$ & $\mathrm{m}$ & $\mathrm{m}$ & $\mathrm{m}$ & $\mathrm{m}$ & $\mathrm{m}$ & $\mathrm{m}$ & $\mathrm{m}$ & $\mathrm{m}$ \\
\hline Ver. Königreich & 20,4 & 18,9 & 21,9 & 8,9 & 8,7 & $x(5)$ & 2,8 & 14,7 & 5,7 & 119 \\
\hline Vereinigte Staaten & 16,8 & 16,5 & 17,3 & 9,1 & 2,6 & 0,1 & 4,1 & 15,4 & 1,5 & $\mathrm{~m}$ \\
\hline Ländermittel & 17,2 & 16,8 & 17,5 & 9,6 & 3,7 & 0,3 & 2,7 & 15,8 & 1,6 & 111 \\
\hline \multicolumn{11}{|l|}{ OECD-Partnerländer } \\
\hline Argentinien $^{2}$ & 17,4 & 16,7 & 18,1 & 10,7 & 2,4 & a & 3,3 & 14,9 & 2,5 & $\mathrm{~m}$ \\
\hline Brasilien ${ }^{2}$ & 16,1 & 15,9 & 16,3 & 10,8 & 2,8 & $\mathrm{~m}$ & 1,1 & 16,1 & $\mathrm{n}$ & $\mathrm{m}$ \\
\hline Chile & 14,9 & 15,1 & 14,7 & 8,3 & 3,7 & a & 1,9 & 14,9 & a & $\mathrm{m}$ \\
\hline China & 11,1 & $\mathrm{~m}$ & $\mathrm{~m}$ & 8,6 & 1,1 & $\mathrm{~m}$ & $\mathrm{~m}$ & 10,9 & 0,2 & $\mathrm{~m}$ \\
\hline Ägypten & 10,4 & 10,6 & 10,1 & 8,1 & 2,1 & $\mathrm{~m}$ & $\mathrm{~m}$ & 10,4 & $n$ & $\mathrm{~m}$ \\
\hline Indien ${ }^{2}$ & 8,5 & 9,5 & 7,5 & 6,5 & 1,3 & $\mathrm{n}$ & 0,5 & 8,3 & 0,2 & $\mathrm{~m}$ \\
\hline Indonesien & 12,0 & 12,1 & 11,9 & 9,6 & 1,2 & a & 0,7 & 12,0 & $n$ & $\mathrm{~m}$ \\
\hline Israel & 15,9 & 15,5 & 16,2 & 8,6 & 3,2 & 0,1 & 3,0 & 15,3 & 0,6 & $\mathrm{~m}$ \\
\hline Jamaika & 12,7 & 12,1 & 13,2 & 8,4 & 1,6 & 0,8 & 0,9 & 12,3 & 0,4 & $\mathrm{~m}$ \\
\hline Jordanien $^{2}$ & 11,8 & 11,4 & 12,3 & 8,9 & 1,4 & a & 1,3 & 11,8 & $\mathrm{n}$ & $\mathrm{m}$ \\
\hline Paraguay ${ }^{2}$ & 12,3 & 12,2 & 12,3 & 9,2 & 1,6 & $\mathrm{~m}$ & 0,7 & 12,3 & $n$ & $\mathrm{~m}$ \\
\hline Peru $^{2}$ & 14,6 & 14,6 & 14,6 & 10,3 & 1,5 & 0,6 & 1,6 & 14,6 & $\mathrm{n}$ & $\mathrm{m}$ \\
\hline Philippinen & 12,0 & 11,5 & 12,0 & 9,3 & 0,7 & 0,3 & 1,4 & 11,7 & 0,3 & $\mathrm{~m}$ \\
\hline Russische Föd. & 14,9 & 14,6 & 15,7 & 6,4 & 1,7 & 0,1 & 3,3 & 12,1 & 2,8 & $\mathrm{~m}$ \\
\hline Thailand & 16,5 & 16,4 & 16,6 & 10,1 & 2,6 & $\mathrm{~m}$ & 2,1 & 13,0 & 3,5 & $\mathrm{~m}$ \\
\hline Tunesien & 14,8 & 14,3 & 15,2 & 9,9 & 2,3 & $\mathrm{~m}$ & 1,0 & 13,5 & 1,2 & $\mathrm{~m}$ \\
\hline Uruguay $^{2}$ & 15,9 & 15,1 & 16,8 & 9,9 & 2,7 & $n$ & 1,9 & 15,9 & $n$ & $\mathrm{~m}$ \\
\hline Simbabwe & 11,5 & 12,0 & 11,0 & 9,0 & 1,1 & $\mathrm{~m}$ & 0,2 & 11,5 & $\mathrm{n}$ & $\mathrm{m}$ \\
\hline
\end{tabular}

Hinweis: $x$ bedeutet, dass die Daten in einer anderen Spalte enthalten sind, deren Referenz in runden Klammern nach dem ,x angegeben ist. So bedeutet $z$. B. $x(2)$, dass die Daten in Spalte 2 enthalten sind.

1. Insgesamt (Männer + Frauen) beinhaltet bei Norwegen Kinder unter 5 Jahren, die aber bei der Verteilung der 5-Jährigen nach Geschlecht nicht enthalten sind.

2. Referenzjahr 2001.

Quelle: OECD. Hinweise s. Anhang 3 unter www.oecd.org/edu/eag2004. 
Tabelle C1.2

Bildungsbeteiligung (2002)

Voll- und Teilzeit-Schüler/Studierende an öffentlichen und privaten Bildungseinrichtungen, nach Alter

\begin{tabular}{|c|c|c|c|c|c|c|c|c|c|}
\hline & \multirow{2}{*}{$\begin{array}{c}\text { Alter, bis zu } \\
\text { dem Schul- } \\
\text { pflicht besteht }\end{array}$} & \multirow{2}{*}{\begin{tabular}{|c|} 
Anzahl der \\
Jahre, in denen \\
über $90 \%$ der \\
Bevölkerung an \\
Bildung teil- \\
nehmen
\end{tabular}} & \multirow{2}{*}{$\begin{array}{c}\text { Altersspanne, } \\
\text { innerhalb derer } \\
\text { über } 90 \% \text { der } \\
\text { Bevölkerung an } \\
\text { Bildung teil- } \\
\text { nehmen }\end{array}$} & \multicolumn{6}{|c|}{ Schüler und Studierende im Alter von } \\
\hline & & & & $\begin{array}{l}\text { 4 J. und jünger } \\
\text { als Prozentsatz } \\
\text { der } 3 \text { - bis } \\
\text { 4-Jährigen } \\
\text { (4) }\end{array}$ & $\begin{array}{c}\text { 5- bis 14-Jährige } \\
\text { als Prozentsatz } \\
\text { der } 5 \text { - bis } \\
\text { 14-Jährigen } \\
\text { (5) }\end{array}$ & $\begin{array}{c}\text { 15- bis 19-Jähri- } \\
\text { ge als Prozent- } \\
\text { satz der } 15 \text { - bis } \\
\text { 19-Jährigen } \\
\text { (6) }\end{array}$ & $\begin{array}{l}\text { 20- bis 29-Jähri- } \\
\text { ge als Prozent- } \\
\text { satz der } 20 \text { - bis } \\
\text { 29-Jährigen } \\
\text { (7) }\end{array}$ & $\begin{array}{l}\text { 30- bis 39-Jähri- } \\
\text { ge als Prozent- } \\
\text { satz der } 30 \text { - bis } \\
\text { 39-Jährigen } \\
\text { (8) }\end{array}$ & $\begin{array}{l}40 \text { J. und älter } \\
\text { als Prozentsatz } \\
\text { der Bevölkerung } \\
\text { im Alter von } 40 \\
\text { J. und älter } \\
\text { (9) }\end{array}$ \\
\hline \multicolumn{10}{|l|}{ OECD-Länder } \\
\hline Australien & 15 & 12 & $5-16$ & 35,9 & 99,3 & 82,6 & 32,9 & 15,2 & 6,7 \\
\hline Belgien & 18 & 15 & $3-17$ & 119,6 & 100,1 & 92,3 & 27,4 & 8,3 & 3,0 \\
\hline Kanada & 16 & $\mathrm{~m}$ & $\mathrm{~m}$ & $\mathrm{~m}$ & $\mathrm{~m}$ & $\mathrm{~m}$ & $\mathrm{~m}$ & $\mathrm{~m}$ & $\mathrm{~m}$ \\
\hline Tschechische Rep. & 15 & 13 & $5-17$ & 78,7 & 99,3 & 88,4 & 15,9 & 1,3 & 0,1 \\
\hline Dänemark & 16 & 12 & $4-16$ & 86,9 & 99,1 & 81,8 & 31,4 & 5,5 & 0,8 \\
\hline Finnland & 16 & 12 & $6-17$ & 39,6 & 94,4 & 85,0 & 39,5 & 10,7 & 2,2 \\
\hline Frankreich & 16 & 15 & $3-17$ & 119,7 & 101,1 & 86,7 & 19,6 & 1,8 & a \\
\hline Deutschland & 18 & 12 & $6-17$ & 80,3 & 97,5 & 89,2 & 25,5 & 2,8 & 0,2 \\
\hline Island & 16 & 14 & $3-16$ & 135,5 & 98,5 & 81,1 & 32,0 & 8,0 & 2,3 \\
\hline Irland & 15 & 12 & $5-16$ & 26,3 & 101,4 & 81,6 & 17,8 & 2,6 & $x(8)$ \\
\hline Italien & 15 & 13 & $3-15$ & 103,0 & 101,7 & 75,8 & 18,4 & 2,5 & 0,1 \\
\hline Japan & 15 & 14 & $4-17$ & 78,1 & 100,8 & $\mathrm{~m}$ & $\mathrm{~m}$ & $\mathrm{~m}$ & $\mathrm{~m}$ \\
\hline Korea & 14 & 12 & $6-17$ & 19,6 & 92,7 & 79,9 & 26,5 & 1,7 & 0,4 \\
\hline Luxemburg & 15 & 11 & $4-15$ & 76,8 & 93,4 & 75,3 & 6,3 & 0,4 & $\mathrm{n}$ \\
\hline Mexiko & 15 & 7 & $6-12$ & 36,7 & 95,7 & 42,4 & 9,4 & 3,0 & 0,4 \\
\hline Niederlande & 18 & 13 & $4-16$ & 48,8 & 99,3 & 86,5 & 23,4 & 2,9 & 0,8 \\
\hline Neuseeland & 16 & 12 & $4-15$ & 86,8 & 99,5 & 72,1 & 25,4 & 10,9 & 4,1 \\
\hline Norwegen & 16 & 12 & $6-17$ & 77,5 & 97,9 & 84,8 & 26,3 & 6,7 & 1,6 \\
\hline Polen & 15 & 12 & $6-17$ & 29,1 & 94,4 & 86,8 & 27,3 & 4,1 & $x(8)$ \\
\hline Portugal & 14 & 10 & $6-15$ & 66,4 & 106,0 & 70,9 & 22,2 & 3,8 & 0,6 \\
\hline Slowakische Rep. & 16 & 11 & $6-16$ & 70,7 & 98,1 & 76,6 & 12,6 & 1,6 & 0,2 \\
\hline Spanien ${ }^{1}$ & 16 & 14 & $3-16$ & 112,5 & 103,8 & 80,4 & 23,3 & 2,6 & 0,4 \\
\hline Schweden & 16 & 13 & $6-18$ & 75,5 & 98,2 & 86,2 & 33,6 & 14,1 & 3,5 \\
\hline Ver. Königreich & 16 & 12 & $4-15$ & 81,2 & 98,9 & 76,8 & 26,8 & 16,2 & 8,3 \\
\hline Vereinigte Staaten & 17 & 10 & $6-15$ & 52,7 & 96,9 & 74,8 & 25,2 & 4,6 & 1,3 \\
\hline Ländermittel & 16 & 12 & & 67,8 & 98,5 & 79,4 & 22,7 & 5,4 & 1,5 \\
\hline \multicolumn{10}{|l|}{ OECD-Partnerländer } \\
\hline Argentinien ${ }^{2}$ & 14 & 10 & $5-14$ & 40,8 & 104,1 & 69,4 & 25,9 & 6,7 & 1,4 \\
\hline Brasilien ${ }^{2}$ & 14 & 8 & $7-14$ & 29,9 & 91,3 & 71,3 & 23,3 & 8,0 & 2,1 \\
\hline Chile & 14 & 9 & $7-15$ & 27,7 & 92,1 & 68,2 & 3,1 & 0,8 & 0,2 \\
\hline China & 14 & 6 & $7-12$ & $\mathrm{n}$ & 80,7 & 12,7 & $\mathrm{~m}$ & $\mathrm{~m}$ & $\mathrm{~m}$ \\
\hline Indien ${ }^{2}$ & 14 & 2 & $6-7$ & 42,4 & 65,0 & 28,1 & $\mathrm{~m}$ & $\mathrm{~m}$ & $\mathrm{~m}$ \\
\hline Indonesien & 15 & 7 & $6-13$ & $\mathrm{n}$ & 93,4 & 45,6 & 3,6 & $\mathrm{n}$ & $\mathrm{n}$ \\
\hline Israel & 15 & 11 & $6-16$ & 100,7 & 96,1 & 65,3 & 21,5 & 5,5 & 1,1 \\
\hline Jamaika & 12 & $\mathrm{~m}$ & $\mathrm{~m}$ & 75,8 & 90,4 & 40,5 & $\mathrm{~m}$ & $\mathrm{~m}$ & $\mathrm{~m}$ \\
\hline Jordanien & 15 & 2 & $6-7$ & 14,2 & 84,5 & 41,7 & a & a & a \\
\hline Malaysia $^{2}$ & 12 & 12 & $6-12$ & 16,0 & 91,9 & 55,4 & 6,8 & 0,2 & 0,1 \\
\hline Paraguay ${ }^{2}$ & 14 & 5 & $7-11$ & 7,7 & 87,9 & 50,3 & 6,4 & 0,7 & 0,1 \\
\hline Peru ${ }^{2}$ & 16 & 9 & $6-14$ & 54,0 & 99,4 & 55,1 & 9,4 & 1,9 & 0,5 \\
\hline Philippinen & 12 & 7 & $7-13$ & 0,4 & 85,4 & 34,8 & 0,5 & a & $a$ \\
\hline Russische Föd. & 15 & 9 & $7-15$ & 31,5 & 84,6 & 73,6 & 12,7 & 0,1 & $\mathrm{n}$ \\
\hline Thailand & 14 & 11 & $4-14$ & 60,9 & 100,3 & 59,3 & 6,0 & 1,4 & 0,3 \\
\hline Tunesien & 16 & 7 & $6-12$ & 17,0 & 90,0 & 57,1 & 4,3 & $\mathrm{n}$ & 6,6 \\
\hline Uruguay ${ }^{2}$ & 15 & 9 & $6-14$ & 27,9 & 97,5 & 68,4 & 21,2 & 4,6 & 0,6 \\
\hline Simbabwe & 12 & 7 & $7-13$ & $\mathrm{n}$ & 83,4 & 32,9 & $\mathrm{~m}$ & $\mathrm{~m}$ & $\mathrm{~m}$ \\
\hline
\end{tabular}

Hinweise: Alter, bis zu dem Schulpflicht besteht, ist das Alter, in dem die Schulpflicht endet, z. B. bedeutet eine Altersangabe von 18 (J.) in dieser Spalte, dass Schüler unter 18 Jahren gesetzlich zum Schulbesuch verpflichtet sind. $x$ bedeutet, dass die Daten in einer anderen Spalte enthalten sind, deren Referenz in runden Klammern nach dem , $x$ ‘ angegeben ist. So bedeutet z. B. x(2), dass die Daten in Spalte 2 enthalten sind. Unterschiede im Erhebungsbereich der Bevölkerungsdaten und der Schüler-/Absolventendaten bedeuten, dass die Teilnahme-/Abschlussquoten von Ländern mit einem Nettoabgang von Schülern/Studierenden wohl zu niedrig und von Ländern mit einem Nettozugang von Schülern/Studierenden wohl zu hoch angesetzt sind.

1. , 4 J. und jünger als Prozentsatz der 3- bis 4-Jährigen“ ist zu hoch angesetzt. Eine beachtliche Zahl von Schülern ist unter drei Jahren. Die Nettoquoten zwischen 3 und 5 Jahren betragen ca. 100\%. 2. Referenzjahr 2001.

Quelle: OECD. Hinweise s. Anhang 3 unter www.oecd.org/edu/eag2004. 


\section{Tabelle C1.3}

Übergangscharakteristika bei 15-, 16-, 17-, 18-, 19- und 20-Jährigen (2002)

Nettobildungsbeteiligung nach Bildungsbereich in öffentlichen und privaten Bildungseinrichtungen (basierend auf Personenzahlen)

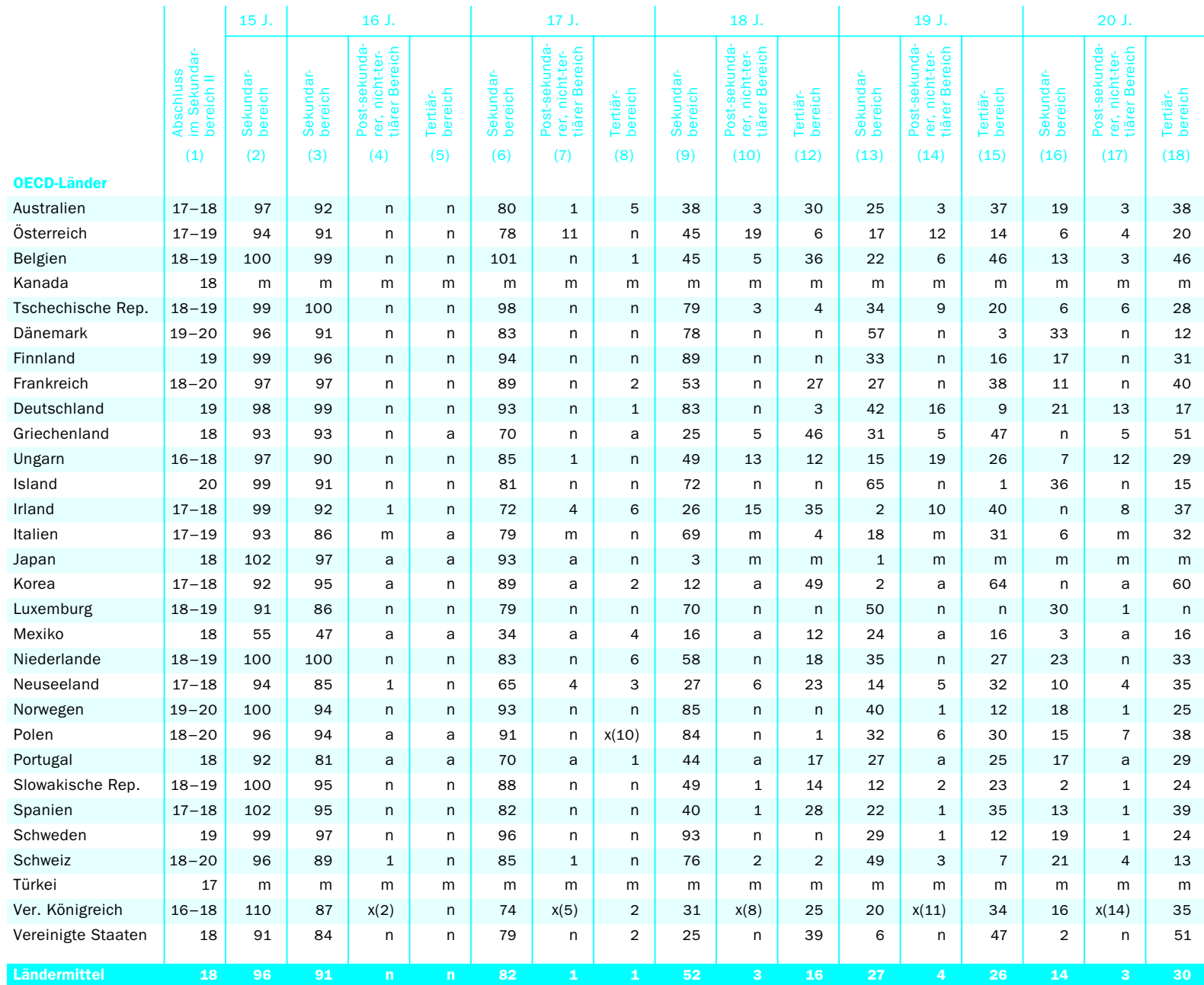

\begin{tabular}{|c|c|c|c|c|c|c|c|c|c|c|c|c|c|c|c|c|c|}
\hline Ländermittel & 18 & 96 & 91 & $n$ & n & 82 & 1 & 1 & 52 & 3 & 16 & 27 & 4 & 26 & 14 & 3 & 30 \\
\hline \multicolumn{18}{|c|}{ OECD-Partnerländer } \\
\hline Argentinien ${ }^{1}$ & 18 & 86 & 78 & $\mathrm{a}$ & $n$ & 71 & a & 5 & 36 & a & 16 & 19 & a & 24 & 10 & a & 28 \\
\hline Brasilien $^{1}$ & $17-18$ & 77 & 75 & $\mathrm{~m}$ & a & 70 & $\mathrm{~m}$ & a & 56 & $\mathrm{~m}$ & a & 40 & $\mathrm{~m}$ & a & 28 & $\mathrm{~m}$ & a \\
\hline Chile & 18 & 91 & 87 & a & $\mathrm{n}$ & 80 & a & $n$ & 55 & a & $\mathrm{m}$ & 20 & a & $\mathrm{m}$ & 8 & a & $\mathrm{m}$ \\
\hline China & 18 & 48 & 10 & $\mathrm{~m}$ & $\mathrm{n}$ & 2 & $\mathrm{~m}$ & $\mathrm{n}$ & $\mathrm{m}$ & $\mathrm{m}$ & $\mathrm{m}$ & $\mathrm{m}$ & $\mathrm{m}$ & $\mathrm{m}$ & $\mathrm{m}$ & $\mathrm{m}$ & $\mathrm{m}$ \\
\hline Indonesien & 18 & 54 & 45 & a & a & 48 & a & a & 29 & a & 18 & 10 & a & 23 & 3 & a & 21 \\
\hline Israel & 17 & 96 & 95 & $n$ & $n$ & 89 & $n$ & $n$ & 24 & 1 & 2 & 5 & 1 & 8 & 1 & 2 & 13 \\
\hline Jamaika & 16 & 82 & 67 & 3 & $\mathrm{~m}$ & 33 & 4 & $\mathrm{~m}$ & 7 & 2 & $m$ & 1 & 1 & $\mathrm{~m}$ & $n$ & $n$ & $\mathrm{~m}$ \\
\hline Jordanien $^{1}$ & 17 & 76 & 68 & $a$ & $n$ & 51 & a & $n$ & 10 & $a$ & $\mathrm{~m}$ & 2 & a & $\mathrm{m}$ & a & a & $\mathrm{m}$ \\
\hline Malaysia $^{1}$ & 19 & $\mathrm{~m}$ & $\mathrm{~m}$ & $\mathrm{n}$ & $n$ & 30 & 18 & 20 & 17 & 32 & 55 & 2 & 13 & 47 & $n$ & 1 & 33 \\
\hline Paraguay 1 & 17 & 57 & 55 & $\mathrm{~m}$ & $n$ & 51 & $\mathrm{~m}$ & $n$ & 43 & $\mathrm{~m}$ & 2 & 17 & $\mathrm{~m}$ & 4 & 9 & $\mathrm{~m}$ & 5 \\
\hline Peru $^{1}$ & $\mathrm{~m}$ & 75 & 67 & 2 & 1 & 39 & 3 & 5 & 23 & 4 & 8 & 12 & 4 & 10 & 7 & 4 & 10 \\
\hline Philippinen & 16 & 68 & 56 & $\mathrm{~m}$ & $\mathrm{~m}$ & 28 & $\mathrm{~m}$ & $\mathrm{~m}$ & 13 & $\mathrm{~m}$ & $\mathrm{~m}$ & 5 & $\mathrm{~m}$ & $m$ & 4 & $m$ & $\mathrm{~m}$ \\
\hline Russische Föd. & 18 & 53 & 69 & 3 & 12 & 27 & 3 & 48 & 7 & 2 & 50 & 2 & 1 & 45 & 1 & 1 & 39 \\
\hline Thailand & 17 & 82 & 67 & $\mathrm{~m}$ & $\mathrm{~m}$ & 56 & $\mathrm{~m}$ & 1 & 35 & $\mathrm{~m}$ & 42 & 7 & $\mathrm{~m}$ & 9 & $\mathrm{~m}$ & $\mathrm{~m}$ & 13 \\
\hline Uruguay $^{1}$ & 17 & 87 & 82 & a & a & 70 & $\mathrm{n}$ & $n$ & 48 & $n$ & 7 & 28 & $\mathrm{n}$ & 15 & 19 & $\mathrm{n}$ & 18 \\
\hline Simbabwe & 19 & 52 & 50 & a & $\mathrm{n}$ & 36 & a & $n$ & 18 & a & $\mathrm{n}$ & 10 & a & $\mathrm{m}$ & $n$ & a & $\mathrm{m}$ \\
\hline
\end{tabular}

Hinweis: $x$ bedeutet, dass die Daten in einer anderen Spalte enthalten sind, deren Referenz in runden Klammern nach dem ,x' angegeben ist. So bedeutet $z$. B. $x(2)$, dass die Daten in Spalte 2 enthalten sind. Unterschiede im Erhebungsbereich der Bevölkerungsdaten und der Schüler-/Absolventendaten bedeuten, dass die Teilnahme-/Abschlussquoten von Ländern mit einem Nettoabgang von Schülern/Studierenden wohl zu niedrig und die von Ländern mit einem Nettozugang von Schülern/ Studierenden wohl zu hoch angesetzt sind.

1. Referenzjahr 2001

Quelle: OECD. Hinweise s. Anhang 3 unter www.oecd.org/edu/eag2004. 


\section{Zugang zum Tertiärbereich, zu erwartende Jahre im Tertiärbereich und Bildungsbeteiligung im Sekundarbereich}

- Im Laufe seines Lebens wird jeder zweite Jugendliche in den OECD-Ländern an einem Studiengang im Tertiärbereich $A$ teilnehmen.

Im Durchschnitt der OECD-Länder wird ein heute 17-Jähriger 2,7 Jahre im Tertiärbereich verbringen, davon 2,0 Jahre in Vollzeit. In Finnland, Korea und den Vereinigten Staaten nimmt ein junger Mensch im Laufe seines Lebens voraussichtlich mindestens 4 Jahre an Vollzeit- und Teilzeitstudiengängen im Tertiärbereich teil.

Mit Ausnahme von Frankreich und Österreich* hat die Bildungsbeteiligung im Tertiärbereich zwischen 1995 und 2002 in allen OECD-Ländern zugenommen.

Während die Mehrzahl der Studierenden an öffentlichen Bildungseinrichtungen eingeschrieben ist, besuchen in Belgien, Japan, Korea, den Niederlanden und dem Vereinigten Königreich die meisten Studierenden privat geleitete Bildungseinrichtungen.

Die Mehrzahl der Schüler im Primar- und Sekundarbereich besucht öffentliche Bildungseinrichtungen. Inzwischen besuchen jedoch durchschnittlich 10 Prozent der Schüler im Primarbereich, 14 Prozent der Schüler im Sekundarbereich I und 20 Prozent der Schüler im Sekundarbereich II privat geleitete Bildungseinrichtungen. 


\section{Abbildung C2.1}

Studienanfängerquoten im Tertiärbereich (2002)

Summe der Netto-Studienanfängerquoten für jeden einzelnen Altersjahrgang, fürTertiärbereich $A$ und $B$

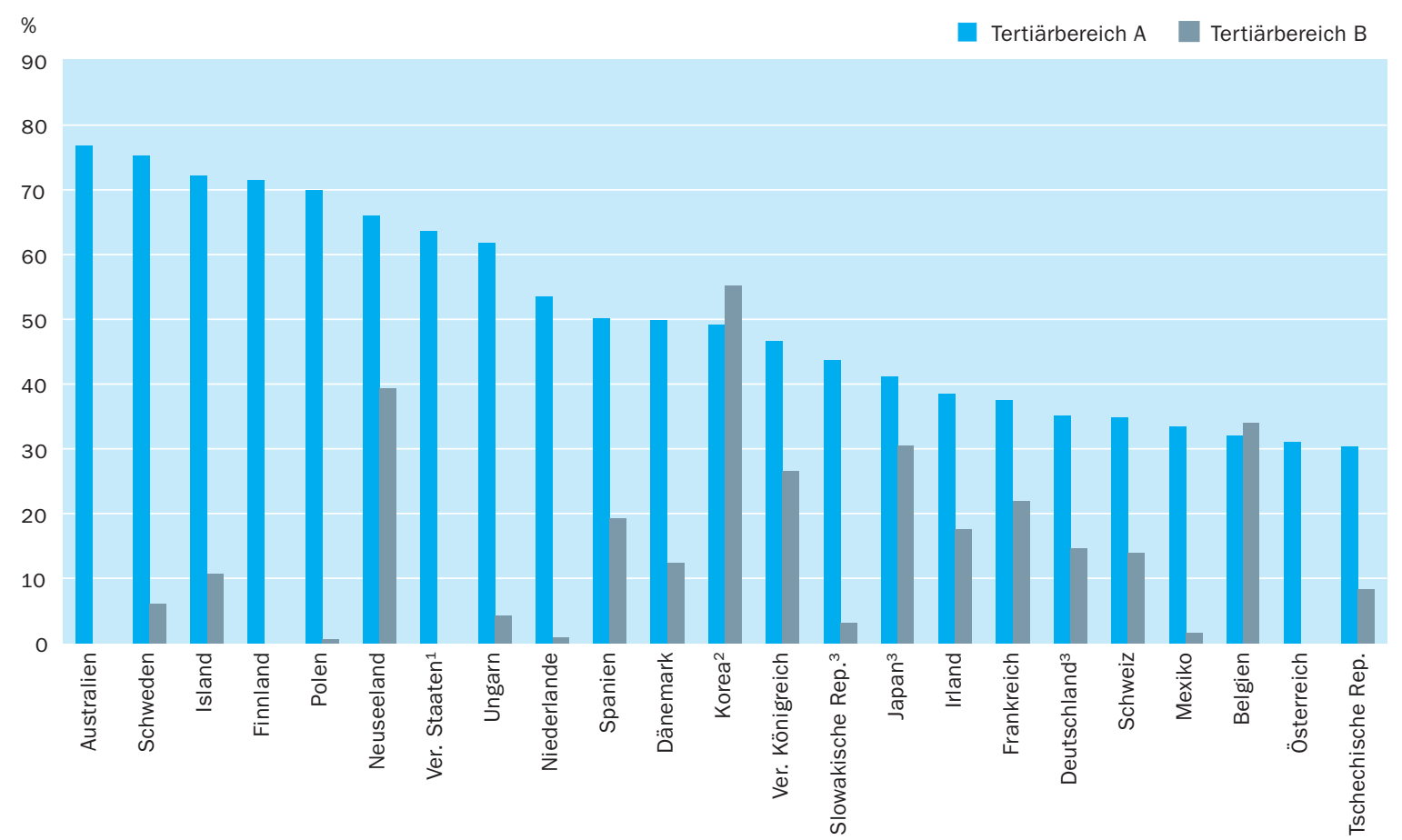

Hinweis: Die Netto-Studienanfängerquoten für Studiengänge im Tertiärbereich A und B können wegen Doppelzählungen nicht einfach aufaddiert werden.

1. Studiengänge im Tertiärbereich A enthalten auch Studiengänge im Tertiärbereich B. 2. Studienanfängerquoten für den Tertiärbereich A und B als Bruttostudienanfängerquote berechnet. 3. Studienanfängerquoten für den Tertiärbereich B als Bruttostudienanfängerquote berechnet.

Anordnung der Länder in absteigender Reihenfolge der Gesamtstudienanfängerquoten im Tertiärbereich A.

Quelle: OECD, Tabelle C2.1. Hinweise s. Anhang 3 unter www.oecd.org/edu/eag2004.

Dieser Indikator zeigt den Prozentsatz junger Menschen, die im Verlaufe ihres Lebens in die verschiedenen Bildungsgänge im Tertiärbereich eintreten werden.

Studienanfänger- und Beteiligungsquoten spiegeln sowohl die Zugangsmöglichkeiten zum Tertiärbereich wider als auch den Wert, der einer tertiären Bildung beigemessen wird.

\section{Politischer Hintergrund}

Hohe Studienanfängerquoten und eine hohe Bildungsbeteiligung im Tertiärbereich tragen dazu bei, die Entwicklung und den Erhalt einer hochqualifizierten Bevölkerung im Allgemeinen und Erwerbsbevölkerung im Speziellen sicherzustellen. Eine Ausbildung im Tertiärbereich wird mit besseren Beschäftigungsaussichten und höheren Verdiensten assoziiert (s. Indikatoren A Io und AII). Die Studienanfängerquoten für den Tertiärbereich sind zum Teil auch ein Anzeichen dafür, inwieweit die Bevölkerung hochqualifizierte Fähigkeiten und Kenntnisse erlangt, die auf dem Arbeitsmarkt einer Wissensgesellschaft von Bedeutung sind.

Da den Studierenden die wirtschaftlichen und sozialen Vorteile einer Ausbildung im Tertiärbereich bewusster geworden sind, ist die Zahl der Studienanfänger sowohl im Tertiärbereich A als auch im Tertiärbereich B gestiegen. Der kontinuierliche Anstieg der Bildungsbeteiligung und die wachsende Vielfalt der persönlichen Hintergründe und Interessen derjenigen, die eine tertiäre Ausbildung anstreben, erfordern ein neuartiges Bildungsangebot. Die tertiären Bildungseinrichtungen werden auf den zunehmenden Bedarf durch die Erhöhung der 
Zahl der zum Studium zugelassenen Studierenden und durch die Anpassung von Studiengängen, Unterrichts- und Lehrverfahren an die unterschiedlichen Bedürfnisse einer neuen Generation von Studierenden reagieren müssen.

Der erfolgreiche Abschluss des Sekundarbereich II wird in den meisten OECDLändern zunehmend zum Normalfall, aber die Bildungsgänge im Sekundarbereich II können sich beispielsweise hinsichtlich der Lerninhalte unterscheiden, je nachdem, auf welche weiteren Bildungsgänge oder welchen Beruf die Schüler vorbereitet werden sollen. Die meisten Bildungsgänge im Sekundarbereich II in den OECD-Ländern zielen vornehmlich auf die Vorbereitung zum weiterführenden Studium im Tertiärbereich ab, ihre Ausrichtung kann allgemein, berufsvorbereitend oder berufsbildend sein. In den meisten OECD-Ländern gibt es auch Bildungsgänge im Sekundarbereich II, die zur Vorbereitung auf den direkten Eintritt in den Arbeitsmarkt ausgelegt sind. In einigen Ländern werden berufsbildende Ausbildungsgänge erst nach Abschluss des Sekundarbereich II angeboten, obwohl diese post-sekundaren Bildungsgänge oft denen des Sekundarbereich II ähneln.

\section{Ergebnisse und Erläuterungen}

\section{Zugang zum Tertiärbereich}

Innerhalb der OECD unterscheiden sich die tertiären Studiengänge darin, dass sie entweder eher theoretisch ausgerichtet sind und darauf abzielen, Studierende für weiterführende Forschungsprogramme oder Berufe mit hohen Qualifikationsanforderungen vorzubereiten (Tertiärbereich A) oder sich eher auf die Vermittlung berufsspezifischer Fähigkeiten und Kenntnisse zum direkten Eintritt in den Arbeitsmarkt konzentrieren (Tertiärbereich B). Zur Klassifizierung der nationalen Bildungsangebote in diesem Bereich, s. Anhang 3 unter www.oecd.org/eduleag2004.

Im Laufe seines Lebens wird jeder zweite Jugendliche in den OECD-Ländern an einem Studiengang im Tertiärbereich A teilnehmen, sofern die aktuellen Studienanfängerquoten auch für die Zukunft gelten. In Australien, Finnland, Island, Neuseeland, Polen und Schweden, Ungarn und den Vereinigten Staaten nehmen sogar mehr als 6o Prozent der jungen Menschen ein derartiges Studium auf (Tab. C2.I).

Für die anderen OECD-Länder gelten wesentlich geringere Quoten für den Ersteintritt in den Tertiärbereich A: die geschätzten Ersteintrittsquoten für Belgien, Österreich, Mexiko und die Tschechische Republik liegen bei rund 30 Prozent.

Der Anteil derjenigen, die ein Studium im Tertiärbereich B wählen, ist im allgemeinen kleiner als der Anteil derjenigen, die sich für den Tertiärbereich A entscheiden. Im Durchschnitt der 20 OECD-Länder, für die Daten vorliegen, werden 16 Prozent der Jugendlichen eine Ausbildung im Tertiärbereich B beginnen. Die Bandbreite reicht von 4 Prozent oder weniger in Italien, Mexiko, den Niederlanden, Polen, Ungarn und der Slowakischen Republik bis zu mehr als 30 Prozent in Belgien, Japan und Neuseeland und mehr als 50 Prozent in Korea (Tab. C2.I und Abb. C2.I).
Der Indikator zeigt auch die Unterschiede bei der Bildungsbeteiligung im Sekundarbereich.

51 Prozent der heutigen Jugendlichen in den OECDLändern werden ein Studium im Tertiärbereich A aufnehmen.

16 Prozent der heutigen Jugendlichen werden ein Studium im Tertiärbereich B aufnehmen. 
In sieben OECD-Ländern können junge Menschen mindestens 3 Jahre Ausbildung im Tertiärbereich erwarten.
In Finnland, Korea und den Vereinigten Staaten verbringt ein junger Mensch voraussichtlich ungefähr 4 Jahre im Tertiärbereich.

Die längeren Studiengänge im Tertiärbereich A führen in der Regel zu einer höheren Gesamtzahl an Studierenden und daher zu einem erhöhten Ressourcenbedarf.
In Belgien gleicht die hohe Bildungsbeteiligung im Tertiärbereich B die vergleichsweise niedrigen Eintrittsquoten für den Tertiärbereich A aus. Andere OECD-Länder, vor allem Polen und Schweden, haben für Studiengänge im Tertiärbereich A Eintrittsquoten, die über dem OECD-Durchschnitt liegen, und vergleichsweise sehr niedrige Studienanfängerquoten für den Tertiärbereich B. Neuseeland sticht innerhalb der OECD-Länder als das Land mit den höchsten Eintrittsquoten für beide tertiären Bereiche hervor.

Die Netto-Studienanfängerquoten im tertiären Bildungsbereich sind auch im Hinblick auf die Beteiligung an post-sekundaren, nicht-tertiären Bildungsgängen zu bewerten, die in einigen OECD-Ländern eine wichtige Alternative zum tertiären Bildungsbereich darstellen (Indikator Cr).

Diejenigen, die in Studiengänge im Tertiärbereich B eintreten, nehmen möglicherweise später im Leben auch ein Studium im Tertiärbereich A auf. Die Ersteintrittsquoten für den Tertiärbereich A und B können daher zur Bestimmung der Gesamteintrittsquoten für den Tertiärbereich nicht einfach aufaddiert werden, da dies zu Doppelzählungen führen kann.

\section{Bildungsbeteiligung im Tertiärbereich}

Die Beteiligungsquoten bieten eine weitere Sicht auf die Bildungsbeteiligung im Tertiärbereich. Sie spiegeln sowohl die gesamte Anzahl derjenigen wider, die einen tertiären Studiengang wählen, als auch die Studien- bzw. Ausbildungsdauer im tertiären Bildungsbereich. Die Summe der Netto-Beteiligungsquoten über die einzelnen Jahrgänge hinweg, die als Bildungserwartung im Tertiärbereich (in Jahren) bezeichnet wird, misst das Ausmaß der tertiären Bildungsaktivitäten eines ganzen Altersjahrgangs und nicht nur einzelner Teilnehmer. Im Gegensatz zu den Studienanfängerquoten kann man die Bildungserwartung im Tertiärbereich (in Jahren), die auf den Studierendenzahlen in den Studiengängen beider Tertiärbereiche basiert, addieren.

In den OECD-Ländern nimmt ein I7-Jähriger im Durchschnitt voraussichtlich 2,7 Jahre an tertiärer Bildung teil, von denen im Durchschnitt voraussichtlich 2 Jahre Vollzeitstudium sein werden. In Australien, Griechenland, Neuseeland, Norwegen, Polen, Spanien und Schweden nimmt ein 17-Jähriger im Laufe seines Lebens voraussichtlich mindestens 3 Jahre an Vollzeit- und Teilzeitstudiengängen im Tertiärbereich teil (Tab. C2.2).

In Finnland, Korea und den Vereinigten Staaten nimmt ein junger Mensch voraussichtlich ungefähr 4 Jahre an Vollzeit- und Teilzeitstudiengängen im Tertiärbereich teil. In Mexiko, der Schweiz, der Slowakischen sowie der Tschechischen Republik dagegen liegt die Bildungserwartung im Tertiärbereich bei weniger als 2 Jahren.

Im Durchschnitt ist in den OECD-Ländern die Bildungserwartung für den Tertiärbereich A (2,3 Jahre) wesentlich höher als für den Tertiärbereich B (o,4 Jahre). Da die Studiengänge im Tertiärbereich A meist länger sind, konzentriert sich dort eine größere Anzahl an Studierenden, was - bei sonst gleichen Voraussetzungen - zu einem erhöhten Ressourcenbedarf führt (s. Indikator BI, Tab. BI.3). 
In der Mehrheit der OECD-Länder werden Bildungsgänge im Tertiärbereich A hauptsächlich durch Bildungseinrichtungen der öffentlichen Hand sowohl angeboten als auch verwaltet (Tab. C2.3). In Belgien, den Niederlanden und dem Vereinigten Königreich besucht die Mehrzahl der Studierenden jedoch Bildungseinrichtungen unter privater Leitung, die überwiegend öffentliche Mittel beziehen. In Japan und Korea werden mehr als 70 Prozent der Studierenden an Bildungseinrichtungen unterrichtet, die sowohl unter privater Leitung stehen als auch vorwiegend aus privaten Mitteln finanziert werden. In Mexiko, Polen und Portugal besuchen ungefähr 30 Prozent der Studierenden derartige Bildungseinrichtungen.

\section{Entwicklungen der Bildungsbeteiligung}

Mit Ausnahme von Österreich und Frankreich hat die Bildungsbeteiligung im Tertiärbereich zwischen 1995 und 2002 in allen OECD-Ländern zugenommen. In der Hälfte der OECD-Länder, für die Daten vorliegen, betrug der Anstieg der Studierenden im Tertiärbereich mehr als 30 Prozent, und in der Tschechischen Republik 68 Prozent, in Griechenland 78 Prozent, in Ungarn Io8 Prozent und in Polen I5I Prozent (Tab. C2.2).
Die Mehrzahl der Studierenden im Tertiärbereich besucht öffentliche Bildungseinrichtungen, in einigen OECD-Ländern besucht die Mehrzahl jedoch private Bildungseinrichtungen.

In den meisten OECD-Ländern ist die Bildungsbeteiligung im Tertiärbereich zwischen 1995 und 2002 gestiegen.

\section{Abbildung C2.2}

Veränderungen in der Zahl der Studierenden im Tertiärbereich im Verhältnis zu veränderten Beteiligungsquoten und demographischen Gegebenheiten (1995-2002)

Index der Veränderung zwischen 1995 und 2002 (1995 = 100)

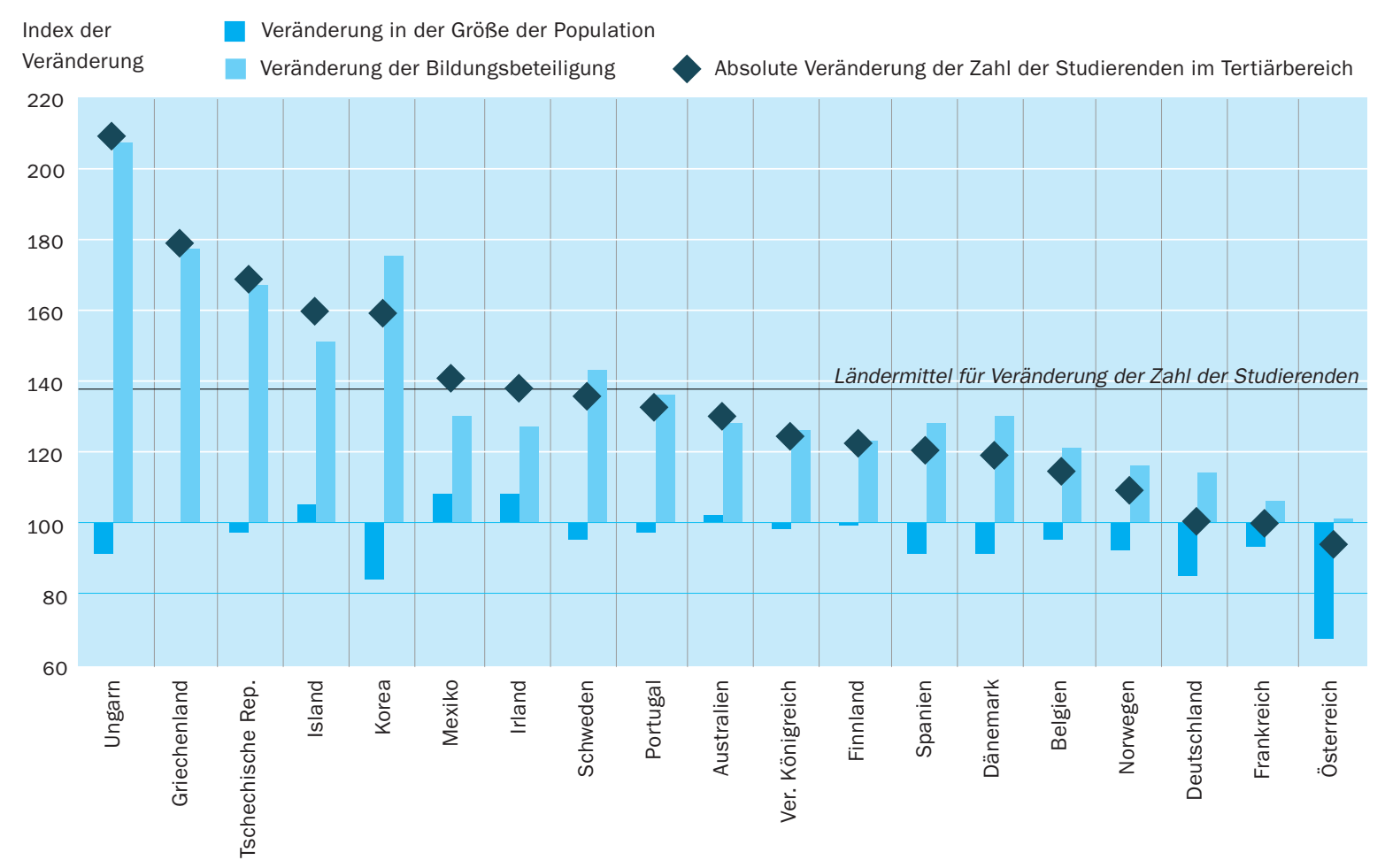


Die steigende Nachfrage, die sich in einer höheren Bildungsbeteiligung niederschlägt, ist die wichtigste Ursache für den Anstieg der Zahl der Studierenden im Tertiärbereich.
In Belgien, Frankreich, Irland, Mexiko, Spanien und der Tschechischen Republik sind mehr als 80 Prozent aller Studienanfänger des Tertiärbereich A jünger als 22 Jahre,

... während in Dänemark, Island, Neuseeland und Schweden mehr als die Hälfte der Studierenden 22 Jahre oder älter sind, wenn sie zum ersten Mal an einem Studiengang in diesem Bereich teilnehmen.

Die Bildungsgänge im Sekundarbereich II werden danach untergliedert, ob sie ...
Im Tertiärbereich sind die Veränderungen der Bildungsbeteiligung nicht so eng mit Veränderungen der Größe der relevanten Altersgruppen verbunden, wie dies im Primar- und Sekundarbereich der Fall ist. Abbildung C2.2 gliedert die Veränderung der Anzahl der eingeschriebenen Studierenden in zwei Komponenten auf: zum einen in die Veränderung der Größe der jeweiligen Altersgruppe und zum anderen in die Veränderung der Beteiligungsquoten. Die steigende Nachfrage, die sich in einer höheren Beteiligungsquote niederschlägt, ist die wichtigste Ursache für den Anstieg der Zahl der Studierenden im Tertiärbereich. Australien, Island, Irland und Mexiko sind die einzigen OECDLänder, in denen ein Anstieg der Bevölkerungszahlen signifikant zu dem Anstieg der Studierendenzahlen im Tertiärbereich beigetragen hat, aber selbst in diesen Ländern war der Anstieg der Beteiligungsquoten noch bedeutend größer. Umgekehrt wäre der tatsächliche Anstieg der Studierendenzahlen im Tertiärbereich in vielen Ländern (insbesondere in Korea und Österreich) deutlich höher gewesen, wenn es dort nicht zu einem Bevölkerungsrückgang gekommen wäre. In Frankreich und Österreich übertraf der Bevölkerungsrückgang sogar die Zunahme bei den Beteiligungsquoten, was bedeutet, dass trotz I bzw. 6 Prozent höherer Beteiligungsquoten die Studierendenzahlen im Tertiärbereich insgesamt leicht gefallen sind.

\section{Das Alter der Studienanfänger}

Traditionell nehmen Studierende das Studium im Tertiärbereich A normalerweise direkt nach dem Abschluss des Sekundarbereich II auf, in vielen OECDLändern gilt dies auch heute noch. In Belgien, Frankreich, Irland, Mexiko, Spanien und der Tschechischen Republik beispielsweise sind mehr als 80 Prozent aller Erststudienanfänger jünger als 22 Jahre (Tab. C2.I).

In anderen Ländern erfolgt der Übergang zum Tertiärbereich häufig erst später, in einigen Fällen erst nach einiger Zeit der Erwerbstätigkeit. In diesen Ländern sind Studienanfänger des Tertiärbereich $\mathrm{A}$ in der Regel älter und gehören zu ganz verschiedenen Altersgruppen. In Dänemark, Island, Neuseeland und Schweden beispielsweise ist mehr als die Hälfte der Studierenden 22 Jahre oder älter, wenn sie sich zum ersten Mal in einem Studiengang in diesem Bereich einschreiben (Tab. C2.I). Der Anteil der älteren Studienanfänger in einem Erststudium im Tertiärbereich A kann, neben anderen Faktoren, ein Anzeichen für die Flexibilität dieser Studiengänge und ihre Eignung für Studierende außerhalb der typischen Altersgruppe sein. Darüber hinaus kann er die besondere Wertschätzung von Berufserfahrung als Hintergrund für ein weiterführendes Hochschulstudium widerspiegeln, die charakteristisch für die nordischen Länder und auch in Australien und Neuseeland durchaus üblich ist, wo ein beträchtlicher Teil der Studierenden mit einem deutlich höheren Alter als dem typischen Eintrittsalter das Studium beginnt. In Australien, Neuseeland und den nordischen Ländern sind mehr als 20 Prozent der Studienanfänger im Erststudium 27 Jahre oder älter.

\section{Bildungsbeteiligung bei den beruflichen Bildungsgängen des Sekundarbereich II}

In den meisten OECD-Ländern bestehen für die Schüler im Sekundarbereich II keine einheitlichen Lehrpläne. Die Bildungsgänge im Sekundarbereich II werden anhand des Umfangs, in dem sie auf bestimmte Berufsfelder vorbereiten 
und zu einer auf dem Arbeitsmarkt verwertbaren Qualifikation führen, in drei Kategorien unterteilt:

Kategorie 1 (allgemeinbildende) Bildungsgänge - sie sollen die Teilnehmer weder explizit auf bestimmte Berufsfelder noch auf den Eintritt in einen weiterführenden berufsbildenden oder technischen Bildungsgang vorbereiten.

Kategorie 2 (berufsuorbereitende) Bildungsgänge - sie sollen den Teilnehmern eher als Einführung in die Arbeitswelt dienen und sie für den späteren Eintritt in einen berufsbildenden oder technischen Bildungsgang vorbereiten. Durch den erfolgreichen Abschluss wird keine für den Arbeitsmarkt relevante berufliche oder technische Qualifikation erworben. Mindestens 25 Prozent des Inhalts des Bildungsgangs sollten berufsbildend oder technisch sein.

Kategorie 3 (berufsbildende) Bildungsgänge - in ihnen sollen die Teilnehmer für die direkte Aufnahme einer Beschäftigung in bestimmten Berufsfeldern, ohne weitere berufliche Qualifizierung, vorbereitet werden. Durch den erfolgreichen Abschluss wird eine für den Arbeitsmarkt relevante berufliche oder technische Qualifikation erworben.

Das Ausmaß der berufsbildenden bzw. allgemeinbildenden Ausrichtung eines Bildungsganges ist nicht unbedingt ausschlaggebend dafür, ob die Teilnehmer Zugang zum Tertiärbereich erhalten. In einigen OECD-Ländern haben Bildungsgänge mit berufsbildender Ausrichtung auch das Ziel, auf ein späteres Studium im Tertiärbereich vorzubereiten, während es in anderen Ländern wiederum viele Bildungsgänge mit allgemeinbildender Ausrichtung gibt, die keinen direkten Zugang zur Hochschulbildung ermöglichen.

In allen OECD-Ländern können die Schüler zwischen berufsbildenden, berufsvorbereitenden und allgemeinbildenden Bildungsgängen wählen. In I5 OECDLändern nimmt die Mehrzahl der Schüler im Sekundarbereich II an einer beruflichen Ausbildung teil. Sowohl in Ländern mit einer Lehrlingsausbildung im dualen System (z. B. Deutschland, Luxemburg, den Niederlanden, Österreich und der Schweiz) als auch in Australien, Belgien, Polen, der Slowakischen Republik, der Tschechischen Republik und dem Vereinigten Königreich nehmen mindestens 6o Prozent der Schüler des Sekundarbereich II an einer beruflichen Ausbildung teil. Island ist die Ausnahme, hier besucht die Mehrzahl der Schüler Bildungsgänge mit allgemeinbildender Ausrichtung, obwohl eine duale Lehrlingsausbildung angeboten wird (Tab. C2.5).

In den meisten Ländern findet die Berufsausbildung in der Schule statt. In Island, Österreich, der Slowakischen Republik und der Tschechischen Republik werden jedoch bei rund der Hälfte der berufsbildenden Ausbildungsgänge in der Schule und im Betrieb vermittelte Elemente kombiniert. In Dänemark, Deutschland, der Schweiz und Ungarn beinhalten mehr als 8o Prozent der berufsbildenden Ausbildungsgänge sowohl schulische als auch betriebliche Elemente.

In mehr als der Hälfte der OECD-Länder nimmt die Mehrzahl der Schüler im Sekundarbereich II an einer beruflichen Ausbildung teil. 
Die Mehrzahl der Schüler im Primar- und Sekundarbereich besucht öffentliche Bildungseinrichtungen.

Im Durchschnitt besuchen jedoch inzwischen 20 Prozent der Schüler im Sekundarbereich II privat geleitete Bildungseinrichtungen ...

\section{Bildungsbeteiligung im Sekundarbereich II nach Art der Bildungs-} einrichtung

In den OECD-Ländern besuchen mehr als 8o Prozent der Schüler im Primarsowie im Sekundarbereich I und II öffentliche Bildungseinrichtungen (Tab.

C2.4).

Inzwischen besuchen jedoch durchschnittlich Io Prozent der Schüler im Primarbereich, I4 Prozent der Schüler im Sekundarbereich I und 20 Prozent der Schüler im Sekundarbereich II privat geleitete Bildungseinrichtungen (Tab. C2.4 und Abb. C2.3).

\section{Abbildung C2.3}
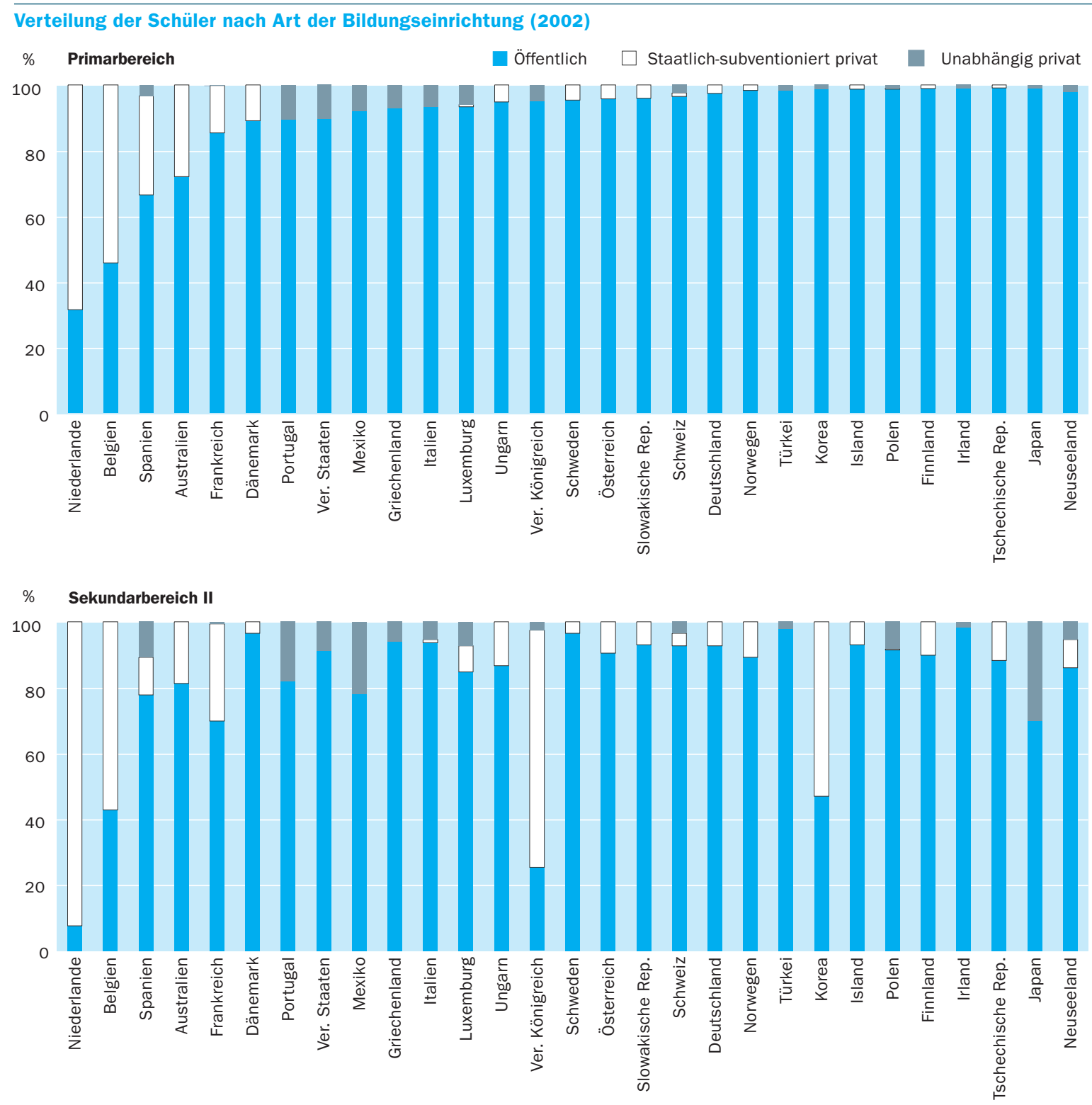
Die Mehrheit der Schüler im Sekundarbereich II in Belgien, Korea, den Niederlanden und dem Vereinigten Königreich besucht staatlich-subventionierte private Bildungseinrichtungen (57, 53, 92 bzw. 72 Prozent). Private Bildungseinrichtungen, die hauptsächlich aus Zahlungen von Privathaushalten finanziert werden, sind im Sekundarbereich II und ihm vorgelagerten Bildungsbereichen weit weniger verbreitet und werden gelegentlich als Barriere für die Bildungsbeteiligung von Schülern aus Familien mit geringem Einkommen angesehen. In Mexiko, Portugal und Spanien jedoch besuchen zwischen Io und 22 Prozent der Schüler des Sekundarbereich II private Bildungseinrichtungen, die hauptsächlich durch nicht-subventionierte Zahlungen privater Haushalte finanziert werden. In Japan liegt diese Zahl bei 30 Prozent (Tab. C2.4).

\section{Definitionen und angewandte Methodik}

Tabelle C2.I enthält die Summe der Netto-Studienanfängerquoten für alle Altersgruppen. Die Netto-Studienanfängerquote einer speziellen Altersgruppe wird berechnet, indem die Anzahl der Studienanfänger der speziellen Altersgruppe in den einzelnen Tertiärbereichen durch die Gesamtpopulation der entsprechenden Altersgruppe geteilt wird (x I0o). Die Summe der Netto-Studienanfängerquoten wird berechnet, indem die Studienanfängerquoten der einzelnen Altersjahrgänge aufsummiert werden. Das Ergebnis repräsentiert den Anteil von Personen einer synthetischen Altersgruppe, die in den Tertiärbereich eintreten, unabhängig von Veränderungen der Populationsgröße und Unterschieden zwischen den einzelnen OECD-Ländern hinsichtlich des typischen Eintrittsalters. Tabelle C2.I zeigt auch das 20., 50. und 80. Perzentil der Altersverteilung der Studienanfänger im Erststudium, d.h. das jeweilige Alter, bei dem man 20, 50 bzw. 80 Prozent der Studienanfänger im Erststudium findet.

Studienanfänger im Erststudium sind diejenigen Studierenden, die sich zum ersten Mal in dem entsprechenden Bildungsbereich einschreiben. Ausländische Studierende, die im Rahmen eines Post-Graduierten-Studiums zum ersten Mal an dem Bildungssystem eines Landes teilnehmen, gelten als Studienanfänger im Erststudium.

Nicht alle OECD-Länder können unterscheiden zwischen Studierenden, die zum ersten Mal einen tertiären Studiengang aufnehmen, und Studierenden, die zwischen tertiären Studiengängen wechseln, einen tertiären Studiengang wiederholen oder nach einer gewissen Unterbrechung wieder aufnehmen. Daher können die Ersteintrittsquoten für die einzelnen Studiengangsarten aufgrund der unvermeidlichen Doppelzählung von Studienanfängern nicht einfach aufaddiert werden, um zu einer Gesamteintrittsquote in den Tertiärbereich zu gelangen.

Tabelle C2.2 zeigt die zu erwartende Anzahl von Jahren, die ein I7-Jähriger im Tertiärbereich studieren wird bzw. die Summe der Netto-Beteiligungsquoten für I7-Jährige und Ältere (geteilt durch Ioo). Diese Kenngröße ist sowohl eine Funktion der Anzahl der im Tertiärbereich teilnehmenden Personen als auch der Verweildauer im Tertiärbereich. Da der Nenner auch diejenigen mit einschließt, die niemals an einer tertiären Ausbildung teilgenommen haben,
... und in Belgien, Korea, den Niederlanden und dem Vereinigten Königreich besuchen die meisten Schüler im Sekundarbereich II privat geleitete Bildungseinrichtungen.

Die Daten beziehen sich auf das Schuljahr 2001/2002 und beruhen auf der alljährlich von der OECD aufgelegten UOE-Datenerhebung zur Bildungsstatistik. 
kann die Kennzahl insgesamt nicht als die durchschnittliche Anzahl an Jahren interpretiert werden, die ein einzelner Studierender im Tertiärbereich verbringen muss, um zu einem Abschluss zu gelangen.

Berufsvorbereitende und berufsbildende Bildungsgänge umfassen sowohl rein schulische als auch kombinierte schulische und betriebliche Ausbildungen, die als Bestandteil des Bildungssystems gelten. Ausschließlich in Betrieben durchgeführte Ausbildungen, die keiner formalen Aufsicht durch eine Bildungsbehörde unterstehen, bleiben unberücksichtigt.

Die Daten für die Bildungsbeteiligung im Tertiärbereich im Studienjahr 1994/95 basieren auf einer speziellen Datenerhebung aus dem Jahr 2000. Die OECD-Länder wurden aufgefordert, die Daten gemäß der ISCED-97 Klassifikation anzugeben. 
Tabelle C2.1

Studienanfängerquoten im Tertiärbereich und Altersverteilung der Studienanfänger (2002)

Summe der Netto-Studienanfängerquoten für jeden einzelnen Altersjahrgang, nach Geschlecht und Ziel des Studiengangs

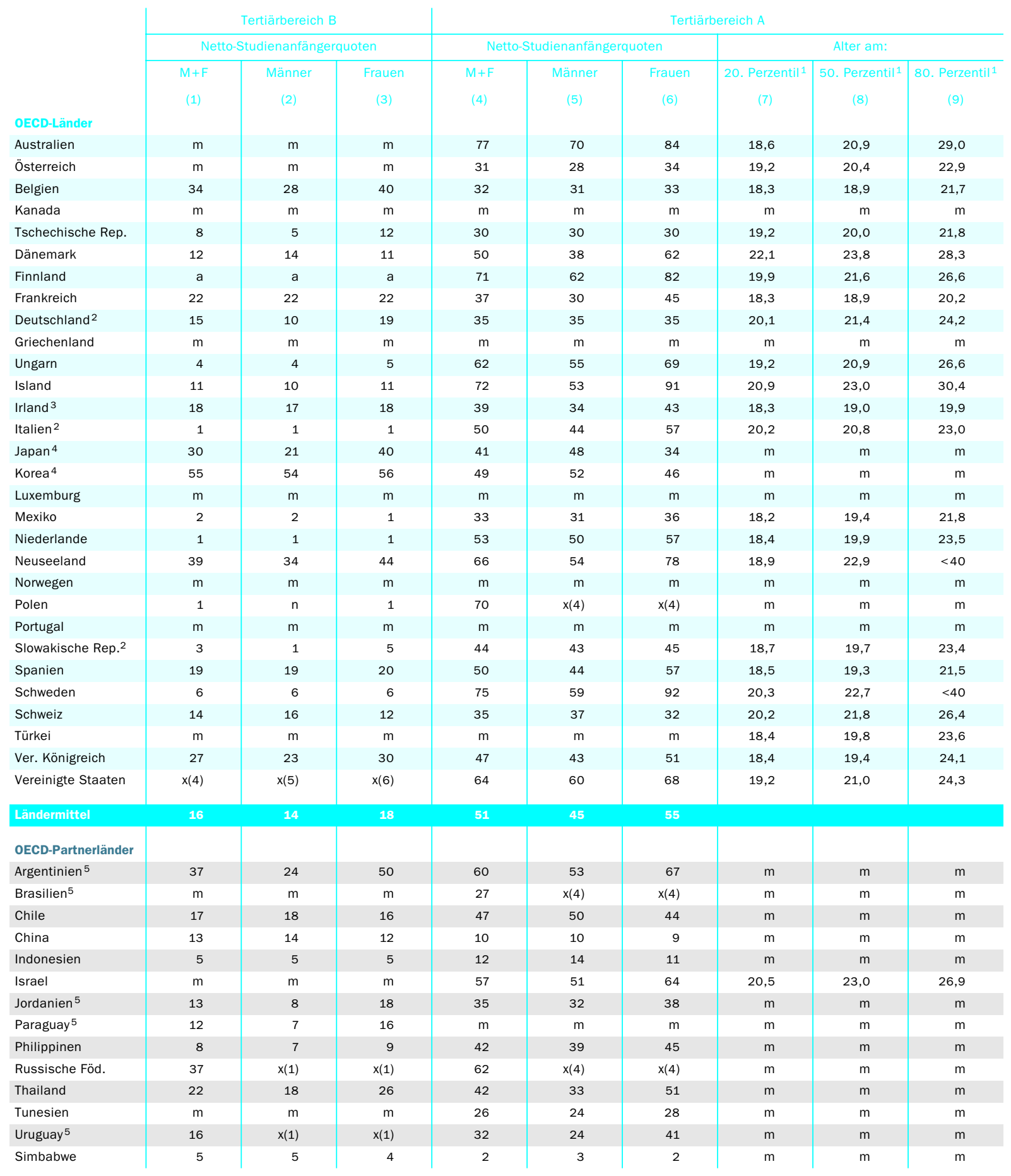

Hinweise: $x$ bedeutet, dass die Daten in einer anderen Spalte enthalten sind, deren Referenz in runden Klammern nach dem , $x$ ' angegeben ist. So bedeutet $z . B$. $x(2)$, dass die Daten in Spalte 2 enthalten sind. Unterschiede im Erhebungsbereich der Bevölkerungsdaten und der Schüler-/Absolventendaten bedeuten, dass die Teilnahme-/Abschlussquoten von Ländern mit einem Nettoabgang von Schülern/Studierenden wohl zu niedrig und die von Ländern mit einem Nettozugang von Schülern/Studierenden wohl zu hoch angesetzt sind.

1. 20/50/80\% der Studienanfänger sind jünger als das angegebene Alter. 2. Studienanfängerquoten für den Tertiärbereich $B$ als Bruttostudienanfängerquote berechnet. 3. Nur Studienanfänger im Vollzeitstudium. 4. Studienanfängerquoten für den Tertiärbereich A und B als Bruttostudienanfängerquote berechnet.

5. Referenzjahr 2001.

Quelle: OECD. Hinweise s. Anhang 3 unter www.oecd.org/edu/eag2004. 


\section{Tabelle C2.2}

Zu erwartende Ausbildungsjahre im Tertiärbereich und Veränderung der Gesamtzahl der Studierenden im Tertiärbereich (2002) Zu erwartende Jahre unter gleichbleibenden Rahmenbedingungen, nach Geschlecht und Vollzeit-/Teilzeitstudium, sowie Index der Veränderung $(1995=100)$

\begin{tabular}{|c|c|c|c|c|c|c|c|c|c|c|c|c|}
\hline & \multicolumn{3}{|c|}{ Tertiärbereich B } & \multicolumn{3}{|c|}{ Tertiärbereich A } & \multicolumn{3}{|c|}{$\begin{array}{l}\text { Gesamter Tertiärbereich } \\
\text { (A, B und weiterführende } \\
\text { Forschungsprogramme) }\end{array}$} & \multicolumn{3}{|c|}{$\begin{array}{l}\text { Veränderung der Bildungs- } \\
\text { beteiligung }(1995=100)\end{array}$} \\
\hline & \multicolumn{2}{|c|}{ Voll- und Teilzeit } & \multirow{2}{*}{$\begin{array}{l}\text { Vollzeit } \\
M+F\end{array}$} & \multicolumn{2}{|c|}{ Voll- und Teilzeit } & \multirow{2}{*}{$\begin{array}{l}\text { Vollzeit } \\
M+F\end{array}$} & \multicolumn{2}{|c|}{ Voll- und Teilzeit } & \multirow{2}{*}{$\begin{array}{l}\text { Vollzeit } \\
M+F\end{array}$} & \multirow{2}{*}{\begin{tabular}{|c|} 
Tertiär- \\
bereich \\
insgesamt
\end{tabular}} & \multicolumn{2}{|c|}{ Hiervon aufgrund } \\
\hline OECD-Länder & $M+F$ & $\begin{array}{l}\text { Frauen } \\
\text { (2) }\end{array}$ & & $M+F$ & $\begin{array}{l}\text { Frauen } \\
\text { (5) }\end{array}$ & & $M+F$ & Frauen & & & $\begin{array}{l}\text { Verände- } \\
\text { rung in der } \\
\text { Größe der } \\
\text { Population } \\
\text { (11) }\end{array}$ & $\begin{array}{l}\text { Verände- } \\
\text { rung der } \\
\text { Bildungs- } \\
\text { beteiligung } \\
\text { (12) }\end{array}$ \\
\hline Australien & 0,7 & 0,7 & 0,2 & 2,9 & 3,2 & 1,9 & 3,6 & 4,0 & 2,2 & 129 & 102 & 128 \\
\hline Österreich & 0,2 & 0,3 & $x(1)$ & 1,7 & 1,8 & $x(4)$ & 2,1 & 2,2 & $x(7)$ & 93 & 67 & 101 \\
\hline Belgien & 1,5 & 1,7 & 1,1 & 1,3 & 1,4 & 1,3 & 2,8 & 3,1 & 2,4 & 114 & 95 & 121 \\
\hline Kanada & $\mathrm{m}$ & $\mathrm{m}$ & $\mathrm{m}$ & $\mathrm{m}$ & $\mathrm{m}$ & $\mathrm{m}$ & $\mathrm{m}$ & $\mathrm{m}$ & $\mathrm{m}$ & $\mathrm{m}$ & $\mathrm{m}$ & $\mathrm{m}$ \\
\hline Tschechische Rep. & 0,2 & 0,3 & 0,2 & 1,5 & 1,5 & 1,3 & 1,8 & 1,9 & 1,6 & 168 & 97 & 167 \\
\hline Dänemark & 0,3 & 0,2 & 0,3 & 2,4 & 2,9 & 2,4 & 2,7 & 3,2 & 2,7 & 118 & 91 & 130 \\
\hline Frankreich & 0,6 & 0,7 & 0,6 & 1,8 & 2,1 & 1,9 & 2,6 & 2,9 & 2,6 & 99 & 93 & 106 \\
\hline Deutschland & 0,3 & 0,4 & 0,3 & 1,8 & 1,7 & 1,8 & 2,1 & 2,1 & 2,1 & 100 & 92 & 114 \\
\hline Griechenland & 1,1 & 1,1 & 1,1 & 2,1 & 2,4 & 2,1 & 3,3 & 3,5 & 3,3 & 178 & 100 & 177 \\
\hline Ungarn & 0,1 & 0,1 & 0,1 & 2,3 & 2,6 & 1,2 & 2,4 & 2,7 & 1,3 & 208 & 91 & 207 \\
\hline Island & 0,2 & 0,2 & 0,1 & 2,5 & 3,2 & 1,9 & 2,7 & 3,4 & 2,0 & 159 & 105 & 151 \\
\hline Irland & $x(7)$ & $x(8)$ & $x(9)$ & $x(7)$ & $x(8)$ & $x(9)$ & 2,7 & 3,0 & 2,0 & 137 & 108 & 127 \\
\hline Italien & $\mathrm{m}$ & $\mathrm{m}$ & $\mathrm{m}$ & 2,5 & 2,8 & 2,5 & 2,5 & 2,9 & 2,5 & 108 & $\mathrm{~m}$ & $\mathrm{~m}$ \\
\hline Japan & $\mathrm{m}$ & $\mathrm{m}$ & $\mathrm{m}$ & $\mathrm{m}$ & $\mathrm{m}$ & $\mathrm{m}$ & $\mathrm{m}$ & $\mathrm{m}$ & $\mathrm{m}$ & $\mathrm{m}$ & $\mathrm{m}$ & $\mathrm{m}$ \\
\hline Korea & 1,7 & 1,3 & 1,7 & 2,3 & 1,8 & 2,3 & 4,0 & 3,0 & 4,0 & 158 & 84 & 175 \\
\hline Luxemburg & $\mathrm{m}$ & $\mathrm{m}$ & $\mathrm{m}$ & $\mathrm{m}$ & $\mathrm{m}$ & $\mathrm{m}$ & $\mathrm{m}$ & $\mathrm{m}$ & $\mathrm{m}$ & $\mathrm{m}$ & $\mathrm{m}$ & $\mathrm{m}$ \\
\hline Mexiko & $n$ & $\mathrm{n}$ & $n$ & 1,1 & 1,0 & 1,1 & 1,1 & 1,1 & 1,1 & 140 & 108 & 130 \\
\hline Niederlande & $n$ & $\mathrm{n}$ & $n$ & 2,5 & 2,6 & 2,1 & 2,6 & 2,6 & 2,1 & $\mathrm{~m}$ & $\mathrm{~m}$ & $\mathrm{~m}$ \\
\hline Neuseeland & 0,8 & 1,0 & 0,4 & 2,4 & 2,8 & 1,7 & 3,3 & 3,8 & 2,2 & $\mathrm{~m}$ & $\mathrm{~m}$ & $\mathrm{~m}$ \\
\hline Norwegen & 0,2 & 0,2 & 0,1 & 3,0 & 3,7 & 2,1 & 3,3 & 3,9 & 2,3 & 109 & 92 & 116 \\
\hline Slowakische Rep. & 0,1 & 0,1 & $n$ & 1,5 & 1,6 & 1,1 & 1,7 & 1,8 & 1,1 & $\mathrm{~m}$ & $\mathrm{~m}$ & $\mathrm{~m}$ \\
\hline Spanien & 0,4 & 0,4 & 0,4 & 2,5 & 2,8 & 2,3 & 3,0 & 3,3 & 2,8 & 120 & 91 & 128 \\
\hline Schweden & 0,1 & 0,1 & 0,1 & 3,1 & 3,8 & 1,7 & 3,4 & 4,1 & 1,9 & 135 & 95 & 143 \\
\hline Schweiz & 0,4 & 0,3 & 0,1 & 1,3 & 1,2 & 1,2 & 1,8 & 1,6 & 1,5 & $\mathrm{~m}$ & $\mathrm{~m}$ & $\mathrm{~m}$ \\
\hline Türkei & $\mathrm{m}$ & $\mathrm{m}$ & $\mathrm{m}$ & $\mathrm{m}$ & $\mathrm{m}$ & $\mathrm{m}$ & $\mathrm{m}$ & $\mathrm{m}$ & $\mathrm{m}$ & $\mathrm{m}$ & $\mathrm{m}$ & $\mathrm{m}$ \\
\hline Ver. Königreich & 0,8 & 1,0 & 0,3 & 1,8 & 2,0 & 1,4 & 2,8 & 3,1 & 1,7 & 124 & 98 & 126 \\
\hline Vereinigte Staaten & 0,2 & 0,2 & 0,1 & 3,9 & 4,3 & 2,9 & 4,1 & 4,5 & 3,0 & $\mathrm{~m}$ & $\mathrm{~m}$ & $\mathrm{~m}$ \\
\hline Ländermittel & 0,4 & 0,4 & 0,3 & 2,3 & 2,5 & 2,1 & 2,7 & 3,1 & 2,0 & 140 & 95 & 137 \\
\hline \multicolumn{13}{|l|}{ OECD-Partnerländer } \\
\hline Argentinien ${ }^{1}$ & 0,8 & 1,2 & 0,8 & 2,5 & 2,8 & a & 3,4 & 4,0 & 0,8 & $\mathrm{~m}$ & $\mathrm{~m}$ & $\mathrm{~m}$ \\
\hline Brasilien ${ }^{1}$ & $x(4)$ & $x(5)$ & $x(6)$ & 1,1 & 1,2 & 1,1 & 1,1 & 1,2 & 1,1 & $\mathrm{~m}$ & $\mathrm{~m}$ & $\mathrm{~m}$ \\
\hline Indonesien & 0,2 & 0,2 & 0,2 & 0,5 & 0,5 & 0,5 & 0,7 & 0,7 & 0,7 & $\mathrm{~m}$ & $\mathrm{~m}$ & $\mathrm{~m}$ \\
\hline Israel & 0,6 & 0,7 & 0,6 & 2,3 & 2,6 & 1,8 & 3,0 & 3,4 & 2,5 & $\mathrm{~m}$ & $\mathrm{~m}$ & $\mathrm{~m}$ \\
\hline Malaysia ${ }^{1}$ & 1,1 & 1,2 & 1,1 & 1,3 & 1,5 & 1,2 & 2,5 & 2,8 & 2,4 & $\mathrm{~m}$ & $\mathrm{~m}$ & $\mathrm{~m}$ \\
\hline Paraguay ${ }^{1}$ & 0,3 & 0,4 & 0,3 & $x(7)$ & $x(8)$ & $x(9)$ & 1,2 & 1,3 & 1,2 & $\mathrm{~m}$ & $\mathrm{~m}$ & $\mathrm{~m}$ \\
\hline Peru ${ }^{1}$ & 0,8 & 0,9 & 0,8 & $\mathrm{~m}$ & $\mathrm{~m}$ & $\mathrm{~m}$ & 2,0 & 2,0 & 2,0 & $\mathrm{~m}$ & $\mathrm{~m}$ & $\mathrm{~m}$ \\
\hline Russische Föd. & 1,0 & 1,2 & 0,7 & 2,4 & 2,8 & 1,2 & 3,4 & 4,0 & 2,0 & $\mathrm{~m}$ & $\mathrm{~m}$ & $\mathrm{~m}$ \\
\hline Thailand & $\mathrm{m}$ & $\mathrm{m}$ & $\mathrm{m}$ & 1,6 & 1,8 & $\mathrm{~m}$ & 2,0 & 2,1 & 0,4 & $\mathrm{~m}$ & $\mathrm{~m}$ & $\mathrm{~m}$ \\
\hline Uruguay $^{1}$ & 0,4 & 0,6 & 0,4 & 1,5 & 1,8 & 1,5 & 1,9 & 2,4 & 1,9 & $\mathrm{~m}$ & $\mathrm{~m}$ & $\mathrm{~m}$ \\
\hline
\end{tabular}

Hinweis: $x$ bedeutet, dass die Daten in einer anderen Spalte enthalten sind, deren Referenz in runden Klammern nach dem ,x angegeben ist. So bedeutet z. B. $x(2)$, dass die Daten in Spalte 2 enthalten sind. Unterschiede im Erhebungsbereich der Bevölkerungsdaten und der Schüler-/Absolventendaten bedeuten, dass die Teilnahme-/Abschlussquoten von Ländern mit einem Nettoabgang von Schülern/Studierenden wohl zu niedrig (z. B. Luxemburg) und die von Ländern mit einem Nettozugang von Schülern/Studierenden wohl zu hoch angesetzt sind.

1. Referenzjahr 2001.

Quelle: OECD. Hinweise s. Anhang 3 unter www.oecd.org/edu/eag2004. 
Tabelle C2.3

Studierende an öffentlichen und privaten Bildungseinrichtungen und in Vollzeit- und Teilzeit-Ausbildung im Tertiärbereich (2002) Verteilung der Studierenden, nach Vollzeit-/Teilzeitausbildung, Art der Bildungseinrichtung und Ziel des Studiengangs

\begin{tabular}{|c|c|c|c|c|c|c|c|c|c|c|}
\hline & \multicolumn{6}{|c|}{ Art der Bildungseinrichtung } & \multicolumn{4}{|c|}{ Vollzeit-/Teilzeitausbildung } \\
\hline & \multicolumn{3}{|c|}{ Tertiärbereich B } & \multicolumn{3}{|c|}{$\begin{array}{l}\text { Tertiärbereich A und weiterführende } \\
\text { Forschungsprogramme }\end{array}$} & \multicolumn{2}{|c|}{ Tertiärbereich B } & \multicolumn{2}{|c|}{$\begin{array}{l}\text { Tertiärbereich } \mathrm{A} \text { und } \\
\text { weiterführende } \\
\text { Forschungsprogramme }\end{array}$} \\
\hline & Öffentlich & $\begin{array}{l}\text { Staatlich- } \\
\text { subventio- } \\
\text { niert privat } \\
\text { (2) }\end{array}$ & $\begin{array}{c}\text { Unabhängig } \\
\text { privat } \\
\text { (3) }\end{array}$ & Öffentlich & $\begin{array}{l}\text { Staatlich- } \\
\text { subventio- } \\
\text { niert privat } \\
\text { (5) }\end{array}$ & $\begin{array}{c}\text { Unabhängig } \\
\text { privat } \\
\text { (6) }\end{array}$ & Vollzeit & Teilzeit & Vollzeit & Teilzeit \\
\hline \multicolumn{11}{|l|}{ OECD-Länder } \\
\hline Australien & 99,1 & 0,9 & a & 100,0 & a & $\mathrm{n}$ & 33,7 & 66,3 & 65,5 & 34,5 \\
\hline Österreich & 63,1 & 36,9 & $\mathrm{n}$ & 92,7 & 7,3 & $\mathrm{n}$ & 66,8 & 33,2 & 100,0 & a \\
\hline Belgien & 47,5 & 52,5 & $\mathrm{~m}$ & 41,5 & 58,5 & $\mathrm{~m}$ & 71,7 & 28,3 & 95,6 & 4,4 \\
\hline Kanada & $\mathrm{m}$ & $\mathrm{m}$ & $\mathrm{m}$ & $\mathrm{m}$ & $\mathrm{m}$ & $\mathrm{m}$ & $\mathrm{m}$ & $\mathrm{m}$ & $\mathrm{m}$ & $\mathrm{m}$ \\
\hline Tschechische Rep. & 67,9 & 32,1 & a & 98,3 & $n$ & 1,7 & 100,0 & $n$ & 89,1 & 10,9 \\
\hline Dänemark & 100,0 & a & a & 99,5 & 0,5 & a & 100,0 & a & 100,0 & $a$ \\
\hline Finnland & 80,1 & 19,9 & $a$ & 89,8 & 10,2 & $a$ & 100,0 & $a$ & 58,8 & 41,2 \\
\hline Deutschland & 64,3 & 35,7 & $x(2)$ & 100,0 & a & a & 85,1 & 14,9 & 100,0 & $a$ \\
\hline Griechenland & 100,0 & a & a & 100,0 & a & a & 100,0 & $\mathrm{a}$ & 100,0 & a \\
\hline Ungarn & 79,6 & 20,4 & a & 85,9 & 14,1 & a & 89,4 & 10,6 & 54,9 & 45,1 \\
\hline Island & 46,6 & 53,4 & $n$ & 90,2 & 9,8 & $\mathrm{n}$ & 54,2 & 45,8 & 76,3 & 23,7 \\
\hline Irland & 93,4 & a & 6,6 & 94,0 & a & 6,0 & 59,4 & 40,6 & 84,6 & 15,4 \\
\hline Italien & 85,3 & $\mathrm{a}$ & 14,7 & 93,5 & $\mathrm{a}$ & 6,5 & 100,0 & $\mathrm{a}$ & 100,0 & $a$ \\
\hline Japan & 9,5 & a & 90,5 & 27,5 & a & 72,5 & 97,0 & 3,0 & 90,6 & 9,4 \\
\hline Korea & 14,1 & a & 85,9 & 22,7 & a & 77,3 & 100,0 & $\mathrm{a}$ & 100,0 & $a$ \\
\hline Luxemburg & 100,0 & a & a & 100,0 & a & a & 97,9 & 2,1 & 92,9 & 7,1 \\
\hline Mexiko & 96,2 & $a$ & 3,8 & 66,3 & a & 33,7 & 100,0 & a & 100,0 & a \\
\hline Niederlande & 9,6 & 90,4 & a & 29,2 & 69,6 & a & 49,4 & 50,6 & 81,3 & 18,7 \\
\hline Neuseeland & 78,5 & 21,5 & 0,6 & 97,3 & 1,4 & $\mathrm{n}$ & 50,9 & 49,6 & 69,6 & 29,1 \\
\hline Norwegen & 85,7 & 14,3 & $x(2)$ & 87,6 & 12,4 & $x(5)$ & 85,8 & 14,2 & 66,7 & 33,3 \\
\hline Polen & 82,6 & a & 17,4 & 71,6 & a & 28,4 & 100,0 & $\mathrm{a}$ & 56,7 & 43,3 \\
\hline Portugal & 43,4 & a & 56,6 & 72,3 & a & 27,7 & 100,0 & $x(7)$ & 100,0 & $x(9)$ \\
\hline Schweden & 69,8 & 1,0 & 29,2 & 94,1 & 5,9 & a & 91,9 & 8,1 & 52,8 & 47,2 \\
\hline Schweiz & 36,2 & 42,0 & 21,8 & 90,4 & 6,8 & 2,8 & 31,2 & 68,8 & 91,0 & 9,0 \\
\hline Türkei & 98,8 & $a$ & 1,2 & 96,0 & a & 4,0 & 100,0 & a & 100,0 & $a$ \\
\hline Ver. Königreich & a & 100,0 & $n$ & a & 100,0 & $\mathrm{n}$ & 27,7 & 72,3 & 72,9 & 27,1 \\
\hline Vereinigte Staaten & 96,8 & a & 3,2 & 76,0 & a & 24,0 & 37,7 & 62,3 & 75,2 & 24,8 \\
\hline Ländermittel & 68,6 & 19,1 & 13,7 & 79,0 & 10,3 & 11,4 & 78,9 & 21,8 & 83,9 & 16,7 \\
\hline \multicolumn{11}{|l|}{ OECD-Partnerländer } \\
\hline Argentinien ${ }^{1}$ & 58,9 & 29,6 & 11,5 & 87,0 & a & 13,0 & 100,0 & a & a & 100,0 \\
\hline Brasilien ${ }^{1}$ & $\mathrm{~m}$ & a & $\mathrm{m}$ & 32,6 & a & 67,4 & $\mathrm{~m}$ & $\mathrm{~m}$ & 100,0 & a \\
\hline Chile & 8,1 & 5,4 & 86,4 & 31,5 & 22,1 & 46,4 & 100,0 & a & 100,0 & a \\
\hline China & $\mathrm{m}$ & $\mathrm{m}$ & $\mathrm{m}$ & $\mathrm{m}$ & $\mathrm{m}$ & $\mathrm{m}$ & 62,8 & 37,2 & 78,7 & 21,3 \\
\hline Indien ${ }^{1}$ & 100,0 & a & a & 100,0 & a & a & 100,0 & a & 85,3 & 14,7 \\
\hline Indonesien & 49,8 & a & 50,2 & 33,5 & a & 66,5 & 100,0 & a & 100,0 & a \\
\hline Israel & 22,0 & 78,0 & $\mathrm{~m}$ & 11,7 & 76,3 & 12,0 & 100,0 & a & 81,7 & 18,3 \\
\hline Jamaika & 74,7 & a & 25,3 & 68,4 & a & 31,6 & 59,5 & 40,5 & 62,1 & 37,9 \\
\hline Jordanien ${ }^{1}$ & 46,5 & a & 53,5 & 71,4 & a & 28,6 & 100,0 & a & 100,0 & $\mathrm{a}$ \\
\hline Paraguay ${ }^{1}$ & 37,4 & 23,7 & 38,9 & 43,1 & a & 56,9 & 100,0 & a & $\mathrm{m}$ & $\mathrm{m}$ \\
\hline Peru $^{1}$ & 46,2 & 0,7 & 53,1 & 58,8 & $\mathrm{~m}$ & 41,2 & 100,0 & a & $\mathrm{m}$ & $\mathrm{m}$ \\
\hline Philippinen & 42,3 & a & 57,7 & 31,9 & a & 68,1 & 100,0 & a & 100,0 & a \\
\hline Russische Föd. & 97,6 & a & 2,4 & 88,7 & a & 11,3 & 72,4 & 27,6 & 51,8 & 45,8 \\
\hline Thailand & 59,1 & a & 40,9 & 86,9 & a & 13,1 & 100,0 & a & 0,3 & $\mathrm{~m}$ \\
\hline Tunesien & 100,0 & a & $\mathrm{m}$ & 100,0 & a & $\mathrm{n}$ & 100,0 & a & 100,0 & $a$ \\
\hline Uruguay $^{1}$ & 98,9 & a & 1,1 & 86,2 & a & 13,8 & 100,0 & a & 100,0 & a \\
\hline Simbabwe & $\mathrm{m}$ & $\mathrm{m}$ & $\mathrm{m}$ & $\mathrm{m}$ & $\mathrm{m}$ & $\mathrm{m}$ & 84,3 & 15,7 & $\mathrm{~m}$ & $\mathrm{~m}$ \\
\hline
\end{tabular}

Hinweis: $x$ bedeutet, dass die Daten in einer anderen Spalte enthalten sind, deren Referenz in runden Klammern nach dem , $x$ ‘ angegeben ist. So bedeutet $z . B . x(2)$, dass die Daten in Spalte 2 enthalten sind.

1. Referenzjahr 2001.

Quelle: OECD. Hinweise s. Anhang 3 unter www.oecd.org/edu/eag2004. 
Tabelle C2.4

Schüler an öffentlichen und privaten Bildungseinrichtungen und Schüler in Vollzeit- und Teilzeit-Ausbildung im Primar- und Sekundarbereich (2002)

Verteilung der Schüler, nach Vollzeit-/Teilzeitausbildung und Art der Bildungseinrichtung

\begin{tabular}{|c|c|c|c|c|c|c|c|c|c|c|c|}
\hline & \multicolumn{9}{|c|}{ Art der Bildungseinrichtung } & \multirow{2}{*}{\multicolumn{2}{|c|}{$\begin{array}{c}\begin{array}{c}\text { Vollzeit-/Teilzeit- } \\
\text { ausbildung }\end{array} \\
\begin{array}{c}\text { Primar- und } \\
\text { Sekundarbereich }\end{array}\end{array}$}} \\
\hline & \multicolumn{3}{|c|}{ Primarbereich } & \multicolumn{3}{|c|}{ Sekundarbereich I } & \multicolumn{3}{|c|}{ Sekundarbereich II } & & \\
\hline & Öffentlich & $\begin{array}{c}\text { Staatlich- } \\
\text { subventio- } \\
\text { niert privat } \\
\text { (2) }\end{array}$ & $\begin{array}{c}\begin{array}{c}\text { Unabhängig } \\
\text { privat } \\
\text { (3) }\end{array} \\
\end{array}$ & Öffentlich & $\begin{array}{c}\text { Staatlich- } \\
\text { subventio- } \\
\text { niert privat } \\
\text { (5) }\end{array}$ & $\begin{array}{c}\text { Unabhängig } \\
\text { privat } \\
\text { (6) }\end{array}$ & Öffentlich & $\begin{array}{c}\text { Staatlich- } \\
\text { subventio- } \\
\text { niert privat } \\
(8)\end{array}$ & $\begin{array}{c}\begin{array}{c}\text { Unabhängig } \\
\text { privat }\end{array} \\
\text { (9) }\end{array}$ & Vollzeit & Teilzeit \\
\hline \multicolumn{12}{|l|}{ OECD-Länder } \\
\hline Australien & 72,0 & 28,0 & a & 69,6 & 30,4 & a & 81,1 & 18,9 & a & 75,9 & 24,1 \\
\hline Österreich & 95,7 & 4,3 & $x(2)$ & 92,3 & 7,7 & $x(5)$ & 90,3 & 9,7 & $x(8)$ & 99,5 & 0,5 \\
\hline Belgien & 45,7 & 54,3 & $\mathrm{~m}$ & 42,3 & 57,7 & $\mathrm{~m}$ & 42,8 & 57,2 & $\mathrm{~m}$ & 80,6 & 19,4 \\
\hline Kanada & $\mathrm{m}$ & $\mathrm{m}$ & $\mathrm{m}$ & $\mathrm{m}$ & $\mathrm{m}$ & $\mathrm{m}$ & $\mathrm{m}$ & $\mathrm{m}$ & $\mathrm{m}$ & $\mathrm{m}$ & $\mathrm{m}$ \\
\hline Tschechische Rep. & 99,0 & 1,0 & a & 98,3 & 1,7 & a & 88,1 & 11,9 & a & 99,9 & 0,1 \\
\hline Dänemark & 89,0 & 11,0 & a & 80,9 & 19,1 & a & 96,5 & 3,5 & a & 100,0 & a \\
\hline Finnland & 98,8 & 1,2 & a & 95,6 & 4,4 & a & 89,7 & 10,3 & a & 100,0 & a \\
\hline Deutschland & 97,4 & 2,6 & $x(2)$ & 93,1 & 6,9 & $x(5)$ & 92,8 & 7,2 & $x(8)$ & 99,8 & 0,2 \\
\hline Griechenland & 92,9 & a & 7,1 & 94,5 & a & 5,5 & 94,0 & a & 6,0 & 97,9 & 2,1 \\
\hline Ungarn & 94,8 & 5,2 & a & 94,0 & 6,0 & a & 86,6 & 13,4 & a & 96,1 & 3,9 \\
\hline Island & 98,7 & 1,3 & $n$ & 99,0 & 1,0 & $n$ & 93,0 & 6,9 & 0,1 & 93,2 & 6,8 \\
\hline Irland & 98,9 & a & 1,1 & 100,0 & a & $\mathrm{n}$ & 98,3 & a & 1,7 & 99,9 & 0,1 \\
\hline Italien & 93,3 & a & 6,7 & 96,6 & a & 3,4 & 93,5 & 1,0 & 5,5 & 99,2 & 0,8 \\
\hline Japan & 99,1 & a & 0,9 & 94,2 & a & 5,8 & 69,7 & a & 30,3 & 98,8 & 1,2 \\
\hline Korea & 98,6 & $a$ & 1,4 & 78,7 & 21,3 & a & 47,0 & 53,0 & a & 100,0 & a \\
\hline Luxemburg & 93,3 & 0,8 & 5,9 & 79,3 & 13,4 & 7,4 & 84,7 & 8,0 & 7,3 & 100,0 & $\mathrm{n}$ \\
\hline Mexiko & 92,1 & a & 7,9 & 86,8 & a & 13,2 & 78,0 & a & 22,0 & 100,0 & a \\
\hline Niederlande & 31,6 & 68,4 & a & 23,9 & 76,1 & a & 7,6 & 92,4 & a & 98,1 & 1,9 \\
\hline Neuseeland & 97,9 & a & 2,1 & 95,7 & a & 4,3 & 85,9 & 8,8 & 5,3 & 93,6 & 7,1 \\
\hline Norwegen & 98,3 & 1,7 & $x(2)$ & 97,9 & 2,1 & $x(5)$ & 89,4 & 10,6 & $x(8)$ & 99,7 & 0,3 \\
\hline Polen & 98,8 & 0,3 & 1,0 & 98,5 & 0,3 & 1,2 & 91,4 & 0,4 & 8,1 & 94,9 & 5,1 \\
\hline Portugal & 89,5 & a & 10,5 & 89,5 & a & 10,5 & 82,0 & a & 18,0 & 93,2 & 6,8 \\
\hline Schweden & 95,4 & 4,6 & a & 95,4 & 4,5 & a & 96,6 & 3,4 & a & 87,6 & 12,4 \\
\hline Schweiz & 96,4 & 1,3 & 2,3 & 93,0 & 2,6 & 4,4 & 92,7 & 3,7 & 3,6 & 99,8 & 0,2 \\
\hline Türkei & 98,3 & a & 1,7 & a & a & a & 97,7 & a & 2,3 & 100,0 & a \\
\hline Ver. Königreich & 95,1 & $a$ & 4,9 & 93,4 & 0,3 & 6,3 & 25,3 & 72,2 & 2,5 & 70,7 & 29,3 \\
\hline Vereinigte Staaten & 89,7 & a & 10,3 & 91,2 & a & 8,8 & 91,2 & a & 8,8 & 100,0 & $n$ \\
\hline Ländermittel & 89,7 & 8,0 & 2,3 & 86,2 & 11,1 & 2,6 & 80,2 & 15,2 & 4,6 & 95,6 & 4,4 \\
\hline \multicolumn{12}{|l|}{ OECD-Partnerländer } \\
\hline Argentinien ${ }^{1}$ & 80,0 & 16,4 & 3,6 & 78,0 & 18,9 & 3,2 & 70,5 & 23,7 & 5,8 & 100,0 & a \\
\hline Brasilien $^{1}$ & 91,9 & a & 8,1 & 90,4 & a & 9,6 & 85,8 & a & 14,2 & 100,0 & a \\
\hline Chile & 53,5 & 39,1 & 7,4 & 56,0 & 36,6 & 7,4 & 50,2 & 35,4 & 14,4 & 100,0 & a \\
\hline Indien ${ }^{1}$ & 83,5 & 8,5 & 8,0 & 65,9 & 19,4 & 14,7 & 45,4 & 36,3 & 18,2 & 99,9 & 0,1 \\
\hline Indonesien & 84,0 & a & 16,0 & 63,6 & a & 36,4 & 46,8 & a & 53,2 & 100,0 & a \\
\hline Israel & 100,0 & $\mathrm{n}$ & $\mathrm{n}$ & 100,0 & $\mathrm{n}$ & $\mathrm{n}$ & 100,0 & a & a & 99,1 & 0,9 \\
\hline Jamaika & 95,2 & a & 4,8 & 97,1 & a & 2,9 & 97,1 & a & 2,9 & $\mathrm{~m}$ & $\mathrm{~m}$ \\
\hline Jordanien $^{1}$ & 70,6 & a & 29,4 & 80,9 & a & 19,1 & 91,1 & a & 8,9 & 100,0 & a \\
\hline Malaysia $^{1}$ & 96,2 & a & 3,8 & 94,1 & a & 5,9 & 92,4 & a & 7,6 & 100,0 & a \\
\hline Paraguay ${ }^{1}$ & 85,1 & 9,6 & 5,2 & 77,3 & 11,0 & 11,7 & 67,9 & 9,2 & 22,9 & 100,0 & a \\
\hline Peru $^{1}$ & 86,5 & 3,3 & 10,1 & 83,5 & 4,7 & 11,9 & 81,5 & 4,8 & 13,7 & 100,0 & a \\
\hline Philippinen & 92,9 & a & 7,1 & 79,2 & a & 20,8 & 75,2 & a & 24,8 & 100,0 & a \\
\hline Russische Föd. & 99,6 & a & 0,4 & 99,7 & $a$ & 0,3 & 99,7 & a & 0,3 & 100,0 & a \\
\hline Thailand & 86,4 & 13,6 & $x(2)$ & 93,3 & 6,7 & $x(2)$ & 89,8 & 10,2 & $x(2)$ & $\mathrm{m}$ & $\mathrm{m}$ \\
\hline Tunesien & 99,2 & a & 0,8 & 98,6 & a & 1,4 & 92,5 & a & 7,5 & 100,0 & a \\
\hline Uruguay $^{1}$ & 87,3 & a & 12,7 & 87,6 & a & 12,4 & 88,6 & a & 11,4 & 100,0 & a \\
\hline Simbabwe & 12,4 & 87,6 & a & 27,0 & 73,0 & a & 30,6 & 69,4 & a & 100,0 & $\mathrm{a}$ \\
\hline
\end{tabular}

Hinweis: $x$ bedeutet, dass die Daten in einer anderen Spalte enthalten sind, deren Referenz in runden Klammern nach dem , $x$ ‘ angegeben ist. So bedeutet $z . B$. $x(2)$, dass die Daten in Spalte 2 enthalten sind.

1. Referenzjahr 2001.

Quelle: OECD. Hinweise s. Anhang 3 unter www.oecd.org/edu/eag2004. 


\section{Tabelle C2.5}

Struktur der Bildungsteillnahme im Sekundarbereich II (2002)

Prozentsatz der Schüler an öffentlichen und privaten Bildungseinrichtungen des Sekundarbereich II, nach Ausrichtung des Bildungsgangs

\begin{tabular}{|c|c|c|c|c|}
\hline \multirow{3}{*}{ OECD-Länder } & \multicolumn{4}{|c|}{ Ausrichtung des Bildungsgangs } \\
\hline & $\begin{array}{l}\text { Allgemeinbildend } \\
\text { (1) }\end{array}$ & $\begin{array}{l}\text { Berufsvorbereitend } \\
\text { (2) }\end{array}$ & $\begin{array}{l}\text { Berufsbildend } \\
\text { (3) }\end{array}$ & $\begin{array}{l}\text { Hiervon: kombinierte schul. } \\
\text { u. betriebl. Ausbildungen } \\
\text { (4) }\end{array}$ \\
\hline & & & & \\
\hline Australien & 37,0 & a & 63,0 & $x(3)$ \\
\hline Österreich & 21,0 & 6,8 & 72,3 & 35,8 \\
\hline Kanada & $\mathrm{m}$ & $\mathrm{m}$ & $\mathrm{m}$ & $\mathrm{m}$ \\
\hline Tschechische Republik & 19,6 & 0,2 & 80,2 & 38,2 \\
\hline Dänemark & 47,0 & a & 53,0 & 53,0 \\
\hline Finnland & 42,8 & a & 57,2 & 10,8 \\
\hline Frankreich & 43,7 & a & 56,3 & 11,8 \\
\hline Deutschland & 37,0 & a & 63,0 & 50,8 \\
\hline Griechenland & 60,0 & a & 40,0 & a \\
\hline Island & 61,7 & 1,3 & 37,0 & 16,7 \\
\hline Irland & 72,7 & 27,3 & a & a \\
\hline Italien & 35,2 & 38,0 & 26,8 & a \\
\hline Japan & 74,3 & 0,8 & 24,9 & a \\
\hline Korea & 67,9 & a & 32,1 & a \\
\hline Luxemburg & 36,0 & a & 64,0 & 13,3 \\
\hline Mexiko & 88,6 & a & 11,4 & a \\
\hline Niederlande & 30,8 & a & 69,2 & 23,5 \\
\hline Neuseeland & 100,0 & a & a & a \\
\hline Norwegen & 42,0 & a & 58,0 & a \\
\hline Polen & 39,1 & a & 60,9 & a \\
\hline Portugal & 71,2 & a & 28,8 & $\mathrm{~m}$ \\
\hline Slowakische Republik & 23,6 & a & 76,4 & 41,3 \\
\hline Spanien & 62,0 & a & 38,0 & 4,8 \\
\hline Türkei & 60,6 & a & 39,4 & 9,3 \\
\hline Vereinigtes Königreich & 27,9 & $x(3)$ & 72,1 & $x(3)$ \\
\hline Vereinigte Staaten & 100,0 & a & a & a \\
\hline Ländermittel & 50,6 & 4,0 & 45,5 & 14,7 \\
\hline OECD-Partnerländer & & & & \\
\hline Argentinien 1 & 22,1 & a & 77,9 & a \\
\hline Brasilien ${ }^{1}$ & 86,0 & a & 14,0 & $\mathrm{~m}$ \\
\hline Chile & 60,4 & a & 39,6 & a \\
\hline China & 57,2 & 38,6 & 4,3 & $\mathrm{~m}$ \\
\hline Indien ${ }^{1}$ & 99,9 & a & 0,1 & a \\
\hline Israel & 65,2 & a & 34,8 & 3,6 \\
\hline Jamaika & 99,5 & a & 0,5 & $\mathrm{~m}$ \\
\hline Jordanien & 94,6 & a & 5,4 & $\mathrm{~m}$ \\
\hline Malaysia $^{1}$ & 85,0 & a & 15,0 & $\mathrm{~m}$ \\
\hline Paraguay ${ }^{1}$ & 79,9 & a & 20,1 & a \\
\hline Philippinen & 100,0 & a & a & a \\
\hline Russische Föderation & 67,1 & a & 32,9 & a \\
\hline Thailand & 76,0 & a & 24,0 & a \\
\hline Tunesien & 93,2 & 2,6 & 4,1 & a \\
\hline Uruguay $^{1}$ & 80,8 & a & 19,2 & a \\
\hline Simbabwe & 100,0 & $a$ & a & a \\
\hline
\end{tabular}

Hinweis: $x$ bedeutet, dass die Daten in einer anderen Spalte enthalten sind, deren Referenz in runden Klammern nach dem ,x‘ angegeben ist. So bedeutet $z$. B. $x(2)$, dass die Daten in Spalte 2 enthalten sind.

1. Referenzjahr 2001.

Quelle: OECD. Hinweise s. Anhang 3 unter www.oecd.org/edu/eag2004. 



\section{Ausländische Studierende im Tertiärbereich}

2002 waren 1,9 Millionen Studierende außerhalb ihres Heimatlandes eingeschrieben. Dies stellt eine Zunahme der Gesamtmobilität Studierender von 15 Prozent gegenüber dem Vorjahr dar.

Fast 73 Prozent aller ausländischen Studierenden im OECD-Raum konzentrieren sich auf 5 Gastländer: Australien, Frankreich, Deutschland, das Vereinigte Königreich und die Vereinigten Staaten.

Absolut gesehen entsenden Deutschland, Frankreich, Griechenland, Japan, Korea und die Türkei die meisten der im Ausland Studierenden aus OECDLändern. Aus den OECD-Partnerländern kommen die meisten Studierenden aus China, Indien und Südostasien.

In Relation zur Gesamtzahl der in einem Land im Tertiärbereich eingeschriebenen Studierenden variiert der Anteil der ausländischen Studierenden in den OECD-Ländern von weniger als 1 Prozent bis zu fast 18 Prozent. Australien, Belgien, Deutschland, Frankreich, Österreich, die Schweiz und das Vereinigte Königreich weisen den größten Zugang ausländischer Studierender auf, wenn ihre Zahl als Prozentsatz der Gesamtzahl an Studierenden in dem jeweiligen Land ausgedrückt wird.

- In Finnland, Spanien und der Schweiz ist mindestens jeder sechste ausländische Studierende in einem der sehr theoretisch orientierten weiterführenden Forschungsprogramme eingeschrieben.

In Australien, Deutschland, Finnland, Schweden, der Schweiz und dem Vereinigten Königreich sind mindestens 30 Prozent der ausländischen Studierenden in naturwissenschaftlich ausgerichteten Fächern oder im Bereich Ingenieurwesen eingeschrieben. 


\section{Abbildung C3.1}

Ausländische Studierende im Tertiärbereich (2002)

Verhältnis ausländischer Studierender zur Gesamtstudierendenzahl im Tertiärbereich (in Prozent)

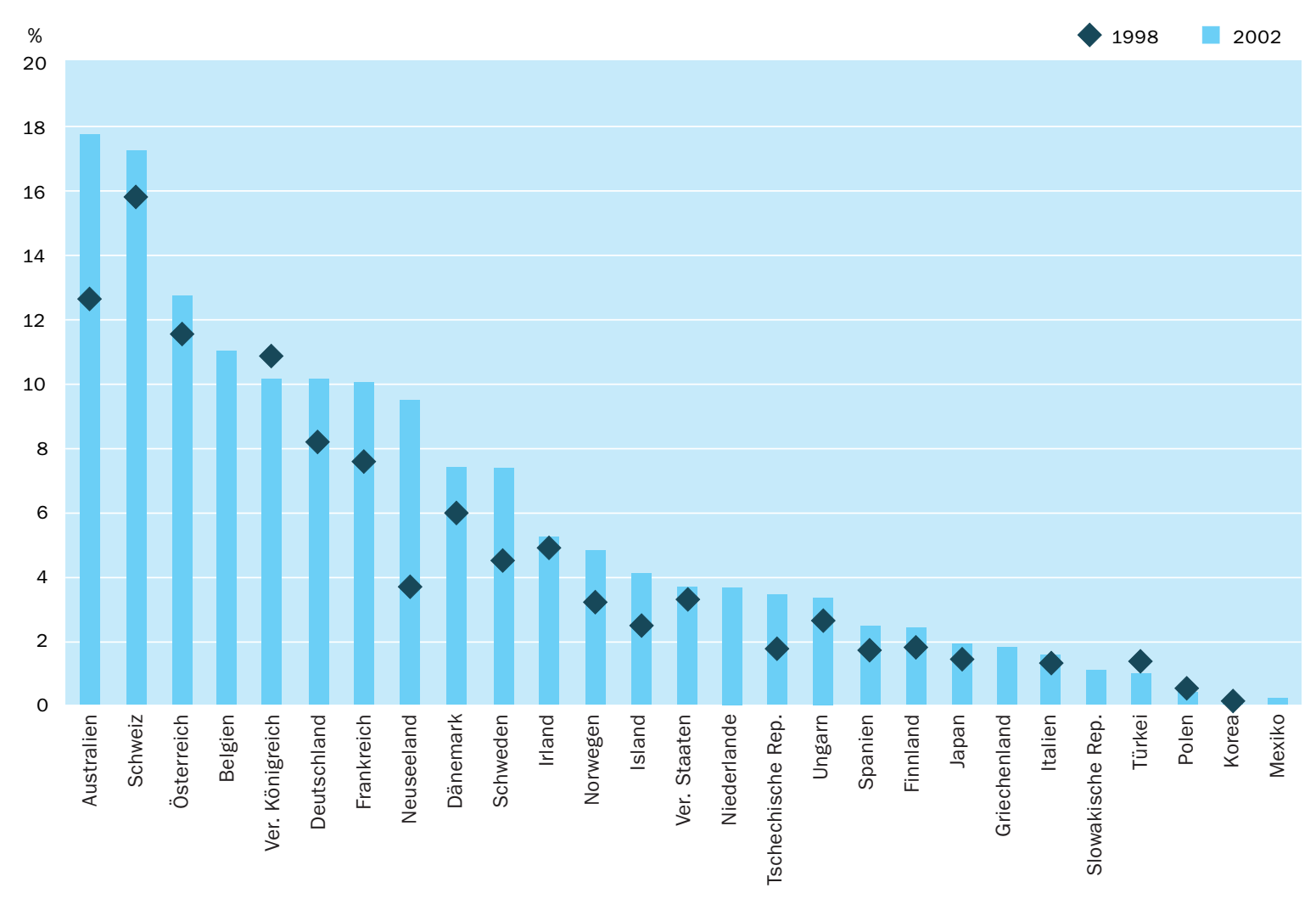

Anordnung der Länder in absteigender Reihenfolge des Prozentsatzes der 2002 im Tertiärbereich eingeschriebenen ausländischen Studierenden.

Quelle: OECD. Tabelle C3.1. Hinweise s. Anhang 3 unter www.oecd.org/edu/eag2004.

Dieser Indikator zeigt die länderübergreifende Mobilität der Studierenden auf ...

\section{Politischer Hintergrund}

Die internationale Dimension der Hochschulausbildung findet von vielerlei Seiten immer mehr Beachtung.

Einerseits hat der generelle Trend zur Freizügigkeit von Kapital, Waren und Arbeitskräften zusammen mit der zunehmenden Öffnung der Arbeitsmärkte in den OECD-Ländern die Nachfrage nach neuartigen Bildungsangeboten verstärkt. Die Regierungen und die Bürger erwarten von den Hochschulen zunehmend, dass sie den Horizont junger Menschen erweitern und ihnen ein umfassenderes Verständnis anderer Sprachen, Kulturen und betriebswirtschaftlicher Methoden vermitteln. Eine Möglichkeit für Studierende, ihre Kenntnisse über andere Kulturen, Gesellschaften und Sprachen zu erweitern und so ihre Chancen auf dem Arbeitsmarkt zu verbessern, besteht darin, tertiäre Bildungseinrichtungen anderer Länder zu besuchen. Die Regierungen einiger OECDLänder haben sogar Programme und Maßnahmen eingeführt, um eine derartige Mobilität zu fördern. 
Die wirtschaftlichen Kosten und der Nutzen der internationalen Mobilität Studierender wird größtenteils von der Politik der Ursprungsländer hinsichtlich der finanziellen Unterstützung eines Auslandsstudiums bestimmt sowie von der Politik der Gastländer hinsichtlich der Unterrichts- bzw. Studiengebühren und der finanziellen Unterstützung ausländischer Studierender. Während sich die kurzfristigen monetären Kosten und der Nutzen dieser Mobilität relativ leicht erfassen lassen, sind die längerfristigen sozialen und wirtschaftlichen Auswirkungen wesentlich schwerer zu quantifizieren.

Aus Sicht der Bildungseinrichtungen können ausländische Studierende eine Belastung der Unterrichtssituationen und -abläufe darstellen, da Lehrplan und Didaktik manchmal für eine kulturell und sprachlich heterogene Studentenschaft angepasst werden müssen. Diese Belastungen werden jedoch durch den umfangreichen Nutzen für die aufnehmenden Hochschulen mehr als ausgeglichen. So kann gerade durch die Teilnahme ausländischer Studierender die notwendige kritische Masse erreicht werden, um die Bandbreite der Bildungsangebote zu erweitern. Sie kann auch dazu beitragen, Schwankungen bei der Teilnahme der inländischen Studierenden auszugleichen. Ferner können hierdurch die finanziellen Mittel der Bildungseinrichtungen im Tertiärbereich gestärkt werden.

Und schließlich unterstreichen die laufenden internationalen Verhandlungen über die Liberalisierung des Handels mit Dienstleistungen die wirtschaftlichen Auswirkungen der Internationalisierung des Angebots von Bildungsdienstleistungen. Es ist anzunehmen, dass der Trend zur weiteren Internationalisierung der Bildung sich immer deutlicher auf die Leistungsbilanzen der einzelnen Länder auswirken wird, in einigen OECD-Ländern gibt es sogar schon erste Anzeichen für eine Spezialisierung auf Bildungsexporte. In diesem Zusammenhang ist zu beachten, dass bei der Internationalisierung und den grenzüberschreitenden Aspekten der Hochschulausbildung nicht nur die Anzahl der im Ausland Studierenden von Bedeutung ist, sondern auch die grenzüberschreitende elektronische Bereitstellung hochflexibler internationaler Bildungsgänge oder eines virtuellen Campus, obwohl hierzu bisher noch keine vergleichbaren Daten vorliegen(Kasten C3.I).

Die Internationalisierung der Hochschulausbildung bringt jedoch wesentlich mehr wirtschaftliche Vorteile, als sich in der Handelsbilanz niederschlagen. Die Internationalisierung der Bildung kann insbesondere für kleinere und/ oder weniger entwickelte Bildungssysteme eine Chance darstellen, ihr Bildungsangebot kosteneffizienter zu gestalten. Ausbildungsmöglichkeiten im Ausland können tatsächlich eine kostengünstige Alternative zur Bereitstellung der gleichen Leistungen im eigenen Land darstellen, denn durch sie werden die Länder in die Lage versetzt, ihre beschränkten Mittel auf diejenigen Bildungsangebote zu konzentrieren, in denen sie Größenvorteile erreichen können.

Die aktuellen und tendenziellen Zahlen der im Ausland studierenden jungen Menschen können einen ersten Eindruck von dem Ausmaß dieser grenzüberschreitenden Mobilität Studierender vermitteln. Künftig wird es wichtig werden, Methoden zu entwickeln, um auch andere Elemente der grenzüberschreitenden Bildung zu quantifizieren und zu messen.
... und zwar in Form der von den ,Sender'- und den ,Empfänger'-Ländern verfolgten Politiken.

Die Internationalisierung bringt für die Einrichtungen sowohl Vorteile als auch Belastungen und Verpflichtungen, ...

...sie wirkt sich auf die Leistungsbilanzen der einzelnen Länder aus...

...und kann eine Chance darstellen, das Bildungsangebot kosteneffizienter zu gestalten. 


\section{Grenzüberschreitende Bildungsaktivitäten - die wichtigsten wirtschaftlichen, sozialen und politischen Aspekte}

Im Juli 2004 brachte die OECD eine Veröffentlichung heraus, die sich ausschließlich mit den wichtigsten Entwicklungen und Fragen grenzüberschreitender post-sekundarer Bildungsaktivitäten befasste. Internationalisation and Trade in Higher Education: Opportunities and Challenges.

Innerhalb der letzten Io Jahre sind neue Formen grenzüberschreitender post-sekundarer Bildungsaktivitäten entstanden. Grenzüberschreitende Bildungsaktivitäten umfassen nicht nur die internationale Mobilität Studierender, sondern auch die Mobilität von Bildungsangeboten und Bildungseinrichtungen über Grenzen hinweg. Die grenzüberschreitende Mobilität Studierender ist mit großem Abstand die wichtigste Art grenzüberschreitender post-sekundarer Bildungsaktivitäten. Grenzüberschreitende Bildungsangebote und -einrichtungen führen für den Einzelnen zu geringeren Kosten als ein Auslandsstudium, und obwohl diese nicht unbedingt die gleichen kulturellen und sprachlichen Erfahrungen ermöglichen wie ein Studium im Ausland, werden sie wahrscheinlich in Zukunft stärker nachgefragt werden. Die Mobilität der Bildungsangebote ist die zweithäufigste Form grenzüberschreitender post-sekundarer Bildungsaktivitäten, die Mobilität der Bildungseinrichtungen ist dagegen noch immer sehr gering. Das zunehmende Angebot an kommerziellen grenzüberschreitenden Bildungsaktivitäten mit offiziellen Abschlüssen, basierend auf der Mobilität von Angeboten und Einrichtungen, ist hauptsächlich darauf zurückzuführen, dass ,traditionelle‘ öffentliche oder private nicht-gewinnorientierte Bildungseinrichtungen zunehmend kommerziell tätig werden. Kommerzielle Angebote nehmen im Asiatisch-Pazifischen Raum vor allem durch Franchise- und Partnerschaftsvereinbarungen immer mehr zu.

In dieser Veröffentlichung zeigen drei regionale Analysen, wie unterschiedlich sich grenzüberschreitende post-sekundare Bildungsaktivitäten innerhalb der Länder und Regionen der OECD entwickelt haben. Im Großen und Ganzen ist die studentische Mobilität in Europa durch politische Rahmenbedingungen vorangetrieben worden, während es im asiatisch-pazifischen Raum die Nachfrage war. Nordamerika hat ausländische Studierende größtenteils einfach magisch angezogen. Überwiegend von den Bildungseinrichtungen selbst angestrebt, wurde die Einkünfte generierende Mobilität von Angeboten und Einrichtungen durch institutionelle Rahmenbedingungen erleichtert, die den Hochschuleinrichtungen grundlegende Autonomie gewährten. Hinzu kam die von den aufnehmenden Ländern verfolgte Politik.

Hinter diesen Entwicklungen stehen vier unterschiedliche Ansätze zur grenzüberschreitenden Bildung, die sich nicht unbedingt gegenseitig ausschließen - gegenseitiges Verständnis, die Migration von qualifizierten Arbeitskräften, die Generierung von Einkünften und der Aufbau von Kompetenzen bilden den jeweiligen Fokus. Während die akademischen, kulturellen, politischen und langfristigen ökonomischen Gründe des Ansatzes des 
gegenseitigen Verständnisses auch weiterhin eine gemeinsame Basis für alle Länder darstellen, nutzen einige Länder grenzüberschreitende Bildungsaktivitäten als Mittel, um qualifizierte Arbeitskräfte für ihre Wissensgesellschaft zu gewinnen und manchmal auch zusätzlich um Exporterlöse im Bildungsbereich zu generieren. Andererseits nutzen aufstrebende Volkswirtschaften den Import von grenzüberschreitenden Bildungsaktivitäten auch, um Kompetenzen im Hochschulbereich aufzubauen sowie ganz allgemein zur wirtschaftlichen Entwicklung.

Das Wachstum der grenzüberschreitenden Bildungsaktivitäten und ihre Vielfalt konfrontieren die Regierungen und Hochschuleinrichtungen der OECD mit einer Vielzahl von Fragen. Werden die jüngsten Entwicklungstendenzen der grenzüberschreitenden Bildungsaktivitäten zu einer Umstrukturierung der Hochschul- und post-sekundaren Bildungssysteme in der OECD führen? Können sie dabei helfen, die Vielfalt und Flexibilität des Bildungsangebots zu verbessern und die Kosten post-sekundarer Bildung für Studierende und Regierungen zu senken? Ist die Liberalisierung eine Lösung für die zunehmende Bedeutung der privaten Bildungsangebote und für die steigende Nachfrage nach post-sekundaren Bildungsangeboten? Welche wichtigen politischen Strategien und Fragen werden sich aus diesen neuen Herausforderungen ergeben?

Grenzüberschreitende Bildungsaktivitäten sind eine wichtige Quelle für Exporterlöse und sind Teil der Verhandlungen über das Allgemeine Abkommen über Handel mit Dienstleistungen (General Agreement on Trade in Services, GATS). Die Veröffentlichung untersucht die möglichen Auswirkungen dieses Abkommens auf die staatliche Finanzierung, auf Subventionen und die Qualität des Bildungsangebots, zeigt aber gleichzeitig, dass grenzüberschreitende post-sekundare Bildungsaktivitäten auch bekannte bildungspolitische Fragen hinsichtlich Qualität, Zugang und Chancengleichheit, Kosten und dem Beitrag der Bildung zum Wirtschaftswachstum aufwerfen. Diese Fragen werden analysiert und bildungspolitische Empfehlungen gegeben, um die Vorteile der grenzüberschreitenden Bildungsaktivitäten zu nutzen, während gleichzeitig ihre Risiken vermieden werden.

\section{Ergebnisse und Erläuterungen}

\section{Entwicklung der Mobilität Studierender}

Im Jahr 2002 waren I,9 Millionen Studierende außerhalb ihres Heimatlandes eingeschrieben, von diesen studierten I,78 Millionen (bzw. 94 Prozent) im OECD-Gebiet. Nach vorliegenden Daten stellt dies eine Zunahme der Gesamtmobilität Studierender von I5 Prozent gegenüber dem Vorjahr dar.

Betrachtet man ausschließlich die OECD-Länder, so erlaubt dies einen längerfristigen Vergleich und macht die Entwicklungen der letzten fünf Jahre sichtbar. Seit 1998 ist die absolute Zahl ausländischer Studierender im OECD-Gebiet um 34,2 Prozent angestiegen, dies entspricht einem durchschnittlichen Wachstum von 7,6 Prozent pro Jahr (Tab. C3.6).
2002 waren 1,9 Millionen Studierende außerhalb ihres Heimatlandes eingeschrieben, .... ... was einen Anstieg um 34 Prozent gegenüber 1998 darstellt. 
Mehr als sieben von zehn Studierenden im Ausland konzentrieren sich auf nur fünf OECD-Länder.
Nicht alle ausländischen

Studierenden sind mit der speziellen Absicht zu studieren in das Gastland gekommen.

Abbildung C3.2

\section{Verteillung der ausländischen Studierenden nach Studienland}

Die große Mehrzahl ausländischer Studierender im OECD-Gebiet und anderen OECD-Partnerländern, für die entsprechende Daten vorliegen, ist in einer relativ geringen Zahl von OECD-Ländern eingeschrieben. Mit 30 Prozent aller ausländischen Studierenden sind die Vereinigten Staaten das größte Aufnahmeland (in absoluten Zahlen), gefolgt vom Vereinigten Königreich und Deutschland (jeweils 12 Prozent), Australien (Io Prozent) sowie Frankreich (9 Prozent). Zusammen nehmen diese fünf Gastländer fast 73 Prozent aller ausländischen Studierenden auf (Abb. C3.2).

Bemerkenswert ist bei diesen fünf führenden Aufnahmeländern, dass Australien im Laufe eines Jahres seinen Anteil an allen Auslandsstudierenden um 2, I Prozentpunkte gesteigert hat. Dies bedeutet in absoluten Zahlen einen Anstieg von fast 59.000 zusätzlichen ausländischen Studierenden (s. Indikator $C_{3}$ in Bildung auf einen Blick 2003).

Im Sinne dieses Indikators gilt derjenige als ausländischer Studierender, der nicht die Staatsangehörigkeit seines Studienlandes besitzt. In den meisten Ländern konnten die ausländischen Studierenden, die aufgrund einer früheren Zuwanderung (bzw. der Zuwanderung mit den Eltern) in diesem Land ihren Aufenthalt haben, nicht von denen unterschieden werden, die speziell zu Bildungszwecken einreisten. Dies führt zu einer überhöhten Anzahl ausländischer Studierender in denjenigen Ländern, die vergleichsweise strenge Einbürgerungsgesetze haben.

Verteilung ausländischer Studierender im Tertiärbereich nach Zielland (2002)

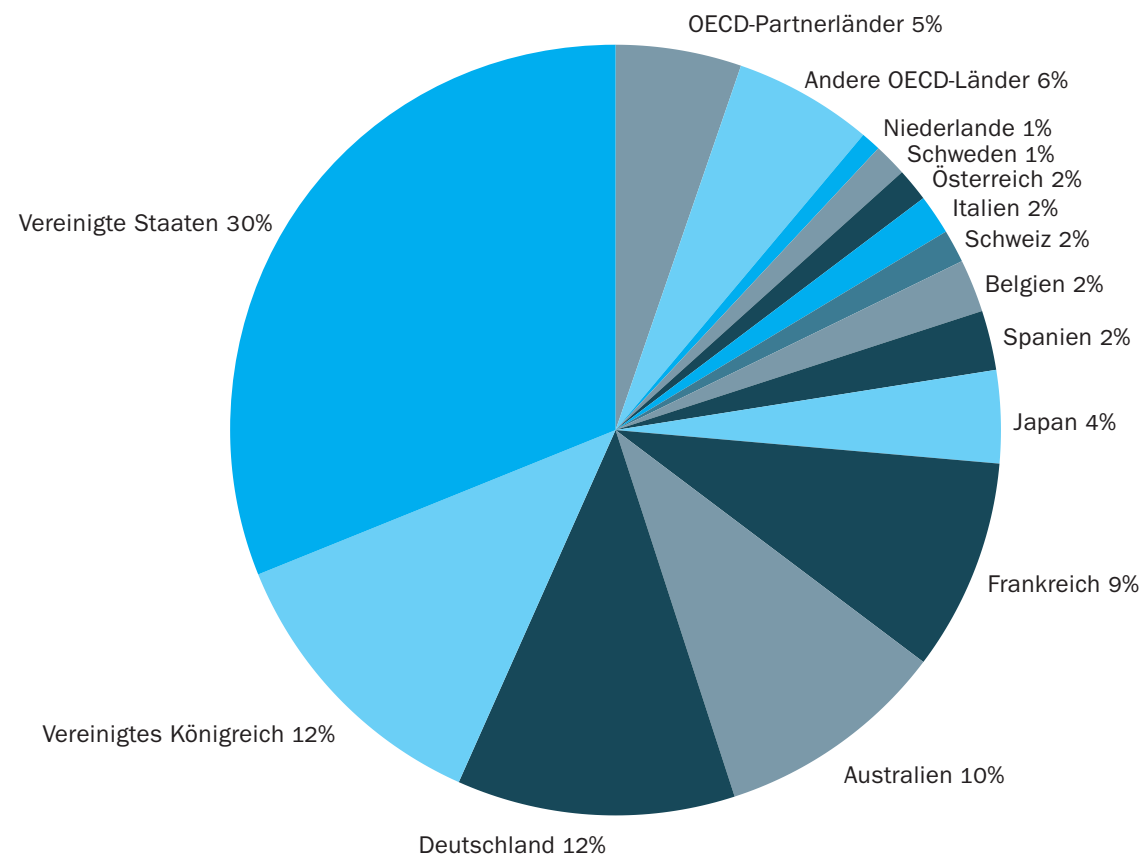

Quelle: OECD. Hinweise s. Anhang 3 unter www.oecd.org/edu/eag2004. 
So ist beispielsweise Deutschland eines der aufnahmestärksten Gastländer, aber nur ungefähr 69 Prozent aller an Bildungseinrichtungen des Tertiärbereich A eingeschriebenen ausländischen Studierenden kommt tatsächlich aus dem Ausland. Dies ist darauf zurückzuführen, dass eine beträchtliche Zahl von ,einheimischen Ausländern', hauptsächlich Kinder von Gastarbeitern, im Sinne dieses Indikators als ,Ausländer' gelten, obwohl sie in Deutschland aufgewachsen sind und dort Daueraufenthaltsrecht genießen.

Außerdem gehören zu den ausländischen Studieren auch einige, die ein Fernstudium durchführen, sie sind im engsten Sinn des Wortes nicht als mobile Studierende zu bezeichnen. Insofern ist bei der Interpretation der Daten zu der Mobilität Studierender Vorsicht angebracht (zu der landespezifischen Definition und Erfassung von ausländischen Studierenden s. Anhang 3 unter www.oecd.org/eduleag2004).

Die Landessprache ist bei der Auswahl des Landes für ein Auslandsstudium entscheidend. Sowohl absolut als auch relativ gesehen, sind diejenigen Länder die wichtigsten Aufnahmeländer für ausländische Studierende, deren Sprache weit verbreitet ist (z. B. Englisch, Französisch, Deutsch).

Die Dominanz englischsprachiger Länder wie Australien, dem Vereinigten Königreich und den Vereinigten Staaten (in absoluten Zahlen) könnte größtenteils darauf zurückzuführen sein, dass auslandsinteressierte Studierende im Heimatland höchstwahrscheinlich Englisch gelernt haben. Es gibt jetzt sogar immer mehr Bildungseinrichtungen in nicht-englischsprachigen Ländern, die Studiengänge in Englisch anbieten, um für ausländische Studierende attraktiv zu sein. Dies trifft insbesondere in den nordischen Ländern zu. Diese relativ neue Art des Bildungsangebots könnte den relativ starken Anstieg des Prozentsatzes (zwischen 50 und 70 Prozent) der zwischen 1998 und 2002 in Island, Norwegen und Schweden eingeschriebenen ausländischen Studierenden im Index erklären (Tab. C3.I).

\section{Anteil der ausländischen Studierenden, nach Heimatländern}

Anders als in früheren Jahren ist der Anstieg der Gesamtzahl der im Ausland Studierenden im Jahr 2002 mit einer Veränderung der geographischen Zusammensetzung der im Ausland Studierenden verbunden.

2002 stellten die asiatischen Studierenden mit 45 Prozent der Gesamtzahl die größte Gruppe der ausländischen Studierenden in denjenigen OECD-Ländern und -Partnerländern dar, die mit Daten vertreten sind. Ihnen folgen die Europäer (30 Prozent), darunter insbesondere EU-Bürger (Ig Prozent). II Prozent aller im Ausland Studierenden kommen aus Afrika, während nur 6 Prozent aus Nordamerika kommen. Ganz am Ende der Liste folgt Südamerika mit weniger als 4 Prozent aller ausländischen Studierenden. Insgesamt stammen 38 Prozent aller in den mit Daten vertretenen OECD-Ländern und -Partnerländern eingeschriebenen ausländischen Studierenden aus einem OECD-Land (Tab. C3.2).

Zwischen 200I und 2002 ist der Anteil der asiatischen Studierenden an den ausländischen Studierenden signifikant um 3 Prozentpunkte angestiegen. Dagegen ist der Anteil europäischer Studierender von 33 auf 30 Prozent der
Die Unterrichtssprache ist ein ausschlaggebender Faktor bei der Auswahl des Landes für ein Auslandsstudium.

Die Entwicklung der geographischen Zusammensetzung der im Ausland Studierenden zeigt, dass die Mobilität unter den asiatischen Studierenden stärker zunimmt. 
Deutschland, Frankreich,

Griechenland, Japan, Korea und die Türkei entsenden die meisten der im Ausland Studierenden aus OECDLändern, ...

...während unter den ausländischen Studierenden, die aus OECD-Partnerländern kommen, die Studierenden aus China, Indien und Südostasien am stärksten vertreten sind.

Der Prozentsatz der in den OECD-Ländern eingeschriebenen ausländischen Studierenden reicht von weniger als 1 bis zu fast 18 Prozent.
Gesamtzahl gesunken. Diese Entwicklung lässt vermuten, dass die Nachfrage nach einem Auslandsstudium in Asien schneller gewachsen ist als in Europa (s. Indikator $\mathrm{C}_{3}$ in Bildung aufeinen Blick 2003).

Auch wenn man ausschließlich die OECD-Länder betrachtet, dominieren die Asiaten und Europäer merklich unter den im Ausland Studierenden. Hierbei stellen die koreanischen und die japanischen Studierenden mit 4,4 und 3,3 Prozent aller ausländischen Studierenden den größten Anteil, gefolgt von den Studierenden aus Deutschland (3,0 Prozent), Frankreich (2,7 Prozent), Griechenland (2,6 Prozent) und der Türkei (2,5 Prozent). Zusammengenommen stellen diese Länder I9 Prozent aller eingeschriebenen ausländischen Studierenden in den OECD-Ländern und -Partnerländern, die Daten meldeten (Tab. C3.2).

Betrachtet man die ausländischen Studierenden, die aus OECD-Partnerländern stammen, so kommen die weitaus meisten aus China, mit 9,6 Prozent aller ausländischen Studierenden (ohne weitere I,6 Prozent aus Hongkong). Die nächstgrößten Gruppen stellen Indien (4,7 Prozent), Marokko (2,7 Prozent), Malaysia (2,o Prozent) und Indonesien (I,9 Prozent). Weitere 2,5 Prozent aller ausländischen Studierenden kommen aus Singapur oder Thailand in Südostasien. (Daten s. Anhang 3 unter www.oecd.org/eduleag2004).

Der internationale Handel, finanzielle, wirtschaftliche und historische Verbindungen spielen bei der Mobilität der Studierenden eine wichtige Rolle. So könnte beispielsweise die regionale wirtschaftliche Integration durch Abkommen und Organisationen wie Europäische Union, NAFTA, ASEAN und APEC die Mobilität der Studierenden beeinflussen, indem sie ihr Interesse an den Kulturen und Sprachen der Partnerländer sowie der Entwicklung bilateraler und multilateraler Netzwerke weckt. Einige Regierungen haben die internationale Mobilität Studierender ausdrücklich zum integralen Bestandteil ihrer sozio-ökonomischen Entwicklungsstrategien erklärt. So haben beispielsweise verschiedene Staaten im asiatisch-pazifischen Raum wie Australien, Japan und Neuseeland für ihre tertiären Bildungseinrichtungen Maßnahmen ergriffen, um ausländische Studierende zum Studium an ihren höheren Bildungseinrichtungen zu gewinnen, häufig um zusätzliche Einnahmen zu generieren, zumindest aber als kostendeckende Maßnahme.

Anteil ausländischer Studierender an der Gesamtzahl der Studierenden Vorstehend wurde die Verteilung der absoluten Anzahl der ausländischen Studierenden nach Herkunfts- und Gastland analysiert. Die Größe des jeweiligen nationalen Tertiärbereichs kann u. a. dadurch erfasst werden, dass man die Gesamtzahl der im Tertiärbereich aufgenommenen Studierenden und der Bürger, die aus diesem Land ins Ausland gehen, in Relation zur gesamten tertiären Bildungsbeteiligung in diesem Land setzt.

Australien und die Schweiz nehmen prozentual zur Gesamtzahl der Studierenden in ihrem Tertiärbereich den größten Prozentsatz ausländischer Studierender auf, mit mehr als I ausländischen Studierenden auf 6 eingeschriebene Studierende. Relativ gesehen ist der Anteil ausländischer Studierender mit Io bis I3 Prozent der inländischen Einschreibungen auch in Belgien, Deutschland, Frankreich, Österreich und dem Vereinigten Königreich beachtlich. Dagegen bleibt der 
Anteil ausländischer Studierender in Griechenland, Italien, Japan, Korea, Mexiko, Polen, der Slowakischen Republik und der Türkei unter 2 Prozent (Abb. C3.I).

Im Vergleich zu den OECD-Ländern nehmen die am World Education Indicators-Programm beteiligten OECD-Partnerländer im Verhältnis zu ihrer Größe nur eine verschwindend geringe Zahl von ausländischen Studierenden auf. Ausnahmen hiervon bilden lediglich Jordanien und Malaysia, wo der Anteil ausländischer Studierender bei 2,7 bzW. 3, o Prozent aller Studierenden liegt (Tab. C3.I).

In einigen OECD-Ländern ist der Anteil der ihre Bildungseinrichtungen besuchenden ausländischen Studierenden im Vergleich zu 1998 erheblich angestiegen. Diese Zunahme ist in Island, Korea, Norwegen, Schweden, Spanien und der Tschechischen Republik mit einem Index der Veränderung von ungefähr I50 oder darüber besonders auffallend.

Diese zunehmende Internationalisierung gilt auch für einige der im Verhältnis zur ihrer Größe wichtigsten Aufnahmeländer wie Australien (mit einem Index der Veränderung von I4I), Deutschland (I24) und vor allem Neuseeland. Hier ist der Anteil ausländischer Studierender von 3,7 auf 9,5 Prozent hochgeschnellt (ein Index von 259), womit Neuseeland jetzt zu den wichtigsten Ländern des internationalen Bildungsmarktes gehört.

\section{Im Ausland Studierende im Verhältnis zur Gesamtzahl der \\ Studierenden}

Man kann anhand des Anteils der im Ausland studierenden Bürger eines Landes an der Gesamtzahl der Studierenden dieses Landes Schätzungen darüber anstellen, in welchem Ausmaß Studierende das Heimatland für ein Auslandsstudium verlassen. Diese Angabe bezieht sich lediglich auf die in anderen OECD-Ländern und -Partnerländern Studierenden, sofern diese Länder Daten gemeldet haben. Somit sind die Studierenden in Ländern, die keine Daten über ausländische Studierende zur Verfügung stellen, in Spalte I der Tabelle CI.3 nicht enthalten. Daher ist wahrscheinlich die Zahl der im Ausland eingeschriebenen Studierenden in diesem Indikator zu niedrig angesetzt. Eine weitere potentielle Fehlerquelle hinsichtlich zu niedrig angesetzter Zahlen könnte die Berechnung des Indikators auf Jahresbasis darstellen, da viele Studierende kein ganzes akademisches Jahr im Ausland verbringen. So verbringt beispielsweise die Mehrzahl der Studierenden, die aus den Vereinigten Staaten ins Ausland gehen, nur maximal ein halbes Jahr dort.

Das Verhältnis der im Ausland eingeschriebenen Studierenden zur Gesamtzahl der Studierenden im Heimatland schwankt sehr stark von unter 2 Prozent in den Vereinigten Staaten (o, 2 Prozent), Australien (o, 5 Prozent), Mexiko (o, 9 Prozent) und dem Vereinigten Königreich (I,2 Prozent), Spanien (I, 5 Prozent) und Japan ( $\mathrm{I}, 6$ Prozent) bis zu ganzen 25 Prozent in Island und sogar 205 Prozent in Luxemburg (s. Tab. C 3.I, Spalte 6). Luxemburg ist jedoch ein Sonderfall, denn dort gibt es nur post-sekundare, nicht-tertiäre Bildungsgänge, bzw. können Studierende dort nur das erste Studienjahr auf Hochschulniveau absolvieren. Da die luxemburgischen Studierenden ihr Studium im Ausland fortsetzen müssen, ist eine große Anzahl im Verhältnis zu den im Inland eingeschriebenen Studierenden im Ausland eingeschrieben.
Obwohl Australien, Deutschland und Neuseeland schon eine recht bedeutende Rolle spielen, werden sie ihre Position auf dem internationalen Bildungsmarkt möglicherweise noch weiter stärken.

Ein relativ großer Anteil der Studierenden aus Griechenland, Island, Irland, Luxemburg und Norwegen studiert im Ausland, während dies nur für relativ wenige Studierende aus Australien, Mexiko und den Vereinigten Staaten zutrifft. 
Im Verhältnis zu ihrer Größe verzeichnen Australien, die Schweiz und das Vereinigte Königreich den stärksten Nettozugang an ausländischen Studierenden.

Eine Reihe von Push- und Pull-Faktoren können zur Erklärung der Charakteristika der Mobilität Studierender beitragen.

Die Nettoaufnahme ausländischer Studierender gibt Hinweise auf den potentiellen Nutzen, den Länder aus dem internationalen Austausch Studierender im Tertiärbereich ziehen können.
Bei den OECD-Partnerländern haben Simbabwe und Jamaika mit 9,8 bzw. ıо, 8 Prozent das höchste Verhältnis der im Ausland eingeschriebenen Studierenden zu den im Inland eingeschriebenen Studierenden.

\section{Saldo des internationalen Austauschs Studierender}

Wenngleich über 544.000 Studierende mehr zum Studium in die Vereinigten Staaten reisen als es US-amerikanische Studierende im Ausland gibt, nehmen andere Länder im Verhältnis zur Größe ihres Tertiärbereichs noch viel mehr ausländische Studierende auf. Der Nettozugang eingeschriebener Studierender, gemessen an der Gesamtzahl der in diesen Ländern im Tertiärbereich eingeschriebenen Studierenden, beträgt in Australien, der Schweiz und dem Vereinigten Königreich zwischen 5,I und 8, I Prozent, (s. Tab. C3.I, Spalte 7). Umgekehrt verzeichnen Griechenland, Island, Norwegen und die Slowakische Republik mit 9,4, 22,I, 5,5 bzw. 7 Prozent der Gesamtbeteiligung im Tertiärbereich den relativ stärksten Nettoabgang von Studierenden. Der Saldo der Bewegungen der Studierenden berücksichtigt nur diejenigen, die aus einem OECDLand oder -Partnerland kommen bzw. in einem solchen Land studieren, das Zahlenmaterial vorlegte. Der absolute Saldo der Länder, die eine erhebliche Zahl an Studierenden aus Ländern aufnehmen bzw. in Länder entsenden, die keine Angaben machten, könnte daher anders aussehen.

Angesichts der vielfältigen Vorteile, die ausländische Studierende ihren Gastländern bringen können, ist es nicht unwichtig herauszufinden, wie sich die Mobilität erhöhen lässt.

Die oben angeführten Charakteristika studentischer Mobilität können mit einer Reihe von Push- und Pull-Faktoren in Zusammenhang gebracht werden, wie z. B. Sprachschwierigkeiten, dem akademischen Ruf bestimmter Bildungseinrichtungen oder Bildungsgänge, der Flexibilität der Studiengänge im Heimatland hinsichtlich der Anrechnung von Auslandsaufenthalten auf die Prüfungsanforderungen, dem eingeschränkten Angebot im Tertiärbereich im Heimatland, restriktiven Zulassungspraktiken der Hochschulen im Heimatland, finanziellen Anreizen und Studiengebühren.

Diese Charakteristika spiegeln auch geografische und historische Beziehungen zwischen den Ländern, zukünftige Beschäftigungschancen, kulturelle Neigungen und die staatliche Politik zur Erleichterung der Anerkennung von Leistungsnachweisen zwischen Heimat- und Gasthochschulen wider. Bei der Wahl einer Bildungseinrichtung ist auch die Transparenz und Flexibilität der Lehrveranstaltungen und der Prüfungsvoraussetzungen entscheidend.

\section{Wirtschaftliche Vorteile der Internationalisierung der Hochschul- ausbildung sowie deren Auswirkungen auf den Handel}

Ein erster direkter Nutzen aus der Aufnahme ausländischer Studierender sind die Einnahmen aus den Studiengebühren und insbesondere der entsprechende Inlandsverbrauch der ausländischen Studierenden, die sich beide in der Leistungsbilanz als Export von Bildungsdienstleistungen niederschlagen. Dieser wirtschaftliche Gewinn ist am größten in denjenigen Gastländern, die gegenüber den ausländischen Studierenden eine Politik der Kostendeckung bei den Studiengebühren verfolgen, während in denjenigen Ländern, die von den aus- 
ländischen Studierenden Unterrichts- bzw. Studiengebühren unterhalb der Selbstkosten für die Bereitstellung der Bildung verlangen, der Nettogewinn vom Ausmaß des Inlandskonsums der ausländischen Studierenden abhängt. In führenden Aufnahmeländern wie Australien und Neuseeland war der Export von Bildungsdienstleistungen 2000/200I der dritt- bzw. viertgrößte Exportfaktor bei den Dienstleistungen, er machte in diesen Ländern I3,I bzW. 8, I Prozent der Gesamtexporte von Dienstleistungen aus (s. Kasten C3.I)

Abgesehen von diesem direkten Vorteil der Internationalisierung der Hochschulausbildung kann es auch indirekte Vorteile geben, z. B. durch einen größeren Kundenkreis für tertiäre Bildung. Denn so entstehen für die Nettoaufnahmeländer Größenvorteile, sie können ihr Angebot an Bildungsgängen erhöhen und/oder ihre Kosten pro Studierenden senken. Dieser Effekt könnte insbesondere für Aufnahmeländer mit einer relativ geringen Bevölkerungszahl von Bedeutung sein (z. B. die Schweiz).

Ferner zwingt das Vorhandensein potentieller ausländischer Kunden (Studierender) die tertiären Bildungseinrichtungen auch dazu, qualitativ hochwertige Studiengänge anzubieten, um sich gegenüber anderen ausländischen Wettbewerbern zu behaupten, was zu einem reaktionsschnellen und kundenorientierten Hochschulsystem beiträgt.

Schließlich kann die Aufnahme ausländischer Studierender bis zu einem gewissen Grad auch einen Technologietransfer bewirken (insbesondere bei weiterführenden Forschungsprogrammen), interkulturelle Kontakte fördern und dazu beitragen, soziale Netzwerke für die Zukunft zu schaffen.

\section{Die Zusammensetzung aufgenommener ausländischer Studierender in den einzelnen Ländern}

In einigen Ländern besucht ein relativ großer Teil der ausländischen Studierenden Bildungsgänge im Tertiärbereich B. Unter den OECD-Ländern zählen hierzu Belgien (44,9 Prozent), Neuseeland (28,5 Prozent) und Korea (I9, 3 Prozent) und außerhalb des OECD-Raums gilt dies in noch größerem Ausmaß für Malaysia (63,9 Prozent).

Im Gegensatz dazu entscheidet sich in anderen Ländern ein großer Prozentsatz der ausländischen Studierenden für eine Einschreibung in den stark theoretisch ausgerichteten weiterführenden Forschungsprogrammen. Dies ist vor allem in Finnland (20 Prozent), Spanien (I9,3 Prozent) und der Schweiz (I8,3 Prozent) der Fall, was vermuten lässt, dass dort attraktive weiterführende Programme für interessierte ausländische Graduierte angeboten werden. In etwas geringerem Maße lässt sich diese Konzentration auch in Schweden (I4,5 Prozent), der Tschechischen Republik (I4,o Prozent), Korea (I3,I Prozent) und dem Vereinigten Königreich (Io Prozent) beobachten. All diese Länder werden vermutlich von einem Technologietransfer durch diese hochqualifizierten ausländischen Studierenden profitieren. Darüber hinaus kann diese Spezialisierung auch zu steigenden Einnahmen aus den Studiengebühren pro ausländischem Studierenden in den Ländern führen, die von ausländischen Studierenden Studiengebühren in voller Höhe verlangen (Tab. C3.4).
Die Zusammensetzung der aufgenommen ausländischen Studierenden ist in den einzelnen Ländern sehr unterschiedlich, was auf unterschiedliche Spezialisierungen im internationalen Bildungsmarkt schließen lässt. 
Die Zusammensetzung aufgenommener ausländischer Studierender nach Studienbereichen lässt Interessensschwerpunkte erkennen.
In Australien wählt jeder fünfte ausländische Studierende (22,I Prozent) ein naturwissenschaftlich ausgerichtetes Fach, in Japan dagegen weniger als einer von fünfzig (I,9 Prozent). In Neuseeland (I5,5 Prozent), dem Vereinigten Königreich (I5,3 Prozent), Deutschland (I4,9 Prozent), Norwegen (I4,7 Prozent), der Schweiz (I4,5 Prozent), Island (I3,6 Prozent) und Schweden (I3,I Prozent) ist ebenfalls ein großer Anteil der ausländischen Studierenden in naturwissenschaftlich ausgerichteten Fächern eingeschrieben.

Abbildung $\mathbf{C 3 . 3}$

Verteilung ausländischer Studierender im Tertiärbereich nach Studienbereichen (2002)

Naturwissenschaften

Ingenieurwesen, Fertigung u. Bauwesen

Gesundheit und Soziales

Agrarwissenschaften

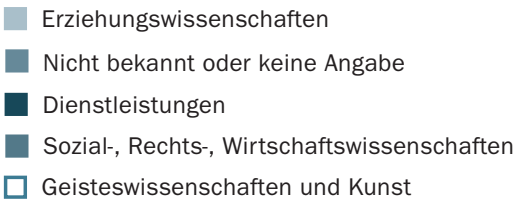

Erziehungswissenschaften

Nicht bekannt oder keine Angabe

Dienstleistungen

Sozial-, Rechts-, Wirtschaftswissenschaften

Geisteswissenschaften und Kunst

$\% \quad 0$

20

40

60

80

100

Finnland

Australien

Deutschland

Ver. Königreich
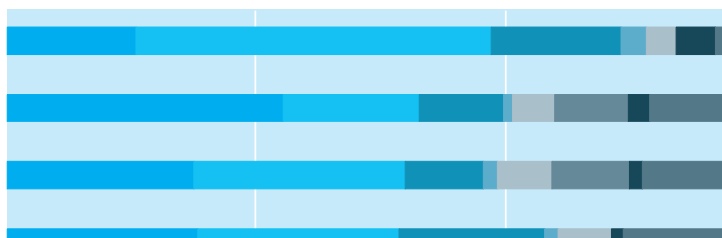

Scheden

Schweiz

Tschechische Rep.

Dänemark

Österreich

Türkei

Norwegen

Neuseeland

Italien

Ungarn

Niederlande

Island

Japan

Slowakische Rep.

Belgien

Polen
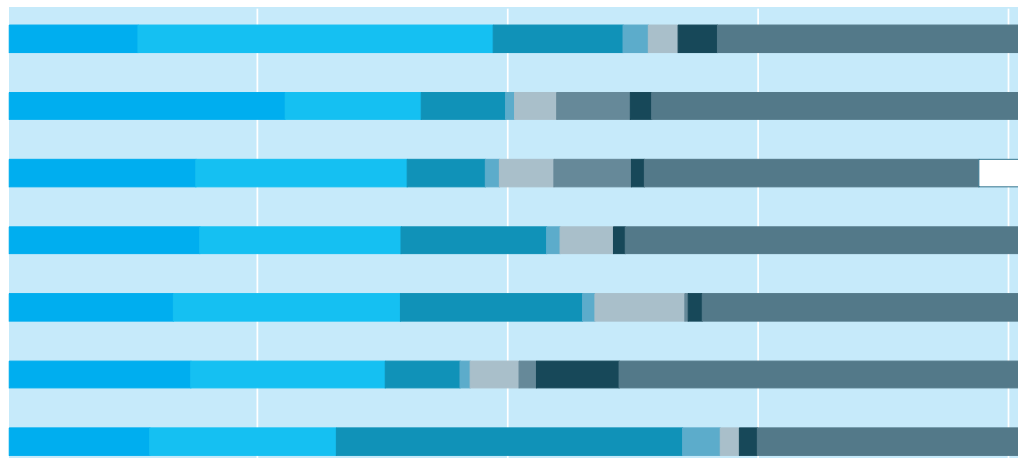

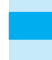
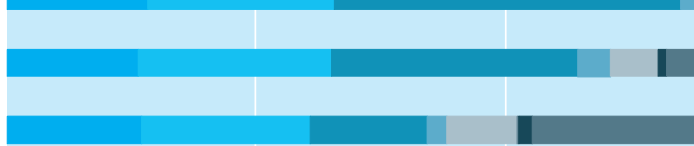

(1)
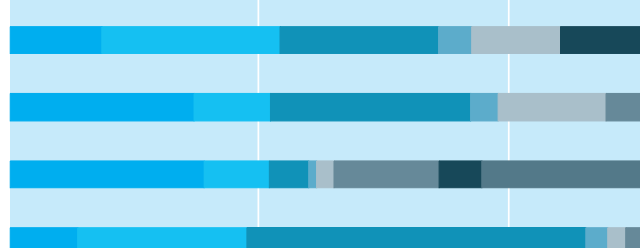

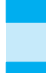

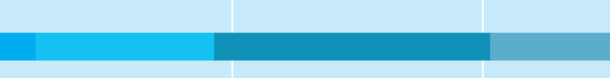

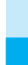
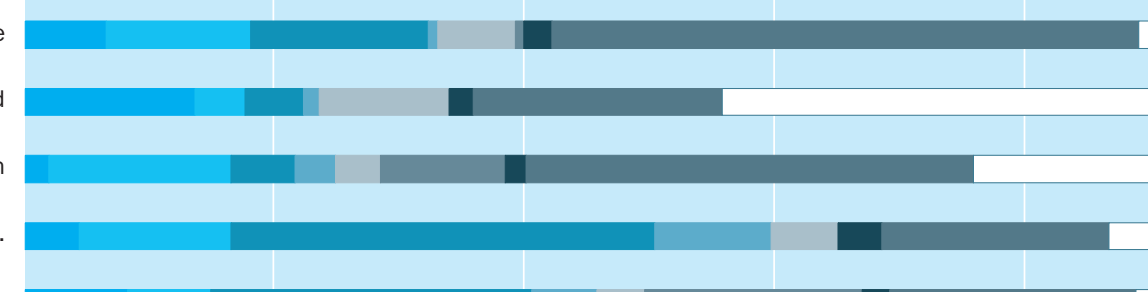

Anordnung der Länder in absteigender Reihenfolge des Anteils ausländischer Studierender, die in Narurwissenschaften, Ingenieurwesen, Fertigung und Bauwesen eingeschrieben sind.

Quelle: OECD. Tabelle C3.5. Hinweise s. Anhang 3 unter www.oecd.org/edu/eag2004. 
Betrachtet man die naturwissenschaftlichen Disziplinen etwas allgemeiner, d. h. zählt man Ingenieurwesen, Fertigung und Bauwesen zu den naturwissenschaftlich ausgerichteten Fächern hinzu, erhält man ein etwas anderes Bild. Denn nun hat Finnland mit 38,7 Prozent den größten Anteil ausländischer Studierender in diesen Studienbereichen. Der Anteil der in naturwissenschaftlich ausgerichteten Fächern oder dem Ingenieurwesen eingeschriebenen ausländischen Studierenden bleibt jedoch hoch in Australien (33,0 Prozent), Deutschland (3I,8 Prozent), dem Vereinigten Königreich (3I,4 Prozent), Schweden (3I,2 Prozent) und der Schweiz (30,0 Prozent). Dagegen sind in Belgien, Polen, Japan und der Slowakischen Republik nur wenige ausländische Studierende in naturwissenschaftlich ausgerichteten Fächern und dem Ingenieurwesen eingeschrieben (Abb. C3.3).

Bemerkenswert ist, dass die meisten Länder, in denen ein großer Anteil ausländischer Studierender in naturwissenschaftlich ausgerichteten Fächern oder dem Ingenieurwesen eingeschrieben ist, Studiengänge in Englisch anbieten. Im Falle Deutschlands könnte der große Anteil ausländischer Studierender in den naturwissenschaftlichen Disziplinen auch ein Ergebnis der traditionellen Stärke des Landes in diesen Bereichen sein.

In den nicht-angelsächsischen Ländern ist dagegen ein großer Anteil der ausländischen Studierenden in den Geisteswissenschaften und Kunst eingeschrieben, was angesichts der Inhalte dieser Bildungsgänge nicht überrascht. Geisteswissenschaften und Kunst werden tatsächlich von 44,3 Prozent der ausländischen Studierenden in Island bevorzugt und von etwa jedem vierten ausländischen Studierenden in Polen (26,5 Prozent), Österreich (24,4 Prozent), Japan (24,2 Prozent) und Deutschland (22,5 Prozent).

Studiengänge im Bereich Sozial-, Wirtschaft- und Rechtswissenschaften sind ebenfalls für eine große Anzahl ausländischer Studierender attraktiv. In Neuseeland und den Niederlanden sind etwa die Hälfte der ausländischen Studierenden in diesen Bereichen eingeschrieben (52,7 bzw. 46,9 Prozent). Auch in der Türkei (42,o Prozent), Australien (40,6 Prozent) und Japan (35,8 Prozent) entscheidet sich ein hoher Prozentsatz der ausländischen Studierenden für die Sozial-, Wirtschaft- und Rechtswissenschaften.

Bei den Studiengängen im Bereich Gesundheit und Soziales hängt die Lage sehr stark von staatlichen Maßnahmen zur Anerkennung von medizinischen Abschlüssen ab. Bildungsgänge im Bereich Gesundheit und Soziales in Ländern der EU und (zum Erhebungszeitpunkt noch) Beitrittsländern sind für viele ausländische Studierende sehr attraktiv. Das gilt besonders für die Slowakische Republik (33,9 Prozent der ausländischen Studierenden), die Tschechische Republik (27,7 Prozent), Italien (27, I Prozent), Belgien (25,6 Prozent) und Ungarn (22, I Prozent). Dies steht in engem Zusammenhang mit den $\mathrm{Zu}$ gangsbeschränkungen, die in vielen europäischen Ländern das inländische Angebot an Bildungsgängen im medizinischen Bereich beschränken. Diese führen zu einer gesteigerten Bildungsnachfrage in anderen EU-Staaten, um diese Zulassungsbeschränkungen zu umgehen, und die Tatsache zu nutzen, dass innerhalb der EU-Staaten medizinische Abschlüsse gemäß der entsprechenden EU-Richtlinie automatisch anerkannt werden. 
Ganz allgemein lässt die Konzentration ausländischer Studierender in bestimmten Fachbereichen des jeweiligen Gastlandes attraktive Bildungsangebote erkennen, die zahlreiche ausländische Studierende anziehen. Diese Anziehungskraft beruht auf mehreren Faktoren sowohl beim Angebot als auch bei der Nachfrage.

Auf der Angebotsseite bieten einige Gastländer ,Kompetenz-Center‘ bzw. traditionelle wissenschaftliche Fachgebiete, die Studierende aus anderen Ländern in großer Zahl anziehen (z. B. Finnland und Deutschland bei den naturwissenschaftlich ausgerichteten Fächern und im Ingenieurwesen). Bei Geisteswissenschaften und Kunst haben einige Länder bei bestimmten Bildungsangeboten ebenfalls ein Art natürliches Monopol. Dies gilt ganz besonders für linguistische und kulturelle Studien, (z. B. Deutschland, Österreich, Island, Japan).

Auf der Nachfrageseite können bestimmte Merkmale der ausländischen Studierenden erklären, weshalb sie sich auf bestimmte Studienbereiche konzentrieren. Studierende in wissenschaftlich ausgerichteten Fächern beherrschen in der Regel seltener mehrere Fremdsprachen, weshalb sie möglicherweise häufiger in Ländern studieren, die Studiengänge in Englisch anbieten, und seltener in Japan. Ebenso kann die Nachfrage vieler asiatischer Studierender nach einer betriebswirtschaftlichen Ausbildung erklären, weshalb die Anzahl ausländischer Studierender im Bereich Sozial-, Wirtschaft- und Rechtswissenschaften im nahegelegenen Australien und Neuseeland so hoch ist. Und schließlich führen die EU-Bestimmungen zur Anerkennung von medizinischen Abschlüssen zur großen Anzahl ausländischer Studierender im Bereich Gesundheit und Soziales in EU-Staaten.

\section{Definitionen und angewandte Methodik}

Die Daten beziehen sich auf das akademische Jahr 2001/2002 und beruhen auf der alljährlich von der $O E C D$ durchgeführten UOE-Datenerhebung zur Bildungsstatistik (s. Anhang 3).
Studierende gelten als ausländische Studierende, wenn sie nicht Staatsangehörige des Landes sind, für das die Daten erhoben werden. Diese Klassifikation ist zwar pragmatisch und operational, kann jedoch aufgrund der unterschiedlichen nationalen Politiken zur Einbürgerung von Migranten und der Tatsache, dass einige Länder die Anzahl der eingereisten und der aufenthaltsberechtigten ausländischen Studierenden nicht separat angeben können, zu Inkonsistenzen führen. Daher wird in den Ländern, in denen eine strenge Einbürgerungspolitik verfolgt wird und nicht zwischen ausländischen Studierenden mit und ohne ständiger Aufenthaltsgenehmigung unterschieden werden kann, die Anzahl der ausländischen Studierenden im Vergleich zu den Ländern, in denen Einwanderer leichter die Staatsbürgerschaft erwerben können, $\mathrm{zu}$ hoch angesetzt. Insofern ist bei allen bilateralen Vergleichen der Angaben zu ausländischen Studierenden Vorsicht angebracht, da sich die Länder in der Definition und Erfassung der bei ihnen studierenden Ausländer unterscheiden (s. Anhang 3 unter www.oecd.org/eduleag2004).

Die Daten über ausländische Studierende wurden von den Gastländern erhoben und beziehen sich somit auf die Studierenden, die in das betreffende Land gekommen sind und nicht auf diejenigen, die aus diesem Land ins Ausland gehen. In diesem Indikator werden als aufnehmende Länder sämtliche OECD- 
Länder mit Ausnahme von Kanada, Luxemburg und Portugal sowie die folgenden OECD-Partnerländer erfasst: Argentinien, Chile, Indien, Indonesien, Jordanien, Malaysia, die Philippinen, die Russische Föderation, Thailand und Tunesien. In diesem Indikator bleiben Studierende in jenen OECD-Ländern unberücksichtigt, die keine Angaben über die Anzahl der bei ihnen studierenden Ausländer machten sowie diejenigen, die in anderen als den genannten OECD-Partnerländern studieren. Daher ist bei allen Aussagen über die Zahl Studierender, die ein Auslandsstudium absolvieren, deren tatsächliche Zahl zu niedrig angesetzt. Dies gilt insbesondere für Länder, die viele Studierende in Länder, die keine Zahlen vorlegen, entsenden.

Die Daten über die Anzahl ausländischer Studierender wurden mit der gleichen Methode gewonnen wie die über die Gesamtzahl der Studierenden, d. h. es werden die Unterlagen über die regulär in einem Bildungsgang eingeschriebenen Studierenden zugrunde gelegt. Üblicherweise wurden die in- und die ausländischen Studierenden an einem bestimmten Tag oder innerhalb eines bestimmten Zeitraums während des Jahres gezählt. Damit lässt sich der Anteil der ausländischen Studierenden bestimmen, die in einem Bildungssystem eingeschrieben sind, aber die tatsächliche Zahl von Personen, die an einem internationalen Austausch teilgenommen haben, kann viel höher liegen, da viele Studierende für weniger als ein ganzes akademisches Jahr ins Ausland gehen oder an einem Austauschprogramm teilnehmen, das keine Einschreibung bei der ausländischen Bildungseinrichtung voraussetzt (z. B. einige Austauschprogramme zwischen Hochschulen sowie kurze Aufenthalte im Rahmen weiterführender Forschungsprogramme).

Tabelle $\mathrm{C}_{3}$.I zeigt den Anteil eingeschriebener ausländischer Studierender an der Gesamtzahl der eingeschriebenen Studierenden im Gastland bzw. im Heimatland (Ursprungsland). Die als Nenner verwendete Zahl für die Gesamtzahl der eingeschriebenen Studierenden umfasst alle in- und ausländischen Studierenden in diesem Land und schließt die Staatsangehörigen dieses Landes, die im Ausland studieren, aus.

Der Index des Umfangs der Aufnahme ausländischer Studierender in Tabelle C3.I vergleicht die Zahl der ausländischen Studierenden als Prozentsatz der inländischen Einschreibungen mit der Durchschnittszahl für die OECD-Länder. Dadurch kann der Maßstab für den Umfang der Aufnahme ausländischer Studierender anhand der Größe des tertiären Bildungsbereichs präzisiert werden. Eine Indexzahl über (unter) I bedeutet, dass anteilsmäßig an der Gesamtzahl der Studierenden mehr (weniger) ausländische Studierende aufgenommen wurden als im OECD-Mittel. Andererseits kann man diesen Index auch als einen Vergleich interpretieren, und zwar zwischen dem Gewicht eines Landes hinsichtlich der Aufnahme ausländischer Studierender aus den OECD-Ländern und seinem Gewicht hinsichtlich der Studierendenzahlen in der OECD. In diesem Fall bedeutet eine Indexzahl über (unter) I, dass dieses Land mehr (weniger) ausländische Studierende aufnimmt als anhand seines Gewichts für die Gesamtzahl der Studierenden innerhalb der OECD zu vermuten wäre.

Die Tabellen $\mathrm{C}_{3.2}, \mathrm{C}_{3} .4$ und $\mathrm{C}_{3.5}$ zeigen die Aufteilung der in einem Bildungssystem eingeschriebenen ausländischen Studierenden nach deren jeweiligem 
Herkunftsland (Tab. C3.2), nach Bildungsbereich und Art des Studiums (Tab. $\mathrm{C}_{3.4}$ ) und nach dem Bildungsbereich, in dem sie eingeschrieben sind (Tab. $\mathrm{C}_{3} \cdot 5$ ).

Tabelle $\mathrm{C}_{3} \cdot 3$ zeigt die Aufteilung der im Ausland Studierenden eines jeden Landes nach Studienland. Wie oben erwähnt, umfasst die als Nenner verwendete Zahl für die Gesamtzahl der eingeschriebenen Studierenden nur die Studierenden, die in Ländern eingeschrieben sind, die Daten gemeldet haben. Daher können die sich daraus ergebenden Verhältnisse verzerrt sein und für die Länder zu hoch angesetzt sein, die eine große Anzahl Studierender in Länder entsenden, die keine Daten melden.

Tabelle $\mathrm{C}_{3} .6$ zeigt Entwicklungen der absoluten Zahl ausländischer Studierender, die OECD-Länder und -Partnerländer meldeten, und Index-Veränderungen zwischen 1998 und 2002 sowie zwischen 2001 und 2002. Es ist zu berücksichtigen, dass diese Zahlen auf der Zahl der ausländischen Studierenden beruht, die in Ländern eingeschrieben sind, die Daten an die OECD melden. Die Anzahl dieser Länder hat sich im Laufe der Zeit erhöht, daher sind die Zahlen nicht unbedingt vergleichbar und nur mit Vorsicht zu interpretieren. 
Tabelle C3.1

Austausch von Studierenden im Tertiärbereich (2002)

Eingeschriebene ausländische Studierende als Prozentsatz aller Studierenden (aus- und inländische), und Austausch von Studierenden als Prozentsatz der Gesamtstudierendenzahl

Bedeutuno der Spalte (1):12.7 Prozent der Studierenden im Tertiärbereich in Österreich sind ausländische Studierende (aus der ganzen Welt).

Bedeutung der Spalte (4): In Australien sind 3,1-mal mehr ausländische Studierende eingeschrieben als im OECD-Durchschnitt, während in Finnland der Anteil ausländischer Studierender das 0,4-fache des OECD-Durchschnitts beträgt.

Bedeutung der Spalte (5): Ausländische Studierende aus anderen Ländern, die Angaben zu ausländischen Studierenden machen, stellen in Österreich 8, 9 Prozent aller Studierenden im Tertiärbereich.

Bedeutung der Spalte (6): 5,5 Prozent aller Studierenden im Tertiärbereich in Österreich studieren in anderen Ländern, die Angaben zu ausländischen Studierenden machen.

Spalte (7) enthält die Differenz zwischen Spalte (5) und Spalte (6)

\begin{tabular}{|c|c|c|c|c|c|c|c|c|c|}
\hline & \multicolumn{3}{|c|}{$\begin{array}{l}\text { Ausländische Studierende aus der ganzen Welt als } \\
\text { Prozentsatz aller Studierenden (aus- und inländisch) }\end{array}$} & \multirow{2}{*}{$\begin{array}{c}\text { Index der } \\
\text { Intensität }{ }^{1} \text { der } \\
\text { Aufnahme } \\
\text { ausländischer } \\
\text { Studierender im } \\
\text { Verhältnis zum } \\
\text { OECD-Referenz- } \\
\text { gebiet }\end{array}$} & \multicolumn{3}{|c|}{$\begin{array}{l}\text { Austausch mit Studierenden aus anderen Ländern }{ }^{2} \text {, die } \\
\text { Angaben zu ausI. Studierenden machen (im Verhältnis } \\
\text { zur Gesamtzahl der Studierenden im Tertiärbereich) }\end{array}$} & \multicolumn{2}{|c|}{$\begin{array}{l}\text { Ausländische Studierende } \\
\text { nach Geschlecht }\end{array}$} \\
\hline & 2002 & (2) & $\begin{array}{l}\text { Index der } \\
\text { Veränderung } \\
(1998=100)\end{array}$ & & $\begin{array}{l}\text { Aufnahme Studie- } \\
\text { render aus ande- } \\
\text { ren Ländern, die } \\
\text { Angaben zu ausl. } \\
\text { Studierenden } \\
\text { machen } \\
\text { (5) }\end{array}$ & $\begin{array}{l}\text { Studierende des } \\
\text { jeweiligen Lan- } \\
\text { des, die in einem } \\
\text { anderen Land, } \\
\text { das Angaben zu } \\
\text { ausl. Studieren- } \\
\text { den macht, einge- } \\
\text { schrieben sind } \\
\text { (6) }\end{array}$ & $\begin{array}{c}\text { Netto-Aufnahme } \\
\text { Studierender aus } \\
\text { Ländern, die } \\
\text { Angaben zu ausl. } \\
\text { Studierenden } \\
\text { machen } \\
\text { (7) }\end{array}$ & \% Männer & \% Frauen \\
\hline \multicolumn{10}{|l|}{ OECD-Länder } \\
\hline Australien & 17,7 & 12,6 & 141 & 3,1 & 8,6 & 0,5 & 8,1 & 52,7 & 47,3 \\
\hline Österreich & 12,7 & 11,5 & 111 & 2,2 & 8,9 & 5,5 & 3,5 & 48,2 & 51,8 \\
\hline Belgien & 11,0 & $\mathrm{~m}$ & $\mathrm{~m}$ & 1,9 & 6,2 & 2,8 & 3,3 & 50,5 & 49,5 \\
\hline Kanada & $\mathrm{m}$ & 2,8 & $\mathrm{~m}$ & $\mathrm{~m}$ & $\mathrm{~m}$ & $\mathrm{~m}$ & $\mathrm{~m}$ & $\mathrm{~m}$ & $\mathrm{~m}$ \\
\hline Tschechische Rep. & 3,4 & 1,9 & 181 & 0,6 & 2,1 & 2,1 & $\mathrm{n}$ & 52,6 & 47,4 \\
\hline Dänemark & 7,4 & 6,0 & 123 & 1,3 & 3,0 & 3,3 & $-0,4$ & 45,2 & 54,8 \\
\hline Finnland & 2,4 & 1,7 & 138 & 0,4 & 1,2 & 3,5 & $-2,3$ & 55,1 & 44,9 \\
\hline Frankreich & 10,0 & 7,7 & 130 & 1,8 & 2,4 & 2,5 & $-0,1$ & $\mathrm{~m}$ & $\mathrm{~m}$ \\
\hline Deutschland $^{3}$ & 10,1 & 8,2 & 124 & 1,8 & 5,6 & 2,6 & 3,0 & 51,2 & 48,8 \\
\hline Griechenland ${ }^{4}$ & 1,6 & $\mathrm{~m}$ & $\mathrm{~m}$ & 0,3 & 0,1 & 9,5 & $-9,4$ & $\mathrm{~m}$ & $\mathrm{~m}$ \\
\hline Ungarn & 3,3 & 2,6 & 128 & 0,6 & 1,3 & 2,2 & $-0,9$ & 54,4 & 45,6 \\
\hline Island & 4,1 & 2,4 & 170 & 0,7 & 3,3 & 25,4 & $-22,1$ & 36,4 & 63,6 \\
\hline Irland & 5,2 & 4,8 & 108 & 0,9 & 3,8 & 8,6 & $-4,8$ & 47,9 & 52,1 \\
\hline Italien & 1,5 & 1,2 & 124 & 0,3 & 0,7 & 2,2 & $-1,5$ & 43,9 & 56,1 \\
\hline Japan & 1,9 & 1,4 & 134 & 0,3 & 0,7 & 1,6 & $-0,9$ & 53,2 & 46,8 \\
\hline Korea & 0,2 & 0,1 & 160 & $\mathrm{n}$ & $\mathrm{n}$ & 2,6 & $-2,6$ & 55,0 & 45,0 \\
\hline Luxemburg & $\mathrm{m}$ & 30,5 & m & $\mathrm{m}$ & $\mathrm{m}$ & 204,8 & $\mathrm{~m}$ & $\mathrm{~m}$ & $\mathrm{~m}$ \\
\hline Mexiko & 0,1 & $\mathrm{~m}$ & $\mathrm{~m}$ & $\mathrm{n}$ & $\mathrm{n}$ & 0,9 & $-0,8$ & $\mathrm{~m}$ & $\mathrm{~m}$ \\
\hline Niederlande $^{3}$ & 3,7 & $\mathrm{~m}$ & $\mathrm{~m}$ & 0,6 & 2,3 & 2,3 & $n$ & 48,8 & 51,2 \\
\hline Neuseeland & 9,5 & 3,7 & 259 & 1,7 & 3,2 & 3,9 & $-0,7$ & 49,5 & 50,5 \\
\hline Norwegen & 4,8 & 3,2 & 152 & 0,8 & 2,6 & 8,0 & $-5,5$ & 44,4 & 55,6 \\
\hline Polen ${ }^{3}$ & 0,4 & 0,5 & 85 & 0,1 & 0,1 & 1,2 & $-1,1$ & 46,1 & 53,6 \\
\hline Portugal & $\mathrm{m}$ & $\mathrm{m}$ & $\mathrm{m}$ & $\mathrm{m}$ & $\mathrm{m}$ & 2,8 & $\mathrm{~m}$ & $\mathrm{~m}$ & $\mathrm{~m}$ \\
\hline Slowakische Rep. & 1,1 & $\mathrm{~m}$ & $\mathrm{~m}$ & 0,2 & 0,4 & 7,4 & $-7,0$ & 59,0 & 41,0 \\
\hline Spanien & 2,4 & 1,7 & 147 & 0,4 & 1,6 & 1,5 & 0,1 & 43,9 & 56,1 \\
\hline Schweden & 7,5 & 4,5 & 167 & 1,0 & 4,6 & 4,0 & 0,6 & 43,8 & 56,2 \\
\hline Schweiz & 17,2 & 15,9 & 108 & 3,0 & 12,3 & 4,8 & 7,5 & 56,6 & 43,4 \\
\hline Türkei ${ }^{3}$ & 1,0 & 1,3 & 74 & 0,2 & 0,2 & 2,8 & $-2,7$ & 71,6 & 28,4 \\
\hline Ver. Königreich & 10,1 & 10,8 & 94 & 1,8 & 6,3 & 1,2 & 5,1 & 51,5 & 48,5 \\
\hline Vereinigte Staaten & 3,7 & 3,2 & 113 & 0,6 & 1,9 & 0,2 & 1,6 & 56,2 & 43,8 \\
\hline Ländermittel & 5,7 & 5,8 & & 1,0 & 3,3 & 4,1 & & 50,7 & 49,3 \\
\hline \multicolumn{10}{|l|}{ OECD-Partnerländer } \\
\hline Argentinien $3,6,7$ & 0,2 & $\mathrm{~m}$ & $\mathrm{~m}$ & $n$ & $\mathrm{n}$ & 0,4 & $-0,3$ & $\mathrm{~m}$ & $\mathrm{~m}$ \\
\hline Brasilien & $\mathrm{m}$ & $\mathrm{m}$ & $\mathrm{m}$ & $\mathrm{m}$ & $\mathrm{m}$ & 0,5 & $\mathrm{~m}$ & $\mathrm{~m}$ & $\mathrm{~m}$ \\
\hline Chile & 0,9 & $\mathrm{~m}$ & $\mathrm{~m}$ & 0,2 & 0,4 & 1,0 & $-0,6$ & $\mathrm{~m}$ & $\mathrm{~m}$ \\
\hline China & $\mathrm{m}$ & $\mathrm{m}$ & $\mathrm{m}$ & $\mathrm{m}$ & $\mathrm{m}$ & 1,4 & $\mathrm{~m}$ & $\mathrm{~m}$ & $\mathrm{~m}$ \\
\hline Indien 7 & 0,1 & $\mathrm{~m}$ & $\mathrm{~m}$ & $n$ & $\mathrm{n}$ & 0,9 & $-0,9$ & $\mathrm{~m}$ & $\mathrm{~m}$ \\
\hline Indonesien & $\mathrm{n}$ & $\mathrm{m}$ & $\mathrm{m}$ & $\mathrm{n}$ & $\mathrm{n}$ & 1,1 & $-1,1$ & $\mathrm{~m}$ & $\mathrm{~m}$ \\
\hline Israel & $\mathrm{m}$ & $\mathrm{m}$ & $\mathrm{m}$ & $\mathrm{m}$ & $\mathrm{m}$ & 2,8 & $\mathrm{~m}$ & $\mathrm{~m}$ & $\mathrm{~m}$ \\
\hline Jamaika & $\mathrm{m}$ & $\mathrm{m}$ & $\mathrm{m}$ & $\mathrm{m}$ & $\mathrm{m}$ & 10,8 & $\mathrm{~m}$ & $\mathrm{~m}$ & $\mathrm{~m}$ \\
\hline Jordanien 4,7 & 2,7 & $\mathrm{~m}$ & $\mathrm{~m}$ & 0,5 & 0,1 & 3,5 & $-3,4$ & $\mathrm{~m}$ & $\mathrm{~m}$ \\
\hline Malaysia $^{7}$ & 3,0 & $\mathrm{~m}$ & $\mathrm{~m}$ & 0,5 & 1,2 & 6,8 & $-5,5$ & $\mathrm{~m}$ & $\mathrm{~m}$ \\
\hline Paraguay & $\mathrm{m}$ & $\mathrm{m}$ & $\mathrm{m}$ & $\mathrm{m}$ & $\mathrm{m}$ & 1,1 & $\mathrm{~m}$ & $\mathrm{~m}$ & $\mathrm{~m}$ \\
\hline Peru & $\mathrm{m}$ & $\mathrm{m}$ & $\mathrm{m}$ & $\mathrm{m}$ & $\mathrm{m}$ & 1,0 & $\mathrm{~m}$ & $\mathrm{~m}$ & $\mathrm{~m}$ \\
\hline Philippinen & 0,1 & $\mathrm{~m}$ & $\mathrm{~m}$ & $\mathrm{n}$ & 0,1 & 0,2 & $-0,2$ & $\mathrm{~m}$ & $\mathrm{~m}$ \\
\hline Russische Föd. ${ }^{3}$ & 0,9 & $\mathrm{~m}$ & $\mathrm{~m}$ & 0,2 & $\mathrm{n}$ & 0,3 & $-0,3$ & $\mathrm{~m}$ & $\mathrm{~m}$ \\
\hline Thailand $^{8}$ & 0,2 & $\mathrm{~m}$ & $\mathrm{~m}$ & $n$ & $n$ & 1,0 & $-1,0$ & $\mathrm{~m}$ & $\mathrm{~m}$ \\
\hline Tunesien & 1,1 & $\mathrm{~m}$ & $\mathrm{~m}$ & 0,2 & $\mathrm{n}$ & 4,7 & $-4,7$ & $\mathrm{~m}$ & $\mathrm{~m}$ \\
\hline Uruguay & $\mathrm{m}$ & $\mathrm{m}$ & $\mathrm{m}$ & $\mathrm{m}$ & $\mathrm{m}$ & 1,5 & $\mathrm{~m}$ & $\mathrm{~m}$ & $\mathrm{~m}$ \\
\hline Simbabwe & $\mathrm{m}$ & $\mathrm{m}$ & $\mathrm{m}$ & $\mathrm{m}$ & $\mathrm{m}$ & 9,8 & $\mathrm{~m}$ & $\mathrm{~m}$ & $\mathrm{~m}$ \\
\hline
\end{tabular}

1. Der Index vergleicht die Anzahl der ausländischen Studierenden als Prozentsatz der inländischen Einschreibungen mit der Durchschnittszahl für die OECD-Länder. Dadurch kann der Maßstab für den Umfang der Aufnahme ausländischer Studierender anhand der Größe des tertiären Bildungsbereichs präzisiert werden. Eine Index zahl über (unter) 1 bedeutet, dass anteilsmäßig an der Gesamtzahl der Studierenden mehr (weniger) ausländische Studierende aufgenommen wurden als im OECDMittel. 2. Die Daten in Spalten (5) und (7) zeigen nicht den weltweiten Austausch von Studierenden. Der Erhebungsbereich ist auf diejenigen in der Tabelle aufgeführten OECD-Länder und -Partnerländer beschränkt, die Angaben für Spalte (1) gemacht haben. Daher sind die Daten nicht mit denen in Spalte (1) vergleichbar.

3. Ohne weiterführende Forschungsprogramme. 4. Ohne Studiengänge im Tertiärbereich B. 5. Ländermittel ohne Luxemburg. 6. Ohne Studiengänge im Tertiärbereich A. 7. Referenzjahr 2001. 8. Die Zahl ausländischer Studierender ist signifikant zu niedrig angesetzt. Einzelheiten s. Anhang 3.

Quelle: OECD. Hinweise s. Anhang 3 unter www.oecd.org/edu/eag2004. 
Tabelle C3.2

Ausländische Studierende im Tertiärbereich nach dem Heimatland (2002)

Zahl der im Tertiärbereich eingeschriebenen ausländischen Studierenden nach ihrem Heimatland als Prozentsatz aller ausländischen Studierenden im Zielland (basierend auf Personenzahlen)

Die Tabelle zeigt für jedes Land den Anteil der ausländischen Studierenden im Tertiärbereich, die Staatsbürger eines bestimmten Heimatlandes sind.

Bedeutung der Spalte (3): 28,5 Prozent der ausländischen Studierenden in Belgien sind französische Staatsbürger, 6,6 Prozent niederländische Staatsbürger, etc. Bedeutung der Zeile (1): 0,2 Prozent der ausländischen Studierenden des Tertiärbereichs in Dänemark sind australische Staatsbürger, 0,7 Prozent der ausländischen Studierenden des Tertiärbereichs in Irland sind australische Staatsbürger, etc.

\begin{tabular}{|c|c|c|c|c|c|c|c|c|c|c|c|c|c|c|c|c|c|c|c|}
\hline \multirow[b]{2}{*}{$\begin{array}{l}\text { Heimatland } \\
\text { OECD-Länder }\end{array}$} & \multicolumn{19}{|c|}{ Zielland } \\
\hline & 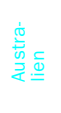 & $\begin{array}{l}\frac{1}{d} \frac{c}{0} \\
\frac{\omega}{6}\end{array}$ & $\frac{\frac{c}{0}}{\frac{0}{\omega 0}}$ & 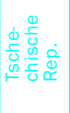 & 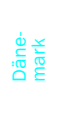 & 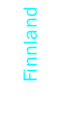 & 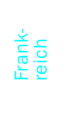 & 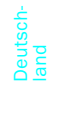 & 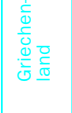 & 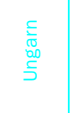 & $\begin{array}{l}\frac{\vec{\sigma}}{\underline{\frac{\pi}{n}}} \\
\frac{0}{\underline{n}}\end{array}$ & $\begin{array}{l}\frac{D}{\frac{E}{0}} \\
\frac{\pi}{I}\end{array}$ & $\frac{\frac{c}{d}}{\frac{d}{ \pm}}$ & 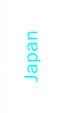 & $\begin{array}{l}\frac{\pi}{0} \\
\frac{0}{0} \\
\check{2}\end{array}$ & 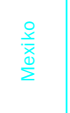 & 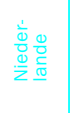 & 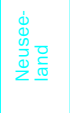 & $\sum_{\substack{0 \\
0}}^{\infty}$ \\
\hline Australien & a & 0,1 & $\mathrm{n}$ & $\mathrm{n}$ & 0,2 & 0,3 & 0,1 & 0,1 & $\mathrm{n}$ & $\mathrm{n}$ & $\mathrm{n}$ & 0,7 & 0,1 & 0,4 & 0,3 & $\mathrm{x}(\mathrm{Oc})$ & 0,2 & $\mathrm{n}$ & 0,2 \\
\hline Österreich & 0,1 & a & 0,1 & 0,1 & 0,2 & 0,4 & 0,2 & 3,2 & $\mathrm{n}$ & 0,2 & 2,1 & 0,4 & 0,3 & $\mathrm{n}$ & $n$ & $x(E u)$ & 0,6 & 0,1 & 0,3 \\
\hline Belgien & 0,1 & 0,3 & a & $\mathrm{n}$ & 0,2 & 0,4 & 1,2 & 0,5 & 0,1 & $\mathrm{n}$ & 0,2 & 0,8 & 0,4 & 0,1 & $\mathrm{n}$ & $x(E u)$ & 10,0 & $\mathrm{n}$ & 0,2 \\
\hline Kanada & 1,4 & 0,1 & 0,2 & 0,3 & 0,4 & 1,0 & 0,6 & 0,2 & $\mathrm{n}$ & 0,6 & 2,3 & 2,3 & 0,2 & 0,3 & 0,8 & 1,1 & 0,3 & 0,8 & 0,5 \\
\hline Dänemark & 0,2 & 0,3 & 0,1 & $\mathrm{n}$ & a & 0,7 & 0,2 & 0,3 & $\mathrm{n}$ & $\mathrm{n}$ & 11,4 & 0,2 & 0,1 & $\mathrm{n}$ & $\mathrm{n}$ & $x(E u)$ & 0,4 & 0,2 & 8,8 \\
\hline Finnland & 0,1 & 0,6 & 0,5 & 0,1 & 0,7 & a & 0,2 & 0,5 & 0,1 & 0,1 & 9,5 & 1,0 & 0,2 & $n$ & $n$ & $x(E u)$ & 0,6 & 0,1 & 2,9 \\
\hline Frankreich & 0,3 & 1,2 & 28,5 & 0,1 & 0,8 & 1,7 & a & 3,0 & 0,1 & 0,1 & 4,2 & 6,0 & 1,7 & 0,3 & $n$ & $x(E u)$ & 2,1 & 0,5 & 1,4 \\
\hline Deutschland & 1,1 & 18,1 & 1,2 & 0,5 & 4,1 & 3,7 & 3,2 & a & 0,3 & 4,4 & 10,4 & 5,4 & 3,1 & 0,4 & 0,4 & $x(E u)$ & 22,2 & 2,4 & 4,7 \\
\hline Griechenland & $\mathrm{n}$ & 0,9 & 1,6 & 3,0 & 0,2 & 0,5 & 1,4 & 3,6 & a & 2,7 & $\mathrm{n}$ & 0,5 & 26,7 & $\mathrm{n}$ & $\mathrm{n}$ & $x(E u)$ & 0,7 & $\mathrm{n}$ & 0,1 \\
\hline Ungarn & $\mathrm{n}$ & 4,2 & 0,2 & 0,1 & 0,2 & 1,6 & 0,3 & 1,4 & 0,1 & a & $\mathrm{n}$ & $\mathrm{n}$ & 0,4 & 0,1 & 0,1 & $x(E u)$ & 0,5 & $\mathrm{n}$ & 0,3 \\
\hline Island & $\mathrm{n}$ & 0,1 & $\mathrm{n}$ & $\mathrm{n}$ & 5,5 & 0,4 & $\mathrm{n}$ & 0,1 & $\mathrm{n}$ & 0,1 & a & 0,1 & 0,1 & $\mathrm{n}$ & $n$ & $x(E u)$ & 0,1 & $\mathrm{n}$ & 2,8 \\
\hline Irland & 0,3 & 0,1 & 0,1 & 0,1 & 0,3 & 0,4 & 0,3 & 0,2 & $\mathrm{n}$ & $\mathrm{n}$ & $\mathrm{n}$ & a & $n$ & $\mathrm{n}$ & $n$ & $x(E u)$ & 0,2 & $\mathrm{n}$ & 0,3 \\
\hline Italien & 0,2 & 21,1 & 7,3 & $\mathrm{n}$ & 0,7 & 1,3 & 2,3 & 3,6 & 0,2 & 0,1 & 3,0 & 1,6 & a & 0,1 & $n$ & $x(E u)$ & 1,7 & $\mathrm{n}$ & 0,7 \\
\hline Korea & 2,2 & 1,1 & 0,2 & 0,1 & $n$ & 0,4 & 1,1 & 2,4 & $\mathrm{n}$ & 0,2 & $\mathrm{n}$ & 0,1 & 0,3 & 25,2 & a & $\mathrm{x}(\mathrm{As})$ & 0,4 & 4,4 & 0,1 \\
\hline Luxemburg & $n$ & 0,9 & 3,5 & $x(n s)$ & $\mathrm{n}$ & $\mathrm{n}$ & 0,9 & 0,8 & $\mathrm{n}$ & $\mathrm{n}$ & $\mathrm{n}$ & 0,1 & 0,1 & $\mathrm{n}$ & $\mathrm{n}$ & $x(E u)$ & 0,1 & $\mathrm{n}$ & $\mathrm{n}$ \\
\hline Mexiko & 0,2 & 0,2 & 0,2 & $\mathrm{n}$ & 0,2 & 0,3 & 0,7 & 0,3 & $\mathrm{n}$ & $\mathrm{n}$ & 0,4 & 0,1 & 0,2 & 0,1 & 0,1 & a & 0,1 & 0,1 & 0,3 \\
\hline Niederlande & 0,3 & 0,4 & 6,6 & $\mathrm{n}$ & 0,7 & 0,7 & 0,3 & 0,8 & $\mathrm{n}$ & $\mathrm{n}$ & 1,3 & 0,6 & 0,2 & 0,1 & $n$ & $x(E u)$ & a & 0,1 & 1,5 \\
\hline Neuseeland & 3,1 & $\mathrm{n}$ & $\mathrm{n}$ & $\mathrm{n}$ & 0,1 & 0,1 & $n$ & $n$ & $\mathrm{n}$ & $\mathrm{n}$ & 0,4 & 0,1 & $n$ & 0,1 & 0,2 & $\mathrm{x}(\mathrm{Oc})$ & $\mathrm{n}$ & a & 0,1 \\
\hline Norwegen & 2,1 & 0,2 & 0,1 & 0,6 & 10,0 & 0,9 & 0,2 & 0,4 & $\mathrm{n}$ & 4,7 & 7,4 & 1,8 & 0,1 & $\mathrm{n}$ & $\mathrm{n}$ & $x(E u)$ & 0,5 & 1,0 & a \\
\hline Polen & 0,1 & 3,4 & 0,7 & 0,9 & 2,0 & 1,2 & 1,4 & 5,4 & 0,3 & 1,1 & 2,5 & 0,5 & 1,8 & 0,1 & 0,1 & $x(E u)$ & 1,3 & $\mathrm{n}$ & 0,9 \\
\hline Portugal & $n$ & 0,1 & 1,7 & 0,2 & 0,2 & 0,3 & 1,6 & 0,9 & $\mathrm{n}$ & $\mathrm{n}$ & 0,2 & 0,1 & 0,1 & $n$ & $n$ & $x(E u)$ & 0,8 & 0,1 & 0,3 \\
\hline Slowakische Republik & 0,1 & 4,3 & 0,1 & 50,4 & 0,1 & 0,3 & 0,2 & 0,6 & $\mathrm{n}$ & 17,6 & 0,4 & $\mathrm{n}$ & 0,3 & $\mathrm{n}$ & $\mathrm{n}$ & $x(E u)$ & 0,1 & $\mathrm{n}$ & 0,1 \\
\hline Spanien & 0,1 & 1,1 & 3,2 & $\mathrm{n}$ & 0,7 & 1,6 & 2,0 & 2,7 & $\mathrm{n}$ & 0,1 & 4,7 & 2,7 & 0,6 & 0,1 & 0,1 & $x(E u)$ & 5,4 & 0,1 & 0,6 \\
\hline Schweden & 0,9 & 0,7 & 0,2 & 0,5 & 5,1 & 8,6 & 0,4 & 0,4 & 0,1 & 0,7 & 7,4 & 0,8 & 0,3 & 0,1 & 0,1 & $x(E u)$ & 0,6 & 0,9 & 10,7 \\
\hline Schweiz & 0,1 & 0,8 & 0,3 & $\mathrm{n}$ & 0,3 & 0,6 & 0,7 & 0,9 & $\mathrm{n}$ & 0,1 & 1,3 & 0,2 & 2,8 & $\mathrm{n}$ & $n$ & $x(E u)$ & 0,4 & 0,1 & 0,5 \\
\hline Türkei & 0,2 & 5,4 & 1,0 & $\mathrm{n}$ & 1,0 & 0,7 & 1,3 & 12,4 & 0,4 & 0,6 & 0,2 & $\mathrm{n}$ & 0,4 & 0,1 & 0,3 & $\mathrm{x}(\mathrm{As})$ & 4,8 & $\mathrm{n}$ & 0,4 \\
\hline Vereinigtes Königreich & 3,3 & 0,6 & 0,6 & 2,4 & 2,8 & 2,1 & 1,5 & 1,0 & $\mathrm{n}$ & 0,3 & 2,3 & 21,3 & 0,4 & 0,5 & 0,2 & $x(E u)$ & 3,3 & 1,1 & 3,7 \\
\hline $\begin{array}{l}\text { Vereinigte Staaten } \\
\text { OECD-Partnerländer }\end{array}$ & 5,0 & 1,1 & 0,5 & 0,6 & 1,5 & 2,6 & 1,5 & 1,6 & 0,3 & 2,1 & 5,9 & 19,2 & 0,7 & 1,5 & 4,0 & 43,9 & 1,3 & 4,1 & 3,3 \\
\hline Argentinien & 0,1 & 0,1 & 0,1 & $x(n s)$ & 0,1 & 0,2 & 0,4 & 0,2 & $n$ & $n$ & 0,2 & 0,1 & 0,5 & 0,1 & 0,1 & $x(S A)$ & 0,1 & 0,1 & $n$ \\
\hline Brasilien & 0,2 & 0,2 & 0,4 & $\mathrm{n}$ & 0,4 & 0,4 & 0,9 & 0,7 & $\mathrm{n}$ & $\mathrm{n}$ & 0,2 & $\mathrm{n}$ & 0,9 & 0,5 & 0,1 & $x(S A)$ & 0,3 & 0,1 & 0,3 \\
\hline Ägypten & 0,1 & 0,5 & 0,2 & 0,1 & 0,1 & 0,2 & 0,5 & 0,6 & 0,3 & 0,1 & $n$ & 0,1 & 0,3 & 0,3 & $n$ & $x(A f)$ & 0,1 & $\mathrm{n}$ & 0,1 \\
\hline Indien & 5,3 & 0,3 & 0,3 & 0,4 & 0,2 & 0,8 & 0,2 & 1,0 & $\mathrm{n}$ & 0,5 & 0,2 & 1,2 & 0,5 & 0,3 & 1,0 & $x(A s)$ & 0,3 & 5,4 & 1,2 \\
\hline Indonesien & 7,6 & 0,1 & 0,2 & $n$ & 0,1 & 0,3 & 0,1 & 1,0 & $n$ & $n$ & 0,2 & 0,1 & $n$ & 1,7 & 0,8 & $x($ As $)$ & 3,0 & 2,1 & 0,1 \\
\hline Jamaika & $\mathrm{n}$ & $\mathrm{n}$ & $\mathrm{n}$ & $x(n s)$ & $\mathrm{n}$ & $\mathrm{n}$ & $n$ & $\mathrm{n}$ & $\mathrm{n}$ & $\mathrm{n}$ & $\mathrm{n}$ & $\mathrm{n}$ & $\mathrm{m}$ & $\mathrm{n}$ & $\mathrm{n}$ & $x(N A)$ & $\mathrm{n}$ & $\mathrm{n}$ & $\mathrm{n}$ \\
\hline Jordanien & 0,2 & 0,2 & $\mathrm{n}$ & 0,3 & $\mathrm{n}$ & 0,1 & 0,1 & 0,5 & 0,7 & 0,2 & 0,4 & 0,2 & 0,4 & $\mathrm{n}$ & $\mathrm{n}$ & $x($ As) & $\mathrm{n}$ & $\mathrm{n}$ & 0,1 \\
\hline Malaysia & 9,8 & $\mathrm{n}$ & $\mathrm{n}$ & $\mathrm{n}$ & $n$ & 0,2 & 0,1 & 0,1 & $\mathrm{n}$ & $\mathrm{n}$ & $\mathrm{n}$ & 5,6 & $\mathrm{n}$ & 2,2 & 0,9 & $x($ As $)$ & 0,1 & 5,0 & 0,1 \\
\hline Paraguay & $n$ & $\mathrm{n}$ & $\mathrm{n}$ & 0,1 & $\mathrm{n}$ & $\mathrm{n}$ & $\mathrm{n}$ & $\mathrm{n}$ & $n$ & $\mathrm{n}$ & $\mathrm{n}$ & $\mathrm{n}$ & $\mathrm{n}$ & 0,1 & 0,3 & $x(S A)$ & $\mathrm{n}$ & $\mathrm{n}$ & $\mathrm{n}$ \\
\hline Peru & $\mathrm{n}$ & 0,2 & 0,2 & 0,1 & 0,1 & 0,2 & 0,2 & 0,4 & $\mathrm{n}$ & $\mathrm{n}$ & $\mathrm{n}$ & 0,1 & 1,2 & 0,2 & $\mathrm{n}$ & $x(S A)$ & 0,1 & 0,1 & 0,2 \\
\hline Philippinen & 0,5 & $n$ & 0,1 & $\mathrm{n}$ & 0,2 & 0,4 & $n$ & 0,1 & $n$ & $\mathrm{n}$ & 0,6 & $\mathrm{n}$ & 0,1 & 0,6 & 1,0 & $x($ As) & 0,2 & 0,3 & 0,2 \\
\hline Russische Föderation & 0,3 & 0,9 & 0,7 & 2,1 & 1,3 & 13,5 & 1,2 & 4,1 & 0,9 & 1,8 & 2,3 & 0,6 & 0,8 & 0,4 & 2,0 & $x(E u)$ & 1,4 & 0,3 & 4,8 \\
\hline Sri Lanka & 1,5 & $n$ & $\mathrm{n}$ & 0,1 & 0,1 & 0,1 & 0,1 & 0,1 & $n$ & $\mathrm{n}$ & $\mathrm{n}$ & 0,1 & $n$ & 0,5 & 0,1 & $x($ As $)$ & 0,1 & 0,6 & 1,0 \\
\hline Thailand & 2,8 & 0,1 & 0,1 & $\mathrm{n}$ & 0,3 & 0,3 & 0,2 & 0,3 & $\mathrm{n}$ & $\mathrm{n}$ & $\mathrm{n}$ & 0,1 & $\mathrm{n}$ & 1,7 & 0,1 & $x($ As $)$ & 0,1 & 1,9 & 0,2 \\
\hline Tunesien & $n$ & 0,1 & 0,7 & $n$ & $n$ & 0,1 & 4,7 & 0,7 & $n$ & $\mathrm{n}$ & 0,2 & $\mathrm{n}$ & 0,4 & 0,1 & $n$ & $x(A f)$ & 0,1 & $\mathrm{n}$ & 0,1 \\
\hline Uruguay & $\mathrm{n}$ & $\mathrm{n}$ & $\mathrm{n}$ & $\mathrm{n}$ & $\mathrm{n}$ & $\mathrm{n}$ & $\mathrm{n}$ & $\mathrm{n}$ & $\mathrm{n}$ & $\mathrm{n}$ & $\mathrm{n}$ & $\mathrm{n}$ & $\mathrm{n}$ & $\mathrm{n}$ & $\mathrm{n}$ & $x(S A)$ & $\mathrm{n}$ & 0,1 & $\mathrm{n}$ \\
\hline Simbabwe & 0,4 & $n$ & $\mathrm{n}$ & 0,1 & 0,1 & $n$ & $\mathrm{n}$ & $n$ & $n$ & $\mathrm{n}$ & $n$ & 0,1 & $n$ & $\mathrm{n}$ & $n$ & $x(A f)$ & $\mathrm{n}$ & 0,1 & 0,2 \\
\hline $\begin{array}{l}\text { Gesamt: OECD-Länder } \\
\text { und OECD-Partnerländer }\end{array}$ & & & & & & & & & & & & & & & & & & & \\
\hline Gesamt: Afrika & 3,5 & 2,2 & 28,8 & 2,3 & 2,9 & 11,3 & 53,3 & 9,5 & 2,1 & 1,4 & 1,9 & 5,4 & 7,7 & 1,0 & 1,3 & 1,0 & 14,2 & 1,1 & 8,2 \\
\hline Gesamt: Asien & 66,7 & 12,7 & 7,0 & 8,4 & 8,3 & 25,8 & 13,9 & 34,5 & 85,9 & 15,1 & 6,8 & 24,9 & 10,4 & 92,2 & 88,6 & 1,4 & 20,1 & 78,4 & 11,6 \\
\hline Gesamt: Europa & 10,4 & 82,2 & 59,7 & 66,4 & 44,5 & 55,0 & 25,6 & 50,5 & 11,4 & 80,6 & 80,1 & 46,6 & 72,5 & 2,9 & 3,7 & 5,9 & 57,0 & 7,4 & 54,6 \\
\hline Gesamt: Nordamerika & 6,7 & 1,5 & 1,2 & 1,0 & 2,2 & 4,3 & 3,5 & 2,5 & 0,3 & 2,7 & 9,1 & 22,0 & 1,8 & 2,1 & 5,1 & 71,5 & 1,9 & 5,2 & 4,4 \\
\hline Gesamt: Ozeanien & 4,4 & 0,1 & $\mathrm{n}$ & $\mathrm{n}$ & 0,3 & 0,5 & 0,1 & 0,2 & $n$ & $\mathrm{n}$ & 0,4 & 0,8 & 0,1 & 0,6 & 0,5 & 0,1 & 0,2 & 7,4 & 0,3 \\
\hline Gesamt: Südamerika & 0,9 & 0,9 & 1,8 & 0,8 & 0,9 & 1,2 & 2,9 & 2,1 & 0,1 & 0,2 & 1,3 & 0,4 & 4,7 & 1,1 & 0,7 & 20,1 & 5,9 & 0,7 & 1,6 \\
\hline Nicht spezifiziert & 7,4 & 0,4 & 1,5 & 21,0 & 40,9 & 2,0 & 0,7 & 0,8 & $n$ & $n$ & 0,4 & $\mathrm{n}$ & 2,9 & $\mathrm{n}$ & n & $\mathrm{n}$ & 0,5 & $n$ & 19,2 \\
\hline $\begin{array}{l}\text { Gesamt: Alle Heimat- } \\
\text { länder zusammen }\end{array}$ & 100,0 & 100,0 & 100,0 & 100,0 & 100,0 & 100,0 & 100,0 & 100,0 & 100,0 & 100,0 & 100,0 & 100,0 & 100,0 & 100,0 & 100,0 & 00,0 & 100,0 & 100,0 & 00,0 \\
\hline
\end{tabular}

Hinweis: $x$ bedeutet, dass die Daten in den Gesamtzahlen für Afrika $(x(A f))$, Asien $(x(A s))$, Europa $(x(E u))$, Nordamerika $(x(N A))$, Ozeanien $(x(O c))$, Südamerika $(x(S A))$ oder nicht spezifiziertes Heimatland $(x(n s))$ enthalten sind.

1. Referenzjahr 2001

Quelle: OECD. Hinweise s. Anhang 3 unter www.oecd.org/edu/eag2004. 
Tabelle C3.2 (Forts.)

Ausländische Studierende im Tertiärbereich nach dem Heimatland (2002)

Zahl der im Tertiärbereich eingeschriebenen ausländischen Studierenden nach ihrem Heimatland als Prozentsatz aller ausländischen Studierenden im Zielland (basierend auf Personenzahlen)

Die Tabelle zeigt für jedes Land den Anteil der ausländischen Studierenden im Tertiärbereich, die Staatsbürger eines bestimmten Heimatlandes sind.

Bedeutung der Spalte (3): 28,5 Prozent der ausländischen Studierenden in Belgien sind französische Staatsbürger, 6, 6 Prozent niederländische Staatsbürger, etc. Bedeutung der Zeile (1): 0,2 Prozent der ausländischen Studierenden des Tertiärbereichs in Dänemark sind australische Staatsbürger, 0,7 Prozent der ausländischen Studierenden des Tertiärbereichs in Irland sind australische Staatsbürger, etc.

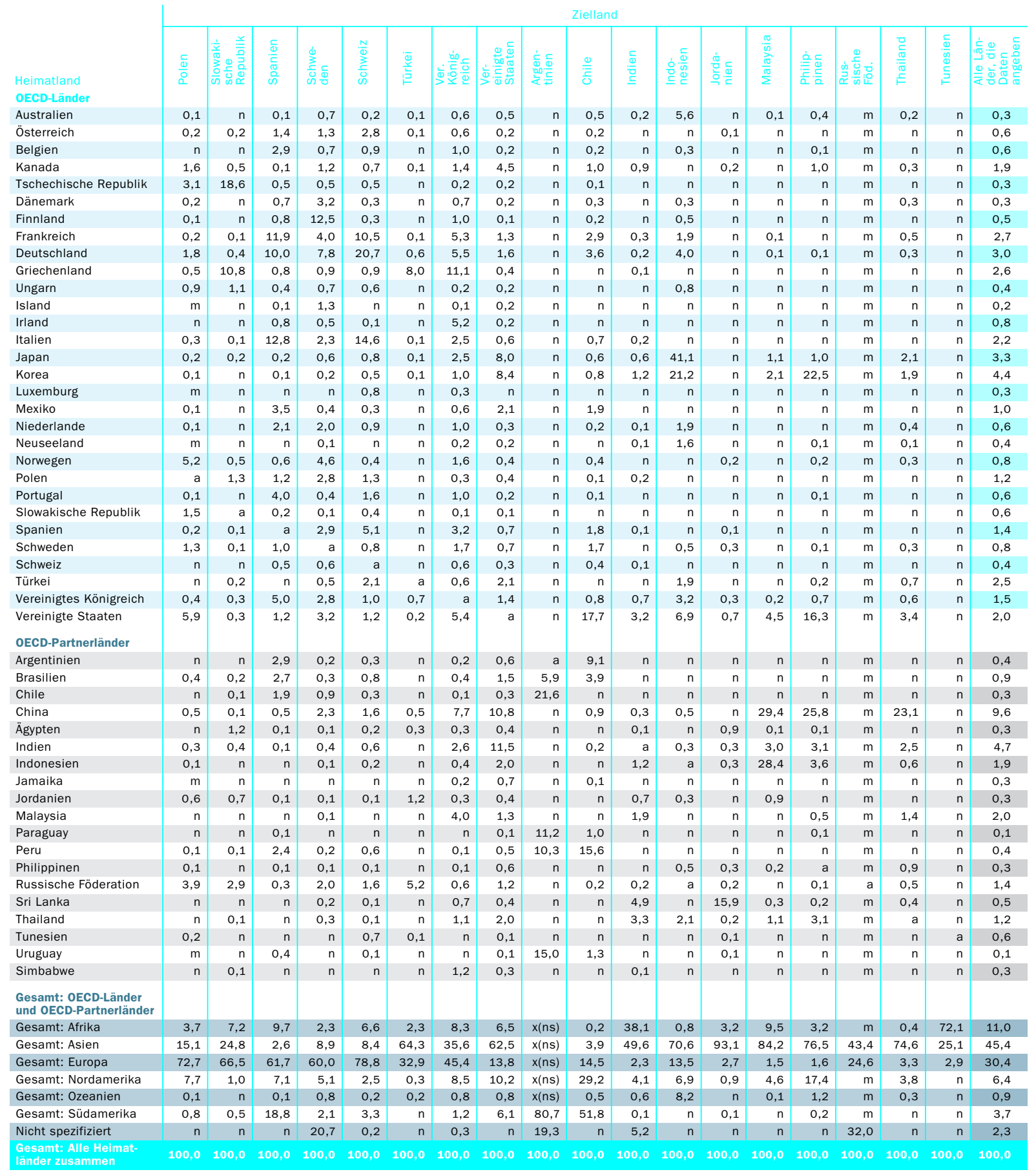

Hinweis: $x$ bedeutet, dass die Daten in den Gesamtzahlen für Afrika (x(Af)), Asien $(x(A s))$, Europa $(x(E u))$, Nordamerika $(x(N A))$, Ozeanien $(x(O c))$, Südamerika $(x(S A))$ oder nicht spezifiziertes Heimatland $(x(n s))$ enthalten sind.

1. Referenzjahr 2001

Quelle: OECD. Hinweise s. Anhang 3 unter www.oecd.org/edu/eag2004. 


\section{Tabelle C3.3}

Ausländische Studierende im Tertiärbereich nach dem Zielland (2002)

Zahl der im Tertiärbereich eingeschriebenen ausländischen Studierenden in einem bestimmten Zielland als Prozentsatz aller im Ausland eingeschriebenen Studierenden (basierend auf Personenzahlen)

Die Tabelle zeigt für jedes Land den Anteil der Studierenden, die im Ausland eingeschrieben sind, aufgegliedert nach dem Zielland.

Bedeutung der Spalte (2): 6,6 Prozent der tschechischen Studierenden im Tertiärbereich, die im Ausland eingeschrieben sind, studieren in Österreich, 9,1 Prozent der deutschen Studierenden im Tertiärbereich, die im Ausland eingeschrieben sind, studieren in Osterreich, etc.

\begin{tabular}{|c|c|c|c|c|c|c|c|c|c|c|c|c|c|c|c|c|c|c|}
\hline \multicolumn{19}{|c|}{ Zielland } \\
\hline 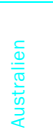 & $\begin{array}{l}\frac{5}{0} \\
\frac{0}{0} \\
\frac{0}{0} \\
0\end{array}$ & $\frac{c}{\frac{c}{00}}$ & 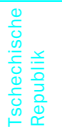 & 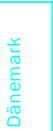 & $\begin{array}{l}\frac{\bar{E}}{\frac{E}{\sigma}} \\
\frac{\pi}{E} \\
\frac{D}{E}\end{array}$ & 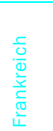 & 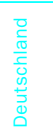 & 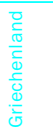 & 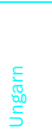 & $\begin{array}{l}\bar{D} \\
\frac{\underline{\sigma}}{\underline{0}}\end{array}$ & 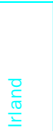 & 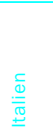 & 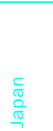 & 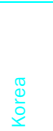 & $\begin{array}{l}\frac{\rho}{x} \\
\frac{0}{x}\end{array}$ & $\begin{array}{l}\frac{0}{0} \\
\frac{\pi}{\pi} \\
\frac{\pi}{2} \\
\frac{\omega}{0} \\
\frac{\omega}{z}\end{array}$ & 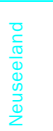 & $\begin{array}{l}c \\
0 \\
0 \\
0 \\
\sum \\
0 \\
\text { z }\end{array}$ \\
\hline a & 0,4 & 0,3 & $\mathrm{n}$ & 0,6 & 0,4 & 3,0 & 5,0 & $\mathrm{n}$ & 0,1 & $\mathrm{n}$ & 1,1 & 0,4 & 5,5 & 0,3 & $\mathrm{n}$ & 0,7 & a & 0,4 \\
\hline 1,9 & a & 0,5 & 0,1 & 0,3 & 0,2 & 3,2 & 56,6 & $\mathrm{n}$ & 0,2 & 0,1 & 0,3 & 0,8 & 0,3 & $n$ & $\mathrm{n}$ & 0,9 & 0,1 & 0,3 \\
\hline 0,9 & 0,8 & a & $\mathrm{n}$ & 0,2 & 0,2 & 19,8 & 9,7 & $n$ & $n$ & $\mathrm{n}$ & 0,7 & 1,2 & 0,4 & $n$ & $\mathrm{n}$ & 18,2 & 0,1 & 0,2 \\
\hline 7,2 & 0,1 & 0,3 & 0,1 & 0,2 & 0,2 & 3,0 & 1,3 & $\mathrm{n}$ & 0,2 & $\mathrm{n}$ & 0,6 & 0,2 & 0,6 & 0,1 & 0,1 & 0,2 & 0,4 & 0,1 \\
\hline 2,1 & 6,6 & 0,7 & a & 0,4 & 0,7 & 7,5 & 34,2 & 0,1 & 0,3 & 0,1 & 0,3 & 1,6 & 0,5 & 0,1 & $\mathrm{n}$ & 0,9 & 0,2 & 0,6 \\
\hline 4,7 & 1,1 & 0,7 & $\mathrm{n}$ & a & 0,7 & 4,5 & 10,7 & $\mathrm{n}$ & $\mathrm{n}$ & 0,8 & 0,3 & 0,3 & 0,3 & $\mathrm{n}$ & $\mathrm{n}$ & 1,1 & 0,6 & 12,9 \\
\hline 1,6 & 1,6 & 2,0 & 0,1 & 1,1 & a & 3,2 & 10,6 & 0,1 & 0,1 & 0,5 & 0,9 & 0,6 & 0,3 & $n$ & $\mathrm{n}$ & 1,1 & 0,1 & 2,8 \\
\hline 1,2 & 0,7 & 22,7 & $n$ & 0,2 & 0,2 & a & 13,1 & $\mathrm{n}$ & $\mathrm{n}$ & $\mathrm{n}$ & 1,1 & 1,0 & 0,4 & $\mathrm{n}$ & $\mathrm{n}$ & 0,8 & 0,2 & 0,3 \\
\hline 3,6 & 9,1 & 0,8 & 0,1 & 1,1 & 0,4 & 9,3 & a & $\mathrm{n}$ & 0,9 & 0,1 & 0,9 & 1,5 & 0,5 & $n$ & $\mathrm{n}$ & 7,4 & 0,8 & 0,8 \\
\hline 0,2 & 0,5 & 1,3 & 0,6 & 0,1 & 0,1 & 4,7 & 16,0 & a & 0,6 & $\mathrm{n}$ & 0,1 & 15,2 & $n$ & $n$ & $\mathrm{n}$ & 0,3 & $\mathrm{n}$ & $\mathrm{n}$ \\
\hline 1,1 & 15,6 & 1,2 & 0,2 & 0,4 & 1,4 & 7,0 & 38,9 & 0,1 & a & $\mathrm{n}$ & 0,1 & 1,6 & 1,2 & $n$ & $\mathrm{n}$ & 1,2 & 0,1 & 0,4 \\
\hline 0,6 & 0,5 & 0,2 & 0,1 & 27,1 & 1,0 & 1,8 & 5,7 & $\mathrm{n}$ & 0,3 & a & 0,3 & 0,5 & 0,2 & $\mathrm{n}$ & $\mathrm{n}$ & 0,7 & 0,1 & 9,0 \\
\hline 3,1 & 0,3 & 0,3 & 0,1 & 0,3 & 0,2 & 3,4 & 3,4 & $\mathrm{n}$ & $n$ & $n$ & a & $n$ & 0,1 & $n$ & $n$ & 0,3 & $n$ & 0,2 \\
\hline 0,7 & 14,5 & 7,1 & $n$ & 0,2 & 0,2 & 9,2 & 18,8 & $\mathrm{n}$ & $\mathrm{n}$ & $\mathrm{n}$ & 0,3 & a & 0,2 & $\mathrm{n}$ & $\mathrm{n}$ & 0,8 & $\mathrm{n}$ & 0,2 \\
\hline 5,2 & 0,4 & 0,3 & $n$ & 0,1 & 0,1 & 2,4 & 3,7 & $n$ & $n$ & $n$ & 0,1 & 0,2 & a & 1,1 & $n$ & 0,1 & 0,8 & $n$ \\
\hline 4,7 & 0,4 & 0,1 & $n$ & $\mathrm{n}$ & $n$ & 2,1 & 6,1 & $\mathrm{n}$ & $\mathrm{n}$ & $\mathrm{n}$ & $\mathrm{n}$ & 0,1 & 22,5 & a & $\mathrm{n}$ & 0,1 & 0,9 & $\mathrm{n}$ \\
\hline 0,1 & 4,4 & 23,3 & $\mathrm{n}$ & $n$ & $n$ & 24,8 & 30,0 & $\mathrm{n}$ & $n$ & $\mathrm{n}$ & 0,2 & 0,4 & $n$ & $n$ & $n$ & 0,3 & $n$ & $\mathrm{n}$ \\
\hline 1,8 & 0,3 & 0,4 & $\mathrm{n}$ & 0,1 & 0,1 & 6,2 & 3,2 & $\mathrm{n}$ & $\mathrm{n}$ & $\mathrm{n}$ & $\mathrm{n}$ & 0,3 & 0,6 & $\mathrm{n}$ & a & 0,1 & 0,1 & 0,1 \\
\hline 3,8 & 0,9 & 22,3 & $n$ & 0,9 & 0,4 & 4,1 & 15,6 & $\mathrm{n}$ & $n$ & 0,1 & 0,5 & 0,5 & 0,4 & $n$ & $n$ & a & 0,2 & 1,2 \\
\hline 75,5 & 0,1 & $\mathrm{n}$ & $\mathrm{n}$ & 0,2 & 0,1 & 0,5 & 0,8 & $\mathrm{n}$ & $\mathrm{n}$ & $\mathrm{n}$ & 0,2 & $\mathrm{n}$ & 1,2 & 0,1 & $n$ & 0,1 & a & 0,1 \\
\hline 24,4 & 0,4 & 0,2 & 0,4 & 9,1 & 0,4 & 1,9 & 5,5 & $n$ & 3,5 & 0,2 & 1,0 & 0,2 & 0,1 & $n$ & $\mathrm{n}$ & 0,6 & 1,1 & a \\
\hline 1,0 & 4,4 & 1,3 & 0,4 & 1,3 & 0,4 & 10,2 & 53,0 & 0,1 & 0,6 & 0,1 & 0,2 & 2,4 & 0,4 & $n$ & $\mathrm{n}$ & 1,1 & $n$ & 0,4 \\
\hline 0,7 & 0,3 & 6,0 & 0,1 & 0,2 & 0,2 & 23,9 & 16,9 & $n$ & $n$ & $\mathrm{n}$ & 0,1 & 0,3 & 0,2 & $n$ & $\mathrm{n}$ & 1,3 & 0,1 & 0,2 \\
\hline 1,0 & 10,8 & 0,5 & 43,6 & 0,1 & 0,2 & 2,5 & 11,6 & $\mathrm{n}$ & 18,4 & $\mathrm{n}$ & $\mathrm{n}$ & 0,8 & 0,2 & $\mathrm{n}$ & $n$ & 0,2 & $\mathrm{n}$ & 0,1 \\
\hline 0,6 & 1,2 & 4,9 & $n$ & 0,4 & 0,4 & 12,5 & 22,3 & $\mathrm{n}$ & 0,1 & 0,1 & 0,9 & 0,6 & 0,2 & $n$ & $\mathrm{n}$ & 3,9 & $\mathrm{n}$ & 0,2 \\
\hline 10,9 & 1,2 & 0,4 & 0,3 & 4,8 & 3,8 & 4,8 & 5,5 & $\mathrm{n}$ & 0,6 & 0,2 & 0,5 & 0,6 & 0,3 & $n$ & $\mathrm{n}$ & 0,7 & 1,0 & 6,7 \\
\hline 3,0 & 2,8 & 1,3 & $\mathrm{n}$ & 0,5 & 0,5 & 13,5 & 24,3 & $\mathrm{n}$ & 0,2 & 0,1 & 0,2 & 9,8 & 0,3 & $n$ & $\mathrm{n}$ & 0,9 & 0,3 & 0,6 \\
\hline 0,6 & 3,2 & 0,9 & $\mathrm{n}$ & 0,3 & 0,1 & 4,6 & 57,3 & 0,1 & 0,1 & $\mathrm{n}$ & $\mathrm{n}$ & 0,2 & 0,2 & $\mathrm{n}$ & $\mathrm{n}$ & 1,9 & $\mathrm{n}$ & 0,1 \\
\hline 21,5 & 0,6 & 0,8 & 0,8 & 1,4 & 0,5 & 9,2 & 8,1 & $\mathrm{n}$ & 0,1 & $n$ & 7,1 & 0,4 & 1,3 & $n$ & $\mathrm{n}$ & 2,3 & 0,7 & 1,3 \\
\hline 23,4 & 0,8 & 0,5 & 0,2 & 0,5 & 0,4 & 6,4 & 8,8 & 0,1 & 0,6 & 0,1 & 4,6 & 0,5 & 3,0 & 0,5 & 2,1 & 0,6 & 1,9 & 0,8 \\
\hline 1,9 & 0,2 & 0,5 & $n$ & 0,1 & 0,2 & 8,3 & 6,4 & $n$ & $n$ & $\mathrm{n}$ & 0,1 & 2,1 & 1,2 & 0,1 & $n$ & 0,3 & 0,2 & $\mathrm{n}$ \\
\hline 2,5 & 0,3 & 1,0 & $n$ & 0,3 & 0,1 & 8,8 & 9,5 & $n$ & $n$ & $\mathrm{n}$ & $\mathrm{n}$ & 1,6 & 2,3 & $n$ & $\mathrm{n}$ & 0,4 & 0,1 & 0,2 \\
\hline 4,3 & 0,4 & 2,1 & $n$ & 0,3 & 0,2 & 7,4 & 9,1 & $n$ & $n$ & $n$ & 0,1 & 1,5 & 0,7 & 0,1 & $n$ & 0,6 & 0,6 & 1,1 \\
\hline 9,5 & 0,2 & 0,4 & $\mathrm{n}$ & 0,2 & 0,6 & 3,0 & 7,7 & $\mathrm{n}$ & $n$ & $\mathrm{n}$ & 0,1 & 0,1 & 22,7 & 1,3 & $\mathrm{n}$ & 0,4 & 4,7 & 0,1 \\
\hline 1,8 & 2,1 & 1,0 & 0,1 & 0,2 & 0,2 & 12,7 & 20,7 & 0,5 & 0,2 & $n$ & 0,2 & 1,2 & 3,8 & $n$ & $n$ & 0,4 & $n$ & 0,2 \\
\hline 10,8 & 0,1 & 0,2 & $\mathrm{n}$ & $\mathrm{n}$ & 0,1 & 0,4 & 2,5 & $\mathrm{n}$ & 0,1 & $\mathrm{n}$ & 0,1 & 0,2 & 0,2 & 0,1 & $n$ & 0,1 & 1,1 & 0,1 \\
\hline 37,8 & 0,1 & 0,2 & $\mathrm{n}$ & $\mathrm{n}$ & 0,1 & 0,6 & 6,2 & $n$ & $n$ & $n$ & $\mathrm{n}$ & $n$ & 3,6 & 0,1 & $n$ & 1,6 & 1,0 & $\mathrm{n}$ \\
\hline 3,1 & 0,4 & 0,5 & 0,7 & 0,5 & 0,2 & 2,9 & 10,3 & 0,3 & 7,5 & $\mathrm{n}$ & $\mathrm{n}$ & 8,0 & 0,4 & $n$ & $\mathrm{n}$ & 1,1 & 0,1 & 0,2 \\
\hline 0,4 & $\mathrm{n}$ & $\mathrm{n}$ & $n$ & $\mathrm{n}$ & $n$ & 0,2 & 0,2 & $\mathrm{n}$ & $n$ & $n$ & $\mathrm{n}$ & $n$ & 0,1 & $n$ & $n$ & $\mathrm{n}$ & 0,1 & 0,1 \\
\hline 5,0 & 0,9 & 0,2 & 0,6 & 0,1 & 0,2 & 3,4 & 18,4 & 1,0 & 0,5 & $\mathrm{n}$ & 0,3 & 2,2 & 0,4 & $\mathrm{n}$ & $\mathrm{n}$ & 0,1 & $\mathrm{n}$ & 0,1 \\
\hline 46,5 & $n$ & $\mathrm{n}$ & $n$ & $\mathrm{n}$ & $n$ & 0,6 & 0,6 & $\mathrm{n}$ & $n$ & $n$ & 1,4 & $n$ & 4,3 & 0,1 & $n$ & 0,1 & 2,4 & $\mathrm{n}$ \\
\hline 0,3 & 0,2 & 0,8 & 0,7 & $\mathrm{n}$ & $n$ & 2,8 & 3,1 & $\mathrm{n}$ & $n$ & $\mathrm{n}$ & $\mathrm{n}$ & 1,2 & 4,0 & 1,5 & $\mathrm{n}$ & $\mathrm{n}$ & 0,6 & 0,1 \\
\hline 0,9 & 0,7 & 1,2 & 0,1 & 0,2 & 0,2 & 4,3 & 10,7 & $\mathrm{n}$ & $n$ & $n$ & 0,1 & 4,3 & 1,7 & $n$ & $n$ & 0,3 & 0,1 & 0,3 \\
\hline 16,3 & 0,2 & 1,0 & $\mathrm{n}$ & 0,4 & 0,5 & 0,8 & 3,9 & $\mathrm{n}$ & $n$ & 0,1 & $\mathrm{n}$ & 0,6 & 7,7 & 0,9 & $n$ & 0,6 & 1,0 & 0,3 \\
\hline 2,3 & 1,0 & 1,1 & 0,8 & 0,7 & 3,5 & 7,5 & 34,7 & 0,3 & 0,8 & $n$ & 0,2 & 0,9 & 1,2 & 0,4 & $n$ & 1,0 & 0,2 & 1,8 \\
\hline 32,3 & 0,1 & 0,2 & 0,1 & 0,2 & 0,1 & 2,1 & 2,2 & $\mathrm{n}$ & $n$ & $\mathrm{n}$ & 0,1 & 0,2 & 4,2 & 0,1 & $n$ & 0,1 & 1,2 & 0,9 \\
\hline 22,3 & 0,1 & 0,1 & $\mathrm{n}$ & 0,2 & 0,1 & 1,7 & 2,8 & $n$ & $\mathrm{n}$ & $n$ & $\mathrm{n}$ & $\mathrm{n}$ & 5,6 & $n$ & $\mathrm{n}$ & 0,1 & 1,5 & 0,1 \\
\hline $\mathrm{n}$ & 0,3 & 2,6 & $\mathrm{n}$ & $\mathrm{n}$ & 0,1 & 74,1 & 13,9 & $\mathrm{n}$ & $\mathrm{n}$ & $n$ & $\mathrm{n}$ & 1,1 & 0,4 & $n$ & $\mathrm{n}$ & 0,1 & $\mathrm{n}$ & 0,1 \\
\hline 1,6 & 0,2 & 0,5 & 0,1 & 0,1 & 0,1 & 3,6 & 2,9 & $n$ & 0,1 & $n$ & 0,1 & 1,0 & 0,6 & $n$ & $n$ & 0,2 & 0,8 & 0,2 \\
\hline 14,1 & 0,1 & 0,2 & 0,1 & 0,1 & $n$ & 0,1 & 0,8 & $\mathrm{n}$ & $n$ & $\mathrm{n}$ & 0,1 & 0,1 & 0,2 & $\mathrm{n}$ & $n$ & 0,1 & 0,5 & 0,4 \\
\hline
\end{tabular}

Hinweis: Der Anteil der im Ausland Studierenden basiert nur auf der Gesamtzahl der in Ländern eingeschriebenen Studierenden, die Daten an die OECD melden. Die sich ergebenden Anteile sind deshalb zu hoch angesetzt, insbesondere bei Ländern, die viele Studierende in Länder entsenden, die keine Daten an die OECD melden. 1. Referenzjahr 2001.

Quelle: OECD. Hinweise s. Anhang 3 unter www.oecd.org/edu/eag2004. 
Tabelle C3.3 (Forts.)

Ausländische Studierende im Tertiärbereich nach dem Zielland (2002)

Zahl der im Tertiärbereich eingeschriebenen ausländischen Studierenden in einem bestimmten Zielland als Prozentsatz aller im Ausland eingeschriebenen Studierenden (basierend auf Personenzahlen)

Die Tabelle zeigt für jedes Land den Anteil der Studierenden, die im Ausland eingeschrieben sind, aufgegliedert nach dem Zielland.

Bedeutung der Spalte (2): 6,6 Prozent der tschechischen Studierenden im Tertiärbereich, die im Ausland eingeschrieben sind, studieren in Österreich, 9,1 Prozent der deutschen Studierenden im Tertiärbereich, die im Ausland eingeschrieben sind, studieren in Österreich, etc.

Bedeutung der Zeile (1): 3.0 Prozent der australischen Studierenden im Tertiärbereich, die im Ausland eingeschrieben sind, studieren in Frankreich, 4,o Prozent der australischen Studierenden im Tertiärbereich, die im Ausland eingeschrieben sind, studieren im Vereinigten Königreich, etc.

\begin{tabular}{|c|c|c|c|c|c|c|c|c|c|c|c|c|c|c|c|c|c|c|c|}
\hline \multirow[b]{2}{*}{$\begin{array}{l}\text { Heimatland } \\
\text { OECD-Länder }\end{array}$} & \multicolumn{19}{|c|}{ Zielland } \\
\hline & $\frac{c}{0}$ & 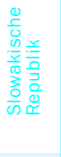 & $\begin{array}{l}\frac{0}{\infty} \\
\frac{0}{\pi} \\
0 \\
0\end{array}$ & 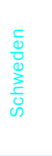 & $\begin{array}{l}\frac{N}{0} \\
\frac{3}{0} \\
\text { in }\end{array}$ & 可 & 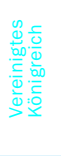 & 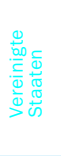 & 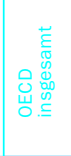 & 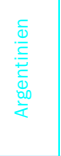 & 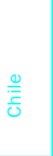 & $\begin{array}{l}\frac{c}{d} \\
\stackrel{ }{\leftrightarrows}\end{array}$ & $\begin{array}{l}\frac{c}{0} \\
\frac{0}{0} \\
\frac{0}{0} \\
\frac{0}{0} \\
\subseteq\end{array}$ & 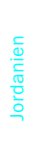 & $\frac{\frac{\pi}{\omega}}{\frac{\pi}{\pi}}$ & 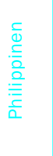 & 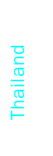 & 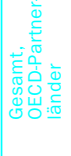 & 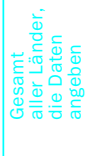 \\
\hline Australien & 0,1 & $\mathrm{n}$ & 0,5 & 3,9 & 1,0 & 0,4 & 24,0 & 50,2 & 98,2 & $n$ & 0,4 & 0,3 & 0,4 & $\mathrm{n}$ & 0,3 & 0,2 & 0,1 & 1,8 & 100 \\
\hline Österreich & 0,1 & $\mathrm{n}$ & 5,1 & 3,0 & 6,8 & 0,1 & 10,3 & 8,8 & 99,9 & $\mathrm{n}$ & 0,1 & $\mathrm{n}$ & $\mathrm{n}$ & $\mathrm{n}$ & $\mathrm{n}$ & $\mathrm{n}$ & $\mathrm{n}$ & 0,1 & 100 \\
\hline Belgien & $n$ & $\mathrm{n}$ & 12,5 & 2,0 & 2,6 & $\mathrm{n}$ & 21,6 & 8,5 & 99,8 & $\mathrm{n}$ & 0,1 & $\mathrm{n}$ & $\mathrm{n}$ & $\mathrm{n}$ & $\mathrm{n}$ & $\mathrm{n}$ & $\mathrm{n}$ & 0,2 & 100 \\
\hline Kanada & 0,3 & $\mathrm{n}$ & 0,2 & 0,9 & 0,5 & $\mathrm{n}$ & 8,7 & 74,0 & 99,5 & $\mathrm{n}$ & 0,1 & 0,2 & $\mathrm{n}$ & $\mathrm{n}$ & $\mathrm{n}$ & 0,1 & $\mathrm{n}$ & 0,5 & 100 \\
\hline Tschechische Republik & 3,8 & 5,1 & 3,7 & 2,3 & 2,3 & $\mathrm{n}$ & 6,6 & 19,3 & 99,9 & $\mathrm{n}$ & 0,1 & $\mathrm{n}$ & $\mathrm{n}$ & $n$ & $\mathrm{n}$ & $\mathrm{n}$ & $n$ & 0,1 & 100 \\
\hline Dänemark & 0,2 & $\mathrm{n}$ & 4,7 & 14,1 & 1,4 & $\mathrm{n}$ & 25,8 & 14,2 & 99,5 & $\mathrm{n}$ & 0,2 & $\mathrm{n}$ & $\mathrm{n}$ & $\mathrm{n}$ & $\mathrm{n}$ & $\mathrm{n}$ & 0,2 & 0,5 & 100 \\
\hline Finnland & 0,1 & $\mathrm{n}$ & 3,8 & 36,4 & 0,9 & $\mathrm{n}$ & 23,7 & 8,3 & 99,8 & $\mathrm{n}$ & 0,1 & $\mathrm{n}$ & $n$ & $\mathrm{n}$ & $\mathrm{n}$ & $\mathrm{n}$ & $n$ & 0,2 & 100 \\
\hline Frankreich & $\mathrm{n}$ & $\mathrm{n}$ & 10,6 & 2,3 & 6,1 & $\mathrm{n}$ & 24,0 & 14,6 & 99,6 & $\mathrm{n}$ & 0,3 & $\mathrm{n}$ & $\mathrm{n}$ & $\mathrm{n}$ & $\mathrm{n}$ & $\mathrm{n}$ & $\mathrm{n}$ & 0,4 & 100 \\
\hline Deutschland & 0,2 & $\mathrm{n}$ & 7,9 & 4,0 & 10,7 & 0,2 & 22,1 & 17,0 & 99,6 & $\mathrm{n}$ & 0,3 & $\mathrm{n}$ & $\mathrm{n}$ & $\mathrm{n}$ & $\mathrm{n}$ & $\mathrm{n}$ & $n$ & 0,4 & 100 \\
\hline Griechenland & 0,1 & 0,4 & 0,8 & 0,5 & 0,5 & 2,6 & 50,4 & 5,2 & 100,0 & $\mathrm{n}$ & $\mathrm{n}$ & $\mathrm{n}$ & $n$ & $n$ & $\mathrm{n}$ & $\mathrm{n}$ & $n$ & $n$ & 100 \\
\hline Ungarn & 0,9 & 0,2 & 2,3 & 2,4 & 2,4 & $\mathrm{n}$ & 5,2 & 16,1 & 99,9 & $\mathrm{n}$ & $n$ & $\mathrm{n}$ & $\mathrm{n}$ & $n$ & $\mathrm{n}$ & $\mathrm{n}$ & $n$ & 0,1 & 100 \\
\hline Island & $\mathrm{n}$ & $\mathrm{n}$ & 0,8 & 12,7 & 0,3 & $\mathrm{n}$ & 7,8 & 30,2 & 100,0 & $\mathrm{n}$ & $\mathrm{n}$ & $\mathrm{n}$ & $\mathrm{n}$ & $n$ & $\mathrm{n}$ & $\mathrm{n}$ & $n$ & $n$ & 100 \\
\hline Irland & $\mathrm{n}$ & $\mathrm{n}$ & 2,3 & 0,9 & 0,3 & $n$ & 78,0 & 6,9 & 99,9 & $\mathrm{n}$ & $\mathrm{n}$ & $\mathrm{n}$ & $\mathrm{n}$ & $n$ & $\mathrm{n}$ & $\mathrm{n}$ & $n$ & 0,1 & 100 \\
\hline Italien & $\mathrm{n}$ & $\mathrm{n}$ & 13,9 & 1,6 & 10,4 & $n$ & 13,6 & 8,1 & 99,9 & $\mathrm{n}$ & 0,1 & $\mathrm{n}$ & $n$ & $\mathrm{n}$ & $\mathrm{n}$ & $\mathrm{n}$ & $n$ & 0,1 & 100 \\
\hline Japan & $\mathrm{n}$ & $\mathrm{n}$ & 0,2 & 0,3 & 0,4 & $n$ & 9,1 & 74,6 & 99,2 & $\mathrm{n}$ & $n$ & 0,1 & 0,2 & $n$ & 0,3 & $n$ & 0,1 & 0,8 & 100 \\
\hline Korea & $\mathrm{n}$ & $\mathrm{n}$ & 0,1 & 0,1 & 0,2 & $n$ & 2,8 & 58,4 & 98,5 & $\mathrm{n}$ & $\mathrm{n}$ & 0,1 & 0,1 & $n$ & 0,4 & 0,7 & 0,1 & 1,5 & 100 \\
\hline Luxemburg & $\mathrm{n}$ & $\mathrm{n}$ & 0,2 & 0,1 & 3,8 & $n$ & 11,3 & 1,0 & 100,0 & $\mathrm{n}$ & $n$ & $n$ & $n$ & $n$ & $\mathrm{n}$ & $n$ & $\mathrm{n}$ & $n$ & 100 \\
\hline Mexiko & $\mathrm{n}$ & $\mathrm{n}$ & 8,6 & 0,6 & 0,5 & $n$ & 8,0 & 68,3 & 99,5 & $\mathrm{n}$ & 0,5 & $n$ & $n$ & $n$ & $\mathrm{n}$ & $\mathrm{n}$ & $n$ & 0,5 & 100 \\
\hline Niederlande & 0,1 & $\mathrm{n}$ & 7,9 & 4,9 & 2,3 & 0,1 & 18,5 & 15,1 & 99,7 & $\mathrm{n}$ & 0,1 & $\mathrm{n}$ & 0,1 & $\mathrm{n}$ & $\mathrm{n}$ & $\mathrm{n}$ & 0,1 & 0,3 & 100 \\
\hline Neuseeland & $\mathrm{n}$ & $\mathrm{n}$ & 0,1 & 0,3 & 0,2 & $n$ & 5,8 & 14,4 & 99,6 & $\mathrm{n}$ & $n$ & 0,1 & 0,1 & $n$ & 0,1 & $\mathrm{n}$ & 0,1 & 0,4 & 100 \\
\hline Norwegen & 2,4 & 0,1 & 1,8 & 8,3 & 0,7 & $n$ & 22,8 & 14,7 & 99,7 & $\mathrm{n}$ & 0,1 & $\mathrm{n}$ & $n$ & 0,1 & $\mathrm{n}$ & $n$ & 0,1 & 0,3 & 100 \\
\hline Polen & a & 0,1 & 2,4 & 3,6 & 1,7 & $n$ & 3,3 & 11,7 & 99,9 & $\mathrm{n}$ & $\mathrm{n}$ & 0,1 & $\mathrm{n}$ & $\mathrm{n}$ & $\mathrm{n}$ & $\mathrm{n}$ & $n$ & 0,1 & 100 \\
\hline Portugal & 0,1 & $\mathrm{n}$ & 16,0 & 1,1 & 4,2 & $\mathrm{n}$ & 19,4 & 8,4 & 99,9 & $n$ & $\mathrm{n}$ & $\mathrm{n}$ & $\mathrm{n}$ & $\mathrm{n}$ & $\mathrm{n}$ & $\mathrm{n}$ & $\mathrm{n}$ & 0,1 & 100 \\
\hline Slowakische Republik & 1,0 & a & 0,8 & 0,3 & 1,1 & $n$ & 1,2 & 5,6 & 100,0 & $\mathrm{n}$ & $\mathrm{n}$ & $\mathrm{n}$ & $\mathrm{n}$ & $\mathrm{n}$ & $\mathrm{n}$ & $n$ & $n$ & $\mathrm{n}$ & 100 \\
\hline Spanien & 0,1 & $\mathrm{n}$ & a & 3,1 & 5,6 & $\mathrm{n}$ & 27,4 & 15,2 & 99,6 & $\mathrm{n}$ & 0,3 & $\mathrm{n}$ & $\mathrm{n}$ & $\mathrm{n}$ & $\mathrm{n}$ & $\mathrm{n}$ & $\mathrm{n}$ & 0,4 & 100 \\
\hline Schweden & 0,6 & $\mathrm{n}$ & 3,0 & a & 1,5 & $n$ & 25,1 & 26,5 & 99,2 & $\mathrm{n}$ & 0,6 & $\mathrm{n}$ & $n$ & 0,1 & $\mathrm{n}$ & $\mathrm{n}$ & 0,1 & 0,8 & 100 \\
\hline Schweiz & $\mathrm{n}$ & $\mathrm{n}$ & 3,0 & 2,2 & a & $n$ & 15,7 & 20,5 & 99,7 & $\mathrm{n}$ & 0,2 & 0,1 & $\mathrm{n}$ & $n$ & $\mathrm{n}$ & $\mathrm{n}$ & $n$ & 0,3 & 100 \\
\hline Türkei & $\mathrm{n}$ & $\mathrm{n}$ & $\mathrm{n}$ & 0,3 & 1,3 & a & 3,0 & 25,5 & 99,9 & $\mathrm{n}$ & $\mathrm{n}$ & $\mathrm{n}$ & $\mathrm{n}$ & $\mathrm{n}$ & $\mathrm{n}$ & $\mathrm{n}$ & 0,1 & 0,1 & 100 \\
\hline Vereinigtes Königreich & 0,1 & $\mathrm{n}$ & 8,1 & 2,9 & 1,1 & 0,4 & a & 30,4 & 99,3 & $\mathrm{n}$ & 0,1 & 0,2 & $n$ & 0,1 & 0,1 & 0,1 & 0,1 & 0,7 & 100 \\
\hline $\begin{array}{l}\text { Vereinigte Staaten } \\
\text { OECD-Partnerländer }\end{array}$ & 1,1 & $\mathrm{n}$ & 1,4 & 2,4 & 0,9 & 0,1 & 31,8 & a & 93,6 & $\mathrm{n}$ & 2,2 & 0,6 & 0,1 & 0,1 & 1,9 & 1,1 & 0,4 & 6,4 & 100 \\
\hline Argentinien & $n$ & $\mathrm{n}$ & 18,0 & 0,6 & 1,3 & $n$ & 5,5 & 47,1 & 93,9 & a & 6,1 & $n$ & $\mathrm{n}$ & $n$ & $\mathrm{n}$ & $n$ & $n$ & 6,1 & 100 \\
\hline Brasilien & 0,2 & $\mathrm{n}$ & 7,3 & 0,6 & 1,3 & $n$ & 6,2 & 54,8 & 97,6 & 1,2 & 1,2 & $\mathrm{n}$ & $n$ & $n$ & $\mathrm{n}$ & $\mathrm{n}$ & $n$ & 2,4 & 100 \\
\hline Chile & $n$ & $\mathrm{n}$ & 15,6 & 5,0 & 1,5 & $n$ & 4,7 & 31,0 & 86,5 & 13,5 & a & $n$ & $n$ & $n$ & $\mathrm{n}$ & $\mathrm{n}$ & $n$ & 13,5 & 100 \\
\hline China & $\mathrm{n}$ & $\mathrm{n}$ & 0,1 & 0,4 & 0,3 & $\mathrm{n}$ & 9,6 & 34,8 & 96,4 & $n$ & $n$ & $\mathrm{n}$ & $\mathrm{n}$ & $n$ & 2,7 & 0,4 & 0,5 & 3,6 & 100 \\
\hline Ägypten & $\mathrm{n}$ & 0,3 & 0,6 & 0,4 & 1,1 & 0,7 & 11,8 & 38,8 & 99,0 & $\mathrm{n}$ & $n$ & 0,1 & $\mathrm{n}$ & 0,6 & 0,3 & $\mathrm{n}$ & $n$ & 1,0 & 100 \\
\hline Indien & $\mathrm{n}$ & $\mathrm{n}$ & 0,1 & 0,1 & 0,2 & $n$ & 6,8 & 76,0 & 99,2 & $\mathrm{n}$ & $\mathrm{n}$ & a & $n$ & $n$ & 0,6 & 0,1 & 0,1 & 0,8 & 100 \\
\hline Indonesien & $n$ & $n$ & $\mathrm{n}$ & 0,1 & 0,1 & $n$ & 2,5 & 32,2 & 86,4 & $\mathrm{n}$ & $\mathrm{n}$ & 0,3 & a & $\mathrm{n}$ & 13,0 & 0,3 & 0,1 & 13,6 & 100 \\
\hline Israel & 0,6 & 1,2 & 0,9 & 0,3 & 0,5 & 0,5 & 18,9 & 40,5 & 99,7 & $\mathrm{n}$ & 0,1 & 0,1 & $n$ & $n$ & $\mathrm{n}$ & $\mathrm{n}$ & $n$ & 0,3 & 100 \\
\hline Jamaika & $\mathrm{n}$ & $\mathrm{n}$ & $\mathrm{n}$ & $n$ & $n$ & $n$ & 10,2 & 88,5 & 99,9 & $n$ & 0,1 & $\mathrm{n}$ & $n$ & $n$ & $\mathrm{n}$ & $\mathrm{n}$ & $n$ & 0,1 & 100 \\
\hline Jordanien & 0,8 & 0,2 & 1,1 & 0,4 & 0,4 & 3,4 & 14,0 & 42,8 & 96,4 & $\mathrm{n}$ & $\mathrm{n}$ & 1,0 & $\mathrm{n}$ & a & 2,5 & $\mathrm{n}$ & $n$ & 3,6 & 100 \\
\hline Malaysia & $n$ & $\mathrm{n}$ & $\mathrm{n}$ & 0,1 & $n$ & $n$ & 23,8 & 19,6 & 99,4 & $\mathrm{n}$ & $\mathrm{n}$ & 0,4 & $n$ & $n$ & a & $\mathrm{n}$ & 0,2 & 0,6 & 100 \\
\hline Paraguay & 0,2 & $\mathrm{n}$ & 5,3 & 0,3 & 0,2 & 0,1 & 1,9 & 36,2 & 59,3 & 36,0 & 4,5 & $\mathrm{n}$ & $\mathrm{n}$ & $\mathrm{n}$ & $\mathrm{n}$ & 0,2 & $\mathrm{n}$ & 40,7 & 100 \\
\hline Peru & 0,1 & $n$ & 14,1 & 0,8 & 2,1 & $n$ & 2,2 & 41,2 & 85,7 & 4,4 & 9,8 & $\mathrm{n}$ & $n$ & $n$ & $\mathrm{n}$ & $\mathrm{n}$ & $n$ & 14,3 & 100 \\
\hline Philippinen & 0,1 & $\mathrm{n}$ & 0,6 & 0,4 & 0,3 & $\mathrm{n}$ & 4,9 & 57,7 & 98,5 & $\mathrm{n}$ & $\mathrm{n}$ & 0,1 & $\mathrm{n}$ & 0,3 & 0,5 & a & 0,6 & 1,5 & 100 \\
\hline Russische Föderation & 1,1 & 0,2 & 0,6 & 2,3 & 1,8 & 3,3 & 5,7 & 26,2 & 99,8 & $\mathrm{n}$ & $\mathrm{n}$ & $\mathrm{n}$ & $n$ & $n$ & $\mathrm{n}$ & $\mathrm{n}$ & 0,1 & 0,2 & 100 \\
\hline Sri Lanka & $\mathrm{n}$ & $\mathrm{n}$ & $\mathrm{n}$ & 0,4 & 0,3 & $\mathrm{n}$ & 17,5 & 24,2 & 86,6 & $\mathrm{n}$ & $\mathrm{n}$ & 4,5 & $\mathrm{n}$ & 8,1 & 0,6 & 0,1 & 0,2 & 13,4 & 100 \\
\hline Thailand & $\mathrm{n}$ & $\mathrm{n}$ & 0,1 & 0,3 & 0,1 & $n$ & 10,8 & 51,6 & 97,6 & $\mathrm{n}$ & $\mathrm{n}$ & 1,2 & $\mathrm{n}$ & $n$ & 0,8 & 0,4 & a & 2,4 & 100 \\
\hline Tunesien & 0,1 & $\mathrm{n}$ & 0,2 & 0,1 & 2,1 & 0,1 & 0,4 & 4,3 & 99,9 & $n$ & $\mathrm{n}$ & $n$ & $n$ & 0,1 & $\mathrm{n}$ & $\mathrm{n}$ & $n$ & 0,1 & 100 \\
\hline Uruguay & $\mathrm{n}$ & $n$ & 12,0 & 1,0 & 1,2 & $n$ & 3,3 & 31,8 & 61,4 & 34,0 & 4,3 & $\mathrm{n}$ & $n$ & 0,3 & $\mathrm{n}$ & $n$ & $n$ & 38,6 & 100 \\
\hline Simbabwe & 0,1 & $\mathrm{n}$ & 0,1 & 0,2 & 0,1 & 0,1 & 47,0 & 35,6 & 99,9 & $\mathrm{n}$ & $\mathrm{n}$ & 0,1 & $n$ & $\mathrm{n}$ & $\mathrm{n}$ & $\mathrm{n}$ & $\mathrm{n}$ & 0,1 & 100 \\
\hline
\end{tabular}

Hinweis: Der Anteil der im Ausland Studierenden basiert nur auf der Gesamtzahl der in Ländern eingeschriebenen Studierenden, die Daten an die OECD melden. Die sich ergebenden Anteile sind deshalb zu hoch angesetzt, insbesondere bei Ländern, die viele Studierende in Länder entsenden, die keine Daten an die OECD melden. 1. Referenzjahr 2001.

Quelle: OECD. Hinweise s. Anhang 3 unter www.oecd.org/edu/eag2004. 


\section{Tabelle C3.4}

Verteilung ausländischer Studierender nach Bildungsbereich (2002)

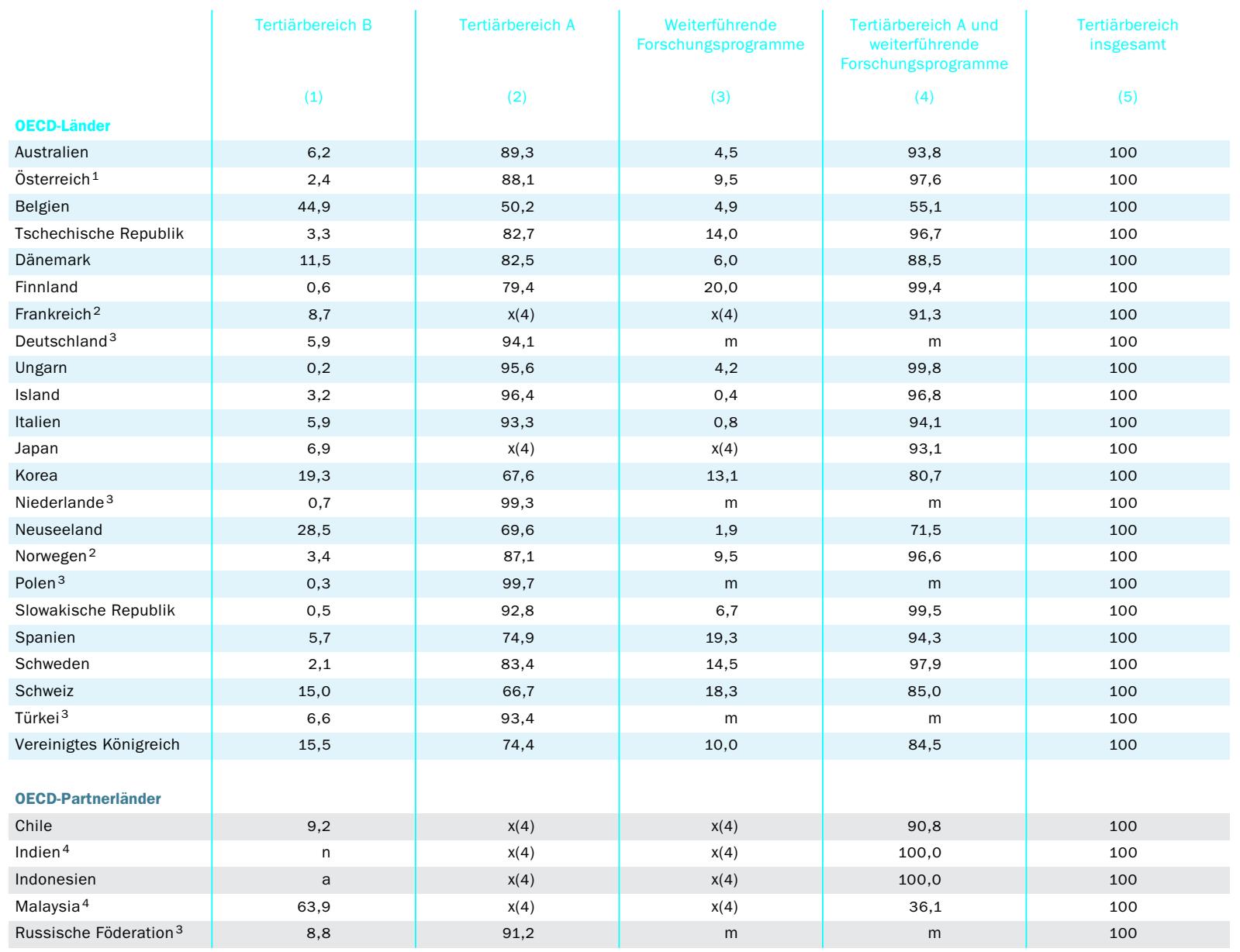

Hinweis: $x$ bedeutet, dass die Daten in einer anderen Spalte enthalten sind, deren Referenz in runden Klammern nach dem ,x' angegeben ist. So bedeutet $z$. B. $x(4)$, dass die Daten in Spalte 4 enthalten sind.

1. Basierend auf der Zahl der Einschreibungen, nicht Personenzahlen. 2. Basierend auf nicht vollständigen Daten, die nur 81 Prozent der ausländischen Studierenden abdecken. 3. Ohne weiterführende Forschungsprogramme. 4. Referenzjahr 2001

Quelle: OECD. Hinweise s. Anhang 3 unter www.oecd.org/edu/eag2004. 
Tabelle C3.5

Verteilung ausländischer Studierender nach Studienbereichen (2002)

\begin{tabular}{|c|c|c|c|c|c|c|c|c|c|c|}
\hline OECD-Länder & $\begin{array}{l}\text { Agrarwissen- } \\
\text { schaften }\end{array}$ & $\begin{array}{l}\text { Erziehungs- } \\
\text { wissen- } \\
\text { schaften }\end{array}$ & $\begin{array}{l}\text { Ingenieur- } \\
\text { wesen, } \\
\text { Fertigung } \\
\text { und } \\
\text { Bauwesen }\end{array}$ & $\begin{array}{c}\text { Gesundheit } \\
\text { und } \\
\text { Soziales }\end{array}$ & $\begin{array}{l}\text { Geistes- } \\
\text { wissen- } \\
\text { schaften } \\
\text { und Kunst }\end{array}$ & $\begin{array}{c}\text { Naturwissen- } \\
\text { schaften }\end{array}$ & $\begin{array}{l}\text { Dienstleis- } \\
\text { tungen }\end{array}$ & $\begin{array}{c}\text { Sozial-, } \\
\text { Rechts-, } \\
\text { Wirtschafts- } \\
\text { wissen- } \\
\text { schaften }\end{array}$ & $\begin{array}{c}\text { Nicht } \\
\text { bekannt } \\
\text { oder keine } \\
\text { Angabe }\end{array}$ & $\begin{array}{c}\text { Alle Studien- } \\
\text { bereiche } \\
\text { zusammen }\end{array}$ \\
\hline Australien & 0,7 & 3,4 & 10,9 & 6,8 & 8,1 & 22,1 & 1,7 & 40,6 & 5,9 & 100 \\
\hline Österreich ${ }^{1}$ & 1,6 & 5,6 & 13,5 & 9,4 & 24,4 & 10,7 & 1,0 & 33,6 & 0,1 & 100 \\
\hline Belgien & 5,2 & 3,8 & 6,7 & 25,6 & 11,2 & 8,2 & 2,2 & 19,7 & 17,4 & 100 \\
\hline Tschechische Rep. & 3,0 & 1,5 & 14,9 & 27,7 & 11,3 & 11,2 & 1,4 & 28,9 & $\mathrm{n}$ & 100 \\
\hline Dänemark & 2,6 & 3,8 & 15,4 & 19,7 & 18,5 & 10,5 & 0,7 & 28,8 & $n$ & 100 \\
\hline Finnland & 2,0 & 2,4 & 28,4 & 10,4 & 18,5 & 10,3 & 3,1 & 24,9 & $\mathrm{n}$ & 100 \\
\hline Deutschland ${ }^{2}$ & 1,1 & 4,3 & 16,9 & 6,2 & 22,5 & 14,9 & 1,0 & 26,8 & 6,2 & 100 \\
\hline Ungarn & 10,7 & 10,2 & 14,3 & 22,1 & 16,0 & 4,2 & 3,1 & 19,6 & $\mathrm{n}$ & 100 \\
\hline Island & 1,3 & 10,4 & 4,0 & 4,7 & 44,3 & 13,6 & 1,9 & 19,9 & $n$ & 100 \\
\hline Italien & 1,8 & 1,4 & 13,5 & 27,1 & 19,5 & 5,4 & 0,8 & 27,7 & 2,7 & 100 \\
\hline Japan & 3,2 & 3,6 & 14,6 & 5,1 & 24,2 & 1,9 & 1,7 & 35,8 & 10,0 & 100 \\
\hline Niederlande $^{2}$ & 0,8 & 6,2 & 11,6 & 14,2 & 11,0 & 6,5 & 2,3 & 46,9 & 0,7 & 100 \\
\hline Neuseeland & 0,6 & 1,4 & 5,2 & 3,2 & 9,6 & 15,5 & 3,4 & 52,7 & 8,4 & 100 \\
\hline Norwegen & 2,2 & 8,6 & 6,1 & 16,0 & 14,5 & 14,7 & 3,2 & 25,5 & 9,1 & 100 \\
\hline Polen ${ }^{2}$ & 0,8 & 8,5 & 6,2 & 19,7 & 26,5 & 2,0 & 1,6 & 34,8 & $\mathrm{n}$ & 100 \\
\hline Slowakische Rep. & 9,3 & 5,4 & 12,1 & 33,9 & 13,3 & 4,3 & 3,5 & 18,2 & $\mathrm{n}$ & 100 \\
\hline Schweden & 1,0 & 7,2 & 18,1 & 14,6 & 16,0 & 13,1 & 1,1 & 28,5 & 0,2 & 100 \\
\hline Schweiz & 0,8 & 3,9 & 15,5 & 6,0 & 16,7 & 14,5 & 6,6 & 34,6 & 1,4 & 100 \\
\hline Türkei² & 2,7 & 7,1 & 14,2 & 12,7 & 6,8 & 7,3 & 7,2 & 42,0 & $\mathrm{n}$ & 100 \\
\hline Ver. Königreich & 1,1 & 4,3 & 16,1 & 11,6 & 16,7 & 15,3 & 0,9 & 34,0 & $n$ & 100 \\
\hline
\end{tabular}

1. Basierend auf der Zahl der Einschreibungen, nicht Personenzahlen. 2. Ohne weiterführende Forschungsprogramme.

Quelle: OECD. Hinweise s. Anhang 3 unter www.oecd.org/edu/eag2004.

\section{Tabelle C3.6}

Entwicklungstendenzen bei der Zahl ausländischer Studierender, die außerhalb ihres Heimatlandes eingeschrieben sind (1998, 2000, 2001, 2002)

Zahl ausländischer Studierender, die außerhalb ihres Heimatlandes eingeschrieben sind (basierend auf Personenzahlen)

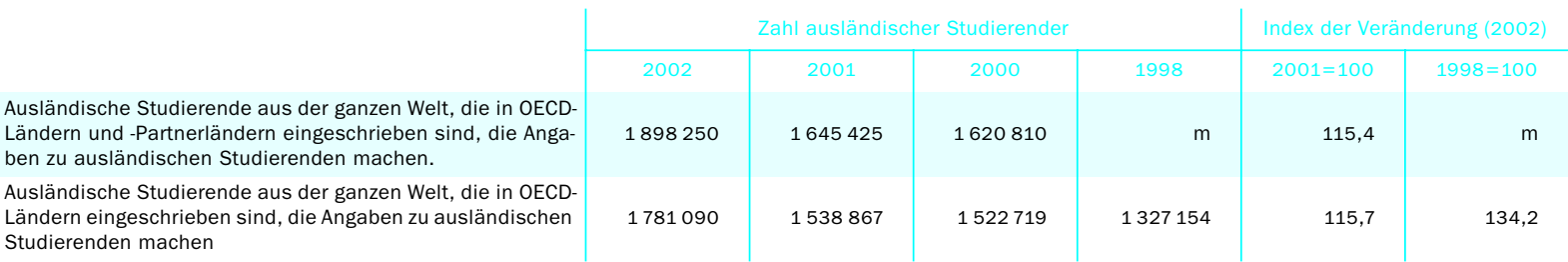

Hinweis: Die Zahlen basieren auf der Zahl ausländischer Studierender, die in OECD-Ländern und -Partnerländern eingeschrieben sind, die Angaben zu ausländischen Studierenden machen. Die Zahl dieser Länder hat im Laufe der Zeit immer zugenommen, so dass die Zahlen nicht uneingeschränkt vergleichbar sind, daher sollte die Interpretation von Entwicklungen mit Vorsicht geschehen.

Quelle: OECD. Hinweise s. Anhang 3 unter www.oecd.org/edu/eag2004. 



\section{Bildungs- und Beschäftigungsstatus junger Menschen}

I Im Durchschnitt konnte ein im Jahr 2002 Fünfzehnjähriger erwarten, für knapp 6,5 Jahre im formalen Bildungssystem zu verbleiben. In 17 der 28 untersuchten Länder liegt dieser Zeitraum zwischen fast 6 und 7,5 Jahren.

Zusätzlich zu den in Ausbildung zu erwartenden Jahren kann ein Fünfzehnjähriger damit rechnen, während der nächsten 15 Jahre für 6,4 Jahre beschäftigt, für insgesamt 0,8 Jahre arbeitslos und für 1,3 Jahre nicht auf dem Arbeitsmarkt zu sein. Die Länder unterscheiden sich am stärksten in der durchschnittlichen Länge der Phasen der Arbeitslosigkeit, was hauptsächlich die unterschiedlichen Beschäftigungsquoten junger Menschen widerspiegelt.

In 23 von 27 OECD-Ländern haben 20- bis 24-jährige Frauen eine höhere Bildungsbeteiligung als gleichaltrige Männer. Die 20- bis 24-jährigen Männer sind eher berufstätig. In den meisten OECD-Ländern liegt der Prozentsatz 20- bis 24-Jähriger, die sich nicht in Ausbildung befinden, zwischen 50 und 70 Prozent.

- In einigen Ländern erfolgen Bildung und Arbeit überwiegend nacheinander, während sie in anderen parallel stattfinden. Duale Ausbildungsgänge, in europäischen Ländern relativ weit verbreitet, bieten eine kohärente berufliche Ausbildung, die zu anerkannten Berufsabschlüssen führt. In anderen Ländern werden Erstausbildung und bezahlte Arbeit selten kombiniert. 
Abbildung C4.1

Zu erwartende Jahre in Ausbildung und nicht in Ausbildung für 15- bis 29-Jährige (2002)

Zahl der Jahre, nach Erwerbsstatus

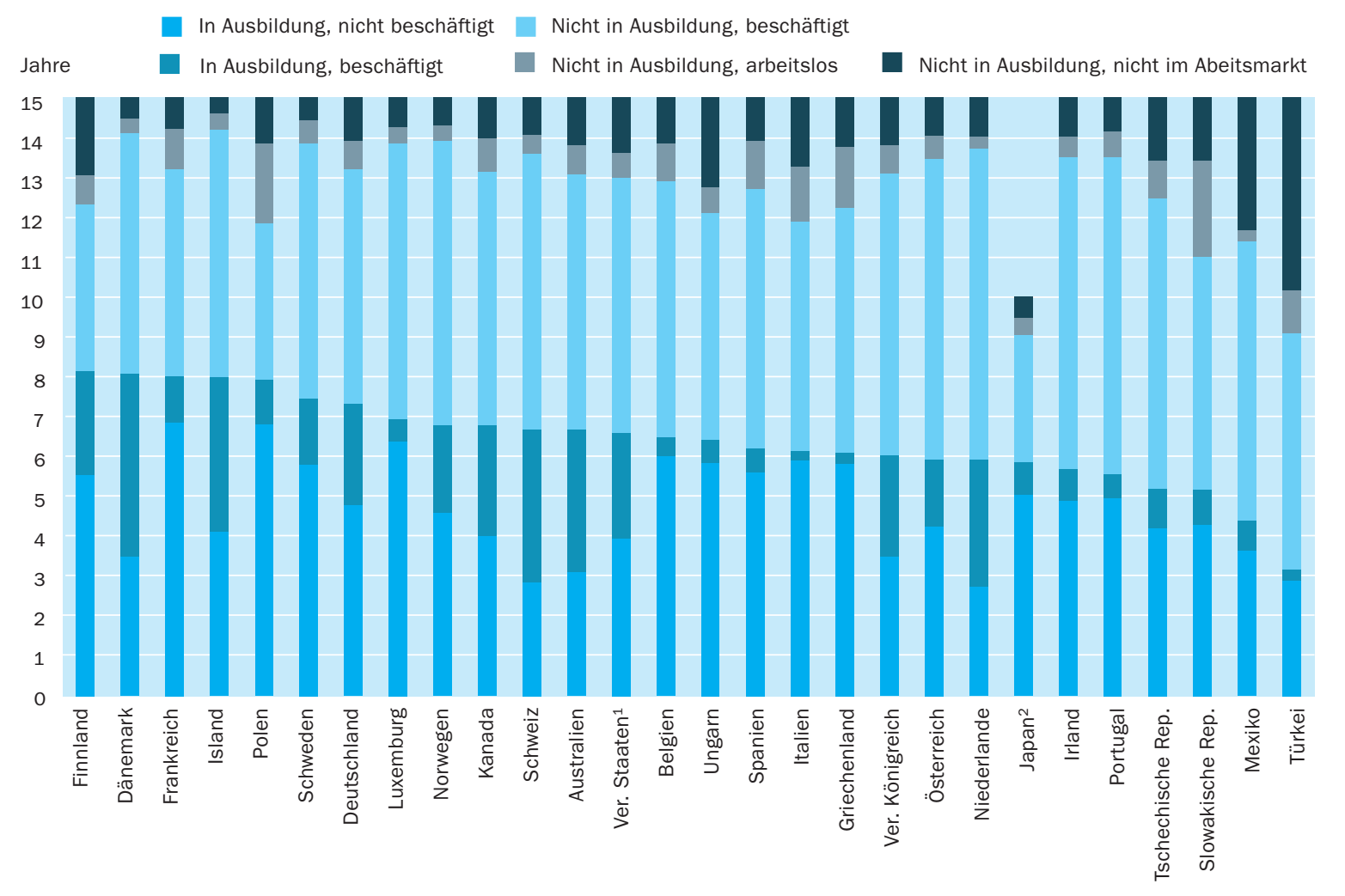

1. Referenzjahr 2001. 2. Daten beziehen sich auf 15- bis 24 Jährige.

Anordnung der Länder in absteigender Reihenfolge der von jungen Menschen zu erwartenden Jahre in Ausbildung.

Quelle: OECD, Tabelle C4.1.a. Hinweise s. Anhang 3 unter www.oecd.org/edu/eag2004.

Dieser Indikator zeigt die zu erwartenden Jahre, die junge Menschen in Ausbildung, Beschäftigung und NichtBeschäftigung zubringen werden ...

... und untersucht den Bildungs- und Beschäftigungsstatus junger Frauen und Männer.

\section{Politischer Hintergrund}

Im Laufe des letzten Jahrzehnts ist die Zeit, die junge Menschen in der Erstausbildung verbringen, gestiegen, so dass sich ihr Eintritt in die Arbeitswelt zeitlich verschiebt. In einem Teil dieser zusätzlichen Zeit werden Arbeit und Ausbildung miteinander verknüpft, eine in einigen Ländern weit verbreitete Praxis. Wenn junge Menschen ihre Erstausbildung abgeschlossen haben, wird der Übergang zum Arbeitsmarkt häufig durch Phasen der Arbeitslosigkeit bzw. der Nicht-Beschäftigung erschwert, wobei Männer und Frauen nicht in gleicher Weise betroffen sind.

Alle OECD-Länder erleben einen rapiden gesellschaftlichen und wirtschaftlichen Wandel, der die Unsicherheit des Übergangs ins Erwerbsleben erhöht. In einigen OECD-Ländern erfolgen Bildung und Arbeit überwiegend nacheinander, während sie in anderen parallel stattfinden können. Es kann entscheidende Auswirkung auf den Erfolg des Übergangs ins Erwerbsleben haben, wie Ausbildung und Arbeit miteinander verbunden wurden. Hier ist insbesondere 
von Interesse, inwieweit eine Beschäftigung neben der Ausbildung (über den normalen ,Ferienjob' hinaus) den Eintritt in den Arbeitsmarkt erleichtert. Es sollte auch berücksichtigt werden, ob Schüler/Studierende, die neben der Ausbildung viele Stunden arbeiten, eher dazu neigen, die Ausbildung abzubrechen, und es ist zu untersuchen, ob gleichzeitiges Arbeiten und Lernen zu einem reibungslosen Übertritt in den Arbeitsmarkt beiträgt.

\section{Ergebnisse und Erläuterungen}

Basierend auf der gegenwärtigen Lage I5- bis 29-Jähriger bildet dieser Indikator die wichtigsten Tendenzen beim Übergang vom (Aus-)Bildungssystem zum Erwerbsleben ab.

Im Durchschnitt konnte ein im Jahr 2002 Fünfzehnjähriger erwarten, ca. 6,5 Jahre im Bildungssystem zu verbleiben (Tab. C4.I). In 17 der 28 untersuchten Länder können I5-Jährige damit rechnen, dass sie zwischen 5,9 und 7,5 Jahren im Bildungssystem verbringen. Es besteht jedoch eine Kluft von ungefähr vier Jahren zwischen den beiden an den Extremen liegenden Ländergruppen - Dänemark, Finnland, Frankreich und Island (mit durchschnittlich mehr als 8 Jahren) auf der einen Seite und Mexiko, der Slowakischen und der Tschechischen Republik sowie der Türkei (mit 4,5 Jahren im Durchschnitt) auf der anderen Seite.

Die Zahl für die zu erwartenden Jahre im Bildungssystem umfasst sehr unterschiedliche Kombinationen von Ausbildung und Arbeit. $\mathrm{Zu}$ den Möglichkeiten der Kombination von Ausbildung und Arbeit gehören sowohl duale Ausbildungsgänge als auch Teilzeitbeschäftigung. Während solche Kombinationen in der Hälfte der untersuchten Länder nur eine Randerscheinung sind, machen sie in der anderen Hälfte zwischen ein und vier Jahre der zusätzlichen Bildungsdauer aus, die junge Menschen erwarten können.

Zusätzlich zu den durchschnittlich 6,5 weiteren Jahren im Bildungssystem kann ein Fünfzehnjähriger damit rechnen, für 6,4 Jahre der kommenden I5 Jahre beschäftigt, für insgesamt o,8 Jahre arbeitslos und für I, 3 Jahre nicht im Arbeitsmarkt zu sein, d.h. weder in Ausbildung noch arbeitssuchend zu sein (Tab. A4.I). Bemerkenswert ist, dass in absoluten Zahlen gesehen, junge Menschen heute nach Beendigung der Erstausbildung kürzere Zeiten der Arbeitslosigkeit zu erwarten haben als vor zehn Jahren.

Die durchschnittliche Länge der Phasen der Arbeitslosigkeit variiert erheblich zwischen den einzelnen Ländern, was hauptsächlich Unterschiede in den Beschäftigungsquoten der jungen Menschen widerspiegelt. Die aufaddierten Phasen der Arbeitslosigkeit belaufen sich im Durchschnitt in Dänemark, Island, Luxemburg, Mexiko, den Niederlanden und Norwegen auf weniger als 5 Monate, während sie in Griechenland, Polen und der Slowakischen Republik mehr als I8 Monate betragen.

Die Tendenz, die in den letzten Jahren zu beobachten war, hält in den meisten Ländern an. Nur in ganz wenigen Ländern bleibt die Lage unverändert: das schon erreichte lange Verbleiben in Ausbildung in Frankreich und Schweden,
Ein Fünfzehnjähriger kann im Durchschnitt erwarten, etwa weitere 6,5 Jahre im Bildungssystem zu verbleiben.

Die Zahl für die zu erwartenden Jahre im Bildungssystem umfasst sehr unterschiedliche Kombinationen von Ausbildung und Arbeit.

Ein Fünfzehnjähriger kann heute damit rechnen, bis er 29 Jahre alt ist, 6,4 Jahre lang beschäftigt, fast ein Jahr arbeitslos und für 1,3 Jahre nicht auf dem Arbeitsmarkt zu sein.

In den meisten Ländern nahm die Zahl der zu erwartenden Jahre in Ausbildung in den letzten fünf Jahren zu. 
die mittlere Dauer in Kanada und den Vereinigten Staaten und ein kurzer Verbleib, der sich in Irland und darüber hinaus in Portugal und der Türkei als bedenklich erweisen könnte (Abb. C4.2).

Nur in Norwegen und Spanien zeigt sich ein Trend zum kürzeren Verbleib im Bildungssystem. In den übrigen Ländern setzt sich der deutliche Aufwärtstrend fort. Seit 1998 nahmen die zu erwartenden Jahre in Ausbildung für einen I5-Jährigen in Australien, Deutschland, Griechenland, Mexiko, Polen, der Slowakischen Republik und Ungarn um mehr als 6 Monate zu.

Die durchschnittliche Gesamtzahl der zu erwartenden Bildungsdauer liegt für Frauen höher als für Männer (6,6 gegenüber 6,3 Jahren). In allen außer sieben Ländern (Deutschland, Japan, Luxemburg, Mexiko, den Niederlanden, der Schweiz und der Türkei) zeigen die Zahlen für Frauen einen längeren Verbleib im Bildungssystem. In der Türkei können Frauen jedoch nur mit einem Jahr weniger Ausbildung rechnen als ihre männlichen Altersgenossen. Am anderen Ende des Spektrums gibt es in Finnland, Island, Norwegen und dem Vereinigten Königreich ungefähr den gleichen Bildungsnachteil für die Männer (Abb. C4·3)

\section{Abbildung C4.2}

Veränderung der zu erwartenden Jahre in Ausbildung für 15- bis 29 Jährige (1998-2002)

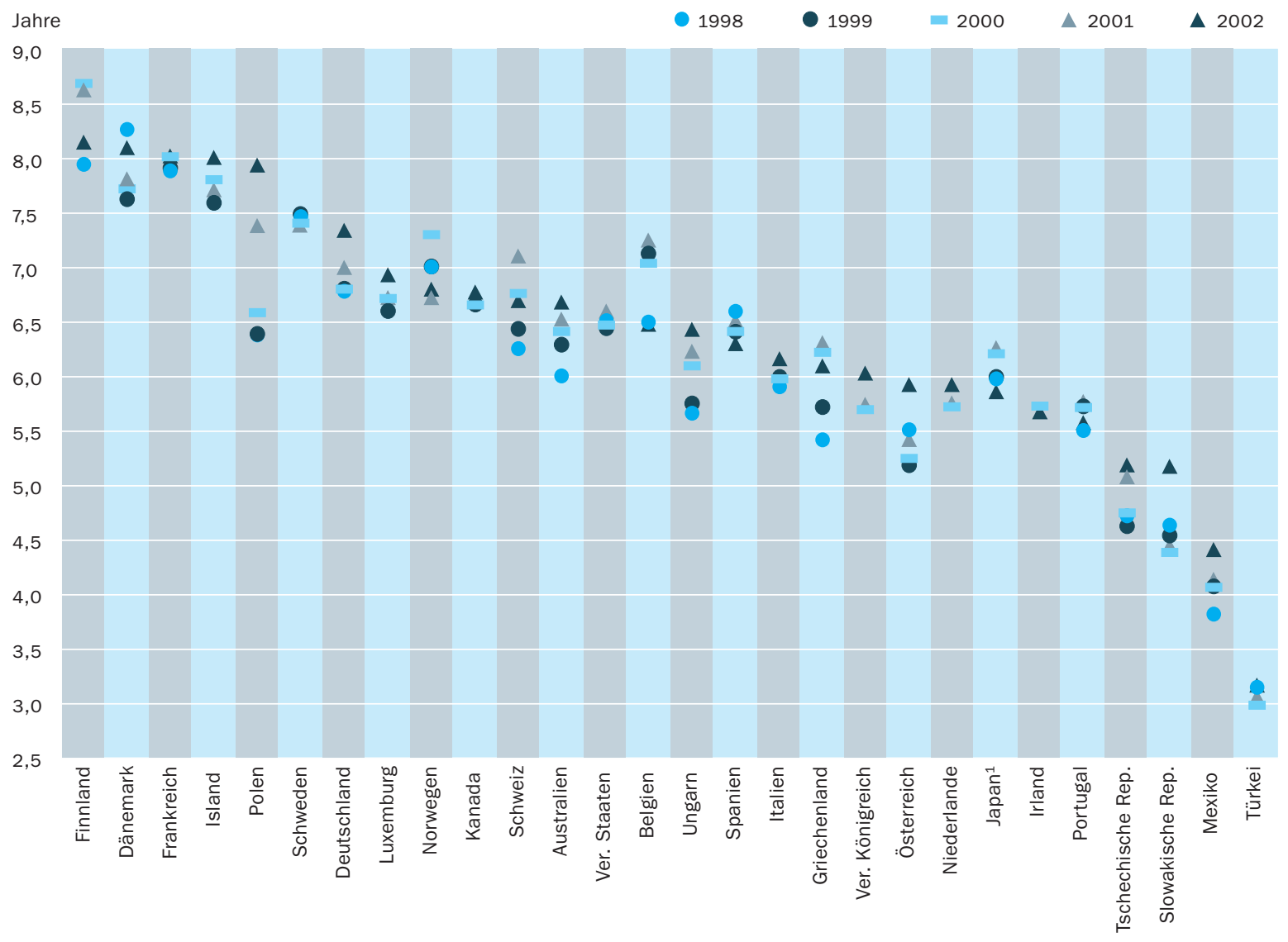

1. Daten beziehen sich auf 15- bis 24 Jährige.

Anordnung der Länder in absteigender Reihenfolge der von jungen Menschen 2002 zu erwartenden Jahre in Ausbildung.

Quelle: OECD, Tabelle C4.1b. Hinweise s. Anhang 3 unter www.oecd.org/edu/eag2004. 
Im Großen und Ganzen unterscheiden sich Männer und Frauen hinsichtlich der zu erwartenden Anzahl von Jahren der Arbeitslosigkeit sehr wenig, obwohl die zu erwartenden Phasen der Arbeitslosigkeit für Männer tendenziell länger sind. In den meisten Ländern ist die Situation für beide Geschlechter ähnlich bzw. es gibt einen leichten Nachteil für die Männer. In Italien, Griechenland, Portugal, Spanien und der Tschechischen Republik dagegen sind die Frauen

\section{Abbildung C4.3}

Geschlechtspezifische Unterschiede bei den zu erwartenden Jahren in Ausbildung und nicht in Ausbildung für 15- bis 29-Jährige (2002)

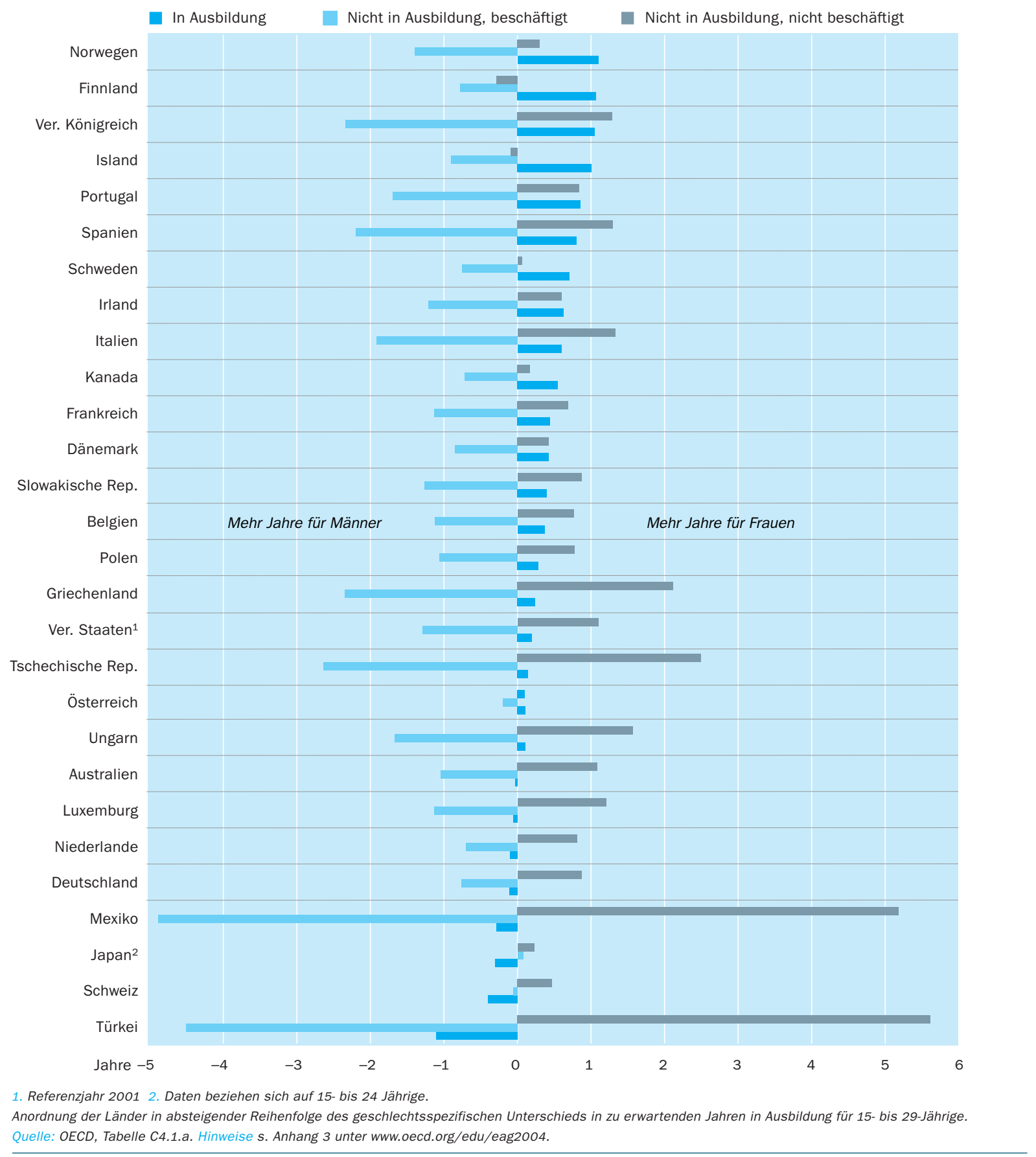


Es ergeben sich nicht nur hinsichtlich der Dauer der Ausbildung, sondern auch hinsichtlich ihrer Kombination mit praktischen Arbeitserfahrungen Unterschiede zwischen den Ländern.
In einigen OECD-Ländern sind duale Ausbildungsgänge und andere Kombinationsmöglichkeiten von Arbeit und Ausbildung weit verbreitet, in anderen hingegen selten. stark und in Kanada, Polen, der Slowakischen Republik, der Türkei und Ungarn immerhin noch spürbar benachteiligt (Tab. C4.Ia). In einigen dieser Länder und vor allem in der Türkei, wird die niedrigere Zahl für Frauen jedoch weitgehend von der Tatsache beeinflusst, dass viele Frauen den Arbeitsmarkt verlassen und somit die Nachfrage nach Arbeitsstellen verringern.

Während junge Männer damit rechnen können, im Alter von 15 bis 29 Jahren knapp über I9 Monate außerhalb von Bildungssystem und Beschäftigung zu verbringen, liegt der Durchschnitt für die Frauen bei über 33 Monaten. In Griechenland, Mexiko, der Tschechischen Republik, der Türkei und Ungarn besteht eine wesentlich stärkere Tendenz junger Frauen, den Arbeitsmarkt zu verlassen, so dass sie weder im Bildungssystem noch beschäftigt sind. In sehr wenigen Ländern - Finnland, Österreich und Schweden - gibt es bei dieser Kennzahl kaum Unterschiede zwischen jungen Männern und Frauen. In allen anderen Ländern sind Frauen zwischen 15 und 29 Jahren im Durchschnitt etwa ıo Monate länger als Männer weder in Ausbildung noch beschäftigt .

Dagegen können Frauen im Alter zwischen 15 und 29 Jahren in allen OECDLändern eine geringere Beschäftigungsdauer nach Abschluss der Ausbildung erwarten. Einer, jedoch nicht der einzige Grund hierfür, ist in der Länge ihrer Bildungsteilnahme zu sehen. In Griechenland, Mexiko, der Tschechischen Republik und der Türkei ist die Anzahl der zu erwartenden Jahre außerhalb von Bildungssystem und Arbeitsmarkt für Frauen deutlich höher als für Männer, während die zu erwartenden Jahre in Ausbildung ähnlich oder sogar geringer sind. In Italien, Spanien und dem Vereinigten Königreich wird bei den Frauen die geringere Anzahl der zu erwartenden Jahre in Beschäftigung zumindest teilweise durch die höhere Anzahl der zu erwartenden Jahre in Ausbildung ausgeglichen.

\section{Kombination von Arbeit und Ausbildung}

Die 27 OECD-Länder, die Daten über den Übertritt junger Menschen in die Arbeitswelt vorlegten, weisen sowohl für die Dauer der Ausbildung als auch für deren Kombination mit betrieblichen Erfahrungen oder dualen Ausbildungsformen deutliche Unterschiede auf (Abb. C4.4).

Die erste Gruppe (Gruppe A) ist die zahlenmäßig kleinste. Nur in drei Ländern gibt es eine lange Ausbildungsdauer, die nicht häufig mit Arbeit kombiniert ist. Die zu erwartende Anzahl von Jahren in Ausbildung für die I5 bis 29-Jährigen beträgt in Finnland, Frankreich und Polen ca. 8 Jahre, wobei die meisten Bildungsteilnehmer der älteren Jahrgänge in Finnland zu verzeichnen sind. Es gibt zwar duale und andere Ausbildungsformen mit praktischen betrieblichen Erfahrungen während der Ausbildung, sie sind jedoch immer noch nicht weit verbreitet.

Die zweite Gruppe (Gruppe B) ist etwas größer: sie umfasst vier Länder. Dort gibt es eine lange Ausbildungsdauer und gleichzeitig umfangreiche praktische Erfahrungen während der Ausbildung. Diese Gruppe mit sowohl starker Beteiligung an der Beschäftigung als auch am Bildungssystem in diesen drei Altersgruppen umfasst auch die nordischen Länder Dänemark, Island und Schweden. Das sich für Deutschland ergebende Profil ist wegen der Kombination von betrieblicher Praxis und Schulbesuch im dualen System ähnlich. 
Abbildung C4.4.

Übergang von der Schule ins Erwerbsleben, nach Ländern (2002)

Prozentsatz der 15- bis 29-Jährigen, die sich in Ausbildung bzw. nicht in Ausbildung befinden, nach Altersgruppe und Beschäftigungsstatus
In Ausbildung, nicht beschäftigt
In dualen Ausbildungsprogrammen
Nicht in Ausbildung, beschäftigt
In Ausbildung, beschäftigt
$\square$ Nicht in Ausbildung, nicht beschäftigt
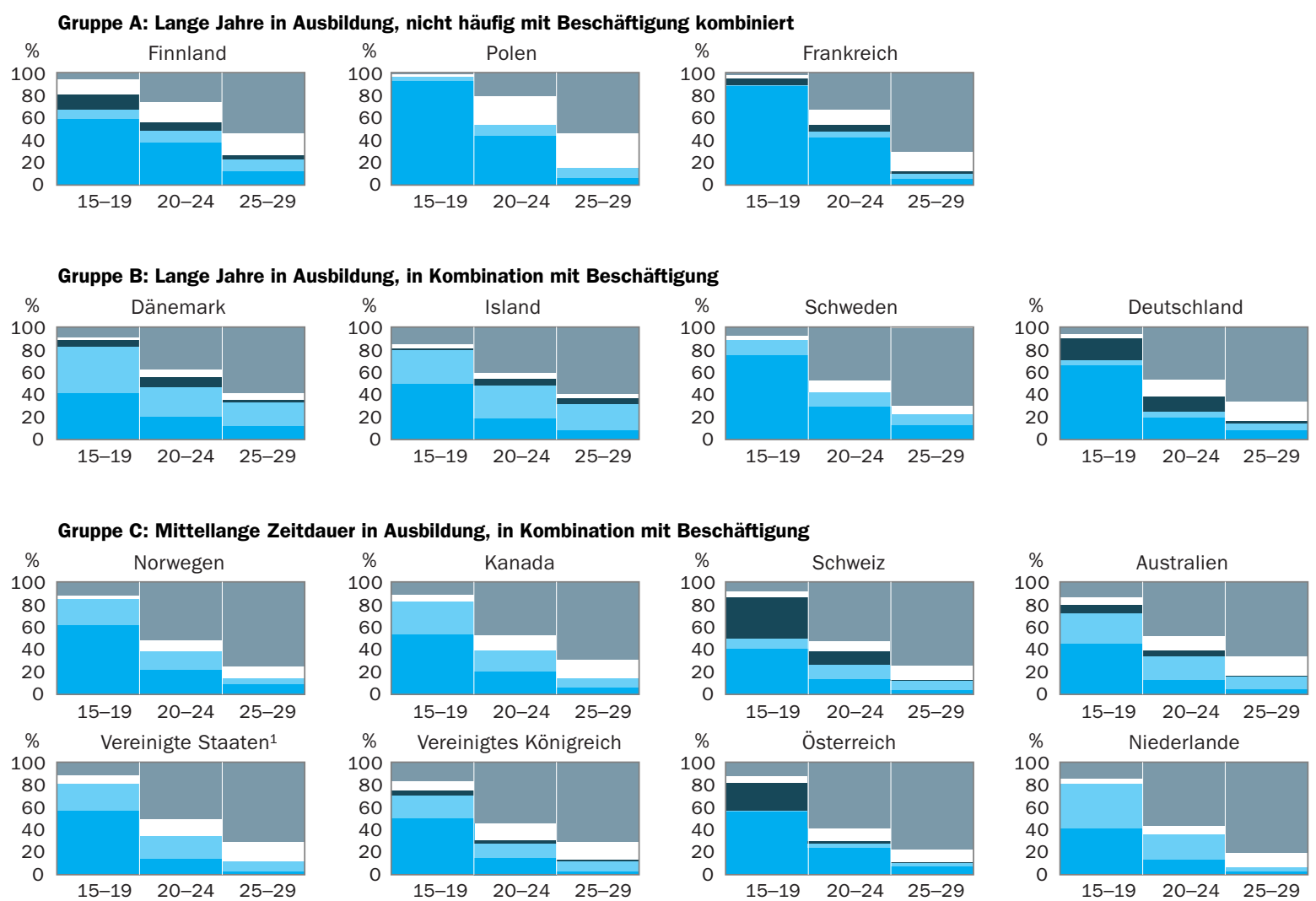

Gruppe D: Mittellange Zeitdauer in Ausbildung, nicht häufig mit Beschäftigung kombiniert
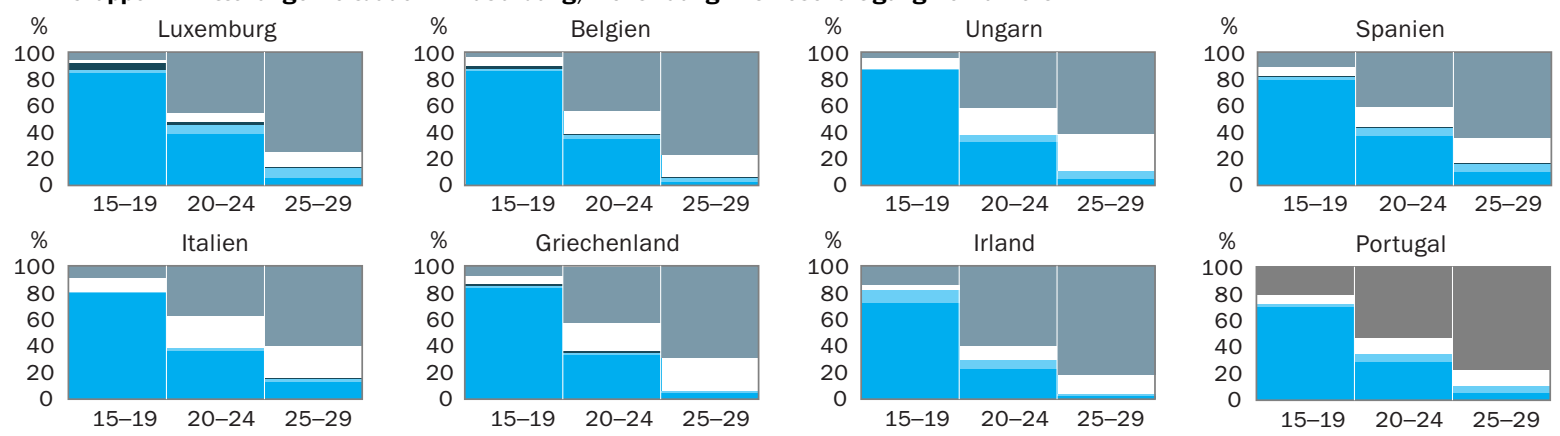

\section{Gruppe E: Wenige Jahre in Ausbildung}
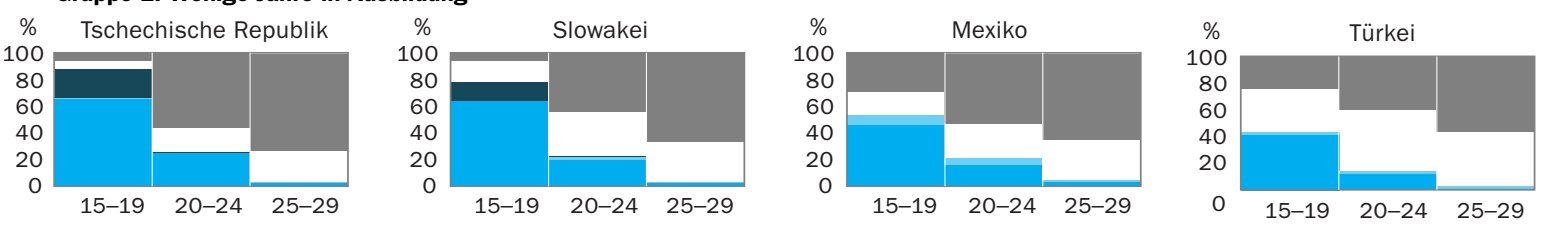

1. Referenzjahr 2001

In jeder Gruppe Anordnung der Länder in absteigender Reihenfolge des Prozentsatzes 15- bis 29-Jähriger in Ausbildung. Quelle: OECD, Tabelle C4.2. Hinweise s. Anhang 3 unter www.oecd.org/edu/eag2004. 
Während der Ausbildungsjahre ist der Beschäftigungsstatus von Männern und Frauen in den meisten OECD-Ländern sehr ähnlich.

Der Übergang von der Ausbildung zum Erwerbsleben findet in den einzelnen OECD-Ländern, abhängig von verschiedenen Bildungs- und Arbeitsmarktfaktoren, zu unterschiedlichen Zeitpunkten statt.
Zu den Gruppen C und D gehört die Mehrheit der Länder mit einem durchschnittlichen Verbleib in Ausbildung. Sie unterscheiden sich deutlich danach, wie Ausbildung mit praktischen Arbeitserfahrungen kombiniert wird. In Gruppe C kann die Arbeit während der Ausbildung in Form eines dualen Ausbildungsganges vorkommen oder als Teilzeitbeschäftigung in der unterrichtsfreien Zeit. Duale Ausbildungsgänge sind in einigen europäischen Ländern wie Österreich und der Schweiz relativ weit verbreitet und bieten eine kohärente berufliche Ausbildung, die zu anerkannten Berufsabschlüssen führt. Viele junge Menschen befinden sich auch neben der Ausbildung noch in einem Beschäftigungsverhältnis. Diese Form des ersten Kontakts mit dem Arbeitsmarkt für Schüler und Studierende im Alter zwischen 15 und 24 Jahren ist in Australien, Kanada, den Niederlanden, dem Vereinigten Königreich und den Vereinigten Staaten wesentlicher Bestandteil des Übergangs zur Erwerbstätigkeit; in geringerem Ausmaß trifft dies auch in Norwegen zu.

In Gruppe D - bestehend aus Belgien, Irland, Luxemburg, Ungarn und den Mittelmeerländern - kommen Erstausbildung und Arbeit selten zusammen vor, weder in Form von bezahlter Beschäftigung neben der Schule noch als dualer Ausbildungsgang.

Das Hauptmerkmal der Gruppe E ist der kurze Verbleib in Ausbildung. Duale Ausbildungsgänge sorgen in der Slowakischen und der Tschechischen Republik für eine relativ hohe Bildungsbeteiligung der I5- bis I9-Jährigen. Dies gilt jedoch nicht für Mexiko und die Türkei. In allen Ländern dieser Gruppe wird die Bildungsbeteiligung ab einem Alter von 20 Jahren sehr gering.

Der Beschäftigungsstatus von Männern und Frauen ist während der Ausbildungsjahre mit Ausnahme von Deutschland, Österreich und der Schweiz, wo die Beteiligung von Männern an dualen Bildungsgängen merklich höher ist, weitgehend ähnlich. In Australien, Dänemark, Finnland, Island, Kanada, den Niederlanden, Norwegen, Schweden und dem Vereinigten Königreich verbinden im Alter von 15 bis 24 Jahren merklich mehr Frauen außerschulische Arbeit und Ausbildung miteinander als Männer (Tab. C4.2a und $\mathrm{C}_{4.2 \mathrm{~b}}$ ).

\section{Eintritt in den Arbeitsmarkt nach der Erstausbildung}

Mit zunehmendem Alter nehmen immer weniger Jugendliche an Ausbildung teil und gehören immer mehr zur Erwerbsbevölkerung. In den meisten OECDLändern liegt der Anteil junger Menschen, die sich nicht in Ausbildung befinden, bei den I5- bis I9-Jährigen zwischen Io und 30 Prozent, steigt bei den 20- bis 24-Jährigen auf 50 bis 70 Prozent und erreicht bei der Altersgruppe der 25- bis 29-Jährigen 80 bis 95 Prozent (Tab. C4.2). In vielen OECD-Ländern findet jedoch der Eintritt junger Menschen in das Erwerbsleben zu einem späteren Zeitpunkt statt und erstreckt sich in einigen Fällen auch über einen längeren Zeitraum. Diese Entwicklung spiegelt nicht nur den Bildungsbedarf, sondern auch die allgemeine Arbeitsmarktlage, die Dauer der Ausbildungsgänge, die Ausrichtung der Ausbildungsprogramme hinsichtlich des Arbeitsmarktes und die Verbreitung von Teilzeitausbildung wider.

Das Alter beim Eintritt in den Arbeitsmarkt nach Abschluss der Erstausbildung hat Auswirkungen auf die Beschäftigung. Insgesamt ist die Wahrschein- 
lichkeit, dass ältere Nicht-Schüler/Studierende eine Beschäftigung haben, höher als für die Nicht-Schüler/Studierenden der Altersgruppe I5 bis I9 Jahre, wobei ein größerer Prozentsatz männlicher als weiblicher Nicht-Schüler/Studierender beschäftigt ist. Im Vergleich sind relativ mehr Frauen als Männer nicht im Arbeitsmarkt, insbesondere während der Jahre, in die typischerweise Schwangerschaft und Kindererziehung fallen, also bei der Altergruppe der 25- bis 29Jährigen im Rahmen dieses Indikators (Tab. $\mathrm{C}_{4} .2 \mathrm{a}$ und $\mathrm{C}_{4.2 \mathrm{~b}}$ ).

Der Anteil Erwerbstätiger an der Bevölkerung junger Erwachsener, die sich nicht in Ausbildung befinden, kann Hinweise auf die Wirksamkeit bestehender Rahmenbedingungen für den Übergang ins Erwerbsleben geben und den politischen Entscheidungsträgern bei deren Bewertung helfen. In 2I von 27 OECD-Ländern arbeiten weniger als 66 (und in einigen sogar weniger als 50) Prozent der sich nicht in Ausbildung befindenden I5- bis I9-Jährigen, was darauf hindeuten könnte, dass die Arbeitgeber davon ausgehen, dass diese Jugendlichen aufgrund ihres frühen Schulabgangs nicht die für eine produktive Beschäftigung erforderlichen Kenntnisse und Fähigkeiten besitzen. Der Anteil Erwerbstätiger Beschäftigter an der Bevölkerung der 20- bis 24-Jährigen liegt im Allgemeinen bei über $6_{5}$ Prozent, in einigen OECD-Ländern wie Finnland, Italien, Polen, der Slowakischen Republik und der Türkei liegt er allerdings nach wie vor um oder unter 6o Prozent. Für die Altersgruppe der 25- bis 29Jährigen beträgt der Anteil in den meisten OECD-Ländern mit Ausnahme von Polen und der Türkei zwischen 67 und 87 Prozent (Tab. C4.2). Die Erwerbstätigenanteile nach dem Ausscheiden aus dem Bildungssystem sind für Männer eher höher als für Frauen, wahrscheinlich aufgrund familiärer Verpflichtungen und weil der Status arbeitsloser Frauen in vielen OECD-Ländern immer noch eher akzeptiert wird als der arbeitsloser Männer (Tab. C4.2a und $\mathrm{C}_{4.2 \mathrm{~b}}$ ).

Arbeitslosenquote und Anteil arbeitsloser junger Menschen, die sich nicht in Ausbildung befinden, an der gesamten jungen Bevölkerung Junge Menschen repräsentieren in den OECD-Ländern die wichtigste Quelle neuer Fähigkeiten und Kenntnisse. In den meisten OECD-Ländern ist die Bildungspolitik daher bemüht, junge Menschen zumindest zu einem Abschluss im Sekundarbereich II zu ermutigen. Da viele der gegenwärtig auf dem Arbeitsmarkt angebotenen Arbeitsplätze ständig umfassendere allgemeine Kompetenzen und flexiblere Lernfähigkeiten verlangen, sehen sich Personen mit einem niedrigen Bildungsstand oft erheblichen Schwierigkeiten gegenüber. Unterschiede im Anteil arbeitsloser junger Menschen, die sich nicht in Ausbildung befinden, an der gesamten Altergruppe junger Menschen, aufgegliedert nach Bildungsstand, geben einen Hinweis darauf, in welchem Ausmaß zusätzliche Bildung die wirtschaftlichen Chancen junger Männer und Frauen verbessert.

Die Jugendarbeitslosenquote nach Altersgruppen ist der allgemein übliche Maßstab zur Beschreibung des Beschäftigungsstatus junger Menschen. Arbeitslosenquoten lassen jedoch Aspekte der (Aus-)Bildung unberücksichtigt. Somit könnte ein arbeitsloser Jugendlicher, der in diesem Quotienten im Zähler auftaucht, in einigen OECD-Ländern auch an einem Ausbildungsgang teilnehmen. Der Nenner kann Jugendliche in der Berufsausbildung beinhalten, wenn diese eine Lehre machen, jedoch nicht vergleichbare Personen, die eine schulische Berufsausbildung absolvieren. Wenn sich also beinahe alle jungen
Die herkömmlichen Arbeitslosenkennzahlen setzen die Arbeitslosigkeit während der Übergangsphase zu hoch an und berücksichtigen die verschiedenen Möglichkeiten der Kombination von Bildung und Arbeit während des Übergangs nicht. 
Die Anteil arbeitsloser junger Menschen ohne einen Abschluss im Sekundarbereich II an der gesamten betreffenden Bevölkerungsgruppe ist im Durchschnitt 1,5-mal höher als bei Absolventen des Sekundarbereich II.
Menschen in einer bestimmten Altersgruppe noch in Ausbildung befinden, bezieht sich die Arbeitslosenquote nur auf die wenigen, die dem Arbeitsmarkt zur Verfügung stehen und kann dann sehr hoch erscheinen. Dies gilt insbesondere für die jüngste Altersgruppe, die in der Regel das Bildungssystem mit sehr geringen Qualifikationen verlassen hat.

Der Anteil arbeitsloser junger Menschen, die sich nicht in Ausbildung befinden, an der gesamten Altersgruppe ist daher geeigneter, die Wahrscheinlichkeit der Jugendarbeitslosigkeit zu belegen. Denn junge Menschen, die sich noch innerhalb des Bildungssystems befinden, suchen normalerweise neben ihrer Ausbildung Teilzeit- oder befristete Arbeit, was auf diejenigen, die nach Verlassen des Bildungssystems in den Arbeitsmarkt eintreten, nicht zutrifft.

Durchschnittlich liegt der Anteil Arbeitsloser an der Bevölkerung junger Menschen (d.h. die Arbeitslosigkeit von denjenigen, die sich nicht in Ausbildung befinden, als Prozentsatz der gesamten Altersgruppe) im Alter zwischen 20 und 24 Jahren bei Personen mit einem Abschluss im Sekundarbereich II um 6 Prozentpunkte niedriger als bei Personen ohne einen solchen Abschluss, bei den 25- bis 29-Jährigen sind es ca. 4 Prozentpunkte (Tab. C4.3). 20 von 27 OECD-Ländern weisen für die 20- bis 24-Jährigen, die sich nicht in Ausbildung befinden, einen Arbeitslosenanteil von unter 8 Prozent auf, wenn diese

\section{Abbildung $\mathbf{C 4 . 5}$}

Verhältnis arbeitsloser 25- bis- 29-Jähriger, die sich nicht in Ausbildung befinden, zur Gesamtpopulation in diesem Alter, nach Bildungsstand (2002)

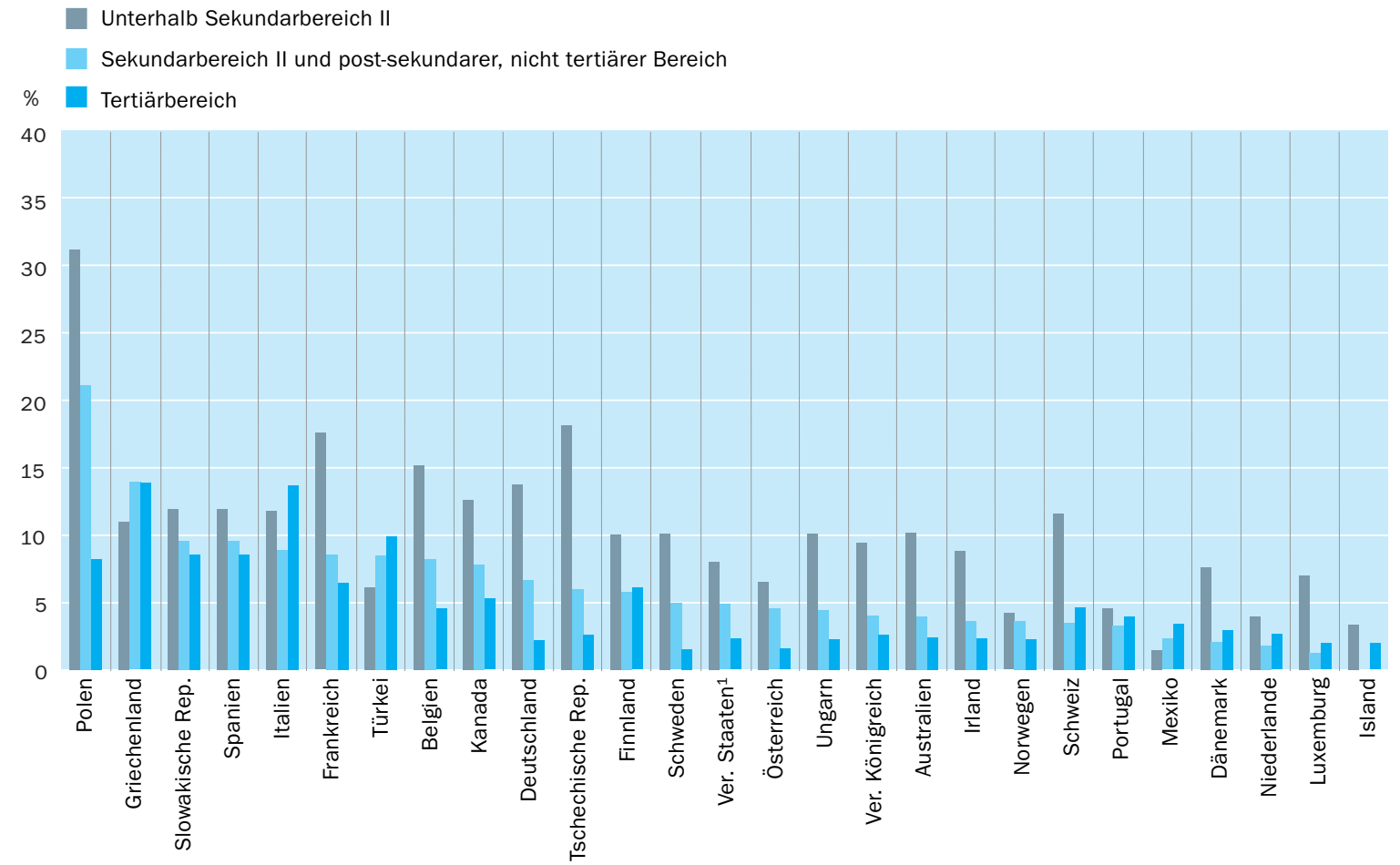

Anordnung der Länder in absteigender Reihenfolge des Anteils arbeitsloser 25- bis-29-Jähriger, die sich nicht in Ausbildung befinden, zur Population in diesem Alter, die einen Abschluss im Sekundarbereich II und im post-sekundaren, nicht-tertiären Bereich hat.

1. Referenzjahr 2001.

Quelle: OECD, Tabelle C4.3. Hinweise s. Anhang 3 unter www.oecd.org/edu/eag2004. 
den Sekundarbereich II oder eine post-sekundare, nicht-tertiäre Ausbildung abgeschlossen haben. Dieser Prozentsatz bleibt bei denjenigen ohne einen Abschluss im Sekundarbereich II nur in sechs OECD-Ländern unter 8 Prozent. Da der Abschluss eines Bildungsgangs im Sekundarbereich II inzwischen in den meisten OECD-Ländern quasi zur Norm geworden ist, sind viele junge Menschen, die keinen Abschluss in diesem Bereich haben, während ihres gesamten Erwerbslebens viel stärker von Beschäftigungsproblemen bedroht.

Am Ende des Übergangszeitraums, wenn die meisten jungen Menschen die Ausbildung abgeschlossen haben und zwischen 25 und 29 Jahren alt sind, hängen die Unterschiede beim Zugang zu Beschäftigung mit dem erreichten Bildungsstand zusammen. Das Nicht-Erreichen des Abschlusses im Sekundarbereich II ist eindeutig ein ernsthaftes Handicap. Umgekehrt bringt der Abschluss einer Ausbildung im Tertiärbereich meist einen Bonus bei der Arbeitsplatzsuche (Abb. $\mathrm{C}_{4 \cdot 5}$ ).

In I2 OECD-Ländern liegt der Anteil arbeitsloser 25- bis 29-Jähriger, die sich nicht in Ausbildung befinden, mit einem Abschluss des Sekundarbereich II an der gleichaltrigen Gesamtbevölkerung über 5 Prozent. In einigen wenigen OECD-Ländern besteht sogar für junge Menschen mit einem Abschluss des Tertiärbereichs beim Eintritt in den Arbeitsmarkt ein erhebliches Arbeitslosigkeitsrisiko. Der Anteil arbeitsloser Nicht-Studierender an der gleichaltrigen Gesamtbevölkerung beträgt in Griechenland, Italien, Polen, Spanien, der Slowakischen Republik und der Türkei 8 Prozent und mehr.(Tab. C4.3).

Ein genauerer Blick auf die zentrale Übergangsphase, (d.h. die Altersgruppe der 20 bis 24-Jährigen) zeigt, wie sich die Häufigkeit der Arbeitslosigkeit und des Rückzugs aus dem Arbeitsmarkt (was ja zwei Fälle von ,Nicht-Beschäftigung' sind) bei denen, die sich nicht mehr in Ausbildung befinden, geändert hat. Über einen Zeitraum von vier Jahren hinweg ist in einigen Ländern ein deutlicher Wandel festzustellen. In den Mittelmeerländern (Griechenland, Italien und Spanien), aber auch in Finnland, wo der Anteil der Nicht-Beschäftigung relativ hoch war, sind die Fortschritte bemerkenswert, auch, wenn die Tendenz sich im letzten Jahr des Beobachtungszeitraums umgekehrt zu haben scheint. Die Türkei stellt mit einer negativen Entwicklung des Nicht-Beschäftigungsanteils, der schon bisher eine der höchsten in der OECD war, eine Ausnahme dar. Die Lage in den mittel- und osteuropäischen Ländern ist sehr gegensätzlich: in Ungarn nimmt die Nicht-Beschäftigung regelmäßig ab, in der Slowakischen Republik regelmäßig zu, in Polen gibt es einen Anstieg, gefolgt von einem Abfall nach einem Spitzenwert im Jahr 2000.

In mehreren Ländern hat sich die Lage in den letzten fünf Jahren jedoch als bemerkenswert stabil erwiesen: auf einem hohen Niveau des Anteils der NichtBeschäftigten in Mexiko, einem niedrigen Niveau in Dänemark und einem mittleren Niveau im Vereinigten Königreich und den Vereinigten Staaten. Obwohl andere Profile nicht so ausgeprägt sind, lässt sich doch ein Gesamtbild erkennen. Eine Ausnahme bilden Norwegen, wo der Anteil der Nicht-Beschäftigten leicht, aber beständig ansteigt, und die Schweiz, deren Kurve sich deutlich als „V“ mit dem Tiefpunkt im Jahr 2000 darstellt; von diesen beiden Ländern abgesehen nahm die Häufigkeit der Arbeitslosigkeit und des Rückzugs
Ein Abschluss des Sekundarbereich II und sogar des Tertiärbereichs ist zwar keine Garantie für einen Arbeitsplatz, erhöht aber signifikant die Chancen auf eine Beschäftigung.

In den meisten Ländern ist die ,Nicht-Beschäftigung، unter den 20 bis 24-Jährigen seit 1998 zurück gegangen. 
Veränderungen im Anteil der 20- bis 24-Jährigen, die sich weder in Ausbildung noch in Beschäftigung befinden (1998-2002)

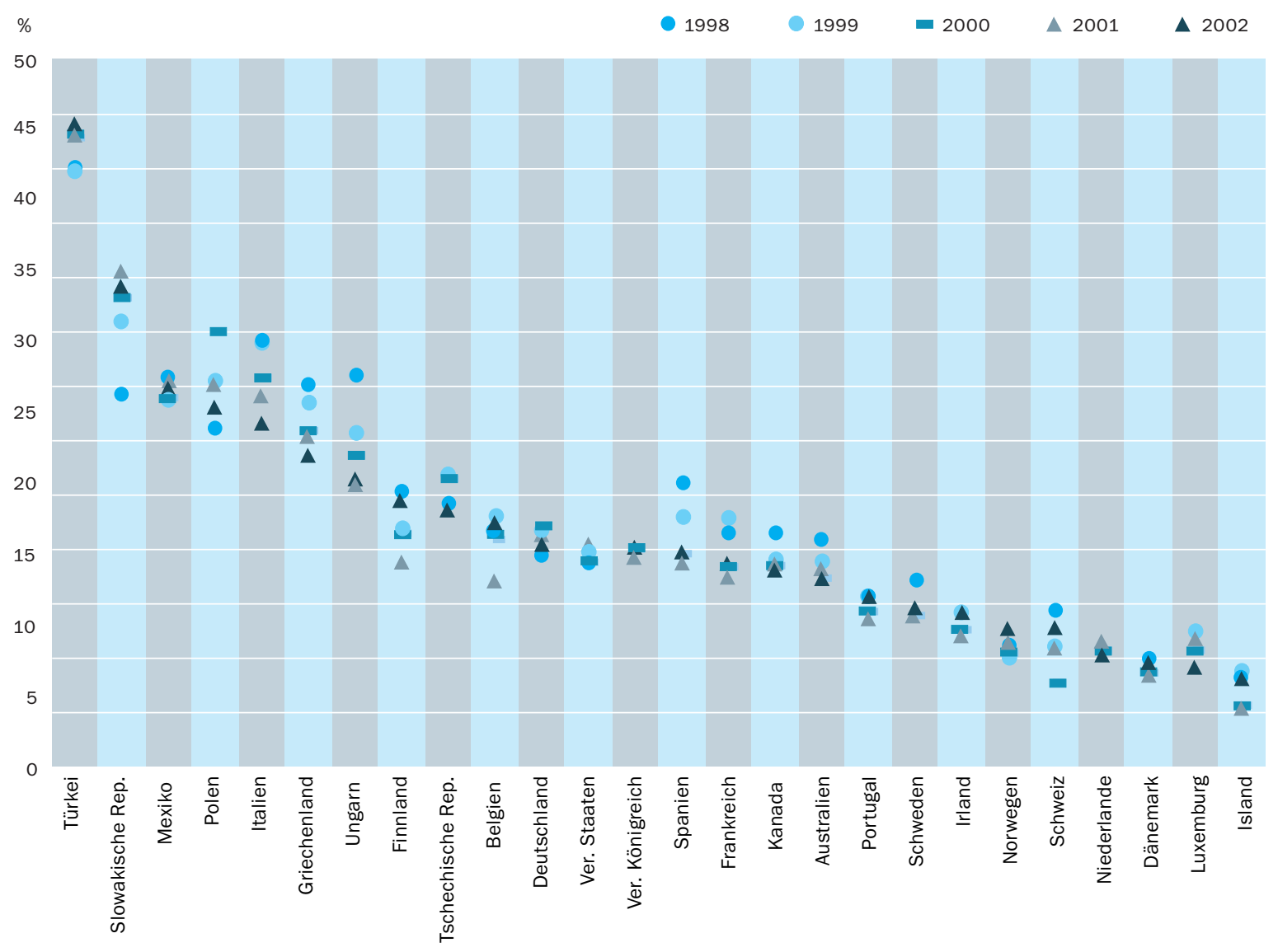

Anordnung der Länder in absteigender Reihenfolge des Anteils 20-bis-24-Jähriger, die sich 2002 weder in Ausbildung noch in Beschäftigung befanden. Quelle: OECD, Tabelle C4.4. Hinweise s. Anhang 3 unter www.oecd.org/edu/eag2004.

Die Daten stammen aus nationalen Arbeitskräfteerhebungen. aus dem Arbeitsmarkt in den meisten Ländern mit nur wenigen Variationen zwischen 1998 und 200I regelmäßig ab, gefolgt von einer Stabilisierung oder sogar wieder eine Zunahme beider Phänomene im Jahr 2002.

\section{Definitionen und angewandte Methodik}

Die vorliegenden Statistiken basieren auf Arbeitskräfteerhebungen über den Anteil bestimmter Altersgruppen junger Menschen an den genannten Kategorien. Diese Anteile wurden dann für die Altersgruppe I5 bis 29 Jahre aufsummiert, um die zu erwartende Anzahl von Jahren in dem angegebenen Beschäftigungsstatus zu erhalten. Bei den Ländern, die Daten erst ab einem Alter von I6 Jahren vorgelegt haben, wird davon ausgegangen, dass sich alle I5-Jährigen in Ausbildung befinden und nicht Teil der Erwerbsbevölkerung sind. Durch diese Verbesserung der Berechnung steigt die durchschnittliche Anzahl der zu erwartenden Ausbildungsjahre gegenüber der letzten Ausgabe von Bildung auf einen Blick tendenziell. Die Berechnung geht also davon aus, dass die heute 
Fünfzehnjährigen im Alter von 15 bis 29 Jahren den gleichen Bildungs- und Arbeitsmustern folgen werden wie die Gruppe im Alter von 15 bis 29 Jahren im vorliegenden Referenzjahr.

Sich in Ausbildung zu befinden, umfasst sowohl Teilzeit- als auch Vollzeitmaßnahmen. Hierbei sollte der Umfang der Bildungsmaßnahme dem der formalen Bildung in den amtlichen Quellen zur Beteiligung möglichst nahe kommen. Daher sind nicht-formale Bildungsmaßnahmen oder solche mit sehr kurzer Dauer, z. B. im Betrieb, nicht zu berücksichtigen.

Die Daten für diesen Indikator stammen aus einer speziellen Erhebung der OECD und beziehen sich normalerweise auf das erste Quartal oder den Durchschnitt der ersten drei Monate des Kalenderjahres, somit sind ,Ferienjobs“ (im Sommer) nicht berücksichtigt. Mit einer Ausnahme entsprechen die Definitionen des Erwerbsstatus in diesem Abschnitt den Richtlinien der Internationalen Arbeitsorganisation (ILO). Für die vorliegenden Indikatoren wurden die Teilnehmer an dualen Ausbildungsprogrammen (s. u.) getrennt unter in Ausbildung und beschäftigt aufgeführt, ohne Bezug auf ihren ILO-Erwerbsstatus während der Erhebungswoche. Da sie sich während der Erhebungswoche nicht zwangsläufig in der betrieblichen Phase des Programms befanden, wären sie zum Zeitpunkt der Erhebung dann möglicherweise nicht beschäftigt. Sonstige Beschäftigung umfasst Personen, die sich entsprechend der ILODefinition in Beschäftigung befinden, hierbei ausgenommen wurden jedoch die Auszubildenden in dualen Ausbildungsgängen, die schon als beschäftigt gezählt wurden. Schließlich sind diejenigen, die nicht im Arbeitsmarkt sind, weder beschäftigt, noch arbeitslos, d.h. sie bemühen sich nicht um eine Arbeitsstelle.

Duale Ausbildungsprogramme stellen eine Kombination aus Arbeiten und Lernen als Teil einer integrierten, formalen Bildung bzw. Ausbildung dar, wie beispielsweise im dualen Berufsbildungssystem in Deutschland; die apprentissage bzw. formation en alternance in Frankreich und Belgien, Praktika oder ,kooperative" Ausbildungen in Kanada und apprenticeships in Irland. Die berufliche Aus- und Weiterbildung erfolgt nicht nur in der Schule, sondern auch in einer Arbeitsumgebung. Je nach der Art der Arbeit und der Ausbildung können die Ausbildungsteilnehmer ein Entgelt erhalten oder nicht.

Die hier verwendeten Angaben zur Bildungsbeteiligung basieren auf Selbstauskünften im Rahmen von Arbeitskräfteerhebungen, diese stimmen jedoch aus mehreren Gründen nicht genau mit den Zahlen zur Bildungsbeteiligung aus amtlichen Quellen überein, die hier an anderer Stelle angegebenen sind. Erstens wird das Alter möglicherweise nicht auf die gleiche Weise erfasst. So wird beispielsweise in den amtlichen Statistiken der OECD-Länder der nördlichen Hemisphäre sowohl die Bildungsbeteiligung als auch das Alter per I. Januar angegeben. In einigen Arbeitskräfteerhebungen hingegen wird die Bildungsbeteiligung in der Erhebungswoche gemessen, das angegebene Alter ist jedoch das Alter, das am Ende des Kalenderjahres erreicht wird, auch wenn die Erhebung Anfang des Jahres durchgeführt wird Daher spiegeln die Angaben zur Bildungsbeteiligung in manchen Fällen eine Population wider, die tatsächlich fast ein Jahr jünger ist als die angegebene Alterspanne. In einem Alter, in
Die Daten für diesen Indikator wurden mit einer speziellen OECD-Erhebung im ersten Quartal des Jahres erhoben. 
dem viele junge Menschen das Bildungssystem verlassen, kann sich dies auf die Bildungsbeteiligung auswirken. Zweitens können die jungen Frauen und Männer auch in mehr als einem Bildungsgang eingeschrieben sein und werden dann in den amtlichen Statistiken manchmal zweimal, in der Arbeitskräfteerhebung jedoch nur einmal gezählt. Ferner erfassen die amtlichen Statistiken vielleicht nicht alle an Bildungsgängen teilnehmenden Personen, insbesondere, wenn sie an gewinnorientierten Bildungseinrichtungen ausgebildet werden. Drittens stimmen die Klassifizierungen der Bildungsgänge in den Selbstauskünften der Arbeitskräfteerhebungen nicht immer mit den Qualifikationsstandards überein, die für die amtlichen Datenerhebungen verwendet werden. Der Arbeitslosenanteil ist die Anzahl der Arbeitslosen dividiert durch die Gesamtzahl der betreffenden Bevölkerung.

Der Erwerbstätigenanteil ist die Anzahl der Beschäftigten dividiert durch die Gesamtzahl der betreffenden Bevölkerung. 
Zu erwartende Jahre in Ausbildung und nicht in Ausbildung für 15- bis 29-Jährige (2002)

Nach Geschlecht und Beschäftigungsstatus

\begin{tabular}{|c|c|c|c|c|c|c|c|c|}
\hline & & Zu erwar & tende Jahre in Al & ildung & & Zu erwarte & Jahre nicht in & bildung \\
\hline OECD-Länder & & Nicht beschäftigt & $\begin{array}{l}\text { Beschäftigt } \\
\text { (einschl. duale } \\
\text { Ausbildungs- } \\
\text { gänge) }\end{array}$ & Zusammen & Beschäftigt & Arbeitslos & $\begin{array}{c}\text { Nicht im } \\
\text { Arbeitsmarkt }\end{array}$ & Zusammen \\
\hline Australien & Männer & 3,2 & 3,5 & 6,7 & 6,9 & 0,8 & 0,5 & 8,3 \\
\hline & Frauen & 3,0 & 3,7 & 6,7 & 5,9 & 0,6 & 1,9 & 8,3 \\
\hline & $M+F$ & 3,1 & 3,6 & 6,7 & 6,4 & 0,7 & 1,2 & 8,3 \\
\hline Österreich & Männer & 3,9 & 2,0 & 5,9 & 7,6 & 0,7 & 0,8 & 9,1 \\
\hline & Frauen & 4,6 & 1,3 & 6,0 & 7,4 & 0,5 & 1,1 & 9,0 \\
\hline & $M+F$ & 4,2 & 1,7 & 5,9 & 7,5 & 0,6 & 1,0 & 9,1 \\
\hline Belgien & Männer & 5,8 & 0,5 & 6,3 & 7,0 & 0,9 & 0,8 & 8,7 \\
\hline & Frauen & 6,2 & 0,5 & 6,7 & 5,9 & 1,0 & 1,5 & 8,3 \\
\hline & $M+F$ & 6,0 & 0,5 & 6,5 & 6,4 & 1,0 & 1,1 & 8,5 \\
\hline Kanada & Männer & 4,1 & 2,4 & 6,5 & 6,7 & 1,1 & 0,7 & 8,5 \\
\hline & Frauen & 4,0 & 3,1 & 7,1 & 6,0 & 0,6 & 1,4 & 7,9 \\
\hline & $M+F$ & 4,0 & 2,8 & 6,8 & 6,4 & 0,8 & 1,0 & 8,2 \\
\hline Tschechische & Männer & 3,9 & 1,2 & 5,1 & 8,6 & 0,9 & 0,4 & 9,9 \\
\hline Republik & Frauen & 4,5 & 0,7 & 5,3 & 5,9 & 1,0 & 2,8 & 9,7 \\
\hline & $M+F$ & 4,2 & 1,0 & 5,2 & 7,3 & 1,0 & 1,6 & 9,8 \\
\hline Dänemark & Männer & 3,4 & 4,5 & 7,9 & 6,4 & 0,4 & 0,3 & 7,1 \\
\hline & Frauen & 3,6 & 4,7 & 8,3 & 5,6 & 0,3 & 0,8 & 6,7 \\
\hline & $M+F$ & 3,5 & 4,6 & 8,1 & 6,0 & 0,4 & 0,5 & 6,9 \\
\hline Finnland & Männer & 5,1 & 2,5 & 7,6 & 4,6 & 0,8 & 2,0 & 7,4 \\
\hline & Frauen & 6,0 & 2,7 & 8,7 & 3,8 & 0,7 & 1,9 & 6,3 \\
\hline & $M+F$ & 5,5 & 2,6 & 8,1 & 4,2 & 0,7 & 1,9 & 6,9 \\
\hline Frankreich & Männer & 6,6 & 1,2 & 7,8 & 5,8 & 1,1 & 0,4 & 7,2 \\
\hline & Frauen & 7,1 & 1,1 & 8,2 & 4,6 & 1,0 & 1,2 & 6,8 \\
\hline & $M+F$ & 6,9 & 1,2 & 8,0 & 5,2 & 1,0 & 0,8 & 7,0 \\
\hline Deutschland & Männer & 4,7 & 2,6 & 7,4 & 6,3 & 0,8 & 0,5 & 7,6 \\
\hline & Frauen & 4,8 & 2,4 & 7,3 & 5,5 & 0,6 & 1,7 & 7,7 \\
\hline & $M+F$ & 4,8 & 2,5 & 7,3 & 5,9 & 0,7 & 1,1 & 7,7 \\
\hline Griechenland & Männer & 5,7 & 0,3 & 6,0 & 7,3 & 1,2 & 0,5 & 9,0 \\
\hline & Frauen & 6,0 & 0,3 & 6,2 & 5,0 & 1,9 & 2,0 & 8,8 \\
\hline & $M+F$ & 5,8 & 0,3 & 6,1 & 6,1 & 1,5 & 1,2 & 8,9 \\
\hline Ungarn & Männer & 5,8 & 0,6 & 6,4 & 6,5 & 0,8 & 1,3 & 8,6 \\
\hline & Frauen & 5,9 & 0,6 & 6,5 & 4,9 & 0,4 & 3,2 & 8,5 \\
\hline & $M+F$ & 5,8 & 0,6 & 6,4 & 5,7 & 0,6 & 2,3 & 8,6 \\
\hline Island & Männer & 3,9 & 3,6 & 7,5 & 6,6 & 0,7 & c & 7,5 \\
\hline & Frauen & 4,3 & 4,2 & 8,5 & 5,7 & c & 0,7 & 6,5 \\
\hline & $M+F$ & 4,1 & 3,9 & 8,0 & 6,2 & 0,4 & 0,4 & 7,0 \\
\hline Irland & Männer & 4,7 & 0,7 & 5,4 & 8,4 & 0,7 & 0,5 & 9,6 \\
\hline & Frauen & 5,1 & 0,9 & 6,0 & 7,2 & 0,4 & 1,4 & 9,0 \\
\hline & $M+F$ & 4,9 & 0,8 & 5,7 & 7,8 & 0,5 & 1,0 & 9,3 \\
\hline Italien & Männer & 5,6 & 0,2 & 5,9 & 6,7 & 1,3 & 1,1 & 9,1 \\
\hline & Frauen & 6,2 & 0,3 & 6,5 & 4,8 & 1,4 & 2,4 & 8,5 \\
\hline & $M+F$ & 5,9 & 0,2 & 6,2 & 5,7 & 1,4 & 1,7 & 8,8 \\
\hline$J^{J a p a n}{ }^{1}$ & Männer & 5,2 & 0,8 & 6,0 & 3,2 & 0,5 & 0,4 & 4,0 \\
\hline & Frauen & 4,9 & 0,8 & 5,7 & 3,2 & 0,4 & 0,7 & 4,3 \\
\hline & $M+F$ & 5,1 & 0,8 & 5,9 & 3,2 & 0,4 & 0,5 & 4,1 \\
\hline Luxemburg & Männer & 6,3 & 0,6 & 7,0 & 7,5 & 0,4 & 0,1 & 8,0 \\
\hline & Frauen & 6,4 & 0,5 & 6,9 & 6,4 & 0,4 & 1,4 & 8,1 \\
\hline & $M+F$ & 6,4 & 0,6 & 6,9 & 6,9 & 0,4 & 0,7 & 8,1 \\
\hline Mexiko & Männer & 3,6 & 1,0 & 4,6 & 9,5 & 0,4 & 0,6 & 10,4 \\
\hline & Frauen & 3,7 & 0,6 & 4,3 & 4,6 & 0,2 & 5,9 & 10,7 \\
\hline & $M+F$ & 3,6 & 0,8 & 4,4 & 7,0 & 0,3 & 3,3 & 10,6 \\
\hline
\end{tabular}

Hinweis: c weist darauf hin, dass zu wenige Daten zur Verfügung stehen, um verlässliche Schätzungen vorzunehmen.

1. Daten beziehen sich auf 15- bis 24-Jährige. 2. Referenzjahr 2001.

Quelle: OECD. Hinweise s. Anhang 3 unter www.oecd.org/edu/eag2004. 


\section{Tabelle C4.1a (Forts.)}

Zu erwartende Jahre in Ausbildung und nicht in Ausbildung für 15- bis 29-Jährige (2002)

Nach Geschlecht und Beschäftigungsstatus

\begin{tabular}{|c|c|c|c|c|c|c|c|c|}
\hline & & Zu erwart & ende Jahre in Au & ildung & & Zu erwarte & Jahre nicht in & bildung \\
\hline & & Nicht beschäftigt & $\begin{array}{l}\text { Beschäftigt } \\
\text { (einschl. duale } \\
\text { Ausbildungs- } \\
\text { gänge) }\end{array}$ & Zusammen & Beschäftigt & Arbeitslos & $\begin{array}{l}\text { Nicht im } \\
\text { Arbeitsmarkt }\end{array}$ & Zusammen \\
\hline OECD-Länder & & & & & & & & \\
\hline Niederlande & Männer & 2,8 & 3,2 & 6,0 & 8,1 & 0,3 & 0,5 & 9,0 \\
\hline & Frauen & 2,7 & 3,1 & 5,9 & 7,4 & 0,3 & 1,4 & 9,1 \\
\hline & $M+F$ & 2,8 & 3,2 & 5,9 & 7,8 & 0,3 & 1,0 & 9,1 \\
\hline Norwegen & Männer & 4,5 & 1,8 & 6,2 & 7,8 & 0,5 & 0,5 & 8,8 \\
\hline & Frauen & 4,8 & 2,6 & 7,3 & 6,4 & 0,3 & 1,0 & 7,7 \\
\hline & $M+F$ & 4,6 & 2,2 & 6,8 & 7,1 & 0,4 & 0,7 & 8,2 \\
\hline Polen & Männer & 6,6 & 1,2 & 7,8 & 4,5 & 2,2 & 0,5 & 7,2 \\
\hline & Frauen & 7,0 & 1,0 & 8,1 & 3,4 & 1,8 & 1,7 & 6,9 \\
\hline & $M+F$ & 6,8 & 1,1 & 7,9 & 3,9 & 2,0 & 1,1 & 7,1 \\
\hline Portugal & Männer & 4,5 & 0,6 & 5,1 & 8,8 & 0,6 & 0,5 & 9,9 \\
\hline & Frauen & 5,4 & 0,6 & 6,0 & 7,1 & 0,7 & 1,2 & 9,0 \\
\hline & $M+F$ & 5,0 & 0,6 & 5,6 & 7,9 & 0,6 & 0,8 & 9,4 \\
\hline Slowakische & Männer & 4,0 & 1,0 & 5,0 & 6,5 & 2,7 & 0,8 & 10,0 \\
\hline Republik & Frauen & 4,7 & 0,7 & 5,4 & 5,2 & 2,1 & 2,4 & 9,6 \\
\hline & $M+F$ & 4,3 & 0,9 & 5,2 & 5,8 & 2,4 & 1,6 & 9,8 \\
\hline Spanien & Männer & 5,3 & 0,6 & 5,9 & 7,5 & 1,1 & 0,6 & 9,1 \\
\hline & Frauen & 6,0 & 0,7 & 6,7 & 5,3 & 1,4 & 1,6 & 8,3 \\
\hline & $M+F$ & 5,6 & 0,6 & 6,3 & 6,5 & 1,2 & 1,1 & 8,7 \\
\hline Schweden & Männer & 5,8 & 1,3 & 7,1 & 6,8 & 0,7 & 0,5 & 7,9 \\
\hline & Frauen & 5,8 & 2,0 & 7,8 & 6,0 & 0,5 & 0,7 & 7,2 \\
\hline & $M+F$ & 5,8 & 1,7 & 7,5 & 6,4 & 0,6 & 0,6 & 7,5 \\
\hline Schweiz & Männer & 2,8 & 4,1 & 6,9 & 6,9 & 0,6 & 0,6 & 8,1 \\
\hline & Frauen & 2,9 & 3,6 & 6,5 & 6,9 & 0,4 & 1,3 & 8,5 \\
\hline & $M+F$ & 2,8 & 3,9 & 6,7 & 6,9 & 0,5 & 0,9 & 8,3 \\
\hline Türkei & Männer & 3,3 & 0,4 & 3,7 & 8,1 & 1,5 & 1,8 & 11,3 \\
\hline & Frauen & 2,4 & 0,2 & 2,6 & 3,6 & 0,7 & 8,2 & 12,4 \\
\hline & $M+F$ & 2,9 & 0,3 & 3,2 & 5,9 & 1,1 & 4,8 & 11,8 \\
\hline Vereinigtes & Männer & 3,3 & 2,3 & 5,6 & 8,1 & 0,8 & 0,5 & 9,4 \\
\hline & Frauen & 3,7 & 2,9 & 6,6 & 5,8 & 0,6 & 2,1 & 8,4 \\
\hline & $M+F$ & 3,5 & 2,5 & 6,0 & 7,1 & 0,7 & 1,2 & 9,0 \\
\hline Vereinigte Staaten ${ }^{2}$ & Männer & 4,1 & 2,4 & 6,5 & 7,1 & 0,7 & 0,8 & 8,5 \\
\hline & Frauen & 3,8 & 2,9 & 6,7 & 5,8 & 0,5 & 2,0 & 8,3 \\
\hline & $M+F$ & 3,9 & 2,6 & 6,6 & 6,4 & 0,6 & 1,4 & 8,4 \\
\hline Ländermittel & Männer & 4,6 & 1,7 & 6,3 & 7,1 & 0,9 & 0,7 & 8,7 \\
\hline & Frauen & 4,8 & 1,8 & 6,6 & 5,6 & 0,7 & 2,0 & 8,4 \\
\hline & $M+F$ & 4,7 & 1,7 & 6,4 & 6,4 & 0,8 & 1,3 & 8,6 \\
\hline OECD-Partnerländer & & & & & & & & \\
\hline Israel & Männer & 4,5 & 1,2 & 5,8 & 4,4 & 1,0 & 3,8 & 9,2 \\
\hline & Frauen & 4,6 & 1,4 & 6,0 & 4,3 & 0,8 & 3,8 & 9,0 \\
\hline & $M+F$ & 4,6 & 1,3 & 5,9 & 4,4 & 0,9 & 3,8 & 9,1 \\
\hline
\end{tabular}

Hinweis: c weist darauf hin, dass zu wenige Daten zur Verfügung stehen, um verlässliche Schätzungen vorzunehmen.

1. Daten beziehen sich auf 15- bis 24-Jährige. 2. Referenzjahr 2001.

Quelle: OECD. Hinweise s. Anhang 3 unter www.oecd.org/edu/eag2004. 
Tabelle C4.1b

Veränderung der zu erwartenden Jahre in Ausbildung und nicht in Ausbildung für 15- bis 29-Jährige (1998-2002) Nach Geschlecht und Beschäftigungsstatus

\begin{tabular}{|c|c|c|c|c|c|c|c|c|c|c|c|}
\hline \multirow{2}{*}{ OECD-Länder } & & \multicolumn{2}{|c|}{1998} & \multicolumn{2}{|c|}{1999} & \multicolumn{2}{|c|}{2000} & \multicolumn{2}{|c|}{2001} & \multicolumn{2}{|c|}{2002} \\
\hline & & $\begin{array}{c}\text { In } \\
\text { Ausbildung }\end{array}$ & $\begin{array}{l}\text { Nicht in } \\
\text { Ausbildung }\end{array}$ & $\begin{array}{c}\text { In } \\
\text { Ausbildung }\end{array}$ & $\begin{array}{c}\text { Nicht in } \\
\text { Ausbildung }\end{array}$ & $\begin{array}{c}\text { In } \\
\text { Ausbildung }\end{array}$ & $\begin{array}{c}\text { Nicht in } \\
\text { Ausbildung }\end{array}$ & $\begin{array}{c}\ln \\
\text { Ausbildung }\end{array}$ & $\begin{array}{c}\text { Nicht in } \\
\text { Ausbildung }\end{array}$ & $\begin{array}{c}\text { In } \\
\text { Ausbildung }\end{array}$ & $\begin{array}{l}\text { Nicht in } \\
\text { Ausbildung }\end{array}$ \\
\hline \multirow[t]{3}{*}{ Australien } & Männer & 6,0 & 9,0 & 6,4 & 8,6 & 6,4 & 8,6 & 6,6 & 8,4 & 6,7 & 8,3 \\
\hline & Frauen & 6,0 & 9,0 & 6,2 & 8,8 & 6,5 & 8,5 & 6,4 & 8,6 & 6,7 & 8,3 \\
\hline & $M+F$ & 6,0 & 9,0 & 6,3 & 8,7 & 6,4 & 8,6 & 6,5 & 8,5 & 6,7 & 8,3 \\
\hline \multirow[t]{3}{*}{ Österreich } & Männer & 5,7 & 9,3 & 5,2 & 9,8 & 5,3 & 9,7 & 5,4 & 9,6 & 5,9 & 9,1 \\
\hline & Frauen & 5,4 & 9,6 & 5,2 & 9,8 & 5,2 & 9,8 & 5,4 & 9,6 & 6,0 & 9,0 \\
\hline & $M+F$ & 5,5 & 9,5 & 5,2 & 9,8 & 5,2 & 9,8 & 5,4 & 9,6 & 5,9 & 9,1 \\
\hline \multirow[t]{3}{*}{ Belgien } & Männer & 6,4 & 8,6 & 7,2 & 7,8 & 6,9 & 8,1 & 7,3 & 7,7 & 6,3 & 8,7 \\
\hline & Frauen & 6,5 & 8,5 & 7,4 & 7,6 & 7,2 & 7,8 & 7,2 & 7,8 & 6,7 & 8,3 \\
\hline & $M+F$ & 6,5 & 8,5 & 7,3 & 7,7 & 7,0 & 8,0 & 7,2 & 7,8 & 6,5 & 8,5 \\
\hline \multirow[t]{3}{*}{ Kanada } & Männer & 6,6 & 8,4 & 6,5 & 8,5 & 6,5 & 8,5 & 6,5 & 8,5 & 6,5 & 8,5 \\
\hline & Frauen & 6,8 & 8,2 & 6,9 & 8,1 & 6,9 & 8,1 & 7,0 & 8,0 & 7,1 & 7,9 \\
\hline & $M+F$ & 6,7 & 8,3 & 6,7 & 8,3 & 6,7 & 8,3 & 6,8 & 8,2 & 6,8 & 8,2 \\
\hline \multirow{3}{*}{$\begin{array}{l}\text { Tschechische } \\
\text { Republik }\end{array}$} & Männer & 4,7 & 10,3 & 4,6 & 10,4 & 4,7 & 10,3 & 5,0 & 10,0 & 5,1 & 9,9 \\
\hline & Frauen & 4,8 & 10,2 & 4,7 & 10,3 & 4,8 & 10,2 & 5,1 & 9,9 & 5,3 & 9,7 \\
\hline & $M+F$ & 4,7 & 10,3 & 4,6 & 10,4 & 4,8 & 10,2 & 5,1 & 9,9 & 5,2 & 9,8 \\
\hline \multirow[t]{3}{*}{ Dänemark } & Männer & 8,1 & 6,9 & 7,3 & 7,7 & 7,1 & 7,9 & 7,6 & 7,4 & 7,9 & 7,1 \\
\hline & Frauen & 8,4 & 6,6 & 8,0 & 7,0 & 8,2 & 6,8 & 8,1 & 6,9 & 8,3 & 6,7 \\
\hline & $M+F$ & 8,3 & 6,7 & 7,6 & 7,4 & 7,7 & 7,3 & 7,8 & 7,2 & 8,1 & 6,9 \\
\hline \multirow[t]{3}{*}{ Finnland } & Männer & 7,4 & 7,6 & 7,7 & 7,3 & 8,1 & 6,9 & 8,1 & 6,9 & 7,6 & 7,4 \\
\hline & Frauen & 8,5 & 6,5 & 8,6 & 6,4 & 9,3 & 5,7 & 9,1 & 5,9 & 8,7 & 6,3 \\
\hline & $M+F$ & 7,9 & 7,1 & 8,1 & 6,9 & 8,7 & 6,3 & 8,6 & 6,4 & 8,1 & 6,9 \\
\hline \multirow[t]{3}{*}{ Frankreich } & Männer & 7,8 & 7,2 & 7,8 & 7,2 & 7,9 & 7,1 & 7,8 & 7,2 & 7,8 & 7,2 \\
\hline & Frauen & 8,0 & 7,0 & 8,0 & 7,0 & 8,1 & 6,9 & 8,1 & 6,9 & 8,2 & 6,8 \\
\hline & $M+F$ & 7,9 & 7,1 & 7,9 & 7,1 & 8,0 & 7,0 & 8,0 & 7,0 & 8,0 & 7,0 \\
\hline \multirow[t]{3}{*}{ Deutschland } & Männer & 6,9 & 8,1 & 6,8 & 8,2 & 6,8 & 8,2 & 7,0 & 8,0 & 7,4 & 7,6 \\
\hline & Frauen & 6,8 & 8,2 & 6,8 & 8,2 & 6,8 & 8,2 & 7,0 & 8,0 & 7,3 & 7,7 \\
\hline & $M+F$ & 6,8 & 8,2 & 6,8 & 8,2 & 6,8 & 8,2 & 7,0 & 8,0 & 7,3 & 7,7 \\
\hline \multirow[t]{3}{*}{ Griechenland } & Männer & 5,5 & 9,5 & 5,8 & 9,2 & 6,1 & 8,9 & 6,2 & 8,8 & 6,0 & 9,0 \\
\hline & Frauen & 5,4 & 9,6 & 5,7 & 9,3 & 6,3 & 8,7 & 6,3 & 8,7 & 6,2 & 8,8 \\
\hline & $M+F$ & 5,4 & 9,6 & 5,7 & 9,3 & 6,2 & 8,8 & 6,3 & 8,7 & 6,1 & 8,9 \\
\hline \multirow[t]{3}{*}{ Ungarn } & Männer & 5,6 & 9,4 & 5,6 & 9,4 & 6,1 & 8,9 & 6,1 & 8,9 & 6,4 & 8,6 \\
\hline & Frauen & 5,7 & 9,3 & 5,9 & 9,1 & 6,1 & 8,9 & 6,4 & 8,6 & 6,5 & 8,5 \\
\hline & $M+F$ & 5,7 & 9,3 & 5,7 & 9,3 & 6,1 & 8,9 & 6,2 & 8,8 & 6,4 & 8,6 \\
\hline Island & Männer & $\mathrm{m}$ & $\mathrm{m}$ & 7,5 & 7,5 & 7,9 & 7,1 & 7,2 & 7,8 & 7,5 & 7,5 \\
\hline & Frauen & $\mathrm{m}$ & $\mathrm{m}$ & 7,6 & 7,4 & 7,7 & 7,3 & 8,3 & 6,7 & 8,5 & 6,5 \\
\hline & $M+F$ & $\mathrm{~m}$ & $\mathrm{~m}$ & 7,6 & 7,4 & 7,8 & 7,2 & 7,7 & 7,3 & 8,0 & 7,0 \\
\hline Irland & Männer & $\mathrm{m}$ & $\mathrm{m}$ & 5,4 & 9,6 & 5,3 & 9,7 & 5,3 & 9,7 & 5,4 & 9,6 \\
\hline & Frauen & $\mathrm{m}$ & $\mathrm{m}$ & 6,0 & 9,0 & 6,1 & 8,9 & 6,1 & 8,9 & 6,0 & 9,0 \\
\hline & $M+F$ & $\mathrm{~m}$ & $\mathrm{~m}$ & 5,7 & 9,3 & 5,7 & 9,3 & 5,7 & 9,3 & 5,7 & 9,3 \\
\hline Italien & Männer & 5,7 & 9,3 & 5,8 & 9,2 & 5,7 & 9,3 & 5,8 & 9,2 & 5,9 & 9,1 \\
\hline & Frauen & 6,2 & 8,8 & 6,2 & 8,8 & 6,2 & 8,8 & 6,3 & 8,7 & 6,5 & 8,5 \\
\hline & $M+F$ & 5,9 & 9,1 & 6,0 & 9,0 & 6,0 & 9,0 & 6,0 & 9,0 & 6,2 & 8,8 \\
\hline Japan $^{1}$ & Männer & 6,2 & 3,8 & 6,2 & 3,8 & 6,5 & 3,5 & 6,6 & 3,4 & 6,0 & 4,0 \\
\hline & Frauen & 5,7 & 4,3 & 5,8 & 4,2 & 5,9 & 4,1 & 5,9 & 4,1 & 5,7 & 4,3 \\
\hline & $M+F$ & 6,0 & 4,0 & 6,0 & 4,0 & 6,2 & 3,8 & 6,3 & 3,7 & 5,9 & 4,1 \\
\hline Luxemburg & Männer & $\mathrm{m}$ & $\mathrm{m}$ & 7,0 & 8,0 & 6,8 & 8,2 & 6,9 & 8,1 & 7,0 & 8,0 \\
\hline & Frauen & $\mathrm{m}$ & $\mathrm{m}$ & 6,2 & 8,8 & 6,6 & 8,4 & 6,5 & 8,5 & 6,9 & 8,1 \\
\hline & $M+F$ & $\mathrm{~m}$ & $\mathrm{~m}$ & 6,6 & 8,4 & 6,7 & 8,3 & 6,7 & 8,3 & 6,9 & 8,1 \\
\hline Mexiko & Männer & 4,0 & 11,0 & 4,2 & 10,8 & 4,2 & 10,8 & 4,3 & 10,7 & 4,6 & 10,4 \\
\hline & Frauen & 3,7 & 11,3 & 4,0 & 11,0 & 4,0 & 11,0 & 4,0 & 11,0 & 4,3 & 10,7 \\
\hline & $M+F$ & 3,8 & 11,2 & 4,1 & 10,9 & 4,1 & 10,9 & 4,1 & 10,9 & 4,4 & 10,6 \\
\hline
\end{tabular}

1. Daten beziehen sich auf 15- bis 24 Jährige.

Quelle: OECD. Hinweise s. Anhang 3 unter www.oecd.org/edu/eag2004. 


\section{Tabelle C4.1b (Forts.)}

Veränderung der zu erwartenden Jahre in Ausbildung und nicht in Ausbildung für 15- bis 29-Jährige (1998-2002) Nach Geschlecht und Beschäftigungsstatus

\begin{tabular}{|c|c|c|c|c|c|c|c|c|c|c|c|}
\hline \multirow[b]{2}{*}{ OECD-Länder } & & \multicolumn{2}{|c|}{1998} & \multicolumn{2}{|c|}{1999} & \multicolumn{2}{|c|}{2000} & \multicolumn{2}{|c|}{2001} & \multicolumn{2}{|c|}{2002} \\
\hline & & \begin{tabular}{c|}
$\ln$ \\
Ausbildung
\end{tabular} & $\begin{array}{l}\text { Nicht in } \\
\text { Ausbildung }\end{array}$ & $\begin{array}{c}\text { In } \\
\text { Ausbildung }\end{array}$ & $\begin{array}{c}\text { Nicht in } \\
\text { Ausbildung }\end{array}$ & $\begin{array}{c}\ln \\
\text { Ausbildung }\end{array}$ & $\begin{array}{c}\text { Nicht in } \\
\text { Ausbildung }\end{array}$ & $\begin{array}{c}\ln \\
\text { Ausbildung }\end{array}$ & $\begin{array}{c}\text { Nicht in } \\
\text { Ausbildung }\end{array}$ & $\begin{array}{c}\ln \\
\text { Ausbildung }\end{array}$ & $\begin{array}{l}\text { Nicht in } \\
\text { Ausbildung }\end{array}$ \\
\hline \multirow[t]{3}{*}{ Niederlande } & Männer & 7,9 & 7,1 & 7,8 & 7,2 & 5,8 & 9,2 & 5,8 & 9,2 & 6,0 & 9,0 \\
\hline & Frauen & 7,3 & 7,7 & 7,4 & 7,6 & 5,7 & 9,3 & 5,7 & 9,3 & 5,9 & 9,1 \\
\hline & $M+F$ & 7,6 & 7,4 & 7,6 & 7,4 & 5,7 & 9,3 & 5,7 & 9,3 & 5,9 & 9,1 \\
\hline \multirow[t]{3}{*}{ Norwegen } & Männer & 6,5 & 8,5 & 6,6 & 8,4 & 6,7 & 8,3 & 6,2 & 8,8 & 6,2 & 8,8 \\
\hline & Frauen & 7,4 & 7,6 & 7,5 & 7,5 & 7,8 & 7,2 & 7,2 & 7,8 & 7,3 & 7,7 \\
\hline & $M+F$ & 7,0 & 8,0 & 7,0 & 8,0 & 7,3 & 7,7 & 6,7 & 8,3 & 6,8 & 8,2 \\
\hline \multirow[t]{3}{*}{ Polen } & Männer & 6,3 & 8,7 & 6,3 & 8,7 & 6,5 & 8,5 & 7,2 & 7,8 & 7,8 & 7,2 \\
\hline & Frauen & 6,4 & 8,6 & 6,5 & 8,5 & 6,6 & 8,4 & 7,5 & 7,5 & 8,1 & 6,9 \\
\hline & $M+F$ & 6,4 & 8,6 & 6,4 & 8,6 & 6,6 & 8,4 & 7,4 & 7,6 & 7,9 & 7,1 \\
\hline \multirow[t]{3}{*}{ Portugal } & Männer & 5,2 & 9,8 & 5,5 & 9,5 & 5,4 & 9,6 & 5,4 & 9,6 & 5,1 & 9,9 \\
\hline & Frauen & 5,8 & 9,2 & 6,0 & 9,0 & 6,0 & 9,0 & 6,1 & 8,9 & 6,0 & 9,0 \\
\hline & $M+F$ & 5,5 & 9,5 & 5,7 & 9,3 & 5,7 & 9,3 & 5,7 & 9,3 & 5,6 & 9,4 \\
\hline \multirow{3}{*}{$\begin{array}{l}\text { Slowakische } \\
\text { Republik }\end{array}$} & Männer & 4,5 & 10,5 & 4,5 & 10,5 & 4,4 & 10,6 & 4,3 & 10,7 & 5,0 & 10,0 \\
\hline & Frauen & 4,8 & 10,2 & 4,6 & 10,4 & 4,4 & 10,6 & 4,5 & 10,5 & 5,4 & 9,6 \\
\hline & $M+F$ & 4,6 & 10,4 & 4,5 & 10,5 & 4,4 & 10,6 & 4,4 & 10,6 & 5,2 & 9,8 \\
\hline \multirow[t]{3}{*}{ Spanien } & Männer & 6,1 & 8,9 & 5,9 & 9,1 & 6,1 & 8,9 & 6,0 & 9,0 & 5,9 & 9,1 \\
\hline & Frauen & 7,1 & 7,9 & 6,9 & 8,1 & 6,8 & 8,2 & 6,9 & 8,1 & 6,7 & 8,3 \\
\hline & $M+F$ & 6,6 & 8,4 & 6,4 & 8,6 & 6,4 & 8,6 & 6,5 & 8,5 & 6,3 & 8,7 \\
\hline \multirow[t]{3}{*}{ Schweden } & Männer & 7,0 & 8,0 & 7,1 & 7,9 & 7,0 & 8,0 & 7,0 & 8,0 & 7,1 & 7,9 \\
\hline & Frauen & 7,9 & 7,1 & 7,9 & 7,1 & 7,8 & 7,2 & 7,7 & 7,3 & 7,8 & 7,2 \\
\hline & $M+F$ & 7,4 & 7,6 & 7,5 & 7,5 & 7,4 & 7,6 & 7,4 & 7,6 & 7,5 & 7,5 \\
\hline \multirow[t]{3}{*}{ Schweiz } & Männer & 6,7 & 8,3 & 6,8 & 8,2 & 7,2 & 7,8 & 7,4 & 7,6 & 6,9 & 8,1 \\
\hline & Frauen & 5,8 & 9,2 & 6,1 & 8,9 & 6,3 & 8,7 & 6,7 & 8,3 & 6,5 & 8,5 \\
\hline & $M+F$ & 6,3 & 8,7 & 6,4 & 8,6 & 6,8 & 8,2 & 7,1 & 7,9 & 6,7 & 8,3 \\
\hline \multirow[t]{3}{*}{ Türkei } & Männer & 3,8 & 11,2 & 3,7 & 11,3 & 3,5 & 11,5 & 3,6 & 11,4 & 3,7 & 11,3 \\
\hline & Frauen & 2,5 & 12,5 & 2,6 & 12,4 & 2,5 & 12,5 & 2,5 & 12,5 & 2,6 & 12,4 \\
\hline & $M+F$ & 3,1 & 11,9 & 3,1 & 11,9 & 3,0 & 12,0 & 3,1 & 11,9 & 3,2 & 11,8 \\
\hline \multirow{3}{*}{$\begin{array}{l}\text { Vereinigtes } \\
\text { Königreich }\end{array}$} & Männer & $\mathrm{m}$ & $\mathrm{m}$ & $\mathrm{m}$ & $\mathrm{m}$ & 6,0 & 9,0 & 5,9 & 9,1 & 5,6 & 9,4 \\
\hline & Frauen & $\mathrm{m}$ & $\mathrm{m}$ & $\mathrm{m}$ & $\mathrm{m}$ & 6,3 & 8,7 & 6,4 & 8,6 & 6,6 & 8,4 \\
\hline & $M+F$ & $\mathrm{~m}$ & $\mathrm{~m}$ & $\mathrm{~m}$ & $\mathrm{~m}$ & 6,1 & 8,9 & 6,1 & 8,9 & 6,0 & 9,0 \\
\hline \multirow{3}{*}{$\begin{array}{l}\text { Vereinigte } \\
\text { Staaten }\end{array}$} & Männer & 6,4 & 8,6 & 6,5 & 8,5 & 6,4 & 8,6 & 6,5 & 8,5 & $\mathrm{~m}$ & $\mathrm{~m}$ \\
\hline & Frauen & 6,6 & 8,4 & 6,4 & 8,6 & 6,6 & 8,4 & 6,7 & 8,3 & $\mathrm{~m}$ & $\mathrm{~m}$ \\
\hline & $M+F$ & 6,5 & 8,5 & 6,5 & 8,5 & 6,5 & 8,5 & 6,6 & 8,4 & $m$ & $\mathrm{~m}$ \\
\hline \multirow[t]{3}{*}{ Ländermittel } & Männer & 6,1 & 8,9 & 6,2 & 8,8 & 6,2 & 8,8 & 6,2 & 8,8 & 6,3 & 8,7 \\
\hline & Frauen & 6,2 & 8,8 & 6,3 & 8,7 & 6,4 & 8,6 & 6,5 & 8,5 & 6,6 & 8,4 \\
\hline & $M+F$ & 6,2 & 8,8 & 6,3 & 8,7 & 6,3 & 8,7 & 6,4 & 8,6 & 6,4 & 8,6 \\
\hline
\end{tabular}

1. Daten beziehen sich auf 15- bis 24 Jährige.

Quelle: OECD. Hinweise s. Anhang 3 unter www.oecd.org/edu/eag2004. 
Prozentsatz junger Menschen, die sich in Ausbildung bzw. nicht in Ausbildung befinden (2002) Nach Altersgruppe und Beschäftigungsstatus

\begin{tabular}{|c|c|c|c|c|c|c|c|c|c|c|c|}
\hline & \multirow{2}{*}{$\begin{array}{l}\text { Alters- } \\
\text { gruppe }\end{array}$} & \multicolumn{5}{|c|}{ In Ausbildung } & \multicolumn{4}{|c|}{ Nicht in Ausbildung } & \multirow{2}{*}{$\begin{array}{c}\text { In Ausbil- } \\
\text { dung und } \\
\text { nicht in } \\
\text { Ausbildung } \\
\text { insgesamt }\end{array}$} \\
\hline OECD-Länder & & \begin{tabular}{|c|} 
In dualer \\
Ausbildung $^{1}$
\end{tabular} & \begin{tabular}{|l|} 
Andere Be- \\
schäftigung
\end{tabular} & Arbeitslos & $\begin{array}{c}\text { Nicht im } \\
\text { Arbeits- } \\
\text { markt }\end{array}$ & Zusammen & Beschäftigt & Arbeitslos & $\begin{array}{c}\text { Nicht im } \\
\text { Arbeits- } \\
\text { markt }\end{array}$ & Zusammen & \\
\hline \multirow{3}{*}{ Australien } & $15-19$ & 7,1 & 27,6 & 5,6 & 39,5 & 79,7 & 13,3 & 4,2 & 2,9 & 20,3 & 100 \\
\hline & $20-24$ & 4,9 & 20,5 & 2,0 & 11,2 & 38,7 & 48,1 & 5,4 & 7,8 & 61,3 & 100 \\
\hline & $25-29$ & 0,9 & 10,9 & 1,2 & 3,6 & 16,5 & 65,7 & 4,7 & 13,1 & 83,5 & 100 \\
\hline \multirow[t]{3}{*}{ Österreich } & $15-19$ & 24,3 & 1,1 & 0,4 & 55,7 & 81,5 & 12,1 & 2,3 & 4,0 & 18,5 & 100 \\
\hline & $20-24$ & 1,9 & 3,9 & 0,2 & 23,5 & 29,4 & 58,9 & 4,8 & 6,9 & 70,6 & 100 \\
\hline & $25-29$ & 0,1 & 3,0 & 0,2 & 7,0 & 10,3 & 77,3 & 4,2 & 8,2 & 89,7 & 100 \\
\hline \multirow[t]{3}{*}{ Belgien } & $15-19$ & 1,9 & 1,0 & 0,3 & 86,4 & 89,6 & 3,6 & 1,9 & 4,9 & 10,4 & 100 \\
\hline & $20-24$ & 0,7 & 2,6 & 0,6 & 34,4 & 38,2 & 44,4 & 8,9 & 8,6 & 61,8 & 100 \\
\hline & $25-29$ & 0,5 & 2,6 & 0,4 & 2,3 & 5,8 & 77,0 & 7,9 & 9,3 & 94,2 & 100 \\
\hline \multirow[t]{3}{*}{ Kanada } & $15-19$ & a & 28,9 & 6,1 & 47,8 & 82,7 & 10,8 & 2,8 & 3,6 & 17,3 & 100 \\
\hline & $20-24$ & a & 18,7 & 1,9 & 18,7 & 39,3 & 46,8 & 7,0 & 6,9 & 60,7 & 100 \\
\hline & $25-29$ & a & 7,7 & 0,6 & 5,9 & 14,2 & 69,0 & 7,0 & 9,7 & 85,8 & 100 \\
\hline \multirow{3}{*}{$\begin{array}{l}\text { Tschechische } \\
\text { Republik }\end{array}$} & $15-19$ & 21,6 & 0,2 & $\mathrm{n}$ & 66,5 & 88,3 & 5,7 & 3,5 & 2,5 & 11,7 & 100 \\
\hline & $20-24$ & 0,3 & 0,5 & 0,1 & 24,8 & 25,7 & 56,2 & 8,8 & 9,3 & 74,3 & 100 \\
\hline & $25-29$ & $n$ & 0,3 & $\mathrm{n}$ & 2,6 & 2,9 & 73,3 & 6,3 & 17,5 & 97,1 & 100 \\
\hline \multirow[t]{3}{*}{ Dänemark } & $15-19$ & 5,9 & 41,0 & 3,5 & 38,4 & 88,7 & 8,9 & 0,4 & 2,0 & 11,3 & 100 \\
\hline & $20-24$ & 8,8 & 25,9 & 2,4 & 18,2 & 55,3 & 37,4 & 3,5 & 3,9 & 44,7 & 100 \\
\hline & $25-29$ & 1,7 & 21,2 & 1,2 & 11,0 & 35,0 & 58,3 & 2,8 & 3,9 & 65,0 & 100 \\
\hline \multirow[t]{3}{*}{ Finnland } & $15-19$ & 13,0 & 7,7 & 4,2 & 55,5 & 80,4 & 4,7 & 2,6 & 12,3 & 19,6 & 100 \\
\hline & $20-24$ & 6,7 & 10,8 & 2,5 & 36,0 & 56,1 & 25,1 & 5,8 & 13,0 & 43,9 & 100 \\
\hline & $25-29$ & 3,1 & 10,9 & 0,9 & 11,8 & 26,7 & 53,6 & 6,3 & 13,5 & 73,3 & 100 \\
\hline \multirow[t]{3}{*}{ Frankreich } & $15-19$ & 5,3 & 0,9 & 0,1 & 88,3 & 94,6 & 1,9 & 1,7 & 1,7 & 5,4 & 100 \\
\hline & $20-24$ & 5,5 & 5,2 & 0,9 & 41,5 & 53,2 & 32,5 & 9,2 & 5,1 & 46,8 & 100 \\
\hline & $25-29$ & 1,7 & 4,6 & 0,4 & 5,0 & 11,7 & 70,1 & 9,4 & 8,9 & 88,3 & 100 \\
\hline \multirow[t]{3}{*}{ Deutschland } & $15-19$ & 19,5 & 4,1 & 0,7 & 65,9 & 90,1 & 5,2 & 1,7 & 3,0 & 9,9 & 100 \\
\hline & $20-24$ & 12,9 & 5,9 & 0,3 & 18,9 & 38,1 & 46,0 & 7,0 & 8,9 & 61,9 & 100 \\
\hline & $25-29$ & 1,6 & 6,1 & 0,3 & 8,3 & 16,3 & 66,3 & 6,5 & 11,0 & 83,7 & 100 \\
\hline \multirow[t]{3}{*}{ Griechenland } & $15-19$ & 1,5 & 1,0 & 0,5 & 83,9 & 86,8 & 6,9 & 3,0 & 3,2 & 13,2 & 100 \\
\hline & $20-24$ & 0,7 & 2,1 & 1,0 & 32,5 & 36,3 & 41,7 & 13,4 & 8,6 & 63,7 & 100 \\
\hline & $25-29$ & $\mathrm{n}$ & 1,3 & 0,3 & 4,4 & 5,9 & 68,7 & 13,1 & 12,1 & 93,9 & 100 \\
\hline \multirow[t]{3}{*}{ Ungarn } & $15-19$ & a & 0,4 & 0,1 & 86,9 & 87,5 & 4,5 & 1,7 & 6,3 & 12,5 & 100 \\
\hline & $20-24$ & a & 4,9 & 0,3 & 32,5 & 37,7 & 42,0 & 5,4 & 14,9 & 62,3 & 100 \\
\hline & $25-29$ & a & 5,9 & 0,3 & 4,4 & 10,6 & 61,8 & 5,1 & 22,5 & 89,4 & 100 \\
\hline \multirow[t]{3}{*}{ Island } & $15-19$ & $\mathrm{c}$ & 29,5 & c & 49,1 & 80,9 & 14,8 & c & c & 19,1 & 100 \\
\hline & $20-24$ & 5,4 & 29,4 & $c$ & 18,2 & 53,8 & 40,1 & c & $c$ & 46,2 & 100 \\
\hline & $25-29$ & c & 23,8 & c & 7,4 & 36,5 & 58,8 & c & c & 63,5 & 100 \\
\hline Irland & $15-19$ & a & 9,2 & 0,6 & 71,8 & 81,6 & 13,6 & 2,4 & 2,4 & 18,4 & 100 \\
\hline & $20-24$ & a & 5,7 & 0,4 & 22,8 & 29,0 & 60,2 & 4,1 & 6,7 & 71,0 & 100 \\
\hline & $25-29$ & a & 0,6 & 0,1 & 2,8 & 3,5 & 81,8 & 4,0 & 10,7 & 96,5 & 100 \\
\hline Italien & $15-19$ & $n$ & 0,5 & 0,7 & 79,6 & 80,7 & 8,7 & 4,3 & 6,2 & 19,2 & 100 \\
\hline & $20-24$ & 0,1 & 1,8 & 1,6 & 34,7 & 38,2 & 37,5 & 11,8 & 12,5 & 61,8 & 100 \\
\hline & $25-29$ & 0,1 & 2,2 & 1,1 & 12,3 & 15,6 & 59,5 & 10,4 & 14,5 & 84,4 & 100 \\
\hline Luxemburg & $15-19$ & 4,4 & 2,3 & 0,4 & 84,2 & 91,3 & 5,7 & 1,6 & 1,4 & 8,7 & 100 \\
\hline & $20-24$ & 1,8 & 6,9 & $n$ & 39,2 & 47,8 & 45,2 & 2,8 & 4,2 & 52,2 & 100 \\
\hline & $25-29$ & 0,5 & 8,3 & 0,2 & 5,0 & 13,9 & 74,5 & 3,2 & 8,4 & 86,1 & 100 \\
\hline Mexiko & $15-19$ & a & 7,5 & 0,3 & 45,7 & 53,4 & 29,0 & 1,7 & 15,8 & 46,6 & 100 \\
\hline & $20-24$ & a & 5,0 & 0,3 & 15,4 & 20,8 & 52,6 & 2,5 & 24,1 & 79,2 & 100 \\
\hline & $25-29$ & a & 1,6 & 0,1 & 2,8 & 4,6 & 64,8 & 1,9 & 28,8 & 95,4 & 100 \\
\hline Niederlande & $15-19$ & $\mathrm{~m}$ & 39,8 & 3,8 & 37,2 & 80,7 & 14,7 & 1,7 & 2,9 & 19,3 & 100 \\
\hline & $20-24$ & $\mathrm{~m}$ & 21,9 & 0,9 & 12,5 & 35,3 & 56,8 & 2,1 & 5,8 & 64,7 & 100 \\
\hline & $25-29$ & $\mathrm{~m}$ & 3,5 & 0,2 & 2,4 & 6,2 & 80,9 & 2,5 & 10,4 & 93,8 & 100 \\
\hline
\end{tabular}

Hinweis: c weist darauf hin, dass zu wenige Daten zur Verfügung stehen, um verlässliche Schätzungen vorzunehmen.

1. Die Teilnehmer an dualen Ausbildungsprogrammen gelten als sowohl in Ausbildung als auch beschäftigt, ohne Bezug auf ihren ILO-Erwerbsstatus.

2. Referenzjahr 2001.

Quelle: OECD. Hinweise s. Anhang 3 unter www.oecd.org/edu/eag2004. 


\section{Tabelle C4.2 (Forts.)}

Prozentsatz junger Menschen, die sich in Ausbildung bzw. nicht in Ausbildung befinden (2002) Nach Altersgruppe und Beschäftigungsstatus

\begin{tabular}{|c|c|c|c|c|c|c|c|c|c|c|c|}
\hline & \multirow{3}{*}{$\begin{array}{l}\text { Alters- } \\
\text { gruppe }\end{array}$} & \multicolumn{5}{|c|}{ In Ausbildung } & \multicolumn{4}{|c|}{ Nicht in Ausbildung } & \multirow{2}{*}{$\begin{array}{l}\text { In Ausbil- } \\
\text { dung und } \\
\text { nicht in } \\
\text { Ausbildung } \\
\text { insgesamt }\end{array}$} \\
\hline & & \begin{tabular}{|c|} 
In dualer \\
Ausbildung 1
\end{tabular} & $\begin{array}{l}\text { Andere Be- } \\
\text { schäftigung }\end{array}$ & Arbeitslos & $\begin{array}{c}\text { Nicht im } \\
\text { Arbeits- } \\
\text { markt }\end{array}$ & Zusammen & Beschäftigt & Arbeitslos & $\begin{array}{c}\text { Nicht im } \\
\text { Arbeits- } \\
\text { markt }\end{array}$ & Zusammen & \\
\hline \multicolumn{11}{|l|}{ OECD-Länder } & \\
\hline \multirow[t]{3}{*}{ Norwegen } & $15-19$ & a & 22,8 & 5,4 & 57,1 & 85,3 & 11,5 & 1,4 & 1,8 & 14,7 & 100 \\
\hline & $20-24$ & a & 16,1 & 2,6 & 19,8 & 38,5 & 51,8 & 3,7 & 6,0 & 61,5 & 100 \\
\hline & $25-29$ & a & 4,9 & 0,8 & 8,5 & 14,2 & 75,0 & 3,2 & 7,5 & 85,8 & 100 \\
\hline \multirow[t]{3}{*}{ Polen } & $15-19$ & a & 3,0 & 0,8 & 92,2 & 95,9 & 1,0 & 1,8 & 1,3 & 4,1 & 100 \\
\hline & $20-24$ & a & 9,9 & 8,3 & 35,7 & 53,8 & 20,8 & 18,0 & 7,4 & 46,2 & 100 \\
\hline & $25-29$ & a & 8,6 & 2,2 & 4,0 & 14,9 & 53,3 & 18,7 & 13,2 & 85,1 & 100 \\
\hline \multirow[t]{3}{*}{ Portugal } & $15-19$ & a & 2,0 & 0,5 & 70,0 & 72,4 & 20,3 & 3,0 & 4,2 & 27,6 & 100 \\
\hline & $20-24$ & a & 5,9 & 0,8 & 28,1 & 34,7 & 53,3 & 5,4 & 6,6 & 65,3 & 100 \\
\hline & $25-29$ & a & 4,6 & 0,4 & 5,6 & 10,7 & 77,1 & 4,1 & 8,1 & 89,3 & 100 \\
\hline \multirow{2}{*}{$\begin{array}{l}\text { Slowakische } \\
\text { Republik }\end{array}$} & $20-24$ & 0,3 & 1,6 & 0,8 & 19,4 & 22,1 & 44,0 & 22,4 & 11,5 & 77,9 & 100 \\
\hline & $25-29$ & 0,2 & 0,8 & 0,2 & 1,8 & 2,9 & 66,6 & 16,0 & 14,5 & 97,1 & 100 \\
\hline \multirow[t]{3}{*}{ Spanien } & $15-19$ & 0,5 & 2,6 & 1,4 & 77,4 & 81,9 & 11,0 & 3,9 & 3,2 & 18,1 & 100 \\
\hline & $20-24$ & 0,6 & 6,2 & 3,0 & 33,6 & 43,4 & 41,5 & 9,3 & 5,8 & 56,6 & 100 \\
\hline & $25-29$ & 0,3 & 5,9 & 2,3 & 7,6 & 16,1 & 64,2 & 9,5 & 10,2 & 83,9 & 100 \\
\hline \multirow[t]{3}{*}{ Schweden } & $15-19$ & a & 12,8 & 3,9 & 71,7 & 88,4 & 7,0 & 1,8 & 2,8 & 11,6 & 100 \\
\hline & $20-24$ & a & 12,2 & 2,4 & 27,1 & 41,7 & 47,0 & 6,0 & 5,2 & 58,3 & 100 \\
\hline & $25-29$ & a & 9,5 & 1,2 & 11,8 & 22,4 & 69,5 & 4,0 & 4,1 & 77,6 & 100 \\
\hline \multirow[t]{3}{*}{ Schweiz } & $15-19$ & 36,7 & 9,2 & c & 38,1 & 86,2 & 8,0 & c & 4,4 & 13,8 & 100 \\
\hline & $20-24$ & 11,4 & 12,9 & c & 12,7 & 38,0 & 52,3 & 3,4 & 6,3 & 62,0 & 100 \\
\hline & $25-29$ & c & 7,9 & c & 4,1 & 12,7 & 74,7 & 4,7 & 7,9 & 87,3 & 100 \\
\hline \multirow[t]{3}{*}{ Türkei } & $15-19$ & a & 1,8 & 0,3 & 41,0 & 43,0 & 24,2 & 5,1 & 27,7 & 57,0 & 100 \\
\hline & $20-24$ & a & 2,1 & 0,9 & 11,5 & 14,5 & 40,1 & 9,8 & 35,6 & 85,5 & 100 \\
\hline & $25-29$ & a & 1,6 & 0,2 & 1,2 & 3,1 & 56,1 & 7,2 & 33,7 & 96,9 & 100 \\
\hline $\begin{array}{l}\text { Vereinigtes } \\
\text { Königreich }\end{array}$ & $25-29$ & 1,0 & 8,9 & 0,6 & 2,8 & 13,3 & 70,7 & 4,2 & 11,8 & 86,7 & 100 \\
\hline \multirow{3}{*}{$\begin{array}{l}\text { Vereinigte } \\
\text { Staaten }^{2}\end{array}$} & $15-19$ & a & 23,9 & 3,5 & 53,7 & 81,2 & 11,4 & 2,8 & 4,7 & 18,8 & 100 \\
\hline & $20-24$ & a & 19,5 & 1,3 & 13,1 & 33,9 & 50,5 & 5,4 & 10,2 & 66,1 & 100 \\
\hline & $25-29$ & a & 8,4 & 0,5 & 2,9 & 11,8 & 70,5 & 4,1 & 13,5 & 88,2 & 100 \\
\hline \multirow[t]{3}{*}{ Ländermittel } & $15-19$ & 6,0 & 11,1 & 1,8 & 62,8 & 81,7 & 10,4 & 2,8 & 5,1 & 18,3 & 100 \\
\hline & $20-24$ & 2,4 & 10,1 & 1,4 & 24,1 & 37,9 & 45,4 & 7,2 & 9,4 & 62,1 & 100 \\
\hline & $25-29$ & 0,6 & 6,5 & 0,6 & 5,5 & 13,3 & 68,1 & 6,4 & 12,2 & 86,7 & 100 \\
\hline \multicolumn{12}{|c|}{ OECD-Partnerländer } \\
\hline \multirow{3}{*}{ Israel } & $15-19$ & a & 4,1 & 0,8 & 64,5 & 69,4 & 6,0 & 1,7 & 22,9 & 30,6 & 100 \\
\hline & $20-24$ & a & 9,5 & 1,6 & 15,7 & 26,8 & 31,7 & 8,2 & 33,4 & 73,2 & 100 \\
\hline & $25-29$ & a & 13,1 & 1,0 & 5,1 & 19,1 & 52,2 & 8,7 & 20,0 & 80,9 & 100 \\
\hline
\end{tabular}

Hinweis: c weist darauf hin, dass zu wenige Daten zur Verfügung stehen, um verlässliche Schätzungen vorzunehmen.

1. Die Teilnehmer an dualen Ausbildungsprogrammen gelten als sowohl in Ausbildung als auch beschäftigt, ohne Bezug auf ihren ILO-Erwerbsstatus.

2. Referenzjahr 2001.

Quelle: OECD. Hinweise s. Anhang 3 unter www.oecd.org/edu/eag2004. 
Prozentsatz junger Männer, die sich in Ausbildung bzw. nicht in Ausbildung befinden (2002) Nach Altersgruppe und Beschäftigungsstatus

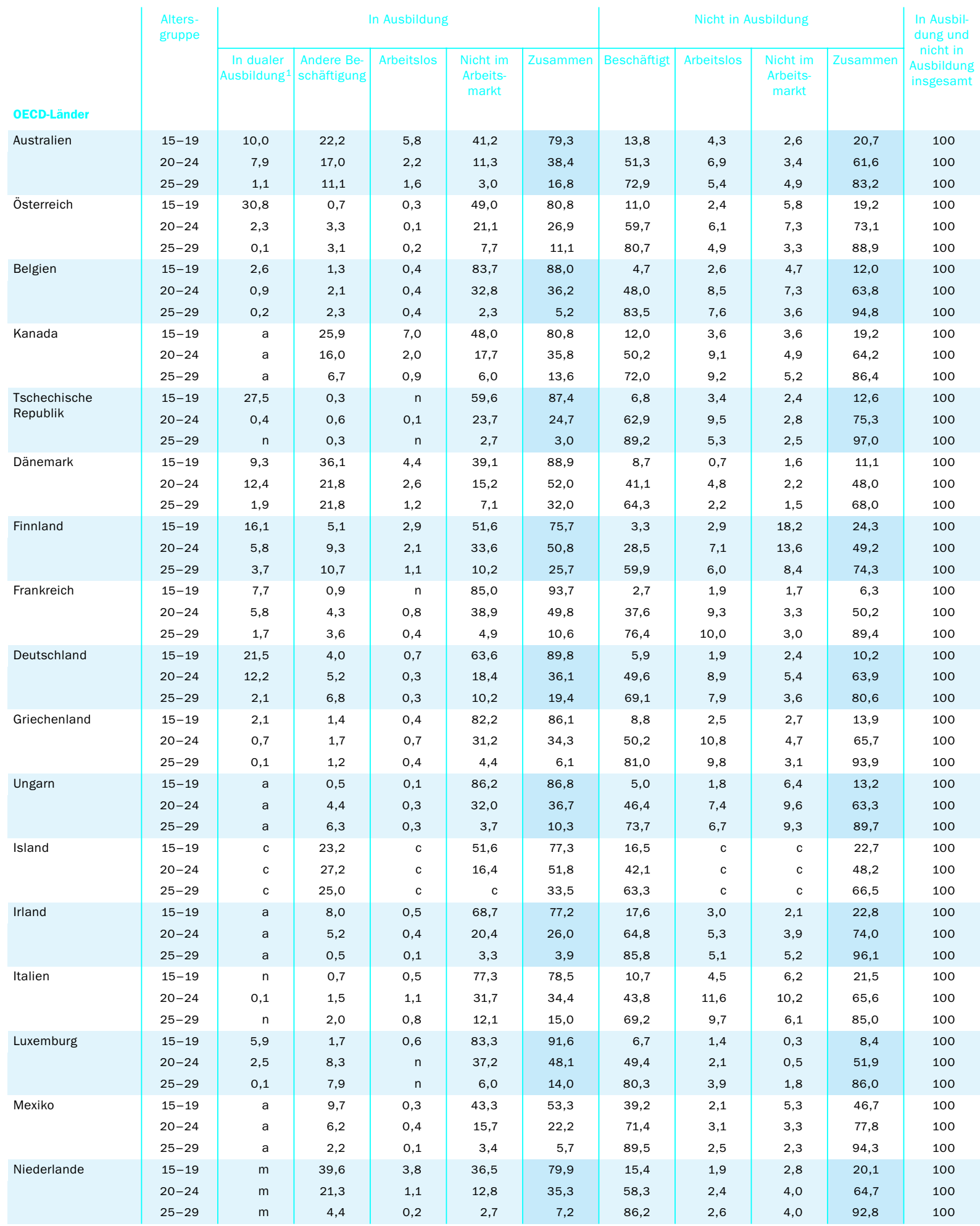

Hinweis: c weist darauf hin, dass zu wenige Daten zur Verfügung stehen, um verlässliche Schätzungen vorzunehmen.

1. Die Teilnehmer an dualen Ausbildungsprogrammen gelten als sowohl in Ausbildung als auch beschäftigt, ohne Bezug auf ihren ILO-Erwerbsstatus.

Referenzjahr 2001.

Quelle: OECD. Hinweise s. Anhang 3 unter www.oecd.org/edu/eag2004. 


\section{Tabelle C4.2a (Forts.)}

Prozentsatz junger Männer, die sich in Ausbildung bzw. nicht in Ausbildung befinden (2002) Nach Altersgruppe und Beschäftigungsstatus

\begin{tabular}{|c|c|c|c|c|c|c|c|c|c|c|c|}
\hline & \multirow{2}{*}{$\begin{array}{l}\text { Alters- } \\
\text { gruppe }\end{array}$} & \multicolumn{5}{|c|}{ In Ausbildung } & \multicolumn{4}{|c|}{ Nicht in Ausbildung } & \multirow{2}{*}{$\begin{array}{l}\text { In Ausbil- } \\
\text { dung und } \\
\text { nicht in } \\
\text { Ausbildung } \\
\text { insgesamt }\end{array}$} \\
\hline OECD-Länder & & \begin{tabular}{|c|} 
In dualer \\
Ausbildung $^{1}$ \\
\end{tabular} & $\begin{array}{c}\text { Andere Be- } \\
\text { schäftigung }\end{array}$ & Arbeitslos & $\begin{array}{c}\text { Nicht im } \\
\text { Arbeits- } \\
\text { markt }\end{array}$ & Zusammen & Beschäftigt & Arbeitslos & $\begin{array}{c}\text { Nicht im } \\
\text { Arbeits- } \\
\text { markt }\end{array}$ & Zusammen & \\
\hline \multirow[t]{3}{*}{ Norwegen } & $15-19$ & a & 18,9 & 5,5 & 57,3 & 81,8 & 14,5 & 1,9 & 1,8 & 18,2 & 100 \\
\hline & $20-24$ & $\mathrm{a}$ & 12,4 & 2,3 & 18,9 & 33,6 & 57,5 & 4,8 & 4,1 & 66,4 & 100 \\
\hline & $25-29$ & a & 4,9 & 0,9 & 7,1 & 12,9 & 79,1 & 3,6 & 4,4 & 87,1 & 100 \\
\hline \multirow[t]{3}{*}{ Polen } & $15-19$ & a & 3,9 & 0,8 & 90,4 & 95,1 & 1,4 & 2,2 & 1,3 & 4,9 & 100 \\
\hline & $20-24$ & a & 9,6 & 8,4 & 33,5 & 51,5 & 23,3 & 20,7 & 4,5 & 48,5 & 100 \\
\hline & $25-29$ & a & 9,3 & 2,2 & 3,5 & 15,0 & 60,6 & 19,9 & 4,6 & 85,0 & 100 \\
\hline \multirow[t]{3}{*}{ Portugal } & $15-19$ & a & 2,0 & 0,3 & 65,1 & 67,4 & 24,9 & 3,5 & 4,2 & 32,6 & 100 \\
\hline & $20-24$ & a & 6,2 & 0,7 & 24,3 & 31,2 & 60,1 & 4,8 & 3,8 & 68,8 & 100 \\
\hline & $25-29$ & a & 4,6 & 0,4 & 4,9 & 9,9 & 82,3 & 3,0 & 4,7 & 90,1 & 100 \\
\hline \multirow{3}{*}{$\begin{array}{l}\text { Slowakische } \\
\text { Republik }\end{array}$} & $15-19$ & 17,9 & $n$ & $n$ & 59,9 & 77,8 & 4,5 & 10,6 & 7,1 & 22,2 & 100 \\
\hline & $20-24$ & 0,4 & 1,2 & 0,5 & 17,1 & 19,2 & 47,2 & 26,8 & 6,8 & 80,8 & 100 \\
\hline & $25-29$ & 0,1 & 0,7 & 0,1 & 1,9 & 2,8 & 77,4 & 16,6 & 3,3 & 97,2 & 100 \\
\hline \multirow[t]{3}{*}{ Spanien } & $15-19$ & 0,6 & 2,4 & 1,2 & 74,2 & 78,4 & 14,7 & 4,2 & 2,7 & 21,6 & 100 \\
\hline & $20-24$ & 0,5 & 5,6 & 2,4 & 30,1 & 38,6 & 49,0 & 8,8 & 3,6 & 61,4 & 100 \\
\hline & $25-29$ & 0,3 & 5,2 & 1,6 & 7,5 & 14,6 & 73,3 & 7,8 & 4,3 & 85,4 & 100 \\
\hline \multirow[t]{3}{*}{ Schweden } & $15-19$ & $a$ & 10,3 & 3,0 & 74,2 & 87,5 & 6,6 & 2,0 & 3,9 & 12,5 & 100 \\
\hline & $20-24$ & $a$ & 9,2 & 2,8 & 25,3 & 37,3 & 50,9 & 7,4 & 4,5 & 62,7 & 100 \\
\hline & $25-29$ & $a$ & 8,6 & 1,2 & 10,8 & 20,7 & 73,5 & 4,2 & 1,6 & 79,3 & 100 \\
\hline \multirow[t]{3}{*}{ Schweiz } & $15-19$ & 41,7 & 8,0 & c & 35,8 & 88,3 & 5,9 & c & c & 11,7 & 100 \\
\hline & $20-24$ & 13,6 & 9,8 & c & 12,6 & 37,2 & 52,1 & c & 6,6 & 62,8 & 100 \\
\hline & $25-29$ & c & 9,5 & c & 4,6 & 14,5 & 78,3 & 5,5 & c & 85,5 & 100 \\
\hline \multirow[t]{3}{*}{ Türkei } & $15-19$ & $a$ & 2,6 & 0,4 & 45,8 & 48,8 & 29,7 & 6,5 & 15,0 & 51,2 & 100 \\
\hline & $20-24$ & a & 2,5 & 1,1 & 14,9 & 18,5 & 54,3 & 13,8 & 13,3 & 81,5 & 100 \\
\hline & $25-29$ & a & 2,2 & 0,2 & 1,3 & 3,7 & 79,9 & 9,7 & 6,7 & 96,3 & 100 \\
\hline \multirow{3}{*}{$\begin{array}{l}\text { Vereinigtes } \\
\text { Königreich }\end{array}$} & $15-19$ & 6,0 & 16,8 & 2,5 & 48,2 & 73,5 & 18,3 & 5,4 & 2,8 & 26,5 & 100 \\
\hline & $20-24$ & 2,9 & 11,5 & 0,9 & 12,8 & 28,1 & 60,6 & 7,0 & 4,3 & 71,9 & 100 \\
\hline & $25-29$ & 0,6 & 7,1 & 0,5 & 2,2 & 10,5 & 81,0 & 4,4 & 4,2 & 89,5 & 100 \\
\hline \multirow{3}{*}{$\begin{array}{l}\text { Vereinigte } \\
\text { Staaten }^{2}\end{array}$} & $15-19$ & a & 21,9 & 3,8 & 54,6 & 80,3 & 12,7 & 3,0 & 4,0 & 19,7 & 100 \\
\hline & $20-24$ & a & 17,7 & 1,2 & 13,5 & 32,5 & 55,3 & 6,3 & 5,8 & 67,5 & 100 \\
\hline & $25-29$ & a & 7,8 & 0,5 & 2,2 & 10,5 & 79,3 & 4,4 & 5,8 & 89,5 & 100 \\
\hline \multirow[t]{3}{*}{ Ländermittel } & $15-19$ & 7,4 & 9,9 & 1,8 & 61,3 & 80,5 & 11,9 & 3,2 & 4,3 & 19,5 & 100 \\
\hline & $20-24$ & 2,8 & 8,9 & 1,4 & 22,7 & 35,8 & 50,6 & 8,2 & 5,3 & 64,2 & 100 \\
\hline & $25-29$ & 0,6 & 6,5 & 0,6 & 5,2 & 12,9 & 76,4 & 6,7 & 4,1 & 87,1 & 100 \\
\hline \multicolumn{12}{|c|}{ OECD-Partnerländer } \\
\hline \multirow[t]{3}{*}{ Israel } & $15-19$ & a & 4,6 & 0,6 & 63,4 & 68,7 & 5,6 & 2,0 & 23,7 & 31,3 & 100 \\
\hline & $20-24$ & a & 7,3 & 0,8 & 14,7 & 22,8 & 31,0 & 8,0 & 38,1 & 77,2 & 100 \\
\hline & $25-29$ & a & 13,3 & 1,2 & 6,2 & 20,7 & 54,9 & 10,5 & 14,0 & 79,3 & 100 \\
\hline
\end{tabular}

Hinweis: c weist darauf hin, dass zu wenige Daten zur Verfügung stehen, um verlässliche Schätzungen vorzunehmen.

1. Die Teilnehmer an dualen Ausbildungsprogrammen gelten als sowohl in Ausbildung als auch beschäftigt, ohne Bezug auf ihren ILO-Erwerbsstatus.

2. Referenzjahr 2001.

Quelle: OECD. Hinweise s. Anhang 3 unter www.oecd.org/edu/eag2004. 
Prozentsatz junger Frauen, die sich in Ausbildung bzw. nicht in Ausbildung befinden (2002) Nach Altersgruppe und Beschäftigungsstatus

\begin{tabular}{|c|c|c|c|c|c|c|c|c|c|c|c|}
\hline & \multirow{2}{*}{$\begin{array}{l}\text { Alters- } \\
\text { gruppe }\end{array}$} & \multicolumn{5}{|c|}{ In Ausbildung } & \multicolumn{4}{|c|}{ Nicht in Ausbildung } & \multirow{2}{*}{$\begin{array}{c}\text { In Ausbil- } \\
\text { dung und } \\
\text { nicht in } \\
\text { Ausbildung } \\
\text { insgesamt }\end{array}$} \\
\hline OECD-Länder & & \begin{tabular}{|c|} 
In dualer \\
Ausbildung \\
\end{tabular} & \begin{tabular}{|l|} 
Andere Be- \\
schäftigung
\end{tabular} & Arbeitslos & $\begin{array}{c}\text { Nicht im } \\
\text { Arbeits- } \\
\text { markt }\end{array}$ & Zusammen & Beschäftigt & Arbeitslos & $\begin{array}{c}\text { Nicht im } \\
\text { Arbeits- } \\
\text { markt }\end{array}$ & Zusammen & \\
\hline \multirow[t]{3}{*}{ Australien } & $15-19$ & 3,9 & 33,1 & 5,3 & 37,6 & 80,0 & 12,8 & 4,0 & 3,1 & 20,0 & 100 \\
\hline & $20-24$ & 1,8 & 24,1 & 1,9 & 11,1 & 38,9 & 44,9 & 3,9 & 12,3 & 61,1 & 100 \\
\hline & $25-29$ & 0,6 & 10,7 & 0,8 & 4,2 & 16,2 & 58,5 & 4,0 & 21,3 & 83,8 & 100 \\
\hline \multirow[t]{3}{*}{ Österreich } & $15-19$ & 17,5 & 1,5 & 0,6 & 62,7 & 82,2 & 13,3 & 2,3 & 2,1 & 17,8 & 100 \\
\hline & $20-24$ & 1,4 & 4,4 & 0,2 & 26,0 & 32,1 & 58,1 & 3,3 & 6,5 & 67,9 & 100 \\
\hline & $25-29$ & 0,2 & 2,8 & 0,2 & 6,4 & 9,6 & 74,0 & 3,4 & 13,0 & 90,4 & 100 \\
\hline \multirow[t]{3}{*}{ Belgien } & $15-19$ & 1,2 & 0,6 & 0,2 & 89,1 & 91,2 & 2,4 & 1,2 & 5,2 & 8,8 & 100 \\
\hline & $20-24$ & 0,5 & 3,0 & 0,7 & 36,1 & 40,3 & 40,6 & 9,3 & 9,9 & 59,7 & 100 \\
\hline & $25-29$ & 0,7 & 3,0 & 0,4 & 2,3 & 6,4 & 70,3 & 8,3 & 15,0 & 93,6 & 100 \\
\hline \multirow[t]{3}{*}{ Kanada } & $15-19$ & $a$ & 32,1 & 5,1 & 47,5 & 84,7 & 9,6 & 2,0 & 3,7 & 15,3 & 100 \\
\hline & $20-24$ & $a$ & 21,4 & 1,7 & 19,8 & 42,8 & 43,2 & 4,8 & 9,1 & 57,2 & 100 \\
\hline & $25-29$ & a & 8,8 & 0,3 & 5,8 & 14,9 & 66,0 & 4,8 & 14,3 & 85,1 & 100 \\
\hline \multirow{3}{*}{$\begin{array}{l}\text { Tschechische } \\
\text { Republik }\end{array}$} & $15-19$ & 15,5 & 0,1 & $n$ & 73,6 & 89,2 & 4,5 & 3,7 & 2,6 & 10,8 & 100 \\
\hline & $20-24$ & 0,2 & 0,5 & 0,1 & 25,9 & 26,6 & 49,2 & 8,0 & 16,1 & 73,4 & 100 \\
\hline & $25-29$ & $\mathrm{n}$ & 0,4 & $\mathrm{n}$ & 2,4 & 2,8 & 56,8 & 7,3 & 33,0 & 97,2 & 100 \\
\hline \multirow[t]{3}{*}{ Dänemark } & $15-19$ & 2,2 & 46,2 & 2,6 & 37,5 & 88,5 & 9,0 & $\mathrm{n}$ & 2,4 & 11,5 & 100 \\
\hline & $20-24$ & 5,4 & 29,8 & 2,1 & 21,0 & 58,3 & 34,0 & 2,2 & 5,4 & 41,7 & 100 \\
\hline & $25-29$ & 1,4 & 20,6 & 1,1 & 14,7 & 37,9 & 52,6 & 3,4 & 6,1 & 62,1 & 100 \\
\hline \multirow[t]{3}{*}{ Finnland } & $15-19$ & 9,6 & 10,7 & 5,7 & 59,8 & 85,8 & 6,3 & 2,2 & 5,6 & 14,2 & 100 \\
\hline & $20-24$ & 7,6 & 12,3 & 2,9 & 38,4 & 61,3 & 21,8 & 4,5 & 12,5 & 38,7 & 100 \\
\hline & $25-29$ & 2,5 & 11,0 & 0,7 & 13,5 & 27,7 & 47,0 & 6,6 & 18,7 & 72,3 & 100 \\
\hline \multirow[t]{3}{*}{ Frankreich } & $15-19$ & 2,7 & 0,9 & 0,2 & 91,8 & 95,6 & 1,2 & 1,5 & 1,7 & 4,4 & 100 \\
\hline & $20-24$ & 5,2 & 6,1 & 1,0 & 44,2 & 56,6 & 27,2 & 9,1 & 7,0 & 43,4 & 100 \\
\hline & $25-29$ & 1,7 & 5,6 & 0,4 & 5,1 & 12,8 & 63,8 & 8,7 & 14,7 & 87,2 & 100 \\
\hline \multirow[t]{3}{*}{ Deutschland } & $15-19$ & 17,4 & 4,3 & 0,6 & 68,2 & 90,5 & 4,4 & 1,5 & 3,7 & 9,5 & 100 \\
\hline & $20-24$ & 13,8 & 6,6 & 0,3 & 19,4 & 40,1 & 42,3 & 5,0 & 12,7 & 59,9 & 100 \\
\hline & $25-29$ & 1,2 & 5,4 & 0,3 & 6,3 & 13,2 & 63,4 & 5,0 & 18,5 & 86,8 & 100 \\
\hline \multirow[t]{3}{*}{ Griechenland } & $15-19$ & 0,9 & 0,5 & 0,6 & 85,6 & 87,6 & 5,1 & 3,5 & 3,8 & 12,4 & 100 \\
\hline & $20-24$ & 0,7 & 2,4 & 1,3 & 33,7 & 38,1 & 33,7 & 15,9 & 12,3 & 61,9 & 100 \\
\hline & $25-29$ & 0,1 & 1,3 & 0,2 & 4,4 & 6,1 & 55,9 & 16,5 & 21,5 & 93,9 & 100 \\
\hline \multirow[t]{3}{*}{ Ungarn } & $15-19$ & a & 0,4 & 0,1 & 87,6 & 88,2 & 4,0 & 1,7 & 6,1 & 11,8 & 100 \\
\hline & $20-24$ & a & 5,3 & 0,4 & 33,0 & 38,7 & 37,8 & 3,4 & 20,1 & 61,3 & 100 \\
\hline & $25-29$ & a & 5,6 & 0,3 & 5,0 & 10,9 & 50,4 & 3,5 & 35,2 & 89,1 & 100 \\
\hline \multirow[t]{3}{*}{ Island } & $15-19$ & c & 35,9 & c & 46,5 & 84,6 & 13,0 & c & c & 15,4 & 100 \\
\hline & $20-24$ & c & 31,8 & c & 20,0 & 55,9 & 37,9 & c & $c$ & 44,1 & 100 \\
\hline & $25-29$ & c & 22,6 & c & 11,3 & 39,6 & 54,1 & c & c & 60,4 & 100 \\
\hline Irland & $15-19$ & a & 10,5 & 0,7 & 75,1 & 86,3 & 9,3 & 1,7 & 2,8 & 13,7 & 100 \\
\hline & $20-24$ & a & 6,3 & 0,4 & 25,2 & 31,9 & 55,6 & 3,0 & 9,5 & 68,1 & 100 \\
\hline & $25-29$ & a & 0,7 & 0,2 & 2,2 & 3,1 & 77,6 & 3,0 & 16,3 & 96,9 & 100 \\
\hline Italien & $15-19$ & $\mathrm{n}$ & 0,2 & 0,8 & 82,1 & 83,1 & 6,6 & 4,0 & 6,3 & 16,9 & 100 \\
\hline & $20-24$ & 0,1 & 2,2 & 2,1 & 37,8 & 42,2 & 31,1 & 11,9 & 14,9 & 57,8 & 100 \\
\hline & $25-29$ & 0,1 & 2,4 & 1,4 & 12,4 & 16,3 & 49,7 & 11,0 & 23,0 & 83,7 & 100 \\
\hline Luxemburg & $15-19$ & 2,8 & 3,0 & 0,1 & 85,2 & 91,1 & 4,7 & 1,8 & 2,4 & 8,9 & 100 \\
\hline & $20-24$ & 1,0 & 5,4 & $\mathrm{n}$ & 41,1 & 47,5 & 40,9 & 3,6 & 7,9 & 52,5 & 100 \\
\hline & $25-29$ & 0,9 & 8,6 & 0,4 & 4,0 & 13,9 & 68,8 & 2,4 & 14,9 & 86,1 & 100 \\
\hline Mexiko & $15-19$ & a & 5,3 & 0,2 & 48,0 & 53,5 & 19,0 & 1,3 & 26,1 & 46,5 & 100 \\
\hline & $20-24$ & a & 4,0 & 0,2 & 15,2 & 19,4 & 35,7 & 2,0 & 42,8 & 80,6 & 100 \\
\hline & $25-29$ & a & 1,2 & 0,2 & 2,3 & 3,7 & 43,7 & 1,3 & 51,3 & 96,3 & 100 \\
\hline Niederlande & $15-19$ & $\mathrm{~m}$ & 40,0 & 3,7 & 37,8 & 81,6 & 14,0 & 1,6 & 2,9 & 18,4 & 100 \\
\hline & $20-24$ & $\mathrm{~m}$ & 22,4 & 0,8 & 12,1 & 35,2 & 55,3 & 1,8 & 7,7 & 64,8 & 100 \\
\hline & $25-29$ & $\mathrm{~m}$ & 2,7 & 0,3 & 2,2 & 5,2 & 75,6 & 2,4 & 16,7 & 94,8 & 100 \\
\hline
\end{tabular}

Hinweis: c weist darauf hin, dass zu wenige Daten zur Verfügung stehen, um verlässliche Schätzungen vorzunehmen.

1. Die Teilnehmer an dualen Ausbildungsprogrammen gelten als sowohl in Ausbildung als auch beschäftigt, ohne Bezug auf ihren ILO-Erwerbsstatus.

2. Referenzjahr 2001.

Quelle: OECD. Hinweise s. Anhang 3 unter www.oecd.org/edu/eag2004. 


\section{Tabelle C4.2b (Forts.)}

Prozentsatz junger Frauen, die sich in Ausbildung bzw. nicht in Ausbildung befinden (2002) Nach Altersgruppe und Beschäftigungsstatus

\begin{tabular}{|c|c|c|c|c|c|c|c|c|c|c|c|}
\hline & \multirow{2}{*}{$\begin{array}{l}\text { Alters- } \\
\text { gruppe }\end{array}$} & \multicolumn{5}{|c|}{ In Ausbildung } & \multicolumn{4}{|c|}{ Nicht in Ausbildung } & \multirow{2}{*}{$\begin{array}{l}\text { In Ausbil- } \\
\text { dung und } \\
\text { nicht in } \\
\text { Ausbildung } \\
\text { insgesamt }\end{array}$} \\
\hline OECD-Länder & & \begin{tabular}{|c|} 
In dualer \\
Ausbildung $^{1}$ \\
\end{tabular} & \begin{tabular}{|c|} 
Andere Be- \\
schäftigung
\end{tabular} & Arbeitslos & $\begin{array}{l}\text { Nicht im } \\
\text { Arbeits- } \\
\text { markt }\end{array}$ & Zusammen & Beschäftigt & Arbeitslos & $\begin{array}{c}\text { Nicht im } \\
\text { Arbeits- } \\
\text { markt }\end{array}$ & Zusammen & \\
\hline \multirow[t]{3}{*}{ Norwegen } & $15-19$ & a & 26,6 & 5,3 & 56,9 & 88,8 & 8,5 & 1,0 & 1,7 & 11,2 & 100 \\
\hline & $20-24$ & a & 20,0 & 2,8 & 20,6 & 43,5 & 45,9 & 2,6 & 8,0 & 56,5 & 100 \\
\hline & $25-29$ & a & 5,0 & 0,7 & 9,9 & 15,6 & 70,8 & 2,7 & 10,8 & 84,4 & 100 \\
\hline \multirow[t]{3}{*}{ Polen } & $15-19$ & a & 2,0 & 0,7 & 94,1 & 96,8 & 0,6 & 1,3 & 1,3 & 3,2 & 100 \\
\hline & $20-24$ & a & 10,1 & 8,2 & 37,7 & 56,1 & 18,4 & 15,4 & 10,2 & 43,9 & 100 \\
\hline & $25-29$ & a & 7,9 & 2,3 & 4,5 & 14,7 & 45,9 & 17,4 & 21,9 & 85,3 & 100 \\
\hline \multirow[t]{3}{*}{ Portugal } & $15-19$ & a & 1,9 & 0,7 & 75,0 & 77,6 & 15,6 & 2,5 & 4,3 & 22,4 & 100 \\
\hline & $20-24$ & a & 5,7 & 0,8 & 31,8 & 38,3 & 46,4 & 6,0 & 9,3 & 61,7 & 100 \\
\hline & $25-29$ & a & 4,6 & 0,5 & 6,3 & 11,4 & 71,9 & 5,1 & 11,6 & 88,6 & 100 \\
\hline \multirow{3}{*}{$\begin{array}{l}\text { Slowakische } \\
\text { Republik }\end{array}$} & $15-19$ & 10,7 & 0,2 & 0,2 & 68,3 & 79,4 & 7,1 & 8,2 & 5,3 & 20,6 & 100 \\
\hline & $20-24$ & 0,2 & 2,0 & 1,1 & 21,9 & 25,1 & 40,7 & 17,8 & 16,4 & 74,9 & 100 \\
\hline & $25-29$ & 0,3 & 0,8 & 0,3 & 1,7 & 3,1 & 55,5 & 15,4 & 26,0 & 96,9 & 100 \\
\hline \multirow[t]{3}{*}{ Spanien } & $15-19$ & 0,4 & 2,7 & 1,6 & 80,8 & 85,5 & 7,0 & 3,6 & 3,8 & 14,5 & 100 \\
\hline & $20-24$ & 0,7 & 6,8 & 3,7 & 37,3 & 48,4 & 33,6 & 9,8 & 8,1 & 51,6 & 100 \\
\hline & $25-29$ & 0,3 & 6,6 & 3,1 & 7,6 & 17,6 & 54,6 & 11,4 & 16,4 & 82,4 & 100 \\
\hline \multirow[t]{3}{*}{ Schweden } & $15-19$ & $a$ & 15,5 & 4,7 & 69,1 & 89,4 & 7,3 & 1,6 & 1,7 & 10,6 & 100 \\
\hline & $20-24$ & $a$ & 15,3 & 2,0 & 29,1 & 46,4 & 43,0 & 4,7 & 5,9 & 53,6 & 100 \\
\hline & $25-29$ & $a$ & 10,4 & 1,1 & 12,7 & 24,3 & 65,3 & 3,8 & 6,7 & 75,7 & 100 \\
\hline \multirow[t]{3}{*}{ Schweiz } & $15-19$ & 31,6 & 10,5 & c & 40,6 & 83,9 & 10,2 & c & 5,0 & 16,1 & 100 \\
\hline & $20-24$ & 9,2 & 16,2 & $c$ & 12,9 & 38,9 & 52,5 & c & 6,0 & 61,1 & 100 \\
\hline & $25-29$ & c & 6,4 & c & $\mathrm{c}$ & 11,0 & 71,3 & c & 13,9 & 89,0 & 100 \\
\hline \multirow[t]{3}{*}{ Türkei } & $15-19$ & $a$ & 0,9 & 0,2 & 35,4 & 36,5 & 18,0 & 3,4 & 42,0 & 63,5 & 100 \\
\hline & $20-24$ & $a$ & 1,7 & 0,7 & 8,3 & 10,7 & 26,5 & 5,9 & 56,9 & 89,3 & 100 \\
\hline & $25-29$ & a & 1,0 & 0,2 & 1,1 & 2,4 & 27,6 & 4,1 & 65,9 & 97,6 & 100 \\
\hline \multirow{3}{*}{$\begin{array}{l}\text { Vereinigtes } \\
\text { Königreich }\end{array}$} & $15-19$ & 2,3 & 23,9 & 2,3 & 48,8 & 77,3 & 13,8 & 3,5 & 5,4 & 22,7 & 100 \\
\hline & $20-24$ & 2,3 & 15,4 & 1,2 & 15,5 & 34,4 & 45,5 & 3,8 & 16,3 & 65,6 & 100 \\
\hline & $25-29$ & 1,4 & 11,2 & 0,8 & 3,7 & 17,1 & 56,8 & 3,9 & 22,2 & 82,9 & 100 \\
\hline \multirow{3}{*}{$\begin{array}{l}\text { Vereinigte } \\
\text { Staaten }^{2}\end{array}$} & $15-19$ & a & 26,0 & 3,2 & 52,8 & 82,0 & 9,9 & 2,6 & 5,4 & 18,0 & 100 \\
\hline & $20-24$ & a & 21,2 & 1,3 & 12,8 & 35,3 & 45,7 & 4,5 & 14,4 & 64,7 & 100 \\
\hline & $25-29$ & a & 9,0 & 0,6 & 3,5 & 13,0 & 62,2 & 3,9 & 20,9 & 87,0 & 100 \\
\hline \multirow[t]{3}{*}{ Ländermittel } & $15-19$ & 4,4 & 12,4 & 1,8 & 64,4 & 83,0 & 8,8 & 2,3 & 5,9 & 17,0 & 100 \\
\hline & $20-24$ & 2,0 & 11,2 & 1,5 & 25,5 & 40,1 & 40,3 & 6,1 & 13,5 & 59,9 & 100 \\
\hline & $25-29$ & 0,6 & 6,5 & 0,6 & 5,9 & 13,7 & 59,6 & 6,0 & 20,6 & 86,3 & 100 \\
\hline \multicolumn{12}{|c|}{ OECD-Partnerländer } \\
\hline \multirow[t]{3}{*}{ Israel } & $15-19$ & a & 3,5 & 1,0 & 65,7 & 70,2 & 6,5 & 1,3 & 22,0 & 29,8 & 100 \\
\hline & $20-24$ & a & 11,8 & 2,4 & 16,7 & 30,9 & 32,4 & 8,3 & 28,5 & 69,1 & 100 \\
\hline & $25-29$ & a & 12,9 & 0,7 & 3,9 & 17,6 & 49,4 & 7,0 & 26,0 & 82,4 & 100 \\
\hline
\end{tabular}

Hinweis: c weist darauf hin, dass zu wenige Daten zur Verfügung stehen, um verlässliche Schätzungen vorzunehmen.

1. Die Teilnehmerinnen an dualen Ausbildungsprogrammen gelten als sowohl in Ausbildung als auch beschäftigt, ohne Bezug auf ihren ILO-Erwerbsstatus.

2. Referenzjahr 2001.

Quelle: OECD. Hinweise s. Anhang 3 unter www.oecd.org/edu/eag2004. 
Tabelle C4.3

Prozentsatz Arbeitsloser, die sich nicht in Ausbildung befinden, an der Gesamtbevölkerung (2002) Nach Bildungsstand, Altergruppe und Geschlecht

\begin{tabular}{|c|c|c|c|c|c|c|c|c|c|c|c|c|c|}
\hline \multirow[b]{2}{*}{ OECD-Länder } & & \multicolumn{3}{|c|}{ Unterhalb Sekundarbereich ॥ } & \multicolumn{3}{|c|}{$\begin{array}{l}\text { Sekundarbereich II und post-se- } \\
\text { kundarer, nicht-tertiärer Bereich }\end{array}$} & \multicolumn{2}{|c|}{ Tertiärbereich } & \multicolumn{4}{|c|}{ Alle Bildungsbereiche zusammen } \\
\hline & & $15-19$ & $20-24$ & $25-29$ & $15-19$ & $20-24$ & $25-29$ & $20-24$ & $25-29$ & $15-19$ & $20-24$ & $25-29$ & $15-29$ \\
\hline \multirow[t]{3}{*}{ Australien } & Männer & 9,3 & 17,6 & 13,1 & 2,2 & 6,1 & 3,4 & 1,6 & 3,1 & 5,0 & 6,9 & 5,4 & 5,8 \\
\hline & Frauen & 8,7 & 8,6 & 7,4 & 2,9 & 5,3 & 4,6 & 1,3 & 1,8 & 5,0 & 3,9 & 4,0 & 4,2 \\
\hline & $M+F$ & 9,0 & 13,3 & 10,1 & 2,6 & 5,8 & 3,9 & 1,4 & 2,4 & 5,0 & 5,4 & 4,7 & 5,0 \\
\hline \multirow{2}{*}{ Österreich } & Frauen & 16,6 & 7,4 & 4,1 & 0,3 & 3,9 & 3,7 & 0,8 & 1,9 & 2,4 & 3,3 & 3,4 & 3,1 \\
\hline & $M+F$ & 12,2 & 11,9 & 6,5 & 1,0 & 5,3 & 4,5 & 0,6 & 1,5 & 2,5 & 4,8 & 4,2 & 3,8 \\
\hline \multirow[t]{3}{*}{ Belgien } & Männer & 2,5 & 15,0 & 13,6 & 3,1 & 6,1 & 6,7 & 8,4 & 5,3 & 2,6 & 8,5 & 7,6 & 6,3 \\
\hline & Frauen & 0,4 & 22,3 & 17,1 & 3,8 & 8,0 & 9,9 & 3,5 & 3,9 & 1,2 & 9,3 & 8,3 & 6,4 \\
\hline & $M+F$ & 1,5 & 18,0 & 15,1 & 3,5 & 7,0 & 8,2 & 5,3 & 4,5 & 1,9 & 8,9 & 7,9 & 6,3 \\
\hline \multirow[t]{2}{*}{ Kanada } & Männer & 2,9 & 17,5 & 16,3 & 5,6 & 8,0 & 9,6 & 6,5 & 6,8 & 3,7 & 9,1 & 9,2 & 7,4 \\
\hline & Frauen & 1,5 & 9,9 & 7,8 & 3,3 & 4,7 & 5,4 & 3,5 & 4,0 & 2,0 & 4,8 & 4,8 & 3,9 \\
\hline \multirow{3}{*}{$\begin{array}{l}\text { Tschechische } \\
\text { Republik }\end{array}$} & Männer & 8,4 & 29,2 & 22,0 & 2,3 & 10,9 & 4,4 & 0,5 & 3,1 & 3,5 & 9,6 & 5,3 & 6,2 \\
\hline & Frauen & 7,6 & 15,3 & 14,6 & 3,1 & 9,7 & 7,5 & 1,8 & 2,1 & 3,9 & 8,0 & 7,3 & 6,6 \\
\hline & $M+F$ & 8,0 & 21,9 & 18,1 & 2,7 & 10,3 & 6,0 & 1,2 & 2,6 & 3,7 & 8,8 & 6,3 & 6,4 \\
\hline \multirow[t]{3}{*}{ Dänemark } & Männer & 1,5 & 10,7 & 2,7 & $a$ & 5,4 & 1,8 & 1,7 & 3,2 & 0,8 & 5,1 & 2,5 & 2,7 \\
\hline & Frauen & $n$ & 6,3 & 12,7 & a & 1,7 & 2,4 & 1,2 & 2,7 & $n$ & 2,4 & 3,8 & 2,3 \\
\hline & $M+F$ & 0,8 & 8,2 & 7,6 & $a$ & 3,7 & 2,0 & 1,4 & 2,9 & 0,4 & 3,7 & 3,1 & 2,5 \\
\hline \multirow[t]{3}{*}{ Finnland } & Männer & 2,1 & 9,1 & 8,8 & 5,9 & 6,7 & 5,9 & 7,2 & 4,7 & 2,9 & 7,1 & 6,0 & 5,4 \\
\hline & Frauen & 0,9 & 5,1 & 12,4 & 10,1 & 3,9 & 5,5 & 8,9 & 6,9 & 2,2 & 4,5 & 6,6 & 4,5 \\
\hline & $M+F$ & 1,5 & 7,4 & 10,0 & 7,6 & 5,3 & 5,7 & 8,4 & 6,0 & 2,6 & 5,8 & 6,3 & 5,0 \\
\hline \multirow[t]{3}{*}{ Frankreich } & Männer & 1,7 & 20,1 & 19,6 & 3,6 & 6,8 & 8,1 & 4,8 & 7,4 & 1,9 & 9,3 & 10,0 & 7,0 \\
\hline & Frauen & 1,2 & 17,2 & 15,3 & 3,6 & 8,6 & 9,0 & 4,2 & 5,7 & 1,5 & 9,1 & 8,7 & 6,5 \\
\hline & $M+F$ & 1,4 & 18,8 & 17,5 & 3,6 & 7,6 & 8,5 & 4,5 & 6,4 & 1,7 & 9,2 & 9,4 & 6,8 \\
\hline \multirow[t]{2}{*}{ Deutschland } & Männer & 3,1 & 22,7 & 18,4 & 0,7 & 8,3 & 8,4 & 0,8 & 2,2 & 1,9 & 8,9 & 7,9 & 6,2 \\
\hline & Frauen & 2,4 & 13,5 & 9,8 & 0,8 & 4,8 & 4,9 & 0,6 & 2,2 & 1,5 & 5,0 & 5,0 & 3,8 \\
\hline \multirow{2}{*}{ Griechenland } & Frauen & 13,8 & 19,7 & 13,1 & 2,5 & 24,4 & 18,3 & 4,4 & 16,2 & 4,3 & 16,1 & 16,7 & 13,2 \\
\hline & $M+F$ & 11,2 & 15,9 & 11,0 & 2,0 & 20,5 & 13,8 & 2,9 & 13,8 & 3,6 & 13,6 & 13,2 & 10,7 \\
\hline \multirow[t]{3}{*}{ Ungarn } & Männer & 1,2 & 17,9 & 15,0 & 4,9 & 5,8 & 5,6 & 3,7 & 0,9 & 1,8 & 7,4 & 6,7 & 5,5 \\
\hline & Frauen & 0,8 & 5,1 & 5,2 & 5,6 & 3,0 & 3,1 & 5,5 & 3,2 & 1,7 & 3,4 & 3,5 & 2,9 \\
\hline & $M+F$ & 1,0 & 11,2 & 10,0 & 5,3 & 4,4 & 4,4 & 4,8 & 2,2 & 1,7 & 5,4 & 5,1 & 4,2 \\
\hline Island & Männer & $c$ & $c$ & $\mathrm{c}$ & $\mathrm{a}$ & a & a & $a$ & $c$ & c & $\mathrm{c}$ & c & 4,6 \\
\hline & Frauen & $c$ & $c$ & a & $\mathrm{a}$ & c & a & a & $\mathrm{a}$ & c & c & a & $\mathrm{c}$ \\
\hline & $M+F$ & $c$ & $c$ & c & $\mathrm{a}$ & c & a & $\mathrm{a}$ & $c$ & c & $\mathrm{c}$ & c & c \\
\hline Irland & Männer & 2,9 & 12,3 & 11,5 & 3,6 & 3,2 & 3,6 & 4,7 & 3,0 & 3,0 & 5,3 & 5,1 & 4,5 \\
\hline & Frauen & 1,2 & 6,0 & 5,2 & 3,0 & 2,9 & 3,6 & 2,0 & 1,8 & 1,7 & 3,0 & 3,1 & 2,6 \\
\hline & $M+F$ & 2,1 & 10,0 & 8,8 & 3,3 & 3,0 & 3,6 & 3,1 & 2,4 & 2,4 & 4,2 & 4,1 & 3,6 \\
\hline Italien & Männer & 3,9 & 16,9 & 11,8 & 9,3 & 9,0 & 7,7 & 9,7 & 13,0 & 4,5 & 11,6 & 9,7 & 8,9 \\
\hline & Frauen & 3,4 & 15,5 & 11,7 & 8,5 & 10,4 & 9,9 & 23,4 & 14,1 & 4,0 & 11,9 & 11,0 & 9,4 \\
\hline & $M+F$ & 3,7 & 16,3 & 11,8 & 8,9 & 9,7 & 8,8 & 17,7 & 13,6 & 4,3 & 11,8 & 10,4 & 9,1 \\
\hline Luxemburg & Männer & 4,0 & 5,9 & 7,1 & $n$ & 2,1 & 2,5 & $\mathrm{n}$ & 2,5 & 1,5 & 2,2 & 4,2 & 2,7 \\
\hline & Frauen & 4,1 & 7,6 & 6,8 & 0,3 & 4,7 & $\mathrm{n}$ & $\mathrm{n}$ & 1,4 & 1,6 & 3,9 & 2,5 & 2,7 \\
\hline & $M+F$ & 4,0 & 6,9 & 7,0 & 0,1 & 3,2 & 1,2 & $\mathrm{n}$ & 2,0 & 1,5 & 3,0 & 3,4 & 2,7 \\
\hline Mexiko & Männer & 2,1 & 3,1 & 2,2 & 6,2 & 4,1 & 2,2 & 2,0 & 3,6 & 2,2 & 2,9 & 2,4 & 2,5 \\
\hline & Frauen & 1,3 & 1,7 & 0,8 & 2,9 & 3,7 & 2,4 & 2,5 & 3,2 & 1,3 & 2,0 & 1,3 & 1,5 \\
\hline & $M+F$ & 1,7 & 2,4 & 1,5 & 4,4 & 3,9 & 2,3 & 2,3 & 3,4 & 1,7 & 2,4 & 1,8 & 2,0 \\
\hline Niederlande & Männer & 1,8 & 3,2 & 4,4 & 2,3 & 1,7 & 1,6 & 5,8 & 3,0 & 1,9 & 2,4 & 2,6 & 2,3 \\
\hline & Frauen & 1,4 & 3,0 & 3,5 & 2,3 & 1,4 & 2,0 & 1,3 & 2,4 & 1,6 & 1,8 & 2,4 & 2,0 \\
\hline & $M+F$ & 1,6 & 3,1 & 4,0 & 2,3 & 1,6 & 1,8 & 2,9 & 2,6 & 1,7 & 2,1 & 2,5 & 2,1 \\
\hline
\end{tabular}

Hinweis: c weist darauf hin, dass zu wenige Daten zur Verfügung stehen, um verlässliche Schätzungen vorzunehmen.

1. Referenzjahr 2001.

Quelle: OECD. Hinweise s. Anhang 3 unter www.oecd.org/edu/eag2004. 


\section{Tabelle C4.3 (Forts.)}

Prozentsatz Arbeitsloser, die sich nicht in Ausbildung befinden, an der Gesamtbevölkerung (2002) Nach Bildungsstand, Altergruppe und Geschlecht

\begin{tabular}{|c|c|c|c|c|c|c|c|c|c|c|c|c|c|}
\hline \multirow[b]{2}{*}{ OECD-Länder } & & \multicolumn{3}{|c|}{ Unterhalb Sekundarbereich II } & \multicolumn{3}{|c|}{$\begin{array}{l}\text { Sekundarbereich II und post-se- } \\
\text { kundarer, nicht-tertiärer Bereich }\end{array}$} & \multicolumn{2}{|c|}{ Tertiärbereich } & \multicolumn{4}{|c|}{ Alle Bildungsbereiche zusammen } \\
\hline & & $15-19$ & $20-24$ & $25-29$ & $15-19$ & $20-24$ & $25-29$ & $20-24$ & $25-29$ & $15-19$ & $20-24$ & $25-29$ & $15-29$ \\
\hline \multirow[t]{3}{*}{ Norwegen } & Männer & 1,3 & 23,8 & 2,7 & 2,3 & 4,4 & 4,5 & 0,7 & 1,3 & 1,9 & 4,6 & 3,4 & 3,3 \\
\hline & Frauen & 0,5 & 7,4 & 5,8 & 1,5 & 2,9 & 2,3 & 1,1 & 2,9 & 1,0 & 2,6 & 2,7 & 2,1 \\
\hline & $M+F$ & 0,9 & 17,4 & 4,2 & 1,9 & 3,7 & 3,6 & 1,0 & 2,2 & 1,4 & 3,6 & 3,1 & 2,7 \\
\hline \multirow{2}{*}{ Polen } & Frauen & 1,5 & 32,9 & 23,0 & 1,3 & 25,1 & 20,5 & 0,7 & 9,5 & 1,3 & 15,4 & 17,4 & 12,0 \\
\hline & $M+F$ & 2,2 & 41,0 & 31,1 & 1,6 & 26,1 & 21,0 & 0,6 & 8,2 & 1,8 & 18,0 & 18,7 & 13,4 \\
\hline \multirow[t]{3}{*}{ Portugal } & Männer & 5,8 & 6,7 & 3,6 & 0,9 & 4,8 & 1,7 & 1,2 & 2,9 & 3,8 & 4,9 & 3,1 & 4,0 \\
\hline & Frauen & 5,8 & 9,8 & 5,8 & 0,6 & 4,7 & 4,6 & 3,1 & 4,6 & 2,9 & 6,2 & 5,2 & 4,9 \\
\hline & $M+F$ & 5,8 & 8,0 & 4,6 & 0,7 & 4,7 & 3,3 & 2,3 & 3,9 & 3,3 & 5,6 & 4,2 & 4,4 \\
\hline \multirow{2}{*}{$\begin{array}{l}\text { Slowakische } \\
\text { Republik }\end{array}$} & Männer & 11,5 & 13,9 & 10,1 & 1,3 & 10,8 & 7,2 & 4,0 & 6,2 & 6,6 & 9,1 & 8,1 & 8,1 \\
\hline & Frauen & 11,8 & 16,6 & 14,3 & 1,8 & 15,5 & 12,1 & 5,4 & 10,4 & 5,9 & 10,3 & 12,0 & 10,2 \\
\hline \multirow[t]{3}{*}{ Spanien } & Männer & 6,7 & 13,9 & 10,1 & 1,3 & 10,8 & 7,2 & 4,0 & 6,2 & 4,8 & 9,1 & 8,1 & 7,6 \\
\hline & Frauen & 6,0 & 16,6 & 14,3 & 1,8 & 15,5 & 12,1 & 5,4 & 10,4 & 4,2 & 10,3 & 12,0 & 9,4 \\
\hline & $M+F$ & 6,4 & 14,9 & 11,9 & 1,6 & 13,2 & 9,6 & 4,8 & 8,5 & 4,5 & 9,7 & 10,0 & 8,5 \\
\hline \multirow[t]{3}{*}{ Schweden } & Männer & 3,7 & 18,4 & 13,0 & 1,3 & 8,6 & 4,4 & 0,2 & 2,0 & 1,9 & 7,3 & 4,3 & 4,5 \\
\hline & Frauen & 3,1 & 14,5 & 6,7 & 0,9 & 6,0 & 5,5 & 0,5 & 1,1 & 1,5 & 4,6 & 3,9 & 3,3 \\
\hline & $M+F$ & 3,4 & 16,7 & 10,0 & 1,1 & 7,4 & 4,9 & 0,4 & 1,5 & 1,7 & 6,0 & 4,1 & 3,9 \\
\hline \multirow[t]{3}{*}{ Schweiz } & Männer & 5,8 & 7,7 & 16,3 & 0,3 & 4,4 & 3,2 & 2,3 & 5,5 & 2,0 & 4,1 & 5,5 & 3,9 \\
\hline & Frauen & 0,5 & 8,9 & 6,4 & 1,0 & 2,6 & 3,7 & 0,4 & 3,4 & 0,8 & 2,6 & 3,9 & 2,5 \\
\hline & $M+F$ & 3,1 & 8,3 & 11,6 & 0,6 & 3,5 & 3,5 & 1,3 & 4,6 & 1,4 & 3,4 & 4,7 & 3,2 \\
\hline \multirow[t]{3}{*}{ Türkei } & Männer & 5,7 & 14,3 & 10,4 & 9,2 & 11,6 & 9,1 & 25,7 & 8,6 & 6,5 & 13,8 & 9,7 & 9,8 \\
\hline & Frauen & 2,2 & 2,2 & 2,2 & 9,0 & 9,0 & 7,3 & 26,0 & 12,6 & 3,4 & 5,9 & 4,1 & 4,5 \\
\hline & $M+F$ & 4,0 & 7,5 & 6,1 & 9,1 & 10,5 & 8,4 & 25,9 & 9,8 & 5,0 & 9,8 & 7,2 & 7,3 \\
\hline \multirow{2}{*}{$\begin{array}{l}\text { Vereinigtes } \\
\text { Königreich }\end{array}$} & Männer & 3,8 & 16,8 & 11,5 & 6,3 & 6,1 & 3,7 & 5,2 & 2,6 & 5,3 & 6,9 & 4,1 & 5,4 \\
\hline & Frauen & 2,0 & 5,3 & 6,8 & 4,2 & 4,0 & 4,4 & 2,9 & 2,5 & 3,4 & 3,9 & 3,9 & 3,7 \\
\hline \multirow{2}{*}{$\begin{array}{l}\text { Vereinigte } \\
\text { Staaten }^{1}\end{array}$} & Frauen & 9,0 & 12,0 & 9,0 & 1,9 & 6,1 & 5,3 & 1,1 & 1,3 & 2,8 & 4,5 & 3,9 & 3,8 \\
\hline & $M+F$ & 9,4 & 12,3 & 8,0 & 1,8 & 6,9 & 4,8 & 1,7 & 2,3 & 3,0 & 5,4 & 4,1 & 4,2 \\
\hline \multirow[t]{3}{*}{ Ländermittel } & Männer & 4,9 & 15,6 & 11,7 & 2,9 & 7,5 & 5,7 & 3,9 & 4,6 & 3,2 & 7,6 & 6,4 & 5,8 \\
\hline & Frauen & 4,0 & 10,8 & 8,9 & 2,9 & 7,2 & 6,3 & 4,1 & 4,9 & 2,4 & 5,9 & 6,0 & 4,9 \\
\hline & $M+F$ & 4,5 & 13,4 & 10,3 & 2,9 & 7,4 & 6,0 & 4,0 & 4,7 & 2,8 & 6,8 & 6,2 & 5,4 \\
\hline \multicolumn{14}{|c|}{ OECD-Partnerländer } \\
\hline \multirow[t]{3}{*}{ Israel } & Männer & 8,3 & 11,2 & 15,9 & 0,8 & 9,4 & 10,1 & 2,6 & 9,0 & 2,0 & 8,0 & 10,5 & 6,7 \\
\hline & Frauen & 5,5 & 6,7 & 1,5 & 0,8 & 12,6 & 9,0 & 2,6 & 6,7 & 1,3 & 8,3 & 7,0 & 5,4 \\
\hline & $M+F$ & 7,2 & 9,6 & 9,6 & 0,8 & 10,9 & 9,6 & 2,6 & 7,8 & 1,7 & 8,2 & 8,7 & 6,1 \\
\hline
\end{tabular}

Hinweis: $c$ weist darauf hin, dass zu wenige Daten zur Verfügung stehen, um verlässliche Schätzungen vorzunehmen.

1. Referenzjahr 2001.

Quelle: OECD. Hinweise s. Anhang 3 unter www.oecd.org/edu/eag2004. 
Tabelle C4.4

Änderung des Prozentsatzes junger Menschen, die sich in Ausbildung bzw. nicht in Ausbildung befinden (1995-2002) Nach Altersgruppe und Beschäftigungsstatus

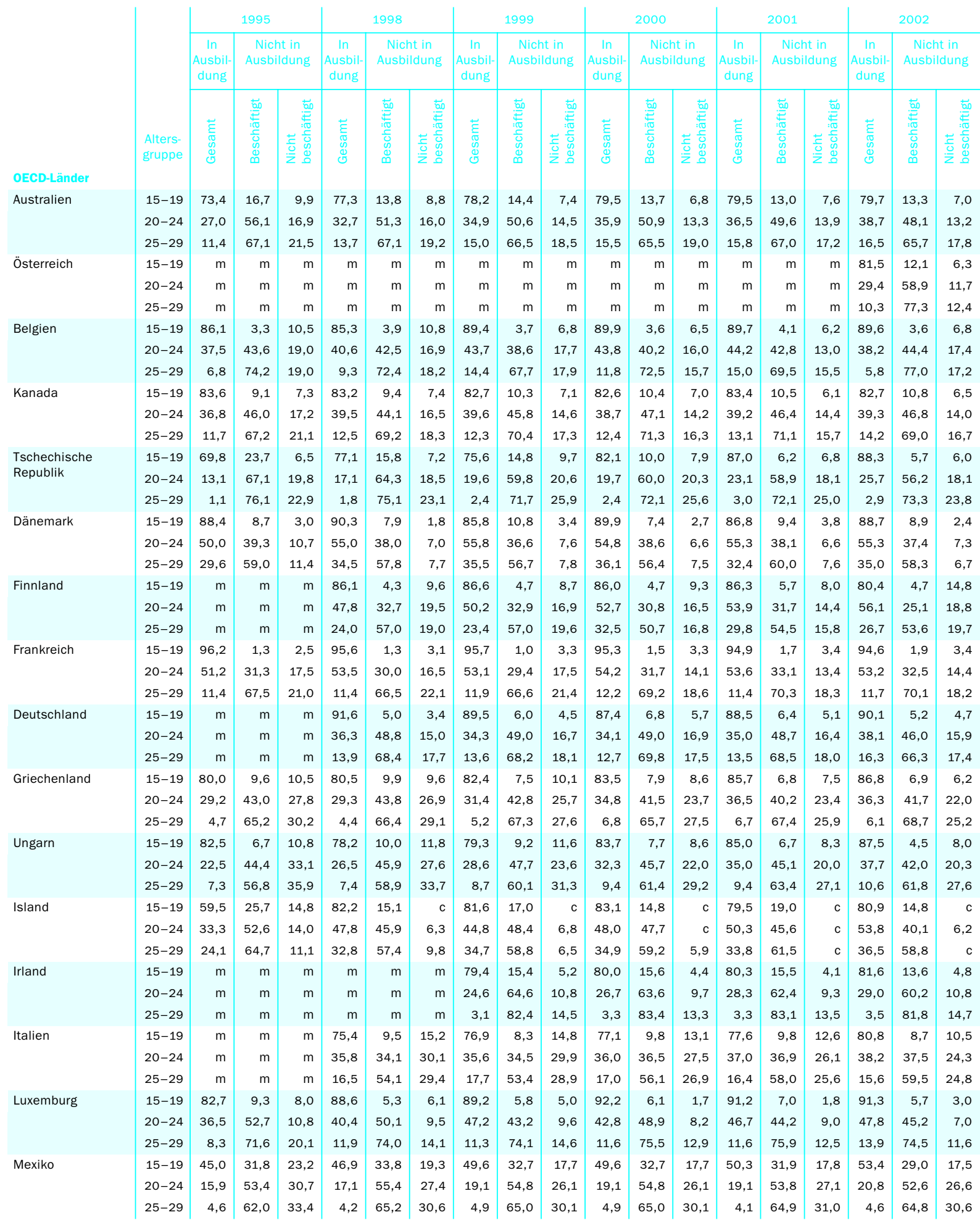




\section{Tabelle C4.4 (Forts.)}

Änderung des Prozentsatzes junger Menschen, die sich in Ausbildung bzw. nicht in Ausbildung befinden (1995-2002) Nach Altersgruppe und Beschäftigungsstatus

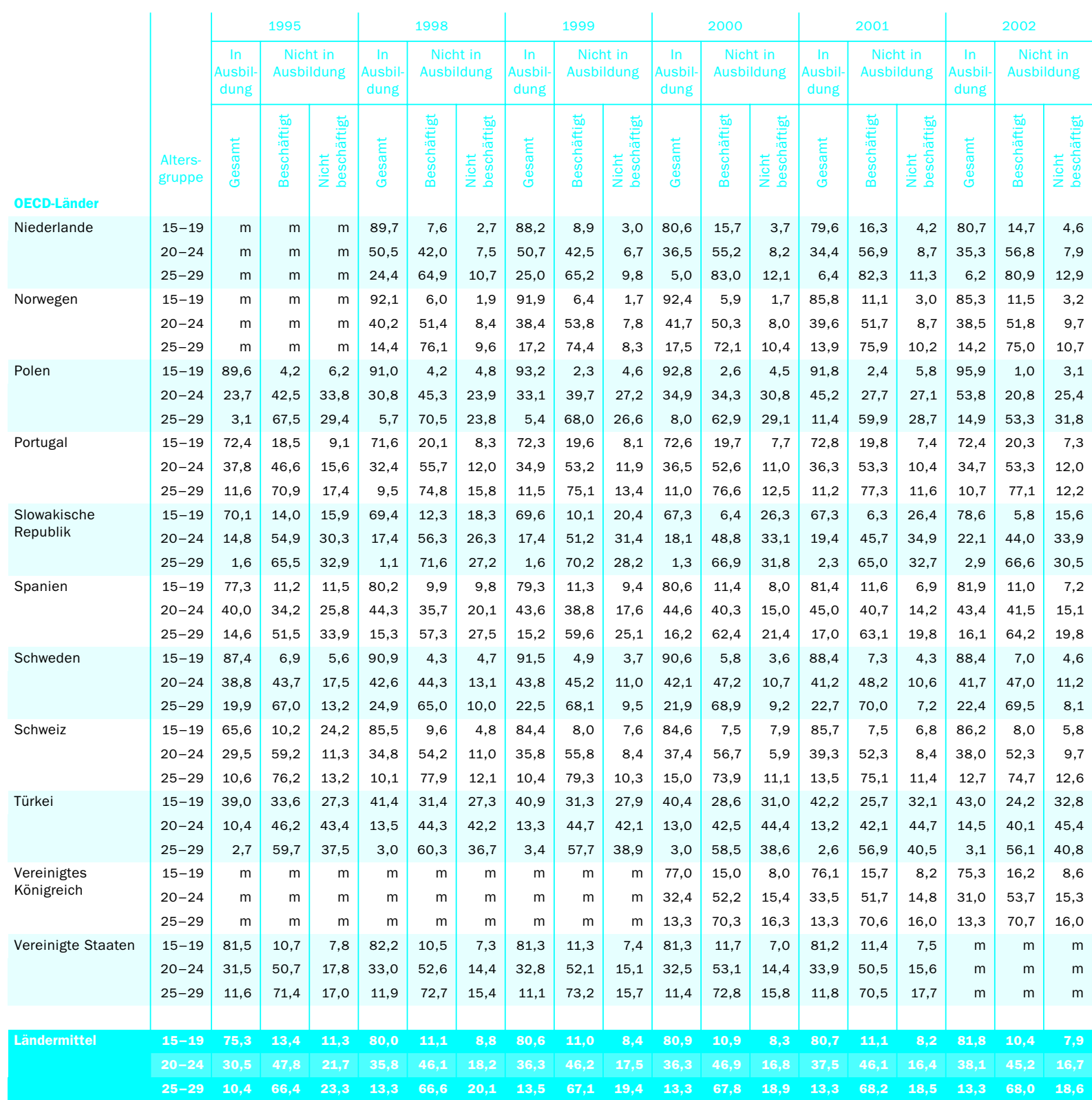

Hinweis: c weist darauf hin, dass zu wenige Daten zur Verfügung stehen, um verlässliche Schätzungen vorzunehmen.

Quelle: OECD. Hinweise s. Anhang 3 unter www.oecd.org/edu/eag2004. 
Änderung des Prozentsatzes junger Männer, die sich in Ausbildung bzw. nicht in Ausbildung befinden (1995-2002) Nach Altersgruppe und Beschäftigungsstatus

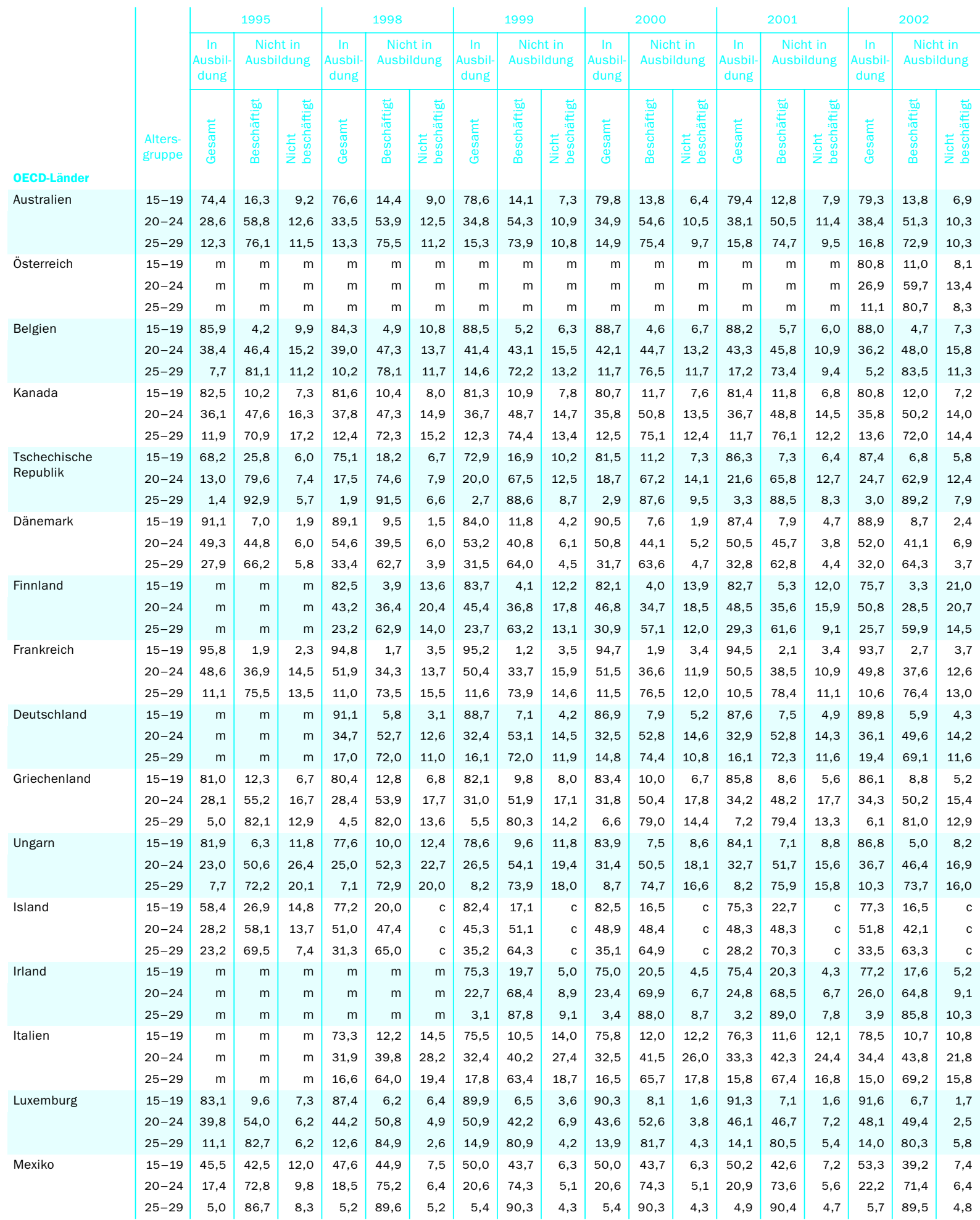


Tabelle C4.4a (Forts.)

Änderung des Prozentsatzes junger Männer, die sich in Ausbildung bzw. nicht in Ausbildung befinden (1995-2002) Nach Altersgruppe und Beschäftigungsstatus

\begin{tabular}{|c|c|c|c|c|c|c|c|c|c|c|c|c|c|c|c|c|c|c|c|}
\hline & & \multicolumn{3}{|c|}{1995} & \multicolumn{3}{|c|}{1998} & \multicolumn{3}{|c|}{1999} & \multicolumn{3}{|c|}{2000} & \multicolumn{3}{|c|}{2001} & \multicolumn{3}{|c|}{2002} \\
\hline & & \multirow{2}{*}{$\begin{array}{c}\text { In } \\
\text { Ausbil- } \\
\text { dung }\end{array}$} & \multicolumn{2}{|c|}{$\begin{array}{l}\text { Nicht in } \\
\text { Ausbildung }\end{array}$} & $\begin{array}{c}\text { In } \\
\text { Ausbil- } \\
\text { dung }\end{array}$ & \multicolumn{2}{|c|}{$\begin{array}{l}\text { Nicht in } \\
\text { Ausbildung }\end{array}$} & $\begin{array}{c}\text { In } \\
\text { Ausbil- } \\
\text { dung }\end{array}$ & \multicolumn{2}{|c|}{$\begin{array}{l}\text { Nicht in } \\
\text { Ausbildung }\end{array}$} & $\begin{array}{c}\text { In } \\
\text { Ausbil- } \\
\text { dung }\end{array}$ & \multicolumn{2}{|c|}{$\begin{array}{l}\text { Nicht in } \\
\text { Ausbildung }\end{array}$} & $\begin{array}{c}\text { In } \\
\text { Ausbil- } \\
\text { dung }\end{array}$ & \multicolumn{2}{|c|}{$\begin{array}{l}\text { Nicht in } \\
\text { Ausbildung }\end{array}$} & $\begin{array}{c}\text { In } \\
\text { Ausbil- } \\
\text { dung }\end{array}$ & \multicolumn{2}{|c|}{$\begin{array}{l}\text { Nicht in } \\
\text { Ausbildung }\end{array}$} \\
\hline OECD-Länder & $\begin{array}{l}\text { Alters- } \\
\text { gruppe }\end{array}$ & & 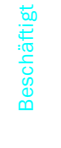 & 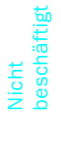 & $\begin{array}{l}\vec{E} \\
\mathbb{E} \\
\tilde{N} \\
0 \\
心\end{array}$ & 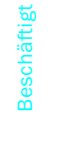 & 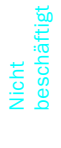 & $\begin{array}{l}\vec{E} \\
\frac{\tilde{N}}{\tilde{N}} \\
\tilde{J} \\
心\end{array}$ & 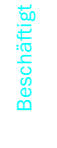 & 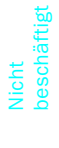 & $\begin{array}{l}\vec{E} \\
\tilde{N} \\
心 \\
心 \\
心\end{array}$ & 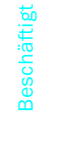 & 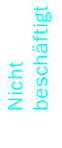 & $\begin{array}{l}\vec{E} \\
\tilde{N} \\
0 \\
心 \\
心\end{array}$ & 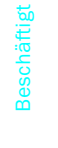 & 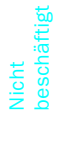 & $\begin{array}{l}\vec{E} \\
\tilde{E} \\
\tilde{N} \\
0 \\
心 \\
心\end{array}$ & 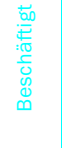 & 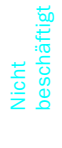 \\
\hline \multirow[t]{3}{*}{ Niederlande } & $15-19$ & $\mathrm{~m}$ & $\mathrm{~m}$ & $\mathrm{~m}$ & 89,4 & 8,4 & 2,2 & 89,8 & 7,6 & 2,6 & 78,6 & 17,5 & 3,8 & 76,6 & 19,6 & 3,8 & 79,9 & 15,4 & 4,7 \\
\hline & $20-24$ & $\mathrm{~m}$ & $\mathrm{~m}$ & $\mathrm{~m}$ & 54,2 & 40,9 & 5,0 & 53,6 & 40,6 & 5,8 & 37,4 & 57,3 & 5,3 & 36,3 & 58,1 & 5,6 & 35,3 & 58,3 & 6,4 \\
\hline & $25-29$ & $\mathrm{~m}$ & $\mathrm{~m}$ & $\mathrm{~m}$ & 27,4 & 65,9 & 6,6 & 27,4 & 67,3 & 5,3 & 6,0 & 88,4 & 5,6 & 7,9 & 86,6 & 5,5 & 7,2 & 86,2 & 6,6 \\
\hline Norwegen & $15-19$ & $\mathrm{~m}$ & $\mathrm{~m}$ & $\mathrm{~m}$ & 90,2 & 8,4 & 1,5 & 90,9 & 7,5 & 1,5 & 90,6 & 7,1 & 2,3 & 83,8 & 12,9 & 3,3 & 81,8 & 14,5 & 3,7 \\
\hline & $20-24$ & $\mathrm{~m}$ & $\mathrm{~m}$ & $\mathrm{~m}$ & 33,3 & 60,1 & 6,7 & 31,8 & 62,2 & 6,0 & 32,7 & 60,2 & 7,1 & 33,3 & 58,7 & 8,0 & 33,6 & 57,5 & 8,9 \\
\hline & $25-29$ & $\mathrm{~m}$ & $\mathrm{~m}$ & $\mathrm{~m}$ & 13,7 & 81,0 & 5,3 & 15,9 & 79,1 & 5,0 & 16,4 & 75,3 & 8,3 & 11,7 & 80,7 & 7,6 & 12,9 & 79,1 & 8,0 \\
\hline Polen & $15-19$ & 87,2 & 5,5 & 7,3 & 89,6 & 5,7 & 4,7 & 91,9 & 2,9 & 5,2 & 91,7 & 3,3 & 5,0 & 90,9 & 2,9 & 6,2 & 95,1 & 1,4 & 3,5 \\
\hline & $20-24$ & 24,6 & 48,4 & 27,1 & 30,1 & 50,5 & 19,3 & 32,0 & 44,7 & 23,4 & 34,5 & 38,4 & 27,2 & 43,0 & 31,4 & 25,6 & 51,5 & 23,3 & 25,2 \\
\hline & $25-29$ & 3,0 & 79,0 & 18,0 & 6,3 & 81,3 & 12,4 & 5,9 & 76,4 & 17,8 & 8,3 & 72,6 & 19,1 & 11,0 & 69,9 & 19,1 & 15,0 & 60,6 & 24,5 \\
\hline Portugal & $15-19$ & 70,4 & 20,9 & 8,7 & 69,1 & 23,9 & 6,9 & 70,3 & 23,0 & 6,7 & 69,7 & 24,1 & 6,2 & 70,3 & 24,3 & 5,4 & 67,4 & 24,9 & 7,7 \\
\hline & $20-24$ & 32,7 & 53,0 & 14,3 & 28,3 & 62,0 & 9,7 & 32,0 & 59,0 & 9,0 & 32,5 & 59,2 & 8,3 & 30,6 & 61,3 & 8,1 & 31,2 & 60,1 & 8,6 \\
\hline & $25-29$ & 11,0 & 78,5 & 10,5 & 10,3 & 79,4 & 10,4 & 10,7 & 81,7 & 7,6 & 11,4 & 81,9 & 6,7 & 11,5 & 81,8 & 6,7 & 9,9 & 82,3 & 7,7 \\
\hline Slowakische & $15-19$ & 69,2 & 13,4 & 17,4 & 68,1 & 10,2 & 21,7 & 69,4 & 8,1 & 22,5 & 67,4 & 4,8 & 27,8 & 68,0 & 4,1 & 27,9 & 77,8 & 4,5 & 17,7 \\
\hline Rерuдmк & $20-24$ & 15,0 & 64,4 & 20,6 & 15,6 & 62,6 & 21,8 & 15,6 & 55,7 & 28,7 & 17,1 & 50,5 & 32,4 & 16,5 & 47,6 & 35,9 & 19,2 & 47,2 & 33,6 \\
\hline & $25-29$ & 2,5 & 79,4 & 18,1 & 1,7 & 83,3 & 14,9 & 1,8 & 79,4 & 18,8 & 1,3 & 75,0 & 23,8 & 2,4 & 72,7 & 24,9 & 2,8 & 77,4 & 19,8 \\
\hline Spanien & $15-19$ & 73,6 & 15,2 & 11,2 & 75,9 & 14,0 & 10,1 & 75,3 & 15,3 & 9,4 & 76,9 & 15,4 & 7,7 & 77,1 & 16,3 & 6,6 & 78,4 & 14,7 & 6,9 \\
\hline & $20-24$ & 35,6 & 41,7 & 22,7 & 39,1 & 43,6 & 17,3 & 38,2 & 47,4 & 14,5 & 39,9 & 48,3 & 11,7 & 40,9 & 48,3 & 10,8 & 38,6 & 49,0 & 12,4 \\
\hline & $25-29$ & 13,2 & 63,6 & 23,2 & 13,8 & 67,5 & 18,7 & 14,1 & 70,5 & 15,3 & 15,5 & 71,8 & 12,7 & 15,8 & 72,1 & 12,1 & 14,6 & 73,3 & 12,1 \\
\hline Schweden & $15-19$ & 85,2 & 6,9 & 8,0 & 89,4 & 4,2 & 6,4 & 90,5 & 4,7 & 4,8 & 89,5 & 5,7 & 4,7 & 87,9 & 6,7 & 5,4 & 87,5 & 6,6 & 5,9 \\
\hline & $20-24$ & 37,0 & 43,9 & 19,1 & 38,5 & 47,1 & 14,4 & 39,2 & 49,5 & 11,4 & 37,2 & 51,4 & 11,4 & 36,9 & 52,6 & 10,6 & 37,3 & 50,9 & 11,8 \\
\hline & $25-29$ & 20,2 & 68,8 & 11,0 & 22,1 & 70,1 & 7,8 & 20,5 & 72,1 & 7,4 & 19,9 & 73,1 & 6,9 & 20,8 & 74,0 & 5,2 & 20,7 & 73,5 & 5,8 \\
\hline Schweiz & $15-19$ & 68,6 & 8,4 & 22,9 & 87,7 & 8,3 & 4,0 & 86,0 & 6,0 & 8,0 & 85,9 & 6,7 & 7,3 & 86,8 & 6,8 & 6,4 & 88,3 & 5,9 & 5,8 \\
\hline & $20-24$ & 32,4 & 58,2 & 9,4 & 37,3 & 54,9 & 7,9 & 38,2 & 54,4 & 7,4 & 38,8 & 56,0 & 5,2 & 42,2 & 48,5 & 9,3 & 37,2 & 52,1 & 10,7 \\
\hline & $25-29$ & 13,4 & 81,9 & 4,7 & 13,1 & 80,0 & 6,9 & 11,1 & 84,8 & 4,0 & 21,0 & 74,5 & 4,5 & 16,4 & 79,2 & 4,4 & 14,5 & 78,3 & 7,2 \\
\hline Türkei & $15-19$ & 46,4 & 39,1 & 14,5 & 47,0 & 39,0 & 14,0 & 46,3 & 38,5 & 15,3 & 46,0 & 36,3 & 17,7 & 48,1 & 33,0 & 19,0 & 48,8 & 29,7 & 21,5 \\
\hline & $20-24$ & 14,7 & 64,7 & 20,6 & 18,6 & 61,7 & 19,6 & 16,6 & 60,1 & 23,3 & 16,0 & 60,5 & 23,5 & 16,6 & 58,3 & 25,1 & 18,5 & 54,3 & 27,1 \\
\hline & $25-29$ & 3,3 & 86,5 & 10,3 & 3,5 & 87,3 & 9,2 & 3,9 & 84,2 & 11,9 & 3,1 & 84,2 & 12,6 & 3,2 & 82,2 & 14,6 & 3,7 & 79,9 & 16,4 \\
\hline Vere & $15-19$ & $\mathrm{~m}$ & $\mathrm{~m}$ & $\mathrm{~m}$ & $\mathrm{~m}$ & $\mathrm{~m}$ & $\mathrm{~m}$ & $\mathrm{~m}$ & $\mathrm{~m}$ & $\mathrm{~m}$ & 76,1 & 15,7 & 8,2 & 75,0 & 16,7 & 8,3 & 73,5 & 18,3 & 8,2 \\
\hline & $20-24$ & $\mathrm{~m}$ & $\mathrm{~m}$ & $\mathrm{~m}$ & $\mathrm{~m}$ & $\mathrm{~m}$ & $\mathrm{~m}$ & $\mathrm{~m}$ & $\mathrm{~m}$ & $\mathrm{~m}$ & 32,2 & 56,7 & 11,1 & 33,1 & 56,4 & 10,5 & 28,1 & 60,6 & 11,3 \\
\hline & $25-29$ & $\mathrm{~m}$ & $\mathrm{~m}$ & $\mathrm{~m}$ & $\mathrm{~m}$ & $\mathrm{~m}$ & $\mathrm{~m}$ & $\mathrm{~m}$ & $\mathrm{~m}$ & $\mathrm{~m}$ & 11,4 & 79,3 & 9,3 & 10,9 & 79,6 & 9,5 & 10,5 & 81,0 & 8,5 \\
\hline ste & $15-19$ & 82,1 & 11,5 & 6,4 & 81,3 & 12,2 & 6,5 & 81,5 & 12,4 & 6,1 & 80,2 & 13,0 & 6,8 & 80,3 & 12,7 & 6,9 & $\mathrm{~m}$ & $\mathrm{~m}$ & $\mathrm{~m}$ \\
\hline & $20-24$ & 31,0 & 57,0 & 12,0 & 32,3 & 58,0 & 9,7 & 32,1 & 57,6 & 10,3 & 30,8 & 58,6 & 10,5 & 32,5 & 55,3 & 12,2 & $\mathrm{~m}$ & $\mathrm{~m}$ & $\mathrm{~m}$ \\
\hline & $25-29$ & 11,0 & 79,6 & 9,4 & 10,9 & 80,3 & 8,8 & 10,7 & 80,9 & 8,4 & 10,0 & 81,0 & 8,9 & 10,5 & 79,3 & 10,2 & $\mathrm{~m}$ & $\mathrm{~m}$ & $\mathrm{~m}$ \\
\hline Ländermittel & $15-19$ & 75,3 & 14,9 & 9,8 & 78,9 & 13,2 & 7,9 & 79,9 & 12,6 & 7,5 & 79,9 & 12,7 & 7,3 & 79,6 & 12,9 & 7,4 & 80,5 & 11,9 & 7,6 \\
\hline & $20-24$ & 30,2 & 54,5 & 15,3 & 35,0 & 51,9 & 13,1 & 34,9 & 51,6 & 13,4 & 34,4 & 52,7 & 12,9 & 35,5 & 51,5 & 12,9 & 36,0 & 50,4 & 13,6 \\
\hline & $25-29$ & 10,6 & 77,5 & 11,8 & 13,3 & 76,1 & 10,6 & 13,6 & 76,0 & 10,4 & 13,3 & 76,4 & 10,3 & 13,1 & 76,9 & 10,0 & 13,0 & 76,3 & 10,8 \\
\hline
\end{tabular}

Hinweis: c weist darauf hin, dass zu wenige Daten zur Verfügung stehen, um verlässliche Schätzungen vorzunehmen.

Quelle: OECD. Hinweise s. Anhang 3 unter www.oecd.org/edu/eag2004. 


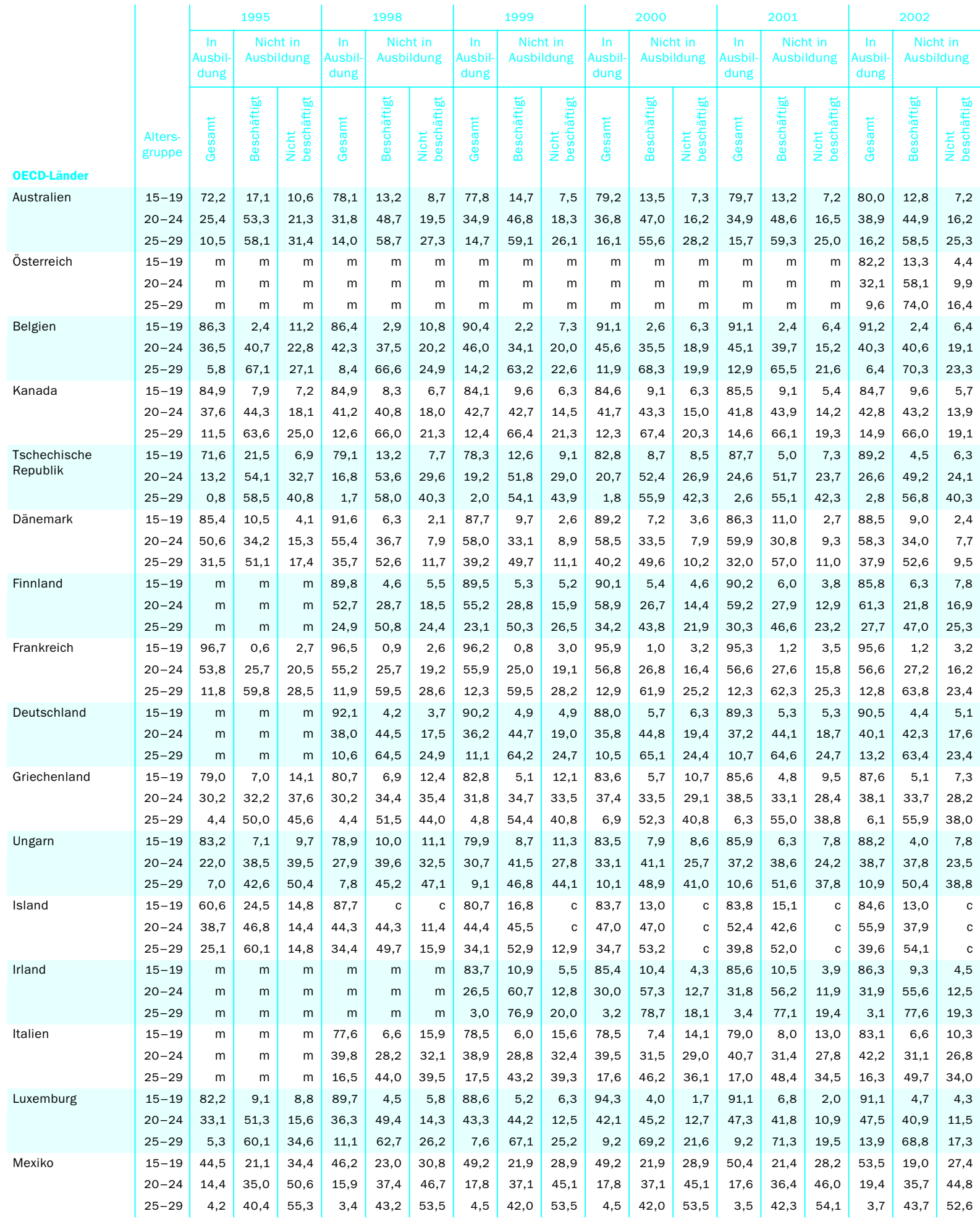


Tabelle C4.4b (Forts.)

Änderung des Prozentsatzes junger Frauen, die sich in Ausbildung bzw. nicht in Ausbildung befinden (1995-2002) Nach Altersgruppe und Beschäftigungsstatus

\begin{tabular}{|c|c|c|c|c|c|c|c|c|c|c|c|c|c|c|c|c|c|c|c|}
\hline & & \multicolumn{3}{|c|}{1995} & \multicolumn{3}{|c|}{1998} & \multicolumn{3}{|c|}{1999} & \multicolumn{3}{|c|}{2000} & \multicolumn{3}{|c|}{2001} & \multicolumn{3}{|c|}{2002} \\
\hline & & \multirow{2}{*}{$\begin{array}{c}\text { In } \\
\text { Ausbil- } \\
\text { dung }\end{array}$} & \multicolumn{2}{|c|}{$\begin{array}{l}\text { Nicht in } \\
\text { Ausbildung }\end{array}$} & $\begin{array}{c}\text { In } \\
\text { Ausbil- } \\
\text { dung }\end{array}$ & \multicolumn{2}{|c|}{$\begin{array}{l}\text { Nicht in } \\
\text { Ausbildung }\end{array}$} & $\begin{array}{c}\text { In } \\
\text { Ausbil- } \\
\text { dung }\end{array}$ & \multicolumn{2}{|c|}{$\begin{array}{l}\text { Nicht in } \\
\text { Ausbildung }\end{array}$} & $\begin{array}{c}\text { In } \\
\text { Ausbil- } \\
\text { dung }\end{array}$ & \multicolumn{2}{|c|}{$\begin{array}{l}\text { Nicht in } \\
\text { Ausbildung }\end{array}$} & $\begin{array}{c}\text { In } \\
\text { Ausbil- } \\
\text { dung }\end{array}$ & \multicolumn{2}{|c|}{$\begin{array}{l}\text { Nicht in } \\
\text { Ausbildung }\end{array}$} & $\begin{array}{c}\text { In } \\
\text { Ausbil- } \\
\text { dung }\end{array}$ & \multicolumn{2}{|c|}{$\begin{array}{l}\text { Nicht in } \\
\text { Ausbildung }\end{array}$} \\
\hline OECD-Länder & $\begin{array}{l}\text { Alters- } \\
\text { gruppe }\end{array}$ & & 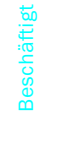 & 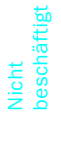 & $\begin{array}{l}\vec{E} \\
\mathbb{E} \\
\tilde{N} \\
0 \\
心\end{array}$ & 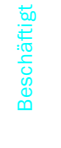 & 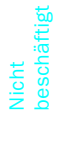 & $\begin{array}{l}\vec{E} \\
\frac{\tilde{N}}{\tilde{N}} \\
\tilde{J} \\
心\end{array}$ & 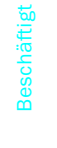 & 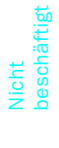 & $\begin{array}{l}\vec{E} \\
\tilde{N} \\
心 \\
心 \\
心\end{array}$ & 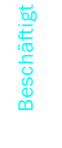 & 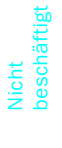 & $\begin{array}{l}\vec{E} \\
\tilde{N} \\
0 \\
心 \\
心\end{array}$ & 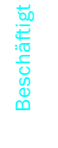 & 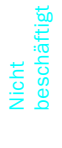 & $\begin{array}{l}\vec{E} \\
\tilde{E} \\
\tilde{N} \\
0 \\
心 \\
心\end{array}$ & $\begin{array}{l}\overrightarrow{50} \\
\stackrel{\rightleftarrows}{ \pm} \\
\frac{0}{c} \\
0 \\
0 \\
0 \\
\infty\end{array}$ & 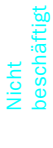 \\
\hline \multirow[t]{3}{*}{ Niederlande } & $15-19$ & $\mathrm{~m}$ & $\mathrm{~m}$ & $\mathrm{~m}$ & 88,4 & 8,0 & 3,6 & 89,6 & 7,6 & 2,9 & 82,6 & 13,8 & 3,6 & 82,7 & 12,8 & 4,5 & 81,6 & 14,0 & 4,4 \\
\hline & $20-24$ & $\mathrm{~m}$ & $\mathrm{~m}$ & $\mathrm{~m}$ & 47,7 & 43,0 & 9,4 & 47,4 & 43,4 & 9,2 & 35,6 & 53,1 & 11,2 & 32,6 & 55,6 & 11,8 & 35,2 & 55,3 & 9,5 \\
\hline & $25-29$ & $\mathrm{~m}$ & $\mathrm{~m}$ & $\mathrm{~m}$ & 19,7 & 62,6 & 17,7 & 21,3 & 62,5 & 16,2 & 3,9 & 77,5 & 18,6 & 4,9 & 78,0 & 17,2 & 5,2 & 75,6 & 19,2 \\
\hline Norwegen & $15-19$ & $\mathrm{~m}$ & $\mathrm{~m}$ & $\mathrm{~m}$ & 94,2 & 3,6 & 2,3 & 93,0 & 5,1 & 1,9 & 94,2 & 4,6 & 1,2 & 87,9 & 9,3 & 2,7 & 88,8 & 8,5 & 2,8 \\
\hline & $20-24$ & $\mathrm{~m}$ & $\mathrm{~m}$ & $\mathrm{~m}$ & 47,4 & 42,4 & 10,1 & 45,3 & 45,2 & 9,6 & 51,1 & 39,9 & 9,0 & 46,1 & 44,5 & 9,4 & 43,5 & 45,9 & 10,6 \\
\hline & $25-29$ & $\mathrm{~m}$ & $\mathrm{~m}$ & $\mathrm{~m}$ & 15,1 & 70,9 & 14,0 & 18,6 & 69,7 & 11,7 & 18,7 & 68,7 & 12,6 & 16,1 & 70,9 & 13,0 & 15,6 & 70,8 & 13,5 \\
\hline Polen & $15-19$ & 92,1 & 2,8 & 5,1 & 92,5 & 2,7 & 4,9 & 94,5 & 1,6 & 3,9 & 94,0 & 2,0 & 4,0 & 92,8 & 1,8 & 5,4 & 96,8 & 0,6 & 2,6 \\
\hline & $20-24$ & 22,9 & 37,1 & 40,0 & 31,4 & 40,3 & 28,3 & 34,2 & 35,0 & 30,8 & 35,4 & 30,4 & 34,2 & 47,4 & 24,1 & 28,5 & 56,1 & 18,4 & 25,5 \\
\hline & $25-29$ & 3,1 & 55,8 & 41,1 & 5,0 & 59,4 & 35,6 & 5,0 & 59,3 & 35,7 & 7,7 & 53,0 & 39,3 & 11,9 & 49,6 & 38,5 & 14,7 & 45,9 & 39,4 \\
\hline Portugal & $15-19$ & 74,5 & 15,9 & 9,6 & 74,1 & 16,3 & 9,7 & 74,4 & 16,0 & 9,6 & 75,6 & 15,1 & 9,2 & 75,4 & 15,1 & 9,5 & 77,6 & 15,6 & 6,8 \\
\hline & $20-24$ & 42,9 & 40,2 & 16,9 & 36,4 & 49,4 & 14,2 & 37,9 & 47,3 & 14,8 & 40,4 & 46,0 & 13,5 & 41,9 & 45,3 & 12,7 & 38,3 & 46,4 & 15,4 \\
\hline & $25-29$ & 12,2 & 63,7 & 24,1 & 8,7 & 70,1 & 21,2 & 12,3 & 68,4 & 19,3 & 10,5 & 71,2 & 18,3 & 10,8 & 72,8 & 16,4 & 11,4 & 71,9 & 16,7 \\
\hline Slowakische & $15-19$ & 71,1 & 14,6 & 14,3 & 70,7 & 14,4 & 14,9 & 69,8 & 12,1 & 18,1 & 67,2 & 8,1 & 24,7 & 66,5 & 8,6 & 24,9 & 79,4 & 7,1 & 13,5 \\
\hline & $20-24$ & 14,5 & 45,0 & 40,5 & 19,2 & 49,9 & 31,0 & 19,3 & 46,4 & 34,3 & 19,1 & 47,1 & 33,8 & 22,4 & 43,8 & 33,8 & 25,1 & 40,7 & 34,2 \\
\hline & $25-29$ & 0,7 & 51,2 & 48,1 & 0,5 & 59,6 & 39,9 & 1,4 & 60,6 & 38,0 & 1,3 & 58,7 & 40,0 & 2,2 & 57,2 & 40,6 & 3,1 & 55,5 & 41,4 \\
\hline Spanien & $15-19$ & 81,2 & 6,9 & 11,9 & 84,7 & 5,7 & 9,6 & 83,5 & 7,1 & 9,3 & 84,5 & 7,3 & 8,2 & 86,0 & 6,7 & 7,3 & 85,5 & 7,0 & 7,5 \\
\hline & $20-24$ & 44,6 & 26,3 & 29,0 & 49,6 & 27,4 & 23,0 & 49,3 & 29,8 & 20,9 & 49,5 & 32,0 & 18,5 & 49,3 & 32,8 & 17,9 & 48,4 & 33,6 & 18,0 \\
\hline & $25-29$ & 16,1 & 39,0 & 45,0 & 16,8 & 46,6 & 36,5 & 16,3 & 48,3 & 35,3 & 16,8 & 52,7 & 30,5 & 18,4 & 53,8 & 27,9 & 17,6 & 54,6 & 27,8 \\
\hline Schweden & $15-19$ & 89,8 & 7,0 & 3,2 & 92,6 & 4,5 & 2,9 & 92,5 & 5,0 & 2,5 & 91,8 & 5,8 & 2,4 & 88,9 & 8,0 & 3,1 & 89,4 & 7,3 & 3,3 \\
\hline & $20-24$ & 40,7 & 43,5 & 15,8 & 47,0 & 41,3 & 11,7 & 48,7 & 40,6 & 10,7 & 47,3 & 42,8 & 9,9 & 45,7 & 43,6 & 10,6 & 46,4 & 43,0 & 10,6 \\
\hline & $25-29$ & 19,5 & 65,1 & 15,4 & 27,8 & 59,8 & 12,4 & 24,5 & 63,9 & 11,6 & 24,0 & 64,5 & 11,6 & 24,8 & 65,9 & 9,3 & 24,3 & 65,3 & 10,5 \\
\hline Schweiz & $15-19$ & 62,4 & 12,1 & 25,5 & 83,3 & 11,0 & 5,7 & 82,8 & 10,1 & 7,1 & 83,3 & 8,3 & 8,5 & 84,5 & 8,3 & 7,2 & 83,9 & 10,2 & 5,8 \\
\hline & $20-24$ & 26,7 & 60,1 & 13,2 & 32,2 & 53,5 & 14,3 & 33,3 & 57,3 & 9,4 & 35,9 & 57,4 & 6,6 & 36,2 & 56,3 & 7,5 & 38,9 & 52,5 & 8,6 \\
\hline & $25-29$ & 7,8 & 70,3 & 22,0 & 7,3 & 75,8 & 16,9 & 9,7 & 74,4 & 15,9 & 9,0 & 73,3 & 17,7 & 10,5 & 71,0 & 18,5 & 11,0 & 71,3 & 17,8 \\
\hline Türkei & $15-19$ & 30,9 & 27,5 & 41,6 & 35,1 & 22,9 & 41,9 & 34,9 & 23,3 & 41,8 & 34,0 & 19,6 & 46,3 & 35,5 & 17,5 & 47,0 & 36,5 & 18,0 & 45,5 \\
\hline & $20-24$ & 6,5 & 29,7 & 63,8 & 9,0 & 29,3 & 61,7 & 10,3 & 31,0 & 58,7 & 10,2 & 25,5 & 64,4 & 10,0 & 26,5 & 63,5 & 10,7 & 26,5 & 62,8 \\
\hline & $25-29$ & 2,1 & 29,7 & 68,2 & 2,4 & 29,9 & 67,7 & 2,8 & 28,5 & 68,7 & 2,8 & 28,2 & 69,0 & 2,0 & 27,0 & 71,1 & 2,4 & 27,6 & 70,0 \\
\hline Vereinig & $15-19$ & $\mathrm{~m}$ & $\mathrm{~m}$ & $\mathrm{~m}$ & $\mathrm{~m}$ & $\mathrm{~m}$ & $\mathrm{~m}$ & $\mathrm{~m}$ & $\mathrm{~m}$ & $\mathrm{~m}$ & 78,0 & 14,2 & 7,9 & 77,3 & 14,7 & 8,0 & 77,3 & 13,8 & 8,9 \\
\hline & $20-24$ & $\mathrm{~m}$ & $\mathrm{~m}$ & $\mathrm{~m}$ & $\mathrm{~m}$ & $\mathrm{~m}$ & $\mathrm{~m}$ & $\mathrm{~m}$ & $\mathrm{~m}$ & $\mathrm{~m}$ & 32,7 & 47,6 & 19,8 & 33,9 & 46,9 & 19,2 & 34,4 & 45,5 & 20,2 \\
\hline & $25-29$ & $\mathrm{~m}$ & $\mathrm{~m}$ & $\mathrm{~m}$ & $\mathrm{~m}$ & $\mathrm{~m}$ & $\mathrm{~m}$ & $\mathrm{~m}$ & $\mathrm{~m}$ & $\mathrm{~m}$ & 15,3 & 61,1 & 23,6 & 15,8 & 61,4 & 22,8 & 17,1 & 56,8 & 26,1 \\
\hline ste & $15-19$ & 80,8 & 9,9 & 9,3 & 83,1 & 8,8 & 8,2 & 81,1 & 10,2 & 8,7 & 82,3 & 10,4 & 7,3 & 82,0 & 9,9 & 8,0 & $\mathrm{~m}$ & $\mathrm{~m}$ & $\mathrm{~m}$ \\
\hline & $20-24$ & 31,9 & 44,6 & 23,5 & 33,6 & 47,4 & 19,0 & 33,4 & 46,8 & 19,8 & 34,1 & 47,5 & 18,3 & 35,3 & 45,7 & 19,0 & $\mathrm{~m}$ & $\mathrm{~m}$ & $\mathrm{~m}$ \\
\hline & $25-29$ & 12,2 & 63,5 & 24,3 & 12,9 & 65,4 & 21,7 & 11,4 & 66,0 & 22,6 & 12,7 & 65,1 & 22,2 & 13,0 & 62,2 & 24,8 & $\mathrm{~m}$ & $\mathrm{~m}$ & $\mathrm{~m}$ \\
\hline Ländermittel & $15-19$ & 75,2 & 11,9 & 12,9 & 81,1 & 9,0 & 9,8 & 81,3 & 9,3 & 9,4 & 81,8 & 8,9 & 9,3 & 81,8 & 9,2 & 9,0 & 83,0 & 8,7 & 8,2 \\
\hline & $20-24$ & 30,9 & 41,2 & 28,0 & 36,7 & 40,4 & 23,0 & 37,6 & 40,9 & 21,5 & 38,2 & 41,2 & 20,6 & 39,5 & 40,8 & 19,8 & 40,3 & 40,1 & 19,6 \\
\hline & $25-29$ & 10,1 & 55,2 & 34,7 & 13,2 & 56,9 & 29,9 & 13,3 & 58,1 & 28,6 & 13,4 & 58,9 & 27,7 & 13,5 & 59,4 & 27,1 & 13,7 & 59,5 & 26,7 \\
\hline
\end{tabular}

Hinweis: c weist darauf hin, dass zu wenige Daten zur Verfügung stehen, um verlässliche Schätzungen vorzunehmen.

Quelle: OECD. Hinweise s. Anhang 3 unter www.oecd.org/edu/eag2004. 


\section{Die Situation junger Menschen mit niedrigem Bildungsniveau}

口 In acht OECD-Ländern liegt bei den 20- bis 24-Jährigen der Anteil derjenigen ohne einen Abschluss des Sekundarbereich II, die sich nicht in Ausbildung befinden, weiterhin unter 10 Prozent.

In 11 von 27 OECD-Ländern gehören dieser potentiellen ,Risikogruppe‘ zwischen 10 und 18 Prozent der Altersgruppe an. In den übrigen acht OECDLändern sind über 20 Prozent der Jugendlichen dieser Kategorie zuzurechnen.

Von diesem Problem sind in 19 von 27 Ländern mehr junge Männer als Frauen betroffen, so z. B. in Griechenland, Island, Irland, Italien, Portugal und Spanien. Das Gegenteil trifft in Dänemark, Luxemburg und der Türkei zu.

Prozentsatz 20- bis 24-Jähriger, die sich nicht in Ausbildung befinden und über keinen Abschluss im Sekundarbereich II verfügen, nach Geschlecht (2002)

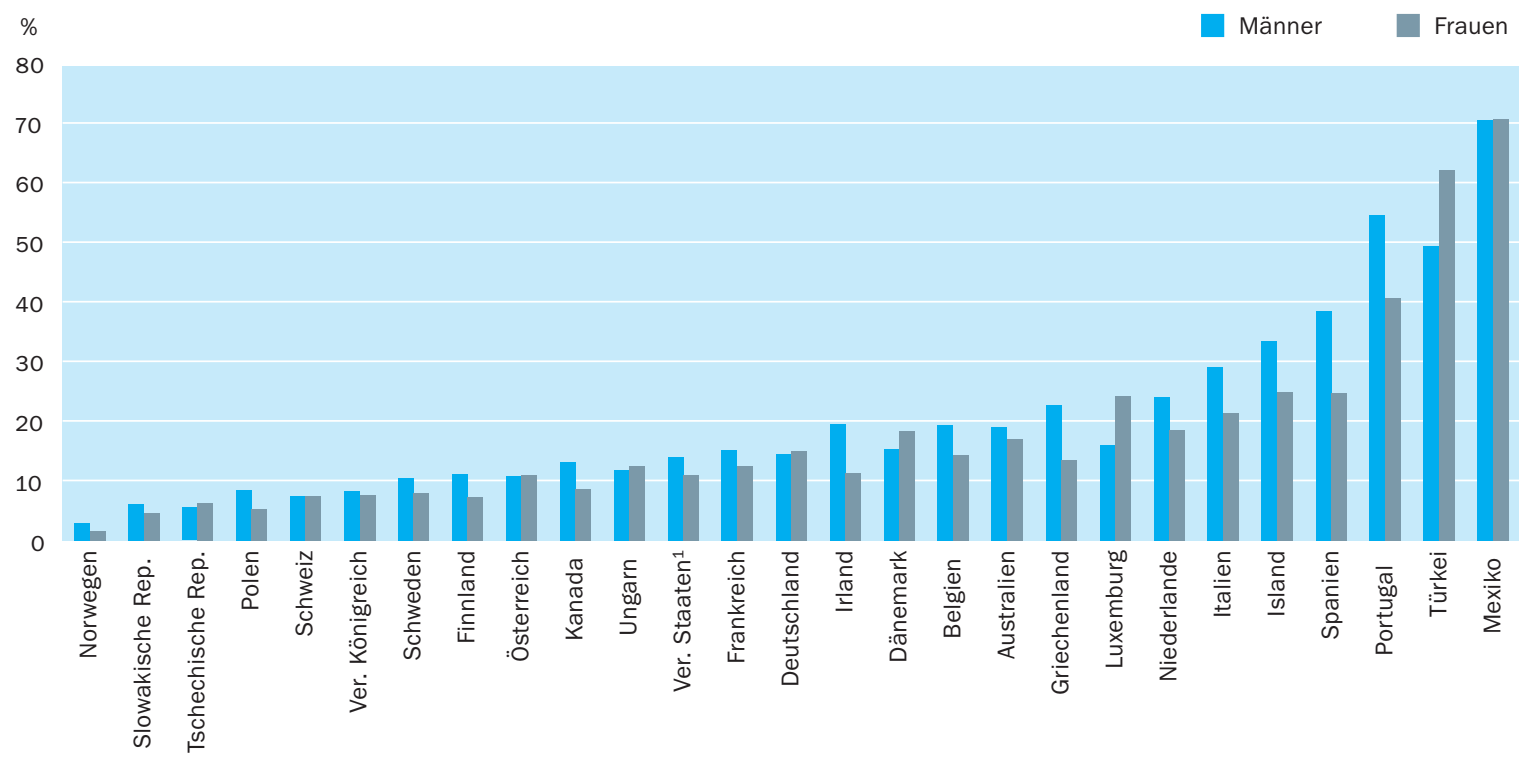




\section{Politischer Hintergrund}

Dieser Indikator beschäftigt sich mit der Lage junger Menschen, die sich weder in Ausbildung noch in Beschäftigung befinden.
Die meisten 15- bis 19-Jährigen besuchen noch die Schule. Von den übrigen ist in vielen OECD-Ländern ein hoher Prozentsatz entweder arbeitslos oder nicht im Arbeitsmarkt.
Der Eintritt in den Arbeitsmarkt stellt oftmals eine schwierige Zeit des Übergangs dar. Während sich einerseits die Verweildauer im Bildungssystem erhöht hat, befindet sich andererseits eine beträchtliche Anzahl junger Menschen weder in Ausbildung noch in Beschäftigung, (d.h. sie sind arbeitslos oder nicht beschäftigt). Dies ist besonders hinsichtlich der jüngeren Altersgruppen besorgniserregend, bei denen viele weder einen Arbeitslosenstatus noch eine andere soziale Absicherung haben.

In dem Maße, in dem die Wechselbeziehungen zwischen Bildung, Wirtschaft und dem Wohlstand der Nationen immer enger werden, wird es zu einer immer wichtigeren politischen Aufgabe, jungen Menschen einen erfolgreichen Bildungsweg und einen gelungenen Übergang von der Erstausbildung in das Erwerbsleben zu ermöglichen. Aufgrund steigender Anforderungen an Kenntnissen und Fähigkeiten in den OECD-Ländern ist ein Abschluss des Sekundarbereich II zur Mindestvoraussetzung für einen erfolgreichen Eintritt in den Arbeitsmarkt und zur Grundlage des lebenslangen Lernens geworden. Jugendliche mit geringeren Qualifikationen laufen eine erhöhte Gefahr, langfristig arbeitslos zu werden und nur instabile oder unbefriedigende Beschäftigungsverhältnisse zu finden, was weitere negative Konsequenzen, wie beispielsweise soziale Ausgrenzung, mit sich bringen kann.

\section{Ergebnisse und Erläuterungen}

\section{Junge Menschen, die sich weder in Ausbildung noch in Beschäftigung befinden}

Im Alter von 15 bis I 9 Jahren befinden sich in den meisten OECD-Ländern über 80 Prozent der Jugendlichen im Bildungssystem. Ein kleiner Teil der Altersgruppe ist nach dem Schulabgang in Beschäftigung, obwohl dieser Anteil in Io OECD-Ländern bei ro Prozent und in drei weiteren sogar bei über 20 Prozent liegt (Tab. C4.2).

Es gibt jedoch eine Gruppe junger Menschen, die sich weder in Ausbildung noch in Beschäftigung befinden. Einige gelten amtlich als arbeitslos, wenn sie aktiv nach einer Arbeitsstelle suchen, andere, die dies nicht tun, als ,nicht beschäftigt' oder anders ausgedrückt als sich , nicht im Arbeitsmarkt' befindend. Ihre Gründe können unterschiedlichster Natur sein: z. B. Entmutigung aufgrund der Schwierigkeiten bei der Arbeitssuche oder freiwilliger Rückzug aus familiären Gründen. In I9 von 27 OECD-Ländern ist der Anteil dieser jungen Menschen höher als der Anteil derjenigen mit Arbeitslosenstatus.

In Dänemark, Frankreich, Luxemburg, Norwegen und Polen gibt es nur eine geringe Zahl von Personen, die sich weder in Ausbildung noch in Beschäftigung befinden; in Finnland, Italien, Mexiko, der Slowakischen Republik und der Türkei ist dies recht häufig der Fall. In diesen Ländern sind über to Prozent der 15- bis I9-Jährigen weder in Ausbildung noch in Beschäftigung (Tab. C4.2). In anderen OECD-Ländern ist dieser Anteil zwar geringer, aber mit 4 bis 9 Prozent auch nicht zu vernachlässigen. Von diesem Problem sind in Finn- 


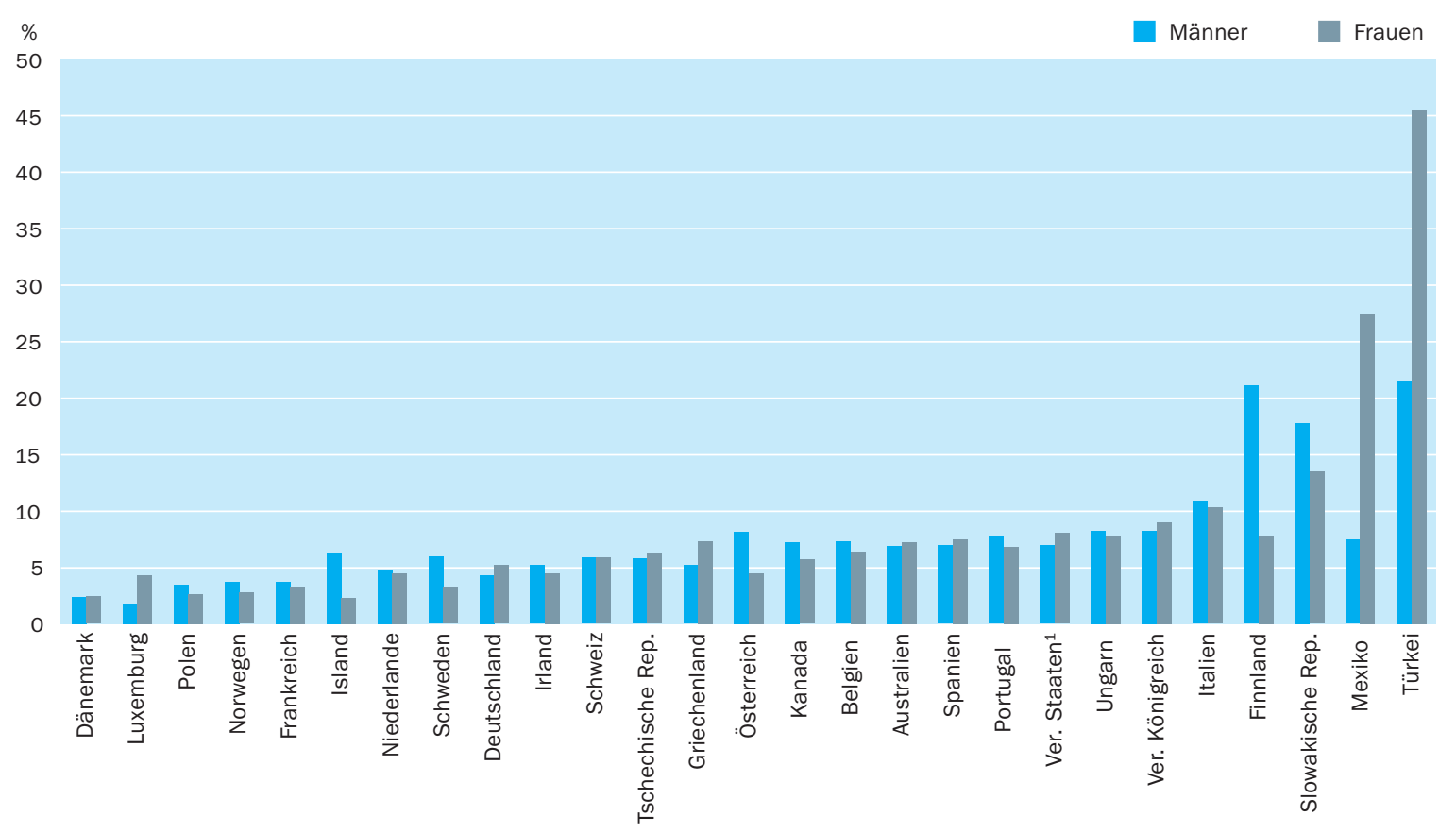

1. Referenzjahr 2001.

Anordnung der Länder in aufsteigender Reihenfolge des Prozentsatzes 15- bis 19-Jähriger, die sich weder in Ausbildung befinden noch beschäftigt sind. Quelle: OECD, Tabellen C4.2a und C4.2b. Hinweise s. Anhang 3 unter www.oecd.org/edu/eag2004.

land, Österreich, Island, Schweden und der Slowakischen Republik hauptsächlich junge Männer betroffen, in Mexiko und der Türkei hauptsächlich junge Frauen (Abb. C5.2). In den anderen Ländern sind die geschlechtsspezifischen Unterschiede relativ gering, auch wenn ganz allgemein mehr junge Männer als Frauen betroffen sind.

Gering qualifizierte Jugendliche können eher von langfristiger Arbeitslosigkeit oder von instabilen oder unbefriedigenden Beschäftigungsverhältnissen bedroht sein, was weitere negative Konsequenzen, wie beispielsweise soziale Ausgrenzung, mit sich bringen kann. Daher ist der vorzeitige Schulabbruch zu einem der größten Probleme für die Bildungspolitik geworden. Bei den 20bis 24-Jährigen wächst das Ausmaß des Problems im Vergleich zur Altersgruppe der I5- bis I9-Jährigen, und erfährt auch eine qualitative Änderung, da die meisten der 20- bis 24-Jährigen nach Abschluss der Erstausbildung zum ersten Mal in den Arbeitsmarkt eintreten. Bevor sie einen sicheren und befriedigenden Arbeitsplatz finden, durchleben sie häufig eine Zeit der Arbeitslosigkeit und der Anpassung.

In acht OECD-Ländern, zu denen die nordischen und die osteuropäischen Länder sowie die Schweiz und das Vereinigte Königreich gehören, liegt der Anteil der 20- bis 24-Jährigen ohne einen Abschluss des Sekundarbereich II, die sich nicht länger in Ausbildung befinden, weiterhin unter so Prozent. Obgleich diese Gruppe nicht sehr groß ist, befindet sie sich nichtsdestotrotz in einer ein-
Bei den 20- bis 24-Jährigen wächst das Ausmaß des Problems, aber es erfährt auch eine qualitative Veränderung, da die meisten jungen Menschen in diesem Alter in den Arbeitsmarkt eintreten. 
deutig schwierigen Lage. In II von 27 OECD-Ländern gehören dieser potentiellen ,Risikogruppe' zwischen io und I8 Prozent der Altersgruppe an. Dort kommt der Aufgabe, die Abschlussquoten im Sekundarbereich II zu steigern, entscheidende Bedeutung zu. In den übrigen acht OECD-Ländern sind über 20 Prozent der Altersgruppe dieser Kategorie zuzurechnen. Von diesem Problem sind in I9 von 27 Ländern mehr junge Männer als Frauen betroffen, so z. B. in Griechenland, Island, Irland, Italien, Portugal und Spanien. Das Gegenteil trifft in Dänemark, Luxemburg und der Türkei zu (Abb. C5.I). In den anderen Ländern sind die geschlechtsspezifischen Unterschiede gering.

Die Folgen eines Schulabgangs ohne einen Abschluss im Sekundarbereich II lassen sich anhand eines Vergleichs des Beschäftigungsstatus derjenigen mit und ohne einen solchen Abschluss erkennen. In allen OECD-Ländern geht ein höherer Bildungsstand mit einer höheren Beschäftigungsquote einher - im Durchschnitt I9 Prozentpunkte (Abb. C5.3). Dieser Vergleich zeigt auch gewisse Charakteristika in Bezug auf die spezielle Organisation des Arbeitsmarktes auf. Die Kluft zwischen den Beschäftigungsquoten junger Menschen mit einem Abschluss des Sekundarbereich II und ohne einen solchen ist in allen Mittelmeerländern bemerkenswert gering, was darauf hindeutet, dass hier die Qualifikationen - mögen sie auch gering sein - und die Beschäftigungsmöglichkeiten sehr gut aufeinander abgestimmt sind. Interessant ist die Situation im Vereinigten Königreich. Dort gibt es unter den OECD-Ländern das ver-

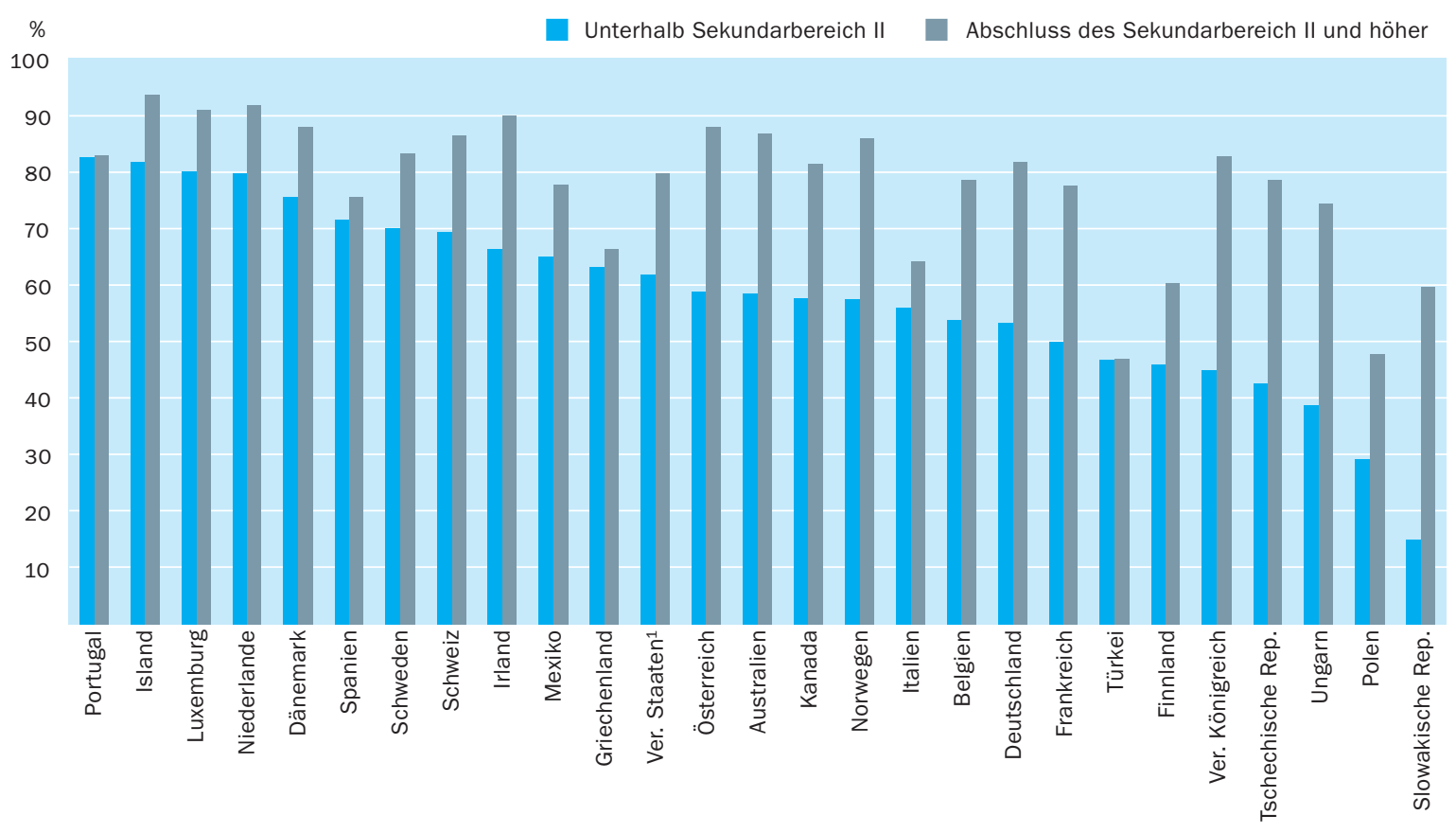

1. Referenzjahr 2001

Anordnung der Länder in absteigender Reihenfolge der Beschäftigungsquote 20-bis 24-Jähriger, die sich nicht in Ausbildung befinden und über keinen Abschluss im Sekundarbereich II verfügen.

Quelle: OECD, Tabelle D5.1. Hinweise s. Anhang 3 unter www.oecd.org/edu/eag2004. 
gleichsweise geringste Vorkommen niedriger Bildungsabschlüsse, aber der Unterschied bei der Arbeitslosigkeit ist besonders hoch, was darauf hindeutet, dass die wenigen Jugendlichen ohne einen Abschluss des Sekundarbereich II besonders benachteiligt sind. Unter anderen wirtschaftlichen Vorzeichen ist dies auch in den osteuropäischen Ländern der Fall: in Ungarn, der Slowakischen und der Tschechischen Republik.

Junge Menschen mit niedrigem Bildungsstand sind häufiger nicht im Wohnsitzland geboren. In einigen Ländern ist ein erheblicher Anteil der jungen Menschen als Einwanderer ins Land gekommen. In Io der I8 Länder, über die Daten vorliegen, stellen Einwanderer über ro Prozent der Bevölkerung im Alter zwischen 20 und 24 Jahren. In aufsteigender Reihenfolge dieses Anteils sind dies folgende Länder: Portugal (Io Prozent), Österreich, Schweden, Kanada, Deutschland (I3 Prozent), Vereinigte Staaten, Schweiz, Australien (I9 Prozent), die Niederlande und Luxemburg (28 Prozent). Der Prozentsatz der im Ausland geborenen 20- bis 24-Jährigen ist unter denen, die sich nicht in Ausbildung befinden und über keinen Abschluss im Sekundarbereich II verfügen, wesentlich höher (Abb. C5.4) Bis auf Australien, Irland, Kanada, Portugal und Spanien ist es in allen Ländern ein klarer Nachteil, wenn jemand im Ausland geboren wurde. Die anderen Länder haben einen bemerkenswert hohen Anteil ausländischer junger Menschen unter den niedrig Qualifizierten, durchschnittlich ist dieser doppelt so hoch wie für Inländer und in Österreich, der Schweiz, der Tschechischen Republik und den Vereinigten Staaten sogar noch wesentlich höher.
Häufig werden Ausländer mit einem niedrigen Bildungsstand in Zusammenhang gebracht.

\section{Abbildung C5.4}

Prozentsatz 20- bis 24-Jähriger, die nicht im Wohnsitzland geboren wurden (2002)

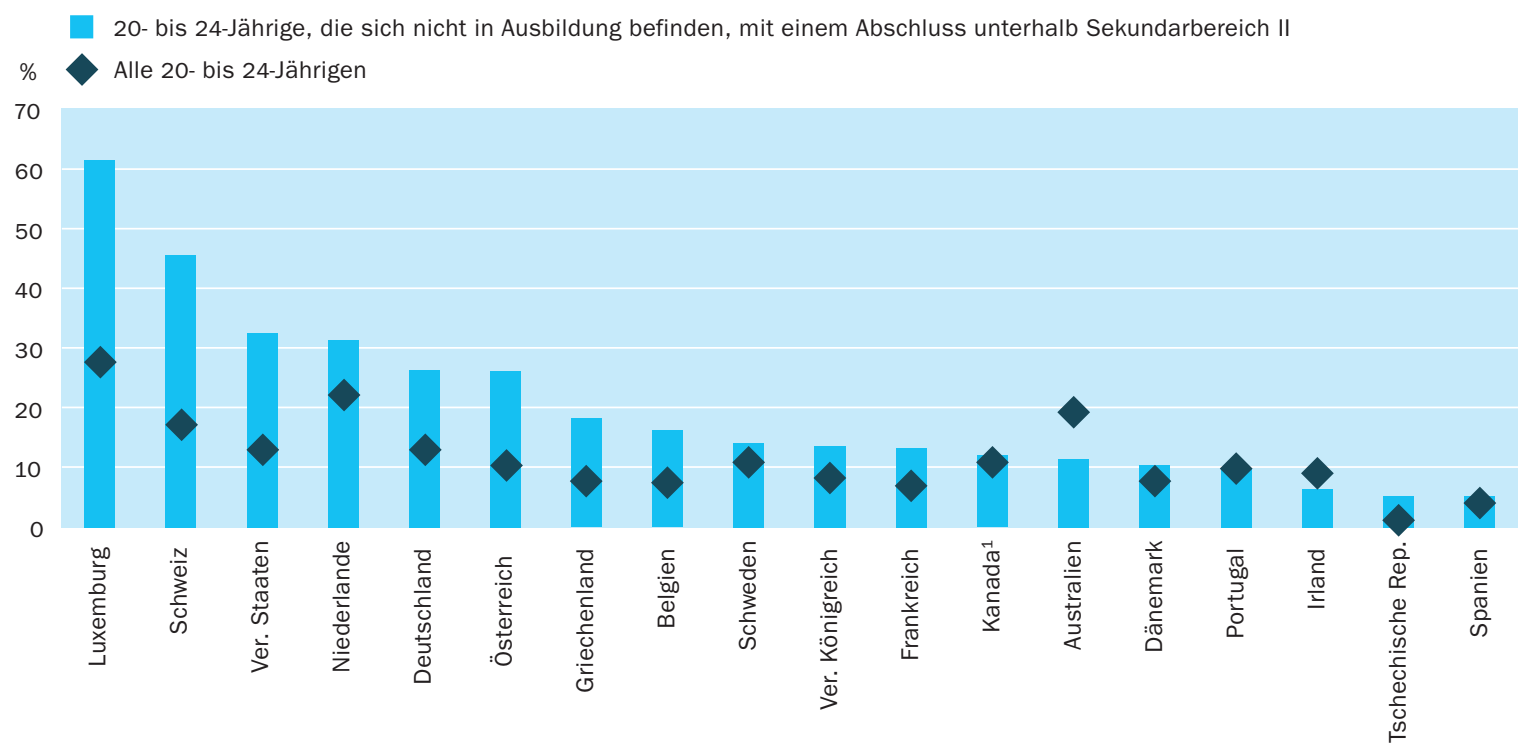

1. Referenzjahr 2001.

Anordnung der Länder in absteigender Reihenfolge des Prozentsatzes 20- bis 24-Jähriger, die sich nicht in Ausbildung befinden, über keinen Abschluss im Sekundarbereich II verfügen und nicht im Wohnsitzland geboren wurden.

Quelle: OECD, Tabelle C5.2. Hinweise s. Anhang 3 unter www.oecd.org/edu/eag2004. 
Ein erheblicher Anteil der unterqualifizierten jungen Menschen bleibt ständig vom Arbeitsmarkt ausgeschlossen (Abb. $\mathrm{C}_{5.5}$ ) Betrachtet man diejenigen, die nicht im Arbeitsmarkt sind (d.h. diejenigen, die nicht aktiv Arbeit suchen), so zeigt sich, dass bei den Männern durchschnittlich jeder zehnte und bei den Frauen jede vierte niemals beschäftigt war. In Portugal, Schweden und Spanien ist dieser Prozentsatz noch gering, er steigt jedoch in den osteuropäischen Ländern und Griechenland dramatisch an. Nicht nur in diesen Ländern, sondern auch in Italien, Irland und dem Vereinigten Königreich, bleiben gerade Frauen häufig vom Arbeitsmarkt ausgeschlossen.

\section{Definitionen und angewandte Methodik}

Die Daten für diesen Indikator wurden aus der speziellen OECD-Datenerhebung zum Übergang von der Schule ins Erwerbsleben berechnet.
Die vorliegenden statistischen Aufstellungen basieren auf Arbeitskräfteerhebungen zu dem Anteil bestimmter Altersgruppen junger Menschen an den genannten Kategorien. Die Definitionen der verschiedenen Arten von Erwerbsstatus für diejenigen, die sich nicht in Ausbildung befinden (und nicht an einer dualen Ausbildung teilnehmen) basieren auf den Richtlinien der Internationalen Arbeitsorganisation (ILO). Die Daten für diesen Indikator wurden aus der OECD-Datenerhebung zum Übergang von der Schule ins Erwerbsleben berechnet (s. Indikator C4). 2003 führte das OECD-Netzwerk B eine gezielte und detailliertere Datenerhebung durch, deren Anforderungen denen der Datenerhebung zum Übergang von der Schule ins Erwerbsleben entsprechen. Sofern das Land selbst keine Daten vorlegte, entnahm das Netzwerk B diese der Eurostat-Arbeitskräfteerhebung. Da für Menschen, die sich ,in Ausbildung'

\section{Abbildung $\mathbf{C 5 . 5}$}

Prozentsatz 20- bis 24-Jähriger mit einem Abschluss unterhalb Sekundarbereich II, die sich nicht im Arbeitsmarkt befinden und nie beschäftigt waren, nach Geschlecht (2002)

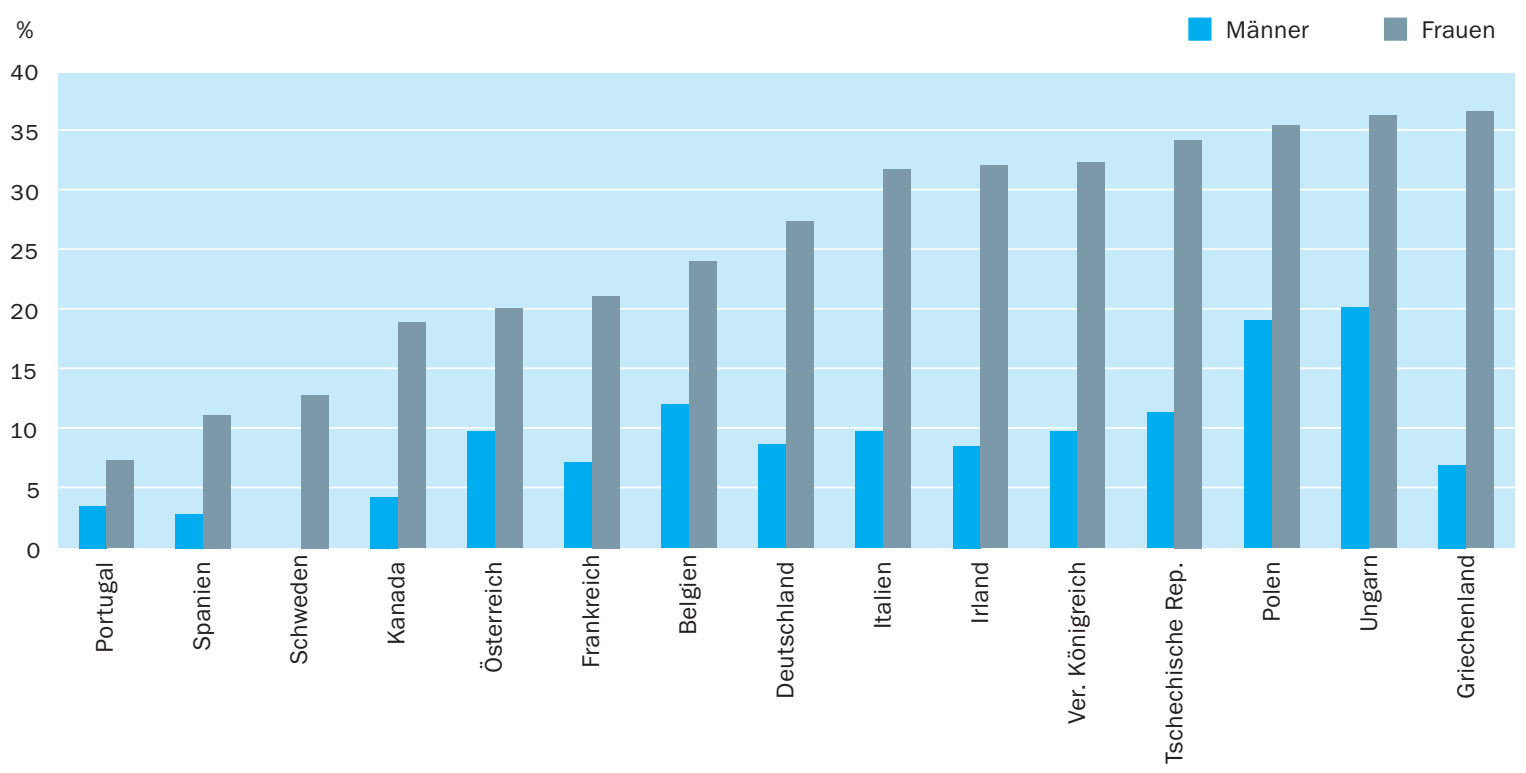


befinden, unterschiedliche Definitionen verwendet wurden, könnte es zu Unstimmigkeiten zwischen der regulären OECD-Datenerhebung zum Übergang und der speziellen Datenerhebung kommen; teilweise wird dies durch die Eurostat-Daten für den Indikator ,Prozentsatz der 20- bis 24-Jährigen, die sich nicht in Ausbildung befinden und über keinen Abschluss im Sekundarbereich II verfügen', aufgefangen. Daher werden die in der Ausgabe 2004 von Bildung auf einen Blick veröffentlichten Prozentzahlen für die frühen Schulabgänger nicht unbedingt mit denen in der geplanten getrennten Veröffentlichung mit detaillierten Ergebnissen zu jungen Erwachsenen mit niedrigem Bildungsstand übereinstimmen.

Ein ,früher Schulabgänger könnte grob definiert werden als ,ein Jugendlicher, der den Sekundarbereich II nicht abgeschlossen hat und sich weder in Ausbildung befindet noch eine duale Ausbildung absolviert, die zu einem Abschluss im Sekundarbereich II oder höher führt'. Diese Definition muss jedoch eine Altersgruppe spezifizieren, in der nur noch sehr wenige Jugendliche den schulischen Primar- oder Sekundarbereich besuchen können. In einer großen Zahl von OECD-Ländern besuchen noch recht viele der I8- und I9-Jährigen den Sekundarbereich II. Jugendliche, die sehr früh von der Schule abgehen, könnten irgendwann wieder dorthin zurückkehren. Ferner könnten die Arbeitsmarktergebnisse für jüngere Menschen nicht unbedingt für das Ergebnis in einem höheren Alter repräsentativ sein. Daher definiert die OECD einen jungen Erwachsenen mit einem niedrigen Bildungsstand als, einen 20- bis 24-Jährigen ohne einen Abschluss im Sekundarbereich II, der weder eine Bildungseinrichtung besucht noch eine duale Ausbildung absolviert‘. 
Tabelle C5.1

Prozentsatz 20- bis 24-Jähriger, die sich nicht in Ausbildung befinden, nach Bildungsstand, Erwerbsstatus und Geschlecht (2002)

\begin{tabular}{|c|c|c|c|c|c|c|c|c|c|c|c|}
\hline & & & & & Nicht in A & usbildung & & & & $\ln$ & 20 - bis \\
\hline & & Absch! & uss unterhal & Sekundarb & reich II & Mindeste & is Abschluss & m Sekund & bereich II & & $\begin{array}{l}\text { 24-Jahrige } \\
\text { insgesamt }\end{array}$ \\
\hline OECD-Länder & & Beschäftigt & Arbeitslos & $\begin{array}{c}\text { Nicht im } \\
\text { Arbeits- } \\
\text { markt }\end{array}$ & Zusammen & Beschäftigt & Arbeitslos & $\begin{array}{c}\text { Nicht im } \\
\text { Arbeits- } \\
\text { markt }\end{array}$ & Zusammen & & \\
\hline Australien & Männer & 13,0 & 3,8 & 2,0 & 18,9 & 38,3 & 3,1 & 1,4 & 42,7 & 38,4 & 100 \\
\hline & Frauen & 7,9 & 1,7 & 7,3 & 17,0 & 37,0 & 2,1 & 4,9 & 44,0 & 38,9 & 100 \\
\hline & $M+F$ & 10,5 & 2,8 & 4,7 & 17,9 & 37,6 & 2,6 & 3,1 & 43,4 & 38,7 & 100 \\
\hline Österreich & Männer & 6,4 & 1,8 & 2,6 & 10,7 & 53,3 & 4,4 & 4,7 & 62,4 & 26,9 & 100 \\
\hline & Frauen & 6,3 & 0,8 & 3,7 & 10,9 & 51,8 & 2,5 & 2,8 & 57,1 & 32,1 & 100 \\
\hline & $M+F$ & 6,4 & 1,3 & 3,2 & 10,8 & 52,6 & 3,5 & 3,7 & 59,8 & 29,4 & 100 \\
\hline Belgien & Männer & 12,1 & 3,5 & 3,7 & 19,3 & 35,9 & 5,0 & 3,6 & 44,5 & 36,2 & 100 \\
\hline & Frauen & 5,9 & 3,7 & 4,6 & 14,2 & 34,7 & 5,6 & 5,2 & 45,5 & 40,3 & 100 \\
\hline & $M+F$ & 9,0 & 3,6 & 4,2 & 16,8 & 35,3 & 5,3 & 4,4 & 45,0 & 38,2 & 100 \\
\hline Kanada & Männer & 8,6 & 2,7 & 1,8 & 13,1 & 41,6 & 6,4 & 3,1 & 51,1 & 35,8 & 100 \\
\hline & Frauen & 3,9 & 1,0 & 3,7 & 8,7 & 39,3 & 3,8 & 5,3 & 48,5 & 42,8 & 100 \\
\hline & $M+F$ & 6,3 & 1,9 & 2,8 & 10,9 & 40,5 & 5,2 & 4,2 & 49,8 & 39,3 & 100 \\
\hline Tschechische & Männer & 3,1 & 1,6 & 0,8 & 5,5 & 59,9 & 7,9 & 1,9 & 69,7 & 24,8 & 100 \\
\hline Republik & Frauen & 1,9 & 1,0 & 3,4 & 6,2 & 47,4 & 7,0 & 12,7 & 67,1 & 26,7 & 100 \\
\hline & $M+F$ & 2,5 & 1,3 & 2,1 & 5,9 & 53,8 & 7,5 & 7,2 & 68,4 & 25,7 & 100 \\
\hline Dänemark & Männer & 12,3 & 1,8 & 1,1 & 15,2 & 31,6 & 3,3 & 1,2 & 36,1 & 48,6 & 100 \\
\hline & Frauen & 13,0 & 1,3 & 4,0 & 18,2 & 23,7 & 1,2 & 1,9 & 26,7 & 55,0 & 100 \\
\hline & $M+F$ & 12,6 & 1,5 & 2,6 & 16,8 & 27,5 & 2,2 & 1,6 & 31,3 & 51,9 & 100 \\
\hline Finnland & Männer & 5,6 & 1,4 & 4,0 & 11,1 & 22,9 & 5,6 & 9,6 & 38,1 & 50,8 & 100 \\
\hline & Frauen & 2,8 & 0,6 & 3,9 & 7,3 & 19,0 & 3,9 & 8,6 & 31,4 & 61,3 & 100 \\
\hline & $M+F$ & 4,2 & 1,0 & 3,9 & 9,2 & 20,9 & 4,7 & 9,1 & 34,8 & 56,1 & 100 \\
\hline Frankreich & Männer & 8,7 & 4,4 & 2,0 & 15,1 & 28,9 & 5,0 & 1,2 & 35,1 & 49,8 & 100 \\
\hline & Frauen & 5,0 & 3,2 & 4,2 & 12,4 & 22,3 & 5,9 & 2,8 & 31,0 & 56,6 & 100 \\
\hline & $M+F$ & 6,9 & 3,8 & 3,1 & 13,8 & 25,6 & 5,4 & 2,0 & 33,1 & 53,2 & 100 \\
\hline Deutschland & Männer & 9,0 & 3,5 & 2,0 & 14,4 & 40,9 & 5,5 & 3,1 & 49,4 & 36,1 & 100 \\
\hline & Frauen & 6,5 & 2,1 & 6,2 & 14,9 & 36,3 & 2,9 & 5,8 & 45,1 & 40,0 & 100 \\
\hline & $M+F$ & 7,8 & 2,8 & 4,1 & 14,7 & 38,7 & 4,2 & 4,4 & 47,3 & 38,0 & 100 \\
\hline Griechenland & Männer & 17,9 & 3,1 & 1,7 & 22,7 & 32,6 & 7,8 & 3,0 & 43,4 & 33,9 & 100 \\
\hline & Frauen & 5,1 & 2,7 & 5,7 & 13,5 & 29,1 & 13,4 & 6,7 & 49,2 & 37,3 & 100 \\
\hline & $M+F$ & 11,3 & 2,9 & 3,8 & 18,0 & 30,8 & 10,7 & 4,9 & 46,4 & 35,6 & 100 \\
\hline Ungarn & Männer & 5,4 & 2,4 & 3,9 & 11,7 & 40,9 & 5,0 & 5,7 & 51,6 & 36,7 & 100 \\
\hline & Frauen & 4,0 & 0,7 & 7,8 & 12,5 & 33,8 & 2,7 & 12,3 & 48,7 & 38,7 & 100 \\
\hline & $M+F$ & 4,7 & 1,6 & 5,8 & 12,1 & 37,3 & 3,8 & 9,0 & 50,2 & 37,7 & 100 \\
\hline Island & Männer & 26,7 & c & c & 33,3 & 18,9 & c & c & 18,9 & 47,8 & 100 \\
\hline & Frauen & 20,8 & c & c & 24,7 & 20,8 & c & c & 23,6 & 51,7 & 100 \\
\hline & $M+F$ & 23,8 & c & c & 29,2 & 19,8 & c & c & 21,2 & 49,7 & 100 \\
\hline Irland & Männer & 14,7 & 2,5 & 2,3 & 19,5 & 50,0 & 2,8 & 1,5 & 54,3 & 26,2 & 100 \\
\hline & Frauen & 5,6 & 0,7 & 4,9 & 11,3 & 49,9 & 2,3 & 4,6 & 56,8 & 32,0 & 100 \\
\hline & $M+F$ & 10,2 & 1,6 & 3,6 & 15,4 & 49,9 & 2,6 & 3,0 & 55,5 & 29,1 & 100 \\
\hline Italien & Männer & 19,0 & 5,7 & 4,3 & 29,0 & 24,8 & 5,9 & 5,8 & 36,6 & 34,4 & 100 \\
\hline & Frauen & 9,0 & 3,8 & 8,4 & 21,3 & 22,0 & 8,1 & 6,4 & 36,6 & 42,2 & 100 \\
\hline & $M+F$ & 14,1 & 4,8 & 6,4 & 25,2 & 23,4 & 7,0 & 6,1 & 36,6 & 38,2 & 100 \\
\hline Luxemburg & Männer & 14,5 & 1,0 & 0,4 & 15,9 & 38,0 & 1,1 & 0,1 & 39,2 & 44,8 & 100 \\
\hline & Frauen & 17,5 & 1,9 & 4,7 & 24,1 & 24,9 & 2,0 & 3,1 & 29,9 & 46,0 & 100 \\
\hline & $M+F$ & 16,0 & 1,5 & 2,5 & 20,0 & 31,5 & 1,6 & 1,6 & 34,6 & 45,4 & 100 \\
\hline Mexiko & Männer & 64,7 & 2,4 & 3,1 & 70,1 & 6,7 & 0,5 & 0,3 & 7,5 & 22,3 & 100 \\
\hline & Frauen & 27,8 & 1,3 & 41,2 & 70,4 & 6,7 & 0,6 & 2,3 & 9,6 & 20,0 & 100 \\
\hline & $M+F$ & 45,6 & 1,9 & 22,8 & 70,3 & 6,7 & 0,6 & 1,3 & 8,6 & 21,1 & 100 \\
\hline Niederlande & Männer & 20,9 & 1,0 & 2,1 & 23,9 & 37,5 & 1,4 & 2,0 & 40,8 & 35,3 & 100 \\
\hline & Frauen & 12,9 & 0,7 & 4,9 & 18,5 & 42,4 & 1,1 & 2,8 & 46,3 & 35,2 & 100 \\
\hline & $M+F$ & 16,9 & 0,9 & 3,4 & 21,2 & 39,9 & 1,2 & 2,4 & 43,5 & 35,3 & 100 \\
\hline
\end{tabular}

Hinweis: c weist darauf hin, dass zu wenige Daten zur Verfügung stehen, um verlässliche Schätzungen vorzunehmen.

Quelle: OECD. Hinweise s. Anhang 3 unter www.oecd.org/edu/eag2004. 
Tabelle C5.1 (Forts.)

Prozentsatz 20- bis 24-Jähriger, die sich nicht in Ausbildung befinden, nach Bildungsstand, Erwerbsstatus und Geschlecht (2002)

\begin{tabular}{|c|c|c|c|c|c|c|c|c|c|c|c|}
\hline & & & & & Nicht in A & usbildung & & & & In & \\
\hline & & Abschl & Iss unterhal & Sekundarb & reich II & Mindeste & Is Abschlus & m Sekund & bereich II & & $\begin{array}{l}\text { 24-Jannge } \\
\text { insgesamt }\end{array}$ \\
\hline & & Beschäftigt & Arbeitslos & $\begin{array}{c}\text { Nicht im } \\
\text { Arbeits- } \\
\text { markt }\end{array}$ & Zusammen & Beschäftigt & Arbeitslos & $\begin{array}{c}\text { Nicht im } \\
\text { Arbeits- } \\
\text { markt }\end{array}$ & Zusammen & & \\
\hline OECD-Länder & & & & & & & & & & & \\
\hline Norwegen & Männer & 1,7 & 0,7 & 0,4 & 2,9 & 55,9 & 3,9 & 3,5 & 63,3 & 33,8 & 100 \\
\hline & Frauen & 0,9 & 0,2 & 0,6 & 1,7 & 45,0 & 2,4 & 6,8 & 54,2 & 44,1 & 100 \\
\hline & $M+F$ & 1,3 & 0,4 & 0,5 & 2,3 & 50,5 & 3,2 & 5,1 & 58,8 & 38,9 & 100 \\
\hline Polen & Männer & 2,8 & 4,0 & 1,7 & 8,6 & 20,4 & 16,7 & 2,8 & 40,0 & 51,5 & 100 \\
\hline & Frauen & 1,2 & 1,8 & 2,3 & 5,3 & 17,2 & 13,6 & 7,9 & 38,7 & 56,1 & 100 \\
\hline & $M+F$ & 2,0 & 2,9 & 2,0 & 6,9 & 18,8 & 15,1 & 5,4 & 39,3 & 53,8 & 100 \\
\hline Portugal & Männer & 48,6 & 3,7 & 2,2 & 54,4 & 12,8 & 1,3 & 0,8 & 14,9 & 30,7 & 100 \\
\hline & Frauen & 29,7 & 4,0 & 6,8 & 40,4 & 17,9 & 2,2 & 2,1 & 22,2 & 37,4 & 100 \\
\hline & $M+F$ & 39,1 & 3,8 & 4,5 & 47,4 & 15,4 & 1,7 & 1,4 & 18,5 & 34,0 & 100 \\
\hline Slowakische & Männer & 1,2 & 3,6 & 1,3 & 6,1 & 46,0 & 23,2 & 5,5 & 74,7 & 19,2 & 100 \\
\hline Republik & Frauen & 0,4 & 1,3 & 3,0 & 4,7 & 40,3 & 16,5 & 13,5 & 70,2 & 25,1 & 100 \\
\hline & $M+F$ & 0,8 & 2,5 & 2,1 & 5,4 & 43,2 & 19,9 & 9,4 & 72,5 & 22,1 & 100 \\
\hline Spanien & Männer & 30,1 & 5,4 & 2,8 & 38,3 & 20,7 & 3,6 & 0,9 & 25,2 & 36,5 & 100 \\
\hline & Frauen & 14,8 & 4,2 & 5,6 & 24,6 & 20,3 & 6,1 & 2,9 & 29,2 & 46,1 & 100 \\
\hline & $M+F$ & 22,6 & 4,8 & 4,2 & 31,7 & 20,5 & 4,8 & 1,8 & 27,2 & 41,2 & 100 \\
\hline Schweden & Männer & 7,8 & 2,0 & 0,6 & 10,4 & 43,9 & 5,3 & 3,8 & 53,0 & 36,5 & 100 \\
\hline & Frauen & 5,0 & 1,2 & 1,7 & 7,9 & 38,7 & 3,4 & 4,1 & 46,2 & 45,9 & 100 \\
\hline & $M+F$ & 6,4 & 1,6 & 1,2 & 9,2 & 41,3 & 4,4 & 3,9 & 49,7 & 41,1 & 100 \\
\hline Schweiz & Männer & 5,8 & c & c & 7,6 & 46,2 & c & 5,4 & 55,2 & 37,2 & 100 \\
\hline & Frauen & 4,6 & c & c & 7,5 & 47,7 & c & c & 53,4 & 39,1 & 100 \\
\hline & $M+F$ & 5,2 & c & c & 7,5 & 46,9 & 2,8 & 4,6 & 54,3 & 38,2 & 100 \\
\hline Türkei & Männer & 35,9 & 7,2 & 6,0 & 49,1 & 18,4 & 6,7 & 7,3 & 32,3 & 18,5 & 100 \\
\hline & Frauen & 16,7 & 1,4 & 43,8 & 61,9 & 9,8 & 4,5 & 13,0 & 27,4 & 10,7 & 100 \\
\hline & $M+F$ & 26,1 & 4,2 & 25,4 & 55,7 & 14,0 & 5,6 & 10,2 & 29,8 & 14,5 & 100 \\
\hline Vereinigtes & Männer & 5,2 & 1,5 & 1,5 & 8,2 & 55,7 & 5,4 & 2,6 & 63,7 & 28,0 & 100 \\
\hline Konigreich & Frauen & 1,6 & 0,4 & 5,6 & 7,7 & 44,5 & 3,4 & 10,3 & 58,3 & 34,1 & 100 \\
\hline & $M+F$ & 3,6 & 1,0 & 3,4 & 8,0 & 50,6 & 4,5 & 6,1 & 61,2 & 30,8 & 100 \\
\hline Vereinigte & Männer & 10,3 & 1,8 & 1,8 & 13,9 & 45,0 & 4,6 & 4,1 & 53,6 & 32,5 & 100 \\
\hline Staaten ${ }^{1}$ & Frauen & 5,0 & 1,3 & 4,6 & 10,8 & 40,8 & 3,2 & 9,9 & 53,9 & 35,3 & 100 \\
\hline & $M+F$ & 7,6 & 1,5 & 3,2 & 12,3 & 42,8 & 3,9 & 7,0 & 53,7 & 33,9 & 100 \\
\hline Ländermittel & Männer & 15,3 & 2,9 & 2,2 & 20,3 & 35,8 & 5,4 & 3,1 & 44,4 & 35,3 & 100 \\
\hline & Frauen & 8,7 & 1,6 & 7,3 & 17,7 & 32,0 & 4,6 & 6,1 & 42,6 & 39,7 & 100 \\
\hline & $M+F$ & 12,0 & 2,3 & 4,8 & 19,0 & 33,9 & 5,0 & 4,6 & 43,5 & 37,5 & 100 \\
\hline OECD-Partne & & & & & & & & & & & \\
\hline Israel & Männer & 8,3 & 1,5 & 3,5 & 13,3 & 22,7 & 6,5 & 34,7 & 63,9 & 22,8 & 100 \\
\hline & Frauen & 1,5 & 0,5 & 5,8 & 7,9 & 30,8 & 7,7 & 22,6 & 61,2 & 30,9 & 100 \\
\hline & $M+F$ & 5,0 & 1,0 & 4,6 & 10,6 & 26,7 & 7,1 & 28,8 & 62,6 & 26,8 & 100 \\
\hline
\end{tabular}

Hinweis: c weist darauf hin, dass zu wenige Daten zur Verfügung stehen, um verlässliche Schätzungen vorzunehmen.

1. Referenzjahr 2001.

Quelle: OECD. Hinweise s. Anhang 3 unter www.oecd.org/edu/eag2004. 


\section{Tabelle C5.2}

Prozentsatz 20- bis 24-Jähriger, nach Geburtsort (2002)

Gesamtbevölkerung und Bevölkerung, die sich nicht in Ausbildung befindet, mit einem Abschluss unterhalb Sekundarbereich II

\begin{tabular}{|c|c|c|c|c|c|c|c|c|}
\hline \multirow[b]{2}{*}{ OECD-Länder } & \multicolumn{4}{|c|}{ Alle 20- bis 24-Jährigen } & \multicolumn{4}{|c|}{$\begin{array}{l}\text { 20- bis 24-Jährige, die sich nicht in Ausbildung befinden, } \\
\text { mit einem Abschluss unterhalb Sekundarbereich II }\end{array}$} \\
\hline & $\begin{array}{l}\text { Im Wohnsitz- } \\
\text { land geboren }\end{array}$ & $\begin{array}{l}\text { In einem } \\
\text { anderen Land } \\
\text { geboren }\end{array}$ & $\begin{array}{l}\text { Keine Informa- } \\
\text { tionen zum } \\
\text { Geburtsland }\end{array}$ & Gesamt & $\begin{array}{l}\text { Im Wohnsitz- } \\
\text { land geboren }\end{array}$ & $\begin{array}{l}\text { In einem } \\
\text { anderen Land } \\
\text { geboren }\end{array}$ & $\begin{array}{l}\text { Keine Informa- } \\
\text { tionen zum } \\
\text { Geburtsland }\end{array}$ & Gesamt \\
\hline Australien & 81 & 19 & $n$ & 100 & 89 & 11 & $n$ & 100 \\
\hline Österreich & 90 & 10 & $n$ & 100 & 74 & 26 & $\mathrm{n}$ & 100 \\
\hline Belgien & 93 & 7 & $n$ & 100 & 84 & 16 & $\mathrm{n}$ & 100 \\
\hline Kanada $^{1}$ & 78 & 11 & 11 & 100 & 88 & $12 *$ & $\mathrm{n}$ & 100 \\
\hline Tschechische Rep. & 99 & 1 & $\mathrm{n}$ & 100 & 95 & 5 & $n$ & 100 \\
\hline Dänemark & 92 & 8 & $\mathrm{n}$ & 100 & 89 & $10 *$ & $\mathrm{n}$ & 100 \\
\hline Frankreich & 93 & 7 & $n$ & 100 & 87 & 13 & $n$ & 100 \\
\hline Deutschland & 80 & 13 & 7 & 100 & 65 & 26 & 9 & 100 \\
\hline Griechenland & 92 & 8 & $n$ & 100 & 82 & $18^{*}$ & $n$ & 100 \\
\hline Irland & 91 & 9 & $n$ & 100 & 93 & 7 & $\mathrm{n}$ & 100 \\
\hline Luxemburg & 72 & 28 & $n$ & 100 & 38 & 62 & $n$ & 100 \\
\hline Niederlande & 78 & 22 & $\mathrm{n}$ & 100 & 69 & 31 & $\mathrm{n}$ & 100 \\
\hline Portugal & 90 & 10 & $n$ & 100 & 90 & 10 & $n$ & 100 \\
\hline Spanien & 96 & 4 & $n$ & 100 & 95 & 5 & $\mathrm{n}$ & 100 \\
\hline Schweden & 88 & 11 & 1 & 100 & 84 & 14 & 2 & 100 \\
\hline Schweiz & 83 & 17 & $\mathrm{n}$ & 100 & 54 & 46 & $\mathrm{n}$ & 100 \\
\hline Ver. Königreich & 92 & 8 & $n$ & 100 & 86 & 14 & $n$ & 100 \\
\hline Vereinigte Staaten & 87 & 13 & $\mathrm{n}$ & 100 & 67 & 33 & $\mathrm{n}$ & 100 \\
\hline Ländermittel & 87 & 11 & 1 & 100 & 79 & 21 & 1 & 100 \\
\hline
\end{tabular}

* Aufgrund des geringen Stichprobenumfangs sind die Daten mit Vorsicht zu interpretieren.

1. Referenzjahr 2001.

Quelle: OECD und EULFS. Hinweise s. Anhang 3 unter www.oecd.org/edu/eag2004.

\section{Tabelle C5.3}

Prozentsatz 20- bis 24-Jähriger, die sich nicht in Ausbildung befinden, über einen niedrigen Bildungsstand verfügen, sich nicht im Arbeitsmarkt befinden und nie beschäftigt waren, nach Geschlecht (2002)

\begin{tabular}{|c|c|c|}
\hline & Männer & Frauen \\
\hline \multicolumn{3}{|l|}{ OECD-Länder } \\
\hline Österreich & 10 & 20 \\
\hline Belgien & 12 & 24 \\
\hline Kanada & 4 & 19 \\
\hline Tschechische Republik & 11 & 34 \\
\hline Frankreich & $7^{*}$ & 21 \\
\hline Deutschland & 9 & 27 \\
\hline Griechenland & 7 & 37 \\
\hline Ungarn & 20 & 36 \\
\hline Irland & $9 *$ & 32 \\
\hline Italien & 10 & 32 \\
\hline Polen & 19 & 35 \\
\hline Portugal & $4 *$ & $7^{*}$ \\
\hline Spanien & 3 & 11 \\
\hline Schweden & $\mathrm{m}$ & 13 \\
\hline Vereinigtes Königreich & 10 & 32 \\
\hline Ländermittel & 10 & 25 \\
\hline
\end{tabular}

* Aufgrund des geringen Stichprobenumfangs sind die Daten mit Vorsicht zu interpretieren.

Hinweis: Teilnehmer an dualen Ausbildungsprogrammen gelten als sowohl in Ausbildung als auch beschäftigt, ohne Bezug auf ihren ILO-Erwerbsstatus.

Quelle: OECD und EULFS. Hinweise s. Anhang 3 unter www.oecd.org/edu/eag2004. 
Das Lernumfeld und die Organisation von Schulen

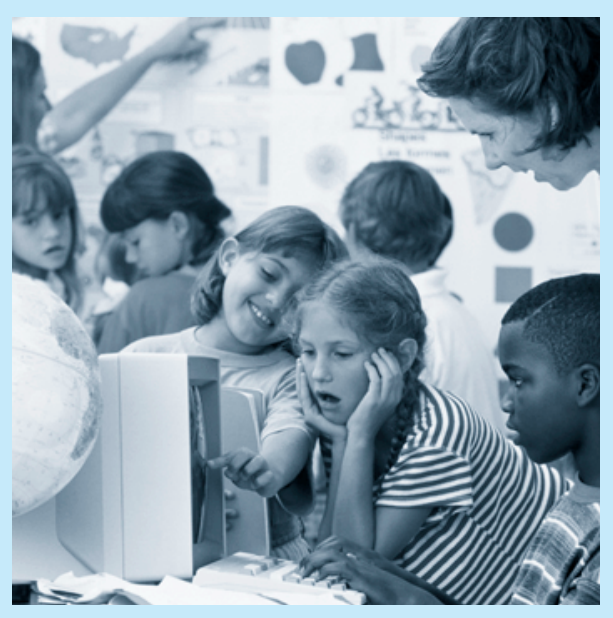





\section{Insgesamt vorgesehene Unterrichtsszeit im Primar- und Sekundarbereich}

Schüler im Alter von 7 bis 14 Jahren erhalten im Durchschnitt 6.868 Stunden Unterricht. Hiervon entfallen 1.576 Stunden auf das 7. und 8. Lebensjahr, 2.510 Stunden auf das 9. bis 11. Lebensjahr und 2.782 auf die Zeit vom 12. bis zum 14. Lebensjahr.

Im Durchschnitt der OECD-Länder haben 7- bis 8-jährige Schüler im Jahr 752 Stunden Unterricht im Pflichtteil des Lehrplans und 788 Stunden vorgesehene Unterrichtszeit im Klassenzimmer. 9- bis 11-jährige Schüler haben pro Jahr fast 50 Stunden Unterricht mehr und 12- bis 14-Jährige wiederum fast 100 Stunden mehr als 9- bis 11-jährige Schüler. Es gibt hierbei jedoch erhebliche Unterschiede zwischen den einzelnen Ländern.

Bei den 9- bis 11-jährigen Schülern entfällt etwa die Hälfte der vorgesehenen Pflicht-Unterrichtszeit auf Lesen und Schreiben, Mathematik und Naturwissenschaften, bei den 12- bis 14-Jährigen sind es 41 Prozent. Der prozentuale Anteil des Lehrplans der 9- bis 11-Jährigen, der für Lesen und Schreiben in der Unterrichtssprache verpflichtend vorgesehen ist, unterscheidet sich jedoch erheblich zwischen den einzelnen Ländern und reicht von 12 Prozent des Lehrplans in Portugal bis zu 31 Prozent in der Slowakischen Republik. 
Abbildung D1.1

Vorgesehene Unterrichtszeit an öffentlichen Bildungseinrichtungen für 7- bis 14-Jährige (2002)

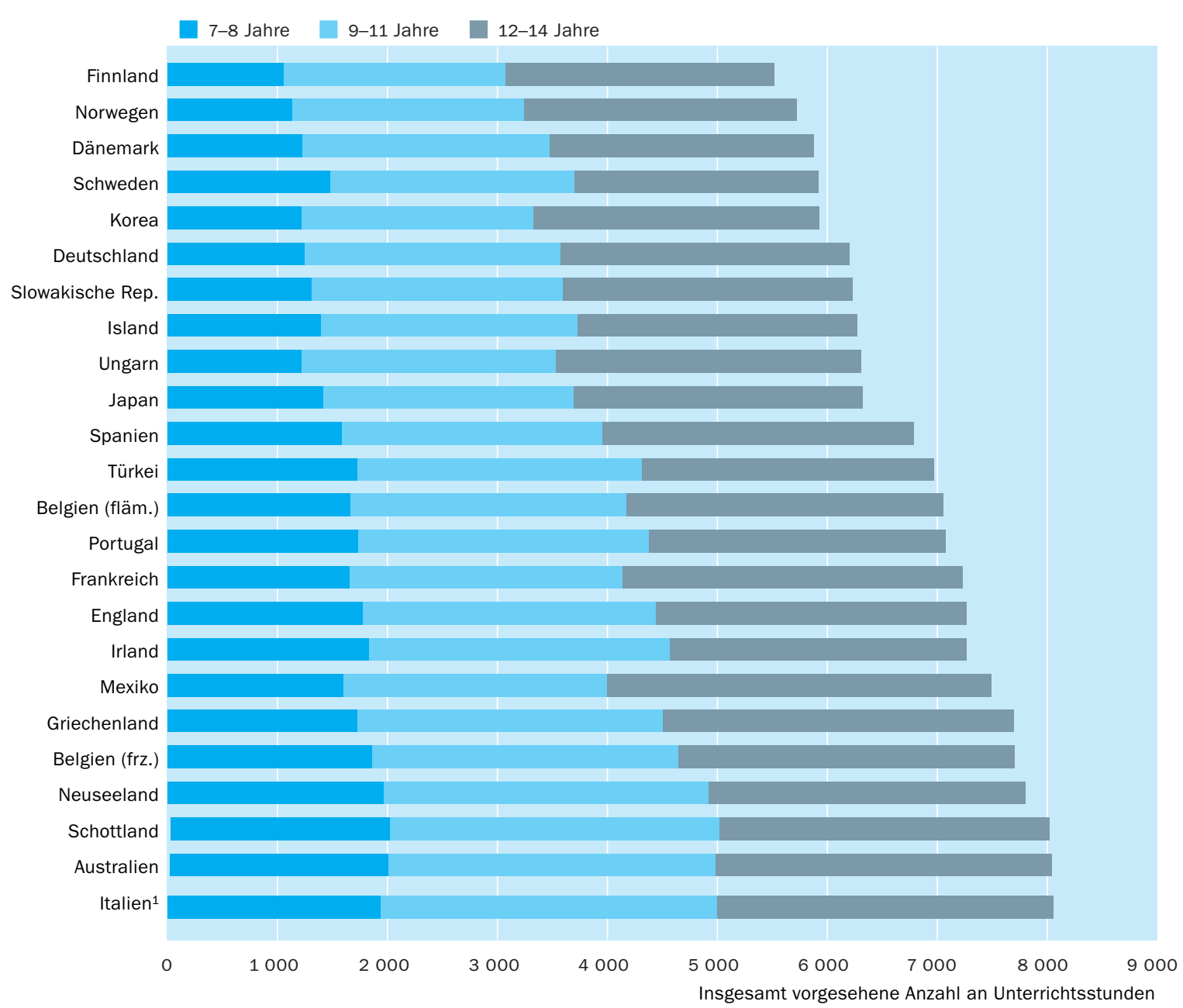

Dieser Indikator zeigt die Gesamtzahl vorgesehener Unterrichtsstunden im Klassenzimmer im formalen Bildungssystem.

\section{Politischer Hintergrund}

Wie viel und wie gut ein Mensch von der frühen Kindheit bis zum Eintritt ins Berufsleben lernt, beeinflusst sein späteres Leben, sowohl unter wirtschaftlichen als auch sozialen Gesichtspunkten. Ein großer Teil der öffentlichen Investitionen in das Lernen der Schüler erfolgt in Form der Bereitstellung von formalem Unterricht im Klassenzimmer. Eine große Aufgabe für die Bildungspolitik besteht nun darin, die zur Verfügung stehenden Ressourcen auf die Bedürfnisse der Schüler abzustimmen und eine zeitliche Optimierung sowohl mit Blick auf die Lernenden als auch mit Blick auf die öffentlichen Investitionen anzustreben. Bildungskosten umfassen im Wesentlichen die Arbeit der Lehrkräfte, Wartung und Unterhalt der Bildungseinrichtungen und andere 
Bildungsressourcen. Daher ist die Zeitdauer, für die diese Ressourcen den Schülern zur Verfügung stehen, wie in diesem Indikator mit der Unterrichtszeit im formalen Bildungssystem erfasst, von großer Bedeutung.

\section{Ergebnisse und Erläuterungen}

\section{Was dieser Indikator zeigt}

Dieser Indikator erfasst die vorgesehene Unterrichtszeit als Kenngröße für die offiziell vorgeschriebene Lernzeit im Klassenzimmer. Er zeigt auch, wie sich die Unterrichtszeit auf die verschiedenen Bereiche des Lehrplans verteilt. Der Indikator ist berechnet als vorgesehene Nettoanzahl an Unterrichtsstunden für die Klassen, in denen die Mehrzahl der Schüler 7 bis 15 Jahre alt ist. Diese Daten sind zwar aufgrund der unterschiedlichen Lehrpläne schwer über die einzelnen Länder hinweg zu vergleichen, geben aber dennoch einen Hinweis darauf, wie viel Unterrichtszeit die Länder für ihre Schüler als notwendig erachten, damit diese die festgesetzten Bildungsziele erreichen.

In einigen Ländern bestehen bei der vorgesehenen Unterrichtszeit beträchtliche Unterschiede zwischen einzelnen Regionen oder verschiedenen Schularten. In vielen Ländern sind lokale Bildungsbehörden oder die Schulen selbst befugt, über die Anzahl und Aufteilung der Unterrichtsstunden zu entscheiden. Oft ist zusätzliche Unterrichtszeit für individuelle Förderkurse oder Zusatzangebote zum Lehrplan eingeplant. Andererseits geht auch Zeit verloren, weil für fehlende Lehrer kein qualifizierter Ersatz zur Verfügung steht oder weil die Schüler selbst Fehlzeiten aufweisen.

Die jährliche Unterrichtszeit sollte auch im Zusammenhang mit der Dauer der Schulpflicht betrachtet werden, die der vom Staat für junge Menschen vorgesehenen Zeit der Bildungsbeteiligung bei voller Finanzierung durch öffentliche Ressourcen entspricht, bzw. dem Zeitraum, in dem die Bildungsbeteiligung der Bevölkerung bei über 90 Prozent liegt (s. Indikator Cr). Außerdem ist zu berücksichtigen, dass die vorgesehene Unterrichtszeit weder die Qualität der Lernangebote während dieser Zeit noch die Art oder Qualität der beteiligten Human- oder Sachressourcen erfasst. Hierfür bietet Indikator D2, der das zahlenmäßige Schüler/Lehrkräfte-Verhältnis erfasst, einige Anhaltspunkte.

\section{Insgesamt vorgesehene Unterrichtszeit im Klassenzimmer im formalen Bildungssystem}

Die insgesamt vorgesehene Unterrichtszeit ist ein Schätzwert der Anzahl an Unterrichtsstunden, in denen Schüler im Pflichtteil und Nicht-Pflichtteil des Lehrplans unterrichtet werden.

Ingesamt liegt die vorgesehene Unterrichtszeit für 7- bis I4-jährige Schüler im Durchschnitt der OECD-Länder bei 6.868 Stunden. Die offiziellen Vorgaben reichen jedoch von 5.523 Stunden in Finnland bis zu ungefähr 8.00o Stunden in Australien, Italien und Schottland. Diese Stundenzahl umfasst Pflicht- und Wahlpflichtstunden, die Schulen den Schülern anbieten müssen. Die vorgesehene Unterrichtszeit in dieser Altersspanne ist zwar ein guter Indikator für das theoretische Arbeitspensum der Schüler, kann aber nicht als tatsächlicher
Die vorgesehene Unterrichtszeit ist ein wichtiger Indikator für die öffentlichen Ressourcen, die in Bildung investiert werden, ...

... sie muss jedoch vor dem Hintergrund oft beträchtlicher Unterschiede zwischen einzelnen Schulen und Regionen gesehen werden ...

... sowie im Zusammenhang mit anderen Zeiten, in denen auch gelernt wird, und der Qualität des Unterrichts, die in diesem Indikator nicht erfasst sind.

Schüler haben im Alter von 7 bis 14 Jahren durchschnittlich 6.868 Stunden Unterricht. 
Unterricht, den die Schüler in den Jahren der Erstschulbildung erhalten, betrachtet werden. In einigen Ländern, deren Schüler ein größeres Arbeitspensum haben, ist die Zeit der Schulpflicht kürzer und die Schüler verlassen das Bildungssystem früher, während in anderen Länder die gleichmäßigere Verteilung der Unterrichtszeit über mehr Schuljahre hinweg letztendlich insgesamt zu einer höheren Unterrichtsstundenzahl für alle führt. Tab. Di.I zeigt die Altersspanne, während der sich mehr als go Prozent der Bevölkerung in Ausbildung befinden und Abb. Di.I zeigt die vorgesehene Gesamtunterrichtszeit für 7- bis I4-Jährige.

\section{Vorgesehene Unterrichtszeit im Klassenzimmer für den Pflichtunterricht im formalen Bildungssystem}

Die insgesamt vorgesehene Unterrichtszeit ist ein Schätzwert der Anzahl an Unterrichtsstunden, in denen Schüler sowohl im Kern-Pflichtteil als auch im Wahl-Pflichtteil des Lehrplans unterrichtet werden.

Für 7- bis 8-Jährige und 9- bis II-Jährige entspricht die insgesamt vorgesehene Unterrichtszeit in den meisten Ländern dem insgesamt vorgesehenen Pflichtteil, während dies für die älteren Altersgruppen weniger häufig der Fall ist. In Dänemark, Deutschland, Island, Korea, Norwegen, Schottland und Schweden entspricht dagegen die vorgesehene Unterrichtszeit für alle 7- bis 15-Jährigen den vorgesehenen Pflichtstunden.

Die Gesamtzahl der insgesamt vorgesehenen Unterrichtsstunden im Klassenzimmer im formalen Bildungssystem liegt im Schnitt bei 752 Stunden jährlich für die 7- bis 8-Jährigen, bei 8I6 Stunden jährlich für die 9- bis II-Jährigen und bei 900 Stunden jährlich für die I2- bis I4-Jährigen. Die Gesamtzahl der durchschnittlich vorgesehenen Pflicht-Unterrichtsstunden im typischen Bildungsgang, den die meisten I5-Jährigen durchlaufen, beträgt 923 Stunden pro Jahr (Tab. Di.I).

\section{Lehrplanreform in Portugal}

Im Schuljahr 200I/2002 wurde in Portugal der Lehrplan des Primarbereichs reformiert. Dies führte zu einem neuen Lehrplan, neuen Prioritäten und einer neuen Zeiteinteilung. Im Sekundarbereich II wurde ein weniger anspruchsvoller Bildungsgang eingeführt, der Schülern einen berufsbildenden ISCED-2 Abschluss bietet und ihnen den direkten Zugang zum Arbeitsmarkt eröffnet.

Im ersten Zyklus (6- bis Io-jährige Schüler) von 25 Pflichtwochenstunden gibt es keine Vorgaben, wie viel Zeit auf jedes einzelne Gebiet zu entfallen hat. Der Lehrplan umfasst sowohl fachspezifischen Unterricht als auch nicht-fachspezifischen Unterricht. Der fachspezifische Unterricht umfasst: Portugiesisch, Mathematik, Umweltkunde und künstlerische und körperliche Ausdrucksfähigkeit. Der nicht-fachspezifische Unterricht umfasst: Projektarbeit, begleitetes Lernen und Staatsbürgerkunde. Im zweiten Zyklus des Primarbereichs (Io- bis II-jährige Schüler) ist die für jedes Gebiet vorgesehene Zeit festgelegt, aber innerhalb des jeweiligen Gebietes können die Schulen in gewissem Maße entscheiden, wie viel Zeit sie auf jedes einzelne 
Fach verwenden. Der Lehrplan enthält sowohl fachspezifische als auch nicht-fachspezifische Gebiete. Die fachspezifischen Gebiete umfassen Sprache und Sozialwissenschaften (Portugiesisch, Fremdsprachen, Geschichte und Geographie Portugals), Mathematik und Naturwissenschaften, künstlerischen und technischen Unterricht. Die nicht-fachspezifischen Gebiete umfassen Projektarbeit, begleitetes Lernen und Staatsbürgerkunde. Schüler können außerhalb des regulären Lehrplans auch am Religionsunterricht teilnehmen.

\section{Lehrplanpolitik}

Die Entscheidungskompetenzen hinsichtlich der Festlegung des Lehrplans unterscheiden sich in den einzelnen Ländern sehr. In den OECD-Ländern gibt es 2 Grundmodelle mit verschiedenen Varianten.

In einem der Grundmodelle zur Festlegung des Lehrplans werden Fächer und Inhalte sowie die dafür vorgesehene Zeit von nationalen oder regionalen Behörden festgelegt. Die Schulen haben bei der Umsetzung dieser nationalen oder regionalen Vorschriften zum Lehrplan unterschiedlichen Handlungsspielraum. So legen beispielsweise in Deutschland, England, Frankreich, Griechenland, Österreich, Portugal und Spanien nationale Behörden (bzw. in Deutschland die Länder, in Spanien die Autonomen Gemeinschaften) die Lehrpläne für alle Schularten, Klassenstufen und Fächer fest. Normalerweise werden in den entsprechenden Vorschriften die Fächer und die dafür vorgesehene Unterrichtszeit sowie der Inhalt mehr oder weniger detailliert nach Klassenstufe und Bildungsgang festgelegt, während die Schulen für das Management und die Vermittlung des Lehrplans verantwortlich sind.

\section{Lehrplanregelung in Spanien}

Durch offizielle Vorschriften legt das spanische Bildungsministerium den nationalen Mindestlehrplan fest, der in den Autonomen Regionen umzusetzen ist ( 55 bis 65 Prozent der Unterrichtszeit). Die verbleibende Unterrichtszeit wird von jeder Autonomen Region nach eigenen Schwerpunkten geregelt. Im Primarbereich hat sich seit I99I die Unterrichtszeit praktisch nicht verändert, die einzige Ausnahme ist in einigen Autonomen Regionen die probeweise Einführung von Fremdsprachenunterricht in den ersten beiden Jahren des Primarbereichs. Im Sekundarbereich I hat das Bildungsministerium Ende 2000 den nationale Mindestlehrplan abgeändert und die Autonomen Regionen mussten daraufhin die Stundenpläne für das Schuljahr 200I/ 2002 anpassen, um die auf nationaler Ebene festgelegten Änderungen abzudecken. Das erklärt den Unterschied zwischen den Daten für 2001 und 2002.
In einigen OECD-Ländern werden Fächer und Inhalte sowie die dafür vorgesehene Zeit auf nationaler (bzw. regionaler) Ebene festgelegt, ... 
...während in anderen Ländern hauptsächlich die lokalen Schulbehörden bzw. die Schule selbst für die Festlegung des Lehrplans zuständig sind, wobei die Leistungsstandards auf nationaler Ebene festgelegt werden.
Die Entwicklung der nationalen Richtlinien in den einzelnen Ländern lässt vermuten, dass die Länder bei Lehrplanentscheidungen ein Gleichgewicht zwischen nationalen Standards und lokaler Autonomie erreichen wollen.

Bei den 9- bis 11-jährigen Schülern entfällt etwa die Hälfte der vorgesehenen Pflicht-Unterrichtszeit auf Lesen und Schreiben, Mathematik und Naturwissenschaften ...
In dem zweiten Modell der Lehrplanregelung legen die nationalen Behörden Leistungsziele oder Standards fest, während lokale Behörden oder die Schulen für die Planung und Umsetzung der Lehrpläne verantwortlich sind. So werden beispielsweise in ganz Belgien, Dänemark, den Niederlanden, Neuseeland, Schottland und der Tschechischen Republik die Leistungsziele mittels nationaler Richtlinien festgelegt, während lokale Behörden bzw. die Schulen die Fächer, die Inhalte und die für die einzelnen Fächer vorgesehene Unterrichtszeit bestimmen. In diesen Ländern bieten nationale Richtlinien oft einen Planungsrahmen, der die Mindestanforderungen in den zu unterrichtenden Fächern, die für jede Fächergruppe aufzuwendende Zeit und/oder erwünschte Studieninhalte festlegt, und damit die Schulen bei der Lehrplangestaltung unterstützt.

\section{Regelungen zum Pflichtlehrplan in Dänemark}

In Dänemark erlässt das Bildungsministerium Vorgaben zu den Bildungszielen in jedem einzelnen Fach sowie Lehrplanleitlinien für einzelne Fächer und zur Verteilung der Unterrichtsstunden. Innerhalb dieses Rahmens können die Schulen und Gemeinden ihren eigenen Lehrplan erstellen.

Nationale Lehrplanrichtlinien haben unabhängig von ihrem rechtlichen Status großen Einfluss auf die Entwicklung der Lehrpläne der Schulen. Zusammen mit den Regelungen der Schulabschlüsse und Prüfungen wird damit eine Harmonisierung der Bildungsinhalte innerhalb der Länder erreicht. Die jüngsten Entwicklungen der Lehrplanrichtlinien gehen in den Ländern, die über viele Jahrzehnte hinweg zentral festgelegte Lehrpläne hatten, jetzt eher hin zu dezentralen Entscheidungsbefugnissen (z.B. in den deutschsprachigen europäischen Ländern sowie in Osteuropa). Gleichzeitig wurden in den Ländern, die traditionell dezentrale Lehrplanrichtlinien einsetzten (z. B. Australien, Neuseeland und das Vereinigte Königreich) in den vergangenen 20 Jahren nationale Leistungsstandards ausgehandelt. Als Ergebnis dieses Wechselspiels wurden die nationalen Lehrplanrichtlinien der Länder einander ähnlicher und es scheint ein internationaler ,Kernlehrplan' zu entstehen - mit ähnlichen Fächergruppen und weitergehend angeglichenen Beschreibungen der angestrebten Kompetenzniveaus.

Für 9- bis II-jährige Schüler entfallen im Durchschnitt 49 Prozent des Pflichtteils des Lehrplans auf die drei Grundlagenfächer: Lesen und Schreiben in der Unterrichtsprache (24 Prozent), Mathematik (I6 Prozent) und Naturwissenschaften (9 Prozent). Durchschnittlich 8 Prozent des Pflichtteils werden der Sozialkunde und 6 Prozent den modernen Fremdsprachen gewidmet. Die zeitlichen Anteile von Kunst und Sport am gesamten Pflichtteil des Lehrplans betragen I2 bzw. 9 Prozent. Diese sieben Grundlagenfächer sind in allen OECD-Ländern Teil des Lehrplans für diese Altersgruppe. Auf dieser Ebene sind jedoch die Lernaktivitäten in den einzelnen Fächern nicht unbedingt als separate Unterrichtsstunden organisiert (Tab. Di.2a und Abb. Di.2a). 
Im Durchschnitt nehmen Lesen und Schreiben den größten Teil des Lehrplans ein, aber dieser Anteil variiert stärker zwischen den Ländern als der Anteil anderer Fächer. In Portugal werden dem Lesen und Schreiben nur I2 Prozent der Unterrichtszeit gewidmet, während es in der Slowakischen Republik 3I Prozent sind. Auch der Anteil der Sozialkunde variiert beträchtlich zwischen 2 Prozent der Unterrichtszeit in Finnland und Österreich und 20 Prozent in Mexiko.

Im Durchschnitt der OECD-Länder entfallen für I2- bis I4-jährige Schüler 4I Prozent des Pflicht-Lehrplans auf drei Grundlagenfächer: Lesen und Schrei... bei den 12- bis 14-Jährigen ben in der Unterrichtsprache (I6 Prozent), Mathematik (I3 Prozent) und Nasind es 41 Prozent. turwissenschaften (I2 Prozent). In dieser Alterskohorte ist ein relativ größerer zeitlicher Anteil des Lehrplans für Sozialkunde (I2 Prozent) und moderne

\section{Abbildung D1.2a}

Vorgesehene Unterrichtszeit für 9- bis 11-Jährige an öffentlichen Bildungseinrichtungen, nach Fach (2002)

Prozentsatz der gesamten vorgesehenen Unterrichtszeit, die auf die einzelnen Fächer innerhalb des Wahl-Pflichtteils und des Nicht-Pflichtteils des Lehrplans entfällt

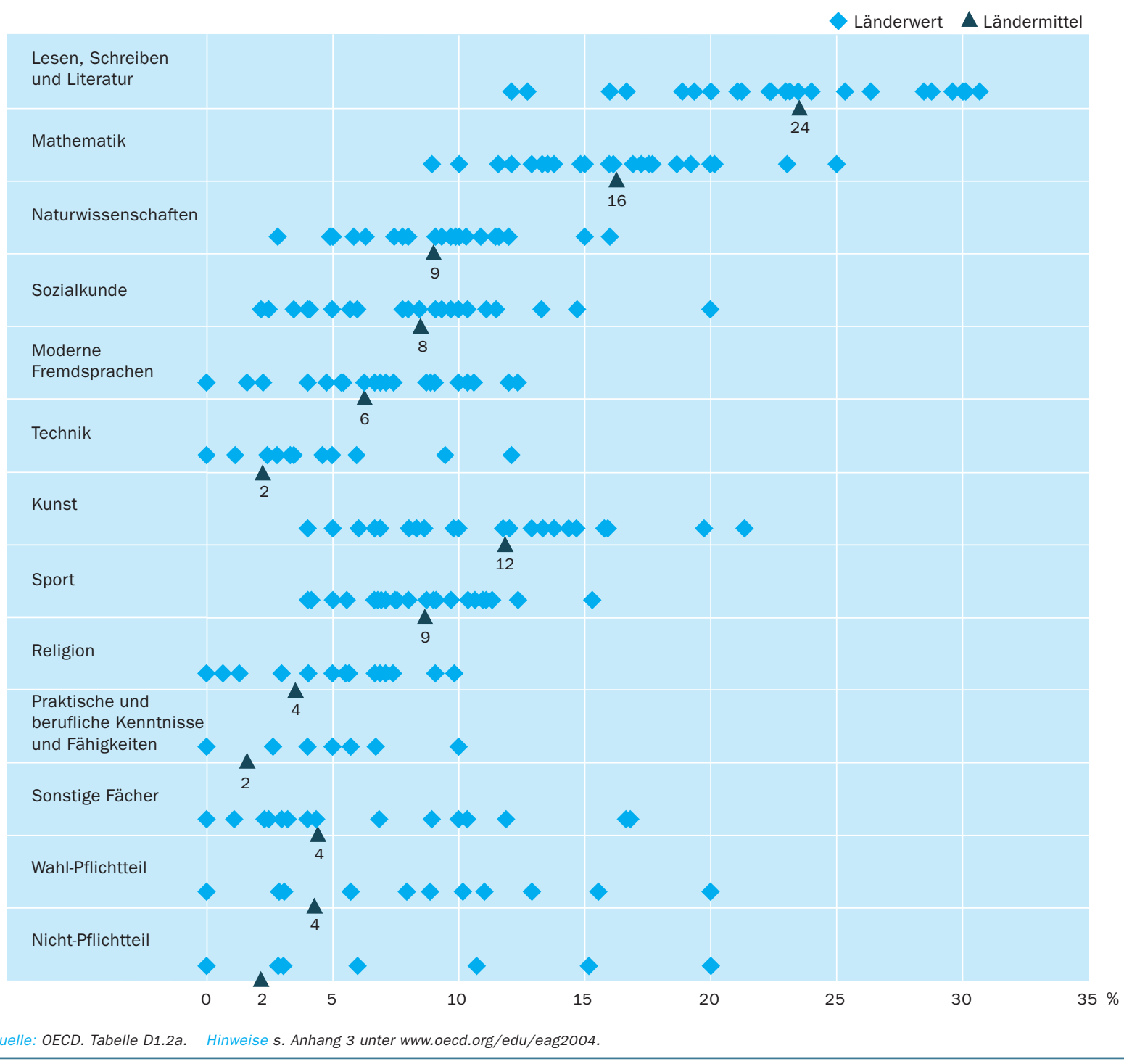


Fremdsprachen (II Prozent) vorgesehen und etwas weniger Zeit für Kunst (8 Prozent). Acht Prozent entfallen auf Sport. Diese sieben Fächergruppen sind in allen OECD-Ländern Teil des Pflichtlehrplans für Schüler des Sekundarbereich I. Technik gehört in etwa der Hälfte der Länder zum Pflichtlehrplan und Religion in mehr als der Hälfte der OECD-Länder (Tabelle Dr.2b und Abb. Di.2b).

Der prozentuale zeitliche Anteil der einzelnen Fächer am Lehrplan unterscheidet sich bei den I2- bis I4-Jährigen weniger stark als bei den 9- bis II- Jährigen. Der größte Unterschied ist wiederum beim Lesen und Schreiben zu beobachten und reicht von Io Prozent in den Niederlanden bis zu 29 Prozent in Irland (Lesen und Schreiben umfasst hier sowohl Englisch als auch Irisch).

\section{Abbildung D1.2b}

Vorgesehene Unterrichtszeit für 12- bis 14-Jährige an öffentlichen Bildungseinrichtungen, nach Fach (2002)

Prozentsatz der gesamten vorgesehenen Unterrichtszeit, die auf die einzelnen Fächer innerhalb des Wahl-Pflichtteils und des Nicht-Pflichtteils des Lehrplans entfällt

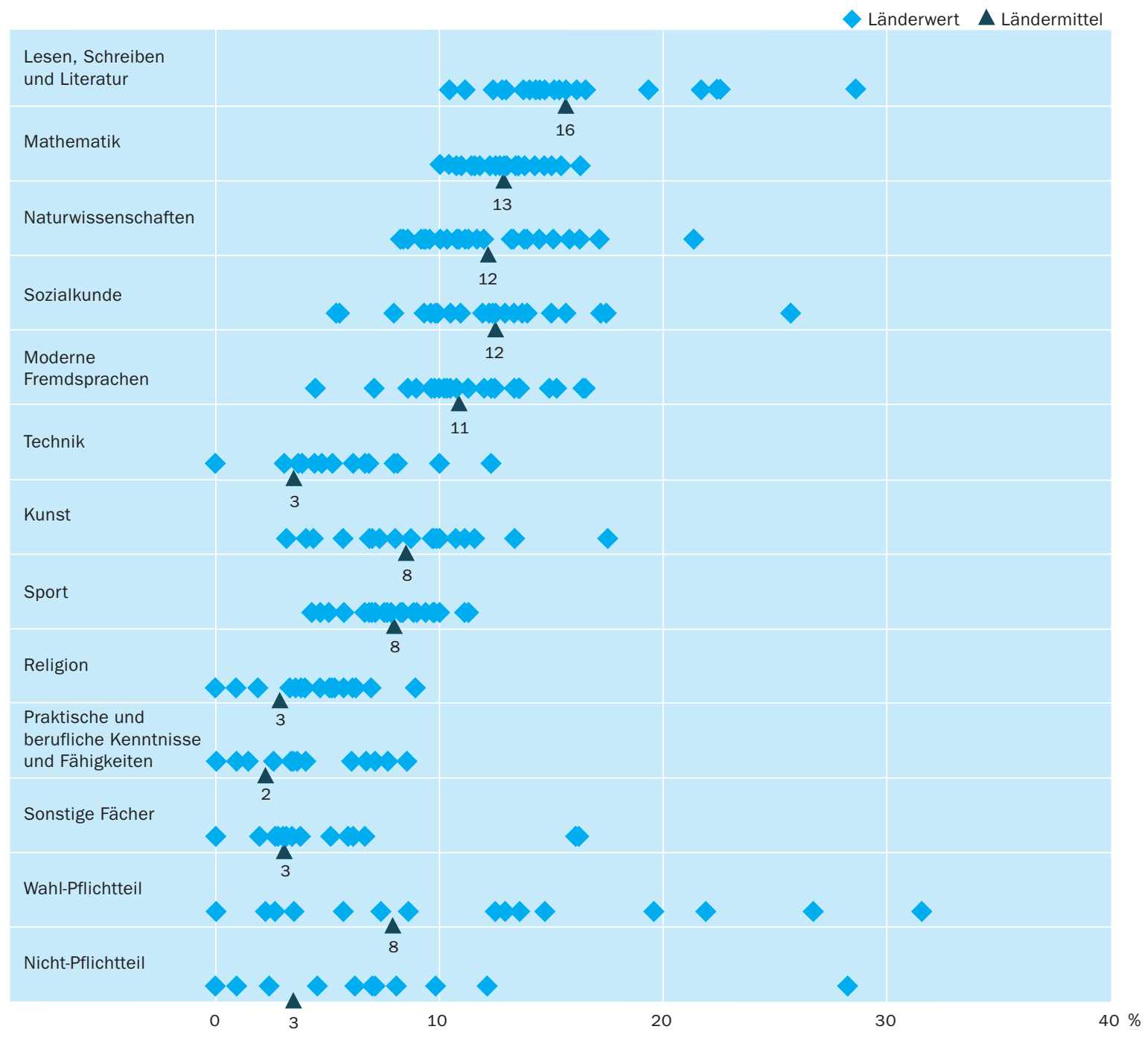


Im Durchschnitt entfallen bei den 9- bis II-Jährigen 2 Prozent der insgesamt vorgesehenen Unterrichtszeit auf den Wahl-Pflichtteil, bei den I2- bis I4-Jährigen sind es 3 Prozent. Aber manchmal wird zusätzlich Nicht-Pflichtunterricht in beträchtlichem Umfang angeboten. Während in den meisten OECDLändern im Primarbereich die gesamte vorgesehene Unterrichtszeit für alle Schüler Pflicht ist, liegt der zusätzliche Nicht-Pflichtteil in der Türkei bei 20 Prozent, in Ungarn bei I5 Prozent und in Belgien (frz.) bei II Prozent. Im Sekundarbereich I gibt es in Australien, Belgien (frz.), England, Finnland, Frankreich, Irland, Spanien, der Slowakischen Republik, der Türkei und Ungarn zusätzlich einen Nicht-Pflichtteil, der von I Prozent in Spanien bis zu 28 Prozent in Ungarn reicht (Tab. Di.2a und Di.2b). Im Durchschnitt entfallen in den Klassen, in denen die Mehrzahl der Schüler 9 bis II Jahre alt ist, 4 Prozent der vorgesehenen Pflicht-Unterrichtszeit auf den Wahl-Pflichtteil, bei den I2- bis I4-Jährigen sind es 8 Prozent.

\section{Der Lehrplan in Irland}

Der Lehrplan für I2- bis I5-jährige Schüler besteht aus Pflicht- und Wahlfächern. Die Pflichtfä̀cher für Schüler des Sekundarbereichs sind Irisch, Englisch, Mathematik, Geschichte, Geographie sowie Staatsbürger- und Sozialkunde und Politikunterricht (civic, social and political education - CSPE). Für Schüler an berufsbildenden Schulen oder an Community Colleges sind Geschichte und Geographie nicht Pflicht. Anstelle dieser beiden Fächer müssen die Schüler eines der folgenden Fächer belegen: technisches Zeichnen, Kunst, Handwerk und Design, Hauswirtschafts- oder Betriebswirtschaftslehre. Die Schüler müssen ebenfalls mindestens zwei weitere Fächer aus der Liste der Wahlfächer wählen, die alle oben genannte Fächer enthält und zusätzlich Latein, Griechisch, Altertumswissenschaften, Hebräische Studien, Spanisch, Italienisch, Französisch, Deutsch, Naturwissenschaften, Technik, Musik, Materialtechnik (Holz), Metallbearbeitung, Schreibmaschinenschreiben, Umwelt- und Sozialkunde sowie Religion. In der Praxis bieten die meisten Schulen eher 3 als 2 Fächer dieser Liste an, und die Schüler belegen auch eher 3 als 2 Fächer. Ab September 2003 müssen alle Schüler dieser Altersgruppe das Fach Ernährung, Gesundheit und Sozialkompetenz (social, personal and health education - SPHE) als Nicht-Prüfungsfach belegen. Sport sollte ebenfalls Teil des Lehrplans sein.

Da die meisten Schüler von dieser Liste Naturwissenschaften und mindestens eine Fremdsprache wählen, wurden diese beiden Fächer als Pflichtfächer in die Daten aufgenommen und das dritte Fach, das Schüler wählen, als Nicht-Pflichtfach.

Es gibt keine Vorschriften über die genaue Zeit, die jedes Jahr auf den Unterricht in den einzelnen Fächer des Lehrplans zu verwenden ist.

In den meisten OECD-Ländern ist die Zahl der Stunden für den Pflichtteil festgelegt. Innerhalb dieses Pflichtteils können die Schüler in unterschiedlich starkem Maße wählen, welche Fächer sie belegen möchten. Bei den 9- bis II-Jährigen bildet jedoch Australien eine Ausnahme, denn hier werden 58 Prozent des
Im Durchschnitt entfallen bei den 9- bis 11-Jährigen 2 Prozent der insgesamt vorgesehenen Unterrichtszeit auf den Nicht-Pflichtteil, bei den 12- bis 14-Jährigen sind es 3 Prozent, wobei es beachtliche Unterschiede zwischen den einzelnen Ländern gibt. 
Die Daten über die Unterrichtszeit stammen aus der OECD/INES-Erhebung $2003 \mathrm{zu}$ Lehrern und Lehrplänen und beziehen sich auf das Schuljahr 2001/2002.
Pflichtunterrichts mit Wahlpflichtfächern abgedeckt. Schottland bietet mit 20 Prozent den zweithöchsten Grad an Flexibilität. Bei den I2- bis I4-Jährigen haben wiederum Australien und Schottland den höchsten Grad an Flexibilität innerhalb des Pflichtteils ( 32 bzw. 27 Prozent), jedoch liegt auch in einigen anderen Ländern (Belgien (frz.), Finnland, Island, Korea, den Niederlanden, Portugal und Spanien) der Anteil der Wahlpflichtfächer im Pflichtteil bei über ro Prozent (Tab. Di.2a und Di.2b).

\section{Definitionen und angewandte Methodik}

Die Unterrichtszeit für 7- bis 15-Jährige bezieht sich auf die formale Anzahl der Zeitstunden pro Schuljahr, die von der Schule für Unterrichtsaktivitäten für Schüler im Referenzschuljahr 2001/2002 organisiert wurden. Für Länder, in denen keine formalen Vorschriften zu der Unterrichtszeit vorliegen, wurde die Zahl der Unterrichtsstunden aufgrund der Erhebungsdaten geschätzt. Stunden, die entfallen, wenn Schulen wegen Feiertagen oder Feierlichkeiten geschlossen sind, werden nicht gezählt. In der vorgesehenen Unterrichtszeit nicht enthalten sind freiwillige Aktivitäten außerhalb der regulären Schulzeit, Einzelförderunterricht, Hausaufgaben, Selbststudium.

Pflichtteil des Lehrplans bezieht sich auf die Anzahl und Aufteilung der Unterrichtsstunden, die fast von jeder Schule zu unterrichten und von fast jedem Schüler zu besuchen sind. Die Erfassung der Zeit, die für bestimmte Fächergruppen (Fächer) vorgesehen ist, konzentriert sich eher auf den kleinsten gemeinsamen Inhalt als auf die durchschnittlich pro Fach aufgewendete Zeit, da die Datenquellen (Richtlinien) keine präziseren Angaben erlauben. Der gesamte Pflichtteil des Lehrplans enthält sowohl den Kern-Pflichtteil als auch den Wahl-Pflichtteil des Lehrplans.

Kern-Pflichtteil des Lehrplans bezieht sich auf die Gruppe von Unterrichtsfächern, die alle Schüler belegen müssen, wie Mathematik, Naturwissenschaften, Sozialkunde, Unterricht in der Landes- bzw. Unterrichtssprache und, in einigen Fällen, eine Fremdsprache. Diese Fächer können als Kernfächer betrachtet werden. Selbst wenn alle Schüler alle Kernfächer abdecken müssen, gibt es doch Wahlmöglichkeiten innerhalb eines Fachbereichs. Beispielsweise kann die Wahl zwischen Naturwissenschaften allgemein oder einzelnen naturwissenschaftlichen Fächern wie Biologie oder Physik möglich sein, oder zwischen verschiedenen Fremdsprachen.

Wahl-Pflichtteil des Lehrplans bezieht sich auf den Teil des Pflicht-Lehrplans, bei dem hinsichtlich der für ein bestimmtes Fach aufzubringenden Zeit und/oder der Auswahl zwischen verschiedenen Fächern eine gewisse Wahlfreiheit besteht. So kann sich beispielsweise eine Schule entscheiden, Religion oder verstärkt Naturwissenschaften oder Kunst zu unterrichten, aber innerhalb des Wahl-Pflichtteil des Lehrplans muss eines der drei Fächer angeboten werden.

Nicht-Pflichtteil des Lehrplans bezieht sich auf die durchschnittliche Unterrichtszeit, auf die Schüler zusätzlich zum Pflichtteil Anspruch haben. Diese 
Fächer variieren oft von Schule zu Schule oder von Region zu Region und können als ,Wahlfächer' angeboten werden.

Vorgesehene Unterrichtszeit bezieht sich auf die Stundenzahl, die Schüler jährlich im Pflicht- und Nicht-Pflichtteil des Lehrplans unterrichtet werden.

Bei den I5-Jährigen bezieht sich die Unterrichtszeit auf typische Bildungsgänge, die die meisten I5-Jährigen besuchen. Das kann ein Bildungsgang im Sekundarbereich I oder II sein; in den meisten Ländern handelt es sich um allgemeinbildende Bildungsgänge. Wenn das betreffende Bildungssystem die Schüler in diesem Alter unterschiedlichen Bildungsgängen zuordnet, wurde in manchen Fällen eine Schätzung der durchschnittlich vorgesehenen Unterrichtszeit für die typischen Bildungsgänge erforderlich, gewichtet nach dem Anteil der Schüler in der Jahrgangsstufe, in der sich die meisten I5-Jährigen befinden. Wenn auch berufsbildende Bildungsgänge mitberechnet wurden, sollte nur der schulische Teil des Bildungsgang in den Berechnungen der durchschnittlichen Unterrichtszeit berücksichtigt sein.

Die Unterrichtszeit für den mindestens zu besuchenden Bildungsgang bezieht sich auf Bildungsgänge, die für Schüler vorgeschrieben sind, die vermutlich nicht über die Zeit der Schulpflicht oder des Sekundarbereich I hinaus weiter zur Schule gehen werden. Solche Bildungsgänge gibt es je nach angewendeter Einteilung in Leistungsgruppen oder Anwendung von Auswahlkriterien möglicherweise nicht in jedem Land. In vielen Ländern erhalten die Schüler in allen oder den meisten Bildungsgängen die gleiche Unterrichtszeit, bei der Auswahl der Fachbereiche oder Fächer gibt es jedoch gewisse Wahlmöglichkeiten. Wenn die Bildungsgänge recht lang sind und sich grundlegend unterscheiden, müssen die entsprechenden Entscheidungen oft frühzeitig getroffen werden.

Zur Klassifizierung der Fächer und Anmerkungen zu den einzelnen Ländern s. Anhang 3 unter www.oecd.org/edu/eag 2004. 


\section{Tabelle D1.1}

Vorgesehene Unterrichtszeit für den Pflicht- und Nicht-Pflichtteil des Lehrplans an öffentlichen Bildungseinrichtungen (2002) Durchschnittliche jährliche Anzahl an Stunden der vorgesehenen Unterrichtszeit für den Pflicht- und Nicht-Pflichtteil des Lehrplans für 7- bis 8-Jährige, 9- bis 11-Jährige, 12-bis 14-Jährige und 15-Jährige

\begin{tabular}{|c|c|c|c|c|c|c|c|c|c|c|c|}
\hline \multirow[b]{2}{*}{ OECD-Länder } & \multirow{2}{*}{$\begin{array}{l}\text { Alters- } \\
\text { spanne, } \\
\text { während der } \\
\text { mehr als } \\
90 \% \text { der } \\
\text { Bevölkerung } \\
\text { an Bildung } \\
\text { teilnehmen }\end{array}$} & \multicolumn{5}{|c|}{$\begin{array}{l}\text { Durchschnittliche jährliche Anzahl an Stunden der } \\
\text { vorgesehenen Unterrichtszeit für den Pflichtteil des Lehrplans }\end{array}$} & \multicolumn{5}{|c|}{$\begin{array}{l}\text { Durchschnittliche jährliche Anzahl an Stunden } \\
\text { der insgesamt vorgesehenen Unterrichtszeit }\end{array}$} \\
\hline & & $7-8 \mathrm{~J}$ & $9-11 \mathrm{~J}$. & $12-14 \mathrm{~J}$. & $\begin{array}{l}15 \mathrm{~J} \text {. } \\
\text { (typischer } \\
\text { Bildungs- } \\
\text { gang) }\end{array}$ & $\begin{array}{l}15 \mathrm{~J} \text {. } \\
\text { (mindes- } \\
\text { tens zu be- } \\
\text { suchender } \\
\text { Bildungs- } \\
\text { gang) }\end{array}$ & $7-8 \mathrm{~J}$ & $9-11 \mathrm{~J}$. & $12-14 \mathrm{~J}$. & $\begin{array}{l}15 \mathrm{~J} . \\
\text { (typischer } \\
\text { Bildungs- } \\
\text { gang) }\end{array}$ & $\begin{array}{l}15 \mathrm{~J} \text {. } \\
\text { (mindes- } \\
\text { tens zu be- } \\
\text { suchender } \\
\text { Bildungs- } \\
\text { gang) }\end{array}$ \\
\hline Australien & $5-16$ & 993 & 994 & 974 & 964 & 964 & 993 & 994 & 1019 & 1021 & 1021 \\
\hline Österreich & $5-16$ & 678 & 833 & 997 & 1095 & 1048 & $\mathrm{~m}$ & $\mathrm{~m}$ & $\mathrm{~m}$ & $\mathrm{~m}$ & $\mathrm{~m}$ \\
\hline Belgien (fläm.) & $3-17$ & $a$ & a & a & a & a & 835 & 835 & 960 & 960 & 450 \\
\hline Belgien (frz.) & $3-17$ & 840 & 840 & 960 & 1020 & $\mathrm{~m}$ & 930 & 930 & 1020 & $\mathrm{~m}$ & $\mathrm{~m}$ \\
\hline Tschechische Rep. & $5-17$ & 645 & 716 & 800 & 881 & 342 & $\mathrm{~m}$ & $\mathrm{~m}$ & $\mathrm{~m}$ & $\mathrm{~m}$ & $\mathrm{~m}$ \\
\hline Dänemark & $4-15$ & 615 & 750 & 800 & 720 & 720 & 615 & 750 & 800 & 720 & 720 \\
\hline England & $4-15$ & 861 & 889 & 870 & 893 & a & 890 & 890 & 940 & 940 & a \\
\hline Finnland & $6-17$ & 530 & 654 & 796 & 858 & a & 530 & 673 & 815 & 858 & a \\
\hline Frankreich & $3-17$ & 829 & 829 & 939 & 1018 & $\mathrm{~m}$ & 829 & 829 & 1031 & 1122 & $\mathrm{~m}$ \\
\hline Deutschland & $6-17$ & 626 & 774 & 877 & 899 & $\mathrm{~m}$ & 626 & 774 & 877 & 899 & $\mathrm{~m}$ \\
\hline Griechenland & $6-16$ & 864 & 928 & 1064 & 1216 & 1034 & 864 & 928 & 1064 & 1459 & 1277 \\
\hline Ungarn & $5-16$ & 555 & 670 & 722 & 832 & 833 & 611 & 772 & 925 & 1206 & 1207 \\
\hline Island & $3-16$ & 700 & 778 & 848 & 863 & a & 700 & 778 & 848 & 863 & a \\
\hline Irland & $5-16$ & 915 & 915 & 839 & 802 & 713 & 915 & 915 & 899 & 891 & 891 \\
\hline Italien ${ }^{1}$ & $3-15$ & 969 & 1020 & 1020 & $\mathrm{~m}$ & $\mathrm{~m}$ & 969 & 1020 & 1020 & $\mathrm{~m}$ & $\mathrm{~m}$ \\
\hline Japan & $4-17$ & 709 & 761 & 875 & $\mathrm{~m}$ & a & 709 & 761 & 875 & $\mathrm{~m}$ & a \\
\hline Korea & $6-17$ & 612 & 703 & 867 & 1020 & a & 612 & 703 & 867 & 1020 & a \\
\hline Mexiko & $6-12$ & 800 & 800 & 1167 & 1058 & a & 800 & 800 & 1167 & 1124 & a \\
\hline Niederlande & $4-16$ & $\mathrm{~m}$ & 1000 & 1067 & $\mathrm{~m}$ & a & $\mathrm{m}$ & 1000 & 1067 & $\mathrm{~m}$ & a \\
\hline Neuseeland & $4-15$ & $\mathrm{~m}$ & $\mathrm{~m}$ & $\mathrm{~m}$ & $\mathrm{~m}$ & $\mathrm{~m}$ & 985 & 985 & 962 & 950 & 950 \\
\hline Norwegen & $6-17$ & 570 & 703 & 827 & 855 & a & 570 & 703 & 827 & 855 & a \\
\hline Portugal & $5-15$ & 870 & 865 & 899 & 827 & 1233 & 870 & 882 & 899 & 827 & 1233 \\
\hline Schottland & $4-15$ & 1000 & 1000 & 1000 & 1000 & a & 1000 & 1000 & 1000 & 1000 & a \\
\hline Slowakische Rep. & $6-16$ & 616 & 716 & 821 & 831 & a & 659 & 759 & 879 & 888 & a \\
\hline Spanien & $3-16$ & 792 & 792 & 936 & 963 & 969 & 792 & 792 & 944 & 969 & 969 \\
\hline Schweden & $6-18$ & 741 & 741 & 741 & 741 & a & 741 & 741 & 741 & 741 & a \\
\hline Schweiz & $6-16$ & $\mathrm{~m}$ & $\mathrm{~m}$ & $\mathrm{~m}$ & $\mathrm{~m}$ & $\mathrm{~m}$ & $\mathrm{~m}$ & $\mathrm{~m}$ & $\mathrm{~m}$ & $\mathrm{~m}$ & $\mathrm{~m}$ \\
\hline Türkei & $7-12$ & 720 & 720 & 791 & 959 & a & 864 & 864 & 887 & 959 & a \\
\hline Vereinigte Staaten & $5-15$ & $\mathrm{~m}$ & $\mathrm{~m}$ & $\mathrm{~m}$ & $\mathrm{~m}$ & $\mathrm{~m}$ & $\mathrm{~m}$ & $\mathrm{~m}$ & $\mathrm{~m}$ & $\mathrm{~m}$ & $\mathrm{~m}$ \\
\hline Ländermittel & & 752 & 816 & 900 & 923 & 873 & 788 & 843 & 933 & 965 & 969 \\
\hline
\end{tabular}

1. Referenzjahr 2001. Spalte 12-14 J. enthält nur 12- bis 13-Jährige.

Quelle: OECD. Hinweise s. Anhang 3 unter www.oecd.org/edu/eag2004. 
Tabelle D1.2a

Unterrichtszeit pro Fach in Prozent der insgesamt vorgesehenen Unterrichtszeit für den Pflichtteil des Lehrplans für 9- bis 11-Jährige (2002)

Unterrichtszeit für einzelne Fächer in Prozent der insgesamt vorgesehenen Unterrichtszeit für den Pflichtteil des Lehrplans

\begin{tabular}{|c|c|c|c|c|c|c|c|c|c|c|c|c|c|c|c|}
\hline & \multicolumn{12}{|c|}{ Kern-Pflichtteil des Lehrplans } & \multirow{2}{*}{$\begin{array}{l}\text { Wahl- } \\
\text { Pflicht- } \\
\text { teil }\end{array}$} & \multirow{2}{*}{$\begin{array}{l}\text { Pflicht- } \\
\text { teil ins- } \\
\text { gesamt }\end{array}$} & \multirow{2}{*}{$\begin{array}{l}\text { Nicht- } \\
\text { Pflicht- } \\
\text { teil }\end{array}$} \\
\hline & $\begin{array}{l}\text { Lesen, } \\
\text { Schrei- } \\
\text { ben und } \\
\text { Literatur }\end{array}$ & $\begin{array}{l}\text { Mathe- } \\
\text { matik }\end{array}$ & $\begin{array}{l}\text { Natur- } \\
\text { wissen- } \\
\text { schaften }\end{array}$ & $\begin{array}{l}\text { Sozial- } \\
\text { kunde }\end{array}$ & $\begin{array}{c}\text { Moderne } \\
\text { Fremd- } \\
\text { sprachen }\end{array}$ & Technik & Kunst & Sport & Religion & $\begin{array}{l}\text { Prakti- } \\
\text { sche u. } \\
\text { berufliche } \\
\text { Kennt- } \\
\text { nisse und } \\
\text { Fähig- } \\
\text { keiten }\end{array}$ & $\begin{array}{c}\text { Sonstige } \\
\text { Fächer } \\
\\
\end{array}$ & $\begin{array}{l}\text { Kern- } \\
\text { Pflicht- } \\
\text { teil ins- } \\
\text { gesamt }\end{array}$ & & & \\
\hline OECD-Länder & (1) & (2) & (3) & (4) & (5) & (6) & (7) & (8) & (9) & (10) & (11) & (12) & (13) & (14) & (15) \\
\hline Australien ${ }^{1}$ & 13 & 9 & 3 & 3 & 2 & 3 & 4 & 4 & 1 & $\mathrm{n}$ & $\mathrm{n}$ & 42 & 58 & 100 & $\mathrm{n}$ \\
\hline Österreich & 23 & 15 & 10 & 2 & 7 & $\mathrm{n}$ & 20 & 12 & 7 & $x(12)$ & 2 & 100 & $x(12)$ & 100 & $\mathrm{~m}$ \\
\hline Belgien (fläm.) & a & a & a & a & a & a & a & a & a & a & a & a & a & a & a \\
\hline Belgien (frz.) ${ }^{1}$ & $\mathrm{x}(11)$ & $x(11)$ & $x(11)$ & $\mathrm{x}(11)$ & 5 & $x(11)$ & $x(11)$ & 7 & 7 & $x(11)$ & 81 & 100 & $\mathrm{~m}$ & 100 & 11 \\
\hline Tschechische Rep. ${ }^{2}$ & 24 & 19 & 16 & 4 & 12 & $n$ & 15 & 8 & $n$ & 3 & $\mathrm{n}$ & 100 & $\mathrm{n}$ & 100 & $\mathrm{~m}$ \\
\hline Dänemark & 25 & 16 & 8 & 4 & 7 & $\mathrm{n}$ & 21 & 11 & 4 & $\mathrm{n}$ & 4 & 100 & $\mathrm{n}$ & 100 & $\mathrm{n}$ \\
\hline England & 28 & 23 & 10 & 8 & $\mathrm{n}$ & 9 & 9 & 7 & 5 & $\mathrm{n}$ & $\mathrm{n}$ & 100 & $\mathrm{n}$ & 100 & $\mathrm{n}$ \\
\hline Finnland & 23 & 16 & 11 & 2 & 9 & $\mathrm{n}$ & 14 & 9 & 6 & $\mathrm{n}$ & $n$ & 90 & 10 & 100 & 3 \\
\hline Frankreich & 28 & 20 & 5 & 10 & 9 & 3 & 8 & 15 & $\mathrm{n}$ & $\mathrm{n}$ & $\mathrm{n}$ & 100 & $\mathrm{n}$ & 100 & $\mathrm{n}$ \\
\hline Deutschland & 21 & 18 & 6 & 6 & 7 & 1 & 16 & 11 & 7 & $\mathrm{n}$ & 4 & 97 & 3 & 100 & $\mathrm{n}$ \\
\hline Griechenland & 29 & 14 & 11 & 11 & 10 & $\mathrm{n}$ & 8 & 7 & 7 & $\mathrm{n}$ & 2 & 100 & $\mathrm{n}$ & 100 & $\mathrm{n}$ \\
\hline Ungarn & 26 & 18 & 6 & 6 & 7 & $\mathrm{n}$ & 13 & 11 & $\mathrm{n}$ & 6 & 7 & 100 & $\mathrm{n}$ & 100 & 15 \\
\hline Island & 16 & 15 & 8 & 8 & 4 & 6 & 12 & 9 & 3 & 5 & 3 & 89 & 11 & 100 & $\mathrm{n}$ \\
\hline Irland & 30 & 12 & 12 & 4 & $\mathrm{n}$ & $\mathrm{n}$ & 12 & 4 & 10 & $\mathrm{n}$ & 17 & 100 & $\mathrm{n}$ & 100 & $\mathrm{n}$ \\
\hline Italien & 17 & 10 & 8 & 11 & 10 & 3 & 13 & 7 & 6 & $\mathrm{n}$ & $\mathrm{n}$ & 84 & 16 & 100 & $\mathrm{n}$ \\
\hline Japan & 23 & 17 & 10 & 10 & $n$ & 5 & 14 & 10 & $\mathrm{n}$ & $n$ & 10 & 100 & $n$ & 100 & $\mathrm{n}$ \\
\hline Korea & 19 & 13 & 10 & 10 & 5 & $\mathrm{n}$ & 13 & 10 & $\mathrm{n}$ & 4 & 3 & 87 & 13 & 100 & $\mathrm{n}$ \\
\hline Mexiko & 30 & 25 & 15 & 20 & $\mathrm{n}$ & $\mathrm{n}$ & 5 & 5 & $\mathrm{n}$ & $\mathrm{n}$ & $\mathrm{n}$ & 100 & $\mathrm{n}$ & 100 & $\mathrm{n}$ \\
\hline Niederlande $^{3}$ & 30 & 19 & $x(4)$ & 15 & 2 & 2 & 10 & 7 & 4 & $n$ & 12 & 100 & $n$ & 100 & $n$ \\
\hline Neuseeland & $\mathrm{m}$ & $\mathrm{m}$ & $\mathrm{m}$ & $\mathrm{m}$ & $\mathrm{m}$ & $\mathrm{m}$ & $\mathrm{m}$ & $\mathrm{m}$ & $\mathrm{m}$ & $\mathrm{m}$ & $\mathrm{m}$ & $\mathrm{m}$ & $\mathrm{m}$ & $\mathrm{m}$ & $\mathrm{m}$ \\
\hline Norwegen & 22 & 15 & 7 & 8 & 6 & $\mathrm{n}$ & 16 & 7 & 9 & $\mathrm{n}$ & 9 & 100 & $\mathrm{n}$ & 100 & $\mathrm{n}$ \\
\hline Portugal $^{4}$ & 12 & 12 & 9 & 9 & 11 & 12 & 6 & 9 & $n$ & $\mathrm{n}$ & 17 & 97 & 3 & 100 & 3 \\
\hline Schottland & 20 & 15 & 5 & 5 & $x(1)$ & 5 & 10 & 5 & 5 & $x(13)$ & 10 & 80 & 20 & 100 & $\mathrm{n}$ \\
\hline Slowakische Rep. & 31 & 20 & 8 & 8 & 5 & $\mathrm{n}$ & 12 & 11 & 1 & 4 & $\mathrm{n}$ & 100 & $\mathrm{n}$ & 100 & 6 \\
\hline Spanien & 21 & 17 & 9 & 9 & 12 & $n$ & 12 & 11 & $\mathrm{x}(13)$ & $n$ & $\mathrm{n}$ & 92 & 8 & 100 & $\mathrm{n}$ \\
\hline Schweden & 22 & 14 & 12 & 13 & 12 & $x(3)$ & 7 & 8 & $x(4)$ & 7 & $\mathrm{n}$ & 94 & 6 & 100 & $\mathrm{n}$ \\
\hline Schweiz & $\mathrm{m}$ & $\mathrm{m}$ & $\mathrm{m}$ & $\mathrm{m}$ & $\mathrm{m}$ & $\mathrm{m}$ & $\mathrm{m}$ & $\mathrm{m}$ & $\mathrm{m}$ & $\mathrm{m}$ & $\mathrm{m}$ & $\mathrm{m}$ & $\mathrm{m}$ & $\mathrm{m}$ & $\mathrm{m}$ \\
\hline Türkei & 19 & 13 & 10 & 10 & 9 & $\mathrm{n}$ & 7 & 6 & 7 & 10 & 1 & 91 & 9 & 100 & 20 \\
\hline Vereinigte Staaten & $\mathrm{m}$ & $\mathrm{m}$ & $\mathrm{m}$ & $\mathrm{m}$ & $\mathrm{m}$ & $\mathrm{m}$ & $\mathrm{m}$ & $\mathrm{m}$ & $\mathrm{m}$ & $\mathrm{m}$ & $\mathrm{m}$ & $\mathrm{m}$ & $\mathrm{m}$ & $\mathrm{m}$ & $\mathrm{m}$ \\
\hline Ländermittel $^{1}$ & 24 & 16 & 9 & 8 & 6 & 2 & 12 & 9 & 4 & 2 & 4 & 96 & 4 & 100 & 2 \\
\hline OECD-Partnerländer & & & & & & & & & & & & & & & \\
\hline Argentinien $^{5}$ & 19 & 19 & 15 & 15 & 7 & 4 & 7 & 7 & a & a & $n$ & 93 & 7 & 100 & $\mathrm{~m}$ \\
\hline Chile & $\mathrm{m}$ & $\mathrm{m}$ & $\mathrm{m}$ & $\mathrm{m}$ & $\mathrm{m}$ & $\mathrm{m}$ & $\mathrm{m}$ & $\mathrm{m}$ & $\mathrm{m}$ & $\mathrm{m}$ & $\mathrm{m}$ & 75 & 25 & 100 & $\mathrm{~m}$ \\
\hline Ägypten & 30 & 15 & 9 & 6 & 9 & 2 & 5 & 7 & 7 & 5 & 5 & 100 & a & 100 & $\mathrm{~m}$ \\
\hline Indien & 19 & 17 & 12 & 12 & 19 & a & 4 & 12 & a & a & a & 96 & 4 & 100 & $\mathrm{~m}$ \\
\hline Indonesien & 22 & 22 & 13 & 11 & a & a & 5 & 5 & 5 & 13 & 5 & 100 & a & 100 & $\mathrm{~m}$ \\
\hline Jordanien & 23 & 15 & 12 & 8 & 15 & a & 3 & a & 9 & 5 & 9 & 100 & a & 100 & $\mathrm{~m}$ \\
\hline Malaysia $^{5}$ & 21 & 15 & 11 & 9 & 15 & $\mathrm{n}$ & 4 & 4 & 13 & 4 & 4 & 100 & a & 100 & $\mathrm{~m}$ \\
\hline Paraguay 5 & 26 & 13 & 8 & 10 & $x(1)$ & 7 & 10 & 7 & 3 & $x(7)$ & 10 & 93 & 7 & 100 & $\mathrm{~m}$ \\
\hline Peru ${ }^{5}$ & 14 & 14 & 12 & 23 & 6 & a & 6 & 6 & 6 & 7 & $n$ & 93 & 7 & 100 & $\mathrm{~m}$ \\
\hline Philippinen & 13 & 13 & 13 & 13 & 13 & a & 8 & 4 & a & 13 & 13 & 100 & a & 100 & $\mathrm{~m}$ \\
\hline Russische Föd. & 31 & 15 & 4 & 9 & 6 & 6 & 6 & 6 & a & $\mathrm{m}$ & $\mathrm{m}$ & 85 & 15 & 100 & $\mathrm{~m}$ \\
\hline Sri Lanka & 13 & 20 & 20 & 10 & 13 & 5 & 5 & 5 & 5 & 5 & $\mathrm{n}$ & 100 & $\mathrm{n}$ & 100 & $\mathrm{~m}$ \\
\hline Thailand & 14 & 10 & $\mathrm{~m}$ & $\mathrm{~m}$ & $\mathrm{~m}$ & $\mathrm{~m}$ & $\mathrm{~m}$ & $\mathrm{~m}$ & $\mathrm{~m}$ & 23 & 39 & 86 & 14 & 100 & $\mathrm{~m}$ \\
\hline Tunesien & 27 & 13 & 5 & 2 & 35 & 2 & 4 & 3 & 4 & $\mathrm{n}$ & 5 & 100 & $\mathrm{n}$ & 100 & $\mathrm{~m}$ \\
\hline Uruguay 5 & 24 & 23 & 12 & 17 & a & a & 8 & 3 & a & a & a & 86 & 14 & 100 & $\mathrm{~m}$ \\
\hline Simbabwe & 19 & 13 & 8 & 8 & 17 & 8 & 4 & 4 & 8 & 8 & $\mathrm{n}$ & 100 & $\mathrm{n}$ & 100 & $\mathrm{~m}$ \\
\hline
\end{tabular}

Hinweis: $x$ bedeutet, dass die Daten in einer anderen Spalte enthalten sind, deren Referenz in runden Klammern nach dem , $x$ ‘ angegeben ist. So bedeutet z. B. $x(2)$, dass die Daten in Spalte 2 enthalten sind.

1. Australien und Belgien (frz.) im Ländermittel nicht enthalten. 2. Bei den 9- bis 10-Jährigen Sozialkunde in Naturwissenschaften enthalten. 3. Nur 9- und 11-Jährige.

4. Nur 10- und 11-Jährige. 5. Referenzjahr 2001.

Quelle: OECD. Hinweise s. Anhang 3 unter www.oecd.org/edu/eag2004. 
Tabelle D1.2b

Unterrichtszeit pro Fach in Prozent der insgesamt vorgesehenen Unterrichtszeit für den Pflichtteil des Lehrplans für 12- bis 14-Jährige (2002)

Unterrichtszeit für einzelne Fächer in Prozent der insgesamt vorgesehenen Unterrichtszeit für den Pflichtteil des Lehrplans

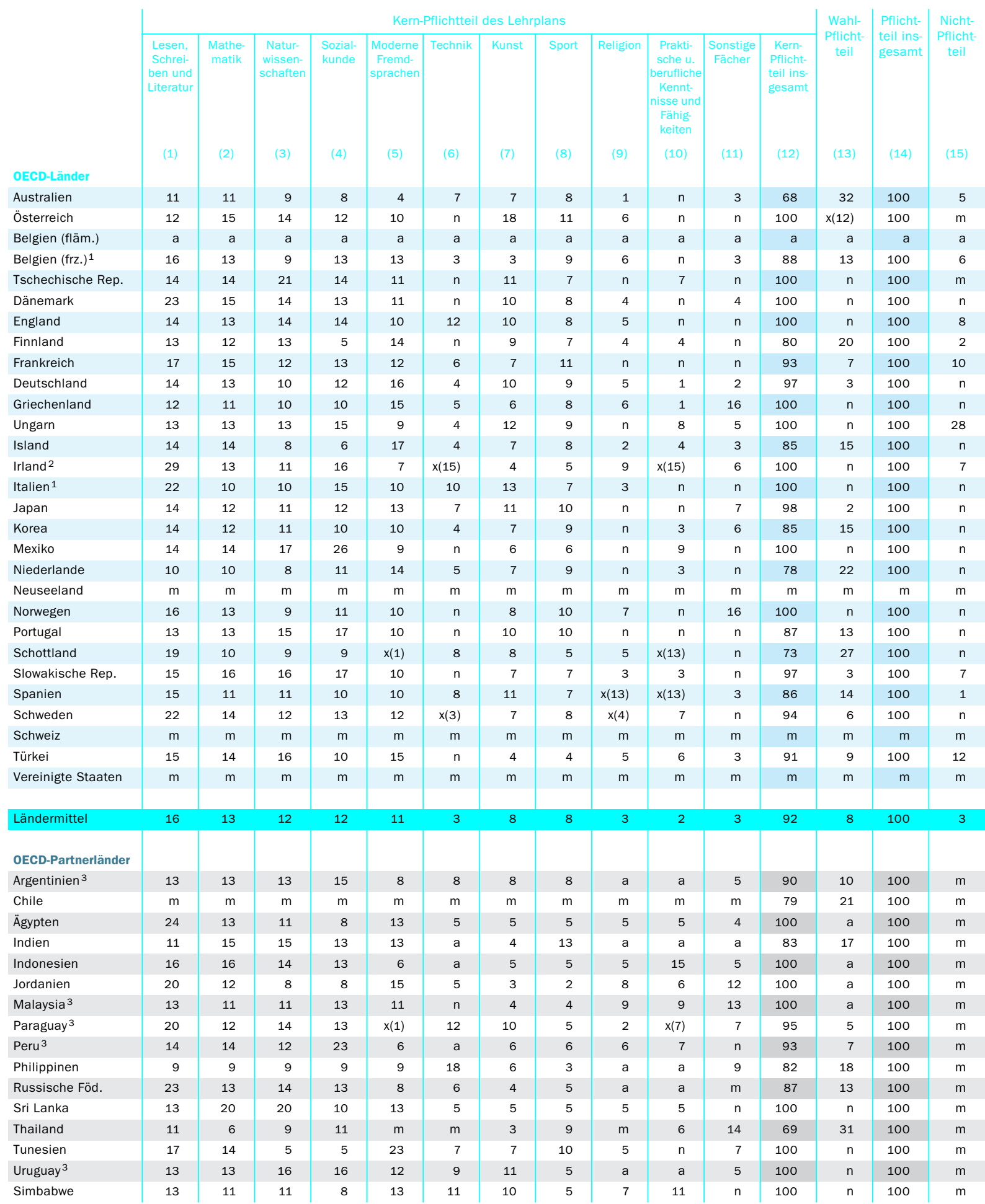

Hinweis: $x$ bedeutet, dass die Daten in einer anderen Spalte enthalten sind, deren Referenz in runden Klammern nach dem , $x$ ‘ angegeben ist. So bedeutet $z . B$. $x(2)$, dass die Daten in Spalte 2 enthalten sind.

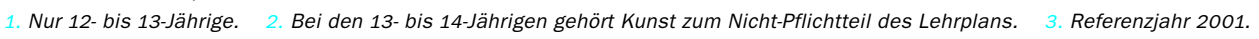

Quelle: OECD. Hinweise s. Anhang 3 unter www.oecd.org/edu/eag2004. 


\section{Klassengrößen und zahlenmäßiges Schüler/ Lehrkräfte-Verhältnis}

Die durchschnittliche Klassengröße liegt im Primarbereich bei 22 Schülern, sie reicht jedoch von $\mathbf{3 6}$ Schülern pro Klasse in Korea bis zu weniger als 18 Schülern in Griechenland, Island und Luxemburg.

Die Zahl der Schüler pro Klasse nimmt vom Primar- zum Sekundarbereich I im Durchschnitt um 2 Schüler zu, aufgrund der höheren Unterrichtsstundenzahl pro Jahr nimmt das zahlenmäßige Schüler/Lehrkräfte-Verhältnis jedoch eher ab, je höher der Bildungsbereich ist.

Die Zahl der unterrichtenden und nicht-unterrichtenden Beschäftigten im Primar- und Sekundarbereich reicht von weniger als 81 Beschäftigten pro 1.000 Schülern in Japan, Korea und Mexiko bis zu 119 Beschäftigten und mehr pro 1.000 Schülern in Frankreich, Island, Italien, Ungarn und den Vereinigten Staaten.

\section{Abbildung D2.1.}

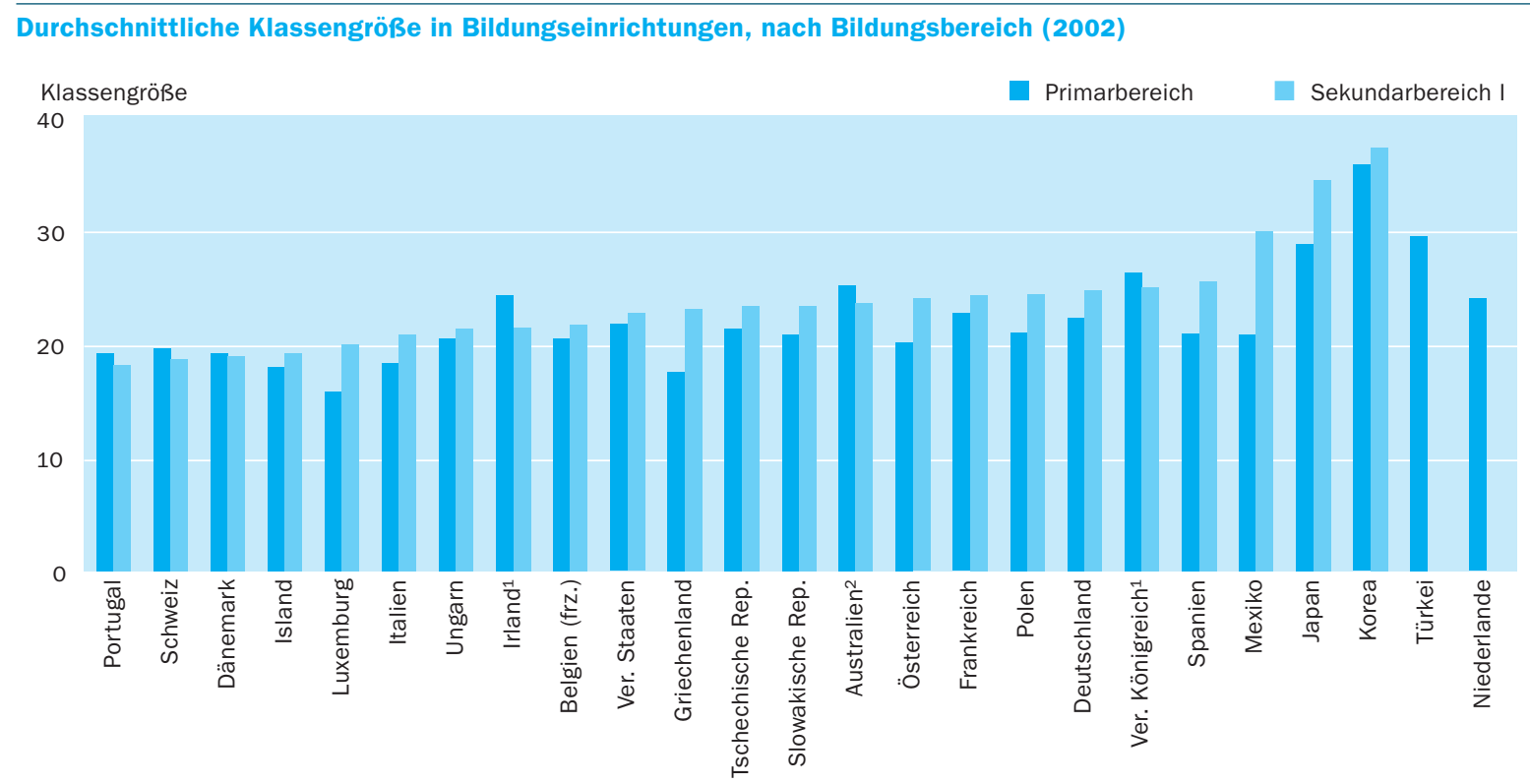




\section{Politischer Hintergrund}

Dieser Indikator gibt Auskunft über Klassengrößen, ...
In vielen OECD-Ländern gibt es intensive Diskussionen über die optimale Klassengröße. Kleinere Klassen werden geschätzt, weil sich dort die Lehrkraft mehr dem einzelnen Schüler widmen kann und sich der mit größeren Klassen verbundene Nachteil, nämlich viele Schüler und deren Arbeit im Auge haben zu müssen, reduziert. Gleichzeitig sind jedoch die Kosten für die Lehrkräfte der größte Einzelposten bei den Bildungsausgaben, so dass eine Verringerung der Klassengröße zu einem starken Anstieg der Bildungskosten führt. Außerdem können kleinere Klassen die Eltern bei der Auswahl der Schule beeinflussen. In dieser Hinsicht gilt die Klassengröße als ein mögliches Kriterium zur Beurteilung der Qualität eines Schulsystems.

Die Qualität der Schule wird auch durch andere Faktoren beeinflusst, u.a. die Zahl der Klassen oder Schüler, für die ein Lehrer verantwortlich ist, das Fächerspektrum, die Zeitaufteilung der Lehrer zwischen Unterricht und anderen Aufgaben, die Zusammenstellung der Klassen und die Praxis des Teamunterrichts. Die Zahl der Schüler pro Klasse umfasst unterschiedliche Qualitätsfaktoren, eine Unterscheidung dieser Faktoren würde es jedoch erlauben, die Qualitätsunterschiede zwischen den Bildungssystemen der einzelnen Ländern herauszuarbeiten (Kasten D2.I).

Kasten D2.1

\section{Zusammenhang zwischen Klassengröße und zahlenmäßigem Schüler/Lehrkräfte-Verhältnis}

Die Zahl der Schüler pro Klasse hängt von verschiedenen Faktoren ab: der Zahl der Schüler im Vergleich zur Zahl der Lehrer, der Zahl der Klassen oder Schüler, für die ein Lehrer verantwortlich ist, der Unterrichtszeit der Schüler im Vergleich zur Länge des Arbeitstags der Lehrkräfte, dem Anteil der Zeit, die Lehrer unterrichten, der Zusammenstellung der Klassen und der Praxis des Teamunterrichts. Der erste Faktor lässt sich ausdrücken als das Verhältnis der Zahl der Schüler zur Zahl der Lehrer, d.h. als zahlenmäßiges Schüler/Lehrkräfte-Verhältnis (gemessen in Vollzeit-Äquivalenten).

In einer Schule mit 48 Vollzeitschülern und 8 Vollzeitlehrkräften ist zum Beispiel das zahlenmäßige Schüler/Lehrkräfte-Verhältnis 6. Wenn man annimmt, dass Lehrkräfte eine 35-Stundenwoche haben, wovon Io Stunden auf Unterricht entfallen, und wenn die Unterrichtszeit für jeden Schüler bei 40 Stunden pro Woche liegt, dann lässt sich die durchschnittliche Klassengröße unabhängig von der Klassenzusammenstellung der Schüler wie folgt berechnen:

Geschätzte Klassengröße $=6$ Schüler pro Lehrer * (40 Unterrichtsstunden pro Schüler / Io Unterrichtsstunden pro Lehrer ) $=24$ Schüler.

Im Vergleich zu dieser errechneten Zahl ist die in Tabelle D2.I dargestellte Klassengröße definiert als der Teil der Schüler in einem allgemeinen Kurs, 
basierend auf der höchsten Zahl der allgemeinen Kurse (normalerweise Pflichtkurse), ohne Unterricht in Kleingruppen. Daher wird die errechnete Klassengröße der durchschnittlichen Klassengröße in Tabelle D2.I dort ziemlich nahe kommen, wo Unterricht in Kleingruppen weniger häufig vorkommt (was im Primar- und Sekundarbereich I der Fall ist).

Aufgrund dieser Definitionen kann ein ähnliches zahlenmäßiges Schüler/Lehrer-Verhältnis in verschiedenen Ländern zu unterschiedlichen Klassengrößen führen. Im Primarbereich haben Japan und die Slowakische Republik beispielsweise das gleiche zahlenmäßige Schüler/Lehrer-Verhältnis (20,3 und 20,I) und doch ist die Klassengröße in Japan deutlich höher als in der Slowakischen Republik (28,8 im Gegensatz zu 20,8 - s. Tab. D2.I). Selbst angenommen, dass die Erfassungsbereiche der Indikatoren sich leicht unterscheiden, liegt die Erklärung hierfür darin, dass die Lehrkräfte in Japan einen geringeren Teil ihrer Arbeitszeit auf den Unterricht verwenden als die in der Slowakischen Republik - in Japan verwenden die Lehrer 31,8 Prozent ihrer Arbeitszeit auf den Unterricht, in der Slowakischen Republik 47,9 Prozent (s. Indikator D4).

Die Bestimmung des zahlenmäßigen Schüler/Lehrkräfte-Verhältnisses soll eine Bewertung der Qualität des Bildungssystems ermöglichen, ausgehend von der Annahme, dass ein geringeres zahlenmäßiges Schüler/Lehrkräfte-Verhältnis bedeutet, dass Schüler besseren Zugang zu den Lehrkräften haben. Dieses Verhältnis wird errechnet, indem (gemessen in Vollzeit-Äquivalenten) die Zahl der Schüler eines bestimmten Bildungsbereichs durch die Zahl der ,Lehrkräfte‘ des gleichen Bildungsbereichs und ähnlicher Bildungseinrichtungen dividiert wird. Dieses Verhältnis berücksichtigt jedoch weder die Unterrichtszeit im Verhältnis zur Länge des Arbeitstages einer Lehrkraft noch wie viel Zeit eine Lehrkraft auf das Unterrichten verwendet und kann daher nicht als Klassengröße interpretiert werden.

Das zahlenmäßige Schüler/Lehrer-Verhältnis ist auch ein wichtiger Indikator für die Ressourcen, die für die (Aus-)Bildung eingesetzt werden. Es mag jedoch abzuwägen sein zwischen einem geringeren zahlenmäßigen Schüler/ Lehrkräfte-Verhältnis und höheren Gehältern für die Lehrer, höheren Investitionen in Unterrichtstechnologien oder dem verstärkten Einsatz von Hilfslehrkräften und anderen Hilfskräften, deren Gehalt oft deutlich unter dem qualifizierter Lehrer liegt. Da außerdem zunehmend mehr Kinder mit speziellem Bildungsbedarf in Regelklassen integriert werden, könnte der verstärkte Einsatz von Fachpersonal und Unterstützungsdiensten die für eine Reduzierung des Schüler/Lehrkräfte-Verhältnisses erforderlichen Ressourcen einschränken.

Die Zahl der unterrichtenden und nicht-unterrichtenden Beschäftigten im Bildungswesen pro I.000 Schüler ist ein Maßstab für den Anteil der Humanressourcen eines Landes, der für die (Aus-)Bildung der Bevölkerung eingesetzt wird. Sowohl die Zahl der Menschen, die entweder als Lehrer oder als pädagogisches Unterstützungspersonal beschäftigt sind, als auch die Höhe der Arbeitsentgelte des Lehrpersonals (Indikator $\mathrm{D}_{3}$ ) sind wichtige Faktoren, die die finanziellen Ressourcen beeinflussen, die Länder für die Bildung aufwenden.
... das zahlenmäßige Schüler/ Lehrkräfte-Verhältnis ...

... und den Anteil der unterrichtenden und nicht-unterrichtenden Beschäftigten im Bildungswesen. 
Die durchschnittliche Klassengröße liegt im Primarbereich bei 22 Schülern, sie reicht jedoch von 36 Schülern pro Klasse bis zu weniger als der Hälfte hiervon.

Vom Primar- zum Sekundarbereich I steigt die Zahl der Schüler pro Klasse durchschnittlich um 2 Schüler an.

In Polen, der Tschechischen Republik und der Türkei sind die Klassen an öffentlichen Schulen im Primarbereich um mindestens 4 Schüler größer als an privaten Bildungseinrichtungen.

In Korea, Mexiko und der Türkei ist das zahlenmäßige Schüler/Lehrkräfte-Verhältnis im Primarbereich etwa dreimal so hoch wie in Italien und Ungarn.

\section{Ergebnisse und Erläuterungen}

\section{Durchschnittliche Klassengröße im Primar- und Sekundarbereich I} Im Primarbereich beträgt im Durchschnitt der OECD-Länder die Klassengröße 22 Schüler pro Klasse, dieser Wert ist jedoch in den einzelnen Ländern sehr unterschiedlich. Er reicht von 36 Schülern pro Primarklasse in Korea bis zu weniger als 20 in Dänemark, Griechenland, Island, Italien, Luxemburg, Portugal und der Schweiz. Im Sekundarbereich I beträgt die durchschnittliche Klassengröße in den OECD-Ländern 24 Schüler pro Klasse und reicht von 37 Schülern pro Klasse in Korea bis zu weniger als 20 Schülern in Dänemark, Island, Luxemburg, Portugal und der Schweiz (Tab. D2.I).

Vom Primar- zum Sekundarbereich I steigt die Zahl der Schüler pro Klasse im Durchschnitt um 2 Schüler an. In Griechenland, Japan, Luxemburg, Mexiko und Spanien steigt die durchschnittliche Klassengröße um mehr als 4 Schüler an, während in Australien, Dänemark, Irland, Portugal und der Schweiz die Zahl der Schüler pro Klasse zwischen diesen beiden Bildungsbereichen zurückgeht (Abb. D2.I). Dieser Indikator zur Klassengröße ist auf den Primar- und Sekundarbereich I beschränkt, da es in den höheren Bildungsbereichen schwierig ist, die Klassengröße zu definieren und zu vergleichen, denn oft bilden die Schüler hier je nach Fach immer neu zusammengesetzte Unterrichtsgruppen.

Im Primarbereich unterscheiden sich die Klassengrößen in öffentlichen Schulen und privaten Bildungseinrichtungen innerhalb einzelner Länder sehr stark, es ergibt sich jedoch kein einheitliches Bild. In Polen, der Tschechischen Republik und der Türkei sind die Klassen im Primarbereich an öffentlichen Schulen durchschnittlich um mindestens 4 Schüler größer als an privaten Bildungseinrichtungen, dagegen ist in Griechenland, Japan, Portugal und Spanien das Gegenteil der Fall. Im Sekundarbereich I sind die Unterschiede tendenziell geringer, hier gibt es mehr private Bildungseinrichtungen und auch hier ist das Bild sehr heterogen. In den Vereinigten Staaten sind die Klassen an öffentlichen Schulen durchschnittlich um 4 Schüler größer als an privaten Bildungseinrichtungen, in Griechenland und Spanien dagegen durchschnittlich um 3 Schüler kleiner (Tab. D2.I).

\section{Zahlenmäßiges Schüler/Lehrkräfte-Verhältnis}

Im Primarbereich reicht das zahlenmäßige Schüler/Lehrkräfte-Verhältnis, ausgedrückt in Vollzeit-Äquivalenten, von ungefähr 30 Schülern pro Lehrer in Korea, Mexiko und der Türkei bis zu weniger als II in Italien und Ungarn. Das Ländermittel im Primarbereich liegt bei I7 Schülern pro Lehrkraft.

Im Sekundarbereich sind die Unterschiede beim zahlenmäßigen Schüler/Lehrkräfte-Verhältnis, ausgedrückt in Vollzeit-Äquivalenten, zwischen den Ländern ähnlich und reichen von etwa 29 Schülern pro vollzeitäquivalentem Lehrer in Mexiko bis zu weniger als ro in Belgien, Griechenland, Luxemburg und Portugal. Im Durchschnitt aller Länder beträgt das zahlenmäßige Schüler/Lehrkräfte-Verhältnis im Sekundarbereich ungefähr I4. Dies liegt sehr nahe bei den für Deutschland (I5), Finnland (I3), Japan (I5), Polen (I4), Schweden (I3), die Slowakische Republik (I4), die Tschechische Republik (I4) und das Vereinigte Königreich (I5) ermittelten Werten (Tab. D2.2). 
Abbildung D2.2

Zahlenmäßiges Schüler/Lehrkräfte-Verhältnis in Bildungseinrichtungen, nach Bildungsbereich (2002)

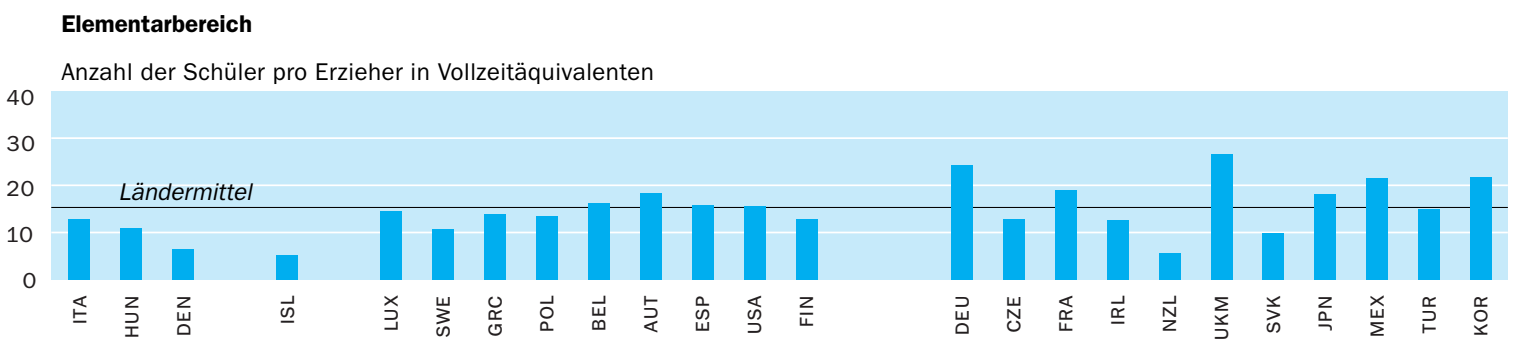

\section{Primarbereich}

Anzahl der Schüler pro Lehrkraft in Vollzeitäquivalenten

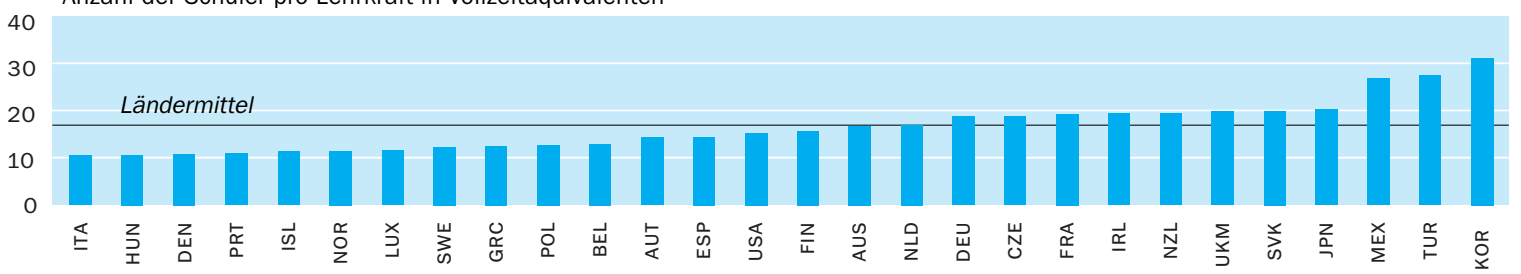

Sekundarbereich I

40

Anzahl der Schüler pro Lehrkraft in Vollzeitäquivalenten

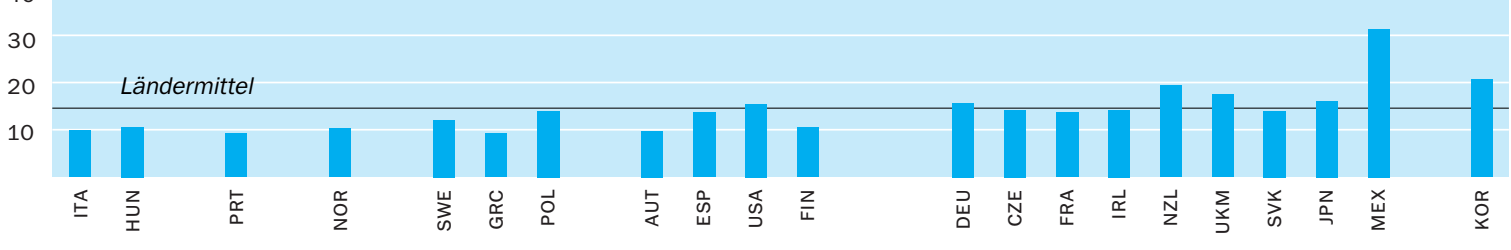

Sekundarbereich II

40

Anzahl der Schüler pro Lehrkraft in Vollzeitäquivalenten

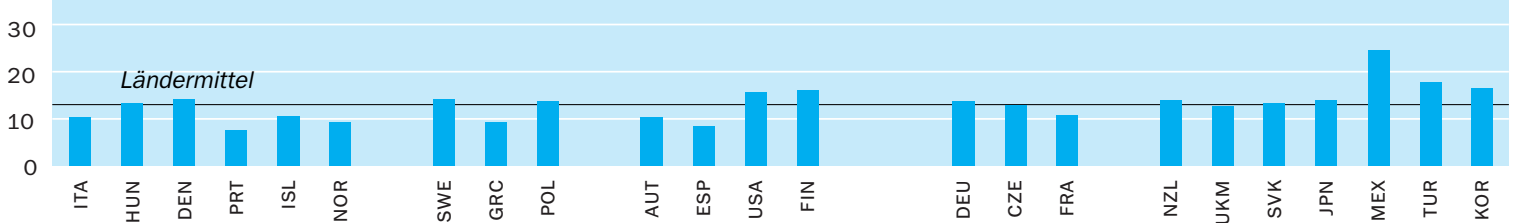

Tertiärbereich

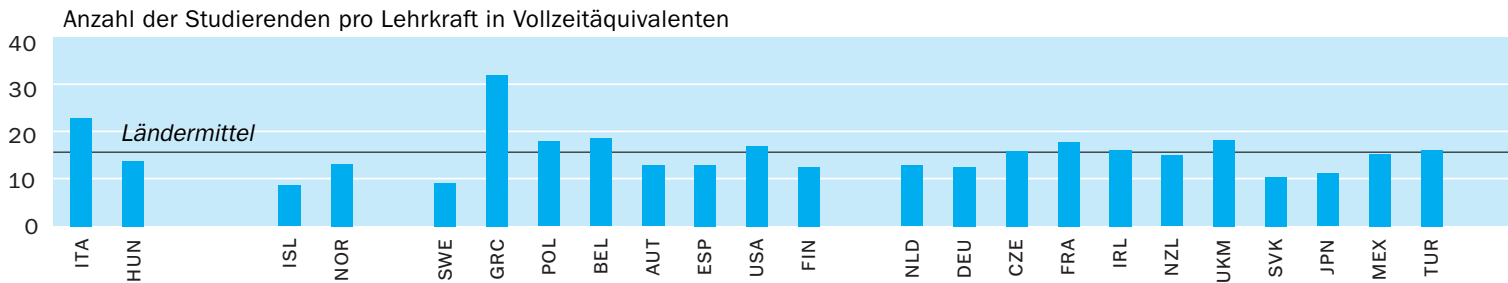

HInweis: Auflistung der verwendeten Ländercodes und der dazugehörenden Ländernamen s. Hinweise für den Leser.

Anordnung der Länder in aufsteigender Reihenfolge der Anzahl der Schüler pro Lehrkraft im Primarbereich.

Quelle: OECD. Tabelle D2.2. Hinweise s. Anhang 3 unter www.oecd.org/edu/eag2004. 
Vom Primar- zum Sekundarbereich nimmt die Zahl der Schüler pro Lehrer ab.
Das zahlenmäßige Schüler/Lehrkräfte-Verhältnis, ausgedrückt in VollzeitÄquivalenten, variiert auch je nach Art der Bildungseinrichtung. Im Sekundarbereich II der 2I Länder mit vergleichbaren Daten kommen in öffentlichen Schulen im Durchschnitt zwei Schüler mehr auf einen Lehrer als in privaten Bildungseinrichtungen (Abb. D2.3). In Frankreich, Island, Japan, Korea, Österreich, Spanien und der Tschechischen Republik kommen jedoch in privaten Bildungseinrichtungen mehr Schüler auf einen Lehrer als an öffentlichen Schulen (mit Ausnahme Österreichs mindestens zwei Schüler mehr). In Italien, Mexiko, der Türkei und dem Vereinigten Königreich kommen dagegen in öffentlichen Schulen mindestens fünf Schüler mehr auf einen Lehrer als in privaten Bildungseinrichtungen.

Wie die unterschiedlichen Mittelwerte für das zahlenmäßige Schüler/Lehrkräfte-Verhältnis zwischen Primar- und Sekundarbereich erkennen lassen, stehen den Schülern um so mehr Lehrer zur Verfügung (jeweils in Vollzeitäquivalenten), je höher sie in ihrer Bildungslaufbahn aufsteigen. Mit Ausnahme von Mexiko, Polen, Schweden, Ungarn und den Vereinigten Staaten verringert sich in allen OECD-Ländern das zahlenmäßige Schüler/Lehrkräfte-Verhältnis vom Primar- zum Sekundarbereich, obwohl die Klassengröße eher zunimmt. Der Grund für die Zunahme der Klassengröße liegt vor allem darin, dass die Unterrichtszeit mit zunehmend höherem Bildungsbereich tendenziell zunimmt.

In Frankreich, Korea und der Türkei ist der Rückgang beim zahlenmäßigen Schüler/Lehrkräfte-Verhältnis vom Primar- zum Sekundarbereich mit zwischen 7 und I3 Schülern pro Lehrer (jeweils in Vollzeitäquivalenten) wesent-

Abbildung D2.3

Zahlenmäßiges Schüler/Lehrkräfte-Verhältnis im Sekundarbereich II, nach Art der Bildungseinrichtung (2002)

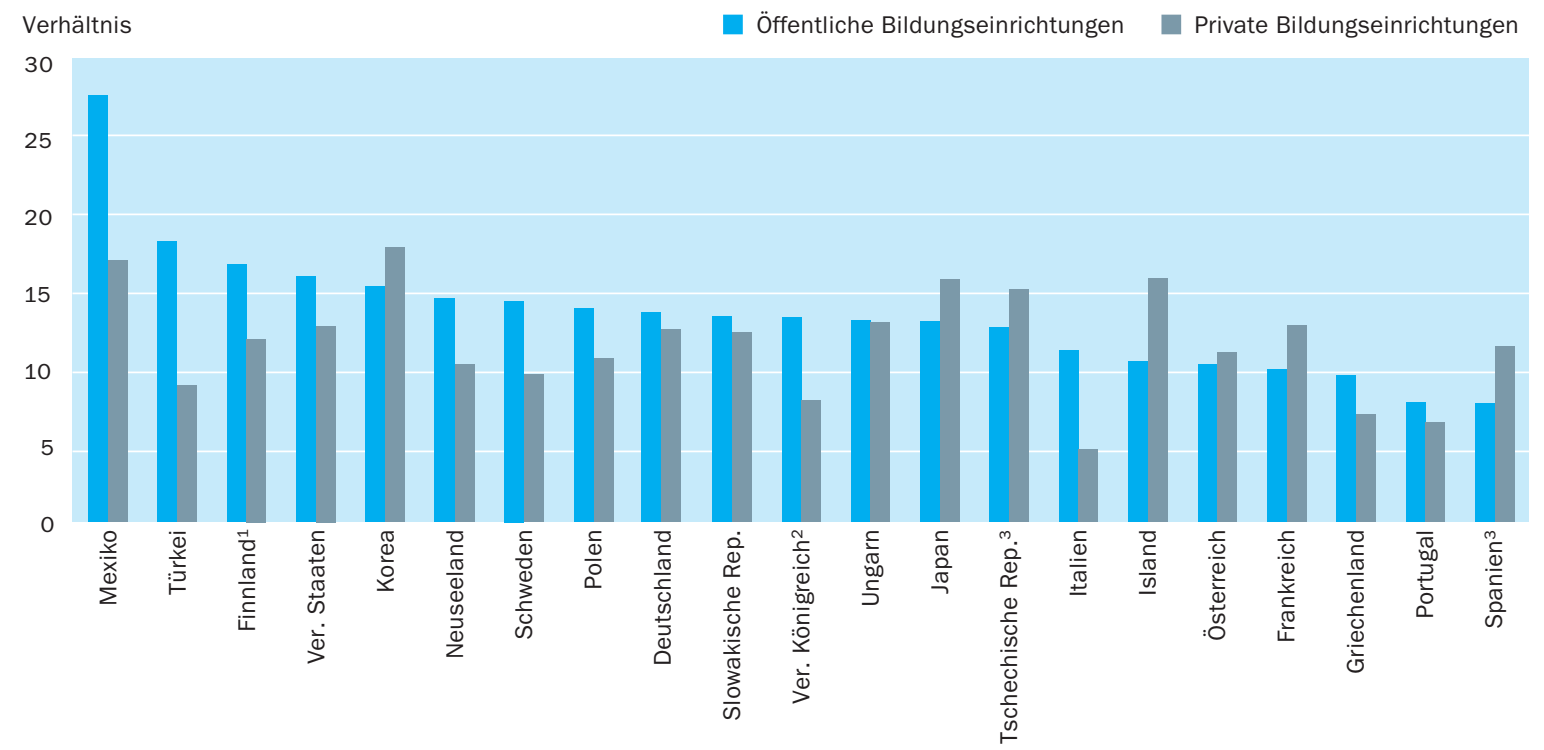

1. Einschließlich Bildungsgängen im post-sekundaren, nicht-tertiären Bereich und Tertiärbereich A und B. 2. Nur Bildungsgänge des Sekundarbereich I und II. 3. Einschließlich Bildungsgänge im post-sekundaren, nicht-tertiären Bereich.

Anordnung der Länder in absteigender Reihenfolge des zahlenmäßigen Schüler/Lehrkräfte-Verhältnis in öffentlichen Bildungseinrichtungen.

Quelle: OECD. Tabelle D2.2. Hinweise s. Anhang 3 unter www.oecd.org/edu/eag2004. 
lich ausgeprägter als in anderen Ländern. In Frankreich und Korea spiegeln diese Unterschiede hauptsächlich Unterschiede bei der jährlichen Unterrichtszeit wider, sie könnten sich aber auch aufgrund zeitlicher Verzögerungen bei der Anpassung der Zahl der Lehrkräfte an veränderte demographische Gegebenheiten oder aufgrund von Unterschieden bei den von Lehrern in den verschiedenen Bildungsbereichen abzuleistenden Unterrichtsstunden ergeben. Dieser Trend ist zwar über alle Länder hinweg zu beobachten, vom pädagogischen Standpunkt her ist jedoch nicht leicht nachvollziehbar, warum auf höherer Bildungsebene eher ein geringeres zahlenmäßiges Schüler/Lehrkräfte-Verhältnis wünschenswert sein sollte (Tab. D2.2).

Im Tertiärbereich variiert das zahlenmäßige Studierende/Lehrende-Verhältnis zwischen 32 Studierenden pro Lehrenden in Griechenland und II und weniger in Island, Japan, Schweden und der Slowakischen Republik (Tab. D2.2). Allerdings sollten solche Vergleiche für den Tertiärbereich mit Vorsicht interpretiert werden, da im Tertiärbereich immer noch Schwierigkeiten bei der Berechnung von vergleichbaren Vollzeitäquivalenten für Studierende und Lehrende bestehen.

In II der I4 Länder, für die Daten für Studiengänge sowohl im Tertiärbereich A und weiterführende Forschungsprogramme als auch im Tertiärbereich B vorliegen, ist das zahlenmäßige Studierende/Lehrende-Verhältnis in Studiengängen des Tertiärbereich $\mathrm{B}$, die generell stärker berufsorientiert sind, niedriger als in Studiengängen des Tertiärbereich A und weiterführenden Forschungsprogrammen (Tab. D2.2). Deutschland, die Tschechische Republik und die Türkei sind die einzigen Länder, die im Tertiärbereich B ein höheres Verhältnis aufweisen, in der Türkei sogar ein beträchtlich höheres.

Im Elementarbereich ist das zahlenmäßige Schüler/Erzieher-Verhältnis tendenziell niedriger als im Primarbereich, aber etwas höher als im Sekundarbereich. Das zahlenmäßige Schüler/Erzieher-Verhältnis im Elementarbereich reicht von weniger als 6 Schülern pro Erzieher in Island und Neuseeland bis zu 2I Schülern und mehr in Deutschland, Korea, Mexiko und dem Vereinigten Königreich. Es besteht offensichtlich nur eine geringe Beziehung zwischen dem zahlenmäßigen Schüler/Lehrkräfte-Verhältnis im Elementar- und dem im Primarbereich, was darauf hindeutet, dass innerhalb der einzelnen Länder der Personalbedarf der einzelnen Bildungsbereiche bzw. sein Stellenwert unterschiedlich bewertet werden (Tab. D2.2).

\section{Unterrichtende und nicht-unterrichtende Beschäftige im Bildungssystem}

Die zwischen den Ländern zu beobachtenden Unterschiede bei der relativen Größe der Lehrerschaft lassen sich nicht allein durch die unterschiedliche Größe der Population im üblichen Schulalter erklären, sondern werden auch durch die durchschnittliche Klassengröße, die Gesamtzahl an Unterrichtsstunden für Schüler (Indikator DI), die durchschnittliche Arbeitszeit der Lehrer (Indikator D4) und die Aufteilung der Zeit der Lehrer zwischen Unterrichten und anderen Pflichten beeinflusst.

Zwischen den einzelnen OECD-Ländern gibt es große Unterschiede innerhalb der im Bildungsbereich Beschäftigten beim Anteil derjenigen, die unterrichten
Im Allgemeinen ist das zahlenmäßige Studierende/Lehrende-Verhältnis im Tertiärbereich tendenziell höher als im Sekundarbereich.

Im Elementarbereich liegt das zahlenmäßige Schüler/Erzieher-Verhältnis zwischen dem des Primar- und des Sekundarbereichs.

Die Unterschiede zwischen den Ländern werden durch Faktoren wie die durchschnittliche Klassengröße, die Gesamtzahl an Unterrichtsstunden und die Arbeitszeit der Lehrer beeinflusst.

Die relativen Anteile von Lehrern und anderen im 
Bildungsbereich Beschäftigten variieren erheblich zwischen den einzelnen Ländern.

An den Schulen des Primarund Sekundarbereichs machen die nicht-unterrichtenden Beschäftigten im Durchschnitt mehr als 30 Prozent der gesamten unterrichtenden und nicht-unterrichtenden Beschäftigten aus. und derjenigen, die andere Tätigkeiten ausüben, was Unterschiede in der Organisation und dem Management des jeweiligen Bildungssystems widerspiegelt. Die Zahl der unterrichtenden und nicht-unterrichtenden Beschäftigten im Primar- und Sekundarbereich reicht von weniger als 8I Beschäftigten pro I.000 Schülern in Japan, Korea und Mexiko bis zu II 9 Beschäftigten und mehr pro I.00o Schülern in Frankreich, Island, Italien, Ungarn und den Vereinigten Staaten (Abb. D2.4).

In den Io Ländern, für die in jeder der Kategorien der im Bildungsbereich Beschäftigten Daten vorliegen, beläuft sich der Anteil der nicht-unterrichtenden Beschäftigten auf durchschnittlich mehr als 30 Prozent des gesamten unterrichtenden und nicht-unterrichtenden Personals im Primar- und Sekundarbereich. In fünf dieser Länder liegt der Anteil dieser Beschäftigten zwischen 30 und 40 Prozent der gesamten unterrichtenden und nicht-unterrichtenden Beschäftigten. In Frankreich und der Tschechischen Republik liegt er bei über 40 Prozent und in Korea ist er mit Ig Prozent am niedrigsten. Im Vergleich zur Anzahl der Schüler im Primar- und Sekundarbereich liegt der Anteil der nichtunterrichtenden Beschäftigten im Bildungsbereich in Frankreich, Island, Italien, der Tschechischen Republik, Ungarn und den Vereinigten Staaten bei über 40 Beschäftigten pro I.000 Schülern (Tab. D2.3 und Abb. D2.4).

Abbildung D2.4

Unterrichtende und nicht-unterrichtende Beschäftigte in Schulen des Primar- und Sekundarbereichs (2002) Unterrichtende und nicht-unterrichtende Beschäftigte in Schulen des Primar- und Sekundarbereichs, pro 1.00o Schüler (basierend auf Vollzeitäquivalenten)

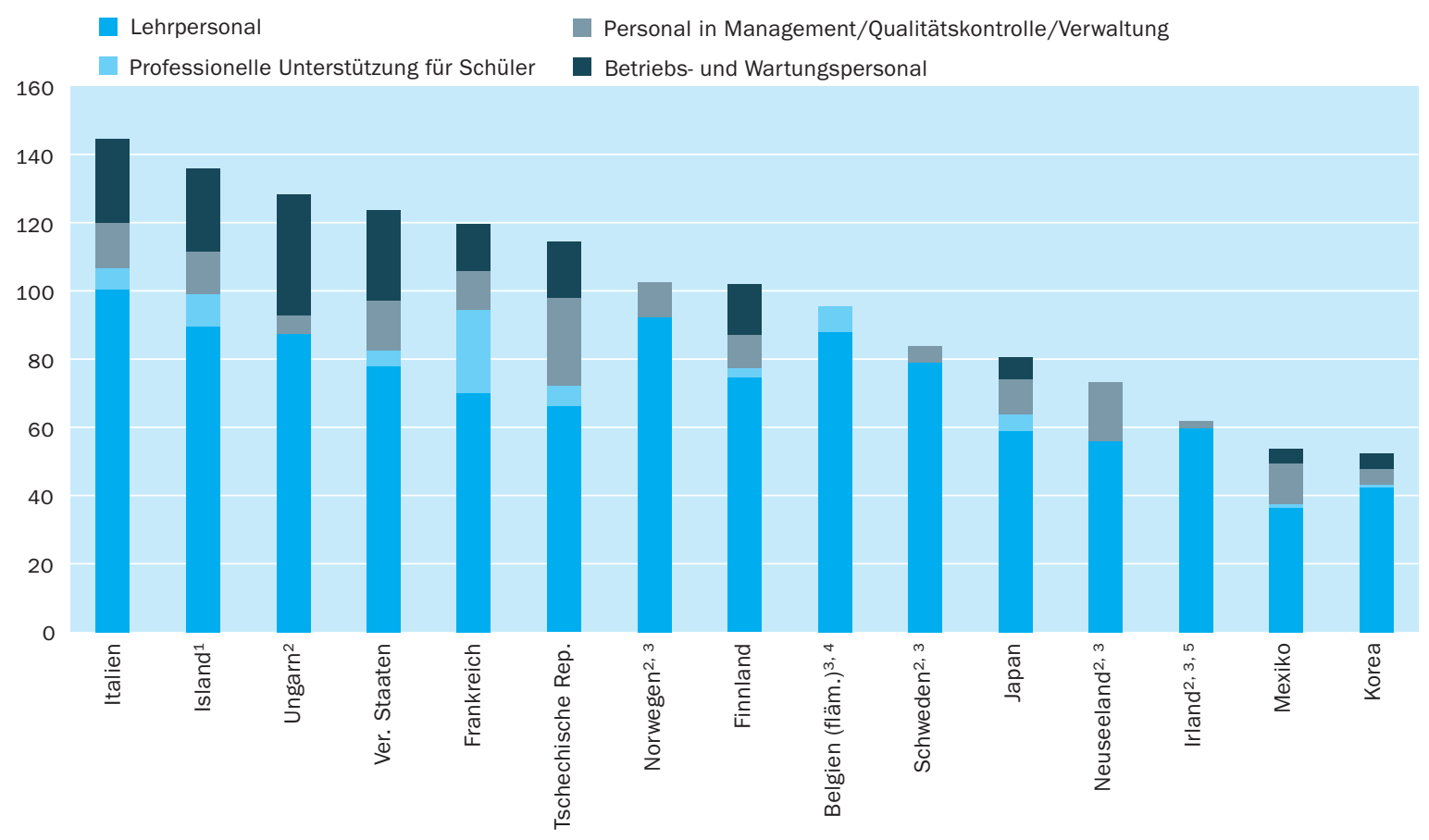

\footnotetext{
1. Daten zu Personal in übergeordnetem Management und Verwaltung nicht verfügbar. 2. Daten zu professioneller Unterstützung für Schüler nicht verfügbar.

3. Daten zu Betriebs- und Wartungspersonal nicht verfügbar. 4. Daten zu Personal in Management/Qualitätskontrolle/Verwaltung nicht verfügbar.

5. Einschließlich Bildungsgänge im post-sekundaren, nicht-tertiären Bereich.

Anordnung der Länder in absteigender Reihenfolge des Anteils der unterrichtenden und nicht-unterrichtenden Beschäftigten pro 1.000 Schüler.

Quelle: OECD. Tabelle D2.3. Hinweise s. Anhang 3 unter www.oecd.org/edu/eag2004.
} 
Diese Unterschiede zeigen, inwieweit ein bestimmtes Land im Bildungsbereich Personal in den nicht-unterrichtenden Bereichen beschäftigt, z. B., Schulleiter ohne Lehrverpflichtung, Berater, Schulschwestern, Bibliothekare, Forscher ohne Lehrverpflichtung, Busfahrer, Hausmeister und Wartungspersonal, sowie Verwaltungs- und Managementbeschäftigte innerhalb und außerhalb der Schule. In Island, Italien, Ungarn und den Vereinigten Staaten macht das Wartungs- und Betriebspersonal in Schulen des Primar- und Sekundarbereichs mehr als 20 Beschäftigte pro I.000 Schüler in diesen Bildungseinrichtungen aus. Das Verwaltungspersonal reicht von 8 bis I2 Beschäftigten pro I.000 Schüler im Primar- und Sekundarbereich in Italien, Mexiko und den Vereinigten Staaten bis zu I8 und mehr Beschäftigten pro I.ooo Schüler in der Tschechischen Republik, während die Zahl der im Management einer Bildungseinrichtung sowie im Management auf einer übergeordneten Ebene Beschäftigten mehr als 6 pro I.00o Schüler in Frankreich, Island, der Slowakischen Republik und der Tschechischen Republik beträgt, ro in Norwegen und I6 in Neuseeland (Tab. D2.3). Schließlich ist die Zahl der Beschäftigten, die als professionelles Unterstützungspersonal für Schüler eingestellt sind, in Frankreich relativ hoch (mehr als 24 Beschäftigte pro I.00o Schüler an Schulen des Primar- und Sekundarbereichs), was in geringerem Ausmaß auch für Island gilt (ungefähr ıo Beschäftigte pro I.000 Schüler an Schulen des Primar- und Sekundarbereichs).

\section{Definitionen und angewandte Methodik}

Die Klassengröße wurde berechnet, indem die Anzahl der Schüler durch die Anzahl der Klassen dividiert wurde. Um die Vergleichbarkeit zwischen den Ländern zu gewährleisten, wurden spezielle Förderprogramme nicht erfasst. Die Daten umfassen ausschließlich die regulären Bildungsgänge im Primarund Sekundarbereich, Unterricht in Kleingruppen außerhalb des regulären Klassenunterrichts ist nicht erfasst.

Das Schüler/Lehrkräfte-Verhältnis wurde berechnet, indem (gemessen in Vollzeit-Äquivalenten) die Zahl der Schüler eines bestimmten Bildungsbereichs durch die Zahl der ,Lehrkräfte' des gleichen Bildungsbereichs und ähnlicher Bildungseinrichtungen dividiert wird.

Die Aufschlüsselung des zahlenmäßigen Schüler/Lehrkräfte-Verhältnisses nach Art der Bildungseinrichtung unterscheidet zwischen Schülern und Lehrkräften an öffentlichen Bildungseinrichtungen und denen an privaten Bildungseinrichtungen (staatlich-subventionierten privaten Bildungseinrichtungen und unabhängigen privaten Bildungseinrichtungen). In einigen Ländern ist der Anteil der Schüler in privaten Bildungseinrichtungen gering (s. Tab. C2.4).

Zu den unterrichtenden Beschäftigen gehören:

Lehrkräfte - voll qualifiziertes Personal, das direkt mit dem Unterrichten der Schüler befasst ist. Diese Kategorie umfasst Lehrkräfte, Förderlehrer, und andere Lehrer, die mit Schülern als ganzer Klasse im Klassenzimmer, in kleinen Gruppen in einem Förderraum oder im Einzelunterricht innerhalb

Die Daten beziehen sich auf das Schuljahr 2001/2002 und beruhen auf der alljährlich von der OECD aufgelegten UOEDatenerhebung zur Bildungsstatistik. 
oder außerhalb des regulären Unterrichts arbeiten. Diese Kategorie umfasst auch Fachgebietsleiter, deren Aufgaben ein gewisses Maß an Unterricht beinhalten, während nicht voll qualifizierte Mitarbeiter, die die Lehrkräfte beim Unterricht unterstützten, wie Hilfslehrkräfte und andere Hilfskräfte, nicht erfasst sind.

Hilfslehrkräfte und Lehr-|Forschungsassistenten - nicht voll qualifizierte Beschäftigte oder Studierende, die die Lehrkräfte beim Unterrichten der Schüler unterstützen. Diese Beschäftigten sind in den Tabellen D2.I und D2.2 nicht erfasst.

Nicht-unterrichtendes Personal wird in 4 Kategorien aufgeteilt:

Professionelle Unterstützung für Schüler/Studierende - voll qualifiziertes Personal, das die Schüler/Studierenden beim Lernen unterstützt. In vielen Fällen haben Angehörige dieser Kategorie zunächst eine Qualifikation als Lehrer erworben, dann aber andere Positionen innerhalb des Bildungssystems übernommen. Diese Kategorie umfasst auch alle im Bildungsbereich Beschäftigten, die Gesundheits- und soziale Unterstützungsdienste für Schüler/ Studierende leisten, wie z. B. Berater, Bibliothekare, Ärzte, Zahnärzte, Krankenschwestern und Pfleger, Psychiater und Psychologen sowie andere Beschäftigte mit ähnlichen Verantwortungsbereichen.

Management einer Bildungseinrichtung sowie Management auf einer übergeordneten Ebene - hauptberuflich Beschäftigte, die für das Management und die Verwaltung von Bildungseinrichtungen verantwortlich sind sowie Beschäftigte, die für die Qualitätskontrolle und das Management auf übergeordneten Ebenen des Bildungssystems verantwortlich sind. Unter diese Kategorie fallen Rektoren/Präsidenten, stellvertretende Rektoren/Präsidenten, Direktoren, stellvertretende Direktoren, Schulleiter, stellvertretende Schulleiter, leitende Beamte im Bildungsbereich und andere Beschäftigte im Bereich Management mit ähnlichen Verantwortungsbereichen.

Verwaltungspersonal in Bildungseinrichtungen und auf übergeordneter Ebene - alle Beschäftigten, die die Verwaltung und das Management einer Bildungseinrichtung unterstützen bzw. auf übergeordneten Ebenen des Bildungssystems unterstützend tätig sind. Zu dieser Kategorie gehören: Beschäftigte am Empfang, in Sekretariaten, Schreibkräfte, Buchhalter und Bürokräfte, Analytiker, Computerprogrammierer, Netzwerkadministratoren oder in anderen Tätigkeiten mit ähnlichen Funktionen und Verantwortungsbereichen Tätige.

Wartungs- und Betriebspersonal - Beschäftigte, die für die Wartung und den Betrieb der Bildungseinrichtungen, den Transport der Schüler/Studierenden zur und von der Schule, die Schulsicherheit und die Kantine eingesetzt werden. Dieser Kategorie zugeordnet sind: Maurer, Zimmerleute, Elektriker, Wartungsarbeiter, Maler und Tapezierer, Gipser, Installateure und Fahrzeugmechaniker. Darüber hinaus Busfahrer und Fahrer anderer Fahrzeuge, Bauarbeiter, Gärtner und Platzwarte, Busbetreuer und Schülerlotsen, Köche, Aufsichtspersonal, Kantinenpersonal und andere Beschäftigte mit ähnlichen Funktionen. 
Tabelle D2.1

Durchschnittliche Klassengröße, nach Art der Bildungseinrichtung und Bildungsbereich (2002)

Basierend auf der Zahl der Schüler und der Zahl der Klassen

\begin{tabular}{|c|c|c|c|c|c|c|c|c|}
\hline & \multicolumn{4}{|c|}{ Primarbereich } & \multicolumn{4}{|c|}{$\begin{array}{l}\text { Sekundarbereich I } \\
\text { (allgemeinbildende Bildungsgänge) }\end{array}$} \\
\hline & $\begin{array}{l}\text { Öffentliche } \\
\text { Bildungs- } \\
\text { einrichtungen } \\
\text { (1) }\end{array}$ & $\begin{array}{c}\text { Staatlich- } \\
\text { subventionierte } \\
\text { private Bildungs- } \\
\text { einrichtungen } \\
\text { (2) }\end{array}$ & \begin{tabular}{|} 
Unabhängige \\
private Bildungs- \\
einrichtungen \\
(3)
\end{tabular} & $\begin{array}{l}\text { Öffentliche und } \\
\text { private Bildungs- } \\
\text { einrichtungen } \\
\text { zusammen } \\
\text { (4) }\end{array}$ & $\begin{array}{l}\text { Öffentliche } \\
\text { Bildungs- } \\
\text { einrichtungen } \\
\text { (5) }\end{array}$ & $\begin{array}{l}\text { Staatlich- } \\
\text { subventionierte } \\
\text { Bildungs- } \\
\text { einrichtungen } \\
\text { (6) }\end{array}$ & \begin{tabular}{|} 
Unabhängige \\
private Bildungs- \\
einrichtungen \\
(7)
\end{tabular} & $\begin{array}{l}\text { Öffentliche und } \\
\text { private Bildungs- } \\
\text { einrichtungen } \\
\text { zusammen } \\
\text { (8) }\end{array}$ \\
\hline \multicolumn{9}{|l|}{ OECD-Länder } \\
\hline Österreich & 20,0 & 21,2 & $\mathrm{~m}$ & 20,1 & 23,8 & 24,8 & $x(6)$ & 23,9 \\
\hline Belgien & $\mathrm{m}$ & $\mathrm{m}$ & $\mathrm{m}$ & $\mathrm{m}$ & $\mathrm{m}$ & $\mathrm{m}$ & $\mathrm{m}$ & $\mathrm{m}$ \\
\hline Belgien (frz.) & 20,0 & 21,0 & a & 20,4 & 21,1 & 21,9 & $\mathrm{a}$ & 21,6 \\
\hline Kanada & $\mathrm{m}$ & $\mathrm{m}$ & $\mathrm{m}$ & $\mathrm{m}$ & $\mathrm{m}$ & $\mathrm{m}$ & $\mathrm{m}$ & $\mathrm{m}$ \\
\hline Tschechische Rep. & 21,3 & 16,8 & a & 21,3 & 23,3 & 20,9 & a & 23,3 \\
\hline Dänemark & 19,4 & 16,7 & a & 19,1 & 19,1 & 17,5 & a & 18,8 \\
\hline Finnland & $\mathrm{m}$ & $\mathrm{m}$ & a & $\mathrm{m}$ & $\mathrm{m}$ & $\mathrm{m}$ & a & $\mathrm{m}$ \\
\hline Deutschland & 22,2 & 23,7 & $x(2)$ & 22,2 & 24,6 & 26,0 & $x(6)$ & 24,7 \\
\hline Griechenland & 17,2 & $a$ & 21,5 & 17,5 & 22,9 & a & 26,0 & 23,0 \\
\hline Ungarn & 20,5 & 19,5 & a & 20,4 & 21,2 & 21,7 & a & 21,3 \\
\hline Island & 17,9 & 18,8 & $n$ & 17,9 & 19,2 & 17,7 & $n$ & 19,1 \\
\hline Irland & 24,2 & $\mathrm{~m}$ & $\mathrm{~m}$ & $\mathrm{~m}$ & 21,4 & $\mathrm{~m}$ & $\mathrm{~m}$ & $\mathrm{~m}$ \\
\hline Italien & 18,1 & a & 20,1 & 18,3 & 20,7 & a & 21,4 & 20,8 \\
\hline Japan & 28,7 & a & 34,3 & 28,8 & 34,2 & a & 36,7 & 34,3 \\
\hline Korea & 35,7 & $a$ & 34,8 & 35,7 & 37,3 & 36,5 & a & 37,1 \\
\hline Luxemburg & 15,6 & 21,3 & 17,6 & 15,7 & 19,9 & 20,5 & 18,8 & 19,9 \\
\hline Mexiko & 20,6 & a & 23,8 & 20,8 & 29,9 & a & 28,7 & 29,8 \\
\hline Niederlande & $x(4)$ & $x(4)$ & $x(4)$ & 23,9 & $\mathrm{~m}$ & $\mathrm{~m}$ & $\mathrm{~m}$ & $\mathrm{~m}$ \\
\hline Neuseeland & $\mathrm{m}$ & $\mathrm{m}$ & $\mathrm{m}$ & $\mathrm{m}$ & $\mathrm{m}$ & $\mathrm{m}$ & $\mathrm{m}$ & $\mathrm{m}$ \\
\hline Norwegen & $\mathrm{m}$ & $\mathrm{m}$ & $\mathrm{m}$ & $\mathrm{m}$ & $\mathrm{m}$ & $\mathrm{m}$ & $\mathrm{m}$ & $\mathrm{m}$ \\
\hline Polen & 21,1 & 12,4 & 12,1 & 20,9 & 24,5 & 24,6 & 14,1 & 24,3 \\
\hline Spanien & 19,4 & 24,9 & 22,5 & 20,9 & 24,4 & 28,2 & 23,5 & 25,4 \\
\hline Schweden & $\mathrm{m}$ & $\mathrm{m}$ & $\mathrm{m}$ & $\mathrm{m}$ & $\mathrm{m}$ & $\mathrm{m}$ & $\mathrm{m}$ & $\mathrm{m}$ \\
\hline Schweiz & 19,7 & 14,9 & 16,6 & 19,6 & 18,7 & 18,5 & 16,2 & 18,6 \\
\hline Türkei & 29,6 & a & 20,2 & 29,4 & a & a & a & a \\
\hline Ver. Königreich & 26,0 & a & $\mathrm{m}$ & $\mathrm{m}$ & 24,7 & $\mathrm{~m}$ & $\mathrm{~m}$ & $\mathrm{~m}$ \\
\hline Vereinigte Staaten & 22,0 & a & 19,6 & 21,7 & 23,2 & a & 18,8 & 22,6 \\
\hline Ländermittel & 21,9 & 20,1 & 22,2 & 21,8 & 23,6 & 23,3 & 21,4 & 23,7 \\
\hline \multicolumn{9}{|l|}{ OECD-Partnerländer } \\
\hline Brasilien ${ }^{1}$ & 27,2 & a & 18,6 & 26,1 & 34,7 & a & 27,0 & 33,7 \\
\hline Chile & 32,8 & 36,0 & 24,0 & 32,9 & 32,3 & 35,5 & 25,3 & 32,6 \\
\hline Ägypten & 41,5 & 36,7 & 35,6 & 40,9 & 44,3 & 41,0 & 32,0 & 43,5 \\
\hline Indien & $x(4)$ & $x(4)$ & $x(4)$ & 40,0 & $x(8)$ & $x(8)$ & $x(8)$ & 40,0 \\
\hline Israel & 25,6 & a & a & 25,6 & 31,0 & a & a & 31,0 \\
\hline Jamaika & 34,3 & $\mathrm{~m}$ & $\mathrm{~m}$ & $\mathrm{~m}$ & 32,4 & $\mathrm{~m}$ & $\mathrm{~m}$ & $\mathrm{~m}$ \\
\hline Jordanien & 28,8 & a & 27,8 & 28,5 & 30,7 & a & 30,2 & 30,6 \\
\hline Malaysia $^{1}$ & 32,9 & a & a & 32,9 & 37,1 & a & a & 37,1 \\
\hline Paraguay ${ }^{1}$ & 18,1 & 22,1 & 16,7 & 18,3 & 27,7 & 27,5 & 19,4 & 26,3 \\
\hline Peru $^{1}$ & 19,5 & 30,5 & 17,0 & 19,5 & 35,2 & 37,9 & 23,2 & 33,3 \\
\hline Philippinen & 40,3 & a & 32,4 & 39,7 & 53,7 & a & 44,9 & 51,6 \\
\hline Russische Föd. & 16,1 & a & 9,8 & 16,1 & 20,7 & a & 10,7 & 20,6 \\
\hline Sri Lanka & 26,2 & $\mathrm{~m}$ & $n$ & $\mathrm{~m}$ & 29,8 & $\mathrm{~m}$ & $n$ & $\mathrm{~m}$ \\
\hline Thailand & 23,2 & 52,1 & a & 25,1 & 36,6 & 32,7 & a & 36,3 \\
\hline Tunesien & 28,3 & a & 25,1 & 28,2 & 33,5 & a & 19,8 & 33,1 \\
\hline Uruguay $^{1}$ & 19,1 & a & $\mathrm{m}$ & $\mathrm{m}$ & 29,5 & a & 26,4 & 29,0 \\
\hline
\end{tabular}

Hinweis: $x$ bedeutet, dass die Daten in einer anderen Spalte enthalten sind, deren Referenz in runden Klammern nach dem ,x' angegeben ist. So bedeutet $z$. B. $x(2)$, dass die Daten in Spalte 2 enthalten sind.

1. Referenzjahr 2001

Quelle: OECD. Hinweise s. Anhang 3 unter www.oecd.org/edu/eag2004. 
Tabelle D2.2

Zahlenmäßiges Schüler/Lehrkräfte-Verhältnis in Bildungseinrichtungen (2002) Nach Bildungsbereich (basierend auf Vollzeitäquivalenten)

\begin{tabular}{|c|c|c|c|c|c|c|c|c|c|}
\hline & \multirow{2}{*}{$\begin{array}{l}\text { Elementar- } \\
\text { bereich }\end{array}$} & \multirow{2}{*}{$\begin{array}{l}\text { Primar- } \\
\text { bereich }\end{array}$} & \multicolumn{3}{|c|}{ Sekundarbereich } & \multirow{2}{*}{$\begin{array}{l}\text { Post- } \\
\text { sekundarer, } \\
\text { nicht-tertiärer } \\
\text { Bereich }\end{array}$} & \multicolumn{3}{|c|}{ Tertiärbereich } \\
\hline & & & $\begin{array}{l}\text { Sekundar- } \\
\text { bereich I }\end{array}$ & $\begin{array}{l}\text { Sekundar- } \\
\text { bereich II }\end{array}$ & $\begin{array}{l}\text { Sekundar- } \\
\text { bereich } \\
\text { insgesamt } \\
\text { (5) }\end{array}$ & & $\begin{array}{c}\text { Tertiär- } \\
\text { bereich B }\end{array}$ & \begin{tabular}{|c|} 
Tertiärbereich \\
A und weiter- \\
führende \\
Forschungs- \\
programme \\
(8)
\end{tabular} & $\begin{array}{c}\text { Tertiär- } \\
\text { bereich } \\
\text { insgesamt } \\
\text { (9) }\end{array}$ \\
\hline \multicolumn{10}{|l|}{ OECD-Länder } \\
\hline Australien ${ }^{1}$ & $\mathrm{~m}$ & 16,9 & $x(5)$ & $x(5)$ & 12,5 & $\mathrm{~m}$ & $\mathrm{~m}$ & 16,2 & $\mathrm{~m}$ \\
\hline Österreich & 18,2 & 14,4 & 9,8 & 10,3 & 10,0 & 10,2 & 7,7 & 13,7 & 13,0 \\
\hline Belgien & 16,3 & 13,1 & $x(5)$ & $x(5)$ & 9,3 & $x(5)$ & $x(9)$ & $x(9)$ & 18,7 \\
\hline Kanada & $\mathrm{m}$ & $\mathrm{m}$ & $\mathrm{m}$ & $\mathrm{m}$ & $\mathrm{m}$ & $\mathrm{m}$ & $\mathrm{m}$ & $\mathrm{m}$ & $\mathrm{m}$ \\
\hline Tschechische Rep & 12,9 & 18,9 & 14,4 & 12,9 & 13,6 & $x(4)$ & 16,3 & 16,0 & 16,1 \\
\hline Dänemark & 6,6 & 10,9 & $x(2)$ & 14,2 & $\mathrm{~m}$ & $\mathrm{~m}$ & $\mathrm{~m}$ & $\mathrm{~m}$ & $\mathrm{~m}$ \\
\hline Finnland & 12,7 & 15,8 & 10,6 & 16,0 & 13,4 & $x(4)$ & $x(4)$ & 12,6 & 12,6 \\
\hline Frankreich & 19,0 & 19,4 & 13,7 & 10,6 & 12,2 & a & 14,1 & 18,7 & 17,9 \\
\hline Deutschland & 24,2 & 18,9 & 15,7 & 13,6 & 15,1 & 14,8 & 16,1 & 12,1 & 12,6 \\
\hline Griechenland & 13,9 & 12,5 & 9,3 & 9,3 & 9,3 & 8,0 & 24,9 & 37,5 & 32,2 \\
\hline Ungarn & 10,9 & 10,8 & 10,7 & 13,1 & 11,7 & 10,4 & $x(9)$ & $x(9)$ & 13,8 \\
\hline Island & 5,2 & 11,4 & $x(2)$ & 10,6 & $\mathrm{~m}$ & $x(5,9)$ & 2,0 & 9,1 & 8,7 \\
\hline Irland & 13,5 & 19,5 & 14,3 & $x(3)$ & $x(3)$ & $x(3)$ & 15,6 & 16,7 & 16,3 \\
\hline Italien & 12,8 & 10,6 & 9,9 & 10,3 & 10,2 & $\mathrm{~m}$ & 7,7 & 23,7 & 23,1 \\
\hline Japan & 18,1 & 20,3 & 16,2 & 13,7 & 14,8 & $x(4,9)$ & 8,4 & 12,6 & 11,2 \\
\hline Korea & 21,7 & 31,4 & 20,7 & 16,5 & 18,4 & a & $\mathrm{m}$ & $\mathrm{m}$ & $\mathrm{m}$ \\
\hline Luxemburg $^{2}$ & 14,5 & 11,6 & $x(5)$ & $x(5)$ & 9,0 & $\mathrm{~m}$ & $\mathrm{~m}$ & $\mathrm{~m}$ & $\mathrm{~m}$ \\
\hline Mexiko & 21,6 & 26,9 & 31,5 & 24,3 & 28,8 & a & $x(9)$ & $x(9)$ & 15,3 \\
\hline Niederlande & $x(2)$ & 17,0 & $x(5)$ & $x(5)$ & 15,9 & $x(5)$ & $x(9)$ & $x(9)$ & 13,0 \\
\hline Neuseeland & 5,6 & 19,6 & 19,4 & 13,8 & 16,6 & 13,0 & 12,1 & 16,1 & 15,0 \\
\hline Norwegen ${ }^{2}$ & $\mathrm{~m}$ & 11,5 & 10,3 & 9,2 & 10,4 & $x(4)$ & $x(9)$ & $x(9)$ & 13,2 \\
\hline Polen & 13,5 & 12,8 & 14,1 & 13,7 & 13,9 & 12,0 & 11,5 & 18,1 & 18,0 \\
\hline Portugal & $\mathrm{m}$ & 11,0 & 9,3 & 7,5 & 8,3 & $\mathrm{~m}$ & $\mathrm{~m}$ & $\mathrm{~m}$ & $\mathrm{~m}$ \\
\hline Slowakische Rep. & 9,8 & 20,1 & 14,0 & 13,3 & 13,7 & 9,6 & 10,1 & 10,5 & 10,5 \\
\hline Spanien & 15,8 & 14,6 & 13,7 & 8,3 & 11,2 & $x(5)$ & 7,9 & 14,6 & 13,0 \\
\hline Schweden & 10,7 & 12,5 & 12,2 & 14,1 & 13,2 & $\mathrm{~m}$ & $x(9)$ & $x(9)$ & 9,1 \\
\hline Schweiz ${ }^{2}$ & $\mathrm{~m}$ & $\mathrm{~m}$ & $\mathrm{~m}$ & $\mathrm{~m}$ & $\mathrm{~m}$ & $\mathrm{~m}$ & $\mathrm{~m}$ & $\mathrm{~m}$ & $\mathrm{~m}$ \\
\hline Türkei & 14,9 & 27,5 & a & 17,7 & 17,7 & a & 47,0 & 13,6 & 16,2 \\
\hline Ver. Königreich ${ }^{1}$ & 26,6 & 19,9 & 17,6 & 12,5 & 14,8 & $\mathrm{~m}$ & $x(9)$ & $x(9)$ & 18,3 \\
\hline Vereinigte Staaten & 15,5 & 15,5 & 15,5 & 15,6 & 15,5 & a & $x(9)$ & $x(9)$ & 17,1 \\
\hline Ländermittel & 14,8 & 16,6 & 14,4 & 13,1 & 13,6 & 11,1 & 14,4 & 16,4 & 15,4 \\
\hline \multicolumn{10}{|l|}{ OECD-Partnerländer } \\
\hline Argentinien $^{3}$ & 25,2 & 19,9 & 23,5 & 17,8 & 21,0 & a & 28,4 & 11,0 & 13,3 \\
\hline Brasilien ${ }^{3}$ & 18,6 & 23,0 & 18,6 & 15,8 & 17,5 & a & $x(9)$ & $x(9)$ & 14,9 \\
\hline Chile & 27,2 & 33,1 & 32,9 & 31,5 & 32,1 & a & $\mathrm{m}$ & $\mathrm{m}$ & $\mathrm{m}$ \\
\hline China & 30,2 & 20,4 & 18,5 & 16,1 & 17,3 & $\mathrm{~m}$ & $\mathrm{~m}$ & 17,3 & $\mathrm{~m}$ \\
\hline Indien & 41,2 & 40,2 & 35,8 & 28,5 & 32,4 & 40,6 & 29,5 & 22,6 & 22,7 \\
\hline Indonesien & 19,5 & 24,3 & 18,0 & 17,3 & 17,7 & a & $x(9)$ & $x(9)$ & 16,1 \\
\hline Israel & $\mathrm{m}$ & 20,3 & 13,0 & 14,0 & 13,6 & $\mathrm{~m}$ & $\mathrm{~m}$ & $\mathrm{~m}$ & $\mathrm{~m}$ \\
\hline Jamaika & 23,5 & 32,2 & $x(5)$ & $x(5)$ & 20,2 & $\mathrm{~m}$ & 16,5 & 11,7 & 14,2 \\
\hline Jordanien & 21,0 & 20,0 & $x(2)$ & 16,0 & 48,5 & a & $\mathrm{m}$ & $\mathrm{m}$ & $\mathrm{m}$ \\
\hline Malaysia $^{3}$ & 21,9 & 19,1 & $x(5)$ & $x(5)$ & 17,2 & 27,1 & 20,6 & $\mathrm{~m}$ & 18,5 \\
\hline Paraguay $^{3}$ & $x(2)$ & 18,9 & 14,4 & 18,1 & 15,6 & $\mathrm{~m}$ & 16,4 & $\mathrm{~m}$ & $\mathrm{~m}$ \\
\hline Peru ${ }^{3}$ & 38,1 & 29,3 & $x(5)$ & $x(5)$ & 20,3 & 31,3 & 20,4 & $\mathrm{~m}$ & $\mathrm{~m}$ \\
\hline Philippinen & 30,0 & 35,4 & 45,3 & 23,2 & 38,3 & 64,8 & $x(9)$ & 22,7 & 24,9 \\
\hline Russische Föd. & 7,0 & 17,1 & $x(5)$ & $x(5)$ & 11,3 & $\mathrm{~m}$ & $\mathrm{~m}$ & $\mathrm{~m}$ & $\mathrm{~m}$ \\
\hline Thailand & 30,2 & 19,1 & 23,4 & 25,1 & 24,3 & a & 29,5 & $\mathrm{~m}$ & 34,9 \\
\hline Tunesien & $\mathrm{m}$ & a & $x(5)$ & $x(5)$ & 21,7 & $\mathrm{~m}$ & $x(9)$ & $x(9)$ & $\mathrm{m}$ \\
\hline Uruguay ${ }^{3}$ & 28,2 & 20,8 & 11,3 & 20,6 & 14,1 & a & $x(9)$ & $x(9)$ & 8,3 \\
\hline Simbabwe & $\mathrm{m}$ & 39,4 & $x(5)$ & $x(5)$ & 39,2 & $\mathrm{~m}$ & $\mathrm{~m}$ & $\mathrm{~m}$ & $\mathrm{~m}$ \\
\hline
\end{tabular}

Hinweis: $x$ bedeutet, dass die Daten in einer anderen Spalte enthalten sind, deren Referenz in runden Klammern nach dem , x angegeben ist. So bedeutet $z$. B. $x(2)$, dass die Daten in Spalte 2 enthalten sind.

1. Nur allgemeinbildende Bildungsgänge im Sekundarbereich I und II. 2. Nur öffentliche Bildungseinrichtungen. 3. Referenzjahr 2001.

Quelle: OECD. Hinweise s. Anhang 3 unter www.oecd.org/edu/eag2004. 


\section{Tabelle D2.3}

Unterrichtende und nicht-unterrichtende Beschäftige in Bildungseinrichtungen (2002)

Unterrichtende und nicht-unterrichtende Beschäftigte im Primar- und Sekundarbereich, pro 1.000 Schüler (basierend auf Vollzeitäquivalenten)

\begin{tabular}{|c|c|c|c|c|c|c|c|}
\hline & \multicolumn{2}{|c|}{ Lehrpersonal } & \multirow{2}{*}{$\begin{array}{l}\text { Professionelle } \\
\text { Unterstüztung } \\
\text { für Schüler }\end{array}$} & \multicolumn{2}{|c|}{$\begin{array}{l}\text { Personal in Management/ } \\
\text { Qualitätskontrolle/Verwaltung }\end{array}$} & \multirow{2}{*}{$\begin{array}{c}\text { Betriebs- und } \\
\text { Wartungs- } \\
\text { personal }\end{array}$} & \multirow{2}{*}{$\begin{array}{l}\text { Unterrichtende } \\
\text { u. nicht- } \\
\text { unterrichtende } \\
\text { Beschäftige } \\
\text { zusammen }\end{array}$} \\
\hline & $\begin{array}{l}\text { Lehrer, Fachlehrer } \\
\text { und sonstige } \\
\text { Lehrende } \\
\text { (1) }\end{array}$ & $\begin{array}{l}\text { Hilfslehrkräfte } \\
\text { und lehrende/ } \\
\text { forschende } \\
\text { Assistenten } \\
\text { (2) }\end{array}$ & & $\begin{array}{l}\text { Personal im } \\
\text { Management der } \\
\text { Schule sowie auf } \\
\text { übergeordneter } \\
\text { Ebene } \\
\text { (4) }\end{array}$ & $\begin{array}{l}\text { Verwaltungs- } \\
\text { personal der } \\
\text { Schule sowie auf } \\
\text { übergeordneter } \\
\text { Ebene } \\
\text { (5) }\end{array}$ & & \\
\hline OECD-Länder & & & & & & & \\
\hline Australien & $\mathrm{m}$ & $\mathrm{m}$ & $\mathrm{m}$ & $\mathrm{m}$ & $\mathrm{m}$ & $\mathrm{m}$ & $\mathrm{m}$ \\
\hline Österreich & 88,7 & $\mathrm{~m}$ & $\mathrm{~m}$ & 5,4 & $\mathrm{~m}$ & $\mathrm{~m}$ & $\mathrm{~m}$ \\
\hline Belgien & 93,4 & $\mathrm{~m}$ & $\mathrm{~m}$ & $\mathrm{~m}$ & $\mathrm{~m}$ & $\mathrm{~m}$ & $\mathrm{~m}$ \\
\hline Belgien (fläm.) & 88,3 & a & 7,3 & $\mathrm{~m}$ & $\mathrm{~m}$ & $\mathrm{~m}$ & $\mathrm{~m}$ \\
\hline Kanada & $\mathrm{m}$ & $\mathrm{m}$ & $\mathrm{m}$ & $\mathrm{m}$ & $\mathrm{m}$ & $\mathrm{m}$ & $\mathrm{m}$ \\
\hline Tschechische Rep. & 66,4 & 0,2 & 5,7 & 7,1 & 18,9 & 16,5 & 114,8 \\
\hline Dänemark & $\mathrm{m}$ & $\mathrm{m}$ & $\mathrm{m}$ & $\mathrm{m}$ & $\mathrm{m}$ & $\mathrm{m}$ & $\mathrm{m}$ \\
\hline Finnland & 69,6 & 5,2 & 2,7 & 2,4 & 7,2 & 14,9 & 102,1 \\
\hline Frankreich & 70,1 & $\mathrm{~m}$ & 24,4 & 7,3 & 4,0 & 13,9 & 119,7 \\
\hline Deutschland & 62,0 & $\mathrm{~m}$ & $\mathrm{~m}$ & $\mathrm{~m}$ & $\mathrm{~m}$ & $\mathrm{~m}$ & $\mathrm{~m}$ \\
\hline Griechenland & 94,6 & $\mathrm{~m}$ & $\mathrm{~m}$ & $\mathrm{~m}$ & $\mathrm{~m}$ & $\mathrm{~m}$ & $\mathrm{~m}$ \\
\hline Ungarn & 87,6 & $\mathrm{~m}$ & $x(1$ or 5$)$ & $x(1$ or 5$)$ & 5,4 & 35,3 & 128,3 \\
\hline Island ${ }^{1}$ & 89,7 & $n$ & 9,7 & 8,1 & 4,4 & 24,2 & 136,0 \\
\hline Irland ${ }^{2}$ & 59,5 & $\mathrm{~m}$ & $\mathrm{~m}$ & 1,9 & $\mathrm{~m}$ & $\mathrm{~m}$ & $\mathrm{~m}$ \\
\hline Italien & 96,8 & 3,7 & 6,3 & 1,8 & 11,6 & 24,7 & 144,8 \\
\hline Japan & 59,0 & $\mathrm{~m}$ & 5,1 & 5,3 & 4,8 & 6,4 & 80,6 \\
\hline Korea & 42,4 & $\mathrm{~m}$ & 0,8 & 2,6 & 2,3 & 4,4 & 52,5 \\
\hline Luxemburg & 97,9 & $\mathrm{a}$ & $\mathrm{m}$ & $\mathrm{m}$ & $\mathrm{m}$ & $\mathrm{m}$ & $\mathrm{m}$ \\
\hline Mexiko & 36,2 & 0,3 & 1,1 & 3,4 & 8,6 & 4,1 & 53,7 \\
\hline Niederlande & 60,6 & $\mathrm{~m}$ & $\mathrm{~m}$ & $\mathrm{~m}$ & $\mathrm{~m}$ & $\mathrm{~m}$ & $\mathrm{~m}$ \\
\hline Neuseeland & 56,0 & $\mathrm{~m}$ & $\mathrm{~m}$ & 16,0 & 1,3 & $\mathrm{~m}$ & $\mathrm{~m}$ \\
\hline Norwegen & 92,3 & $\mathrm{~m}$ & $\mathrm{~m}$ & 10,2 & $\mathrm{~m}$ & $\mathrm{~m}$ & $\mathrm{~m}$ \\
\hline Polen & 74,8 & a & $\mathrm{m}$ & $\mathrm{m}$ & $\mathrm{m}$ & $\mathrm{m}$ & $\mathrm{m}$ \\
\hline Portugal & 105,1 & $\mathrm{~m}$ & $\mathrm{~m}$ & $\mathrm{~m}$ & $\mathrm{~m}$ & $\mathrm{~m}$ & $\mathrm{~m}$ \\
\hline Slowakische Rep. & 66,0 & $\mathrm{~m}$ & $\mathrm{~m}$ & 6,5 & $\mathrm{~m}$ & $\mathrm{~m}$ & $\mathrm{~m}$ \\
\hline Spanien $^{2}$ & 79,6 & $\mathrm{~m}$ & $\mathrm{~m}$ & $\mathrm{~m}$ & $\mathrm{~m}$ & $\mathrm{~m}$ & $\mathrm{~m}$ \\
\hline Schweden & 77,9 & 1,2 & $\mathrm{~m}$ & 4,8 & $\mathrm{~m}$ & $\mathrm{~m}$ & $\mathrm{~m}$ \\
\hline Schweiz & $\mathrm{m}$ & $\mathrm{m}$ & $\mathrm{m}$ & $\mathrm{m}$ & $\mathrm{m}$ & $\mathrm{m}$ & $\mathrm{m}$ \\
\hline Türkei & 40,5 & $\mathrm{~m}$ & $\mathrm{~m}$ & $\mathrm{~m}$ & $\mathrm{~m}$ & $\mathrm{~m}$ & $\mathrm{~m}$ \\
\hline Ver. Königreich & 49,7 & $\mathrm{~m}$ & $\mathrm{~m}$ & $\mathrm{~m}$ & $\mathrm{~m}$ & $\mathrm{~m}$ & $\mathrm{~m}$ \\
\hline Vereinigte Staaten & 64,6 & 13,4 & 4,6 & 3,7 & 10,9 & 26,3 & 123,5 \\
\hline Ländermittel & 72,9 & 4,0 & 6,8 & 5,8 & 7,2 & 17,1 & 105,6 \\
\hline
\end{tabular}

Hinweis: $x$ bedeutet, dass die Daten in einer anderen Spalte enthalten sind, deren Referenz in runden Klammern nach dem , $x^{\prime}$ angegeben ist. So bedeutet $z . B . x(2)$, dass die Daten in Spalte 2 enthalten sind.

1. Daten zu übergeordnetem Management- und Vewaltungspersonal nicht verfügbar. 2. Einschließlich Beschäftigte im post-sekundaren, nicht-tertiären Bereich.

Quelle: OECD. Hinweise s. Anhang 3 unter www.oecd.org/edu/eag2004. 



\section{Gehälter von Lehrern}

Die mittleren Gehälter von Lehrern des Sekundarbereich I reichen von weniger als 10.000 US-Dollar in der Slowakischen Republik bis zu 40.000 USDollar und mehr in Australien, Deutschland, Japan, Korea, Schottland, der Schweiz und den Vereinigten Staaten.

- Im Durchschnitt liegt das Gehalt je Unterrichtsstunde für einen Lehrer im Sekundarbereich II um rund 40 Prozent über dem eines Lehrers im Primarbereich, wobei dieser Unterschied in Neuseeland, der Türkei und den Vereinigten Staaten weniger als 5 Prozent ausmacht, während er in Spanien ganze 82 Prozent beträgt. Dort ist die Differenz zwischen Primar- und Sekundarbereich II in der Anzahl der zu leistenden Unterrichtsstunden am größten.

Sowohl im Primar- als auch im Sekundarbereich sind die Höchstgehälter im Durchschnitt um rund 70 Prozent höher als die Anfangsgehälter, wobei dies von Land zu Land variiert und im Großen und Ganzen im Verhältnis zur Anzahl der Jahre steht, die ein Lehrer benötigt, um alle Gehaltsstufen zu durchlaufen. Die Höchstgehälter in Korea sind beispielsweise fast dreimal so hoch wie die Anfangsgehälter, doch dauert es 37 Jahre, bis man die Spitze der Gehaltsskala erreicht.

Zwischen 1996 und 2002 sind die Lehrergehälter in praktisch allen Ländern real angestiegen, wobei der größte Anstieg in Mexiko und Ungarn zu verzeichnen war. In Spanien kam es im gleichen Zeitraum zu einem realen Rückgang der Gehälter im Primar- und Sekundarbereich II. 


\section{Abbildung D3.1}

Lehrergehälter im Sekundarbereich I (2002)

Gesetzliche bzw. vertraglich vereinbarte Jahresgehälter von Lehrern an öffentlichen Bildungseinrichtungen, in US-Dollar (kaufkraftbereinigt) sowie das Verhältnis des Gehalts nach 15 Jahren Berufserfahrung zum BIP pro Kopf

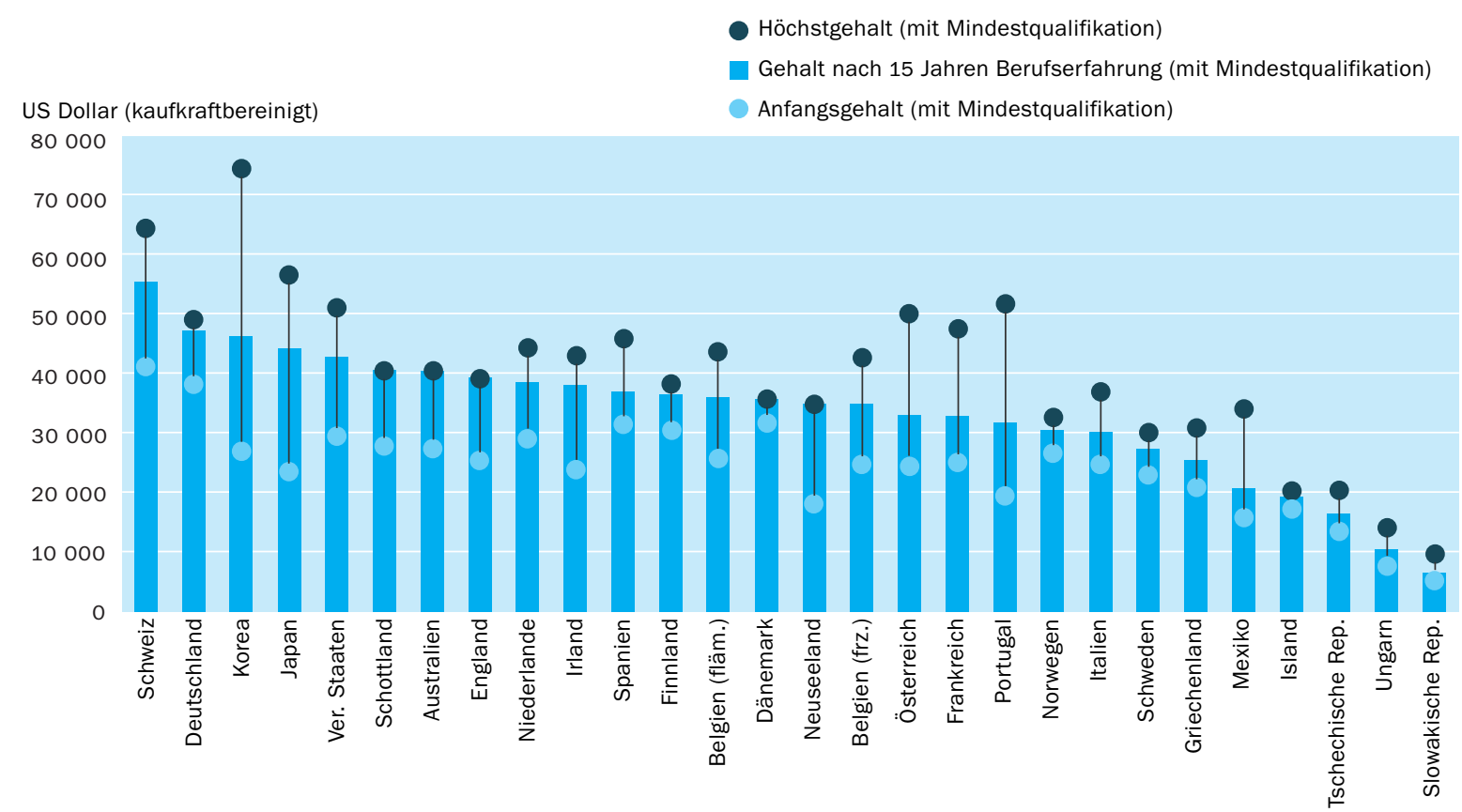

Verhältnis des Gehalts nach 15 Jahren Berufserfahrung zum BIP pro Kopf

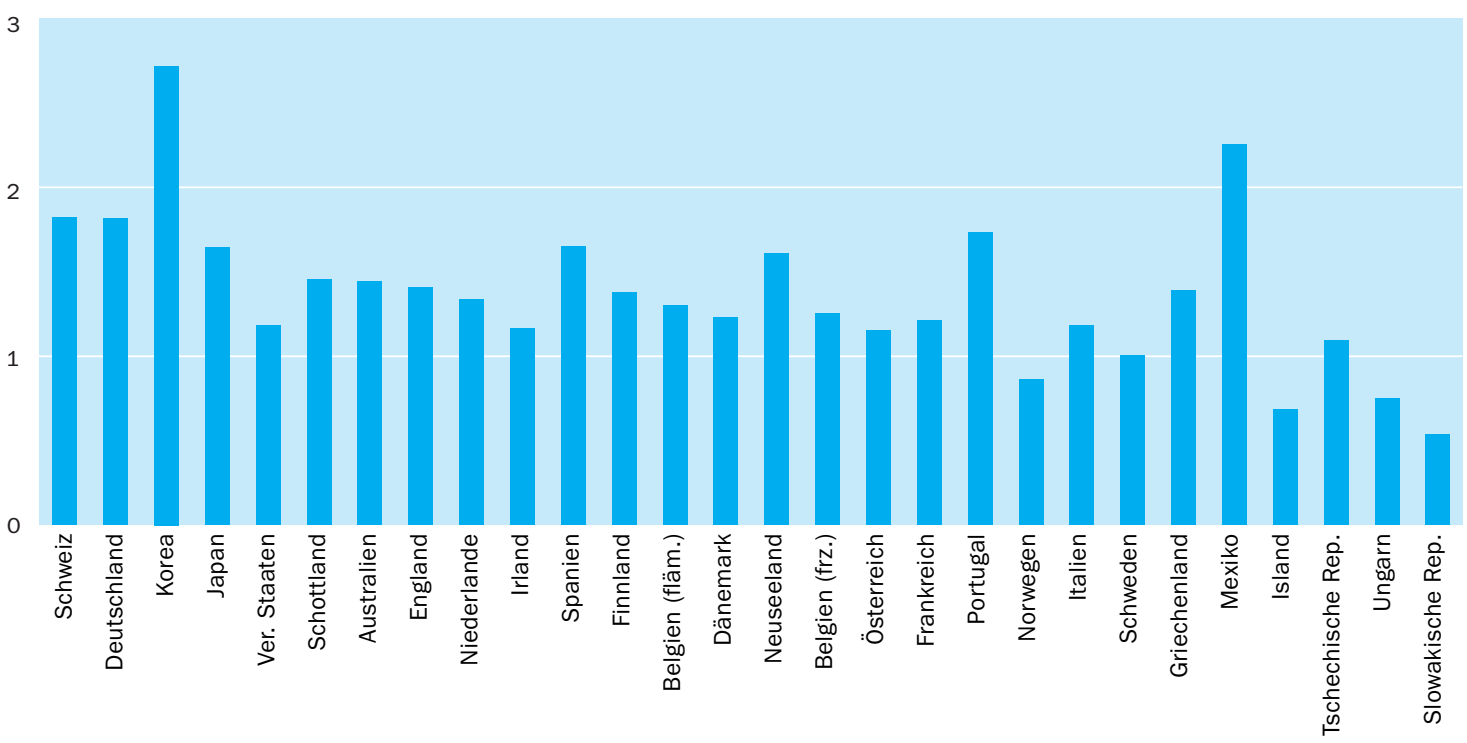




\section{Politischer Hintergrund}

Im Bildungssystem ist eine große Anzahl von qualifizierten Kräften unter zunehmend wettbewerbsorientierten Marktbedingungen beschäftigt, und allen OECD-Ländern ist es ein großes Anliegen, dafür Sorge zu tragen, dass es genug qualifizierte Lehrkräfte gibt. Das Angebot an qualifizierten Lehrkräften wird hauptsächlich bestimmt durch die Gehälter und Arbeitsbedingungen von Lehrern, einschließlich dem Anfangsgehalt und dem System der Besoldungsund Vergütungsgruppen, sowie die dem Einzelnen während der Ausbildung zum Lehrer entstehenden Kosten im Vergleich zu den Gehältern und Kosten für andere hochqualifizierte Berufe. Beides beeinflusst die beruflichen Entscheidungen potentieller Lehrer und derjenigen, die sich für den Lehrerberuf interessieren.

Die Lehrergehälter sind der größte Einzelposten, wenn es um die Kosten der Bildung geht, und daher ein entscheidender Faktor für die politischen Entscheidungsträger, die sowohl die Qualität des Unterrichts aufrechterhalten wollen als auch einen ausgeglichenen Bildungsetat anstreben. Die Höhe der Bildungsetats spiegelt das Ausbalancieren vieler miteinander in Zusammenhang stehender Faktoren wider. Hierzu gehören die Lehrergehälter, das zahlenmäßige Schüler/Lehrkräfte-Verhältnis, der Umfang der für Schüler vorgesehenen Unterrichtszeit und die vorgesehene Anzahl der Unterrichtsstunden der Lehrer.

\section{Ergebnisse und Erläuterungen}

\section{Vergleich der Lehrergehälter}

Der erste Teil dieses Indikators vergleicht die Höhe des gesetzlichen bzw. vertraglich vereinbarten Anfangsgehalts, des mittleren und des Höchstgehalts von Lehrern mit der Mindestqualifikation zum Unterrichten an öffentlichen Schulen des Primar- und Sekundarbereichs. Zunächst wird die absolute Höhe des gesetzlichen bzw. vertraglich vereinbarten Anfangsgehalts, des mittleren und des Höchstgehalts verglichen (in US-Dollar, kaufkraftbereinigt). Dies erlaubt Rückschlüsse darauf, wie sich Berufserfahrung auf die Einstufung in den jeweiligen landesspezifischen Besoldungsgruppen und auf die Kosten der Unterrichtszeit in den einzelnen Ländern auswirkt. Als Zweites werden die Zulagen-Systeme untersucht. Im dritten Schritt werden dann die Veränderungen in den Lehrergehältern zwischen 1996 und 2002 verglichen.

Die Besoldungs- und Vergütungsgruppen basieren in der Regel zwar auf dem einfachen Prinzip der Qualifikationsstufen und der Dienstjahre, in Wirklichkeit aber ist die Struktur der Besoldungssysteme für Lehrer doch weit komplexer. Viele Länder bieten beispielsweise als Teil des Bruttojahresgehaltes Ortszuschläge für das Unterrichten in abgelegenen Regionen oder Familienzulagen. Leistungsansprüche können Fahrpreisermäßigungen im öffentlichen Verkehr, Steuerermäßigungen beim Erwerb kultureller Güter sowie andere quasi-pekuniäre Ansprüche enthalten, die zum Grundgehalt eines Lehrers beitragen. Innerhalb der OECD-Länder gibt es darüber hinaus große Unterschiede bei der Besteuerung und den Sozialversicherungssystemen. Aus diesem Grunde ist bei einem Vergleich der Lehrergehälter Vorsicht geboten.

Dieser Indikator beschreilbt das Anfangs-, das mittlere und das Höchstgehalt von Lehrern an öffentlichen Schulen des Primar- und Sekundarbereichs sowie verschiedene Anreizsysteme der Besoldungsund Vergütungsordnungen für Lehrer. 
Ein Vergleich der gesetzlichen bzw. vertraglich vereinbarten Lehrergehälter im Verhältnis zum jeweiligen BIP pro Kopf zeigt, ...

... dass die mittleren Gehälter der Lehrer im Primar- und Sekundarbereich I in Island, Norwegen, der Slowakischen Republik und Ungarn niedrig sind, während sie in Korea und der Türkei relativ hoch sind.

Einige Länder investieren trotz niedrigerer Volkseinkommen massiv in die Humanressourcen.

In den meisten Ländern steigen die Gehälter je höher der Bildungsbereich ist, in dem der betreffende Lehrer tätig ist.
Die gesetzlichen bzw. vertraglich festgelegten Gehälter für Lehrer mit I5 Jahren Berufserfahrung an Schulen des Sekundarbereich I reichen von weniger als I0.000 US-Dollar in der Slowakischen Republik bis zu über 50.000 US-Dollar in der Schweiz (Tab. D3.I).

Die gesetzlichen bzw. vertraglich festgelegten Gehälter, die mit diesem Indikator erfasst sind, beziehen sich auf die gemäß offiziellen Besoldungs- und Vergütungsgruppen festgelegten Gehälter. Diese sind zu unterscheiden sowohl von den tatsächlichen Gehaltsverpflichtungen, die den Regierungen entstehen, als auch von den Durchschnittsgehältern der Lehrer, die auch durch andere Faktoren beeinflusst werden, wie z. B. die Altersstruktur der Lehrerschaft und die Häufigkeit von Teilzeitarbeit. Indikator B6 zeigt die Gesamtbeträge, die für Lehrergehälter und -vergütungen aufgewendet werden. Da außerdem die Unterrichtszeit und die Arbeitsbelastung der Lehrer in den einzelnen Ländern stark voneinander abweichen können, sind diese Faktoren bei einem Vergleich der gesetzlichen bzw. vertraglich vereinbarten Lehrergehälter in den einzelnen Ländern ebenfalls zu berücksichtigen (s. Indikator $\mathrm{D}_{4}$ ).

Neben anderen Aspekten werden die Ausgaben der Länder für Lehrkräfte von den Möglichkeiten eines Landes, Bildungsausgaben zu finanzieren, beeinflusst. Ein Vergleich der gesetzlichen bzw. vertraglich vereinbarten Lehrergehälter im Verhältnis zum BIP pro Kopf ist daher eine weitere Möglichkeit, den relativen Status der Lehrergehälter in den einzelnen Ländern zu bewerten.

Die mittleren Gehälter der Lehrer im Primar- und Sekundarbereich I bezogen auf das BIP pro Kopf sind in Island $(0,68)$, Norwegen $(0,86)$, der Slowakischen Republik $(0,54)$ und Ungarn $(0,75)$ am niedrigsten und in Korea $(2,72)$ und der Türkei $(\mathrm{I}, 98)$ am höchsten. Im Sekundarbereich II (allgemeinbildend) ist das Verhältnis in Island $(0,99)$, Norwegen $(0,86)$, der Slowakischen Republik $(0,54)$ und Ungarn $(0,92)$ am niedrigsten, während die mittleren Gehälter im Verhältnis zum BIP pro Kopf in Korea $(2,72)$ und der Schweiz $(2,08)$ am höchsten sind (Tab. D3.I).

Einige Länder wie die Slowakische Republik, die Tschechische Republik und Ungarn weisen sowohl ein relativ niedriges BIP pro Kopf als auch niedrige Lehrergehälter auf. Andere Länder, z. B. Korea, Mexiko, Neuseeland, Portugal und Spanien, deren BIP pro Kopf auch relativ niedrig ist, weisen jedoch Lehrergehälter auf, die mit Ländern vergleichbar sind, die über ein viel höheres BIP verfügen. Deutschland und die Schweiz haben ein hohes BIP pro Kopf und hohe Lehrergehälter (Abb. D3.I und Tab. D3.I), wohingegen Norwegen ein hohes BIP pro Kopf aufweist, bei den mittleren Lehrergehältern jedoch unter dem Durchschnitt liegt.

Während in Australien, England, Griechenland, Irland, Japan, Korea, Neuseeland, Norwegen, Portugal, Schottland, der Slowakischen Republik, der Türkei und den Vereinigten Staaten die Lehrergehälter im Sekundarbereich II und im Primarbereich vergleichbar sind, steigen in den restlichen OECD-Ländern die Lehrergehälter in absoluten Zahlen, je höher der Bildungsbereich ihrer Lehrtätigkeit ist. So liegt beispielsweise in Belgien, Island, den Niederlanden und der Schweiz das mittlere Gehalt eines Lehrers im Sekundarbereich II mindestens 30 Prozent über dem eines Lehrers im Primarbereich (Tab. D3.I). 
Ein alternativer Maßstab für die Gehälter und die Kosten der Unterrichtszeit ergibt sich, wenn man das gesetzlich bzw. vertraglich vereinbarte Gehalt für einen Vollzeitlehrer in Beziehung setzt zu der Anzahl an Unterrichtsstunden, die dieser Lehrer pro Jahr zu unterrichten hat (s. Indikator D4). Bei diesem Maßstab erfolgt zwar keine Anpassung der Gehälter aufgrund der gesamten Zeit, die Lehrer für die unterschiedlichen unterrichtsbezogenen Aktivitäten aufwenden, es ergibt sich jedoch ein ungefährer Eindruck der Kosten für die Zeit, die Lehrer wirklich im Klassenzimmer verbringen. Das durchschnittliche Gehalt je Unterrichtsstunde nach I5 Jahren Berufserfahrung liegt im Primarbereich bei 38 US-Dollar, im Sekundarbereich I bei 47 US-Dollar und an allgemeinbildenden Schulen des Sekundarbereich II bei 54 US-Dollar. Im Primarbereich sind die Gehaltskosten je Unterrichtsstunde in Mexiko, der Slowakischen sowie der Tschechischen Republik, der Türkei und Ungarn relativ niedrig (ungefähr 20 US-Dollar oder weniger), in Dänemark, Deutschland, Japan und Korea jedoch relativ hoch (fast 60 US-Dollar und mehr). In allgemeinbildenden Schulen des Sekundarbereich II variieren die Gehaltskosten je Unterrichtsstunde sogar in noch stärkerem Ausmaß und liegen zwischen höchstens 2I US-Dollar in der Slowakischen Republik, der Türkei und Ungarn und mehr als 8o US-Dollar in Japan und Korea (Tab. D3.I und Abb. D3.2).
Das durchschnittliche Gehalt je Unterrichtsstunde nach 15 Jahren Berufserfahrung liegt im Primarbereich bei 38 USDollar, im Sekundarbereich I bei 47 US-Dollar und an allgemeinbildenden Schulen des Sekundarbereich II beí 54 USDollar.

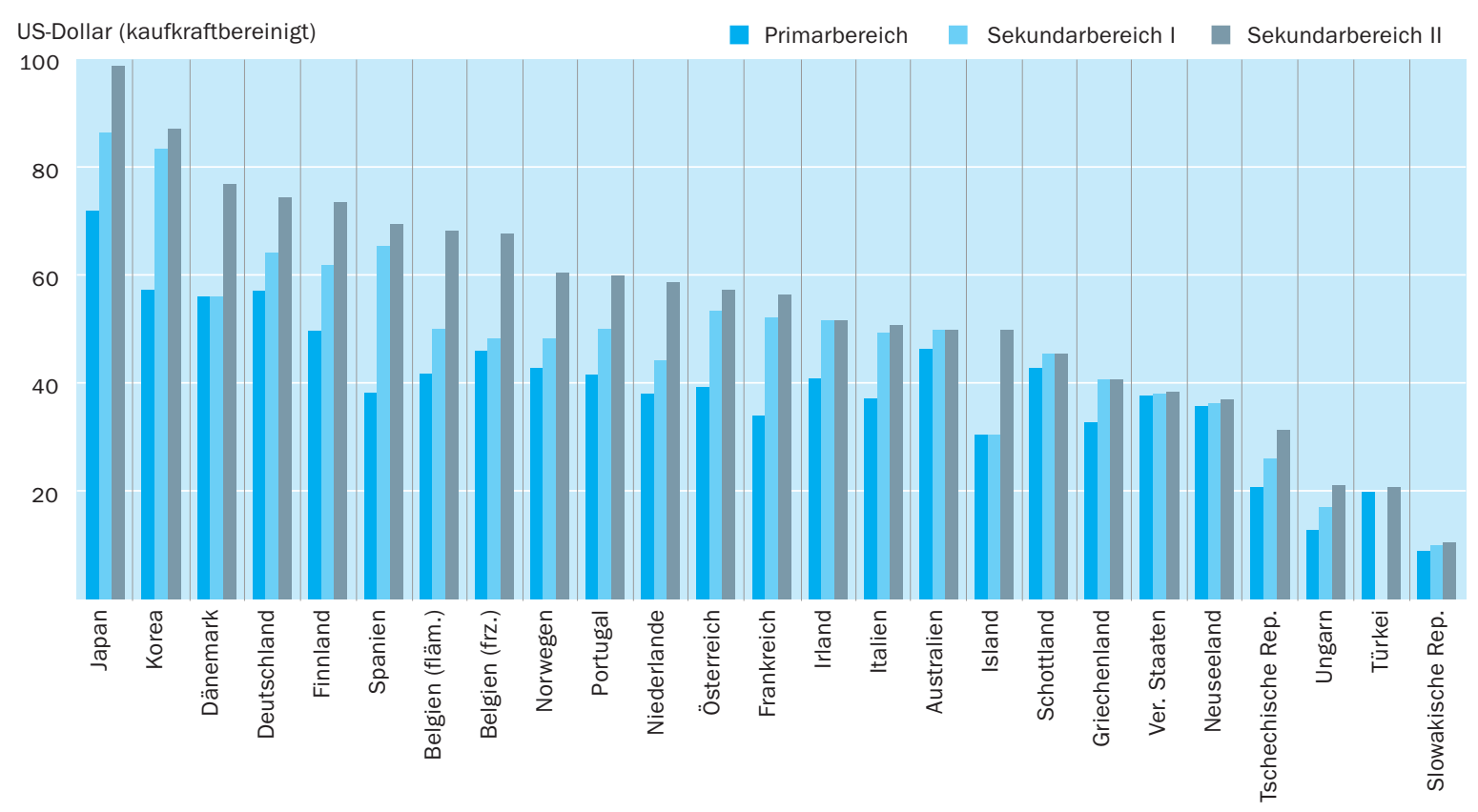


Das Gehalt je Unterrichtsstunde eines Lehrers im Sekundarbereich II liegt im Durchschnitt 40 Prozent über dem eines Lehrers im Primarbereich.

Lehrerfahrung und Qualifikationen wirken sich in vielen OECD-Ländern auf die Gehaltseinstufung der Lehrer aus.
Selbst in Ländern, in denen die gesetzlichen bzw. vertraglich vereinbarten Gehälter im Primar- und Sekundarbereich gleich sind, sind die Gehälter je Unterrichtsstunde in der Regel im Sekundarbereich II höher als im Primarbereich, denn in den meisten Ländern müssen Lehrer im Sekundarbereich weniger Unterrichtsstunden ableisten als Lehrer im Primarbereich, wie in Indikator D4 gezeigt wird. Im Durchschnitt liegt das Gehalt je Unterrichtsstunde für einen Lehrer im Sekundarbereich II um ungefähr 40 Prozent über dem eines Lehrers im Primarbereich. In Australien, Neuseeland, Schottland, der Türkei und den Vereinigten Staaten beläuft sich diese Differenz jedoch auf höchstens Io Prozent, während sie in Belgien (fläm.), Frankreich, Island und Ungarn ungefähr 6o Prozent und mehr beträgt. In Spanien, wo die Differenz zwischen Primarund Sekundarbereich II bei der Anzahl der zu leistenden Unterrichtsstunden am größten ist, liegt sie sogar bei 82 Prozent (Tab. D3.I).

Ein Vergleich der Bruttogehälter der Lehrer in den verschiedenen Ländern beim Berufsanfang, nach I5 Jahren Berufserfahrung und an der Spitze der Gehaltsskala ermöglicht Rückschlüsse über das Ausmaß, in dem die Berufserfahrung in den einzelnen Ländern die Gehaltseinstufung der Lehrer beeinflusst. Die Differenz zwischen dem gesetzlichen bzw. vertraglich vereinbarten Anfangsgehalt und den nachfolgenden Gehaltssteigerungen ist ein Anzeichen dafür, wie sehr sich Lehrerfahrung finanziell auszahlt. Im Durchschnitt der OECD-Länder liegen die gesetzlichen bzw. vertraglich vereinbarten Gehälter für Lehrer mit I5 Jahren Berufserfahrung im Primarbereich sowie im Sekundarbereich I und II (allgemeinbildend) um jeweils 37, 38 und 4I Prozent höher als die Anfangsgehälter.

Die Höchstgehälter sind sowohl im Primar- als auch im Sekundarbereich im Durchschnitt rund 70 Prozent höher als die Anfangsgehälter. Allerdings variiert dieser Prozentsatz beträchtlich zwischen den einzelnen Ländern. In Frankreich, Japan, Korea, Mexiko, Österreich und Portugal betragen die Höchstgehälter mehr als das Doppelte der Anfangsgehälter, während sie in Dänemark, Deutschland, Finnland, Island, Norwegen und der Türkei lediglich 30 Prozent höher sind (Tab. D3.I).

Das Verhältnis von Anfangs- zu Höchstgehalt hängt in der Regel damit zusammen, wie lange es dauert, bis alle Gehaltsstufen durchlaufen sind. In Australien, Dänemark, England, Neuseeland und Schottland erreichen Lehrer im Sekundarbereich I das Höchstgehalt nach 7 bis 9 Dienstjahren. In Belgien, Deutschland, Finnland, Irland, Norwegen, Portugal, der Schweiz und der Slowakischen Republik flacht die Kurve nach 20 bis 28 Jahren ab. In Frankreich, Griechenland, Italien, Japan, Korea, Österreich, Spanien, der Tschechischen Republik und Ungarn erreichen Lehrer erst nach mehr als 30 Dienstjahren das Höchstgehalt (Tab. D3.I)

Bei einem Vergleich des Index der Veränderung zwischen 1996 und 2002 bei den Lehrergehältern zeigt sich, dass diese in fast allen Ländern real angestiegen sind, und zwar sowohl im Primar- als auch im Sekundarbereich. In Mexiko und Ungarn sind die stärksten Anstiege für alle Bildungsbereiche mit mehr als 40 Prozent zu verzeichnen, obwohl die Gehälter in beiden Ländern weiterhin unter dem OECD-Durchschnitt liegen und im Fall von Ungarn auch im 
Verhältnis zum BIP pro Kopf niedrig sind. In einigen Ländern kam es allerdings zu einem realen Gehaltsrückgang zwischen 1996 und 2002, am auffälligsten in Spanien im Primarbereich und Sekundarbereich II (Tab. D3.3 und Abb. D3.3).

Die Gesamtentwicklung der Gehälter unterscheidet sich auch bei den Gehältern auf verschiedenen Stufen der Gehaltsskala, was auf eine unterschiedliche Situation bezüglich Lehrerangebot und -nachfrage in den Ländern hindeutet. So sind beispielsweise in Australien, Dänemark, England, Finnland und Schottland die Anfangsgehälter schneller angestiegen als die mittleren oder die Höchstgehälter, was auf das Bemühen hindeutet, in diesen Ländern neue Lehrer für den Beruf zu gewinnen. Im Gegensatz dazu sind die mittleren Gehälter und die Höchstgehälter in Japan und Portugal relativ schnell gestiegen, wo das politische Augenmerk stärker auf dem Halten bereits aktiver Lehrer als auf der Gewinnung neuer Lehrkräfte liegt. Die mittleren und die Höchstgehälter sind auch in Neuseeland schneller gestiegen als die Anfangsgehälter, wobei die Gehaltsskala hier allerdings relativ kurz ist (man erreicht die oberste Stufe in 7 Jahren). Dort ist in der Tat die Neueinstellung von Lehrern das Hauptziel.

Veränderungen der Lehrergehälter im Sekundarbereich I in Punkten auf der Gehaltsskala (1996 / 2002)

Index der Veränderung zwischen 1996 und 2002, unter Verwendung des BIP-Deflators zu Preisen von 2002 (1996=100)

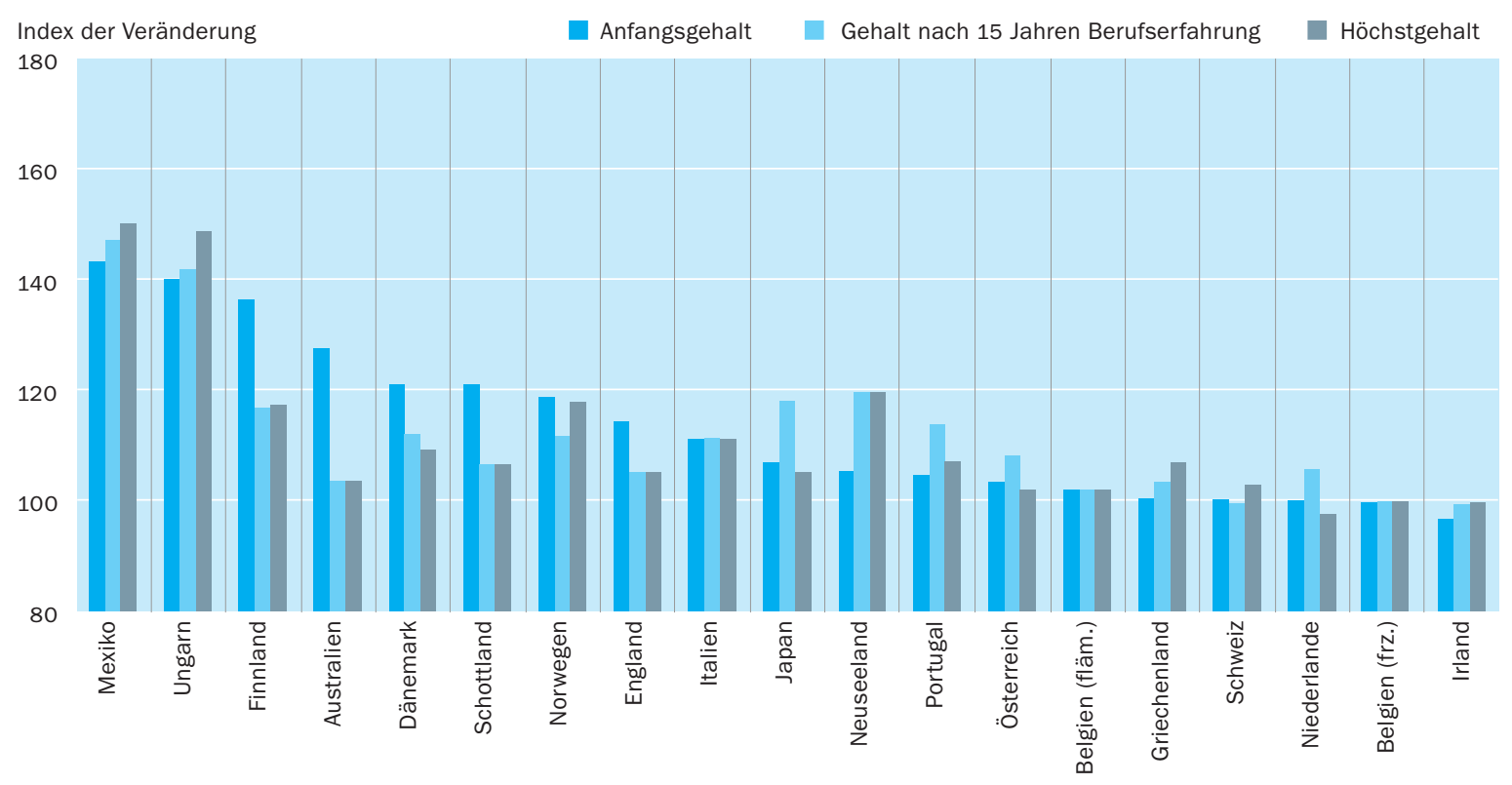


Zusätzlich können Vergünstigungen und Zulagen gewährt werden, wenn Lehrer permanent oder vorübergehend besondere Pflichten oder Verantwortungen übernehmen.
Eine Reduzierung der zu leistenden Unterrichtsstunden ersetzt oft eine finanzielle Zulage bei der Vergütung der Lehrer.

\section{Vergleichende Analyse der Lehrergehälter in Irland}

Die irischen Lehrergehälter wurden zusammen mit allen anderen Gehältern im öffentlichen Sektor einer vergleichenden Analyse unterzogen, die im Jahr 2002 abgeschlossen wurde. Bei dieser Analyse wurden Tätigkeiten, Vergütungen und Arbeitsbedingungen von Beschäftigten im öffentlichen Dienst eingehend untersucht und mit ähnlichen Arbeitsplätzen im Privatsektor verglichen. Als Ergebnis dieses Prozesses wurde die Empfehlung ausgesprochen, die Lehrervergütung um I3 Prozent anzuheben. Die Regierung erklärte sich bereit, mit Wirkung zum I. Dezember 2002 ein Viertel der empfohlenen Erhöhung zu zahlen.

Zusätzlich zu den allgemeinen Besoldungs- und Vergütungsgruppen wurden in vielen Ländern Anreizprogramme für Lehrer entwickelt, entweder in Form finanzieller Vergütungen und/oder in Form der Reduzierung der zu leistenden Unterrichtsstunden. In Verbindung mit dem Anfangsgehalt beeinflussen solche Anreizprogramme die Entscheidung, den Lehrerberuf zu ergreifen und ihn auch langfristig auszuüben. Anreizprogramme für Berufsanfänger können Familienzulagen oder Ortszuschläge für die Lehrtätigkeit an bestimmten Orten sein, ein höheres Anfangsgehalt für Qualifikationen, die über die für den Lehrberuf erforderlichen Mindestanforderungen hinausgehen, und weitere Zulagen für Lehrqualifikationen in mehreren Fachgebieten oder die Qualifikation, Schüler mit einem speziellen Bildungsbedarf zu unterrichten.

Zulagen zum Grundgehalt können den Lehrern an öffentlichen Schulen entweder vom Fachbereichs- oder Schulleiter oder von amtlicher Seite auf lokaler, regionaler oder nationaler Ebene gewährt werden. Diese Gehaltsanpassungen lassen sich in drei grundsätzliche Kategorien einteilen: Kriterien, die auf Unterrichtsbedingungen und -verantwortlichkeiten beruhen, Kriterien im Zusammenhang mit den Qualifikationen, der Ausbildung und der Leistung eines Lehrers, sowie auf demographischen und anderen Kennzahlen beruhende Kriterien.

\section{Tarifvertrag in Finnland}

Der Tarifvertrag für staatliche und kommunale Beamte legt bezüglich des Vergütungssystems für den Lehrbereich ein Mindestgehalt fest, wobei das System es allerdings auch ermöglicht, auf lokaler Ebene bessere Bedingungen zu vereinbaren.

Eine spezielle Art von Zulage ist die Reduzierung der zu leistenden Unterrichtsstunden. In einigen Ländern werden so Berufserfahrung bzw. lange Dienstzeiten anerkannt (z. B. in Griechenland und Island), in anderen werden Lehrer für die Übernahme zusätzlicher Aufgaben oder Aktivitäten (z. B. Leitung der Theatergruppe oder die Tätigkeit als Supervisor für angehende Lehrer) anstelle einer zusätzlichen Vergütung durch eine Reduzierung der Anzahl der Unterrichtsstunden belohnt. 


\section{Reduzierung der zu leistenden Unterrichtsstunden in Griechenland} In Griechenland beträgt die Unterrichtszeit für einen Lehrer im Sekundarbereich beim Eintritt in den Beruf 2I Unterrichtsstunden pro Woche. Nach 6 Dienstjahren reduziert sich die Unterrichtszeit auf ig Unterrichtsstunden pro Woche. Nach I2 Jahren sind es I8 Unterrichtsstunden pro Woche, und nach 20 Jahren schließlich sind $\mathrm{I} 6$ Unterrichtsstunden pro Woche abzuleisten. Die verbleibenden Stunden der Pflichtarbeitszeit müssen die Lehrer innerhalb der Schule ableisten.

In den meisten Ländern erhalten alle oder fast alle Lehrer Zulagen, wenn sie Managementaufgaben übernehmen: mehr Stunden oder Klassen als in einem Vollzeitvertrag vorgesehen unterrichten (z.B.Stellvertretungspflichten) oder besondere Aufgaben übernehmen wie die Beratung oder das Ausbilden von angehenden Lehrern. Obwohl in vielen Ländern die Zulagen für Überstunden, Managementaufgaben und besondere Aufgaben und Aktivitäten auf nationaler Ebene geregelt sind, liegt in etwa der Hälfte der OECD-Länder mit vergleichbaren Daten (Australien, Dänemark, England, Finnland, Griechenland, Island, Italien, Neuseeland, Österreich, Portugal, Schottland, Schweden, Slowakische Republik, Tschechische Republik und Ungarn) die Zuständigkeit für Entscheidungen hinsichtlich Höhe und Ausmaß der Zulagen für solche Tätigkeiten teilweise auch bei den Schulen selbst.

\section{Individuelles Vergütungssystem in Schweden}

In Schweden wurde Mitte der goer Jahre das starre Besoldungs- und Vergütungssystem für Lehrer als Teil einer Vereinbarung zur Förderung der lokalen Autonomie und Flexibilität im Schulsystem abgeschafft. Die Regierung verpflichtete sich zu einer deutlichen Erhöhung der Lehrergehälter über einen Zeitraum von fünf Jahren, jedoch unter der Bedingung, dass nicht alle Lehrer die gleiche Erhöhung bekommen. Dementsprechend gibt es keine festgelegte Obergrenze, und nur ein Mindestgrundgehalt wird zentral verhandelt, genauso wie die Gesamterhöhung in den Gehaltsaufwendungen für Lehrer. Gehälter werden verhandelt, wenn ein Lehrer eingestellt wird, und Lehrer und Arbeitgeber einigen sich auf das Gehalt, das bei Aufnahme des Arbeitsverhältnisses zu zahlen ist. Der Aufgabenbereich des Lehrers und seine Leistung werden bei den Verhandlungen berücksichtigt und fließen in die Gehaltshöhe ein. Es gibt nun wesentlich größere Unterschiede bei den Lehrergehältern, wobei diejenigen, die in einem Bereich mit Lehrermangel tätig sind oder nachweislich bessere Leistungen vorweisen können, höhere Gehälter aushandeln können.

In den meisten Ländern werden Managementpositionen von lokalen, regionalen oder nationalen Behörden in Abhängigkeit vom jeweiligen Schultyp besetzt. In Österreich beispielsweise hat der entsprechende Lehrer dann ein gesetzlich bzw. vertraglich festgelegtes Recht auf eine Reduzierung der abzuleistenden Unterrichtsstunden (bzw. Freistellung von Lehrverpflichtungen) und auf eine Zulage, die von der Besoldungs- und Vergütungsgruppe, der Anzahl an Dienstjahren und der Größe der Schule abhängt (mit einer Sonderzulage
In rund der Hälfte der OECDLänder sind die Schulen zumindest mitverantwortlich für die Entscheidung über Höhe und Ausmaß der Zulagen für spezielle Aufgaben und zusätzliche Aktivitäten, die die Lehrer übernehmen ...

... doch in vielen Ländern gibt es festgelegte Zulagen für die Übernahme von Managementpositionen und Verwaltungsaufgaben, ... 
... während die Schulleiter bei der Vergabe zusätzlicher Zulagen für herausragende Leistungen tendenziell eine größere Entscheidungsbefugnis haben. bei langfristiger Ausübung der Funktion). Lehrer, die eingeschränktere Verwaltungs- oder Koordinierungsaufgaben übernehmen, erhalten eine Zulage in fester Höhe oder eine Reduzierung ihrer Lehrbelastung. Beides wird zentral festgelegt und fällt immer dann an, wenn eine solche Funktion vergeben wird (in der Regel durch den Schulleiter). Der Schulleiter kann mittels eines gewissen Budgets für Sonderleistungen über Zulagen in fester Höhe bei Übernahme zusätzlicher Verpflichtungen selbst verfügen. Für bestimmte Projekte kann das Ministerium für Bildung, Wissenschaft und Kultur eine Reduzierung der abzuleistenden Unterrichtsstunden gewähren.

In England wurden ab dem I. September 2000 Zusatzpunkte in den Besoldungs- und Vergütungsgruppen für die Übernahme zusätzlicher Aufgaben durch Zulagen in fester Höhe ersetzt, wenn wichtige, genau spezifizierte Managementaufgaben übernommen werden, die das für die meisten Lehrer übliche Maß überschreiten. Für Schulleiter und ihre Stellvertreter gab es gesonderte Besoldungs- und Vergütungsgruppen.

In Portugal erhalten die Schulleiter während ihrer Amtszeit ein höheres Gehalt, während Fachbereichsleitern, Koordinatoren der Lehrer einer Klassenstufe und Klassenlehrern für den Zeitraum, in dem sie diese Position innehaben, eine Reduzierung der abzuleistenden Unterrichtsstunden gewährt wird. Der Schulvorstand entscheidet über eine Reduzierung der abzuleistenden Unterrichtsstunden für diejenigen, die Aufgaben im mittleren Management übernehmen.

In Spanien sollte es im Sekundarbereich I und II für jeden didaktischen Fachbereich einen Leiter geben. Wenn es eine Lehrkraft mit dem anerkannten Status eines ,Catedrático“ gibt (Beförderungsstufe für dienstältere, erfahrene Lehrer), übernimmt er/sie die Fachbereichsleitung. Falls es mehr als einen ,Catedrático' gibt, kann der Fachbereich dem Schulleiter einen dieser Lehrer als Fachbereichsleiter vorschlagen, doch in jedem Fall entscheidet der Schulleiter über die definitive Nominierung, und die örtliche Bildungsbehörde trifft die endgültige Entscheidung. Falls es in einem Fachbereich keinen ,Catedrático' gibt, kann jeder der anderen Lehrer Fachbereichsleiter werden (in der Regel nehmen die Lehrer diese Funktion im Rotationsverfahren wahr). Alle Fachbereichsleiter erhalten eine Gehaltszulage in fester Höhe während des Zeitraums, in dem sie diese Verantwortung übernehmen. Das ,Mandat' eines Fachbereichsleiters hat in der Regel eine Dauer von vier Jahren. Im Primarbereich kann jeder Lehrer die Funktion eines Koordinators für die Lehrer einer Klassenstufe übernehmen, allerdings wird für diese Position keinerlei Gehaltszulage gewährt (Tab. D3.2 a. b, c und d sowie Anhang 3 unter www.oecd.org/edul eag2004.

In den einzelnen Ländern gibt es verschiedene Methoden zur Feststellung und Anerkennung guter Unterrichtsleistungen. In manchen Fällen wird der Abschluss beruflicher Weiterentwicklungsmaßnahmen oder die Übernahme zusätzlicher Aufgaben durch gesonderte finanzielle Zulagen anerkannt, und manchmal können diese auch explizit für herausragende Leistungen wie etwa durch einen Lehrer verbesserte Schülerleistungen vergeben werden (Tabellen D3.2 a, b, c und d). 


\section{Gehaltszulagen für herausragende Unterrichtsleistungen in der} Slowakischen Republik

Slowakische Lehrkräfte, die außergewöhnliche Kompetenzen und Fähigkeiten aufweisen und hervorragende Ergebnisse erzielen und die bei voller Qualifikation über mindestens I2 Jahre praktische Erfahrung verfügen, können als ,Top-Kräfte‘ eingestuft werden. Ihr Gehalt errechnet sich dann aus einer gesonderten Gehaltstabelle. Nur etwa 6 Prozent aller Lehrer erhalten eine Vergütung als ,Top-Kraft‘.

In England können für herausragende Leistungen Sonderpunkte in den Vergütungs- und Besoldungsgruppen vergeben werden. Erfahrene Lehrer können auch beantragen, dass sie auf das Erreichen eines außergewöhnlichen Leistungsniveaus hin bewertet werden. Dabei findet dann ein Vergleich mit nationalen Standards statt. Bei Erfolg erreichen sie die ,obere Vergütungs- und Besoldungsgruppe' mit der Aussicht auf weitere leistungsbasierte Gehaltserhöhungen. Auch in Dänemark, Mexiko, Neuseeland, Norwegen, Portugal, Schweden, der Slowakischen Republik, der Tschechischen Republik, der Türkei und Ungarn werden Zulagen für herausragende Leistungen gewährt. In Mexiko erhalten Lehrer die Zulagen für herausragende Leistungen basierend auf einer Bewertung der Lernleistungen der Schüler in einer Klasse oder einem Fach. In Portugal können sich Lehrer nach I5 Unterrichtsjahren und nach einer Beurteilung mit ,gut' durch den Fachbereichsleiter um eine Sonderbewertung ihres Lebenslaufes bewerben und eine Beförderung um zwei Jahresstufen erreichen; dies geschieht jedoch nur selten. In der Türkei beruht die Zahlung von Gehaltszulagen für herausragende Leistungen von Lehrern auf einer Bewertung durch das Provinzdirektorat für Bildung und das Ministerium (Tab. D3.2 a, b, c und d sowie Anhang 3 unter www.oecd.org/edu/eag2004). Durch Unterschiede bei der Besteuerung, beim Sozialversicherungssystem, bei Beihilfen und Leistungsansprüchen kann das Grundgehalt der Lehrer in den einzelnen OECD-Ländern unterschiedlich stark aufgestockt werden.

\section{Leistungsbasiertes Gehalt in der Schweiz}

In den Kantonen St. Gallen und Zürich kann ein Lehrer nur zur nächsten Stufe der Gehaltsskala aufrücken, wenn er eine positive Beurteilung erhält, die auf einem Verfahren mit Selbstbewertung und externer Beurteilung basiert. Hierbei werden verschiedenste Kriterien herangezogen, und die Lehrer erstellen ein Portfolio, mit dem sie ihre Arbeit und ihre Leistungen dokumentieren.

Allgemein gibt es zunehmend besondere Anreize, mit denen Lehrer für das Unterrichten unter besonders schwierigen Bedingungen entlohnt werden. Finanzielle Anreize wie etwa Gehaltszulagen für das Unterrichten in problematischen Gebieten, Transportkostenzuschüsse für Lehrer in abgelegenen Regionen oder Zulagen für das Unterrichten an Schulen mit besonderen Anforderungen finden sich heute in größerem Maße. Das Kriterium ,Unterrichten in benachteiligten oder abgelegenen Gebieten oder in Gebieten mit hohen Lebenshaltungskosten“ wird in I9 von 27 Ländern angewendet. Die Gehalts- 
anpassungen werden häufiger von offiziellen Stellen auf nationaler, lokaler oder regionaler Ebene vorgenommen als durch den Fachbereichs- oder Schulleiter.

Gewinnung von Lehrern für abgelegene und ländliche Regionen in Australien

Um Lehrer dafür zu gewinnen, in abgelegenen und ländlichen Regionen in Australien zu unterrichten, werden in Staaten wie Queensland oder New South Wales besondere Anreize und Einführungsprogramme angeboten. Sie werden ergänzt durch Weiterbildungsangebote vor dem Berufseinstieg, in denen angehenden Lehrern ein Austausch mit ländlichen Schulen ermöglicht wird, so dass sie aus erster Hand Erfahrungen mit dem Leben und Unterrichten in ländlichen Gegenden sammeln können.

\section{Definitionen und angewandte Methodik}

Die Daten stammen aus der OECD/INES-Erhebung 2003 zu Lehrern und Lehrplänen und beziehen sich auf das Schuljahr 2001/2002.
Die Daten zu den gesetzlichen bzw. vertraglich vereinbarten Gehältern und den Zulagen für Lehrer (Tab. D3.I) stammen aus der OECD/INES-Erhebung von $2003 \mathrm{zu}$ Lehrern und Lehrplänen und beziehen sich auf das Schuljahr 2001/2002. Die Gehaltsdaten sind gemäß den offiziellen Vorschriften für öffentliche Einrichtungen angegeben.

Die gesetzlichen bzw. vertraglich vereinbarten Gehälter (Tab. D3.I) beziehen sich auf das reguläre Gehalt gemäß offizieller Besoldungs- und Vergütungsgruppen. Die angegebenen Gehälter sind definiert als Bruttogehälter (die vom Arbeitgeber für die Arbeit bezahlte Gesamtsumme) abzüglich der Arbeitgeberbeiträge zur Sozial- und Rentenversicherung (gemäß bestehender Besoldungsund Vergütungsgruppen). Die Gehälter werden vor Steuer, d. h. vor Abzug der Einkommensteuern angegeben.

Die kaufkraftbereinigten Wechselkurse zur Umrechnung der Bruttogehälter der Lehrer stammen aus den ,Volkswirtschaftlichen Gesamtrechnungen' der OECD. Das Referenzdatum für das BIP pro Kopf ist das Kalenderjahr 200I, während der Referenzzeitraum für die Lehrergehälter der Zeitraum zwischen dem 30. Juni 200I und dem 30. Juni 2002 ist. Referenzzeitraum für die Kaufkraftparitäten ist 2001/2002. Die Daten wurden auf den Januar 2002 inflationsbereinigt. Bei Ländern mit vom OECD-Standard abweichendem Haushaltsjahr (d.h. Australien und Neuseeland) und bei Ländern, deren genauer Zeitraum für die Gehälter der Lehrer geringfügig abweicht (z.B. Island, Norwegen, Spanien und Ungarn), wurde der Deflator nur dann angepasst, wenn die sich ergebende Anpassung über I Prozent lag. Geringere Anpassungen wurden vernachlässigt, weil selbst für Gehälter, die sich auf 200I/2002 beziehen, der genaue Zeitraum, in dem die Gehälter gelten, nur geringfügig abweicht. Die Referenzstatistiken sowie die Referenzjahre für die Gehälter der Lehrer sind in Anhang 2 aufgeführt. 
Die angegebenen Anfangsgehälter beziehen sich auf das reguläre durchschnittliche Bruttojahresgehalt eines Vollzeitlehrers am Anfang der Lehrerlaufbahn mit der für eine Lehrerqualifikation erforderlichen Mindestausbildung.

Die Gehälter für Lehrer mit I5 Jahren Berufserfahrung beziehen sich auf das reguläre Jahresgehalt eines Vollzeitlehrers mit der für eine Lehrerqualifikation erforderlichen Mindestausbildung und ${ }_{5}$ Jahren Berufserfahrung. Die erfassten Höchstgehälter beziehen sich auf das reguläre maximale Jahresgehalt (an der Spitze der Vergütungs-/Besoldungsordnung) eines Vollzeitlehrers mit dem für seine Stelle mindestens erforderlichen Ausbildungsstand.

Zulagen zum Grundgehalt sind hier definiert als jegliche Abweichung beim Gehalt zwischen dem, was ein bestimmter Lehrer als Einkommen für die an der Schule geleistete Arbeit bezieht, und dem Betrag, den er ausschließlich aufgrund seiner Erfahrung bekommen müsste (d.h. der Anzahl der Berufsjahre als Lehrer). Zulagen können dauerhaft oder zeitlich befristet sein und dazu führen, dass ein Lehrer in den ,außertariflichen Bereich' oder auf die nächsthöhere Besoldungs-/Vergütungsstufe gelangt. 
Tabelle D3.1

Lehrergehälter (2002)

Gesetzliche bzw. vertraglich vereinbarte Jahresgehälter von Lehrern an öffentlichen Bildungseinrichtungen: Anfangsgehalt, Gehalt nach 15 Jahren Berufserfahrung und Höchstgehalt, nach Bildungsbereich, in US Dollar, kaufkraftbereinigt

\begin{tabular}{|c|c|c|c|c|c|c|c|c|c|c|c|c|}
\hline & \multicolumn{4}{|c|}{ Primarbereich } & \multicolumn{4}{|c|}{ Sekundarbereich I } & \multicolumn{4}{|c|}{ Sekundarbereich II (allgemeinbildend) } \\
\hline OECD-Länder & $\begin{array}{c}\text { Anfangs- } \\
\text { gehalt/ } \\
\text { Mindest- } \\
\text { ausbildung }\end{array}$ & \begin{tabular}{|c|} 
Gehalt nach \\
15 Jahren \\
Berufs- \\
erfahrung/ \\
Mindest- \\
ausbildung
\end{tabular} & \begin{tabular}{|c|} 
Höchst- \\
gehalt/ \\
Mindest- \\
ausbildung
\end{tabular} & $\begin{array}{c}\text { Verhältnis } \\
\text { des Gehalts } \\
\text { nach } 15 \text { Jah- } \\
\text { ren Berufs- } \\
\text { ausbildung } \\
\text { zum BIP pro } \\
\text { Kopf }\end{array}$ & $\begin{array}{c}\text { Anfangs- } \\
\text { gehalt/ } \\
\text { Mindest- } \\
\text { ausbildung }\end{array}$ & $\begin{array}{l}\text { Gehalt nach } \\
15 \text { Jahren } \\
\text { Berufs- } \\
\text { erfahrung/ } \\
\text { Mindest- } \\
\text { ausbildung }\end{array}$ & $\begin{array}{c}\text { Höchst- } \\
\text { gehalt/ } \\
\text { Mindest- } \\
\text { ausbildung }\end{array}$ & $\begin{array}{c}\text { Verhältnis } \\
\text { des Gehalts } \\
\text { nach 15 Jah- } \\
\text { ren Berufs- } \\
\text { ausbildung } \\
\text { zum BIP pro } \\
\text { Kopf }\end{array}$ & $\begin{array}{l}\text { Anfangs- } \\
\text { gehalt/ } \\
\text { Mindest- } \\
\text { ausbildung }\end{array}$ & \begin{tabular}{|c|} 
Gehalt nach \\
15 Jahren \\
Berufs- \\
erfahrung/ \\
Mindest- \\
ausbildung
\end{tabular} & $\begin{array}{l}\text { Höchst- } \\
\text { gehalt/ } \\
\text { Mindest- } \\
\text { ausbildung }\end{array}$ & $\begin{array}{c}\text { Verhältnis } \\
\text { des Gehalts } \\
\text { nach } 15 \text { Jah- } \\
\text { ren Berufs- } \\
\text { ausbildung } \\
\text { zum BIP pro } \\
\text { Kopf }\end{array}$ \\
\hline Österreich & 23511 & 31112 & 46540 & 1,08 & 24363 & 33138 & 50071 & 1,15 & 24846 & 34444 & 52294 & 1,19 \\
\hline Belgien (fläm.) & 25731 & 34913 & 41652 & 1,26 & 25731 & 36032 & 43927 & 1,30 & 31924 & 46076 & 55383 & 1,66 \\
\hline Belgien (frz.) & 24319 & 33334 & 40106 & 1,20 & 24713 & 34874 & 42717 & 1,26 & 30793 & 44854 & 54100 & 1,62 \\
\hline Tschechische Rep. & 13557 & 16453 & 20558 & 1,09 & 13557 & 16453 & 20558 & 1,09 & 15476 & 18898 & 23452 & 1,25 \\
\hline Dänemark & 31745 & 35809 & 35809 & 1,23 & 31745 & 35809 & 35809 & 1,23 & 30384 & 43063 & 46096 & 1,47 \\
\hline England & 25403 & 39350 & 39350 & 1,41 & 25403 & 39350 & 39350 & 1,41 & 25403 & 39350 & 39350 & 1,41 \\
\hline Finnland & 26647 & 31687 & 33558 & 1,20 & 30514 & 36552 & 38249 & 1,38 & 32136 & 40482 & 42652 & 1,53 \\
\hline Deutschland & 36934 & 44671 & 47921 & 1,72 & 38319 & 47165 & 49239 & 1,82 & 41441 & 50805 & 53085 & 1,96 \\
\hline Griechenland & 20906 & 25563 & 31013 & 1,39 & 20906 & 25563 & 31013 & 1,39 & 20906 & 25563 & 31013 & 1,39 \\
\hline Ungarn & 7585 & 10412 & 14104 & 0,75 & 7585 & 10412 & 14104 & 0,75 & 8790 & 12851 & 16797 & 0,92 \\
\hline Island & 17244 & 19377 & 20346 & 0,68 & 17244 & 19377 & 20346 & 0,68 & 22017 & 27941 & 30551 & 0,99 \\
\hline Irland & 22980 & 38066 & 43137 & 1,17 & 23767 & 38066 & 43137 & 1,17 & 23767 & 38066 & 43137 & 1,17 \\
\hline Italien & 22915 & 27726 & 33575 & 1,08 & 24710 & 30220 & 36906 & 1,18 & 24710 & 31073 & 38604 & 1,22 \\
\hline Japan & 23493 & 44345 & 56579 & 1,65 & 23493 & 44345 & 56579 & 1,65 & 23493 & 44372 & 58286 & 1,65 \\
\hline Korea & 26983 & 46400 & 74672 & 2,73 & 26852 & 46269 & 74541 & 2,72 & 26852 & 46269 & 74541 & 2,72 \\
\hline Mexiko & 12375 & 16324 & 27038 & 1,77 & 15862 & 20722 & 34181 & 2,25 & $\mathrm{~m}$ & $\mathrm{~m}$ & $\mathrm{~m}$ & $\mathrm{~m}$ \\
\hline Niederlande & 28003 & 35307 & 40406 & 1,22 & 29050 & 38697 & 44388 & 1,33 & 29326 & 51444 & 58913 & 1,77 \\
\hline Neuseeland & 18109 & 35034 & 35034 & 1,61 & 18109 & 35034 & 35034 & 1,61 & 18109 & 35034 & 35034 & 1,61 \\
\hline Norwegen & 26637 & 30533 & 32695 & 0,86 & 26637 & 30533 & 32695 & 0,86 & 26637 & 30533 & 32695 & 0,86 \\
\hline Portugal & 19445 & 31876 & 51829 & 1,73 & 19445 & 31876 & 51829 & 1,73 & 19445 & 31876 & 51829 & 1,73 \\
\hline Schottland & 27789 & 40619 & 40619 & 1,45 & 27789 & 40619 & 40619 & 1,45 & 27789 & 40619 & 40619 & 1,45 \\
\hline Schweden & 23059 & 27359 & 30162 & 1,01 & 23059 & 27359 & 30162 & 1,01 & 24544 & 29315 & 31711 & 1,08 \\
\hline Schweiz & 34818 & 46713 & 55304 & 1,53 & 41045 & 55431 & 64544 & 1,82 & 48704 & 63200 & 74689 & 2,08 \\
\hline Türkei & 11214 & 12700 & 14283 & 1,98 & a & a & a & a & 10272 & 11759 & 13342 & 1,84 \\
\hline Vereinigte Staaten & 29513 & 42801 & 52104 & 1,18 & 29525 & 42801 & 51170 & 1,18 & 29641 & 42918 & 51308 & 1,19 \\
\hline Ländermittel & 22910 & 31366 & 37778 & 1,33 & 24236 & 33345 & 40177 & 1,37 & 25292 & 35691 & 42683 & 1,45 \\
\hline OECD-Partnerländer & & & & & & & & & & & & \\
\hline Argentinien ${ }^{1}$ & 8398 & 11794 & 11794 & 1,00 & 12076 & 17007 & 17007 & 1,45 & 12076 & 17007 & 17007 & 1,45 \\
\hline Brasilien $^{1}$ & 8191 & 10610 & $\mathrm{~m}$ & 1,44 & 9883 & 13322 & $\mathrm{~m}$ & 1,81 & 13853 & 16397 & $\mathrm{~m}$ & 2,23 \\
\hline Chile & 11033 & 12857 & 13306 & 1,35 & 11033 & 12857 & 13306 & 1,35 & 11033 & 13454 & 13926 & 1,41 \\
\hline Ägypten & 891 & 1988 & 2278 & 0,57 & 891 & 1988 & 2278 & 0,57 & $\mathrm{~m}$ & $\mathrm{~m}$ & $\mathrm{~m}$ & $\mathrm{~m}$ \\
\hline Indien ${ }^{1}$ & 12347 & 18247 & 18247 & 6,21 & 15027 & 23001 & 23001 & 7,82 & 18247 & 26831 & 26831 & 9,12 \\
\hline Indonesien & 975 & 1543 & 1543 & 0,54 & 975 & 1543 & 1990 & 0,54 & 1014 & 1858 & 1990 & 0,64 \\
\hline Jamaika & 10955 & 12686 & 12686 & 3,43 & 10955 & 12686 & 12686 & 3,43 & 10955 & 12686 & 12686 & 3,43 \\
\hline Jordanien & 7976 & 10414 & 868 & 2,76 & 7976 & 10414 & 868 & 2,76 & 7976 & 10414 & 868 & 2,76 \\
\hline Malaysia $^{1}$ & 9344 & 14670 & 14670 & 1,70 & 13647 & 23315 & 23315 & 2,69 & 13647 & 23315 & 23315 & 2,69 \\
\hline Paraguay 1,2 & 9789 & 9789 & 9789 & 1,88 & 15269 & 15269 & 15269 & 2,93 & 15269 & 15269 & 15269 & 2,93 \\
\hline Peru ${ }^{1,2}$ & 4627 & 4627 & 5530 & 1,00 & 4577 & 4577 & 5273 & 0,99 & 4577 & 4577 & 5273 & 0,99 \\
\hline Philippinen & 9857 & 10880 & 10880 & 2,84 & 9857 & 10880 & 10880 & 2,84 & 9857 & 10880 & 10880 & 2,84 \\
\hline Sri Lanka & 2809 & 3574 & 3319 & 1,12 & 2809 & 4085 & 3319 & 1,28 & 3574 & 4596 & 3319 & 1,44 \\
\hline Thailand & 5862 & 14406 & 14406 & 2,39 & 5862 & 14406 & 14406 & 2,39 & 5862 & 14406 & 14406 & 2,39 \\
\hline Tunesien & 12835 & 12974 & 16783 & 2,00 & 16330 & 16487 & 21339 & 2,55 & 19878 & 20065 & 26167 & 3,10 \\
\hline Uruguay 1,2 & 5397 & 6467 & a & 0,77 & 5397 & 6467 & a & 0,77 & 5873 & 6944 & a & 0,83 \\
\hline
\end{tabular}

1. Referenzjahr 2001. 2. Gehalt für eine Stelle mit 20 Wochenstunden. Die Mehrzahl der Lehrer hat 2 Stellen inne.

Quelle: OECD. Hinweise s. Anhang 3 unter www.oecd.org/edu/eag2004. 
Tabelle D3.1 (Forts.)

Lehrergehälter (2002)

Gesetzliche bzw. vertraglich vereinbarte Jahresgehälter von Lehrern an öffentlichen Bildungseinrichtungen: Anfangsgehalt, Gehalt nach 15 Jahren Berufserfahrung und Höchstgehalt, nach Bildungsbereich, in US Dollar, kaufkraftbereinigt

\begin{tabular}{|c|c|c|c|c|c|c|c|c|}
\hline & \multicolumn{3}{|c|}{$\begin{array}{l}\text { Verhältnis des Gehalts nach } 15 \text { Jahren } \\
\text { Berufserfahrung zum Anfangsgehalt }\end{array}$} & \multirow{3}{*}{$\begin{array}{l}\text { Jahre zwischen } \\
\text { Anfangs- und } \\
\text { Höchstgehalt } \\
\text { (Sekundar- } \\
\text { bereich I) }\end{array}$} & \multicolumn{3}{|c|}{$\begin{array}{c}\text { Gehalt pro Unterrichtsstunde nach } 15 \text { Jahren } \\
\text { Berufserfahrung }\end{array}$} & \multirow{3}{*}{\begin{tabular}{|} 
Verhältnis des \\
Gehalts pro Unter- \\
richtsstunde von \\
Lehrern des Sekun- \\
darbereich II/ \\
Lehrern des Primar- \\
bereichs (nach \\
15 Jahren Berufs- \\
erfahrung)
\end{tabular}} \\
\hline & Primarbereich & $\begin{array}{l}\text { Sekundar- } \\
\text { bereich I }\end{array}$ & $\begin{array}{l}\text { Sekundar- } \\
\text { bereich II } \\
\text { (allgemein- } \\
\text { bildend) }\end{array}$ & & Primarbereich & $\begin{array}{l}\text { Sekundar- } \\
\text { bereich I }\end{array}$ & $\begin{array}{l}\text { Sekundar- } \\
\text { bereich II } \\
\text { (allgemein- } \\
\text { bildend) }\end{array}$ & \\
\hline \multicolumn{7}{|l|}{ OECD-Länder } & & \\
\hline Australien & 1,47 & 1,48 & 1,48 & 9 & 46 & 50 & 50 & 1,08 \\
\hline Österreich & 1,98 & 2,06 & 2,10 & 34 & 39 & 53 & 57 & 1,46 \\
\hline Belgien (fläm.) & 1,62 & 1,71 & 1,73 & 27 & 42 & 50 & 68 & 1,63 \\
\hline Belgien (frz.) & 1,65 & 1,73 & 1,76 & 27 & 46 & 48 & 68 & 1,46 \\
\hline Tschechische Rep. & 1,52 & 1,52 & 1,52 & 32 & 21 & 26 & 31 & 1,51 \\
\hline Dänemark & 1,13 & 1,13 & 1,52 & 8 & 56 & 56 & 77 & 1,37 \\
\hline England & 1,55 & 1,55 & 1,55 & 8 & $\mathrm{~m}$ & $\mathrm{~m}$ & $\mathrm{~m}$ & $\mathrm{~m}$ \\
\hline Frankreich & 1,98 & 1,89 & 1,88 & 34 & 34 & 52 & 56 & 1,66 \\
\hline Deutschland & 1,30 & 1,28 & 1,28 & 28 & 57 & 64 & 74 & 1,30 \\
\hline Griechenland & 1,48 & 1,48 & 1,48 & 33 & 33 & 41 & 41 & 1,24 \\
\hline Ungarn & 1,86 & 1,86 & 1,91 & 40 & 13 & 17 & 21 & 1,65 \\
\hline Island & 1,18 & 1,18 & 1,39 & 18 & 31 & 31 & 50 & 1,63 \\
\hline Irland & 1,88 & 1,82 & 1,82 & 22 & 42 & 52 & 52 & 1,25 \\
\hline Italien & 1,47 & 1,49 & 1,56 & 35 & 37 & 49 & 51 & 1,37 \\
\hline Japan & 2,41 & 2,41 & 2,48 & 31 & 72 & 86 & 99 & 1,38 \\
\hline Korea & 2,77 & 2,78 & 2,78 & 37 & 57 & 83 & 87 & 1,52 \\
\hline Mexiko & 2,18 & 2,15 & $\mathrm{~m}$ & 14 & 20 & 18 & $\mathrm{~m}$ & $\mathrm{~m}$ \\
\hline Niederlande & 1,44 & 1,53 & 2,01 & 19 & 38 & 44 & 59 & 1,55 \\
\hline Neuseeland & 1,93 & 1,93 & 1,93 & 7 & 36 & 36 & 37 & 1,04 \\
\hline Norwegen & 1,23 & 1,23 & 1,23 & 24 & 43 & 48 & 60 & 1,41 \\
\hline Portugal & 2,67 & 2,67 & 2,67 & 26 & 42 & 50 & 60 & 1,44 \\
\hline Spanien & 1,49 & 1,46 & 1,45 & 39 & 38 & 65 & 69 & 1,82 \\
\hline Schweden ${ }^{1}$ & $\mathrm{~m}$ & $\mathrm{~m}$ & $\mathrm{~m}$ & a & a & a & a & a \\
\hline Schweiz & 1,59 & 1,57 & 1,53 & 25 & $\mathrm{~m}$ & $\mathrm{~m}$ & $\mathrm{~m}$ & $\mathrm{~m}$ \\
\hline Türkei & 1,27 & a & 1,30 & a & 20 & a & 21 & 1,04 \\
\hline Vereinigte Staaten & 1,77 & 1,73 & 1,73 & $\mathrm{~m}$ & 38 & 38 & 38 & 1,02 \\
\hline Ländermittel & 1,69 & 1,71 & 1,73 & 24 & 38 & 47 & 54 & 1,39 \\
\hline
\end{tabular}

1. Das Verhältnis zwischen Höchst- und Anfangsgehalt wurde für Schweden nicht berechnet, da die zugrundeliegenden Gehälter Schätzwerte sind, die aus den tatsächlichen und nicht aus den gesetzlich vorgeschriebenen Gehältern abgeleitet wurden.

Quelle: OECD. Hinweise s. Anhang 3 unter www.oecd.org/edu/eag2004. 


\section{Tabelle D3.2a}

Zulagen zum Grundgehalt für Lehrer an öffentlichen Bildungseinrichtungen (2002)

Arten von Kriterien für die Gewährung von Zulagen zum Grundgehalt für Lehrer an öffentlichen Bildungseinrichtungen

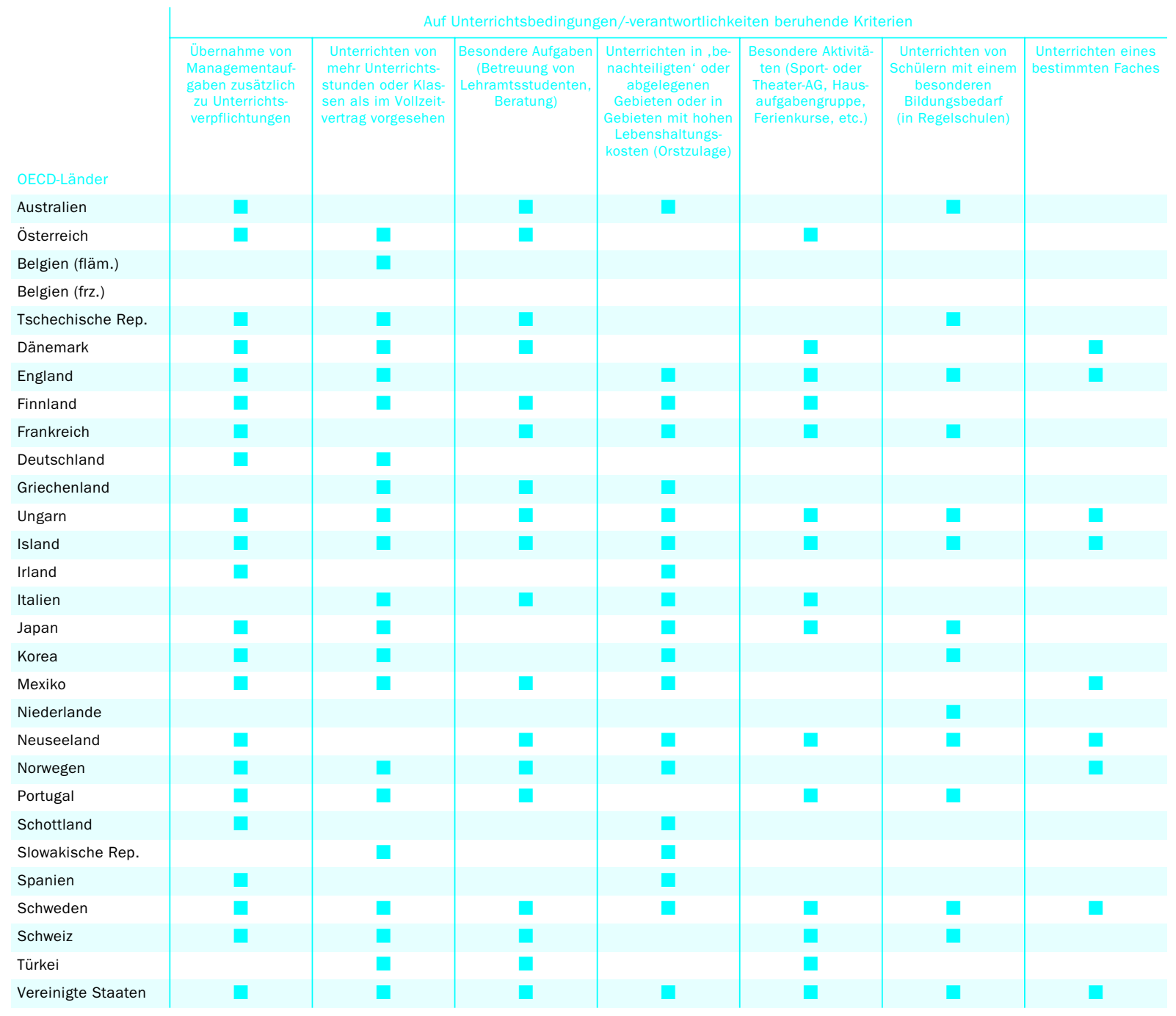

Quelle: OECD. Hinweise s. Anhang 3 unter www.oecd.org/edu/eag2004. 
Tabelle D3.2a (Forts.)

Zulagen zum Grundgehalt für Lehrer an öffentlichen Bildungseinrichtungen (2002)

Arten von Kriterien für die Gewährung von Zulagen zum Grundgehalt für Lehrer an öffentlichen Bildungseinrichtungen

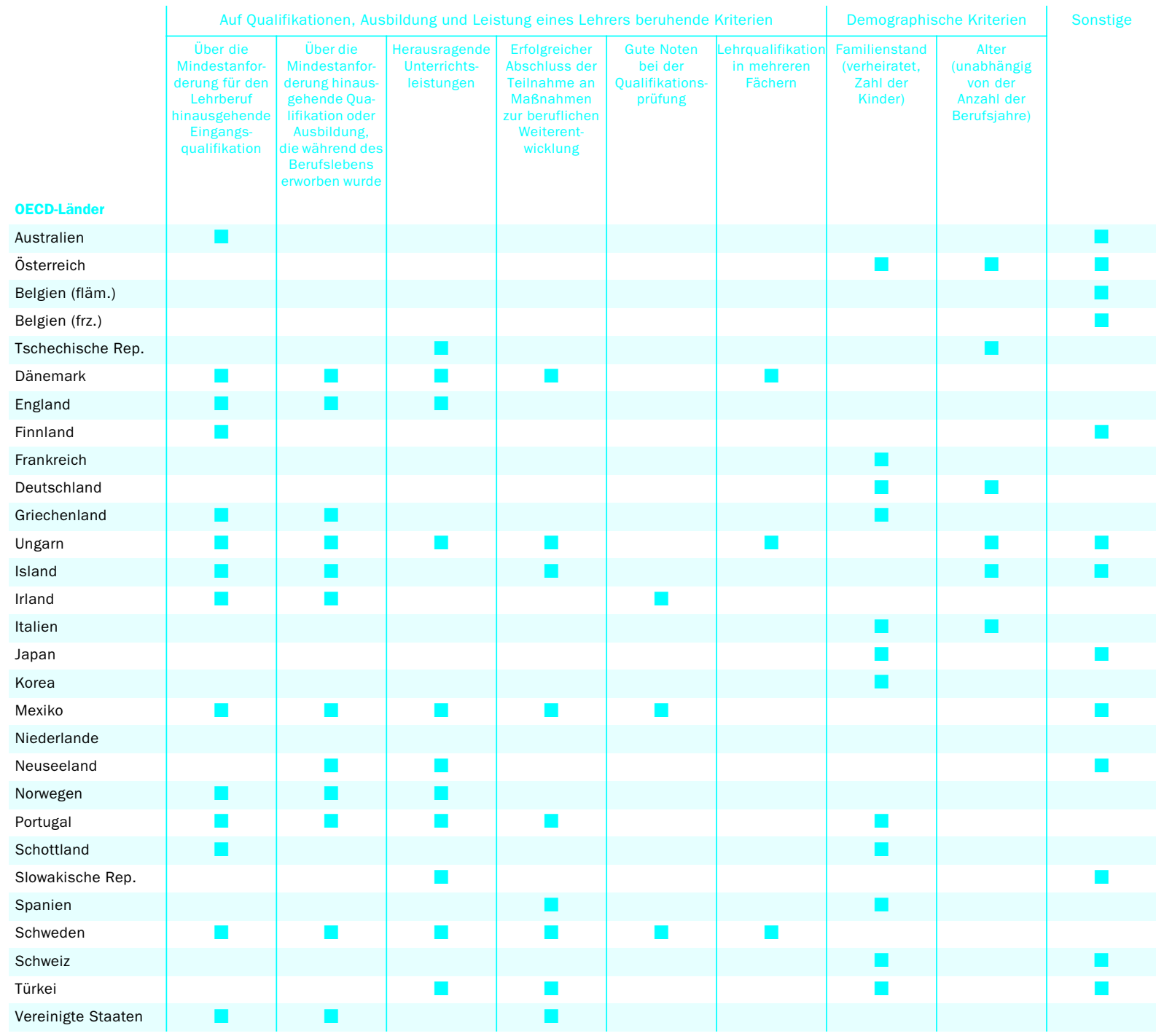

Quelle: OECD. Hinweise s. Anhang 3 unter www.oecd.org/edu/eag2004. 


\section{Tabelle D3.2b}

Zulagen zum Grundgehalt für Lehrer an öffentlichen Bildungseinrichtungen, über die vom Schulleiter entschieden wird (2002) Arten von Kriterien für die Gewährung von Zulagen zum Grundgehalt für Lehrer an öffentlichen Bildungseinrichtungen, bei denen der Schulleiter über die Gewährung der Zulage entscheidet

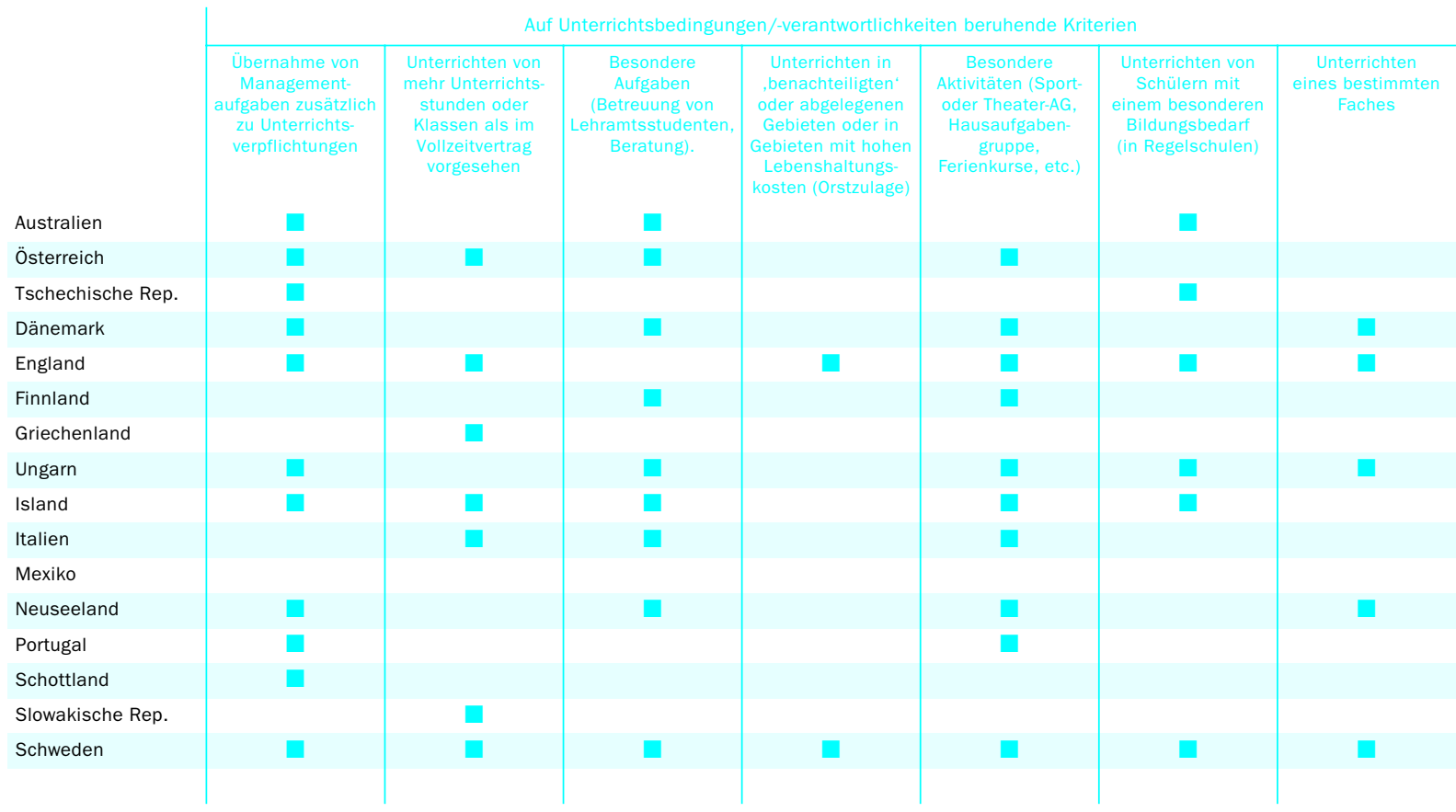

Australien

Österreich

Tschechische Rep.

Dänemark

England

Finnland

Griechenland

Ungarn

Island

Italien

Mexiko

Neuseeland

Portugal

Schottland

Slowakische Rep.

Schweden

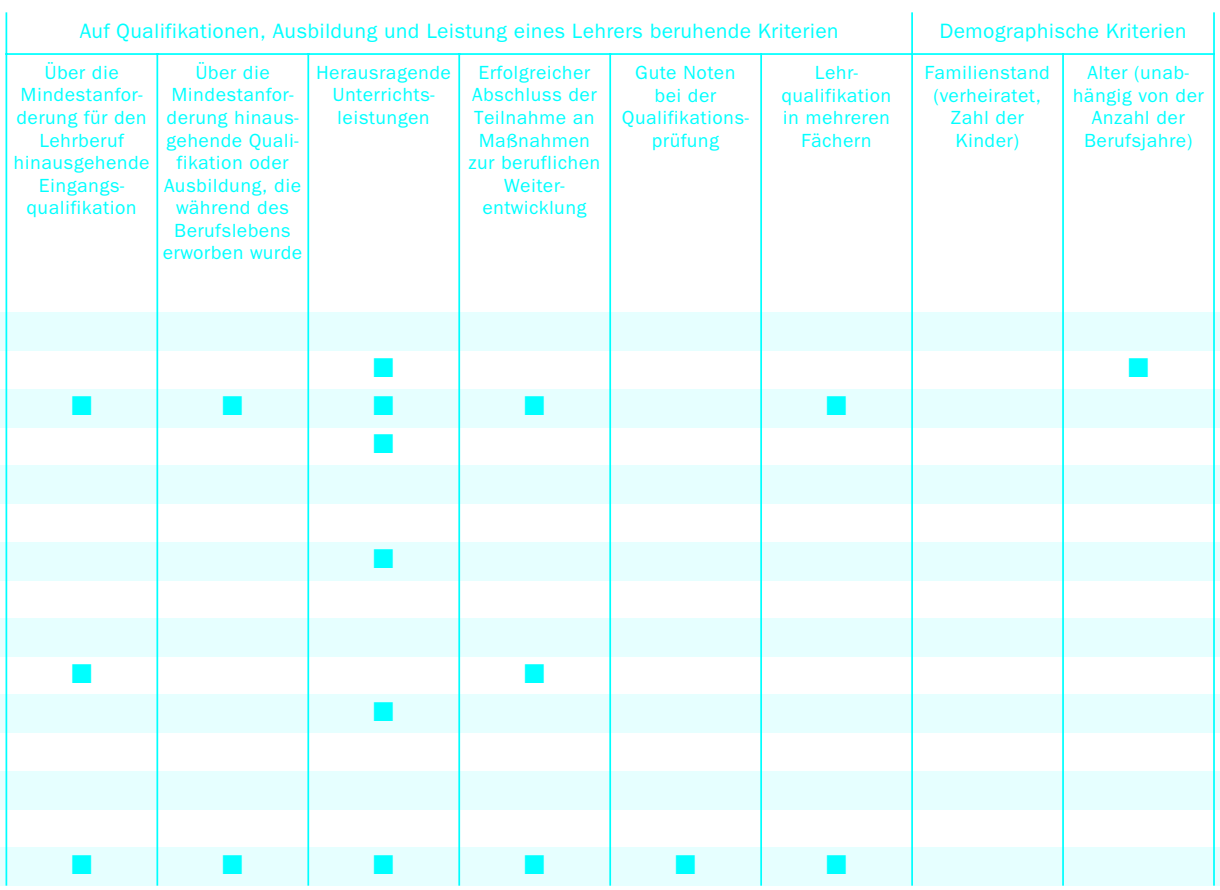

Hinweis: Länder, in denen die genannte Stelle keine Entscheidungen über die Gewährung von Gehaltszulagen trifft, sind in der Tabelle nicht aufgeführt. Quelle: OECD. Hinweise s. Anhang 3 unter www.oecd.org/edu/eag2004. 
Tabelle D3.2c

Zulagen zum Grundgehalt für Lehrer an öffentlichen Bildungseinrichtungen, über die von der lokalen oder regionalen Behörde entschieden wird (2002)

Arten von Kriterien für die Gewährung von Zulagen zum Grundgehalt für Lehrer an öffentlichen Bildungseinrichtungen, bei denen die lokale oder regionale Behörde über die Gewährung der Zulage entscheidet
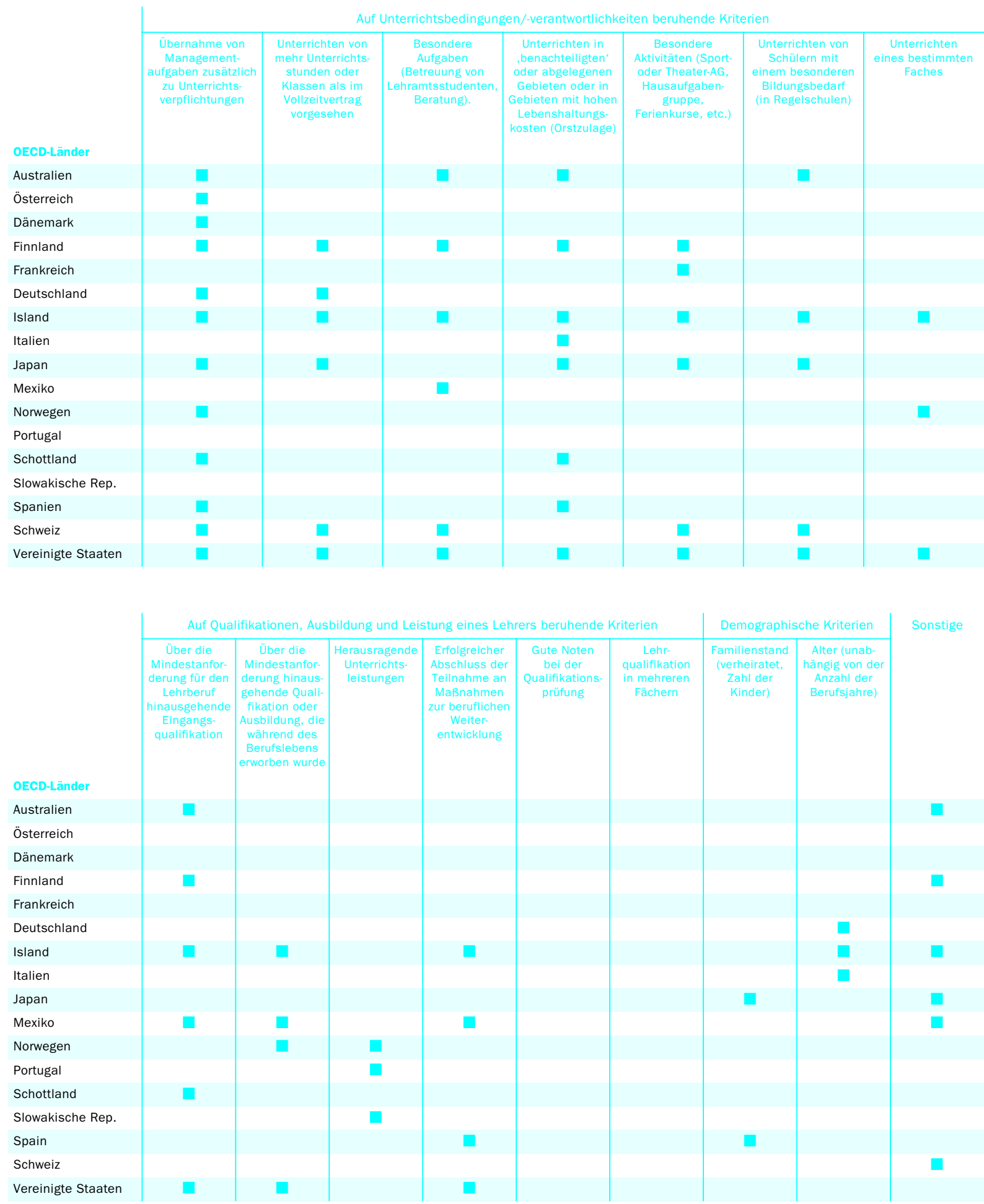

Hinweis: Länder, in denen die genannte Stelle keine Entscheidungen über die Gewährung von Gehaltszulagen trifft, sind in der Tabelle nicht aufgeführt. Quelle: OECD. Hinweise s. Anhang 3 unter www.oecd.org/edu/eag2004. 
Tabelle D3.2d

Zulagen zum Grundgehalt für Lehrer an öffentlichen Bildungseinrichtungen, über die von der nationalen Behörde entschieden wird (2002)

Arten von Kriterien für die Gewährung von Zulagen zum Grundgehalt für Lehrer an öffentlichen Bildungseinrichtungen, bei denen die nationale Behörde über die Gewährung der Zulage entscheidet

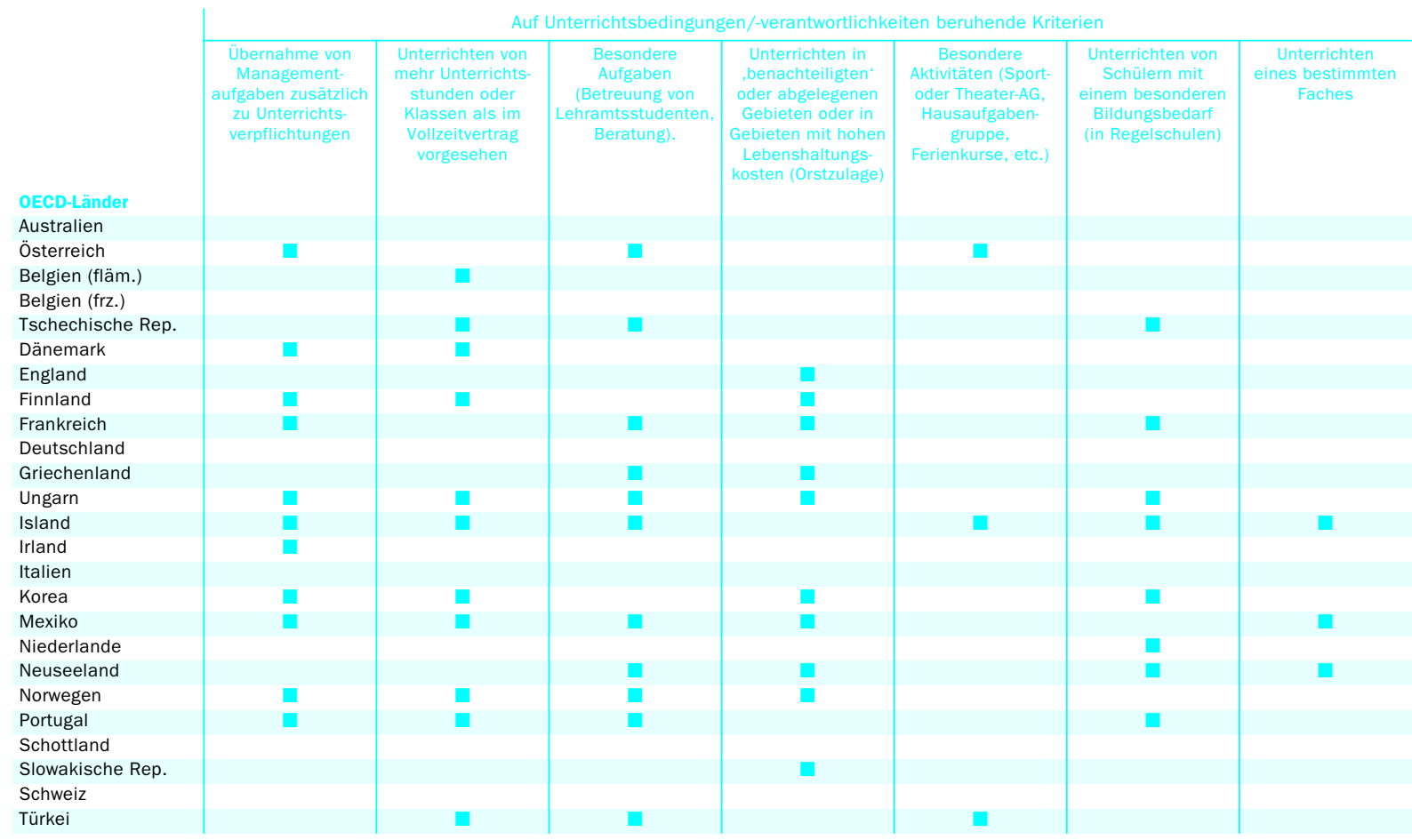

D

OECD-Länder Australien Österreich Belgien (fläm.) Belgien (frz.)

Tschechische Rep.

Dänemark

England

Finnland

Frankreich

Deutschland

Griechenland

Ungarn

Island

Irland

Italien

Korea

Mexiko

Niederlande

Neuseeland

Norwegen

Portugal

Schottland

Slowakische Rep.

Schweiz

Türkei

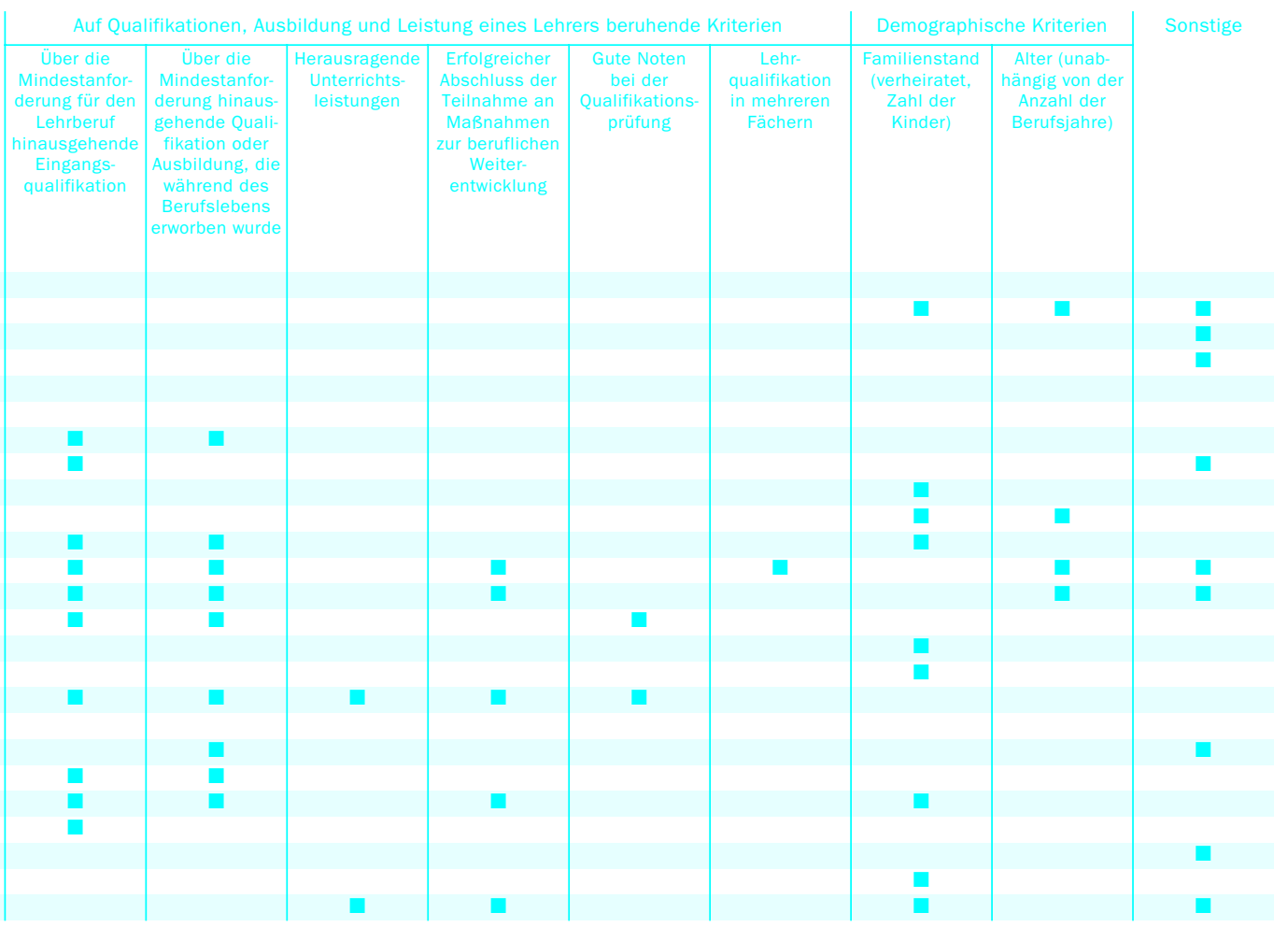

Hinweis: Länder, in denen die genannte Stelle keine Entscheidungen über die Gewährung von Gehaltszulagen trifft, sind in der Tabelle nicht aufgeführt. Quelle: OECD. Hinweise s. Anhang 3 unter www.oecd.org/edu/eag2004. 
Tabelle D3.3

Veränderungen der Lehrergehälter (1996/2002)

Index der Veränderung der Lehrergehälter zwischen 1996 und 2002 beim Anfangsgehalt, nach 15 Jahren Berufserfahrung und dem Höchstgehalt, nach Bildungsbereichen, unter Verwendung des BIP-Deflators zu Preisen von 2002 umgerechnet (1996=100)

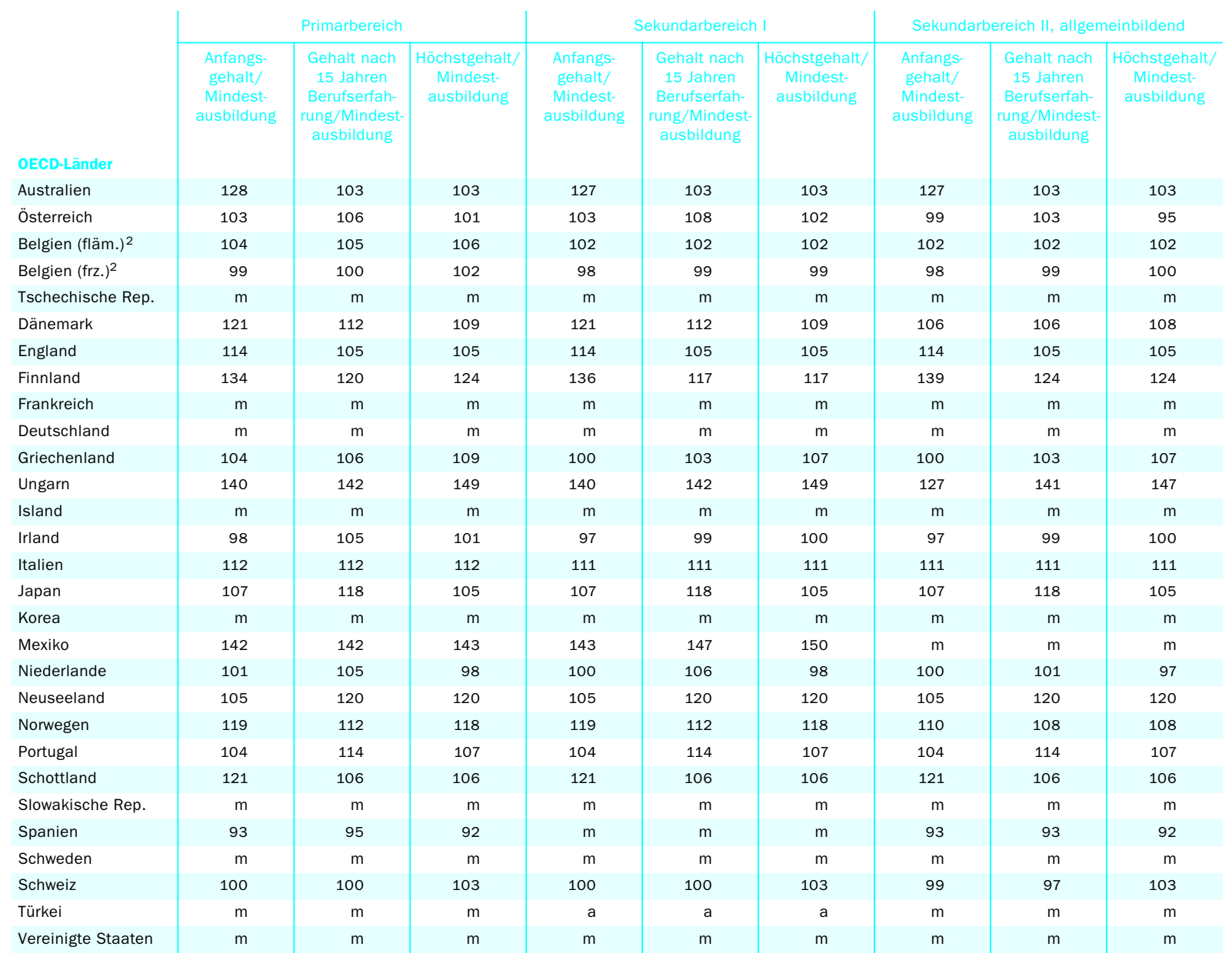

1. Der Index ist folgendermaßen berechnet: Lehrergehalt in 2002 in Landeswährung * 100 / Lehrergehalt in 1996 in Landeswährung * BIP-Deflator 2002 (1996=100). Hinweise zu den Statistiken über BIP-Deflatoren und Gehälter von 1996 und 2002 in Landeswährung s. Anhang 2. 2. Die Daten für Belgien im Jahr 1996 basieren auf ganz Belgien.

Quelle: OECD. HInweise s. Anhang 3 unter www.oecd.org/edu/eag2004. 



\section{Unterrichtszeit und Arbeitszeit der Lehrer}

Die durchschnittliche jährliche Zahl der Unterrichtsstunden an öffentlichen Schulen des Primarbereichs beträgt 803 Stunden, reicht aber von 617 Stunden in Japan bis zu 1.139 Stunden in den Vereinigten Staaten.

- Im Sekundarbereich I liegt die Zahl der Unterrichtsstunden bei durchschnittlich 717 Stunden im Jahr, die Spannweite reicht jedoch von 513 Stunden in Japan bis zu 1.167 Stunden in Mexiko.

- Im Sekundarbereich II liegt die Zahl der Unterrichtsstunden bei durchschnittlich 674 Stunden im Jahr, sie reicht jedoch von 449 Stunden in Japan bis zu 1.121 Stunden in den Vereinigten Staaten.

Der prozentuale Anteil der auf das Unterrichten entfallenden Arbeitszeit ist im Primarbereich höher als im Sekundarbereich. In beiden Bereichen ist der Anteil der auf das Unterrichten entfallenden Arbeitszeit nur in wenigen Ländern höher als 50 Prozent.

Die Vorgaben für die Arbeitszeit der Lehrer differieren in den einzelnen Ländern. In den meisten Ländern müssen die Lehrer gesetzlich oder vertraglich geregelt eine bestimmte Zahl von Stunden arbeiten; einige Länder dagegen legen nur die Zahl der wöchentlich abzuleistenden Unterrichtsstunden fest. 


\section{Abbildung D4.1}

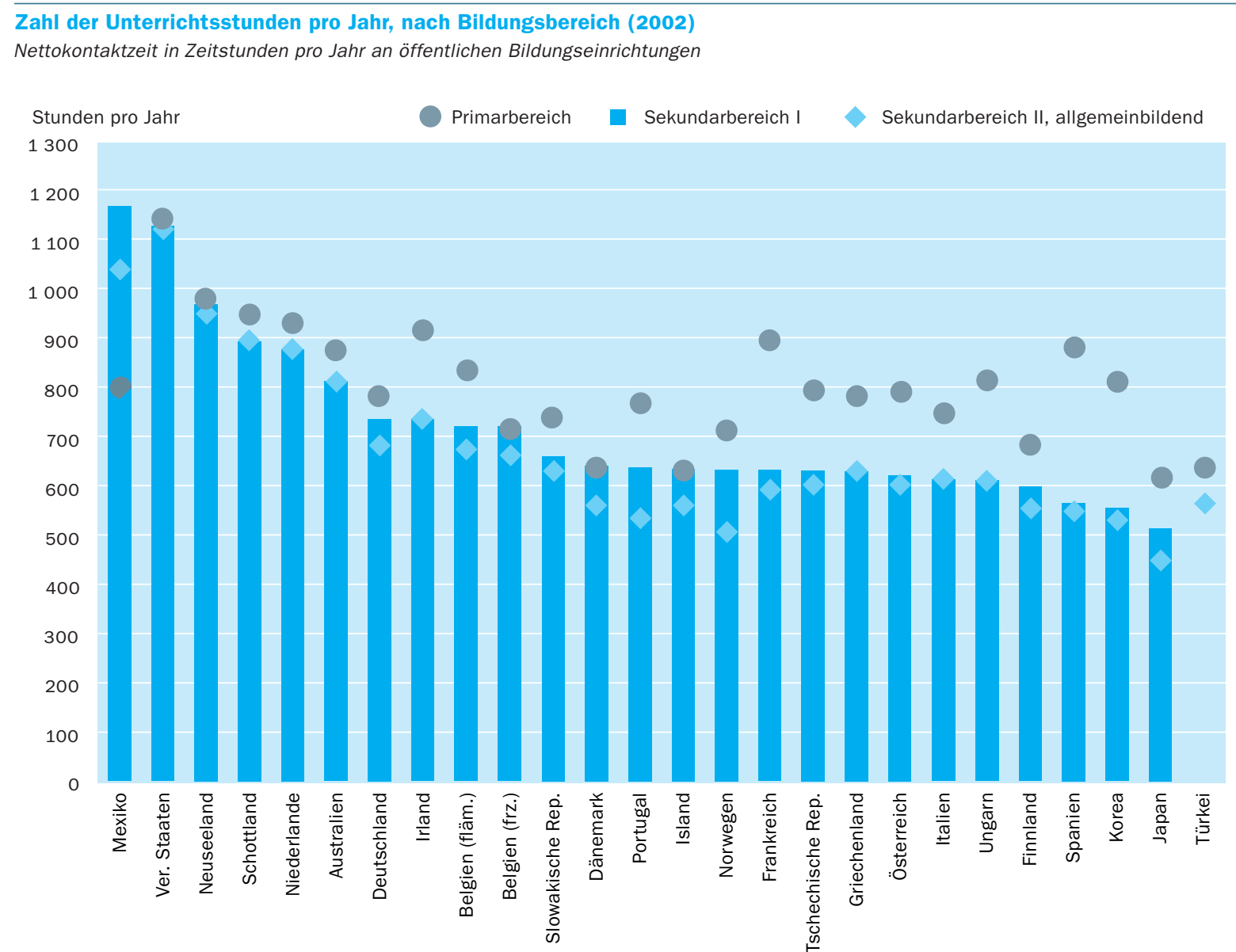

Anordnung der Länder in absteigender Reihenfolge der Zahl an Unterrichtsstunden im Sekundarbereich I.

Quelle: OECD. Tabelle D4.1. Hinweise s. Anhang 3 unter www.oecd.org/edu/eag2004.

Dieser Indikator gibt die Jahresstundenzahl an, die Vollzeitlehrer nach den offiziellen Regelungen des jeweiligen Landes unterrichten müssen.

\section{Politischer Hintergrund}

Zusammen mit Faktoren wie der Klassengröße und dem zahlenmäßigen Schüler/Lehrer-Verhältnis (Indikator D2), der Unterrichtszeit der Schüler (Indikator DI) und den Lehrergehältern (Indikator $\mathrm{D}_{3}$ ) beeinflusst die Zeit, die ein Lehrer tatsächlich unterrichtet, die von den einzelnen Ländern für Bildung aufzuwendenden Finanzmittel. Die Unterrichtszeit und die nicht unmittelbar unterrichtsbezogenen Aktivitäten sind auch ein entscheidender Bestandteil der Arbeitsbedingungen der Lehrer und beeinflussen so die Attraktivität des Lehrerberufs.

Der prozentuale Anteil der auf das Unterrichten entfallenden Arbeitszeit der Lehrer kann als Maßstab der Arbeitsbelastung der Lehrer interpretiert werden. Dieser Anteil gibt Aufschluss darüber, wie viel Zeit für andere Aktivitäten, wie die Unterrichtsvorbereitung, Korrekturen, interne Fortbildung und Besprechungen zur Verfügung steht. 


\section{Ergebnisse und Erläuterungen}

\section{Unterrichtszeit}

Sowohl im Primar- als auch im Sekundarbereich unterscheidet sich die Anzahl der Unterrichtsstunden, die ein Lehrer an einer öffentlichen Schule durchschnittlich unterrichten muss, von Land zu Land. In der Regel ist die Zahl der Unterrichtsstunden im Primarbereich höher als im Sekundarbereich.

Ein Lehrer im Primarbereich unterrichtet im Durchschnitt 803 Stunden pro Jahr, die Zahl variiert jedoch von 650 Stunden oder weniger in Dänemark, Island, Japan und der Türkei bis zu 900 Stunden oder mehr in Irland, den Niederlanden, Neuseeland, Schottland und den Vereinigten Staaten (Abb. D4.I und Tab. D4.I).

Im Sekundarbereich I unterrichtet ein Lehrer durchschnittlich 717 Stunden pro Jahr. Die Lehrbelastung der Lehrer variiert hier zwischen 600 Stunden und weniger in Finnland, Japan, Korea und Spanien und mehr als goo Stunden in Mexiko, Neuseeland und den Vereinigten Staaten (Abb. D4.I und Tab. D4.I).

Im Sekundarbereich II ist die Lehrbelastung normalerweise geringer als im Sekundarbereich I. Ein Lehrer allgemeiner Fächer ist im OECD-Durchschnitt gesetzlich bzw. vertraglich verpflichtet, 674 Stunden pro Jahr zu unterrichten. Die Lehrbelastung reicht von weniger als 500 Stunden in Japan bis zu mehr als 900 Stunden in Mexiko, Neuseeland und den Vereinigten Staaten (Abb. D4.I und Tab. D4.I).

In Frankreich und Spanien muss ein Lehrer im Primarbereich über 300 Stunden mehr unterrichten als ein Lehrer im Sekundarbereich II (allgemeinbildend). Demgegenüber beträgt diese Differenz in Australien, Belgien (frz.), Dänemark, Deutschland, Island, den Niederlanden, Neuseeland, Schottland, der Türkei und den Vereinigten Staaten Ioo Stunden oder weniger. In Neuseeland und den Vereinigten Staaten beträgt die Differenz sogar weniger als 50 Stunden. Auf der anderen Seite unterrichtet in Mexiko ein Lehrer im Sekundarbereich II fast 240 Stunden mehr als ein Lehrer im Primarbereich (Abb. D4.I).

Beim Vergleich der Zahl der abzuleistenden Unterrichtsstunden zwischen den einzelnen Ländern sollte man jedoch berücksichtigen, dass die Nettokontaktzeit, wie in diesem Indikator verwendet, nicht notwendigerweise der Lehrbelastung entspricht. Die Kontaktzeit selbst ist zwar ein bedeutender Bestandteil hiervon, aber die Vorbereitung der Stunden sowie die erforderliche Nachbereitung (einschließlich der Korrektur der Schülerarbeiten) sind in einem Vergleich der Lehrbelastung ebenfalls zu berücksichtigen. Andere Elemente der Lehrbelastung (wie z.B. die Zahl der unterrichteten Fächer, die Zahl der zu unterrichtenden Schüler oder wie viele Jahre ein Lehrer dieselben Schüler unterrichtet) sind bei der Berechnung der durchschnittlichen Lehrbelastung der Lehrer innerhalb eines Landes ebenfalls zu berücksichtigen. Diese Faktoren lassen sich jedoch oft nur auf Schulebene ermitteln und bewerten.
Ein Lehrer an einer öffentlichen Schule des Primarbereichs unterrichtet im Durchschnitt 803 Stunden pro Jahr. Im Sekundarbereich I unterrichtet ein Lehrer durchschnittlich 717 Stunden pro Jahr, im Sekundarbereich II sind es 674 Stunden.

In den meisten Ländern unterrichtet ein Lehrer im Primarbereich mehr Stunden als ein Kollege im Sekundarbereich I und II, aber diese Differenz variiert stark zwischen den einzelnen Ländern. 
Mit Ausnahme von Belgien (frz.), Österreich, Spanien, der Tschechischen Republik und Ungarn hat sich die Zahl der abzuleistenden Unterrichtsstunden zwischen 1996 und 2002 nicht wesentlich geändert.

Die Vorgaben für die Arbeitszeit der Lehrer unterscheiden sich in den einzelnen Ländern sehr.

In den meisten Ländern müssen die Lehrer formell eine bestimmte Zahl von Stunden arbeiten,...

...wobei in einigen Ländern auch die an der Schule abzuleistende Arbeitszeit festgelegt wird, ...
Mit Ausnahme von Belgien (frz.) (Primarbereich), Österreich (Primarbereich), Spanien (Sekundarbereich II), der Tschechischen Republik (Primarbereich) und Ungarn (Sekundarbereich) war in den meisten OECD-Ländern die Zahl der abzuleistenden Unterrichtsstunden 1996 und 2002 in etwa gleich. In Ungarn jedoch mussten die Lehrer im Sekundarbereich im Jahr 200229 Prozent mehr Unterrichtsstunden ableisten als 1996, wohingegen in Belgien (frz.) die Nettokontaktzeit im Primarbereich um I6 Prozent zurückging (Tab. D4.2).

\section{Arbeitszeit der Lehrer}

Die Vorgaben für die Arbeitszeit der Lehrer unterscheiden sich in den einzelnen Ländern sehr. Während in einigen Ländern nur die Kontaktzeit formell festgelegt ist, wird in anderen auch die Arbeitszeit insgesamt festgelegt. Einige Länder sehen innerhalb der formell festgelegten Arbeitszeit sowohl Zeit für den Unterricht als auch für Tätigkeiten außerhalb des Unterrichts vor. Innerhalb dieses Rahmens festgelegter Arbeitszeit und der Zahl abzuleistender Unterrichtsstunden kann die tatsächliche Arbeitsbelastung der Lehrer stark variieren.

In den meisten Ländern müssen die Lehrer formell eine bestimmte Stundenzahl pro Woche arbeiten, um ein Vollzeitgehalt zu erhalten. Hierin sind sowohl Unterrichtszeiten als auch Zeiten außerhalb des Unterrichts enthalten. Innerhalb dieses Rahmens gibt es jedoch zwischen den einzelnen Ländern Unterschiede hinsichtlich der weiteren Bestimmungen, wie viel Zeit unterrichtend und wie viel Zeit mit anderen Aktivitäten zu verbringen ist. Normalerweise wird die Zahl der zu unterrichtenden Stunden festgelegt, aber einige Ländern legen auch auf nationaler Ebene fest, wie viel Zeit die Lehrer in der Schule verbringen müssen.

In Australien, Belgien (frz., Primarbereich), England, Griechenland, Island, Irland, Mexiko (Primar- und Sekundarbereich I), Neuseeland, Norwegen, Portugal, Schweden, Spanien, der Türkei und den Vereinigten Staaten wird die Arbeitszeit festgelegt, die die Lehrer an der Schule sowohl für Unterricht als auch für nicht unmittelbar unterrichtsbezogene Aktivitäten zur Verfügung stehen müssen.

\section{Arbeitszeit in Österreich}

Auf Bundesebene ist die abzuleistende Unterrichtszeit durch das Bundeslehrer-Lehrverpflichtungsgesetz festgelegt. Auf Länderebene erfolgt die Festlegung durch das Landeslehrer-Dienstrechtgesetz, das ein Jahresarbeitszeitmodell verwendet.

Für Bundeslehrer werden die Unterrichtsstunden in den einzelnen Fächern mit unterschiedlichen Werteinheiten auf die Lehrverpflichtung von 20 Wochenstunden angerechnet.

Für Landeslehrer im Sekundarbereich I der Schulpflicht wird eine Jahresunterrichtszeit (Jahresnorm) festgelegt, die der Dienstzeit eines vergleichbaren öffentlich Bediensteten entspricht. Diese Jahresnorm deckt drei unterschiedliche Tätigkeitsfelder ab: Unterrichtsverpflichtungen einschließlich 
Aufsichtspflichten, Vor-, Nachbereitung und Korrektur sowie Stunden für sonstige Tätigkeiten .

In Dänemark, Deutschland, Japan, Korea, Mexiko (Sekundarbereich II), den Niederlanden, Österreich (Primar- und Sekundarbereich I), Schottland, der Slowakischen Republik, der Tschechischen Republik und Ungarn ist die Jahresarbeitszeit der Lehrer festgelegt. Zusätzlich dazu wird in einigen Ländern auch (teilweise) die Anzahl der Stunden festgelegt, die für Aktivitäten außerhalb des Unterrichts aufzuwenden ist. Allerdings ist nicht vorgegeben, ob die Lehrer die nicht unmittelbar unterrichtsbezogenen Stunden an der Schule verbringen müssen oder dies auch außerhalb der Schule tun können.

Abb. D4.2 zeigt die Unterrichtszeit (netto) als Prozentsatz der vertraglich festgelegten Gesamtarbeitszeit. Der Prozentsatz der auf das Unterrichten entfallenden Arbeitszeit ist in allen Ländern im Primarbereich höher als im Sekundarbereich. Im Primarbereich liegt der prozentuale Anteil der Unterrichtszeit in II der 16 Länder, für die Daten vorliegen, unter 50 Prozent und im Sekundarbereich liegt der Anteil der Unterrichtszeit nur in den Niederlanden und in Schottland bei über 50 Prozent.

\section{BAPO in den Niederlanden - Maßnahmen zur Steigerung der Lehrtätigkeit älterer Beschäftigter}

Als Anreiz für ältere Menschen, den Lehrberuf zu ergreifen oder weiter auszuüben, wurde 1994 das sogenannte BAPO-Modell eingeführt. Das BAPOModell ermöglicht es Lehrkräften ab dem 52. Lebensjahr, ihre Gesamtarbeitszeit, verbunden mit einer relativ geringen Gehaltskürzung, zu verringern. Im Alter zwischen 52 und 55 Jahren kann die Arbeitszeit bei einer Gehaltskürzung von 2,5 Prozent um ro Prozent verringert werden. Ab dem Alter von 56 Jahren ist eine Verringerung der Arbeitszeit um 20 Prozent, verbunden mit einer Gehaltskürzung von 5 Prozent möglich. Da die Möglichkeit besteht, diese Arbeitszeitverkürzung auf später zu verschieben, kann der tatsächliche Prozentsatz höher sein. Diese Verschiebung könnte später auch zu (finanziellen) Problemen für die Schulen führen, wenn eine große Zahl älterer Lehrkräfte ihre, angesparte' Arbeitszeitverkürzung in Form eines vorgezogenen Ruhestands auf einmal in Anspruch nimmt.

In Australien, Belgien (fläm.), England, Frankreich, Irland, Italien, Mexiko (mit Ausnahme des Sekundarbereich II), Neuseeland und den Vereinigten Staaten ist nicht formell festgelegt, wie viel Zeit für Aktivitäten außerhalb des Unterrichts aufgewendet werden sollte. Dies bedeutet allerdings nicht, dass die Lehrer in der Gestaltung anderer Aufgaben völlig frei sind. In Österreich beruhen die Vorgaben für die Unterrichtszeit auf der Annahme, dass die Pflichten eines Lehrers (einschließlich der Vorbereitung des Unterrichts und der Klassenarbeiten, der Korrektur und Benotung von Klassenarbeiten, Prüfungen und Verwaltungsaufgaben) zu einer wöchentlichen Arbeitszeit von 40 Stunden führen. In Belgien (fläm.) werden die zusätzlichen Stunden in der Schule für Aufgaben außerhalb des Unterrichts auf Schulebene festgelegt. Es gibt keine ...während in anderen Ländern lediglich die gesetzliche bzW. vertraglich festgelegte Gesamtarbeitszeit in Stunden pro Jahr festgelegt ist.

In 9 von 27 OECD-Ländern mit verfügbaren Daten gibt es keine formellen Bestimmungen für Zeiten außerhalb des Unterrichts. 


\section{Abbildung D4.2}

Prozentualer Anteil der auf das Unterrichten entfallenden Arbeitszeit der Lehrer, nach Bildungsbereich (2002) Netto-Unterrichtszeit als Prozentsatz der insgesamt gesetzlich bzw. vertraglich vorgesehenen Arbeitszeit

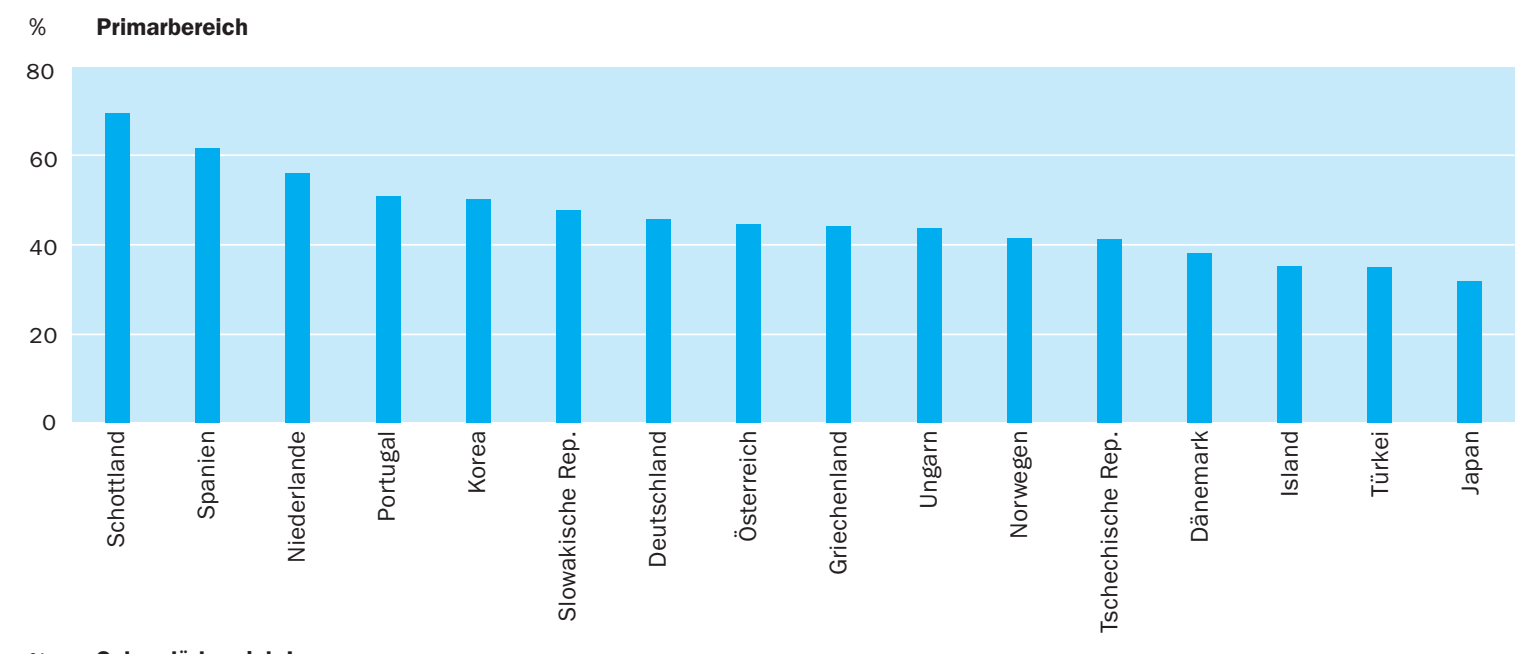

\% Sekundärbereich
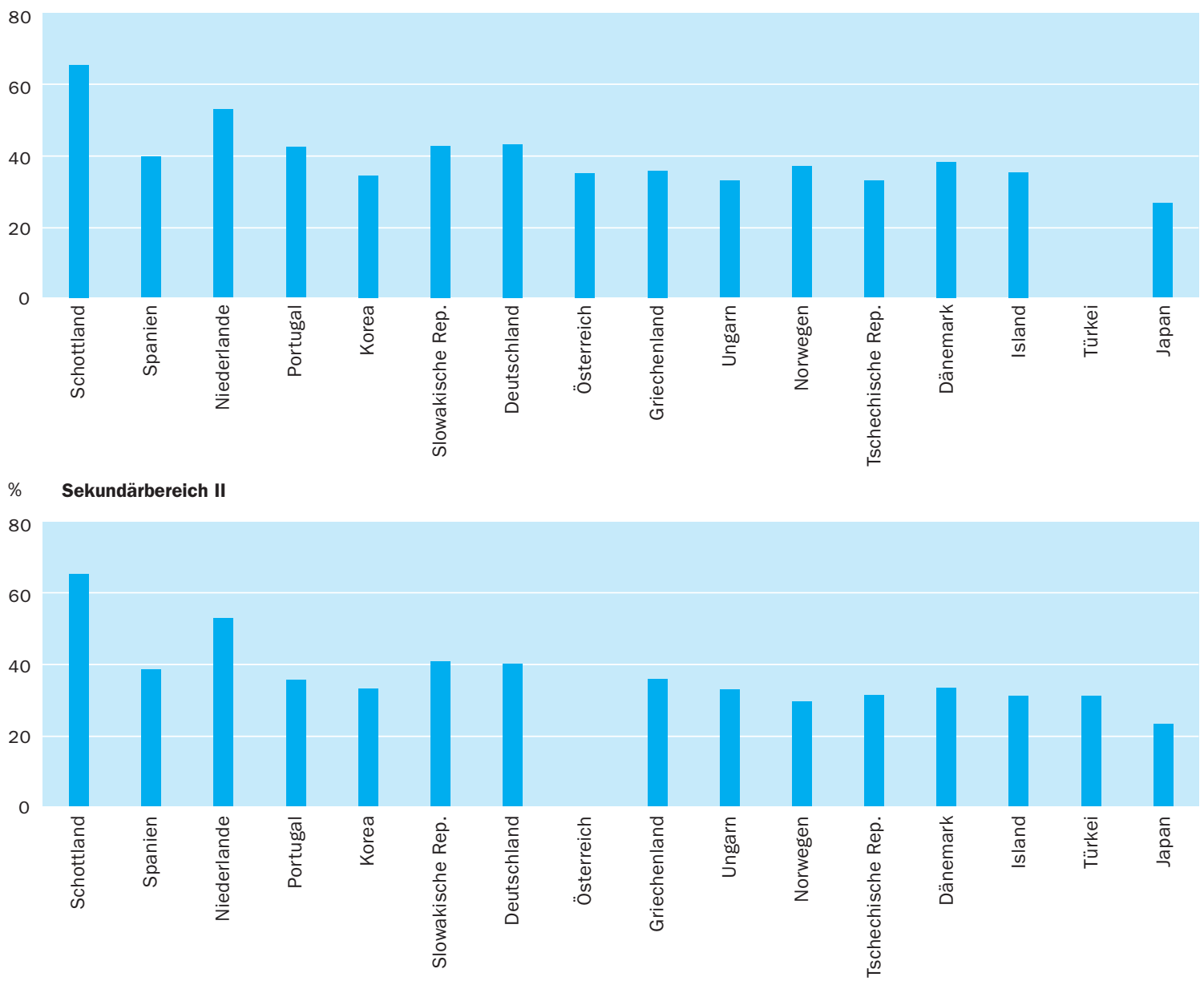
Vorschriften hinsichtlich der Unterrichtsvorbereitung, der Korrektur und Benotung von Klassenarbeiten, usw. Die Regierung legt lediglich die wöchentliche Mindest- und Höchstzahl von Unterrichtseinheiten (von je 50 Minuten Dauer) für den jeweiligen Bildungsbereich fest.

In Japan, Korea und der Tschechischen Republik haben Lehrer die gleiche Arbeitszeit wie Beamte. Es gibt auf nationaler Ebene keine weiteren Vorgaben zur Anzahl der abzuleistenden Unterrichtsstunden oder zur Zeit für Tätigkeiten außerhalb des Unterrichts. In Korea sind die Lehrer jedoch angehalten, zusätzlich während der Schulferien nach ihrem eigenen Plan an ihrer beruflichen Weiterbildung zu arbeiten (Tab. D4.I).

Die Arbeitsbelastung der Lehrer in der Slowakischen Republik. Die Lehr- und Unterrichtsverpflichtungen der slowakischen Lehrkräfte sind im Regierungsgesetz Nr. I62 vom I. April 2002 festgelegt. Die wöchentliche Arbeitszeit der Lehrkräfte besteht aus der eigentlichen Unterrichtszeit und der Zeit, die für andere Aktivitäten im Zusammenhang mit dem Unterricht verbracht wird, je nach den Arbeitsvorschriften der Schule bzw. schulischen Einrichtung. Die wöchentliche Arbeitsbelastung eines regulären Lehrers hängt vom Schultyp ab und reicht von 15 bis zu 35 Stunden. Eine Unterrichtsstunde in theoretischen Fächern, Übungen und praktischen Anwendungen dauert 45 Minuten. Eine Unterrichtsstunde in praktischen Fächern dauert an verschiedenen Schuleinrichtungen oder an berufsbildenden Schulen 6o Minuten. Jede Unterrichts- und Lehraktivität, die über diese grundlegende Unterrichtszeit hinausgeht, gilt als Überstunde.

Die STRB (School Teachers' Review Body) in England und Wales Die Regierung hat mit den STRB in England und Wales vereinbart, dass sowohl der lange Arbeitstag der Lehrer als auch die jetzige durchschnittliche Wochenarbeitszeit von 52 Stunden während des Schuljahres reduziert werden müssen.

Alle stimmen darin überein, dass eine derartige Obergrenze nicht im Arbeitsvertrag eines Lehrer enthalten sein sollte, denn solch eine vertraglich festgelegte Obergrenze wäre aus praktischen Gründen nicht nachvollziehbar und für Akademiker ungewöhnlich.

Dennoch möchte die Regierung, dass innerhalb der nächsten vier Jahre die Gesamtarbeitszeit der Lehrer schrittweise reduziert wird. Die Regierung wird dies in den Schulen unterstützen und mit Hilfe der STRB die Fortschritte durch formale Erhebungen überwachen.
In Japan, Korea und der Tschechischen Republik ist die Arbeitszeit der Lehrer nur in den allgemeinen Vorschriften über die Arbeitszeit von Beamten geregelt. 


\section{Definitionen und angewandte Methodik}

Die Daten stammen aus der OECD/INES-Erhebung 2003 zu Lehrern und Lehrplänen und beziehen sich auf das Schuljahr 2001/2002.

\section{Unterrichtszeit}

Die Zahl der Unterrichtsstunden wird definiert als die Zahl an Stunden pro Jahr, die ein Vollzeitlehrer gemäß den offiziellen Vorschriften des Landes mit dem Unterricht einer Gruppe oder Klasse verbringt. Sie wird berechnet aus der Zahl der Unterrichtstage pro Jahr multipliziert mit der Anzahl Stunden, die ein Lehrer pro Tag unterrichtet (ohne Zeiten, die offiziell als Pausen zwischen einzelnen Stunden oder Stundenblöcken vorgesehen sind). Im Elementar- und Primarbereich sind jedoch kurze Pausen zwischen den einzelnen Unterrichtsstunden, während derer der Lehrer für die Klasse verantwortlich ist, eingeschlossen.

\section{Arbeitszeit}

Die Arbeitszeit bezieht sich auf die regulären Arbeitsstunden eines Vollzeitlehrers. Gemäß den formellen Vorgaben in einem bestimmten Land kann sich die Arbeitszeit beziehen auf:

ausschließlich für den Unterricht aufgewendete Zeit (und andere lehrplanbezogene Tätigkeiten für die Schüler, wie Haus- und Klassenarbeiten, jedoch keine jährlichen Prüfungen)

oder auch Zeit, die in direktem Zusammenhang mit dem Unterricht steht, sowie Stunden, die anderen unterrichtsbezogenen Tätigkeiten gewidmet sind, z. B. Unterrichtsvorbereitung, Beratung der Schüler, Korrekturen von Haus- und Klassenarbeiten, Tätigkeiten zur beruflichen Weiterentwicklung, Besprechungen mit den Eltern, Lehrerkonferenzen und allgemeine schulische Aufgaben.

Nicht enthalten sind vergütete Überstunden.

\section{Arbeitszeit in der Schule}

Arbeitszeit in der Schule bezieht sich auf die Arbeitszeit, die Lehrer an der Schule verbringen müssen und enthält sowohl die Unterrichtszeit als auch Zeit für Tätigkeiten außerhalb des Unterrichts.

\section{Anzahl der Unterrichtswochen und -tage}

Die Anzahl der Unterrichtswochen bezieht sich auf die Anzahl der Unterrichtswochen ohne die Ferienzeiten. Die Anzahl der Unterrichtstage wird berechnet als Anzahl der Unterrichtswochen multipliziert mit der Anzahl Tage, die ein Lehrer pro Woche unterrichtet, abzüglich der Tage, an denen die Schule wegen Feierlichkeiten geschlossen ist. 
Tabelle D4.1

Aufteilung der Arbeitszeit von Lehrern (2002)

Anzahl der Unterrichtswochen, Unterrichtstage, Netto-Unterrichtszeit in Stunden, und Arbeitszeit von Lehrern pro Schuljahr

\begin{tabular}{|c|c|c|c|c|c|c|c|c|c|c|c|c|c|c|c|}
\hline & \multicolumn{3}{|c|}{$\begin{array}{c}\text { Anzahl der } \\
\text { Unterrichtswochen }\end{array}$} & \multicolumn{3}{|c|}{$\begin{array}{c}\text { Anzahl der } \\
\text { Unterrichtstage }\end{array}$} & \multicolumn{3}{|c|}{$\begin{array}{l}\text { Netto-Unterrichtszeit } \\
\text { in Stunden }\end{array}$} & \multicolumn{3}{|c|}{$\begin{array}{l}\text { In der Schule } \\
\text { abzuleistende Arbeitszeit } \\
\text { in Stunden }\end{array}$} & \multicolumn{3}{|c|}{$\begin{array}{c}\text { Gesetzlich, bzw. vertraglich } \\
\text { festgelegte Gesamtarbeits- } \\
\text { zeit in Stunden }\end{array}$} \\
\hline OECD-Länder & $\begin{array}{l}\text { Primar- } \\
\text { bereich }\end{array}$ & $\begin{array}{l}\text { Sekun- } \\
\text { darbe- } \\
\text { reich I }\end{array}$ & $\begin{array}{l}\text { Sekun- } \\
\text { darbe- } \\
\text { reich II, } \\
\text { allge- } \\
\text { meinbil- } \\
\text { dend }\end{array}$ & $\begin{array}{l}\text { Primar- } \\
\text { bereich }\end{array}$ & $\begin{array}{l}\text { Sekun- } \\
\text { darbe- } \\
\text { reich I }\end{array}$ & $\begin{array}{l}\text { Sekun- } \\
\text { darbe- } \\
\text { reich II, } \\
\text { allge- } \\
\text { meinbil- } \\
\text { dend }\end{array}$ & $\begin{array}{l}\text { Primar- } \\
\text { bereich }\end{array}$ & $\begin{array}{l}\text { Sekun- } \\
\text { darbe- } \\
\text { reich I }\end{array}$ & $\begin{array}{c}\text { Sekun- } \\
\text { darbe- } \\
\text { reich II, } \\
\text { allge- } \\
\text { meinbil- } \\
\text { dend }\end{array}$ & $\begin{array}{l}\text { Primar- } \\
\text { bereich }\end{array}$ & $\begin{array}{l}\text { Sekun- } \\
\text { darbe- } \\
\text { reich I }\end{array}$ & $\begin{array}{c}\text { Sekun- } \\
\text { darbe- } \\
\text { reich II, } \\
\text { allge- } \\
\text { meinbil- } \\
\text { dend }\end{array}$ & $\begin{array}{l}\text { Primar- } \\
\text { bereich }\end{array}$ & $\begin{array}{l}\text { Sekun- } \\
\text { darbe- } \\
\text { reich I }\end{array}$ & $\begin{array}{l}\text { Sekun- } \\
\text { darbe- } \\
\text { reich II, } \\
\text { allge- } \\
\text { meinbil- } \\
\text { dend }\end{array}$ \\
\hline Australien & 40 & 40 & 40 & 197 & 197 & 197 & 875 & 811 & 811 & 1240 & 1261 & 1261 & a & $\mathrm{a}$ & a \\
\hline Österreich & 38 & 38 & 38 & 184 & 184 & 184 & 792 & 621 & 602 & a & a & a & 1776 & 1776 & a \\
\hline Belgien (fläm.) & 37 & 37 & 37 & 179 & 180 & 180 & 836 & 720 & 675 & a & a & a & a & a & a \\
\hline Belgien (frz.) & 37 & 37 & 37 & 162 & 180 & 180 & 717 & 720 & 661 & 962 & $\mathrm{~m}$ & $\mathrm{~m}$ & $\mathrm{~m}$ & $\mathrm{~m}$ & $\mathrm{~m}$ \\
\hline Tschechische Rep. & 39 & 39 & 39 & 191 & 191 & 191 & 793 & 630 & 602 & a & a & a & 1920 & 1920 & 1920 \\
\hline Dänemark & 42 & 42 & 42 & 200 & 200 & 200 & 640 & 640 & 560 & $\mathrm{~m}$ & $\mathrm{~m}$ & $\mathrm{~m}$ & 1680 & 1680 & 1680 \\
\hline England & 38 & 38 & 38 & 190 & 190 & 190 & $\mathrm{~m}$ & $\mathrm{~m}$ & $\mathrm{~m}$ & 1265 & 1265 & 1265 & $\mathrm{~m}$ & $\mathrm{~m}$ & $\mathrm{~m}$ \\
\hline Finnland & 38 & 38 & 38 & 190 & 190 & 190 & 684 & 599 & 556 & a & a & a & $\mathrm{m}$ & $\mathrm{m}$ & $\mathrm{m}$ \\
\hline Frankreich & 35 & 35 & 35 & $\mathrm{~m}$ & $\mathrm{~m}$ & $\mathrm{~m}$ & 897 & 631 & 593 & a & a & a & a & a & a \\
\hline Deutschland & 40 & 40 & 40 & 189 & 189 & 189 & 782 & 735 & 684 & a & a & a & 1708 & 1708 & 1708 \\
\hline Griechenland & 40 & 38 & 38 & 195 & 185 & 185 & 780 & 629 & 629 & 1500 & 1425 & 1425 & 1762 & 1762 & 1762 \\
\hline Ungarn & 37 & 37 & 37 & 185 & 185 & 185 & 814 & 611 & 611 & a & a & a & 1864 & 1864 & 1864 \\
\hline Island & 35 & 35 & 36 & 170 & 170 & 175 & 634 & 634 & 560 & 1650 & 1650 & 1720 & 1800 & 1800 & 1800 \\
\hline Irland & 37 & 33 & 33 & 183 & 167 & 167 & 915 & 735 & 735 & 915 & 735 & 735 & a & a & a \\
\hline Italien & 34 & 34 & 34 & $\mathrm{~m}$ & $\mathrm{~m}$ & $\mathrm{~m}$ & 748 & 612 & 612 & a & a & a & a & a & a \\
\hline Japan & 35 & 35 & 35 & 193 & 193 & 193 & 617 & 513 & 449 & a & a & a & 1940 & 1940 & 1940 \\
\hline Korea & 37 & 37 & 37 & 220 & 220 & 220 & 811 & 554 & 531 & a & a & a & 1613 & 1613 & 1613 \\
\hline Mexiko & 42 & 42 & 36 & 200 & 200 & 174 & 800 & 1167 & 1037 & 800 & 1167 & a & a & a & 971 \\
\hline Niederlande & 40 & 40 & 40 & 195 & 195 & 195 & 930 & 876 & 876 & a & a & a & 1659 & 1659 & 1659 \\
\hline Neuseeland & 39 & 39 & 38 & 197 & 194 & 190 & 985 & 968 & 950 & 985 & 968 & 950 & a & a & a \\
\hline Norwegen & 38 & 38 & 38 & 190 & 190 & 190 & 713 & 633 & 505 & 903 & 823 & 695 & 1718 & 1718 & 1718 \\
\hline Portugal & 36 & 36 & 33 & 174 & 174 & 160 & 767 & 637 & 533 & 870 & 766 & 640 & 1505 & 1505 & 1505 \\
\hline Schottland & 38 & 38 & 38 & 190 & 190 & 190 & 950 & 893 & 893 & a & a & a & 1365 & 1365 & 1365 \\
\hline Slowakische Rep. & 39 & 39 & 39 & 191 & 191 & 191 & 739 & 659 & 630 & a & a & a & 1544 & 1544 & 1544 \\
\hline Spanien & 37 & 36 & 35 & 176 & 171 & 166 & 880 & 564 & 548 & 1140 & 1140 & 1140 & 1425 & 1425 & 1425 \\
\hline Schweden & a & a & a & a & a & a & a & a & a & 1360 & 1360 & 1360 & 1767 & 1767 & 1767 \\
\hline Schweiz & $\mathrm{m}$ & $\mathrm{m}$ & $\mathrm{m}$ & $\mathrm{m}$ & $\mathrm{m}$ & $\mathrm{m}$ & $\mathrm{m}$ & $\mathrm{m}$ & $\mathrm{m}$ & $\mathrm{m}$ & $\mathrm{m}$ & $\mathrm{m}$ & $\mathrm{m}$ & $\mathrm{m}$ & $\mathrm{m}$ \\
\hline Türkei & 38 & a & 38 & 180 & a & 180 & 639 & a & 567 & 870 & a & 756 & 1824 & a & 1824 \\
\hline Vereinigte Staaten & 36 & 36 & 36 & 180 & 180 & 180 & 1139 & 1127 & 1121 & 1353 & 1371 & 1371 & a & a & a \\
\hline \multicolumn{16}{|l|}{ OECD-Partnerländer } \\
\hline Argentinien ${ }^{1}$ & 38 & 38 & 38 & 180 & 180 & 180 & 810 & 900 & 900 & $\mathrm{~m}$ & $\mathrm{~m}$ & $\mathrm{~m}$ & $\mathrm{~m}$ & $\mathrm{~m}$ & $\mathrm{~m}$ \\
\hline Brasilien $^{1}$ & 40 & 40 & 40 & 200 & 200 & 200 & 800 & 800 & 800 & $\mathrm{~m}$ & $\mathrm{~m}$ & $\mathrm{~m}$ & $\mathrm{~m}$ & $\mathrm{~m}$ & $\mathrm{~m}$ \\
\hline Chile & 40 & 40 & 40 & 192 & 192 & 192 & 864 & 864 & 864 & $\mathrm{~m}$ & $\mathrm{~m}$ & $\mathrm{~m}$ & $\mathrm{~m}$ & $\mathrm{~m}$ & $\mathrm{~m}$ \\
\hline Ägypten & 36 & 36 & 36 & 187 & 187 & 187 & 748 & 748 & 748 & $\mathrm{~m}$ & $\mathrm{~m}$ & $\mathrm{~m}$ & $\mathrm{~m}$ & $\mathrm{~m}$ & $\mathrm{~m}$ \\
\hline Indien & 52 & 52 & 52 & 225 & 225 & 225 & 1013 & 1125 & 1125 & $\mathrm{~m}$ & $\mathrm{~m}$ & $\mathrm{~m}$ & $\mathrm{~m}$ & $\mathrm{~m}$ & $\mathrm{~m}$ \\
\hline Indonesien & 44 & 44 & 44 & 252 & 252 & 252 & 1260 & 738 & 738 & $\mathrm{~m}$ & $\mathrm{~m}$ & $\mathrm{~m}$ & $\mathrm{~m}$ & $\mathrm{~m}$ & $\mathrm{~m}$ \\
\hline Jordanien & 36 & 36 & 36 & 162 & 162 & 162 & 810 & 810 & 810 & $\mathrm{~m}$ & $\mathrm{~m}$ & $\mathrm{~m}$ & $\mathrm{~m}$ & $\mathrm{~m}$ & $\mathrm{~m}$ \\
\hline Malaysia $^{1}$ & 41 & 41 & 41 & 193 & 193 & 193 & 762 & 778 & 778 & $\mathrm{~m}$ & $\mathrm{~m}$ & $\mathrm{~m}$ & $\mathrm{~m}$ & $\mathrm{~m}$ & $\mathrm{~m}$ \\
\hline Paraguay ${ }^{1}$ & 38 & 38 & 38 & 183 & 183 & 183 & 732 & 814 & 915 & $\mathrm{~m}$ & $\mathrm{~m}$ & $\mathrm{~m}$ & $\mathrm{~m}$ & $\mathrm{~m}$ & $\mathrm{~m}$ \\
\hline Peru $^{1}$ & 36 & 36 & 36 & 172 & 172 & 172 & 774 & 619 & 619 & $\mathrm{~m}$ & $\mathrm{~m}$ & $\mathrm{~m}$ & $\mathrm{~m}$ & $\mathrm{~m}$ & $\mathrm{~m}$ \\
\hline Philippinen & 40 & 40 & 40 & 196 & 196 & 196 & 1176 & 1176 & 980 & $\mathrm{~m}$ & $\mathrm{~m}$ & $\mathrm{~m}$ & $\mathrm{~m}$ & $\mathrm{~m}$ & $\mathrm{~m}$ \\
\hline Russische Föd. & 45 & 45 & 45 & 215 & 215 & 215 & 860 & 774 & 774 & $\mathrm{~m}$ & $\mathrm{~m}$ & $\mathrm{~m}$ & $\mathrm{~m}$ & $\mathrm{~m}$ & $\mathrm{~m}$ \\
\hline Sri Lanka & 40 & 40 & 40 & 200 & 200 & 200 & 960 & 1200 & 1200 & $\mathrm{~m}$ & $\mathrm{~m}$ & $\mathrm{~m}$ & $\mathrm{~m}$ & $\mathrm{~m}$ & $\mathrm{~m}$ \\
\hline Thailand & 40 & 40 & 40 & 181 & 181 & 181 & 760 & 652 & 652 & $\mathrm{~m}$ & $\mathrm{~m}$ & $\mathrm{~m}$ & $\mathrm{~m}$ & $\mathrm{~m}$ & $\mathrm{~m}$ \\
\hline Tunesien & 32 & 30 & 30 & 147 & 137 & 137 & 735 & 548 & 548 & $\mathrm{~m}$ & $\mathrm{~m}$ & $\mathrm{~m}$ & $\mathrm{~m}$ & $\mathrm{~m}$ & $\mathrm{~m}$ \\
\hline Uruguay $^{1}$ & 37 & 36 & 36 & 165 & 160 & 160 & 720 & 480 & 480 & $\mathrm{~m}$ & $\mathrm{~m}$ & $\mathrm{~m}$ & $\mathrm{~m}$ & $\mathrm{~m}$ & $\mathrm{~m}$ \\
\hline Simbabwe & 37 & 37 & 37 & 180 & 180 & 180 & 954 & 954 & 954 & $\mathrm{~m}$ & $\mathrm{~m}$ & $\mathrm{~m}$ & $\mathrm{~m}$ & $\mathrm{~m}$ & $\mathrm{~m}$ \\
\hline
\end{tabular}




\section{Tabelle D4.2}

Zahl der Unterrichtsstunden pro Jahr (1996, 2002)

Nettokontaktzeit in Stunden pro Jahr an öffentlichen Bildungseinrichtungen, nach Bildungsbereich, und Index der Veränderung zwischen 1996 und 2002

\begin{tabular}{|c|c|c|c|c|c|c|c|c|c|}
\hline \multirow[b]{2}{*}{ OECD-Länder } & \multicolumn{3}{|c|}{ Primarbereich } & \multicolumn{3}{|c|}{ Sekundarbereich I } & \multicolumn{3}{|c|}{ Sekundarbereich II, allgemeinbildend } \\
\hline & 2002 & 1996 & $\begin{array}{c}\text { Index der } \\
\text { Veränderung } \\
1996-2002 \\
(1996=100)\end{array}$ & 2002 & 1996 & $\begin{array}{c}\text { Index der } \\
\text { Veränderung } \\
1996-2002 \\
(1996=100)\end{array}$ & 2002 & 1996 & $\begin{array}{c}\text { Index der } \\
\text { Veränderung } \\
1996-2002 \\
(1996=100)\end{array}$ \\
\hline Australien & 875 & $\mathrm{~m}$ & $\mathrm{~m}$ & 811 & $\mathrm{~m}$ & $\mathrm{~m}$ & 811 & $\mathrm{~m}$ & $\mathrm{~m}$ \\
\hline Österreich & 792 & 684 & 116 & 621 & 658 & 94 & 602 & 623 & 97 \\
\hline Belgien (fläm.) & 836 & 841 & 99 & 720 & 724 & 99 & 675 & 679 & 99 \\
\hline Belgien (frz.) & 717 & 858 & 84 & 720 & 734 & 98 & 661 & 677 & 98 \\
\hline Tschechische Rep. & 793 & 635 & 125 & 630 & 607 & 104 & 602 & 580 & 104 \\
\hline Dänemark & 640 & 640 & 100 & 640 & 640 & 100 & 560 & 560 & 100 \\
\hline England & $\mathrm{m}$ & 780 & $\mathrm{~m}$ & $\mathrm{~m}$ & 720 & $\mathrm{~m}$ & $\mathrm{~m}$ & $\mathrm{~m}$ & $\mathrm{~m}$ \\
\hline Finnland & 684 & $\mathrm{~m}$ & $\mathrm{~m}$ & 599 & $\mathrm{~m}$ & $\mathrm{~m}$ & 556 & $\mathrm{~m}$ & $\mathrm{~m}$ \\
\hline Frankreich & 897 & 900 & 100 & 631 & 647 & 98 & 593 & $\mathrm{~m}$ & $\mathrm{~m}$ \\
\hline Deutschland & 782 & 772 & 101 & 735 & 715 & 103 & 684 & 671 & 102 \\
\hline Griechenland & 780 & 780 & 100 & 629 & 629 & 100 & 629 & 629 & 100 \\
\hline Ungarn & 814 & $\mathrm{~m}$ & $\mathrm{~m}$ & 611 & 473 & 129 & 611 & 473 & 129 \\
\hline Island & 634 & $\mathrm{~m}$ & $\mathrm{~m}$ & 634 & $\mathrm{~m}$ & $\mathrm{~m}$ & 560 & $\mathrm{~m}$ & $\mathrm{~m}$ \\
\hline Irland & 915 & 915 & 100 & 735 & 735 & 100 & 735 & 735 & 100 \\
\hline Italien & 748 & 748 & 100 & 612 & 612 & 100 & 612 & 612 & 100 \\
\hline Japan & 617 & $\mathrm{~m}$ & $\mathrm{~m}$ & 513 & $\mathrm{~m}$ & $\mathrm{~m}$ & 449 & $\mathrm{~m}$ & $\mathrm{~m}$ \\
\hline Korea & 811 & $\mathrm{~m}$ & $\mathrm{~m}$ & 554 & $\mathrm{~m}$ & $\mathrm{~m}$ & 531 & $\mathrm{~m}$ & $\mathrm{~m}$ \\
\hline Mexiko & 800 & 800 & 100 & 1167 & 1182 & 99 & 1037 & $\mathrm{~m}$ & $\mathrm{~m}$ \\
\hline Niederlande & 930 & 930 & 100 & 876 & 867 & 101 & 876 & 867 & 101 \\
\hline Neuseeland & 985 & 985 & 100 & 968 & 968 & 100 & 950 & 950 & 100 \\
\hline Norwegen & 713 & 713 & 100 & 633 & 633 & 100 & 505 & 505 & 100 \\
\hline Portugal & 767 & 783 & 98 & 637 & 644 & 99 & 533 & 574 & 93 \\
\hline Schottland & 950 & 975 & 97 & 893 & $\mathrm{~m}$ & $\mathrm{~m}$ & 893 & 917 & 97 \\
\hline Slowakische Rep. & 739 & $\mathrm{~m}$ & $\mathrm{~m}$ & 659 & $\mathrm{~m}$ & $\mathrm{~m}$ & 630 & $\mathrm{~m}$ & $\mathrm{~m}$ \\
\hline Spanien & 880 & 900 & 98 & 564 & a & $\mathrm{m}$ & 548 & 630 & 87 \\
\hline Schweden & a & 624 & $\mathrm{~m}$ & a & 576 & $\mathrm{~m}$ & a & 528 & $\mathrm{~m}$ \\
\hline Schweiz & $\mathrm{m}$ & 871 & $\mathrm{~m}$ & $\mathrm{~m}$ & 850 & $\mathrm{~m}$ & $\mathrm{~m}$ & 669 & $\mathrm{~m}$ \\
\hline Türkei & 639 & $\mathrm{~m}$ & $\mathrm{~m}$ & a & a & a & 567 & $\mathrm{~m}$ & $\mathrm{~m}$ \\
\hline Vereinigte Staaten & 1139 & $\mathrm{~m}$ & $\mathrm{~m}$ & 1127 & $\mathrm{~m}$ & $\mathrm{~m}$ & 1121 & $\mathrm{~m}$ & $\mathrm{~m}$ \\
\hline Ländermittel & 803 & 807 & & 717 & 716 & & 674 & 660 & \\
\hline
\end{tabular}

Quelle: OECD. Hinweise s. Anhang 3 unter www.oecd.org/edu/eag2004. 


\section{Kriterien zur Aufnahme, Klassenzuweisung und -zusammensetzung in Schulen des Sekundarbereich II}

Die schulischen Leistungen sind das am häufigsten genutzte Kriterium zur Aufnahme von Schülern an Schulen des Sekundarbereich II, obwohl es zwischen den Ländern große Unterschiede gibt. In Finnland, Norwegen und Ungarn besuchen mehr als 80 Prozent der Schüler eine Schule, in der die schulischen Leistungen der Schüler immer als Aufnahmekriterium dienen, dagegen sind es in Spanien weniger als 10 Prozent.

Die anderen häufig verwendeten Aufnahmekriterien sind die Bedürfnisse der Schüler und ihr Interesse an einem Bildungsgang sowie ihr Wohnort.

Die Klassenzusammensetzung wird am häufigsten durch die Auswahl eines bestimmten Faches oder Bildungsganges durch die Schüler bestimmt; im Durchschnitt besuchen 73 Prozent der Schüler eine Schule, die dieses Kriterium immer verwendet. Dagegen besucht in Mexiko fast die Hälfte der Schüler eine Schule, an der dies nie so gehandhabt wird. Die nächst häufige Vorgehensweise besteht darin, Klassen so zusammenzusetzen, dass sie eine Mischung von Fähigkeiten enthalten, danach folgt die Zusammenstellung nach dem Alter der Schüler.

Die Schulen in Belgien (fläm.), Irland, Italien und Ungarn sind im Durchschnitt sowohl bei der Aufnahme der Schüler als auch bei der Klassenzusammensetzung selektiver als der internationale Durchschnitt. Im Gegensatz dazu scheinen Schulen in Schweden und Spanien bei ihrer Aufnahmepolitik weniger selektiv vorzugehen als der internationale Durchschnitt und auch die Klassenzusammensetzung folgt tendenziell seltener selektiven Regeln. 


\section{Abbildung D5.1}

Kriterien zur Aufnahme und Klassenzuweisung in Schulen des Sekundarbereich II (2001)

Prozentsatz Schüler des Sekundarbereich II, die eine Schule besuchen, deren Schulleiter angab, bestimmte Faktoren bei der Aufnahme und Klassenzuweisung immer zu berücksichtigen
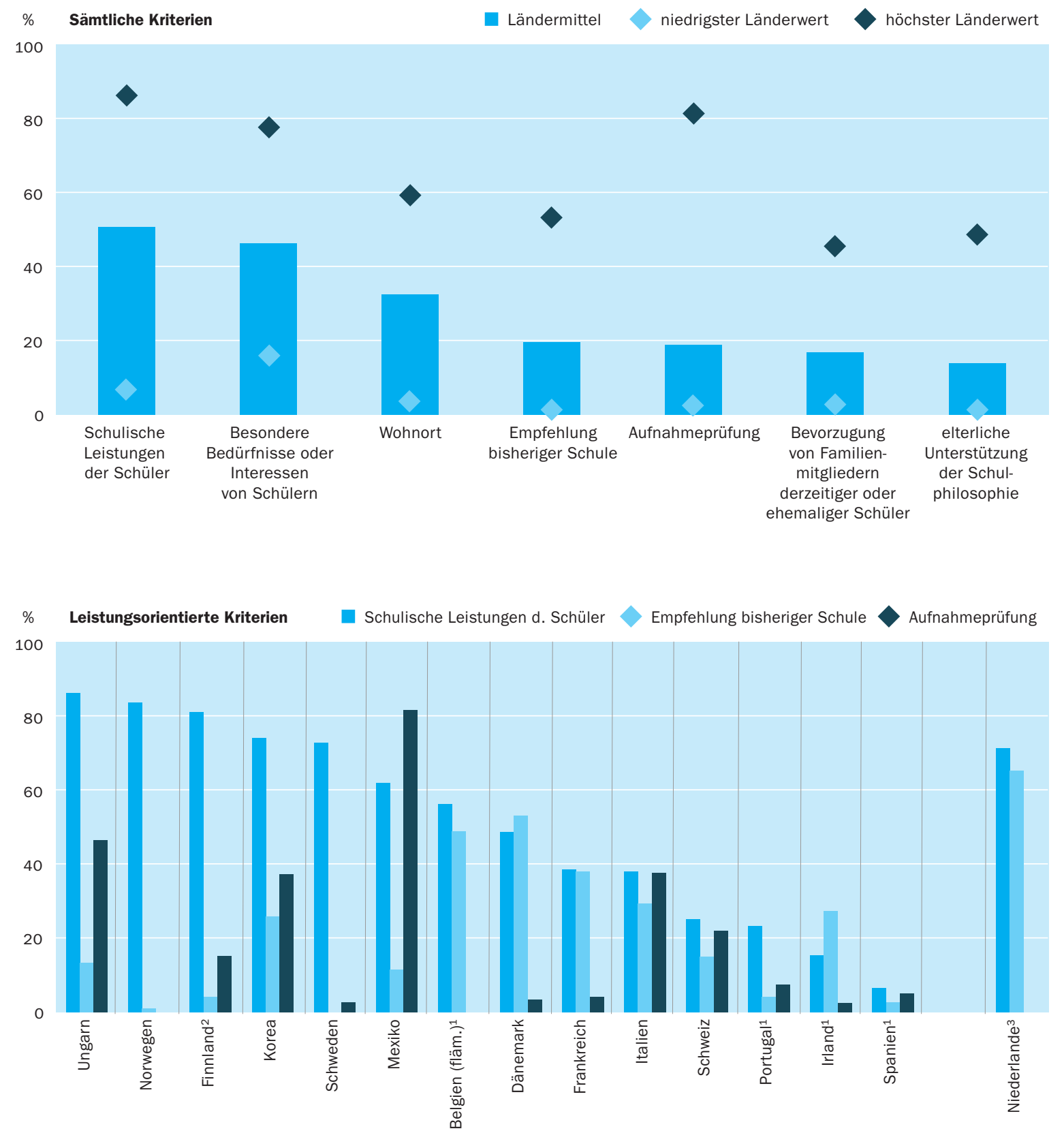

1. Die Frage der Aufnahmepolitik bezieht sich eher auf den Sekundarbereich I als II. In den meisten Fällen werden die Schüler zu Beginn des Sekundarbereich I an der Schule aufgenommen. 2. In Finnland haben einige Schulen des Sekundarbereich II einen Intensivzug in Naturwissenschaften, Musik, Fremdsprachen, Kultur, Kunst oder Sport. Einige berufsbildenden Schulen des Sekundarbereich II bieten zusätzliche Fächer z. B. natürliche Ressourcen und Umweltfragen. In der Regel bewerben sich Schüler an diesen Schulen, weil die Eltern das Angebot der Schule unterstützen. 3. Land erfüllte nicht internationale Anforderungen an die Stichprobe. Die vorgelegten Daten sind nicht gewichtet.

Anordnung der Länder in absteigender Reihenfolge des Prozentsatzes Schüler des Sekundarbereich II, die eine Schule besuchen, deren Schulleiter angab, die schulischen Leistungen der Schüler immer als Aufnahmekriterium zu berücksichtigen.

Quelle: OECD. Tabelle D5.1. Hinweise s. Anhang 3 unter www.oecd.org/edu/eag2004. 


\section{Politischer Hintergrund}

Kriterien zur Aufnahme und Klassenzuweisung von Schülern sind der Rahmen für die Auswahl von Schülern für schulische Bildungsgänge und die Einteilung der Schüler nach ihren angestrebten Schullaufbahnen und ihren Bildungsbedürfnissen. In Ländern, in denen traditionell eine sozioökonomische Trennung durch Wohngebiete besteht oder in denen signifikante Unterschiede zwischen Bildungsgängen und Schulen des Sekundarbereich II existieren, sind Regeln und Kriterien zur Aufnahme und Klassenzusammensetzung von großer Bedeutung für Eltern und Schüler. Gute Schulen sind erfolgreicher darin, motivierte Schüler anzuziehen und gute Lehrer zu halten; im Gegensatz dazu könnten andere Schulen durch einen ,Braindrain“ von Schülern und Lehrkräften schlechter werden, es sei denn eine Politik der Chancengleichheit begrenzt die Selektivität der Schulen, oder es werden Vorkehrungen getroffen, um allen eine gleichwertige Bildung zu ermöglichen.

Nach der Aufnahme in eine Schule werden Schüler Mitglieder einer Gemeinschaft von Gleichaltrigen und Erwachsenen. Die Zusammensetzung der Klassen innerhalb dieser Gemeinschaft beeinflusst das Lernumfeld der Schüler. Es gibt zwischen den Ländern große Unterschiede darin, wie die Klassen zusammengesetzt werden und länderübergreifende Vergleiche vernachlässigen diese Unterschiede oft als unbekannten Kontextfaktor.

200I wurden im Rahmen der Untersuchung International Survey of Upper Secondary Schools (ISUSS - Internationale Studie der Schulen des Sekundarbereich II) Schulleiter zu den Vorgaben zur Aufnahme und Klassenzuweisung der Schüler an ihrer Schule befragt. Zur Beschreibung der Studie siehe Anhang 3 unter www.oecd.org/edu/eag2004.)

In allen Ländern, die an der Studie teilnahmen, werden Schüler auf unterschiedliche Bildungsgänge,verteilt‘. Einzelne Schulen können sich auf einen Bildungsgang spezialisieren oder zahlreiche unterschiedliche Bildungsgänge anbieten. Sie bereiten die Schüler vor und qualifizieren sie für den Eintritt in den Hochschulbereich oder den Arbeitsmarkt und manchmal für beides.

Angesichts unterschiedlicher Bildungsangebote haben Schulen des Sekundarbereich II mehr Autonomie bei der Auswahl der Schüler und der Zusammensetzung der Klassen als Schulen des Primarbereichs und des Sekundarbereich I. Der Grad der Autonomie unterscheidet sich von Land zu Land; die Studie untersuchte das Ausmaß, in dem die Schüler in den einzelnen Ländern ,verteilt‘ werden.

\section{Ergebnisse und Erläuterungen}

\section{Aufnahmepolitik für Schüler im Sekundarbereich II}

Die Strukturen der Schulen und Bildungsgänge eines Landes bestimmen, wann Schüler zum ersten Mal zwischen unterschiedlichen Bildungsgängen mit unterschiedlichen Zielen wählen müssen, oder wann sie zum ersten Mal die Gelegenheit haben, eine Schule auszuwählen, deren Bildungsangebot
In der Untersuchung International Survey of Upper Secondary Schools (ISUSS Internationale Studie der Schulen des Sekundarbereich II) der OECD wurden Schulleiter nach den Vorgaben zur Aufnahme und Klassenzuweisung von Schülern an ihrer Schule befragt. 
Bisherige schulische

Leistungen und Interesse an

einem Bildungsgang sind

die wichtigsten Kriterien zur

Klassenzuweisung ... ihren Bildungszielen entspricht. In den Ländern, in denen der Sekundarbereich I typischerweise in Form von einheitlichen Schulen und damit vom aufgegliederten Sekundarbereich II getrennt organisiert ist, erfolgt die erste wichtige Auswahl zwischen den Schulen zu Beginn des Sekundarbereich II. Das gilt für Dänemark, Frankreich, Finnland, Korea, Norwegen, Schweden und die Schweiz. In den Ländern, die den Sekundarbereich I und II jedoch typischerweise an einer Schule abdecken, wählen Schüler eine Schule manchmal schon früher, bzw. erhalten die Berechtigung für bestimmte Schulen schon früher, und zwar nach Beendigung des Primarbereichs. Das gilt für Belgien (fläm.), Irland, Portugal und Spanien. In Ungarn wechseln Schüler typischerweise die Schule nach Ende des Sekundarbereich I, aber es besteht auch die Möglichkeit, sich für lange Bildungsgänge im Sekundarbereich zu bewerben, die den Sekundarbereich I ganz oder teilweise gemeinsam mit dem Sekundarbereich II kombinieren. Ähnliche Schulen - überwiegend private Bildungseinrichtungen - gibt es in Finnland, Frankreich, Mexiko und der Schweiz.

Im Sekundarbereich II haben Schulen in den meisten Ländern ein relativ hohes Maß an Autonomie bei der Auswahl von Schülern und bei der Entscheidung darüber, wie die Bedürfnisse und Qualifizierungsanforderungen der Schüler durch Bildungsgänge und Kursangebote erfüllt werden können. Aber auch hier gibt es Einschränkungen. Die Aufnahmepolitik kann von der Finanzierungsform der Schulen abhängen und davon, ob die Anzahl der Bewerber der Kapazität der Schule entspricht oder diese übersteigt. Staatliche Gesetze zur schulischen Wahlfreiheit und uneingeschränkten Aufnahme an den Schulen beeinflussen die Aufnahmepolitik von Schulen ebenfalls.

Abbildung D5.I zeigt den prozentualen Anteil der Schüler, deren Schulleiter angeben, dass jedes der sieben genannten Kriterien immer berücksichtigt werde. Die Ergebnisse unterscheiden sich stark von Land zu Land. In Finnland, Korea, Norwegen, Schweden und Ungarn besuchen mindestens 70 Prozent der Schüler eine Schule, die die schulischen Leistungen immer als Aufnahmekriterium verwendet. Dagegen ist dies in Irland, Portugal, der Schweiz und Spanien normalerweise kein Aufnahmekriterium. In Irland, Portugal und Spanien wechseln die Schüler vom Sekundarbereich I zum Sekundarbereich II an derselben Schule, die Aufnahme erfolgt daher schon zu einem früheren Zeitpunkt, wenn die Leistung im Vergleich zu anderen Kriterien weniger wichtig ist.

Obwohl die schulischen Leistungen das wichtigste Aufnahmekriterium sind, werden diese normalerweise nicht durch eine Aufnahmeprüfung bewertet. In Mexiko besuchen 8I Prozent der Schüler eine Schule, die ihre Schüler immer anhand einer Aufnahmeprüfung auswählt. In Dänemark, Italien, Korea, der Schweiz und Ungarn besucht etwa die Hälfte der Schüler eine Schule, die wenigstens gelegentlich so vorgeht. Dagegen werden in Belgien (fläm.), Frankreich, Irland, Norwegen, Portugal und Spanien kaum jemals Aufnahmeprüfungen durchgeführt. In einigen Fällen liegt dies jedoch daran, dass die Schüler die entsprechende Schule bereits besuchen, wenn sie den Sekundarbereich II erreichen (Abb. D5.I und Tab. D5.I).

Das Interesse der Schüler an einem bestimmten Bildungsgang wird dann berücksichtigt, wenn die Wahl zwischen verschiedenen Bildungsgängen oder 
Zügen an einer Schule besteht. In Belgien (fläm.), Dänemark, Frankreich, Italien und Ungarn besuchen mindestens zwei Drittel der Schüler eine Schule, die ihren Aufnahmewunsch aufgrund des Interesses an einem bestimmten Bildungsgang immer in Betracht zieht. In Finnland und Korea gilt dies jedoch für weniger als jeden fünften Schüler (Tab. D5.I).

Wenn lokale Bildungsbehörden dafür verantwortlich sind, allen Bewerbern innerhalb eines festgelegten Wohngebietes einen Schulplatz zu bieten, müssen Schulen alle Schüler eines bestimmten Gebietes aufnehmen und können nur dann andere Schüler aufnehmen, wenn sie noch zusätzliche Plätze frei haben. Dies gilt vor allem für kleine Städte, in denen die Schulen vor allem für Schüler vor Ort da sind, aber in einigen Ländern gelten auch für große städtische Schulsysteme Kriterien zur Aufnahmepolitik, wozu unter anderem auch die Einteilung in Schulbezirke gehören kann. Dieses System kann die Integration der Schüler in sozial heterogenen Gebieten fördern. Es kann aber auch zu einer Verfestigung der Ungleichheit bei den Bildungschancen führen, wenn Wohngebiete nach sozialer Schicht getrennt sind oder das Bildungssystem auf andere Weise selektiv ist.

Die Bedeutung dieses Faktors variiert sehr stark - zwar besuchen im Durchschnitt ein Drittel der Schüler eine Schule, an der dieses Kriterium immer benutzt wird, aber die Hälfte der Schüler besucht auch eine Schule, an der dies nie relevant ist. In Frankreich, Portugal und Spanien ist der Wohnsitz ein wichtiger Aufnahmefaktor, in diesen Ländern besuchen mehr als 50 Prozent der Schüler eine Schule, an der dieses Kriterium immer berücksichtigt wird, während nur eine Minderheit eine Schule besucht, an der die schulischen Leistungen immer berücksichtigt werden. In Frankreich wird jedoch das Interesse der Schüler an einem bestimmten Bildungsgang häufiger berücksichtigt als ihr Wohnsitz. Dagegen ist in Belgien (fläm.) und Finnland der Wohnsitz bei der Aufnahme von Schülern in den Sekundarbereich II nahezu irrelevant (Tab. D5.I).

Der Wohnsitz, die Leistungen und die Wünsche der Schüler sind zwar die vorherrschenden Aufnahmekriterien, einige Schulen berücksichtigen jedoch auch andere Faktoren. Empfehlungen der bisherigen Schulen werden im Durchschnitt der Ländern nicht häufig berücksichtigt, dennoch besuchen 50 Prozent der Schüler im Sekundarbereich II in Belgien (fläm.) und Dänemark eine Schule, deren Schulleiter angibt, dieses Kriterium immer bei der Aufnahme von Schülern anzulegen. In Finnland, Norwegen, Portugal und Spanien liegt der Anteil bei unter 5 Prozent. In Schweden gibt es überhaupt keine Empfehlungen seitens der bisherigen Schule. Andererseits besuchen zwei Drittel der Schüler in Belgien (fläm.) und fast die Hälfte der Schüler in Irland und Ungarn eine Schule, deren Schulleiter angab, bei der Aufnahme von Schülern wenigstens gelegentlich zu berücksichtigen, ob die Eltern die spezielle Philosophie der Schule unterstützen. In anderen Ländern ist diese Praxis weit seltener und in einigen Ländern nicht einmal geduldet. In Schweden verbietet beispielsweise das Gesetz den Schulen, Schüler aus diesen Gründen zu bevorzugen (Abb. D5.I und Tab. D5.I).
... aber auch der Wohnsitz kann gelegentlich das wichtigste Kriterium sein ...

.. .und andere Faktoren, wie Empfehlungen der vorherigen Schule oder die elterliche Unterstützung der religiösen oder pädagogischen Ausrichtung einer Schule, spielen in einigen Ländern ebenfalls eine wichtige Rolle. 
Die Auswahl anhand der Leistungen der Schüler lässt sich in einem internationalen Index zusammenfassen.
In der Untersuchung International Survey of Upper Secondary Schools (ISUSS - Internationale Studie der Schulen des Sekundarbereich II) wurden Schulleiter gefragt, wie sie die Klassen zusammensetzen.
Jedes Land hat seine eigene spezielle Mischung von Klassenzuweisungs- und Aufnahmekriterien. Ein Schlüsselaspekt der Aufnahme - die Auswahl der Schüler anhand ihrer Leistungen - lässt sich in einem internationalen Index zusammenfassen. Die Angaben der Schulleiter zur Aufnahme gemäß schulischen Leistungen, Aufnahmeprüfungen und Empfehlungen bisheriger Schulen werden kombiniert und ergeben einen ,Index der leistungsorientierten Aufnahmepolitik'. Ein positiver Indexwert eines Landes zeigt, dass die Aufnahmepolitik im Durchschnitt selektiver ist als im Mittel aller untersuchten Länder, dagegen zeigt ein negativer Indexwert, dass die Aufnahmepolitik des Landes weniger selektiv als der Durchschnitt ist. Tabelle D5.2 zeigt die Verteilung der Schulen innerhalb der Länder auf diesem Index (Tab. D5.2).

Die Ergebnisse zeigen, dass die Länder die Leistungen der Schüler in sehr unterschiedlichem Maße als Kriterium für die Aufnahme zum Sekundarbereich II verwenden. In Dänemark, Mexiko und Ungarn scheinen die Schulleiter der überwiegenden Mehrheit der Schüler die Eingangsleistungen der Schüler weit stärker zu berücksichtigen als der auf diesem Index basierende internationale Durchschnitt. Dagegen besuchen in Irland, Portugal, Schweden und Spanien weniger als 25 Prozent der Schüler eine Schule, an der dies der Fall ist, allerdings könnte dies in einigen Fällen dadurch erklärt werden, dass die Sekundarbereiche I und II an derselben Schule angeboten werden. Italien weist den größten Unterschied bei den Anforderungen an die Eingangsleistungen auf: während die Hälfte der Schüler eine Schule besuchen, die im Hinblick auf die schulischen Leistungen weniger selektiv ist als der internationale Durchschnitt, besucht wenigstens ein Viertel aller Schüler im Sekundarbereich II eine sehr selektive Schule.

\section{Klassenzusammensetzung im Sekundarbereich II}

In einigen Ländern gibt es im Sekundarbereich II keine feststehenden Schulklassen mehr, d. h. die Schüler besuchen Kurse in verschiedenen Fächern in jeweils unterschiedlichen Gruppen. In anderen Schulsystemen werden die Schüler eher nach dem Niveau der Kurse, die sie besuchen, zusammengruppiert, und weniger nach Alter oder Jahrgang (Klasse), und ihre Mitschüler können einem großen Altersspektrum angehören. Andere Bildungssysteme haben „administrative Klassen“, d. h. feste Schülergruppen, die in allen oder fast allen Fächern gemeinsam unterrichtet werden und den gesamten Bildungsgang gemeinsam absolvieren (z. B. in Belgien (fläm.) und Ungarn). Abgesehen von systemischen Unterschieden gibt es auch auf Schulebene zahlreiche Variationen. Im Sekundarbereich II haben die Schüler auch Wahlfächer, für die sie aus unterschiedlichen ,administrativen Klassen' innerhalb ihrer Jahrgangsstufe zusammengezogen werden können. Andererseits können aber die gleichen Fächer auf unterschiedlichen Leistungsstufen angeboten werden, was die Schulen dazu veranlassen kann, die Jahrgangsstufen bei der Gruppierung zu ignorieren.

Die Antworten auf die Frage, welche Kriterien für die Zusammensetzung der Klassen genutzt werden, sind in Tabelle D5.3 zusammengefasst. Das am häufigsten genannte Kriterium für die Klassenzusammensetzung war die Auswahl eines Bildungsganges oder eines Faches durch die Schüler: 73 Prozent der Schüler besuchen eine Schule, die ihre Wahl ,immer' für die Klassenzusammensetzung heranzieht. Der prozentuale Anteil in den einzelnen Ländern ist in Abb. D5.2 dargestellt. 


\section{Abbildung D5.2}

Kriterien für die Klassenzusammensetzung im Sekundarbereich II (2001)

Prozentsatz Schüler des Sekundarbereich II, die eine Schule besuchen, deren Schulleiter angab, bestimmte Faktoren bei der Klassenzusammensetzung immer zu berücksichtigen
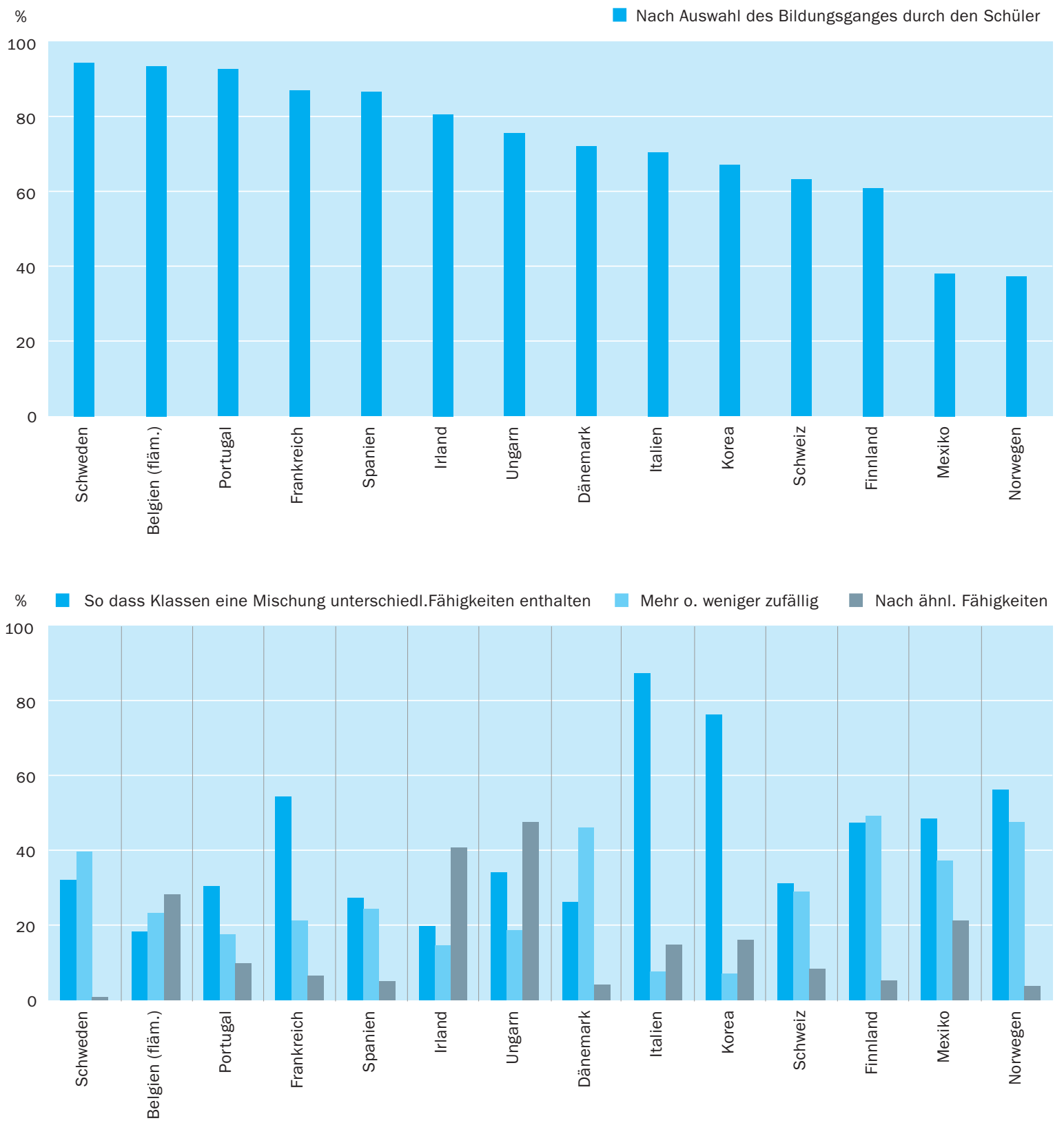
Im Sekundarbereich II ist die Wahl eines bestimmten Bildungsganges oder Faches am häufigsten die Grundlage für die Zusammensetzung der Klassen.

In einigen wenigen Schulen erfolgt die Klassenzusammensetzung nach den Fähigkeiten der Schüler und verstärkt die Selektion.

In Schweden und Ungarn werden die Schüler des Sekundarbereich II typischerweise nach ihrem Alter in Klassen eingeteilt, dagegen
Über alle diese Faktoren hinaus gibt es jedoch noch die Frage, ob Klassen nach dem Alter der Schüler zusammengestellt werden. Hier gibt es unterschiedliche Vorgehensweisen, wobei der Anteil der Schüler, die eine Schule besuchen, die Klassen ,nie' nach dem Alter zusammensetzt (48 Prozent), etwas größer ist als der Anteil derer, die eine Schule besuchen, in der das ,immer' der Fall ist (40 Prozent).

Zwei weitere Faktoren - Fachkenntnis der Lehrer und Wunsch der Eltern werden nur selten als Kriterium für die Klassenzusammensetzung genutzt.

Wie in Abbildung D5.2 und Tabelle $\mathrm{D}_{5} .3$ gezeigt, ist die Wahl eines bestimmten Bildungsganges oder Faches am häufigsten die Grundlage für die Zusammensetzung der Klassen. In Belgien (fläm.), Frankreich, Portugal und Schweden ist dies mit Abstand das wichtigste Kriterium, das von fast allen Schulen verwendet wird. In Mexiko besucht dagegen nur ein Drittel der Schüler eine Schule, die die Wahl eines bestimmten Bildungsganges oder Faches immer als Grundlage für die Zusammensetzung der Klassen verwendet und die Hälfte der Schüler besucht eine Schule, an der die Wahl eines bestimmten Bildungsganges oder Faches nie als Grundlage für die Zusammensetzung der Klassen verwendet wird. In Norwegen erfolgt die Klassenzusammensetzung aufgrund der Wahl eines Bildungsganges oder Faches bei bestimmten Fächern sowie in technischen Fachschulen nach dem ersten Jahr.

Die Zusammensetzung aufgrund ähnlicher Fähigkeiten wird gelegentlich als ,verdeckte' Auswahlpolitik betrieben und verstärkt den offensichtlicheren Effekt der Aufnahme auf Grundlage der Fähigkeiten. Oft wird behauptet, dass eine Einteilung nach Fähigkeiten sowohl den schlechten als auch den guten Schülern dabei helfe, in einem angemessenen Lernumfeld Fortschritte zu erzielen. Neuere Forschungsergebnisse belegen jedoch, dass sowohl die guten wie die schlechten Schüler unter einer derartigen Klassenzusammensetzung leiden können.

Die Ergebnisse zeigen, dass insgesamt im Durchschnitt nur I5 Prozent der Schüler eine Schule besuchen, die üblicherweise die Klassenzusammensetzung nach Fähigkeiten vornimmt, dagegen mehr als 50 Prozent eine Schule, die die Klassen nie nach Fähigkeiten zusammenstellt. Fast die Hälfte der Schüler in Irland und Ungarn besucht eine Schule, an der die Klassen üblicherweise nach Fähigkeiten der Schüler zusammengestellt werden. In Dänemark, Finnland, Frankreich, Norwegen, Schweden, der Schweiz und Spanien sind es dagegen weniger als Io Prozent der Schüler. In vielen Schulen wird eine entgegengesetzte Politik verfolgt - dort werden die Klassen so zusammengestellt, dass sich eine Mischung unterschiedlicher Fähigkeiten ergibt. Im Durchschnitt aller Länder besuchen 42 Prozent der Schüler eine Schule, deren Schulleiter angibt, so zu verfahren, in Italien und Korea sind es über 75 Prozent.

Das Alter der Schüler scheint in diesem Bildungsbereich weniger relevant für die Klassenzusammensetzung zu sein als im Primar- und Sekundarbereich I. In Schweden und Ungarn werden jedoch die Schüler eines Jahrgangs immer noch gemeinsam unterrichtet. In Dänemark, Finnland, Frankreich und Korea besuchen dagegen mindestens zwei Drittel der Schüler eine Schule, deren 
Schulleiter angibt, bei der Klassenzusammensetzung nie das Alter der Schüler zu berücksichtigen. Systembedingte Unterschiede bei der Organisation des Sekundarbereich II könnten als Erklärung für die unterschiedlichen Angaben dienen. Aber selbst offensichtliche Ähnlichkeiten können grundlegende bildungspolitische Unterschiede verbergen. Die automatische Versetzung der Schüler führt dazu, dass Schüler einer Altersgruppe gemeinsam unterrichtet werden. Andererseits können strikte Selektion und Einteilung zum gleichen Ergebnis führen: Schüler steigen mit ihrer Alterskohorte in die nächste Klasse auf, verlassen die Schule oder werden an einen anderen Bildungsgang verwiesen, der für dieselbe Altersgruppe aber mit anderen Bildungszielen und -interessen ausgelegt ist, wie zum Beispiel in Ungarn.

Aus den in Tabelle D5.3 genannten Kriterien wurde ein Index der selektiven Praxis zur Klassenzusammensetzung entwickelt, der auch den Wunsch der Eltern bzw. eines Vormundes berücksichtigt. Es wurde angenommen, dass eine zufällige Klassenzusammensetzung und eine Zusammensetzung, die darauf abzielt, eine Mischung an Fähigkeiten zu erreichen, Leistungsunterschiede eher nicht verstärken (daher wurde diesen ein negativer Indexwert zugewiesen) und eine Zusammensetzung nach Fähigkeiten oder nach Wunsch der Eltern dagegen Leistungsunterschiede eher verstärkt (daher wurde diesen ein positiver Indexwert zugeteilt). Der Index wurde auf einer internationalen Skala standardisiert. Tabelle D5.4 zeigt den Indexmittelwert der selektiven Praxis der Klassenzusammensetzung nach Ländern (ein positiver Indexwert bedeutet selektivere Praxis im Vergleich zu den anderen erfassten Ländern) sowie die Unterschiede zwischen den Schulen eines Landes.

In Finnland, Korea und Norwegen besuchen mehr als 75 Prozent der Schüler des Sekundarbereich II eine Schule, die weniger selektive Kriterien zur Klassenzusammensetzung einsetzt als der internationale Durchschnitt und in Dänemark, Frankreich, Italien, Mexiko, Schweden, der Schweiz und Spanien sind es mehr als die Hälfte. In Belgien (fläm.), Portugal und Ungarn besucht die Mehrzahl der Schüler eine Schule, an der die Klassenzusammensetzung die Leistungsunterschiede zwischen den Schülern eher verstärkt. Der hohe Indexwert in Irland lässt sich dadurch erklären, dass die Schüler die Fächer und die zu absolvierende Prüfungsstufe selbst auswählen und dann entsprechend in Klassen eingeteilt werden. In diesem prüfungsbasierten Umfeld hat die Klassenzusammensetzung nach Fähigkeiten eine andere Bedeutung als in Schulsystemen, in denen die Kursstruktur durch festgelegte Lehrpläne strukturiert wird.

Welcher Zusammenhang besteht zwischen einer selektiven Praxis der Aufnahme und der Klassenzusammensetzung? Abb. D5.3 vergleicht die Selektivität der beiden Komponenten. Auf der horizontalen Achse kombiniert ein Index der Selektivität die Ergebnisse der leistungsorientierten Selektivität der Aufnahme mit einem Auswahlindex, der auf der Unterstützung der Schulphilosophie durch die Eltern beruht. Auf der vertikalen Achse ist der Index der selektiven Klassenzusammensetzung innerhalb der Schule aufgetragen. erfolgt in Dänemark, Finnland, Frankreich und Korea selten eine Einteilung nach Alter.

Ein auswahlbezogener Index erfasst die unterschiedliche Praxis zur Klassenzusammensetzung in den einzelnen Ländern.

In Schweden und Spanien sind selektive Kriterien zur Aufnahme und Klassenzusammensetzung seltener als in anderen Ländern. 


\section{Abbildung D5.3}

Leistungsorientierte Aufnahmepolitik und selektive Praxis der Klassenzusammensetzung (2001)

Ländermittel auf den standardisierten Indizes der selektiven Praxis der Klassenzusammensetzung und der Selektivität der Zulassungspolitik

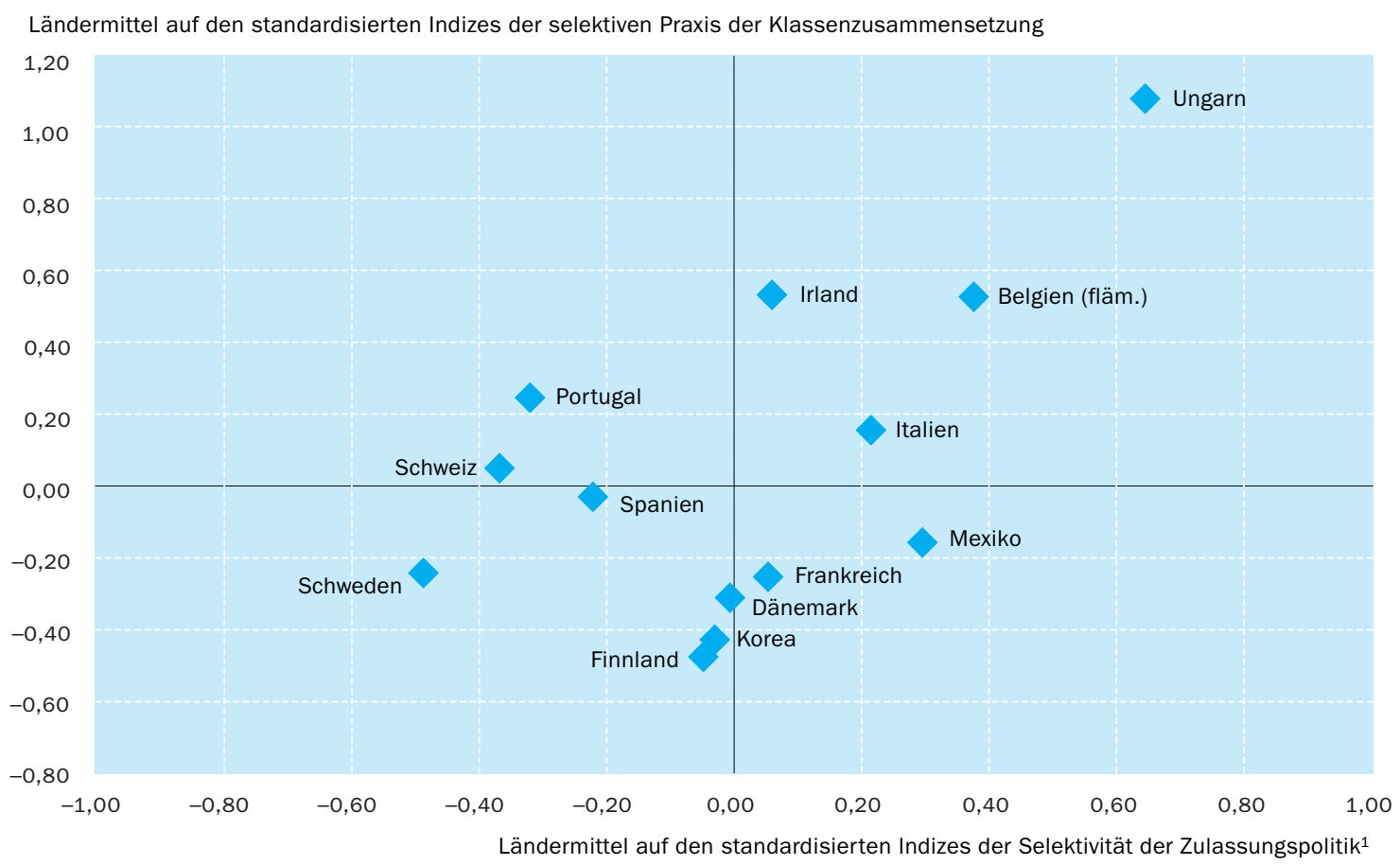

Beispiel: ein Land im oberen rechten Quadranten hat sowohl eine selektivere Aufnahmepolitik als auch selektivere Praxis der Klassenzusammensetzung als der Durchschnitt.

Hinweis: Der internationale Index enthält nur Länder, die international vergleichbare Daten meldeten.

1. Die Werte entsprechen dem Durchschnitt des standardisierten Index der leistungsorientierten Zulassungspolitik sowie dem standardisierten Index der Zulassungspolitik aufgrund elterlichen Unterstützung der Schulphilosophie. Ein positiver Wert bedeutet eine selektivere Praxis als der Durchschnitt der erfassten Länder. Quelle: OECD. Tabellen D5.2 und D5.4. Hinweise s. Anhang 3 unter www.oecd.org/edu/eag2004.

Diese Grafik zeigt, dass in Belgien (fläm.), Irland, Italien und Ungarn die Schulen im Durchschnitt sowohl bei der Aufnahme als auch bei der Klassenzusammensetzung selektiver vorgehen als der internationale Durchschnitt. In Schweden und Spanien dagegen scheinen die Schulen eine weniger selektive Aufnahmepolitik zu verfolgen als der internationale Durchschnitt und auch bei der Klassenzusammensetzung tendenziell seltener selektiv vorzugehen. Die beiden Formen der Selektivität müssen jedoch nicht zwangsläufig gemeinsam verfolgt werden. Es wäre beispielsweise möglich, dass Schulen, die ihre Schüler strikt nach schulischen Leistungen auswählen, weniger Grund haben, Klassen nach Fähigkeiten zusammen zu setzen, als weniger selektiv aufnehmende Schulen. Frankreich und Mexiko sind zwar bei der Aufnahme etwas selektiver als der Durchschnitt aber bei der Klassenzusammensetzung etwas weniger selektiv. In Portugal ist das Gegenteil der Fall. Dies sind jedoch die einzigen drei der 13 Länder, in denen die Selektivität bei der Auswahl und der Klassenzusammensetzung gegenläufige Trends aufweisen. 
Dieser erste Versuch, die Selektivität von Schulsystemen zu klassifizieren, ist mit Vorsicht zu interpretieren. Ein Problem besteht darin, dass eine bestimmte Politik zu unterschiedlichen Zwecken eingesetzt werden kann. Je nach gesellschaftlichem und pädagogischem Kontext kann beispielsweise die Klassenzusammensetzung nach Fähigkeiten entweder dazu genutzt werden, schulisch benachteiligten Schülern zusätzliche Unterstützung oder ein angemesseneres Lernumfeld zu bieten, oder aber dazu führen, dass sozial Benachteiligte ausgegrenzt werden.

Ganz allgemein ist festzustellen, dass der Zusammenhang zwischen der Aufgliederung der Schüler im Sekundarbereich II und der Chancengleichheit der Bildungssysteme und der in ihnen erreichten Erfolge keineswegs eindeutig ist. Dies lässt sich teilweise durch die Wechselwirkung zwischen Aspekten der Chancengleichheit mit Aspekten der ,Steuerung، in diesem Bereich erklären. Da Schüler mit unterschiedlichen Begabungen und anderen Merkmalen unterschiedliche Lebenswege einschlagen werden, besteht das gerechteste Bildungsangebot nicht zwangsläufig darin, sie alle an der gleichen Schule oder in der gleichen Klasse zu belassen. Dennoch besteht die Gefahr, dass die Aufgliederung zu einer ungerechten Verteilung der Chancen führt.

\section{Definitionen und angewandte Methodik}

Die Daten dieses Indikators wurden den Antworten der Schulleiter bei der Untersuchung International Survey of Upper Secondary Schools (ISUSS - Internationale Studie der Schulen des Sekundarbereich II) entnommen, einer Studie des regulären Sekundarbereich II, die im Schuljahr 200I/2002 an 4.400 Schulen in I5 Ländern durchgeführt wurde. Nähere Informationen s. Anhang 3 unter www.oecd.orgleduleag2004.

Es werden folgende Kriterien zur Aufnahme von Schülern unterschieden: Wohnsitz, schulische Leistungen der Schüler, Aufnahmeprüfungen, Empfehlungen der bisherigen Schule, die elterliche Unterstützung der Schulphilosophie, ob der Schüler an einem bestimmten Bildungsgang interessiert ist oder bestimmte Bedürfnisse hat, ob Familienmitglieder jetziger oder ehemaliger Schüler bevorzugt werden.

Die selektive Praxis der Klassenzusammensetzung ist durch die Art der Klassenzusammensetzung definiert. Die Klassenzusammensetzung erfolgt: mehr oder weniger zufällig, nach ähnlichen Fähigkeiten, mit dem Ziel, eine Mischung an Fähigkeiten zu erreichen, nach der Fachkenntnis der Lehrer, nach Alter der Schüler, nach der Auswahl eines bestimmten Faches oder Bildungsganges durch die Schüler, auf Wunsch der Eltern.

Der Index der leistungsorientierten Aufnahmepolitik errechnet sich als Summe der Antworten der Schulleiter auf die Frage, wie oft sie die folgenden Kriterien bei der Aufnahme von Schülern oder bei der Zuweisung der Schüler zu einer Klasse im Sekundarbereich II berücksichtigen: die schulischen Leistungen des Schülers, Aufnahmeprüfungen und Empfehlungen der bisherigen Schule. Den Angaben ,immer' oder , oft' wurde der Code 2 zugewiesen, , manchmal' wurde der Code I zugewiesen und ,nie‘ erhielt den Code o.
Selektivität zu messen, ist jedoch nicht einfach und die Auswirkungen der Kriterien auf die Chancengleichheit sind nicht unmittelbar abzuleiten.

Die Daten über Vorgaben zur Aufnahme von Schülern und zur Klassenzusammensetzung stammen aus der Untersuchung International Survey of Upper Secondary Schools (ISUSS - Internationale Studie der Schulen des Sekundarbereich II) von 2001. 
Der Index der selektiven Praxis der Klassenzusammensetzung innerhalb einer Schule errechnet sich als Summe der Antworten der Schulleiter auf die Frage, wie oft die Klassenzusammensetzung im Sekundarbereich II mehr oder weniger zufällig, nach ähnlichen Fähigkeiten, mit dem Ziel, eine Mischung an Fähigkeiten zu erreichen, aufWunsch der Eltern oder eines Vormundes erfolgt. Bei der Berechnung des Gesamtindex wurden die ,integrativen' Methoden (d.h. die zufällige Zusammensetzung oder die Zusammensetzung mit dem Ziel, eine Mischung an Fähigkeiten zu erreichen) mit einem negativen Vorzeichen versehen. Den Angaben ,immer' oder ,oft' wurde ein Code von 2 zugewiesen, ,manchmal' wurde der Code I zugewiesen und ,nie' erhielt den Code o. Ein hoher Indexwert steht daher für eine starke Neigung, Schüler nach Fähigkeiten oder soziokulturellem Hintergrund einzuteilen. Ein negativer Wert steht für einen integrativen Ansatz bei der Klassenzusammensetzung. 
Tabelle D5.1

Kriterien zur Aufnahme von Schülern und Klassenzuweisung im Sekundarbereich II nach Angaben der Schulleiter (2001) Prozentsatz Schüler des Sekundarbereich II, die eine Schule besuchen, deren Schulleiter angab, bestimmte Faktoren bei der Aufnahme von Schülern und der Klassenzuweisung an der Schule immer, manchmal oder nie zu berücksichtigen

\begin{tabular}{|c|c|c|c|c|c|c|c|c|c|c|c|c|}
\hline \multirow[b]{2}{*}{ OECD-Länder } & \multicolumn{3}{|c|}{ Wohnort } & \multicolumn{3}{|c|}{$\begin{array}{l}\text { Schulische Leistungen } \\
\text { des Schülers }\end{array}$} & \multicolumn{3}{|c|}{ Aufnahmeprüfung } & \multicolumn{3}{|c|}{ Empfehlung bisheriger Schule } \\
\hline & Nie & Manchmal & Immer & Nie & Manchmal & Immer & $\mathrm{Nie}$ & Manchmal & Immer & Nie & Manchmal & Immer \\
\hline Belgien (fläm.) ${ }^{1}$ & 92 & 5 & 3 & 16 & 28 & 56 & 94 & 6 & $\mathrm{n}$ & 14 & 37 & 49 \\
\hline Dänemark & 55 & 18 & 26 & 19 & 32 & 48 & 33 & 63 & 3 & 19 & 28 & 53 \\
\hline Finnland ${ }^{2}$ & 80 & 15 & 4 & 9 & 10 & 81 & 62 & 22 & 15 & 64 & 32 & 4 \\
\hline Frankreich & 27 & 17 & 57 & 23 & 38 & 38 & 89 & 7 & 4 & 21 & 41 & 38 \\
\hline Ungarn & 67 & 10 & 23 & 7 & 7 & 86 & 45 & 8 & 46 & 58 & 29 & 13 \\
\hline Irland ${ }^{1}$ & 76 & 11 & 14 & 56 & 28 & 15 & 93 & 5 & 2 & 42 & 30 & 27 \\
\hline Italien & 56 & 18 & 26 & 51 & 11 & 38 & 53 & 10 & 38 & 48 & 23 & 29 \\
\hline Korea & 34 & 13 & 53 & 17 & 10 & 74 & 55 & 8 & 37 & 63 & 11 & 26 \\
\hline Mexiko & 65 & 19 & 16 & 22 & 16 & 62 & 11 & 7 & 81 & 66 & 23 & 11 \\
\hline Norwegen & 31 & 20 & 50 & 5 & 11 & 83 & 92 & 8 & $\mathrm{n}$ & 64 & 35 & 1 \\
\hline Portugal $^{1}$ & 20 & 21 & 59 & 43 & 34 & 23 & 92 & 0 & 8 & 66 & 30 & 4 \\
\hline Spanien $^{1}$ & 32 & 9 & 59 & 78 & 15 & 7 & 76 & 19 & 5 & 81 & 16 & 3 \\
\hline Schweden & 51 & 18 & 31 & 9 & 18 & 73 & 67 & 31 & 3 & 100 & $\mathrm{n}$ & $n$ \\
\hline Schweiz & 47 & 19 & 33 & 58 & 17 & 25 & 29 & 50 & 22 & 60 & 25 & 15 \\
\hline Ländermittel & 52 & 15 & 32 & 30 & 20 & 51 & 64 & 17 & 19 & 55 & 26 & 20 \\
\hline Niederlande $^{3}$ & 100 & $\mathrm{n}$ & $n$ & 11 & 18 & 71 & 87 & 13 & $\mathrm{n}$ & 6 & 29 & 65 \\
\hline
\end{tabular}

\begin{tabular}{|c|c|c|c|c|c|c|c|c|c|}
\hline \multirow[b]{2}{*}{ OECD-Länder } & \multicolumn{3}{|c|}{$\begin{array}{l}\text { Elterliche Unterstützung } \\
\text { der Schulphilosophie }\end{array}$} & \multicolumn{3}{|c|}{$\begin{array}{l}\text { Besondere Bedürfnisse oder } \\
\text { Interessen von Schülern }\end{array}$} & \multicolumn{3}{|c|}{$\begin{array}{l}\text { Bevorzugung von Familienmitgliedern } \\
\text { derzeitiger oder ehemaliger Schüler }\end{array}$} \\
\hline & $\mathrm{Nie}$ & Manchmal & Immer & Nie & Manchmal & Immer & Nie & Manchmal & Immer \\
\hline Belgien (fläm.) $)^{1}$ & 34 & 18 & 48 & 5 & 30 & 65 & 78 & 16 & 6 \\
\hline Dänemark & 95 & 5 & $n$ & 15 & 22 & 63 & 81 & 12 & 7 \\
\hline Finnland ${ }^{2}$ & 70 & 8 & 22 & 33 & 52 & 16 & 98 & 1 & $\mathrm{n}$ \\
\hline Ungarn & 55 & 11 & 34 & 10 & 12 & 77 & 41 & 32 & 28 \\
\hline Irland $^{1}$ & 52 & 27 & 21 & 29 & 39 & 32 & 44 & 20 & 36 \\
\hline Italien & 72 & 11 & 18 & 16 & 15 & 68 & 46 & 29 & 25 \\
\hline Korea & 84 & 10 & 6 & 60 & 22 & 18 & 87 & 9 & 4 \\
\hline Mexiko & 74 & 9 & 17 & 51 & 23 & 26 & 77 & 17 & 6 \\
\hline Norwegen 4 & 98 & 2 & $n$ & 28 & 45 & 26 & 100 & a & a \\
\hline Portugal $^{1}$ & 81 & 13 & 5 & 12 & 34 & 54 & 55 & 30 & 15 \\
\hline Schweden & 100 & a & a & 16 & 26 & 58 & 100 & a & a \\
\hline Schweiz & 96 & 3 & 2 & 27 & 31 & 42 & 92 & 6 & 2 \\
\hline Ländermittel & 77 & 9 & 14 & 25 & 29 & 46 & 71 & 19 & 17 \\
\hline Niederlande ${ }^{3}$ & 64 & 24 & 13 & 14 & 18 & 68 & 100 & $\mathrm{n}$ & $\mathrm{n}$ \\
\hline
\end{tabular}

1. Die Frage der Aufnahmepolitik bezieht sich eher auf den Sekundarbereich I als II. In den meisten Fällen werden die Schüler zu Beginn des Sekundarbereich I an der Schule aufgenommen. 2. In Finnland haben einige Schulen des Sekundarbereich II einen Intensivzug in Naturwissenschaften, Musik, Fremdsprachen, Kultur, Kunst oder Sport. Einige berufsbildende Schulen des Sekundarbereich II bieten zusätzliche Fächer z. B. natürliche Ressourcen und Umweltfragen. In der Regel bewerben sich Schüler an diesen Schulen, weil die Eltern das Angebot der Schule unterstützen. 3. Land erfüllte nicht internationale Anforderungen an die Stichprobe. Die vorgelegten Daten sind nicht gewichtet. 4. Zahlen für Norwegen geschätzt, da diese Frage in der norwegischen Erhebung so nicht gestellt wurde.

Quelle: OECD. Hinweise s. Anhang 3 unter www.oecd.org/edu/eag2004. 


\section{Tabelle D5.2}

Index der Praxis zur Aufnahme von Schülern und Klassenzuweisung im Zusammenhang mit den Leistungen der Schüler (2001) Ländermittel und Standardabweichungen auf dem internationalen standardisierten Index und Indexwerte verschiedener Perzentile der Schülerpopulation im Sekundarbereich II

\begin{tabular}{|c|c|c|c|c|c|c|c|c|}
\hline \multirow[b]{3}{*}{ OECD-Länder } & \multicolumn{8}{|c|}{$\begin{array}{l}\text { Standardisierter Index der leistungsorientierten Aufnahmepolitik } \\
\text { (schulische Leistungen der Schüler, Aufnahmeprüfung und Empfehlung der bisherigen Schule) }\end{array}$} \\
\hline & \multirow[t]{2}{*}{ Mittel } & \multirow{2}{*}{$\begin{array}{l}\text { Standard- } \\
\text { abweichung }\end{array}$} & \multirow[t]{2}{*}{ Standardfehler } & \multicolumn{5}{|c|}{ Perzentil } \\
\hline & & & & 10. & 25. & Median & 75. & 90. \\
\hline Belgien (fläm.) ${ }^{1}$ & 0,25 & 0,78 & $(0,05)$ & $-0,86$ & $-0,24$ & 0,38 & 1,00 & 1,00 \\
\hline Dänemark & 0,57 & 0,97 & $(0,08)$ & $-0,86$ & $-0,24$ & 1,00 & 1,62 & 1,62 \\
\hline Finnland $^{2}$ & 0,16 & 0,78 & $(0,05)$ & $-0,86$ & $-0,24$ & 0,38 & 0,38 & 1,00 \\
\hline Frankreich & 0,04 & 0,90 & $(0,05)$ & $-1,48$ & $-0,24$ & 0,38 & 1,00 & 1,00 \\
\hline Ungarn & 0,58 & 0,90 & $(0,05)$ & $-0,24$ & $-0,24$ & 1,00 & 1,00 & 1,62 \\
\hline Irland ${ }^{1}$ & $-0,54$ & 0,84 & $(0,06)$ & $-1,48$ & $-1,48$ & $-0,86$ & $-0,24$ & 0,38 \\
\hline Italien & 0,07 & 1,40 & $(0,07)$ & $-1,48$ & $-1,48$ & $-0,24$ & 1,62 & 2,24 \\
\hline Korea & 0,32 & 0,99 & $(0,06)$ & $-0,86$ & $-0,24$ & $-0,24$ & 1,00 & 1,62 \\
\hline Mexiko & 0,68 & 0,92 & $(0,05)$ & $-0,24$ & $-0,24$ & 1,00 & 1,00 & 1,62 \\
\hline Norwegen & $-0,10$ & 0,52 & $(0,04)$ & $-0,86$ & $-0,24$ & $-0,24$ & 0,38 & 0,38 \\
\hline Portugal $^{1}$ & $-0,66$ & 0,86 & $(0,06)$ & $-1,48$ & $-1,48$ & $-0,86$ & $-0,24$ & 0,38 \\
\hline Spanien $^{1}$ & $-0,99$ & 0,67 & $(0,04)$ & $-1,48$ & $-1,48$ & $-1,48$ & $-0,86$ & $-0,24$ \\
\hline Schweden & $-0,25$ & 0,55 & $(0,04)$ & $-0,86$ & $-0,24$ & $-0,24$ & $-0,24$ & 0,38 \\
\hline Schweiz & $-0,16$ & 0,97 & $(0,04)$ & $-1,48$ & $-0,86$ & $-0,24$ & 0,38 & 1,00 \\
\hline Ländermittel & 0,00 & 0,86 & $(0,05)$ & $-1,03$ & $-0,64$ & $-0,02$ & 0,56 & 1,00 \\
\hline
\end{tabular}

Hinweis: Der internationale Index enthält nur Länder, die international vergleichbare Daten meldeten.

1. Die Frage der Aufnahmepolitik bezieht sich eher auf den Sekundarbereich I als II. In den meisten Fällen werden die Schüler zu Beginn des Sekundarbereich I an der Schule aufgenommen. 2. In Finnland haben einige Schulen des Sekundarbereich II einen Intensivzug in Naturwissenschaften, Musik, Fremdsprachen, Kultur, Kunst oder Sport. Einige berufsbildende Schulen des Sekundarbereich II bieten zusätzliche Fächer z. B. natürliche Ressourcen und Umweltfragen. In der Regel bewerben sich Schüler an diesen Schulen, weil die Eltern das Angebot der Schule unterstützen.

Quelle: OECD. Hinweise s. Anhang 3 unter www.oecd.org/edu/eag2004. 


\section{Tabelle D5.3}

Häufigkeit, mit der laut Angaben der Schulleiter bestimmte Kriterien bei der Klassenzusammensetzung im Sekundarbereich II berücksichtig werden (2001)

Prozentsatz Schüler des Sekundarbereich II, die eine Schule besuchen, deren Schulleiter angab, bestimmte Kriterien zur Klassenzusammensetzung immer, manchmal oder nie zu verwenden

\begin{tabular}{|c|c|c|c|c|c|c|c|c|c|c|c|c|}
\hline & \multicolumn{12}{|c|}{ Schüler werden in Klassen eingeteilt ... } \\
\hline & \multicolumn{3}{|c|}{ Mehr oder weniger zufällig } & \multicolumn{3}{|c|}{ Nach ähnlichen Fähigkeiten } & \multicolumn{3}{|c|}{$\begin{array}{c}\text { So dass Klassen eine Mischung } \\
\text { unterschiedlicher Fähigkeiten } \\
\text { enthalten }\end{array}$} & \multicolumn{3}{|c|}{$\begin{array}{l}\text { Nach dem besonderen } \\
\text { Fachwissen der Lehrer }\end{array}$} \\
\hline OECD-Länder & $\mathrm{Nie}$ & Manchmal & Immer & $\mathrm{Nie}$ & Manchmal & Immer & Nie & Manchmal & Immer & $\mathrm{Nie}$ & Manchmal & Immer \\
\hline Belgien (fläm.) & 54 & 23 & 23 & 41 & 31 & 28 & 49 & 32 & 18 & 85 & 13 & 2 \\
\hline Dänemark & 31 & 23 & 46 & 72 & 24 & 4 & 50 & 24 & 26 & 83 & 15 & 2 \\
\hline Finnland & 26 & 25 & 49 & 58 & 37 & 5 & 41 & 11 & 47 & 74 & 23 & 4 \\
\hline Frankreich & 50 & 28 & 21 & 68 & 26 & 7 & 24 & 22 & 54 & 54 & 19 & 27 \\
\hline Ungarn & 64 & 18 & 19 & 26 & 26 & 48 & 41 & 25 & 34 & 81 & 10 & 9 \\
\hline Irland & 49 & 37 & 15 & 9 & 50 & 41 & 25 & 55 & 20 & 61 & 28 & 11 \\
\hline Italien & 83 & 10 & 8 & 70 & 15 & 15 & 8 & 4 & 87 & 86 & 12 & 1 \\
\hline Korea & 75 & 18 & 7 & 58 & 26 & 16 & 12 & 12 & 76 & 78 & 13 & 9 \\
\hline Mexiko & 44 & 19 & 37 & 50 & 29 & 21 & 30 & 21 & 48 & 75 & 20 & 5 \\
\hline Norwegen & 25 & 27 & 48 & 56 & 40 & 4 & 21 & 23 & 56 & 76 & 21 & 3 \\
\hline Portugal & 67 & 16 & 18 & 74 & 16 & 10 & 45 & 25 & 31 & 70 & 15 & 15 \\
\hline Spanien & 57 & 19 & 24 & 79 & 16 & 5 & 52 & 21 & 27 & 97 & 3 & $\mathrm{n}$ \\
\hline Schweden & 41 & 19 & 40 & 85 & 14 & 1 & 48 & 20 & 32 & 70 & 25 & 5 \\
\hline Schweiz & 48 & 23 & 29 & 44 & 48 & 8 & 40 & 29 & 31 & 73 & 10 & 16 \\
\hline Ländermittel & 51 & 22 & 27 & 56 & 28 & 15 & 35 & 23 & 42 & 76 & 16 & 8 \\
\hline Niederlande ${ }^{1}$ & 100 & $\mathrm{n}$ & $\mathrm{n}$ & 100 & $\mathrm{n}$ & $\mathrm{n}$ & 100 & $\mathrm{n}$ & $\mathrm{n}$ & 100 & $\mathrm{n}$ & $\mathrm{n}$ \\
\hline
\end{tabular}

\begin{tabular}{|c|c|c|c|c|c|c|c|c|c|}
\hline \multirow[b]{3}{*}{ OECD-Länder } & \multicolumn{9}{|c|}{ Schüler werden in Klassen eingeteilt ... } \\
\hline & \multicolumn{3}{|c|}{ Nach Alter der Schüler } & \multicolumn{3}{|c|}{$\begin{array}{l}\text { Nach Auswahl eines bestimmten Bildungs- } \\
\text { ganges oder Faches durch den Schüler }\end{array}$} & \multicolumn{3}{|c|}{ Nach Wunsch der Eltern } \\
\hline & Nie & Manchmal & Immer & Nie & Manchmal & Immer & $\mathrm{Nie}$ & Manchmal & Immer \\
\hline Belgien (fläm.) & 50 & 8 & 42 & 4 & 3 & 93 & 47 & 49 & 4 \\
\hline Dänemark & 65 & 29 & 6 & 13 & 15 & 72 & 67 & 32 & 1 \\
\hline Finnland & 67 & 16 & 16 & 12 & 27 & 61 & 81 & 18 & 1 \\
\hline Frankreich & 73 & 7 & 20 & 3 & 10 & 87 & 73 & 25 & 2 \\
\hline Ungarn & 4 & 2 & 94 & 11 & 14 & 75 & 19 & 39 & 42 \\
\hline Irland & 57 & 10 & 33 & 7 & 13 & 80 & 63 & 33 & 4 \\
\hline Italien & 38 & 10 & 52 & 19 & 10 & 70 & 14 & 68 & 18 \\
\hline Korea & 77 & 4 & 19 & 15 & 18 & 67 & 88 & 10 & 2 \\
\hline Mexiko & 51 & 20 & 29 & 48 & 14 & 38 & 73 & 22 & 5 \\
\hline Norwegen & 39 & 7 & 55 & 27 & 36 & 37 & 83 & 17 & $\mathrm{n}$ \\
\hline Portugal & 31 & 38 & 31 & 5 & 3 & 93 & 48 & 45 & 7 \\
\hline Spanien & 58 & 10 & 32 & 7 & 7 & 86 & 75 & 20 & 5 \\
\hline Schweden & $\mathrm{n}$ & $\mathrm{n}$ & 100 & $\mathrm{n}$ & 6 & 94 & 60 & 37 & 3 \\
\hline Schweiz & 60 & 9 & 30 & 10 & 27 & 63 & 70 & 26 & 4 \\
\hline Ländermittel & 48 & 12 & 40 & 13 & 14 & 73 & 62 & 31 & 7 \\
\hline Niederlande $^{1}$ & 100 & $\mathrm{n}$ & $\mathrm{n}$ & 1 & $\mathrm{n}$ & 99 & 100 & $\mathrm{n}$ & $\mathrm{n}$ \\
\hline
\end{tabular}

1. Land erfüllte nicht internationale Anforderungen an die Stichprobe. Die vorgelegten Daten sind ungewichtet.

Quelle: OECD. Hinweise s. Anhang 3 unter www.oecd.org/edu/eag2004. 


\section{Tabelle D5.4}

Index der selektiven Praxis der Klassenzusammensetzung in Schulen, nach Angaben der Schulleiter (2001) Ländermittel und Standardabweichungen auf dem internationalen standardisierten Index und Indexwerte verschiedener Perzentile der Schülerpopulation im Sekundarbereich II

\begin{tabular}{|c|c|c|c|c|c|c|c|c|}
\hline \multirow[b]{2}{*}{ OECD-Länder } & \multirow[t]{2}{*}{ Mittelwert } & \multirow{2}{*}{$\begin{array}{l}\text { Standard- } \\
\text { abweichung }\end{array}$} & \multirow[t]{2}{*}{ Standardfehler } & \multicolumn{5}{|c|}{ Perzentil } \\
\hline & & & & 10. & 25. & Median & 75. & 90. \\
\hline Belgien (fläm.) & 0,52 & 0,97 & $(0,06)$ & $-0,68$ & $-0,08$ & 0,52 & 1,13 & 1,73 \\
\hline Dänemark & $-0,25$ & 0,87 & $(0,07)$ & $-1,28$ & $-0,68$ & $-0,08$ & 0,52 & 1,13 \\
\hline Finnland & $-0,47$ & 0,86 & $(0,05)$ & $-1,89$ & $-1,28$ & $-0,68$ & $-0,08$ & 0,52 \\
\hline Frankreich & $-0,32$ & 0,81 & $(0,04)$ & $-1,28$ & $-0,68$ & $-0,08$ & 0,52 & 0,52 \\
\hline Ungarn & 1,07 & 1,12 & $(0,06)$ & $-0,68$ & $-0,08$ & 1,13 & 1,73 & 2,33 \\
\hline Irland & 0,53 & 0,97 & $(0,06)$ & $-0,68$ & $-0,08$ & 0,52 & 1,13 & 1,73 \\
\hline Italien & 0,15 & 0,76 & $(0,04)$ & $-0,68$ & $-0,08$ & $-0,08$ & 0,52 & 1,13 \\
\hline Korea & $-0,43$ & 0,84 & $(0,05)$ & $-1,89$ & $-0,68$ & $-0,68$ & $-0,08$ & 0,52 \\
\hline Mexiko & $-0,16$ & 0,95 & $(0,05)$ & $-1,28$ & $-0,68$ & $-0,08$ & 0,52 & 1,13 \\
\hline Norwegen & $-0,65$ & 0,72 & $(0,05)$ & $-1,89$ & $-1,28$ & $-0,68$ & $-0,08$ & 0,52 \\
\hline Portugal & 0,24 & 0,87 & $(0,06)$ & $-0,68$ & $-0,08$ & 0,52 & 0,52 & 1,13 \\
\hline Spanien & $-0,03$ & 0,89 & $(0,05)$ & $-1,28$ & $-0,68$ & $-0,08$ & 0,52 & 1,13 \\
\hline Schweden & $-0,25$ & 0,86 & $(0,06)$ & $-1,28$ & $-0,68$ & $-0,08$ & 0,52 & 1,13 \\
\hline Schweiz & 0,05 & 0,93 & $(0,04)$ & $-1,28$ & $-0,68$ & $-0,08$ & 0,52 & 1,13 \\
\hline Ländermittel & 0,00 & 0,89 & $(0,05)$ & $-1,20$ & $-0,55$ & 0,01 & 0,57 & 1,13 \\
\hline
\end{tabular}

Hinweis: Der Internationale Index enthält nur die Länder, die international vergleichbare Daten meldeten.

Quelle: OECD. Hinweise s. Anhang 3 unter www.oecd.org/edu/eag2004. 


\section{Entscheidungskompetenzen im Bildungsbereich}

In Australien, Griechenland, Luxemburg, Mexiko, Österreich, Portugal, Spanien und der Türkei sind die Entscheidungskompetenzen am stärksten zentralisiert (d.h. sie werden auf zentraler und/oder bundesstaatlicher Ebene getroffen), wobei die Zentralregierung in Griechenland (mit 88 Prozent der Entscheidungen auf zentraler Ebene) und Luxemburg (66 Prozent) besonders dominiert.

In England, Neuseeland, der Slowakischen Republik, der Tschechischen Republik und Ungarn werden Entscheidungen häufiger auf Schulebene getroffen. In den Niederlanden ist dies bei allen Entscheidungen der Fall.

Entscheidungen zur Unterrichtsorganisation werden in allen OECD-Ländern überwiegend auf Schulebene getroffen, dagegen fallen Entscheidungen zu strukturellen und Planungsangelegenheiten überwiegend in den Kompetenzbereich eher zentraler Regierungsebenen. Bei den Entscheidungen über Ressourcen und Personalangelegenheiten ist das Bild heterogener.

Knapp die Hälfte der auf Schulebene getroffenen Entscheidungen erfolgen in völliger Autonomie und etwa der gleiche Anteil an Entscheidungen wird innerhalb von Rahmenrichtlinien getroffen, die von höherer Ebene festgelegt werden. Relativ wenige Entscheidungen auf Schulebene werden nach Beratung mit anderen getroffen. Strukturelle und Planungsentscheidungen werden von den Schulen in der Regel seltener autonom gefällt als andere Entscheidungen.

Zwischen 1998 und 2003 wurden die Entscheidungskompetenzen in den meisten Ländern stärker dezentralisiert, das gilt besonders für Korea, die Tschechische Republik und die Türkei. In Belgien (frz.) und Griechenland ist jedoch ein gegenläufiger Trend zu beobachten. 


\section{Abbildung D6.1}

Prozentsatz an Entscheidungen in Bezug auf öffentliche Bildungseinrichtungen im Sekundarbereich I, die auf der jeweiligen Entscheidungsebene getroffen werden (2003)

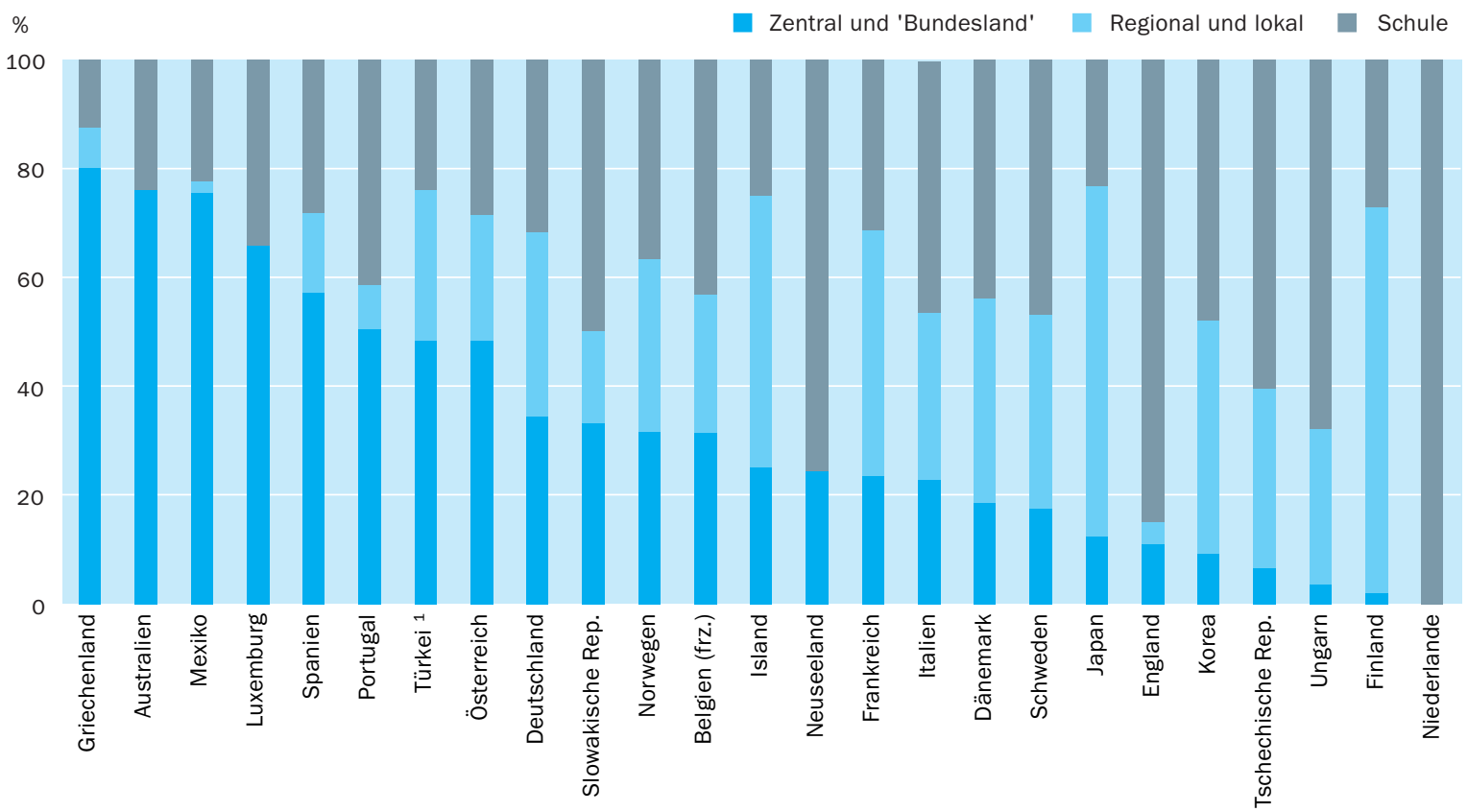

Beispiel: In Griechenland werden 80 Prozent der Entscheidungen auf der höchsten Ebene (Zentralregierung und 'Bundesland'), 7 Prozent auf regionaler und lokaler Ebene und 13 Prozent auf Schulebene gefällt.

Anordnung der Länder in absteigender Reihenfolge des Prozentsatzes an Entscheidungen, die auf zentraler und auf Ebene des 'Bundeslandes' getroffen werden.

1. Daten beziehen sich auf den Primarbereich.

Quelle: OECD. Tabelle D6.1. Hinweise s. Anhang 3 unter www.oecd.org/edu/eag2004.

\section{Politischer Hintergrund}

Dieser Indikator zeigt, wo Entscheidungen zum Sekundarbereich I innerhalb des Bildungssystems getroffen werden, und zwar aufgegliedert nach Entscheidungsbereich und Entscheidungsart.

Außerdem bietet er Aufschluss über die relative Bedeutung der Verwaltungsebenen innerhalb der Bildungssysteme.
Ein wichtiger Aspekt der Bildungspolitik ist die Verteilung der Zuständigkeiten zwischen nationalen, regionalen und lokalen Behörden und den Schulen. Eine Verlagerung der Kompetenzen auf untere Ebenen des Bildungssystems war in vielen Ländern ein zentrales Anliegen bei der seit Anfang der achtziger Jahre realisierten Umstrukturierung und Reform des Bildungssystems. Gleichzeitig jedoch gab es immer wieder Beispiele für eine Stärkung des Einflusses der Zentralbehörden in einigen Bereichen. Beispielsweise kann die Dezentralisierung von Verfahrens- und Finanzvorgaben mit einer verstärkten zentralen Ergebniskontrolle und nationalen Richtlinien für den Lehrplan einhergehen.

Es gibt zahlreiche Gründe, die Zentralisierung der Zuständigkeiten zu verändern und diese Gründe variieren von Land zu Land. Die häufigsten Ziele sind Effizienzsteigerungen und eine verbesserte finanzielle Kontrolle, Abbau der Bürokratie, besseres Eingehen auf die lokalen Bedürfnisse, kreatives Personalmanagement, verbessertes Innovationspotenzial und die verstärkte Schaffung von Anreizen für eine Verbesserung der Qualität der Schulbildung. Zu den umstritteneren bildungspolitischen Themen gehört ein größeres Interesse an 
Maßnahmen zur Förderung der Verantwortlichkeiten und der Chancengleichheit. Diese beiden Themen sind gelegentlich Anlass für eher ,zentralisierte Maßnahmen, wie nationale Leistungsbewertungen und zentral festgelegte Rahmenrichtlinien.

Die Motivation für eine größere Autonomie der Schulen beruht unter anderem auf der Annahme, dass diese die Qualität und Effektivität der Schulbildung und die Verantwortlichkeit der Schule steigere und ein besseres Eingehen auf lokale Belange ermögliche. Was die Chancengleichheit betrifft, sind die Auswirkungen größerer Autonomie umstrittener. Einerseits wird davon ausgegangen, dass die Autonomie den Schulen ein verstärktes Eingehen auf lokale Belange ermöglicht, andererseits besteht jedoch die Möglichkeit, dass dadurch Auswahlmechanismen zum Tragen kommen, die ohnehin bevorzugte gesellschaftliche Gruppen weiter begünstigen. Die zentrale Festlegung von Rahmenrichtlinien, innerhalb derer die einzelnen Schulen Entscheidungen treffen, könnte ein Gegengewicht zur vollständigen Schulautonomie bilden.

Dieser Indikator zeigt Ergebnisse der Datenerhebung zu Entscheidungskompetenzen im Sekundarbereich I und ergänzt die Daten der vorherigen Erhebung von 1998. Die Antworten erstellten Expertengremien in jedem Land, welche die unterschiedlichen Entscheidungsebenen im Sekundarbereich I repräsentierten. Zwar war der Fragebogen 2003 im Vergleich zu I998 nahezu unverändert, die Zusammensetzung der Expertengremien hatte sich jedoch sicherlich geändert. Daher können die beobachteten Veränderungen beim Vergleich der beiden Erhebungen ein subjektives Element enthalten.

\section{Ergebnisse und Erläuterungen}

In I4 von 25 Ländern werden die meisten Arten der Entscheidungen, die den Sekundarbereich I betreffen, lokal oder auf Schulebene getroffen. In England, Neuseeland, der Tschechischen Republik und Ungarn ist die Schule die wichtigste Entscheidungsebene, hier werden mehr als die Hälfte aller Entscheidungen auf Schulebene getroffen. Dies gilt insbesondere auch für die Niederlande, wo sämtliche Entscheidungen auf Schulebene gefällt werden. In Finnland liegen die Entscheidungskompetenzen im Sekundarbereich I dagegen auf lokaler statt auf schulischer Ebene, hier fallen 70 Prozent der Entscheidungen. In etwas geringerem Maße gilt dies auch für Island und Japan mit einem Anteil von etwa 50 Prozent.

In Griechenland und Luxemburg, und in geringerem Maße auch in Portugal und der Türkei, dominiert die Zentralregierung, die etwa 50 Prozent oder mehr der Entscheidungen fällt. Im Gegensatz dazu legt die Zentralregierung in Australien, Belgien (frz.), den Niederlanden und Spanien oft die Rahmenrichtlinien für Entscheidungen fest, trifft aber keine endgültigen Entscheidungen hinsichtlich ihrer Umsetzung. In Deutschland, England, Finnland, Korea, der Tschechischen Republik und Ungarn ist die Rolle der Zentralregierung ziemlich eingeschränkt.
Die Dezentralisierungsbemühungen konzentrieren sich hauptsächlich auf die Autonomie der Schulen.

In 14 von 25 OECD-Ländern werden die meisten Arten der Entscheidungen lokal oder von der Schule selbst getroffen.

In Griechenland, Luxemburg und Portugal ist der wichtigste Entscheidungsträger auch weiterhin die Zentralregierung, während in anderen Ländern ihre Entscheidungskompetenz begrenzt ist. 
Die Entscheidungsbefugnisse im Bereich Unterrichtsorganisation, Personalangelegenheiten, Strukturelle und Planungsangelegenheiten sowie Ressourcen können bei unterschiedlichen Entscheidungsebenen liegen.

Im Bereich Unterrichtsorganisation werden Entscheidungen überwiegend auf Schulebene getroffen,...

... in anderen Entscheidungsbereichen ergibt sich jedoch ein gemischteres Bild.
In föderativen Ländern ebenso wie in Ländern mit überwiegend autonomen Provinzen sind eher die ,Bundesländer' oder autonomen Provinzen die wichtigsten zentralisierten Entscheidungsträger. Dies gilt besonders für Australien und Spanien, wo 76 bzw. 57 Prozent der Entscheidungen auf Ebene der ,Bundesländer' fallen.

In einigen Ländern wie Deutschland, Frankreich, Norwegen und der Türkei sind die Entscheidungskompetenzen gleichmäßiger zwischen zentraler, mittlerer und schulischer Ebene verteilt (Tab. D6.I und Abb. D6.I). In drei Ländern - Australien, Luxemburg und Neuseeland - ist, abgesehen von den Schulen selbst, nur eine Entscheidungsebene für Entscheidungen im Bildungsbereich zuständig.

\section{Entscheidungsbereiche}

Da eine allgemeine Bewertung der Kompetenzen im Entscheidungsprozess Entscheidungen in unterschiedlichen Bereichen erfasst, kann diese kombinierte Kenngröße Unterschiede im Ausmaß der Zentralisierung bei verschiedenen Entscheidungsarten verbergen. Beispielsweise kann ein Land nahezu alle Entscheidungen zum Lehrplan zentral treffen, die Entscheidungen über Lehrmethoden jedoch vollständig den Schulen überlassen. Die Verteilung der Entscheidungen über vier Entscheidungsbereiche (Unterrichtsorganisation, Personalangelegenheiten, strukturelle und Planungsangelegenheiten sowie Ressourcen, vgl. Definitionen und angewandte Methodik am Ende des Indikators) auf die verschiedenen Verwaltungsebenen ist ein Indikator der ,funktionalen Dezentralisierung' und berücksichtigt, dass einzelne Länder in einigen Bereichen dezentral und in anderen zentral organisiert sein können.

Eine Aufteilung der Entscheidungen nach Bereichen macht deutlich, dass in allen OECD-Ländern, die Daten gemeldet haben, Entscheidungen im Bereich Unterrichtsorganisation überwiegend auf Schulebene getroffen werden. Entscheidungen über die Auswahl der Unterrichtsmethoden und Lehrbücher, Kriterien für die Klassenzusammensetzung und Beurteilungsmethoden der Schülerleistungen fallen daher überwiegend in die Entscheidungsbefugnis der Schulen. In England, Italien, Neuseeland, den Niederlanden und Ungarn befinden sogar ausschließlich die Schulen darüber. Selbst in Griechenland, dem am stärksten zentralisierten Land, werden etwa 50 Prozent der Entscheidungen in diesem Bereich auf Schulebene getroffen, wobei dies allerdings der einzige Bereich ist, in dem griechische Schulen Entscheidungen treffen (Tab. D6.2).

In den drei anderen Bereichen (Personalangelegenheiten, Strukturelle und Planungsangelegenheiten sowie Ressourcen) ist die Zahl der auf Schulebene getroffenen Entscheidungen im Allgemeinen deutlich geringer und die Verteilung heterogener. Im Allgemeinen haben die Schulen bei strukturellen und Planungsangelegenheiten (vom Einrichten oder Schließen von Schulen über den Entwurf von Bildungsgängen bis zur Zeugnisvergabe) die geringsten Entscheidungskompetenzen. In I3 von 25 Ländern werden hier mindestens 50 Prozent der Entscheidungen zentral gefällt und in Griechenland sogar alle Entscheidungen. Selbst in einigen Ländern, die eher dezentral organisiert sind, wie z.B. Australien, Island und Schweden, spielt die Zentralregierung bei Entscheidungen in strukturellen und Planungsangelegenheiten eine wichtige Rolle. 
Im Bereich Personalangelegenheiten (einschließlich Entscheidungen über Einstellung und Entlassung von Mitarbeitern, Festlegung der Gehälter und Arbeitsbedingungen) werden mehr als 50 Prozent der Entscheidungen in Griechenland, Luxemburg, Portugal und der Türkei zentral gefällt, in Australien, Mexiko und Spanien auf ,Bundesland'- oder Provinzebene. In Finnland und Island treffen lokale Verwaltungen die meisten Entscheidungen im Bereich Personalangelegenheiten. In England, Neuseeland, den Niederlanden (IOo Prozent), Schweden, der Slowakischen Republik und Ungarn sind es dagegen die Schulen. In Korea hat die Zentralverwaltung nur in den Bereichen Unterrichtsorganisation und Personalangelegenheiten gewisse Entscheidungsbefugnisse (Tab. D6.2).

Im Durchschnitt ist die Zuweisung und der Einsatz von Mitteln der Entscheidungsbereich, in dem die lokale Regierungsebene die meisten Befugnisse hat und in etwa der Hälfte der Länder spielt diese lokale Ebene eine beachtliche Rolle. In Finnland und Island werden faktisch sämtliche Entscheidungen dieses Bereiches lokal gefällt. In Deutschland haben die Länder zwar generell große Entscheidungsverantwortung, bei der Mittelzuweisung und -verwendung werden jedoch keine Entscheidungen auf Länderebene gefällt. Diese Entscheidungen werden vielmehr überwiegend auf lokaler Ebene getroffen (Tab. D6.2).

\section{Entscheidungsart}

Tabelle D6.3 zeigt den jeweiligen prozentualen Anteil an den von Schulen getroffenen Entscheidungen hinschtlich der Entscheidungsart bzw. dem Grad der Autonomie bei der jeweiligen Entscheidung. Im Durchschnitt aller Länder werden die meisten Entscheidungen - in gleichem Ausmaß - entweder in völliger Autonomie getroffen oder innerhalb eines von einer höheren Ebene vorgegebenen Rahmens. Im Durchschnitt fallen nur relativ wenige Entscheidungen nach Beratung mit anderen Akteuren im Bildungswesen oder unter anderen Bedingungen.

In den drei Ländern, in denen Schulen die größten Entscheidungskompetenzen haben - England (85 Prozent), Neuseeland (75 Prozent) und die Niederlande (Ioo Prozent) - werden wenigstens 50 Prozent dieser Entscheidungen in völliger Autonomie getroffen und zwischen 30 und 50 Prozent innerhalb eines von einer höheren Ebene vorgegebenen Rahmens. Die verbleibenden Entscheidungen fallen überwiegend nach Beratung mit anderen Akteuren im Bildungswesen. Im Gegensatz dazu treffen in der Slowakischen und der Tschechischen Republik, wo der Anteil der auf Schulebene getroffenen Entscheidungen ebenfalls über dem Durchschnitt liegt, die Schulen ihre Entscheidungen vorwiegend innerhalb eines von einer höheren Ebene vorgegebenen Rahmens. Wie vielleicht zu erwarten, treffen die Schulen in Ländern mit stärker zentralisierten Entscheidungskompetenzen ihre Entscheidungen eher innerhalb eines vorgegebenen Rahmens. Das gilt für Belgien (frz.), Deutschland, Griechenland und Spanien.

Innerhalb der vier Entscheidungsbereiche werden Entscheidungen der Schulen in strukturellen und Planungsangelegenheiten sehr selten in völliger Autonomie, sondern vielmehr häufiger innerhalb eines vorgegebenen Rahmens getroffen (Tab. D6.4 und Abb. D6.2). Die Niederlande sind hierfür ein beson-
Das Ausmaß, in dem die Schulen Entscheidungen autonom fällen können, variiert. 
Zwischen 1998 und 2003 wurden die Entscheidungskompetenzen in den meisten Ländern stärker dezentral organisiert. ders gutes Beispiel. Dort werden Entscheidungen auf Schulebene in völliger Autonomie getroffen und zwar in allen Bereichen bis auf die strukturellen und Planungsangelegenheiten (wo sämtliche Entscheidungen innerhalb von Rahmenvorgaben getroffen werden). Im Gegensatz dazu treffen die Schulen in Neuseeland zwei Drittel der Entscheidungen bei strukturellen und Planungsangelegenheiten in völliger Autonomie.

In den übrigen Bereichen werden Entscheidungen der Schulen im Durchschnitt genauso häufig in völliger Autonomie wie innerhalb eines von einer höheren Ebene vorgegebenen Rahmens getroffen; es gibt hierbei aber Unterschiede zwischen den einzelnen Ländern. In Frankreich und Korea werden beispielsweise alle Entscheidungen der Schulen im Bereich Unterrichtsorganisation in völliger Autonomie getroffen, dagegen können Schulen in Griechenland und Spanien derartige Fragen nicht autonom entscheiden.

Im Durchschnitt haben die Schulen zwar die geringsten Entscheidungskompetenzen im Bereich Mittelzuweisung und -verwendung, aber sie werden bei Entscheidungen, die von anderen Akteuren in diesem Bereich getroffen werden, am ehesten konsultiert. In Dänemark, Finnland und Luxemburg werden über 50 Prozent der Entscheidungen zu Ressourcen nach Beratungen mit den Schulen gefällt.

Tabelle D6.6 und Abbildung D6.3 zeigen, dass in I4 von I9 Ländern Entscheidungen im Jahr 2003 auf dezentralerer Ebene gefällt wurden als im Jahr 1998. Dies ist in Korea, der Tschechischen Republik und der Türkei besonders deutlich, wo mehr als 30 Prozent der Entscheidungen im Jahr 2003 auf einer dezentraleren Ebene fielen als fünf Jahre zuvor. Betrachtet man die Schulebene, so stieg in England, Korea, den Niederlanden und Norwegen der Anteil der auf Schulebene getroffenen Entscheidungen im gleichen Zeitraum um mehr als 20 Prozent an. Gleichzeitig waren jedoch in Belgien (frz.) und Griechenland Verschiebungen hin zu stärker zentralisierten Entscheidungskompetenzen zu beobachten. In Griechenland hat beispielsweise die Anzahl der Entscheidungen, die von der Zentralregierung getroffen werden, 2003 um 25 Prozent gegenüber 1998 zugenommen.

\section{Dezentralisierung in Dänemark}

In jüngster Zeit wurde die Dezentralisierung in Dänemark durch eine Art neuer Zentralisierung leicht beeinträchtigt, im Rahmen derer Kommunen und Bildungseinrichtungen kooperieren oder in größeren Einheiten mit gemeinsamem Management zusammengefasst werden. Die Kooperation von Kommunen wurde in unterschiedlicher Weise und mit unterschiedlichem Umfang an formalen Regelungen eingerichtet. Die Kooperation und $\mathrm{Zu}$ sammenlegung sollen angesichts zunehmender Herausforderungen und Ansprüche seitens der Gesellschaft zu Größenvorteilen und Qualitätssicherung führen. Diese neuen Chancen für den gemeinsamen Betrieb und die gemeinsame Leitung von Grundschulen und zwischen Arten von Schulen entstanden durch eine Novellierung des Gesetzes über die Folkskole. 
Abbildung D6.2

Prozentsatz an Entscheidungen in Bezug auf öffentliche Bildungseinrichtungen im Sekundarbereich I, die auf Schulebene getroffen werden, nach Entscheidungsbereich und -art (2003)

- In völliger Autonomie $\square$ In Beratung mit anderen $\square$ Innerhalb eines vorgegebenen Rahmens $\quad$ Sonstige

$\%$ Unterrichtsorganisation

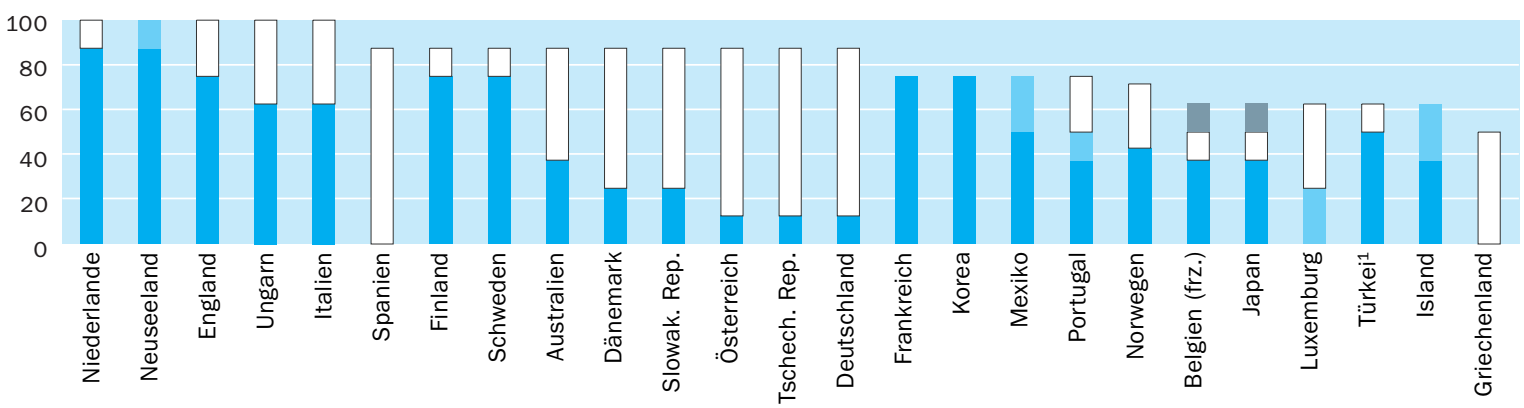

\% Personalangelegenheiten

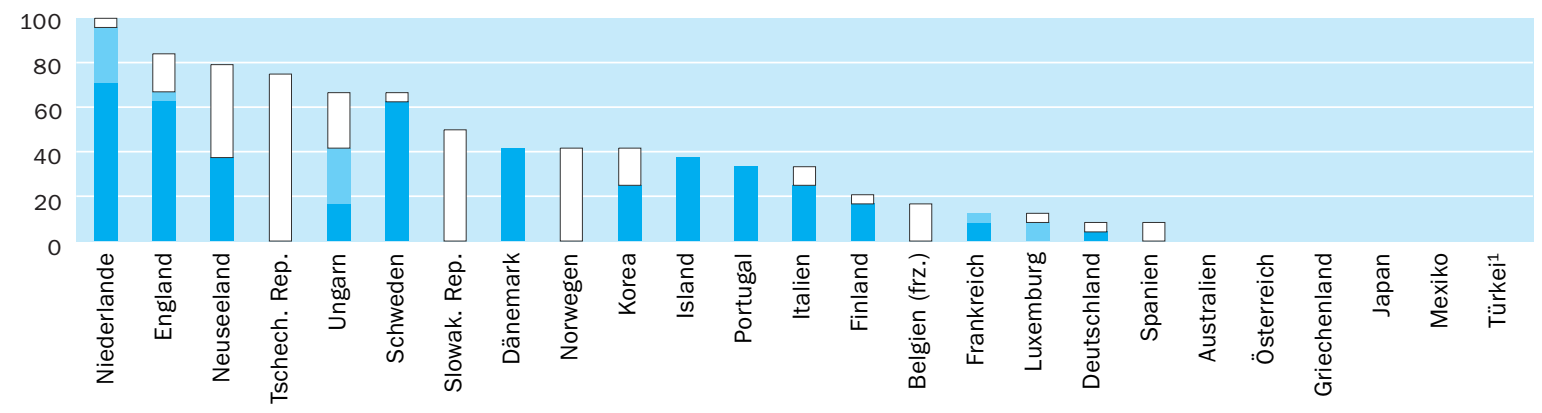

\% Strukturelle und Planungsangelegenheiten (Schulen und Lehrpläne)

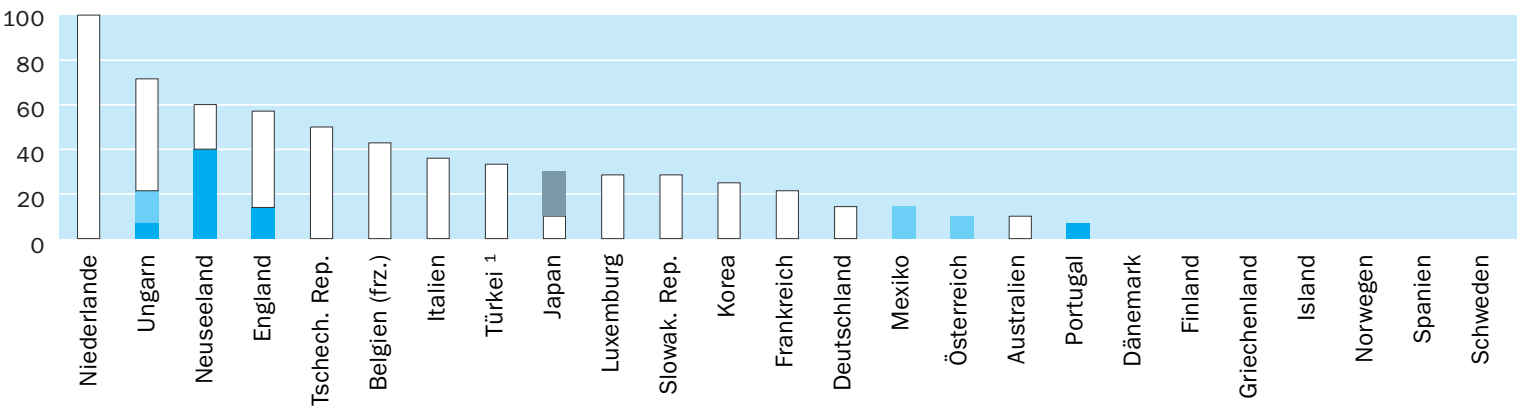

\% Ressourcen (Zuweisung und Verwendung)

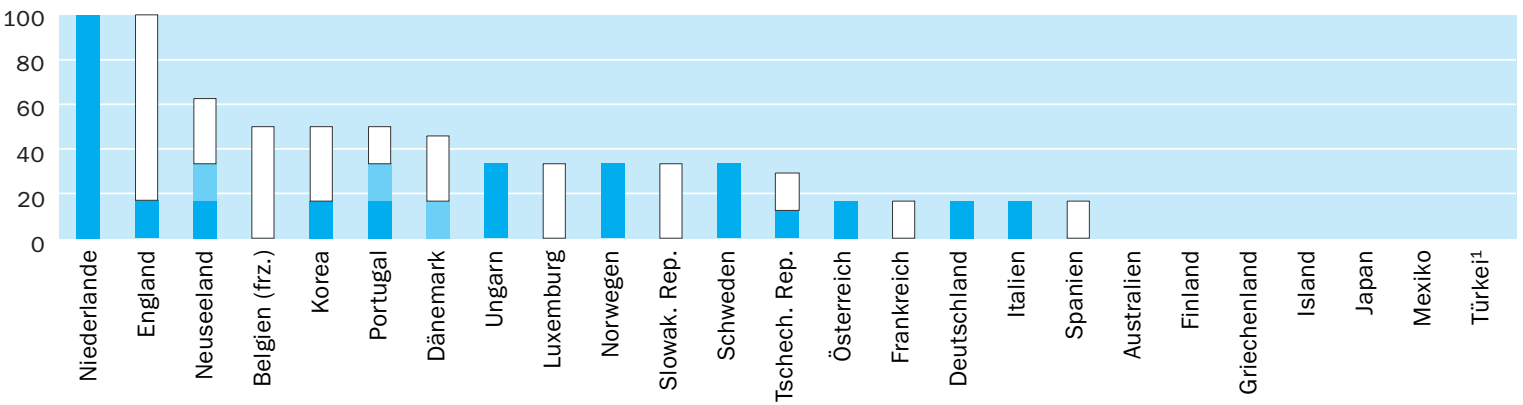

Beispiel: In den Niederlanden fallen sämtliche Entscheidungen auf Schulebene. Diese Entscheidungen können jedoch entweder in völliger Autonomie, in Beratung mit anderen oder innerhalb eines vorgegebenen Rahmens getroffen werden. Alle Entscheidungen über Ressourcen werden in völliger Autonomie getroffen, dagegen fallen Entscheidungen über strukturelle und Planungsangelegenheiten innerhalb eines von einer höheren Ebene festgelegten Rahmens.

Anordnung der Länder in absteigender Reihenfolge nach dem Prozentsatz an Entscheidungen, die innerhalb jedes Bereiches von den Schulen getroffen werden.

1. Daten beziehen sich auf den Primarbereich.

Quelle: OECD. Tabelle 6.4. Hinweise s. Anhang 3 unter www.oecd.org/edu/eag2004. 
Abbildung D6.3

Zentralisierung und Dezentralisierung der Entscheidungen in Bezug auf öffentliche Bildungseinrichtungen des Sekundarbereich I (1998-2003)

Prozentsatz an Entscheidungen, die 2003 auf zentralerer bzw. dezentralerer Ebene gefällt wurden als 1998

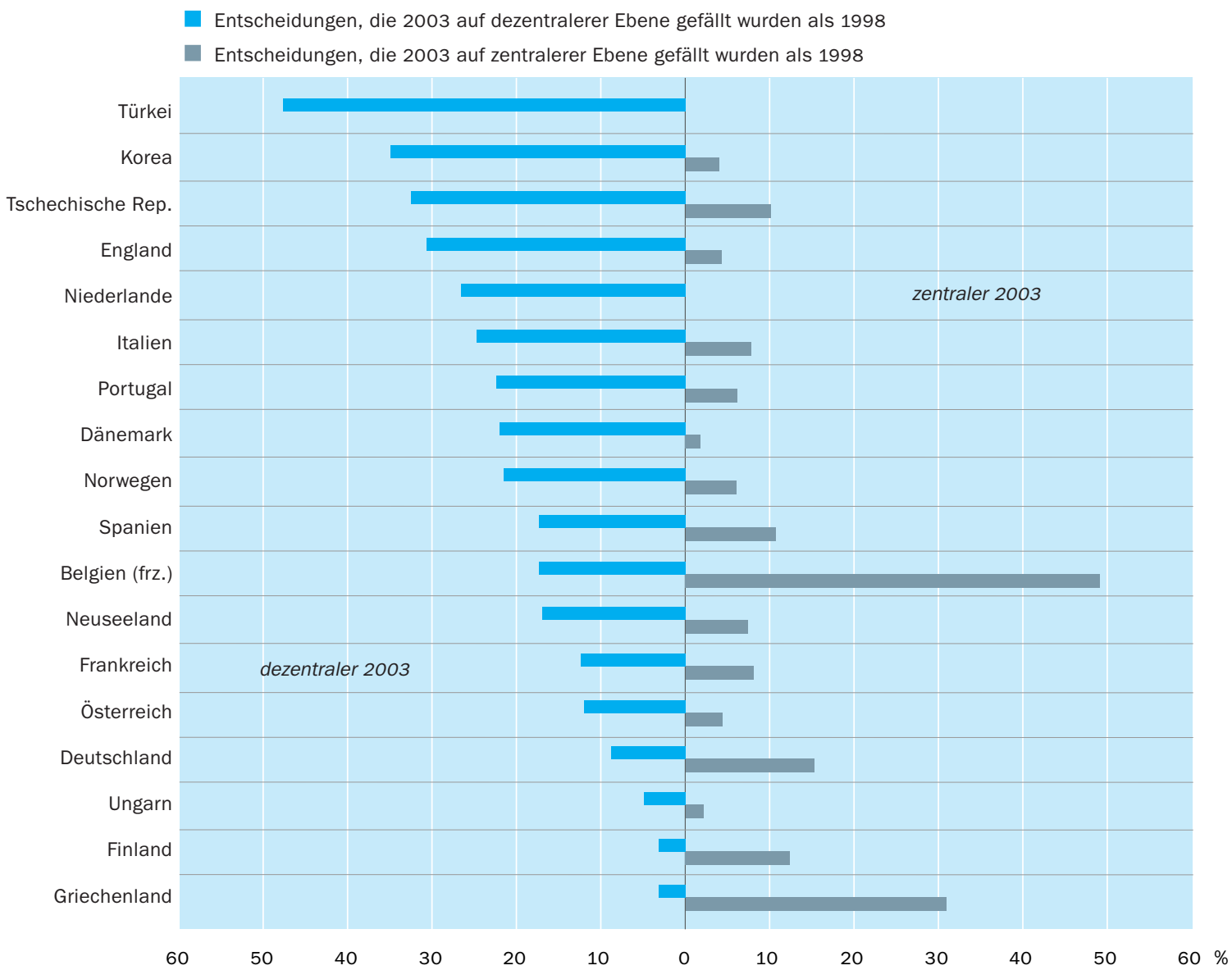

Beispiel: In Österreich wurden 5 Prozent der Entscheidungen 2003 auf zentralerer Ebene gefällt als 1998 und 12 Prozent auf dezentralerer Ebene. Die restlichen Entscheidungen wurden 2003 auf derselben Ebene gefällt wie 1998.

Hinweis: Unterschiedliche Methoden der Datenerhebung in den beiden Jahren könnten zu einer leichten Verzerrung der gemeldeten Veränderungen führen, sollten aber den allgemeinen Trend nicht beeinflussen.

Anordnung der Länder in absteigender Reihenfolge nach dem Prozentsatz an Entscheidungen, die 2003 auf dezentralerer Ebene gefällt wurden als 1998. Quelle: OECD. Hinweise s. Anhang 3 unter www.oecd.org/edu/eag2004.

\footnotetext{
Verschiebungen innerhalb der vierstufigen Entscheidungsorganisation in Frankreich

Den vier staatlichen Entscheidungsebenen (Zentralregierung, Region, Departement, Kommune) entsprechen innerhalb der Schulverwaltung die Ebenen der Zentralverwaltung, der Akademien (unter einem recteur), der Departments (unter einem Akademischen Inspektor) und der Schulen. Die Machtverhältnisse zwischen diesen unterschiedlichen Ebenen haben sich im Laufe der letzten 25 Jahre im Sinne eines Dezentralisierungsprozesses (d.h. der Übertragung von zentralen Kompetenzen auf regionale/lokale Behörden und Schulen) und eines Konzentrationsabbaus (d.h. der Delegation von Entscheidungskompetenzen auf eine niedrigere Entscheidungsebene innerhalb der staatlichen Verwaltung) verschoben. Die Verabschiedung
} 
eines neuen Gesetzes im Jahr 2003, das eine weitere Dezentralisierungsrunde vorsieht, belegt, dass keiner dieser Prozesse bereits das Endstadium erreicht hat.

Im öffentlichen Bildungsbereich sind die Departments für die Colleges verantwortlich, die Regionen für die Gymnasien und Berufsgymnasien. Dies gilt sowohl für den Betrieb als auch für die Liegenschaften (Investitionen in Gebäude und Instandhaltung); der Staat hat sich die Kontrolle über den Unterrichtsinhalt, die Einstellung und berufliche Weiterentwicklung von unterrichtenden und nicht-unterrichtenden Beschäftigten sowie die verwaltungstechnische und pädagogische Kontrolle vorbehalten. Die meisten Entscheidungen zu Fortbildung und Verwaltung des Personals erfolgen auf regionaler Ebene (Akademien), mit einer bemerkenswerten Ausnahme bei der Einstellung von Lehrkräften und Managern.

\section{Hauptziele der griechischen Bildungspolitik}

Die Gesellschaft des EU-Mitgliedslandes Griechenlands ist durch rasante wirtschaftliche, politische und demographische Veränderungen gekennzeichnet. Diese Veränderungen betreffen die Staatsausgaben, die öffentliche Verwaltung, die zunehmende Diversifizierung der Bevölkerung sowie den Wissens- und Informationsbedarf der griechischen Gesellschaft und stellen große Herausforderungen an das Bildungssystem. Es wurden Innovationen und neue Technologien eingeführt und alle Bildungsbereiche modernisiert. Um den neuen Anforderungen gerecht zu werden, wurde eine Reihe von Veränderungen im Bildungssystem vorgenommen, wie zum Beispiel die Dezentralisierung von Finanz- und Verwaltungsangelegenheiten, eine größere Vielfalt im Hinblick auf Bildungsverläufe sowie die Verbesserung der Bildungsqualität.

\section{Einstellung, Auswahl und Zuteilung der Lehrkräfte in Norwegen}

Die Einstellung, Auswahl und Ernennung von Lehrkräften obliegt den lokalen Behörden, und wird entweder durch die lokale Verwaltung der Schule (im Sekundarbereich II) oder von den lokalen Behörden (Pflichtschulzeit) durchgeführt. Auch bei den Schulen, die die Schulpflicht abdecken, erfolgt die Einstellung von Lehrern in zunehmendem Maße auf Schulebene. Diese Entwicklung folgt dem allgemeinen Trend zur Dezentralisierung der $\mathrm{Zu}$ ständigkeiten und Entscheidungskompetenzen. Die größte Herausforderung für diejenigen, die für die Einstellung, Auswahl und Ernennung von Lehrkräften verantwortlich sind, ist sicherzustellen, dass die Lehrkräfte jeder einzelnen Schule insgesamt die erforderlichen Kompetenzen aufweisen, um den Erfordernissen der Schule zu genügen. 


\section{Definitionen und angewandte Methodik}

Die Daten stammen aus der OECD/INES-Erhebung von 2003 über Entscheidungsbefugnisse im Bildungsbereich und beziehen sich auf das Schuljahr 2003/2004.
Dieser Indikator zeigt den prozentualen Anteil der bildungspolitischen Entscheidungen, die in öffentlichen Bildungseinrichtungen im Sekundarbereich I auf den jeweiligen Ebenen getroffen werden. Die Dezentralisierung bezieht sich auf die Kompetenzverteilung zwischen verschiedenen Regierungsebenen. Dieses Konzept umfasst zwei unterschiedliche Dimensionen: I. den Ort der Entscheidung, d.h. auf welcher Ebene die entscheidungsbefugte Stelle angesiedelt ist und 2. die Art der Entscheidung, die sich auf das Ausmaß bezieht, in dem Entscheidungen autonom oder gemeinsam mit anderen gefällt werden.

Der Fragebogen erfasste sechs verschiedene Entscheidungsebenen: Zentralregierung, ,Bundesland'-Regierungen, Provinz- oder Regionalbehörden oder -regierungen, Kreis- oder Stadtbehörden oder -regierungen, lokale Behörden oder Regierungen, Schulen, Schulgremien oder -ausschüsse.

Der Fragebogen bot Informationen zu vier Bereichen:

Unterrichtsorganisation: Aufnahme von Schülern, Schullaufbahnen von Schülern; Unterrichtszeit, die Auswahl der Lehrbücher, Klassenzusammensetzung, zusätzliche Fördermaßnahmen, Unterrichtsmethoden und regelmäßige Beurteilung der Schüler.

Personalangelegenheiten: Einstellung und Entlassung von unterrichtenden und nicht-unterrichtenden Beschäftigten, Festlegung der Aufgaben und dienstlichen Pflichten sowie der Arbeitsbedingungen der Beschäftigten, Festlegung der Besoldungs- und Vergütungsgruppen der Beschäftigten und Einfluss auf die Karriereaussichten.

Strukturelle und Planungsangelegenheiten: Einrichten oder Schließen von Schulen, Einrichten oder Schließen von einzelnen Jahrgangsstufen, Entwurf von Bildungsgängen, Auswahl der Unterrichtsangebote an einer bestimmten Schule, Auswahl der Fachgebiete an einer bestimmten Schule, die Festlegung der Kursinhalte, Festlegung der erforderlichen Prüfungen für Zeugnisse oder Diplome und Zeugnisvergabe (Prüfungsinhalte, Benotung und Verwaltung).

Ressourcen: Zuweisung und Verwendung von Ressourcen für unterrichtende und nicht-unterrichtende Beschäftigte, laufende Ausgaben, Investitionsausgaben. 
Der Fragebogen untersuchte auch, wie autonom Entscheidungen getroffen werden. Der wichtigste Faktor zur Bestimmung der Art der Entscheidung ist ,wer entscheidet'. Hier bestehen die folgenden Kategorien: in völliger Autonomie, nach Beratung mit Akteuren auf einer anderen Ebene des Bildungswesens, unabhängig aber innerhalb eines von einer höheren Behörde vorgegebenen Rahmens, andere Art.

Nähere Einzelheiten unter www.oecd.org/edu/eag 2004.

Die Indikatoren wurden so ausgelegt, dass jeder der vier Bereiche gleiche Bedeutung erhält. Jeder Bereich trägt 25 Prozent zu den Ergebnissen der Indikatoren bei. Da die Anzahl der Unterpunkte nicht in allen Bereichen gleich groß ist, wurde jeder Unterpunkt mit der inversen Anzahl von Unterpunkten des jeweiligen Bereichs gewichtet. 


\section{Tabelle D6.1}

Prozentsatz an Entscheidungen in Bezug auf öffentliche Bildungseinrichtungen im Sekundarbereich I, die auf der jeweiligen Entscheidungsebene getroffen werden (2003)

\begin{tabular}{|c|c|c|c|c|c|c|c|}
\hline OECD-Länder & Zentral & ,Bundesland' & Provinz/Region & Sub-regional & Lokal & Schule & Gesamt \\
\hline Australien & & 76 & & & & 24 & 100 \\
\hline Österreich & 27 & 22 & & & 23 & 29 & 100 \\
\hline Belgien (frz. $)^{1}$ & & 32 & 25 & & & 43 & 100 \\
\hline Tschechische Rep. & 7 & & 1 & & 32 & 60 & 100 \\
\hline Dänemark & 19 & & & & 38 & 44 & 100 \\
\hline England & 11 & & & & 4 & 85 & 100 \\
\hline Finnland & 2 & & & & 71 & 27 & 100 \\
\hline Frankreich & 24 & & 10 & 35 & & 31 & 100 \\
\hline Deutschland & 4 & 30 & 17 & & 17 & 32 & 100 \\
\hline Griechenland & 80 & & 4 & & 3 & 13 & 100 \\
\hline Ungarn & 4 & & & & 29 & 68 & 100 \\
\hline Island & 25 & & & & 50 & 25 & 100 \\
\hline Italien & 23 & & 16 & & 15 & 46 & 100 \\
\hline Japan & 13 & & 21 & & 44 & 23 & 100 \\
\hline Korea & 9 & & 34 & & 8 & 48 & 100 \\
\hline Luxemburg & 66 & & & & & 34 & 100 \\
\hline Mexiko & 30 & 45 & 2 & & & 22 & 100 \\
\hline Niederlande & & & & & & 100 & 100 \\
\hline Neuseeland & 25 & & & & & 75 & 100 \\
\hline Norwegen & 32 & & & & 32 & 37 & 100 \\
\hline Portugal & 50 & & 8 & & & 41 & 100 \\
\hline Slowakische Rep. & 33 & & 2 & & 15 & 50 & 100 \\
\hline Spanien & & 57 & 15 & & & 28 & 100 \\
\hline Schweden & 18 & & & & 36 & 47 & 100 \\
\hline Türkei² & 49 & & 27 & & & 24 & 100 \\
\hline
\end{tabular}

Hinweis: Leerstelle bedeutet keine primären Entscheidungskompetenzen auf dieser Ebene.

1. Für Belgien (frz.) bedeutet ,Provinz/Region` für 61 Prozent der Schulen Zentralregierung, für 21 Prozent der Schulen Provinz- oder Regionalbehörde und für 18 Prozent der Schulen lokale Behörden. 2. Daten beziehen sich auf den Primarbereich.

Quelle: OECD. Hinweise s. Anhang 3 unter www.oecd.org/edu/eag2004. 
Tabelle D6.2

Prozentsatz an Entscheidungen in Bezug auf öffentliche Bildungseinrichtungen im Sekundarbereich I, die auf der jeweiligen Entscheidungsebene getroffen werden, nach Entscheidungsbereichen (2003)

\begin{tabular}{|c|c|c|c|c|c|c|c|c|c|c|c|c|c|c|}
\hline \multirow[b]{2}{*}{ OECD-Länder } & \multicolumn{7}{|c|}{ Unterrichtsorganisation } & \multicolumn{7}{|c|}{ Personalangelegenheiten } \\
\hline & Zentral & $\begin{array}{c}\text { Bundes- } \\
\text { land }\end{array}$ & $\begin{array}{c}\text { Provinz/ } \\
\text { Region }\end{array}$ & $\begin{array}{c}\text { Sub- } \\
\text { regional }\end{array}$ & Lokal & Schule & Gesamt & Zentral & $\begin{array}{l}\text {,Bundes- } \\
\text { land" }\end{array}$ & $\begin{array}{c}\text { Provinz/ } \\
\text { Region }\end{array}$ & $\begin{array}{c}\text { Sub- } \\
\text { regional }\end{array}$ & Lokal & Schule & Gesamt \\
\hline Australien & & 13 & & & & 88 & 100 & & 100 & & & & & 100 \\
\hline Österreich & 13 & & & & & 88 & 100 & 25 & 38 & & & 38 & & 100 \\
\hline Belgien (frz.) $)^{1}$ & & 13 & 25 & & & 63 & 100 & & 33 & 50 & & & 17 & 100 \\
\hline Tschechische Rep. & 13 & & & & & 88 & 100 & 4 & & 4 & & 17 & 75 & 100 \\
\hline Dänemark & & & & & 13 & 88 & 100 & 25 & & & & 33 & 42 & 100 \\
\hline England & & & & & & 100 & 100 & 17 & & & & & 83 & 100 \\
\hline Finnland & & & & & 13 & 88 & 100 & 8 & & & & 71 & 21 & 100 \\
\hline Frankreich & 13 & & & 13 & & 75 & 100 & 46 & & 42 & & & 13 & 100 \\
\hline Deutschland & & 13 & & & & 88 & 100 & 17 & 38 & 38 & & & 8 & 100 \\
\hline Griechenland & 38 & & & & 13 & 50 & 100 & 100 & & & & & & 100 \\
\hline Ungarn & & & & & & 100 & 100 & & & & & 33 & 67 & 100 \\
\hline Island & 25 & & & & 13 & 63 & 100 & 4 & & & & 58 & 38 & 100 \\
\hline Italien & & & & & & 100 & 100 & 42 & & 25 & & & 33 & 100 \\
\hline Japan & & & & & 38 & 63 & 100 & & & 54 & & 46 & & 100 \\
\hline Korea & 13 & & & & 13 & 75 & 100 & 25 & & 25 & & 8 & 42 & 100 \\
\hline Luxemburg & 38 & & & & & 63 & 100 & 88 & & & & & 13 & 100 \\
\hline Mexiko & 25 & & & & & 75 & 100 & 25 & 67 & 8 & & & & 100 \\
\hline Niederlande & & & & & & 100 & 100 & & & & & & 100 & 100 \\
\hline Neuseeland & & & & & & 100 & 100 & 21 & & & & & 79 & 100 \\
\hline Norwegen & 14 & & & & 14 & 71 & 100 & 29 & & & & 29 & 42 & 100 \\
\hline Portugal & 25 & & & & & 75 & 100 & 63 & & 4 & & & 33 & 100 \\
\hline Slowakische Rep. & 13 & & & & & 88 & 100 & 4 & & & & 46 & 50 & 100 \\
\hline Spanien & & 13 & & & & 88 & 100 & & 92 & & & & 8 & 100 \\
\hline Schweden & & & & & 13 & 88 & 100 & & & & & 33 & 67 & 100 \\
\hline Türkei² & 25 & & 13 & & & 63 & 100 & 94 & & 6 & & & & 100 \\
\hline
\end{tabular}

\begin{tabular}{|c|c|c|c|c|c|c|c|c|c|c|c|c|c|c|}
\hline \multirow[b]{2}{*}{ OECD-Länder } & \multicolumn{7}{|c|}{ Strukturelle und Planungsangelegenheiten } & \multicolumn{7}{|c|}{ Ressourcen } \\
\hline & Zentral & $\begin{array}{l}\text { "Bundes- } \\
\text { land" }\end{array}$ & $\begin{array}{l}\text { Provinz/ } \\
\text { Region }\end{array}$ & \begin{tabular}{|l} 
Sub- \\
regional
\end{tabular} & Lokal & Schule & Gesamt & Zentral & $\begin{array}{l}\text { "Bundes- } \\
\text { land" }\end{array}$ & $\begin{array}{l}\text { Provinz/ } \\
\text { Region }\end{array}$ & $\begin{array}{l}\text { Sub- } \\
\text { regional }\end{array}$ & Lokal & Schule & Gesamt \\
\hline Australien & & 90 & & & & 10 & 100 & & 100 & & & & & 100 \\
\hline Österreich & 70 & 20 & & & & 10 & 100 & & 29 & & & 54 & 17 & 100 \\
\hline Belgien (frz.) ${ }^{1}$ & & 43 & 14 & & & 43 & 100 & & 38 & 13 & & & 50 & 100 \\
\hline Tschechische Rep. & 10 & & & & 40 & 50 & 100 & & & & & 71 & 29 & 100 \\
\hline Dänemark & 50 & & & & 50 & & 100 & & & & & 54 & 46 & 100 \\
\hline England & 29 & & & & 14 & 57 & 100 & & & & & & 100 & 100 \\
\hline Finnland & & & & & 100 & & 100 & & & & & 100 & & 100 \\
\hline Frankreich & 36 & & & 43 & & 21 & 100 & & & & 83 & & 17 & 100 \\
\hline Deutschland & & 71 & & & 14 & 14 & 100 & & & 29 & & 54 & 17 & 100 \\
\hline Griechenland & 100 & & & & & & 100 & 83 & & 17 & & & & 100 \\
\hline Ungarn & 14 & & & & 14 & 71 & 100 & & & & & 67 & 33 & 100 \\
\hline Island & 71 & & & & 29 & & 100 & & & & & 100 & & 100 \\
\hline Italien & 50 & & 14 & & & 36 & 100 & & & 25 & & 58 & 17 & 100 \\
\hline Japan & 50 & & & & 20 & 30 & 100 & & & 29 & & 71 & & 100 \\
\hline Korea & & & 75 & & & 25 & 100 & & & 38 & & 13 & 50 & 100 \\
\hline Luxemburg & 71 & & & & & 29 & 100 & 67 & & & & & 33 & 100 \\
\hline Mexiko & 71 & 14 & & & & 14 & 100 & & 100 & & & & & 100 \\
\hline Niederlande & & & & & & 100 & 100 & & & & & & 100 & 100 \\
\hline Neuseeland & 40 & & & & & 60 & 100 & 38 & & & & & 63 & 100 \\
\hline Norwegen & 83 & & & & 17 & & 100 & & & & & 67 & 33 & 100 \\
\hline Portugal & 64 & & 29 & & & 7 & 100 & 50 & & & & & 50 & 100 \\
\hline Slowakische Rep. & 50 & & 7 & & 14 & 29 & 100 & 67 & & & & & 33 & 100 \\
\hline Spanien & & 100 & & & & & 100 & & 25 & 58 & & & 17 & 100 \\
\hline Schweden & 70 & & & & 30 & & 100 & & & & & 67 & 33 & 100 \\
\hline Türkei² & 50 & & 17 & & & 33 & 100 & 25 & & 75 & & & & 100 \\
\hline
\end{tabular}

Hinweis: Leerstelle bedeutet keine primären Entscheidungskompetenzen auf dieser Ebene.

1. Für Belgien (frz.) bedeutet ,Provinz/Region' für 61 Prozent der Schulen Zentralregierung, für 21 Prozent der Schulen Provinz- oder Regionalbehörde und für 18 Prozent der Schulen lokale Behörden. 2. Daten beziehen sich auf den Primarbereich.

Quelle: OECD. Hinweise s. Anhang 3 unter www.oecd.org/edu/eag2004. 


\section{Tabelle D6.3}

Prozentsatz an Entscheidungen in Bezug auf öffentliche Bildungseinrichtungen im Sekundarbereich I, die auf Schulebene getroffen werden, nach Entscheidungsart (2003)

\begin{tabular}{|c|c|c|c|c|c|c|c|}
\hline OECD-Länder & $\begin{array}{l}\text { In völliger } \\
\text { Autonomie }\end{array}$ & $\begin{array}{l}\text { Nach Beratung } \\
\text { mit anderen } \\
\text { Akteuren des } \\
\text { Bildungswesen }\end{array}$ & $\begin{array}{l}\text { Innerhalb eines } \\
\text { von einer höheren } \\
\text { Ebene vorgege- } \\
\text { benen Rahmens }\end{array}$ & Sonstige & $\begin{array}{l}\text { Insgesamt, ohne } \\
\text { Entscheidungen, } \\
\text { bei denen die } \\
\text { Schulen konsultiert } \\
\text { werden }\end{array}$ & \begin{tabular}{|c|} 
Auf anderen \\
Ebenene getroffene \\
Entscheidungen, \\
bei denen die \\
Schulen konsultiert \\
werden ${ }^{1}$
\end{tabular} & $\begin{array}{c}\text { Insgesamt, } \\
\text { einschließlich } \\
\text { Entscheidungen, } \\
\text { bei denen die } \\
\text { Schulen konsultiert } \\
\text { werden }\end{array}$ \\
\hline Australien & 9 & & 15 & & 24 & & 24 \\
\hline Österreich & 7 & 3 & 19 & & 29 & 4 & 33 \\
\hline Belgien (frz.) & 9 & & 31 & 3 & 43 & & 43 \\
\hline Tschechische Rep. & 6 & & 54 & & 60 & & 60 \\
\hline Dänemark & 17 & 4 & 23 & & 44 & 19 & 63 \\
\hline England & 42 & 1 & 42 & & 85 & & 85 \\
\hline Finnland & 23 & & 4 & & 27 & 17 & 44 \\
\hline Frankreich & 21 & 1 & 10 & & 31 & 4 & 36 \\
\hline Deutschland & 8 & & 23 & & 32 & 17 & 48 \\
\hline Griechenland & & & 13 & & 13 & 5 & 18 \\
\hline Ungarn & 30 & 10 & 28 & & 68 & 1 & 69 \\
\hline Island & 19 & 6 & & & 25 & & 25 \\
\hline Italien & 26 & & 20 & & 46 & & 46 \\
\hline Japan & 9 & & 6 & 8 & 23 & 5 & 28 \\
\hline Korea & 29 & & 19 & & 48 & & 48 \\
\hline Luxemburg & & 8 & 26 & & 34 & 36 & 70 \\
\hline Mexiko & 13 & 10 & & & 22 & & 22 \\
\hline Niederlande & 65 & 6 & 29 & & 100 & & 100 \\
\hline Neuseeland & 45 & 7 & 23 & & 75 & 10 & 85 \\
\hline Norwegen & 19 & & 18 & & 37 & & 37 \\
\hline Portugal & 24 & 7 & 10 & & 41 & 4 & 45 \\
\hline Slowakische Rep. & 6 & & 44 & & 50 & 2 & 52 \\
\hline Spanien & & & 28 & & 28 & 8 & 36 \\
\hline Schweden & 43 & & 4 & & 47 & & 47 \\
\hline Türkei² & 13 & & 11 & & 24 & & 24 \\
\hline
\end{tabular}

Hinweis: Leerstelle bedeutet, Schulen sind bei der angegebenen Entscheidungsart nicht beteiligt.

1. Anzahl der Entscheidungen, die auf anderen Entscheidungsebenen, aber nach Beratung mit der Schule getroffen werden, als Prozentsatz aller Entscheidungen.

2. Daten beziehen sich auf Primarbereich.

Quelle: OECD. Hinweise s. Anhang 3 unter www.oecd.org/edu/eag2004." 


\section{Tabelle D6.4}

Prozentsatz an Entscheidungen in Bezug auf öffentliche Bildungseinrichtungen im Sekundarbereich I, die auf Schulebene getroffen werden, nach Entscheidungsbereich und Entscheidungsart (2003)

\begin{tabular}{|c|c|c|c|c|c|c|c|c|c|c|c|c|c|c|}
\hline \multirow[b]{2}{*}{ OECD-Länder } & \multicolumn{7}{|c|}{ Unterrichtsorganisation } & \multicolumn{7}{|c|}{ Personalangelegenheiten } \\
\hline & \begin{tabular}{|l|} 
In völliger \\
Autonomie
\end{tabular} & $\begin{array}{c}\text { Nach } \\
\text { Beratung } \\
\text { mit } \\
\text { anderen } \\
\text { Akteuren } \\
\text { des } \\
\text { Bildungs- } \\
\text { wesen }\end{array}$ & $\begin{array}{c}\text { Innerhalb } \\
\text { eines von } \\
\text { einer } \\
\text { höheren } \\
\text { Ebene } \\
\text { vorgege- } \\
\text { benen } \\
\text { Rahmens }\end{array}$ & Sonstige & $\begin{array}{l}\text { Insgesamt, } \\
\text { ohne Ent- } \\
\text { scheidun- } \\
\text { gen, bei } \\
\text { denen die } \\
\text { Schulen } \\
\text { konsultiert } \\
\text { werden }\end{array}$ & \begin{tabular}{|c|} 
Auf ande- \\
ren Ebenen \\
getroffene \\
Entschei- \\
dungen, bei \\
denen die \\
Schulen \\
konsultiert \\
werden
\end{tabular} & $\begin{array}{l}\text { Insgesamt, } \\
\text { einschließ- } \\
\text { lich Ent- } \\
\text { scheidun- } \\
\text { gen, bei } \\
\text { denen die } \\
\text { Schulen } \\
\text { konsultiert } \\
\text { werden }\end{array}$ & \begin{tabular}{|c|} 
In völliger \\
Autonomie
\end{tabular} & $\begin{array}{c}\text { Nach } \\
\text { Beratung } \\
\text { mit } \\
\text { anderen } \\
\text { Akteuren } \\
\text { des } \\
\text { Bildungs- } \\
\text { wesen }\end{array}$ & $\begin{array}{c}\text { Innerhalb } \\
\text { eines von } \\
\text { einer } \\
\text { höheren } \\
\text { Ebene } \\
\text { vorgege- } \\
\text { benen } \\
\text { Rahmens }\end{array}$ & Sonstige & \begin{tabular}{|c|} 
Insgesamt, \\
ohne Ent- \\
scheidun- \\
gen, bei \\
denen die \\
Schulen \\
konsultiert \\
werden
\end{tabular} & \begin{tabular}{|c|} 
Auf ande- \\
ren Ebenen \\
getroffene \\
Entschei- \\
dungen, bei \\
denen die \\
Schulen \\
konsultiert \\
werden
\end{tabular} & $\begin{array}{l}\text { Insgesamt, } \\
\text { einschließ- } \\
\text { lich Ent- } \\
\text { scheidun- } \\
\text { gen, bei } \\
\text { denen die } \\
\text { Schulen } \\
\text { konsultiert } \\
\text { werden }\end{array}$ \\
\hline Australien & 38 & & 50 & & 88 & & 88 & & & & & & & \\
\hline Österreich & 13 & & 75 & & 88 & & 88 & & & & & & & \\
\hline Belgien (frz.) & 38 & & 13 & 13 & 63 & & 63 & & & 17 & & 17 & & 17 \\
\hline Tschechische Rep. & 13 & & 75 & & 88 & & 88 & & & 75 & & 75 & & 75 \\
\hline Dänemark & 25 & & 63 & & 88 & & 88 & 42 & & & & 42 & 8 & 50 \\
\hline England & 75 & & 25 & & 100 & & 100 & 63 & 4 & 17 & & 83 & & 83 \\
\hline Finnland & 75 & & 13 & & 88 & & 88 & 17 & & 4 & & 21 & 8 & 29 \\
\hline Frankreich & 75 & & & & 75 & & 75 & 8 & 4 & & & 13 & & 13 \\
\hline Deutschland & 13 & & 75 & & 88 & & 88 & 4 & & 4 & & 8 & 21 & 29 \\
\hline Griechenland & & & 50 & & 50 & 13 & 63 & & & & & & 8 & 8 \\
\hline Ungarn & 63 & & 38 & & 100 & & 100 & 17 & 25 & 25 & & 67 & 4 & 71 \\
\hline Island & 38 & 25 & & & 63 & & 63 & 38 & & & & 38 & & 38 \\
\hline Italien & 63 & & 38 & & 100 & & 100 & 25 & & 8 & & 33 & & 33 \\
\hline Japan & 38 & & 13 & 13 & 63 & & 63 & & & & & & 21 & 21 \\
\hline Korea & 75 & & & & 75 & & 75 & 25 & & 17 & & 42 & & 42 \\
\hline Luxemburg & & 25 & 38 & & 63 & & 63 & & 8 & 4 & & 13 & 33 & 46 \\
\hline Mexiko & 50 & 25 & & & 75 & & 75 & & & & & & & \\
\hline Niederlande & 88 & & 13 & & 100 & & 100 & 71 & 25 & 4 & & 100 & & 100 \\
\hline Neuseeland & 88 & 13 & & & 100 & & 100 & 38 & & 42 & & 79 & & 79 \\
\hline Norwegen & 43 & & 29 & & 71 & & 71 & & & 42 & & 42 & & 42 \\
\hline Portugal & 38 & 13 & 25 & & 75 & & 75 & 33 & & & & 33 & & 33 \\
\hline Slowakische Rep. & 25 & & 63 & & 88 & & 88 & & & 50 & & 50 & 8 & 58 \\
\hline Spanien & & & 88 & & 88 & & 88 & & & 8 & & 8 & & 8 \\
\hline Schweden & 75 & & 13 & & 88 & & 88 & 63 & & 4 & & 67 & & 67 \\
\hline Türkei ${ }^{1}$ & 50 & & 13 & & 63 & & 63 & & & & & & & \\
\hline
\end{tabular}

\begin{tabular}{|c|c|c|c|c|c|c|c|c|c|c|c|c|c|c|}
\hline \multirow[b]{2}{*}{ OECD-Länder } & \multicolumn{7}{|c|}{ Strukturelle und Planungsangelegenheiten } & \multicolumn{7}{|c|}{ Ressourcen } \\
\hline & \begin{tabular}{|l|} 
In völliger \\
Autonomie
\end{tabular} & $\begin{array}{c}\text { Nach } \\
\text { Beratung } \\
\text { mit } \\
\text { anderen } \\
\text { Akteuren } \\
\text { des } \\
\text { Bildungs- } \\
\text { wesen }\end{array}$ & $\begin{array}{c}\text { Innerhalb } \\
\text { eines von } \\
\text { einer } \\
\text { höheren } \\
\text { Ebene } \\
\text { vorgege- } \\
\text { benen } \\
\text { Rahmens }\end{array}$ & Sonstige & $\begin{array}{l}\text { Insgesamt, } \\
\text { ohne Ent- } \\
\text { scheidun- } \\
\text { gen, bei } \\
\text { denen die } \\
\text { Schulen } \\
\text { konsultiert } \\
\text { werden }\end{array}$ & $\begin{array}{l}\text { Auf ande- } \\
\text { ren Ebenen } \\
\text { getroffene } \\
\text { Entschei- } \\
\text { dungen, bei } \\
\text { denen die } \\
\text { Schulen } \\
\text { konsultiert } \\
\text { werden }\end{array}$ & \begin{tabular}{|c|} 
Insgesamt, \\
einschließ- \\
lich Ent- \\
scheidun- \\
gen, bei \\
denen die \\
Schulen \\
konsultiert \\
werden
\end{tabular} & \begin{tabular}{|c|} 
In völliger \\
Autonomie \\
\end{tabular} & 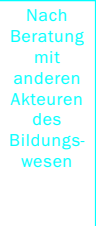 & $\begin{array}{l}\text { Innerhalb } \\
\text { eines von } \\
\text { einer } \\
\text { höheren } \\
\text { Ebene } \\
\text { vorgege- } \\
\text { benen } \\
\text { Rahmens }\end{array}$ & Sonstige & $\begin{array}{l}\text { Insgesamt, } \\
\text { ohne Ent- } \\
\text { scheidun- } \\
\text { gen, bei } \\
\text { denen die } \\
\text { Schulen } \\
\text { konsultiert } \\
\text { werden }\end{array}$ & \begin{tabular}{|c|} 
Auf ande- \\
ren Ebenen \\
getroffene \\
Entschei- \\
dungen, bei \\
denen die \\
Schulen \\
konsultiert \\
werden
\end{tabular} & $\begin{array}{l}\text { Insgesamt, } \\
\text { einschließ- } \\
\text { lich Ent- } \\
\text { scheidun- } \\
\text { gen, bei } \\
\text { denen die } \\
\text { Schulen } \\
\text { konsultiert } \\
\text { werden }\end{array}$ \\
\hline Österreich & & 10 & & & 10 & & 10 & 17 & & & & 17 & 17 & 33 \\
\hline Belgien (frz.) & & & 43 & & 43 & & 43 & & & 50 & & 50 & & 50 \\
\hline Tschechische Rep. & & & 50 & & 50 & & 50 & 13 & & 17 & & 29 & & 29 \\
\hline Dänemark & & & & & & 14 & 14 & & 17 & 29 & & 46 & 54 & 100 \\
\hline England & 14 & & 43 & & 57 & & 57 & 17 & & 83 & & 100 & & 100 \\
\hline Finnland & & & & & & & & & & & & & 58 & 58 \\
\hline Frankreich & & & 21 & & 21 & & 21 & & & 17 & & 17 & 17 & 33 \\
\hline Deutschland & & & 14 & & 14 & & 14 & 17 & & & & 17 & 46 & 63 \\
\hline Griechenland & & & & & & & & & & & & & & \\
\hline Island & & & & & & & & & & & & & & \\
\hline Italien & & & 36 & & 36 & & 36 & 17 & & & & 17 & & 17 \\
\hline Japan & & & 10 & 20 & 30 & & 30 & & & & & & & \\
\hline Korea & & & 25 & & 25 & & 25 & 17 & & 33 & & 50 & & 50 \\
\hline Luxemburg & & & 29 & & 29 & 43 & 71 & & & 33 & & 33 & 67 & 100 \\
\hline Mexiko & & 14 & & & 14 & & 14 & & & & & & & \\
\hline Niederlande & & & 100 & & 100 & & 100 & 100 & & & & 100 & & 100 \\
\hline Neuseeland & 40 & & 20 & & 60 & 40 & 100 & 17 & 17 & 29 & & 63 & & 63 \\
\hline Norwegen & & & & & & & & 33 & & & & 33 & & 33 \\
\hline Portugal & 7 & & & & 7 & 14 & 21 & 17 & 17 & 17 & & 50 & & 50 \\
\hline Slowakische Rep. & & & 29 & & 29 & & 29 & & & 33 & & 33 & & 33 \\
\hline Spanien & & & & & & & & & & 17 & & 17 & 33 & 50 \\
\hline Schweden & & & & & & & & 33 & & & & 33 & & 33 \\
\hline Türkei ${ }^{1}$ & & & 33 & & 33 & & 33 & & & & & & & \\
\hline
\end{tabular}

Hinweis: Leerstelle bedeutet, Schulen sind beim angegebenen Entscheidungsbereich/der Entscheidungsart nicht beteiligt.

1. Daten beziehen sich auf den Primarbereich.

Quelle: OECD. Hinweise s. Anhang 3 unter www.oecd.org/edu/eag2004. 
Tabelle D6.5

Entscheidungsebene, auf der verschiedene Entscheidungen über den Lehrplan an öffentlichen Bildungseinrichtungen im Sekundarbereich I getroffen werden (2003)

\begin{tabular}{|c|c|c|c|}
\hline & Auswahl der Lehrbücher & $\begin{array}{l}\text { Entwurf von } \\
\text { Bildungsgängen }\end{array}$ & $\begin{array}{l}\text { Auswahl des } \\
\text { Unterrichtsangebots }\end{array}$ \\
\hline OECD-Länder & & & \\
\hline Australien & $\begin{array}{l}\text { Schule } \\
\text { Rahmen auf Ebene } \\
\text { des ,Bundeslandes" }\end{array}$ & $\begin{array}{l}\text {,Bundesland } \\
\text { Autonom }\end{array}$ & $\begin{array}{l}\text {,Bundesland } \\
\text { Autonom }\end{array}$ \\
\hline Österreich & $\begin{array}{l}\text { Schule } \\
\text { Rahmen auf } \\
\text { zentraler Ebene }\end{array}$ & $\begin{array}{l}\text { Zentral } \\
\text { Beratung mit } \\
\text {,Bundeslandsebene }\end{array}$ & $\begin{array}{l}\text { Schule } \\
\text { Beratung mit } \\
\text {,Bundeslandsebene }\end{array}$ \\
\hline Belgien (frz.) & $\begin{array}{l}\text { Schule } \\
\text { sonstige }\end{array}$ & $\begin{array}{l}\text {,Bundesland } \\
\text { Autonom }\end{array}$ & $\begin{array}{l}\text {,Bundesland } \\
\text { Autonom }\end{array}$ \\
\hline Tschechische Rep. & $\begin{array}{l}\text { Schule } \\
\text { Autonom }\end{array}$ & $\begin{array}{l}\text { Schule } \\
\text { Rahmen auf } \\
\text { zentraler Ebene }\end{array}$ & $\begin{array}{l}\text { Schule } \\
\text { Rahmen auf } \\
\text { zentraler Ebene }\end{array}$ \\
\hline Dänemark & $\begin{array}{l}\text { Schule } \\
\text { Autonom }\end{array}$ & $\begin{array}{l}\text { Zentral } \\
\text { Autonom }\end{array}$ & $\begin{array}{l}\text { Lokal } \\
\text { Rahmen auf } \\
\text { zentraler Ebene }\end{array}$ \\
\hline England & $\begin{array}{l}\text { Schule } \\
\text { Autonom }\end{array}$ & $\begin{array}{l}\text { Schule } \\
\text { Rahmen auf } \\
\text { zentraler Ebene }\end{array}$ & $\begin{array}{l}\text { Schule } \\
\text { Rahmen auf } \\
\text { zentraler Ebene }\end{array}$ \\
\hline Finnland & $\begin{array}{l}\text { Schule } \\
\text { Autonom }\end{array}$ & $\begin{array}{l}\text { Lokal } \\
\text { Rahmen auf } \\
\text { zentraler Ebene }\end{array}$ & $\begin{array}{l}\text { Lokal } \\
\text { Rahmen auf } \\
\text { zentraler Ebene }\end{array}$ \\
\hline Frankreich & $\begin{array}{l}\text { Schule } \\
\text { Autonom }\end{array}$ & $\begin{array}{l}\text { Zentral } \\
\text { Autonom }\end{array}$ & $\begin{array}{l}\text { Zentral } \\
\text { Autonom }\end{array}$ \\
\hline Deutschland & $\begin{array}{l}\text { Schule } \\
\text { Rahmen auf } \\
\text { Bundeslandsebene }\end{array}$ & $\begin{array}{l}\text { Bundesland } \\
\text { Autonom }\end{array}$ & $\begin{array}{l}\text { Bundesland } \\
\text { Autonom }\end{array}$ \\
\hline Griechenland & $\begin{array}{l}\text { Zentral } \\
\text { Autonom }\end{array}$ & $\begin{array}{l}\text { Zentral } \\
\text { Autonom }\end{array}$ & $\begin{array}{l}\text { Zentral } \\
\text { Autonom }\end{array}$ \\
\hline Ungarn & $\begin{array}{l}\text { Schule } \\
\text { Rahmen auf } \\
\text { zentraler Ebene }\end{array}$ & $\begin{array}{l}\text { Schule } \\
\text { Rahmen auf } \\
\text { zentraler Ebene }\end{array}$ & $\begin{array}{l}\text { Schule } \\
\text { Autonom }\end{array}$ \\
\hline Island & $\begin{array}{l}\text { Zentral } \\
\text { Autonom }\end{array}$ & $\begin{array}{l}\text { Zentral } \\
\text { Autonom }\end{array}$ & $\begin{array}{l}\text { Zentral } \\
\text { Autonom }\end{array}$ \\
\hline Italien & $\begin{array}{l}\text { Schule } \\
\text { Rahmen auf } \\
\text { zentraler Ebene }\end{array}$ & $\begin{array}{l}\text { Zentral } \\
\text { Autonom }\end{array}$ & $\begin{array}{l}\text { Schule } \\
\text { Rahmen auf } \\
\text { zentraler Ebene }\end{array}$ \\
\hline Japan & $\begin{array}{l}\text { Lokal } \\
\text { Rahmen } \\
\text { auf regionaler Ebene }\end{array}$ & $\begin{array}{l}\text { Zentral } \\
\text { Autonom }\end{array}$ & $\begin{array}{l}\text { Zentral } \\
\text { Autonom }\end{array}$ \\
\hline Korea & $\begin{array}{l}\text { Schule } \\
\text { Autonom }\end{array}$ & $\begin{array}{l}\text { Regional } \\
\text { Rahmen auf } \\
\text { zentraler Ebene }\end{array}$ & $\begin{array}{l}\text { Regional } \\
\text { Autonom }\end{array}$ \\
\hline Luxemburg & $\begin{array}{l}\text { Zentral } \\
\text { Rahmen auf } \\
\text { zentraler Ebene }\end{array}$ & $\begin{array}{l}\text { Zentral } \\
\text { Beratung } \\
\text { mit Schule }\end{array}$ & $\begin{array}{l}\text { Zentral } \\
\text { Beratung } \\
\text { mit Schule }\end{array}$ \\
\hline Mexiko & $\begin{array}{l}\text { Zentral } \\
\text { Autonom }\end{array}$ & $\begin{array}{l}\text { Zentral } \\
\text { Beratung mit } \\
\text {,Bundeslandsebene }\end{array}$ & $\begin{array}{l}\text { Zentral } \\
\text { Beratung } \\
\text {,Bundeslandsebene }\end{array}$ \\
\hline Niederlande & $\begin{array}{l}\text { Schule } \\
\text { Autonom }\end{array}$ & $\begin{array}{l}\text { Schule } \\
\text { Rahmen auf } \\
\text { zentraler Ebene }\end{array}$ & $\begin{array}{l}\text { Schule } \\
\text { Rahmen auf } \\
\text { zentraler Ebene }\end{array}$ \\
\hline Neuseeland & $\begin{array}{l}\text { Schule } \\
\text { Autonom }\end{array}$ & $\begin{array}{l}\text { Schule } \\
\text { Rahmen auf } \\
\text { zentraler Ebene }\end{array}$ & $\begin{array}{l}\text { Schule } \\
\text { Autonom }\end{array}$ \\
\hline Norwegen & $\begin{array}{l}\text { Schule } \\
\text { Autonom }\end{array}$ & $\begin{array}{l}\text { Zentral } \\
\text { Autonom }\end{array}$ & $\begin{array}{l}\text { Zentral } \\
\text { Autonom }\end{array}$ \\
\hline Portugal & $\begin{array}{l}\text { Schule } \\
\text { Autonom }\end{array}$ & $\begin{array}{l}\text { Zentral } \\
\text { Autonom }\end{array}$ & $\begin{array}{l}\text { Zentral } \\
\text { Autonom }\end{array}$ \\
\hline Slowakische Rep. & $\begin{array}{l}\text { Schule } \\
\text { Rahmen auf } \\
\text { zentraler Ebene }\end{array}$ & $\begin{array}{l}\text { Zentral } \\
\text { Autonom }\end{array}$ & $\begin{array}{l}\text { Regional } \\
\text { Beratung mit } \\
\text { subregionaler Ebene }\end{array}$ \\
\hline Spanien & $\begin{array}{l}\text { Schule } \\
\text { Rahmen auf Ebene } \\
\text { autonome Region }\end{array}$ & $\begin{array}{l}\text {,Bundesland } \\
\text { Rahmen auf } \\
\text { zentraler Ebene }\end{array}$ & $\begin{array}{l}\text {,Bundesland } \\
\text { Beratung mit } \\
\text { regionaler Ebene }\end{array}$ \\
\hline Schweden & $\begin{array}{l}\text { Schule } \\
\text { Autonom }\end{array}$ & $\begin{array}{l}\text { Zentral } \\
\text { Autonom }\end{array}$ & $\begin{array}{l}\text { Lokal } \\
\text { Autonom }\end{array}$ \\
\hline Türkei ${ }^{1}$ & $\begin{array}{l}\text { Zentral } \\
\text { Autonom }\end{array}$ & $\begin{array}{l}\text { Zentral } \\
\text { Autonom }\end{array}$ & $\begin{array}{l}\text { Zentral } \\
\text { Autonom }\end{array}$ \\
\hline
\end{tabular}

\begin{tabular}{|c|c|}
\hline $\begin{array}{l}\text { Auswahl der Fachgebiete } \\
\text { an einer bestimmten Schule }\end{array}$ & Festlegung der Kursinhalte \\
\hline $\begin{array}{l}\text { Schule } \\
\text { Rahmen auf Ebene } \\
\text { des ,Bundeslandes" }\end{array}$ & $\begin{array}{l}\text {,Bundesland } \\
\text { Autonom }\end{array}$ \\
\hline $\begin{array}{l}\text { Zentral } \\
\text { Beratung } \\
\text {,Bundeslandsebene }\end{array}$ & $\begin{array}{l}\text { Zentral } \\
\text { Beratung } \\
\text {,Bundeslandsebene }\end{array}$ \\
\hline $\begin{array}{l}\text {,Bundesland } \\
\text { Autonom }\end{array}$ & $\begin{array}{l}\text {,Bundesland } \\
\text { sonstige }\end{array}$ \\
\hline $\begin{array}{l}\text { Zentral } \\
\text { Beratung mit } \\
\text { regionaler Ebene }\end{array}$ & $\begin{array}{l}\text { Schule } \\
\text { Rahmen auf } \\
\text { zentraler Ebene }\end{array}$ \\
\hline $\begin{array}{l}\text { Zentral } \\
\text { Autonom }\end{array}$ & $\begin{array}{l}\text { Lokal } \\
\text { Beratung mit Schule }\end{array}$ \\
\hline $\begin{array}{l}\text { Schule } \\
\text { Rahmen auf } \\
\text { zentraler Ebene }\end{array}$ & $\begin{array}{l}\text { Schule } \\
\text { Rahmen auf } \\
\text { zentraler Ebene }\end{array}$ \\
\hline $\begin{array}{l}\text { Lokal } \\
\text { Rahmen auf } \\
\text { zentraler Ebene }\end{array}$ & $\begin{array}{l}\text { Lokal } \\
\text { Rahmen auf } \\
\text { zentraler Ebene }\end{array}$ \\
\hline $\begin{array}{l}\text { Schule } \\
\text { Rahmen auf } \\
\text { regionaler Ebene }\end{array}$ & $\begin{array}{l}\text { Schule } \\
\text { Rahmen auf } \\
\text { zentraler Ebene }\end{array}$ \\
\hline $\begin{array}{l}\text { Bundesland } \\
\text { Autonom }\end{array}$ & $\begin{array}{l}\text { Bundesland } \\
\text { Autonom }\end{array}$ \\
\hline $\begin{array}{l}\text { Zentral } \\
\text { Autonom }\end{array}$ & $\begin{array}{l}\text { Zentral } \\
\text { Autonom }\end{array}$ \\
\hline $\begin{array}{l}\text { Schule } \\
\text { Rahmen auf } \\
\text { zentraler Ebene }\end{array}$ & $\begin{array}{l}\text { Schule } \\
\text { Rahmen auf } \\
\text { zentraler Ebene }\end{array}$ \\
\hline $\begin{array}{l}\text { Zentral } \\
\text { Autonom }\end{array}$ & $\begin{array}{l}\text { Zentral } \\
\text { Autonom }\end{array}$ \\
\hline $\begin{array}{l}\text { Schule } \\
\text { Rahmen auf } \\
\text { zentraler Ebene }\end{array}$ & $\begin{array}{l}\text { Schule } \\
\text { Rahmen auf } \\
\text { zentraler Ebene }\end{array}$ \\
\hline $\begin{array}{l}\text { Schule } \\
\text { Rahmen } \\
\text { auf regionaler Ebene }\end{array}$ & $\begin{array}{l}\text { Schule } \\
\text { sonstige }\end{array}$ \\
\hline $\begin{array}{l}\text { Regional } \\
\text { Rahmen auf } \\
\text { zentraler Ebene }\end{array}$ & $\begin{array}{l}\text { Schule } \\
\text { Rahmen auf } \\
\text { regionaler Ebene }\end{array}$ \\
\hline $\begin{array}{l}\text { Zentral } \\
\text { Beratung } \\
\text { mit Schule }\end{array}$ & $\begin{array}{l}\text { Schule } \\
\text { Rahmen auf } \\
\text { zentraler Ebene }\end{array}$ \\
\hline $\begin{array}{l}\text { Zentral } \\
\text { Autonom }\end{array}$ & $\begin{array}{l}\text { Zentral } \\
\text { Autonom }\end{array}$ \\
\hline $\begin{array}{l}\text { Schule } \\
\text { Rahmen auf } \\
\text { zentraler Ebene }\end{array}$ & $\begin{array}{l}\text { Schule } \\
\text { Rahmen auf } \\
\text { zentraler Ebene }\end{array}$ \\
\hline $\begin{array}{l}\text { Schule } \\
\text { Autonom }\end{array}$ & $\begin{array}{l}\text { Schule } \\
\text { Autonom }\end{array}$ \\
\hline $\begin{array}{l}\text { Zentral } \\
\text { Autonom }\end{array}$ & $\begin{array}{l}\text { Zentral } \\
\text { Autonom }\end{array}$ \\
\hline $\begin{array}{l}\text { Schule } \\
\text { Autonom }\end{array}$ & $\begin{array}{l}\text { Zentral } \\
\text { Autonom }\end{array}$ \\
\hline $\begin{array}{l}\text { Zentral } \\
\text { Sonstige }\end{array}$ & $\begin{array}{l}\text { Schule } \\
\text { Rahmen auf } \\
\text { zentraler Ebene }\end{array}$ \\
\hline ,Bundesland & ,Bundesland“ \\
\hline $\begin{array}{l}\text { Rahmen auf } \\
\text { zentraler Ebene }\end{array}$ & $\begin{array}{l}\text { Rahmen auf } \\
\text { zentraler Ebene }\end{array}$ \\
\hline $\begin{array}{l}\text { Zentral } \\
\text { Autonom }\end{array}$ & $\begin{array}{l}\text { Zentral } \\
\text { Autonom }\end{array}$ \\
\hline $\begin{array}{l}\text { Zentral } \\
\text { Autonom }\end{array}$ & $\begin{array}{l}\text { Zentral } \\
\text { Autonom }\end{array}$ \\
\hline
\end{tabular}

1. Daten beziehen sich auf den Primarbereich.

Quelle: OECD. Hinweise s. Anhang 3 unter www.oecd.org/edu/eag2004. 
Tabelle D6.6

Prozensatz an Entscheidungen in Bezug auf öffentliche Bildungseinrichtungen im Sekundarbereich I, die auf der jeweiligen Entscheidungsebene getroffen werden $(1998,2003)$

\begin{tabular}{|c|c|c|c|c|c|c|c|c|c|c|c|c|c|c|}
\hline \multirow[b]{2}{*}{ OECD-Länder } & \multicolumn{7}{|c|}{2003} & \multicolumn{7}{|c|}{1998} \\
\hline & Zentral & $\begin{array}{l}\text { Bundes- } \\
\text { land }\end{array}$ & $\begin{array}{c}\text { Provinz/ } \\
\text { Region }\end{array}$ & $\begin{array}{l}\text { Sub- } \\
\text { regional }\end{array}$ & Lokal & Schule & Gesamt & Zentral & $\begin{array}{l}\text {,Bundes- } \\
\text { land" }\end{array}$ & $\begin{array}{l}\text { Provinz/ } \\
\text { Region }\end{array}$ & $\begin{array}{l}\text { Sub- } \\
\text { regional }\end{array}$ & Lokal & Schule & Gesamt \\
\hline Australien & & 76 & & & & 24 & 100 & $\mathrm{~m}$ & $\mathrm{~m}$ & $\mathrm{~m}$ & $\mathrm{~m}$ & $\mathrm{~m}$ & $\mathrm{~m}$ & $\mathrm{~m}$ \\
\hline Österreich & 27 & 22 & & & 23 & 29 & 100 & 35 & 18 & & & 22 & 25 & 100 \\
\hline Belgien (frz.) ${ }^{1}$ & & 32 & 25 & & & 43 & 100 & $\mathrm{~m}$ & $\mathrm{~m}$ & $\mathrm{~m}$ & $\mathrm{~m}$ & $\mathrm{~m}$ & $\mathrm{~m}$ & $\mathrm{~m}$ \\
\hline Tschechische Rep. & 7 & & 1 & & 32 & 60 & 100 & 17 & & & 21 & 10 & 52 & 100 \\
\hline Dänemark & 19 & & & & 38 & 44 & 100 & 26 & & & & 43 & 31 & 100 \\
\hline England & 11 & & & & 4 & 85 & 100 & 20 & & & & 18 & 62 & 100 \\
\hline Finnland & 2 & & & & 71 & 27 & 100 & & & & & 64 & 36 & 100 \\
\hline Frankreich & 24 & & 10 & 35 & & 31 & 100 & 32 & & 11 & 27 & & 29 & 100 \\
\hline Deutschland & 4 & 30 & 17 & & 17 & 32 & 100 & 4 & 28 & 15 & & 16 & 37 & 100 \\
\hline Griechenland & 80 & & 4 & & 3 & 13 & 100 & 56 & & 22 & & & 23 & 100 \\
\hline Ungarn & 4 & & & & 29 & 68 & 100 & & & & & 35 & 65 & 100 \\
\hline Island & 25 & & & & 50 & 25 & 100 & $\mathrm{~m}$ & $\mathrm{~m}$ & $\mathrm{~m}$ & $\mathrm{~m}$ & $\mathrm{~m}$ & $\mathrm{~m}$ & $\mathrm{~m}$ \\
\hline Italien & 21 & & 16 & & 15 & 48 & 100 & 39 & & 25 & & 3 & 33 & 100 \\
\hline Japan & 13 & & 21 & & 44 & 23 & 100 & $\mathrm{~m}$ & $\mathrm{~m}$ & $\mathrm{~m}$ & $\mathrm{~m}$ & $\mathrm{~m}$ & $\mathrm{~m}$ & $\mathrm{~m}$ \\
\hline Korea & 9 & & 34 & & 8 & 48 & 100 & 37 & & 31 & & 7 & 25 & 100 \\
\hline Luxemburg & 66 & & & & & 34 & 100 & $\mathrm{~m}$ & $\mathrm{~m}$ & $\mathrm{~m}$ & $\mathrm{~m}$ & $\mathrm{~m}$ & $\mathrm{~m}$ & $\mathrm{~m}$ \\
\hline Mexiko & 30 & 45 & 2 & & & 22 & 100 & $\mathrm{~m}$ & $\mathrm{~m}$ & $\mathrm{~m}$ & $\mathrm{~m}$ & $\mathrm{~m}$ & $\mathrm{~m}$ & $\mathrm{~m}$ \\
\hline Niederlande & & & & & & 100 & 100 & 24 & & & & 3 & 73 & 100 \\
\hline Neuseeland & 25 & & & & & 75 & 100 & 34 & & & & & 66 & 100 \\
\hline Norwegen & 32 & & & & 32 & 37 & 100 & 35 & & & & 55 & 9 & 100 \\
\hline Portugal & 50 & & 8 & & & 41 & 100 & 69 & & 7 & & & 24 & 100 \\
\hline Slowakische Rep. & 33 & & 2 & & 15 & 50 & 100 & $\mathrm{~m}$ & $\mathrm{~m}$ & $\mathrm{~m}$ & $\mathrm{~m}$ & $\mathrm{~m}$ & $\mathrm{~m}$ & $\mathrm{~m}$ \\
\hline Spanien & & 57 & 15 & & & 28 & 100 & 3 & 46 & 10 & & & 41 & 100 \\
\hline Schweden & 18 & & & & 36 & 47 & 100 & $\mathrm{~m}$ & $\mathrm{~m}$ & $\mathrm{~m}$ & $\mathrm{~m}$ & $\mathrm{~m}$ & $\mathrm{~m}$ & $\mathrm{~m}$ \\
\hline Türkei ${ }^{2}$ & 49 & & 27 & & & 24 & 100 & 94 & & & & & 6 & 100 \\
\hline
\end{tabular}

\begin{tabular}{|c|c|c|c|c|c|c|}
\hline \multirow[b]{2}{*}{ OECD-Länder } & \multicolumn{6}{|c|}{ Differenz 2003 zu 1998} \\
\hline & Zentral & ,Bundesland' & Provinz/Region & Sub-regional & Lokal & Schule \\
\hline Australien & $\mathrm{m}$ & $\mathrm{m}$ & $\mathrm{m}$ & $\mathrm{m}$ & $\mathrm{m}$ & $\mathrm{m}$ \\
\hline Österreich & -9 & 4 & & & 1 & 4 \\
\hline Belgien (frz.) ${ }^{1}$ & $\mathrm{~m}$ & $\mathrm{~m}$ & $\mathrm{~m}$ & $\mathrm{~m}$ & $\mathrm{~m}$ & $\mathrm{~m}$ \\
\hline Tschechische Rep. & -10 & & 1 & -21 & 21 & 9 \\
\hline Dänemark & -8 & & & & -5 & 13 \\
\hline England & -8 & & & & -15 & 23 \\
\hline Finnland & 2 & & & & 7 & -9 \\
\hline Frankreich & -9 & & -1 & 7 & & 2 \\
\hline Deutschland & & 2 & 2 & & 1 & -5 \\
\hline Griechenland & 25 & & -18 & & 3 & -10 \\
\hline Ungarn & 4 & & & & -6 & 3 \\
\hline Island & $\mathrm{m}$ & $\mathrm{m}$ & $\mathrm{m}$ & $\mathrm{m}$ & $\mathrm{m}$ & $\mathrm{m}$ \\
\hline Italien & -18 & & -9 & & 11 & 15 \\
\hline Japan & $\mathrm{m}$ & $\mathrm{m}$ & $\mathrm{m}$ & $\mathrm{m}$ & $\mathrm{m}$ & $\mathrm{m}$ \\
\hline Korea & -28 & & 3 & & 1 & 23 \\
\hline Luxemburg & $\mathrm{m}$ & $\mathrm{m}$ & $\mathrm{m}$ & $\mathrm{m}$ & $\mathrm{m}$ & $\mathrm{m}$ \\
\hline Mexiko & $\mathrm{m}$ & $\mathrm{m}$ & $\mathrm{m}$ & $\mathrm{m}$ & $\mathrm{m}$ & $\mathrm{m}$ \\
\hline Niederlande & -24 & & & & -3 & 27 \\
\hline Neuseeland & -10 & & & & & 10 \\
\hline Norwegen & -4 & & & & -24 & 27 \\
\hline Portugal & -18 & & 1 & & & 17 \\
\hline Slowakische Rep. & $\mathrm{m}$ & $\mathrm{m}$ & $\mathrm{m}$ & $\mathrm{m}$ & $\mathrm{m}$ & $\mathrm{m}$ \\
\hline Spanien & -3 & 12 & 5 & & & -13 \\
\hline Schweden & $\mathrm{m}$ & $\mathrm{m}$ & $\mathrm{m}$ & $\mathrm{m}$ & $\mathrm{m}$ & $\mathrm{m}$ \\
\hline Türkei² & -45 & & 27 & & & 18 \\
\hline
\end{tabular}

Hinweis: Leerstelle bedeutet keine primären Entscheidungskompetenzen auf dieser Ebene.

1. Für Belgien (frz.) bedeutet ,Provinz/Region` für 61 Prozent der Schulen Zentralregierung, für 21 Prozent der Schulen Provinz- oder Regionalbehörde und für 18 Prozent der Schulen lokale Behörden. 2. Daten beziehen sich auf den Primarbereich.

Quelle: OECD. Hinweise s. Anhang 3 unter www.oecd.org/edu/eag2004. 



\section{Merkmale der Bildungssysteme}

Das typische Abschlussalter ist das Alter am Ende des letzten Schul-/ Studienjahres des betreffenden Bildungsbereichs und -gangs, in dem der Schüler bzw. Studierende den Abschluss erlangt Es ist dies das Alter, in dem der Abschluss ,normalerweise erworben wird. (Es sei darauf hingewiesen, dass in einigen Bildungsbereichen der Begriff „Abschlussalter" nicht wörtlich zu verstehen ist, und hier rein aus Definitionsgründen verwendet wird) 

Tabelle X1.1a

Typisches Abschlussalter im Sekundarbereich II

\begin{tabular}{|c|c|c|c|c|c|c|}
\hline & \multicolumn{2}{|c|}{ Ausrichtung des Bildungsgangs } & \multicolumn{4}{|c|}{ Ziel des Bildungsgangs: weitere Ausbildung/Arbeitsmarkteintritt } \\
\hline & allgemeinbildend & $\begin{array}{l}\text { berufsvorbereitend/ } \\
\text { berufsbildend }\end{array}$ & ISCED 3 A & ISCED 3B & ISCED 3 C kurz ${ }^{1}$ & ISCED 3 C lang ${ }^{1}$ \\
\hline \multicolumn{7}{|l|}{ OECD-Länder } \\
\hline Australien & $\mathrm{m}$ & $\mathrm{m}$ & 17 & $\mathrm{~m}$ & $\mathrm{~m}$ & $\mathrm{~m}$ \\
\hline Österreich & 18 & 18 & 18 & 18 & 18 & a \\
\hline Belgien & 18 & 18 & 18 & a & 18 & 18 \\
\hline Dänemark & $19-20$ & $19-20$ & $19-20$ & a & a & $19-20$ \\
\hline Finnland & 19 & 19 & 19 & a & a & a \\
\hline Frankreich & $18-19$ & $17-20$ & $18-19$ & $19-20$ & $17-20$ & $18-21$ \\
\hline Deutschland & 19 & 19 & 19 & 19 & a & a \\
\hline Griechenland & $17-18$ & $17-18$ & $17-18$ & a & a & $17-18$ \\
\hline Ungarn & $18-20$ & $16-17$ & $18-20$ & $20-22$ & $16-17$ & 18 \\
\hline Island & 19 & 19 & 19 & 18 & 17 & 19 \\
\hline Italien & 19 & 19 & 19 & 19 & 17 & a \\
\hline Japan & 18 & 18 & 18 & 18 & 16 & 18 \\
\hline Korea & $17-18$ & $17-18$ & $17-18$ & a & a & $17-18$ \\
\hline Luxemburg & 19 & $17-19$ & $17-19$ & 19 & $\mathrm{n}$ & $17-19$ \\
\hline Mexiko & 18 & 19 & 18 & a & 19 & 19 \\
\hline Niederlande & $17-18$ & $18-20$ & $17-18$ & a & $18-19$ & $18-20$ \\
\hline Neuseeland & $\mathrm{m}$ & a & 18 & 17 & 17 & 17 \\
\hline Norwegen & $18-19$ & $18-19$ & $18-19$ & a & $\mathrm{m}$ & $16-18$ \\
\hline Polen & 19 & 20 & $19-20$ & a & 18 & a \\
\hline Slowakische Rep. & 18 & $16-18$ & 18 & a & 17 & 16 \\
\hline Spanien & 17 & 17 & 17 & a & 17 & 17 \\
\hline Schweden & 19 & 19 & 19 & 19 & a & 19 \\
\hline Schweiz & $18-20$ & $18-20$ & $18-20$ & $18-20$ & $17-19$ & $17-19$ \\
\hline Türkei & 16 & 16 & 16 & a & a & $\mathrm{m}$ \\
\hline \multicolumn{7}{|l|}{ OECD-Partnerländer } \\
\hline Argentinien & 17 & 17 & 17 & a & a & a \\
\hline Brasilien & 17 & 17 & 17 & 17 & a & 17 \\
\hline Chile & 18 & 18 & 18 & 18 & a & a \\
\hline China & 18 & 18 & 18 & a & $17-18$ & 18 \\
\hline Ägypten ${ }^{2}$ & 17 & 17 & 17 & 17 & a & 17 \\
\hline Indien & 18 & 18 & 18 & a & $\mathrm{m}$ & $\mathrm{m}$ \\
\hline Indonesien & 18 & $18-19$ & 18 & 18 & a & a \\
\hline Israel & 18 & 18 & 18 & 18 & 18 & 18 \\
\hline Jamaika & 17 & 17 & 17 & 17 & a & a \\
\hline Jordanien $^{2}$ & 18 & 18 & 18 & a & 18 & 18 \\
\hline Malaysia $^{3}$ & $17-19$ & 17 & 19 & a & a & 17 \\
\hline Paraguay ${ }^{2}$ & 17 & 17 & 17 & a & a & 17 \\
\hline Peru & 17 & 17 & 17 & 17 & a & a \\
\hline Philippinen ${ }^{2}$ & 16 & a & 16 & a & a & a \\
\hline Russische Föd. ${ }^{2}$ & 17 & $17-18$ & 17 & a & $\mathrm{m}$ & $\mathrm{m}$ \\
\hline Thailand & 17 & 17 & 17 & 17 & a & a \\
\hline Tunesien $^{2}$ & 19 & 19 & 19 & 19 & a & 19 \\
\hline Uruguay ${ }^{2}$ & 17 & 18 & 18 & 18 & a & a \\
\hline Simbabwe $^{2}$ & 19 & 17 & 19 & $a$ & a & 17 \\
\hline
\end{tabular}

1. Zeitliche Einteilung bei ISCED $3 C$ - kurz: mindestens ein Jahr kürzer als ISCED 3A/3B Bildungsgänge; lang: ähnlich lang wie ISCED $3 A / 3 B$ Bildungsgänge.

2. Schätzung der OECD. 3. Schätzung der OECD für allgemeinbildende und berufsvorbereitende/berufsbildende Bildungsgänge.

Quelle: OECD. 
Tabelle X1.1b

Typisches Abschlussalter im post-sekundaren, nicht-tertiären Bereich

\begin{tabular}{|c|c|c|c|}
\hline \multirow[b]{3}{*}{ OECD-Länder } & \multicolumn{3}{|c|}{ Ziel des Bildungsgangs: weitere Ausbildung/Arbeitsmarkteintritt } \\
\hline & ISCED 4A & ISCED 4B & ISCED 4C \\
\hline & & & \\
\hline Österreich & 19 & 20 & 20 \\
\hline Belgien & 19 & a & $19-21$ \\
\hline Tschechische Republik & 20 & a & 20 \\
\hline Dänemark & $21-22$ & a & $21-22$ \\
\hline Finnland & a & a & $25-29$ \\
\hline Frankreich & $18-21$ & a & $19-21$ \\
\hline Deutschland & 22 & 22 & a \\
\hline Ungarn & $20-22$ & a & $19-22$ \\
\hline Island & a & a & 20 \\
\hline Irland & a & a & 19 \\
\hline Italien & a & a & 20 \\
\hline Korea & a & a & a \\
\hline Luxemburg & a & a & $20-25$ \\
\hline Mexiko & a & a & a \\
\hline Niederlande & a & a & $18-20$ \\
\hline Neuseeland & 18 & 18 & 18 \\
\hline Norwegen & $20-25$ & a & $20-25$ \\
\hline Polen & a & a & 21 \\
\hline Slowakische Republik & $20-21$ & a & a \\
\hline Spanien & 18 & 18 & a \\
\hline Schweden & $\mathrm{m}$ & $\mathrm{m}$ & $19-20$ \\
\hline Schweiz & $19-21$ & $21-23$ & a \\
\hline Türkei & a & a & a \\
\hline Vereinigte Staaten & a & a & 20 \\
\hline OECD-Partnerländer & & & \\
\hline Argentinien & a & a & a \\
\hline Brasilien & a & a & $a$ \\
\hline China & a & 20 & 20 \\
\hline Indonesien & a & a & a \\
\hline Jordanien $^{1}$ & a & a & a \\
\hline Malaysia $^{1}$ & 20 & 18 & 19 \\
\hline Paraguay & a & a & a \\
\hline Peru & a & a & $\mathrm{m}$ \\
\hline Philippinen ${ }^{1}$ & 19 & 19 & 17 \\
\hline Russische Föderation & a & a & 18 \\
\hline Thailand $^{1}$ & $a$ & $a$ & 19 \\
\hline Tunesien & a & 21 & a \\
\hline
\end{tabular}


Tabelle X1.1c

Typisches Abschlussalter im Tertiärbereich

\begin{tabular}{|c|c|c|c|c|c|c|}
\hline & \multirow{2}{*}{$\begin{array}{l}\text { Tertiärbereich B } \\
\text { (ISCED 5B) }\end{array}$} & \multirow[t]{2}{*}{ Alle Studiengänge } & \multicolumn{3}{|c|}{ Tertiärbereich A (ISCED 5A) } & \multirow{2}{*}{$\begin{array}{l}\text { Weiterführende } \\
\text { Forschungspro- } \\
\text { gramme (ISCED 6) }\end{array}$} \\
\hline & & & $\begin{array}{c}3 \text { bis zu weniger } \\
\text { als } 5 \text { Jahre }\end{array}$ & 5 bis 6 Jahre & Länger als 6 Jahre & \\
\hline \multicolumn{7}{|l|}{ OECD-Länder } \\
\hline Australien & $\mathrm{m}$ & a & $20-21$ & $22-23$ & 24 & $25-29$ \\
\hline Österreich & $\mathrm{m}$ & a & 22 & 23 & a & 25 \\
\hline Belgien & $\mathrm{m}$ & a & $\mathrm{m}$ & $\mathrm{m}$ & $\mathrm{m}$ & $25-29$ \\
\hline Tschechische Rep. & 22 & a & 22 & 24 & a & 26 \\
\hline Dänemark & $21-25$ & a & $22-24$ & $25-26$ & $27-30$ & 30 \\
\hline Finnland & $21-22$ & a & $25-29$ & $25-29$ & $30-34$ & 29 \\
\hline Frankreich & $20-21$ & a & $21-22$ & $23-24$ & 25 & $25-26$ \\
\hline Deutschland & 21 & a & 25 & 26 & a & 28 \\
\hline Griechenland & $\mathrm{m}$ & a & $\mathrm{m}$ & $\mathrm{m}$ & $\mathrm{m}$ & $24-28$ \\
\hline Ungarn & $\mathrm{m}$ & a & $\mathrm{m}$ & $\mathrm{m}$ & $\mathrm{m}$ & 30 \\
\hline Island & $22-24$ & a & 23 & 25 & 27 & 29 \\
\hline Irland & 20 & a & 21 & 23 & 24 & 27 \\
\hline Italien & $22-23$ & a & 22 & $23-25$ & $25-27$ & $27-29$ \\
\hline Japan & 20 & a & 22 & 24 & a & 27 \\
\hline Korea & $\mathrm{m}$ & a & $\mathrm{m}$ & $\mathrm{m}$ & $\mathrm{m}$ & 26 \\
\hline Mexiko & $\mathrm{m}$ & a & $\mathrm{m}$ & $\mathrm{m}$ & $\mathrm{m}$ & $24-28$ \\
\hline Niederlande & $\mathrm{m}$ & a & $\mathrm{m}$ & $\mathrm{m}$ & $\mathrm{m}$ & 25 \\
\hline Neuseeland & 20 & 21 & $\mathrm{~m}$ & $\mathrm{~m}$ & $\mathrm{~m}$ & 28 \\
\hline Norwegen & $\mathrm{m}$ & a & $\mathrm{m}$ & $\mathrm{m}$ & $\mathrm{m}$ & 29 \\
\hline Polen & $\mathrm{m}$ & 24 & $\mathrm{~m}$ & $\mathrm{~m}$ & $\mathrm{~m}$ & $\mathrm{~m}$ \\
\hline Slowakische Rep. & $20-21$ & a & $\mathrm{m}$ & $\mathrm{m}$ & $\mathrm{m}$ & 27 \\
\hline Spanien & 19 & $20-22$ & $\mathrm{~m}$ & $\mathrm{~m}$ & $\mathrm{~m}$ & $25-27$ \\
\hline Schweden & $22-23$ & a & $23-25$ & $25-26$ & a & $27-29$ \\
\hline Schweiz & $23-29$ & a & $23-26$ & $23-26$ & 28 & 29 \\
\hline Türkei & $\mathrm{m}$ & $\mathrm{m}$ & $\mathrm{m}$ & $\mathrm{m}$ & $\mathrm{m}$ & $28-29$ \\
\hline Ver. Königreich & 20 & a & 21 & 23 & 24 & 24 \\
\hline Vereinigte Staaten & $\mathrm{m}$ & $\mathrm{m}$ & $\mathrm{m}$ & $\mathrm{m}$ & $\mathrm{m}$ & 28 \\
\hline
\end{tabular}

Hinweis: Wenn Daten zum Tertiärbereich A, aufgegliedert nach der Dauer der Studiengänge, verfügbar waren, ist die Abschlussquote für alle Studiengänge die Summe der Abschlussquoten, aufgegliedert nach der Dauer der Studiengänge. Quelle: $O E C D$. 


\section{Tabelle X1.2a}

Für die Berechnung der Indikatoren verwendete Haushalts- und Schuljahre

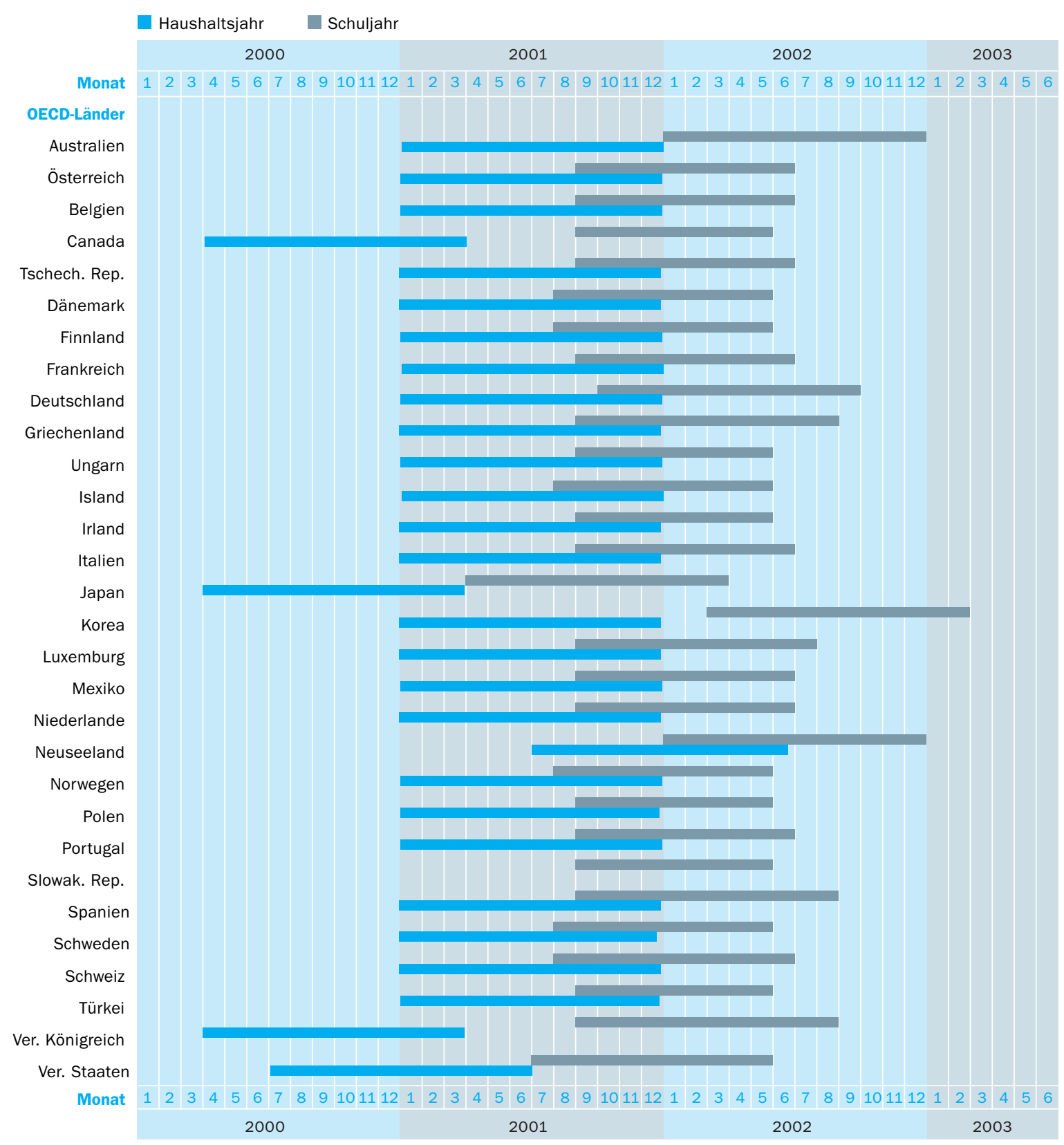

Quelle: $O E C D$. 
Tabelle X1.2b

Für die Berechnung der Indikatoren verwendete Haushalts- und Schuljahre

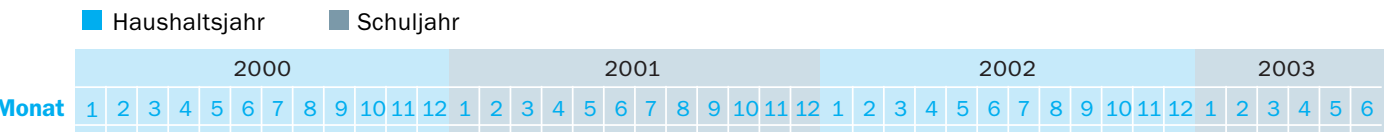

OECD-Partnerländer

Argentinie

Brasilien

Chile

China

Ägypten

Indien

Indonesien

Israel

Jamaika

Jordanien

Malaysia

Paraguay

Peru

Philippinen

Russische Föd.

Sri Lanka

Thailand

Tunesien

Uruguay

Simbabwe

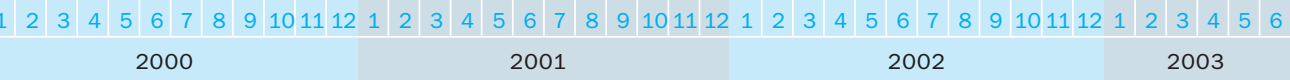

Quelle: $O E C D$. 
Tabelle X1.3

Abschlussanforderungen für Bildungsgänge im Sekundarbereich II (ISCED 3)

\begin{tabular}{|c|c|c|c|c|c|c|c|c|c|c|c|c|}
\hline \multirow[b]{2}{*}{ OECD-Länder } & \multicolumn{4}{|c|}{ ISCED 3 A } & \multicolumn{4}{|c|}{ ISCED 3B } & \multicolumn{4}{|c|}{ ISCED $3 C$} \\
\hline & $\begin{array}{l}\text { Abschluss- } \\
\text { prüfung }\end{array}$ & $\begin{array}{l}\text { Reihe von } \\
\text { Prüfungen } \\
\text { während } \\
\text { des } \\
\text { Bildungs- } \\
\text { gangs }\end{array}$ & \begin{tabular}{|c|} 
Bestimmte \\
Anzahl \\
von Kurs- \\
stunden \\
plus \\
Prüfung
\end{tabular} & $\begin{array}{c}\text { Nur } \\
\text { bestimmte } \\
\text { Anzahl } \\
\text { von Kurs- } \\
\text { stunden }\end{array}$ & $\begin{array}{l}\text { Abschluss- } \\
\text { prüfung }\end{array}$ & $\begin{array}{l}\text { Reihe von } \\
\text { Prüfungen } \\
\text { während } \\
\text { des } \\
\text { Bildungs- } \\
\text { gangs }\end{array}$ & $\begin{array}{l}\text { Bestimmte } \\
\text { Anzahl } \\
\text { von Kurs- } \\
\text { stunden } \\
\text { plus } \\
\text { Prüfung }\end{array}$ & $\begin{array}{c}\text { Nur } \\
\text { bestimmte } \\
\text { Anzahl } \\
\text { von Kurs- } \\
\text { stunden }\end{array}$ & $\begin{array}{c}\text { Abschluss- } \\
\text { prüfung }\end{array}$ & $\begin{array}{c}\text { Reihe von } \\
\text { Prüfungen } \\
\text { während } \\
\text { des } \\
\text { Bildungs- } \\
\text { gangs }\end{array}$ & \begin{tabular}{|c} 
Bestimmte \\
Anzahl \\
von Kurs- \\
stunden \\
plus \\
Prüfung
\end{tabular} & $\begin{array}{c}\text { Nur } \\
\text { bestimmte } \\
\text { Anzahl } \\
\text { von Kurs- } \\
\text { stunden }\end{array}$ \\
\hline Australien ${ }^{1,2}$ & $\mathrm{~N} / \mathrm{J}$ & $J$ & J & $\mathrm{N}$ & $\mathrm{N}$ & $J$ & $\mathrm{~N}$ & $\mathrm{~N}$ & $\mathrm{~N}$ & J & $\mathrm{N}$ & $\mathrm{N}$ \\
\hline Österreich & $J$ & $J$ & $J$ & $\mathrm{~N}$ & J & $J$ & J & $\mathrm{N}$ & $\mathrm{N}$ & J & $J$ & $\mathrm{~N}$ \\
\hline Belgien (fläm.) ${ }^{3}$ & J & $J$ & $\mathrm{~N}$ & $\mathrm{~N}$ & a & a & a & a & $J$ & J & $\mathrm{N}$ & $\mathrm{N}$ \\
\hline Belgien (frz.) & $J$ & $J$ & $\mathrm{~N}$ & $\mathrm{~N}$ & a & a & a & a & $J$ & $J$ & $\mathrm{~N}$ & $\mathrm{~N}$ \\
\hline Canada (Québec) ${ }^{1}$ & $\mathrm{~N}$ & $J$ & J & $\mathrm{N}$ & & & & & $\mathrm{N}$ & J & $J$ & $\mathrm{~N}$ \\
\hline Tschechische Rep. ${ }^{1}$ & J & $J$ & J & $\mathrm{N}$ & $\mathrm{N}$ & $J$ & J & $\mathrm{N}$ & J & J & $J$ & $\mathrm{~N}$ \\
\hline Dänemark ${ }^{1}$ & J & $J$ & J & & a & a & a & a & J & J & $J$ & \\
\hline Finnland & $\mathrm{J} / \mathrm{N}$ & $J$ & $J$ & $\mathrm{~N}$ & & & & & & & & \\
\hline Frankreich & $J$ & $\mathrm{~N}$ & J & $\mathrm{N}$ & a & a & a & a & $\mathrm{J} / \mathrm{N}$ & J & $\mathrm{N}$ & \\
\hline Deutschland & $J$ & $J$ & $\mathrm{~N}$ & $\mathrm{~N}$ & $J$ & $J$ & $\mathrm{~N}$ & $\mathrm{~N}$ & a & a & a & a \\
\hline Griechenland $^{1}$ & $\mathrm{~N}$ & $J$ & $\mathrm{~N}$ & $\mathrm{~N}$ & & & & & $\mathrm{~N}$ & J & $\mathrm{N}$ & $\mathrm{N}$ \\
\hline Ungarn & J & $\mathrm{N}$ & J & $\mathrm{N}$ & $J$ & $\mathrm{~N}$ & J & $\mathrm{N}$ & $J$ & $\mathrm{~N}$ & $J$ & $\mathrm{~N}$ \\
\hline Island ${ }^{1}$ & $\mathrm{~J} / \mathrm{N}$ & $J$ & $\mathrm{~N}$ & $\mathrm{~N}$ & $J$ & $J$ & $\mathrm{~N}$ & $\mathrm{~N}$ & $\mathrm{~J} / \mathrm{N}$ & J & $\mathrm{N}$ & $\mathrm{N}$ \\
\hline Irland $^{1}$ & J & $\mathrm{N}$ & $\mathrm{N}$ & $\mathrm{N}$ & a & a & a & a & J & J & $J$ & $\mathrm{~N}$ \\
\hline Italien & $J$ & $\mathrm{~N}$ & $\mathrm{~J} / \mathrm{N}$ & $\mathrm{N}$ & $J$ & $\mathrm{~J} / \mathrm{N}$ & $\mathrm{J} / \mathrm{N}$ & $\mathrm{N}$ & J & $\mathrm{N}$ & $\mathrm{J} / \mathrm{N}$ & $\mathrm{N}$ \\
\hline$|s r a e|^{1}$ & $\mathrm{~J} / \mathrm{N}$ & $J$ & $J$ & $\mathrm{~N}$ & a & a & a & a & $\mathrm{J} / \mathrm{N}$ & $J$ & $J$ & \\
\hline Japan & $N$ & $\mathrm{~N}$ & J & $\mathrm{N}$ & $\mathrm{N}$ & $\mathrm{N}$ & J & $\mathrm{N}$ & $\mathrm{N}$ & $\mathrm{N}$ & $J$ & $\mathrm{~N}$ \\
\hline Korea & $\mathrm{N}$ & $\mathrm{N}$ & $\mathrm{N}$ & J & & & & & $\mathrm{N}$ & $\mathrm{N}$ & $\mathrm{N}$ & $J$ \\
\hline Luxemburg & $J$ & $J$ & $J$ & $\mathrm{~N}$ & $J$ & $J$ & J & $\mathrm{N}$ & $J$ & J & $J$ & $\mathrm{~N}$ \\
\hline Mexiko & $\mathrm{N}$ & $J$ & J & $\mathrm{N}$ & & & & & $\mathrm{J} / \mathrm{N}$ & J & $J$ & $\mathrm{~N}$ \\
\hline Niederlande ${ }^{1}$ & J & $J$ & $J$ & $\mathrm{~N}$ & a & a & a & a & J & J & $J$ & $\mathrm{~N}$ \\
\hline Neuseeland & $J$ & $\mathrm{~N}$ & $\mathrm{~N}$ & $\mathrm{~N}$ & & & & & & & & \\
\hline Norwegen & $\mathrm{N}$ & $J$ & $J$ & $\mathrm{~N}$ & a & a & a & a & $\mathrm{N}$ & J & $J$ & $\mathrm{~N}$ \\
\hline Polen & $\mathrm{J} / \mathrm{N}$ & $\mathrm{N}$ & $\mathrm{N}$ & $\mathrm{N}$ & a & a & a & a & $J$ & $\mathrm{~N}$ & $\mathrm{~N}$ & $\mathrm{~N}$ \\
\hline Portugal & $\mathrm{m}$ & $\mathrm{m}$ & $\mathrm{m}$ & $\mathrm{m}$ & $\mathrm{m}$ & $\mathrm{m}$ & $\mathrm{m}$ & $\mathrm{m}$ & $\mathrm{m}$ & $\mathrm{m}$ & $\mathrm{m}$ & $\mathrm{m}$ \\
\hline Slowakische Rep. ${ }^{1}$ & $J$ & $\mathrm{~N}$ & J & $\mathrm{N}$ & & & & & $J$ & $\mathrm{~N}$ & $J$ & $\mathrm{~N}$ \\
\hline Spanien & $\mathrm{N}$ & $J$ & J & $\mathrm{N}$ & & & & & $\mathrm{J} / \mathrm{N}$ & $\mathrm{J} / \mathrm{N}$ & $\mathrm{J} / \mathrm{N}$ & $\mathrm{N}$ \\
\hline Schweden & $\mathrm{J} / \mathrm{N}$ & $J / N$ & $\mathrm{~N}$ & $J / N$ & & & & & & & & \\
\hline Schweiz & J & $J$ & J & & $J$ & $J$ & J & & J & & $J$ & \\
\hline Türkei $^{1}$ & $\mathrm{~N}$ & $\mathrm{~N}$ & J & $\mathrm{N}$ & $\mathrm{N}$ & $\mathrm{N}$ & J & $\mathrm{N}$ & $\mathrm{N}$ & $\mathrm{N}$ & $J$ & $\mathrm{~N}$ \\
\hline Ver. Königreich ${ }^{1}$ & N4 & $J$ & $\mathrm{~N}$ & $\mathrm{~N}$ & a & a & a & a & & J & $\mathrm{N}$ & $\mathrm{N}$ \\
\hline Vereinigte Staaten ${ }^{1}$ & $\begin{array}{l}20 \text { Bundes- } \\
\text { staaten Ja; } \\
\text { 30 Nein }\end{array}$ & $\begin{array}{l}\text { Einige } \\
\text { Bundes- } \\
\text { staaten }\end{array}$ & $\begin{array}{l}\text { Einige } \\
\text { Bundes- } \\
\text { staaten }\end{array}$ & $J^{5}$ & a & a & a & a & a & a & a & a \\
\hline
\end{tabular}

Hinweis: $J=J a ; N=$ Nein .

1. Weitere Hinweise zu Abschlussanforderungen s. Anhang 3 unter www.oecd.org/edu/eag2004. 2. Die Abschlussanforderungen für Bildungsgänge ISCED 3A unterscheiden sich je nach Bundesstaat und Territorium. Die in dieser Tabelle gemachten Angaben sind eine verallgemeinernde Darstellung der verschiedenen Anforderungen. 3. Nur bei allgemeinbildenden Bildungsgängen. 4. Normalerweise gibt es keine Abschlussprüfung, obwohl es einige ISCED 3A Bildungsgänge geben kann, die so abgeschlossen werden. 5. Fast alle Bundesstaaten legen eine bestimmte Anzahl von, Carnegie Credits' fest (die durch einen zweisemestrigen Kurs in bestimmten Fächern erworben werden, die je nach Bundesstaat unterschiedlich sind).

Quelle: $O E C D$. 


\section{Statistische Bezugsdaten}



Tabelle X2.1

Überblick über das wirtschaftliche Umfeld anhand von grundlegenden Kennzahlen

(Referenzzeitraum: Kalenderjahr 2001, zu konstanten Preisen von 2001)

\begin{tabular}{|c|c|c|c|}
\hline & $\begin{array}{l}\text { Öffentliche Gesamtausgaben } \\
\text { als Prozentsatz des BIP }\end{array}$ & $\begin{array}{l}\text { BIP pro Kopf (in US-Dollar, } \\
\text { kaufkraftbereinigt) }\end{array}$ & BIP-Deflator $(1995=100)$ \\
\hline \multicolumn{4}{|l|}{ OECD-Länder } \\
\hline Australien & 34,9 & 26685 & 113,10 \\
\hline Österreich & 52,2 & 28372 & 107,08 \\
\hline Belgien & 49,5 & 27096 & 109,03 \\
\hline Kanada & 40,3 & 29290 & 109,34 \\
\hline Tschechische Republik & 46,3 & 14861 & 143,81 \\
\hline Dänemark & 55,3 & 29223 & 113,28 \\
\hline Finnland & 49,2 & 26344 & 111,37 \\
\hline Frankreich ${ }^{2}$ & 50,9 & 26818 & 106,85 \\
\hline Deutschland & 47,0 & 25453 & 104,41 \\
\hline Griechenland & $\mathrm{m}$ & 17020 & 132,97 \\
\hline Ungarn & $\mathrm{m}$ & 13043 & 209,13 \\
\hline Island & 45,0 & 28968 & 127,71 \\
\hline Italien & 48,3 & 25377 & 117,94 \\
\hline Japan & 34,0 & 26636 & 94,53 \\
\hline Korea & 27,5 & 15916 & 111,79 \\
\hline Luxemburg & 39,1 & 49229 & 116,74 \\
\hline Mexiko & 21,1 & 9148 & 244,10 \\
\hline Niederlande & 46,6 & 28711 & 116,77 \\
\hline Neuseeland $^{1}$ & $\mathrm{~m}$ & 21230 & 112,16 \\
\hline Norwegen & $\mathrm{m}$ & 36587 & 133,87 \\
\hline Polen & $\mathrm{m}$ & 10360 & 180,43 \\
\hline Portugal & 46,2 & 17912 & 123,62 \\
\hline Slowakische Republik & 54,1 & 11323 & 139,86 \\
\hline Spanien & 39,2 & 21347 & 120,10 \\
\hline Schweden & 57,2 & 26902 & 107,77 \\
\hline Schweiz & $\mathrm{m}$ & 30036 & 103,47 \\
\hline Vereinigte Staaten & 32,7 & 35179 & 111,61 \\
\hline \multicolumn{4}{|l|}{ OECD-Partnerländer } \\
\hline Argentinien & 35,7 & 11703 & \\
\hline Brasilien $^{3}$ & 36,3 & 7265 & \\
\hline Chile $^{4}$ & 23,7 & 9681 & \\
\hline Indien & 31,7 & 2822 & \\
\hline Indonesien & 13,2 & 2881 & \\
\hline Israel & 51,8 & 21128 & \\
\hline Jamaika & 51,8 & 3696 & \\
\hline Jordanien & 33,9 & 3761 & \\
\hline Malaysia & 39,5 & 8674 & \\
\hline Paraguay & 46,6 & 5214 & \\
\hline Peru & 12,4 & 4602 & \\
\hline Philippinen & 23,0 & 3831 & \\
\hline Russische Föderation & 26,8 & 7140 & \\
\hline Thailand & 17,8 & 6036 & \\
\hline Tunesien & 37,6 & 6404 & \\
\hline Uruguay & 24,6 & 8397 & \\
\hline Simbabwe $^{4}$ & $\mathrm{~m}$ & 4430 & \\
\hline
\end{tabular}

1. Neuseeland: BIP pro Kopf, öffentliche Gesamtausgaben als Prozentsatz des BIP und BIP-Deflator für das Haushaltsjahr berechnet. 2. Ohne Übersee-Departments (DOM). 3. Referenzjahr 2000. 4. Referenzjahr: 2002.

Quelle: OECD. Quelle für OECD-Partnerländer: World Bank Datenbank „World Development Indicators“. 
Tabelle X2.2

Grundlegende statistische Bezugsdaten (Referenzzeitraum: Kalenderjahr 2001, zu konstanten Preisen von 2001) 1

\begin{tabular}{|c|c|c|c|c|c|}
\hline & $\begin{array}{l}\text { Bruttoinlandsprodukt } \\
\text { (in Millionen, } \\
\text { Landeswährung) }\end{array}$ & $\begin{array}{c}\text { Bruttoinladsprodukt (an- } \\
\text { gepasst an das nationale } \\
\text { Haushaltsjahr) }\end{array}$ & $\begin{array}{l}\text { Öffentliche Gesamt- } \\
\text { ausgaben (in Millionen, } \\
\text { Landeswährung) }\end{array}$ & $\begin{array}{l}\text { Gesamtbevölkerung, } \\
\text { in Tausend (Schätzung } \\
\text { zur Mitte des Jahres) }\end{array}$ & $\begin{array}{c}\text { Kaufkraftparitäten } \\
(\text { KKP) }\end{array}$ \\
\hline \multicolumn{6}{|l|}{ OECD-Länder } \\
\hline Australien $^{2}$ & 714370 & 692745 & 242019 & 19413 & 1,33725 \\
\hline Österreich & 212511 & & 110841 & 8032 & 0,932571 \\
\hline Belgien & 253800 & & 125640 & 10281 & 0,911059 \\
\hline Kanada & 1091424 & 1067900 & 439645 & 31111 & 1,197749 \\
\hline Tschechische Republik & 2175238 & & 1007743 & 10219 & 14,323983 \\
\hline Dänemark & 1325512 & & 732632 & 5357 & 8,467164 \\
\hline Finnland & 135228 & & 66545 & 5188 & 0,989448 \\
\hline Frankreich ${ }^{4}$ & 1460806 & & 744050 & 59703 & 0,912351 \\
\hline Deutschland & 2073700 & & 975465 & 82350 & 0,989346 \\
\hline Griechenland & 131026 & & $\mathrm{~m}$ & 10938 & 0,703823 \\
\hline Ungarn & 14849623 & & $\mathrm{~m}$ & 10188 & 111,758778 \\
\hline Island & 743563 & & 327192 & 285 & 90,04885 \\
\hline Irland & 114743 & & 38515 & 3853 & 0,99872 \\
\hline Italien & 1220147 & & 588755 & 57927 & 0,830039 \\
\hline $\operatorname{Japan}^{5}$ & 507455500 & 511896475 & 172726900 & 127291 & 149,671323 \\
\hline Korea & 551557522 & & 151565446 & 47343 & 731,989038 \\
\hline Luxemburg & 21987 & & 8604 & 442 & 1,011608 \\
\hline Mexiko & 5828591 & & 1232647 & 99109 & 6,428364 \\
\hline Niederlande & 429127 & & 200033 & 16043 & 0,931642 \\
\hline Neuseeland & 122241 & & $\mathrm{~m}$ & 3912 & 1,471862 \\
\hline Norwegen & 1526601 & & $\mathrm{~m}$ & 4513 & 9,245684 \\
\hline Polen & 750786 & & $\mathrm{~m}$ & 38641 & 1,875379 \\
\hline Portugal & 123054 & & 56878 & 10299 & 0,66704 \\
\hline Slowakische Republik & 1009839 & & 546022 & 5403 & 16,505804 \\
\hline Spanien & 653289 & & 256150 & 40266 & 0,760055 \\
\hline Schweden & 2266387 & & 1296116 & 8896 & 9,470012 \\
\hline Schweiz & 422811 & & $\mathrm{~m}$ & 7260 & 1,938927 \\
\hline Türkei & 178412438500 & & $\mathrm{~m}$ & 68610 & 430135,6343 \\
\hline Vereinigtes Königreich & 994037 & 961958 & 394616 & 58837 & 0,632409 \\
\hline $\begin{array}{l}\text { Vereinigte Staaten } \\
\text { OECD-Partnerländer }\end{array}$ & 10019700 & 9955300 & 3273700 & 284822 & 1 \\
\hline Argentinien & 268638 & & 96018 & 36260 & 0,633052 \\
\hline Brasilien $^{6}$ & 1086700 & & 394350 & 169799 & 0,880890 \\
\hline Chile $^{7}$ & 44197827 & & 10494139 & 15589 & 292,850000 \\
\hline Indien & 21354446 & & 6763044 & 996945 & 7,590000 \\
\hline Indonesien & 1490974140 & & 197030300 & 213537 & 2423,683891 \\
\hline Israel & 495390 & & 256640 & 6509 & \\
\hline Jamaika & 358036 & & 185437 & 2608 & 37,147777 \\
\hline Jordanien & 6260 & & 2123 & 5182 & 0,321175 \\
\hline Malaysia & 334589 & & 132023 & 24013 & 1,606316 \\
\hline Paraguay & 29586000 & & 13790321 & 5633 & 1007,180083 \\
\hline Peru & 189532 & & 23588 & 26156 & 1,574713 \\
\hline Philippinen & 3642820 & & 838888 & 78591 & 12,099934 \\
\hline Russische Föderation & 9040821 & & 2419400 & 143954 & 8,795869 \\
\hline Thailand & 5100677 & & 910000 & 64889 & 13,022094 \\
\hline Tunesien & 28759 & & 10820 & 9660 & 0,464892 \\
\hline Uruguay & 248619 & & 61044 & 3361 & 8,809891 \\
\hline Simbabwe $^{7}$ & 976895 & & $\mathrm{~m}$ & 13165 & 16,750000 \\
\hline
\end{tabular}

1. Angaben zu BIP, KKP und öffentlichen Gesamtausgaben für Länder in der Euro-Zone in Euro angegeben. 2. In Australien BIP und in Neuseeland: BIP und öffentliche Gesamtausgaben für das Haushaltsjahr berechnet. 3. Bei Ländern, für die das BIP nicht für denselben Referenzzeitraum wie die Daten zu den Bildungsfinanzen angegeben wurde, wurde das BIP als wt-1 (BIPt-1) + wt (BIPt) berechnet, mit wt and wt-1 als Gewichtung für die entsprechenden Anteile der beiden Referenzzeiträume für das BIP innerhalb des Finanzjahrs für Bildung. In Kapitel B wurden für Australien, Japan, Kanada, das Vereinigtes Königreich und die Vereinigten Staaten Anpassungen vorgenommen. 4. Ohne Übersee-Departments (DOM). 5. Öffentliche Gesamtausgaben an das Haushaltsjahr angepasst. 6. Referenzjahr 20oo. 7. Referenzjahr 2002.

Quelle: OECD. Quelle OECD-Partnerländer: World Bank Datenbank „World Development Indicators“. 
Tabelle X2.3

Grundlegende statistische Bezugsdaten (Referenzzeitraum: Kalenderjahr 1995, zu konstanten Preisen von 1995) ${ }^{1}$

\begin{tabular}{|c|c|c|c|c|c|c|}
\hline OECD-Länder & \begin{tabular}{|} 
Bruttoinlandsprodukt \\
(in Millionen, \\
Landeswährung)
\end{tabular} & $\begin{array}{l}\text { Bruttoinladsprodukt } \\
\text { (angepasst an } \\
\text { das nationale } \\
\text { Haushaltsjahr) }\end{array}$ & $\begin{array}{l}\text { Bruttoinlandsprodukt } \\
\text { (zu konstanten } \\
\text { Preisen von 2001, } \\
\text { Baisjahr }=1995 \text { ) }\end{array}$ & $\begin{array}{l}\text { Öffentliche } \\
\text { Gesamtausgaben } \\
\text { (in Millionen, } \\
\text { Landeswährung) }\end{array}$ & $\begin{array}{c}\text { Gesamtbevölkerung, } \\
\text { in Tausend } \\
\text { (Schätzung zur Mitte } \\
\text { des Jahres) }\end{array}$ & $\begin{array}{c}\text { Kaufkraftparitäten } \\
\text { (KKP) }\end{array}$ \\
\hline Australien ${ }^{2}$ & 502828 & 487088 & 620073 & 184372 & 18072 & 1,31766 \\
\hline Österreich & 172287 & & 198464 & 98676 & 7948 & 0,99802 \\
\hline Belgien & 202174 & & 233216 & 106832 & 10137 & 0,91083 \\
\hline Kanada & 798300 & 768883 & 998170 & 381542 & 29354 & 1,18256 \\
\hline Tschechische Rep. & 1381049 & & 1512626 & 783678 & 10327 & 10,81133 \\
\hline Dänemark & 1009756 & & 1169943 & 608853 & 5230 & 8,41666 \\
\hline Finnland & 95262 & & 121419 & 56546 & 5108 & 0,98583 \\
\hline Frankreich ${ }^{4}$ & 1168124 & & 1367115 & 625707 & 58020 & 0,98485 \\
\hline Deutschland & 1801300 & & 1986200 & 858030 & 81661 & 1,03058 \\
\hline Griechenland & 79927 & & 98466 & 37026 & 10635 & 0,59599 \\
\hline Ungarn & 5614042 & & 7100585 & 2327299 & 10329 & 60,55234 \\
\hline Island & 452139 & & 582217 & 186845 & 267 & 75,17 \\
\hline Irland & 52641 & & 89320 & 21876 & 3601 & 0,80588 \\
\hline Italien & 923052 & & 1034549 & 492878 & 57301 & 0,80067 \\
\hline Japan $^{5}$ & 498872300 & 493620575 & 536800700 & 159540300 & 125570 & 169,94188 \\
\hline Korea & 377349800 & & 493380314 & 80035900 & 45093 & 730,50462 \\
\hline Luxemburg & 13214 & & 18835 & 6016 & 410 & 0,96362 \\
\hline Mexiko & 1837019 & & 2387804 & 380924 & 90164 & 2,95733 \\
\hline Niederlande & 302233 & & 367499 & 170327 & 15460 & 0,92001 \\
\hline Neuseeland ${ }^{2}$ & 92679 & & 108992 & 36441 & 3707 & 1,46721 \\
\hline Norwegen & 937445 & & 1140349 & 457033 & 4358 & 9,14417 \\
\hline Polen & 308104 & & 399910 & 147561 & 38588 & 1,13714 \\
\hline Portugal & 80827 & & 99540 & 36403 & 10027 & 0,59394 \\
\hline Slowakische Republik & 568923 & & 707348 & 324312 & 5364 & 11,8966 \\
\hline Spanien & 437787 & & 542569 & 192633 & 39223 & 0,7337 \\
\hline Schweden & 1772021 & & 2103223 & 1201025 & 8827 & 9,7281 \\
\hline Schweiz & 363329 & & 400972 & 141545 & 7041 & 2,01088 \\
\hline Türkei & 7762456069 & & 8713855000 & $\mathrm{~m}$ & 61646 & 22334,21 \\
\hline Ver. Königreich & 719176 & 690789 & 847022 & 317455 & 57958 & 0,65391 \\
\hline Vereinigte Staaten & 7338400 & 7252125 & 8977800 & 2516200 & 266327 & 1 \\
\hline
\end{tabular}

1. Angaben zu BIP, KKP und öffentlichen Gesamtausgaben für Länder in der Euro-Zone in Euro angegeben. 2. BIP in Australien sowie BIP und öffentliche Gesamtausgaben in Neuseeland für das Haushaltsjahr berechnet. 3. Bei Ländern, für die das BIP nicht für denselben Referenzzeitraum wie die Daten zu den Bildungsfinanzen agegeben wurde, wurde das BIP als wt-1 (BIPt-1) + wt (BIPt) berechnet, mit wt and wt-1 als Gewichtung für die entsprechenden Anteile der beiden Referenzzeiträume für das BIP innerhalb des Finanzjahrs für Bildung. In Kapitel B wurden für Australien, Japan, Kanada, das Vereinigtes Königreich und die Vereinigten Staaten Anpassungen vorgenommen. 4. Ohne Übersee-Departments. 5. Öffentliche Gesamtausgaben an das Haushaltsjahr angepasst.

Quelle: $O E C D$. 
Tabelle X2.4a

Statistische Bezugsdaten zur Berechnung der Lehrergehälter, nach Bildungsbereich (1996, 2002)

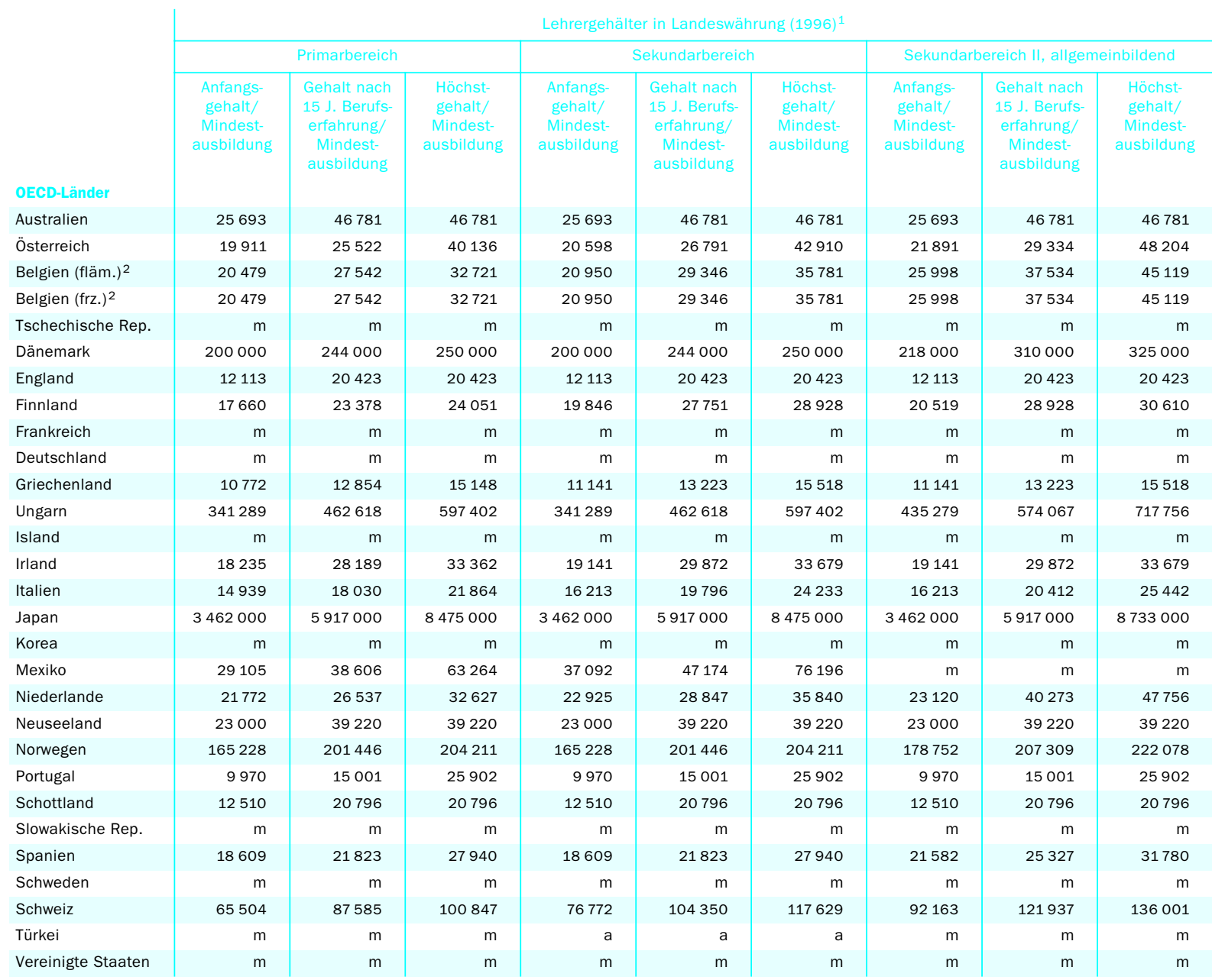

1. Angaben zu den Lehrergehältern in Ländern der aktuellen Euro-Zone in Euro. 2. Angaben zu den Lehrergehältern von 1996 beziehen sich auf ganz Belgien.

Quelle: OECD. 
Tabelle X2.4a (Forts.)

Statistische Bezugsdaten zur Berechnung der Lehrergehälter, nach Bildungsbereich $(1996,2002)^{1}$

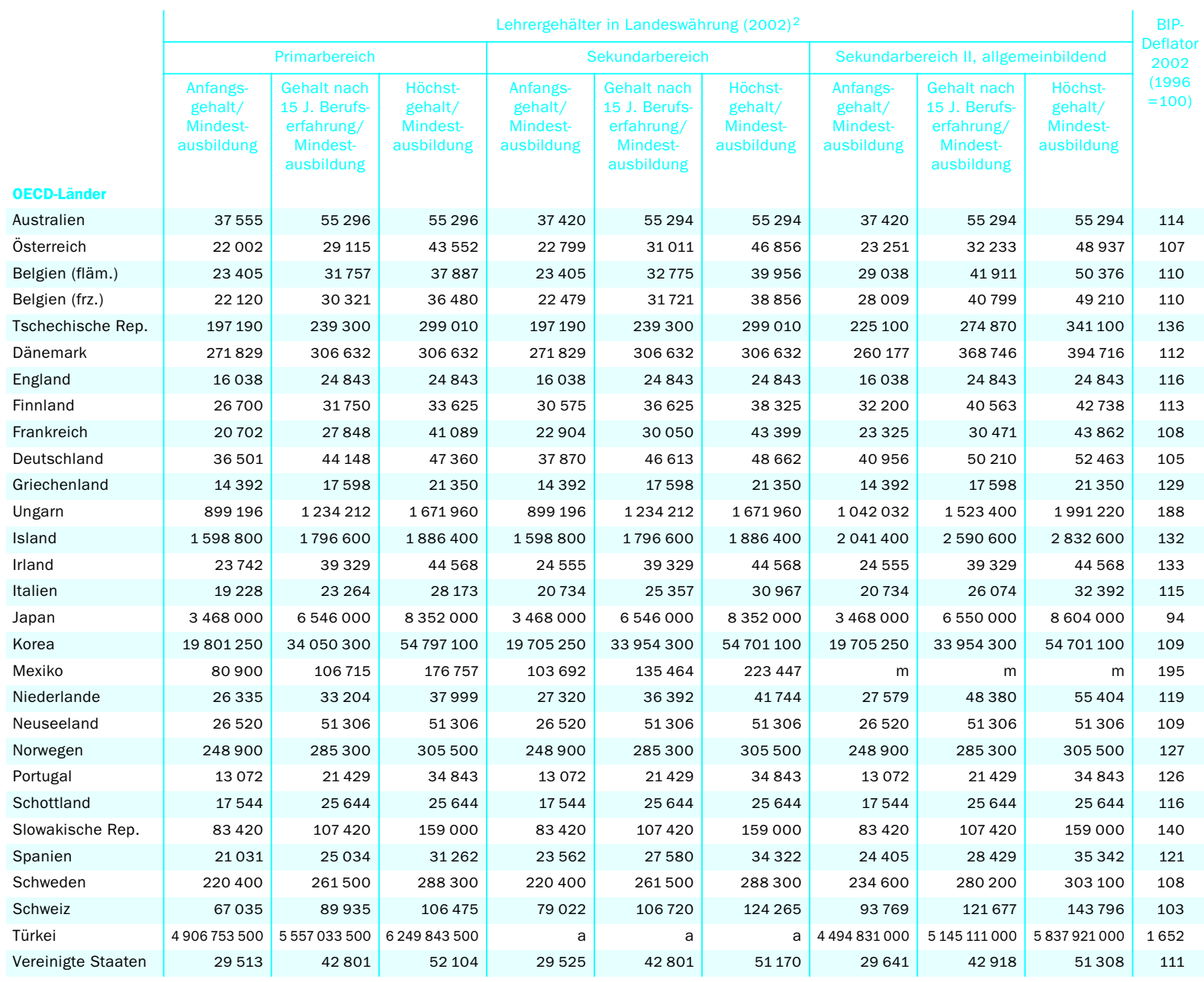

1. Für die Berechnung der Lehrergehälter in US-Dollar, kaufkraftbereinigt, wie in Indikator D3 aufgeführt, wurden die Lehrergehälter aus der Landeswährung mittels KKP vom Januar 2002 in US-Dollar umgerechnet und gegebenenfalls inflationsbereinigt. 2. Angaben zu den Lehrergehältern von Ländern der aktuellen Euro-Zone in Euro. Quelle: OECD. 
Tabelle X2.4b

Statistische Bezugsdaten zur Berechnung der Lehrergehälter $(1996,2002)$

\begin{tabular}{|c|c|c|c|c|c|c|c|c|}
\hline OECD-Länder & $\begin{array}{c}\text { Kaufkraft- } \\
\text { paritäten (KKP) } \\
(2001)^{1}\end{array}$ & $\begin{array}{c}\text { Kaufkraft- } \\
\text { paritäten (KKP) } \\
(2002)^{1}\end{array}$ & $\begin{array}{c}\text { Kaufkraft- } \\
\text { paritäten (KKP) } \\
(\text { Januar 2002) }\end{array}$ & $\begin{array}{l}\text { Bruttoinlands- } \\
\text { produkt } \\
\text { (in Millionen, } \\
\text { Landeswährung, } \\
\text { Kalenderjahr } \\
\text { 2002)1 }\end{array}$ & $\begin{array}{c}\text { Gesamt- } \\
\text { bevölkerung } \\
\text { in Tausend } \\
\text { (Kalenderjahr } \\
\text { 2002) }\end{array}$ & $\begin{array}{l}\text { BIP pro Kopf } \\
\text { (in US-Dollar, } \\
\text { kaufkraft- } \\
\text { bereinigt, } \\
\text { Kalenderjahr } \\
\text { 2002)2 }\end{array}$ & $\begin{array}{l}\text { Referenzjahr } \\
\text { für die } \\
\text { Gehaltsdaten } \\
2002\end{array}$ & $\begin{array}{c}\text { Inflations- } \\
\text { bedingte } \\
\text { Anpassungen } \\
(2001)\end{array}$ \\
\hline Australien & 1,34 & 1,36 & 1,35 & 752760 & 19752 & 28068 & 30. Juni 2002 & 0,99 \\
\hline Österreich & 0,93 & 0,94 & 0,94 & 218333 & 8053 & 28872 & 2002 & 1,00 \\
\hline Belgien (fläm.) ${ }^{3}$ & 0,91 & 0,91 & 0,91 & 260011 & 10330 & 27716 & 1. Januar 2002 & 1,00 \\
\hline Belgien (frz.) ${ }^{3}$ & 0,91 & 0,91 & 0,91 & 260011 & 10330 & 27716 & $2001 / 2002$ & 1,00 \\
\hline Tschechische Rep. & 14,32 & 14,77 & 14,54 & 2275609 & 10205 & 15102 & $2001 / 2002$ & 1,00 \\
\hline Dänemark & 8,47 & 8,66 & 8,56 & 1360710 & 5376 & 29231 & 2002 & 1,00 \\
\hline England ${ }^{4}$ & 0,63 & 0,63 & 0,63 & 1043945 & 59207 & 27976 & $2001 / 2002$ & 1,00 \\
\hline Finnland & 0,99 & 1,01 & 1,00 & 139716 & 5201 & 26478 & 1. Oktober 2002 & 1,00 \\
\hline Frankreich & 0,91 & 0,91 & 0,91 & 1520804 & 61230 & 27217 & $2001 / 2002$ & 1,00 \\
\hline Deutschland & 0,99 & 0,99 & 0,99 & 2110400 & 82482 & 25917 & $2001 / 2002$ & 1,00 \\
\hline Griechenland & 0,70 & 0,70 & 0,70 & 141354 & 10950 & 18439 & 2001 & 1,02 \\
\hline Ungarn & 111,76 & 118,63 & 115,19 & 16743688 & 10159 & 13894 & 1. Mai 2002 & 0,97 \\
\hline Island & 90,05 & 95,39 & 92,72 & 778960 & 288 & 28355 & 1. Januar 2002 & 1,00 \\
\hline Irland & 1,00 & 1,01 & 1,01 & 129344 & 3909 & 32646 & 2002 & 0,97 \\
\hline Italien & 0,83 & 0,85 & 0,84 & 1258349 & 58028 & 25568 & 2002 & 1,00 \\
\hline Japan & 149,67 & 145,56 & 147,62 & 499986500 & 127435 & 26954 & $2001 / 2002$ & 1,00 \\
\hline Korea & 731,99 & 735,69 & 733,84 & 596381161 & 47640 & 17016 & 2002 & 1,00 \\
\hline Mexiko & 6,43 & 6,65 & 6,54 & 6151219 & 100443 & 9215 & $2001 / 2002$ & 1,00 \\
\hline Niederlande & 0,93 & 0,95 & 0,94 & 444649 & 16148 & 29009 & 1. Januar 2002 & 1,00 \\
\hline Neuseeland & 1,47 & 1,46 & 1,46 & 126195 & 3976 & 21783 & 2002 & 1,00 \\
\hline Norwegen & 9,25 & 9,44 & 9,34 & 1520728 & 4539 & 35482 & 2002 & 1,00 \\
\hline Portugal & 0,67 & 0,68 & 0,67 & 129280 & 10374 & 18394 & $2001 / 2002$ & 1,00 \\
\hline Schottland ${ }^{4}$ & 0,63 & 0,63 & 0,63 & 1043945 & 59207 & 27976 & $2001 / 2002$ & 1,00 \\
\hline Slowakische Rep. & 16,51 & 16,63 & 16,57 & 1096384 & 5379 & 12255 & 2001 & 1,02 \\
\hline Spanien & 0,76 & 0,77 & 0,76 & 696208 & 40546 & 22406 & 2001 & 1,02 \\
\hline Schweden & 9,47 & 9,65 & 9,56 & 2342554 & 8925 & 27209 & 2001 & 1,00 \\
\hline Schweiz & 1,94 & 1,91 & 1,93 & 427787 & 7348 & 30455 & 2002 & 1,00 \\
\hline Türkei & 430136 & 618281 & 524208 & 276002987851 & 69666 & 6408 & 2001 & 1,20 \\
\hline Vereinigte Staaten & 1,00 & 1,00 & 1,00 & 10383100 & 287456 & 36121 & $2001 / 2002$ & 1,00 \\
\hline
\end{tabular}

1. Angaben zu KKP und BIP für Länder in der aktuellen Euro-Zone in Euro. 2. BIP pro Kopf in Landeswährung (2002) wurde aus der Gesamtbevölkerung (2002) und dem Gesamt-BIP (2002) berechnet und mittels KKP (2002) in US-Dollar umgerechnet. Diese Angaben liegen in dieser Tabelle vor. 3. Angaben zum Bruttoinlandsprodukt und der Gesamtbevölkerung beziehen sich auf ganz Belgien. 4. Angaben zum Bruttoinlandsprodukt und der Gesamtbevölkerung beziehen sich auf das Vereinigte Köngreich.

Quelle: $O E C D$. 


\section{Allgemeine Hinweise}

\section{Definitionen}

Das Bruttoinlandsprodukt (BIP) entspricht der Wertschöpfung der von inländischen Herstellern produzierten Waren und Dienstleistungen, einschließlich Handel und Transport, abzüglich des Werts für den Zwischenverbrauch des Käufers plus Importzölle. Das BIP wird in der jeweiligen Landeswährung (in Millionen) angegeben. Für Länder, die diese Informationen für ein Bezugsjahr angeben, das vom Kalenderjahr abweicht (z. B. Australien und Neuseeland), werden Anpassungen durch lineareGewichtung des jeweiligen BIP zwischen zwei aufeinanderfolgenden nationalen Bezugsjahren entsprechend dem Kalenderjahr vorgenommen.

Der BIP-Deflator wird berechnet durch Division des BIP zu Marktpreisen durch das BIP zu konstanten Preisen. Er liefert einen Hinweis auf das relative Preisniveau in einem Land. Die Daten basieren auf dem Jahr 1995.

Das BIP pro Kopf ist das Bruttoinlandsprodukt (in US-Dollar, kaufkraftbereinigt) dividiert durch die Bevölkerungszahl.

Die Kaufkraftparitäts-Umrechnungskurse (KKP) sind die Währungsumrechnungskurse, die die Kaufkraft verschiedener Währungen ausgleichen. Dies bedeutet, dass man mit einer bestimmten Geldsumme, wenn sie anhand der KKP-Kurse in die verschiedenen Währungen umgerechnet wird, in allen Ländern den gleichen Waren und Dienstleistungskorb erwerben kann. Daher sind es die KKP-Umrechnungskurse, die die Preisniveau-Unterschiede zwischen den Ländern aufheben. Werden Ausgaben bezogen auf das BIP für verschiedene Länder mit Hilfe der KKP in eine einheitliche Währung umgerechnet, werden sie praktisch anhand der gleichen internationalen Preise ausgedrückt, so dass Vergleiche zwischen den Ländern nur die Unterschiede im Volumen der gekauften Waren und Dienstleistungen widerspiegeln.
Die öffentlichen Gesamtausgaben, wie bei der Berechnung der Indikatoren verwendet, entsprechen den nicht rückzahlbaren laufenden Ausgaben und Investitionsausgaben auf allen Ebenen des Staates. Die laufenden Ausgaben umfassen die konsumtiven Ausgaben (z. B. Arbeitsentgelte für Mitarbeiter, Verbrauch von Vorprodukten und -dienstleistungen, Verbrauch von Sachvermögen und Militärausgaben), geleistete Besitzeinkommen, Subventionen und andere geleistete Transferzahlungen (z.B. Sozialversicherungen, Sozialhilfe, Renten und sonstige Wohlfahrtsleistungen). Investitionsausgaben sind Ausgaben zum Erwerb und/oder der Wertsteigerung von Gütern des Anlagevermögens, Grundstücken, immateriellen Vermögensgegenständen, Staatsanleihen und nicht-militärischen Sachvermögen und Ausgaben zur Finanzierung von Nettokapitaltransfers.

\section{Quellen}

Die Ausgabe des Jahres 2004 der National Accounts of OECD countries: Main Aggregates, Volume I

Der theoretische Rahmen der OECD National Accounts wurde viele Jahre von der UN-Publikation A System of National Accounts vorgegeben, die 1968 erschien. Im Jahr 1993 erschien eine überarbeitete Fassung (im Allgemeinen als SNA93 bezeichnet).

OECD Analytical Data Base, Januar 2004. 



\section{Quellen, Methoden und technische Hinweise}

Anhang 3 zu Quellen und Methoden

liegt nur in elektronischer Form vor.

Er kann eingesehen werden unter

www. oecd.org/edu/eag 2004. 

Glossar 
Abbruchquote: Abbruchquoten werden definiert als der Anteil der Schüler bzw. Studierenden, die den jeweiligen Bildungsbereich ohne einen ersten $\mathrm{Ab}$ schluss verlassen. Siehe auch Erfolgsquoten.

Abschluss: Der Begriff Abschluss wird von den Ländern nicht einheitlich definiert. In manchen Ländern erhält man einen Abschluss als Folge einer oder mehrerer bestandener Prüfungen, in anderen wird der Abschluss nach Ableistung einer vorgeschriebenen Anzahl von Unterrichtsstunden erreicht (auch wenn der Abschluss eines Teils oder aller Unterrichtsstunden auch Prüfungen erfordern kann). Ein Abschluss sollte den Nachweis durch den Schüler/Studierenden über die Kenntnisse und Fähigkeiten sowie das Wissen, wie sie von jemandem auf dem Bildungsstand des abgeschlossenen Bildungsgangs erwartet werden, beinhalten. In jedem Fall sollte ein erfolgreicher Abschluss in einem Zertifikat resultieren, das innerhalb des Bildungssystems und auf dem Arbeitsmarkt anerkannt ist. Siehe auch Absolventen, Brutto-Abschlussquoten, Netto-Abschlussquoten. und Anzahl der Absolventen ohne Doppelzählungen

Abschlussalter: Das Abschlussalter sollte das Alter am Ende des letzten Schul-/Studienjahres des betreffenden Bildungsbereichs und -gangs sein, in dem der Schüler bzw. Studierende den Abschluss erlangt. Es sei darauf hingewiesen, dass in einigen Bildungsbereichen der Begriff ,Abschlussalter nicht wörtlich zu verstehen ist, und hier rein aus Definitionsgründen verwendet wird. Siehe auch Theoretisches Alter und Typisches Alter.

Abschlussquote: Siehe Brutto-Abschlussquoten und NettoAbschlussquoten.

Absolventen: Absolventen sind definiert als Schüler oder Studierende, die im Abschlussjahr eines Bildungsbereichs (z. B. des Sekundarbereich II) an einem Bildungsgang teilnahmen und diesen im Bezugsjahr, unabhängig von ihrem Alter, erfolgreich beendeten. Es gibt jedoch Ausnahmen (insbesondere im Hochschulbereich), wo durch die Verleihung eines Zertifikats ein Abschluss auch zuerkannt werden kann, ohne dass der Absolvent in dem betreffenden Bildungsgang eingeschrieben sein muss. Siehe auch Abschluss, Brutto-Abschlussquo- ten, Netto-Abschlussquoten und Anzahl der Absolventen ohne Doppelzählungen.

Allgemeinbildende Bildungsgänge: Allgemeinbildende Bildungsgänge sollen die Teilnehmer weder explizit auf bestimmte Berufsfelder noch auf den Eintritt in einen weiterführenden berufsbildenden oder technischen Bildungsgang vorbereiten. Weniger als 25 Prozent des Inhalts des Bildungsgangs sollten berufsbildend oder technisch sein. Siehe auch Berufsvorbereitende Bildungsgänge, Ausrichtung eines Bildungsgangs, Sekundarbereich II (ISCED 3) und Berufsbildende Bildungsgänge.

Anteil der Bevölkerung, die sich nicht im Arbeitsmarkt befindet: Der Anteil der Bevölkerung, die sich nicht im Arbeitsmarkt befindet, (ausgedrückt als Prozentsatz) ist gemäß der Definition in den Richtlinien des Internationalen Arbeitsamts (ILO) die Zahl derjenigen Personen, die sich nicht im Arbeitsmarkt befinden, dividiert durch die Gesamtzahl der Personen in der entsprechenden Bevölkerung.

Anzahl der Absolventen ohne Doppelzählungen: Die Anzahl der Absolventen ohne Doppelzählungen wird ermittelt, indem man die Anzahl der Absolventen abzieht, die in einem vorherigen Jahr einen anderen Bildungsgang im Sekundarbereich II abgeschlossen haben und/oder die während des Referenzzeitraums mehr als einen Abschluss in dem entsprechenden Bereich erworben haben. Es handelt sich daher um die Anzahl der Absolventen und nicht um die Anzahl der erteilten Abschlüsse. Siehe auch Absolventen, Abschluss, Netto-Abschlussquoten und Anzahl der Absolventen ohne Doppelzählungen.

Arbeitslose: Die Arbeitslosen sind gemäß den ILORichtlinien als Personen im Alter von mindestens I5 Jahren definiert, die ohne Arbeit und arbeitssuchend sind und derzeit dem Arbeitsmarkt zur Verfügung stehen, entsprechend der Definition in den OECD-Arbeitskräftestatistiken. Siehe auch Erwerbsstatus, Beschäftigte, Erwerbsbevölkerung, Erwerbsquote, Arbeitslosenquote.

Arbeitslosenanteil: Der Arbeitslosenanteil (ausgedrückt in Prozent) ist die Zahl der Arbeitslosen gemäß der Definition in den Richtlinien des Internationalen Arbeitsamts (ILO) dividiert durch die Ge- 
samtzahl der betreffenden Bevölkerung (Erwerbsund Nicht-Erwerbspersonen).

Arbeitslosenquote: Die Arbeitslosenquote ist gemäß der Definition in den Richtlinien des Internationalen Arbeitsamts (ILO) die Anzahl der Arbeitslosen dividiert durch die Anzahl der Erwerbspersonen, die Angabe erfolgt in Prozent. Siehe auch Beschäftigte, Erwerbsbevölkerung, Erwerbsquote und Arbeitslose.

Arbeitsproduktivität: BIP dividiert durch die Zahl der Beschäftigten.

Arbeitszeit in der Schule: Arbeitszeit in der Schule bezieht sich auf die Arbeitszeit, die Lehrer an der Schule verbringen müssen und enthält sowohl die Unterrichtszeit als auch Zeit für Tätigkeiten außerhalb des Unterrichts. Siehe auch Unterrichtstage, Zahl der Unterrichtsstunden, Unterrichtswochen und Arbeitszeit.

Arbeitszeit: Die Arbeitszeit bezieht sich auf die regulären Arbeitsstunden eines Vollzeit-Lehrers. Gemäß den formellen Vorschriften in einem bestimmten Land kann sich die Arbeitszeit beziehen auf ausschließlich für den Unterricht aufgewendete Zeit (und andere lehrplanbezogene Tätigkeiten für die Schüler, wie Haus- und Klassenarbeiten, außer jährlichen Prüfungen), oder auch auf Zeit, die in direktem Zusammenhang mit dem Unterricht steht, sowie Stunden, die anderen unterrichtsbezogenen Tätigkeiten gewidmet sind, z. B. Unterrichtsvorbereitung, Beratung der Schüler, Korrekturen von Haus- und Klassenarbeiten, Tätigkeiten zur beruflichen Weiterentwicklung, Besprechungen mit den Eltern, Lehrerkonferenzen und allgemeine schulische Aufgaben. Nicht enthalten sind vergütete Überstunden. Siehe auch Beschäftige im Bildungswesen, Vollzeitäquivalente Lehrer, Vollzeit-Lehrer, Unterrichtende Beschäftigte, Teilzeit-Lehrer, Zahlenmäßiges Schüler/Lehrkräfte-Verhältnis, Unterrichtstage, Lehrkräfte, Zahl der Unterrichtsstunden, Unterrichtswochen und Arbeitszeit in der Schule.

Ausbildungs-|Studienanfänger: Ausbildungs-/Studienanfänger in einem bestimmten Bildungsbereich sind Schüler/Studierende, die im Laufe des aktuellen Berichtszeitraums erstmalig einen beliebigen Bildungsgang beginnen, der $\mathrm{zu}$ einem aner- kannten Abschluss des betreffenden Bildungsbereichs führt, unabhängig davon, ob diese Schüler/Studierenden zu Beginn des Bildungsgangs oder in einem fortgeschrittenen Stadium einsteigen. Siehe auch Studienanfängerquoten.

Ausgaben für Bildungseinrichtungen: Die Ausgaben für Bildungseinrichtungen umfassen sowohl Ausgaben für unterrichterteilende Bildungseinrichtungen als auch für solche, die keinen Unterricht erteilen. Siehe auch Direkte Ausgaben für Bildungseinrichtungen, Unterrichterteilende Bildungseinrichtungen und Nicht-unterrichterteilende Bildungseinrichtungen.

Ausgaben für eigentliche Bildungsdienstleistungen: Die Ausgaben für eigentliche Bildungsdienstleistungen umfassen alle Ausgaben, die direkt mit Unterricht und Bildung in Zusammenhang stehen. Hierin sollten alle Ausgaben für Lehrer, Schulgebäude, Unterrichtsmaterial, Unterricht außerhalb der Schulen und die Verwaltung enthalten sein. Siehe auch Ausgaben für zusätzliche Dienstleistungen und Ausgaben für Forschung und Entwicklung (F\&-E-Ausgaben).

Ausgaben für Forschung und Entwicklung (F\&E-Ausgaben): Die Ausgaben für Forschung und Entwicklung (F\&E-Ausgaben) enthalten sämtliche Ausgaben für Forschung an Hochschulen und anderen tertiären Bildungseinrichtungen, unabhängig davon, ob diese aus dem allgemeinen Etat der Einrichtungen, über separate Zuschüsse oder über Verträge mit öffentlichen oder privaten Geldgebern finanziert werden. Dies umfasst alle Forschungsinstitute und Versuchsstationen, die Hochschuleinrichtungen direkt unterstehen, von diesen verwaltet werden oder mit ihnen assoziiert sind. Siehe auch Ausgaben für zusätzliche Dienstleistungen und Ausgaben für eigentliche Bildungsdienstleistungen.

Ausgaben für nicht unterrichtsbezogene Dienstleistungen im Bildungsbereich: Hierzu gehören z. B. öffentliche Ausgaben für zusätzliche Dienstleistungen wie Mahlzeiten, Transport zur Schule, Unterbringung auf dem Campus, private Mittel für zusätzliche Dienstleistungen, subventionierte private Ausgaben für den Lebensunterhalt der Schüler/Studierenden bzw. reduzierte Tarife im ÖPNV und private Ausgaben für den Lebensunterhalt der Schüler/Studierenden bzw. Transportkosten. Siehe auch Ausga- 
ben für zusätzliche Dienstleistungen, Ausgaben für eigentliche Bildungsdienstleistungen und Ausgaben für Forschung und Entwicklung (F\&E-Ausgaben).

Ausgaben für zusätzliche Dienstleistungen: ,Zusätzliche Dienstleistungen' sind Dienstleistungen, die von den Bildungseinrichtungen neben dem eigentlichen Bildungsauftrag erbracht werden. Die beiden Hauptkomponenten hierbei sind soziale Dienste für Schüler/Studierende und Dienstleistungen für die Allgemeinheit. Auf den ISCED-Stufen o-3 umfassen die sozialen Dienstleistungen die Bereitstellung von Mahlzeiten, die Gesundheitsdienste sowie Schultransporte. Im Tertiärbereich sind es Wohnheime, Mensen und Gesundheitsdienste. $\mathrm{Zu}$ den Dienstleistungen für die Allgemeinheit zählen Museen, Radio- und Fernsehsendungen, Sport-, Freizeit- und Kulturprogramme. Kinderbetreuungsangebote, sowohl tagsüber als auch abends, durch Einrichtungen des Elementar- und Primarbereichs zählen nicht zu den zusätzlichen Dienstleistungen. $\mathrm{Zu}$ den Einheiten, die zusätzliche Dienstleistungen erbringen, gehören separate Organisationen und Unternehmen, die bildungsbezogene Dienstleistungen wie Berufs- oder psychologische Beratung, Vermittlung von Stellen und Praktika, Transport von Schülern/Studierenden, sowie Unterkunft und Verpflegung für Schüler/Studierende anbieten. Siehe auch Ausgaben für eigentliche Bildungsdienstleistungen und Ausgaben für Forschung und Entwicklung (F\&-E-Ausgaben).

Ausgaben über die durchschnittliche Dauer tertiärer Studiengänge: Die erwarteten Ausgaben über die durchschnittliche Dauer tertiärer Studiengänge werden durch Multiplikation der aktuellen jährlichen Ausgaben mit der typischen Dauer solcher Studiengänge berechnet.

Ausländische Studierende: Studierende, die nicht Staatsangehörige des Landes sind, für das die Daten erhoben werden, gelten als ausländische Studierende. Diese Klassifikation ist zwar pragmatisch und operational, kann jedoch aufgrund der unterschiedlichen nationalen Politiken zur Einbürgerung von Migranten zu Inkonsistenzen führen. Hinzu kommt, dass einige Länder keine separaten Angaben über ausländische Studierende machen können, die eine ständige Aufenthaltsgenehmi- gung besitzen. Daher wird in den Ländern, in denen eine strenge Einbürgerungspolitik verfolgt wird und nicht zwischen ausländischen Studierenden mit und ohne ständige Aufenthaltsgenehmigung unterschieden werden kann, die Anzahl der ausländischen Studierenden im Vergleich zu den Ländern, in denen Einwanderer leichter die Staatsbürgerschaft erwerben können, möglicherweise zu hoch angesetzt.

Ausrichtung eines Bildungsgangs: Die Ausrichtung eines Bildungsgangs in der Definition der Internationalen Standard-Klassifikation des Bildungswesen (ISCED) bezieht sich darauf, inwieweit ein Bildungsgang speziell auf eine bestimmte Art von Berufen oder Tätigkeiten ausgerichtet ist und hier $\mathrm{zu}$ einer arbeitsmarktrelevanten Qualifikation führt. Bei der Ausrichtung von Bildungsgängen unterscheidet man Allgemeinbildende Bildungsgänge, Berufsvorbereitende Bildungsgänge und Berufsbildende Bildungsgänge. Siehe auch Allgemeinbildende Bildungsgänge, Berufsvorbereitende Bildungsgänge und Berufsbildende Bildungsgänge.

Berufliche Weiterentwicklung: bezieht sich auf jegliche Aktivität, die der Weiterentwicklung der Kenntnisse und Fähigkeiten, des Wissens, der Fachkenntnisse und anderer Charakteristika eines Einzelnen als Lehrer dienen. Dazu gehören individuelles Studium und Reflektion, die gemeinsame Entwicklung neuer Ansätze ebenso wie formal gestaltete Kurse.

Berufsbildende Bildungsgänge: Berufsbildende Bildungsgänge bereiten die Teilnehmer für die direkte Aufnahme einer Beschäftigung in bestimmten Berufsfeldern, ohne weitere berufliche Qualifizierung, vor. Der erfolgreiche Abschluss eines solchen Bildungsganges führt $\mathrm{zu}$ einer für den Arbeitsmarkt relevanten beruflichen Qualifikation. Bei einigen Indikatoren wird bei den berufsbildenden Bildungsgängen zwischen schulischen Ausbildungen und kombinierten schulischen und betrieblichen Ausbildungen unterschieden, und zwar auf der Grundlage des jeweiligen Ausbildungsumfangs in Bildungseinrichtungen und am Arbeitsplatz. Siehe auch Kombinierte schulische und betriebliche Ausbildungen, Allgemeinbildende Bildungsgänge, Berufsvorbereitende Bildungsgänge, Ausrichtung eines 
Bildungsgangs, Schulische Ausbildungsgänge und Sekundarbereich II (ISCED 3).

Berufsvorbereitende Bildungsgänge: Berufsvorbereitende Bildungsgänge sollen den Teilnehmern eher als Einführung in die Arbeitswelt dienen und sie für den späteren Eintritt in einen berufsbildenden oder technischen Bildungsgang vorbereiten. Durch den erfolgreichen Abschluss wird keine für den Arbeitsmarkt relevante berufliche oder technische Qualifikation erworben. Siehe auch Allgemeinbildende Bildungsgänge, Ausrichtung eines Bildungsgangs, Sekundarbereich II (ISCED 3) und Berufsbildende Bildungsgänge.

Beschäftigte im Bildungsbereich: Die Klassifikation beruht auf der vorrangigen/hauptsächlichen Funktion und gliedert die Beschäftigten nach vier Hauptfunktionen. Die Klassifikation unterscheidet: I. Unterrichtende Beschäftigte, 2. Professionelle Unterstützung für Schüler/Studierende, 3. Beschäftigte in Management/Qualitätskontrolle/Verwaltung und 4. Wartungs- und Betriebspersonal. Die unterrichtenden Beschäftigten werden weiter unterteilt in Lehrkräfte (Lehrer) und Hilfslehrkräfte. Für die Berechnung des zahlenmäßigen Schüler-/Lehrkräfte-Verhältnisses werden nur die Lehrkräfte berücksichtigt. Siehe auch Vollzeit-Lehrer, Vollzeitäquivalente Lehrer, Unterrichtende Beschäftigte, Wartungsund Betriebspersonal, Beschäftigte in Management/Qualitätskontrolle/Verwaltung, Teilzeit-Lehrer, Professionelle Unterstützung für Schüler/Studierende, Zahlenmäßiges Schüler/Lehrkräfte-Verhältnis und Zahl der Unterrichtsstunden.

Beschäftigte in Management/Qualitätskontrolle/Verwtung: Beschäftigte in Management/Qualitätskontrolle/ Verwaltung werden in vier Kategorien unterteilt: Beschäftige im Management einer Bildungseinrichtung sowie auf übergeordneter Ebene und Verwaltungspersonal in Bildungseinrichtungen und auf übergeordneter Ebene auf allen ISCEDStufen. Siehe auch Beschäftigte im Bildungsbereich, Unterrichtende Beschäftigte, Wartungs- und Betriebspersonal, Professionelle Unterstützung für Schüler/Studierende, Zahlenmäßiges Schüler/Lehrkräfte-Verhältnis und Lehrkräfte.

Beschäftigte: Beschäftigte sind gemäß der Definition in den Richtlinien des Internationalen Arbeits- amts (ILO) diejenigen Personen im Alter von mindestens I5 Jahren, die während der untersuchten Bezugswoche: mindestens eine Stunde für ein Gehalt (Arbeitnehmer) oder für einen Gewinn (Selbständige und unentgeltlich mithelfende Familienangehörige) arbeiten, oder einen Arbeitsplatz haben, aber vorübergehend nicht zur Arbeit gehen (aufgrund von Verletzung, Krankheit, Urlaub oder Ferien, Streik oder Aussperrung, Bildungs- oder Schulungsurlaub, Mutterschafts- oder Erziehungsurlaub, usw.) und eine formelle Bindung an ihren Arbeitsplatz haben. Siehe auch Erwerbsbevölkerung, Erwerbsquote, Arbeitslose, Arbeitslosenquote und Erwerbsstatus.

Beschäftigungsquote: Die Beschäftigungsquote für eine bestimmte Altersgruppe wird berechnet aus der Anzahl der Beschäftigen in der Bevölkerung gemäß der Definition in den Richtlinien des Internationalen Arbeitsamts (ILO) geteilt durch die Gesamtzahl der betreffenden Bevölkerung (Beschäftige, Arbeitslose und Nicht-Erwerbspersonen.)

Bildungsbeteiligung: Die Bildungsbeteiligung wird als Netto-Bildungsbeteiligung angegeben, die berechnet wird, indem die Zahl der Lernenden einer bestimmten Altersgruppe in allen Bildungsbereichen durch die Gesamtzahl der Personen in der entsprechenden Altersgruppe in der Bevölkerung dividiert wird.

Bildungseinrichtungen: Bildungseinrichtungen sind definiert als Einheiten, die Einzelpersonen Unterrichtsleistungen bzw. Einzelnen und anderen Einrichtungen bildungsbezogene Dienstleistungen anbieten. Siehe Private Bildungseinrichtungen und Öffentliche Bildungseinrichtungen.

Bildungserwartung (in Jahren): Die Bildungserwartung (in Jahren) ist die voraussichtliche durchschnittliche Dauer der formalen Bildung eines 5-jährigen Kindes während seines gesamten Lebens. Die Berechnung erfolgt durch Addition der Netto-Bildungsbeteiligung für jede einzelne Altersstufe $a b$ dem 5 . Lebensjahr. Siehe auch Bildungsbeteiligung.

Bildungsstand: Der Bildungsstand wird ausgedrückt durch den höchsten abgeschlossenen Bildungsbereich, wobei die Bildungsbereiche gemäß der In- 
ternationalen Standard-Klassifikation des Bildungswesens (ISCED) definiert sind. Siehe Internationale Standard-Klassifikation des Bildungswesens.

\section{BIP: Siehe Bruttoinlandsprodukt}

Brutto-Abschlussquoten: Die Brutto-Abschlussquoten beziehen sich auf die Gesamtzahl der Absolventen des spezifischen Bildungsbereichs (die jeden Alters sein können) dividiert durch die Bevölkerung im typischen Abschlussalter des Bildungsbereichs. In vielen Ländern ist es jedoch schwierig, ein typisches Abschlussalter anzugeben, weil die Altersverteilung der Absolventen sehr weit gestreut ist. Siehe auch Absolventen, Abschluss, Netto-Abschlussquoten und Anzahl der Absolventen ohne Doppelzählungen.

Bruttoinlandsprodukt (BIP): Das Bruttoinlandsprodukt bezieht sich auf den Herstellungswert der Bruttoproduktion inländischer Produzenten, einschließlich Vertrieb und Transport, abzüglich des Werts des Zwischenverbrauchs der Endverbraucher, zuzüglich Einfuhrzölle. Das BIP wird in der jeweiligen Landeswährung (in Millionen) angegeben. Für Länder, die diese Informationen für ein Bezugsjahr angeben, das vom Kalenderjahr abweicht (z.B. Australien und Neuseeland), werden Anpassungen durch lineare Gewichtung ihres BIP zwischen zwei aufeinanderfolgenden nationalen Bezugsjahren entsprechend dem Kalenderjahr vorgenommen. Die BIP-Daten sind Anhang 2 zu entnehmen. Weitere Informationen siehe Ausgabe des Jahres 2004 der National Accounts of the OECD countries.

Dauer von Bildungsgängen: Die Dauer von Bildungsgängen bezieht sich auf die festgelegte Anzahl von Jahren, in denen ein Bildungsgang abgeschlossen werden kann.

Direkte Ausgaben für Bildungseinrichtungen: Direkte Ausgaben für Bildungseinrichtungen umfassen den durch eine staatliche Stelle selbst vorgenommenen Erwerb von Bildungsressourcen zur Verwendung durch Bildungseinrichtungen (z. B. direkte Zahlungen von Gehältern an Lehrer durch ein zentrales oder regionales Bildungsministerium, direkte Zahlungen einer Kommune an Baufirmen zur Errichtung von Schulgebäuden, und die Beschaf- fung von Lehrbüchern durch eine zentrale oder regionale Behörde zur späteren Verteilung an lokale Behörden oder Schulen), sowie Zahlungen einer staatlichen Stelle an Bildungseinrichtungen, die für den Erwerb von Bildungsressourcen selbst verantwortlich sind (z.B. vom Staat bereitgestellte Haushaltsmittel oder pauschale Zuschüsse für eine Hochschule, die diese zur Besoldung des Personals und zum Erwerb sonstiger Ressourcen verwendet, staatliche Zuweisungen an finanziell autonome öffentliche Schulen, staatliche Subventionen an private Schulen sowie staatliche Zahlungen für vertraglich an private Unternehmen vergebene Forschungsaufträge im Bereich Bildung). $\mathrm{Zu}$ den direkten Ausgaben einer staatlichen Stelle zählen nicht die Bedienung von Schulden sowie die Schulund Studiengebühren, die diese Behörde von Schülern/Studierenden an öffentlichen Bildungseinrichtungen in ihrem Zuständigkeitsbereich erhält (oder von deren Familien), auch wenn die Schulund Studiengebühren zunächst einmal an die staatliche Stelle gezahlt werden, und nicht an die betreffende Bildungseinrichtung. Siehe auch Unterrichterteilende Bildungseinrichtungen und Nicht-unterrichterteilende Bildungseinrichtungen.

Dritte Internationale Mathematik- und Naturwissenschaften-Studie (TIMSS): Die von der IEA durchgeführte Dritte Internationale Mathematik- und Naturwissenschaften-Studie testete die mathematischen und naturwissenschaftlichen Leistungen von Viertund Achtklässlern in den Jahren I995, 1999 und 2003.

Duale Ausbildungsprogramme: Siehe Kombinierte schulische und betriebliche Ausbildungen.

Eigentliche Bildungsdienstleistungen: Siehe Ausgaben für eigentliche Bildungsdienstleistungen.

Elementarbereich (ISCED o): Der Elementarbereich ist definiert als erste Stufe organisierten Unterrichts, der sehr kleine Kinder an eine schulähnliche Umgebung heranführen soll, d.h. er soll eine Brücke zwischen der Atmosphäre im Elternhaus und der in der Schule herstellen. Programme auf ISCEDStufe o sollten in Einrichtungen oder Schulen stattfinden, die dazu geeignet sind, den Bedürfnissen von mindestens 3 Jahre alten Kindern hinsichtlich 
ihrer Erziehung und Bildung sowie Entwicklung gerecht zu werden, und über entsprechend ausgebildetes Personal verfügen, um für Kinder dieser Altersgruppe adäquate Angebote durchzuführen. Siehe auch Internationale Standard-Klassifikation des Bildungswesens (ISCED).

Entscheidungsart: Bei der Art der Entscheidung wird danach unterschieden, ob Entscheidungen autonom getroffen werden, nach Beratung mit anderen oder unabhängig, jedoch in einem von einer höheren Stelle vorgegebenen Rahmen.

Entscheidungsbereich: Die Themenbereiche, in denen Entscheidungen zu treffen sind, und zwar Unterrichtsorganisation, Personalangelegenheiten, strukturelle und Planungsangelegenheiten (Planung und Strukturierung von Unterricht und Lehrplänen) sowie die Zuweisung und Verwendung von Ressourcen.

Erfolgsquoten: Erfolgsquoten im Tertiärbereich werden definiert als Prozentsatz derjenigen Studienanfänger im jeweiligen Bildungsbereich, die diesen mit einem ersten Abschluss beenden. Die Erfolgsquote wird berechnet als das Verhältnis der Anzahl der Studierenden, die einen ersten Abschluss erwerben, zur Anzahl der Studienanfänger im entsprechenden Bildungsbereich vor $n$ Jahren, wobei n der Anzahl an Jahren entspricht, die zum Erwerb des Abschlusses in einem Vollzeitstudium erforderlich sind. Siehe auch Studienabbrecher.

Erwerbsbevölkerung: Die Erwerbsbevölkerung insgesamt oder die derzeitige Erwerbsbevölkerung, definiert gemäß den ILO-Richtlinien, umfasst alle Personen, die gemäß der Definition in der OECD-Arbeitsmarktstatistik die Voraussetzungen für die Zugehörigkeit zur Gruppe der Beschäftigten oder Arbeitslosen erfüllen. Siehe auch Erwerbsstatus.

Erwerbseinkommen: Erwerbseinkommen sind die jährlichen monetären Einkommen, die direkte Zahlungen für erbrachte Arbeitsleistungen darstellen, vor Steuern. Einkommen aus anderen Quellen, wie staatliche Transferzahlungen, Kapitalerträge, die Netto-Wertsteigerung eines vom Eigentümer betriebenen Geschäfts/Unternehmens und andere Einkommensarten, die nicht direkt mit Arbeit in
Verbindung stehen, sind nicht erfasst. Siehe auch Relative Erwerbseinkommen.

Erwerbsquote: Die Erwerbsquote, die gemäß den Richtlinien des Internationalen Arbeitsamts (ILO) definiert ist, entspricht dem Prozentsatz der Personen in der Bevölkerung der gleichen Altersgruppe, die entweder beschäftigt oder arbeitslos sind. Siehe auch Beschäftigte, Erwerbsbevölkerung, Arbeitslose und Arbeitslosenquote.

Erwerbsstatus: Der Erwerbsstatus gemäß der Definitionen der ILO-Richtlinien bezieht sich auf den Status innerhalb der Erwerbsbevölkerung, wie in den OECD-Arbeitskräftestatistiken festgelegt. Siehe auch Beschäftigte, Erwerbsbevölkerung und Arbeitslose.

Erwerbstätigenanteil: Der Erwerbstätigenanteil (ausgedrückt in Prozent) ist die Anzahl der Beschäftigten gemäß der Definition in den Richtlinien des Internationalen Arbeitsamts (ILO) dividiert durch die Gesamtzahl der betreffenden Bevölkerung (Erwerbs- und Nicht-Erwerbspersonen).

Finanzhilfen für Studierende: Finanzhilfen für Studierende umfassen: I. Staatliche Stipendien und andere staatliche Zuschüsse an Studierende oder Privathaushalte. Dazu zählen neben Stipendien und ähnlichen Zuschüssen (Forschungszuschüsse, Auszeichnungen, Preise, etc.) der Wert von speziellen an Studierende in Bar- oder Sachleistungen gezahlten Unterstützungen, wie kostenlose oder ermäßigte Fahrten mit öffentlichen Verkehrsmitteln, sowie Familienbeihilfen oder Kindergeldzahlungen, die abhängig vom Schüler-/Studierendenstatus gezahlt werden. Nicht berücksichtigt werden jegliche Vergünstigungen für Schüler/Studierende oder Privathaushalte in Form von Steuerermäßigungen, Steuersubventionen oder anderen steuerrechtlichen Sonderregelungen. 2. Schüler-/Studierendendarlehen, die brutto angegeben werden, d.h. ohne Abzug oder Herausrechnung von Rückoder Zinszahlungen seitens der Darlehensnehmer (Schüler/Studierende oder Privathaushalte).

Gehälter von Lehrern: Die Gehälter von Lehrern werden als gesetzliche bzw. vertraglich vereinbarte Gehälter angegeben und beziehen sich auf das reguläre Gehalt gemäß offizieller Besoldungs- und Ver- 
gütungsgruppen. Die angegebenen Gehälter sind definiert als die Bruttogehälter (die vom Arbeitgeber für die Arbeit bezahlte Gesamtsumme) abzüglich der Arbeitgeberbeiträge zur Sozial- und Rentenversicherung (gemäß bestehender Besoldungsund Vergütungsgruppen).

- Die angegebenen Anfangsgehälter beziehen sich auf das reguläre durchschnittliche Bruttojahresgehalt eines Vollzeitlehrers am Anfang der Lehrerlaufbahn mit der für eine Lehrerqualifikation erforderlichen Mindestausbildung.

- Die Gehälter für Lehrer mit I5 Jahren Berufserfahrung beziehen sich auf das reguläre Jahresgehalt eines Vollzeitlehrers mit der für eine Lehrerqualifikation erforderlichen Mindestausbildung und ${ }_{5}$ Jahren Berufserfahrung.

- Die erfassten Höchstgehälter beziehen sich auf das reguläre maximale Jahresgehalt (an der Spitze der Vergütungs-/Besoldungsordnung) eines Vollzeitlehrers mit dem für seine Stelle mindestens erforderlichen Ausbildungsstand.

Die Gehälter sind angegeben vor Abzug der Einkommenssteuern. Siehe auch Zulagen zum Grundgehalt.

Geleistete Netto-Kapitaltransferzahlungen: Sie umfassen Kapitaltransferzahlungen an private Haushalte des Inlands und ins Ausland abzüglich von Kapitaltransferzahlungen, die von privaten Haushalten des Inlands und aus dem Ausland erhalten wurden. Weitere Informationen siehe Ausgabe des Jahres 2004 der National Accounts of the OECD countries.

Gesamtbevölkerung: Im Gegensatz zu den Indikatoren, die aus Arbeitskräfteerhebungen abgeleitet sind, umfassen Gesamtbevölkerungsdaten, die zur Berechnung der Abschluss- und Zugangsquoten und der Bildungsbeteiligung verwendet werden, alle Staatsbürger eines Landes, die in diesem Land leben oder nur vorübergehend abwesend sind, sowie Ausländer, die dauerhaft in diesem Land ansässig sind. $\mathrm{Zu}$ weiteren Informationen s. OECD-Arbeitsmarktstatistik. Siehe auch PISA Zielpopulation.

Gesamtskala Politisches Wissen: Sie ergab sich aus der IEA-Studie zur politischen Bildung, bei der das politi- sche Wissen I4-Jähriger untersucht wurde. Bei der Untersuchung sollten die Kenntnisse der grundlegenden demokratischen Prinzipien der Schüler und ihre Fähigkeiten der Auslegung von Material mit politischem und staatsbürgerlichem Inhalt erfasst werden.

Gesellschaftliche Ertragsrate: Die Ertragsrate ist ein Maß für die langfristig resultierenden Erträge im Verhältnis zu den ursprünglichen Kosten für die Investition in die Ausbildung. Spezifischer ausgedrückt entspricht die gesellschaftliche Ertragsrate dem diskontierten Ertrag, der sich ergibt, wenn man den gesellschaftlichen Kosten der Ausbildung den gesellschaftlichen Nutzen aus der Ausbildung gegenüberstellt. $\mathrm{Zu}$ den gesellschaftlichen Kosten der Ausbildung gehören die Opportunitätskosten dafür, dass Menschen nicht im Produktionsprozess tätig sind, sowie die Kosten für das Bildungsangebot in voller Höhe, also nicht nur die vom Einzelnen getragenen Kosten. Zum gesellschaftlichen Nutzen gehören die höhere Produktivität, die mit Bildungsinvestitionen einhergeht, sowie ferner eine ganze Palette potentieller, nicht direkt materieller Nutzeffekte, wie eine niedrigere Kriminalitätsrate, stärkerer sozialer Zusammenhalt, informiertere und mündigere Bürger. Siehe auch Individuelle Ertragsrate.

Gesetzliche bzw. vertraglich festgelegte Gehälter von Lehrern: Siehe Gehälter von Lehrern.

Heimatland: Das Heimatland ist das Land, dessen Staatsangehörigkeit eine Person innehat.

Humankapital: Humankapital ist der produktive Bildungsstand in Form von Arbeitskraft, Fähigkeiten und Wissen.

IEA-Studie zur politischen Bildung: Die International Association for the Evaluation of Educational Achievement (IEA) hat eine internationale Vergleichsstudie zur politischen Bildung durchgeführt, die IEA-Studie zur politischen Bildung. Im Rahmen der Studie nahmen I4-Jährige in 28 Ländern, einschließlich I7 OECDLändern, an Tests zu ihren Kenntnissen staatsbürgerschaftlicher Inhalte, zu ihren Fähigkeiten des Verständnisses politischer Kommunikation, zu ihren Vorstellungen und Einstellungen zu staatsbürgerlichen Sachverhalten und ihrem Verhalten, bzw. 
ihrer aktiven Teilnahme in diesem Bereich teil. Man wollte herausfinden, wie junge Menschen innerhalb und außerhalb der Schule - auf ihre Rolle als Staatsbürger in einer Demokratie vorbereitet werden.

IGLU: Internationale Grundschul-Lese-Untersuchung (Progress in Reading Literacy Study - PIRLS) die im Jahr 200I von der International Association for the Evaluation of Educational Achievement (IEA) durchgeführt wurde und sich auf den Erwerb der Lesekompetenz von Schülern der 4. Jahrgangsstufe konzentrierte.

IGLU-Zielpopulation: Die IGLU-Zielpopulation waren die Schüler in der höheren der zwei aufeinanderfolgenden Jahrgangsstufen, die zum Zeitpunkt des Tests den größten Anteil 9-jähriger Schüler aufwiesen. Abgesehen von dem in der Definition enthaltenen Alterskriterium sollte die Zielpopulation den Zeitpunkt im Lehrplan repräsentieren, an dem die Schüler den Erwerb der Grundkenntnisse im Bereich Lesen abgeschlossen haben und sich in den nachfolgenden Jahrgangsstufen mehr auf das ,Lesen, um zu lernen' konzentrieren. Deshalb wurde davon ausgegangen, dass die Zielstufe die 4. Jahrgangsstufe sei.

Index der leistungsorientierten Aufnahmepolitik: Der Index der leistungsorientierten Aufnahmepolitik errechnet sich als Summe der Antworten der Schulleiter auf die Frage, wie oft sie die folgenden Kriterien bei der Aufnahme von Schülern oder bei der Zuweisung der Schüler zu einer Klasse im Sekundarbereich II berücksichtigen: die schulischen Leistungen des Schülers, Aufnahmeprüfungen und Empfehlungen der bisherigen Schule. Es wurde eine Dreipunkteskala mit folgenden Antwortkategorien verwendet: „immer oder oft“, „manchmal“ und „nie“.

Index der selektiven Praxis der Klassenzusammensetzung: Der Index der selektiven Praxis der Klassenzusammensetzung innerhalb einer Schule errechnet sich als Summe der Antworten der Schulleiter auf die Frage, wie oft die Klassenzusammensetzung im Sekundarbereich II mehr oder weniger zufällig, nach ähnlichen Fähigkeiten, mit dem Ziel, eine Mischung an Fähigkeiten zu erreichen, auf Wunsch der Eltern oder eines Vormundes erfolgt. Bei der
Berechnung des Gesamtindex wurden die ,integrativen' Methoden (d.h. die zufällige Zusammensetzung oder die Zusammensetzung mit dem Ziel, eine Mischung an Fähigkeiten zu erreichen) mit einem negativen Vorzeichen versehen. Es wurde eine Dreipunkteskala mit folgenden Antwortkategorien verwendet: „immer oder oft“, „manchmal“ und „nie“. Ein hoher Indexwert steht für eine starke Neigung, Schüler nach Fähigkeiten oder soziokulturellem Hintergrund einzuteilen. Ein negativer Wert steht für einen integrativen Ansatz bei der Klassenzusammensetzung.

Index des Umfangs der Aufnahme ausländischer Studierender: Der Index des Umfangs der Aufnahme ausländischer Studierender vergleicht die Anzahl der ausländischen Studierenden als Prozentsatz der inländischen Einschreibungen mit der Durchschnittszahl für die OECD-Länder. Dadurch kann der Maßstab für den Umfang der Aufnahme ausländischer Studierender anhand der Größe des tertiären Bildungsbereichs präzisiert werden. Das Verhältnis wird wie folgt berechnet:

Eine Indexzahl über (unter) I bedeutet, dass anteilsmäßig an der Gesamtzahl der Studierenden mehr (weniger) ausländische Studierende aufge-

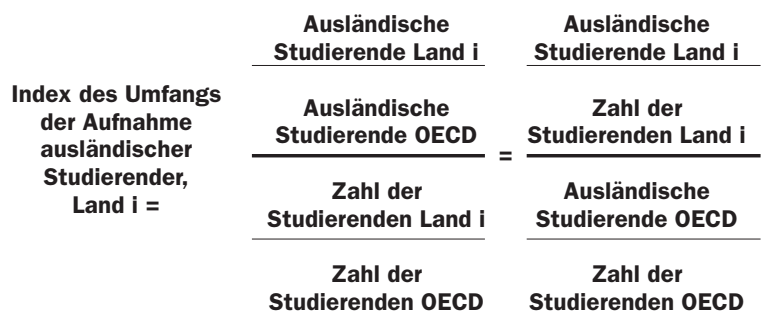

nommen wurden als im OECD-Mittel. Andererseits kann man diesen Index auch als einen Vergleich interpretieren, und zwar zwischen dem Gewicht eines Landes hinsichtlich der Aufnahme ausländischer Studierender aus den OECD-Ländern und seinem Gewicht hinsichtlich der Studierendenzahlen in der OECD. In diesem Fall bedeutet eine Indexzahl über (unter) I, dass dieses Land mehr (weniger) ausländische Studierende aufnimmt als anhand seines Gewichts für die Gesamtzahl der Studierenden innerhalb der OECD zu erwarten wäre. 
Individuelle Ertragsrate: Die Ertragsrate ist ein Maß für die langfristig resultierenden Erträge im Verhältnis zu den ursprünglichen Kosten für die Investition in die Ausbildung. Spezifischer ausgedrückt entspricht die individuelle Ertragsrate dem diskontierten Ertrag, der sich ergibt, wenn man den Kosten der Ausbildung während der Ausbildung die Gewinne aus der Ausbildung zu einem späteren Zeitpunkt gegenüberstellt. In ihrer umfassendsten Form entsprechen die Kosten den Studiengebühren, dem entgangenen Einkommen (versteuert und um die Beschäftigungswahrscheinlichkeit bereinigt), abzüglich der Fördermittel in Form von Beihilfen oder Darlehen. Siehe auch Gesellschaftliche Ertragsrate.

International Survey of Upper Secondary Schools (ISUSS): Eine Erhebung mittels Fragebogen, die während des Schuljahrs 2000/200I an 4.400 Schulen des Sekundarbereichs II in I5 Ländern durchgeführt wurde. In der Erhebung wurden Schulleiter zur Personalsituation, Aufnahme- und Klassenzusammensetzungpraxis, Förderung der beruflichen Weiterentwicklung, Teilnahme von Lehrern an Maßnahmen zur beruflichen Weiterentwicklung, Verfügbarkeit und Nutzung von Computern an der Schule, den Kontakten der Schulen, zum Feedback über das Funktionieren der Schulen und zur Berufsberatung befragt.

Internationale Schulleistungsstudie PISA: Die von der OECD durchgeführte Schulleistungsstudie PISA ist eine internationale Vergleichsstudie, in der untersucht wurde, wie gut junge Menschen im Alter von I5 Jahren, also gegen Ende der Schulpflicht, auf die Aufgaben und Herausforderungen der heutigen Wissensgesellschaft vorbereitet sind.

Internationale Standardklassifikation der Berufe (ISCO): Die Internationale Standardklassifikation der Berufe (I998) klassifiziert Personen gemäß ihrer tatsächlichen und potentiellen Verbindung mit bestimmten Tätigkeiten (jobs). Die Tätigkeiten werden hinsichtlich der durchgeführten bzw. durchzuführenden Arbeit eingeordnet. Grundlegende Kriterien zur Festlegung der vier Gliederungsebenen (Berufshauptgruppen, Berufsgruppen, Berufsuntergruppen und Berufsgattungen) sind der ,skill level', der Grad der Komplexität der entsprechenden Aufgaben, und die ,skill specialisation', im Grunde das Gebiet, in dem Kenntnisse erforderlich sind, damit die jeweiligen Aufgaben kompetent ausgeführt werden können. Es gibt separate Hauptgruppen für ,Angehörige gesetzgebender Körperschaften, leitende Verwaltungsbedienstete und Führungskräfte in der Privatwirtschaft' und für die ,Streitkräfte‘.

Internationale Standard-Klassifikation des Bildungswesen (ISCED): Die Internationale Standard-Klassifikation des Bildungswesens (ISCED-97) dient in dieser Veröffentlichung als Grundlage zur Festlegung der Bildungsbereiche und Bildungsgänge. Einzelheiten zu ISCED-97 und ihrer landesspezifischen Umsetzung finden sich in „Classifying Educational Programmes: Manual For ISCED-97 Implementation in OECD Countries" (Paris, 1999). Siehe auch Elementarbereich (ISCED o), Primarbereich (ISCED 1), Sekundarbereich I (ISCED 2), Sekundarbereich II (ISCED 3), Post-sekundarer, nicht-tertiärer Bereich (ISCED 4), Tertiärbereich A (ISCED 5A), Tertiärbereich B (ISCED 5B) und Weiterführende Forschungsprogramme (ISCED 6).

Internationaler sozio-ökonomischer Index der beruflichen Stellung (ISEI): Der in der PISA-Studie verwendete Internationale sozio-ökonomische Index der beruflichen Stellung (ISEI) wurde von den Schülerantworten auf die Frage nach dem Beruf der Eltern abgeleitet. Der Index erfasst die Merkmale von Berufen, durch die sich die Bildungsabschlüsse der Eltern in deren Einkommen niederschlagen. Zur Konstruktion dieses Index wurden die Berufsgruppen auf einer linearen Skala so angeordnet, dass der indirekte Einfluss der Bildung auf das Einkommen mittels der Bildungsabschlüsse maximiert und der direkte Einfluss der Bildung auf das Einkommen, unabhängig vom Beruf, minimiert wurde (bei beiden Effekten wurde dem Alter nicht Rechnung getragen). Der in PISA verwendete Internationale sozio-ökonomische Index der beruflichen Stellung basiert auf dem Beruf des Vaters oder der Mutter, je nachdem wer die höhere Stellung hat.

Investitionsausgaben: Investitionsausgaben stellen den Wert des während des betreffenden Jahres erworbenen oder geschaffenen Kapitals für das Bildungswesen (d.h. den Betrag der Kapitalbildung) dar, unabhängig davon, ob der Kapitalaufwand aus 
laufenden Erträgen oder durch Kreditaufnahme finanziert wurde. Investitionsausgaben umfassen Ausgaben für Bau, Renovierung und umfangreiche Reparaturen von Gebäuden sowie Ausgaben für neue oder Ersatzausstattungen. Die Investitionsausgaben erfordern zwar einen höheren Anfangsaufwand, die Gebäude und Einrichtungen haben jedoch eine Lebensdauer, die sich über viele Jahre erstreckt.

ISCED: Siehe Internationale Standard-Klassifikation des Bildungswesen

Kaufkraftparitäten (KKP): Kaufkraftparitäten (KKP) sind die Währungsumrechnungskurse, die die Kaufkraft verschiedener Währungen ausgleichen. Dies bedeutet, dass man mit einer bestimmten Geldsumme, wenn sie anhand der KKP in die verschiedenen Währungen umgerechnet wird, in allen Ländern den gleichen Waren- und Dienstleistungskorb erwerben kann. Mit anderen Worten, die KKP sind Währungsumrechnungskurse, die die Preisniveau-Unterschiede zwischen den Ländern aufheben. Werden daher Ausgaben im Verhältnis zum Bruttoinlandsprodukt (BIP) für verschiedene Länder mit Hilfe der KKP in eine gemeinsame Währung umgerechnet, werden sie tatsächlich in der gleichen internationalen Preisgruppe ausgedrückt, so dass Vergleiche zwischen den Ländern nur Unterschiede im Umfang der erworbenen Waren und Dienstleistungen widerspiegeln. Die in der vorliegenden Veröffentlichung verwendeten Kaufkraftparitäten sind in Anhang 2 aufgeführt.

Kern-Pflichtteil des Lehrplans: Der Kern-Pflichtteil des Lehrplans umfasst den erforderlichen Mindestzeitaufwand für die Kernfächer und -fächergruppen innerhalb des Pflicht-Lehrplans (Fächer und Fächergruppen, die für alle Schüler vorgegeben sind). Siehe auch Pflichtteil des Lehrplans, Wahl-Pflichtteil des Lehrplans, Vorgesehene Unterrichtszeit und Nicht-Pflichtteil des Lehrplans.

Klassengröße: Die Klassengröße ist die durchschnittliche Zahl von Schülern pro Klasse, sie wird berechnet, indem die Anzahl der Schüler durch die Anzahl der Klassen dividiert wird. Um die Vergleichbarkeit zwischen den Ländern zu gewährleisten, wurden spezielle Förderprogramme nicht erfasst. Die Daten umfassen ausschließlich die regulären Bildungsgänge im Primar- und Sekundarbereich, auch Unterricht in Kleingruppen außerhalb des regulären Klassenunterrichts ist nicht erfasst.

Kombinierte schulische und betriebliche Ausbildungen: In kombinierten schulischen und betrieblichen Ausbildungen ist der Unterricht zwischen Bildungseinrichtung und Arbeitsplatz aufgeteilt, erfolgt jedoch hauptsächlich am Arbeitsplatz. Ausbildungen gelten als kombinierte schulische und betriebliche Bildungsgänge, wenn weniger als 75 Prozent des Lehrplans in der Bildungseinrichtung oder in einem Fernkurs behandelt werden. Ausbildungen, bei denen über 90 Prozent im Betrieb erfolgen, werden nicht berücksichtigt. Duale Ausbildungsprogramme stellen eine Kombination aus Phasen des Arbeitens und des Lernens dar, die beide Bestandteil einer integrierten, formalen Bildung bzw. Ausbildung sind. $\mathrm{Zu}$ solchen Programmen zählen beispielsweise das duale Berufsbildungssystem in Deutschland, die apprentissage oder formation en alternance in Frankreich und Belgien, Praktika oder ,kooperative" Ausbildungen in Kanada, apprenticeship in Irland und youth training im Vereinigten Königreich. Siehe auch Allgemeinbildende Bildungsgänge, Ausrichtung eines Bildungsgangs, Schulische Ausbildungsgänge und Berufsbildende Bildungsgänge.

Kosten, die außerhalb von Bildungseinrichtungen anfallen: Kosten, die außerhalb von Bildungseinrichtungen anfallen, sind Ausgaben für Bildungsdienstleistungen, die außerhalb von Bildungseinrichtungen erworben werden, z.B. Bücher, Computer, Nachhilfestunden, etc. Enthalten sind auch Lebenshaltungskosten der Schüler/Studierenden sowie Kosten für nicht von den Bildungseinrichtungen bereitgestellte Transportmöglichkeiten für Schüler/Studierende.

Laufende Ausgaben: Laufende Ausgaben sind Ausgaben für Güter und Dienstleistungen, die innerhalb des laufenden Haushaltsjahres verbraucht werden und die jedes Jahr für den laufenden Betrieb dieser Einrichtungen erforderlich sind. Geringfügige Ausgaben für Ausrüstungsgüter unterhalb einer gewissen Wertgrenze werden auch als laufende Ausgaben erfasst. Die laufenden Ausgaben betref- 
fen konsumtive Ausgaben, Pacht-, Miet- und Zinszahlungen, Subventionen sowie sonstige laufende Transferzahlungen (z. B. Sozialversicherungen, Sozialhilfe, Renten und sonstige Wohlfahrtsleistungen). Siehe auch Sonstige laufende Transferzahlungen.

Lehrkräfte: Der Begriff ,Lehrkräfte' umfasst Lehrkräfte auf den ISCED-Stufen 0-4 und akademische Kräfte auf den ISCED-Stufen 5-6. Der Begriff, Lehrkraft' umfasst voll qualifiziertes Personal, dass direkt mit dem Unterrichten der Schüler befasst ist; Förderlehrer, und andere Lehrer, die mit Schülern als ganzer Klasse im Klassenzimmer, in kleinen Gruppen in einem Förderraum oder im Einzelunterricht innerhalb oder außerhalb des regulären Unterrichts arbeiten. Diese Kategorie umfasst auch Fachgebietsleiter, deren Aufgaben ein gewisses $\mathrm{Maß}$ an Unterricht beinhalten, während nicht vollqualifizierte Mitarbeiter, die die Lehrkräfte beim Unterricht unterstützten, wie Hilfslehrkräfte und andere Hilfskräfte, nicht erfasst sind. Zur Unterkategorie der akademischen Kräfte gehören Mitarbeiter, deren Hauptaufgabe im Unterrichten, in der Forschung oder dem Erbringen von Dienstleistungen für die Allgemeinheit liegt. Sie umfasst Mitarbeiter, die einen akademischen Rang innehaben mit Titeln wie Professor, stellvertretender Professor, Dozent oder einer vergleichbaren akademischen Bezeichnung. Personal mit anderen Titeln (z.B. Dekan, Direktor, stellvertretender Dekan, Fachbereichsleiter) ist in dieser Kategorie enthalten, wenn der Schwerpunkt der jeweiligen Tätigkeit im Unterrichten oder in der Forschung liegt. Nicht eingeschlossen sind Lehrer in der praktischen Ausbildung oder Lehr- und Forschungsassistenten. Der Begriff Lehrkräfte deckt nur einen Teil der unterrichtenden Beschäftigten ab. Siehe auch Beschäftigte im Bildungsbereich, Vollzeit-Lehrer, Vollzeitäquivalente Lehrer, Unterrichtende Beschäftigte, Wartungs- und Betriebspersonal, Beschäftigte in Management/Qualitätssicherung/Verwaltung, Teilzeit-Lehrer, Professionelle Unterstützung für Schüler/Studierende, Zahlenmäßiges Schüler/Lehrkräfte-Verhältnis und Zahl der Unterrichtsstunden.

Lernpensum: Es gibt zwei grundlegende Kenngrößen für das Lernpensum: die Zeit im Klassenzimmer und das Fortschreiten in Richtung einer Qualifikation. Die Zeit im Klassenzimmer soll die Dauer an Unterricht erfassen, die der einzelne Schüler er- hält und kann in Form von Unterrichtsstunden pro Tag oder pro Jahr, der Anzahl der belegten Kurse oder mittels einer Kombination aus beidem gemessen werden. Diese Kenngrößen basieren auf den Merkmalen des Kurses bzw. der Teilnahme, nicht aber auf Merkmalen des Bildungsgangs, an dem der Schüler teilnimmt. Daher ist eine solche Kenngröße hilfreich, wenn es keine feste Struktur des Bildungsgangs gibt oder die Strukturen nicht miteinander vergleichbar sind. Die zweite Kenngröße zum Lernpensum betrifft die Lerneinheit, anhand derer sich ein Fortschreiten in Richtung Qualifikation ablesen lässt. Hierbei liegt der Schwerpunkt weniger auf dem Umfang an Unterricht, sondern mehr auf dem „Bildungs(mehr)wert“ des Unterrichts. Es lässt sich leicht nachvollziehen, dass Kurse mit dem gleichen Unterrichtspensum von unterschiedlichem ,Bildungs(mehr)wert' sein können. Dieser wäre nur gleich, wenn der Lernfortschritt in Unterrichtseinheiten gemessen würde. Siehe auch Vollzeitäquivalente Schüler/Studierende, Vollzeit-Schüler/Studierende, Vollzeit-|Teilzeit-Ausbildung und Teilzeit-Schüler/Studierende.

Lesefähigkeiten und Leseverständnis: Lesefähigkeiten und Leseverständnis, auch als Lesekompetenz bezeichnet (reading literacy) sind im Rahmen von PISA definiert als die Fähigkeit, geschriebene Texte zu verstehen, zu nutzen und über sie zu reflektieren, um eigene Ziele zu erreichen, das eigene Wissen und Potential weiterzuentwickeln und aktiv am gesellschaftlichen Leben teilzunehmen. Siehe auch Mathematische Grundbildung und Naturwissenschaftliche Grundbildung. In IGLU wurde die Lesekompetenz ähnlich definiert als die Fähigkeit, jene Formen der Schriftsprache zu verstehen und zu nutzen, die von der Gesellschaft erwartet werden und/oder vom Einzelnen geschätzt werden.

Mathematische Grundbildung: Mathematische Grundbildung (mathematical literacy) im Rahmen von PISA ist definiert als die Fähigkeit, mathematische Probleme zu identifizieren, zu verstehen und sich mit ihnen zu befassen und fundierte Urteile über die Rolle abzugeben, die die Mathematik im gegenwärtigen und künftigen Privatleben der Betreffenden, im Berufsleben, im sozialen Kontakt mit Peers und Verwandten und im Leben dieser Person als konstruktivem, engagiertem und reflektierendem 
Bürger spielt. Siehe auch Lesefähigkeiten und Leseverständnis und Naturwissenschaftliche Grundbildung.

Naturwissenschaftliche Grundbildung: Im Rahmen von PISA wird naturwissenschaftliche Grundbildung (scientific literacy) als die Fähigkeit definiert, naturwissenschaftliches Wissen anzuwenden, naturwissenschaftliche Fragen zu erkennen und aus Belegen Schlussfolgerungen zu ziehen, um Entscheidungen $\mathrm{zu}$ verstehen und $\mathrm{zu}$ treffen, die die natürliche Welt und die durch menschliches Handeln an ihr vorgenommenen Veränderungen betreffen. Siehe auch Mathematische Grundbildung und Lesefähigkeiten und Leseverständnis.

Netto-Abschlussquoten: Die Netto-Abschlussquoten sind der prozentuale Anteil einer fiktiven Altersgruppe, der einen Abschluss im Tertiärbereich erwirbt, womit die Netto-Abschlussquoten unbeeinflusst von Änderungen des Umfangs der entsprechenden Bevölkerungsgruppe oder des typischen Abschlussalters sind. Netto-Abschlussquoten werden berechnet, indem man für jeden einzelnen $\mathrm{Al}$ tersjahrgang die Zahl der Absolventen durch die entsprechende Bevölkerung dividiert und diese Quoten über alle Altersjahrgänge aufsummiert. Siehe auch Absolventen, Abschluss, Netto-Abschlussquoten und Anzahl der Absolventen ohne Doppelzählungen.

Nicht-Pflichtteil des Lehrplans: Der Nicht-Pflichtteil des Lehrplans ist definiert als die durchschnittliche Unterrichtszeit, auf die Schüler zusätzlich zum Pflichtteil Anspruch haben. Die Fächer, die unter den Nicht-Pflichtteil des Lehrplans fallen, unterscheiden sich oft von Schule zu Schule oder von Region zu Region und können in Form von „wählbaren Nicht-Pflichtfächern" angeboten werden. Siehe auch Kern-Pflichtteil des Lehrplans, Pflichtteil des Lehrplans, Wahl-Pflichtteil des Lehrplans und Vorgesehene Unterrichtszeit.

Nicht-unterrichterteilende Bildungseinrichtungen: Nichtunterrichterteilende Einrichtungen erbringen anderen Bildungseinrichtungen gegenüber bildungsbezogene administrative, beratende oder fachliche Dienstleistungen, nehmen jedoch selbst keine Schüler/Studierenden auf. Beispiele hierfür sind nationale, bundesstaatliche und regionale Bildungsministerien oder -abteilungen, sonstige auf den verschiedenen staatlichen Ebenen für Bildungsfragen zuständige Organe oder entsprechende private Einrichtungen, sowie Organisationen, die derartige bildungsbezogenen Dienstleistungen wie Berufs- oder psychologische Beratung, Vermittlung von Stellen und Praktika, Durchführung von Tests, Finanzhilfe für Schüler/Studierende, Lehrplanentwicklung, Bildungsforschung, Betrieb und Instandhaltung von Gebäuden, Transport von Schülern/Studierenden, sowie Unterkunft und Verpflegung für Schüler/Studierende anbieten. Siehe auch Ausgaben für Bildungseinrichtungen und Unterrichterteilende Bildungseinrichtungen.

Nicht-unterrichtsbezogene Ausgaben: Nicht-unterrichtsbezogene Ausgaben umfassen alle Ausgaben, die grob gesehen mit den Lebenshaltungskosten der Schüler/Studierenden zusammenhängen.

Öffentliche Bildungsausgaben: Öffentliche Bildungsausgaben beziehen sich auf die Ausgaben für Bildung von staatlichen Behörden aller Ebenen. Ausgaben, die nicht direkt mit dem Bildungswesen zu tun haben (z. B. Kultur, Sport, Jugend, etc.) sind dabei grundsätzlich ausgeschlossen, es sei denn, es handelt sich um von den Bildungseinrichtungen als zusätzliche Dienstleistungen angebotene Aktivitäten. Bildungsausgaben anderer Ministerien oder äquivalenter Institutionen, wie etwa Gesundheits- und Landwirtschaftministerium, werden jedoch berücksichtigt.

Öffentliche Bildungseinrichtungen: Eine Bildungseinrichtung wird als ,öffentlich' eingestuft, wenn sie direkt von einer staatlichen Bildungsbehörde beaufsichtigt und geführt wird oder entweder direkt von einer Regierungsbehörde oder von einem Verwaltungsgremium (Rat, Ausschuss usw.) beaufsichtigt und geführt wird, dessen Mitglieder überwiegend entweder von einer staatlichen Behörde ernannt oder mit öffentlichem Wahlrecht gewählt werden. Siehe Bildungseinrichtungen und Private Bildungseinrichtungen.

Ort der Entscheidung: Hier wird festgelegt, auf welcher Ebene die entscheidungsbefugte Stelle angesiedelt ist. 
Personenzahlen: Dies bezieht sich auf die Methode der Datenerhebung: erfasst wird die Anzahl der Personen, unabhängig davon, ob es sich um Volloder Teilzeit-Schüler/Studierende handelt und unabhängig von der Länge des jeweiligen Bildungsganges. Siehe auch Vollzeit-Schüler/Studierende, Teilzeit-Schüler/Studierende, Vollzeit-Lehrer und Teilzeit-Lehrer.

Pflichtteil des Lehrplans: Der Pflichtteil des Lehrplans bezieht sich auf die Anzahl und Aufteilung der Unterrichtsstunden, die von fast jeder Schule zu unterrichten und von fast jedem Schüler zu besuchen sind. Er beinhaltet den Kern-Pflichtteil und den Wahl-Pflichtteil des Lehrplans. Siehe auch KernPflichtteil des Lehrplans, Wahl-Pflichtteil des Lehrplans, Vorgesehene Unterrichtszeit und Nicht-Pflichtteil des Lehrplans.

PISA: Siehe Internationale Schulleistungsstudie PISA.

PISA-Index der differenzierten Übungsstrategien: Der PISA-Index der differenzierten Übungsstrategien wurde davon abgeleitet, wie häufig die Schüler folgende Strategien beim Lernen nutzen: ich versuche, den neuen Stoff mit Dingen zu verbinden, die ich in anderen Fächern gelernt habe; ich überlege, inwiefern die Information im wirklichen Leben nützlich sein könnte; ich versuche, den Stoff besser zu verstehen, indem ich Verbindungen zu Dingen herstelle, die ich schon kenne, und ich überlege, wie der Stoff mit dem zusammenhängt, was ich schon gelernt habe. Es wurde eine Vierpunkteskala mit folgenden Antwortkategorien verwendet: „fast nie“, „manchmal“, „oft" und „fast immer“.

PISA-Index der kontrollbezogenen Strategien: Der PISAIndex der kontrollbezogenen Strategien wurde davon abgeleitet, wie häufig die Schüler folgende Strategien beim Lernen nutzen: ich überlege mir zuerst, was genau ich lernen muss; ich zwinge mich zu prüfen, ob ich das Wichtigste behalte; und wenn ich lerne und etwas nicht verstehe, suche ich nach zusätzlichen Informationen, um das Problem zu klären. Es wurde eine Vierpunkteskala mit folgenden Antwortkategorien verwendet: „fast nie“, „manchmal“, „oft“ und „fast immer“.
PISA-Index des eigenen Konzepts zur Lesefertigkeit: Der PISA-Index des eigenen Konzepts zur Lesefertigkeit wurde davon abgeleitet, inwieweit die Schüler folgende Aussagen für zutreffend hielten: im < Testsprachenfach $>$ bin ich ein hoffnungsloser Fall; im $<$ Testsprachenfach> lerne ich schnell; und im $<$ Testsprachenfach $>$ bekomme ich gute Noten. Es wurde ein Vierpunkteskala mit folgenden Antwortkategorien verwendet: „trifft nicht zu“, „trifft eher nicht zu“, „trifft eher zu“ und „trifft zu“.

PISA-Index des Interesses am Lesen: Der PISA -Index des Interesses am Lesen wurde davon abgeleitet, inwieweit die Schüler folgenden Aussagen zustimmten: weil mir das Lesen Spaß macht, würde ich es nicht gerne aufgeben; ich lese in meiner Freizeit; und wenn ich lese, vergesse ich manchmal alles um mich herum. Es wurde ein Vierpunkteskala mit folgenden Antwortkategorien verwendet: „trifft nicht $z u$ “, „trifft eher nicht zu“, „trifft eher zu“ und „trifft zu“.

PISA-Index der Anstrengung und Ausdauer: Der PISA-Index der Anstrengung und Ausdauer wurde davon abgeleitet, wie häufig die Schüler folgende Strategien beim Lernen nutzen: ich arbeite so fleißig wie möglich; ich arbeite auch dann weiter, wenn der Stoff schwierig ist; ich versuche, mein Bestes zu geben, um mir das Wissen und die Fähigkeiten anzueignen; und ich gebe mein Bestes. Es wurde eine Vierpunkteskala mit folgenden Antwortkategorien verwendet: „fast nie“, „manchmal“, „oft“ und „fast immer".

PISA-Index der Freude am Lesen: Der PISA-Index der Freude am Lesen basiert auf drei Komponenten: der Lesehäufigkeit, der Vielfalt und der Art des Lesestoffs und dem Interesse am Lesen. Zur Bewertung der ersten Komponente wurden Schüler gefragt, wie viel Zeit sie in der Regel täglich zum Vergnügen lesen. Zur Bewertung der zweiten Komponente wurden Schüler gebeten anzugeben, welches Lesematerial sie lesen: Zeitungen, Zeitschriften, Belletristik, Sachliteratur, Comics, EMails und Internetseiten und mit welcher Häufigkeit sie jedes Material lesen. Zur Bewertung der dritten Komponente enthielt der Fragebogen eine Liste mit neun positiven und negativen Aussagen zur Leseeinstellung. Die Schüler wurden gebeten, 
den Grad ihrer Zustimmung zu jeder Aussage anzugeben. Aufgrund dieser Fragen wurde ein Index der ,Freude am Lesen“ entwickelt. Die Indexskalen reichen von - I bis I, mit o als Mittelwert für die gesamte Schülerpopulation der OECD.

\section{PISA-Index der Selbstwirksamkeit: Der PISA-Index der} Selbstwirksamkeit wurde davon abgeleitet, inwieweit die Schüler den folgenden Aussagen zustimmen: ich bin sicher, dass ich auch den schwierigsten Stoff in Unterrichtstexten verstehen kann; ich bin überzeugt, dass ich auch den kompliziertesten Stoff, den der Lehrer vorstellt, verstehen kann; ich bin überzeugt, dass ich in Hausaufgaben und Klassenarbeiten gute Leistungen erzielen kann und ich bin überzeugt, dass ich die Fertigkeiten, die gelehrt werden, beherrschen kann. Es wurde eine Vierpunkteskala mit folgenden Antwortkategorien verwendet: „fast nie“, „manchmal“, „oft“ und „fast immer".

PISA-Index der wiederholungsbezogenen Strategien: Der PISA-Index der wiederholungsbezogenen Strategien wurde davon abgeleitet, wie häufig die Schüler folgende Strategien beim Lernen nutzen: Ich versuche, alles auswendig zu lernen, was drankommen könnte; ich lerne so viel wie möglich auswendig; ich präge mir alles Neue so ein, dass ich es aufsagen kann, und ich lerne, indem ich den Stoff immer wieder aufsage. Es wurde eine Vierpunkteskala mit folgenden Antwortkategorien verwendet: „fast nie“, „manchmal“, „oft“ und „fast immer“.

PISA-Index der zielgerichteten Motivation: Der PISA-Index der zielgerichteten Motivation wurde davon abgeleitet, wie häufig die Schüler folgende Gründe für das Lernen angeben: um meine Berufsaussichten zu verbessern; damit ich in der Zukunft finanziell abgesichert sein werde und um eine gute Arbeitsstelle zu bekommen. Es wurde eine Vierpunkteskala mit folgenden Antwortkategorien verwendet: „f fast nie“, „manchmal“, „oft“ und „fast immer“.

PISA-Index des akademischen Selbstkonzepts: Auf ähnliche Weise wurde der PISA-Index des akademischen Selbstkonzepts davon abgeleitet, inwieweit die Schüler folgende Aussagen als zutreffend bezeichneten: in den meisten Schulfächern lerne ich schnell; ich bin in den meisten Schulfächern gut und in den meisten Schulfächern schneide ich bei Klassenarbeiten gut ab. Es wurde ein Vierpunkteskala mit folgenden Antwortkategorien verwendet: „trifft nicht zu“, „trifft eher nicht zu“, „trifft eher $z u$ " und „trifft $z u “$.

PISA-Index des Interesses an Mathematik: Der PISA-Index des Interesses an Mathematik wurde davon abgeleitet, inwieweit die Schüler folgenden Aussagen zustimmten: wenn ich mich mit Mathematik beschäftige, vergesse ich manchmal alles um mich herum; Mathematik ist mir persönlich wichtig; und weil mir die Beschäftigung mit Mathematik Spaß macht, würde ich das nicht gerne aufgeben. Es wurde ein Vierpunkteskala mit folgenden Antwortkategorien verwendet: „trifft nicht zu“, „trifft eher nicht zu“, „trifft eher zu“ und „trifft $z u$ “.

PISA-Index des kooperativen Lernens: Der PISA-Index des kooperativen Lernens wurde davon abgeleitet, inwieweit die Schüler folgende Aussagen als zutreffend bezeichneten: ich arbeite gern mit anderen Schülern zusammen; ich helfe anderen gerne dabei, in einer Gruppe gute Arbeit zu leisten; und wenn man an einem Projekt arbeitet, ist es nützlich, die Ideen von allen zusammen zu bringen. Es wurde ein Vierpunkteskala mit folgenden Antwortkategorien verwendet: „trifft nicht zu“, „trifft eher nicht zu“, „trifft eher zu“ und „trifft zu“.

PISA-Index des mathematischen Selbstkonzepts: Der PISA-Index des mathematischen Selbstkonzepts wurde davon abgeleitet, inwieweit die Schüler folgende Aussagen als zutreffend bezeichneten: im Fach Mathematik bekomme ich gute Noten; Mathematik ist eins meiner besten Fächer; und ich war schon immer gut in Mathematik. Es wurde ein Vierpunkteskala mit folgenden Antwortkategorien verwendet: „trifft nicht zu“, ,trifft eher nicht zu“, „trifft eher zu“ und „trifft zu“.

PISA-Index des wettbewerbsorientierten Lernens: Der PISA-Index des wettbewerbsorientierten Lernens wurde davon abgeleitet, inwieweit die Schüler folgende Aussagen als zutreffend bezeichneten: ich versuche gerne, besser zu sein als andere Schüler; wenn ich versuche, besser zu sein als andere, leiste ich gute Arbeit; ich wäre gerne in irgendeinem 
Bereich die/der Beste; und ich lerne schneller, wenn ich versuche, besser zu sein als die anderen. Es wurde ein Vierpunkteskala mit folgenden Antwortkategorien verwendet: „trifft nicht zu“, „trifft eher nicht zu“, „trifft eher zu“ und „trifft zu“.

PISA-Index des Zugehörigkeitsgefühls der Schüler: Der PISA-Index des Zugehörigkeitsgefühls der Schüler zu ihrer Schule wurde davon abgeleitet, inwieweit die Schüler folgende Aussagen in Bezug auf ihre Schule für zutreffend hielten: ich fühle mich als Außenseiter; ich finde leicht Freunde; ich fühle mich dazugehörig; ich fühle mich unwohl und fehl am Platz; ich bin anscheinend beliebt; und ich fühle mich einsam. Es wurde ein Vierpunkteskala mit folgenden Antwortkategorien verwendet: „stimmt überhaupt nicht“, „stimmt eher nicht“, „stimmt eher" und „stimmt ganz genau“.

PISA-Leseprofile: Im Rahmen der PISA-Studie wurden Schüler gebeten anzugeben, wie häufig sie unterschiedliche Druckerzeugnisse, wie Zeitschriften, Zeitungen, Comics, Belletristik und Sachbücher lesen. Je nach Antwort wurden die Schüler vier unterschiedlichen Leseprofilen zugeordnet. Die Einteilung dieser Profile beruht auf zwei Dimensionen: der Lesehäufigkeit einerseits und der Vielfalt der Lektüre andererseits. Diese beiden Dimensionen schlagen sich in der Formulierung, diversifizierte Lesegewohnheiten' nieder. Für die Profilanalyse dieses Indikators wurde die Aussage, ein bestimmtes Lesematerial „mehrmals pro Monat" oder „mehrmals pro Woche“ zu lesen als regelmäßiges Lesen betrachtet, die Angabe „einige Mal pro Jahr" und „einmal pro Monat" als geringes Lesen und „nie oder kaum“ als Nichtlesen.

PISA-Mittelwert: Um die Interpretation der von den Schülern erzielten Punktwerte zu erleichtern, wurde der Mittelwert für die Schülerleistungen in den drei Grundkompetenzen in den OECD-Ländern auf 500 und die Standardabweichung auf Ioo festgelegt und die Daten so gewichtet, dass alle OECDLänder gleichermaßen berücksichtigt werden. Der Mittelwert der IGLU-Studie wurde auf ähnliche Art und Weise berechnet.

PISA-Zielpopulation: PISA erfasste Schüler, die zu Beginn der Testperiode im Alter von I5 Jahren und 3 (vollen) Monaten bis zu I6 Jahren und 2 (vollen) Monaten alt waren, gleichgültig welche Klasse oder Art von Bildungseinrichtung sie besuchten und unabhängig davon, ob es sich um eine Ganztags- oder Halbtagsschule handelte.

Post-sekundarer, nicht-tertiärer Bereich (ISCED 4): Bildungsgänge im post-sekundaren, nicht-tertiären Bereich befinden sich aus internationaler Sicht im Grenzbereich zwischen Sekundarbereich II und post-sekundarem Bereich, auch wenn sie im nationalen Zusammenhang eindeutig als zum Sekundarbereich II oder zum post-sekundaren Bereich gehörig angesehen werden können. Selbst wenn der Inhalt dieser Bildungsgänge nicht wesentlich anspruchsvoller ist als der des Sekundarbereich II, können sie doch den Kenntnisstand derjenigen, die schon einen Abschluss im Sekundarbereich II erworben haben, erweitern. Die Teilnehmer der betreffenden Bildungsgänge sind in der Regel älter als im Sekundarbereich II. Siehe auch Internationale Standard-Klassifikation des Bildungswesens (ISCED).

Primarbereich (ISCED 1): Der Primarbereich beginnt normalerweise im Alter von 5, 6 oder 7 Jahren und dauert vier bis sechs Jahre (der Normalfall in den OECD-Ländern ist sechs Jahre). Bildungsgänge des Primarbereichs erfordern normalerweise keine vorherige formale Bildung, obwohl es immer häufiger vorkommt, dass Kinder vor dem Primarbereich schon den Elementarbereich besucht haben. Die Grenze zwischen Elementar- und Primarbereich wird normalerweise durch den Beginn des für den Primarbereich üblichen systematischen Lernens, z. B. des Lesens, Schreibens und Rechnens gekennzeichnet. Es ist jedoch üblich, dass schon im Elementarbereich mit den ersten Lese-, Schreibe- und Rechenübungen begonnen wird. Siehe auch Internationale Standard-Klassifikation des Bildungswesens (ISCED).

Private Bildungsausgaben: Private Bildungsausgaben beziehen sich auf aus privaten Quellen, d.h. von privaten Haushalten und anderen privaten Einheiten, finanzierte Ausgaben. Der Begriff, private Haushalte' umfasst Schüler bzw. Studierende und ihre Familien. ,Andere private Einheiten' umfasst private Unternehmen und gemeinnützige Organisationen, einschließlich kirchlicher Organisatio- 
nen, Wohltätigkeitsvereine sowie Arbeitgeberverbände und Arbeitnehmervereinigungen. Private Ausgaben umfassen Schulgebühren, Lehrbücher und Unterrichtsmaterial, Beförderung zur Schule (sofern von der Schule organisiert), Verpflegung (sofern von der Schule angeboten), Internatskosten sowie Ausgaben der Arbeitgeber für die erste berufliche Ausbildung. Es ist zu beachten, dass private Bildungseinrichtungen als Bildungsanbieter angesehen werden, und nicht als Finanzquellen.

Private Bildungseinrichtungen: Eine Bildungseinrichtung wird als privat angesehen, wenn sie von einer nichtstaatlichen Organisation (z.B. einer Kirche, Gewerkschaft oder einem Wirtschaftsunternehmen) beaufsichtigt und geführt wird oder wenn ihr Verwaltungsgremium zur Mehrheit aus Mitgliedern besteht, die nicht von einer staatlichen Stelle oder Behörde ernannt wurden. Siehe auch Bildungseinrichtungen, Staatlich-subventionierte private Bildungseinrichtungen, Unabhängige private Bildungseinrichtungen und Öffentliche Bildungseinrichtungen.

Professionelle Unterstützung für Schüler|Studierende: Professionelle Unterstützung für Schüler/Studierende umfasst pädagogische Unterstützung auf den ISCED-Stufen $0-4$ und akademische Unterstützung auf den ISCED-Stufen 5-6; ebenso Unterstützung in Gesundheits- und sozialen Fragen auf den ISCED-Stufen 0-6. Siehe auch Beschäftigte im Bildungsbereich, Unterrichtende Beschäftigte, Wartungs- und Betriebspersonal, Beschäftige in Management/Qualitätskontrolle/Verwaltung, Zahlenmäßiges Schüler/LehrkräfteVerhältnis und Lehrkräfte.

Relative Erwerbseinkommen: Das relative Erwerbseinkommen ist definiert als das mittlere Einkommen aus einer Erwerbstätigkeit von Personen mit einem bestimmten Bildungsstand, dividiert durch das mittlere Einkommen aus einer Erwerbstätigkeit von Personen mit einem Abschluss im Sekundarbereich II. Siehe auch Erwerbseinkommen.

Schüler/Studierende: Ein Schüler bzw. Studierender ist definiert als eine Person, die an einem Bildungsgang teilnimmt, der von der vorliegenden Statistik erfasst wird. Die Schüler- bzw. Studierendenzahl (Personenzahl) bezieht sich auf die Anzahl der Schüler bzw. Studierenden, die im Bezugszeitraum an einem Bildungsgang teilnehmen, und nicht unbedingt auf die Anzahl der Anmeldungen. Jeder Bildungsteilnehmer wird nur einmal gezählt. Siehe auch Vollzeit-Schüler/Studierende, Vollzeitäquivalente Schüler/Studierende, Teilzeit-Schüler/Studierende und Lernpensum.

Schulische Ausbildungsgänge: In schulischen (beruflichen und technischen) Ausbildungsgängen erfolgt der Unterricht (entweder teilweise oder ausschließlich) in Bildungseinrichtungen. Dazu zählen auch spezielle Berufsausbildungszentren, die von öffentlichen oder privaten Stellen oder betrieblichen Ausbildungszentren betrieben werden, sofern diese als Bildungseinrichtungen anerkannt sind. Diese Bildungsgänge können eine Komponente der Ausbildung am Arbeitsplatz umfassen, d.h. eine Komponente der praktischen Erfahrung am Arbeitsplatz. Ausbildungen gelten als schulische Ausbildungsgänge, wenn mindestens 75 Prozent des Lehrplans in der Bildungseinrichtung (die dabei den gesamten Bildungsgang abdeckt) behandelt werden, wobei Fernkurse eingeschlossen sind. Siehe auch Kombinierte schulische und betriebliche Ausbildungen, Allgemeinbildende Bildungsgänge, Ausrichtung eines Bildungsgangs und Berufsbildende Bildungsgänge.

Schulpflicht: Die Zeitdauer, für die Kinder bzw. Jugendliche gesetzlich zum Schulbesuch verpflichtet sind. Die Festlegung einschließlich der Determinanten (z. B. Alter, Anzahl der Schuljahre, etc.) erfolgt länderspezifisch..

Schulstätte: Die Untersuchungseinheit bei Indikatoren, die sich auf die Daten in der Studie „International Survey of Upper Secondary Schools“ (ISUSS) beziehen. Schulstätte bezieht sich auf eine Einrichtung, an der Bildung im Rahmen eines oder mehrerer Bildungsgänge angeboten wird. Eine Schulstätte besteht normalerweise aus einem einzigen Gebäude, es kann sich aber auch um zwei oder mehr Gebäude handeln, die in wenigen Minuten zu Fuß erreichbar sind. Eine Schulstätte hat festes Lehrpersonal und eine permanente Schülerpopulation. In vielen Ländern haben Schulen nicht mehr als eine Schulstätte (daher ist dort die Unterscheidung zwischen Schule und Schulstätte nicht erforderlich), aber es gibt Länder, in denen das klassische 
Bild einer Schule, die in einem einzelnen Gebäude untergebracht ist, nicht mehr auf alle Schulen zutrifft. Recht häufig hat eine Schule, als Verwaltungs- oder Haushalts-Rechnungseinheit, mehrere Schulstätten, die weit auseinander liegen (womöglich in unterschiedlichen Gemeinden).

Sekundarbereich (ISCED 2-3): Siehe Sekundarbereich I und Sekundarbereich II

Sekundarbereich I (ISCED 2): Der Sekundarbereich I setzt inhaltlich die grundlegenden Bildungsgänge des Primarbereichs fort, wenn auch normalerweise stärker fachorientiert, wobei häufig stärker spezialisierte Lehrer zum Einsatz kommen, die Unterricht in ihren Spezialfächern erteilen. Der Sekundarbereich I ist entweder ,abschließend' (d.h. er bereitet die Schüler auf den direkten Eintritt in den Arbeitsmarkt vor) und/oder, vorbereitend' (d.h. er bereitet Schüler auf den Sekundarbereich II vor). Dieser Bereich umfasst in der Regel zwei bis sechs Schuljahre (der Normalfall in den OECD-Ländern ist drei Jahre). Siehe auch Internationale StandardKlassifikation des Bildungswesens (ISCED).

Sekundarbereich II (ISCED 3): Der Sekundarbereich II entspricht in den meisten OECD-Ländern der letzten Phase des Sekundarbereichs. Der Unterricht ist oft fächerspezifischer als auf der ISCED-Stufe 2 und die Lehrkräfte benötigen in der Regel höherwertigere, bzw. fächerspezifischere Qualifikationen als auf ISCED-Stufe 2. Das Eintrittsalter für diesen Bildungsbereich liegt normalerweise bei I5 oder 16 Jahren. Es gibt wesentliche Unterschiede in der typischen Dauer von ISCED-3 Bildungsgängen, sowohl zwischen den einzelnen Ländern als auch innerhalb der Länder, normalerweise beträgt sie zwischen 2 und 5 Jahren. ISCED 3 kann entweder ,abschließend' sein (d. h. die Schüler auf den direkten Eintritt in das Erwerbsleben vorbereiten) und/oder ,vorbereitend“ (d.h. die Schüler auf den Tertiärbereich vorbereiten). Die Bildungsgänge auf ISCED-Stufe 3 kann man auch in drei Kategorien einteilen, je nachdem bis zu welchem Grad der Bildungsgang speziell auf eine bestimmte Gruppe von Berufen oder Tätigkeiten vorbereitet und auf arbeitsmarktrelevante Qualifikationen vorbereitet: allgemeinbildend, berufsvorbereitend oder berufsbildend/technisch. Siehe auch Allgemeinbildende Bil- dungsgänge, Internationale Standard-Klassifikation des Bildungswesens (ISCED), Berufsuorbereitende Bildungsgänge und Berufsbildende Bildungsgänge.

Sonstige laufende Transferzahlungen: Sonstige laufende Transferzahlungen sind Nettobeiträge zur Haftpflichtversicherung, Sozialversicherungsleistungen, Sozialhilfe, umlagenfinanzierte Pensionszahlungen und Sozialleistungen (direkt an ehemalige oder heutige Beschäftigte ausgezahlt, ohne spezielle Fonds, Reserven oder Versicherungen für diesen Zweck), laufende Transferzahlungen an private gemeinnützige Organisationen, die Haushalte versorgen, sowie laufende Transferzahlungen an den Rest der Welt. Siehe auch Laufende Ausgaben. Weitere Informationen siehe Ausgabe des Jahres 2004 der National Accounts of the OECD countries.

Staatlich-subventionierte private Bildungseinrichtungen: Eine staatlich-subventionierte private Bildungseinrichtung ist eine Bildungseinrichtung, die mehr als 50 Prozent ihrer Kernfinanzierung von staatlichen Stellen erhält und deren Lehrkräfte von staatlichen Stellen bezahlt werden. Der Ausdruck staatlich-finanziert bezieht sich nur auf den Grad der Abhängigkeit einer privaten Bildungseinrichtung von der Finanzierung durch den Staat; nicht jedoch darauf, inwieweit sie staatlichen Vorschriften oder einer staatlichen Leitung unterliegt. Siehe auch Bildungseinrichtungen, Staatlich-subventionierte private Bildungseinrichtungen, Private Bildungseinrichtungen und Öffentliche Bildungseinrichtungen.

Standardfehler (SF): Standardfehler drücken den Grad der Unsicherheit einer Schätzung aus. Die Schätzwerte der nationalen Leistung basieren auf Schülerstichproben und wurden nicht aus den Antworten sämtlicher Schüler eines Landes zu den jeweiligen Fragen errechnet. Daher ist es wichtig, den in den Schätzungen enthaltenen Grad an Unsicherheit zu kennen.

Statistische Signifikanz: Unterschiede werden als statistisch signifikant bezeichnet, wenn ein Unterschied der entsprechenden Größe oder darüber in weniger als 5 Prozent der Fälle beobachtet würde, obwohl bei den entsprechenden Populationswerten ein solcher Unterschied tatsächlich nicht vorhanden ist. Somit wird das Risiko, eine Differenz 
als signifikant zu bezeichnen, wenn tatsächlich keine Korrelation zwischen zwei Messgrößen besteht, auf 5 Prozent begrenzt.

Studienanfängerquoten: Anfängerquoten werden als Netto-Anfängerquoten angegeben. Sie stellen den Anteil von Personen einer synthetischen Alterskohorte dar, die in den Tertiärbereich eintreten, unabhängig von Veränderungen der Populationsgröße und Unterschieden zwischen den einzelnen OECDLändern hinsichtlich des für den Tertiärbereich typischen Eintrittsalters. Die Netto-Studienanfängerquote einer speziellen Altersgruppe wird berechnet, indem die Anzahl der Studienanfänger der speziellen Altersgruppe in den einzelnen Tertiärbereichen durch die Gesamtpopulation der entsprechenden Altersgruppe geteilt wird (x IOo). Die Summe der Netto-Studienanfängerquoten wird berechnet, indem die Netto-Studienanfängerquoten der einzelnen Altersjahrgänge aufsummiert werden. Siehe auch Ausbildungs-|Studienanfänger.

Studienbereich: Ein Studienbereich ist gemäß der Definition der Internationalen Standard-Klassifikation des Bildungswesens (ISCED) der fachliche Inhalt, der in einem Bildungsgang unterrichtet wird. Detaillierte Angaben sowie Informationen zur Umsetzung finden sich in Fields of Education and Training - Manual (EUROSTAT, r999).

Teilzeit-Lehrer: Ein Lehrer, der für den Zeitraum eines kompletten Schuljahres für weniger als go Prozent der normalen oder gesetzlichen Arbeitsstundenzahl eines Vollzeit-Lehrers eingestellt ist, gilt als Teilzeit-Lehrer. Siehe auch Beschäftigte im Bildungsbereich, Vollzeitäquivalente Lehrer, Vollzeitlehrer, Unterrichtende Beschäftigte, Zahlenmäßiges Schüler-/Lehrerverhältnis und Lehrkräfte, Zahl der Unterrichtsstunden und Arbeitszeit.

Teilzeit-Schüler/Studierende: Im Allgemeinen gelten Schüler im Primar- und Sekundarbereich als Teilzeit-Schüler, wenn sie die Schule für weniger als 75 Prozent des Schultages oder der Schulwoche (gemäß der jeweiligen lokalen Definition) besuchen und normalerweise ihre Teilnahme an dem betreffenden Bildungsgang während des gesamten Schuljahres zu erwarten ist. Im Tertiärbereich gilt eine Person als Teilzeit-Studierender, wenn sie ein
Kurspensum hat oder an einem Bildungsgang teilnimmt, das bzw. der weniger als 75 Prozent der Zeit und Ressourcen eines Vollzeitstudiums erfordert. Siehe auch Vollzeitäquivalente Schüler/Studierende, Vollzeit-Schüler/Studierende, Vollzeit-|Teilzeit-Ausbildung, Schüler/Studierende und

Tertiärbereich (ISCED 5-6): Siehe auch Tertiärbereich A (ISCED 5A), Tertiärbereich B (ISCED 5B) und Weiterführende Forschungsprogramme (ISCED 6).

Tertiärbereich A (ISCED 5A): Der Tertiärbereich A ist weitgehend theoretisch orientiert und soll hinreichende Qualifikationen für den Zugang zu weiterführenden Forschungsprogrammen und Berufen mit hohem Qualifikationsniveau, wie Medizin, Zahnmedizin oder Architektur, vermitteln. Die theoretische Gesamtdauer eines tertiären Studiengangs des Tertiärbereich A beträgt mindestens drei Jahre (vollzeitäquivalent), normalerweise dauert er jedoch 4 Jahre oder länger. Derartige Studiengänge werden nicht ausschließlich an Universitäten angeboten. Umgekehrt erfüllen nicht alle Studiengänge, die national als Universitätsstudium anerkannt werden, die Kriterien für die Einstufung im Tertiärbereich A. Der Tertiärbereich A schließt Zweitabschlüsse wie den amerikanischen ,Master mit ein. Erst- und Zweitabschlüsse sind klassifiziert nach der Gesamtstudiendauer, d. h. nach der Gesamtstudiendauer im Tertiärbereich, die notwendig ist, um den Abschluss zu erhalten. Siehe auch Internationale Standard-Klassifikation des Bildungswesens (ISCED) und Tertiärbereich B (ISCED 5B).

Tertiärbereich B (ISCED 5B): Studiengänge des Tertiärbereich B sind typischerweise kürzer als im Tertiärbereich A und konzentrieren sich auf praktische/technische/berufsbezogene Fähigkeiten für den direkten Eintritt in den Arbeitsmarkt, obwohl in diesen Studiengängen auch einige theoretische Grundlagen vermittelt werden können. Sie dauern mindestens 2 Jahre (vollzeitäquivalent). Siehe auch Internationale Standard-Klassifikation des Bildungswesens (ISCED) und Tertiärbereich A (ISCED 5A).

Theoretisches Alter: Das theoretische Alter bezieht sich auf das gesetzlich oder durch Verordnung festgelegte Alter für den Beginn und die Beendigung eines Bildungsabschnitts. Es ist zu beachten, dass 
das theoretische Alter signifikant vom typischen Alter abweichen kann. Siehe auch Typisches Alter und Abschlussalter.

Transfer- und sonstige Zahlungen an andere private Einheiten: Hierzu zählen staatliche Transferzahlungen und bestimmte andere Zahlungen (hauptsächlich Subventionen) an andere private Einheiten (Unternehmen und gemeinnützige Organisationen). Sie können verschiedene Formen annehmen, z.B. Transferzahlungen an Arbeitgeberverbände oder Arbeitnehmervereinigungen, die Erwachsenenbildung anbieten, Subventionen an Firmen oder Gewerkschaften (oder Vereinigungen solcher Einrichtungen), die Lehrlingsausbildungsprogramme durchführen sowie Zinssubventionen und Ausfallbürgschaften an private Finanzinstitute zur Bereitstellung von Schüler-/Studierendendarlehen.

Transferzahlungen zwischen Gebietskörperschaften: Transferzahlungen zwischen Gebietskörperschaften sind Zahlungen von für das Bildungssystem bestimmten Geldern von einer Gebietskörperschaft an die andere. Die Beschränkung auf zweckgebundene, d.h. nur für die Bildung bestimmte Gelder, ist sehr wichtig, um Unsicherheiten hinsichtlich der Herkunft der Gelder zu vermeiden. Nicht berücksichtigt werden allgemeine Transferzahlungen zwischen Gebietskörperschaften (z.B. Finanzausgleichszahlungen, allgemeine Steuerausgleichszahlungen oder Zahlungen der Regierung von Anteilen des Steueraufkommens an Provinzen, Bundesstaaten oder Bundesländer), auch wenn durch derartige Transferzahlungen die Gelder bereitgestellt werden, auf die regionale und kommunale Behörden zur Bildungsfinanzierung zurückgreifen.

Typisches Alter: Typisches Alter bezieht sich auf das jeweilige Alter, das normalerweise dem Beginn und der Beendigung eines Bildungsabschnitts entspricht. Siehe auch Theoretisches Alter und Abschlussalter.

Unabhängige private Bildungseinrichtungen: Eine unabhängige private Bildungseinrichtung ist eine Bildungseinrichtung, die weniger als 50 Prozent ihrer Kernfinanzierung von staatlichen Stellen erhält und deren Lehrkräfte nicht von staatlichen Stellen bezahlt werden. Der Ausdruck, unabhängig bezieht sich nur auf den Grad der Abhängigkeit einer privaten Bildungseinrichtung von der Finanzierung durch den Staat, nicht jedoch darauf, inwieweit sie staatlichen Vorschriften oder einer staatlichen Leitung unterliegt. Siehe auch Bildungseinrichtungen, Staatlich-subventionierte private Bildungseinrichtungen, Private Bildungseinrichtungen und Öffentliche Bildungseinrichtungen.

Unterrichtende Beschäftigte: Unterrichtende Beschäftige umfassen zwei Unterkategorien: Lehrkräfte, also Lehrer auf den ISCED-Stufen - - 4 und akademische Mitarbeiter auf den ISCED-Stufen 5-6 sowie andererseits Hilfslehrkräfte auf den ISCED-Stufen 0-4 und Lehr-/Forschungsassistenten auf den ISCED-Stufen 5-6. Siehe auch Beschäftigte im Bildungsbereich, Wartungs- und Betriebspersonal, Beschäftigte in Management/Qualitätskontrolle/Verwaltung, Professionelle Unterstützung für Schüler/Studierende, Zahlenmäßiges Schüler-|Lehrerverhältnis , Lehrkräfte und Zahl der Unterrichtsstunden.

Unterrichterteilende Bildungseinrichtungen: Unterrichterteilende Bildungseinrichtungen sind Bildungseinrichtungen, die einzelnen Personen in organisierter Form direkten Unterricht in der Gruppe oder per Fernunterricht erteilen. Nicht enthalten sind hierin Unternehmen oder sonstige Einrichtungen, die kurze Ausbildungs- oder Lehrkurse in Form von Einzelunterricht anbieten. Siehe auch Ausgaben für Bildungseinrichtungen und Nicht-unterrichterteilende Bildungseinrichtungen.

Unterrichtstage: Die Zahl der Unterrichtstage entspricht der Zahl der Tage, die ein Lehrer pro Jahr unterrichtet. Sie wird berechnet als Anzahl der Tage, die ein Lehrer pro Woche unterrichtet, multipliziert mit der Anzahl der Unterrichtswochen pro Jahr, abzüglich der Tage, an denen die Schule wegen Feierlichkeiten geschlossen ist. Siehe auch Zahl der Unterrichtsstunden, Unterrichtswochen, Arbeitszeit und Arbeitszeit in der Schule.

Unterrichtswochen: Die Zahl der Unterrichtswochen bezieht sich auf die Zahl der Unterrichtswochen pro Jahr ohne die Ferienzeiten. Siehe auch Unterrichtstage, Zahl der Unterrichtsstunden, Arbeitszeit und Arbeitszeit in der Schule. 
Unterrichtszeit: Siehe Vorgesehene Unterrichtszeit.

Vergütung der Beschäftigten: Die Vergütung der Beschäftigten umfasst die Bruttogehälter, Ausgaben der Altersvorsorge (nur Arbeitgeberbeiträge) sowie andere Lohnnebenleistungen. Siehe auch Gehälter.

Voll qualifizierter Lehrer: Voll qualifiziert bedeutet, dass ein Lehrer alle Ausbildungsanforderungen für das Unterrichten eines bestimmten Fachs in einem bestimmten Bildungsbereich gemäß den landesspezifischen Bedingungen erfüllt hat und darüber hinaus alle weiteren verwaltungstechnischen Anforderungen für eine Vollzeitstelle (z. B. Probezeit) erfüllt.

Vollzeit-/Teilzeitausbildung: Vollzeit-/Teilzeitausbildung bezieht sich darauf, ob es sich um eine Vollzeit- oder Teilzeitteilnahme der Schüler/Studierenden handelt. Siehe auch Vollzeit-Schüler/Studierende, Vollzeitäquivalente Schüler/Studierende, Teilzeit-Schüler/Studierende, Schüler/Studierende und Lernpensum.

Vollzeitäquivalente Lehrer: Mit dem Vollzeitäquivalent (VZÄ) soll die Unterrichtsbelastung eines VollzeitLehrers gegenüber der eines Teilzeit-Lehrers standardisiert werden. Grundlage für die Berechnung ist die gesetzliche bzw. vertraglich vorgeschriebene Anzahl an Arbeitsstunden und nicht die tatsächliche oder Gesamtarbeitsstundenzahl oder die tatsächliche oder Gesamtunterrichtsstundenzahl. Das Vollzeitäquivalent eines Teilzeit-Lehrers erhält man, indem das Verhältnis seiner Arbeitsstundenzahl zur gesetzlichen bzw. vertraglichen Arbeitsstundenzahl eines Vollzeit-Lehrers während des Schuljahres berechnet wird. Siehe auch Beschäftigte im Bildungsbereich, Vollzeit-Lehrer, Unterrichtende Beschäftigte, Teilzeit-Lehrer, Zahlenmäßiges Schüler/Lehrkräfte-Verhältnis, Lehrkräfte und Zahl der Unterrichtsstunden.

Vollzeitäquivalente Schüler/Studierende: Mit dem Vollzeitäquivalent (VZÄ) soll das tatsächliche Kurspensum eines Schülers oder Studierenden im Verhältnis zum normalen Pensum standardisiert werden. Zur Berechnung des Vollzeit-/Teilzeitstatus benötigt man Informationen zu den Unterrichtsstunden bei tatsächlichem gegenüber normalem Aufwand. Sofern Daten und Standardwerte hinsichtlich der
Beteiligung des Einzelnen verfügbar sind, wird das VZÄ als Quotient aus tatsächlichem Kurspensum und normalem Pensum multipliziert mit dem Quotienten aus tatsächlicher Studiendauer und normaler Studiendauer des Schul-/Studienjahres gemessen. $[\mathrm{VZÄ}=$ (tatsächliches Kurspensum/normales Kurspensum) multipliziert mit (tatsächliche Ausbildungsdauer während des Bezugszeitraums/normale Ausbildungsdauer während des Bezugszeitraums)]. Liegen keine Daten über das tatsächliche Kurspensum vor, gilt ein Vollzeit-Schüler/Studierender als Vollzeitäquivalent. Siehe auch VollzeitSchüler/Studierende, Vollzeit-/Teilzzit-Ausbildung, TeilzeitSchüler/Studierende, Schüler/Studierende und Lernpensum.

Vollzeit-Lehrer: Ein Lehrer, der für den Zeitraum eines kompletten Schuljahres für mindestens 9o Prozent der normalen oder gesetzlichen Arbeitsstundenzahl eines Vollzeit-Lehrers eingestellt ist, gilt als Vollzeit-Lehrer. Siehe auch Beschäftigte im Bildungsbereich, Vollzeitäquivalente Lehrer, Unterrichtende Beschäftigte, Teilzeit-Lehrer, Zahlenmäßiges Schüler/Lehrkräfte-Verhältnis, Lehrkräfte und Arbeitszeit.

Vollzeit-Schüler/Studierende: Im Allgemeinen gelten Schüler im Primar- und Sekundarbereich als Vollzeit-Schüler, wenn sie die Schule mindestens für die Dauer von 75 Prozent des Schultages oder der Schulwoche (gemäß der jeweiligen lokalen Definition) besuchen und normalerweise ihre Teilnahme an dem betreffenden Bildungsgang während des gesamten Schuljahres zu erwarten ist. Bei der Feststellung des Vollzeit-/Teilzeitstatus wird die betriebliche Komponente in kombinierten schulischen und betrieblichen Ausbildungen mit berücksichtigt. Im Tertiärbereich gilt eine Person als Vollzeit-Studierender, wenn sie ein Kurspensum hat oder an einem Bildungsgang teilnimmt, das bzw. der mindestens 75 Prozent der Zeit und Ressourcen eines Vollzeitstudiums erfordert. Darüber hinaus wird davon ausgegangen, dass der Studierende während des gesamten Jahres an dem Studiengang teilnimmt. Siehe auch Vollzeitäquivalente Schüler/Studierende, Vollzeit-/Teilzeit-Ausbildung, TeilzeitSchüler/Studierende, Schüler/Studierende und Lernpensum.

Vorgesehene Unterrichtszeit: Die vorgesehene Unterrichtszeit bezieht sich auf die Anzahl an Unterrichtsstunden, in denen Schüler im Pflichtteil und 
Nicht-Pflichtteil des Lehrplans unterrichtet werden sollten. Für Länder, in denen keine formellen Vorschriften zu der Unterrichtszeit vorliegen, wurde die Zahl der Unterrichtsstunden aufgrund der Erhebungsdaten geschätzt. Stunden, die entfallen, wenn Schulen wegen Feiertagen oder Feierlichkeiten geschlossen sind, werden nicht gezählt. In der vorgesehenen Unterrichtszeit nicht enthalten sind freiwillige Aktivitäten außerhalb der regulären Schulzeit. Ebenso wenig enthalten sind die Zeit für Hausaufgaben, Privatunterricht und Selbststudium vor oder nach der Schule. Siehe auch Kern-Pflichtteil des Lehrplans, Pflichtteil des Lehrplans, Wahl-Pflichtteil des Lehrplans und Nicht-Pflichtteil des Lehrplans.

Wahl-Pflichtteil des Lehrplans: Der Wahl-Pflichtteil des Lehrplans bezieht sich auf den Teil des Pflichtteils des Lehrplans, bei dem die Schule oder die Schüler Entscheidungsspielraum bzw. oder Wahlfreiheit haben (bezüglich der Zeit, die sie auf ein Fach oder auf eine Auswahl von Fächergruppen verwenden). So kann sich beispielsweise eine Schule dafür entscheiden, innerhalb der vorgegebenen Pflichtzeit in den naturwissenschaftlichen Fächern mehr als die Pflichtstunden zu unterrichten, während es in Kunst lediglich die Mindeststundenzahl ist. Siehe auch Kern-Pflichtteil des Lehrplans, Pflichtteil des Lehrplans, Vorgesehene Unterrichtszeit und Nicht-Pflichtteil des Lehrplans.

Wartungs- und Betriebspersonal: Wartungs- und Betriebspersonal bezieht sich auf Beschäftigte, die in der Wartung und dem Betrieb der Bildungseinrichtungen, der Schulsicherheit und zusätzlichen Dienstleistungen eingesetzt werden, wie z.B. den Transport der Schüler/Studierenden zur und von der Schule und den Betrieb der Kantine. Dieser Kategorie zugeordnet sind: Maurer, Zimmerleute, Elektriker, Schlosser, Wartungsarbeiter, Maler und Tapezierer, Gipser, Installateure und Fahrzeugmechaniker. Darüber hinaus Busfahrer und Fahrer anderer Fahrzeuge, Bauarbeiter, Gärtner und Platzwarte, Busbetreuer und Schülerlotsen, Köche/ Ernährungsberater, Aufsichtspersonal, Kantinenpersonal, Aufsichten in den Schlafsälen und Sicherheitspersonal. Siehe auch Beschäftigte im Bildungsbereich, Unterrichtende Beschäftige, Beschäftigte in Management/Qualitätskontrolle/Verwaltung, Professionelle Unterstützung für Schüler/Studierende, Zahlenmäßiges Schüler-|Lehrerverhältnis und Lehrkräfte.
Weiterführende Forschungsprogramme (ISCED 6): In dieser Bildungsstufe werden tertiäre Studiengänge eingestuft, die direkt zum Erwerb eines weiterführenden Forschungsabschlusses führen, z. B. einer Promotion. Die theoretische Vollzeitstudiendauer eines solchen Programms beträgt in den meisten Ländern 3 Jahre (bei einer Vollzeitausbildungsdauer insgesamt von mindestens 7 Jahren im Tertiärbereich), obwohl die Studierenden häufig länger eingeschrieben sind. Die Ausbildungsgänge umfassen fortgeschrittene Studien und originäre Forschungsarbeiten. Siehe auch Internationale StandardKlassifikation des Bildungswesens (ISCED).

Zahl der Unterrichtsstunden: Die Zahl der Unterrichtsstunden wird definiert als die Zahl an Stunden pro Jahr, die ein Vollzeitlehrer gemäß den offiziellen Vorschriften des Jahres mit dem Unterricht einer Gruppe oder Klasse verbringt. Sie wird berechnet aus der Zahl der Unterrichtstage pro Jahr multipliziert mit der Anzahl Zeitstunden, die ein Lehrer pro Tag unterrichtet (ohne Zeiten, die offiziell als Pausen zwischen einzelnen Stunden oder Stundenblöcken vorgesehen sind). Im Elementar- und Primarbereich sind jedoch kurze Pausen zwischen den einzelnen Unterrichtsstunden, während derer der Lehrer für die Klasse verantwortlich ist, enthalten. Siehe auch Unterrichtstage, Unterrichtswochen, Arbeitszeit und Arbeitszeit in der Schule.

Zahlenmäßiges Schüler/Lehrkräfte-Verhältnis: Das zahlenmäßige Schüler/Lehrkräfte-Verhältnis wird berechnet, indem die Gesamtzahl an vollzeitäquivalenten Schülern durch die Gesamtzahl an vollzeitäquivalenten Lehrern dividiert wurde. Siehe auch Beschäftige im Bildungsbereich, Vollzeitäquivalente Schüler/Studierende, Vollzeitäquivalente Lehrer, Unterrichtende Beschäftigte, Wartungs- und Betriebspersonal, Beschäftigte in Management/Qualitätskontrolle/Verwaltung, Professionelle Unterstützung für Schüler/Studierende, Lehrkräfte und Zahl der Unterrichtsstunden.

Ziel eines Bildungsgangs: Das Ziel eines Bildungsgangs, gemäß der Definition der Internationalen Standard-Klassifikation des Bildungswesens (ISCED), bezieht sich auf das Ziel, auf das ein Bildungsgang die Schüler/Studierenden vorbereiten soll, z. B. den nächst höheren Bildungsbereich, den Arbeitsmarkt oder andere Bildungsgänge im gleichen oder anderen Bildungsbereichen. 
- Bildungsgänge der Kategorie A sollen die Schüler/Studierenden auf den unmittelbaren Zugang zum nächsthöheren Bildungsbereich vorbereiten;

- Bildungsgänge der Kategorie B sollen Schüler/ Studierende auf den Zugang zu bestimmten, aber nicht allen Bildungsgängen des nächsthöheren Bildungsbereichs vorbereiten und

- Bildungsgänge der Kategorie C sollen Schüler/ Studierende auf den direkten Zugang zum Arbeitsmarkt oder zu anderen Bildungsgängen im gleichen Bildungsbereich vorbereiten.

Zu erwartende Jahre in Ausbildung: Siehe Bildungserwartung (in Jahren).

Zulagen zum Grundgehalt: Zulagen zum Grundgehalt sind Zahlungen, die Lehrer zusätzlich zu der Summe erhalten können, die sie aufgrund ihrer beruflichen Qualifikationen und Erfahrungen gezahlt bekommen (Besoldungs-/Vergütungsgruppe). Diese Zulagen können z. B. für das Unterrichten in abgelegenen Regionen, für die Teilnahme an besonderen Schulprojekten oder -aktivitäten, für die Übernahme von Managementaufgaben zusätzlich zu Unterrichtsverpflichtungen, oder für außergewöhnliche Unterrichtsleistungen gewährt werden. Siehe auch Gehälter von Lehrern.

Zusätzliche Dienstleistungen: Siehe Ausgaben für zusätzliche Dienstleistungen. 



\section{Mitwirkende an dieser Publikation}

Viele Personen haben bei der Erstellung dieser Publikation mitgewirkt. Im folgenden Anhang sind die Namen der Ländervertreter, Forscher und Experten aufgeführt, die bei den vorbereitenden Arbeiten für die Veröffentlichung dieser Ausgabe von Bildung auf einen Blick OECD-Indikatoren 2004 aktiv mitgewirkt haben. Die OECD möchte ihnen allen an dieser Stelle für ihren wertvollen Beitrag danken. 


\section{Landeskoordinatoren}

Herr Dan ANDERSSON (Schweden)

Herr Jorge BARATA (Portugal)

Herr Dominique BARTHÉLÉMY (Belgien)

Herr Eric DALMIJN (Niederlande)

Herr Michal FEDEROWICZ (Polen)

Herr Guillermo GIL (Spanien)

Herr Heinz GILOMEN (Schweiz)

Frau Margrét HARDARDÓTTIR (Island)

Herr G. Douglas HODGKINSON (Kanada)

Frau Judit KADAR-FULOP (Ungarn)

Herr Gregory KAFETZOPOULOS (Griechenland)

Herr I.Z. KARABIYIK (Türkei)

Herr Kwan-Bok KIM (Korea)

Herr Matti KYRÖ (Finnland)

Herr Antonio Giunta LA SPADA (Italien)

Herr David LAMBIE (Neuseeland)

Herr Jérôme LEVY (Luxemburg)
Herr Dietrich MAGERKURTH (Deutschland)

Herr Victor MANUEL VELÁZQUEZ CASTAÑEDA (Mexiko)

Herr Lubomir MARTINEC (Tschechische Republik)

Herr Gerardo MUÑOZ SANCHEZ-BRUNETE (Spanien)

Herr Mark NEMET (Österreich)

Herr Torlach O'CONNOR (Irland)

Herr Laurence OGLE (Vereinigte Staaten)

Herr Brendan O'REILLY (Australien)

Herr Vladimir POKOJNY (Slowakische Republik)

Frau Janice ROSS (Vereinigtes Königreich)

Herr Ingo RUSS (Deutschland)

Herr Claude SAUVAGEOT (Frankreich)

Herr Ole-Jacob SKODVIN (Norwegen)

Herr Ken THOMASSEN (Dänemark)

Frau Ann VAN DRIESSCHE (Belgien)

Herr Jerzy WISNIEWSKI (Polen)

Herr Michio YAMADA (Japan)

\section{Technische Gruppe für Bildungsstatistik und Bildungsindikatoren \\ Herr Ruud ABELN (Niederlande) \\ Herr Paul AMACHER (Schweiz) \\ Frau Birgitta ANDRÉN (EUROSTAT) \\ Frau Marie ARNEBERG (Norwegen) \\ Frau Karin ARVEMO-NOTSTRAND (Schweden) \\ Frau Alina BARAN (Polen) \\ Frau Eva BOLIN (Schweden) \\ Herr Fernando CELESTINO REY (Spanien) \\ Herr Eduardo DE LA FUENTE (Spanien) \\ Frau Gemma DE SANCTIS (Italien) \\ Herr Philippe DIEU (Belgien) \\ Herr Kjetil DIGRE (Norwegen) \\ Frau Maria DOKOU (Griechenland) \\ Frau Mary DUNNE (Irland) \\ Frau Nilgün DURAN (Türkei) \\ Herr Timo ERTOLA (Finnland) \\ Herr Pierre FALLOURD (Frankreich) \\ Frau Alzbeta FERENCICOVÀ (Slowakische Republik) \\ Frau Catherine FREEMAN (Vereinigte Staaten) \\ Herr Yosef GIDANIAN (Israel) \\ Herr Paul GINI (Neuseeland) \\ Herr Bengt GREF (Schweden) \\ Herr Heinz-WERNER HETMEIER (Deutschland) \\ Herr Steve HEWITT (Vereinigtes Königreich) \\ Frau Maria HRABINSKA (Slowakische Republik) \\ Herr Jesus IBANEZ MILLA (Spanien) \\ Herr Klaus JACOBSEN (Dänemark) \\ Frau Michèle JACQUOT (Frankreich) \\ Frau Nathalie JAUNIAUX (Belgien) \\ Frau Alison KENNEDY (UNESCO) \\ Frau Michaela KLENHOVÁ (Tschechische Republik) \\ Herr Felix KOSCHIN (Tschechische Republik) \\ Frau Judit LUKÁCS (Ungarn) \\ Herr Dietrich MAGERKURTH (Deutschland) \\ Herr Robert MAHEU (Kanada) \\ Frau Sabine MARTINSCHITZ (Österreich) \\ Frau Giuliana MATTEOCCI (Italien) \\ Frau Midori MIYATA (Japan) \\ Herr Yoshiro NAKAYA (Japan) \\ Frau Anna NOWOZYNSKA (Polen) \\ Herr Geir NYGARD (Norwegen) \\ Herr Muiris O'CONNOR (Irland) \\ Herr Brendan O'REILLY (Australien) \\ Herr Miikka PAAJAVUORI (Finnland) \\ Herr Jose PAREDES (Portugal) \\ Herr Wolfgang PAULI (Österreich) \\ Herr Adrian PAWSEY (Australien) \\ Herr João PEREIRA DE MATOS (Portugal) \\ Herr Jose PESSOA (Kanada) \\ Herr Spyridon PILOS (EUROSTAT) \\ Frau Elena REBROSOVA (Slowakische Republik) \\ Herr Alexander RENNER (Deutschland) \\ Herr Ingo RUSS (Deutschland) \\ Herr Pascal SCHMIDT (EUROSTAT) \\ Herr Thomas SNYDER (Vereinigte Staaten) \\ Frau Maria Pia SORVILLO (Italien) \\ Frau Dalia SPRINZAK (Israel) \\ Herr Konstantinos STOUKAS (Griechenland) \\ Herr Dick TAKKENBERG (Niederlande) \\ Herr Ken THOMASSEN (Dänemark) \\ Herr Mika TUONONEN (Finnland) \\ Herr Shuichi UEHARA (Japan) \\ Frau Manon UNSEN (Luxemburg) \\ Frau Ásta URBANCIC (Island)}


Frau Natalia KOVALEVA (Russia)

Herr Steve LEMAN (Vereinigtes Königreich)

Herr Jérôme LEVY (Luxemburg)

Herr László LIMBACHER (Ungarn)
Herr Matti VAISANEN (Finnland)

Frau Erika VALLE BUTZE (Mexiko)

Frau Ann VAN DRIESSCHE (Belgien)

Herr Rik VERSTRAETE (Belgien)
Netzwerk A: Bildungsergebnisse

Vorsitz: Vereinigte Staaten

Netzwerkvorsitz: Herr Eugene OWEN

Herr Helmut BACHMANN (Österreich)

Frau Anna BARKLUND (Schweden)

Herr Giray BERBEROGLU (Türkei)

Frau Iris BLANKE (Luxemburg)

Frau Christiane BLONDIN (Belgien)

Herr Fernando CORDOVA CALDERON (Mexiko)

Frau Chiara CROCE (Italien)

Herr Guillermo GIL (Spanien)

Frau Zsuzsa HAMORI-VACZY (Ungarn)

Herr Jürgen HORSCHINEGG (Österreich)

Frau Anne-Berit KAVLI (Norwegen)

Herr Jorma KUUSELA (Finnland)

Frau Mariann LEMKE (Vereinigte Staaten)

Herr Felipe MARTINEZ RIZO (Mexiko)

Herr Jay MOSKOWITZ (Vereinigte Staaten)

Herr Jerry MUSSIO (Kanada)

Herr Michael O'GORMAN (Kanada)

Herr Jules PESCHAR (Niederlande)
Frau Glória RAMALHO (Portugal)

Herr Erich RAMSEIER (Schweiz)

Herr Thierry ROCHER (Frankreich)

Herr Vladislav ROSA (Slowakische Republik)

Herr Jochen SCHWEITZER (Deutschland)

Frau Elois SCOTT (Vereinigte Staaten)

Herr Gerry SHIEL (Irland)

Herr Joern SKOVSGAARD (Dänemark)

Frau Maria STEPHENS (Vereinigte Staaten)

Herr Jason TARSH (Vereinigtes Königreich)

Herr Luc VAN DE POELE (Belgien)

Herr Paul VAN OIJEN (Niederlande)

Frau Evangelia VARNAVA-SKOURA (Griechenland)

Herr Ryo WATANABE (Japan)

Frau Anita WESTER (Schweden)

Frau Wendy WHITHAM (Australien)

Frau Lynne WHITNEY (Neuseeland)

Frau Pavla ZIELENCIOVA (Tschechische Republik)

\section{Netzwerk B: Bildung und sozio-ökonomische Auswirkungen}

Vorsitz: Schweden

Netzwerkvorsitz: Herr Dan ANDERSSON

Frau Yupin BAE (Vereinigte Staaten)

Frau Ariane BAYE (Belgien)

Frau Irja BLOMQVIST (Finnland)

Frau Anna BORKOWSKY (Schweiz)

Herr Fernando CELESTINO REY (Spanien)

Frau Jihee CHOI (Korea)

Herr Erik DAHL (Norwegen)

Herr Eric DALMIJN (Niederlande)

Herr Patrice DE BROUCKER (Kanada)

Herr Kjetil DIGRE (Norwegen)

Frau Isabelle ERAUW (Belgien)

Frau Lisa HUDSON (Vereinigte Staaten)

Herr Evangelos INTZIDIS (Griechenland)

Frau Anna JÖNSSON (Schweden)

Herr Olof JOS (Schweden)

Herr Jens KROGSTRUP (Dänemark)

Frau Christiane KRÜGER-HEMMER (Deutschland)

Herr Jérôme LEVY (Luxemburg)

Frau Anne-Frankreich MOSSOUX (Europäische Kommission) Herr Johan VAN DER VALK (Niederlande)

Herr Philip O’CONNELL (Irland)
Herr Brendan O’REILLY (Australien)

Herr Ali PANAL (Türkei)

Herr Kenny PETERSSON (Schweden)

Frau Simona PIKALKOVA (Tschechische Republik)

Herr Spyridon PILOS (EUROSTAT)

Frau Pascale POULET-COULIBANDO (Frankreich)

Frau Cheryl REMINGTON (Neuseeland)

Frau Aila REPO (Finnland)

Frau Emilia SAO PEDRO (Portugal)

Frau Astrid SCHORN-BUCHNER (Luxemburg)

Herr Peter SCRIMGEOUR (Vereinigtes Königreich)

Herr Dan SHERMAN (Vereinigte Staaten)

Frau Irena SKRZYPCZAK (Polen)

Frau Maria-Pia SORVILLO (Italien)

Herr Stig FORNENG (Schweden)

Frau Pauline THOOLEN (Niederlande)

Frau Mariá THURZOVÁ (Slowakische Republik)

Frau Éva TÓT (Ungarn) 
Netzwerk C: Merkmale der Schulen und dort ablaufende Prozesse

Vorsitz: Niederlande

Netzwerkvorsitz: Herr Jaap SCHEERENS

Frau Dominique ALLAIN (Frankreich)

Frau Bodhild BAASLAND (Norwegen)

Herr Vassilios CHARISMIADIS (Griechenland)

Herr Jerzy CHODNICKI (Polen)

Frau Maria DO CARMO CLÍMACO (Portugal)

Herr Eric DALMIJN (Niederlande)

Herr Philippe DELOOZ (Belgien)

Frau Alexia DENEIRE (Belgien)

Frau Nilgün DURAN (Türkei)

Frau Flora GIL TRAVER (Spanien)

Herr Paul GINI (Neuseeland)

Herr Sean GLENNANE (Irland)

Frau Kerry GRUBER (Vereinigte Staaten)

Herr Helder GUERREIRO (Portugal)

Frau Annika HAGLUND (Schweden)

Frau Maria HENDRIKS (Niederlande)

Frau Maria HRABINSKA (Slowakische Republik)

Frau Anna IMRE (Ungarn)

Frau Alison Kennedy (UNESCO)

Frau Michaela KLENHOVÁ (Tschechische Republik)

Herr Christian KRENTHALLER (Österreich)

Herr Hannu-Pekka LAPPALAINEN (Finnland)

Frau Ulla LINDQVIST (Schweden)

Frau Nelly MCEWEN (Kanada)

Herr Gerd MÖLLER (Deutschland)

Frau Hyun-Jeong PARK (Korea)

Herr Jørgen Balling RASMUSSEN (Dänemark)

Frau Astrid SCHORN (Luxemburg)

Herr Joel SHERMAN (Vereinigte Staaten)

Frau Pavlina STASTNOVA (Tschechische Republik)

Herr Eugene STOCKER (Schweiz)

Herr Jason TARSH (Vereinigtes Königreich)

Frau Erika VALLE BUTZE (Mexiko)

Herr Peter VAN PETEGEM (Belgien)

Frau Caterina VEGLIONE (Italien)

\section{World Education Indicators}

Herr Mark AGRANOVITCH (Russische Föderation)

Herr Peter AMARASINGHE (Sri Lanka)

Herr Ramon BACANI (Philippinen)

Herr C. BALAKRISHNAN (Indien)

Frau Barbara ALLEN (Jamaika)

Herr Ade CAHYANA (Indonesien)

Herr Farai CHOGA (Simbabwe)

Frau Jehad Jamil Abu EL-SHAAR (Jordanien)

Frau Vivian HEYL (Chile)

Herr Mohsen KTARI (Tunesien)
Frau Zhi hua LIN (China)

Frau Khalijah MOHAMMAD (Malaysia)

Herr Eliezer MOREIRA PACHECO (Brasilien)

Frau Irene Beatriz OIBERMAN (Argentinien)

Frau Mara PEREZ TORRANO (Uruguay)

Herr Mohammed RAGHEB (Ägypten)

Frau Sirivarn SVASTIWAT (Thailand)

Frau Patricia VALDIVIA (Peru)

Frau Dalila ZARZA PAREDES (Paraguay)

\author{
Sonstige Mitwirkende dieser Publikation \\ Herr Kai v. AHLEFELD (Layout) \\ Herr Gilles BURST (Layout) \\ Frau Delphine GRANDRIEUX (OECD) \\ Frau Katja HETTLER (Layout) \\ Frau Marion SCHNEPF (Layout)
}

Herr Tom KRÄHENBÜHL (Layout)

Frau Melissa PEERLESS (Editor)

Herr Ingo RUSS (BMBF, Deutschland)

Herr Stephan VINCENT-LANCRIN (OECD) 


\section{Weiterführende OECD-Publikationen}

Classifying Educational Programmes: Manual for ISCED-97 Implementation in OECD Countries (1999)

ISBN 92-64-17037-5 €41,- $\quad$ US\$43,- $\quad € 26,-\quad ¥ 5.050$

From Initial Education to Working Life: Making Transitions Work (2000)

ISBN 92-64-17631-4 €39,- US\$37,- $€ 23,-\quad ¥ 3.900$

Lernen für das Leben: Erste Ergebnisse von PISA 2000 (2001)

ISBN 92-64-59671-2 € 21,- US\$19,- $\quad € 13,-\quad ¥ 2.110$

Teachers for Tomorrow's Schools: Analysis of the 2000 World Education Indicators (2001)

ISBN 92-64-18699-9 €22,- US\$20,- $€ 14,-\quad ¥ 2.200$

Financing Education: Investments and Returns - Analysis of the World Education Indicators (2002)

ISBN 92-64-19971-3 €25,- US\$25,- $\quad$ € 16,- $¥ 3.050$

PISA 2000 Technical Report (2002)

ISBN 92-64-19951-9 € $\quad$ 30,- US\$30,- $\quad € 19,-\quad ¥ 3.500$

Manual for the PISA 2000 Database (2002)

ISBN 92-64-19822-9 € 20,- US\$19,- $\quad € 12,-\quad ¥ 2.300$

Sample Tasks from the PISA 2000 Assessment: Reading, Mathematical and Scientific Literacy (2002)

ISBN 92-64-19765-6 € 20,- US\$19,- $\quad € 12,-\quad ¥ 2.300$

Reading for Change: Performance and Engagement across Countries (2003)

ISBN 92-64-09926-3 € 24,- $\quad$ US\$24,- $\quad € 15,-\quad ¥ 2.800$

Literacy Skills for the World of Tomorrow: Further Results from PISA 2000 (2003)

ISBN 92-64-10286-8 €21,- US\$24,- $\quad € 14,-\quad ¥ 2.700$

The PISA 2003 Assessment Framework: Mathematics, Reading, Science and Problem Solving Knowledge and Skills (2003)

ISBN 92-64-10172-1 $\quad € 24,-\quad$ US\$28,- $\quad € 16,-\quad ¥ 3.100$

Learners for Life: Student Approaches to Learning: Results from PISA 2000 (2003)

ISBN 92-64-10390-2 $€ 21,-\quad$ US\$24,- $\quad € 14,-\quad ¥ 2.700$

Student Engagement at School: A Sense of Belonging and Participation: Results from PISA 2000 (2003)

ISBN 92-64-01892-1 $\quad € 21,-\quad$ US\$24,- $\quad € 14,-\quad ¥ 2.700$

OECD Handbook for Internationally Comparative Education Statistics: Concepts, Standards,

Definitions and Classifications (2004)

ISBN 92-64-10410-0 € $45,-\quad$ US\$56,- $\quad € 31,-\quad ¥ 5.800$

Completing the Foundation for Lifelong Learning: An OECD Survey of Upper Secondary Schools (2004)

ISBN 92-64-10372-4 €28,- US\$32,- $\quad$ £ 20,- $\quad ¥ 3.800$

OECD Survey of Upper Secondary Schools: Technical Report (2004)

ISBN 92-64-10572-7 $\quad € 32,-\quad$ US\$37,- $\quad € 22,-\quad ¥ 4.400$

Internationalisation and Trade in Higher Education: Opportunities and Challenges (2004)

ISBN 96-64-01504-3 € 50,- $\quad$ US\$63,- $\quad € 35,-\quad ¥ 6.400$

Bildungspolitische Analyse 2004 (Veröffentlichung im 4. Quartal 2004)

First Results from PISA 2003 (Veröffentlichung am 7. Dezember 2004)

PISA 2003 Report on Problem Solving (Veröffentlichung am 7. Dezember 2004)

Die genannten Veröffentlichungen sind im OECD Online-Bookshop erhältlich www.oecd.org/bookshop 
OECD PUbliCATIONS, 2, rue André-Pascal, 75775 PARIS CEDEX i6

Gestaltung: www.lokbase.com, Bielefeld

Gesamtherstellung: W. Bertelsmann Verlag, Bielefeld

Gedruckt in Deutschland

ISBN 92-64-or 820-4 